\title{
Discovery of Novel Epidermal Growth Factor Receptor (EGFR) Inhibitors Using Computational Approaches
}

Donghui Huo, Shiyu Wang, Yue Kong, Zijian Qin, Aixia Yan*

State Key Laboratory of Chemical Resource Engineering, College of Life Science and Technology, Beijing University of Chemical Technology, Beijing 100029, China.

Email: yanax@mail.buct.edu.cn

Table S1 Dataset 1 of EGFR inhibitors for building SAR and QSAR models

Table S2 Dataset 2 for generating queries from crystal structures

Table S3 The optimized parameters used in SAR and QSAR models

Table S4 IC 50 curves for hit compounds experimented on EGFR and ErbB-2

Fig. S1 The ROC curves and AUC values of 3 queries

Fig. S2 The virtual screening cascade of novel EGFR inhibitors

Kinase assay method

Table S1. Dataset 1 of EGFR inhibitors for SAR and QSAR study.

\begin{tabular}{|c|c|c|c|}
\hline Num & SMILES & $\begin{array}{l}\mathrm{IC}_{50} \\
\mathrm{nM}\end{array}$ & $\begin{array}{c}\text { Subset3 } \\
\text { pIC }_{50}\end{array}$ \\
\hline 1 & Brc1ecce $(\mathrm{Nc} 2 \mathrm{ncnc} 3 \mathrm{cc} 4 \mathrm{cccc} 4 \mathrm{cc} 23) \mathrm{c} 1$ & 0.003 & * \\
\hline 2 & $\mathrm{CCOc} 1 \mathrm{cc} 2 \mathrm{ncnc}(\mathrm{Nc} 3 \mathrm{ccc}(\mathrm{Br}) \mathrm{c} 3) \mathrm{c} 2 \mathrm{cc} 1 \mathrm{OCC}$ & 0.006 & $*$ \\
\hline
\end{tabular}




\begin{tabular}{|c|c|c|c|}
\hline 3 & $\mathrm{CN}(\mathrm{C}) \mathrm{c} 1 \mathrm{cc} 2 \mathrm{c}(\mathrm{Nc} 3 \operatorname{ccc}(\mathrm{Br}) \mathrm{c} 3) \mathrm{n} n \mathrm{nc} 2 \mathrm{cn} 1$ & 0.006 & * \\
\hline 4 & $\operatorname{Brc} 1 \mathrm{cccc}(\mathrm{Nc} 2 \mathrm{ncnc} 3 \mathrm{cc} 4[\mathrm{nH}] \mathrm{cnc} 4 \mathrm{cc} 23) \mathrm{c} 1$ & 0.008 & * \\
\hline 5 & $\mathrm{CNc} 1 \mathrm{cc} 2 \mathrm{c}(\mathrm{Nc} 3 \mathrm{cccc}(\mathrm{Br}) \mathrm{c} 3) \mathrm{ncnc} 2 \mathrm{cn} 1$ & 0.008 & $*$ \\
\hline 6 & Cn1 cnc2cc3ncnc(Nc4cecc(Br)c4)c3cc21 & 0.01 & $*$ \\
\hline 7 & Cn1 $\operatorname{cnc} 2 \mathrm{cc} 3 \mathrm{c}(\mathrm{Nc} 4 \mathrm{cccc}(\mathrm{Br}) \mathrm{c} 4) \mathrm{ncnc} 3 \mathrm{cc} 21$ & 0.025 & $*$ \\
\hline 8 & $\mathrm{C} \# \mathrm{CCNC} / \mathrm{C}=\mathrm{C} / \mathrm{C}(=\mathrm{O}) \mathrm{Nc} 1 \mathrm{cc} 2 \mathrm{c}(\mathrm{Nc} 3 \mathrm{ccc}(\mathrm{F}) \mathrm{c}(\mathrm{Cl}) \mathrm{c} 3) \mathrm{c}(\mathrm{C} \# \mathrm{~N}) \mathrm{cnc} 2 \mathrm{cc} 1 \mathrm{OCC}$ & 0.03 & 10.52 \\
\hline 9 & $\mathrm{COc} 1 \mathrm{cc} 2 \mathrm{ncnc}(\mathrm{Nc} 3 \mathrm{ccc}(\mathrm{Br}) \mathrm{c}(\mathrm{Br}) \mathrm{c} 3) \mathrm{c} 2 \mathrm{cc} 1 \mathrm{OC}$ & 0.072 & $*$ \\
\hline 10 & $\mathrm{CCOc} 1 \mathrm{cc} 2 \mathrm{ncc}(\mathrm{C} \# \mathrm{~N}) \mathrm{c}(\mathrm{Nc} 3 \mathrm{ccc}(\mathrm{OCc} 4 \mathrm{ccccn} 4) \mathrm{c}(\mathrm{Cl}) \mathrm{c} 3) \mathrm{c} 2 \mathrm{cc} 1 \mathrm{NC}(=\mathrm{O}) / \mathrm{C}=\mathrm{C} / \mathrm{CN}(\mathrm{C}) \mathrm{C}$ & 0.08 & 8.41 \\
\hline 11 & $\mathrm{CN}(\mathrm{C}) \mathrm{c} 1 \mathrm{cc} 2 \mathrm{ncnc}(\mathrm{Nc} 3 \mathrm{cccc}(\mathrm{Br}) \mathrm{c} 3) \mathrm{c} 2 \mathrm{cn} 1$ & 0.091 & $*$ \\
\hline 12 & $\mathrm{CCC}(=\mathrm{O}) \mathrm{Nc} 1 \mathrm{ccc} 2 \mathrm{ncnc}(\mathrm{Nc} 3 \mathrm{cccc}(\mathrm{Br}) \mathrm{c} 3) \mathrm{c} 2 \mathrm{c} 1$ & 0.1 & 9.68 \\
\hline 13 & $\mathrm{Nc} 1 \mathrm{ccc} 2 \mathrm{c}(\mathrm{Nc} 3 \mathrm{cccc}(\mathrm{Br}) \mathrm{c} 3) \mathrm{ncnc} 2 \mathrm{c} 1$ & 0.1 & $*$ \\
\hline 14 & $\mathrm{Nc} 1 \mathrm{ccc} 2 \mathrm{cncnc2c1}$ & 0.1 & * \\
\hline 15 & $\mathrm{O}=\mathrm{C}(\mathrm{CCCCCCn} 1 \mathrm{cc}(-\mathrm{c} 2 \mathrm{ccc} 3 \mathrm{ncnc}(\mathrm{Nc} 4 \mathrm{cccc}(\mathrm{Cl}) \mathrm{c} 4 \mathrm{~F}) \mathrm{c} 3 \mathrm{c} 2) \mathrm{nn} 1) \mathrm{NO}$ & 0.12 & * \\
\hline 16 & $\mathrm{CNc} 1 \mathrm{cc} 2 \mathrm{ncnc}(\mathrm{Nc} 3 \mathrm{cccc}(\mathrm{Br}) \mathrm{c} 3) \mathrm{c} 2 \mathrm{cn} 1$ & 0.13 & $*$ \\
\hline 17 & $\mathrm{Nc} 1 \mathrm{cc} 2 \mathrm{c}(\mathrm{Nc} 3 \mathrm{cccc}(\mathrm{Br}) \mathrm{c} 3) \mathrm{ncnc} 2 \mathrm{cn} 1$ & 0.13 & $*$ \\
\hline 18 & $\mathrm{CN}(\mathrm{C}) \mathrm{C} / \mathrm{C}=\mathrm{C}(\mathrm{F}) \mathrm{C}(=\mathrm{O}) \mathrm{Nc} 1 \mathrm{cc} 2 \mathrm{c}(\mathrm{Nc} 3 \mathrm{ccc}(\mathrm{F}) \mathrm{c}(\mathrm{Cl}) \mathrm{c} 3) \mathrm{ncnc} 2 \mathrm{cc} 1 \mathrm{O}[\mathrm{C} @ \mathrm{H}] 1 \mathrm{CCOC} 1$ & 0.16 & 9.80 \\
\hline 19 & $\mathrm{C}=\mathrm{CC}(=\mathrm{O}) \mathrm{Nc} 1 \mathrm{nc} 2 \mathrm{c}(\mathrm{Nc} 3 \mathrm{ccc}(\mathrm{F}) \mathrm{c}(\mathrm{Cl}) \mathrm{c} 3) \mathrm{ncnc} 2 \mathrm{cc} 1 / \mathrm{C}=\mathrm{C} / \mathrm{CCN} 1 \mathrm{CCOCC} 1$ & 0.16 & $*$ \\
\hline 20 & Oc1 1c22ncnc(Nc3ecce(Br)c3)c2cc1O & 0.17 & * \\
\hline 21 & CCCOc1cc2ncnc(Nc3ecce(Br)c3)c2cc1OCCC & 0.17 & * \\
\hline 22 & $\mathrm{C}=\mathrm{CC}(=\mathrm{O}) \mathrm{N}(\mathrm{C}) \mathrm{c} 1 \mathrm{cc} 2 \mathrm{c}(\mathrm{Nc} 3 \mathrm{cccc}(\mathrm{Br}) \mathrm{c} 3) \mathrm{ncn} \mathrm{c} 2 \mathrm{cn} 1$ & 0.17 & $*$ \\
\hline 23 & $\mathrm{CCOc} 1 \mathrm{cc} 2 \mathrm{ncnc}(\mathrm{Nc} 3 \operatorname{ccc}(\mathrm{OCc} 4 \mathrm{ccc} n 4) \mathrm{c}(\mathrm{Cl}) \mathrm{c} 3) \mathrm{c} 2 \mathrm{cc} 1 \mathrm{NC}(=\mathrm{O}) / \mathrm{C}(\mathrm{F})=\mathrm{C} / \mathrm{CN}(\mathrm{C}) \mathrm{C}$ & 0.18 & 9.74 \\
\hline 24 & $\mathrm{C}=\mathrm{CC}(=\mathrm{O}) \mathrm{Nc} 1 \mathrm{cc} 2 \mathrm{c}(\mathrm{Nc} 3 \mathrm{ccc}(\mathrm{F}) \mathrm{c}(\mathrm{Cl}) \mathrm{c} 3) \mathrm{ncnc} 2 \mathrm{cc} 1 \mathrm{OCC}$ & 0.18 & 9.74 \\
\hline 25 & $\mathrm{OCC}(\mathrm{O}) \mathrm{CNc} 1 \mathrm{cc} 2 \mathrm{c}(\mathrm{Nc} 3 \mathrm{cccc}(\mathrm{Br}) \mathrm{c} 3) \mathrm{ncnc} 2 \mathrm{cn} 1$ & 0.18 & $*$ \\
\hline 26 & $\mathrm{CN}(\mathrm{C}) \mathrm{C} / \mathrm{C}=\mathrm{C} / \mathrm{C}(=\mathrm{O}) \mathrm{Nc} 1 \mathrm{cc} 2 \mathrm{c}(\mathrm{Nc} 3 \mathrm{ccc}(\mathrm{F}) \mathrm{c}(\mathrm{Cl}) \mathrm{c} 3) \mathrm{ncnc} 2 \mathrm{cc} 1 \mathrm{O}[\mathrm{C} @ \mathrm{H}] 1 \mathrm{CCOC} 1$ & 0.19 & 8.76 \\
\hline 27 & OCCNc1cc2c(Nc3ecce(Br)c3)ncnc2cn1 & 0.19 & $*$ \\
\hline 28 & $\mathrm{CNc} 1 \mathrm{cc} 2 \mathrm{c}(\mathrm{Nc} 3 \mathrm{cccc}(\mathrm{Cl}) \mathrm{c} 3) \mathrm{ncnc} 2 \mathrm{cn} 1$ & 0.19 & $*$ \\
\hline 29 & $\mathrm{COc} 1 \mathrm{cc} 2 \mathrm{ncnc}(\mathrm{Nc} 3 \mathrm{ccc}(\mathrm{F}) \mathrm{c}(\mathrm{Cl}) \mathrm{c} 3) \mathrm{c} 2 \mathrm{cc} 1 \mathrm{NC}(=\mathrm{O}) / \mathrm{C}(\mathrm{F})=\mathrm{C} / \mathrm{CN}(\mathrm{C}) \mathrm{C}$ & 0.2 & 9.70 \\
\hline 30 & $\mathrm{CC} \# \mathrm{CC}(=\mathrm{O}) \mathrm{Nc} 1 \mathrm{ccc} 2 \mathrm{ncnc}(\mathrm{Nc} 3 \mathrm{cccc}(\mathrm{Br}) \mathrm{c} 3) \mathrm{c} 2 \mathrm{c} 1$ & 0.2 & $*$ \\
\hline 31 & $\mathrm{COc1cc}(\mathrm{CO}) \mathrm{ccc} 1-\mathrm{c} 1 \mathrm{cc} 2 \mathrm{c}(\mathrm{N}[\mathrm{C} @ \mathrm{H}](\mathrm{CO}) \mathrm{c} 3 \mathrm{ccccc} 3) \mathrm{ncnc} 2[\mathrm{nH}] 1$ & 0.2 & $*$ \\
\hline 32 & $\mathrm{COc1cc}(\mathrm{CO}) \mathrm{ccc} 1-\mathrm{c} 1 \mathrm{cc} 2 \mathrm{c}(\mathrm{N}[\mathrm{C} @ \mathrm{H}](\mathrm{C}) \mathrm{c} 3 \mathrm{ccccc} 3) \mathrm{ncnc} 2[\mathrm{nH}] 1$ & 0.2 & $*$ \\
\hline 33 & $\mathrm{CC} 1(\mathrm{C}) \mathrm{Cc} 2 \mathrm{c}(\mathrm{sc}(=\mathrm{S}) \mathrm{n} 2-\mathrm{c} 2 \mathrm{ccccc} 2)-\mathrm{c} 2 \mathrm{c} 1 \mathrm{sc}(\mathrm{NC} 1=\mathrm{C}(\mathrm{Cl}) \mathrm{C}(\mathrm{c} 3 \mathrm{ccc}(\mathrm{Cl}) \mathrm{cc} 3) \mathrm{C}(\mathrm{C} \# \mathrm{~N})=\mathrm{C}(\mathrm{O}) \mathrm{O} 1) \mathrm{c} 2 \mathrm{C} \# \mathrm{~N}$ & 0.21 & * \\
\hline 34 & $\mathrm{CN}(\mathrm{C}) \mathrm{C} / \mathrm{C}=\mathrm{C} / \mathrm{C}(=\mathrm{O}) \mathrm{Nc} 1 \mathrm{ccc} 2 \mathrm{ncnc}(\mathrm{Nc} 3 \mathrm{cccc}(\mathrm{Br}) \mathrm{c} 3) \mathrm{c} 2 \mathrm{c} 1$ & 0.22 & 8.81 \\
\hline 35 & $\mathrm{CN}(\mathrm{CCO}) \mathrm{c} 1 \mathrm{cc} 2 \mathrm{c}(\mathrm{Nc} 3 \mathrm{cccc}(\mathrm{Br}) \mathrm{c} 3) \mathrm{ncnc} 2 \mathrm{cn} 1$ & 0.22 & $*$ \\
\hline 36 & $\mathrm{CN} 1 \mathrm{CCN}(\mathrm{CCC}(=\mathrm{O}) \mathrm{Nc} 2 \mathrm{ccc} 3 \mathrm{ncnc}(\mathrm{Nc} 4 \mathrm{cccc}(\mathrm{Br}) \mathrm{c} 4) \mathrm{c} 3 \mathrm{c} 2) \mathrm{CC} 1$ & 0.23 & 9.64 \\
\hline 37 & OCCNc1cc2ncnc(Nc3ecce(Br)c3)c2cn1 & 0.24 & $*$ \\
\hline 38 & $\mathrm{COc} 1 \mathrm{cc} 2 \mathrm{ncnc}(\mathrm{Nc} 3 \mathrm{cccc}(\mathrm{C}(\mathrm{F})(\mathrm{F}) \mathrm{F}) \mathrm{c} 3) \mathrm{c} 2 \mathrm{cc} 1 \mathrm{OC}$ & 0.24 & $*$ \\
\hline 39 & OCCNc1c(Br)cccc1Nc1ncnc2cencc12 & 0.2455 & $*$ \\
\hline 40 & $\mathrm{CCOc} 1 \mathrm{cc} 2 \mathrm{ncc}(\mathrm{C \# N}) \mathrm{c}(\mathrm{Nc} 3 \operatorname{ccc}(\mathrm{F}) \mathrm{c}(\mathrm{Cl}) \mathrm{c} 3) \mathrm{c} 2 \mathrm{cc} 1 \mathrm{NC}(=\mathrm{O}) / \mathrm{C}=\mathrm{C} / \mathrm{CNC}$ & 0.25 & 9.60 \\
\hline 41 & $\mathrm{C}=\mathrm{CC}(=\mathrm{O}) \mathrm{Nc} 1 \mathrm{ccc} 2 \mathrm{c}(\mathrm{Nc} 3 \operatorname{ccc}(\mathrm{Cl}) \mathrm{c} 3) \mathrm{ncnc} 2 \mathrm{c} 1$ & 0.25 & $*$ \\
\hline 42 & $\mathrm{Nc} 1 \mathrm{ccc} 2 \mathrm{c}(\mathrm{Nc} 3 \mathrm{cccc}(\mathrm{Cl}) \mathrm{c} 3) \mathrm{ncnc} 2 \mathrm{c} 1$ & 0.25 & $*$ \\
\hline 43 & Brc1ccce(Nc2ncnc3enc(NCCc4c[nH]cn4)nc23)c1 & 0.25 & $*$ \\
\hline 44 & $\mathrm{CC} 1(\mathrm{C}) \mathrm{Cc} 2 \mathrm{c}(\mathrm{sc}(=\mathrm{S}) \mathrm{n} 2-\mathrm{c} 2 \mathrm{ccccc} 2)-\mathrm{c} 2 \mathrm{c}(\mathrm{C \# N}) \mathrm{c}(\mathrm{N}) \mathrm{cc}(\mathrm{C \# N}) \mathrm{c} 21$ & 0.25 & $*$ \\
\hline 45 & $\mathrm{O}=\mathrm{C}(\mathrm{Nc} 1 \mathrm{cc} 2 \mathrm{c}(\mathrm{Nc} 3 \mathrm{ccc}(\mathrm{F}) \mathrm{c}(\mathrm{Cl}) \mathrm{c} 3) \mathrm{ncnc} 2 \mathrm{cc} 1 \mathrm{O}[\mathrm{C} @ \mathrm{H}] 1 \mathrm{CCOC} 1) / \mathrm{C}(\mathrm{F})=\mathrm{C} / \mathrm{CN} 1 \mathrm{CCOCC} 1$ & 0.26 & 9.59 \\
\hline
\end{tabular}




\begin{tabular}{|c|c|c|c|}
\hline 46 & $\mathrm{C} \# \mathrm{Cc} 1 \mathrm{cccc}(\mathrm{Nc} 2 \mathrm{ncnc} 3 \mathrm{cc}(\mathrm{OCCCCn} 4 \mathrm{ccnc} 4[\mathrm{~N}+](=\mathrm{O})[\mathrm{O}-]) \mathrm{c}(\mathrm{OC}) \mathrm{cc} 23) \mathrm{c} 1$ & 0.26 & 9.59 \\
\hline 47 & $\mathrm{COc} 1 \mathrm{cc} 2 \mathrm{ncnc}(\mathrm{Nc} 3 \mathrm{ccc}(\mathrm{F}) \mathrm{c}(\mathrm{Cl}) \mathrm{c} 3) \mathrm{c} 2 \mathrm{cc} 1 \mathrm{NC}(=\mathrm{O}) / \mathrm{C}(\mathrm{F})=\mathrm{C} / \mathrm{CN} 1 \mathrm{CCCCC} 1$ & 0.27 & 9.57 \\
\hline 48 & $\mathrm{CCOc} 1 \mathrm{cc} 2 \mathrm{ncnc}(\mathrm{Nc} 3 \mathrm{ccc}(\mathrm{F}) \mathrm{c}(\mathrm{Cl}) \mathrm{c} 3) \mathrm{c} 2 \mathrm{cc} 1 \mathrm{NC}(=\mathrm{O}) \mathrm{CCN}(\mathrm{C}) \mathrm{C}$ & 0.27 & 9.57 \\
\hline 49 & $\mathrm{O}=\mathrm{C}(\mathrm{CCN} 1 \mathrm{CCCCC} 1) \mathrm{Nc} 1 \mathrm{ccc} 2 \mathrm{ncnc}(\mathrm{Nc} 3 \mathrm{cccc}(\mathrm{Br}) \mathrm{c} 3) \mathrm{c} 2 \mathrm{c} 1$ & 0.27 & 9.57 \\
\hline 50 & $\mathrm{O}=\mathrm{C}(\mathrm{CCCCCn} 1 \mathrm{cc}(-\mathrm{c} 2 \mathrm{ccc} 3 \mathrm{ncnc}(\mathrm{Nc} 4 \mathrm{cccc}(\mathrm{Cl}) \mathrm{c} 4 \mathrm{~F}) \mathrm{c} 3 \mathrm{c} 2) \mathrm{nn} 1) \mathrm{NO}$ & 0.27 & $*$ \\
\hline 51 & $\mathrm{O}=\mathrm{C}(\mathrm{O}) \mathrm{CCN} 1 \mathrm{cc} 2 \mathrm{c}(\mathrm{Nc} 3 \mathrm{cccc}(\mathrm{Br}) \mathrm{c} 3) \mathrm{ncn} 2 \mathrm{cn} 1$ & 0.27 & $*$ \\
\hline 52 & $\mathrm{Nc} 1 \mathrm{ccc} 2 \mathrm{sc} 3 \mathrm{c}(\mathrm{Nc} 4 \mathrm{cccc}(\mathrm{Br}) \mathrm{c} 4) \mathrm{ncnc} 3 \mathrm{c} 2 \mathrm{c} 1$ & 0.27 & $*$ \\
\hline 53 & $\mathrm{CC} 1(\mathrm{C}) \mathrm{CC}(=\mathrm{O}) \mathrm{C}(=\mathrm{NNc} 2 \mathrm{ccc}(\mathrm{Cl}) \mathrm{cc} 2) \mathrm{c} 2 \mathrm{c} 1 \mathrm{sc}(\mathrm{N}) \mathrm{c} 2 \mathrm{C \# N}$ & 0.27 & * \\
\hline 54 & $\mathrm{CN}(\mathrm{C}) \mathrm{CCC}(=\mathrm{O}) \mathrm{Nc} 1 \mathrm{ccc} 2 \mathrm{ncnc}(\mathrm{Nc} 3 \mathrm{cccc}(\mathrm{Br}) \mathrm{c} 3) \mathrm{c} 2 \mathrm{c} 1$ & 0.28 & 9.55 \\
\hline 55 & $\mathrm{O}=\mathrm{C}(\mathrm{O}) \mathrm{CCCNc} 1 \mathrm{cc} 2 \mathrm{ncnc}(\mathrm{Nc} 3 \mathrm{cccc}(\mathrm{Br}) \mathrm{c} 3) \mathrm{c} 2 \mathrm{cn} 1$ & 0.28 & $*$ \\
\hline 56 & $\mathrm{O}=\mathrm{C}(\mathrm{O}) \mathrm{CNc} 1 \mathrm{cc} 2 \mathrm{c}(\mathrm{Nc} 3 \mathrm{cccc}(\mathrm{Br}) \mathrm{c} 3) \mathrm{ncnc} 2 \mathrm{cn} 1$ & 0.28 & * \\
\hline 57 & $\mathrm{O}=\mathrm{C}(\mathrm{O}) \mathrm{CCCNc} 1 \mathrm{c}(\mathrm{Br}) \mathrm{cccc} 1 \mathrm{Nc} 1 \mathrm{ncnc} 2 \mathrm{ccncc} 12$ & 0.2818 & * \\
\hline 58 & $\mathrm{CNC} / \mathrm{C}=\mathrm{C} / \mathrm{C}(=\mathrm{O}) \mathrm{Nc} 1 \mathrm{cc} 2 \mathrm{c}(\mathrm{Nc} 3 \mathrm{ccc}(\mathrm{F}) \mathrm{c}(\mathrm{Cl}) \mathrm{c} 3) \mathrm{c}(\mathrm{C \# N}) \mathrm{cnc} 2 \mathrm{cc} 1 \mathrm{OCCF}$ & 0.29 & 9.54 \\
\hline 59 & $\mathrm{CCOc} 1 \mathrm{cc} 2 \mathrm{ncnc}(\mathrm{Nc} 3 \mathrm{ccc}(\mathrm{F}) \mathrm{c}(\mathrm{Cl}) \mathrm{c} 3) \mathrm{c} 2 \mathrm{cc} 1 \mathrm{NC}(=\mathrm{O}) \mathrm{CCN} 1 \mathrm{CCOCC} 1$ & 0.29 & 9.54 \\
\hline 60 & $\mathrm{C}=\mathrm{CC}(=\mathrm{O}) \mathrm{Nc} 1 \mathrm{cccc}(\mathrm{N} 2 \mathrm{C}(=\mathrm{O}) \mathrm{N}(\mathrm{Cc} 3 \operatorname{cccc} 3) \mathrm{Cc} 3 \operatorname{cnc}(\mathrm{Nc} 4 \mathrm{ccc}(\mathrm{N} 5 \mathrm{CCN}(\mathrm{C}) \mathrm{CC} 5) \mathrm{cc} 4 \mathrm{OC}) \mathrm{nc} 32) \mathrm{c} 1$ & 0.29 & 9.54 \\
\hline 61 & $\mathrm{Cc} 1 \mathrm{nc} 2 \mathrm{cc} 3 \mathrm{c}(\mathrm{Nc} 4 \mathrm{cccc}(\mathrm{Br}) \mathrm{c} 4) \mathrm{ncnc} 3 \mathrm{cc} 2[\mathrm{nH}] 1$ & 0.29 & $*$ \\
\hline 62 & $\mathrm{COc} 1 \mathrm{cc} 2 \mathrm{ncnc}(\mathrm{Nc} 3 \operatorname{ccc}(\mathrm{F}) \mathrm{c}(\mathrm{Cl}) \mathrm{c} 3) \mathrm{c} 2 \mathrm{cc} 1 \mathrm{NC}(=\mathrm{O}) / \mathrm{C}(\mathrm{F})=\mathrm{ClCN} 1 \mathrm{CCOCC} 1$ & 0.3 & 9.52 \\
\hline 63 & $\mathrm{C}=\mathrm{CC}(=\mathrm{O}) \mathrm{Nc} 1 \operatorname{ccc}(\mathrm{N} 2 \mathrm{C}(=\mathrm{O}) \mathrm{N}(\mathrm{c} 3 \operatorname{ccccc} 3) \mathrm{Cc} 3 \mathrm{cnc}(\mathrm{Nc} 4 \mathrm{ccc}(\mathrm{N} 5 \mathrm{CCN}(\mathrm{C}) \mathrm{CC} 5) \mathrm{cc} 4 \mathrm{OC}) \mathrm{nc} 32) \mathrm{c} 1$ & 0.3 & 9.52 \\
\hline 64 & $\mathrm{CC} \# \mathrm{CC}(=\mathrm{O}) \mathrm{Nc} 1 \mathrm{cc} 2 \mathrm{c}(\mathrm{Nc} 3 \mathrm{ccc}(\mathrm{F}) \mathrm{c}(\mathrm{Cl}) \mathrm{c} 3) \mathrm{ncnc} 2 \mathrm{cn} 1$ & 0.3 & * \\
\hline 65 & $\mathrm{COc} 1 \mathrm{cc} 2 \mathrm{ncnc}(\mathrm{Nc} 3 \operatorname{cccc}(\mathrm{Cl}) \mathrm{c} 3 \mathrm{~F}) \mathrm{c} 2 \mathrm{cc} 1 \mathrm{OC}(=\mathrm{O}) \mathrm{N} 1 \mathrm{CCN}(\mathrm{C}) \mathrm{C}[\mathrm{C} @ \mathrm{H}] 1 \mathrm{C}$ & 0.3 & * \\
\hline 66 & $\operatorname{COc} 1 \mathrm{cc} 2 n \mathrm{ncnc}(\mathrm{Nc} 3 \operatorname{cccc}(\mathrm{Br}) \mathrm{c} 3) \mathrm{c} 2 \mathrm{cc} 1 \mathrm{OCCCOP}(\mathrm{N})(=\mathrm{O}) \mathrm{N}(\mathrm{CCCl}) \mathrm{CCCl}$ & 0.3 & $*$ \\
\hline 67 & OCCc1nc(-c2 $\operatorname{ccc}(\mathrm{F}) \mathrm{cc} 2) \mathrm{c}(-\mathrm{c} 2 \mathrm{ccnc} 3[\mathrm{nH}] \mathrm{c}(-\mathrm{c} 4 \mathrm{ccccc} 4) \mathrm{cc} 23)[\mathrm{nH}] 1$ & 0.3 & $*$ \\
\hline 68 & OCCCCc1nc(-c2 $2 \mathrm{ccc}(\mathrm{F}) \mathrm{cc} 2) \mathrm{c}(-\mathrm{c} 2 \mathrm{ccnc} 3[\mathrm{nH}] \mathrm{c}(-\mathrm{c} 4 \mathrm{ccccc} 4) \mathrm{cc} 23)[\mathrm{nH}] 1$ & 0.3 & $*$ \\
\hline 69 & $\mathrm{C}=\mathrm{CC}(=\mathrm{O}) \mathrm{Nc} 1 \mathrm{cccc}(-\mathrm{c} 2 \mathrm{c}[\mathrm{nH}] \mathrm{c} 3 \mathrm{nccc}(-\mathrm{c} 4[\mathrm{nH}] \mathrm{c}(\mathrm{CCCO}) \mathrm{nc} 4-\mathrm{c} 4 \mathrm{ccc}(\mathrm{F}) \mathrm{cc} 4) \mathrm{c} 23) \mathrm{c} 1$ & 0.3 & * \\
\hline 70 & 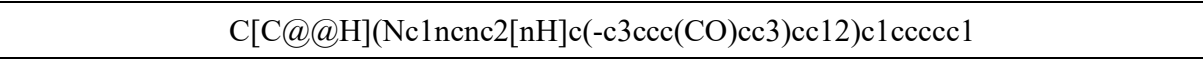 & 0.3 & $*$ \\
\hline 71 & $\mathrm{COc} 1 \mathrm{cc}(\mathrm{C}=\mathrm{O}) \mathrm{ccc} 1-\mathrm{c} 1 \mathrm{cc} 2 \mathrm{c}(\mathrm{N}[\mathrm{C} @ \mathrm{H}](\mathrm{CO}) \mathrm{c} 3 \mathrm{ccccc} 3) \mathrm{ncnc} 2[\mathrm{nH}] 1$ & 0.3 & $*$ \\
\hline 72 & $\mathrm{C}[\mathrm{C} @ @ \mathrm{H}](\mathrm{Nc} 1 \mathrm{ncnc} 2[\mathrm{nH}] \mathrm{c}(-\mathrm{c} 3 \mathrm{cccc}(\mathrm{CO}) \mathrm{c} 3) \mathrm{cc} 12) \mathrm{c} 1 \mathrm{ccccc} 1$ & 0.3 & * \\
\hline 73 & OCc1 ccc(-c2cc3c(N[C@H](CO)c4ccccc4)ncnc3[nH]2)c(F)c1 & 0.3 & $*$ \\
\hline 74 & COc1cc2ncnc(Nc3ccc(OCc4ccce(F)c4)c(Cl)c3)c2cc1OCCCN1CCNCCNCCNCC1 & 0.3 & * \\
\hline 75 & $\mathrm{CN}(\mathrm{C}) \mathrm{C} / \mathrm{C}=\mathrm{C}(/ \mathrm{F}) \mathrm{C}(=\mathrm{O}) \mathrm{Nc} 1 \mathrm{cc} 2 \mathrm{c}(\mathrm{Nc} 3 \mathrm{ccc}(\mathrm{F}) \mathrm{c}(\mathrm{Cl}) \mathrm{c} 3) \mathrm{ncnc} 2 \mathrm{cc} 1 \mathrm{O}[\mathrm{C} @ \mathrm{H}] 1 \mathrm{CCOC} 1$ & 0.31 & 9.51 \\
\hline 76 & $\mathrm{COc} 1 \mathrm{cc} 2 \mathrm{c}(\mathrm{Nc} 3 \operatorname{ccc}(\mathrm{F}) \mathrm{c}(\mathrm{Cl}) \mathrm{c} 3) \mathrm{ncnc} 2 \mathrm{cc} 1 \mathrm{OCCCCn} 1 \mathrm{ccnc} 1[\mathrm{~N}+](=\mathrm{O})[\mathrm{O}-]$ & 0.31 & 9.51 \\
\hline 77 & $\mathrm{COc} 1 \mathrm{cc} 2 \mathrm{ncnc}(\mathrm{Nc} 3 \mathrm{cccc}(\mathrm{Cl}) \mathrm{c} 3) \mathrm{c} 2 \mathrm{cc} 1 \mathrm{OC}$ & 0.31 & $*$ \\
\hline 78 & $\operatorname{COc} 1 \mathrm{cc} 2 \mathrm{ncnc}(\mathrm{Nc} 3 \mathrm{ccc}(\mathrm{F}) \mathrm{c}(\mathrm{Cl}) \mathrm{c} 3) \mathrm{c} 2 \mathrm{cc} 1 \mathrm{OCCCCCCn} 1 \mathrm{ccnc} 1[\mathrm{~N}+](=\mathrm{O})[\mathrm{O}-]$ & 0.32 & 9.49 \\
\hline 79 & $\operatorname{COc} 1 \mathrm{cc} 2 \mathrm{c}(\mathrm{Nc} 3 \mathrm{ccc}(\mathrm{F}) \mathrm{c}(\mathrm{Cl}) \mathrm{c} 3) \mathrm{ncnc} 2 \mathrm{cc} 1 \mathrm{OCCOCCn} 1 \mathrm{ccnc} 1[\mathrm{~N}+](=\mathrm{O})[\mathrm{O}-]$ & 0.32 & 9.49 \\
\hline 80 & $\mathrm{COc} 1 \mathrm{cc} 2 \mathrm{c}(\mathrm{Nc} 3 \operatorname{ccc}(\mathrm{Br}) \mathrm{c} 3) n \mathrm{ncnc} 2 \mathrm{cc} 1 \mathrm{OCCCCCn} 1 \mathrm{ccnc} 1[\mathrm{~N}+](=\mathrm{O})[\mathrm{O}-]$ & 0.33 & 9.48 \\
\hline 81 & 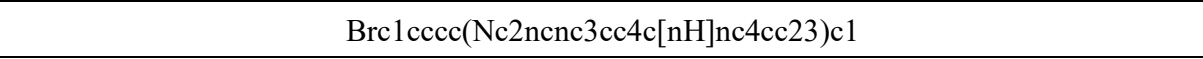 & 0.34 & $*$ \\
\hline 82 & $\mathrm{OCCN}(\mathrm{CCO}) \mathrm{CCCNc} 1 \mathrm{cc} 2 \mathrm{c}(\mathrm{Nc} 3 \mathrm{cccc}(\mathrm{Br}) \mathrm{c} 3) \mathrm{ncnc} 2 \mathrm{cn} 1$ & 0.35 & * \\
\hline 83 & $\mathrm{Nc} 1 \mathrm{ccc} 2 \mathrm{c}(\mathrm{Nc} 3 \mathrm{cccc}(\mathrm{I}) \mathrm{c} 3) \mathrm{ncnc} 2 \mathrm{c} 1$ & 0.35 & $*$ \\
\hline 84 & $\mathrm{COc} 1 \mathrm{cc} 2 \mathrm{c}(\mathrm{Nc} 3 \operatorname{ccc}(\mathrm{Br}) \mathrm{c} 3) \mathrm{ncnc} 2 \mathrm{cc} 1 \mathrm{OCCCCn} 1 \mathrm{ccnc} 1[\mathrm{~N}+](=\mathrm{O})[\mathrm{O}-]$ & 0.37 & 9.43 \\
\hline 85 & $\mathrm{Cn} 1 \mathrm{ncc} 2 \mathrm{cc} 3 \mathrm{c}(\mathrm{Nc} 4 \mathrm{cccc}(\mathrm{Br}) \mathrm{c} 4) \mathrm{ncnc} 3 \mathrm{cc} 21$ & 0.37 & $*$ \\
\hline 86 & $\mathrm{O}=\mathrm{C}(\mathrm{O}) / \mathrm{C}=\mathrm{C} / \mathrm{C}(=\mathrm{O}) \mathrm{Nc} 1 \mathrm{ccc} 2 \mathrm{ncnc}(\mathrm{Nc} 3 \operatorname{cccc}(\mathrm{Br}) \mathrm{c} 3) \mathrm{c} 2 \mathrm{c} 1$ & 0.37 & * \\
\hline 87 & $\mathrm{C}=\mathrm{CC}(=\mathrm{O}) \mathrm{Nc} 1 \operatorname{cccc}(\mathrm{N} 2 \mathrm{C}(=\mathrm{O}) \mathrm{N}(\mathrm{C}(\mathrm{C}) \mathrm{C}) \mathrm{Cc} 3 \mathrm{cnc}(\mathrm{Nc} 4 \operatorname{ccc}(\mathrm{N} 5 \mathrm{CCN}(\mathrm{C}) \mathrm{CC} 5) \operatorname{cc} 4 \mathrm{OC}) \mathrm{nc} 32) \mathrm{c} 1$ & 0.38 & 9.42 \\
\hline 88 & $\mathrm{C}[\mathrm{C} @ @ \mathrm{H}](\mathrm{Nc} 1 \mathrm{ncn} 2 \mathrm{oc}(-\mathrm{c} 3 \mathrm{ccc}(\mathrm{NCCN}(\mathrm{C}) \mathrm{C}) \mathrm{cc} 3) \mathrm{cc} 12) \mathrm{c} 1 \mathrm{ccccc} 1$ & 0.4 & 9.40 \\
\hline
\end{tabular}




\begin{tabular}{|c|c|c|c|}
\hline 89 & $\operatorname{COc} 1 \mathrm{cc}(\mathrm{C}(=\mathrm{O}) \mathrm{NCCN}(\mathrm{C}) \mathrm{C}) \mathrm{cc}(\mathrm{OC}) \mathrm{c} 1-\mathrm{c} 1 \mathrm{cc} 2 \mathrm{c}(\mathrm{N}[\mathrm{C} @ \mathrm{H}](\mathrm{C}) \mathrm{c} 3 \mathrm{cccc} 3) n \mathrm{ncnc} 2 \mathrm{~s} 1$ & 0.4 & 9.40 \\
\hline 90 & $\mathrm{C}=\mathrm{CC}(=\mathrm{O}) \mathrm{Nc} 1 \mathrm{ccc} 2 \mathrm{ncnc}(\mathrm{N} 3 \mathrm{CCc} 4 \mathrm{ccc}(\mathrm{Br}) \mathrm{cc} 43) \mathrm{c} 2 \mathrm{c} 1$ & 0.4 & $*$ \\
\hline 91 & OCc1 $1 \mathrm{ccc}(-\mathrm{c} 2 \mathrm{cc} 3 \mathrm{c}(\mathrm{N}[\mathrm{C} @ \mathrm{H}](\mathrm{CO}) \mathrm{c} 4 \mathrm{ccccc} 4) \mathrm{ncnc} 3[\mathrm{nH}] 2) \mathrm{cc} 1$ & 0.4 & $*$ \\
\hline 92 & COC[C@@H](Nc1ncnc2[nH]c(-c3ecccc3)cc12)c1 ccccc1 & 0.4 & * \\
\hline 93 & Brc1 $1 \mathrm{ccc}(\mathrm{Nc} 2 \mathrm{ncnc} 3 \mathrm{ccc}(\mathrm{NCCCN} 4 \mathrm{CCCCC} 4) \mathrm{cc} 23) \mathrm{c} 1$ & 0.41 & 9.39 \\
\hline 94 & $\mathrm{C}=\mathrm{CC}(=\mathrm{O}) \mathrm{Nc} 1 \mathrm{cccc}(\mathrm{N} 2 \mathrm{C}(=\mathrm{O}) \mathrm{N}(\mathrm{C}) \mathrm{Cc} 3 \operatorname{cnc}(\mathrm{Nc} 4 \mathrm{ccc}(\mathrm{N} 5 \mathrm{CCN}(\mathrm{C}) \mathrm{CC} 5) \mathrm{c}(\mathrm{OC}) \mathrm{c} 4) \mathrm{nc} 32) \mathrm{c} 1$ & 0.41 & 9.39 \\
\hline 95 & $\mathrm{CCOC} 1=\mathrm{C} 2 \mathrm{C}(=\mathrm{CCc} 3 \mathrm{c} 2 \mathrm{sc}(\mathrm{N}) \mathrm{c} 3 \mathrm{C}(=\mathrm{O}) \mathrm{Nc} 2 \mathrm{ccc}(\mathrm{Cl}) \mathrm{cc} 2) \mathrm{OC}(\mathrm{O})=\mathrm{C} 1 \mathrm{C} \# \mathrm{~N}$ & 0.41 & $*$ \\
\hline 96 & $\mathrm{C}=\mathrm{CC}(=\mathrm{O}) \mathrm{Nc} 1 \mathrm{ccc} 2 \mathrm{ncnc}(\mathrm{Nc} 3 \operatorname{cccc}(\mathrm{C}) \mathrm{c} 3) \mathrm{c} 2 \mathrm{c} 1$ & 0.42 & * \\
\hline 97 & $\mathrm{CC} 1(\mathrm{C}) \mathrm{C} 2=\mathrm{C}(\mathrm{OC}(\mathrm{O})=\mathrm{C}(\mathrm{C} \# \mathrm{~N}) \mathrm{C} 2 \mathrm{c} 2 \mathrm{cccc} 2) \mathrm{C}(=\mathrm{NNc} 2 \mathrm{ccc}(\mathrm{Cl}) \mathrm{cc} 2) \mathrm{c} 2 \mathrm{c} 1 \mathrm{sc}(\mathrm{N}) \mathrm{c} 2 \mathrm{C \# N}$ & 0.42 & * \\
\hline 98 & $\mathrm{Nc} 1 \mathrm{sc} 2 \mathrm{c}(\mathrm{c} 1 \mathrm{C}(=\mathrm{O}) \mathrm{Nc} 1 \mathrm{ccc}(\mathrm{Cl}) \mathrm{cc} 1) \mathrm{CCC}(=\mathrm{O}) \mathrm{C} 2=\mathrm{NNc} 1 \mathrm{ccc}(\mathrm{Cl}) \mathrm{cc} 1$ & 0.42 & $*$ \\
\hline 99 & $\mathrm{C}=\mathrm{CC}(=\mathrm{O}) \mathrm{Nc} 1 \mathrm{cccc}(\mathrm{N} 2 \mathrm{C}(=\mathrm{O}) \mathrm{N}(\mathrm{C}) \mathrm{Cc} 3 \mathrm{cnc}(\mathrm{Nc} 4 \mathrm{ccc}(\mathrm{N} 5 \mathrm{CCN}(\mathrm{C}) \mathrm{CC} 5) \mathrm{cc} 4) \mathrm{nc} 32) \mathrm{c} 1$ & 0.43 & 9.37 \\
\hline 100 & $\mathrm{C}=\mathrm{CS}(=\mathrm{O})(=\mathrm{O}) \mathrm{c} 1 \mathrm{cc} 2 \mathrm{c}(\mathrm{Nc} 3 \mathrm{cccc}(\mathrm{Br}) \mathrm{c} 3) \mathrm{ncnc} 2 \mathrm{cn} 1$ & 0.43 & $*$ \\
\hline 101 & $\operatorname{Brc1} 1 \mathrm{ccc}(\mathrm{Nc} 2 \mathrm{ncnc} 3 \mathrm{cc} 4[\mathrm{nH}] \mathrm{ncc} 4 \mathrm{cc} 23) \mathrm{c} 1$ & 0.44 & $*$ \\
\hline 102 & Brc1 $1 \mathrm{ccc}(\mathrm{Nc} 2 \mathrm{ncnc} 3 \mathrm{cc} 4[\mathrm{nH}] \mathrm{ccc} 4 \mathrm{cc} 23) \mathrm{c} 1$ & 0.44 & $*$ \\
\hline 103 & $\mathrm{CN}(\mathrm{CC}(=\mathrm{O}) \mathrm{O}) \mathrm{c} 1 \mathrm{cc} 2 \mathrm{c}(\mathrm{Nc} 3 \mathrm{cccc}(\mathrm{Br}) \mathrm{c} 3) \mathrm{ncnc} 2 \mathrm{cn} 1$ & 0.44 & * \\
\hline 104 & $\mathrm{CN}(\mathrm{C}) \mathrm{CCCNC}(=\mathrm{O}) / \mathrm{C}=\mathrm{C} / \mathrm{C}(=\mathrm{O}) \mathrm{Nc} 1 \mathrm{ccc} 2 \mathrm{ncnc}(\mathrm{Nc} 3 \mathrm{cccc}(\mathrm{Br}) \mathrm{c} 3) \mathrm{c} 2 \mathrm{c} 1$ & 0.44 & * \\
\hline 105 & $\mathrm{CNc} 1 \mathrm{cc} 2 \mathrm{c}(\mathrm{Nc} 3 \mathrm{cccc}(\mathrm{C}) \mathrm{c} 3) \mathrm{ncnc} 2 \mathrm{cn} 1$ & 0.45 & $*$ \\
\hline 106 & $\mathrm{C}=\mathrm{CC}(=\mathrm{O}) \mathrm{Nc} 1 \mathrm{ccc} 2 \mathrm{c}(\mathrm{Nc} 3 \mathrm{ccc}(\mathrm{Br}) \mathrm{c} 3) \mathrm{ncnc} 2 \mathrm{c} 1$ & 0.45 & $*$ \\
\hline 107 & $\mathrm{CCN}(\mathrm{CC}) \mathrm{CC}(\mathrm{O}) \mathrm{CNC}(=\mathrm{O}) \mathrm{c} 1 \mathrm{cc}(\mathrm{C}) \mathrm{c}(/ \mathrm{C}=\mathrm{C} 2 \backslash \mathrm{C}(=\mathrm{O}) \mathrm{Nc} 3 \mathrm{ncnc}(\mathrm{Nc} 4 \mathrm{ccc}(\mathrm{F}) \mathrm{c}(\mathrm{Cl}) \mathrm{c} 4) \mathrm{c} 32)[\mathrm{nH}] 1$ & 0.45 & $*$ \\
\hline 108 & COc1cc2ncnc(Nc3ccc(F)c(Cl)c3)c2cc1OCCCCn1 ccnc1 $[\mathrm{N}+](=\mathrm{O})[\mathrm{O}-]$ & 0.47 & 9.33 \\
\hline 109 & $\mathrm{C} \# \mathrm{Cc} 1 \mathrm{cccc}(\mathrm{Nc} 2 \mathrm{ncnc} 3 \mathrm{cc}(\mathrm{OCCCCCn} 4 \mathrm{ccnc} 4[\mathrm{~N}+](=\mathrm{O})[\mathrm{O}-]) \mathrm{c}(\mathrm{OC}) \mathrm{cc} 23) \mathrm{c} 1$ & 0.47 & 9.33 \\
\hline 110 & $\mathrm{COc1cc} 2 \mathrm{ncnc}(\mathrm{Nc} 3 \operatorname{cccc}(\mathrm{Br}) \mathrm{c} 3) \mathrm{c} 2 \mathrm{cc} 1 \mathrm{NC}(=\mathrm{O})[\mathrm{C} @ @ \mathrm{H}] 1 \mathrm{COC}(=\mathrm{O}) \mathrm{N} 1$ & 0.47 & 9.33 \\
\hline 111 & $\mathrm{Cl} . \mathrm{Nc} 1 \mathrm{ccc} 2 \mathrm{c}(\mathrm{c} 1) \operatorname{sc} 1 \mathrm{c}(\mathrm{Nc} 3 \operatorname{cccc}(\mathrm{Br}) \mathrm{c} 3) \mathrm{ncnc} 12$ & 0.47 & $*$ \\
\hline 112 & $\mathrm{C}=\mathrm{CC}(=\mathrm{O}) \mathrm{Nc} 1 \mathrm{cc} 2 \mathrm{c}(\mathrm{Nc} 3 \mathrm{cccc}(\mathrm{C}) \mathrm{c} 3) \mathrm{ncnc} 2 \mathrm{cn} 1$ & 0.48 & $*$ \\
\hline 113 & $\mathrm{CHCc} 1 \mathrm{cccc}(\mathrm{Nc} 2 \mathrm{ncnc} 3 \mathrm{cc}(\mathrm{OC}) \mathrm{c}(\mathrm{OCCCCCn} 4 \mathrm{ccnc} 4[\mathrm{~N}+](=\mathrm{O})[\mathrm{O}-]) \mathrm{cc} 23) \mathrm{c} 1$ & 0.49 & 9.31 \\
\hline 114 & $\mathrm{COc} 1 \mathrm{cc} 2 \mathrm{c}(\mathrm{Nc} 3 \operatorname{cccc}(\mathrm{Br}) \mathrm{c} 3) \mathrm{ncnc} 2 \mathrm{cc} 1 \mathrm{OCCCn} 1 \mathrm{ccnc} 1[\mathrm{~N}+](=\mathrm{O})[\mathrm{O}-]$ & 0.49 & 9.31 \\
\hline 115 & $\mathrm{O}=\mathrm{C}(\mathrm{O})[\mathrm{C} @ \mathrm{H}] 1 \mathrm{O}[\mathrm{C} @ @ \mathrm{H}] 1 \mathrm{C}(=\mathrm{O}) \mathrm{Nc} 1 \mathrm{ccc} 2 \mathrm{ncnc}(\mathrm{Nc} 3 \mathrm{cccc}(\mathrm{Br}) \mathrm{c} 3) \mathrm{c} 2 \mathrm{c} 1$ & 0.49 & 9.31 \\
\hline 116 & $\mathrm{CHCc} 1 \mathrm{cccc}(\mathrm{Nc} 2 \mathrm{ncnc} 3 \mathrm{cc}(\mathrm{OC}) \mathrm{c}(\mathrm{OCCCCCCn} 4 \mathrm{ccnc} 4[\mathrm{~N}+](=\mathrm{O})[\mathrm{O}-]) \mathrm{cc} 23) \mathrm{c} 1$ & 0.5 & 9.30 \\
\hline 117 & $\mathrm{O}=\mathrm{C}(\mathrm{O})[\mathrm{C} @ @ \mathrm{H}] 1 \mathrm{O}[\mathrm{C} @ \mathrm{H}] 1 \mathrm{C}(=\mathrm{O}) \mathrm{Nc} 1 \mathrm{ccc} 2 \mathrm{ncnc}(\mathrm{Nc} 3 \mathrm{cccc}(\mathrm{Br}) \mathrm{c} 3) \mathrm{c} 2 \mathrm{c} 1$ & 0.5 & 9.30 \\
\hline 118 & $\mathrm{COc1cc}(\mathrm{C}(=\mathrm{O}) \mathrm{NCCN}(\mathrm{C}) \mathrm{C}) \mathrm{ccc} 1-\mathrm{c} 1 \mathrm{cc} 2 \mathrm{c}(\mathrm{N}[\mathrm{C} @ \mathrm{H}](\mathrm{C}) \mathrm{c} 3 \mathrm{ccccc} 3) \mathrm{ncnc} 2 \mathrm{~s} 1$ & 0.5 & 9.30 \\
\hline 119 & $\operatorname{COc} 1 \mathrm{ccc}(\mathrm{C}(=\mathrm{O}) \mathrm{NCCN}(\mathrm{C}) \mathrm{C}) \mathrm{cc} 1-\mathrm{c} 1 \mathrm{cc} 2 \mathrm{c}(\mathrm{N}[\mathrm{C} @ \mathrm{H}](\mathrm{C}) \mathrm{c} 3 \mathrm{ccccc} 3) \mathrm{ncnc} 2 \mathrm{~s} 1$ & 0.5 & 9.30 \\
\hline 120 & $\mathrm{C}=\mathrm{CC}(=\mathrm{O}) \mathrm{N} 1 \mathrm{CC}[\mathrm{C} @ \mathrm{H}](\mathrm{N} 2 \mathrm{C}(=\mathrm{O}) \mathrm{N}(\mathrm{c} 3 \mathrm{ccccc} 3 \mathrm{Cl}) \mathrm{Cc} 3 \mathrm{cnc}(\mathrm{Nc} 4 \mathrm{ccc}(\mathrm{N} 5 \mathrm{CCN}(\mathrm{C}) \mathrm{CC} 5) \mathrm{c}(\mathrm{C}) \mathrm{c} 4) \mathrm{nc} 32) \mathrm{C} 1$ & 0.5 & 9.30 \\
\hline 121 & $\mathrm{CN} 1 \mathrm{CCN}(\mathrm{CCC} \# \mathrm{CC}(=\mathrm{O}) \mathrm{Nc} 2 \mathrm{cc} 3 \mathrm{c}(\mathrm{Nc} 4 \mathrm{ccc}(\mathrm{F}) \mathrm{c}(\mathrm{Cl}) \mathrm{c} 4) \mathrm{ncnc} 3 \mathrm{cn} 2) \mathrm{CC} 1$ & 0.5 & $*$ \\
\hline 122 & $\mathrm{C} / \mathrm{C}=\mathrm{C} / \mathrm{C}(=\mathrm{O}) \mathrm{Nc} 1 \mathrm{cc} 2 \mathrm{c}(\mathrm{Nc} 3 \operatorname{ccc}(\mathrm{Br}) \mathrm{c} 3) \mathrm{ncnc} 2 \mathrm{cn} 1$ & 0.5 & $*$ \\
\hline 123 & $\mathrm{COc} 1 \mathrm{cc} 2 \mathrm{ncnc}(\mathrm{Nc} 3 \mathrm{ccc}(\mathrm{F}) \mathrm{c}(\mathrm{Cl}) \mathrm{c} 3) \mathrm{c} 2 \mathrm{cc} 1 \mathrm{OCCCOP}(\mathrm{N})(=\mathrm{O}) \mathrm{N}(\mathrm{CCCl}) \mathrm{CCCl}$ & 0.5 & * \\
\hline 124 & OCCCc1nc(-c2 $2 \mathrm{ccc}(\mathrm{F}) \mathrm{cc} 2) \mathrm{c}(-\mathrm{c} 2 \mathrm{ccnc} 3[\mathrm{nH}] \mathrm{c}(-\mathrm{c} 4 \mathrm{ccccc} 4) \mathrm{cc} 23)[\mathrm{nH}] 1$ & 0.5 & $*$ \\
\hline 125 & $\mathrm{NCc} 1 \mathrm{cccc}(-\mathrm{c} 2 \mathrm{nc}(-\mathrm{c} 3 \mathrm{ccc}(\mathrm{F}) \mathrm{cc} 3) \mathrm{c}(-\mathrm{c} 3 \mathrm{ccnc} 4[\mathrm{nH}] \mathrm{c}(-\mathrm{c} 5 \mathrm{ccccc} 5) \mathrm{cc} 34)[\mathrm{nH}] 2) \mathrm{c} 1$ & 0.5 & $*$ \\
\hline 126 & $\mathrm{COc} 1 \mathrm{cc}(\mathrm{C}=\mathrm{O}) \mathrm{ccc} 1-\mathrm{c} 1 \mathrm{cc} 2 \mathrm{c}(\mathrm{N}[\mathrm{C} @ \mathrm{H}](\mathrm{C}) \mathrm{c} 3 \mathrm{ccccc} 3) \mathrm{ncnc} 2[\mathrm{nH}] 1$ & 0.5 & $*$ \\
\hline 127 & COc1cccc1-c1cc2c(N[C@H](CO)c3ccccs3)ncnc2[nH]1 & 0.5 & $*$ \\
\hline 128 & $\mathrm{COc} 1 \mathrm{cc}(\mathrm{C}=\mathrm{O}) \mathrm{ccc} 1-\mathrm{c} 1 \mathrm{cc} 2 \mathrm{c}(\mathrm{NCc} 3 \mathrm{ccccc} 3) \mathrm{ncnc} 2[\mathrm{nH}] 1$ & 0.5 & $*$ \\
\hline 129 & $\mathrm{COc} 1 \mathrm{cc} 2 \mathrm{ncnc}(\mathrm{Nc} 3 \mathrm{ccc}(\mathrm{F}) \mathrm{c}(\mathrm{Cl}) \mathrm{c} 3) \mathrm{c} 2 \mathrm{cc} 1 \mathrm{OCCCC} n 1 \mathrm{ccnc} 1[\mathrm{~N}+](=\mathrm{O})[\mathrm{O}-]$ & 0.51 & 9.29 \\
\hline 130 & $\mathrm{O}=\mathrm{C}(\mathrm{CCN} 1 \mathrm{CCOCC} 1) \mathrm{Nc} 1 \mathrm{ccc} 2 \mathrm{ncnc}(\mathrm{Nc} 3 \mathrm{cccc}(\mathrm{Br}) \mathrm{c} 3) \mathrm{c} 2 \mathrm{c} 1$ & 0.51 & 9.29 \\
\hline 131 & $\mathrm{CCOc} 1 \mathrm{cc} 2 \mathrm{ncnc}(\mathrm{Nc} 3 \mathrm{ccc}(\mathrm{F}) \mathrm{c}(\mathrm{Cl}) \mathrm{c} 3) \mathrm{c} 2 \mathrm{cc} 1 \mathrm{NC}(=\mathrm{O}) \mathrm{CCN} 1 \mathrm{CCCCC} 1$ & 0.51 & 9.29 \\
\hline
\end{tabular}




\begin{tabular}{|c|c|c|c|}
\hline 132 & Brc1 $1 \mathrm{ccc}(\mathrm{Nc} 2 \mathrm{ncnc} 3 \mathrm{cc}(\mathrm{NCCCn} 4 \mathrm{ccnc} 4) \mathrm{ncc} 23) \mathrm{c} 1$ & 0.51 & $*$ \\
\hline 133 & Brc1 $\operatorname{ccc}(\mathrm{Nc} 2 \mathrm{ncnc} 3 \mathrm{ccncc} 23) \mathrm{c} 1 \mathrm{NCCCn} 1 \mathrm{ccnc} 1$ & 0.5129 & $*$ \\
\hline 134 & $\mathrm{COc} 1 \mathrm{cc} 2 \mathrm{c}(\mathrm{Nc} 3 \mathrm{ccc}(\mathrm{F}) \mathrm{c}(\mathrm{Cl}) \mathrm{c} 3) \mathrm{ncn} 2 \mathrm{cc} 1 \mathrm{OCCCCCn} 1 \mathrm{ccn} 1[\mathrm{~N}+](=\mathrm{O})[\mathrm{O}-]$ & 0.52 & 9.28 \\
\hline 135 & $\mathrm{CC} 1(\mathrm{C}) \mathrm{Cc} 2 \mathrm{c}(\mathrm{nn}(-\mathrm{c} 3 \mathrm{ccc}(\mathrm{Cl}) \mathrm{cc} 3) \mathrm{c}(=\mathrm{O}) \mathrm{c} 2 \mathrm{C} \# \mathrm{~N})-\mathrm{c} 2 \mathrm{c} 1 \mathrm{sc}(\mathrm{N}) \mathrm{c} 2 \mathrm{C} \# \mathrm{~N}$ & 0.52 & $*$ \\
\hline 136 & $\mathrm{COc} 1 \mathrm{cc} 2 \mathrm{ncnc}(\mathrm{Nc} 3 \mathrm{ccc}(\mathrm{F}) \mathrm{c}(\mathrm{Cl}) \mathrm{c} 3) \mathrm{c} 2 \mathrm{cc} 1 \mathrm{NC}(=\mathrm{O}) / \mathrm{C}(\mathrm{F})=\mathrm{C} / \mathrm{CN} 1 \mathrm{CCOCC} 1$ & 0.53 & 9.28 \\
\hline 137 & $\operatorname{COc} 1 \mathrm{cc} 2 \mathrm{ncnc}(\mathrm{Nc} 3 \operatorname{ccc}(\mathrm{F}) \mathrm{c}(\mathrm{Cl}) \mathrm{c} 3) \mathrm{c} 2 \mathrm{cc} 1 \mathrm{OCCCCn} 1 \mathrm{c}([\mathrm{N}+](=\mathrm{O})[\mathrm{O}-]) \mathrm{cnc} 1 \mathrm{C}$ & 0.53 & 9.28 \\
\hline 138 & $\mathrm{C} \# \mathrm{Cc} 1 \mathrm{cccc}(\mathrm{Nc} 2 \mathrm{ncnc} 3 \mathrm{cc}(\mathrm{OCCOCCn} 4 \mathrm{ccnc} 4[\mathrm{~N}+](=\mathrm{O})[\mathrm{O}-]) \mathrm{c}(\mathrm{OC}) \mathrm{cc} 23) \mathrm{c} 1$ & 0.54 & 9.27 \\
\hline 139 & $\mathrm{C}=\mathrm{CC}(=\mathrm{O}) \mathrm{Nc} 1 \mathrm{cc} 2 \mathrm{ncnc}(\mathrm{Nc} 3 \operatorname{cccc}(\mathrm{Br}) \mathrm{c} 3) \mathrm{c} 2 \mathrm{cn} 1$ & 0.54 & $*$ \\
\hline 140 & $\mathrm{C} / \mathrm{C}=\mathrm{C} / \mathrm{C}(=\mathrm{O}) \mathrm{Nc} 1 \mathrm{ccc} 2 \mathrm{ncnc}(\mathrm{Nc} 3 \operatorname{ccc}(\mathrm{Br}) \mathrm{c} 3) \mathrm{c} 2 \mathrm{c} 1$ & 0.55 & $*$ \\
\hline 141 & $\mathrm{CHCc} 1 \mathrm{cccc}(\mathrm{Nc} 2 \mathrm{ncnc} 3 \mathrm{cc}(\mathrm{OC}) \mathrm{c}(\mathrm{OCCCCn} 4 \mathrm{ccnc} 4[\mathrm{~N}+](=\mathrm{O})[\mathrm{O}-]) \mathrm{cc} 23) \mathrm{c} 1$ & 0.56 & 9.25 \\
\hline 142 & $\mathrm{CN}(\mathrm{CC}(\mathrm{O}) \mathrm{CO}) \mathrm{c} 1 \mathrm{cc} 2 \mathrm{c}(\mathrm{Nc} 3 \mathrm{cccc}(\mathrm{Br}) \mathrm{c} 3) \mathrm{ncnc} 2 \mathrm{cn} 1$ & 0.56 & * \\
\hline 143 & $\mathrm{O}=\mathrm{C}(/ \mathrm{C}=\mathrm{C} / \mathrm{C}(=\mathrm{O}) \mathrm{Nc} 1 \mathrm{cc} 2 \mathrm{c}(\mathrm{Nc} 3 \mathrm{ccc}(\mathrm{Br}) \mathrm{c} 3) \mathrm{ncnc} 2 \mathrm{cn} 1) \mathrm{NCCCn} 1 \mathrm{ccnc} 1$ & 0.56 & $*$ \\
\hline 144 & $\mathrm{C \# Cc} 1 \mathrm{cccc}(\mathrm{Nc} 2 \mathrm{ncnc} 3 \mathrm{cc}(\mathrm{OCCCCCCn} 4 \mathrm{ccnc} 4[\mathrm{~N}+](=\mathrm{O})[\mathrm{O}-]) \mathrm{c}(\mathrm{OC}) \mathrm{cc} 23) \mathrm{c} 1$ & 0.57 & 9.24 \\
\hline 145 & $\mathrm{CCOc} 1 \mathrm{cc} 2 \mathrm{ncc}(\mathrm{C \# N}) \mathrm{c}(\mathrm{Nc} 3 \mathrm{ccc}(\mathrm{F}) \mathrm{c}(\mathrm{Cl}) \mathrm{c} 3) \mathrm{c} 2 \mathrm{cc} 1 \mathrm{NC}(=\mathrm{O}) / \mathrm{C}=\mathrm{C} / \mathrm{CN}(\mathrm{C}) \mathrm{Cc} 1 \mathrm{ccc}(\mathrm{F}) \mathrm{cc} 1$ & 0.57 & 9.24 \\
\hline 146 & $\mathrm{C}=\mathrm{CC}(=\mathrm{O}) \mathrm{Nc} 1 \mathrm{ccc}(\mathrm{N} 2 \mathrm{C}(=\mathrm{O}) \mathrm{N}(\mathrm{C} 3 \mathrm{CC} 3) \mathrm{Cc} 3 \mathrm{cnc}(\mathrm{Nc} 4 \mathrm{ccc}(\mathrm{N} 5 \mathrm{CCN}(\mathrm{C}) \mathrm{CC} 5) \mathrm{cc} 4 \mathrm{OC}) \mathrm{nc} 32) \mathrm{c} 1$ & 0.58 & 9.24 \\
\hline 147 & $\mathrm{CHCc} 1 \mathrm{ccc}(\mathrm{Nc} 2 \mathrm{ncnc} 3 \mathrm{cc}(\mathrm{OCCOC}) \mathrm{c}(\mathrm{OCCOC}) \mathrm{cc} 23) \mathrm{c} 1$ & 0.6 & 7.86 \\
\hline 148 & $\mathrm{CCOc} 1 \mathrm{cc} 2 \mathrm{ncc}(\mathrm{C \# N}) \mathrm{c}(\mathrm{Nc} 3 \operatorname{ccc}(\mathrm{F}) \mathrm{c}(\mathrm{Cl}) \mathrm{c} 3) \mathrm{c} 2 \mathrm{cc} 1 \mathrm{NC}(=\mathrm{O}) / \mathrm{C}=\mathrm{C} / \mathrm{CN}(\mathrm{C}) \mathrm{C}$ & 0.6 & 8.00 \\
\hline 149 & C[C@@H](Nc1ncnc2oc(-c3ccc(NCCN4CCCCC4)cc3)cc12)c1 ccccc1 & 0.6 & 9.22 \\
\hline 150 & $\mathrm{C \# CC}(=\mathrm{O}) \mathrm{Nc} 1 \mathrm{cc} 2 \mathrm{c}(\mathrm{Nc} 3 \mathrm{ccc}(\mathrm{Br}) \mathrm{c} 3) \mathrm{ncnc} 2 \mathrm{cn} 1$ & 0.6 & $*$ \\
\hline 151 & $\mathrm{O}=\mathrm{Cc} 1 \mathrm{ccc}(-\mathrm{c} 2 \mathrm{cc} 3 \mathrm{c}(\mathrm{N}[\mathrm{C} @ \mathrm{H}](\mathrm{CO}) \mathrm{c} 4 \mathrm{ccccc} 4) \mathrm{ncnc} 3[\mathrm{nH}] 2) \mathrm{c}(\mathrm{F}) \mathrm{c} 1$ & 0.6 & $*$ \\
\hline 152 & $\mathrm{O}=\mathrm{C}(\mathrm{O}) \mathrm{CCNc} 1 \mathrm{cc} 2 \mathrm{ncnc}(\mathrm{Nc} 3 \mathrm{ccc}(\mathrm{Br}) \mathrm{c} 3) \mathrm{c} 2 \mathrm{cn} 1$ & 0.61 & $*$ \\
\hline 153 & $\mathrm{O}=\mathrm{C}(/ \mathrm{C}=\mathrm{C} / \mathrm{C}(=\mathrm{O}) \mathrm{Nc} 1 \mathrm{cc} 2 \mathrm{c}(\mathrm{Nc} 3 \operatorname{ccc}(\mathrm{F}) \mathrm{c}(\mathrm{Cl}) \mathrm{c} 3) \mathrm{ncn} \operatorname{con} 1) \mathrm{NCCCN} 1 \mathrm{CCOCC} 1$ & 0.61 & $*$ \\
\hline 154 & $\mathrm{O}=\mathrm{C}(\mathrm{O}) \mathrm{CCNc} 1 \mathrm{c}(\mathrm{Br}) \mathrm{cccc} 1 \mathrm{Nc} 1 \mathrm{ncnc} 2 \mathrm{ccncc} 12$ & 0.6166 & $*$ \\
\hline 155 & $\operatorname{CCOC}(=\mathrm{O}) \mathrm{c} 1 \mathrm{cc}(\mathrm{N}) \mathrm{c}(\mathrm{C}(=\mathrm{O}) \mathrm{OCC}) \mathrm{c} 2 \mathrm{c} 1 \mathrm{C}(\mathrm{C})(\mathrm{C}) \mathrm{Cc} 1 \mathrm{c}-2 \mathrm{sc}(=\mathrm{S}) \mathrm{n} 1-\mathrm{c} 1 \mathrm{cccc} 1$ & 0.62 & $*$ \\
\hline 156 & $\mathrm{Nc} 1 \mathrm{sc} 2 \mathrm{c}(\mathrm{c} 1 \mathrm{C}(=\mathrm{O}) \mathrm{Nc} 1 \mathrm{ccc}([\mathrm{N}+](=\mathrm{O})[\mathrm{O}-]) \mathrm{cc} 1) \mathrm{CCC}(=\mathrm{O}) \mathrm{C} 2=\mathrm{NNc} 1 \mathrm{ccc}(\mathrm{Cl}) \mathrm{cc} 1$ & 0.62 & $*$ \\
\hline 157 & $\mathrm{O}=\mathrm{C}(\mathrm{CCCN} 1 \mathrm{CCCCC} 1) \mathrm{Nc} 1 \mathrm{ccc} 2 \mathrm{ncnc}(\mathrm{Nc} 3 \mathrm{ccc}(\mathrm{Br}) \mathrm{c} 3) \mathrm{c} 2 \mathrm{c} 1$ & 0.63 & 9.20 \\
\hline 158 & $\mathrm{COc} 1 \mathrm{ccc}(\mathrm{NN}=\mathrm{C} 2 \mathrm{C}(=\mathrm{O}) \mathrm{CCc} 3 \mathrm{c} 2 \mathrm{sc}(\mathrm{N}) \mathrm{c} 3 \mathrm{C}(=\mathrm{O}) \mathrm{Nc} 2 \mathrm{ccc}(\mathrm{Cl}) \mathrm{cc} 2) \mathrm{cc} 1$ & 0.63 & $*$ \\
\hline 159 & $\mathrm{CCOC}(=\mathrm{O}) \mathrm{c} 1 \mathrm{c}(\mathrm{NC}(=\mathrm{O}) \mathrm{CCl}) \operatorname{sc} 2 \mathrm{c} 1-\mathrm{c} 1 \mathrm{sc}(=\mathrm{S}) \mathrm{n}(-\mathrm{c} 3 \operatorname{cccc} 3) \mathrm{c} 1 \mathrm{CC} 2(\mathrm{C}) \mathrm{C}$ & 0.64 & $*$ \\
\hline 160 & $\mathrm{C} \# \mathrm{Cc} 1 \mathrm{cccc}(\mathrm{Nc} 2 \mathrm{ncnc} 3 \mathrm{cc}(\mathrm{OCCCn} 4 \mathrm{ccnc} 4[\mathrm{~N}+](=\mathrm{O})[\mathrm{O}-]) \mathrm{c}(\mathrm{OC}) \mathrm{cc} 23) \mathrm{c} 1$ & 0.65 & 9.19 \\
\hline 161 & $\mathrm{O}=\mathrm{C}(\mathrm{CCCCCn} 1 \mathrm{cc}(-\mathrm{c} 2 \mathrm{ccc} 3 \mathrm{ncnc}(\mathrm{Nc} 4 \mathrm{ccc}(\mathrm{F}) \mathrm{c}(\mathrm{Cl}) \mathrm{c} 4) \mathrm{c} 3 \mathrm{c} 2) \mathrm{nn} 1) \mathrm{NO}$ & 0.65 & $*$ \\
\hline 162 & Brc1cece(Nc2ncnc3enc(NCCN4CCOCC4)cc23)c1 & 0.65 & $*$ \\
\hline 163 & $\mathrm{COc} 1 \mathrm{cc} 2 \mathrm{ncnc}(\mathrm{Nc} 3 \operatorname{ccc}(\mathrm{Br}) \mathrm{c} 3) \mathrm{c} 2 \mathrm{cc} 1 \mathrm{OCCCn} 1 \mathrm{ccnc} 1[\mathrm{~N}+](=\mathrm{O})[\mathrm{O}-]$ & 0.66 & 9.18 \\
\hline 164 & $\mathrm{COc} 1 \mathrm{cc} 2 \mathrm{ncnc}(\mathrm{Nc} 3 \operatorname{ccc}(\mathrm{F}) \mathrm{c}(\mathrm{Cl}) \mathrm{c} 3) \mathrm{c} 2 \mathrm{cc} 1 \mathrm{NC}(=\mathrm{O}) / \mathrm{C}(\mathrm{F})=\mathrm{C} \backslash \mathrm{CN} 1 \mathrm{CCCCC} 1$ & 0.67 & 9.17 \\
\hline 165 & $\mathrm{COc} 1 \mathrm{cc} 2 \mathrm{ncnc}(\mathrm{Nc} 3 \mathrm{cccc}(\mathrm{Br}) \mathrm{c} 3) \mathrm{c} 2 \mathrm{c}(\mathrm{OC}) \mathrm{c} 1 \mathrm{OC}$ & 0.67 & $*$ \\
\hline 166 & $\mathrm{CCOc} 1 \mathrm{cc} 2 \mathrm{ncc}(\mathrm{CHN}) \mathrm{c}(\mathrm{Nc} 3 \operatorname{ccc}(\mathrm{F}) \mathrm{c}(\mathrm{Cl}) \mathrm{c} 3) \mathrm{c} 2 \mathrm{cc} 1 \mathrm{NC}(=\mathrm{O}) \mathrm{CCN}(\mathrm{C}) \mathrm{C}$ & 0.68 & 9.17 \\
\hline 167 & $\mathrm{O}=\mathrm{C}(\mathrm{CCCCCCn} 1 \mathrm{cc}(-\mathrm{c} 2 \mathrm{ccc} 3 \mathrm{ncnc}(\mathrm{Nc} 4 \mathrm{ccc}(\mathrm{F}) \mathrm{c}(\mathrm{Cl}) \mathrm{c} 4) \mathrm{c} 3 \mathrm{c} 2) \mathrm{nn} 1) \mathrm{NO}$ & 0.69 & $*$ \\
\hline 168 & $\mathrm{C}=\mathrm{CC}(=\mathrm{O}) \mathrm{Nc} 1 \mathrm{ccc} 2 \mathrm{ncnc}(\mathrm{Nc} 3 \mathrm{ccc}(\mathrm{F}) \mathrm{c}(\mathrm{Br}) \mathrm{c} 3) \mathrm{c} 2 \mathrm{c} 1$ & 0.69 & $*$ \\
\hline 169 & $\mathrm{CNc} 1 \mathrm{cc} 2 \mathrm{ncnc}(\mathrm{Nc} 3 \operatorname{ccc}(\mathrm{Br}) \mathrm{c} 3) \mathrm{c} 2 \mathrm{cc} 1 \mathrm{~N}$ & 0.69 & $*$ \\
\hline 170 & $\mathrm{O}=\mathrm{C}(/ \mathrm{C}=\mathrm{C} / \mathrm{Cl}) \mathrm{Nc} 1 \mathrm{cc} 2 \mathrm{c}(\mathrm{Nc} 3 \operatorname{ccc}(\mathrm{Br}) \mathrm{c} 3) \mathrm{ncnc} 2 \mathrm{cn} 1$ & 0.69 & $*$ \\
\hline 171 & $\mathrm{CC} 1(\mathrm{C}) \mathrm{Cc} 2 \mathrm{c}(\mathrm{sc}(=\mathrm{S}) \mathrm{n} 2-\mathrm{c} 2 \mathrm{ccccc} 2)-\mathrm{c} 2 \mathrm{c} 1 \mathrm{nn}(-\mathrm{c} 1 \mathrm{ccc}(\mathrm{Cl}) \mathrm{cc} 1) \mathrm{c}(=\mathrm{O}) \mathrm{c} 2 \mathrm{C} \# \mathrm{~N}$ & 0.69 & $*$ \\
\hline 172 & $\mathrm{CC} 1(\mathrm{C}) \mathrm{Cc} 2 \mathrm{c}(\mathrm{sc}(=\mathrm{S}) \mathrm{n} 2-\mathrm{c} 2 \mathrm{ccccc} 2)-\mathrm{c} 2 \mathrm{c} 1 \mathrm{sc}(\mathrm{NC}(=\mathrm{O}) \mathrm{CCl}) \mathrm{c} 2 \mathrm{C \# N}$ & 0.69 & $*$ \\
\hline 173 & OC[C@@H](Nc1ncnc2[nH]c(-c3ccccc3)cc12)c1 ccccc1 & 0.7 & $*$ \\
\hline 174 & $\mathrm{C}=\mathrm{CC}(=\mathrm{O}) \mathrm{Nc} 1 \mathrm{cccc}(\mathrm{n} 2 \mathrm{c}(=\mathrm{O}) \mathrm{n}(\mathrm{CCc} 3 \mathrm{cccc} 3) \mathrm{c}(=\mathrm{O}) \mathrm{c} 3 \mathrm{cnc}(\mathrm{Nc} 4 \mathrm{ccc}(\mathrm{N} 5 \mathrm{CCC}(\mathrm{N}(\mathrm{C}) \mathrm{C}) \mathrm{CC} 5) \mathrm{cc} 4 \mathrm{OC}) \mathrm{nc} 32) \mathrm{c} 1$ & 0.7 & $*$ \\
\hline
\end{tabular}




\begin{tabular}{|c|c|c|c|}
\hline 175 & $\mathrm{CN}(\mathrm{CC}(=\mathrm{O}) \mathrm{O}) \mathrm{Cc} 1 \mathrm{c}[\mathrm{nH}] \mathrm{c} 2 \mathrm{cc} 3 \mathrm{ncnc}(\mathrm{Nc} 4 \mathrm{cccc}(\mathrm{Br}) \mathrm{c} 4) \mathrm{c} 3 \mathrm{cc} 12$ & 0.72 & $*$ \\
\hline 176 & $\mathrm{C}=\mathrm{CC}(=\mathrm{O}) \mathrm{Nc} 1 \mathrm{cc} 2 \mathrm{c}(\mathrm{Nc} 3 \mathrm{ccc}(\mathrm{F}) \mathrm{c}(\mathrm{Br}) \mathrm{c} 3) \mathrm{ncnc} 2 \mathrm{cn} 1$ & 0.72 & $*$ \\
\hline 177 & $\mathrm{CCN}(\mathrm{CC}) \mathrm{CCCNC}(=\mathrm{O}) / \mathrm{C}=\mathrm{C} / \mathrm{C}(=\mathrm{O}) \mathrm{Nc} 1 \mathrm{cc} 2 \mathrm{c}(\mathrm{Nc} 3 \operatorname{ccc}(\mathrm{Br}) \mathrm{c} 3) \mathrm{ncnc} 2 \mathrm{cn} 1$ & 0.73 & $*$ \\
\hline 178 & $\mathrm{C}=\mathrm{CC}(=\mathrm{O}) \mathrm{Nc} 1 \mathrm{ccc} 2 \mathrm{ncnc}(\mathrm{Nc} 3 \mathrm{ccc}(\mathrm{F}) \mathrm{c}(\mathrm{Cl}) \mathrm{c} 3) \mathrm{c} 2 \mathrm{c} 1$ & 0.75 & $*$ \\
\hline 179 & $\mathrm{C}=\mathrm{CC}(=\mathrm{O}) \mathrm{Nc} 1 \mathrm{ccc} 2 \mathrm{ncnc}(\mathrm{Nc} 3 \mathrm{ccc}(\mathrm{F}) \mathrm{c}(\mathrm{Cl}) \mathrm{c} 3) \mathrm{c} 2 \mathrm{n} 1$ & 0.75 & $*$ \\
\hline 180 & $\mathrm{CNc} 1 \mathrm{ncc} 2 \mathrm{ncnc}(\mathrm{Nc} 3 \mathrm{cccc}(\mathrm{Br}) \mathrm{c} 3) \mathrm{c} 2 \mathrm{n} 1$ & 0.76 & $*$ \\
\hline 181 & $\mathrm{C}=\mathrm{CS}(=\mathrm{O})(=\mathrm{O}) \mathrm{Nc} 1 \mathrm{cc} 2 \mathrm{c}(\mathrm{Nc} 3 \operatorname{ccc}(\mathrm{Br}) \mathrm{c} 3) \mathrm{ncnc} 2 \mathrm{cn} 1$ & 0.76 & $*$ \\
\hline 182 & $\operatorname{COc} 1 \mathrm{cc} 2 \mathrm{c}(\mathrm{Nc} 3 \mathrm{ccc}(\mathrm{F}) \mathrm{c}(\mathrm{Cl}) \mathrm{c} 3) \mathrm{ncnc} 2 \mathrm{cc} 1 \mathrm{OCCCn} 1 \mathrm{ccnc} 1[\mathrm{~N}+](=\mathrm{O})[\mathrm{O}-]$ & 0.77 & 9.11 \\
\hline 183 & $\mathrm{C}=\mathrm{CC}(=\mathrm{O}) \mathrm{Nc} 1 \mathrm{cc} 2 \mathrm{c}(\mathrm{Nc} 3 \mathrm{ccc}(\mathrm{F}) \mathrm{c}(\mathrm{Cl}) \mathrm{c} 3) \mathrm{ncnc} 2 \mathrm{cn} 1$ & 0.77 & $*$ \\
\hline 184 & $\mathrm{O}=\mathrm{C}(\mathrm{NCCN} 1 \mathrm{CCCCC} 1) \mathrm{Nc} 1 \mathrm{ccc} 2 \mathrm{ncnc}(\mathrm{Nc} 3 \operatorname{cccc}(\mathrm{Br}) \mathrm{c} 3) \mathrm{c} 2 \mathrm{c} 1$ & 0.772 & 9.11 \\
\hline 185 & $\mathrm{COc} 1 \mathrm{cc} 2 \mathrm{c}(\mathrm{Nc} 3 \operatorname{cccc}(\mathrm{Br}) \mathrm{c} 3) \mathrm{ncnc} 2 \operatorname{cc} 1 \mathrm{OCCCCCCn} 1 \mathrm{ccnc} 1[\mathrm{~N}+](=\mathrm{O})[\mathrm{O}-]$ & 0.78 & 9.11 \\
\hline 186 & $\mathrm{C}=\mathrm{CC}(=\mathrm{O}) \mathrm{Nc} 1 \mathrm{cc} 2 \mathrm{c}(\mathrm{Nc} 3 \operatorname{ccc}(\mathrm{Br}) \mathrm{c} 3) \mathrm{ncn} 2 \mathrm{cc} 1 \mathrm{SCCCN}(\mathrm{CC}) \mathrm{CC}$ & 0.78 & $*$ \\
\hline 187 & $\operatorname{Brc} 1 \mathrm{cccc}(\mathrm{Nc} 2 \mathrm{ncnc} 3 \mathrm{cnc}(\mathrm{NCCc} 4 \mathrm{c}[\mathrm{nH}] \mathrm{cn} 4) \mathrm{cc} 23) \mathrm{c} 1$ & 0.78 & $*$ \\
\hline 188 & $\mathrm{Nc} 1 \mathrm{ccc} 2 \mathrm{ncncc} 2 \mathrm{c} 1$ & 0.79 & $*$ \\
\hline 189 & $\mathrm{CCOc} 1 \mathrm{cc} 2 \mathrm{ncc}(\mathrm{C \# N}) \mathrm{c}(\mathrm{Nc} 3 \operatorname{ccc}(\mathrm{F}) \mathrm{c}(\mathrm{Cl}) \mathrm{c} 3) \mathrm{c} 2 \mathrm{cc} 1 \mathrm{NC}(=\mathrm{O}) / \mathrm{C}=\mathrm{C} / \mathrm{CN}(\mathrm{C}) \mathrm{CCF}$ & 0.8 & 9.10 \\
\hline 190 & $\mathrm{C}=\mathrm{CC}(=\mathrm{O}) \mathrm{Nc} 1 \mathrm{ccc}(\mathrm{N} 2 \mathrm{C}(=\mathrm{O}) \mathrm{N}(\mathrm{c} 3 \operatorname{ccc} 4 \operatorname{ccc} c 4 \mathrm{c} 3) \mathrm{Cc} 3 \mathrm{cnc}(\mathrm{Nc} 4 \mathrm{ccc}(\mathrm{N} 5 \mathrm{CCN}(\mathrm{C}) \mathrm{CC} 5) \operatorname{cc} 4 \mathrm{OC}) \mathrm{nc} 32) \mathrm{c} 1$ & 0.8 & 9.10 \\
\hline 191 & $\mathrm{Cn} 1 \mathrm{ccc} 2 \mathrm{cc} 3 \mathrm{c}(\mathrm{Nc} 4 \mathrm{cccc}(\mathrm{Br}) \mathrm{c} 4) \mathrm{ncnc} 3 \mathrm{cc} 21$ & 0.8 & $*$ \\
\hline 192 & $\mathrm{OCCNc} 1 \mathrm{nc}(\mathrm{NCc} 2 \operatorname{ccccc} 2) \mathrm{c} 2 \mathrm{cn}[\mathrm{nH}] \mathrm{c} 2 \mathrm{n} 1$ & 0.8 & $*$ \\
\hline 193 & $\mathrm{C}[\mathrm{C} @ @ \mathrm{H}](\mathrm{Nc} 1 \mathrm{ncnc} 2[\mathrm{nH}] \mathrm{c}(-\mathrm{c} 3 \mathrm{cccc}(\mathrm{O}) \mathrm{c} 3) \mathrm{cc} 12) \mathrm{c} 1 \mathrm{ccccc} 1$ & 0.8 & $*$ \\
\hline 194 & $\mathrm{C}[\mathrm{C} @ @ \mathrm{H}](\mathrm{Nc} 1 \mathrm{ncnc} 2[\mathrm{nH}] \mathrm{c}(-\mathrm{c} 3 \mathrm{ccccc} 3 \mathrm{CO}) \mathrm{cc} 12) \mathrm{c} 1 \mathrm{ccccc} 1$ & 0.8 & $*$ \\
\hline 195 & $\mathrm{CCOC} 1=\mathrm{C} 2 \mathrm{C}(=\mathrm{CCc} 3 \mathrm{c} 2 \mathrm{sc}(\mathrm{N}) \mathrm{c} 3 \mathrm{C}(=\mathrm{O}) \mathrm{Nc} 2 \mathrm{ccc}(\mathrm{Cl}) \mathrm{cc} 2) \mathrm{OC}(\mathrm{N})=\mathrm{C} 1 \mathrm{C \# N}$ & 0.8 & $*$ \\
\hline 196 & $\mathrm{C}=\mathrm{CC}(=\mathrm{O}) \mathrm{Nc} 1 \mathrm{cccc}(\mathrm{N} 2 \mathrm{C}(=\mathrm{O}) \mathrm{N}(\mathrm{c} 3 \operatorname{ccc} 4 \mathrm{cccc} 34) \mathrm{Cc} 3 \operatorname{cnc}(\mathrm{Nc} 4 \mathrm{ccc}(\mathrm{N} 5 \mathrm{CCN}(\mathrm{C}) \mathrm{CC} 5) \mathrm{cc} 4 \mathrm{OC}) \mathrm{nc} 32) \mathrm{c} 1$ & 0.8 & * \\
\hline 197 & $\mathrm{NC}(=\mathrm{O}) \mathrm{Nc} 1 \mathrm{ccc} 2 \mathrm{ncnc}(\mathrm{Nc} 3 \mathrm{ccc}(\mathrm{Br}) \mathrm{cc} 3) \mathrm{c} 2 \mathrm{c} 1$ & 0.803 & 9.10 \\
\hline 198 & $\mathrm{Nc} 1 \mathrm{cc} 2 \mathrm{ncnc}(\mathrm{Nc} 3 \mathrm{ccc}(\mathrm{Br}) \mathrm{c} 3) \mathrm{c} 2 \mathrm{cc} 1 \mathrm{~N}$ & 0.81 & 9.09 \\
\hline 199 & Brc1ccec(Nc2ncnc3enc(NCCN4CCOCC4)nc23)c1 & 0.81 & $*$ \\
\hline 200 & $\mathrm{O}=\mathrm{C}(/ \mathrm{C}=\mathrm{C} / \mathrm{C}(=\mathrm{O}) \mathrm{Nc} 1 \mathrm{cc} 2 \mathrm{c}(\mathrm{Nc} 3 \mathrm{cccc}(\mathrm{Br}) \mathrm{c} 3) \mathrm{ncnc} 2 \mathrm{cn} 1) \mathrm{NCCCN} 1 \mathrm{CCOCC} 1$ & 0.81 & $*$ \\
\hline 201 & $\mathrm{CCOC}(=\mathrm{O}) \mathrm{c} 1 \mathrm{c}(\mathrm{NC} 2=\mathrm{C}(\mathrm{Cl}) \mathrm{C}(\mathrm{c} 3 \mathrm{ccc}(\mathrm{Cl}) \mathrm{cc} 3) \mathrm{C}(\mathrm{CHN})=\mathrm{C}(\mathrm{O}) \mathrm{O} 2) \operatorname{sc} 2 \mathrm{c} 1-\mathrm{c} 1 \mathrm{sc}(=\mathrm{S}) \mathrm{n}(-\mathrm{c} 3 \operatorname{ccccc} 3) \mathrm{c} 1 \mathrm{CC} 2(\mathrm{C}) \mathrm{C}$ & 0.81 & $*$ \\
\hline 202 & $\operatorname{COc} 1 \mathrm{cc} 2 \mathrm{c}(\mathrm{Nc} 3 \operatorname{cccc}(\mathrm{Br}) \mathrm{c} 3) \mathrm{ncnc} 2 \mathrm{cc} 1 \mathrm{OCCOCCn} 1 \mathrm{ccnc} 1[\mathrm{~N}+](=\mathrm{O})[\mathrm{O}-]$ & 0.82 & 9.09 \\
\hline 203 & $\mathrm{CC} 1(\mathrm{C}) \mathrm{C} 2=\mathrm{C}(\mathrm{OC}(\mathrm{N})=\mathrm{C}(\mathrm{C \# N}) \mathrm{C} 2 \mathrm{c} 2 \operatorname{ccccc} 2) \mathrm{C}(=\mathrm{NNc} 2 \operatorname{ccc}(\mathrm{Cl}) \mathrm{cc} 2) \mathrm{c} 2 \mathrm{c} 1 \mathrm{sc}(\mathrm{N}) \mathrm{c} 2 \mathrm{C} \# \mathrm{~N}$ & 0.83 & $*$ \\
\hline 204 & $\mathrm{NC}(=\mathrm{O}) \mathrm{Nc} 1 \mathrm{ccc} 2 \mathrm{ncnc}(\mathrm{Nc} 3 \mathrm{ccc}(\mathrm{F}) \mathrm{c}(\mathrm{Cl}) \mathrm{c} 3) \mathrm{c} 2 \mathrm{c} 1$ & 0.854 & 9.07 \\
\hline 205 & $\mathrm{CC} 1(\mathrm{C}) \mathrm{Cc} 2 \mathrm{c}(\mathrm{sc}(=\mathrm{S}) \mathrm{n} 2-\mathrm{c} 2 \mathrm{ccccc} 2)-\mathrm{c} 2 \mathrm{c} 1 \mathrm{sc}(\mathrm{N}) \mathrm{c} 2 \mathrm{C \# N}$ & 0.86 & $*$ \\
\hline 206 & $\mathrm{CCOc} 1 \mathrm{cc} 2 \mathrm{ncnc}(\mathrm{Nc} 3 \mathrm{ccc}(\mathrm{OCc} 4 \mathrm{ccccn} 4) \mathrm{c}(\mathrm{Cl}) \mathrm{c} 3) \mathrm{c} 2 \mathrm{cc} 1 \mathrm{NC}(=\mathrm{O}) / \mathrm{C}(\mathrm{F})=\mathrm{C} \backslash \mathrm{CN}(\mathrm{C}) \mathrm{C}$ & 0.89 & 9.05 \\
\hline 207 & $\operatorname{COc} 1 \mathrm{cc} 2 \mathrm{ncnc}(\mathrm{Nc} 3 \operatorname{ccc}(\mathrm{F}) \mathrm{c}(\mathrm{Cl}) \mathrm{c} 3) \mathrm{c} 2 \mathrm{cc} 1 \mathrm{OCCCn} 1 \mathrm{ccnc} 1[\mathrm{~N}+](=\mathrm{O})[\mathrm{O}-]$ & 0.89 & 9.05 \\
\hline 208 & $\mathrm{COc} 1 \mathrm{cc} 2 \mathrm{ncnc}(\mathrm{Nc} 3 \mathrm{cccc}(\mathrm{I}) \mathrm{c} 3) \mathrm{c} 2 \mathrm{cc} 1 \mathrm{OC}$ & 0.89 & $*$ \\
\hline 209 & COc1 cccc(OC)c1-c1cc2c(N[C@H](CO)c3ccccs3)ncnc2s1 & 0.9 & 9.05 \\
\hline 210 & $\mathrm{C}[\mathrm{C} @ @ \mathrm{H}](\mathrm{Nc} 1 \mathrm{ncnc} 2 \mathrm{sc}(-\mathrm{c} 3 \operatorname{ccc}(\mathrm{C}(=\mathrm{O}) \mathrm{NCCN}(\mathrm{C}) \mathrm{C}) \mathrm{c} 3) \mathrm{cc} 12) \mathrm{c} 1 \mathrm{ccccc} 1$ & 0.9 & 9.05 \\
\hline 211 & $\mathrm{O}=\mathrm{C}(\mathrm{C} \# \mathrm{CCCN} 1 \mathrm{CCCCC} 1) \mathrm{Nc} 1 \mathrm{cc} 2 \mathrm{c}(\mathrm{Nc} 3 \mathrm{ccc}(\mathrm{F}) \mathrm{c}(\mathrm{Cl}) \mathrm{c} 3) \mathrm{ncnc} 2 \mathrm{cn} 1$ & 0.9 & $*$ \\
\hline 212 & $\mathrm{O}=\mathrm{C}(/ \mathrm{C}=\mathrm{C} / \mathrm{CN} 1 \mathrm{CC} 2 \mathrm{CCC} 1 \mathrm{C}(=\mathrm{O}) \mathrm{C} 2) \mathrm{Nc} 1 \mathrm{cc} 2 \mathrm{c}(\mathrm{Nc} 3 \mathrm{ccc}(\mathrm{F}) \mathrm{c}(\mathrm{Cl}) \mathrm{c} 3) \mathrm{ncnc} 2 \mathrm{~s} 1$ & 0.9 & $*$ \\
\hline 213 & $\mathrm{CCOc} 1 \mathrm{cc} 2 \mathrm{ncnc}(\mathrm{Nc} 3 \operatorname{ccc}(\mathrm{F}) \mathrm{c}(\mathrm{Cl}) \mathrm{c} 3) \mathrm{c} 2 \mathrm{cc} 1 \mathrm{NC}(=\mathrm{O}) / \mathrm{C}=\mathrm{C} / \mathrm{CNC} 1 \mathrm{CC} 1$ & 0.9 & $*$ \\
\hline 214 & $\mathrm{CN}(\mathrm{C}) \mathrm{C} 1 \mathrm{CCN}(\mathrm{c} 2 \mathrm{ccc}(\mathrm{Nc} 3 \mathrm{cc} 4 \mathrm{c}(\mathrm{N} 5 \mathrm{CCCCC} 5) \mathrm{nc}(\mathrm{Nc} 5 \mathrm{ccccc} 5) \mathrm{nc} 4 \mathrm{cn} 3) \mathrm{nc} 2) \mathrm{CC} 1$ & 0.9 & $*$ \\
\hline 215 & $\mathrm{CN}(\mathrm{C}) \mathrm{C} 1 \mathrm{CCN}(\mathrm{c} 2 \mathrm{ccc}(\mathrm{Nc} 3 \mathrm{cc} 4 \mathrm{c}(\mathrm{N} 5 \mathrm{CCOCC} 5) \mathrm{nc}(\mathrm{Nc} 5 \mathrm{ccc}(\mathrm{F}) \mathrm{cc} 5 \mathrm{~F}) \mathrm{nc} 4 \mathrm{cn} 3) \mathrm{nc} 2) \mathrm{CC} 1$ & 0.9 & $*$ \\
\hline 216 & Brc1 $1 \mathrm{ccc}(\mathrm{Nc} 2 \mathrm{ncnc} 3 \mathrm{cc}(\mathrm{NCCc} 4 \mathrm{c}[\mathrm{nH}] \mathrm{cn} 4) \mathrm{ncc} 23) \mathrm{c} 1$ & 0.91 & $*$ \\
\hline 217 & $\mathrm{C}=\mathrm{CC}(=\mathrm{O}) \mathrm{Nc} 1 \mathrm{ccc} 2 \mathrm{ncnc}(\mathrm{Nc} 3 \operatorname{ccc}(\mathrm{C}(\mathrm{F})(\mathrm{F}) \mathrm{F}) \mathrm{c} 3) \mathrm{c} 2 \mathrm{c} 1$ & 0.91 & $*$ \\
\hline
\end{tabular}




\begin{tabular}{|c|c|c|c|}
\hline 218 & $\mathrm{C}=\mathrm{CC}(=\mathrm{O}) \mathrm{Nc} 1 \mathrm{cc} 2 \mathrm{c}(\mathrm{Nc} 3 \mathrm{cccc}(\mathrm{Br}) \mathrm{c} 3) \mathrm{ncnc} 2 \mathrm{cn} 1$ & 0.91 & $*$ \\
\hline 219 & Brc1ccce(Nc2ncnc3ccncc23)c1NCCc1c[nH]cn1 & 0.912 & $*$ \\
\hline 220 & $\mathrm{OCC}(\mathrm{O}) \mathrm{CNc} 1 \mathrm{cc} 2 \mathrm{ncnc}(\mathrm{Nc} 3 \mathrm{cccc}(\mathrm{Br}) \mathrm{c} 3) \mathrm{c} 2 \mathrm{cn} 1$ & 0.92 & * \\
\hline 221 & OCCN(CCO)CCNc1cc2c(Nc3ecce(Br)c3)ncnc2cn1 & 0.93 & $*$ \\
\hline 222 & $\mathrm{OCC}(\mathrm{O}) \mathrm{CNc} 1 \mathrm{c}(\mathrm{Br}) \mathrm{ccc} 1 \mathrm{Nc} 1 \mathrm{ncn} 2 \mathrm{ccncc} 12$ & 0.9333 & * \\
\hline 223 & $\mathrm{C}=\mathrm{CC}(=\mathrm{O}) \mathrm{Nc} 1 \mathrm{nc} 2 \mathrm{c}(\mathrm{Nc} 3 \mathrm{ccc}(\mathrm{F}) \mathrm{c}(\mathrm{Cl}) \mathrm{c} 3) \mathrm{ncnc} 2 \mathrm{cc} 1 \mathrm{OC}$ & 0.95 & $*$ \\
\hline 224 & $\mathrm{CN}(\mathrm{C}) \mathrm{c} 1 \mathrm{ncc} 2 \mathrm{ncnc}(\mathrm{Nc} 3 \mathrm{cccc}(\mathrm{Br}) \mathrm{c} 3) \mathrm{c} 2 \mathrm{n} 1$ & 0.95 & * \\
\hline 225 & $\mathrm{C}=\mathrm{CC}(=\mathrm{O}) \mathrm{Nc} 1 \mathrm{nc} 2 \mathrm{c}(\mathrm{Nc} 3 \mathrm{ccc}(\mathrm{F}) \mathrm{c}(\mathrm{Cl}) \mathrm{c} 3) \mathrm{ncnc} 2 \mathrm{cc} 1 \mathrm{OCCOC}$ & 0.97 & * \\
\hline 226 & $\mathrm{O}=\mathrm{C}(\mathrm{Nc} 1 \mathrm{cc} 2 \mathrm{c}(\mathrm{Nc} 3 \mathrm{ccc}(\mathrm{F}) \mathrm{c}(\mathrm{Cl}) \mathrm{c} 3) \mathrm{ncnc} 2 \mathrm{cc} 1 \mathrm{O}[\mathrm{C} @ \mathrm{H}] 1 \mathrm{CCOC} 1) / \mathrm{C}(\mathrm{F})=\mathrm{C} \backslash \mathrm{CN} 1 \mathrm{CCOCC} 1$ & 1 & 9.00 \\
\hline 227 & $\mathrm{C} \# \mathrm{Cc} 1 \mathrm{cccc}(\mathrm{Nc} 2 \mathrm{ncnc} 3 \mathrm{cc}(\mathrm{OCCO}) \mathrm{c}(\mathrm{OCCOC}) \mathrm{cc} 23) \mathrm{c} 1$ & 1 & 9.00 \\
\hline 228 & $\mathrm{COc} 1 \mathrm{cc} 2 \mathrm{ncnc}(\mathrm{Nc} 3 \mathrm{cc}(\mathrm{Cl}) \operatorname{ccc} 3 \mathrm{~F}) \mathrm{c} 2 \mathrm{cc} 1 \mathrm{OC} 1 \mathrm{CCN}(\mathrm{S}(\mathrm{C})(=\mathrm{O})=\mathrm{O}) \mathrm{CC} 1$ & 1 & $*$ \\
\hline 229 & COc1cccc1-c1cc2c(N[C@H](CO)c3ecccc3)ncnc2s1 & 1 & * \\
\hline 230 & $\mathrm{CC}(\mathrm{C})(\mathrm{O}) \mathrm{CC}(=\mathrm{O}) \mathrm{NCCn} 1 \mathrm{ccc} 2 \mathrm{ncnc}(\mathrm{Nc} 3 \operatorname{ccc}(\mathrm{Oc} 4 \mathrm{ccc}(\mathrm{C}(\mathrm{F})(\mathrm{F}) \mathrm{F}) \mathrm{c} 4) \mathrm{c}(\mathrm{Cl}) \mathrm{c} 3) \mathrm{c} 21$ & 1 & * \\
\hline 231 & $\mathrm{C}=\mathrm{CC}(=\mathrm{O}) \mathrm{Nc} 1 \mathrm{cccc}(-\mathrm{n} 2 \mathrm{c}(=\mathrm{O}) \mathrm{c}(\mathrm{Cc} 3 \mathrm{cccc} 3) \mathrm{cc} 3 \mathrm{cnc}(\mathrm{Nc} 4 \mathrm{ccc}(\mathrm{N} 5 \mathrm{CCN}(\mathrm{C}) \mathrm{CC} 5) \mathrm{cc} 4 \mathrm{OC}) \mathrm{nc} 32) \mathrm{c} 1$ & 1 & $*$ \\
\hline 232 & $\mathrm{CS}(=\mathrm{O})(=\mathrm{O}) \mathrm{CCNCc} 1 \mathrm{ccc}(-\mathrm{c} 2 \mathrm{cc} 3 \mathrm{ncnc}(\mathrm{Nc} 4 \mathrm{ccc}(\mathrm{OCc} 5 \operatorname{cccc}(\mathrm{F}) \mathrm{c} 5) \mathrm{c}(\mathrm{Cl}) \mathrm{c} 4) \mathrm{c} 3 \mathrm{~s} 2) \mathrm{o} 1$ & 1 & $*$ \\
\hline 233 & Brc1ccec(Nc2nenc3enc(NCCCN4CCOCC4)cc23)c1 & 1 & * \\
\hline 234 & Oc1 ccce $(\mathrm{Nc} 2[\mathrm{nH}] \mathrm{nc} 3 \mathrm{ncnc}(\mathrm{Nc} 4 \mathrm{cccc}(\mathrm{Cl}) \mathrm{c} 4) \mathrm{c} 23) \mathrm{c} 1$ & 1 & $*$ \\
\hline 235 & $\mathrm{Cc} 1 \mathrm{cccc}(\mathrm{Nc} 2 \mathrm{cc}(\mathrm{NCCO}) \mathrm{ncn} 2) \mathrm{c} 1$ & 1 & $*$ \\
\hline 236 & $\mathrm{Nc} 1 \mathrm{cc} 2 \mathrm{sc} 3 \mathrm{c}(\mathrm{Nc} 4 \mathrm{cccc}(\mathrm{Br}) \mathrm{c} 4) \mathrm{ncnc} 3 \mathrm{c} 2 \mathrm{cc} 1 \mathrm{~F}$ & 1 & $*$ \\
\hline 237 & $\mathrm{COc} 1 \mathrm{cc} 2 \mathrm{c}(\mathrm{Nc} 3 \mathrm{ccc}(\mathrm{NC}(=\mathrm{O}) \mathrm{Nc} 4 \mathrm{ccc}(\mathrm{Cl}) \mathrm{cc} 4) \mathrm{c}(\mathrm{Cl}) \mathrm{c} 3) \operatorname{ncnc} 2 \mathrm{cc} 1 \mathrm{OCCCN} 1 \mathrm{CCN}(\mathrm{C}) \mathrm{CC} 1$ & 1 & * \\
\hline 238 & $\mathrm{COc} 1 \mathrm{cc} 2 \mathrm{c}(\mathrm{Nc} 3 \mathrm{ccc}(\mathrm{NC}(=\mathrm{O}) \mathrm{Nc} 4 \mathrm{ccc}(\mathrm{C}) \mathrm{c}(\mathrm{C}) \mathrm{c} 4) \mathrm{c}(\mathrm{Cl}) \mathrm{c} 3) \mathrm{ncnc} 2 \mathrm{cc} 1 \mathrm{OCCCN} 1 \mathrm{CCN}(\mathrm{C}) \mathrm{CC} 1$ & 1 & * \\
\hline 239 & $\mathrm{c} 1 \mathrm{ccc}(\mathrm{CCCN}(\mathrm{c} 2 \mathrm{cc} 3 \mathrm{ncnc}(\mathrm{Nc} 4 \mathrm{ccc} 5[\mathrm{nH}] \mathrm{ccc} 5 \mathrm{c} 4) \mathrm{c} 3 \mathrm{~s} 2) \mathrm{n} 2 \mathrm{ccnc} 2) \mathrm{cc} 1$ & 1 & $*$ \\
\hline 240 & $\mathrm{c} 1 \mathrm{csc}(-\mathrm{c} 2 \mathrm{cc} 3 \mathrm{nccc}(\mathrm{Nc} 4 \mathrm{ccc} 5[\mathrm{nH}] \operatorname{ccc} 5 \mathrm{c} 4) \mathrm{c} 3 \mathrm{~s} 2) \mathrm{c} 1$ & 1 & $*$ \\
\hline 241 & $\mathrm{c} 1 \mathrm{ccc}(\mathrm{NCCN}(\mathrm{c} 2 \mathrm{cc} 3 \mathrm{ncnc}(\mathrm{Nc} 4 \mathrm{ccc} 5[\mathrm{nH}] \mathrm{ccc} 5 \mathrm{c} 4) \mathrm{c} 3 \mathrm{~s} 2) \mathrm{n} 2 \mathrm{cccc} 2) \mathrm{cc} 1$ & 1 & * \\
\hline 242 & $\mathrm{c} 1 \mathrm{csc}(-\mathrm{c} 2 \mathrm{cc} 3 \mathrm{ncnc}(\mathrm{Nc} 4 \mathrm{ccc} 5[\mathrm{nH}] \mathrm{ccc} 5 \mathrm{c} 4) \mathrm{c} 3 \mathrm{~s} 2) \mathrm{c} 1$ & 1 & $*$ \\
\hline 243 & OCc1 $\operatorname{ccc}(-\mathrm{c} 2 \mathrm{cc} 3 \mathrm{ncnc}(\mathrm{Nc} 4 \mathrm{ccc} 5[\mathrm{nH}] \operatorname{ccc} 5 \mathrm{c} 4) \mathrm{c} 3 \mathrm{~s} 2) \mathrm{cc} 1$ & 1 & $*$ \\
\hline 244 & $\mathrm{NC}(=\mathrm{O}) \mathrm{C} 1 \mathrm{CCN}(\mathrm{Cc} 2 \operatorname{ccc}(-\mathrm{c} 3 \operatorname{cc} 4 n \operatorname{ccc}(\mathrm{Nc} 5 \operatorname{ccc} 6[\mathrm{nH}] \operatorname{ccc} 6 \mathrm{c} 5) \mathrm{c} 4 \mathrm{~s} 3) \mathrm{cc} 2) \mathrm{CC} 1$ & 1 & * \\
\hline 245 & $\mathrm{COc} 1 \mathrm{cc}(\mathrm{F}) \mathrm{ccc} 1-\mathrm{c} 1 \mathrm{cc} 2 \mathrm{c}(\mathrm{NC}(\mathrm{CO}) \mathrm{c} 3 \mathrm{ccccc} 3) \mathrm{ncnc} 2[\mathrm{nH}] 1$ & 1 & $*$ \\
\hline 246 & $\mathrm{CN}(\mathrm{C}) \mathrm{CC}=\mathrm{CC}(=\mathrm{O}) \mathrm{Nc} 1 \mathrm{cc} 2 \mathrm{c}(\mathrm{Nc} 3 \mathrm{ccc}(\mathrm{F}) \mathrm{c}(\mathrm{Cl}) \mathrm{c} 3) \mathrm{ncnc} 2 \mathrm{cc} 1 \mathrm{O}[\mathrm{C} @ \mathrm{H}] 1 \mathrm{CCOC} 1$ & 1 & $*$ \\
\hline 247 & $\mathrm{C}=\mathrm{CC}(=\mathrm{O}) \mathrm{Nc} 1 \mathrm{cccc}(\mathrm{Nc} 2 \mathrm{cc}(-\mathrm{c} 3[\mathrm{nH}] \mathrm{c}(\mathrm{SC}) \mathrm{nc} 3-\mathrm{c} 3 \mathrm{ccc}(\mathrm{F}) \mathrm{cc} 3) \mathrm{ccn} 2) \mathrm{c} 1$ & 1 & $*$ \\
\hline 248 & $\mathrm{C}=\mathrm{CC}(=\mathrm{O}) \mathrm{Nc} 1 \mathrm{ccc}(\mathrm{OC}) \mathrm{c}(\mathrm{Nc} 2 \mathrm{cc}(-\mathrm{c} 3[\mathrm{nH}] \mathrm{c}(\mathrm{SC}) \mathrm{nc} 3-\mathrm{c} 3 \mathrm{ccc}(\mathrm{F}) \mathrm{cc} 3) \mathrm{ccn} 2) \mathrm{c} 1$ & 1 & $*$ \\
\hline 249 & $\mathrm{CCC}(=\mathrm{O}) \mathrm{Nc} 1 \mathrm{ccc}(\mathrm{OC}) \mathrm{c}(\mathrm{Nc} 2 \mathrm{cc}(-\mathrm{c} 3[\mathrm{nH}] \mathrm{c}(\mathrm{SC}) \mathrm{nc} 3-\mathrm{c} 3 \mathrm{ccc}(\mathrm{F}) \mathrm{cc} 3) \mathrm{ccn} 2) \mathrm{c} 1$ & 1 & $*$ \\
\hline 250 & $\mathrm{C}=\mathrm{CC}(=\mathrm{O}) \mathrm{Nc} 1 \mathrm{cc}(\mathrm{Nc} 2 \mathrm{cc}(-\mathrm{c} 3[\mathrm{nH}] \mathrm{c}(\mathrm{SC}) \mathrm{nc} 3-\mathrm{c} 3 \mathrm{ccc}(\mathrm{F}) \mathrm{cc} 3) \mathrm{ccn} 2) \mathrm{cc}(\mathrm{N} 2 \mathrm{CCOCC} 2) \mathrm{c} 1$ & 1 & $*$ \\
\hline 251 & $\mathrm{C}=\mathrm{CC}(=\mathrm{O}) \mathrm{Nc} 1 \mathrm{cc}(\mathrm{Nc} 2 \mathrm{cc}(-\mathrm{c} 3[\mathrm{nH}] \mathrm{c}(\mathrm{SC}) \mathrm{nc} 3-\mathrm{c} 3 \mathrm{ccc}(\mathrm{F}) \mathrm{cc} 3) \mathrm{ccn} 2) \mathrm{cc}(\mathrm{N} 2 \mathrm{CCN}(\mathrm{C}) \mathrm{CC} 2) \mathrm{c} 1$ & 1 & $*$ \\
\hline 252 & $\mathrm{C}=\mathrm{CC}(=\mathrm{O}) \mathrm{Nc} 1 \mathrm{cccc}(\mathrm{Nc} 2 \mathrm{cc}(-\mathrm{c} 3[\mathrm{nH}] \mathrm{c}(\mathrm{SC}) \mathrm{nc} 3-\mathrm{c} 3 \mathrm{ccc}(\mathrm{F}) \mathrm{cc} 3) \mathrm{ccn} 2) \mathrm{n} 1$ & 1 & $*$ \\
\hline 253 & $\mathrm{C}=\mathrm{CC}(=\mathrm{O}) \mathrm{Nc} 1 \mathrm{ccc}(\mathrm{OC}) \mathrm{c}(\mathrm{Nc} 2 \mathrm{cc}(-\mathrm{c} 3[\mathrm{nH}] \mathrm{c}(\mathrm{SC}) \mathrm{nc} 3-\mathrm{c} 3 \mathrm{ccc} 4 \mathrm{ccccc} 4 \mathrm{c} 3) \mathrm{ccn} 2) \mathrm{c} 1$ & 1 & $*$ \\
\hline 254 & $\mathrm{C}=\mathrm{CC}(=\mathrm{O}) \mathrm{Nc} 1 \mathrm{ccc}(\mathrm{OC}) \mathrm{c}(\mathrm{Nc} 2 \mathrm{cc}(-\mathrm{c} 3[\mathrm{nH}] \mathrm{c}(\mathrm{SC}) \mathrm{nc} 3 \mathrm{C} 3 \mathrm{CCCC} 3) \mathrm{ccn} 2) \mathrm{c} 1$ & 1 & $*$ \\
\hline 255 & $\mathrm{C}=\mathrm{CC}(=\mathrm{O}) \mathrm{Nc} 1 \mathrm{ccc}(\mathrm{OC}) \mathrm{c}(\mathrm{Nc} 2 \mathrm{cc}(-\mathrm{c} 3[\mathrm{nH}] \mathrm{c}(\mathrm{CCCO}) \mathrm{nc} 3-\mathrm{c} 3 \mathrm{ccc}(\mathrm{F}) \mathrm{cc} 3) \mathrm{ccn} 2) \mathrm{c} 1$ & 1 & $*$ \\
\hline 256 & $\mathrm{CCC}(=\mathrm{O}) \mathrm{Nc} 1 \mathrm{ccc}(\mathrm{OC}) \mathrm{c}(\mathrm{Nc} 2 \mathrm{cc}(-\mathrm{c} 3[\mathrm{nH}] \mathrm{c}(\mathrm{CCCO}) \mathrm{nc} 3-\mathrm{c} 3 \mathrm{ccc}(\mathrm{F}) \mathrm{cc} 3) \mathrm{ccn} 2) \mathrm{c} 1$ & 1 & $*$ \\
\hline 257 & $\mathrm{C}=\mathrm{CC}(=\mathrm{O}) \mathrm{Nc} 1 \mathrm{ccc}(\mathrm{OC}) \mathrm{c}(\mathrm{Nc} 2 \mathrm{cc}(-\mathrm{c} 3[\mathrm{nH}] \mathrm{c}(\mathrm{SC}) \mathrm{nc} 3-\mathrm{c} 3 \operatorname{cccs} 3) \mathrm{ccn} 2) \mathrm{c} 1$ & 1 & $*$ \\
\hline 258 & $\mathrm{C}=\mathrm{CC}(=\mathrm{O}) \mathrm{Nc} 1 \mathrm{cccc}(\mathrm{Nc} 2 \mathrm{cc}(-\mathrm{c} 3[\mathrm{nH}] \mathrm{c}(\mathrm{SCCNC}(=\mathrm{O}) \mathrm{CC}) \mathrm{nc} 3-\mathrm{c} 3 \mathrm{ccccc} 3) \mathrm{ccn} 2) \mathrm{c} 1$ & 1 & $*$ \\
\hline 259 & $\mathrm{C}=\mathrm{CC}(=\mathrm{O}) \mathrm{Nc} 1 \mathrm{ccc}(\mathrm{OC}) \mathrm{c}(\mathrm{Nc} 2 \mathrm{cc}(-\mathrm{c} 3[\mathrm{nH}] \mathrm{c}(\mathrm{SC}) \mathrm{nc} 3 \mathrm{C} 3 \mathrm{CCC} 3) \mathrm{ccn} 2) \mathrm{c} 1$ & 1 & $*$ \\
\hline 260 & $\mathrm{CC}(=\mathrm{O}) \mathrm{Nc} 1 \mathrm{ccc} 2 \mathrm{ncnc}(\mathrm{Nc} 3 \operatorname{ccc}(\mathrm{Br}) \mathrm{c} 3) \mathrm{c} 2 \mathrm{c} 1$ & 1.01 & 9.00 \\
\hline
\end{tabular}




\begin{tabular}{|c|c|c|c|}
\hline 261 & $\mathrm{O}=\mathrm{C}(\mathrm{NCCN} 1 \mathrm{CCCCC} 1) \mathrm{Nc} 1 \mathrm{ccc} 2 \mathrm{ncnc}(\mathrm{Nc} 3 \mathrm{ccc}(\mathrm{F}) \mathrm{c}(\mathrm{Cl}) \mathrm{c} 3) \mathrm{c} 2 \mathrm{c} 1$ & 1.06 & 8.97 \\
\hline 262 & $\mathrm{COc} 1 \mathrm{cc} 2 \mathrm{ncnc}(\mathrm{Nc} 3 \mathrm{ccc}(\mathrm{F}) \mathrm{c}(\mathrm{Cl}) \mathrm{c} 3) \mathrm{c} 2 \mathrm{cc} 1 \mathrm{NC}(=\mathrm{O})[\mathrm{C} @ @ \mathrm{H}] \mathrm{COC}(=\mathrm{O}) \mathrm{N} 1$ & 1.06 & 8.97 \\
\hline 263 & $\mathrm{C} \# \mathrm{Cc} 1 \mathrm{ccc}(\mathrm{Nc} 2 \mathrm{ncnc} 3 \mathrm{cc}(\mathrm{OC}) \mathrm{c}(\mathrm{OCCCn} 4 \mathrm{ccnc} 4[\mathrm{~N}+](=\mathrm{O})[\mathrm{O}-]) \mathrm{cc} 23) \mathrm{c} 1$ & 1.08 & 8.97 \\
\hline 264 & C[C@@H](Nc1ncnc2oc(-c3ccc(NCCN4CCOCC4)cc3)cc12)c1 ccccc1 & 1.1 & 8.96 \\
\hline 265 & $\mathrm{CN}(\mathrm{C}) \mathrm{CCNc} 1 \mathrm{cc} 2 \mathrm{c}(\mathrm{Nc} 3 \mathrm{cccc}(\mathrm{Br}) \mathrm{c} 3) \mathrm{ncnc} 2 \mathrm{cn} 1$ & 1.1 & $*$ \\
\hline 266 & $\mathrm{CNc} 1 \mathrm{cc} 2 \mathrm{c}(\mathrm{Nc} 3 \operatorname{cccc}(\mathrm{C}(\mathrm{F})(\mathrm{F}) \mathrm{F}) \mathrm{c} 3) \mathrm{ncnc} 2 \mathrm{cn} 1$ & 1.1 & $*$ \\
\hline 267 & $\mathrm{C}=\mathrm{CC}(=\mathrm{O}) \mathrm{Nc} 1 \mathrm{ccc} 2 \mathrm{ncnc}(\mathrm{Nc} 3 \operatorname{ccc}(\mathrm{Br}) \mathrm{c} 3) \mathrm{c} 2 \mathrm{n} 1$ & 1.1 & $*$ \\
\hline 268 & CCO.CNc1 cec2sc3c(Nc4cece(Br)c4)ncnc3c2c1 & 1.1 & $*$ \\
\hline 269 & $\mathrm{C}=\mathrm{C} / \mathrm{C}=\mathrm{C} / \mathrm{C}(=\mathrm{O}) \mathrm{Nc} 1 \mathrm{cc} 2 \mathrm{c}(\mathrm{Nc} 3 \mathrm{cccc}(\mathrm{Br}) \mathrm{c} 3) \mathrm{ncnc} 2 \mathrm{cn} 1$ & 1.1 & $*$ \\
\hline 270 & $\mathrm{CN}(\mathrm{C}) \mathrm{CCCNC}(=\mathrm{O}) / \mathrm{C}=\mathrm{C} / \mathrm{C}(=\mathrm{O}) \mathrm{Nc} 1 \mathrm{cc} 2 \mathrm{c}(\mathrm{Nc} 3 \mathrm{cccc}(\mathrm{Br}) \mathrm{c} 3) \mathrm{ncnc} 2 \mathrm{cn} 1$ & 1.1 & $*$ \\
\hline 271 & $\mathrm{Cc} 1 \mathrm{cc}(\mathrm{C}(=\mathrm{O}) \mathrm{NCCN} 2 \mathrm{CCOCC} 2)[\mathrm{nH}] \mathrm{c} 1 / \mathrm{C}=\mathrm{C} 1 \backslash \mathrm{C}(=\mathrm{O}) \mathrm{Nc} 2 \mathrm{ncnc}(\mathrm{Nc} 3 \operatorname{ccc} 4 \mathrm{c}(\operatorname{ccn} 4 \mathrm{Cc} 4 \mathrm{ccccc} 4) \mathrm{c} 3) \mathrm{c} 21$ & 1.1 & $*$ \\
\hline 272 & $\mathrm{CN} 1 \mathrm{CCN}(\mathrm{c} 2 \mathrm{ccc}(\mathrm{Nc} 3 \mathrm{cc} 4 \mathrm{c}(\mathrm{N} 5 \mathrm{CCCCC} 5) \mathrm{nc}(\mathrm{Nc} 5 \mathrm{ccccc} 5) \mathrm{nc} 4 \mathrm{cn} 3) \mathrm{nc} 2) \mathrm{CC} 1$ & 1.1 & $*$ \\
\hline 273 & COc1cccc1-c1cc2c(N[C@H](C)c3ecccs3)ncnc2[nH]1 & 1.1 & $*$ \\
\hline 274 & $\mathrm{COc} 1 \mathrm{cc} 2 \mathrm{ncnc}(\mathrm{Nc} 3 \operatorname{cccc}(\mathrm{C}(=\mathrm{O}) \mathrm{NC} 45 \mathrm{CC} 6 \mathrm{CC}(\mathrm{CC}(\mathrm{C} 6) \mathrm{C} 4) \mathrm{C} 5) \mathrm{c} 3) \mathrm{c} 2 \mathrm{cc} 1 \mathrm{OCCCN} 1 \mathrm{CCOCC} 1$ & 1.12 & 8.95 \\
\hline 275 & $\operatorname{COc} 1 \mathrm{cc} 2 \mathrm{ncnc}(\mathrm{Nc} 3 \operatorname{ccc}(\mathrm{Br}) \mathrm{c} 3) \mathrm{c} 2 \mathrm{cc} 1 \mathrm{OCCCn} 1 \mathrm{c}([\mathrm{N}+](=\mathrm{O})[\mathrm{O}-]) \mathrm{cnc} 1 \mathrm{C}$ & 1.18 & 8.93 \\
\hline 276 & $\mathrm{CCOc} 1 \mathrm{cc} 2 \mathrm{ncnc}(\mathrm{Nc} 3 \operatorname{ccc}(\mathrm{OCc} 4 \operatorname{cccc}(\mathrm{F}) \mathrm{c} 4) \mathrm{c}(\mathrm{Cl}) \mathrm{c} 3) \mathrm{c} 2 \mathrm{cc} 1 \mathrm{NC}(=\mathrm{O})[\mathrm{C} @ \mathrm{H}] 1 \mathrm{COC}(=\mathrm{O}) \mathrm{N} 1$ & 1.19 & 8.92 \\
\hline 277 & $\mathrm{C} \# \mathrm{Cc} 1 \mathrm{cccc}(\mathrm{Nc} 2 \mathrm{ncnc} 3 \mathrm{cc}(\mathrm{O}[\mathrm{C} @ \mathrm{H}] 4 \mathrm{CCOC} 4) \mathrm{c}(\mathrm{NC}(=\mathrm{O}) / \mathrm{C}=\mathrm{C} / \mathrm{CN}(\mathrm{C}) \mathrm{C}) \mathrm{cc} 23) \mathrm{c} 1$ & 1.2 & $*$ \\
\hline 278 & $\mathrm{C} \# \mathrm{Cc} 1 \mathrm{cccc}(\mathrm{Nc} 2 \mathrm{ncnc} 3 \mathrm{cc}(\mathrm{OCCOC}) \mathrm{c}(\mathrm{NC}(=\mathrm{O}) / \mathrm{C}=\mathrm{C} / \mathrm{CN}(\mathrm{C}) \mathrm{C}) \mathrm{cc} 23) \mathrm{c} 1$ & 1.2 & $*$ \\
\hline 279 & $\mathrm{COCCOc} 1 \mathrm{cc} 2 \mathrm{ncnc}(\mathrm{Nc} 3 \operatorname{ccc}(\mathrm{F}) \mathrm{c}(\mathrm{Cl}) \mathrm{c} 3) \mathrm{c} 2 \mathrm{cc} 1 \mathrm{NC}(=\mathrm{O}) / \mathrm{C}=\mathrm{C} / \mathrm{CN}(\mathrm{C}) \mathrm{C}$ & 1.2 & $*$ \\
\hline 280 & $\mathrm{OCCN}(\mathrm{CCO}) \mathrm{CCCNc} 1 \mathrm{cc} 2 \mathrm{ncnc}(\mathrm{Nc} 3 \mathrm{cccc}(\mathrm{Br}) \mathrm{c} 3) \mathrm{c} 2 \mathrm{cn} 1$ & 1.2 & $*$ \\
\hline 281 & $\mathrm{CN}(\mathrm{C}) \mathrm{CCCNc} 1 \mathrm{cc} 2 \mathrm{c}(\mathrm{Nc} 3 \mathrm{ccc}(\mathrm{Br}) \mathrm{c} 3) \mathrm{ncnc} 2 \mathrm{cn} 1$ & 1.2 & $*$ \\
\hline 282 & Brc1 $\operatorname{ccc}(\mathrm{Nc} 2 \mathrm{ncnc} 3 \mathrm{cnc}(\mathrm{NCCc} 4 \mathrm{ccc} n 4) \mathrm{cc} 23) \mathrm{c} 1$ & 1.2 & $*$ \\
\hline 283 & $\mathrm{C}=\mathrm{CC}(=\mathrm{O}) \mathrm{Nc} 1 \mathrm{ccc} 2 \mathrm{ncnc}(\mathrm{Nc} 3 \mathrm{ccc}(\mathrm{F}) \mathrm{c}(\mathrm{Br}) \mathrm{c} 3) \mathrm{c} 2 \mathrm{n} 1$ & 1.2 & $*$ \\
\hline 284 & $\mathrm{COc} 1 \mathrm{ccc} 2[\mathrm{nH}] \mathrm{c} 3 \mathrm{ncnc}(\mathrm{Nc} 4 \mathrm{cccc}(\mathrm{Br}) \mathrm{c} 4) \mathrm{c} 3 \mathrm{c} 2 \mathrm{c} 1$ & 1.2 & $*$ \\
\hline 285 & $\mathrm{C}=\mathrm{C}(\mathrm{C}) \mathrm{C}(=\mathrm{O}) \mathrm{Nc} 1 \mathrm{ccc} 2 \mathrm{ncnc}(\mathrm{Nc} 3 \operatorname{ccc}(\mathrm{Br}) \mathrm{c} 3) \mathrm{c} 2 \mathrm{c} 1$ & 1.2 & $*$ \\
\hline 286 & $\mathrm{CC}(=\mathrm{O}) / \mathrm{C}=\mathrm{C} / \mathrm{C}(=\mathrm{O}) \mathrm{Nc} 1 \mathrm{ccc} 2 \mathrm{ncnc}(\mathrm{Nc} 3 \operatorname{cccc}(\mathrm{Br}) \mathrm{c} 3) \mathrm{c} 2 \mathrm{c} 1$ & 1.2 & $*$ \\
\hline 287 & $\mathrm{CCN}(\mathrm{CC}) \mathrm{CCNC}(=\mathrm{O}) \mathrm{c} 1 \mathrm{cc}(\mathrm{C}) \mathrm{c}(/ \mathrm{C}=\mathrm{C} 2 \backslash \mathrm{C}(=\mathrm{O}) \mathrm{Nc} 3 \mathrm{ncnc}(\mathrm{Nc} 4 \mathrm{ccc}(\mathrm{F}) \mathrm{c}(\mathrm{Cl}) \mathrm{c} 4) \mathrm{c} 32)[\mathrm{nH}] 1$ & 1.2 & $*$ \\
\hline 288 & $\mathrm{C}=\mathrm{CC}(=\mathrm{O}) \mathrm{Nc} 1 \mathrm{cccc}(-\mathrm{n} 2 \mathrm{c}(=\mathrm{O}) \mathrm{n}(\mathrm{Cc} 3 \mathrm{ccccc} 3) \mathrm{c}(=\mathrm{O}) \mathrm{c} 3 \mathrm{cnc}(\mathrm{Nc} 4 \mathrm{ccc}(\mathrm{N} 5 \mathrm{CCC}(\mathrm{N}(\mathrm{C}) \mathrm{C}) \mathrm{CC} 5) \mathrm{cc} 4 \mathrm{OC}) \mathrm{nc} 32) \mathrm{c} 1$ & 1.2 & $*$ \\
\hline 289 & $\mathrm{OCCN}(\mathrm{CCO}) \mathrm{CCCNc} 1 \mathrm{c}(\mathrm{Br}) \mathrm{cccc} 1 \mathrm{Nc} 1 \mathrm{ncnc} 2 \mathrm{ccncc} 12$ & 1.202 & $*$ \\
\hline 290 & $\mathrm{C}=\mathrm{CC}(=\mathrm{O}) \mathrm{Nc} 1 \mathrm{cccc}(-\mathrm{n} 2 \mathrm{c}(=\mathrm{O}) \mathrm{cnc} 3 \mathrm{cnc}(\mathrm{Nc} 4 \mathrm{ccc}(\mathrm{N} 5 \mathrm{CCN}(\mathrm{C}) \mathrm{CC} 5) \mathrm{cc} 4) \mathrm{nc} 32) \mathrm{c} 1$ & 1.21 & 8.92 \\
\hline 291 & $\mathrm{O}=\mathrm{C}(\mathrm{Nc} 1 \mathrm{ccc} 2 \mathrm{ncnc}(\mathrm{Nc} 3 \mathrm{cccc}(\mathrm{Br}) \mathrm{c} 3) \mathrm{c} 2 \mathrm{c} 1)[\mathrm{C} @ @ \mathrm{H}] 1 \mathrm{O}[\mathrm{C} @ \mathrm{H}] 1 \mathrm{CN} 1 \mathrm{CCCCC} 1$ & 1.24 & 8.91 \\
\hline 292 & $\operatorname{Brc} 1 \mathrm{cccc}(\mathrm{Nc} 2 \mathrm{ncnc} 3 \mathrm{ccc} 4 \mathrm{cc}[\mathrm{nH}] \mathrm{c} 4 \mathrm{c} 23) \mathrm{c} 1$ & 1.24 & $*$ \\
\hline 293 & $\mathrm{CCOC} 1=\mathrm{C} 2 \mathrm{C}(=\mathrm{CCc} 3 \mathrm{c} 2 \mathrm{sc}(\mathrm{N}) \mathrm{c} 3 \mathrm{C}(=\mathrm{O}) \mathrm{Nc} 2 \mathrm{ccc}([\mathrm{N}+](=\mathrm{O})[\mathrm{O}-]) \mathrm{cc} 2) \mathrm{OC}(\mathrm{O})=\mathrm{C} 1 \mathrm{C} \# \mathrm{~N}$ & 1.24 & $*$ \\
\hline 294 & $\mathrm{CC} 1(\mathrm{C}) \mathrm{Cc} 2 \mathrm{c}(\mathrm{sc}(=\mathrm{S}) \mathrm{n} 2-\mathrm{c} 2 \mathrm{ccccc} 2)-\mathrm{c} 2 \mathrm{c} 1 \mathrm{sc}(\mathrm{NC} 1=\mathrm{C}(\mathrm{Cl}) \mathrm{C}(\mathrm{c} 3 \mathrm{ccc}(\mathrm{Cl}) \mathrm{cc} 3) \mathrm{C}(\mathrm{C \# N})=\mathrm{C}(\mathrm{N}) \mathrm{O} 1) \mathrm{c} 2 \mathrm{C \# N}$ & 1.27 & $*$ \\
\hline 295 & $\mathrm{Nc} 1 \operatorname{sc} 2 \mathrm{c}(\mathrm{c} 1 \mathrm{C}(=\mathrm{O}) \mathrm{Nc} 1 \mathrm{ccc}(\mathrm{Cl}) \mathrm{cc} 1) \mathrm{CCC}(=\mathrm{O}) \mathrm{C} 2=\mathrm{NNc} 1 \mathrm{ccccc} 1$ & 1.28 & $*$ \\
\hline 296 & $\mathrm{Nc} 1 \mathrm{sc} 2 \mathrm{c}(\mathrm{c} 1 \mathrm{C}(=\mathrm{O}) \mathrm{Nc} 1 \mathrm{ccc}(\mathrm{Cl}) \mathrm{cc} 1) \mathrm{CC}=\mathrm{C} 1 \mathrm{C} 2 \mathrm{SC}(=\mathrm{S}) \mathrm{N} 1 \mathrm{c} 1 \mathrm{ccccc} 1$ & 1.29 & $*$ \\
\hline 297 & $\mathrm{COc} 1 \mathrm{cc} 2 \mathrm{ncnc}(\mathrm{Nc} 3 \operatorname{ccc}(\mathrm{OCc} 4 \mathrm{cccc}(\mathrm{F}) \mathrm{c} 4) \mathrm{c}(\mathrm{Cl}) \mathrm{c} 3) \mathrm{c} 2 \mathrm{cc} 1 \mathrm{NC}(=\mathrm{O}) / \mathrm{C}(\mathrm{F})=\mathrm{C} \backslash \mathrm{CN}(\mathrm{C}) \mathrm{C}$ & 1.3 & 8.89 \\
\hline 298 & $\mathrm{~N} \# \mathrm{Cc} 1 \mathrm{ccc}(\mathrm{F}) \mathrm{c}(\mathrm{C}(=\mathrm{O}) \mathrm{Nc} 2 \mathrm{cc} 3 \mathrm{c}(\mathrm{Nc} 4 \mathrm{ccc}(\mathrm{F}) \mathrm{c}(\mathrm{Cl}) \mathrm{c} 4) \mathrm{ncnc} 3 \mathrm{cc} 2 \mathrm{OCCCN} 2 \mathrm{CCOCC} 2) \mathrm{c} 1$ & 1.3 & 8.89 \\
\hline 299 & $\mathrm{O}=\mathrm{C}(\mathrm{C} \# \mathrm{CCCN} 1 \mathrm{CCOCC} 1) \mathrm{Nc} 1 \mathrm{cc} 2 \mathrm{c}(\mathrm{Nc} 3 \mathrm{ccc}(\mathrm{F}) \mathrm{c}(\mathrm{Cl}) \mathrm{c} 3) \mathrm{ncnc} 2 \mathrm{cn} 1$ & 1.3 & $*$ \\
\hline 300 & $\mathrm{Cc} 1 \mathrm{cccc}(\mathrm{Nc} 2 \mathrm{ncnc} 3 \mathrm{cnc}(\mathrm{NCCc} 4 \mathrm{c}[\mathrm{nH}] \mathrm{cn} 4) \mathrm{cc} 23) \mathrm{c} 1$ & 1.3 & $*$ \\
\hline 301 & $\mathrm{CN}(\mathrm{C}) \mathrm{CCn} 1 \mathrm{cnc} 2 \mathrm{cc} 3 \mathrm{ncnc}(\mathrm{Nc} 4 \mathrm{cccc}(\mathrm{Br}) \mathrm{c} 4) \mathrm{c} 3 \mathrm{cc} 21$ & 1.32 & $*$ \\
\hline 302 & CCOc1cc2ncnc $(\mathrm{Nc} 3 \operatorname{ccc}(\mathrm{OCc} 4 \mathrm{cccc}(\mathrm{F}) \mathrm{c} 4) \mathrm{c}(\mathrm{Cl}) \mathrm{c} 3) \mathrm{c} 2 \mathrm{cc} 1 \mathrm{NC}(=\mathrm{O})[\mathrm{C} @ @ \mathrm{H}] 1 \mathrm{COC}(=\mathrm{O}) \mathrm{N} 1$ & 1.34 & 8.87 \\
\hline 303 & $\mathrm{O}=\mathrm{C}(\mathrm{C} \# \mathrm{CCO}) \mathrm{Nc} 1 \mathrm{ccc} 2 \mathrm{ncnc}(\mathrm{Nc} 3 \mathrm{ccc}(\mathrm{F}) \mathrm{c}(\mathrm{Cl}) \mathrm{c} 3) \mathrm{c} 2 \mathrm{c} 1$ & 1.4 & $*$ \\
\hline
\end{tabular}




\begin{tabular}{|c|c|c|c|}
\hline 304 & $\mathrm{O}=\mathrm{S}(=\mathrm{O})(\mathrm{O}) \mathrm{CCNc} 1 \mathrm{cc} 2 \mathrm{ncnc}(\mathrm{Nc} 3 \mathrm{cccc}(\mathrm{Br}) \mathrm{c} 3) \mathrm{c} 2 \mathrm{cn} 1$ & 1.4 & $*$ \\
\hline 305 & $\mathrm{CNc} 1 \mathrm{cc} 2 \mathrm{ncnc}(\mathrm{Nc} 3 \mathrm{cccc}(\mathrm{C}) \mathrm{c} 3) \mathrm{c} 2 \mathrm{cn} 1$ & 1.4 & * \\
\hline 306 & $\mathrm{C}=\mathrm{CS}(=\mathrm{O})(=\mathrm{O}) \mathrm{Nc} 1 \mathrm{ccc} 2 \mathrm{ncnc}(\mathrm{Nc} 3 \operatorname{cccc}(\mathrm{Br}) \mathrm{c} 3) \mathrm{c} 2 \mathrm{c} 1$ & 1.4 & * \\
\hline 307 & $\mathrm{Cc} 1 \mathrm{ccccc} 1 \mathrm{Nc} 1 \mathrm{nc} 2 \mathrm{cc}(\mathrm{F}) \mathrm{c}(\mathrm{N}(\mathrm{C}) \mathrm{C}(=\mathrm{O}) / \mathrm{C}=\mathrm{C} / \mathrm{CN}(\mathrm{C}) \mathrm{C}) \mathrm{cc} 2 \mathrm{n} 2 \mathrm{cncc} 12$ & 1.4 & * \\
\hline 308 & $\mathrm{C}=\mathrm{CC}(=\mathrm{O}) \mathrm{Nc} 1 \mathrm{cccc}(-\mathrm{n} 2 \mathrm{c}(=\mathrm{O}) \mathrm{c}(=\mathrm{O}) \mathrm{n}(\mathrm{C}(\mathrm{C}) \mathrm{C}) \mathrm{c} 3 \mathrm{cnc}(\mathrm{Nc} 4 \mathrm{ccc}(\mathrm{N} 5 \mathrm{CCN}(\mathrm{C}) \mathrm{CC} 5) \mathrm{c}(\mathrm{C}) \mathrm{c} 4) \mathrm{nc} 32) \mathrm{c} 1$ & 1.4 & * \\
\hline 309 & $\mathrm{C}=\mathrm{CC}(=\mathrm{O}) \mathrm{Nc} 1 \mathrm{cc}(\mathrm{Nc} 2 \mathrm{n}[\mathrm{nH}] \mathrm{c} 3 \mathrm{cc}(-\mathrm{c} 4 \mathrm{cccc} 5 \mathrm{ccccc} 45) \mathrm{ccc} 23) \mathrm{c}(\mathrm{OC}) \mathrm{cc} 1 \mathrm{~N}(\mathrm{C}) \mathrm{CCN}(\mathrm{C}) \mathrm{C}$ & 1.4 & * \\
\hline 310 & COc1cc2ncnc(Nc3ecc(OCc4ccce(F)c4)c(Cl)c3)c2cc1OCCCN1CCNCCNCC1 & 1.4 & * \\
\hline 311 & $\mathrm{C}=\mathrm{CC}(=\mathrm{O}) \mathrm{Nc} 1 \mathrm{cccc}(\mathrm{N} 2 \mathrm{C}(=\mathrm{O}) \mathrm{N}(\mathrm{c} 3 \operatorname{ccc}(-\mathrm{c} 4 \mathrm{ccccc} 4) \mathrm{cc} 3) \mathrm{Cc} 3 \mathrm{cnc}(\mathrm{Nc} 4 \operatorname{ccc}(\mathrm{N} 5 \mathrm{CCN}(\mathrm{C}) \mathrm{CC} 5) \mathrm{cc} 4 \mathrm{OC}) \mathrm{nc} 32) \mathrm{c} 1$ & 1.41 & 8.85 \\
\hline 312 & $\mathrm{O}=\mathrm{S}(=\mathrm{O})(\mathrm{O}) \mathrm{CCNc} 1 \mathrm{c}(\mathrm{Br}) \mathrm{cccc} 1 \mathrm{Nc} 1 \mathrm{ncnc} 2 \mathrm{ccncc} 12$ & 1.413 & $*$ \\
\hline 313 & $\mathrm{O}=\mathrm{C}(\mathrm{NCCN} 1 \mathrm{CCOCC} 1) \mathrm{Nc} 1 \mathrm{ccc} 2 \mathrm{ncnc}(\mathrm{Nc} 3 \mathrm{cccc}(\mathrm{Br}) \mathrm{c} 3) \mathrm{c} 2 \mathrm{c} 1$ & 1.43 & 8.84 \\
\hline 314 & $\operatorname{COc} 1 \mathrm{cc} 2 \mathrm{c}(\mathrm{Nc} 3 \mathrm{ccc}(\mathrm{F}) \mathrm{c}(\mathrm{Cl}) \mathrm{c} 3) \operatorname{ncnc} 2 \mathrm{cc} 1 \mathrm{OCCCCCCn} 1 \mathrm{ccnc} 1[\mathrm{~N}+](=\mathrm{O})[\mathrm{O}-]$ & 1.44 & 8.84 \\
\hline 315 & $\mathrm{CN}(\mathrm{C}) \mathrm{CCCNC}(=\mathrm{O}) / \mathrm{C}=\mathrm{C} / \mathrm{C}(=\mathrm{O}) \mathrm{N}(\mathrm{C}) \mathrm{c} 1 \mathrm{cc} 2 \mathrm{c}(\mathrm{Nc} 3 \mathrm{cccc}(\mathrm{Br}) \mathrm{c} 3) \mathrm{ncnc} 2 \mathrm{cn} 1$ & 1.45 & $*$ \\
\hline 316 & $\mathrm{C}=\mathrm{CC}(=\mathrm{O}) \mathrm{Nc} 1 \mathrm{cc} 2 \mathrm{c}(\mathrm{Nc} 3 \mathrm{ccc}(\mathrm{F}) \mathrm{c}(\mathrm{Cl}) \mathrm{c} 3) \mathrm{c}(\mathrm{C} \# \mathrm{~N}) \mathrm{cnc} 2 \mathrm{cc} 1 \mathrm{OCC}$ & 1.46 & 8.84 \\
\hline 317 & $\mathrm{C}=\mathrm{CC}(=\mathrm{O}) \mathrm{Nc} 1 \operatorname{cccc}(\mathrm{N} 2 \mathrm{C}(=\mathrm{O}) \mathrm{N}(\mathrm{C}) \mathrm{Cc} 3 \mathrm{cnc}(\mathrm{Nc} 4 \operatorname{ccc}(\mathrm{N} 5 \mathrm{CCCN}(\mathrm{C}) \mathrm{CC} 5) \mathrm{cc} 4 \mathrm{OC}) \mathrm{nc} 32) \mathrm{c} 1$ & 1.47 & 8.83 \\
\hline 318 & $\mathrm{Nc} 1 \operatorname{sc} 2 \mathrm{c}(\mathrm{c} 1 \mathrm{C}(=\mathrm{O}) \mathrm{Nc} 1 \mathrm{ccc}([\mathrm{N}+](=\mathrm{O})[\mathrm{O}-]) \mathrm{cc} 1) \mathrm{CC}=\mathrm{C} 1 \mathrm{C} 2 \mathrm{SC}(=\mathrm{S}) \mathrm{N} 1 \mathrm{c} 1 \mathrm{ccccc} 1$ & 1.49 & $*$ \\
\hline 319 & Fc1 cccc(COc2cce(Nc3ncnc4cce(NC(=S)NCCCN5CCOCC5)cc34)cc2Cl)c1 & 1.5 & 8.82 \\
\hline 320 & C[C@@H](Nc1ncnc2oc(-c3ccc(O)cc3)cc12)c1 ccccc1 & 1.5 & 8.82 \\
\hline 321 & $\mathrm{COc1c}(\mathrm{CO}) \mathrm{cccc} 1-\mathrm{c} 1 \mathrm{cc} 2 \mathrm{c}(\mathrm{N}[\mathrm{C} @ \mathrm{H}](\mathrm{C}) \mathrm{c} 3 \mathrm{ccccc} 3) \mathrm{ncnc} 2 \mathrm{~s} 1$ & 1.5 & 8.82 \\
\hline 322 & $\mathrm{COc} 1 \mathrm{cc}(\mathrm{C}(\mathrm{N})=\mathrm{O}) \mathrm{ccc} 1-\mathrm{c} 1 \mathrm{cc} 2 \mathrm{c}(\mathrm{N}[\mathrm{C} @ \mathrm{H}](\mathrm{CO}) \mathrm{c} 3 \mathrm{ccccc} 3) \mathrm{ncnc} 2 \mathrm{~s} 1$ & 1.5 & 8.82 \\
\hline 323 & $\mathrm{O}=\mathrm{C}(\mathrm{C} \# \mathrm{CCCN} 1 \mathrm{CCOCC} 1) \mathrm{Nc} 1 \mathrm{cc} 2 \mathrm{c}(\mathrm{Nc} 3 \mathrm{ccc}(\mathrm{F}) \mathrm{c}(\mathrm{Br}) \mathrm{c} 3) \mathrm{ncn} 2 \mathrm{cn} 1$ & 1.5 & * \\
\hline 324 & $\mathrm{C}=\mathrm{CC}(=\mathrm{O}) \mathrm{Nc} 1 \mathrm{ccc} 2 \mathrm{ncnc}(\mathrm{Nc} 3 \mathrm{cccc}(\mathrm{C}) \mathrm{c} 3 \mathrm{~F}) \mathrm{c} 2 \mathrm{c} 1$ & 1.5 & * \\
\hline 325 & $\mathrm{C}=\mathrm{CC}(=\mathrm{O}) \mathrm{Nc} 1 \mathrm{cc} 2 \mathrm{c}(\mathrm{Nc} 3 \mathrm{cccc}(\mathrm{C}) \mathrm{c} 3) \mathrm{ncn} 2 \mathrm{cc} 1 \mathrm{OCCCN} 1 \mathrm{CCOCC} 1$ & 1.5 & $*$ \\
\hline 326 & $\mathrm{C}=\mathrm{CC}(=\mathrm{O}) \mathrm{Nc} 1 \mathrm{nc} 2 \mathrm{c}(\mathrm{Nc} 3 \mathrm{ccc}(\mathrm{F}) \mathrm{c}(\mathrm{Cl}) \mathrm{c} 3) \mathrm{ncnc} 2 \mathrm{cc} 1 \mathrm{OCCCN} 1 \mathrm{CCOCC} 1$ & 1.5 & * \\
\hline 327 & $\mathrm{O}=\mathrm{C}(\mathrm{O}) \mathrm{CNc} 1 \mathrm{cc} 2 \mathrm{ncnc}(\mathrm{Nc} 3 \mathrm{cccc}(\mathrm{Br}) \mathrm{c} 3) \mathrm{c} 2 \mathrm{cn} 1$ & 1.5 & * \\
\hline 328 & $\operatorname{Brc} 1 \mathrm{cccc}(\mathrm{Nc} 2 \mathrm{ncnc} 3 \mathrm{cnc}(\mathrm{NCc} 4 \mathrm{cccnc} 4) \mathrm{cc} 23) \mathrm{c} 1$ & 1.5 & $*$ \\
\hline 329 & $\mathrm{Cc} 1 \mathrm{cccc}(\mathrm{Nc} 2 \mathrm{ncnc} 3 \mathrm{cnc}(\mathrm{NCCN} 4 \mathrm{CCOCC} 4) \mathrm{cc} 23) \mathrm{c} 1$ & 1.5 & $*$ \\
\hline 330 & $\mathrm{Nc} 1 \mathrm{ncc} 2 \mathrm{ncnc}(\mathrm{Nc} 3 \operatorname{cccc}(\mathrm{Br}) \mathrm{c} 3) \mathrm{c} 2 \mathrm{n} 1$ & 1.5 & * \\
\hline 331 & $\mathrm{CCOC}(=\mathrm{O}) / \mathrm{C}=\mathrm{C} / \mathrm{C}(=\mathrm{O}) \mathrm{Nc} 1 \mathrm{cc} 2 \mathrm{c}(\mathrm{Nc} 3 \mathrm{cccc}(\mathrm{Br}) \mathrm{c} 3) \mathrm{ncnc} 2 \mathrm{cn} 1$ & 1.5 & $*$ \\
\hline 332 & $\mathrm{C}=\mathrm{CC}(=\mathrm{O}) \mathrm{N}[\mathrm{C} @ \mathrm{H}] 1 \mathrm{CCN}(\mathrm{c} 2 \mathrm{nc}(\mathrm{Nc} 3 \mathrm{ccccc} 3) \mathrm{nc} 3 \mathrm{cnc}(\mathrm{Nc} 4 \mathrm{ccc}(\mathrm{N} 5 \mathrm{CCN}(\mathrm{C}) \mathrm{CC} 5) \mathrm{cn} 4) \mathrm{cc} 23) \mathrm{C} 1$ & 1.5 & * \\
\hline 333 & $\mathrm{CN}(\mathrm{C}) \mathrm{C} 1 \mathrm{CCN}(\mathrm{c} 2 \mathrm{ccc}(\mathrm{Nc} 3 \mathrm{cc} 4 \mathrm{c}(\mathrm{N} 5 \mathrm{CCOCC} 5) \mathrm{nc}(\mathrm{Nc} 5 \mathrm{ccc}(\mathrm{F}) \mathrm{cc} 5) \mathrm{nc} 4 \mathrm{cn} 3) \mathrm{nc} 2) \mathrm{CC} 1$ & 1.5 & * \\
\hline 334 & $\operatorname{COc} 1 \mathrm{ccc}(\mathrm{NN}=\mathrm{C} 2 \mathrm{C}(=\mathrm{O}) \mathrm{CCc} 3 \mathrm{c} 2 \mathrm{sc}(\mathrm{N}) \mathrm{c} 3 \mathrm{C}(=\mathrm{O}) \mathrm{Nc} 2 \mathrm{ccc}([\mathrm{N}+](=\mathrm{O})[\mathrm{O}-]) \mathrm{cc} 2) \mathrm{cc} 1$ & 1.51 & * \\
\hline 335 & $\mathrm{O}=\mathrm{C}(\mathrm{O}) \mathrm{CNc} 1 \mathrm{c}(\mathrm{Br}) \mathrm{cccc} 1 \mathrm{Nc} 1 \mathrm{ncn} \mathrm{c} \mathrm{ccncc} 12$ & 1.514 & * \\
\hline 336 & $\mathrm{C}=\mathrm{CC}(=\mathrm{O}) \mathrm{Nc} 1 \mathrm{cccc}(\mathrm{N} 2 \mathrm{C}(=\mathrm{O}) \mathrm{N}(\mathrm{c} 3 \mathrm{ccc}(\mathrm{Oc} 4 \mathrm{ccccc} 4) \mathrm{cc} 3) \mathrm{Cc} 3 \mathrm{cnc}(\mathrm{Nc} 4 \mathrm{ccc}(\mathrm{N} 5 \mathrm{CCN}(\mathrm{C}) \mathrm{CC} 5) \mathrm{cc} 4 \mathrm{OC}) \mathrm{nc} 32) \mathrm{c} 1$ & 1.52 & 8.82 \\
\hline 337 & $\mathrm{COc} 1 \mathrm{cc} 2 \mathrm{ncnc}(\mathrm{Nc} 3 \operatorname{ccc}(\mathrm{OCc} 4 \mathrm{cccc}(\mathrm{F}) \mathrm{c} 4) \mathrm{c}(\mathrm{Cl}) \mathrm{c} 3) \mathrm{c} 2 \mathrm{cc} 1 \mathrm{NC}(=\mathrm{O}) / \mathrm{C}(\mathrm{F})=\mathrm{C} / \mathrm{CN}(\mathrm{C}) \mathrm{C}$ & 1.56 & 8.81 \\
\hline 338 & $\mathrm{C} \# \mathrm{CC}(=\mathrm{O}) \mathrm{Nc} 1 \mathrm{ccc} 2 \mathrm{ncnc}(\mathrm{Nc} 3 \mathrm{cccc}(\mathrm{Br}) \mathrm{c} 3) \mathrm{c} 2 \mathrm{c} 1$ & 1.6 & $*$ \\
\hline 339 & $\mathrm{OCC}(\mathrm{O}) \mathrm{Cn} 1 \mathrm{ccc} 2 \mathrm{cc} 3 \mathrm{c}(\mathrm{Nc} 4 \mathrm{cccc}(\mathrm{Br}) \mathrm{c} 4) \mathrm{ncnc} 3 \mathrm{cc} 21$ & 1.6 & * \\
\hline 340 & $\mathrm{C}=\mathrm{CC}(=\mathrm{O}) \mathrm{Nc} 1 \mathrm{ccc} 2 \mathrm{c}(\mathrm{Nc} 3 \operatorname{cccc}(\mathrm{C}) \mathrm{c} 3) \mathrm{ncnc} 2 \mathrm{c} 1$ & 1.6 & $*$ \\
\hline 341 & $\mathrm{C}=\mathrm{CC}(=\mathrm{O}) \mathrm{Nc} 1 \mathrm{ccc} 2 \mathrm{ncnc}(\mathrm{Nc} 3 \operatorname{cccc}(\mathrm{Cl}) \mathrm{c} 3) \mathrm{c} 2 \mathrm{c} 1$ & 1.6 & $*$ \\
\hline 342 & $\mathrm{C}=\mathrm{C}(\mathrm{C}) \mathrm{C}(=\mathrm{O}) \mathrm{Nc} 1 \mathrm{cc} 2 \mathrm{c}(\mathrm{Nc} 3 \mathrm{cccc}(\mathrm{Br}) \mathrm{c} 3) \mathrm{ncnc} 2 \mathrm{cn} 1$ & 1.6 & * \\
\hline 343 & $\mathrm{C}=\mathrm{C}=\mathrm{CC}(=\mathrm{O}) \mathrm{Nc} 1 \mathrm{ccc} 2 \mathrm{ncnc}(\mathrm{Nc} 3 \operatorname{cccc}(\mathrm{Br}) \mathrm{c} 3) \mathrm{c} 2 \mathrm{c} 1$ & 1.6 & $*$ \\
\hline 344 & $\mathrm{C}=\mathrm{CC}(=\mathrm{O}) \mathrm{NCCSc} 1 \mathrm{nc}(-\mathrm{c} 2 \mathrm{ccc}(\mathrm{F}) \mathrm{cc} 2) \mathrm{c}(-\mathrm{c} 2 \mathrm{ccnc}(\mathrm{Nc} 3 \mathrm{cccc} 3) \mathrm{c} 2)[\mathrm{nH}] 1$ & 1.6 & * \\
\hline 345 & $\mathrm{CC} 1(\mathrm{C}) \mathrm{Cc} 2 \mathrm{nn}(-\mathrm{c} 3 \mathrm{ccc}(\mathrm{Cl}) \mathrm{cc} 3) \mathrm{nc} 2-\mathrm{c} 2 \mathrm{c} 1 \mathrm{sc} 1 \mathrm{nc}(=\mathrm{NO}) \mathrm{n}(-\mathrm{c} 3 \mathrm{ccccc} 3) \mathrm{c}(\mathrm{O}) \mathrm{c} 21$ & 1.6 & * \\
\hline 346 & $\mathrm{COCCOc} 1 \mathrm{cc} 2 \mathrm{ncnc}(\mathrm{Nc} 3 \mathrm{cccc}(\mathrm{NC}(=\mathrm{O}) \mathrm{C} 45 \mathrm{CC} 6 \mathrm{CC}(\mathrm{CC}(\mathrm{C} 6) \mathrm{C} 4) \mathrm{C} 5) \mathrm{c} 3) \mathrm{c} 2 \mathrm{cc} 1 \mathrm{OCCOC}$ & 1.63 & 8.79 \\
\hline
\end{tabular}




\begin{tabular}{|c|c|c|c|}
\hline 347 & COC[C@H]1Oc2cc3ncnc(Nc4cccc(I)c4)c3cc2O[C@@H]1COC & 1.66 & $*$ \\
\hline 348 & $\mathrm{C}=\mathrm{CC}(=\mathrm{O}) \mathrm{Nc} 1 \mathrm{cccc}(\mathrm{N} 2 \mathrm{C}(=\mathrm{O}) \mathrm{N}(\mathrm{c} 3 \operatorname{ccc}(\mathrm{OCc} 4 \mathrm{ccccc} 4) \mathrm{cc} 3) \mathrm{Cc} 3 \mathrm{cnc}(\mathrm{Nc} 4 \mathrm{ccc}(\mathrm{N} 5 \mathrm{CCN}(\mathrm{C}) \mathrm{CC} 5) \mathrm{cc} 4 \mathrm{OC}) \mathrm{nc} 32) \mathrm{c} 1$ & 1.67 & 8.78 \\
\hline 349 & $\mathrm{C}=\mathrm{CC}(=\mathrm{O}) \mathrm{Nc} 1 \mathrm{ccc} 2 \mathrm{ncnc}(\mathrm{Nc} 3 \mathrm{cccc}(\mathrm{Br}) \mathrm{c} 3) \mathrm{c} 2 \mathrm{c} 1$ & 1.69 & 8.77 \\
\hline 350 & $\mathrm{CN}(\mathrm{C}) \mathrm{CCCC}(=\mathrm{O}) \mathrm{Nc} 1 \mathrm{ccc} 2 \mathrm{nccc}(\mathrm{Nc} 3 \mathrm{cccc}(\mathrm{Br}) \mathrm{c} 3) \mathrm{c} 2 \mathrm{c} 1$ & 1.7 & 8.77 \\
\hline 351 & $\mathrm{COC}(=\mathrm{O}) \mathrm{c} 1 \mathrm{ccc} 2 \mathrm{oc} 3 \mathrm{cnnc}(\mathrm{Nc} 4 \mathrm{cccc}(\mathrm{Cl}) \mathrm{c} 4) \mathrm{c} 3 \mathrm{c} 2 \mathrm{c} 1$ & 1.7 & 8.77 \\
\hline 352 & $\mathrm{O}=\mathrm{C}(\mathrm{C} \# \mathrm{CCCN} 1 \mathrm{CCOCC} 1) \mathrm{Nc} 1 \mathrm{ccc} 2 \mathrm{ncnc}(\mathrm{Nc} 3 \mathrm{ccc}(\mathrm{F}) \mathrm{c}(\mathrm{Cl}) \mathrm{c} 3) \mathrm{c} 2 \mathrm{c} 1$ & 1.7 & * \\
\hline 353 & $\mathrm{CCCC} \# \mathrm{CC}(=\mathrm{O}) \mathrm{Nc} 1 \mathrm{cc} 2 \mathrm{c}(\mathrm{Nc} 3 \mathrm{ccc}(\mathrm{F}) \mathrm{c}(\mathrm{Cl}) \mathrm{c} 3) \mathrm{ncnc} 2 \mathrm{cn} 1$ & 1.7 & $*$ \\
\hline 354 & $\mathrm{C}=\mathrm{CC}(=\mathrm{O}) \mathrm{Nc} 1 \mathrm{cc} 2 \mathrm{c}(\mathrm{Nc} 3 \mathrm{cccc}(\mathrm{Br}) \mathrm{c} 3) \mathrm{ncnc} 2 \mathrm{cc} 1 \mathrm{OCCCN} 1 \mathrm{CCN}(\mathrm{C}) \mathrm{CC} 1$ & 1.7 & * \\
\hline 355 & $\mathrm{C}=\mathrm{CC}(=\mathrm{O}) \mathrm{Nc} 1 \mathrm{cc} 2 \mathrm{c}(\mathrm{Nc} 3 \mathrm{ccc}(\mathrm{F}) \mathrm{c}(\mathrm{Cl}) \mathrm{c} 3) \mathrm{ncnc} 2 \mathrm{cc} 1 \mathrm{OCCOCCCCO}$ & 1.7 & $*$ \\
\hline 356 & Brc1cece(Nc2ncnc3cc4ncenc4cc23)c1 & 1.7 & $*$ \\
\hline 357 & $\mathrm{CN}(\mathrm{CCO}) \mathrm{CCNc} 1 \mathrm{cc} 2 \mathrm{c}(\mathrm{Nc} 3 \mathrm{cccc}(\mathrm{Br}) \mathrm{c} 3) \mathrm{ncnc} 2 \mathrm{cn} 1$ & 1.7 & * \\
\hline 358 & Brc1 $\mathrm{cccc}(\mathrm{Nc} 2 \mathrm{ncnc} 3 \mathrm{cnc}(\mathrm{NCCCn} 4 \mathrm{ccnc} 4) \mathrm{cc} 23) \mathrm{c} 1$ & 1.7 & $*$ \\
\hline 359 & $\mathrm{Nc} 1 \operatorname{sc} 2 \mathrm{c}(\mathrm{c} 1 \mathrm{C}(=\mathrm{O}) \mathrm{Nc} 1 \mathrm{ccc}([\mathrm{N}+](=\mathrm{O})[\mathrm{O}-]) \mathrm{cc} 1) \mathrm{CCC}(=\mathrm{O}) \mathrm{C} 2=\mathrm{NNc} 1 \mathrm{ccccc} 1$ & 1.73 & $*$ \\
\hline 360 & $\mathrm{O}=\mathrm{C}(/ \mathrm{C}=\mathrm{C} / \mathrm{C}(\mathrm{F})(\mathrm{F}) \mathrm{F}) \mathrm{Nc} 1 \mathrm{ccc} 2 \mathrm{ncnc}(\mathrm{Nc} 3 \operatorname{ccc}(\mathrm{Br}) \mathrm{c} 3) \mathrm{c} 2 \mathrm{c} 1$ & 1.75 & $*$ \\
\hline 361 & COc1cc2c(Nc3ccc(F)c(Cl)c3)ncnc2cc1OCCN1C[C@H](O)[C@@H](O)[C@H](O)[C@H]1CO & 1.79 & * \\
\hline 362 & COc1cc2c(Nc3ccc(F)c(Cl)c3)ncnc2cc1OCCCN1C[C@H](O)[C@@H](O)[C@H](O)[C@H]1CO & 1.79 & * \\
\hline 363 & $\mathrm{CCN}(\mathrm{CC}) \mathrm{CCC} \# \mathrm{CC}(=\mathrm{O}) \mathrm{Nc} 1 \mathrm{ccc} 2 \mathrm{ncnc}(\mathrm{Nc} 3 \mathrm{ccc}(\mathrm{F}) \mathrm{c}(\mathrm{Cl}) \mathrm{c} 3) \mathrm{c} 2 \mathrm{c} 1$ & 1.8 & $*$ \\
\hline 364 & $\mathrm{C} \# \mathrm{Cc} 1 \mathrm{cccc}(\mathrm{Nc} 2 \mathrm{ncnc} 3 \mathrm{cc}(\mathrm{OCCOC}) \mathrm{c}(\mathrm{NC}(=\mathrm{O}) \mathrm{C}=\mathrm{C}) \mathrm{cc} 23) \mathrm{c} 1$ & 1.8 & $*$ \\
\hline 365 & $\mathrm{COc} 1 \mathrm{cc} 2 \mathrm{ncnc}(\mathrm{Nc} 3 \mathrm{ccc}(\mathrm{F}) \mathrm{c}(\mathrm{Cl}) \mathrm{c} 3) \mathrm{c} 2 \mathrm{cc} 1 \mathrm{NC}(=\mathrm{O}) / \mathrm{C}=\mathrm{C} / \mathrm{CN} 1 \mathrm{CCCCC} 1$ & 1.8 & * \\
\hline 366 & $\mathrm{CCOc} 1 \mathrm{cc} 2 \mathrm{ncnc}(\mathrm{C \# Cc} 3 \mathrm{c}[\mathrm{nH}] \mathrm{nc} 3-\mathrm{c} 3 \mathrm{ccc}(\mathrm{F}) \mathrm{cc} 3) \mathrm{c} 2 \mathrm{cc} 1 \mathrm{OCC}$ & 1.8 & $*$ \\
\hline 367 & $\mathrm{C}=\mathrm{CC}(=\mathrm{O}) \mathrm{Nc} 1 \mathrm{cc} 2 \mathrm{c}(\mathrm{Nc} 3 \mathrm{ccc}(\mathrm{F}) \mathrm{c}(\mathrm{Br}) \mathrm{c} 3) \mathrm{ncn} 2 \mathrm{cc} 1 \mathrm{OCCCN} 1 \mathrm{CCOCC} 1$ & 1.8 & $*$ \\
\hline 368 & $\mathrm{CN}(\mathrm{C}) \mathrm{CCCCNc} 1 \mathrm{cc} 2 \mathrm{c}(\mathrm{Nc} 3 \mathrm{cccc}(\mathrm{Br}) \mathrm{c} 3) \mathrm{ncnc} 2 \mathrm{cn} 1$ & 1.8 & $*$ \\
\hline 369 & $\mathrm{Cc} 1 \mathrm{cccc}(\mathrm{Nc} 2 \mathrm{ncnc} 3 \mathrm{cnc}(\mathrm{NCCCN} 4 \mathrm{CCOCC} 4) \mathrm{cc} 23) \mathrm{c} 1$ & 1.8 & $*$ \\
\hline 370 & Brc1 $1 \mathrm{ccc}(\mathrm{Nc} 2 \mathrm{ncnc} 3 \mathrm{c} 2 \mathrm{sc} 2 \mathrm{ccccc} 23) \mathrm{c} 1$ & 1.8 & * \\
\hline 371 & $\operatorname{Cc} 1 \mathrm{cc}(\mathrm{C}(=\mathrm{O}) \mathrm{N} 2 \mathrm{CCOCC} 2)[\mathrm{nH}] \mathrm{c} 1 / \mathrm{C}=\mathrm{C} 1 \backslash \mathrm{C}(=\mathrm{O}) \mathrm{Nc} 2 \mathrm{ncnc}(\mathrm{Nc} 3 \mathrm{ccc} 4 \mathrm{c}(\operatorname{cnn} 4 \mathrm{Cc} 4 \mathrm{ccccc} 4) \mathrm{c} 3) \mathrm{c} 21$ & 1.8 & $*$ \\
\hline 372 & $\mathrm{COc} 1 \mathrm{ccc}(-\mathrm{c} 2 \mathrm{cc} 3 \mathrm{c}(\mathrm{N}[\mathrm{C} @ \mathrm{H}](\mathrm{C}) \mathrm{c} 4 \mathrm{ccccc} 4 \mathrm{~F}) \mathrm{ncnc} 3[\mathrm{nH}] 2) \mathrm{cc} 1$ & 1.8 & $*$ \\
\hline 373 & $\mathrm{CC}[\mathrm{C} @ @ \mathrm{H}](\mathrm{Nc} 1 \mathrm{ncnc} 2[\mathrm{nH}] \mathrm{c}(-\mathrm{c} 3 \mathrm{ccc}(\mathrm{OC}) \mathrm{cc} 3) \mathrm{cc} 12) \mathrm{c} 1 \mathrm{ccccc} 1$ & 1.8 & * \\
\hline 374 & $\mathrm{~S}=\mathrm{C}(\mathrm{NCCN} 1 \mathrm{CCOCC} 1) \mathrm{Nc} 1 \mathrm{ccc} 2 \mathrm{ncnc}(\mathrm{Nc} 3 \mathrm{cccc}(\mathrm{Br}) \mathrm{c} 3) \mathrm{c} 2 \mathrm{c} 1$ & 1.81 & 8.74 \\
\hline 375 & $\mathrm{CCOc} 1 \mathrm{cc} 2 \mathrm{ncc}(\mathrm{C} \# \mathrm{~N}) \mathrm{c}(\mathrm{Nc} 3 \mathrm{ccc}(\mathrm{F}) \mathrm{c}(\mathrm{Cl}) \mathrm{c} 3) \mathrm{c} 2 \mathrm{cc} 1 \mathrm{NC}(=\mathrm{O}) / \mathrm{C}=\mathrm{C} / \mathrm{CNCc} 1 \mathrm{cn}(\mathrm{CCF}) \mathrm{nn} 1$ & 1.81 & 8.74 \\
\hline 376 & $\mathrm{CC} 1(\mathrm{C}) \mathrm{CC}(=\mathrm{NN}) \mathrm{C}(=\mathrm{NNc} 2 \mathrm{ccc}(\mathrm{Cl}) \mathrm{cc} 2) \mathrm{c} 2 \mathrm{c} 1 \mathrm{sc}(\mathrm{N}) \mathrm{c} 2 \mathrm{C} \# \mathrm{~N}$ & 1.83 & $*$ \\
\hline 377 & $\mathrm{CN}(\mathrm{C}) \mathrm{C} / \mathrm{C}=\mathrm{C} / \mathrm{C}(=\mathrm{O}) \mathrm{Nc} 1 \mathrm{cc} 2 \mathrm{c}(\mathrm{Nc} 3 \mathrm{cccc}(\mathrm{Br}) \mathrm{c} 3) \mathrm{c}(\mathrm{C} \# \mathrm{~N}) \mathrm{cnc} 2 \mathrm{cn} 1$ & 1.9 & 8.72 \\
\hline 378 & $\mathrm{O}=\mathrm{C}(\mathrm{CCCCCn} 1 \mathrm{cc}(-\mathrm{c} 2 \mathrm{ccc} 3 \mathrm{ncnc}(\mathrm{Nc} 4 \mathrm{ccc}(\mathrm{OCc} 5 \mathrm{cccc}(\mathrm{F}) \mathrm{c} 5) \mathrm{c}(\mathrm{Cl}) \mathrm{c} 4) \mathrm{c} 3 \mathrm{c} 2) \mathrm{nn} 1) \mathrm{NO}$ & 1.9 & $*$ \\
\hline 379 & Brc1 $1 \mathrm{ccc}(\mathrm{Nc} 2 \mathrm{ncnc} 3 \mathrm{cc}(\mathrm{NCCCN} 4 \mathrm{CCOCC} 4) \mathrm{ncc} 23) \mathrm{c} 1$ & 1.9 & $*$ \\
\hline 380 & OCCn1 ccc2ncnc( $(\mathrm{Nc} 3 \operatorname{ccc}(\mathrm{Oc} 4 \mathrm{cccc} 5[\mathrm{nH}] \mathrm{ncc} 45) \mathrm{c}(\mathrm{Cl}) \mathrm{c} 3) \mathrm{c} 21$ & 1.9 & $*$ \\
\hline 381 & $\mathrm{C}=\mathrm{CC}(=\mathrm{O}) \mathrm{N} 1 \mathrm{CCC}[\mathrm{C} @ \mathrm{H}](\mathrm{Nc} 2 \mathrm{nc}(\mathrm{Nc} 3 \mathrm{ccccc} 3) \mathrm{nc} 3 \mathrm{cnc}(\mathrm{Nc} 4 \mathrm{ccc}(\mathrm{N} 5 \mathrm{CCN}(\mathrm{C}) \mathrm{CC} 5) \mathrm{cn} 4) \mathrm{cc} 23) \mathrm{C} 1$ & 1.9 & * \\
\hline 382 & $\mathrm{COc} 1 \mathrm{cccc}(-\mathrm{c} 2 \mathrm{cc} 3 \mathrm{c}(\mathrm{N}[\mathrm{C} @ \mathrm{H}](\mathrm{C}) \mathrm{c} 4 \mathrm{ccccc} 4) \mathrm{ncnc} 3[\mathrm{nH}] 2) \mathrm{c} 1$ & 1.9 & * \\
\hline 383 & Brc1 $1 \mathrm{ccc}(\mathrm{Ne} 2 \mathrm{ncnc} 3 \mathrm{ccncc} 23) \mathrm{c} 1 \mathrm{NCCCN} 1 \mathrm{CCOCC} 1$ & 1.905 & $*$ \\
\hline 384 & $\mathrm{C}=\mathrm{CC}(=\mathrm{O}) \mathrm{Nc} 1 \operatorname{cccc}(\mathrm{N} 2 \mathrm{C}(=\mathrm{O}) \mathrm{N}(\mathrm{C}) \mathrm{Cc} 3 \operatorname{cnc}(\mathrm{Nc} 4 \operatorname{ccc}(\mathrm{N} 5 \mathrm{CCN}(\mathrm{C}) \mathrm{CC} 5) \mathrm{cc} 4 \mathrm{C}) \mathrm{nc} 32) \mathrm{c} 1$ & 1.95 & 8.71 \\
\hline 385 & $\mathrm{COc} 1 \mathrm{cc} 2 \mathrm{ncnc}(\mathrm{Nc} 3 \mathrm{ccc}(\mathrm{F}) \mathrm{c}(\mathrm{Cl}) \mathrm{c} 3) \mathrm{c} 2 \mathrm{cc} 1 \mathrm{NC}(=\mathrm{O})[\mathrm{C} @ \mathrm{H}] 1 \mathrm{NC}=\mathrm{O}) \mathrm{O}[\mathrm{C} @ @ \mathrm{H}] 1 \mathrm{C}$ & 1.98 & 8.70 \\
\hline 386 & $\mathrm{COc} 1 \mathrm{cc} 2 \mathrm{ncnc}(\mathrm{Nc} 3 \mathrm{ccc}(\mathrm{F}) \mathrm{c}(\mathrm{Cl}) \mathrm{c} 3) \mathrm{c} 2 \mathrm{cc} 1 \mathrm{SCCCCCCC}(=\mathrm{O}) \mathrm{NO}$ & 1.99 & 8.70 \\
\hline 387 & OC[C@@H](Nc1ncnc2oc(-c3ccc(O)cc3)cc12)c1 1 cccc1 & 2 & 8.70 \\
\hline 388 & $\mathrm{C}[\mathrm{C} @ @ \mathrm{H}](\mathrm{Nc} 1 \mathrm{ncnc} 2 \mathrm{oc}(-\mathrm{c} 3 \mathrm{ccccc} 3 \mathrm{O}) \mathrm{cc} 12) \mathrm{c} 1 \mathrm{ccccc} 1$ & 2 & 8.70 \\
\hline 389 & $\mathrm{COc} 1 \mathrm{ccc}(\mathrm{OC}) \mathrm{c} 1-\mathrm{c} 1 \mathrm{cc} 2 \mathrm{c}(\mathrm{N}[\mathrm{C} @ \mathrm{H}](\mathrm{C}) \mathrm{c} 3 \mathrm{cccc} 3) \mathrm{ncnc} 2 \mathrm{~s} 1$ & 2 & 8.70 \\
\hline
\end{tabular}




\begin{tabular}{|c|c|c|c|}
\hline 390 & $\mathrm{CN}(\mathrm{C}) \mathrm{CCNC}(=\mathrm{O}) \mathrm{c} 1 \mathrm{ccc}(-\mathrm{c} 2 \mathrm{cc} 3 \mathrm{c}(\mathrm{N}[\mathrm{C} @ \mathrm{H}](\mathrm{CO}) \mathrm{c} 4 \mathrm{cccc} 4) \mathrm{ncnc} 3 \mathrm{~s} 2) \mathrm{cc} 1$ & 2 & 8.70 \\
\hline 391 & $\mathrm{C}[\mathrm{C} @ @ \mathrm{H}](\mathrm{Nc} 1 \mathrm{ncnc} 2 \mathrm{sc}(-\mathrm{c} 3 \mathrm{ccc}(\mathrm{C}(=\mathrm{O}) \mathrm{NCCN}(\mathrm{C}) \mathrm{C}) \mathrm{cc} 3) \mathrm{cc} 12) \mathrm{c} 1 \mathrm{cccc} 1$ & 2 & 8.70 \\
\hline 392 & $\mathrm{COc} 1 \mathrm{cc}(\mathrm{CO}) \mathrm{ccc} 1-\mathrm{c} 1 \mathrm{cc} 2 \mathrm{c}(\mathrm{Nc} 3 \mathrm{ccc}(\mathrm{F}) \mathrm{c}(\mathrm{Cl}) \mathrm{c} 3) \mathrm{ncnc} 2 \mathrm{~s} 1$ & 2 & 8.70 \\
\hline 393 & $\mathrm{COc} 1 \mathrm{cc}(\mathrm{C}(\mathrm{N})=\mathrm{O}) \mathrm{ccc} 1-\mathrm{c} 1 \mathrm{cc} 2 \mathrm{c}(\mathrm{N}[\mathrm{C} @ \mathrm{H}](\mathrm{C}) \mathrm{c} 3 \mathrm{cccc} 3) \mathrm{ncnc} 2 \mathrm{~s} 1$ & 2 & 8.70 \\
\hline 394 & $\mathrm{COc} 1 \mathrm{cc} 2 \mathrm{ncnc}(\mathrm{Nc} 3 \operatorname{ccc}(\mathrm{Cl}) \mathrm{c} 3 \mathrm{~F}) \mathrm{c} 2 \mathrm{cc} 1 \mathrm{OCC} 1 \mathrm{CCN}(\mathrm{C}) \mathrm{CC} 1$ & 2 & $*$ \\
\hline 395 & $\mathrm{COc} 1 \mathrm{cc} 2 \mathrm{ncnc}(\mathrm{Nc} 3 \mathrm{ccc}(\mathrm{Cl}) \mathrm{c} 3 \mathrm{~F}) \mathrm{c} 2 \mathrm{cc} 1 \mathrm{OC} 1 \mathrm{CCN}(\mathrm{C}) \mathrm{CC} 1$ & 2 & $*$ \\
\hline 396 & $\mathrm{COc} 1 \mathrm{cc} 2 \mathrm{ncnc}(\mathrm{Nc} 3 \operatorname{cccc}(\mathrm{Cl}) \mathrm{c} 3 \mathrm{~F}) \mathrm{c} 2 \mathrm{cc} 1 \mathrm{OC} 1 \mathrm{CCN}(\mathrm{CC}(\mathrm{N})=\mathrm{O}) \mathrm{CC} 1$ & 2 & $*$ \\
\hline 397 & $\operatorname{COc} 1 \mathrm{cc} 2 \mathrm{ncnc}(\mathrm{Nc} 3 \operatorname{ccc}(\mathrm{Cl}) \mathrm{c} 3 \mathrm{~F}) \mathrm{c} 2 \mathrm{cc} 1 \mathrm{OC} 1 \mathrm{CCN}(\mathrm{S}(\mathrm{C})(=\mathrm{O})=\mathrm{O}) \mathrm{CC} 1$ & 2 & $*$ \\
\hline 398 & $\mathrm{COC}(\mathrm{CN}(\mathrm{C}) \mathrm{C} / \mathrm{C}=\mathrm{C} / \mathrm{C}(=\mathrm{O}) \mathrm{Nc} 1 \mathrm{cc} 2 \mathrm{c}(\mathrm{Nc} 3 \mathrm{ccc}(\mathrm{F}) \mathrm{c}(\mathrm{Cl}) \mathrm{c} 3) \mathrm{ncnc} 2 \mathrm{~s} 1) \mathrm{OC}$ & 2 & $*$ \\
\hline 399 & $\mathrm{O}=\mathrm{C}(/ \mathrm{C}=\mathrm{C} / \mathrm{CN} 1 \mathrm{CCC} 2(\mathrm{CC} 1) \mathrm{OCCO} 2) \mathrm{Nc} 1 \mathrm{cc} 2 \mathrm{c}(\mathrm{Nc} 3 \mathrm{ccc}(\mathrm{F}) \mathrm{c}(\mathrm{Cl}) \mathrm{c} 3) \mathrm{ncnc} 2 \mathrm{~s} 1$ & 2 & $*$ \\
\hline 400 & $\mathrm{CCOc} 1 \mathrm{cc} 2 \mathrm{ncnc}(\mathrm{Nc} 3 \mathrm{ccc}(\mathrm{F}) \mathrm{c}(\mathrm{Cl}) \mathrm{c} 3) \mathrm{c} 2 \mathrm{c} 2 \mathrm{c} 1 \mathrm{OCCO} 2$ & 2 & * \\
\hline 401 & $\mathrm{CCC}(=\mathrm{O}) \mathrm{Nc} 1 \mathrm{cc} 2 \mathrm{c}(\mathrm{Nc} 3 \mathrm{ccc}(\mathrm{F}) \mathrm{c}(\mathrm{Cl}) \mathrm{c} 3) \mathrm{ncnc} 2 \mathrm{cc} 1 \mathrm{OC}$ & 2 & $*$ \\
\hline 402 & $\mathrm{COc} 1 \mathrm{cc} 2 \mathrm{ncnc}(\mathrm{Nc} 3 \operatorname{ccc}(\mathrm{F}) \mathrm{c}(\mathrm{Cl}) \mathrm{c} 3) \mathrm{c} 2 \mathrm{cc} 1 \mathrm{NC}(=\mathrm{O}) / \mathrm{C}=\mathrm{C} / \mathrm{CN}(\mathrm{C}(\mathrm{C}) \mathrm{C}) \mathrm{C}(\mathrm{C}) \mathrm{C}$ & 2 & $*$ \\
\hline 403 & $\mathrm{CN}(\mathrm{C}) \mathrm{C} / \mathrm{C}=\mathrm{C} / \mathrm{C}(=\mathrm{O}) \mathrm{Nc} 1 \mathrm{cc} 2 \mathrm{c}(\mathrm{Nc} 3 \mathrm{ccc}(\mathrm{F}) \mathrm{c}(\mathrm{Cl}) \mathrm{c} 3) \mathrm{ncnc} 2 \mathrm{cn} 1$ & 2 & $*$ \\
\hline 404 & $\mathrm{COc} 1 \mathrm{cc} 2 \mathrm{ncnc}(\mathrm{Nc} 3 \mathrm{ccc}(\mathrm{F}) \mathrm{c}(\mathrm{Cl}) \mathrm{c} 3) \mathrm{c} 2 \mathrm{cc} 1 \mathrm{OCCNCCN}(\mathrm{C}) \mathrm{C}$ & 2 & $*$ \\
\hline 405 & $\mathrm{CN}(\mathrm{C}) \mathrm{Cc} 1 \mathrm{ccc}(-\mathrm{c} 2 \mathrm{cc} 3 \mathrm{ncnc}(\mathrm{Nc} 4 \mathrm{ccc}(\mathrm{OCc} 5 \mathrm{cccc}(\mathrm{F}) \mathrm{c} 5) \mathrm{c}(\mathrm{Cl}) \mathrm{c} 4) \mathrm{c} 3 \mathrm{~s} 2) \mathrm{o} 1$ & 2 & $*$ \\
\hline 406 & $\mathrm{Clc} 1 \mathrm{cccc}(\mathrm{Nc} 2 \mathrm{ncnc} 3 \mathrm{cc} 4 \mathrm{c}(\mathrm{cc} 23) \mathrm{OCCOCCOCCO} 4) \mathrm{c} 1$ & 2 & $*$ \\
\hline 407 & $\mathrm{Fc} 1 \mathrm{ccc}(\mathrm{Nc} 2 \mathrm{ncnc} 3 \mathrm{cc} 4 \mathrm{c}(\mathrm{cc} 23) \mathrm{OCCOCCOCCO} 4) \mathrm{cc} 1 \mathrm{Cl}$ & 2 & $*$ \\
\hline 408 & $\mathrm{CHCc} 1 \mathrm{cccc}(\mathrm{Nc} 2 \mathrm{ncnc} 3 \mathrm{cc} 4 \mathrm{c}(\mathrm{cc} 23) \mathrm{OCCOCCOCCO}) \mathrm{c} 1$ & 2 & $*$ \\
\hline 409 & $\mathrm{c} 1 \mathrm{ccc}(-\mathrm{c} 2 \mathrm{cccc}(\mathrm{Nc} 3 \mathrm{ncnc} 4 \mathrm{cc} 5 \mathrm{c}(\mathrm{cc} 34) \mathrm{OCO} 5) \mathrm{c} 2) \mathrm{cc} 1$ & 2 & $*$ \\
\hline 410 & $\mathrm{C}=\mathrm{CC}(=\mathrm{O}) \mathrm{Nc} 1 \mathrm{cc} 2 \mathrm{c}(\mathrm{Nc} 3 \operatorname{ccc}(\mathrm{C}) \mathrm{c} 3) \mathrm{ncnc} 2 \mathrm{cc} 1 \mathrm{OCCCN} 1 \mathrm{CCN}(\mathrm{C}) \mathrm{CC} 1$ & 2 & $*$ \\
\hline 411 & $\mathrm{Nc} 1 \mathrm{ccc} 2 \mathrm{c}(\mathrm{Nc} 3 \mathrm{cccc}(\mathrm{F}) \mathrm{c} 3) \mathrm{ncnc} 2 \mathrm{c} 1$ & 2 & $*$ \\
\hline 412 & $\mathrm{Nc1} \operatorname{ccc}(-\mathrm{c} 2[\mathrm{nH}] \mathrm{nc} 3 \mathrm{ncnc}(\mathrm{Nc} 4 \mathrm{cccc}(\mathrm{Cl}) \mathrm{c} 4) \mathrm{c} 23) \mathrm{cc} 1$ & 2 & $*$ \\
\hline 413 & Cl.c1 $1 \mathrm{ccc}(-\mathrm{c} 2 \mathrm{cccc}(\mathrm{Nc} 3 \mathrm{ncnc} 4 \mathrm{cc} 5 \mathrm{c}(\mathrm{cc} 34) \mathrm{OCO} 5) \mathrm{c} 2) \mathrm{cc} 1$ & 2 & $*$ \\
\hline 414 & $\mathrm{C}=\mathrm{CC}(=\mathrm{O}) \mathrm{Nc} 1 \mathrm{cc}(\mathrm{Nc} 2 \mathrm{nccc}(-\mathrm{c} 3 \mathrm{cn}(\mathrm{C}) \mathrm{c} 4 \mathrm{ccccc} 34) \mathrm{n} 2) \mathrm{c}(\mathrm{OC}) \mathrm{cc} 1 \mathrm{~N} 1 \mathrm{CCN}(\mathrm{C}) \mathrm{CC} 1$ & 2 & $*$ \\
\hline 415 & $\mathrm{O}=\mathrm{C}(\mathrm{C} \# \mathrm{CCO}) \mathrm{Nc} 1 \mathrm{ccc} 2 \mathrm{ncnc}(\mathrm{Nc} 3 \mathrm{cccc}(\mathrm{Br}) \mathrm{c} 3) \mathrm{c} 2 \mathrm{c} 1$ & 2 & $*$ \\
\hline 416 & $\mathrm{C}[\mathrm{C} @ \mathrm{H}](\mathrm{CN}(\mathrm{C}) \mathrm{C}(=\mathrm{O}) \mathrm{CO}) \mathrm{Oc} 1 \mathrm{cccc} 2 \mathrm{ncnc}(\mathrm{Nc} 3 \mathrm{ccc}(\mathrm{OCc} 4 \mathrm{ccc} n 4) \mathrm{c}(\mathrm{Cl}) \mathrm{c} 3) \mathrm{c} 12$ & 2 & * \\
\hline 417 & $\mathrm{CC}(=\mathrm{O}) \mathrm{NCCNCc} 1 \mathrm{ccc}(-\mathrm{c} 2 \mathrm{cc} 3 \mathrm{nccc}(\mathrm{Nc} 4 \mathrm{ccc} 5[\mathrm{nH}] \operatorname{ccc} 5 \mathrm{c} 4) \mathrm{c} 3 \mathrm{~s} 2) \mathrm{cc} 1$ & 2 & $*$ \\
\hline 418 & OCCNCc1 $1 \mathrm{ccc}(-\mathrm{c} 2 \mathrm{cc} 3 \mathrm{nccc}(\mathrm{Nc} 4 \mathrm{ccc} 5[\mathrm{nH}] \mathrm{ccc} 5 \mathrm{c} 4) \mathrm{c} 3 \mathrm{~s} 2) \mathrm{cc} 1$ & 2 & $*$ \\
\hline 419 & $\mathrm{CCN} 1 \mathrm{CCN}(\mathrm{Cc} 2 \mathrm{ccc}(-\mathrm{c} 3 \mathrm{cc} 4 \mathrm{c}(\mathrm{N}[\mathrm{C} @ \mathrm{H}](\mathrm{C}) \mathrm{c} 5 \mathrm{ccccc} 5) \mathrm{ncnc} 4[\mathrm{nH}] 3) \mathrm{cc} 2) \mathrm{CC} 1$ & 2 & $*$ \\
\hline 420 & $\mathrm{CCCN} 1 \mathrm{CCC}(\mathrm{Oc} 2 \mathrm{cc}(\mathrm{OC}) \mathrm{cc} 3 \mathrm{ncnc}(\mathrm{Nc} 4 \mathrm{ccc}(\mathrm{F}) \mathrm{c}(\mathrm{Cl}) \mathrm{c} 4) \mathrm{c} 23) \mathrm{CC} 1$ & 2 & $*$ \\
\hline 421 & $\mathrm{CCN} 1 \mathrm{CCC}(\mathrm{Oc} 2 \mathrm{cc}(\mathrm{OC}) \mathrm{cc} 3 \mathrm{ncnc}(\mathrm{Nc} 4 \mathrm{ccc}(\mathrm{F}) \mathrm{c}(\mathrm{Cl}) \mathrm{c} 4) \mathrm{c} 23) \mathrm{CC} 1$ & 2 & $*$ \\
\hline 422 & $\mathrm{C}=\mathrm{CC}(=\mathrm{O}) \mathrm{Nc} 1 \mathrm{cccc}(-\mathrm{n} 2 \mathrm{c}(=\mathrm{O}) \mathrm{c}(=\mathrm{O}) \mathrm{n}(\mathrm{C}(\mathrm{C}) \mathrm{C}) \mathrm{c} 3 \mathrm{cnc}(\mathrm{Nc} 4 \mathrm{ccc}(\mathrm{N} 5 \mathrm{CCN}(\mathrm{C}) \mathrm{CC} 5) \mathrm{cc} 4 \mathrm{OC}) \mathrm{nc} 32) \mathrm{c} 1$ & 2 & $*$ \\
\hline 423 & $\mathrm{COc} 1 \mathrm{cc} 2 \mathrm{ncnc}(\mathrm{Nc} 3 \mathrm{ccc}(\mathrm{C}(=\mathrm{O}) \mathrm{NC} 45 \mathrm{CC} 6 \mathrm{CC}(\mathrm{CC}(\mathrm{C} 6) \mathrm{C} 4) \mathrm{C} 5) \mathrm{cc} 3) \mathrm{c} 2 \mathrm{cc} 1 \mathrm{OCCCN} 1 \mathrm{CCOCC} 1$ & 2.01 & 8.70 \\
\hline 424 & $\mathrm{CCOc} 1 \mathrm{cc} 2 \mathrm{ncc}(\mathrm{CHN}) \mathrm{c}(\mathrm{Nc} 3 \mathrm{ccc}(\mathrm{F}) \mathrm{c}(\mathrm{Cl}) \mathrm{c} 3) \mathrm{c} 2 \mathrm{cc} 1 \mathrm{NC}(=\mathrm{O}) \mathrm{CCN} 1 \mathrm{CCOCC} 1$ & 2.02 & 8.69 \\
\hline 425 & $\mathrm{C} \# \mathrm{Cc} 1 \mathrm{cccc}(\mathrm{Nc} 2 \mathrm{ncnc} 3 \operatorname{ccc}(\mathrm{NC}(\mathrm{C})=\mathrm{O}) \operatorname{cc} 23) \mathrm{c} 1$ & 2.04 & 8.69 \\
\hline 426 & $\mathrm{COc} 1 \mathrm{cc} 2 \mathrm{ncnc}(\mathrm{Nc} 3 \operatorname{ccc}(\mathrm{F}) \mathrm{c}(\mathrm{Cl}) \mathrm{c} 3) \mathrm{c} 2 \mathrm{cc} 1 \mathrm{NC}(=\mathrm{O}) \mathrm{CCCCCCC}(=\mathrm{O}) \mathrm{NO}$ & 2.1 & 8.68 \\
\hline 427 & $\mathrm{C}=\mathrm{CC}(=\mathrm{O}) \mathrm{Nc} 1 \mathrm{ccc} 2 \mathrm{ncnc}(\mathrm{Nc} 3 \mathrm{ccc}(\mathrm{Br}) \mathrm{cc} 3 \mathrm{~F}) \mathrm{c} 2 \mathrm{c} 1$ & 2.1 & $*$ \\
\hline 428 & $\mathrm{COc} 1 \mathrm{cc} 2 \mathrm{ncnc}(\mathrm{Nc} 3 \operatorname{ccc}(\mathrm{F}) \mathrm{c}(\mathrm{Cl}) \mathrm{c} 3) \mathrm{c} 2 \mathrm{cc} 1 \mathrm{NC}(=\mathrm{O}) / \mathrm{C}=\mathrm{C} / \mathrm{CNC} 1 \mathrm{CC} 1$ & 2.1 & $*$ \\
\hline 429 & $\operatorname{COCCOc} 1 \mathrm{cc} 2 \mathrm{ncnc}(\mathrm{Nc} 3 \mathrm{ccc}(\mathrm{F}) \mathrm{c}(\mathrm{Cl}) \mathrm{c} 3) \mathrm{c} 2 \mathrm{cc} 1 \mathrm{NC}(=\mathrm{O}) / \mathrm{C}=\mathrm{C} / \mathrm{CN} 1 \mathrm{CCCCC} 1$ & 2.1 & $*$ \\
\hline 430 & $\mathrm{Cc} 1 \mathrm{cccc}(\mathrm{Nc} 2 \mathrm{ncnc} 3 \mathrm{c} 2 \mathrm{sc} 2 \mathrm{ccc}(\mathrm{N}) \mathrm{cc} 23) \mathrm{c} 1$ & 2.1 & $*$ \\
\hline 431 & $\mathrm{CN}(\mathrm{C}) \mathrm{C} 1 \mathrm{CCN}(\mathrm{c} 2 \mathrm{ccc}(\mathrm{Nc} 3 \mathrm{cc} 4 \mathrm{c}(\mathrm{N} 5 \mathrm{CCC}(\mathrm{CO}) \mathrm{CC} 5) \mathrm{nc}(\mathrm{Nc} 5 \mathrm{ccccc} 5) \mathrm{nc} 4 \mathrm{cn} 3) \mathrm{nc} 2) \mathrm{CC} 1$ & 2.1 & $*$ \\
\hline 432 & $\mathrm{COc} 1 \mathrm{cc}(\mathrm{CO}) \operatorname{ccc} 1-\mathrm{c} 1 \mathrm{cc} 2 \mathrm{c}(\mathrm{NCc} 3 \operatorname{ccc} c 3) \mathrm{ncnc} 2[\mathrm{nH}] 1$ & 2.1 & $*$ \\
\hline
\end{tabular}




\begin{tabular}{|c|c|c|c|}
\hline 433 & $\mathrm{CSc} 1 n c(-\mathrm{c} 2 \mathrm{ccc}(\mathrm{F}) \mathrm{cc} 2) \mathrm{c}(-\mathrm{c} 2 \mathrm{ccnc}(\mathrm{Nc} 3 \mathrm{cc}(\mathrm{N} 4 \mathrm{CCN}(\mathrm{C}) \mathrm{CC} 4) \mathrm{cc}([\mathrm{N}+](=\mathrm{O})[\mathrm{O}-]) \mathrm{c} 3) \mathrm{c} 2)[\mathrm{nH}] 1$ & 2.1 & $*$ \\
\hline 434 & $\mathrm{O}=\mathrm{C}(\mathrm{NO}) \mathrm{c} 1 \mathrm{ccc}(-\mathrm{c} 2 \mathrm{ccc} 3 \mathrm{ncnc}(\mathrm{Nc} 4 \mathrm{ccc}(\mathrm{OCc} 5 \mathrm{ccc}(\mathrm{F}) \mathrm{c} 5) \mathrm{c}(\mathrm{Cl}) \mathrm{c} 4) \mathrm{c} 3 \mathrm{c} 2) \mathrm{s} 1$ & 2.2 & $*$ \\
\hline 435 & $\mathrm{C}=\mathrm{CC}(=\mathrm{O}) \mathrm{Nc} 1 \mathrm{ccc} 2 \mathrm{ncnc}(\mathrm{Nc} 3 \mathrm{c}(\mathrm{F}) \mathrm{cccc} 3 \mathrm{Br}) \mathrm{c} 2 \mathrm{c} 1$ & 2.2 & $*$ \\
\hline 436 & $\mathrm{C}=\mathrm{CC}(=\mathrm{O}) \mathrm{Nc} 1 \mathrm{ccc} 2 \mathrm{ncnc}(\mathrm{Nc} 3 \mathrm{ccc}(\mathrm{Br}) \mathrm{cc} 3 \mathrm{C}) \mathrm{c} 2 \mathrm{c} 1$ & 2.2 & $*$ \\
\hline 437 & $\mathrm{C}=\mathrm{CC}(=\mathrm{O}) \mathrm{Nc} 1 \mathrm{cccc}(-\mathrm{n} 2 \mathrm{c}(=\mathrm{O}) \mathrm{c}(=\mathrm{O}) \mathrm{n}(\mathrm{CCC}) \mathrm{c} 3 \mathrm{cnc}(\mathrm{Nc} 4 \mathrm{ccc}(\mathrm{N} 5 \mathrm{CCN}(\mathrm{C}) \mathrm{CC} 5) \mathrm{cc} 4 \mathrm{OC}) \mathrm{nc} 32) \mathrm{c} 1$ & 2.2 & $*$ \\
\hline 438 & $\mathrm{CCOc} 1 \mathrm{cc} 2 \mathrm{ncc}(\mathrm{C \# N}) \mathrm{c}(\mathrm{Nc} 3 \mathrm{ccc}(\mathrm{F}) \mathrm{c}(\mathrm{Cl}) \mathrm{c} 3) \mathrm{c} 2 \mathrm{cc} 1 \mathrm{NC}(=\mathrm{O}) \mathrm{CCN} 1 \mathrm{CCCCC} 1$ & 2.21 & 8.66 \\
\hline 439 & $\mathrm{C} \# \mathrm{Cc} 1 \mathrm{cccc}(\mathrm{Nc} 2 \mathrm{ncnc} 3 \operatorname{ccc}(\mathrm{NC}(\mathrm{N})=\mathrm{O}) \mathrm{cc} 23) \mathrm{c} 1$ & 2.22 & 8.65 \\
\hline 440 & $\mathrm{Fc} 1 \mathrm{ccc}(\mathrm{Nc} 2 \mathrm{ncnc} 3 \mathrm{ccc}(\mathrm{NC}(=\mathrm{S}) \mathrm{NCCN} 4 \mathrm{CCOCC} 4) \mathrm{cc} 23) \mathrm{cc} 1 \mathrm{Cl}$ & 2.25 & 8.65 \\
\hline 441 & $\mathrm{Fc} 1 \mathrm{ccc}(\mathrm{COc} 2 \mathrm{ccc}(\mathrm{Nc} 3 \mathrm{ncnc} 4 \mathrm{ccc}(\mathrm{NC}(=\mathrm{S}) \mathrm{NCCN} 5 \mathrm{CCOCC} 5) \mathrm{cc} 34) \mathrm{cc} 2 \mathrm{Cl}) \mathrm{c} 1$ & 2.26 & 8.65 \\
\hline 442 & $\mathrm{C}=\mathrm{CC}(=\mathrm{O}) \mathrm{Nc} 1 \mathrm{ccc} 2 \mathrm{ncnc}(\mathrm{Nc} 3 \mathrm{ccc}(\mathrm{Br}) \mathrm{c}(\mathrm{C}) \mathrm{c} 3) \mathrm{c} 2 \mathrm{c} 1$ & 2.3 & $*$ \\
\hline 443 & $\mathrm{COc} 1 \mathrm{ccc}(\mathrm{CNc} 2 \mathrm{cc} 3 \mathrm{c}(\mathrm{Nc} 4 \mathrm{ccc}(\mathrm{Br}) \mathrm{c} 4) \mathrm{ncnc} 3 \mathrm{cn} 2) \mathrm{cc} 1$ & 2.3 & * \\
\hline 444 & Brc1cecc(Nc2ncnc3enc(NCCCn4cenc4)nc23)c1 & 2.3 & $*$ \\
\hline 445 & $\mathrm{Cc} 1 \mathrm{ccc}(\mathrm{Nc} 2 \mathrm{ncnc} 3 \mathrm{cnc}(\mathrm{NCCN} 4 \mathrm{CCOCC} 4) \mathrm{nc} 23) \mathrm{c} 1$ & 2.3 & $*$ \\
\hline 446 & $\mathrm{NP}(=\mathrm{O})(\mathrm{OCCCCCOc} 1 \mathrm{ccc} 2 \mathrm{ncnc}(\mathrm{Nc} 3 \mathrm{cccc}(\mathrm{Br}) \mathrm{c} 3) \mathrm{c} 2 \mathrm{c} 1) \mathrm{N}(\mathrm{CCCl}) \mathrm{CCCl}$ & 2.3 & $*$ \\
\hline 447 & $\mathrm{C}=\mathrm{CC}(=\mathrm{O}) \mathrm{Nc} 1 \mathrm{ccc}(\mathrm{OC}) \mathrm{c}(\mathrm{Nc} 2 \mathrm{cc}(-\mathrm{c} 3[\mathrm{nH}] \mathrm{c}(\mathrm{SC}) \mathrm{nc} 3 \mathrm{C} 3 \mathrm{CC} 3) \mathrm{ccn} 2) \mathrm{c} 1$ & 2.3 & $*$ \\
\hline 448 & Brc1ecec(Nc2ncnc3enc(NCCn4cenc4)nc23)c1 & 2.344 & $*$ \\
\hline 449 & $\mathrm{C \# Cc1} \operatorname{ccc}(\mathrm{Nc} 2 \mathrm{ncnc} 3 \mathrm{cc}(\mathrm{OC}) \mathrm{c}(\mathrm{OCCCCCCC}(=\mathrm{O}) \mathrm{NO}) \mathrm{cc} 23) \mathrm{c} 1$ & 2.4 & 8.62 \\
\hline 450 & 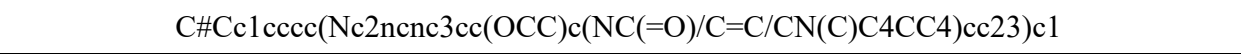 & 2.4 & $*$ \\
\hline 451 & $\mathrm{CN}(\mathrm{C}) / \mathrm{C}=\mathrm{C} / \mathrm{C}(=\mathrm{O}) \mathrm{Nc} 1 \mathrm{cc} 2 \mathrm{c}(\mathrm{Nc} 3 \mathrm{ccc}(\mathrm{F}) \mathrm{c}(\mathrm{Cl}) \mathrm{c} 3) \mathrm{ncnc} 2 \mathrm{cc} 1 \mathrm{O}[\mathrm{C} @ \mathrm{H}] 1 \mathrm{CCOC} 1$ & 2.4 & $*$ \\
\hline 452 & $\mathrm{CN}(\mathrm{C}) \mathrm{CCCOC}(=\mathrm{O}) / \mathrm{C}=\mathrm{C} / \mathrm{C}(=\mathrm{O}) \mathrm{Nc} 1 \mathrm{ccc} 2 \mathrm{ncnc}(\mathrm{Nc} 3 \operatorname{ccc}(\mathrm{Br}) \mathrm{c} 3) \mathrm{c} 2 \mathrm{c} 1$ & 2.4 & $*$ \\
\hline 453 & $\mathrm{COc} 1 \mathrm{ncc}(-\mathrm{c} 2 \mathrm{ccc} 3 \mathrm{ncnc}(\mathrm{Nc} 4 \mathrm{ccc}(\mathrm{F}) \mathrm{c}(\mathrm{Cl}) \mathrm{c} 4) \mathrm{c} 3 \mathrm{c} 2) \operatorname{cc} 1 \mathrm{NS}(\mathrm{C})(=\mathrm{O})=\mathrm{O}$ & 2.4 & $*$ \\
\hline 454 & $\mathrm{CC} 1(\mathrm{C}) \mathrm{Cc} 2 \mathrm{c}(\mathrm{sc}(=\mathrm{S}) \mathrm{n} 2-\mathrm{c} 2 \mathrm{cccc} 2) \mathrm{C}(=\mathrm{O}) \mathrm{C} 1=\mathrm{NNc} 1 \mathrm{ccc}(\mathrm{Cl}) \mathrm{cc} 1$ & 2.44 & * \\
\hline 455 & $\mathrm{C}=\mathrm{CC}(=\mathrm{O}) \mathrm{Nc} 1 \operatorname{cccc}(\mathrm{N} 2 \mathrm{C}(=\mathrm{O}) \mathrm{C} 3 \mathrm{CCCCN} 3 \mathrm{C}(=\mathrm{O}) \mathrm{c} 3 \mathrm{cnc}(\mathrm{Nc} 4 \mathrm{ccc}(\mathrm{N} 5 \mathrm{CCN}(\mathrm{C}) \mathrm{CC} 5) \mathrm{cc} 4 \mathrm{OC}) \mathrm{nc} 32) \mathrm{c} 1$ & 2.45 & 8.61 \\
\hline 456 & $\mathrm{O}=\mathrm{C}(/ \mathrm{C}=\mathrm{C} / \mathrm{c} 1 \operatorname{ccc}(-\mathrm{c} 2 \mathrm{ccc} 3 \mathrm{ncnc}(\mathrm{Nc} 4 \operatorname{ccc}(\mathrm{OCc} 5 \operatorname{cccc}(\mathrm{F}) \mathrm{c} 5) \mathrm{c}(\mathrm{Cl}) \mathrm{c} 4) \mathrm{c} 3 \mathrm{c} 2) \mathrm{o} 1) \mathrm{NO}$ & 2.5 & $*$ \\
\hline 457 & $\mathrm{C}=\mathrm{CC}(=\mathrm{O}) \mathrm{Nc} 1 \mathrm{ccc} 2 \mathrm{ncnc}(\mathrm{Nc} 3 \mathrm{ccc}(\mathrm{Br}) \mathrm{c}(\mathrm{OC}) \mathrm{c} 3) \mathrm{c} 2 \mathrm{c} 1$ & 2.5 & $*$ \\
\hline 458 & C[C@@H](Nc1ncnc2[nH]c(-c3ecc(O)cc3)cc12)c1 ccccc1 & 2.5 & $*$ \\
\hline 459 & $\mathrm{CHCCCCOc1cc2c(Nc3ccc(F)c(Cl)c3)ncnc2cc1OC}$ & 2.53 & $*$ \\
\hline 460 & $\mathrm{O}=\mathrm{C}(\mathrm{Nc} 1 \mathrm{cc} 2 \mathrm{c}(\mathrm{Nc} 3 \mathrm{ccc}(\mathrm{F}) \mathrm{c}(\mathrm{Cl}) \mathrm{c} 3) \mathrm{ncnc} 2 \mathrm{cc} 1 \mathrm{O}[\mathrm{C} @ \mathrm{H}] 1 \mathrm{CCOC} 1) / \mathrm{C}(\mathrm{F})=\mathrm{C} \backslash \mathrm{CN} 1 \mathrm{CCCCC} 1$ & 2.55 & 8.59 \\
\hline 461 & $\mathrm{CCOc} 1 \mathrm{cc} 2 \mathrm{ncnc}(\mathrm{Nc} 3 \mathrm{ccc}(\mathrm{OCc} 4 \mathrm{cccc}(\mathrm{F}) \mathrm{c} 4) \mathrm{c}(\mathrm{Cl}) \mathrm{c} 3) \mathrm{c} 2 \mathrm{cc} 1 \mathrm{NC}(=\mathrm{O})[\mathrm{C} @ \mathrm{H}] 1 \mathrm{NC}(=\mathrm{O}) \mathrm{O}[\mathrm{C} @ @ \mathrm{H}] 1 \mathrm{C}$ & 2.57 & 8.59 \\
\hline 462 & $\mathrm{COc} 1 \mathrm{cc} 2 \mathrm{ncnc}(\mathrm{Nc} 3 \mathrm{cccc}(\mathrm{Br}) \mathrm{c} 3) \mathrm{c} 2 \mathrm{cc} 1 \mathrm{OC}$ & 2.6 & 7.87 \\
\hline 463 & $\mathrm{O}=\mathrm{C}(\mathrm{Nc} 1 \mathrm{cc} 2 \mathrm{c}(\mathrm{Nc} 3 \mathrm{ccc}(\mathrm{F}) \mathrm{c}(\mathrm{Cl}) \mathrm{c} 3) \mathrm{ncnc} 2 \mathrm{cc} 1 \mathrm{O}[\mathrm{C} @ \mathrm{H}] 1 \mathrm{CCOC} 1) / \mathrm{C}(\mathrm{F})=\mathrm{C} / \mathrm{CN} 1 \mathrm{CCCCC} 1$ & 2.6 & 8.59 \\
\hline 464 & $\mathrm{COc} 1 \mathrm{cc} 2 \mathrm{ncnc}(\mathrm{Nc} 3 \operatorname{cccc}(\mathrm{Br}) \mathrm{c} 3) \mathrm{c} 2 \mathrm{cc} 1 \mathrm{NC}(=\mathrm{O}) / \mathrm{C}(\mathrm{F})=\mathrm{C} / \mathrm{CN}(\mathrm{C}) \mathrm{C}$ & 2.6 & 8.59 \\
\hline 465 & $\mathrm{O}=\mathrm{C}(\mathrm{Nc} 1 \mathrm{cc} 2 \mathrm{c}(\mathrm{Nc} 3 \mathrm{ccc}(\mathrm{F}) \mathrm{c}(\mathrm{Cl}) \mathrm{c} 3) n \mathrm{cnc} 2 \mathrm{cc} 1 \mathrm{OCCCN} 1 \mathrm{CCNCC} 1) \mathrm{c} 1 \mathrm{cc}([\mathrm{N}+](=\mathrm{O})[\mathrm{O}-]) \mathrm{ccc} 1 \mathrm{~F}$ & 2.6 & 8.59 \\
\hline 466 & $\mathrm{COc} 1 \mathrm{cc} 2 \mathrm{c}(\mathrm{Nc} 3 \mathrm{cccc}(\mathrm{Br}) \mathrm{c} 3) \mathrm{ncnc} 2 \mathrm{cn} 1$ & 2.6 & $*$ \\
\hline 467 & $\mathrm{CN}(\mathrm{C}) \mathrm{Cc} 1 \mathrm{c}[\mathrm{nH}] \mathrm{c} 2 \mathrm{cc} 3 \mathrm{ncnc}(\mathrm{Nc} 4 \mathrm{cccc}(\mathrm{Br}) \mathrm{c} 4) \mathrm{c} 3 \mathrm{cc} 12$ & 2.6 & $*$ \\
\hline 468 & $\mathrm{CN}(\mathrm{CCO}) \mathrm{c} 1 \mathrm{cc} 2 \mathrm{ncnc}(\mathrm{Nc} 3 \mathrm{cccc}(\mathrm{Br}) \mathrm{c} 3) \mathrm{c} 2 \mathrm{cn} 1$ & 2.6 & $*$ \\
\hline 469 & $\mathrm{CC}(\mathrm{C})(\mathrm{N}) \mathrm{C}(=\mathrm{O}) \mathrm{NCCn} 1 \mathrm{ccc} 2 \mathrm{ncnc}(\mathrm{Nc} 3 \operatorname{ccc}(\mathrm{Oc} 4 \mathrm{cccc} 5 \operatorname{sncc} 45) \mathrm{c}(\mathrm{Cl}) \mathrm{c} 3) \mathrm{c} 21$ & 2.6 & $*$ \\
\hline 470 & $\mathrm{C} / \mathrm{C}=\mathrm{C} / \mathrm{C}(=\mathrm{O}) \mathrm{Nc} 1 \mathrm{cc} 2 \mathrm{c}(\mathrm{N} 3 \mathrm{CCc} 4 \mathrm{ccccc} 43) \mathrm{ncnc} 2 \mathrm{cc} 1 \mathrm{OC} 1 \mathrm{CCOC} 1$ & 2.61 & $*$ \\
\hline 471 & $\mathrm{CN}(\mathrm{CCO}) \mathrm{c} 1 \mathrm{c}(\mathrm{Br}) \mathrm{cccc} 1 \mathrm{Nc} 1 \mathrm{ncnc} 2 \mathrm{ccncc} 12$ & 2.63 & $*$ \\
\hline 472 & $\mathrm{COc} 1 \mathrm{ccc}(-\mathrm{c} 2 \mathrm{cc} 3 \mathrm{c}(\mathrm{N}[\mathrm{C} @ \mathrm{H}](\mathrm{CO}) \mathrm{c} 4 \mathrm{ccccc} 4) \mathrm{ncnc} 3 \mathrm{o} 2) \mathrm{cc} 1$ & 2.7 & 8.57 \\
\hline 473 & $\mathrm{C}=\mathrm{CC}(=\mathrm{O}) \mathrm{Nc} 1 \mathrm{ccc} 2 \mathrm{ncnc}(\mathrm{Nc} 3 \operatorname{cccc}(\mathrm{CC}) \mathrm{c} 3) \mathrm{c} 2 \mathrm{c} 1$ & 2.7 & $*$ \\
\hline 474 & $\mathrm{C} \# \mathrm{Cc} 1 \mathrm{cccc}(\mathrm{Nc} 2 \mathrm{ncnc} 3 \mathrm{cc}(\mathrm{OC}) \mathrm{c}(\mathrm{NC}(=\mathrm{O}) / \mathrm{C}=\mathrm{C} / \mathrm{CN} 4 \mathrm{CCCCC} 4) \mathrm{cc} 23) \mathrm{c} 1$ & 2.7 & $*$ \\
\hline 475 & $\mathrm{C}=\mathrm{CC}(=\mathrm{O}) \mathrm{Nc} 1 \mathrm{nc} 2 \mathrm{c}(\mathrm{Nc} 3 \mathrm{ccc}(\mathrm{F}) \mathrm{c}(\mathrm{Cl}) \mathrm{c} 3) \mathrm{ncn} \mathrm{c} 2 \mathrm{c} 1 \mathrm{CCCCN} 1 \mathrm{CCOCC} 1$ & 2.7 & $*$ \\
\hline
\end{tabular}




\begin{tabular}{|c|c|c|c|}
\hline 476 & CO.Nc1 ccce $2 \mathrm{c} 1 \mathrm{sc} 1 \mathrm{c}(\mathrm{Nc} 3 \mathrm{ccc}(\mathrm{Br}) \mathrm{c} 3) \mathrm{ncnc} 12$ & 2.7 & $*$ \\
\hline 477 & $\operatorname{CCOC}(=\mathrm{O}) / \mathrm{C}=\mathrm{C} / \mathrm{C}(=\mathrm{O}) \mathrm{Nc} 1 \mathrm{ccc} 2 \mathrm{ncnc}(\mathrm{Nc} 3 \operatorname{cccc}(\mathrm{Br}) \mathrm{c} 3) \mathrm{c} 2 \mathrm{c} 1$ & 2.7 & $*$ \\
\hline 478 & $\mathrm{C}=\mathrm{CC}(=\mathrm{O}) \mathrm{N}(\mathrm{CCCN} 1 \mathrm{CCOCC} 1) \mathrm{c} 1 \mathrm{cc} 2 \mathrm{c}(\mathrm{Nc} 3 \mathrm{ccc}(\mathrm{Br}) \mathrm{c} 3) \mathrm{ncn} 2 \mathrm{cn} 1$ & 2.7 & $*$ \\
\hline 479 & $\mathrm{C}=\mathrm{CC}(=\mathrm{O}) \mathrm{N}[\mathrm{C} @ @ \mathrm{H}] 1 \mathrm{CCN}(\mathrm{c} 2 \mathrm{nc}(\mathrm{Nc} 3 \mathrm{ccccc} 3) \mathrm{nc} 3 \mathrm{cnc}(\mathrm{Nc} 4 \mathrm{ccc}(\mathrm{N} 5 \mathrm{CCN}(\mathrm{C}) \mathrm{CC} 5) \mathrm{cn} 4) \mathrm{cc} 23) \mathrm{C} 1$ & 2.7 & $*$ \\
\hline 480 & Cl.Nc1cccc2c1sc1c(Nc3ecce(Br)c3)ncnc12 & 2.7 & $*$ \\
\hline 481 & $\mathrm{CN}(\mathrm{C}) \mathrm{C} / \mathrm{C}=\mathrm{C} / \mathrm{C}(=\mathrm{O}) \mathrm{NCCSc} 1 \mathrm{nc}(-\mathrm{c} 2 \operatorname{ccc}(\mathrm{F}) \mathrm{cc} 2) \mathrm{c}(-\mathrm{c} 2 \mathrm{ccnc}(\mathrm{Nc} 3 \operatorname{cccc} 3) \mathrm{c} 2)[\mathrm{nH}] 1$ & 2.7 & $*$ \\
\hline 482 & $\mathrm{Nc} 1 \operatorname{ccccc} 1 \mathrm{NC}(=\mathrm{O}) \mathrm{c} 1 \mathrm{ccc}(-\mathrm{c} 2 \mathrm{ccc} 3 \mathrm{ncnc}(\mathrm{Nc} 4 \mathrm{ccc}(\mathrm{OCc} 5 \mathrm{cccc}(\mathrm{F}) \mathrm{c} 5) \mathrm{c}(\mathrm{Cl}) \mathrm{c} 4) \mathrm{c} 3 \mathrm{c} 2) \mathrm{s} 1$ & 2.8 & $*$ \\
\hline 483 & $\mathrm{Cc} 1 \mathrm{cccc}(\mathrm{Nc} 2 \mathrm{ncnc} 3 \operatorname{cnc}(\mathrm{N}(\mathrm{C}) \mathrm{C}) \mathrm{cc} 23) \mathrm{c} 1$ & 2.8 & * \\
\hline 484 & $\mathrm{Cc} 1 \mathrm{cc}(\mathrm{C}(=\mathrm{O}) \mathrm{N} 2 \mathrm{CCN}(\mathrm{C}) \mathrm{CC} 2)[\mathrm{nH}] \mathrm{c} 1 / \mathrm{C}=\mathrm{C} 1 \backslash \mathrm{C}(=\mathrm{O}) \mathrm{Nc} 2 \mathrm{ncnc}(\mathrm{Nc} 3 \mathrm{ccc}(\mathrm{F}) \mathrm{c}(\mathrm{Cl}) \mathrm{c} 3) \mathrm{c} 21$ & 2.8 & $*$ \\
\hline 485 & $\mathrm{O}=\mathrm{C} 1 \mathrm{Cc} 2 \mathrm{cccc}(\mathrm{Oc} 3 \mathrm{ccc}(\mathrm{Nc} 4 \mathrm{ncnc} 5 \mathrm{ccn}(\mathrm{CCO}) \mathrm{c} 45) \mathrm{cc} 3 \mathrm{Cl}) \mathrm{c} 2 \mathrm{~N} 1$ & 2.8 & $*$ \\
\hline 486 & COc1ccc(-c2cc3c(N[C@H](C)c4ccc(F)cc4)ncnc3[nH]2)cc1 & 2.8 & * \\
\hline 487 & $\mathrm{C}=\mathrm{CC}(=\mathrm{O}) \mathrm{Nc} 1 \mathrm{cccc}(-\mathrm{n} 2 \mathrm{c}(=\mathrm{O}) \mathrm{c}(=\mathrm{O})[\mathrm{nH}] \mathrm{c} 3 \mathrm{cnc}(\mathrm{Nc} 4 \mathrm{ccc}(\mathrm{N} 5 \mathrm{CCN}(\mathrm{C}) \mathrm{CC} 5) \mathrm{cc} 4 \mathrm{OC}) \mathrm{nc} 32) \mathrm{c} 1$ & 2.8 & $*$ \\
\hline 488 & $\mathrm{C}=\mathrm{CC}(=\mathrm{O}) \mathrm{Nc} 1 \mathrm{cc}(\mathrm{Nc} 2 \mathrm{n}[\mathrm{nH}] \mathrm{c} 3 \mathrm{cc}(-\mathrm{c} 4 \mathrm{cncc} 5 \mathrm{ccccc} 45) \operatorname{ccc} 23) \mathrm{c}(\mathrm{OC}) \mathrm{cc} 1 \mathrm{~N}(\mathrm{C}) \mathrm{CCN}(\mathrm{C}) \mathrm{C}$ & 2.8 & $*$ \\
\hline 489 & $\mathrm{Nc} 1 \mathrm{ccccc} 1 \mathrm{NC}(=\mathrm{O}) \mathrm{c} 1 \mathrm{ccc}(-\mathrm{c} 2 \mathrm{ccc} 3 \mathrm{ncnc}(\mathrm{Nc} 4 \mathrm{ccc}(\mathrm{OCc} 5 \mathrm{cccc}(\mathrm{F}) \mathrm{c} 5) \mathrm{c}(\mathrm{Cl}) \mathrm{c} 4) \mathrm{c} 3 \mathrm{c} 2) \mathrm{o} 1$ & 2.9 & $*$ \\
\hline 490 & Brc1cecc(Nc2ncnc3enc(NCCCN4CCOCC4)nc23)c1 & 2.9 & $*$ \\
\hline 491 & $\mathrm{CC}(=\mathrm{O}) \mathrm{NCCn} 1 \mathrm{ccc} 2 \mathrm{ncnc}(\mathrm{Nc} 3 \operatorname{ccc}(\mathrm{Oc} 4 \mathrm{cccc} 5 \operatorname{sncc} 45) \mathrm{c}(\mathrm{Cl}) \mathrm{c} 3) \mathrm{c} 21$ & 2.9 & $*$ \\
\hline 492 & $\mathrm{COCCOc} 1 \mathrm{cc} 2 \mathrm{ncnc}(\mathrm{Nc} 3 \mathrm{ccc}(\mathrm{NC}(=\mathrm{O}) \mathrm{C} 45 \mathrm{CC} 6 \mathrm{CC}(\mathrm{CC}(\mathrm{C} 6) \mathrm{C} 4) \mathrm{C} 5) \mathrm{c}(\mathrm{C}) \mathrm{c} 3) \mathrm{c} 2 \mathrm{cc} 1 \mathrm{OCCOC}$ & 2.92 & 8.53 \\
\hline 493 & $\mathrm{O}=\mathrm{C}(\mathrm{NCCN} 1 \mathrm{CCOCC} 1) \mathrm{Nc} 1 \mathrm{ccc} 2 \mathrm{ncnc}(\mathrm{Nc} 3 \mathrm{ccc}(\mathrm{F}) \mathrm{c}(\mathrm{Cl}) \mathrm{c} 3) \mathrm{c} 2 \mathrm{c} 1$ & 2.92 & 8.53 \\
\hline 494 & $\mathrm{CNC}(=\mathrm{O}) \mathrm{c} 1 \mathrm{cc}(\mathrm{Oc} 2 \mathrm{ccc}(\mathrm{NC}(=\mathrm{O}) \mathrm{Nc} 3 \operatorname{ccc}(\mathrm{Cl}) \mathrm{c}(\mathrm{C}(\mathrm{F})(\mathrm{F}) \mathrm{F}) \mathrm{c} 3) \mathrm{cc} 2) \mathrm{ccn} 1$ & 2.96 & $*$ \\
\hline 495 & $\mathrm{Cn} 1 \mathrm{cc}(-\mathrm{c} 2 \mathrm{ccc} 3 \mathrm{ncnc}(\mathrm{Nc} 4 \mathrm{ccc}(\mathrm{F}) \mathrm{c}(\mathrm{Cl}) \mathrm{c} 4) \mathrm{c} 3 \mathrm{c} 2) \mathrm{cn} 1$ & 2.97 & 8.53 \\
\hline 496 & $\mathrm{Cc} 1 \mathrm{ncnc}(\mathrm{Nc} 2 \mathrm{ccc}(\mathrm{OCc} 3 \operatorname{ccc}(\mathrm{F}) \mathrm{c} 3) \mathrm{c}(\mathrm{Cl}) \mathrm{c} 2) \mathrm{c} 1 \mathrm{C \# Cc1} \operatorname{ccc}(\mathrm{CNC}(\mathrm{C}) \mathrm{C}) \mathrm{cc} 1$ & 3 & 8.52 \\
\hline 497 & $\mathrm{Cc} 1 \mathrm{ncnc}(\mathrm{Nc} 2 \mathrm{ccc}(\mathrm{OCc} 3 \operatorname{ccc}(\mathrm{F}) \mathrm{c} 3) \mathrm{c}(\mathrm{Cl}) \mathrm{c} 2) \mathrm{c} 1 / \mathrm{C}=\mathrm{C}(\backslash \mathrm{F}) \mathrm{C}(=\mathrm{O}) \mathrm{NCCN} 1 \mathrm{CCCC} 1$ & 3 & 8.52 \\
\hline 498 & $\operatorname{COc} 1 \mathrm{c}(\mathrm{C}(=\mathrm{O}) \mathrm{NCCN}(\mathrm{C}) \mathrm{C}) \mathrm{cccc} 1-\mathrm{c} 1 \mathrm{cc} 2 \mathrm{c}(\mathrm{N}[\mathrm{C} @ \mathrm{H}](\mathrm{C}) \mathrm{c} 3 \operatorname{ccccc} 3) n \mathrm{cnc} 2 \mathrm{~s} 1$ & 3 & 8.52 \\
\hline 499 & $\mathrm{COc} 1 \mathrm{ccc}(\mathrm{C}=\mathrm{O}) \mathrm{cc} 1-\mathrm{c} 1 \mathrm{cc} 2 \mathrm{c}(\mathrm{N}[\mathrm{C} @ \mathrm{H}](\mathrm{C}) \mathrm{c} 3 \mathrm{ccccc} 3) \mathrm{ncnc} 2 \mathrm{~s} 1$ & 3 & 8.52 \\
\hline 500 & OCc1 cccc(-c2cc3c(N[C@H](CO)c4ccccs4)ncnc3s2)c1 & 3 & 8.52 \\
\hline 501 & $\mathrm{O}=\mathrm{C}(\mathrm{Nc} 1 \mathrm{cc} 2 \mathrm{c}(\mathrm{Nc} 3 \mathrm{ccc}(\mathrm{F}) \mathrm{c}(\mathrm{Cl}) \mathrm{c} 3) \mathrm{ncn} \mathrm{c} 2 \mathrm{cc} 1 \mathrm{OCCCN} 1 \mathrm{CCOCC} 1) \mathrm{c} 1 \mathrm{cccc} 1 \mathrm{~F}$ & 3 & 8.52 \\
\hline 502 & $\mathrm{C}=\mathrm{CC}(=\mathrm{O}) \mathrm{Nc} 1 \mathrm{cc} 2 \mathrm{c}(\mathrm{Nc} 3 \mathrm{ccc}(\mathrm{F}) \mathrm{c}(\mathrm{Cl}) \mathrm{c} 3) \mathrm{ncn} \mathrm{c} 2 \mathrm{cc} 1 \mathrm{OCCCN} 1 \mathrm{CCOCC} 1 . \mathrm{Cl} . \mathrm{Cl}$ & 3 & $*$ \\
\hline 503 & $\mathrm{COc} 1 \mathrm{cc} 2 \mathrm{ncnc}(\mathrm{Nc} 3 \mathrm{ccc}(\mathrm{F}) \mathrm{c}(\mathrm{Cl}) \mathrm{c} 3) \mathrm{c} 2 \mathrm{cc} 1 \mathrm{OCC} 1 \mathrm{CCN}(\mathrm{C}) \mathrm{CC} 1$ & 3 & $*$ \\
\hline 504 & $\mathrm{COCCN} 1 \mathrm{CCC}(\mathrm{Oc} 2 \mathrm{cc} 3 \mathrm{c}(\mathrm{Nc} 4 \mathrm{cccc}(\mathrm{Cl}) \mathrm{c} 4 \mathrm{~F}) \mathrm{ncnc} 3 \mathrm{cc} 2 \mathrm{OC}) \mathrm{CC} 1$ & 3 & $*$ \\
\hline 505 & 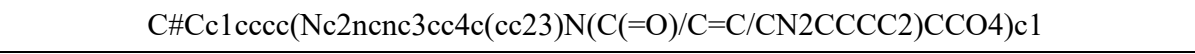 & 3 & * \\
\hline 506 & $\mathrm{C} \# \mathrm{Cc} 1 \mathrm{cccc}(\mathrm{Nc} 2 \mathrm{ncnc} 3 \mathrm{cc} 4 \mathrm{c}(\mathrm{cc} 23) \mathrm{N}(\mathrm{C}(=\mathrm{O}) / \mathrm{C}=\mathrm{C} / \mathrm{CN}(\mathrm{C}) \mathrm{C}) \mathrm{CCO} 4) \mathrm{c} 1$ & 3 & $*$ \\
\hline 507 & $\mathrm{CS}(=\mathrm{O})(=\mathrm{O}) \mathrm{CCNC} / \mathrm{C}=\mathrm{C} / \mathrm{C}(=\mathrm{O}) \mathrm{Nc} 1 \mathrm{cc} 2 \mathrm{c}(\mathrm{Nc} 3 \mathrm{ccc}(\mathrm{F}) \mathrm{c}(\mathrm{Cl}) \mathrm{c} 3) \mathrm{ncnc} 2 \mathrm{~s} 1$ & 3 & $*$ \\
\hline 508 & $\mathrm{O}=\mathrm{C}(/ \mathrm{C}=\mathrm{C} / \mathrm{CN} 1 \mathrm{CCOCC} 1) \mathrm{Nc} 1 \mathrm{cc} 2 \mathrm{c}(\mathrm{Nc} 3 \mathrm{ccc}(\mathrm{F}) \mathrm{c}(\mathrm{Cl}) \mathrm{c} 3) \mathrm{ncnc} 2 \mathrm{~s} 1$ & 3 & $*$ \\
\hline 509 & $\operatorname{COCCOc} 1 \mathrm{cc} 2 \mathrm{ncnc}(\mathrm{Nc} 3 \operatorname{ccc}(\mathrm{Br}) \mathrm{cc} 3 \mathrm{~F}) \mathrm{c} 2 \mathrm{cc} 1 \mathrm{NC}(=\mathrm{O}) / \mathrm{C}=\mathrm{C} / \mathrm{CN}(\mathrm{C}) \mathrm{C}$ & 3 & $*$ \\
\hline 510 & $\mathrm{CC}(=\mathrm{O}) \mathrm{Nc} 1 \mathrm{ccc} 2 \mathrm{ncnc}(\mathrm{Nc} 3 \mathrm{ccc}(\mathrm{OCc} 4 \mathrm{ccc} n 4) \mathrm{c}(\mathrm{Cl}) \mathrm{c} 3) \mathrm{c} 2 \mathrm{c} 1$ & 3 & $*$ \\
\hline 511 & $\mathrm{CS}(=\mathrm{O})(=\mathrm{O}) \mathrm{CCNCc} 1 \mathrm{cc}(-\mathrm{c} 2 \mathrm{cc} 3 \mathrm{ncnc}(\mathrm{Nc} 4 \mathrm{ccc}(\mathrm{OCc} 5 \operatorname{ccc}(\mathrm{F}) \mathrm{c} 5) \mathrm{c}(\mathrm{Cl}) \mathrm{c} 4) \mathrm{c} 3 \mathrm{~s} 2) \mathrm{cs} 1$ & 3 & $*$ \\
\hline 512 & OCc1 $1 \mathrm{cc}(-\mathrm{c} 2 \mathrm{cc} 3 \mathrm{ncnc}(\mathrm{Nc} 4 \mathrm{ccc}(\mathrm{OCc} 5 \operatorname{ccc}(\mathrm{F}) \mathrm{c} 5) \mathrm{c}(\mathrm{Cl}) \mathrm{c} 4) \mathrm{c} 3 \mathrm{~s} 2) \mathrm{o} 1$ & 3 & $*$ \\
\hline 513 & 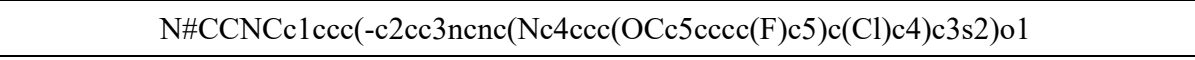 & 3 & * \\
\hline 514 & $\mathrm{CCN}(\mathrm{CC})[\mathrm{C} @ @](\mathrm{C})(\mathrm{C} \# \mathrm{Cc} 1 \mathrm{ncnc} 2 \mathrm{cc}(\mathrm{OC}) \mathrm{c}(\mathrm{OC}) \mathrm{cc} 12) \mathrm{Cc} 1 \mathrm{cccc} 1$ & 3 & $*$ \\
\hline 515 & $\mathrm{C}=\mathrm{CC}(=\mathrm{O}) \mathrm{Nc} 1 \mathrm{cc} 2 \mathrm{c}(\mathrm{Nc} 3 \mathrm{cccc}(\mathrm{Br}) \mathrm{c} 3) \mathrm{ncnc} 2 \mathrm{cc} 1 \mathrm{OCCCn} 1 \mathrm{ccnc} 1$ & 3 & $*$ \\
\hline 516 & $\mathrm{CN} 1 \mathrm{CCC}(\mathrm{Nc} 2 \mathrm{ncc} 3 \mathrm{ncnc}(\mathrm{Nc} 4 \mathrm{ccc}(\mathrm{F}) \mathrm{c}(\mathrm{Cl}) \mathrm{c} 4) \mathrm{c} 3 \mathrm{n} 2) \mathrm{CC} 1$ & 3 & $*$ \\
\hline 517 & $\mathrm{Cc} 1 \mathrm{cccc}(\mathrm{Nc} 2 \mathrm{ncnc} 3 \mathrm{cnc}(\mathrm{NCCc} 4 \mathrm{c}[\mathrm{nH}] \mathrm{cn} 4) \mathrm{nc} 23) \mathrm{c} 1$ & 3 & $*$ \\
\hline 518 & $\mathrm{CN} 1 \mathrm{CCC}(\mathrm{Oc} 2 \mathrm{cccc} 3 \mathrm{ncnc}(\mathrm{Nc} 4 \mathrm{ccc}(\mathrm{F}) \mathrm{c}(\mathrm{Cl}) \mathrm{c} 4) \mathrm{c} 23) \mathrm{CC} 1$ & 3 & $*$ \\
\hline
\end{tabular}




\begin{tabular}{|c|c|c|c|}
\hline 519 & $\mathrm{O}=\mathrm{C} 1 \mathrm{Cc} 2 \mathrm{c}(\operatorname{ccc} 2 \mathrm{Oc} 2 \mathrm{ccc}(\mathrm{Nc} 3 \mathrm{ncnc} 4 \mathrm{ccn}(\mathrm{CCO}) \mathrm{c} 34) \mathrm{cc} 2 \mathrm{Cl}) \mathrm{N} 1$ & 3 & $*$ \\
\hline 520 & $\mathrm{Cl} . \mathrm{O}=\mathrm{C}(\mathrm{NCCn} 1 \mathrm{ccc} 2 \mathrm{ncnc}(\mathrm{Nc} 3 \mathrm{ccc}(\mathrm{Oc} 4 \mathrm{cccc} 5 \mathrm{snc} 45) \mathrm{c}(\mathrm{Cl}) \mathrm{c} 3) \mathrm{c} 21)[\mathrm{C} @ @ \mathrm{H}] 1 \mathrm{CCCN} 1$ & 3 & $*$ \\
\hline 521 & $\mathrm{C}[\mathrm{C} @ \mathrm{H}](\mathrm{COc} 1 \mathrm{cccc} 2 \mathrm{ncnc}(\mathrm{Nc} 3 \mathrm{ccc}(\mathrm{OCc} 4 \mathrm{ccc} n 4) \mathrm{c}(\mathrm{Cl}) \mathrm{c} 3) \mathrm{c} 12) \mathrm{N}(\mathrm{C}) \mathrm{C}(=\mathrm{O}) \mathrm{CO}$ & 3 & $*$ \\
\hline 522 & $\mathrm{CN}(\mathrm{CCO}) \mathrm{Cc} 1 \mathrm{ccc}(-\mathrm{c} 2 \mathrm{cc} 3 \mathrm{nccc}(\mathrm{Nc} 4 \mathrm{ccc} 5[\mathrm{nH}] \mathrm{ccc} 5 \mathrm{c} 4) \mathrm{c} 3 \mathrm{~s} 2) \mathrm{cc} 1$ & 3 & * \\
\hline 523 & $\mathrm{c} 1 \mathrm{cc}(\mathrm{Nc} 2 \mathrm{ccc} 3[\mathrm{nH}] \mathrm{ccc} 3 \mathrm{c} 2) \mathrm{c} 2 \mathrm{sc}(-\mathrm{c} 3 \mathrm{ccc}(\mathrm{CNCCN} 4 \mathrm{CCNCC} 4) \mathrm{cc} 3) \mathrm{cc} 2 \mathrm{n} 1$ & 3 & $*$ \\
\hline 524 & $\mathrm{NP}(=\mathrm{O})(\mathrm{OCCCOc} 1 \mathrm{ccc} 2 \mathrm{ncnc}(\mathrm{Nc} 3 \mathrm{cccc}(\mathrm{Br}) \mathrm{c} 3) \mathrm{c} 2 \mathrm{c} 1) \mathrm{N}(\mathrm{CCCl}) \mathrm{CCCl}$ & 3 & * \\
\hline 525 & $\mathrm{Nc} 1 \mathrm{ccc}(-\mathrm{c} 2 \mathrm{cc} 3 \mathrm{c}(\mathrm{Nc} 4 \mathrm{cccc}(\mathrm{Cl}) \mathrm{c} 4) \mathrm{ncnc} 3[\mathrm{nH}] 2) \mathrm{cc} 1$ & 3 & $*$ \\
\hline 526 & Nc1 $1 \mathrm{cc}(-\mathrm{c} 2 \mathrm{cc} 3 \mathrm{c}(\mathrm{Nc} 4 \mathrm{cccc}(\mathrm{Cl}) \mathrm{c} 4) \mathrm{ncnc} 3 \mathrm{o} 2) \mathrm{cc} 1$ & 3 & * \\
\hline 527 & C[C@@H](Nc1ncnc2oc(-c3cccc(N)c3)cc12)c1 ccccc1 & 3 & * \\
\hline 528 & $\mathrm{Nc} 1 \mathrm{cccc}(-\mathrm{c} 2 \mathrm{cc} 3 \mathrm{c}(\mathrm{Nc} 4 \mathrm{cc}(\mathrm{Cl}) \mathrm{ccc} 4 \mathrm{O}) \mathrm{ncnc} 3 \mathrm{o} 2) \mathrm{c} 1$ & 3 & $*$ \\
\hline 529 & $\mathrm{CCN}(\mathrm{CC}) \mathrm{C}(\mathrm{C})(\mathrm{C \# Cc} 1 \mathrm{ncnc} 2 \mathrm{cc}(\mathrm{OC}) \mathrm{c}(\mathrm{OC}) \mathrm{cc} 12) \mathrm{Cc} 1 \mathrm{ccccc} 1$ & 3 & * \\
\hline 530 & $\mathrm{CC} 1 \mathrm{CCCCN} 1 \mathrm{CC}=\mathrm{CC}(=\mathrm{O}) \mathrm{N} 1 \mathrm{CCO} 2 \mathrm{cc} 3 \mathrm{ncnc}(\mathrm{Nc} 4 \mathrm{ccc}(\mathrm{F}) \mathrm{c}(\mathrm{Cl}) \mathrm{c} 4) \mathrm{c} 3 \mathrm{cc} 21$ & 3 & $*$ \\
\hline 531 & $\mathrm{O}=\mathrm{C}(\mathrm{C}=\mathrm{CCN} 1 \mathrm{CCCC} 1) \mathrm{N} 1 \mathrm{CCO} 2 \mathrm{cc} 3 \mathrm{ncnc}(\mathrm{Nc} 4 \mathrm{ccc}(\mathrm{F}) \mathrm{c}(\mathrm{Cl}) \mathrm{c} 4) \mathrm{c} 3 \mathrm{cc} 21$ & 3 & * \\
\hline 532 & $\mathrm{COc} 1 \mathrm{cc} 2 \mathrm{ncnc}(\mathrm{N} 3 \mathrm{CCc} 4 \mathrm{ccccc} 43) \mathrm{c} 2 \mathrm{cc} 1 \mathrm{NC}(=\mathrm{O}) / \mathrm{C}=\mathrm{C} / \mathrm{CN} 1 \mathrm{CCCC} 1$ & 3 & $*$ \\
\hline 533 & $\operatorname{COc} 1 \mathrm{cc} 2 \mathrm{ncnc}(\mathrm{Nc} 3 \mathrm{ccc}(\mathrm{F}) \mathrm{c}(\mathrm{Cl}) \mathrm{c} 3) \mathrm{c} 2 \mathrm{cc} 1 \mathrm{OCCn} 1 \mathrm{ccnc} 1[\mathrm{~N}+](=\mathrm{O})[\mathrm{O}-]$ & 3.05 & 8.52 \\
\hline 534 & COc1 1ce2ncnc(Nc3cce(F)c(Cl)c3)c2cc1OCCCN1CCOCC1 & 3.1 & 8.48 \\
\hline 535 & $\mathrm{COc} 1 \mathrm{cc} 2 \mathrm{ncnc}(\mathrm{Nc} 3 \mathrm{ccc}(\mathrm{F}) \mathrm{c}(\mathrm{Cl}) \mathrm{c} 3) \mathrm{c} 2 \mathrm{cc} 1 \mathrm{OCCCCCCC}(=\mathrm{O}) \mathrm{NO}$ & 3.1 & 8.51 \\
\hline 536 & $\mathrm{CCN}(\mathrm{CC}) \mathrm{CC} \# \mathrm{CC}(=\mathrm{O}) \mathrm{Nc} 1 \mathrm{ccc} 2 \mathrm{ncnc}(\mathrm{Nc} 3 \mathrm{ccc}(\mathrm{F}) \mathrm{c}(\mathrm{Cl}) \mathrm{c} 3) \mathrm{c} 2 \mathrm{c} 1$ & 3.1 & $*$ \\
\hline 537 & $\mathrm{O}=\mathrm{C}(\mathrm{C} \# \mathrm{CCN} 1 \mathrm{CCOCC} 1) \mathrm{Nc} 1 \mathrm{cc} 2 \mathrm{c}(\mathrm{Nc} 3 \mathrm{ccc}(\mathrm{F}) \mathrm{c}(\mathrm{Cl}) \mathrm{c} 3) \mathrm{ncnc} 2 \mathrm{cn} 1$ & 3.1 & * \\
\hline 538 & $\mathrm{CNC} 1=\mathrm{CC} 2 \mathrm{~N}=\mathrm{CN}(\mathrm{C}) / \mathrm{C}(=\mathrm{N} \backslash \mathrm{c} 3 \operatorname{cccc}(\mathrm{Br}) \mathrm{c} 3) \mathrm{C} 2 \mathrm{C}=\mathrm{N} 1$ & 3.1 & $*$ \\
\hline 539 & $\mathrm{Cc} 1 \mathrm{cccc}(\mathrm{Nc} 2 \mathrm{ncnc} 3 \mathrm{cnc}(\mathrm{N}) \mathrm{cc} 23) \mathrm{c} 1$ & 3.1 & $*$ \\
\hline 540 & OCCn1 $\operatorname{ccc} 2 \mathrm{ncnc}(\mathrm{Nc} 3 \operatorname{ccc}(\mathrm{Oc} 4 \mathrm{cccc} 5[\mathrm{nH}] \mathrm{ccc} 45) \mathrm{c}(\mathrm{Cl}) \mathrm{c} 3) \mathrm{c} 21$ & 3.1 & $*$ \\
\hline 541 & $\mathrm{COc} 1 \mathrm{cc} 2 \mathrm{ncnc}(\mathrm{Nc} 3 \mathrm{cccc}(\mathrm{NC}(=\mathrm{O}) \mathrm{C} 45 \mathrm{CC} 6 \mathrm{CC}(\mathrm{CC}(\mathrm{C} 6) \mathrm{C} 4) \mathrm{C} 5) \mathrm{c} 3) \mathrm{c} 2 \mathrm{cc} 1 \mathrm{OCCCN} 1 \mathrm{CCOCC} 1$ & 3.11 & 8.51 \\
\hline 542 & $\mathrm{C}=\mathrm{C}=\mathrm{CCCCOc} 1 \mathrm{cc} 2 \mathrm{c}(\mathrm{Nc} 3 \mathrm{ccc}(\mathrm{F}) \mathrm{c}(\mathrm{Cl}) \mathrm{c} 3) \mathrm{ncnc} 2 \mathrm{cc} 1 \mathrm{O}$ & 3.16 & $*$ \\
\hline 543 & $\mathrm{C}=\mathrm{CC}(=\mathrm{O}) \mathrm{Nc} 1 \mathrm{cccc}(\mathrm{Oc} 2 \mathrm{nc}(\mathrm{Nc} 3 \mathrm{ccc}(\mathrm{N} 4 \mathrm{CCN}(\mathrm{C}) \mathrm{CC} 4) \mathrm{cc} 3 \mathrm{OC}) \mathrm{ncc} 2 \mathrm{Cl}) \mathrm{c} 1$ & 3.2 & 8.32 \\
\hline 544 & $\mathrm{C}=\mathrm{CC}(=\mathrm{O}) \mathrm{Nc} 1 \mathrm{ccc} 2 \mathrm{ncnc}(\mathrm{Nc} 3 \mathrm{ccc}(\mathrm{CC}) \mathrm{cc} 3) \mathrm{c} 2 \mathrm{c} 1$ & 3.2 & $*$ \\
\hline 545 & $\mathrm{CN}(\mathrm{CC}(\mathrm{O}) \mathrm{CO}) \mathrm{c} 1 \mathrm{cc} 2 \mathrm{ncnc}(\mathrm{Nc} 3 \mathrm{cccc}(\mathrm{Br}) \mathrm{c} 3) \mathrm{c} 2 \mathrm{cn} 1$ & 3.2 & * \\
\hline 546 & $\mathrm{CN}(\mathrm{CC}(\mathrm{O}) \mathrm{C}(\mathrm{O}) \mathrm{C}(\mathrm{O}) \mathrm{C}(\mathrm{O}) \mathrm{CO}) \mathrm{c} 1 \mathrm{cc} 2 \mathrm{ncnc}(\mathrm{Nc} 3 \mathrm{cccc}(\mathrm{Br}) \mathrm{c} 3) \mathrm{c} 2 \mathrm{cn} 1$ & 3.2 & $*$ \\
\hline 547 & Brc1 ccce(Nc2ncnc3cc(NCCN4CCOCC4)ncc23)c1 & 3.2 & $*$ \\
\hline 548 & $\mathrm{C}=\mathrm{C}=\mathrm{CC}(=\mathrm{O}) \mathrm{Nc} 1 \mathrm{cc}(\mathrm{Nc} 2 \mathrm{nccc}(\mathrm{C} 3=\mathrm{CNC} 4 \mathrm{C}=\mathrm{CC}=\mathrm{CC} 34) \mathrm{n} 2) \mathrm{c}(\mathrm{OC}) \mathrm{cc} 1 \mathrm{~N}(\mathrm{C}) \mathrm{CCN}(\mathrm{C}) \mathrm{C}$ & 3.2 & $*$ \\
\hline 549 & $\mathrm{C}=\mathrm{C}=\mathrm{CC}(=\mathrm{O}) \mathrm{Nc} 1 \mathrm{cc}(\mathrm{Nc} 2 \mathrm{nccc}(-\mathrm{c} 3 \mathrm{c}[\mathrm{nH}] \mathrm{c} 4 \mathrm{ccccc} 34) \mathrm{n} 2) \mathrm{c}(\mathrm{OC}) \mathrm{cc} 1 \mathrm{~N}(\mathrm{C}) \mathrm{CCN}(\mathrm{C}) \mathrm{C}$ & 3.2 & * \\
\hline 550 & $\mathrm{C}[\mathrm{C} @ @ \mathrm{H}](\mathrm{Nc} 1 \mathrm{ncnc} 2[\mathrm{nH}] \mathrm{c}(-\mathrm{c} 3 \mathrm{ccccc} 3) \mathrm{cc} 12) \mathrm{c} 1 \mathrm{cccc} 1$ & 3.2 & $*$ \\
\hline 551 & $\mathrm{CN}(\mathrm{CC}(\mathrm{O}) \mathrm{CO}) \mathrm{c} 1 \mathrm{c}(\mathrm{Br}) \mathrm{cccc} 1 \mathrm{Nc} 1 \mathrm{ncnc} 2 \mathrm{ccncc} 12$ & 3.236 & $*$ \\
\hline 552 & Brc1 $1 \mathrm{ccc}(\mathrm{Nc} 2 \mathrm{ncnc} 3 \mathrm{ccncc} 23) \mathrm{c} 1 \mathrm{NCCN} 1 \mathrm{CCOCC} 1$ & 3.236 & $*$ \\
\hline 553 & $\mathrm{C}=\mathrm{CC}(=\mathrm{O}) \mathrm{NCc} 1 \operatorname{coc}(-\mathrm{c} 2 \mathrm{c}(\mathrm{N}) \mathrm{ncnc} 2 \mathrm{Nc} 2 \mathrm{ccc}(\mathrm{OCc} 3 \operatorname{ccc} \mathrm{c} 3) \mathrm{c}(\mathrm{Cl}) \mathrm{c} 2) \mathrm{n} 1$ & 3.3 & 8.48 \\
\hline 554 & $\mathrm{C} \# \mathrm{Cc} 1 \mathrm{cccc}(\mathrm{Nc} 2 \mathrm{ncnc} 3 \mathrm{cc}(\mathrm{OC}) \mathrm{c}(\mathrm{NC}(=\mathrm{O}) / \mathrm{C}=\mathrm{C} / \mathrm{CN}(\mathrm{C}) \mathrm{C} 4 \mathrm{CC} 4) \mathrm{cc} 23) \mathrm{c} 1$ & 3.3 & $*$ \\
\hline 555 & $\mathrm{Nc} 1 \mathrm{ccc} 2 \mathrm{c}(\mathrm{Nc} 3 \operatorname{cccc}(\mathrm{C}(\mathrm{F})(\mathrm{F}) \mathrm{F}) \mathrm{c} 3) \mathrm{ncnc} 2 \mathrm{c} 1$ & 3.3 & * \\
\hline 556 & $\mathrm{C}=\mathrm{CC}(=\mathrm{O}) \mathrm{N}(\mathrm{CCCN} 1 \mathrm{CCOCC} 1) \mathrm{c} 1 \mathrm{ccc} 2 \mathrm{ncnc}(\mathrm{Nc} 3 \mathrm{cccc}(\mathrm{Br}) \mathrm{c} 3) \mathrm{c} 2 \mathrm{c} 1$ & 3.3 & * \\
\hline 557 & C[C@@H](Nc1[nH]cnc2nc(-c3ccccc3)cc1-2)c1 ccccc1 & 3.3 & * \\
\hline 558 & Br.Oc1 $1 \mathrm{ccc}(-\mathrm{c} 2 \mathrm{cc} 3 \mathrm{c}(\mathrm{NCc} 4 \mathrm{ccccc} 4) \mathrm{ncnc} 3[\mathrm{nH}] 2) \mathrm{cc} 1$ & 3.3 & $*$ \\
\hline 559 & $\mathrm{NP}(=\mathrm{O})(\mathrm{OCCCC}(=\mathrm{O}) \mathrm{Nc} 1 \mathrm{ccc} 2 \mathrm{ncnc}(\mathrm{Nc} 3 \mathrm{cccc}(\mathrm{Br}) \mathrm{c} 3) \mathrm{c} 2 \mathrm{c} 1) \mathrm{N}(\mathrm{CCCl}) \mathrm{CCCl}$ & 3.3 & $*$ \\
\hline 560 & $\mathrm{C}=\mathrm{CC}(=\mathrm{O}) \mathrm{N} 1 \mathrm{CC}[\mathrm{C} @ @ \mathrm{H}](\mathrm{Nc} 2 \mathrm{nc}(\mathrm{Nc} 3 \mathrm{ccccc} 3) \mathrm{nc} 3 \mathrm{cnc}(\mathrm{Nc} 4 \mathrm{ccc}(\mathrm{N} 5 \mathrm{CCN}(\mathrm{C}) \mathrm{CC} 5) \mathrm{cn} 4) \mathrm{cc} 23) \mathrm{C} 1$ & 3.3 & * \\
\hline 561 & $\mathrm{Cc} 1 \mathrm{ccc}(\mathrm{F}) \mathrm{cc} 1 \mathrm{Nc} 1 \mathrm{nc} 2 \mathrm{cc}(\mathrm{Cl}) \mathrm{c}(\mathrm{N}(\mathrm{C}) \mathrm{C}(=\mathrm{O}) / \mathrm{C}=\mathrm{C} / \mathrm{CN}(\mathrm{C}) \mathrm{C}) \mathrm{cc} 2 \mathrm{n} 2 \mathrm{cncc} 12$ & 3.35 & * \\
\hline
\end{tabular}




\begin{tabular}{|c|c|c|c|}
\hline 562 & $\mathrm{COc} 1 \mathrm{cc} 2 \mathrm{ncnc}(\mathrm{Nc} 3 \mathrm{ccc}(\mathrm{F}) \mathrm{c}(\mathrm{Cl}) \mathrm{c} 3) \mathrm{c} 2 \mathrm{cc} 1 \mathrm{OCCCCCC}(=\mathrm{O}) \mathrm{NO}$ & 3.4 & 8.47 \\
\hline 563 & $\operatorname{COC}(=\mathrm{O}) \mathrm{c} 1 \mathrm{ccc} 2 \mathrm{oc} 3 \mathrm{cnn}(\mathrm{Nc} 4 \mathrm{cccc} 5 \mathrm{ccccc} 45) \mathrm{c} 3 \mathrm{c} 2 \mathrm{c} 1$ & 3.4 & 8.47 \\
\hline 564 & $\mathrm{C}=\mathrm{CC}(=\mathrm{O}) \mathrm{Nc} 1 \mathrm{ccc} 2 \mathrm{ncnc}(\mathrm{NC} 3 \mathrm{CCCCC} 3) \mathrm{c} 2 \mathrm{c} 1$ & 3.4 & $*$ \\
\hline 565 & $\mathrm{COC}(=\mathrm{O}) \mathrm{CN}(\mathrm{C}) \mathrm{Cc} 1 \mathrm{c}[\mathrm{nH}] \mathrm{c} 2 \mathrm{cc} 3 \mathrm{ncnc}(\mathrm{Nc} 4 \mathrm{cccc}(\mathrm{Br}) \mathrm{c} 4) \mathrm{c} 3 \mathrm{cc} 12$ & 3.4 & * \\
\hline 566 & $\mathrm{C}[\mathrm{C} @ @ \mathrm{H}](\mathrm{Nc} 1 \mathrm{ncnc} 2[\mathrm{nH}] \mathrm{c}(-\mathrm{c} 3 \mathrm{ccc}(\mathrm{O}) \mathrm{cc} 3) \mathrm{cc} 12) \mathrm{c} 1 \mathrm{ccc}(\mathrm{F}) \mathrm{cc} 1$ & 3.4 & $*$ \\
\hline 567 & $\mathrm{COc} 1 \mathrm{cc} 2 \mathrm{ncnc}(\mathrm{Nc} 3 \mathrm{ccc}(\mathrm{F}) \mathrm{c}(\mathrm{Cl}) \mathrm{c} 3) \mathrm{c} 2 \mathrm{cc} 1 \mathrm{OCCCn} 1 \mathrm{c}([\mathrm{N}+](=\mathrm{O})[\mathrm{O}-]) \mathrm{cnc} 1 \mathrm{C}$ & 3.43 & 8.46 \\
\hline 568 & $\mathrm{OCCN}(\mathrm{CCO}) \mathrm{Cc} 1 \mathrm{c}[\mathrm{nH}] \mathrm{c} 2 \mathrm{cc} 3 \mathrm{ncnc}(\mathrm{Nc} 4 \mathrm{cccc}(\mathrm{Br}) \mathrm{c} 4) \mathrm{c} 3 \mathrm{cc} 12$ & 3.5 & $*$ \\
\hline 569 & $\mathrm{Cc} 1 \mathrm{cccc}(\mathrm{Nc} 2 \mathrm{ncnc} 3 \mathrm{cc}(\mathrm{NCCCn} 4 \mathrm{ccnc} 4) \mathrm{ncc} 23) \mathrm{c} 1$ & 3.5 & $*$ \\
\hline 570 & $\mathrm{C}=\mathrm{CC}(=\mathrm{O}) \mathrm{Nc} 1 \mathrm{ccc}(\mathrm{N} 2 \mathrm{C}(=\mathrm{O}) \mathrm{N}(\mathrm{C}) \mathrm{Cc} 3 \mathrm{cnc}(\mathrm{Nc} 4 \mathrm{ccc}(\mathrm{N} 5 \mathrm{CCC}(\mathrm{N}(\mathrm{C}) \mathrm{C}) \mathrm{CC} 5) \operatorname{cc} 4 \mathrm{OC}) \mathrm{nc} 32) \mathrm{c} 1$ & 3.52 & 8.45 \\
\hline 571 & $\mathrm{Cc} 1 \mathrm{ccc}(\mathrm{Nc} 2 \mathrm{ncnc} 3 \mathrm{ccncc} 23) \mathrm{c} 1 \mathrm{NCCCn} 1 \mathrm{ccnc} 1$ & 3.548 & $*$ \\
\hline 572 & 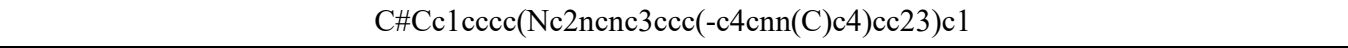 & 3.58 & 8.45 \\
\hline 573 & $\mathrm{CCOc} 1 \mathrm{cc} 2 \mathrm{ncnc}(\mathrm{Nc} 3 \mathrm{ccc}(\mathrm{OCC} 4 \mathrm{CC} 4) \mathrm{c}(\mathrm{Cl}) \mathrm{c} 3) \mathrm{c} 2 \mathrm{cc} 1 \mathrm{NC}(=\mathrm{O}) / \mathrm{C}(\mathrm{F})=\mathrm{C} / \mathrm{CN}(\mathrm{C}) \mathrm{C}$ & 3.6 & 8.44 \\
\hline 574 & $\mathrm{CCOc} 1 \mathrm{cc} 2 \mathrm{ncnc}(\mathrm{Nc} 3 \mathrm{ccc}(\mathrm{C}) \mathrm{cc} 3) \mathrm{c} 2 \mathrm{c} 2 \mathrm{c} 1 \mathrm{OCCO} 2$ & 3.6 & $*$ \\
\hline 575 & $\mathrm{O}=\mathrm{C}(\mathrm{CCCCCCn} 1 \mathrm{cc}(-\mathrm{c} 2 \mathrm{ccc} 3 \mathrm{ncnc}(\mathrm{Nc} 4 \mathrm{ccc}(\mathrm{OCc} 5 \mathrm{nccs} 5) \mathrm{c}(\mathrm{Cl}) \mathrm{c} 4) \mathrm{c} 3 \mathrm{c} 2) \mathrm{nn} 1) \mathrm{NO}$ & 3.6 & $*$ \\
\hline 576 & $\mathrm{COc} 1 \mathrm{ccc}(/ \mathrm{C}=\mathrm{C} / \mathrm{C}(=\mathrm{O}) \mathrm{Nc} 2 \mathrm{cc} 3 \mathrm{c}(\mathrm{Nc} 4 \mathrm{ccc}(\mathrm{F}) \mathrm{c}(\mathrm{Cl}) \mathrm{c} 4) \mathrm{ncnc} 3 \mathrm{cc} 2 \mathrm{O}[\mathrm{C} @ \mathrm{H}] 2 \mathrm{CCOC} 2) \mathrm{c}(\mathrm{OC}) \mathrm{c} 1 \mathrm{OC}$ & 3.6 & $*$ \\
\hline 577 & $\mathrm{C}=\mathrm{CC}(=\mathrm{O}) \mathrm{Nc} 1 \mathrm{cc} 2 \mathrm{c}(\mathrm{Nc} 3 \mathrm{cccc}(\mathrm{Br}) \mathrm{c} 3) \mathrm{ncnc} 2 \mathrm{cc} 1 \mathrm{OCCCN} 1 \mathrm{CCOCC} 1$ & 3.6 & $*$ \\
\hline 578 & $\mathrm{C}=\mathrm{CC}(=\mathrm{O}) \mathrm{Nc} 1 \mathrm{ccc} 2 \mathrm{ncnc}(\mathrm{Nc} 3 \operatorname{ccc}(\mathrm{OCc} 4 \operatorname{ccccc} 4) \operatorname{cc} 3) \mathrm{c} 2 \mathrm{c} 1$ & 3.6 & $*$ \\
\hline 579 & $\mathrm{Clc} 1 \mathrm{ccc}(\mathrm{Nc} 2 \mathrm{ncnc} 3[\mathrm{nH}] \mathrm{ccc} 23) \mathrm{cc} 1 \mathrm{Br}$ & 3.63 & $*$ \\
\hline 580 & $\mathrm{Fc} 1 \mathrm{ccc}(\mathrm{Nc} 2 \mathrm{ncnc} 3 \mathrm{ccc}(\mathrm{NC}(=\mathrm{S}) \mathrm{NCCN} 4 \mathrm{CCCCC} 4) \mathrm{cc} 23) \mathrm{cc} 1 \mathrm{Cl}$ & 3.7 & 8.43 \\
\hline 581 & Brc1cece $(\mathrm{Nc} 2 \mathrm{ncnc} 3 \mathrm{cc} 4 \mathrm{c}(\mathrm{cnn} 4 \mathrm{CCN} 4 \mathrm{CCOCC} 4) \mathrm{cc} 23) \mathrm{c} 1$ & 3.7 & $*$ \\
\hline 582 & Brc1 $\operatorname{ccc}(\mathrm{Nc} 2 \mathrm{ncnc} 3 \mathrm{cc} 4 \mathrm{c}(\mathrm{ccn} 4 \mathrm{CCN} 4 \mathrm{CCOCC} 4) \mathrm{cc} 23) \mathrm{c} 1$ & 3.7 & $*$ \\
\hline 583 & Br.C[C@@H](Nc1ncnc2[nH]c(-c3ecc(O)cc3)cc12)c1 ccccc1 & 3.7 & $*$ \\
\hline 584 & $\mathrm{COc} 1 \mathrm{ccc}(-\mathrm{c} 2 \mathrm{cc} 3 \mathrm{c}(\mathrm{NCc} 4 \mathrm{ccccc} 4) \mathrm{ncnc} 3[\mathrm{nH}] 2) \mathrm{cc} 1$ & 3.7 & $*$ \\
\hline 585 & $\mathrm{C}=\mathrm{CC}(=\mathrm{O}) \mathrm{N} 1 \mathrm{CCc} 2 \mathrm{c}(\operatorname{sc} 3 n \mathrm{cnc}(\mathrm{Nc} 4 \operatorname{ccc}(\mathrm{Br}) \mathrm{cc} 4 \mathrm{~F}) \mathrm{c} 23) \mathrm{C} 1$ & 3.71 & $*$ \\
\hline 586 & $\operatorname{Brc} 1 \mathrm{cccc}(\mathrm{Nc} 2 \mathrm{ncnc} 3[\mathrm{nH}] \mathrm{ccc} 23) \mathrm{c} 1$ & 3.76 & $*$ \\
\hline 587 & $\mathrm{COc} 1 \mathrm{cc} 2 \mathrm{ncnc}(\mathrm{Nc} 3 \mathrm{cccc}(\mathrm{Br}) \mathrm{c} 3) \mathrm{c} 2 \mathrm{cc} 1 \mathrm{~N}$ & 3.8 & $*$ \\
\hline 588 & $\mathrm{COc} 1 \mathrm{cc} 2 \mathrm{ncnc}(\mathrm{Nc} 3 \operatorname{cccc}(\mathrm{F}) \mathrm{c} 3) \mathrm{c} 2 \mathrm{cc} 1 \mathrm{OC}$ & 3.8 & $*$ \\
\hline 589 & COc1ncc2ncnc(Nc3ecce(Br)c3)c2n1 & 3.8 & $*$ \\
\hline 590 & Br.C[C@@H](Nc1ncnc2[nH]c(-c3ecc(O)cc3)cc12)c1 ccc(F)cc1 & 3.8 & $*$ \\
\hline 591 & $\mathrm{c} 1 \mathrm{ccc}(\mathrm{CNc} 2 \mathrm{ncnc} 3[\mathrm{nH}] \mathrm{c}(-\mathrm{c} 4 \mathrm{ccccc} 4) \mathrm{cc} 23) \mathrm{cc} 1$ & 3.8 & * \\
\hline 592 & $\mathrm{C}=\mathrm{CC}(=\mathrm{O}) \mathrm{Nc} 1 \mathrm{cccc}(-\mathrm{n} 2 \mathrm{c}(=\mathrm{O}) \mathrm{n}(\mathrm{CCCc} 3 \operatorname{ccccc} 3) \mathrm{c}(=\mathrm{O}) \mathrm{c} 3 \mathrm{cnc}(\mathrm{Nc} 4 \mathrm{ccc}(\mathrm{N} 5 \mathrm{CCC}(\mathrm{N}(\mathrm{C}) \mathrm{C}) \mathrm{CC} 5) \mathrm{cc} 4 \mathrm{OC}) \mathrm{nc} 32) \mathrm{c} 1$ & 3.8 & $*$ \\
\hline 593 & $\mathrm{C}=\mathrm{CC}(=\mathrm{O}) \mathrm{Nc} 1 \mathrm{cccc}(-\mathrm{n} 2 \mathrm{c}(=\mathrm{O}) \mathrm{cnc} 3 \mathrm{cnc}(\mathrm{Nc} 4 \mathrm{ccc}(\mathrm{N} 5 \mathrm{CCN}(\mathrm{C}) \mathrm{CC} 5) \mathrm{cc} 4 \mathrm{OC}) \mathrm{nc} 32) \mathrm{c} 1$ & 3.82 & 8.42 \\
\hline 594 & OC[C@@H](Nc1ncnc2oc(-c3ecccc3)cc12)c1 ccccc1 & 3.9 & 8.41 \\
\hline 595 & $\mathrm{O}=\mathrm{C}(\mathrm{NO}) \mathrm{c} 1 \mathrm{ccc}(-\mathrm{c} 2 \mathrm{ccc} 3 \mathrm{n} \operatorname{cnc}(\mathrm{Nc} 4 \mathrm{ccc}(\mathrm{OCc} 5 \mathrm{cccc}(\mathrm{F}) \mathrm{c} 5) \mathrm{c}(\mathrm{Cl}) \mathrm{c} 4) \mathrm{c} 3 \mathrm{c} 2) \mathrm{o} 1$ & 3.9 & $*$ \\
\hline 596 & $\mathrm{C}=\mathrm{CC}(=\mathrm{O}) \mathrm{Nc} 1 \mathrm{cc} 2 \mathrm{c}(\mathrm{Nc} 3 \mathrm{ccc}(\mathrm{Br}) \mathrm{c} 3) \mathrm{ncnc} 2 \mathrm{cc} 1 \mathrm{OCCCCN}(\mathrm{C}) \mathrm{C}$ & 3.9 & $*$ \\
\hline 597 & $\mathrm{CN} 1 \mathrm{CCN}(\mathrm{NCCCNc} 2 \mathrm{cc} 3 \mathrm{c}(\mathrm{Nc} 4 \mathrm{cccc}(\mathrm{Br}) \mathrm{c} 4) \mathrm{ncnc} 3 \mathrm{cn} 2) \mathrm{CC} 1$ & 3.9 & $*$ \\
\hline 598 & $\mathrm{C}=\mathrm{CC}(=\mathrm{O}) \mathrm{N} 1 \mathrm{CCc} 2 \mathrm{c}(\operatorname{sc} 3 \mathrm{ncnc}(\mathrm{Nc} 4 \operatorname{cccc}(\mathrm{C}) \mathrm{c} 4 \mathrm{~F}) \mathrm{c} 23) \mathrm{C} 1$ & 3.95 & $*$ \\
\hline 599 & $\mathrm{CC}(=\mathrm{O}) \mathrm{Nc} 1 \mathrm{ccc} 2 \mathrm{ncnc}(\mathrm{Nc} 3 \operatorname{ccc}(\mathrm{OCc} 4 \mathrm{cccc}(\mathrm{F}) \mathrm{c} 4) \mathrm{c}(\mathrm{Cl}) \mathrm{c} 3) \mathrm{c} 2 \mathrm{c} 1$ & 3.96 & 8.40 \\
\hline 600 & COc1ccc(-c2cc3c(N[C@H](CCO)c4ccccc4)ncnc3o2)cc1 & 4 & 8.40 \\
\hline 601 & COc1 ccccc1-c1cc2c(N[C@H](C)c3ecccc3)ncnc2o1 & 4 & 8.40 \\
\hline 602 & $\mathrm{COC}(=\mathrm{O}) \mathrm{c} 1 \mathrm{cc}(\mathrm{OC}) \mathrm{c}(-\mathrm{c} 2 \mathrm{cc} 3 \mathrm{c}(\mathrm{N}[\mathrm{C} @ \mathrm{H}](\mathrm{C}) \mathrm{c} 4 \mathrm{ccccc} 4) \mathrm{ncnc} 3 \mathrm{~s} 2) \mathrm{c}(\mathrm{OC}) \mathrm{c} 1$ & 4 & 8.40 \\
\hline 603 & $\mathrm{CACc} 1 \operatorname{ccc}(\mathrm{Nc} 2 \mathrm{ncnc} 3 \mathrm{cc} 4 \mathrm{c}(\operatorname{cc} 23) \mathrm{N}(\mathrm{C}(=\mathrm{O}) / \mathrm{C}=\mathrm{C} / \mathrm{CN} 2 \mathrm{CCCCC} 2) \mathrm{CCO} 4) \mathrm{c} 1$ & 4 & $*$ \\
\hline 604 & $\mathrm{O}=\mathrm{C}(/ \mathrm{C}=\mathrm{C} / \mathrm{CN} 1 \mathrm{CCC}(\mathrm{F}) \mathrm{CC} 1) \mathrm{Nc} 1 \mathrm{cc} 2 \mathrm{c}(\mathrm{Nc} 3 \mathrm{ccc}(\mathrm{F}) \mathrm{c}(\mathrm{Cl}) \mathrm{c} 3) \mathrm{ncnc} 2 \mathrm{~s} 1$ & 4 & $*$ \\
\hline
\end{tabular}




\begin{tabular}{|c|c|c|c|}
\hline 605 & $\mathrm{NC}(=\mathrm{O}) \mathrm{Nc} 1 \mathrm{ccc} 2 \mathrm{ncnc}(\mathrm{Nc} 3 \operatorname{ccc}(\mathrm{Oc} 4 \operatorname{cccc}(\mathrm{C}(\mathrm{F})(\mathrm{F}) \mathrm{F}) \mathrm{c} 4) \mathrm{c}(\mathrm{Cl}) \mathrm{c} 3) \mathrm{c} 2 \mathrm{c} 1$ & 4 & $*$ \\
\hline 606 & $\mathrm{CN}(\mathrm{C}) \mathrm{Cc} 1 \mathrm{ccc}(-\mathrm{c} 2 \mathrm{cc} 3 \mathrm{ncnc}(\mathrm{Nc} 4 \mathrm{ccc}(\mathrm{OCc} 5 \mathrm{cccc}(\mathrm{F}) \mathrm{c} 5) \mathrm{c}(\mathrm{Cl}) \mathrm{c} 4) \mathrm{c} 3 \mathrm{~s} 2)[\mathrm{nH}] 1$ & 4 & $*$ \\
\hline 607 & $\mathrm{CS}(=\mathrm{O})(=\mathrm{O}) \mathrm{CCNCc} 1 \mathrm{cc}(-\mathrm{c} 2 \mathrm{cc} 3 \mathrm{ncnc}(\mathrm{Nc} 4 \mathrm{ccc}(\mathrm{OCc} 5 \mathrm{ccc}(\mathrm{F}) \mathrm{c} 5) \mathrm{c}(\mathrm{Cl}) \mathrm{c} 4) \mathrm{c} 3 \mathrm{~s} 2) \mathrm{co} 1$ & 4 & $*$ \\
\hline 608 & $\mathrm{COc} 1 \mathrm{cc} 2 \mathrm{ncnc}(/ \mathrm{C}=\mathrm{C} / \mathrm{CCc} 3 \operatorname{ccc} c 3) \mathrm{c} 2 \mathrm{cc} 1 \mathrm{OC}$ & 4 & $*$ \\
\hline 609 & $\mathrm{CNc} 1 \mathrm{ccc} 2 \mathrm{cncnc} 2 \mathrm{c} 1$ & 4 & $*$ \\
\hline 610 & $\mathrm{COc} 1 \mathrm{cc} 2 \mathrm{ncnc}(\mathrm{NCc} 3 \mathrm{cccc} 3) \mathrm{c} 2 \mathrm{cc} 1 \mathrm{OC} . \mathrm{Cl}$ & 4 & $*$ \\
\hline 611 & $\mathrm{CNc} 1 \mathrm{ccc} 2 \mathrm{c}(\mathrm{Nc} 3 \operatorname{ccc}(\mathrm{Br}) \mathrm{c} 3) \mathrm{ncnc} 2 \mathrm{c} 1$ & 4 & $*$ \\
\hline 612 & $\mathrm{CNc} 1 \mathrm{ccc} 2 \mathrm{ncnc}(\mathrm{Nc} 3 \operatorname{ccc}(\mathrm{Br}) \mathrm{c} 3) \mathrm{c} 2 \mathrm{c} 1$ & 4 & * \\
\hline 613 & $\mathrm{Cc} 1 \mathrm{cccc}(\mathrm{Nc} 2 \mathrm{ncnc} 3 \mathrm{cnc}(\mathrm{N}(\mathrm{C}) \mathrm{C}) \mathrm{nc} 23) \mathrm{c} 1$ & 4 & $*$ \\
\hline 614 & $\mathrm{CN} 1 \mathrm{CCN}(\mathrm{c} 2 \mathrm{ccc}(\mathrm{Nc} 3 \mathrm{ncc} 4 \mathrm{nc}(\mathrm{Nc} 5 \mathrm{cccc} 5) \mathrm{n}(\mathrm{C} 5 \mathrm{CCCC} 5) \mathrm{c} 4 \mathrm{n} 3) \mathrm{cc} 2) \mathrm{CC} 1$ & 4 & $*$ \\
\hline 615 & OCCOCCNCc1 $1 \mathrm{ccc}(-\mathrm{c} 2 \mathrm{cc} 3 \mathrm{nccc}(\mathrm{Nc} 4 \mathrm{ccc} 5[\mathrm{nH}] \mathrm{ccc} 5 \mathrm{c} 4) \mathrm{c} 3 \mathrm{~s} 2) \mathrm{cc} 1$ & 4 & * \\
\hline 616 & $\mathrm{NCc} 1 \mathrm{ccc}(-\mathrm{c} 2 \mathrm{cc} 3 \mathrm{ncnc}(\mathrm{Nc} 4 \mathrm{ccc} 5[\mathrm{nH}] \mathrm{ccc} 5 \mathrm{c} 4) \mathrm{c} 3 \mathrm{~s} 2) \mathrm{cc} 1$ & 4 & $*$ \\
\hline 617 & $\mathrm{NC} 1 \mathrm{CCN}(\mathrm{Cc} 2 \mathrm{ccn} 3 \mathrm{ncnc}(\mathrm{Nc} 4 \mathrm{cccc}(\mathrm{Cl}) \mathrm{c} 4) \mathrm{c} 23) \mathrm{CC} 1$ & 4 & $*$ \\
\hline 618 & $\mathrm{NC} 1 \mathrm{CCN}(\mathrm{Cc} 2 \mathrm{ccn} 3 \mathrm{ncnc}(\mathrm{Nc} 4 \mathrm{cccc}(\mathrm{Br}) \mathrm{c} 4) \mathrm{c} 23) \mathrm{CC} 1$ & 4 & $*$ \\
\hline 619 & Br.CC[C@@H](Nc1ncnc2[nH]c(-c3ccc(O)cc3)cc12)c1 ccccc1 & 4 & $*$ \\
\hline 620 & $\mathrm{Nc} 1 \mathrm{cccc}(-\mathrm{c} 2 \mathrm{cc} 3 \mathrm{c}(\mathrm{Nc} 4 \mathrm{ccc}(\mathrm{Cl}) \mathrm{c} 4) \mathrm{ncnc} 3[\mathrm{nH}] 2) \mathrm{c} 1$ & 4 & $*$ \\
\hline 621 & $\mathrm{OC}[\mathrm{C} @ @ \mathrm{H}](\mathrm{Nc} 1 \mathrm{ncnc} 2[\mathrm{nH}] \mathrm{c}(-\mathrm{c} 3 \mathrm{ccc}(\mathrm{F}) \mathrm{cc} 3) \mathrm{cc} 12) \mathrm{c} 1 \mathrm{ccccc} 1$ & 4 & $*$ \\
\hline 622 & $\mathrm{O}=\mathrm{C}(\mathrm{C}=\mathrm{CCN} 1 \mathrm{CCCCC} 1) \mathrm{N} 1 \mathrm{CCOc} 2 \mathrm{cc} 3 \mathrm{ncnc}(\mathrm{Nc} 4 \mathrm{ccc}(\mathrm{F}) \mathrm{c}(\mathrm{Cl}) \mathrm{c} 4) \mathrm{c} 3 \mathrm{cc} 21$ & 4 & $*$ \\
\hline 623 & $\mathrm{CN}(\mathrm{C}) \mathrm{CC}=\mathrm{CC}(=\mathrm{O}) \mathrm{N} 1 \mathrm{CCOc} 2 \mathrm{cc} 3 \mathrm{ncnc}(\mathrm{Nc} 4 \mathrm{ccc}(\mathrm{F}) \mathrm{c}(\mathrm{Cl}) \mathrm{c} 4) \mathrm{c} 3 \mathrm{cc} 21$ & 4 & $*$ \\
\hline 624 & $\mathrm{COc} 1 \mathrm{cc} 2 \mathrm{ncnc}(\mathrm{N} 3 \mathrm{CCc} 4 \mathrm{cccc} 43) \mathrm{c} 2 \mathrm{cc} 1 \mathrm{NC}(=\mathrm{O}) / \mathrm{C}=\mathrm{C} / \mathrm{CN} 1 \mathrm{CCC}(\mathrm{CO}) \mathrm{CC} 1$ & 4 & $*$ \\
\hline 625 & $\mathrm{CCOc} 1 \mathrm{cc} 2 \mathrm{ncc}(\mathrm{C} \# \mathrm{~N}) \mathrm{c}(\mathrm{Nc} 3 \mathrm{ccc}(\mathrm{F}) \mathrm{c}(\mathrm{Cl}) \mathrm{c} 3) \mathrm{c} 2 \mathrm{cc} 1 \mathrm{NC}(=\mathrm{O}) / \mathrm{C}=\mathrm{C} / \mathrm{c} 1 \mathrm{cn}(\mathrm{CCF}) \mathrm{nn} 1$ & 4.05 & 8.39 \\
\hline 626 & $\mathrm{CCOc} 1 \mathrm{cc} 2 \mathrm{ncnc}(\mathrm{NC} 3=\mathrm{CC}(=\mathrm{O}) \mathrm{C}(\mathrm{OCc} 4 \operatorname{cccc}(\mathrm{F}) \mathrm{c} 4)=\mathrm{CC} 3=\mathrm{O}) \mathrm{c} 2 \mathrm{cc} 1 \mathrm{NC}(=\mathrm{O}) / \mathrm{C}=\mathrm{C} / \mathrm{CN}(\mathrm{C}) \mathrm{C}$ & 4.1 & 8.39 \\
\hline 627 & $\mathrm{CN}(\mathrm{C})[\mathrm{C} @ \mathrm{H}](\mathrm{CS}(\mathrm{C})(=\mathrm{O})=\mathrm{O}) \mathrm{c} 1 \mathrm{ccc}(-\mathrm{c} 2 \mathrm{ccc} 3 \mathrm{ncnc}(\mathrm{Nc} 4 \mathrm{ccc}(\mathrm{OCc} 5 \mathrm{ccc}(\mathrm{F}) \mathrm{c} 5) \mathrm{c}(\mathrm{Cl}) \mathrm{c} 4) \mathrm{c} 3 \mathrm{c} 2) \mathrm{o} 1$ & 4.1 & $*$ \\
\hline 628 & $\mathrm{O}=\mathrm{C}(\mathrm{Nc} 1 \mathrm{ccc}(\mathrm{CN} 2 \mathrm{CCCC} 2) \mathrm{cc} 1) \mathrm{Nc} 1 \mathrm{ccc} 2 \mathrm{ncnc}(\mathrm{Nc} 3 \operatorname{cccc}(\mathrm{C}(\mathrm{F})(\mathrm{F}) \mathrm{F}) \mathrm{c} 3) \mathrm{c} 2 \mathrm{c} 1$ & 4.1 & $*$ \\
\hline 629 & $\operatorname{Brc} 1 \operatorname{ccc}(\mathrm{Nc} 2 \mathrm{ncnc} 3 \mathrm{cc} 4[\mathrm{nH}] \mathrm{nnc} 4 \mathrm{cc} 23) \mathrm{c} 1$ & 4.1 & * \\
\hline 630 & OCCn $1 \mathrm{ccc} 2 \mathrm{ncnc}(\mathrm{Nc} 3 \mathrm{ccc}(\mathrm{Oc} 4 \mathrm{cccc} 5 \operatorname{sncc} 45) \mathrm{c}(\mathrm{Cl}) \mathrm{c} 3) \mathrm{c} 21$ & 4.1 & $*$ \\
\hline 631 & 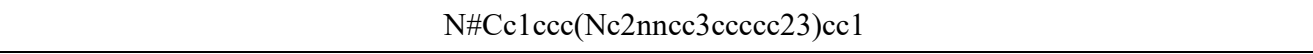 & 4.1 & $*$ \\
\hline 632 & $\mathrm{CC}(\mathrm{C}) \mathrm{N}(\mathrm{CC} \# \mathrm{CC}(=\mathrm{O}) \mathrm{Nc} 1 \mathrm{ccc} 2 \mathrm{ncnc}(\mathrm{Nc} 3 \operatorname{ccc}(\mathrm{F}) \mathrm{c}(\mathrm{Cl}) \mathrm{c} 3) \mathrm{c} 2 \mathrm{c} 1) \mathrm{C}(\mathrm{C}) \mathrm{C}$ & 4.2 & $*$ \\
\hline 633 & $\mathrm{CACc} 1 \mathrm{cccc}(\mathrm{Nc} 2 \mathrm{ncnc} 3 \mathrm{cc}(\mathrm{OCC}) \mathrm{c}(\mathrm{NC}(=\mathrm{O}) / \mathrm{C}=\mathrm{C} / \mathrm{CNC} 4 \mathrm{CC} 4) \mathrm{cc} 23) \mathrm{c} 1$ & 4.2 & $*$ \\
\hline 634 & $\mathrm{O}=\mathrm{C}(\mathrm{CCCCCCn} 1 \mathrm{cc}(-\mathrm{c} 2 \mathrm{ccc} 3 \mathrm{ncnc}(\mathrm{Nc} 4 \mathrm{ccc}(\mathrm{OCc} 5 \mathrm{cccc}(\mathrm{F}) \mathrm{c} 5) \mathrm{c}(\mathrm{Cl}) \mathrm{c} 4) \mathrm{c} 3 \mathrm{c} 2) \mathrm{nn} 1) \mathrm{NO}$ & 4.2 & * \\
\hline 635 & CCOc1cc2ncnc $(\mathrm{C} \# \mathrm{C}[\mathrm{C} @ @](\mathrm{C})(\mathrm{Cc} 3 \operatorname{ccccc} 3) \mathrm{N} 3 \mathrm{CCC}(\mathrm{C}(=\mathrm{O}) \mathrm{O}) \mathrm{CC} 3) \mathrm{c} 2 \mathrm{cc} 1 \mathrm{OCC}$ & 4.2 & $*$ \\
\hline 636 & $\mathrm{C}=\mathrm{CC}(=\mathrm{O}) \mathrm{N}(\mathrm{CCN}(\mathrm{C}) \mathrm{C}) \mathrm{c} 1 \mathrm{cc} 2 \mathrm{c}(\mathrm{Nc} 3 \operatorname{cccc}(\mathrm{Br}) \mathrm{c} 3) \mathrm{ncn} \mathrm{c} 2 \mathrm{cn} 1$ & 4.2 & $*$ \\
\hline 637 & $\operatorname{CCOC}(=\mathrm{O}) \mathrm{C} 1 \mathrm{CCN}([\mathrm{C} @ @](\mathrm{C})(\mathrm{C} \# \mathrm{Cc} 2 \mathrm{ncnc} 3 \mathrm{cc}(\mathrm{OCC}) \mathrm{c}(\mathrm{OCC}) \mathrm{cc} 23) \mathrm{Cc} 2 \mathrm{cccc} 2) \mathrm{CC} 1$ & 4.2 & $*$ \\
\hline 638 & OC[C@@H](Nc1ncnc2[nH]c(-c3ecc(Br)cc3)cc12)c1cccc1 & 4.2 & $*$ \\
\hline 639 & $\mathrm{CCOC}(=\mathrm{O}) \mathrm{c} 1 \mathrm{c}(\mathrm{NC} 2=\mathrm{C}(\mathrm{Cl}) \mathrm{C}(\mathrm{c} 3 \operatorname{ccc}(\mathrm{Cl}) \mathrm{cc} 3) \mathrm{C}(\mathrm{C \# N})=\mathrm{C}(\mathrm{N}) \mathrm{O} 2) \operatorname{sc} 2 \mathrm{c} 1-\mathrm{c} 1 \mathrm{sc}(=\mathrm{S}) \mathrm{n}(-\mathrm{c} 3 \operatorname{ccccc} 3) \mathrm{c} 1 \mathrm{CC} 2(\mathrm{C}) \mathrm{C}$ & 4.28 & $*$ \\
\hline 640 & $\mathrm{O}=\mathrm{C}(\mathrm{Nc} 1 \mathrm{cc} 2 \mathrm{c}(\mathrm{Nc} 3 \mathrm{ccc}(\mathrm{F}) \mathrm{c}(\mathrm{Cl}) \mathrm{c} 3) \mathrm{ncn} 2 \mathrm{cc} 1 \mathrm{OCCCN} 1 \mathrm{CCOCC} 1) \mathrm{c} 1 \mathrm{ccc} n \mathrm{c} 1 \mathrm{~F}$ & 4.3 & 8.37 \\
\hline 641 & $\mathrm{COc} 1 \mathrm{ccc} 2 \mathrm{ncnc}(\mathrm{Nc} 3 \operatorname{ccc}(\mathrm{Br}) \mathrm{c} 3) \mathrm{c} 2 \mathrm{n} 1$ & 4.3 & $*$ \\
\hline 642 & $\mathrm{CNc} 1 \mathrm{ncc} 2 \mathrm{ncnc}(\mathrm{Nc} 3 \operatorname{cccc}(\mathrm{C}) \mathrm{c} 3) \mathrm{c} 2 \mathrm{n} 1$ & 4.3 & * \\
\hline 643 & $\mathrm{NP}(=\mathrm{O})(\mathrm{OCCOc} 1 \mathrm{ccc} 2 \mathrm{ncnc}(\mathrm{Nc} 3 \mathrm{cccc}(\mathrm{Br}) \mathrm{c} 3) \mathrm{c} 2 \mathrm{c} 1) \mathrm{N}(\mathrm{CCCl}) \mathrm{CCCl}$ & 4.3 & $*$ \\
\hline 644 & $\mathrm{C}=\mathrm{CC}(=\mathrm{O}) \mathrm{N} 1 \mathrm{CCc} 2 \mathrm{c}(\operatorname{sc} 3 \mathrm{ncnc}(\mathrm{Nc} 4 \mathrm{ccc}(\mathrm{Br}) \mathrm{c}(\mathrm{C}) \mathrm{c} 4) \mathrm{c} 23) \mathrm{C} 1$ & 4.4 & $*$ \\
\hline 645 & $\mathrm{CCOc} 1 \mathrm{cc} 2 \mathrm{ncnc}(\mathrm{Nc} 3 \mathrm{cccc}(\mathrm{OC}) \mathrm{c} 3) \mathrm{c} 2 \mathrm{c} 2 \mathrm{c} 1 \mathrm{OCCO} 2$ & 4.4 & $*$ \\
\hline 646 & $\mathrm{CN}(\mathrm{CCCl}) \mathrm{CCNN}=\mathrm{Nc} 1 \mathrm{ccc} 2 \mathrm{ncnc}(\mathrm{Nc} 3 \mathrm{cccc}(\mathrm{Cl}) \mathrm{c} 3) \mathrm{c} 2 \mathrm{c} 1$ & 4.4 & $*$ \\
\hline 647 & $\operatorname{CCOC}(=\mathrm{O}) \mathrm{c} 1 \mathrm{ccc}(\mathrm{Nc} 2 \mathrm{nncc} 3 \operatorname{ccccc} 23) \mathrm{cc} 1$ & 4.4 & $*$ \\
\hline
\end{tabular}




\begin{tabular}{|c|c|c|c|}
\hline 648 & $\mathrm{CN} 1 \mathrm{CCN}(\mathrm{c} 2 \mathrm{ccc}(\mathrm{Nc} 3 \mathrm{cc} 4 \mathrm{c}(\mathrm{N} 5 \mathrm{CCCC} 5) \mathrm{nc}(\mathrm{Nc} 5 \mathrm{cccc} 5) \mathrm{nc} 4 \mathrm{cn} 3) \mathrm{nc} 2) \mathrm{CC} 1$ & 4.4 & * \\
\hline 649 & $\mathrm{CN}(\mathrm{CCCl}) \mathrm{CCN} / \mathrm{N}=\mathrm{N} / \mathrm{c} 1 \mathrm{ccc} 2 \mathrm{ncnc}(\mathrm{Nc} 3 \mathrm{cccc}(\mathrm{Cl}) \mathrm{c} 3) \mathrm{c} 2 \mathrm{c} 1 .[\mathrm{H}+]$ & 4.4 & $*$ \\
\hline 650 & $\mathrm{C}=\mathrm{CC}(=\mathrm{O}) \mathrm{Nc} 1 \mathrm{cccc}(\mathrm{N} 2 \mathrm{C}(=\mathrm{O}) \mathrm{N}(\mathrm{C}) \mathrm{Cc} 3 \mathrm{cnc}(\mathrm{Nc} 4 \mathrm{ccc}(\mathrm{N} 5 \mathrm{CCN}(\mathrm{C}) \mathrm{CC} 5) \mathrm{cc} 4 \mathrm{OCC}) \mathrm{nc} 32) \mathrm{c} 1$ & 4.41 & 8.36 \\
\hline 651 & $\mathrm{C}=\mathrm{C}=\mathrm{CCCCCCOc} 1 \mathrm{cc} 2 \mathrm{c}(\mathrm{Nc} 3 \mathrm{ccc}(\mathrm{F}) \mathrm{c}(\mathrm{Cl}) \mathrm{c} 3) \mathrm{ncnc} 2 \mathrm{cc} 1 \mathrm{O}$ & 4.45 & $*$ \\
\hline 652 & $\mathrm{CCOc} 1 \mathrm{cc} 2 \mathrm{ncnc}(\mathrm{Nc} 3 \operatorname{ccc}(\mathrm{Oc} 4 \operatorname{ccc}(\mathrm{C}) \mathrm{nc} 4) \mathrm{c}(\mathrm{Cl}) \mathrm{c} 3) \mathrm{c} 2 \mathrm{cc} 1 \mathrm{NC}(=\mathrm{O}) / \mathrm{C}(\mathrm{F})=\mathrm{C} / \mathrm{CN}(\mathrm{C}) \mathrm{C}$ & 4.5 & 8.35 \\
\hline 653 & $\mathrm{Cc} 1 \mathrm{cc}(\mathrm{C}(=\mathrm{O}) \mathrm{N} 2 \mathrm{CCOCC} 2)[\mathrm{nH}] \mathrm{c} 1 / \mathrm{C}=\mathrm{C} 1 \backslash \mathrm{C}(=\mathrm{O}) \mathrm{Nc} 2 \mathrm{ncnc}(\mathrm{Nc} 3 \mathrm{ccc} 4 \mathrm{c}(\mathrm{ccn} 4 \mathrm{Cc} 4 \mathrm{ccccc} 4) \mathrm{c} 3) \mathrm{c} 21$ & 4.5 & * \\
\hline 654 & $\mathrm{COCCOc} 1 \mathrm{cc} 2 \mathrm{ncnc}(\mathrm{Nc} 3 \mathrm{ccc}(\mathrm{NC}(=\mathrm{O}) \mathrm{C} 45 \mathrm{CC} 6 \mathrm{CC}(\mathrm{CC}(\mathrm{C} 6) \mathrm{C} 4) \mathrm{C} 5) \mathrm{cc} 3 \mathrm{C}) \mathrm{c} 2 \mathrm{cc} 1 \mathrm{OCCOC}$ & 4.52 & 8.34 \\
\hline 655 & COc1cc2c(Nc3ccc(OCc4cccs(F)c4)c(Cl)c3)ncnc2cc1OCCN1C[C@H](O)[C@@H](O)[C@H](O)[C@H]1CO & 4.53 & $*$ \\
\hline 656 & $\mathrm{COc1cc} 2 \mathrm{c}(\mathrm{Nc} 3 \mathrm{ccc}(\mathrm{OCc} 4 \mathrm{cccc}(\mathrm{F}) \mathrm{c} 4) \mathrm{c}(\mathrm{Cl}) \mathrm{c} 3) \mathrm{ncnc} 2 \mathrm{cc} 1 \mathrm{OCCCN} 1 \mathrm{C}[\mathrm{C} @ \mathrm{H}](\mathrm{O})[\mathrm{C} @ @ \mathrm{H}](\mathrm{O})[\mathrm{C} @ \mathrm{H}](\mathrm{O})[\mathrm{C} @ \mathrm{H}] 1 \mathrm{CO}$ & 4.53 & * \\
\hline 657 & $\mathrm{O}=\mathrm{C} 1 \mathrm{~N}[\mathrm{C} @ \mathrm{H}](\mathrm{C}(=\mathrm{O}) \mathrm{Nc} 2 \mathrm{cc} 3 \mathrm{c}(\mathrm{Nc} 4 \mathrm{ccc}(\mathrm{F}) \mathrm{c}(\mathrm{Cl}) \mathrm{c} 4) \mathrm{ncnc} 3 \mathrm{cc} 2 \mathrm{OCCCN} 2 \mathrm{CCOCC} 2) \mathrm{CO} 1$ & 4.54 & 8.34 \\
\hline 658 & C[C@@H](Nc1ncnc2oc(-c3cccc(O)c3)cc12)c1 1cccc1 & 4.6 & 8.34 \\
\hline 659 & $\mathrm{C} \# \mathrm{Cc} 1 \mathrm{cccc}(\mathrm{Nc} 2 \mathrm{ncnc} 3 \mathrm{cc}(\mathrm{OC}) \mathrm{c}(\mathrm{OCCCCCC}(=\mathrm{O}) \mathrm{NO}) \mathrm{cc} 23) \mathrm{c} 1$ & 4.6 & 8.34 \\
\hline 660 & $\mathrm{CN}(\mathrm{C}) \mathrm{C} / \mathrm{C}=\mathrm{C} / \mathrm{C}(=\mathrm{O}) \mathrm{NCCn} 1 \mathrm{ccc} 2 \mathrm{ncnc}(\mathrm{Nc} 3 \operatorname{ccc}(\mathrm{Oc} 4 \operatorname{cccc}(\mathrm{C}(\mathrm{F})(\mathrm{F}) \mathrm{F}) \mathrm{c} 4) \mathrm{c}(\mathrm{Cl}) \mathrm{c} 3) \mathrm{c} 21$ & 4.6 & * \\
\hline 661 & $\mathrm{CCN}(\mathrm{CC}) \mathrm{CC}(\mathrm{O}) \mathrm{CNc} 1 \mathrm{cc} 2 \mathrm{c}(\mathrm{Nc} 3 \mathrm{cccc}(\mathrm{Br}) \mathrm{c} 3) \mathrm{ncnc} 2 \mathrm{cn} 1$ & 4.6 & * \\
\hline 662 & $\mathrm{C}=\mathrm{C}[\mathrm{S}+]([\mathrm{O}-]) \mathrm{c} 1 \mathrm{cc} 2 \mathrm{c}(\mathrm{Nc} 3 \mathrm{cccc}(\mathrm{Br}) \mathrm{c} 3) \mathrm{ncnc} 2 \mathrm{cn} 1$ & 4.6 & * \\
\hline 663 & $\mathrm{Clc} 1 \mathrm{ccc}(/ \mathrm{C}=\mathrm{C} / \mathrm{C}(=\mathrm{N} / \mathrm{Nc} 2 \mathrm{nncc} 3 \operatorname{ccccc} 23) \mathrm{c} 2 \mathrm{ccccc} 2) \mathrm{cc} 1$ & 4.6 & * \\
\hline 664 & $\mathrm{CN}(\mathrm{C}) \mathrm{C} 1 \mathrm{CCN}(\mathrm{c} 2 \mathrm{ccc}(\mathrm{Nc} 3 \mathrm{cc} 4 \mathrm{c}(\mathrm{N} 5 \mathrm{CCOCC} 5) \mathrm{nc}(\mathrm{Nc} 5 \mathrm{ccccc} 5) \mathrm{nc} 4 \mathrm{cn} 3) \mathrm{nc} 2) \mathrm{CC} 1$ & 4.6 & $*$ \\
\hline 665 & $\mathrm{C}=\mathrm{CC}(=\mathrm{O}) \mathrm{Nc} 1 \mathrm{ccc}(\mathrm{N} 2 \mathrm{C}(=\mathrm{O}) \mathrm{C}(\mathrm{Cc} 3 \operatorname{cccc} 3) \mathrm{N}(\mathrm{C}) \mathrm{C}(=\mathrm{O}) \mathrm{c} 3 \mathrm{cnc}(\mathrm{Nc} 4 \mathrm{ccc}(\mathrm{N} 5 \mathrm{CCN}(\mathrm{C}) \mathrm{CC} 5) \mathrm{cc} 4 \mathrm{OC}) \mathrm{nc} 32) \mathrm{c} 1$ & 4.68 & 8.33 \\
\hline 666 & Oc1 1cce2c(Nc3ccce(Br)c3)ncnc2c1 & 4.7 & * \\
\hline 667 & $\mathrm{Cc} 1 \mathrm{cc}(\mathrm{CCC}(=\mathrm{O}) \mathrm{O})[\mathrm{nH}] \mathrm{c} 1 / \mathrm{C}=\mathrm{C} 1 \backslash \mathrm{C}(=\mathrm{O}) \mathrm{Nc} 2 \mathrm{ncnc}(\mathrm{Nc} 3 \mathrm{ccc}(\mathrm{F}) \mathrm{c}(\mathrm{Cl}) \mathrm{c} 3) \mathrm{c} 21$ & 4.7 & $*$ \\
\hline 668 & $\mathrm{COc} 1 \mathrm{ccc}(-\mathrm{c} 2 \mathrm{cc} 3 \mathrm{c}(\mathrm{N}[\mathrm{C} @ \mathrm{H}](\mathrm{C}) \mathrm{c} 4 \mathrm{ccccc} 4) \mathrm{ncnc} 3[\mathrm{nH}] 2) \mathrm{cc} 1$ & 4.7 & $*$ \\
\hline 669 & $\mathrm{C}=\mathrm{CC}(=\mathrm{O}) \mathrm{N} 1 \mathrm{CCC}[\mathrm{C} @ @ \mathrm{H}](\mathrm{Nc} 2 \mathrm{nc}(\mathrm{Nc} 3 \mathrm{cccc} 3) \mathrm{nc} 3 \mathrm{cnc}(\mathrm{Nc} 4 \mathrm{ccc}(\mathrm{N} 5 \mathrm{CCN}(\mathrm{C}) \mathrm{CC} 5) \mathrm{cn} 4) \mathrm{cc} 23) \mathrm{C} 1$ & 4.7 & $*$ \\
\hline 670 & $\mathrm{COc} 1 \mathrm{cc} 2 \mathrm{ncnc}(\mathrm{Nc} 3 \mathrm{ccc}(\mathrm{C}(=\mathrm{O}) \mathrm{NC} 45 \mathrm{CC} 6 \mathrm{CC}(\mathrm{CC}(\mathrm{C} 6) \mathrm{C} 4) \mathrm{C} 5) \mathrm{c}(\mathrm{C \# N}) \mathrm{c} 3) \mathrm{c} 2 \mathrm{cc} 1 \mathrm{OCCCN} 1 \mathrm{CCOCC} 1$ & 4.71 & 8.33 \\
\hline 671 & $\mathrm{O}=\mathrm{C}(/ \mathrm{C}=\mathrm{C} / \mathrm{c} 1 \mathrm{ccc}(-\mathrm{c} 2 \mathrm{ccc} 3 \mathrm{ncnc}(\mathrm{Nc} 4 \mathrm{ccc}(\mathrm{OCc} 5 \operatorname{cccc}(\mathrm{F}) \mathrm{c} 5) \mathrm{c}(\mathrm{Cl}) \mathrm{c} 4) \mathrm{c} 3 \mathrm{c} 2) \mathrm{s} 1) \mathrm{NO}$ & 4.8 & $*$ \\
\hline 672 & $\operatorname{Brc} 1 \mathrm{ccc}(\mathrm{Nc} 2 \mathrm{ncnc} 3 \mathrm{cc} 4[\mathrm{nH}] \mathrm{cc}(\mathrm{CN} 5 \mathrm{CCOCC} 5) \mathrm{c} 4 \mathrm{cc} 23) \mathrm{c} 1$ & 4.8 & * \\
\hline 673 & $\mathrm{OCC}(\mathrm{O}) \mathrm{C}(\mathrm{O}) \mathrm{C}(\mathrm{O}) \mathrm{C}(\mathrm{O}) \mathrm{CNc} 1 \mathrm{cc} 2 \mathrm{ncnc}(\mathrm{Nc} 3 \mathrm{cccc}(\mathrm{Br}) \mathrm{c} 3) \mathrm{c} 2 \mathrm{cn} 1$ & 4.8 & $*$ \\
\hline 674 & NCCSc1nc(-c2 $\operatorname{ccc}(\mathrm{F}) \mathrm{cc} 2) \mathrm{c}(-\mathrm{c} 2 \mathrm{ccnc}(\mathrm{Nc} 3 \mathrm{ccccc} 3) \mathrm{c} 2)[\mathrm{nH}] 1$ & 4.8 & * \\
\hline 675 & $\mathrm{CC} 1(\mathrm{C}) \mathrm{Cc} 2 \mathrm{c}(\mathrm{nn}(-\mathrm{c} 3 \mathrm{ccc}(\mathrm{Cl}) \mathrm{cc} 3) \mathrm{c}(=\mathrm{N}) \mathrm{c} 2 \mathrm{C} \# \mathrm{~N})-\mathrm{c} 2 \mathrm{c} 1 \mathrm{sc}(\mathrm{N}) \mathrm{c} 2 \mathrm{C} \# \mathrm{~N}$ & 4.8 & $*$ \\
\hline 676 & C\#Cc1cccc(Nc2ncnc3cc(OCCN4C[C@H](O)[C@@H](O)[C@H](O)[C@H]4CO)c(OC)cc23)c1 & 4.87 & $*$ \\
\hline 677 & C\#Cc1cccc(Nc2ncnc3cc(OCCCN4C[C@H](O)[C@@H](O)[C@H](O)[C@H]4CO)c(OC)cc23)c1 & 4.87 & * \\
\hline 678 & $\mathrm{COc} 1 \mathrm{cc} 2 \mathrm{ncnc}(\mathrm{Nc} 3 \mathrm{ccc}(\mathrm{F}) \mathrm{c}(\mathrm{Cl}) \mathrm{c} 3) \mathrm{c} 2 \mathrm{cc} 1 \mathrm{OCCn} 1 \mathrm{c}([\mathrm{N}+](=\mathrm{O})[\mathrm{O}-]) \mathrm{cnc} 1 \mathrm{C}$ & 4.9 & 8.31 \\
\hline 679 & $\mathrm{CN} 1 \mathrm{CCN}(\mathrm{CCCNc} 2 \mathrm{cc} 3 \mathrm{ncnc}(\mathrm{Nc} 4 \mathrm{cccc}(\mathrm{Br}) \mathrm{c} 4) \mathrm{c} 3 \mathrm{cn} 2) \mathrm{CC} 1$ & 4.9 & $*$ \\
\hline 680 & $\mathrm{COc1ccc}(-\mathrm{c} 2 \mathrm{cc} 3 \mathrm{c}(\mathrm{N}[\mathrm{C} @ \mathrm{H}](\mathrm{C}) \mathrm{c} 4 \mathrm{cccc}(\mathrm{F}) \mathrm{c} 4) \mathrm{ncnc} 3[\mathrm{nH}] 2) \mathrm{cc} 1$ & 4.9 & $*$ \\
\hline 681 & $\mathrm{C}=\mathrm{CC}(=\mathrm{O}) \mathrm{Nc} 1 \operatorname{cccc}(\mathrm{N} 2 \mathrm{C}(=\mathrm{O}) \mathrm{N}(\mathrm{C}) \mathrm{Cc} 3 \operatorname{cnc}(\mathrm{Nc} 4 \operatorname{ccc}(\mathrm{N}(\mathrm{C}) \mathrm{C}) \operatorname{cc} 4 \mathrm{OC}) \mathrm{nc} 32) \mathrm{c} 1$ & 4.99 & 8.30 \\
\hline 682 & $\mathrm{O}=\mathrm{C}(\mathrm{Nc} 1 \mathrm{cc} 2 \mathrm{c}(\mathrm{Nc} 3 \operatorname{ccc}(\mathrm{F}) \mathrm{c}(\mathrm{Cl}) \mathrm{c} 3) n \mathrm{ncnc} 2 \mathrm{cc} 1 \mathrm{OCCCN} 1 \mathrm{CCOCC} 1) \mathrm{c} 1 \mathrm{cc}([\mathrm{N}+](=\mathrm{O})[\mathrm{O}-]) \operatorname{ccc} 1 \mathrm{~F}$ & 5 & 7.46 \\
\hline 683 & $\mathrm{COc} 1 \mathrm{cc} 2 \mathrm{ncnc}(\mathrm{Nc} 3 \operatorname{ccc}(\mathrm{Br}) \mathrm{c} 3) \mathrm{c} 2 \mathrm{cc} 1 \mathrm{NC}(=\mathrm{O}) / \mathrm{C}(\mathrm{F})=\mathrm{ClCN}(\mathrm{C}) \mathrm{C}$ & 5 & 8.30 \\
\hline 684 & $\mathrm{C} \# \mathrm{Cc} 1 \mathrm{cccc}(\mathrm{Nc} 2 \mathrm{ncnc} 3 \mathrm{cc}(\mathrm{OCCOC}(=\mathrm{O}) \mathrm{c} 4 \mathrm{ccccc} 4 \mathrm{OC}(\mathrm{C})=\mathrm{O}) \mathrm{c}(\mathrm{OCCOC}) \mathrm{cc} 23) \mathrm{c} 1$ & 5 & 8.30 \\
\hline 685 & $\mathrm{C}[\mathrm{C} @ @ \mathrm{H}](\mathrm{Nc} 1 \mathrm{ncnc} 2 \mathrm{sc}(-\mathrm{c} 3 \operatorname{cccc}(\mathrm{C}(\mathrm{N})=\mathrm{O}) \mathrm{c} 3) \mathrm{cc} 12) \mathrm{c} 1 \mathrm{ccccc} 1$ & 5 & 8.30 \\
\hline 686 & $\mathrm{COc} 1 \mathrm{cc}(\mathrm{C}=\mathrm{O}) \mathrm{ccc} 1-\mathrm{c} 1 \mathrm{cc} 2 \mathrm{c}(\mathrm{Nc} 3 \mathrm{ccc}(\mathrm{F}) \mathrm{c}(\mathrm{Cl}) \mathrm{c} 3) \mathrm{ncnc} 2 \mathrm{~s} 1$ & 5 & 8.30 \\
\hline 687 & $\mathrm{COc} 1 \mathrm{cc}(\mathrm{CO}) \mathrm{ccc} 1-\mathrm{c} 1 \mathrm{cc} 2 \mathrm{c}(\mathrm{NCc} 3 \mathrm{cccc} 3) \mathrm{ncnc} 2 \mathrm{~s} 1$ & 5 & 8.30 \\
\hline 688 & $\mathrm{COc1ccc}(-\mathrm{c} 2 \mathrm{cc} 3 \mathrm{c}(\mathrm{N}[\mathrm{C} @ \mathrm{H}](\mathrm{C}) \mathrm{c} 4 \mathrm{ccccc} 4) \mathrm{ncnc} 3 \mathrm{~s} 2) \mathrm{c}(\mathrm{OC}) \mathrm{c} 1$ & 5 & 8.30 \\
\hline 689 & $\mathrm{COc1ccc}(\mathrm{CO}) \mathrm{cc} 1-\mathrm{c} 1 \mathrm{cc} 2 \mathrm{c}(\mathrm{N}[\mathrm{C} @ \mathrm{H}](\mathrm{C}) \mathrm{c} 3 \mathrm{cccc} 3) \mathrm{ncnc} 2 \mathrm{~s} 1$ & 5 & 8.30 \\
\hline 690 & 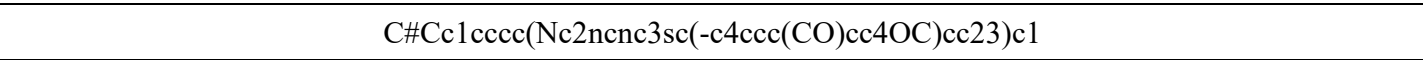 & 5 & 8.30 \\
\hline
\end{tabular}




\begin{tabular}{|c|c|c|c|}
\hline 691 & $\mathrm{C} \# \mathrm{Cc} 1 \mathrm{cccc}(\mathrm{Nc} 2 \mathrm{ncnc} 3 \mathrm{cc} 4 \mathrm{c}(\mathrm{cc} 23) \mathrm{N}(\mathrm{C}(=\mathrm{O}) / \mathrm{C}=\mathrm{C} / \mathrm{CN} 2 \mathrm{CCC}(\mathrm{C}) \mathrm{CC} 2) \mathrm{CCO} 4) \mathrm{c} 1$ & 5 & $*$ \\
\hline 692 & $\mathrm{CACc} 1 \operatorname{ccc}(\mathrm{Nc} 2 \mathrm{ncnc} 3 \mathrm{cc} 4 \mathrm{c}(\operatorname{cc} 23) \mathrm{N}(\mathrm{C}(=\mathrm{O}) / \mathrm{C}=\mathrm{C} / \mathrm{CN} 2 \mathrm{CCCCC} 2 \mathrm{C}) \mathrm{CCO} 4) \mathrm{c} 1$ & 5 & $*$ \\
\hline 693 & $\mathrm{C} \# \mathrm{Cc} 1 \mathrm{cccc}(\mathrm{Nc} 2 \mathrm{ncnc} 3 \mathrm{cc} 4 \mathrm{c}(\operatorname{cc} 23) \mathrm{N}(\mathrm{C}(=\mathrm{O}) / \mathrm{C}=\mathrm{C} / \mathrm{CN}(\mathrm{CC}) \mathrm{CC}) \mathrm{CCO} 4) \mathrm{c} 1$ & 5 & $*$ \\
\hline 694 & $\mathrm{COc} 1 \mathrm{ccccc} 1-\mathrm{c} 1 \mathrm{cc} 2 \mathrm{c}(\mathrm{Nc} 3 \mathrm{ccc}(\mathrm{F}) \mathrm{c}(\mathrm{Cl}) \mathrm{c} 3) \mathrm{ncnc} 2 \mathrm{~s} 1$ & 5 & $*$ \\
\hline 695 & $\mathrm{O}=\mathrm{C}(\mathrm{Nc} 1 \mathrm{ccc}(\mathrm{CN} 2 \mathrm{CCCCC} 2) \mathrm{cc} 1) \mathrm{Nc} 1 \mathrm{ccc} 2 \mathrm{ncnc}(\mathrm{Nc} 3 \operatorname{ccc}(\mathrm{C}(\mathrm{F})(\mathrm{F}) \mathrm{F}) \mathrm{c} 3) \mathrm{c} 2 \mathrm{c} 1$ & 5 & $*$ \\
\hline 696 & $\mathrm{CNCC}(\mathrm{O}) \mathrm{COc} 1 \mathrm{cc} 2 \mathrm{c}(\mathrm{Nc} 3 \mathrm{ccc}(\mathrm{F}) \mathrm{c}(\mathrm{Cl}) \mathrm{c} 3) \mathrm{ncnc} 2 \mathrm{cc} 1 \mathrm{OC}$ & 5 & $*$ \\
\hline 697 & $\mathrm{COc} 1 \mathrm{cc} 2 \mathrm{ncnc}(\mathrm{Nc} 3 \mathrm{ccc}(\mathrm{F}) \mathrm{c}(\mathrm{Cl}) \mathrm{c} 3) \mathrm{c} 2 \mathrm{cc} 1 \mathrm{OCC}(\mathrm{O}) \mathrm{CN}(\mathrm{CCO}) \mathrm{CCO}$ & 5 & $*$ \\
\hline 698 & $\mathrm{COc} 1 \mathrm{cc} 2 \mathrm{ncnc}(\mathrm{Nc} 3 \mathrm{cccc}(\mathrm{C}) \mathrm{c} 3) \mathrm{c} 2 \mathrm{cc} 1 \mathrm{OC}$ & 5 & * \\
\hline 699 & $\mathrm{C}=\mathrm{CC}(=\mathrm{O}) \mathrm{Nc} 1 \mathrm{cc} 2 \mathrm{c}(\mathrm{Nc} 3 \mathrm{ccc}(\mathrm{F}) \mathrm{c}(\mathrm{Cl}) \mathrm{c} 3) \mathrm{ncnc} 2 \mathrm{cc} 1 \mathrm{OCCCN} 1 \mathrm{CCOCC} 1$ & 5 & * \\
\hline 700 & $\mathrm{CN} 1 \mathrm{CCN}(\mathrm{Cc} 2 \mathrm{ccc}(-\mathrm{c} 3 \mathrm{cc} 4 \mathrm{ncnc}(\mathrm{Nc} 5 \mathrm{ccc}(\mathrm{OCc} 6 \mathrm{cccc}(\mathrm{F}) \mathrm{c} 6) \mathrm{c}(\mathrm{Cl}) \mathrm{c} 5) \mathrm{c} 4 \mathrm{~s} 3) \mathrm{o} 2) \mathrm{CC} 1$ & 5 & $*$ \\
\hline 701 & $\mathrm{CCOc} 1 \mathrm{cc} 2 \mathrm{ncnc}(/ \mathrm{C}=\mathrm{C} / \mathrm{CCc} 3 \operatorname{ccccc} 3) \mathrm{c} 2 \mathrm{cc} 1 \mathrm{OCC}$ & 5 & * \\
\hline 702 & $\mathrm{Brc} 1 \mathrm{cccc}(\mathrm{Nc} 2 \mathrm{ncnc} 3 \mathrm{cc} 4 \mathrm{c}(\mathrm{cc} 23) \mathrm{OCCOCCOCCO}) \mathrm{c} 1$ & 5 & $*$ \\
\hline 703 & Brc1 cecc $(\mathrm{Nc} 2 \mathrm{ncnc} 3 \mathrm{cc} 4 \mathrm{c}(\mathrm{cc} 23) \mathrm{OCCOCOCOCCO}) \mathrm{c} 1$ & 5 & $*$ \\
\hline 704 & $\mathrm{Nc} 1 \mathrm{ccc}(\mathrm{Nc} 2[\mathrm{nH}] \mathrm{nc} 3 \mathrm{ncnc}(\mathrm{Nc} 4 \mathrm{cccc}(\mathrm{Cl}) \mathrm{c} 4) \mathrm{c} 23) \mathrm{cc} 1$ & 5 & $*$ \\
\hline 705 & $\mathrm{Nc} 1 \mathrm{cccc}(-\mathrm{c} 2[\mathrm{nH}] \mathrm{nc} 3 \mathrm{ncnc}(\mathrm{Nc} 4 \mathrm{cccc}(\mathrm{Cl}) \mathrm{c} 4) \mathrm{c} 23) \mathrm{c} 1$ & 5 & $*$ \\
\hline 706 & $\mathrm{CN} 1 \mathrm{CCC}(\mathrm{Oc} 2 \mathrm{cccc} 3 \mathrm{nenc}(\mathrm{Nc} 4 \mathrm{ccc}(\mathrm{OCc} 5 \operatorname{cccc}(\mathrm{F}) \mathrm{c} 5) \mathrm{c}(\mathrm{Cl}) \mathrm{c} 4) \mathrm{c} 23) \mathrm{CC} 1$ & 5 & * \\
\hline 707 & $\mathrm{COc} 1 \mathrm{cc}(\mathrm{ON} 2 \mathrm{CCC}(\mathrm{C}) \mathrm{CC} 2) \mathrm{c} 2 \mathrm{c}(\mathrm{Nc} 3 \mathrm{ccc}(\mathrm{OCc} 4 \mathrm{ccc} n 4) \mathrm{c}(\mathrm{Cl}) \mathrm{c} 3) \mathrm{ncnc} 2 \mathrm{c} 1$ & 5 & $*$ \\
\hline 708 & $\mathrm{CCO} / \mathrm{N}=\mathrm{C} / \mathrm{c} 1 \mathrm{c}(\mathrm{N}) \mathrm{ncnc} 1 \mathrm{Nc} 1 \mathrm{ccc} 2 \mathrm{c}(\mathrm{cnn} 2 \mathrm{Cc} 2 \mathrm{cccc}(\mathrm{F}) \mathrm{c} 2) \mathrm{c} 1$ & 5 & $*$ \\
\hline 709 & $\mathrm{Cc} 1 \mathrm{c}[\mathrm{nH}] \mathrm{c} 2 \mathrm{ccc}(\mathrm{Nc} 3 \mathrm{ncnc} 4 \mathrm{cc}(-\mathrm{c} 5 \mathrm{ccccc} 5) \mathrm{sc} 34) \mathrm{cc} 12$ & 5 & $*$ \\
\hline 710 & $\mathrm{CC}(=\mathrm{O}) \mathrm{NCCNCc} 1 \mathrm{ccc}(-\mathrm{c} 2 \mathrm{cc} 3 \mathrm{ncnc}(\mathrm{Nc} 4 \mathrm{ccc} 5[\mathrm{nH}] \operatorname{ccc} 5 \mathrm{c} 4) \mathrm{c} 3 \mathrm{~s} 2) \mathrm{cc} 1$ & 5 & $*$ \\
\hline 711 & $\mathrm{CN}(\mathrm{C}) \mathrm{CCc} 1 \mathrm{ccc}(-\mathrm{c} 2 \mathrm{cc} 3 \mathrm{ncnc}(\mathrm{Nc} 4 \mathrm{ccc} 5[\mathrm{nH}] \mathrm{ccc} 5 \mathrm{c} 4) \mathrm{c} 3 \mathrm{~s} 2) \mathrm{cc} 1$ & 5 & $*$ \\
\hline 712 & $\mathrm{Cc} 1 \mathrm{cccc}(\mathrm{Nc} 2 \mathrm{ncnn} 3 \operatorname{ccc}(\mathrm{CN} 4 \mathrm{CCC}(\mathrm{N}) \mathrm{CC} 4) \mathrm{c} 23) \mathrm{c} 1$ & 5 & $*$ \\
\hline 713 & $\mathrm{Nc} 1 \mathrm{cccc}(-\mathrm{c} 2 \mathrm{cc} 3 \mathrm{c}(\mathrm{Nc} 4 \mathrm{cccc}(\mathrm{Cl}) \mathrm{c} 4) \mathrm{ncnc} 3 \mathrm{o} 2) \mathrm{c} 1$ & 5 & $*$ \\
\hline 714 & $\mathrm{Nc} 1 \mathrm{cccc}(-\mathrm{c} 2 \mathrm{cc} 3 \mathrm{c}(\mathrm{Nc} 4 \mathrm{cccc}([\mathrm{N}+](=\mathrm{O})[\mathrm{O}-]) \mathrm{c} 4) \mathrm{ncnc} 3 \mathrm{o} 2) \mathrm{c} 1$ & 5 & $*$ \\
\hline 715 & $\mathrm{COc} 1 \mathrm{ccc}(-\mathrm{c} 2 \mathrm{cc} 3 \mathrm{c}(\mathrm{NCc} 4 \mathrm{ccc}(\mathrm{F}) \mathrm{cc} 4) \mathrm{ncnc} 3[\mathrm{nH}] 2) \mathrm{cc} 1$ & 5 & $*$ \\
\hline 716 & $\mathrm{CC} 1 \mathrm{CCN}(\mathrm{CC}=\mathrm{CC}(=\mathrm{O}) \mathrm{N} 2 \mathrm{CCOc} 3 \mathrm{cc} 4 \mathrm{ncnc}(\mathrm{Nc} 5 \mathrm{ccc}(\mathrm{F}) \mathrm{c}(\mathrm{Cl}) \mathrm{c} 5) \mathrm{c} 4 \mathrm{cc} 32) \mathrm{CC} 1$ & 5 & $*$ \\
\hline 717 & $\mathrm{C}=\mathrm{CC}(=\mathrm{O}) \mathrm{Nc} 1 \mathrm{cc}(\mathrm{Nc} 2 \mathrm{n}[\mathrm{nH}] \mathrm{c} 3 \mathrm{cc}(-\mathrm{c} 4 \mathrm{cccc}(\mathrm{F}) \mathrm{c} 4) \operatorname{ccc} 23) \mathrm{c}(\mathrm{OC}) \mathrm{cc} 1 \mathrm{~N}(\mathrm{C}) \mathrm{CCN}(\mathrm{C}) \mathrm{C}$ & 5 & $*$ \\
\hline 718 & $\mathrm{CN}(\mathrm{C}) \mathrm{C} / \mathrm{C}=\mathrm{C} / \mathrm{C}(=\mathrm{O}) \mathrm{Nc} 1 \mathrm{cc} 2 \mathrm{c}(\mathrm{Nc} 3 \mathrm{ccc}(\mathrm{F}) \mathrm{c}(\mathrm{Cl}) \mathrm{c} 3) \mathrm{ncnc} 2 \mathrm{cc} 1 \mathrm{O}[\mathrm{C} @ @ \mathrm{H}] 1 \mathrm{CCOC} 1$ & 5 & $*$ \\
\hline 719 & $\mathrm{CN}(\mathrm{C}) \mathrm{CC}=\mathrm{CC}(=\mathrm{O}) \mathrm{Nc} 1 \mathrm{cc} 2 \mathrm{c}(\mathrm{Nc} 3 \mathrm{ccc}(\mathrm{F}) \mathrm{c}(\mathrm{Cl}) \mathrm{c} 3) \mathrm{ncnc} 2 \mathrm{cc} 1 \mathrm{O}[\mathrm{C} @ @ \mathrm{H}] 1 \mathrm{CCOC} 1$ & 5 & $*$ \\
\hline 720 & $\mathrm{CN}(\mathrm{C}) \mathrm{C} / \mathrm{C}=\mathrm{C} / \mathrm{C}(=\mathrm{O}) \mathrm{Nc} 1 \mathrm{cc} 2 \mathrm{c}(\mathrm{N} 3 \mathrm{CCc} 4 \mathrm{ccccc} 43) \mathrm{ncnc} 2 \mathrm{cc} 1 \mathrm{OC} 1 \mathrm{CCOC} 1$ & 5 & $*$ \\
\hline 721 & $\mathrm{COCCOc} 1 \mathrm{cc} 2 \mathrm{ncnc}(\mathrm{Nc} 3 \mathrm{ccc}(\mathrm{NC}(=\mathrm{O}) \mathrm{C} 45 \mathrm{CC} 6 \mathrm{CC}(\mathrm{CC}(\mathrm{C} 6) \mathrm{C} 4) \mathrm{C} 5) \mathrm{c}(\mathrm{C \# N}) \mathrm{c} 3) \mathrm{c} 2 \mathrm{cc} 1 \mathrm{OCCOC}$ & 5.01 & 8.30 \\
\hline 722 & $\mathrm{CN} 1 \mathrm{CCN}(\mathrm{CCCNc} 2 \mathrm{c}(\mathrm{Br}) \operatorname{ccc} 2 \mathrm{Nc} 2 \mathrm{ncnc} 3 \mathrm{ccncc} 23) \mathrm{CC} 1$ & 5.012 & $*$ \\
\hline 723 & $\mathrm{~S}=\mathrm{C}(\mathrm{NCCN} 1 \mathrm{CCOCC} 1) \mathrm{Nc} 1 \mathrm{ccc} 2 \mathrm{ncnc}(\mathrm{Nc} 3 \mathrm{ccc}(\mathrm{Cl}) \mathrm{cc} 3) \mathrm{c} 2 \mathrm{c} 1$ & 5.06 & 8.30 \\
\hline 724 & OCc1 cce $(-\mathrm{c} 2 \operatorname{ccc} 3 \mathrm{ncnc}(\mathrm{Nc} 4 \mathrm{ccc}(\mathrm{OCc} 5 \mathrm{cccc}(\mathrm{F}) \mathrm{c} 5) \mathrm{c}(\mathrm{Cl}) \mathrm{c} 4) \mathrm{c} 3 \mathrm{c} 2) \mathrm{o} 1$ & 5.06 & $*$ \\
\hline 725 & $\mathrm{O}=\mathrm{C}(\mathrm{O}) \mathrm{Cn} 1 \mathrm{ccc} 2 \mathrm{cc} 3 \mathrm{c}(\mathrm{Nc} 4 \mathrm{cccc}(\mathrm{Br}) \mathrm{c} 4) \mathrm{ncnc} 3 \mathrm{cc} 21$ & 5.1 & $*$ \\
\hline 726 & $\mathrm{C}=\mathrm{C}=\mathrm{CC}(=\mathrm{O}) \mathrm{Nc} 1 \mathrm{cc}(\mathrm{Nc} 2 \mathrm{ncc}(\mathrm{C}) \mathrm{c}(\mathrm{C} 3=\mathrm{CN}(\mathrm{C}) \mathrm{C} 4 \mathrm{C}=\mathrm{CC}=\mathrm{CC} 34) \mathrm{n} 2) \mathrm{c}(\mathrm{OC}) \mathrm{cc} 1 \mathrm{~N}(\mathrm{C}) \mathrm{CCN}(\mathrm{C}) \mathrm{C}$ & 5.2 & $*$ \\
\hline 727 & $\mathrm{O}=\mathrm{C}(\mathrm{CNCc} 1 \mathrm{cccc} 1) \mathrm{Nc} 1 \mathrm{ccc} 2 \mathrm{ncnc}(\mathrm{Nc} 3 \mathrm{cccc}(\mathrm{Br}) \mathrm{c} 3) \mathrm{c} 2 \mathrm{c} 1$ & 5.2 & $*$ \\
\hline 728 & $\mathrm{C}=\mathrm{C}=\mathrm{CC}(=\mathrm{O}) \mathrm{Nc} 1 \mathrm{cc}(\mathrm{Nc} 2 \mathrm{ncc}(\mathrm{C}) \mathrm{c}(-\mathrm{c} 3 \mathrm{cn}(\mathrm{C}) \mathrm{c} 4 \mathrm{ccccc} 34) \mathrm{n} 2) \mathrm{c}(\mathrm{OC}) \operatorname{cc} 1 \mathrm{~N}(\mathrm{C}) \mathrm{CCN}(\mathrm{C}) \mathrm{C}$ & 5.2 & $*$ \\
\hline 729 & $\mathrm{C}=\mathrm{CC}(=\mathrm{O}) \mathrm{Nc} 1 \mathrm{cccc}(-\mathrm{n} 2 \mathrm{c}(=\mathrm{O}) \mathrm{c}(\mathrm{C}) \mathrm{nc} 3 \mathrm{cnc}(\mathrm{Nc} 4 \mathrm{ccc}(\mathrm{OC}) \mathrm{cc} 4) \mathrm{nc} 32) \mathrm{c} 1$ & 5.29 & 8.28 \\
\hline 730 & $\mathrm{COc} 1 \mathrm{ccc}(-\mathrm{c} 2 \mathrm{cc} 3 \mathrm{c}(\mathrm{N}[\mathrm{C} @ \mathrm{H}](\mathrm{C}) \mathrm{c} 4 \mathrm{ccccc} 4) \mathrm{ncnc} 3 \mathrm{o} 2) \mathrm{cc} 1$ & 5.3 & 8.28 \\
\hline 731 & $\mathrm{O}=\mathrm{C}(/ \mathrm{C}=\mathrm{C} / \mathrm{CN} 1 \mathrm{CCCCC} 1) \mathrm{Nc} 1 \mathrm{cc} 2 \mathrm{c}(\mathrm{Nc} 3 \mathrm{ccc}(\mathrm{F}) \mathrm{c}(\mathrm{Cl}) \mathrm{c} 3) \mathrm{ncnc} 2 \mathrm{cc} 1 \mathrm{O}[\mathrm{C} @ \mathrm{H}] 1 \mathrm{CCOC} 1$ & 5.3 & $*$ \\
\hline 732 & 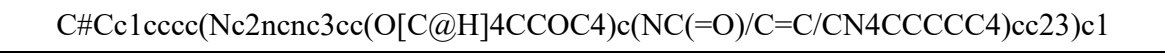 & 5.3 & $*$ \\
\hline 733 & $\mathrm{COCCOc} 1 \mathrm{cc} 2 \mathrm{ncnc}(\mathrm{Nc} 3 \operatorname{ccc}(\mathrm{OCc} 4 \mathrm{ccc} n 4) \mathrm{c}(\mathrm{Cl}) \mathrm{c} 3) \mathrm{c} 2 \mathrm{cc} 1 \mathrm{NC}(=\mathrm{O}) / \mathrm{C}=\mathrm{C} / \mathrm{CN}(\mathrm{C}) \mathrm{C}$ & 5.4 & $*$ \\
\hline
\end{tabular}




\begin{tabular}{|c|c|c|c|}
\hline 734 & Brc1 ccce(Nc2ncnc3ec(NCCCCN4CCOCC4)ncc23)c1 & 5.4 & $*$ \\
\hline 735 & $\mathrm{Cc} 1 \mathrm{cccc}(\mathrm{Nc} 2 \mathrm{ncnc} 3 \mathrm{cc}(\mathrm{NCCCCN}(\mathrm{C}) \mathrm{C}) \mathrm{ncc} 23) \mathrm{c} 1$ & 5.4 & $*$ \\
\hline 736 & $\mathrm{COc} 1 \mathrm{ccc}(/ \mathrm{C}=\mathrm{C} / \mathrm{C}(=\mathrm{N} / \mathrm{Nc} 2 \mathrm{nncc} 3 \operatorname{cccc} 23) \mathrm{c} 2 \mathrm{ccc}(\mathrm{Cl}) \mathrm{cc} 2) \mathrm{cc} 1$ & 5.4 & $*$ \\
\hline 737 & $\mathrm{C}=\mathrm{CC}(=\mathrm{O}) \mathrm{N}[\mathrm{C} @ @ \mathrm{H}] 1 \mathrm{CCCN}(\mathrm{c} 2 \mathrm{nc}(\mathrm{Nc} 3 \mathrm{cccc} 3) \mathrm{nc} 3 \mathrm{cnc}(\mathrm{Nc} 4 \mathrm{ccc}(\mathrm{N} 5 \mathrm{CCN}(\mathrm{C}) \mathrm{CC} 5) \mathrm{cn} 4) \mathrm{cc} 23) \mathrm{C} 1$ & 5.4 & $*$ \\
\hline 738 & $\mathrm{CN} 1 \mathrm{CCN}(\mathrm{c} 2 \mathrm{ccc}(\mathrm{Nc} 3 \mathrm{cc} 4 \mathrm{c}(\mathrm{N} 5 \mathrm{CCOCC} 5) \mathrm{nc}(\mathrm{Nc} 5 \mathrm{cccc} 5) \mathrm{nc} 4 \mathrm{cn} 3) \mathrm{nc} 2) \mathrm{CC} 1$ & 5.4 & $*$ \\
\hline 739 & $\mathrm{CC}[\mathrm{C} @ @ \mathrm{H}](\mathrm{Nc} 1 \mathrm{ncnc} 2[\mathrm{nH}] \mathrm{c}(-\mathrm{c} 3 \mathrm{ccccc} 3) \mathrm{cc} 12) \mathrm{c} 1 \mathrm{ccccc} 1$ & 5.4 & $*$ \\
\hline 740 & Brc1ecc(Nc2ncnc3ecnec23)c1NCCCCN1CCOCC1 & 5.495 & $*$ \\
\hline 741 & $\mathrm{Cc} 1 \mathrm{ccc}(\mathrm{Nc} 2 \mathrm{ncnc} 3 \mathrm{ccncc} 23) \mathrm{c} 1 \mathrm{NCCCCN}(\mathrm{C}) \mathrm{C}$ & 5.495 & $*$ \\
\hline 742 & $\mathrm{CCOc} 1 \mathrm{cc} 2 \mathrm{ncnc}(\mathrm{Nc} 3 \operatorname{ccc}(\mathrm{F}) \mathrm{c}(\mathrm{Cl}) \mathrm{c} 3) \mathrm{c} 2 \mathrm{cc} 1 \mathrm{NC}(=\mathrm{O}) / \mathrm{C}=\mathrm{C} / \mathrm{CN}(\mathrm{C}) \mathrm{C} 1 \mathrm{CC} 1$ & 5.5 & $*$ \\
\hline 743 & $\mathrm{CC}(\mathrm{C})(\mathrm{C}(=\mathrm{O}) \mathrm{NCCn} 1 \mathrm{ccc} 2 \mathrm{ncnc}(\mathrm{Nc} 3 \operatorname{ccc}(\mathrm{Oc} 4 \operatorname{ccc} 5 \operatorname{snc} 45) \mathrm{c}(\mathrm{Cl}) \mathrm{c} 3) \mathrm{c} 21) \mathrm{S}(\mathrm{C})(=\mathrm{O})=\mathrm{O}$ & 5.5 & $*$ \\
\hline 744 & $\mathrm{CN}(\mathrm{C}) \mathrm{C} 1 \mathrm{CCN}(\mathrm{c} 2 \mathrm{ccc}(\mathrm{Nc} 3 \mathrm{cc} 4 \mathrm{c}(\mathrm{N} 5 \mathrm{CCCC} 5) \mathrm{nc}(\mathrm{Nc} 5 \mathrm{ccccc} 5) \mathrm{nc} 4 \mathrm{cn} 3) \mathrm{nc} 2) \mathrm{CC} 1$ & 5.5 & $*$ \\
\hline 745 & CCOc1cc2ncnc(N[C@@H](C)c3ecccs)c2cc1NC(=O)[C@@H]1COC $(=\mathrm{O}) \mathrm{N} 1$ & 5.52 & 8.26 \\
\hline 746 & $\mathrm{O}=\mathrm{C}(\mathrm{c} 1 \mathrm{cc} 2 \mathrm{ccccc} 2[\mathrm{nH}] 1) \mathrm{c} 1 \mathrm{cc} 2 \mathrm{c}(\mathrm{Nc} 3 \operatorname{ccc}(\mathrm{F}) \mathrm{c}(\mathrm{Cl}) \mathrm{c} 3) \mathrm{ncnc} 2 \mathrm{~s} 1$ & 5.54 & $*$ \\
\hline 747 & $\mathrm{C} \# \mathrm{Cc} 1 \mathrm{cccc}(\mathrm{Nc} 2 \mathrm{ncnc} 3 \mathrm{cc}(\mathrm{O}[\mathrm{C} @ \mathrm{H}] 4 \mathrm{CCOC} 4) \mathrm{c}(\mathrm{NC}(=\mathrm{O}) / \mathrm{C}=\mathrm{C} / \mathrm{CNC} 4 \mathrm{CC} 4) \mathrm{cc} 23) \mathrm{c} 1$ & 5.6 & $*$ \\
\hline 748 & $\mathrm{Cc} 1 \mathrm{cccc}(\mathrm{Nc} 2 \mathrm{ncnc} 3 \mathrm{cc}(\mathrm{NCCCN} 4 \mathrm{CCN}(\mathrm{C}) \mathrm{CC} 4) \mathrm{ncc} 23) \mathrm{c} 1$ & 5.6 & $*$ \\
\hline 749 & $\mathrm{C}(=\mathrm{C} / \mathrm{c} 1 \mathrm{cccc} 1) \backslash \mathrm{C}(=\mathrm{N} \backslash \mathrm{Nc} 1 \mathrm{nncc} 2 \operatorname{ccccc} 12) \mathrm{c} 1 \operatorname{ccccc} 1$ & 5.6 & $*$ \\
\hline 750 & $\mathrm{C}=\mathrm{CC}(=\mathrm{O}) \mathrm{N} 1 \mathrm{CCC}[\mathrm{C} @ @ \mathrm{H}](\mathrm{n} 2 \mathrm{nc}(-\mathrm{c} 3 \mathrm{ccc}(\mathrm{Oc} 4 \mathrm{ccccc} 4) \mathrm{cc} 3) \mathrm{c} 3 \mathrm{c}(\mathrm{N}) \mathrm{ncnc} 32) \mathrm{C} 1$ & 5.6 & $*$ \\
\hline 751 & $\mathrm{COc} 1 \mathrm{cc} 2 \mathrm{ncnc}(\mathrm{Nc} 3 \mathrm{ccc}(\mathrm{F}) \mathrm{c}(\mathrm{Br}) \mathrm{c} 3) \mathrm{c} 2 \mathrm{cc} 1 \mathrm{OCCCN} 1 \mathrm{CCNCCNCC} 1$ & 5.6 & $*$ \\
\hline 752 & $\mathrm{Cc} 1 \mathrm{cccc}(\mathrm{Nc} 2 \mathrm{ncnc} 3 \mathrm{ccncc} 23) \mathrm{c} 1 \mathrm{NCCCN} 1 \mathrm{CCN}(\mathrm{C}) \mathrm{CC} 1$ & 5.623 & $*$ \\
\hline 753 & $\mathrm{NP}(=\mathrm{O})(\mathrm{OCCCOc} 1 \mathrm{ccc} 2 \mathrm{ncnc}(\mathrm{Nc} 3 \operatorname{ccc}(\mathrm{F}) \mathrm{c}(\mathrm{Cl}) \mathrm{c} 3) \mathrm{c} 2 \mathrm{c} 1) \mathrm{N}(\mathrm{CCCl}) \mathrm{CCCl}$ & 5.7 & $*$ \\
\hline 754 & OCCOCCn1 ccc2ncnc $(\mathrm{Nc} 3 \operatorname{ccc}(\mathrm{Oc} 4 \mathrm{cccc}(\mathrm{Cl}) \mathrm{c} 4) \mathrm{c}(\mathrm{Cl}) \mathrm{c} 3) \mathrm{c} 21$ & 5.7 & $*$ \\
\hline 755 & $\mathrm{C}=\mathrm{CC}(=\mathrm{O}) \mathrm{Nc} 1 \operatorname{ccc}(\mathrm{N} 2 \mathrm{C}(=\mathrm{O}) \mathrm{C}(\mathrm{Cc} 3 \operatorname{ccc}(\mathrm{F}) \mathrm{cc} 3) \mathrm{N}(\mathrm{C}) \mathrm{C}(=\mathrm{O}) \mathrm{c} 3 \mathrm{cnc}(\mathrm{Nc} 4 \mathrm{ccc}(\mathrm{N} 5 \mathrm{CCN}(\mathrm{C}) \mathrm{CC} 5) \operatorname{cc} 4 \mathrm{OC}) \mathrm{nc} 32) \mathrm{c} 1$ & 5.78 & 8.24 \\
\hline 756 & $\mathrm{C}=\mathrm{CC}(=\mathrm{O}) \mathrm{Nc} 1 \mathrm{cc} 2 \mathrm{c}(\mathrm{Nc} 3 \mathrm{ccc}(\mathrm{F}) \mathrm{c}(\mathrm{Cl}) \mathrm{c} 3) \mathrm{ncnc} 2 \mathrm{cc} 1 \mathrm{O}[\mathrm{C} @ \mathrm{H}] 1 \mathrm{CCOC} 1$ & 5.8 & $*$ \\
\hline 757 & $\mathrm{COc} 1 \mathrm{cc}(\mathrm{Nc} 2 \mathrm{ncnc} 3 \operatorname{ccc}(-\mathrm{c} 4 \mathrm{cn}(\mathrm{CCCCCC}(=\mathrm{O}) \mathrm{NO}) \mathrm{nn} 4) \operatorname{cc} 23) \operatorname{ccc} 1 \mathrm{Oc} 1 \mathrm{ccccc} 1$ & 5.8 & $*$ \\
\hline 758 & $\mathrm{C}=\mathrm{CC}(=\mathrm{O}) \mathrm{Nc} 1 \mathrm{ccc} 2 \mathrm{ncnc}(\mathrm{Nc} 3 \mathrm{ccc}(\mathrm{Oc} 4 \mathrm{ccccc} 4) \mathrm{cc} 3) \mathrm{c} 2 \mathrm{c} 1$ & 5.8 & $*$ \\
\hline 759 & $\mathrm{C}=\mathrm{C}=\mathrm{CC}(=\mathrm{O}) \mathrm{Nc} 1 \mathrm{cc}(\mathrm{Nc} 2 \mathrm{nccc}(\mathrm{C} 3=\mathrm{CN}(\mathrm{C}) \mathrm{C} 4 \mathrm{C}=\mathrm{CC}=\mathrm{CC} 34) \mathrm{n} 2) \mathrm{c}(\mathrm{OC}) \mathrm{cc} 1 \mathrm{~N} 1 \mathrm{CCC}(\mathrm{N} 2 \mathrm{CCN}(\mathrm{C}) \mathrm{CC} 2) \mathrm{CC} 1$ & 5.8 & $*$ \\
\hline 760 & $\mathrm{C}=\mathrm{C}=\mathrm{CC}(=\mathrm{O}) \mathrm{Nc} 1 \mathrm{cc}(\mathrm{Nc} 2 \mathrm{nccc}(-\mathrm{c} 3 \mathrm{cn}(\mathrm{C}) \mathrm{c} 4 \mathrm{ccccc} 34) \mathrm{n} 2) \mathrm{c}(\mathrm{OC}) \mathrm{cc} 1 \mathrm{~N} 1 \mathrm{CCC}(\mathrm{N} 2 \mathrm{CCN}(\mathrm{C}) \mathrm{CC} 2) \mathrm{CC} 1$ & 5.8 & $*$ \\
\hline 761 & Fc1 $1 \mathrm{cccc} 1 \mathrm{CNc} 1 \mathrm{ncnc} 2[\mathrm{nH}] \mathrm{c}(-\mathrm{c} 3 \mathrm{ccccc} 3) \mathrm{cc} 12$ & 5.8 & $*$ \\
\hline 762 & $\mathrm{Cc} 1 \mathrm{cc}(\mathrm{C}(=\mathrm{O}) \mathrm{N} 2 \mathrm{CC}(\mathrm{C}) \mathrm{NC}(\mathrm{C}) \mathrm{C} 2)[\mathrm{nH}] \mathrm{c} 1 / \mathrm{C}=\mathrm{C} 1 \backslash \mathrm{C}(=\mathrm{O}) \mathrm{Nc} 2 \mathrm{ncnc}(\mathrm{Nc} 3 \operatorname{ccc}(\mathrm{F}) \mathrm{c}(\mathrm{Cl}) \mathrm{c} 3) \mathrm{c} 21$ & 5.9 & $*$ \\
\hline 763 & $\mathrm{COc} 1 \mathrm{ccc} 2[\mathrm{nH}] \mathrm{c}(\mathrm{C}(=\mathrm{O}) \mathrm{c} 3 \mathrm{cc} 4 \mathrm{c}(\mathrm{Nc} 5 \mathrm{ccc}(\mathrm{F}) \mathrm{c}(\mathrm{Cl}) \mathrm{c} 5) \mathrm{ncnc} 4 \mathrm{~s} 3) \mathrm{cc} 2 \mathrm{c} 1$ & 5.93 & * \\
\hline 764 & $\mathrm{COCCOc} 1 \mathrm{cc} 2 \mathrm{ncnc}(\mathrm{Nc} 3 \mathrm{ccc}(\mathrm{NC}(=\mathrm{O}) \mathrm{C} 45 \mathrm{CC} 6 \mathrm{CC}(\mathrm{CC}(\mathrm{C} 6) \mathrm{C} 4) \mathrm{C} 5) \mathrm{c}(\mathrm{OC}) \mathrm{c} 3) \mathrm{c} 2 \mathrm{cc} 1 \mathrm{OCCOC}$ & 5.94 & 8.23 \\
\hline 765 & $\mathrm{Fc} 1 \mathrm{cc}(\mathrm{Nc} 2 \mathrm{ncnc} 3[\mathrm{nH}] \mathrm{ccc} 23) \mathrm{ccc} 1 \mathrm{Cl}$ & 5.98 & $*$ \\
\hline 766 & $\mathrm{Cc} 1 \mathrm{ccc}(\mathrm{C}(=\mathrm{O}) \mathrm{Nc} 2 \mathrm{ccc}(\mathrm{CN} 3 \mathrm{CCN}(\mathrm{C}) \mathrm{CC} 3) \mathrm{c}(\mathrm{C}(\mathrm{F})(\mathrm{F}) \mathrm{F}) \mathrm{c} 2) \mathrm{cc} 1 \mathrm{NC}(=\mathrm{O}) \mathrm{c} 1 \mathrm{cnc}(\mathrm{Nc} 2 \mathrm{ccccc} 2) \mathrm{nc} 1$ & 6 & 8.22 \\
\hline 767 & $\operatorname{COc} 1 \mathrm{cc}(\mathrm{C}=\mathrm{O}) \operatorname{ccc} 1-\mathrm{c} 1 \mathrm{cc} 2 \mathrm{c}(\mathrm{NCc} 3 \operatorname{ccc} c 3) \mathrm{ncnc} 2 \mathrm{~s} 1$ & 6 & 8.22 \\
\hline 768 & $\mathrm{C}[\mathrm{C} @ @ \mathrm{H}](\mathrm{Nc} 1 \mathrm{ncnc} 2 \mathrm{sc}(-\mathrm{c} 3 \mathrm{ccc}(\mathrm{C}=\mathrm{O}) \mathrm{c} 3) \mathrm{cc} 12) \mathrm{c} 1 \mathrm{ccccc} 1$ & 6 & 8.22 \\
\hline 769 & $\mathrm{COc} 1 \mathrm{cc}(\mathrm{F}) \mathrm{ccc} 1-\mathrm{c} 1 \mathrm{cc} 2 \mathrm{c}(\mathrm{N}[\mathrm{C} @ \mathrm{H}](\mathrm{C}) \mathrm{c} 3 \mathrm{ccccc} 3) \mathrm{ncnc} 2 \mathrm{~s} 1$ & 6 & 8.22 \\
\hline 770 & $\mathrm{COc} 1 \mathrm{cc} 2 \mathrm{ncnc}(\mathrm{Nc} 3 \mathrm{ccc}(\mathrm{F}) \mathrm{c}(\mathrm{Cl}) \mathrm{c} 3) \mathrm{c} 2 \mathrm{cc} 1 \mathrm{CN} 1 \mathrm{CCC}[\mathrm{C} @ @ \mathrm{H}] 1 \mathrm{C}(\mathrm{N})=\mathrm{O}$ & 6 & $*$ \\
\hline 771 & $\operatorname{COCCN} 1 \mathrm{CC}(\mathrm{C}(\mathrm{N})=\mathrm{O})(\mathrm{N}(\mathrm{C}) \mathrm{Cc} 2 \mathrm{cc} 3 \mathrm{c}(\mathrm{Nc} 4 \mathrm{cccc}(\mathrm{Cl}) \mathrm{c} 4 \mathrm{~F}) \mathrm{ncnc} 3 \mathrm{cc} 2 \mathrm{OC}) \mathrm{C} 1$ & 6 & $*$ \\
\hline 772 & $\mathrm{C} \# \mathrm{Cc} 1 \mathrm{cccc}(\mathrm{Nc} 2 \mathrm{ncnc} 3 \mathrm{cc}(\mathrm{OC} 4 \mathrm{CCOCC} 4) \mathrm{c}(\mathrm{NC}(=\mathrm{O}) / \mathrm{C}=\mathrm{C} / \mathrm{CN}(\mathrm{C}) \mathrm{C}) \mathrm{cc} 23) \mathrm{c} 1$ & 6 & $*$ \\
\hline 773 & $\mathrm{CCC}(=\mathrm{O}) \mathrm{Nc} 1 \mathrm{cc} 2 \mathrm{c}(\mathrm{Nc} 3 \mathrm{ccc} 4[\mathrm{nH}] \mathrm{ccc} 4 \mathrm{c} 3) \mathrm{ncnc} 2 \mathrm{cc} 1 \mathrm{OC}$ & 6 & $*$ \\
\hline 774 & $\mathrm{CCOc} 1 \mathrm{cc} 2 \mathrm{ncnc}(\mathrm{Nc} 3 \operatorname{ccc} 4 \mathrm{c}(\operatorname{cnn} 4 \mathrm{Cc} 4 \mathrm{ccccc} 4) \mathrm{c} 3) \mathrm{c} 2 \mathrm{cc} 1 \mathrm{NC}(=\mathrm{O}) / \mathrm{C}=\mathrm{C} / \mathrm{CN}(\mathrm{C}) \mathrm{C}$ & 6 & $*$ \\
\hline 775 & $\mathrm{COc} 1 \mathrm{cc} 2 \mathrm{ncnc}(\mathrm{Nc} 3 \mathrm{ccc}(\mathrm{F}) \mathrm{c}(\mathrm{Cl}) \mathrm{c} 3) \mathrm{c} 2 \mathrm{cc} 1 \mathrm{OCC}(\mathrm{O}) \mathrm{CN}$ & 6 & $*$ \\
\hline 776 & $\mathrm{CCNCc} 1 \mathrm{ccc}(-\mathrm{c} 2 \mathrm{cc} 3 \mathrm{ncnc}(\mathrm{Nc} 4 \mathrm{ccc}(\mathrm{OCc} 5 \mathrm{cccc}(\mathrm{F}) \mathrm{c} 5) \mathrm{c}(\mathrm{Cl}) \mathrm{c} 4) \mathrm{c} 3 \mathrm{~s} 2)[\mathrm{nH}] 1$ & 6 & $*$ \\
\hline
\end{tabular}




\begin{tabular}{|c|c|c|c|}
\hline 777 & $\mathrm{Clc} 1 \mathrm{cccc}(\mathrm{Nc} 2[\mathrm{nH}] \mathrm{cnc} 3 \mathrm{nc} 4 \mathrm{ccccc} 4 \mathrm{c} 2-3) \mathrm{c} 1$ & 6 & $*$ \\
\hline 778 & Oc1 $\operatorname{ccc}(-\mathrm{c} 2[\mathrm{nH}] \mathrm{nc} 3 \mathrm{ncnc}(\mathrm{Nc} 4 \mathrm{cccc}(\mathrm{Cl}) \mathrm{c} 4) \mathrm{c} 23) \mathrm{cc} 1$ & 6 & $*$ \\
\hline 779 & $\mathrm{Fc} 1 \mathrm{ccc}(\mathrm{Nc} 2 \mathrm{nncc} 3 \operatorname{ccccc} 23) \mathrm{cc} 1$ & 6 & $*$ \\
\hline 780 & $\mathrm{CN}(\mathrm{C}) \mathrm{CC} \# \mathrm{CC}(=\mathrm{O}) \mathrm{Nc} 1 \mathrm{ccc} 2 \mathrm{ncnc}(\mathrm{Nc} 3 \mathrm{cccc}(\mathrm{Br}) \mathrm{c} 3) \mathrm{c} 2 \mathrm{c} 1$ & 6 & * \\
\hline 781 & $\mathrm{NC} 1 \mathrm{CCN}(\mathrm{Cc} 2 \mathrm{ccn} 3 \mathrm{ncnc}(\mathrm{Nc} 4 \mathrm{cccc}(\mathrm{F}) \mathrm{c} 4) \mathrm{c} 23) \mathrm{CC} 1$ & 6 & $*$ \\
\hline 782 & $\mathrm{Cc} 1 \mathrm{ccc}(\mathrm{Nc} 2 \mathrm{ncnn} 3 \mathrm{ccc}(\mathrm{CN} 4 \mathrm{CCC}(\mathrm{N}) \mathrm{CC} 4) \mathrm{c} 23) \mathrm{cc} 1$ & 6 & $*$ \\
\hline 783 & $\mathrm{NC} 1 \mathrm{CCN}(\mathrm{Cc} 2 \mathrm{ccn} 3 \mathrm{ncnc}(\mathrm{Nc} 4 \mathrm{ccc}(\mathrm{F}) \mathrm{c}(\mathrm{Cl}) \mathrm{c} 4) \mathrm{c} 23) \mathrm{CC} 1$ & 6 & $*$ \\
\hline 784 & $\mathrm{NP}(=\mathrm{O})(\mathrm{OCCCCOc} 1 \mathrm{ccc} 2 \mathrm{ncnc}(\mathrm{Nc} 3 \mathrm{ccc}(\mathrm{F}) \mathrm{c}(\mathrm{Cl}) \mathrm{c} 3) \mathrm{c} 2 \mathrm{c} 1) \mathrm{N}(\mathrm{CCCl}) \mathrm{CCCl}$ & 6 & $*$ \\
\hline 785 & $\mathrm{C}=\mathrm{CC}(=\mathrm{O}) \mathrm{N} 1 \mathrm{CCc} 2 \mathrm{ncnc}(\mathrm{Nc} 3 \mathrm{cc}(\mathrm{Cl}) \mathrm{cc}(\mathrm{Cl}) \mathrm{c} 3) \mathrm{c} 2 \mathrm{C} 1$ & 6 & $*$ \\
\hline 786 & $\mathrm{CN}(\mathrm{C}) \mathrm{CC}=\mathrm{CC}(=\mathrm{O}) \mathrm{Nc} 1 \mathrm{cc} 2 \mathrm{c}(\mathrm{Nc} 3 \mathrm{ccc}(\mathrm{F}) \mathrm{c}(\mathrm{Cl}) \mathrm{c} 3) \mathrm{ncnc} 2 \mathrm{cc} 1 \mathrm{OC} 1 \mathrm{CCOC} 1$ & 6 & * \\
\hline 787 & $\mathrm{C} \# \mathrm{Cc} 1 \mathrm{cccc}(\mathrm{Nc} 2 \mathrm{ncnc} 3 \mathrm{cc}(\mathrm{OCC}) \mathrm{c}(\mathrm{NC}(=\mathrm{O}) / \mathrm{C}=\mathrm{C} / \mathrm{CN} 4 \mathrm{CCCCC} 4) \mathrm{cc} 23) \mathrm{c} 1$ & 6.1 & $*$ \\
\hline 788 & $\mathrm{O}=\mathrm{C}(\mathrm{Nc} 1 \mathrm{ccc} 2 \mathrm{ncnc}(\mathrm{Nc} 3 \operatorname{cccc}(\mathrm{Cl}) \mathrm{c} 3) \mathrm{c} 2 \mathrm{c} 1) \mathrm{C} 1 \mathrm{CCCCC} 1$ & 6.13 & $*$ \\
\hline 789 & $\mathrm{O}=\mathrm{C}(\mathrm{O}) \mathrm{c} 1 \mathrm{ccc}(\mathrm{Nc} 2 \mathrm{nncc} 3 \mathrm{cccc} 23) \mathrm{cc} 1$ & 6.2 & $*$ \\
\hline 790 & $\mathrm{CN}(\mathrm{C}) \mathrm{C} / \mathrm{C}=\mathrm{C} / \mathrm{C}(=\mathrm{O}) \mathrm{NCc} 1 \mathrm{cccc}(-\mathrm{c} 2 \mathrm{nc}(-\mathrm{c} 3 \operatorname{ccc}(\mathrm{F}) \mathrm{cc} 3) \mathrm{c}(-\mathrm{c} 3 \operatorname{ccnc} 4[\mathrm{nH}] \mathrm{c}(-\mathrm{c} 5 \operatorname{ccccc} 5) \mathrm{cc} 34)[\mathrm{nH}] 2) \mathrm{c} 1$ & 6.2 & $*$ \\
\hline 791 & $\mathrm{C}=\mathrm{CC}(=\mathrm{O}) \mathrm{Nc} 1 \mathrm{ccc}(\mathrm{N} 2 \mathrm{C}(=\mathrm{O}) \mathrm{CN}(\mathrm{Cc} 3 \operatorname{cccc} 3) \mathrm{C}(=\mathrm{O}) \mathrm{c} 3 \mathrm{cnc}(\mathrm{Nc} 4 \operatorname{ccc}(\mathrm{N} 5 \mathrm{CCN}(\mathrm{C}) \mathrm{CC} 5) \operatorname{cc} 4 \mathrm{OC}) \mathrm{nc} 32) \mathrm{c} 1$ & 6.26 & 8.20 \\
\hline 792 & $\operatorname{Oc} 1 \mathrm{cc}(\mathrm{O}) \mathrm{c} 2 \mathrm{cc}(\mathrm{O}) \mathrm{c}(-\mathrm{c} 3 \mathrm{cc}(\mathrm{O}) \mathrm{c}(\mathrm{O}) \mathrm{c}(\mathrm{O}) \mathrm{c} 3)\left[\mathrm{o}^{+}\right] \mathrm{c} 2 \mathrm{c} 1 .[\mathrm{Cl}-]$ & 6.27 & $*$ \\
\hline 793 & $\mathrm{CN}(\mathrm{C}) \mathrm{CCCCOc} 1 \mathrm{cc} 2 \mathrm{ncnc}(\mathrm{Nc} 3 \operatorname{ccc}(\mathrm{F}) \mathrm{c}(\mathrm{Cl}) \mathrm{c} 3) \mathrm{c} 2 \mathrm{cc} 1 \mathrm{NC}(=\mathrm{O}) \mathrm{c} 1 \mathrm{cc}([\mathrm{N}+](=\mathrm{O})[\mathrm{O}-]) \operatorname{ccc} 1 \mathrm{~F}$ & 6.3 & 8.20 \\
\hline 794 & $\mathrm{Clc} 1 \mathrm{ccc}(\mathrm{C}(/ \mathrm{C}=\mathrm{C} / \mathrm{c} 2 \operatorname{ccccc} 2)=\mathrm{N} \backslash \mathrm{Nc} 2 \mathrm{nncc} 3 \operatorname{ccccc} 23) \mathrm{cc} 1$ & 6.3 & $*$ \\
\hline 795 & $\mathrm{C}=\mathrm{C}=\mathrm{CC}(=\mathrm{O}) \mathrm{Nc} 1 \mathrm{cc}(\mathrm{Nc} 2 \mathrm{nccc}(\mathrm{C} 3=\mathrm{CN}(\mathrm{C}) \mathrm{C} 4 \mathrm{C}=\mathrm{CC}=\mathrm{CC} 34) \mathrm{n} 2) \mathrm{c}(\mathrm{OC}) \mathrm{cc} 1 \mathrm{~N} 1 \mathrm{CCC}(\mathrm{N}(\mathrm{C}) \mathrm{C}) \mathrm{CC} 1$ & 6.3 & $*$ \\
\hline 796 & $\mathrm{C}=\mathrm{C}=\mathrm{CC}(=\mathrm{O}) \mathrm{Nc} 1 \mathrm{cc}(\mathrm{Nc} 2 \mathrm{nccc}(\mathrm{C} 3=\mathrm{CN}(\mathrm{C}) \mathrm{C} 4 \mathrm{C}=\mathrm{CC}=\mathrm{CC} 34) \mathrm{n} 2) \mathrm{c}(\mathrm{OC}) \mathrm{cc} 1 \mathrm{~N} 1 \mathrm{CCN}(\mathrm{C}) \mathrm{CC} 1$ & 6.3 & $*$ \\
\hline 797 & $\mathrm{C}=\mathrm{C}=\mathrm{CC}(=\mathrm{O}) \mathrm{Nc} 1 \mathrm{cc}(\mathrm{Nc} 2 \mathrm{ncc}(\mathrm{OC}) \mathrm{c}(\mathrm{C} 3=\mathrm{CN}(\mathrm{C}) \mathrm{C} 4 \mathrm{C}=\mathrm{CC}=\mathrm{CC} 34) \mathrm{n} 2) \mathrm{c}(\mathrm{OC}) \mathrm{cc} 1 \mathrm{~N}(\mathrm{C}) \mathrm{CCN}(\mathrm{C}) \mathrm{C}$ & 6.3 & $*$ \\
\hline 798 & $\mathrm{C}=\mathrm{C}=\mathrm{CC}(=\mathrm{O}) \mathrm{Nc} 1 \mathrm{cc}(\mathrm{Nc} 2 \mathrm{nccc}(-\mathrm{c} 3 \mathrm{cn}(\mathrm{C}) \mathrm{c} 4 \mathrm{cccc} 34) \mathrm{n} 2) \mathrm{c}(\mathrm{OC}) \mathrm{cc} 1 \mathrm{~N} 1 \mathrm{CCC}(\mathrm{N}(\mathrm{C}) \mathrm{C}) \mathrm{CC} 1$ & 6.3 & $*$ \\
\hline 799 & $\mathrm{C}=\mathrm{C}=\mathrm{CC}(=\mathrm{O}) \mathrm{Nc} 1 \mathrm{cc}(\mathrm{Nc} 2 \mathrm{nccc}(-\mathrm{c} 3 \mathrm{cn}(\mathrm{C}) \mathrm{c} 4 \mathrm{cccc} 34) \mathrm{n} 2) \mathrm{c}(\mathrm{OC}) \mathrm{cc} 1 \mathrm{~N} 1 \mathrm{CCN}(\mathrm{C}) \mathrm{CC} 1$ & 6.3 & $*$ \\
\hline 800 & $\mathrm{C}=\mathrm{C}=\mathrm{CC}(=\mathrm{O}) \mathrm{Nc} 1 \mathrm{cc}(\mathrm{Nc} 2 \mathrm{ncc}(\mathrm{OC}) \mathrm{c}(-\mathrm{c} 3 \mathrm{cn}(\mathrm{C}) \mathrm{c} 4 \mathrm{cccc} 34) \mathrm{n} 2) \mathrm{c}(\mathrm{OC}) \mathrm{cc} 1 \mathrm{~N}(\mathrm{C}) \mathrm{CCN}(\mathrm{C}) \mathrm{C}$ & 6.3 & $*$ \\
\hline 801 & $\mathrm{C} \# \mathrm{Cc} 1 \mathrm{cccc}(\mathrm{Nc} 2 \mathrm{ncnc} 3 \mathrm{cc}(\mathrm{O}[\mathrm{C} @ \mathrm{H}] 4 \mathrm{CCOC} 4) \mathrm{c}(\mathrm{NC}(=\mathrm{O}) / \mathrm{C}=\mathrm{C} / \mathrm{CNC}(\mathrm{C}) \mathrm{C}) \mathrm{cc} 23) \mathrm{c} 1$ & 6.4 & $*$ \\
\hline 802 & $\mathrm{Cc} 1 \mathrm{ccc}(\mathrm{Oc} 2 \mathrm{ccc}(\mathrm{Nc} 3 \mathrm{ncnc} 4 \mathrm{ccc}(-\mathrm{c} 5 \mathrm{cn}(\mathrm{CCCCCC}(=\mathrm{O}) \mathrm{NO}) \mathrm{nn} 5) \operatorname{cc} 34) \mathrm{cc} 2 \mathrm{C}) \mathrm{cn} 1$ & 6.4 & $*$ \\
\hline 803 & $\mathrm{COc} 1 \mathrm{cc} 2 \mathrm{ncnc}(\mathrm{Nc} 3 \mathrm{cncc} 4 \mathrm{cccc} 34) \mathrm{c} 2 \mathrm{cc} 1 \mathrm{OC}$ & 6.4 & $*$ \\
\hline 804 & $\mathrm{CN} 1 \mathrm{CCN}(\mathrm{c} 2 \mathrm{cc} 3 \mathrm{c}(\mathrm{Nc} 4 \mathrm{cccc}(\mathrm{Br}) \mathrm{c} 4) \mathrm{ncnc} 3 \mathrm{cn} 2) \mathrm{CC} 1$ & 6.4 & $*$ \\
\hline 805 & $\mathrm{COc} 1 \mathrm{cc} 2 \mathrm{ncnc}(\mathrm{Nc} 3 \mathrm{ccc}(\mathrm{C}(=\mathrm{O}) \mathrm{NC} 45 \mathrm{CC} 6 \mathrm{CC}(\mathrm{CC}(\mathrm{C} 6) \mathrm{C} 4) \mathrm{C} 5) \mathrm{c}(\mathrm{Cl}) \mathrm{c} 3) \mathrm{c} 2 \mathrm{cc} 1 \mathrm{OCCCN} 1 \mathrm{CCOCC} 1$ & 6.42 & 8.19 \\
\hline 806 & $\mathrm{O}=\mathrm{C}(/ \mathrm{C}=\mathrm{C} / \mathrm{CN} 1 \mathrm{CCCCC} 1) \mathrm{Nc} 1 \mathrm{cc} 2 \mathrm{c}(\mathrm{Nc} 3 \mathrm{ccc}(\mathrm{F}) \mathrm{c}(\mathrm{Cl}) \mathrm{c} 3) \mathrm{ncnc} 2 \mathrm{cc} 1 \mathrm{OCCF}$ & 6.44 & $*$ \\
\hline 807 & $\mathrm{O}=\mathrm{C}(/ \mathrm{C}=\mathrm{C} / \mathrm{CNC} 1 \mathrm{CC} 1) \mathrm{Nc} 1 \mathrm{cc} 2 \mathrm{c}(\mathrm{Nc} 3 \mathrm{ccc}(\mathrm{F}) \mathrm{c}(\mathrm{Cl}) \mathrm{c} 3) \mathrm{ncnc} 2 \mathrm{cc} 1 \mathrm{O}[\mathrm{C} @ \mathrm{H}] 1 \mathrm{CCOC} 1$ & 6.5 & * \\
\hline 808 & $\mathrm{Nc} 1 \mathrm{cc} 2 \mathrm{c}(\mathrm{Nc} 3 \mathrm{cccc}(\mathrm{Br}) \mathrm{c} 3) \mathrm{ncnc} 2 \mathrm{cc} 1 \mathrm{Cl}$ & 6.5 & $*$ \\
\hline 809 & $\mathrm{Cc} 1 \mathrm{cc}(\mathrm{C}(=\mathrm{O}) \mathrm{NCCN} 2 \mathrm{CCOCC} 2)[\mathrm{nH}] \mathrm{c} 1 / \mathrm{C}=\mathrm{C} 1 \backslash \mathrm{C}(=\mathrm{O}) \mathrm{Nc} 2 \mathrm{ncnc}(\mathrm{Nc} 3 \mathrm{ccc}(\mathrm{F}) \mathrm{c}(\mathrm{Cl}) \mathrm{c} 3) \mathrm{c} 21$ & 6.5 & $*$ \\
\hline 810 & $\mathrm{Cc} 1 \operatorname{ccc}(\mathrm{C}(/ \mathrm{C}=\mathrm{C} / \mathrm{c} 2 \mathrm{ccc}(\mathrm{F}) \mathrm{cc} 2)=\mathrm{N} \backslash \mathrm{Nc} 2 \mathrm{nncc} 3 \operatorname{ccccc} 23) \mathrm{cc} 1$ & 6.5 & $*$ \\
\hline 811 & $\mathrm{CN} 1 \mathrm{CCN}(\mathrm{CCCOc} 2 \mathrm{cc} 3 \mathrm{ncnc}(\mathrm{Nc} 4 \mathrm{ccc}(\mathrm{F}) \mathrm{c}(\mathrm{Cl}) \mathrm{c} 4) \mathrm{c} 3 \mathrm{cc} 2 \mathrm{NC}(=\mathrm{O}) \mathrm{c} 2 \mathrm{cc}([\mathrm{N}+](=\mathrm{O})[\mathrm{O}-]) \operatorname{ccc} 2 \mathrm{~F}) \mathrm{CC} 1$ & 6.6 & 8.18 \\
\hline 812 & $\mathrm{C}=\mathrm{CC}(=\mathrm{O}) \mathrm{Nc} 1 \mathrm{nc} 2 \mathrm{c}(\mathrm{Nc} 3 \mathrm{ccc}(\mathrm{F}) \mathrm{c}(\mathrm{Cl}) \mathrm{c} 3) \mathrm{ncnc} 2 \mathrm{cc} 1 \mathrm{OCCCN} 1 \mathrm{CCN}(\mathrm{C}) \mathrm{CC} 1$ & 6.6 & $*$ \\
\hline 813 & $\mathrm{C}[\mathrm{C} @ @ \mathrm{H}](\mathrm{Nc} 1 \mathrm{ncnc} 2[\mathrm{nH}] \mathrm{c}(-\mathrm{c} 3 \mathrm{ccc}(\mathrm{F}) \mathrm{cc} 3) \mathrm{cc} 12) \mathrm{c} 1 \mathrm{ccccc} 1$ & 6.6 & $*$ \\
\hline 814 & $\mathrm{COc} 1 \mathrm{ccc}(-\mathrm{c} 2 \mathrm{cc} 3 \mathrm{c}(\mathrm{N}[\mathrm{C} @ \mathrm{H}](\mathrm{C}) \mathrm{c} 4 \mathrm{ccccc} 4 \mathrm{O}) \mathrm{ncnc} 3[\mathrm{nH}] 2) \mathrm{cc} 1$ & 6.6 & $*$ \\
\hline 815 & COc1cc2ncnc(Nc3cce(F)c(Cl)c3)c2cc1OCCCN1CCNCCNCCNCC1 & 6.6 & $*$ \\
\hline 816 & $\mathrm{Clc} 1 \mathrm{cccc}(\mathrm{Nc} 2 \mathrm{ncnc} 3[\mathrm{nH}] \operatorname{ccc} 23) \mathrm{c} 1$ & 6.63 & $*$ \\
\hline 817 & $\mathrm{COC}(=\mathrm{O}) \mathrm{c} 1 \mathrm{ccc} 2 \mathrm{oc} 3 \mathrm{cnn} c(\mathrm{Nc} 4 \mathrm{ccc}(\mathrm{F}) \mathrm{c}(\mathrm{Cl}) \mathrm{c} 4) \mathrm{c} 3 \mathrm{c} 2 \mathrm{c} 1$ & 6.7 & 8.17 \\
\hline 818 & $\mathrm{CCOc} 1 \mathrm{cc} 2 \mathrm{ncnc}(\mathrm{Nc} 3 \mathrm{ccc}(\mathrm{C}) \mathrm{c}(\mathrm{Cl}) \mathrm{c} 3) \mathrm{c} 2 \mathrm{c} 2 \mathrm{c} 1 \mathrm{OCCO} 2$ & 6.7 & $*$ \\
\hline 819 & $\mathrm{CS}(=\mathrm{O})(=\mathrm{O}) \mathrm{CC}(=\mathrm{O}) \mathrm{NCCn} 1 \mathrm{ccc} 2 \mathrm{ncnc}(\mathrm{Nc} 3 \mathrm{ccc}(\mathrm{Oc} 4 \mathrm{cccc}(\mathrm{Cl}) \mathrm{c} 4) \mathrm{c}(\mathrm{Cl}) \mathrm{c} 3) \mathrm{c} 21$ & 6.7 & * \\
\hline
\end{tabular}




\begin{tabular}{|c|c|c|c|}
\hline 820 & $\mathrm{Cc} 1 \mathrm{cc}(\mathrm{C}) \mathrm{nc}(\mathrm{NS}(=\mathrm{O})(=\mathrm{O}) \mathrm{c} 2 \mathrm{ccc}(\mathrm{Nc} 3 \mathrm{nncc} 4 \mathrm{cccc} 34) \mathrm{cc} 2) \mathrm{n} 1$ & 6.7 & $*$ \\
\hline 821 & Clc1ecc(Nc2ncnc3[nH]ccc23) $\operatorname{cc} 1 \mathrm{Cl}$ & 6.7 & $*$ \\
\hline 822 & $\mathrm{CN}(\mathrm{C}) \mathrm{C}(\mathrm{CS}(\mathrm{C})(=\mathrm{O})=\mathrm{O}) \mathrm{c} 1 \mathrm{ccc}(-\mathrm{c} 2 \mathrm{ccc} 3 \mathrm{ncnc}(\mathrm{Nc} 4 \mathrm{ccc}(\mathrm{OCc} 5 \mathrm{ccc}(\mathrm{F}) \mathrm{c} 5) \mathrm{c}(\mathrm{Cl}) \mathrm{c} 4) \mathrm{c} 3 \mathrm{c} 2) \mathrm{o} 1$ & 6.8 & $*$ \\
\hline 823 & $\mathrm{C}=\mathrm{CC}(=\mathrm{O}) \mathrm{Nc} 1 \mathrm{cc}(\mathrm{Nc} 2 \mathrm{n}[\mathrm{nH}] \mathrm{c} 3 \mathrm{ccc}(-\mathrm{c} 4 \mathrm{ccc}(\mathrm{F}) \mathrm{cc} 4) \operatorname{cc} 23) \mathrm{c}(\mathrm{OC}) \mathrm{cc} 1 \mathrm{~N}(\mathrm{C}) \mathrm{CCN}(\mathrm{C}) \mathrm{C}$ & 6.8 & $*$ \\
\hline 824 & $\mathrm{O}=\mathrm{C}(/ \mathrm{C}=\mathrm{C} / \mathrm{CNC} 1 \mathrm{CC} 1) \mathrm{Nc} 1 \mathrm{cc} 2 \mathrm{c}(\mathrm{Nc} 3 \mathrm{ccc}(\mathrm{F}) \mathrm{c}(\mathrm{Cl}) \mathrm{c} 3) \mathrm{ncnc} 2 \mathrm{cc} 1 \mathrm{OCC}(\mathrm{F})(\mathrm{F}) \mathrm{F}$ & 6.9 & $*$ \\
\hline 825 & $\mathrm{O}=\mathrm{C}(\mathrm{CCCCCn} 1 \mathrm{cc}(-\mathrm{c} 2 \mathrm{ccc} 3 \mathrm{ncnc}(\mathrm{Nc} 4 \mathrm{ccc}(\mathrm{OCc} 5 \mathrm{nccs} 5) \mathrm{c}(\mathrm{Cl}) \mathrm{c} 4) \mathrm{c} 3 \mathrm{c} 2) \mathrm{nn} 1) \mathrm{NO}$ & 6.9 & $*$ \\
\hline 826 & $\mathrm{O}=\mathrm{C}(\mathrm{Nc} 1 \mathrm{ccc}(\mathrm{Oc} 2 \mathrm{ccc}(\mathrm{Nc} 3 \mathrm{ncnc} 4 \mathrm{ccn}(\mathrm{CCOCCO}) \mathrm{c} 34) \mathrm{cc} 2 \mathrm{Cl}) \mathrm{c} 1) \mathrm{NC} 1 \mathrm{CCCCC} 1$ & 6.9 & $*$ \\
\hline 827 & $\mathrm{Fc} 1 \mathrm{ccc}(/ \mathrm{C}=\mathrm{C} / \mathrm{C}(=\mathrm{N} / \mathrm{Nc} 2 \mathrm{nncc} 3 \operatorname{ccccc} 23) \mathrm{c} 2 \operatorname{ccccc} 2) \operatorname{cc} 1$ & 6.9 & $*$ \\
\hline 828 & $\mathrm{C}=\mathrm{CC}(=\mathrm{O}) \mathrm{Nc} 1 \mathrm{cccc}(-\mathrm{n} 2 \mathrm{c}(=\mathrm{O}) \mathrm{cnc} 3 \mathrm{cnc}(\mathrm{Nc} 4 \mathrm{ccc}(\mathrm{N} 5 \mathrm{CCOCC} 5) \mathrm{cc} 4) \mathrm{nc} 32) \mathrm{c} 1$ & 6.95 & 8.16 \\
\hline 829 & $\mathrm{C}=\mathrm{CC}(=\mathrm{O}) \mathrm{Nc} 1 \operatorname{cccc}(\mathrm{N} 2 \mathrm{C}(=\mathrm{O}) \mathrm{N}(\mathrm{C}) \mathrm{Cc} 3 \mathrm{cnc}(\mathrm{Nc} 4 \mathrm{ccccc} 4) \mathrm{nc} 32) \mathrm{c} 1$ & 6.95 & 8.16 \\
\hline 830 & $\mathrm{C}=\mathrm{CC}(=\mathrm{O}) \mathrm{Nc} 1 \mathrm{ccc}(\mathrm{N} 2 \mathrm{C}(=\mathrm{O}) \mathrm{CN}(\mathrm{c} 3 \operatorname{ccccc} 3) \mathrm{C}(=\mathrm{O}) \mathrm{c} 3 \mathrm{cnc}(\mathrm{Nc} 4 \mathrm{ccc}(\mathrm{N} 5 \mathrm{CCN}(\mathrm{C}) \mathrm{CC} 5) \operatorname{cc} 4 \mathrm{OC}) \mathrm{nc} 32) \mathrm{c} 1$ & 6.99 & 8.16 \\
\hline 831 & $\mathrm{Cc} 1 n \mathrm{nnc}(\mathrm{Nc} 2 \mathrm{ccc}(\mathrm{OCc} 3 \operatorname{ccc}(\mathrm{F}) \mathrm{c} 3) \mathrm{c}(\mathrm{Cl}) \mathrm{c} 2) \mathrm{c} 1 \mathrm{C} \# \mathrm{Cc} 1 \mathrm{ccc}(\mathrm{CN}(\mathrm{C}) \mathrm{C}) \mathrm{cc} 1$ & 7 & 8.15 \\
\hline 832 & $\mathrm{COc} 1 \mathrm{cccc}(-\mathrm{c} 2 \mathrm{cc} 3 \mathrm{c}(\mathrm{N}[\mathrm{C} @ \mathrm{H}](\mathrm{C}) \mathrm{c} 4 \mathrm{ccccc} 4) \mathrm{ncnc} 3 \mathrm{o} 2) \mathrm{c} 1$ & 7 & 8.15 \\
\hline 833 & $\mathrm{COc} 1 \mathrm{cc} 2 \mathrm{c}(\mathrm{Nc} 3 \mathrm{ccc}(\mathrm{F}) \mathrm{c}(\mathrm{Cl}) \mathrm{c} 3) \mathrm{ncnc} 2 \mathrm{cc} 1 \mathrm{OCCCCCCC}(=\mathrm{O}) \mathrm{NO}$ & 7 & 8.15 \\
\hline 834 & $\mathrm{CCOc} 1 \mathrm{cc} 2 \mathrm{ncc}(\mathrm{C \# N}) \mathrm{c}(\mathrm{Nc} 3 \operatorname{ccc}(\mathrm{OCc} 4 \mathrm{cccc}(\mathrm{Cl}) \mathrm{c} 4) \mathrm{c}(\mathrm{Cl}) \mathrm{c} 3) \mathrm{c} 2 \mathrm{cc} 1 \mathrm{NC}(=\mathrm{O}) / \mathrm{C}=\mathrm{C} / \mathrm{CN}(\mathrm{C}) \mathrm{C}$ & 7 & 8.15 \\
\hline 835 & $\mathrm{COC}(=\mathrm{O}) \mathrm{c} 1 \mathrm{ccc}(\mathrm{OC}) \mathrm{c}(-\mathrm{c} 2 \mathrm{cc} 3 \mathrm{c}(\mathrm{N}[\mathrm{C} @ \mathrm{H}](\mathrm{C}) \mathrm{c} 4 \mathrm{ccccc} 4) \mathrm{ncnc} 3 \mathrm{~s} 2) \mathrm{c} 1$ & 7 & 8.15 \\
\hline 836 & $\mathrm{C}[\mathrm{C} @ @ \mathrm{H}](\mathrm{Nc} 1 \mathrm{ncnc} 2 \mathrm{sc}(-\mathrm{c} 3 \mathrm{ccc}(\mathrm{C}(\mathrm{N})=\mathrm{O}) \mathrm{cc} 3) \mathrm{cc} 12) \mathrm{c} 1 \mathrm{ccccc} 1$ & 7 & 8.15 \\
\hline 837 & $\mathrm{Cc} 1 \mathrm{cc}(\mathrm{Nc} 2 \mathrm{ncc} 3 \mathrm{c}(\mathrm{n} 2) \mathrm{N}([\mathrm{C} @ \mathrm{H}] 2 \mathrm{CCN}(\mathrm{C}(=\mathrm{O}) \mathrm{CO}) \mathrm{C} 2) \mathrm{C}(=\mathrm{O}) \mathrm{N}(\mathrm{c} 2 \mathrm{cccc} 2 \mathrm{Cl}) \mathrm{C} 3) \operatorname{ccc} 1 \mathrm{~N} 1 \mathrm{CCN}(\mathrm{C}) \mathrm{CC} 1$ & 7 & 8.15 \\
\hline 838 & $\mathrm{O}=\mathrm{C}(/ \mathrm{C}=\mathrm{C} / \mathrm{CN} 1 \mathrm{CC} 2(\mathrm{COC} 2) \mathrm{C} 1) \mathrm{Nc} 1 \mathrm{cc} 2 \mathrm{c}(\mathrm{Nc} 3 \mathrm{ccc}(\mathrm{F}) \mathrm{c}(\mathrm{Cl}) \mathrm{c} 3) \mathrm{ncnc} 2 \mathrm{~s} 1$ & 7 & $*$ \\
\hline 839 & $\mathrm{O}=\mathrm{C}(/ \mathrm{C}=\mathrm{C} / \mathrm{CN} 1 \mathrm{CCC}(\mathrm{F})(\mathrm{F}) \mathrm{CC} 1) \mathrm{Nc} 1 \mathrm{cc} 2 \mathrm{c}(\mathrm{Nc} 3 \mathrm{ccc}(\mathrm{F}) \mathrm{c}(\mathrm{Cl}) \mathrm{c} 3) \mathrm{ncnc} 2 \mathrm{~s} 1$ & 7 & $*$ \\
\hline 840 & $\mathrm{O}=\mathrm{C}(\mathrm{Nc} 1 \mathrm{ccc}(\mathrm{CN} 2 \mathrm{CCCC} 2) \mathrm{cc} 1) \mathrm{c} 1 \mathrm{sc} 2 \mathrm{ncnc} 3 \mathrm{c} 2 \mathrm{c} 1 \mathrm{NC}(=\mathrm{O}) \mathrm{N} 3 \mathrm{c} 1 \mathrm{ccc}(\mathrm{F}) \mathrm{c}(\mathrm{Cl}) \mathrm{c} 1$ & 7 & $*$ \\
\hline 841 & $\mathrm{CC}(\mathrm{C}) \mathrm{NC} / \mathrm{C}=\mathrm{C} / \mathrm{C}(=\mathrm{O}) \mathrm{Nc} 1 \mathrm{cc} 2 \mathrm{c}(\mathrm{Nc} 3 \mathrm{ccc}(\mathrm{F}) \mathrm{c}(\mathrm{Cl}) \mathrm{c} 3) \mathrm{ncnc} 2 \mathrm{cc} 1 \mathrm{O}[\mathrm{C} @ \mathrm{H}] 1 \mathrm{CCOC} 1$ & 7 & $*$ \\
\hline 842 & $\mathrm{O}=\mathrm{C}(\mathrm{Nc} 1 \mathrm{cc} 2 \mathrm{c}(\mathrm{Nc} 3 \mathrm{ccc}(\mathrm{F}) \mathrm{c}(\mathrm{Cl}) \mathrm{c} 3) \mathrm{ncnc} 2 \mathrm{cc} 1 \mathrm{OCCCN} 1 \mathrm{CCOCC} 1) \mathrm{C} 1=\mathrm{CCCC} 1$ & 7 & $*$ \\
\hline 843 & $\mathrm{CCOc} 1 \mathrm{cc} 2 \mathrm{ncnc}(\mathrm{Nc} 3 \operatorname{ccc} 4 \mathrm{c}(\operatorname{cnn} 4 \mathrm{Cc} 4 \mathrm{ccccc} 4) \mathrm{c} 3) \mathrm{c} 2 \mathrm{cc} 1 \mathrm{NC}(=\mathrm{O}) / \mathrm{C}=\mathrm{C} / \mathrm{CN} 1 \mathrm{CCCC} 1$ & 7 & $*$ \\
\hline 844 & $\mathrm{COCCOc} 1 \mathrm{cc} 2 \mathrm{ncnc}(\mathrm{Nc} 3 \operatorname{ccc} 4 \mathrm{c}(\mathrm{cnn} 4 \mathrm{Cc} 4 \mathrm{cccc} 4) \mathrm{c} 3) \mathrm{c} 2 \mathrm{cc} 1 \mathrm{NC}(=\mathrm{O}) / \mathrm{C}=\mathrm{C} / \mathrm{CN}(\mathrm{C}) \mathrm{C}$ & 7 & $*$ \\
\hline 845 & $\mathrm{COc} 1 \mathrm{cc} 2 \mathrm{ncnc}(\mathrm{Nc} 3 \mathrm{ccc}(\mathrm{F}) \mathrm{c}(\mathrm{Cl}) \mathrm{c} 3) \mathrm{c} 2 \mathrm{cc} 1 \mathrm{OCCN}(\mathrm{C}) \mathrm{C}$ & 7 & $*$ \\
\hline 846 & $\mathrm{CS}(=\mathrm{O})(=\mathrm{O}) \mathrm{CCNCc} 1 \mathrm{ccc}(-\mathrm{c} 2 \mathrm{cc} 3 \mathrm{ncnc}(\mathrm{Nc} 4 \mathrm{ccc}(\mathrm{OCc} 5 \operatorname{cccc}(\mathrm{F}) \mathrm{c} 5) \mathrm{c}(\mathrm{Cl}) \mathrm{c} 4) \mathrm{c} 3 \mathrm{~s} 2)[\mathrm{nH}] 1$ & 7 & $*$ \\
\hline 847 & $\mathrm{C}=\mathrm{CC}(=\mathrm{O}) \mathrm{Nc} 1 \mathrm{cccc}(-\mathrm{c} 2 \mathrm{c}(-\mathrm{c} 3 \operatorname{ccccc} 3) \mathrm{oc} 3 \mathrm{n} \operatorname{cnc}(\mathrm{N}[\mathrm{C} @ \mathrm{H}](\mathrm{CO}) \mathrm{c} 4 \mathrm{ccccc} 4) \mathrm{c} 23) \mathrm{c} 1$ & 7 & $*$ \\
\hline 848 & $\mathrm{CN}(\mathrm{C}) \mathrm{C} / \mathrm{C}=\mathrm{C} / \mathrm{C}(=\mathrm{O}) \mathrm{N} 1 \mathrm{CCc} 2 \mathrm{c}(\operatorname{sc} 3 \mathrm{ncnc}(\mathrm{N}[\mathrm{C} @ \mathrm{H}](\mathrm{CO}) \mathrm{c} 4 \mathrm{ccccc} 4) \mathrm{c} 23) \mathrm{C} 1$ & 7 & * \\
\hline 849 & Brc1ccec(Nc2ncnc3cc4c(cc23)OCCSCCO4)c1 & 7 & $*$ \\
\hline 850 & $\mathrm{CN}(\mathrm{C}) \mathrm{c} 1 \mathrm{cc} 2 \mathrm{c}(\mathrm{Nc} 3 \mathrm{ccc} 4 \mathrm{c}(\mathrm{cnn} 4 \mathrm{Cc} 4 \mathrm{ccccc} 4) \mathrm{c} 3) \mathrm{ncnc} 2 \mathrm{cn} 1$ & 7 & $*$ \\
\hline 851 & Fc1cccc(COc2ccc(Nc3ncnc4cc(C\#C[C@H]5CCCN5)sc34)cc2Cl)c1 & 7 & $*$ \\
\hline 852 & $\mathrm{CNc} 1 \mathrm{ccc} 2 \mathrm{ncncc} 2 \mathrm{c} 1$ & 7 & $*$ \\
\hline 853 & $\mathrm{Clc} 1 \mathrm{cccc}(\mathrm{Nc} 2[\mathrm{nH}] \mathrm{cnc} 3 \mathrm{nnc}(\mathrm{NCc} 4 \mathrm{cccc} 4) \mathrm{c} 2-3) \mathrm{c} 1$ & 7 & $*$ \\
\hline 854 & $\mathrm{COc} 1 \mathrm{ccc}(\mathrm{CNc} 2[\mathrm{nH}] \mathrm{nc} 3 \mathrm{ncnc}(\mathrm{Nc} 4 \mathrm{cccc}(\mathrm{Cl}) \mathrm{c} 4) \mathrm{c} 23) \mathrm{cc} 1$ & 7 & $*$ \\
\hline 855 & $\mathrm{CC}(\mathrm{C})(\mathrm{O}) \mathrm{C}(=\mathrm{O}) \mathrm{NCCn} 1 \mathrm{ccc} 2 \mathrm{ncnc}(\mathrm{Nc} 3 \operatorname{ccc}(\mathrm{Oc} 4 \operatorname{ccc} 5 \operatorname{sncc} 45) \mathrm{c}(\mathrm{Cl}) \mathrm{c} 3) \mathrm{c} 21 . \mathrm{CS}(=\mathrm{O})(=\mathrm{O}) \mathrm{O}$ & 7 & $*$ \\
\hline 856 & $\mathrm{CC}(\mathrm{C})(\mathrm{CO}) \mathrm{C}(=\mathrm{O}) \mathrm{NCCn} 1 \mathrm{ccc} 2 \mathrm{ncnc}(\mathrm{Nc} 3 \mathrm{ccc}(\mathrm{Oc} 4 \mathrm{cccc} 5 \operatorname{sncc} 45) \mathrm{c}(\mathrm{Cl}) \mathrm{c} 3) \mathrm{c} 21$ & 7 & $*$ \\
\hline 857 & $\mathrm{C}=\mathrm{CC}(=\mathrm{O}) \mathrm{NCC}(=\mathrm{O}) \mathrm{Nc} 1 \mathrm{cccc}(\mathrm{Nc} 2 \mathrm{ncc}(\mathrm{NC}(=\mathrm{O}) \mathrm{c} 3 \operatorname{cc}(\mathrm{NC}(=\mathrm{O}) \mathrm{c} 4 \operatorname{cccc}(\mathrm{C}(\mathrm{F})(\mathrm{F}) \mathrm{F}) \mathrm{c} 4) \operatorname{ccc} 3 \mathrm{C}) \mathrm{cn} 2) \mathrm{c} 1$ & 7 & $*$ \\
\hline 858 & $\mathrm{NC}(=\mathrm{O}) \mathrm{C} 1 \mathrm{CCN}(\mathrm{Cc} 2 \operatorname{ccc}(-\mathrm{c} 3 \operatorname{cc} 4 \mathrm{ncnc}(\mathrm{Nc} 5 \mathrm{ccc} 6[\mathrm{nH}] \operatorname{ccc} 6 \mathrm{c} 5) \mathrm{c} 4 \mathrm{~s} 3) \mathrm{cc} 2) \mathrm{CC} 1$ & 7 & $*$ \\
\hline 859 & $\mathrm{C} \# \mathrm{Cc} 1 \mathrm{cccc}(\mathrm{Nc} 2 \mathrm{ncnn} 3 \mathrm{ccc}(\mathrm{CN} 4 \mathrm{CCC}(\mathrm{N}) \mathrm{CC} 4) \mathrm{c} 23) \mathrm{c} 1$ & 7 & $*$ \\
\hline 860 & Fc1 $1 \mathrm{ccc}(\mathrm{COc} 2 \mathrm{ccc}(\mathrm{Nc} 3 \mathrm{ncnc} 4 \mathrm{cc}(\mathrm{OCCCN} 5 \mathrm{CCOCC} 5) \mathrm{c}(\mathrm{OCCCN} 5 \mathrm{CCOCC} 5) \mathrm{cc} 34) \mathrm{cc} 2 \mathrm{Cl}) \mathrm{c} 1$ & 7 & $*$ \\
\hline 861 & $\mathrm{O}=[\mathrm{N}+]([\mathrm{O}-]) \mathrm{c} 1 \mathrm{cccc}(-\mathrm{c} 2 \mathrm{cc} 3 \mathrm{c}(\mathrm{Nc} 4 \mathrm{cccc}(\mathrm{Cl}) \mathrm{c} 4) \mathrm{ncnc} 3 \mathrm{o} 2) \mathrm{c} 1$ & 7 & $*$ \\
\hline 862 & $\mathrm{c} 1 \mathrm{nc}(\mathrm{Nc} 2 \mathrm{ccc}(\mathrm{N} 3 \mathrm{CCOCC} 3) \mathrm{cc} 2) \mathrm{cc}(\mathrm{Nc} 2 \mathrm{ccc} 3[\mathrm{nH}] \operatorname{ccc} 3 \mathrm{c} 2) \mathrm{n} 1$ & 7 & $*$ \\
\hline
\end{tabular}




\begin{tabular}{|c|c|c|c|}
\hline 863 & $\mathrm{O}=\mathrm{C}(\mathrm{C}=\mathrm{CCN} 1 \mathrm{CCOCC} 1) \mathrm{N} 1 \mathrm{CCOc} 2 \mathrm{cc} 3 \mathrm{ncnc}(\mathrm{Nc} 4 \mathrm{ccc}(\mathrm{F}) \mathrm{c}(\mathrm{Cl}) \mathrm{c} 4) \mathrm{c} 3 \mathrm{cc} 21$ & 7 & $*$ \\
\hline 864 & $\mathrm{COc} 1 \mathrm{cc} 2 \mathrm{ncnc}(\mathrm{Nc} 3 \operatorname{ccc}(\mathrm{F}) \mathrm{c}(\mathrm{Cl}) \mathrm{c} 3) \mathrm{c} 2 \mathrm{cc} 1 \mathrm{OCCC}(=\mathrm{O}) \mathrm{NO}$ & 7.1 & 8.15 \\
\hline 865 & $\mathrm{NNc} 1 \mathrm{cc} 2 \mathrm{ncnc}(\mathrm{Nc} 3 \mathrm{cccc}(\mathrm{Br}) \mathrm{c} 3) \mathrm{c} 2 \mathrm{cn} 1$ & 7.1 & $*$ \\
\hline 866 & $\mathrm{Cc} 1 \mathrm{cccc}(\mathrm{Nc} 2 \mathrm{ncnc} 3 \mathrm{cc}(\mathrm{NCCc} 4 \mathrm{c}[\mathrm{nH}] \mathrm{cn} 4) \mathrm{ncc} 23) \mathrm{c} 1$ & 7.2 & * \\
\hline 867 & $\mathrm{C \# Cc1} \operatorname{ccc}(\mathrm{Nc} 2 \mathrm{ncnc} 3 \operatorname{ccc}(\mathrm{OCCCOP}(\mathrm{N})(=\mathrm{O}) \mathrm{N}(\mathrm{CCCl}) \mathrm{CCCl}) \mathrm{cc} 23) \mathrm{c} 1$ & 7.2 & $*$ \\
\hline 868 & $\mathrm{NNc} 1 \mathrm{c}(\mathrm{Br}) \mathrm{cccc} 1 \mathrm{Nc} 1 \mathrm{ncnc} 2 \mathrm{ccncc} 12$ & 7.244 & $*$ \\
\hline 869 & $\operatorname{CCOC}(=\mathrm{O}) \operatorname{CCCn} 1 \mathrm{c}(=\mathrm{O}) \mathrm{oc} 2 \mathrm{cc} 3 \mathrm{ncnc}(\mathrm{Nc} 4 \mathrm{cc}(\mathrm{C}(=\mathrm{O}) \mathrm{OCC}) \operatorname{ccc} 4 \mathrm{O}) \mathrm{c} 3 \mathrm{cc} 21$ & 7.3 & $*$ \\
\hline 870 & $\mathrm{C}=\mathrm{CC}(=\mathrm{O}) \mathrm{N} 1 \mathrm{CCc} 2 \mathrm{c}(\operatorname{sc} 3 \mathrm{ncnc}(\mathrm{Nc} 4 \mathrm{ccc}(\mathrm{CC}) \mathrm{cc} 4) \mathrm{c} 23) \mathrm{C} 1$ & 7.38 & $*$ \\
\hline 871 & $\mathrm{CN}(\mathrm{C}) \mathrm{CCCCNc} 1 \mathrm{cc} 2 \mathrm{ncnc}(\mathrm{Nc} 3 \mathrm{cccc}(\mathrm{Br}) \mathrm{c} 3) \mathrm{c} 2 \mathrm{cn} 1$ & 7.4 & $*$ \\
\hline 872 & $\mathrm{NP}(=\mathrm{O})(\mathrm{OCCCCOc} 1 \mathrm{ccc} 2 \mathrm{ncnc}(\mathrm{Nc} 3 \operatorname{ccc}(\mathrm{Br}) \mathrm{c} 3) \mathrm{c} 2 \mathrm{c} 1) \mathrm{N}(\mathrm{CCCl}) \mathrm{CCCl}$ & 7.4 & $*$ \\
\hline 873 & $\mathrm{CN}(\mathrm{C}) \mathrm{CCCCNc} 1 \mathrm{c}(\mathrm{Br}) \mathrm{cccc} 1 \mathrm{Nc} 1 \mathrm{ncn} 2 \mathrm{ccncc} 12$ & 7.413 & $*$ \\
\hline 874 & $\mathrm{CN}(\mathrm{C}) \mathrm{CCN}(\mathrm{C}) \mathrm{Cc} 1 \mathrm{c}[\mathrm{nH}] \mathrm{c} 2 \mathrm{cc} 3 \mathrm{ncnc}(\mathrm{Nc} 4 \mathrm{cccc}(\mathrm{Br}) \mathrm{c} 4) \mathrm{c} 3 \mathrm{cc} 12$ & 7.5 & $*$ \\
\hline 875 & COc1 $1 \mathrm{ccc}(-\mathrm{c} 2 \mathrm{cc} 3 \mathrm{c}(\mathrm{NC}(\mathrm{C}) \mathrm{c} 4 \mathrm{ccccc} 4 \mathrm{C}) \mathrm{ncnc} 3[\mathrm{nH}] 2) \mathrm{cc} 1$ & 7.5 & $*$ \\
\hline 876 & $\mathrm{CCC}(=\mathrm{O}) \mathrm{N} 1 \mathrm{CC}[\mathrm{C} @ \mathrm{H}](\mathrm{N} 2 \mathrm{C}(=\mathrm{O}) \mathrm{N}(\mathrm{c} 3 \mathrm{cccc} 3 \mathrm{C}) \mathrm{Cc} 3 \mathrm{cnc}(\mathrm{Nc} 4 \mathrm{ccc}(\mathrm{N} 5 \mathrm{CCN}(\mathrm{C}) \mathrm{CC} 5) \mathrm{c}(\mathrm{C}) \mathrm{c} 4) \mathrm{nc} 32) \mathrm{C} 1$ & 7.6 & 8.12 \\
\hline 877 & $\mathrm{Fc} 1 \mathrm{cccc}(\mathrm{COc} 2 \mathrm{ccc}(\mathrm{Nc} 3 \mathrm{ncnc} 4 \mathrm{cc}[\mathrm{nH}] \mathrm{c} 34) \mathrm{cc} 2 \mathrm{Cl}) \mathrm{c} 1$ & 7.7 & $*$ \\
\hline 878 & $\mathrm{COc} 1 \mathrm{cc} 2 \mathrm{ncnc}(\mathrm{Nc} 3 \operatorname{ccc}(\mathrm{F}) \mathrm{c}(\mathrm{Cl}) \mathrm{c} 3) \mathrm{c} 2 \mathrm{cc} 1 \mathrm{OCCCC}(=\mathrm{O}) \mathrm{NO}$ & 7.8 & 8.11 \\
\hline 879 & $\mathrm{C}=\mathrm{CC}(=\mathrm{O}) \mathrm{Nc} 1 \mathrm{cccc}(-\mathrm{n} 2 \mathrm{c}(=\mathrm{O}) \mathrm{c}(-\mathrm{c} 3 \mathrm{cccc} 3) \mathrm{cc} 3 \mathrm{cnc}(\mathrm{Nc} 4 \mathrm{ccc}(\mathrm{N} 5 \mathrm{CCN}(\mathrm{C}) \mathrm{CC} 5) \mathrm{cc} 4 \mathrm{OC}) \mathrm{nc} 32) \mathrm{c} 1$ & 7.8 & $*$ \\
\hline 880 & $\mathrm{O}=\mathrm{C} 1 \mathrm{NCc} 2 \mathrm{ccc}(\mathrm{Oc} 3 \mathrm{ccc}(\mathrm{Nc} 4 \mathrm{ncnc} 5 \mathrm{ccn}(\mathrm{CCO}) \mathrm{c} 45) \mathrm{cc} 3 \mathrm{Cl}) \mathrm{cc} 21$ & 7.8 & $*$ \\
\hline 881 & $\mathrm{C} \# \mathrm{Cc} 1 \mathrm{cccc}(\mathrm{Nc} 2 \mathrm{ncnc} 3 \mathrm{cc}(\mathrm{OC}) \mathrm{c}(\mathrm{NC}(=\mathrm{O}) / \mathrm{C}=\mathrm{C} / \mathrm{CNC} 4 \mathrm{CC} 4) \mathrm{cc} 23) \mathrm{c} 1$ & 7.9 & $*$ \\
\hline 882 & $\mathrm{CCNc} 1 \mathrm{cc} 2 \mathrm{sc} 3 \mathrm{c}(\mathrm{Nc} 4 \mathrm{cccc}(\mathrm{Br}) \mathrm{c} 4) \mathrm{ncnc} 3 \mathrm{c} 2 \mathrm{cc} 1 \mathrm{~F} . \mathrm{CCO}$ & 7.9 & $*$ \\
\hline 883 & $\mathrm{Cc} 1 \mathrm{ccc}(\mathrm{C}(=\mathrm{O}) \mathrm{Nc} 2 \mathrm{ccc}(\mathrm{CN} 3 \mathrm{CCN}(\mathrm{C}) \mathrm{CC} 3) \mathrm{c}(\mathrm{C}(\mathrm{F})(\mathrm{F}) \mathrm{F}) \mathrm{c} 2) \operatorname{cc} 1 \mathrm{NC}(=\mathrm{O}) \mathrm{c} 1 \mathrm{cnc} 2[\mathrm{nH}] \operatorname{ccc} 2 \mathrm{c} 1$ & 8 & 8.10 \\
\hline 884 & $\mathrm{CN} 1 \mathrm{CCN}(\mathrm{c} 2 \mathrm{ccc}(\mathrm{Nc} 3 \mathrm{ncnc} 4 \mathrm{cc} 5 \mathrm{oc}(=\mathrm{O}) \mathrm{n}(\mathrm{CCOC}(=\mathrm{O}) \mathrm{CBr}) \mathrm{c} 5 \mathrm{cc} 34) \mathrm{cc} 2 \mathrm{Cl}) \mathrm{CC} 1$ & 8 & 8.10 \\
\hline 885 & $\mathrm{C}[\mathrm{C} @ @ \mathrm{H}](\mathrm{Nc} 1 \mathrm{ncnc} 2 \mathrm{sc}(-\mathrm{c} 3 \mathrm{ccc}(\mathrm{F}) \mathrm{c}(\mathrm{C}=\mathrm{O}) \mathrm{c} 3) \mathrm{cc} 12) \mathrm{c} 1 \mathrm{ccccc} 1$ & 8 & 8.10 \\
\hline 886 & C[C@@H](Nc1ncnc2sc(-c3eccc $(\mathrm{C}(=\mathrm{O}) \mathrm{O}) \mathrm{c} 3) \mathrm{cc} 12) \mathrm{c} 1 \mathrm{ccccc} 1$ & 8 & 8.10 \\
\hline 887 & $\mathrm{COc} 1 \mathrm{cc} 2 \mathrm{ncnc}(\mathrm{Nc} 3 \operatorname{ccc}(\mathrm{Cl}) \mathrm{c} 3 \mathrm{~F}) \mathrm{c} 2 \mathrm{cc} 1 \mathrm{CN} 1 \mathrm{CCCC}[\mathrm{C} @ @ \mathrm{H}] 1 \mathrm{C}(\mathrm{N})=\mathrm{O}$ & 8 & $*$ \\
\hline 888 & $\mathrm{COc} 1 \mathrm{cc} 2 \mathrm{ncnc}(\mathrm{Nc} 3 \operatorname{ccc}(\mathrm{Cl}) \mathrm{c} 3 \mathrm{~F}) \mathrm{c} 2 \mathrm{cc} 1 \mathrm{CN}(\mathrm{C})[\mathrm{C} @ @ \mathrm{H}](\mathrm{C}) \mathrm{C}(\mathrm{N})=\mathrm{O}$ & 8 & $*$ \\
\hline 889 & $\mathrm{CN}(\mathrm{C}) \mathrm{CCC}(=\mathrm{O}) \mathrm{Nc} 1 \mathrm{cccc}(-\mathrm{c} 2 \mathrm{c}(-\mathrm{c} 3 \operatorname{ccccc} 3) \mathrm{oc} 3 \mathrm{ncnc}(\mathrm{N}[\mathrm{C} @ \mathrm{H}](\mathrm{CO}) \mathrm{c} 4 \mathrm{cccc} 4) \mathrm{c} 23) \mathrm{c} 1$ & 8 & $*$ \\
\hline 890 & $\mathrm{O}=\mathrm{C}(/ \mathrm{C}=\mathrm{C} / \mathrm{CNCc} 1 \mathrm{nccc} 1) \mathrm{Nc} 1 \mathrm{cc} 2 \mathrm{c}(\mathrm{Nc} 3 \mathrm{ccc}(\mathrm{F}) \mathrm{c}(\mathrm{Cl}) \mathrm{c} 3) \mathrm{ncnc} 2 \mathrm{~s} 1$ & 8 & $*$ \\
\hline 891 & $\mathrm{CCN}(\mathrm{CC}) \mathrm{C} / \mathrm{C}=\mathrm{C} / \mathrm{C}(=\mathrm{O}) \mathrm{Nc} 1 \mathrm{cc} 2 \mathrm{c}(\mathrm{Nc} 3 \mathrm{ccc}(\mathrm{F}) \mathrm{c}(\mathrm{Cl}) \mathrm{c} 3) \mathrm{ncnc} 2 \mathrm{~s} 1$ & 8 & $*$ \\
\hline 892 & $\mathrm{COc} 1 \mathrm{ccccc} 1-\mathrm{c} 1 \mathrm{cc} 2 \mathrm{c}(\mathrm{NC}(\mathrm{CO}) \mathrm{c} 3 \mathrm{ccccc} 3) \mathrm{ncnc} 2 \mathrm{~s} 1$ & 8 & $*$ \\
\hline 893 & $\mathrm{CCOc} 1 \mathrm{cc} 2 \mathrm{ncnc}(\mathrm{Nc} 3 \operatorname{ccc} 4 \mathrm{c}(\operatorname{cnn} 4 \mathrm{Cc} 4 \mathrm{cccc} 4) \mathrm{c} 3) \mathrm{c} 2 \mathrm{cc} 1 \mathrm{NC}(=\mathrm{O}) / \mathrm{C}=\mathrm{C} / \mathrm{CN} 1 \mathrm{CCCCC} 1$ & 8 & $*$ \\
\hline 894 & $\mathrm{CNCCOc} 1 \mathrm{cc} 2 \mathrm{c}(\mathrm{Nc} 3 \mathrm{ccc}(\mathrm{F}) \mathrm{c}(\mathrm{Cl}) \mathrm{c} 3) \mathrm{ncnc} 2 \mathrm{cc} 1 \mathrm{OC}$ & 8 & $*$ \\
\hline 895 & COCCNCCOc1cc2c(Nc3ecc(F)c(Cl)c3)ncnc2cc1OC & 8 & $*$ \\
\hline 896 & $\mathrm{COc} 1 \mathrm{cc} 2 \mathrm{ncnc}(\mathrm{Nc} 3 \mathrm{ccc}(\mathrm{F}) \mathrm{c}(\mathrm{Cl}) \mathrm{c} 3) \mathrm{c} 2 \mathrm{cc} 1 \mathrm{OCC}(\mathrm{O}) \mathrm{Cn} 1 \mathrm{ccnc} 1$ & 8 & $*$ \\
\hline 897 & $\mathrm{Fc} 1 \mathrm{cccc}(\mathrm{COc} 2 \mathrm{ccc}(\mathrm{Nc} 3 \mathrm{ncnc} 4 \mathrm{cc}(-\mathrm{c} 5 \mathrm{cccs} 5) \mathrm{sc} 34) \mathrm{cc} 2 \mathrm{Cl}) \mathrm{c} 1$ & 8 & $*$ \\
\hline 898 & $\mathrm{C}=\mathrm{CC}(=\mathrm{O}) \mathrm{N} 1 \mathrm{CCc} 2 \mathrm{c}(\operatorname{sc} 3 n \mathrm{nnc}(\mathrm{N}[\mathrm{C} @ \mathrm{H}](\mathrm{CO}) \mathrm{c} 4 \mathrm{ccccc} 4) \mathrm{c} 23) \mathrm{C} 1$ & 8 & $*$ \\
\hline 899 & $\mathrm{CO} / \mathrm{N}=\mathrm{C} / \mathrm{c} 1 \mathrm{c}(\mathrm{N}) \mathrm{ncnc} 1 \mathrm{Nc} 1 \mathrm{ccc} 2 \mathrm{c}(\mathrm{cnn} 2 \mathrm{Cc} 2 \mathrm{cccc}(\mathrm{F}) \mathrm{c} 2) \mathrm{c} 1$ & 8 & $*$ \\
\hline 900 & $\mathrm{CN}(\mathrm{C}) / \mathrm{N}=\mathrm{C} / \mathrm{c} 1 \mathrm{c}(\mathrm{N}) \mathrm{ncnc} 1 \mathrm{Nc} 1 \mathrm{ccc} 2 \mathrm{c}(\mathrm{cnn} 2 \mathrm{Cc} 2 \mathrm{cccc}(\mathrm{F}) \mathrm{c} 2) \mathrm{c} 1$ & 8 & * \\
\hline 901 & Brc1ccec(Nc2ncnc3ec4c(cc23)OCCCSCCCO4)c1 & 8 & $*$ \\
\hline 902 & Oc1 cce $(\mathrm{Nc} 2[\mathrm{nH}] \mathrm{nc} 3 \mathrm{ncnc}(\mathrm{Nc} 4 \mathrm{cccc}(\mathrm{Cl}) \mathrm{c} 4) \mathrm{c} 23) \mathrm{cc} 1$ & 8 & $*$ \\
\hline 903 & $\mathrm{COc} 1 \mathrm{cccc}(\mathrm{Nc} 2[\mathrm{nH}] \mathrm{nc} 3 \mathrm{ncnc}(\mathrm{Nc} 4 \operatorname{cccc}(\mathrm{Cl}) \mathrm{c} 4) \mathrm{c} 23) \mathrm{c} 1$ & 8 & $*$ \\
\hline 904 & $\mathrm{COc} 1 \mathrm{cccc}(\mathrm{CNc} 2[\mathrm{nH}] \mathrm{nc} 3 \mathrm{ncnc}(\mathrm{Nc} 4 \mathrm{cccc}(\mathrm{Cl}) \mathrm{c} 4) \mathrm{c} 23) \mathrm{c} 1$ & 8 & $*$ \\
\hline 905 & $\mathrm{Oc} 1 \mathrm{cc}(\mathrm{O}) \mathrm{c} 2 \mathrm{c}(\mathrm{O}) \mathrm{c}(-\mathrm{c} 3 \mathrm{ccc}(\mathrm{Cl}) \mathrm{c} 3) \mathrm{cnc} 2 \mathrm{c} 1$ & 8 & $*$ \\
\hline
\end{tabular}




\begin{tabular}{|c|c|c|c|}
\hline 906 & $\mathrm{CC}(\mathrm{C})(\mathrm{CO}) \mathrm{NCc} 1 \mathrm{ccc}(-\mathrm{c} 2 \mathrm{cc} 3 \mathrm{ncnc}(\mathrm{Nc} 4 \mathrm{ccc} 5[\mathrm{nH}] \operatorname{ccc} 5 \mathrm{c} 4) \mathrm{c} 3 \mathrm{~s} 2) \mathrm{cc} 1$ & 8 & $*$ \\
\hline 907 & Br.C[C@@H](Nc1ncnc2[nH]c(-c3ecc(O)cc3)cc12)c1 ccccc1F & 8 & $*$ \\
\hline 908 & $\mathrm{COc} 1 \mathrm{cc} 2 \mathrm{ncnc}(\mathrm{Nc} 3 \mathrm{ccc}(\mathrm{Cl}) \mathrm{c} 3 \mathrm{~F}) \mathrm{c} 2 \mathrm{cc} 1 \mathrm{CNC}(=\mathrm{O})[\mathrm{C} @ \mathrm{H}] 1 \mathrm{CCCCN} 1 \mathrm{C}$ & 8 & $*$ \\
\hline 909 & $\mathrm{C}=\mathrm{CC}(=\mathrm{O}) \mathrm{N} 1 \mathrm{CCc} 2 \mathrm{ncnc}(\mathrm{Nc} 3 \operatorname{ccc}(\mathrm{OCc} 4 \mathrm{ccc} n 4) \mathrm{c}(\mathrm{Cl}) \mathrm{c} 3) \mathrm{c} 2 \mathrm{C} 1$ & 8 & $*$ \\
\hline 910 & $\mathrm{C}=\mathrm{CC}(=\mathrm{O}) \mathrm{N} 1 \mathrm{CCc} 2 \mathrm{ncnc}(\mathrm{Nc} 3 \mathrm{ccc}(\mathrm{SCc} 4 \mathrm{cccc}(\mathrm{F}) \mathrm{c} 4) \mathrm{c}(\mathrm{Cl}) \mathrm{c} 3) \mathrm{c} 2 \mathrm{C} 1$ & 8 & $*$ \\
\hline 911 & $\mathrm{CHCc} 1 \mathrm{ccc}(\mathrm{Nc} 2 \mathrm{ncnc} 3 \mathrm{cc}(\mathrm{OC} 4 \mathrm{CCN}(\mathrm{C}) \mathrm{CC} 4) \mathrm{c}(\mathrm{NC}(=\mathrm{O}) / \mathrm{C}=\mathrm{C} / \mathrm{CN}(\mathrm{C}) \mathrm{C}) \mathrm{cc} 23) \mathrm{c} 1$ & 8.1 & $*$ \\
\hline 912 & $\mathrm{CN}(\mathrm{C}) \mathrm{C} / \mathrm{C}=\mathrm{C} / \mathrm{C}(=\mathrm{O}) \mathrm{Nc} 1 \mathrm{cc} 2 \mathrm{c}(\mathrm{Nc} 3 \operatorname{ccc}(\mathrm{OCc} 4 \mathrm{ccc} n 4) \mathrm{c}(\mathrm{Cl}) \mathrm{c} 3) \mathrm{ncnc} 2 \mathrm{cc} 1 \mathrm{O}[\mathrm{C} @ \mathrm{H}] 1 \mathrm{CCOC} 1$ & 8.1 & $*$ \\
\hline 913 & $\mathrm{CN}(\mathrm{C}) \mathrm{CCN}(\mathrm{C}) \mathrm{c} 1 \mathrm{cc} 2 \mathrm{c}(\mathrm{Nc} 3 \mathrm{cccc}(\mathrm{Br}) \mathrm{c} 3) \mathrm{ncnc} 2 \mathrm{cn} 1$ & 8.1 & $*$ \\
\hline 914 & $\mathrm{COc} 1 \mathrm{ccc}(-\mathrm{c} 2 \mathrm{cc} 3 \mathrm{c}(\mathrm{N}[\mathrm{C} @ \mathrm{H}](\mathrm{C}) \mathrm{c} 4 \mathrm{cccc} 4 \mathrm{Cl}) \mathrm{ncnc} 3[\mathrm{nH}] 2) \mathrm{cc} 1$ & 8.1 & $*$ \\
\hline 915 & $\mathrm{C}=\mathrm{CC}(=\mathrm{O}) \mathrm{Nc} 1 \mathrm{cc}(\mathrm{Nc} 2 \mathrm{n}[\mathrm{nH}] \mathrm{c} 3 \operatorname{ccc}(-\mathrm{c} 4 \mathrm{ccc} 5 \mathrm{cccc} 5 \mathrm{c} 4) \operatorname{cc} 23) \mathrm{c}(\mathrm{OC}) \mathrm{cc} 1 \mathrm{~N}(\mathrm{C}) \mathrm{CCN}(\mathrm{C}) \mathrm{C}$ & 8.1 & $*$ \\
\hline 916 & $\mathrm{C} \# \mathrm{Cc} 1 \mathrm{cccc}(\mathrm{Nc} 2 \mathrm{ncnc} 3 \mathrm{cc}(\mathrm{OCCCCCCC}(=\mathrm{O}) \mathrm{NO}) \mathrm{c}(\mathrm{OC}) \mathrm{cc} 23) \mathrm{c} 1$ & 8.2 & 8.09 \\
\hline 917 & $\mathrm{O}=\mathrm{C}(\mathrm{Nc} 1 \mathrm{cc} 2 \mathrm{c}(\mathrm{Nc} 3 \mathrm{ccc}(\mathrm{F}) \mathrm{c}(\mathrm{Cl}) \mathrm{c} 3) \mathrm{ncnc} 2 \mathrm{cc} 1 \mathrm{OCCCN} 1 \mathrm{CCOCC} 1) \mathrm{c} 1 \mathrm{cc}([\mathrm{N}+](=\mathrm{O})[\mathrm{O}-]) \operatorname{ccc} 1 \mathrm{Cl}$ & 8.3 & 8.08 \\
\hline 918 & $\mathrm{Clc} 1 \mathrm{cccc}(\mathrm{Nc} 2 \mathrm{ncnc} 3 \mathrm{cc} 4 \mathrm{c}(\mathrm{cc} 23) \mathrm{OCCO} 4) \mathrm{c} 1$ & 8.3 & $*$ \\
\hline 919 & $\mathrm{COc} 1 \mathrm{cc} 2 \mathrm{ncnc}(\mathrm{Nc} 3 \mathrm{ccc}(\mathrm{F}) \mathrm{c}(\mathrm{Cl}) \mathrm{c} 3) \mathrm{c} 2 \mathrm{cc} 1 \mathrm{OCCCN} 1 \mathrm{CCNCCNCC} 1$ & 8.3 & $*$ \\
\hline 920 & $\mathrm{CC} 1(\mathrm{C}) \mathrm{CC}(=\mathrm{NNc} 2 \operatorname{cccc} 2) \mathrm{C}(=\mathrm{NNc} 2 \mathrm{ccc}(\mathrm{Cl}) \mathrm{cc} 2) \mathrm{c} 2 \mathrm{c} 1 \mathrm{sc}(\mathrm{N}) \mathrm{c} 2 \mathrm{C} \# \mathrm{~N}$ & 8.31 & $*$ \\
\hline 921 & $\mathrm{CN} 1 \mathrm{CCN}(\mathrm{Cc} 2 \mathrm{ccc}(\mathrm{NC}(=\mathrm{O}) \mathrm{Nc} 3 \mathrm{ccc} 4 \mathrm{ncnc}(\mathrm{Nc} 5 \mathrm{ccc}(\mathrm{OCc} 6 \mathrm{ccc}(\mathrm{F}) \mathrm{c} 6) \mathrm{c}(\mathrm{Cl}) \mathrm{c} 5) \mathrm{c} 4 \mathrm{c} 3) \mathrm{cc} 2) \mathrm{CC} 1$ & 8.4 & $*$ \\
\hline 922 & $\mathrm{CN}(\mathrm{C}) \mathrm{CCCCCNc} 1 \mathrm{cc} 2 \mathrm{ncnc}(\mathrm{Nc} 3 \mathrm{cccc}(\mathrm{Br}) \mathrm{c} 3) \mathrm{c} 2 \mathrm{cn} 1$ & 8.4 & $*$ \\
\hline 923 & $\mathrm{O}=\mathrm{C}(\mathrm{Nc} 1 \mathrm{ccc} 2 \mathrm{ncnc}(\mathrm{Nc} 3 \mathrm{ccc}(\mathrm{Br}) \mathrm{c} 3) \mathrm{c} 2 \mathrm{c} 1) \mathrm{c} 1 \mathrm{ccco} 1$ & 8.4 & $*$ \\
\hline 924 & $\mathrm{O}=\mathrm{C}(\mathrm{COc} 1 \mathrm{ccc}(\mathrm{F}) \mathrm{cc} 1) \mathrm{Nc} 1 \mathrm{ccc} 2 \mathrm{ncnc}(\mathrm{Nc} 3 \mathrm{cccc}(\mathrm{Br}) \mathrm{c} 3) \mathrm{c} 2 \mathrm{c} 1$ & 8.43 & 8.07 \\
\hline 925 & $\mathrm{Cc} 1 \mathrm{cc}(\mathrm{Nc} 2 \mathrm{ncc} 3 \mathrm{c}(\mathrm{n} 2) \mathrm{N}([\mathrm{C} @ \mathrm{H}] 2 \mathrm{CCN}(\mathrm{C}(=\mathrm{O}) \mathrm{C}(\mathrm{C}) \mathrm{C}) \mathrm{C} 2) \mathrm{C}(=\mathrm{O}) \mathrm{N}(\mathrm{c} 2 \mathrm{cccc} 2 \mathrm{Cl}) \mathrm{C} 3) \operatorname{ccc} 1 \mathrm{~N} 1 \mathrm{CCN}(\mathrm{C}) \mathrm{CC} 1$ & 8.5 & 8.07 \\
\hline 926 & $\mathrm{CN}(\mathrm{C}) \mathrm{CCCCCNc} 1 \mathrm{c}(\mathrm{Br}) \mathrm{ccc} 1 \mathrm{Nc} 1 \mathrm{ncnc} 2 \mathrm{ccncc} 12$ & 8.511 & $*$ \\
\hline 927 & $\mathrm{C}=\mathrm{C}=\mathrm{CC}(=\mathrm{O}) \mathrm{Nc} 1 \mathrm{cc}(\mathrm{Nc} 2 \mathrm{nccc}(\mathrm{C} 3=\mathrm{CN}(\mathrm{C}) \mathrm{C} 4 \mathrm{C}=\mathrm{CC}=\mathrm{CC} 34) \mathrm{n} 2) \mathrm{c}(\mathrm{OC}) \mathrm{cc} 1 \mathrm{~N} 1 \mathrm{CCC}(\mathrm{N} 2 \mathrm{CCOCC} 2) \mathrm{CC} 1$ & 8.6 & $*$ \\
\hline 928 & $\mathrm{C}=\mathrm{C}=\mathrm{CC}(=\mathrm{O}) \mathrm{Nc} 1 \mathrm{cc}(\mathrm{Nc} 2 \mathrm{nccc}(-\mathrm{c} 3 \mathrm{cn}(\mathrm{C}) \mathrm{c} 4 \mathrm{ccccc} 34) \mathrm{n} 2) \mathrm{c}(\mathrm{OC}) \mathrm{cc} 1 \mathrm{~N} 1 \mathrm{CCC}(\mathrm{N} 2 \mathrm{CCOCC} 2) \mathrm{CC} 1$ & 8.6 & $*$ \\
\hline 929 & $\mathrm{C}=\mathrm{CC}(=\mathrm{O}) \mathrm{Nc} 1 \mathrm{cccc}(-\mathrm{n} 2 \mathrm{c}(=\mathrm{O}) \mathrm{c}(=\mathrm{O}) \mathrm{n}(\mathrm{C}(\mathrm{C}) \mathrm{C}) \mathrm{c} 3 \mathrm{cnc}(\mathrm{Nc} 4 \mathrm{ccc}(\mathrm{N} 5 \mathrm{CCN}(\mathrm{C}) \mathrm{CC} 5) \mathrm{c}(\mathrm{OC}) \mathrm{c} 4) \mathrm{nc} 32) \mathrm{c} 1$ & 8.6 & $*$ \\
\hline 930 & $\operatorname{CCOC}(=\mathrm{O}) \operatorname{CCCn} 1 \mathrm{c}(=\mathrm{O}) \mathrm{oc} 2 \mathrm{cc} 3 \operatorname{nenc}(\mathrm{Nc} 4 \mathrm{cccc}(\mathrm{O}) \mathrm{c} 4) \mathrm{c} 3 \mathrm{cc} 21$ & 8.7 & $*$ \\
\hline 931 & $\mathrm{NP}(=\mathrm{O})(\mathrm{OCCCC}(=\mathrm{O}) \mathrm{Nc} 1 \mathrm{ccc} 2 \mathrm{ncnc}(\mathrm{Nc} 3 \mathrm{ccc}(\mathrm{F}) \mathrm{c}(\mathrm{Cl}) \mathrm{c} 3) \mathrm{c} 2 \mathrm{c} 1) \mathrm{N}(\mathrm{CCCl}) \mathrm{CCCl}$ & 8.7 & $*$ \\
\hline 932 & $\mathrm{C}=\mathrm{CC}(=\mathrm{O}) \mathrm{N} 1 \mathrm{CCc} 2 \mathrm{c}(\mathrm{sc} 3 \mathrm{ncnc}(\mathrm{Nc} 4 \mathrm{cccc}(\mathrm{CC}) \mathrm{c} 4) \mathrm{c} 23) \mathrm{C} 1$ & 8.73 & $*$ \\
\hline 933 & Brc1cece $(\mathrm{Nc} 2 \mathrm{ncnc} 3 \mathrm{cc} 4 \mathrm{c}(\mathrm{cnn} 4 \mathrm{CCCN} 4 \mathrm{CCOCC} 4) \mathrm{cc} 23) \mathrm{c} 1$ & 8.8 & $*$ \\
\hline 934 & $\mathrm{CN}(\mathrm{C}) \mathrm{CCCNc} 1 \mathrm{cc} 2 \mathrm{ncnc}(\mathrm{Nc} 3 \mathrm{cccc}(\mathrm{Br}) \mathrm{c} 3) \mathrm{c} 2 \mathrm{cn} 1$ & 8.8 & $*$ \\
\hline 935 & OCCn $1 \mathrm{ccc} 2 \mathrm{ncnc}(\mathrm{Nc} 3 \operatorname{ccc}(\mathrm{Oc} 4 \mathrm{cccc} 5 \operatorname{scc} 45) \mathrm{c}(\mathrm{Cl}) \mathrm{c} 3) \mathrm{c} 21$ & 8.8 & $*$ \\
\hline 936 & $\mathrm{C}=\mathrm{CC}(=\mathrm{O}) \mathrm{Nc} 1 \mathrm{cccc}(\mathrm{N} 2 \mathrm{C}(=\mathrm{O}) \mathrm{N}(\mathrm{C}) \mathrm{Cc} 3 \mathrm{cnc}(\mathrm{Nc} 4 \mathrm{ccc}(\mathrm{N} 5 \mathrm{CCN}(\mathrm{C}) \mathrm{CC} 5) \operatorname{cc} 4 \mathrm{OC}(\mathrm{C}) \mathrm{C}) \mathrm{nc} 32) \mathrm{c} 1$ & 8.81 & 8.06 \\
\hline 937 & $\mathrm{COCCOc} 1 \mathrm{cc} 2 \mathrm{ncnc}(\mathrm{Nc} 3 \mathrm{ccc}(\mathrm{F}) \mathrm{c}(\mathrm{Cl}) \mathrm{c} 3) \mathrm{c} 2 \mathrm{cc} 1 \mathrm{NC}(=\mathrm{O}) / \mathrm{C}=\mathrm{C} / \mathrm{CN}(\mathrm{C}) \mathrm{C} 1 \mathrm{CC} 1$ & 8.9 & $*$ \\
\hline 938 & $\operatorname{Oc} 1 \mathrm{ccc}(\mathrm{NC}(=\mathrm{S}) \mathrm{Nc} 2 \mathrm{ccc} 3 \mathrm{ncnc}(\mathrm{Nc} 4 \mathrm{cccc}(\mathrm{Br}) \mathrm{c} 4) \mathrm{c} 3 \mathrm{c} 2) \mathrm{cc} 1$ & 8.9 & $*$ \\
\hline 939 & $\mathrm{O}=\mathrm{C}(\mathrm{NCc} 1 \mathrm{cccc} 1) \mathrm{Nc} 1 \mathrm{ccc} 2 \mathrm{ncnc}(\mathrm{Nc} 3 \mathrm{cccc}(\mathrm{Br}) \mathrm{c} 3) \mathrm{c} 2 \mathrm{c} 1$ & 8.9 & $*$ \\
\hline 940 & $\mathrm{CN} 1 \mathrm{CCN}(\mathrm{CC} 2 \mathrm{COc} 3 \mathrm{cc} 4 \mathrm{ncnc}(\mathrm{Nc} 5 \mathrm{cccc}(\mathrm{Br}) \mathrm{c} 5) \mathrm{c} 4 \mathrm{cc} 3 \mathrm{O} 2) \mathrm{CC} 1$ & 8.9 & $*$ \\
\hline 941 & $\mathrm{CN}(\mathrm{C}) \mathrm{CCCNc} 1 \mathrm{c}(\mathrm{Br}) \mathrm{ccc} 1 \mathrm{Nc} 1 \mathrm{ncnc} 2 \mathrm{ccncc} 12$ & 8.913 & $*$ \\
\hline 942 & $\mathrm{Cc} 1 \mathrm{ncnc}(\mathrm{Nc} 2 \mathrm{ccc}(\mathrm{OCc} 3 \operatorname{ccc}(\mathrm{F}) \mathrm{c} 3) \mathrm{c}(\mathrm{Cl}) \mathrm{c} 2) \mathrm{c} 1 \mathrm{C} \# \mathrm{Cc} 1 \mathrm{ccc}(\mathrm{CN} 2 \mathrm{CCCC} 2) \mathrm{cc} 1$ & 9 & 8.05 \\
\hline 943 & $\mathrm{C \# Cc1} \operatorname{cccc}(\mathrm{Nc} 2 \mathrm{ncnc} 3 \mathrm{cc}(\mathrm{OCCOC}(=\mathrm{O}) \mathrm{C}(\mathrm{C}) \mathrm{c} 4 \mathrm{ccc}(\mathrm{CC}(\mathrm{C}) \mathrm{C}) \mathrm{cc} 4) \mathrm{c}(\mathrm{OCCOC}) \mathrm{cc} 23) \mathrm{c} 1$ & 9 & 8.05 \\
\hline 944 & $\mathrm{C}=\mathrm{CC}(=\mathrm{O}) \mathrm{N} 1 \mathrm{CCC}[\mathrm{C} @ \mathrm{H}] 1 \mathrm{C}(=\mathrm{O}) \mathrm{Nc} 1 \mathrm{cc} 2 \mathrm{c}(\mathrm{Nc} 3 \mathrm{ccc}(\mathrm{F}) \mathrm{c}(\mathrm{Cl}) \mathrm{c} 3 \mathrm{~F}) \mathrm{ncnc} 2 \mathrm{cc} 1 \mathrm{OCCOC}$ & 9 & 8.05 \\
\hline 945 & $\mathrm{CCN} 1 \mathrm{CCN}(\mathrm{CCCC} \# \mathrm{Cc} 2 \mathrm{c}(\mathrm{C}) \mathrm{ncnc} 2 \mathrm{Nc} 2 \mathrm{ccc}(\mathrm{OCc} 3 \mathrm{cccc}(\mathrm{F}) \mathrm{c} 3) \mathrm{c}(\mathrm{Cl}) \mathrm{c} 2) \mathrm{CC} 1$ & 9 & 8.05 \\
\hline 946 & $\mathrm{COC}(=\mathrm{O}) \mathrm{c} 1 \mathrm{cccc}(-\mathrm{c} 2 \mathrm{cc} 3 \mathrm{c}(\mathrm{N}[\mathrm{C} @ \mathrm{H}](\mathrm{C}) \mathrm{c} 4 \mathrm{cccc} 4) \mathrm{ncnc} 3 \mathrm{~s} 2) \mathrm{c} 1 \mathrm{OC}$ & 9 & 8.05 \\
\hline 947 & OC[C@@H](Nc1ncnc2sc(-c3ecccc3)cc12)c1 ccccc1 & 9 & 8.05 \\
\hline 948 & $\mathrm{COc} 1 \mathrm{cc} 2 \mathrm{ncnc}(\mathrm{Nc} 3 \operatorname{ccc}(\mathrm{Cl}) \mathrm{c} 3 \mathrm{~F}) \mathrm{c} 2 \mathrm{cc} 1 \mathrm{CN}(\mathrm{C})[\mathrm{C} @ \mathrm{H}](\mathrm{C}) \mathrm{C}(\mathrm{N})=\mathrm{O}$ & 9 & $*$ \\
\hline
\end{tabular}




\begin{tabular}{|c|c|c|c|}
\hline 949 & $\mathrm{COc} 1 \mathrm{cc} 2 \mathrm{ncnc}(\mathrm{Nc} 3 \operatorname{ccc}(\mathrm{Cl}) \mathrm{c} 3 \mathrm{~F}) \mathrm{c} 2 \mathrm{cc} 1 \mathrm{CN}(\mathrm{C}) \mathrm{C} 1(\mathrm{C}(\mathrm{N})=\mathrm{O}) \mathrm{CCN}(\mathrm{C}) \mathrm{CC} 1$ & 9 & $*$ \\
\hline 950 & $\mathrm{COc} 1 \mathrm{cc} 2 \mathrm{ncnc}(\mathrm{Nc} 3 \operatorname{ccc}(\mathrm{Cl}) \mathrm{c} 3 \mathrm{~F}) \mathrm{c} 2 \mathrm{cc} 1 \mathrm{CN}(\mathrm{C}) \mathrm{C} 1(\mathrm{C}(\mathrm{N})=\mathrm{O}) \mathrm{CN}(\mathrm{C}(\mathrm{C}) \mathrm{C}) \mathrm{C} 1$ & 9 & $*$ \\
\hline 951 & $\mathrm{COc} 1 \mathrm{cc} 2 \mathrm{ncnc}(\mathrm{Nc} 3 \mathrm{cc}(\mathrm{Cl}) \mathrm{ccc} 3 \mathrm{~F}) \mathrm{c} 2 \mathrm{cc} 1 \mathrm{OCC} 1 \mathrm{CCN}(\mathrm{C}) \mathrm{CC} 1$ & 9 & $*$ \\
\hline 952 & $\mathrm{COc} 1 \mathrm{cc} 2 \mathrm{ncnc}(\mathrm{Nc} 3 \mathrm{cc}(\mathrm{Cl}) \operatorname{ccc} 3 \mathrm{~F}) \mathrm{c} 2 \mathrm{cc} 1 \mathrm{OC} 1 \mathrm{CCN}(\mathrm{CC}(\mathrm{N})=\mathrm{O}) \mathrm{CC} 1$ & 9 & $*$ \\
\hline 953 & $\mathrm{O}=\mathrm{C}(/ \mathrm{C}=\mathrm{C} / \mathrm{CN} 1 \mathrm{CCCCC} 1) \mathrm{Nc} 1 \mathrm{cc} 2 \mathrm{c}(\mathrm{Nc} 3 \mathrm{ccc}(\mathrm{F}) \mathrm{c}(\mathrm{Cl}) \mathrm{c} 3) \mathrm{ncnc} 2 \mathrm{~s} 1$ & 9 & $*$ \\
\hline 954 & COc1cccc1-c1cc2c(N[C@H](C)c3ecccs3)ncnc2s1 & 9 & $*$ \\
\hline 955 & $\mathrm{CN}(\mathrm{C}) \mathrm{C} / \mathrm{C}=\mathrm{C} / \mathrm{C}(=\mathrm{O}) \mathrm{Nc} 1 \mathrm{cc} 2 \mathrm{c}(\mathrm{Nc} 3 \mathrm{ccc}(\mathrm{OCc} 4 \mathrm{ccc} n 4) \mathrm{cc} 3) \mathrm{ncnc} 2 \mathrm{cc} 1 \mathrm{O}[\mathrm{C} @ \mathrm{H}] 1 \mathrm{CCOC} 1$ & 9 & $*$ \\
\hline 956 & $\mathrm{NC}(=\mathrm{O}) \mathrm{Nc} 1 \mathrm{ccc}(\mathrm{C}(=\mathrm{O}) \mathrm{Nc} 2 \mathrm{ccc} 3 \mathrm{ncnc}(\mathrm{Nc} 4 \mathrm{ccc}(\mathrm{F}) \mathrm{c}(\mathrm{Cl}) \mathrm{c} 4) \mathrm{c} 3 \mathrm{c} 2) \mathrm{cc} 1$ & 9 & $*$ \\
\hline 957 & $\mathrm{CCC}(=\mathrm{O}) \mathrm{Nc} 1 \mathrm{cc} 2 \mathrm{c}(\mathrm{Nc} 3 \mathrm{ccc}(\mathrm{F}) \mathrm{c}(\mathrm{Cl}) \mathrm{c} 3) \mathrm{ncn} 2 \mathrm{cc} 1 \mathrm{OCCCN} 1 \mathrm{CCOCC} 1$ & 9 & $*$ \\
\hline 958 & $\mathrm{Fc} 1 \mathrm{cccc}(\mathrm{COc} 2 \mathrm{ccc}(\mathrm{Nc} 3 \mathrm{ncnc} 4 \mathrm{sc}(-\mathrm{c} 5 \mathrm{cccs} 5) \mathrm{cc} 34) \mathrm{cc} 2 \mathrm{Cl}) \mathrm{c} 1$ & 9 & $*$ \\
\hline 959 & $\mathrm{CCN}(\mathrm{CC}) \mathrm{C} / \mathrm{C}=\mathrm{C} / \mathrm{C}(=\mathrm{O}) \mathrm{N} 1 \mathrm{CCc} 2 \mathrm{c}(\operatorname{sc} 3 n \mathrm{nnc}(\mathrm{N}[\mathrm{C} @ \mathrm{H}](\mathrm{CO}) \mathrm{c} 4 \mathrm{ccccc} 4) \mathrm{c} 23) \mathrm{C} 1$ & 9 & $*$ \\
\hline 960 & COc1cc2ncnc(C\#C[C@](C)(O)Cc3cccc3)c2cc1OC & 9 & $*$ \\
\hline 961 & $\mathrm{Nc} 1 \mathrm{ncn} c(\mathrm{Nc} 2 \mathrm{ccc} 3 \mathrm{c}(\mathrm{cnn} 3 \mathrm{Cc} 3 \operatorname{ccc}(\mathrm{F}) \mathrm{c} 3) \mathrm{c} 2) \mathrm{c} 1 / \mathrm{C}=\mathrm{N} / \mathrm{N} 1 \mathrm{CCN}(\mathrm{CCO}) \mathrm{CC} 1$ & 9 & $*$ \\
\hline 962 & $\mathrm{CNc} 1 \mathrm{cc} 2 \mathrm{c}(\mathrm{Nc} 3 \mathrm{cccc} 3) \mathrm{ncnc} 2 \mathrm{cn} 1$ & 9 & $*$ \\
\hline 963 & $\mathrm{COCC} \# \mathrm{CC}(=\mathrm{O}) \mathrm{Nc} 1 \mathrm{ccc} 2 \mathrm{ncnc}(\mathrm{Nc} 3 \mathrm{ccc}(\mathrm{Br}) \mathrm{c} 3) \mathrm{c} 2 \mathrm{c} 1$ & 9 & $*$ \\
\hline 964 & OCCCNCc1 $1 \mathrm{ccc}(-\mathrm{c} 2 \mathrm{cc} 3 \mathrm{nccc}(\mathrm{Nc} 4 \mathrm{ccc} 5[\mathrm{nH}] \mathrm{ccc} 5 \mathrm{c} 4) \mathrm{c} 3 \mathrm{~s} 2) \mathrm{cc} 1$ & 9 & $*$ \\
\hline 965 & $\mathrm{O}=\mathrm{C}(\mathrm{c} 1 \mathrm{ccccc} 1) \mathrm{c} 1 \mathrm{cc} 2 \mathrm{ncnc}(\mathrm{Nc} 3 \mathrm{ccc} 4[\mathrm{nH}] \operatorname{ccc} 4 \mathrm{c} 3) \mathrm{c} 2 \mathrm{~s} 1$ & 9 & $*$ \\
\hline 966 & $\mathrm{NC} 1 \mathrm{CCN}(\mathrm{Cc} 2 \mathrm{ccn} 3 \mathrm{ncnc}(\mathrm{Nc} 4 \mathrm{ccccc} 4) \mathrm{c} 23) \mathrm{CC} 1$ & 9 & $*$ \\
\hline 967 & Br.C[C@@H](Nc1ncnc2[nH]c(-c3ecc(O)cc3)cc12)c1 cccc(F)c1 & 9 & $*$ \\
\hline 968 & $\mathrm{Cc} 1 \operatorname{ccc}(\mathrm{NC}(=\mathrm{O}) \mathrm{CSc} 2 \mathrm{nc} 3 \operatorname{cc} 4 \operatorname{ccc} c 4 \operatorname{cc} 3 \mathrm{c}(=\mathrm{O}) \mathrm{n} 2-\operatorname{coc} \operatorname{cc}(\mathrm{S}(\mathrm{N})(=\mathrm{O})=\mathrm{O}) \operatorname{cc} 2) \operatorname{cc} 1$ & 9 & $*$ \\
\hline 969 & $\mathrm{Nc} 1 \mathrm{cccc}(-\mathrm{c} 2 \mathrm{cc} 3 \mathrm{c}(\mathrm{Nc} 4 \mathrm{ccc}(\mathrm{Cl}) \mathrm{cc} 4 \mathrm{~F}) \mathrm{ncnc} 3 \mathrm{o} 2) \mathrm{c} 1$ & 9 & $*$ \\
\hline 970 & $\mathrm{COc} 1 \mathrm{cc} 2 \mathrm{ncnc}(\mathrm{C} \# \mathrm{CC}(\mathrm{C})(\mathrm{O}) \mathrm{Cc} 3 \mathrm{ccccc} 3) \mathrm{c} 2 \mathrm{cc} 1 \mathrm{OC}$ & 9 & $*$ \\
\hline 971 & $\mathrm{C}=\mathrm{CC}(=\mathrm{O}) \mathrm{N} 1 \mathrm{CCc} 2 \mathrm{ncnc}(\mathrm{Nc} 3 \operatorname{ccc}(\mathrm{Br}) \mathrm{c} 3) \mathrm{c} 2 \mathrm{C} 1$ & 9 & $*$ \\
\hline 972 & $\mathrm{C}=\mathrm{CC}(=\mathrm{O}) \mathrm{N} 1 \mathrm{CCc} 2 \mathrm{ncnc}(\mathrm{Nc} 3 \operatorname{ccc}(\mathrm{OCc} 4 \mathrm{cccc}(\mathrm{F}) \mathrm{c} 4) \mathrm{c}(\mathrm{Cl}) \mathrm{c} 3) \mathrm{c} 2 \mathrm{C} 1$ & 9 & $*$ \\
\hline 973 & $\mathrm{CN} 1 \mathrm{CCN}(\mathrm{CC}=\mathrm{CC}(=\mathrm{O}) \mathrm{N} 2 \mathrm{CCOc} 3 \mathrm{cc} 4 \mathrm{ncnc}(\mathrm{Nc} 5 \mathrm{ccc}(\mathrm{F}) \mathrm{c}(\mathrm{Cl}) \mathrm{c} 5) \mathrm{c} 4 \mathrm{cc} 32) \mathrm{CC} 1$ & 9 & $*$ \\
\hline 974 & $\mathrm{~S}=\mathrm{C}(\mathrm{NCCN} 1 \mathrm{CCOCC} 1) \mathrm{Nc} 1 \mathrm{ccc} 2 \mathrm{ncnc}(\mathrm{Nc} 3 \mathrm{ccc}(\mathrm{Cl}) \mathrm{c}(\mathrm{Cl}) \mathrm{c} 3) \mathrm{c} 2 \mathrm{c} 1$ & 9.05 & 8.04 \\
\hline 975 & $\mathrm{COc} 1 \mathrm{cc} 2 \mathrm{ncnc}(\mathrm{Nc} 3 \operatorname{ccc}(\mathrm{OCc} 4 \mathrm{ccc}(\mathrm{F}) \mathrm{c} 4) \mathrm{c}(\mathrm{Cl}) \mathrm{c} 3) \mathrm{c} 2 \mathrm{cc} 1 \mathrm{OCCCCCCC}(=\mathrm{O}) \mathrm{NO}$ & 9.08 & 8.04 \\
\hline 976 & $\mathrm{COc} 1 \mathrm{ccc}(/ \mathrm{C}=\mathrm{C} / \mathrm{C}(=\mathrm{O}) \mathrm{Nc} 2 \mathrm{cc} 3 \mathrm{c}(\mathrm{Nc} 4 \mathrm{ccc}(\mathrm{F}) \mathrm{c}(\mathrm{Cl}) \mathrm{c} 4) \mathrm{ncnc} 3 \mathrm{cc} 2 \mathrm{O}[\mathrm{C} @ \mathrm{H}] 2 \mathrm{CCOC} 2) \mathrm{cc} 1$ & 9.1 & $*$ \\
\hline 977 & $\mathrm{O}=\mathrm{C}(/ \mathrm{C}=\mathrm{C} / \mathrm{c} 1 \mathrm{ccccc} 1) \mathrm{Nc} 1 \mathrm{cc} 2 \mathrm{c}(\mathrm{Nc} 3 \operatorname{ccc}(\mathrm{Br}) \mathrm{c} 3) \mathrm{ncnc} 2 \mathrm{cn} 1$ & 9.1 & $*$ \\
\hline 978 & $\mathrm{CNC}(=\mathrm{S}) \mathrm{Nc} 1 \mathrm{ccc} 2 \mathrm{ncnc}(\mathrm{Nc} 3 \operatorname{ccc}(\mathrm{Br}) \mathrm{c} 3) \mathrm{c} 2 \mathrm{c} 1$ & 9.1 & $*$ \\
\hline 979 & $\mathrm{C}=\mathrm{CC}(=\mathrm{O}) \mathrm{Nc} 1 \mathrm{cccc}(\mathrm{N} 2 \mathrm{C}(=\mathrm{O}) \mathrm{CN}(\mathrm{C}) \mathrm{C}(=\mathrm{O}) \mathrm{c} 3 \mathrm{cnc}(\mathrm{Nc} 4 \mathrm{ccc}(\mathrm{N} 5 \mathrm{CCN}(\mathrm{C}) \mathrm{CC} 5) \mathrm{cc} 4 \mathrm{OC}) \mathrm{nc} 32) \mathrm{c} 1$ & 9.14 & 8.04 \\
\hline 980 & $\mathrm{CN}(\mathrm{C}) \mathrm{CCCOc} 1 \mathrm{cc} 2 \mathrm{ncnc}(\mathrm{Nc} 3 \operatorname{ccc}(\mathrm{F}) \mathrm{c}(\mathrm{Cl}) \mathrm{c} 3) \mathrm{c} 2 \mathrm{cc} 1 \mathrm{NC}(=\mathrm{O}) \mathrm{c} 1 \mathrm{cc}([\mathrm{N}+](=\mathrm{O})[\mathrm{O}-]) \operatorname{ccc} 1 \mathrm{~F}$ & 9.2 & 8.04 \\
\hline 981 & 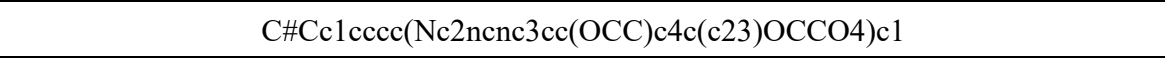 & 9.2 & $*$ \\
\hline 982 & $\mathrm{OCCN}(\mathrm{CCO}) \mathrm{CCNc} 1 \mathrm{cc} 2 \mathrm{ncnc}(\mathrm{Nc} 3 \mathrm{cccc}(\mathrm{Br}) \mathrm{c} 3) \mathrm{c} 2 \mathrm{cn} 1$ & 9.2 & $*$ \\
\hline 983 & $\mathrm{NP}(=\mathrm{O})(\mathrm{Oc} 1 \mathrm{ccc} 2 \mathrm{ncnc}(\mathrm{Nc} 3 \mathrm{cccc}(\mathrm{Br}) \mathrm{c} 3) \mathrm{c} 2 \mathrm{c} 1) \mathrm{N}(\mathrm{CCCl}) \mathrm{CCCl}$ & 9.2 & $*$ \\
\hline 984 & Cl. $\mathrm{Cn} 1 \mathrm{ccc} 2 \mathrm{ncnc}(\mathrm{Nc} 3 \operatorname{ccc}(\mathrm{Oc} 4 \mathrm{cccc}(\mathrm{Cl}) \mathrm{c} 4) \mathrm{c}(\mathrm{Cl}) \mathrm{c} 3) \mathrm{c} 21$ & 9.2 & $*$ \\
\hline 985 & $\mathrm{O}=\mathrm{C}(\mathrm{COc} 1 \mathrm{cccc} 1) \mathrm{Nc} 1 \mathrm{ccc} 2 \mathrm{ncnc}(\mathrm{Nc} 3 \mathrm{cccc}(\mathrm{Br}) \mathrm{c} 3) \mathrm{c} 2 \mathrm{c} 1$ & 9.25 & 8.03 \\
\hline 986 & $\mathrm{Cc} 1 \mathrm{cccc}(\mathrm{Nc} 2 \mathrm{ncnc} 3 \mathrm{cc}(\mathrm{NCCCN} 4 \mathrm{CCOCC} 4) \mathrm{ncc} 23) \mathrm{c} 1$ & 9.3 & $*$ \\
\hline 987 & $\mathrm{C}=\mathrm{CC}(=\mathrm{O}) \mathrm{Nc} 1 \mathrm{cc}(\mathrm{Nc} 2 \mathrm{n}[\mathrm{nH}] \mathrm{c} 3 \mathrm{cc}(-\mathrm{c} 4 \mathrm{cn}(\mathrm{C}) \mathrm{c} 5 \mathrm{cccc} 45) \operatorname{ccc} 23) \mathrm{c}(\mathrm{OC}) \mathrm{cc} 1 \mathrm{~N}(\mathrm{C}) \mathrm{CCN}(\mathrm{C}) \mathrm{C}$ & 9.3 & $*$ \\
\hline 988 & $\mathrm{OCCN}(\mathrm{CCO}) \mathrm{CCNc} 1 \mathrm{c}(\mathrm{Br}) \mathrm{cccc} 1 \mathrm{Nc} 1 \mathrm{ncnc} 2 \mathrm{ccncc} 12$ & 9.333 & $*$ \\
\hline 989 & $\mathrm{Cc} 1 \mathrm{ccc}(\mathrm{Ne} 2 \mathrm{ncnc} 3 \mathrm{ccncc} 23) \mathrm{c} 1 \mathrm{NCCCN} 1 \mathrm{CCOCC} 1$ & 9.333 & $*$ \\
\hline 990 & $\mathrm{COc} 1 \mathrm{cc} 2 \mathrm{ncnc}(\mathrm{Nc} 3 \operatorname{ccc}(\mathrm{F}) \mathrm{c}(\mathrm{Cl}) \mathrm{c} 3) \mathrm{c} 2 \mathrm{cc} 1 \mathrm{OCCCCC}(=\mathrm{O}) \mathrm{NO}$ & 9.4 & 8.03 \\
\hline 991 & CCO.Nc1 $\operatorname{ccc} 2 \mathrm{sc} 3 \mathrm{c}(\mathrm{Nc} 4 \mathrm{cccc} 4) \mathrm{ncnc} 3 \mathrm{c} 2 \mathrm{c} 1$ & 9.4 & $*$ \\
\hline
\end{tabular}




\begin{tabular}{|c|c|c|c|}
\hline 992 & $\mathrm{Nc} 1 \mathrm{ccc} 2 \mathrm{sc} 3 \mathrm{c}(\mathrm{Ne} 4 \mathrm{cccc} 4) \mathrm{ncnc} 3 \mathrm{c} 2 \mathrm{c} 1$ & 9.4 & $*$ \\
\hline 993 & $\operatorname{COc} 1 \operatorname{ccc}(\mathrm{NN}=\mathrm{C} 2 \mathrm{C}(=\mathrm{O}) \mathrm{CCc} 3 \mathrm{c} 2 \mathrm{sc}(\mathrm{N}) \mathrm{c} 3 \mathrm{C}(=\mathrm{O}) \mathrm{Nc} 2 \operatorname{ccccc} 2) \mathrm{cc} 1$ & 9.42 & $*$ \\
\hline 994 & $\mathrm{CCOc} 1 \mathrm{cc} 2 \mathrm{ncnc}(\mathrm{Nc} 3 \operatorname{ccc}(\mathrm{Oc} 4 \mathrm{ccc}(\mathrm{C}) \mathrm{nc} 4) \mathrm{c}(\mathrm{Cl}) \mathrm{c} 3) \mathrm{c} 2 \mathrm{cc} 1 \mathrm{NC}(=\mathrm{O}) / \mathrm{C}(\mathrm{F})=\mathrm{C} \backslash \mathrm{CN}(\mathrm{C}) \mathrm{C}$ & 9.5 & 8.02 \\
\hline 995 & $\mathrm{NS}(=\mathrm{O})(=\mathrm{O}) \mathrm{c} 1 \mathrm{ccc}(\mathrm{NC}(=\mathrm{S}) \mathrm{Nc} 2 \mathrm{ccc} 3 \mathrm{ncnc}(\mathrm{Nc} 4 \mathrm{cccc}(\mathrm{Br}) \mathrm{c} 4) \mathrm{c} 3 \mathrm{c} 2) \mathrm{cc} 1$ & 9.5 & $*$ \\
\hline 996 & OCCN(CCO)CC1COc2ce3ncnc(Nc4cccc(I)c4)c3ec2O1 & 9.5 & $*$ \\
\hline 997 & OCCn1 ccc2ncnc $(\mathrm{Nc} 3 \operatorname{ccc}(\mathrm{Oc} 4 \mathrm{cccc}(\mathrm{Cl}) \mathrm{c} 4) \mathrm{c}(\mathrm{Cl}) \mathrm{c} 3) \mathrm{c} 21$ & 9.5 & $*$ \\
\hline 998 & $\mathrm{O}=\mathrm{C}(/ \mathrm{C}=\mathrm{C} / \mathrm{CNC} 1 \mathrm{CC} 1) \mathrm{Nc} 1 \mathrm{cc} 2 \mathrm{c}(\mathrm{Nc} 3 \mathrm{ccc}(\mathrm{F}) \mathrm{c}(\mathrm{Cl}) \mathrm{c} 3) n \mathrm{cnc} 2 \mathrm{cc} 1 \mathrm{OC}(\mathrm{F}) \mathrm{F}$ & 9.6 & $*$ \\
\hline 999 & $\mathrm{COCCOc} 1 \mathrm{cc} 2 \mathrm{ncnc}(\mathrm{Nc} 3 \operatorname{ccc}(\mathrm{C}(=\mathrm{O}) \mathrm{NC} 45 \mathrm{CC} 6 \mathrm{CC}(\mathrm{CC}(\mathrm{C} 6) \mathrm{C} 4) \mathrm{C} 5) \mathrm{cc} 3) \mathrm{c} 2 \mathrm{cc} 1 \mathrm{OCCOC}$ & 9.61 & 8.02 \\
\hline 1000 & $\mathrm{C}=\mathrm{CC}(=\mathrm{O}) \mathrm{Nc} 1 \mathrm{ccc} 2 \mathrm{ncc}(\mathrm{CHN}) \mathrm{c}(\mathrm{Nc} 3 \operatorname{cccc}(\mathrm{Br}) \mathrm{c} 3) \mathrm{c} 2 \mathrm{c} 1$ & 9.7 & 6.82 \\
\hline 1001 & $\mathrm{CCOc} 1 \mathrm{cc} 2 \mathrm{ncnc}(\mathrm{Nc} 3 \operatorname{ccc}([\mathrm{N}+](=\mathrm{O})[\mathrm{O}-]) \mathrm{c} 3) \mathrm{c} 2 \mathrm{c} 2 \mathrm{c} 1 \mathrm{OCCO} 2$ & 9.7 & $*$ \\
\hline 1002 & $\mathrm{C}=\mathrm{CC}(=\mathrm{O}) \mathrm{Nc} 1 \operatorname{ccc} 2 \mathrm{ncnc}(\mathrm{Nc} 3 \operatorname{ccc}(\mathrm{S}(=\mathrm{O})(=\mathrm{O}) \mathrm{Nc} 4 \operatorname{ccc} \operatorname{con} 4) \operatorname{cc} 3) \mathrm{c} 2 \mathrm{c} 1$ & 9.8 & $*$ \\
\hline 1003 & $\mathrm{CC}(\mathrm{C}(=\mathrm{O}) \mathrm{NCCn} 1 \mathrm{ccc} 2 \mathrm{ncnc}(\mathrm{Nc} 3 \operatorname{ccc}(\mathrm{Oc} 4 \operatorname{ccc}(\mathrm{Cl}) \mathrm{c} 4) \mathrm{c}(\mathrm{Cl}) \mathrm{c} 3) \mathrm{c} 21) \mathrm{S}(\mathrm{C})(=\mathrm{O})=\mathrm{O}$ & 9.8 & $*$ \\
\hline 1004 & $\mathrm{CC}(\mathrm{C})(\mathrm{O}) \mathrm{CC}(=\mathrm{O}) \mathrm{NCCc} 1 \mathrm{ccc} 2 \mathrm{ncnc}(\mathrm{Nc} 3 \operatorname{ccc}(\mathrm{Oc} 4 \operatorname{ccc}(\mathrm{C}(\mathrm{F})(\mathrm{F}) \mathrm{F}) \mathrm{c} 4) \mathrm{c}(\mathrm{Cl}) \mathrm{c} 3) \mathrm{c} 2 \mathrm{c} 1$ & 9.8 & $*$ \\
\hline 1005 & $\mathrm{O}=\mathrm{C}(/ \mathrm{C}=\mathrm{C} / \mathrm{CN} 1 \mathrm{CCCCC} 1) \mathrm{Nc} 1 \mathrm{cc} 2 \mathrm{c}(\mathrm{Nc} 3 \mathrm{ccc}(\mathrm{F}) \mathrm{c}(\mathrm{Cl}) \mathrm{c} 3) \mathrm{ncnc} 2 \mathrm{cc} 1 \mathrm{OCC}(\mathrm{F}) \mathrm{F}$ & 9.87 & $*$ \\
\hline 1006 & $\mathrm{C}=\mathrm{CC}(=\mathrm{O}) \mathrm{N} 1 \mathrm{CC}[\mathrm{C} @ \mathrm{H}](\mathrm{Nc} 2 \mathrm{nc}(\mathrm{Nc} 3 \mathrm{cccc} 3) \mathrm{nc} 3 \mathrm{cnc}(\mathrm{Nc} 4 \mathrm{ccc}(\mathrm{N} 5 \mathrm{CCN}(\mathrm{C}) \mathrm{CC} 5) \mathrm{cn} 4) \mathrm{cc} 23) \mathrm{C} 1$ & 9.9 & $*$ \\
\hline 1007 & $\mathrm{CS}(=\mathrm{O})(=\mathrm{O}) \mathrm{CCNCc} 1 \mathrm{ccc}(-\mathrm{c} 2 \operatorname{ccc} 3 n \mathrm{ncnc}(\mathrm{Nc} 4 \mathrm{ccc}(\mathrm{OCc} 5 \operatorname{cccc}(\mathrm{F}) \mathrm{c} 5) \mathrm{c}(\mathrm{Cl}) \mathrm{c} 4) \mathrm{c} 3 \mathrm{c} 2) \mathrm{o} 1$ & 10 & 7.82 \\
\hline 1008 & $\mathrm{O}=\mathrm{C}(\mathrm{CBr}) \mathrm{OCCn} 1 \mathrm{c}(=\mathrm{O}) \mathrm{oc} 2 \mathrm{cc} 3 \mathrm{ncnc}(\mathrm{Nc} 4 \mathrm{ccc}(\mathrm{N} 5 \mathrm{CCOCC} 5) \mathrm{c}(\mathrm{Cl}) \mathrm{c} 4) \mathrm{c} 3 \mathrm{cc} 21$ & 10 & 8.00 \\
\hline 1009 & $\mathrm{CCOc} 1 \mathrm{cc} 2 \mathrm{ncc}(\mathrm{C \# N}) \mathrm{c}(\mathrm{Nc} 3 \mathrm{ccc}(\mathrm{OCc} 4 \mathrm{ccc} 5 \mathrm{ccccc} 45) \mathrm{c}(\mathrm{Cl}) \mathrm{c} 3) \mathrm{c} 2 \mathrm{cc} 1 \mathrm{NC}(=\mathrm{O}) / \mathrm{C}=\mathrm{C} / \mathrm{CN}(\mathrm{C}) \mathrm{C}$ & 10 & 8.00 \\
\hline 1010 & COc1cc2ncnc $(\mathrm{Nc} 3 \operatorname{ccc}(\mathrm{Cl}) \mathrm{c} 3 \mathrm{~F}) \mathrm{c} 2 \mathrm{cc} 1 \mathrm{CN} 1 \mathrm{CCC}[\mathrm{C} @ @ \mathrm{H}] 1 \mathrm{C}(\mathrm{N})=\mathrm{O}$ & 10 & $*$ \\
\hline 1011 & COc1cc2ncnc(Nc3cccc $(\mathrm{Cl}) \mathrm{c} 3 \mathrm{~F}) \mathrm{c} 2 \mathrm{cc} 1 \mathrm{CN} 1 \mathrm{C}[\mathrm{C} @ \mathrm{H}](\mathrm{OC}) \mathrm{C}[\mathrm{C} @ @ \mathrm{H}] 1 \mathrm{C}(\mathrm{N})=\mathrm{O}$ & 10 & $*$ \\
\hline 1012 & $\operatorname{COCCN}(\mathrm{Cc} 1 \mathrm{cc} 2 \mathrm{c}(\mathrm{Nc} 3 \operatorname{ccc}(\mathrm{Cl}) \mathrm{c} 3 \mathrm{~F}) \mathrm{ncnc} 2 \mathrm{cc} 1 \mathrm{OC})[\mathrm{C} @ @ \mathrm{H}](\mathrm{C}) \mathrm{C}(\mathrm{N})=\mathrm{O}$ & 10 & $*$ \\
\hline 1013 & $\mathrm{COCC}[\mathrm{C} @ @ \mathrm{H}](\mathrm{C}(\mathrm{N})=\mathrm{O}) \mathrm{N}(\mathrm{C}) \mathrm{Cc} 1 \mathrm{cc} 2 \mathrm{c}(\mathrm{Nc} 3 \mathrm{cccc}(\mathrm{Cl}) \mathrm{c} 3 \mathrm{~F}) \mathrm{ncnc} 2 \mathrm{cc} 1 \mathrm{OC}$ & 10 & $*$ \\
\hline 1014 & $\mathrm{COc} 1 \mathrm{cc} 2 \mathrm{ncnc}(\mathrm{Nc} 3 \mathrm{ccc}(\mathrm{F}) \mathrm{c}(\mathrm{Cl}) \mathrm{c} 3) \mathrm{c} 2 \mathrm{cc} 1 \mathrm{OC} 1 \mathrm{CCN}(\mathrm{C}) \mathrm{CC} 1$ & 10 & $*$ \\
\hline 1015 & $\mathrm{O}=\mathrm{C}(/ \mathrm{C}=\mathrm{C} / \mathrm{CNCC} 1 \mathrm{COC} 1) \mathrm{Nc} 1 \mathrm{cc} 2 \mathrm{c}(\mathrm{Nc} 3 \mathrm{ccc}(\mathrm{F}) \mathrm{c}(\mathrm{Cl}) \mathrm{c} 3) \mathrm{ncnc} 2 \mathrm{~s} 1$ & 10 & $*$ \\
\hline 1016 & COCCOc1cc2ncnc $(\mathrm{Nc} 3 \operatorname{ccc}(\mathrm{OCc} 4 \operatorname{ccc} n 4) \mathrm{cc} 3) \mathrm{c} 2 \mathrm{cc} 1 \mathrm{NC}(=\mathrm{O}) / \mathrm{C}=\mathrm{C} / \mathrm{CN}(\mathrm{C}) \mathrm{C}$ & 10 & $*$ \\
\hline 1017 & COCCOc1cc2ncnc $(\mathrm{Nc} 3 \operatorname{ccc} 4 \mathrm{c}(\operatorname{cnn} 4 \mathrm{Cc} 4 \mathrm{ccccc} 4) \mathrm{c} 3) \mathrm{c} 2 \mathrm{cc} 1 \mathrm{NC}(=\mathrm{O}) / \mathrm{C}=\mathrm{C} / \mathrm{CN} 1 \mathrm{CCCC} 1$ & 10 & $*$ \\
\hline 1018 & $\mathrm{Cc} 1 \mathrm{ccc}(\mathrm{Oc} 2 \operatorname{ccc}(\mathrm{Nc} 3 \mathrm{n} \operatorname{cnc} 4 \operatorname{ccc}(-\mathrm{c} 5 \operatorname{cn}(\mathrm{CCCCCCC}(=\mathrm{O}) \mathrm{NO}) \mathrm{nn} 5) \operatorname{cc} 34) \operatorname{cc} 2 \mathrm{C}) \mathrm{cn} 1$ & 10 & $*$ \\
\hline 1019 & $\mathrm{COc} 1 \mathrm{cc} 2 \mathrm{ncnc}(\mathrm{Nc} 3 \mathrm{ccc}(\mathrm{F}) \mathrm{c}(\mathrm{Cl}) \mathrm{c} 3) \mathrm{c} 2 \mathrm{cc} 1 \mathrm{OCCN} 1 \mathrm{CCN}(\mathrm{C}) \mathrm{CC} 1$ & 10 & $*$ \\
\hline 1020 & COc1cc2ncnc $(\mathrm{Nc} 3 \mathrm{ccc}(\mathrm{F}) \mathrm{c}(\mathrm{Cl}) \mathrm{c} 3) \mathrm{c} 2 \mathrm{cc} 1 \mathrm{OCCN} 1 \mathrm{CCOCC} 1$ & 10 & $*$ \\
\hline 1021 & $\mathrm{Fc} 1 \mathrm{cccc}(\mathrm{COc} 2 \mathrm{ccc}(\mathrm{Nc} 3 \mathrm{ncnc} 4 \mathrm{cc}(-\mathrm{c} 5 \mathrm{ccco} 5) \mathrm{sc} 34) \mathrm{cc} 2 \mathrm{Cl}) \mathrm{c} 1$ & 10 & $*$ \\
\hline 1022 & $\mathrm{CCOc} 1 \mathrm{cc} 2 \mathrm{ncnc}(\mathrm{CHCc} 3[\mathrm{nH}] \mathrm{ccc} 3-\mathrm{c} 3 \mathrm{ccccc} 3) \mathrm{c} 2 \mathrm{cc} 1 \mathrm{OCC}$ & 10 & $*$ \\
\hline 1023 & $\mathrm{COc} 1 \mathrm{cc} 2 \mathrm{ncnc}(\mathrm{NCc} 3 \operatorname{cccc} 3) \mathrm{c} 2 \mathrm{cc} 1 \mathrm{OC}$ & 10 & $*$ \\
\hline 1024 & $\mathrm{COc} 1 \mathrm{ccc} 2 \mathrm{c}(\mathrm{Nc} 3 \mathrm{cccc}(\mathrm{Br}) \mathrm{c} 3) \mathrm{ncnc} 2 \mathrm{c} 1$ & 10 & $*$ \\
\hline 1025 & $\mathrm{COc} 1 \mathrm{cc} 2 \mathrm{ncnc}(\mathrm{NC} 3 \mathrm{CC} 3 \mathrm{c} 3 \mathrm{ccccc} 3) \mathrm{c} 2 \mathrm{cc} 1 \mathrm{OC}$ & 10 & $*$ \\
\hline 1026 & $\mathrm{Nc} 1 \mathrm{cc} 2 \mathrm{ncnc}(\mathrm{Nc} 3 \mathrm{cccc}(\mathrm{Br}) \mathrm{c} 3) \mathrm{c} 2 \mathrm{cn} 1$ & 10 & $*$ \\
\hline 1027 & COc1cce2cnenc2c1 & 10 & $*$ \\
\hline 1028 & $\mathrm{COc} 1 \mathrm{cc} 2 \mathrm{ncnc}(\mathrm{Sc} 3 \operatorname{ccc}(\mathrm{Cl}) \mathrm{c} 3) \mathrm{c} 2 \mathrm{cc} 1 \mathrm{OC}$ & 10 & $*$ \\
\hline 1029 & $\mathrm{Cc} 1 \mathrm{c}(-\mathrm{c} 2 \mathrm{ccccc} 2)[\mathrm{nH}] \mathrm{c} 2 \mathrm{ncnc}(\mathrm{Nc} 3 \mathrm{cccc}(\mathrm{Cl}) \mathrm{c} 3) \mathrm{c} 12$ & 10 & * \\
\hline 1030 & $\mathrm{ClCCNc} 1 \mathrm{ccc} 2 \mathrm{ncnc}(\mathrm{Nc} 3 \mathrm{cccc}(\mathrm{Br}) \mathrm{c} 3) \mathrm{c} 2 \mathrm{c} 1$ & 10 & $*$ \\
\hline 1031 & $\mathrm{COc} 1 \mathrm{cc}(\mathrm{OC} 2 \mathrm{CCNCC} 2) \mathrm{c} 2 \mathrm{c}(\mathrm{Nc} 3 \mathrm{ccc}(\mathrm{F}) \mathrm{c}(\mathrm{Cl}) \mathrm{c} 3) \mathrm{ncnc} 2 \mathrm{c} 1$ & 10 & $*$ \\
\hline 1032 & $\mathrm{CCN} 1 \mathrm{CCN}(\mathrm{CC} / \mathrm{C}=\mathrm{C} / \mathrm{c} 2 \mathrm{ccc} 3 \mathrm{c}(\mathrm{Nc} 4 \mathrm{ccc}(\mathrm{Sc} 5 \mathrm{nccn} 5 \mathrm{C}) \mathrm{c}(\mathrm{Cl}) \mathrm{c} 4) \mathrm{c}(\mathrm{C \# N}) \mathrm{cnc} 3 \mathrm{c} 2) \mathrm{CC} 1$ & 10 & $*$ \\
\hline 1033 & $\mathrm{Nc} 1 \mathrm{c}(\mathrm{Br}) \mathrm{cccc} 1 \mathrm{Nc} 1 \mathrm{ncnc} 2 \mathrm{ccncc} 12$ & 10 & $*$ \\
\hline 1034 & COc1cc2ncnc $(\operatorname{Sc} 3 \operatorname{ccc}(\mathrm{NC}(=\mathrm{S}) \mathrm{Nc} 4 \operatorname{ccc}(\mathrm{F}) \mathrm{c}(\mathrm{C}(\mathrm{F})(\mathrm{F}) \mathrm{F}) \mathrm{c} 4) \mathrm{c} 3) \mathrm{c} 2 \mathrm{cc} 1 \mathrm{OC}$ & 10 & $*$ \\
\hline
\end{tabular}




\begin{tabular}{|c|c|c|c|}
\hline 1035 & $\mathrm{COc} 1 \mathrm{cc} 2 \mathrm{ncnc}(\mathrm{Sc} 3 \operatorname{ccc}(\mathrm{NC}(=\mathrm{S}) \mathrm{Nc} 4 \operatorname{ccc}(\mathrm{Br}) \mathrm{c}(\mathrm{C}(\mathrm{F})(\mathrm{F}) \mathrm{F}) \mathrm{c} 4) \mathrm{c} 3) \mathrm{c} 2 \mathrm{cc} 1 \mathrm{OC}$ & 10 & $*$ \\
\hline 1036 & $\mathrm{C}=\mathrm{CC}(=\mathrm{O}) \mathrm{Cc} 1 \mathrm{cc}(\mathrm{Nc} 2 \mathrm{ncc} 3 \mathrm{ncn}(-\mathrm{c} 4 \mathrm{ccc}(\mathrm{F}) \mathrm{c}(\mathrm{Br}) \mathrm{c} 4) \mathrm{c} 3 \mathrm{n} 2) \mathrm{c}(\mathrm{OC}) \mathrm{cc} 1 \mathrm{~N}(\mathrm{C}) \mathrm{CCN}(\mathrm{C}) \mathrm{C}$ & 10 & $*$ \\
\hline 1037 & $\mathrm{O}=[\mathrm{N}+]([\mathrm{O}-]) \mathrm{c} 1 \mathrm{ccc}(-\mathrm{c} 2 \mathrm{cc} 3 \mathrm{c}(\mathrm{Nc} 4 \mathrm{ccc}(\mathrm{Cl}) \mathrm{c} 4) \mathrm{ncnc} 3 \mathrm{o} 2) \mathrm{cc} 1$ & 10 & $*$ \\
\hline 1038 & $\mathrm{C}[\mathrm{C} @ @ \mathrm{H}](\mathrm{Nc} 1 \mathrm{ncnc} 2 \mathrm{oc}(-\mathrm{c} 3 \operatorname{ccc}([\mathrm{N}+](=\mathrm{O})[\mathrm{O}-]) \mathrm{c} 3) \mathrm{cc} 12) \mathrm{c} 1 \mathrm{ccccc} 1$ & 10 & * \\
\hline 1039 & $\mathrm{Nc} 1 \mathrm{ccc}(-\mathrm{c} 2 \mathrm{cc} 3 \mathrm{c}(\mathrm{Nc} 4 \mathrm{ccc}(\mathrm{Cl}) \mathrm{cc} 4 \mathrm{~F}) \mathrm{ncnc} 3 \mathrm{o} 2) \mathrm{cc} 1$ & 10 & $*$ \\
\hline 1040 & $\mathrm{CC}(\mathrm{C})(\mathrm{C}) \mathrm{C}(\mathrm{Nc} 1 \mathrm{ncnc} 2[\mathrm{nH}] \mathrm{c}(-\mathrm{c} 3 \mathrm{ccccc} 3) \mathrm{cc} 12) \mathrm{c} 1 \mathrm{ccccc} 1$ & 10 & $*$ \\
\hline 1041 & $\mathrm{c} 1 \mathrm{nc}(\mathrm{Nc} 2 \mathrm{ccc}(\mathrm{N} 3 \mathrm{CCOCC} 3) \mathrm{cc} 2) \mathrm{cc}(\mathrm{Oc} 2 \mathrm{ccc} 3[\mathrm{nH}] \mathrm{ccc} 3 \mathrm{c} 2) \mathrm{n} 1$ & 10 & $*$ \\
\hline 1042 & $\mathrm{COC}[\mathrm{C} @ \mathrm{H}] 1 \mathrm{Oc} 2 \mathrm{cc} 3 \mathrm{ncnc}(\mathrm{Nc} 4 \mathrm{cccc}(\mathrm{Cl}) \mathrm{c} 4) \mathrm{c} 3 \mathrm{cc} 2 \mathrm{O}[\mathrm{C} @ @ \mathrm{H}] 1 \mathrm{COC}$ & 10.08 & $*$ \\
\hline 1043 & $\mathrm{C}=\mathrm{CC}(=\mathrm{O}) \mathrm{Nc} 1 \mathrm{cccc}(\mathrm{N} 2 \mathrm{C}(=\mathrm{O}) \mathrm{C}(\mathrm{C}(\mathrm{C}) \mathrm{CC}) \mathrm{N}(\mathrm{C}) \mathrm{C}(=\mathrm{O}) \mathrm{c} 3 \mathrm{cnc}(\mathrm{Nc} 4 \mathrm{ccc}(\mathrm{N} 5 \mathrm{CCN}(\mathrm{C}) \mathrm{CC} 5) \mathrm{cc} 4 \mathrm{OC}) \mathrm{nc} 32) \mathrm{c} 1$ & 10.18 & 7.99 \\
\hline 1044 & $\mathrm{C}=\mathrm{CC}(=\mathrm{O}) \mathrm{Nc} 1 \mathrm{cccc}(\mathrm{N} 2 \mathrm{C}(=\mathrm{O}) \mathrm{C}(\mathrm{CC}(\mathrm{C}) \mathrm{C}) \mathrm{N}(\mathrm{C}) \mathrm{C}(=\mathrm{O}) \mathrm{c} 3 \mathrm{cnc}(\mathrm{Nc} 4 \mathrm{ccc}(\mathrm{N} 5 \mathrm{CCN}(\mathrm{C}) \mathrm{CC} 5) \mathrm{cc} 4 \mathrm{OC}) \mathrm{nc} 32) \mathrm{c} 1$ & 10.18 & * \\
\hline 1045 & $\mathrm{~S}=\mathrm{C}(\mathrm{Nc} 1 \mathrm{cccnc} 1) \mathrm{Nc} 1 \mathrm{ccc} 2 \mathrm{ncnc}(\mathrm{Nc} 3 \operatorname{ccc}(\mathrm{Br}) \mathrm{c} 3) \mathrm{c} 2 \mathrm{c} 1$ & 10.2 & $*$ \\
\hline 1046 & $\mathrm{Nc} 1 \operatorname{sc} 2 \mathrm{c}(\mathrm{c} 1 \mathrm{C}(=\mathrm{O}) \mathrm{Nc} 1 \mathrm{cccc} 1) \mathrm{CCC}(=\mathrm{O}) \mathrm{C} 2=\mathrm{NNc} 1 \mathrm{ccc}(\mathrm{Cl}) \mathrm{cc} 1$ & 10.37 & $*$ \\
\hline 1047 & $\mathrm{COCCOc} 1 \mathrm{cc} 2 \mathrm{ncnc}(\mathrm{Nc} 3 \mathrm{ccc}(\mathrm{F}) \mathrm{c}(\mathrm{Cl}) \mathrm{c} 3) \mathrm{c} 2 \mathrm{cc} 1 \mathrm{OCCCCCCC}(=\mathrm{O}) \mathrm{NO}$ & 10.4 & 7.98 \\
\hline 1048 & $\mathrm{CN}(\mathrm{C}) \mathrm{C} 1 \mathrm{CCN}(\mathrm{c} 2 \mathrm{ccc}(\mathrm{Nc} 3 \mathrm{cc} 4 \mathrm{c}(\mathrm{N} 5 \mathrm{CCC}(\mathrm{CO}) \mathrm{CC} 5) \mathrm{nc}(\mathrm{Nc} 5 \mathrm{ccc}(\mathrm{F}) \mathrm{cc} 5) \mathrm{nc} 4 \mathrm{cn} 3) \mathrm{nc} 2) \mathrm{CC} 1$ & 10.4 & $*$ \\
\hline 1049 & $\mathrm{O}=\mathrm{C}(\mathrm{Nc} 1 \mathrm{ccc}(\mathrm{F}) \mathrm{c}(\mathrm{Cl}) \mathrm{c} 1) \mathrm{c} 1 \mathrm{ccc}(\mathrm{OCCCN} 2 \mathrm{CCOCC} 2) \mathrm{cc} 1 \mathrm{O}$ & 10.4 & $*$ \\
\hline 1050 & $\mathrm{C}=\mathrm{C}=\mathrm{CC}(=\mathrm{O}) \mathrm{Nc} 1 \mathrm{cc}(\mathrm{Nc} 2 \mathrm{nccc}(\mathrm{C} 3=\mathrm{CN}(\mathrm{C}) \mathrm{C} 4 \mathrm{C}=\mathrm{C}(\mathrm{F}) \mathrm{C}=\mathrm{CC} 34) \mathrm{n} 2) \mathrm{c}(\mathrm{OC}) \operatorname{cc} 1 \mathrm{~N}(\mathrm{C}) \mathrm{CCN}(\mathrm{C}) \mathrm{C}$ & 10.5 & $*$ \\
\hline 1051 & $\mathrm{C}=\mathrm{CC}(=\mathrm{O}) \mathrm{Nc} 1 \mathrm{cccc}(-\mathrm{c} 2 \mathrm{c}[\mathrm{nH}] \mathrm{c} 3 \mathrm{nccc}(-\mathrm{c} 4[\mathrm{nH}] \mathrm{c}(-\mathrm{c} 5 \mathrm{cccc} 5) \mathrm{nc} 4-\mathrm{c} 4 \mathrm{ccc}(\mathrm{F}) \mathrm{cc} 4) \mathrm{c} 23) \mathrm{c} 1$ & 10.5 & $*$ \\
\hline 1052 & $\mathrm{C}=\mathrm{C}=\mathrm{CC}(=\mathrm{O}) \mathrm{Nc} 1 \mathrm{cc}(\mathrm{Nc} 2 \mathrm{nccc}(-\mathrm{c} 3 \mathrm{cn}(\mathrm{C}) \mathrm{c} 4 \mathrm{cc}(\mathrm{F}) \mathrm{ccc} 34) \mathrm{n} 2) \mathrm{c}(\mathrm{OC}) \mathrm{cc} 1 \mathrm{~N}(\mathrm{C}) \mathrm{CCN}(\mathrm{C}) \mathrm{C}$ & 10.5 & $*$ \\
\hline 1053 & COc1cc2ncnc(Nc3ccc(F)c(Cl)c3)c2cc1OCCN1C[C@H](O)[C@@H](O)[C@H](O)[C@H]1CO & 10.71 & $*$ \\
\hline 1054 & COc1cc2ncnc $(\mathrm{Nc} 3 \operatorname{ccc}(\mathrm{F}) \mathrm{c}(\mathrm{Cl}) \mathrm{c} 3) \mathrm{c} 2 \mathrm{cc} 1 \mathrm{OCCCN} 1 \mathrm{C}[\mathrm{C} @ \mathrm{H}](\mathrm{O})[\mathrm{C} @ @ \mathrm{H}](\mathrm{O})[\mathrm{C} @ \mathrm{H}](\mathrm{O})[\mathrm{C} @ \mathrm{H}] 1 \mathrm{CO}$ & 10.71 & $*$ \\
\hline 1055 & $\mathrm{O}=\mathrm{C}(\mathrm{c} 1 \mathrm{cc} 2 \mathrm{ccccc} 2 \mathrm{~s} 1) \mathrm{c} 1 \mathrm{cc} 2 \mathrm{c}(\mathrm{Nc} 3 \mathrm{ccc}(\mathrm{F}) \mathrm{c}(\mathrm{Cl}) \mathrm{c} 3) \mathrm{ncnc} 2 \mathrm{~s} 1$ & 10.8 & $*$ \\
\hline 1056 & $\mathrm{Cc} 1 \mathrm{ccc}(\mathrm{S}(=\mathrm{O})(=\mathrm{O}) \mathrm{O}) \operatorname{cc} 1 . \mathrm{NS}(=\mathrm{O})(=\mathrm{O}) \mathrm{CCNCc} 1 \mathrm{ccc}(-\mathrm{c} 2 \mathrm{ccc} 3 \mathrm{ncnc}(\mathrm{Nc} 4 \mathrm{ccc}(\mathrm{OCc} 5 \operatorname{ccc}(\mathrm{F}) \mathrm{c} 5) \mathrm{c}(\mathrm{Cl}) \mathrm{c} 4) \mathrm{c} 3 \mathrm{c} 2) \mathrm{o} 1$ & 10.8 & $*$ \\
\hline 1057 & $\mathrm{Cc} 1 \mathrm{ccc}(\mathrm{S}(=\mathrm{O})(=\mathrm{O}) \mathrm{O}) \mathrm{cc} 1 . \mathrm{Fc} 1 \mathrm{cccc}(\mathrm{COc} 2 \mathrm{ccc}(\mathrm{Nc} 3 \mathrm{ncnc} 4 \mathrm{ccc}(-\mathrm{c} 5 \mathrm{ccc}(\mathrm{CN} 6 \mathrm{CCNCC} 6) \mathrm{o} 5) \operatorname{cc} 34) \mathrm{cc} 2 \mathrm{Cl}) \mathrm{c} 1$ & 10.8 & * \\
\hline 1058 & $\mathrm{CS}(=\mathrm{O})(=\mathrm{O}) \mathrm{C}[\mathrm{C} @ @ \mathrm{H}](\mathrm{N}) \mathrm{c} 1 \mathrm{ccc}(-\mathrm{c} 2 \mathrm{ccc} 3 \mathrm{ncnc}(\mathrm{Nc} 4 \mathrm{ccc}(\mathrm{OCc} 5 \mathrm{cccc}(\mathrm{F}) \mathrm{c} 5) \mathrm{c}(\mathrm{Cl}) \mathrm{c} 4) \mathrm{c} 3 \mathrm{c} 2) \mathrm{o} 1$ & 10.8 & * \\
\hline 1059 & $\mathrm{CHCc} 1 \mathrm{cccc}(\mathrm{Nc} 2 \mathrm{ncnc} 3 \mathrm{cc}(\mathrm{OC}) \mathrm{c} 4 \mathrm{c}(\mathrm{c} 23) \mathrm{OCCO} 4) \mathrm{c} 1$ & 10.9 & * \\
\hline 1060 & $\mathrm{C}[\mathrm{C} @ @ \mathrm{H}](\mathrm{Nc} 1 \mathrm{ncnc} 2 \mathrm{oc}(-\mathrm{c} 3 \mathrm{ccccc} 3) \mathrm{cc} 12) \mathrm{c} 1 \mathrm{ccccc} 1$ & 11 & 7.96 \\
\hline 1061 & $\mathrm{Cc} 1 \mathrm{ncnc}(\mathrm{Nc} 2 \mathrm{ccc}(\mathrm{OCc} 3 \mathrm{cccc}(\mathrm{F}) \mathrm{c} 3) \mathrm{c}(\mathrm{Cl}) \mathrm{c} 2) \mathrm{c} 1 \mathrm{C} \# \mathrm{CCCCN} 1 \mathrm{CCCC} 1$ & 11 & 7.96 \\
\hline 1062 & $\mathrm{CCOc} 1 \mathrm{cc} 2 \mathrm{ncc}(\mathrm{C} \# \mathrm{~N}) \mathrm{c}(\mathrm{Nc} 3 \operatorname{ccc}(\mathrm{OCc} 4 \mathrm{ccccc} 4 \mathrm{Cl}) \mathrm{c}(\mathrm{Cl}) \mathrm{c} 3) \mathrm{c} 2 \mathrm{cc} 1 \mathrm{NC}(=\mathrm{O}) / \mathrm{C}=\mathrm{C} / \mathrm{CN}(\mathrm{C}) \mathrm{C}$ & 11 & 7.96 \\
\hline 1063 & 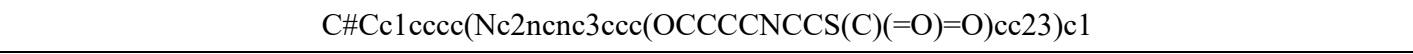 & 11 & $*$ \\
\hline 1064 & $\mathrm{CC}(\mathrm{C})(\mathrm{C}(=\mathrm{O}) \mathrm{NCCn} 1 \mathrm{ccc} 2 \mathrm{ncnc}(\mathrm{Nc} 3 \operatorname{ccc}(\mathrm{Oc} 4 \mathrm{cccc}(\mathrm{Cl}) \mathrm{c} 4) \mathrm{c}(\mathrm{Cl}) \mathrm{c} 3) \mathrm{c} 21) \mathrm{S}(\mathrm{C})(=\mathrm{O})=\mathrm{O} \cdot \mathrm{Cc} 1 \mathrm{ccc}(\mathrm{S}(=\mathrm{O})(=\mathrm{O}) \mathrm{O}) \mathrm{cc} 1$ & 11 & * \\
\hline 1065 & $\mathrm{CC}(\mathrm{C})(\mathrm{C}(=\mathrm{O}) \mathrm{NCCn} 1 \mathrm{ccc} 2 \mathrm{ncnc}(\mathrm{Nc} 3 \operatorname{ccc}(\mathrm{Oc} 4 \mathrm{cccc}(\mathrm{Cl}) \mathrm{c} 4) \mathrm{c}(\mathrm{Cl}) \mathrm{c} 3) \mathrm{c} 21) \mathrm{S}(\mathrm{C})(=\mathrm{O})=\mathrm{O}$ & 11 & $*$ \\
\hline 1066 & $\mathrm{CN}(\mathrm{C}) \mathrm{c} 1 \mathrm{ccc} 2 \mathrm{cncnc} 2 \mathrm{c} 1$ & 11 & $*$ \\
\hline 1067 & $\mathrm{CN}(\mathrm{C}) \mathrm{c} 1 \mathrm{ccc} 2 \mathrm{c}(\mathrm{Nc} 3 \mathrm{cccc}(\mathrm{Br}) \mathrm{c} 3) \mathrm{ncnc} 2 \mathrm{c} 1$ & 11 & $*$ \\
\hline 1068 & Brc1ecec(Nc2ncne3 $\operatorname{ccsc} 23) \mathrm{c} 1$ & 11 & $*$ \\
\hline 1069 & $\mathrm{Cc} 1 \mathrm{cccc}(\mathrm{Nc} 2 \mathrm{ncnc} 3 \mathrm{c} 2 \mathrm{sc} 2 \mathrm{ccc}([\mathrm{N}+](=\mathrm{O})[\mathrm{O}-]) \mathrm{cc} 23) \mathrm{c} 1 . \mathrm{Cl}$ & 11 & $*$ \\
\hline 1070 & $\mathrm{C}=\mathrm{CC}(=\mathrm{O}) \mathrm{Nc} 1 \mathrm{cccc}(\mathrm{Nc} 2 \mathrm{ncc}(\mathrm{NC}(=\mathrm{O}) \mathrm{c} 3 \mathrm{cc}(\mathrm{NC}(=\mathrm{O}) \mathrm{c} 4 \operatorname{ccc}(\mathrm{C}(\mathrm{F})(\mathrm{F}) \mathrm{F}) \mathrm{c} 4) \operatorname{ccc} 3 \mathrm{C}) \mathrm{cn} 2) \mathrm{c} 1$ & 11 & $*$ \\
\hline 1071 & $\mathrm{CN}(\mathrm{C}) \mathrm{N}=\mathrm{Nc} 1 \mathrm{ccc} 2 \mathrm{ncnc}(\mathrm{Nc} 3 \mathrm{cccc}(\mathrm{Br}) \mathrm{c} 3) \mathrm{c} 2 \mathrm{c} 1$ & 11 & $*$ \\
\hline 1072 & $\mathrm{C \# Cc1} \operatorname{cccc}(\mathrm{Nc} 2 \mathrm{ncnc} 3 \operatorname{ccc}(\mathrm{OCCCCOP}(\mathrm{N})(=\mathrm{O}) \mathrm{N}(\mathrm{CCCl}) \mathrm{CCCl}) \mathrm{cc} 23) \mathrm{c} 1$ & 11 & $*$ \\
\hline 1073 & OCCSc1nc(-c2 $\operatorname{ccc}(\mathrm{F}) \mathrm{cc} 2) \mathrm{c}(-\mathrm{c} 2 \mathrm{ccnc}(\mathrm{Nc} 3 \mathrm{ccccc} 3) \mathrm{c} 2)[\mathrm{nH}] 1$ & 11 & $*$ \\
\hline 1074 & $\mathrm{CCOc} 1 \mathrm{cc} 2 \mathrm{ncnc}(\mathrm{Nc} 3 \mathrm{ccc}(\mathrm{OCC} 4 \mathrm{CC} 4) \mathrm{c}(\mathrm{Cl}) \mathrm{c} 3) \mathrm{c} 2 \mathrm{cc} 1 \mathrm{NC}(=\mathrm{O}) / \mathrm{C}(\mathrm{F})=\mathrm{C} \backslash \mathrm{CN}(\mathrm{C}) \mathrm{C}$ & 11.2 & 7.95 \\
\hline 1075 & $\mathrm{O}=\mathrm{C}(/ \mathrm{C}=\mathrm{C} / \mathrm{CN} 1 \mathrm{CCCCC} 1) \mathrm{Nc} 1 \mathrm{cc} 2 \mathrm{c}(\mathrm{Nc} 3 \mathrm{ccc}(\mathrm{F}) \mathrm{c}(\mathrm{Cl}) \mathrm{c} 3) \mathrm{ncn} \mathrm{e} 2 \mathrm{cc} 1 \mathrm{OCCCN} 1 \mathrm{CCOCC} 1$ & 11.35 & $*$ \\
\hline 1076 & $\mathrm{CC}(=\mathrm{O}) \mathrm{N} 1 \mathrm{CCN}(\mathrm{Cc} 2 \mathrm{ccc}(-\mathrm{c} 3 \mathrm{ccc} 4 \mathrm{ncnc}(\mathrm{Nc} 5 \mathrm{ccc}(\mathrm{OCc} 6 \mathrm{cccc}(\mathrm{F}) \mathrm{c} 6) \mathrm{c}(\mathrm{Cl}) \mathrm{c} 5) \mathrm{c} 4 \mathrm{c} 3) \mathrm{o} 2) \mathrm{CC} 1 . \mathrm{Cc} 1 \mathrm{ccc}(\mathrm{S}(=\mathrm{O})(=\mathrm{O}) \mathrm{O}) \mathrm{cc} 1$ & 11.4 & $*$ \\
\hline 1077 & $\mathrm{~S}=\mathrm{C}(\mathrm{NCc} 1 \mathrm{ccccc} 1) \mathrm{Nc} 1 \mathrm{ccc} 2 \mathrm{ncnc}(\mathrm{Nc} 3 \operatorname{ccc}(\mathrm{Cl}) \mathrm{c} 3) \mathrm{c} 2 \mathrm{c} 1$ & 11.4 & $*$ \\
\hline
\end{tabular}




\begin{tabular}{|c|c|c|c|}
\hline 1078 & $\mathrm{CC} 1(\mathrm{C}) \mathrm{OOC} 2(\mathrm{CCC}(\mathrm{C}(=\mathrm{O}) \mathrm{Nc} 3 \mathrm{ccc} 4 \mathrm{ncnc}(\mathrm{Nc} 5 \mathrm{ccc}(\mathrm{Cl}) \mathrm{c} 5) \mathrm{c} 4 \mathrm{c} 3) \mathrm{CC} 2) \mathrm{OO} 1$ & 11.42 & $*$ \\
\hline 1079 & $\operatorname{COc} 1 \mathrm{cc}(\mathrm{Nc} 2 \mathrm{ncnc} 3 \mathrm{ccc}(-\mathrm{c} 4 \mathrm{cn}(\mathrm{CCCCCCC}(=\mathrm{O}) \mathrm{NO}) \mathrm{nn} 4) \mathrm{cc} 23) \mathrm{ccc} 1 \mathrm{Oc} 1 \mathrm{ccccc} 1$ & 11.6 & $*$ \\
\hline 1080 & $\mathrm{CCOc} 1 \mathrm{cc} 2 \mathrm{ncnc}(\mathrm{C} \# \mathrm{CC}(\mathrm{C})(\mathrm{Cc} 3 \operatorname{ccccc} 3) \mathrm{N} 3 \mathrm{CCC}(\mathrm{C}(=\mathrm{O}) \mathrm{O}) \mathrm{CC} 3) \mathrm{c} 2 \mathrm{cc} 1 \mathrm{OCC}$ & 11.7 & * \\
\hline 1081 & $\mathrm{CNC} 1 \mathrm{CC} 2 \mathrm{OC}(\mathrm{C})(\mathrm{C} 1 \mathrm{OC}) \mathrm{n} 1 \mathrm{c} 3 \operatorname{ccc} c 3 \mathrm{c} 3 \mathrm{c} 4 \mathrm{c}(\mathrm{c} 5 \mathrm{c} 6 \mathrm{ccccc} 6 \mathrm{n} 2 \mathrm{c} 5 \mathrm{c} 31) \mathrm{C}(=\mathrm{O}) \mathrm{NC} 4$ & 11.8 & $*$ \\
\hline 1082 & $\mathrm{COc} 1 \mathrm{cc} 2 \mathrm{c}(\mathrm{Nc} 3 \mathrm{ccc}(\mathrm{OCc} 4 \mathrm{ccc}(\mathrm{F}) \mathrm{c} 4) \mathrm{c}(\mathrm{Cl}) \mathrm{c} 3) \mathrm{ncnc} 2 \mathrm{cc} 1 \mathrm{OCCCCn} 1 \mathrm{ccnc} 1[\mathrm{~N}+](=\mathrm{O})[\mathrm{O}-]$ & 11.9 & 7.92 \\
\hline 1083 & $\mathrm{C}=\mathrm{Cc} 1 \mathrm{cccc}(\mathrm{Nc} 2 \mathrm{ncnc} 3 \mathrm{cc}(\mathrm{OCCOC}) \mathrm{c}(\mathrm{OCCOC}) \mathrm{cc} 23) \mathrm{c} 1$ & 11.9 & $*$ \\
\hline 1084 & $\mathrm{Nc} 1 \mathrm{ccc}(\mathrm{C}(=\mathrm{O}) \mathrm{Nc} 2 \mathrm{ccc} 3 \mathrm{ncnc}(\mathrm{Nc} 4 \mathrm{cccc}(\mathrm{Br}) \mathrm{c} 4) \mathrm{c} 3 \mathrm{c} 2) \mathrm{cc} 1$ & 11.9 & * \\
\hline 1085 & $\mathrm{CC}(=\mathrm{O}) \mathrm{Nc} 1 \mathrm{cccc}(\mathrm{CHC} 2 \mathrm{cncnc} 2 \mathrm{Nc} 2 \mathrm{ccc}(\mathrm{OCc} 3 \operatorname{cccc}(\mathrm{F}) \mathrm{c} 3) \mathrm{c}(\mathrm{Cl}) \mathrm{c} 2) \mathrm{c} 1$ & 12 & * \\
\hline 1086 & $\mathrm{C} \# \mathrm{Cc} 1 \mathrm{cccc}(\mathrm{Nc} 2 \mathrm{ncnc} 3 \mathrm{cc} 4 \mathrm{c}(\mathrm{cc} 23) \mathrm{N}(\mathrm{C}(=\mathrm{O}) / \mathrm{C}=\mathrm{C} / \mathrm{CN} 2 \mathrm{CCOCC} 2) \mathrm{CCO} 4) \mathrm{c} 1$ & 12 & $*$ \\
\hline 1087 & $\mathrm{O}=\mathrm{C}(/ \mathrm{C}=\mathrm{C} / \mathrm{CN} 1 \mathrm{CCOCC} 1) \mathrm{Nc} 1 \mathrm{cc} 2 \mathrm{c}(\mathrm{Nc} 3 \mathrm{ccc}(\mathrm{F}) \mathrm{c}(\mathrm{Cl}) \mathrm{c} 3) \mathrm{ncnc} 2 \mathrm{cn} 1$ & 12 & * \\
\hline 1088 & $\mathrm{CS}(=\mathrm{O})(=\mathrm{O}) \mathrm{CCNCc} 1 \mathrm{ccc}(-\mathrm{c} 2 \mathrm{cc} 3 \mathrm{c}(\mathrm{Nc} 4 \mathrm{ccc}(\mathrm{OCc} 5 \mathrm{cccc}(\mathrm{F}) \mathrm{c} 5) \mathrm{c}(\mathrm{Cl}) \mathrm{c} 4) \mathrm{ncnc} 3 \mathrm{~s} 2) \mathrm{o} 1$ & 12 & * \\
\hline 1089 & $\mathrm{C}[\mathrm{C} @ @ \mathrm{H}](\mathrm{Nc} 1 \mathrm{ncnc} 2 \mathrm{sc} 3 \mathrm{c}(\mathrm{c} 12) \mathrm{CCN}(\mathrm{C}(=\mathrm{O}) / \mathrm{C}=\mathrm{C} / \mathrm{CN}(\mathrm{C}) \mathrm{C}) \mathrm{C} 3) \mathrm{c} 1 \mathrm{ccccc} 1$ & 12 & * \\
\hline 1090 & $\mathrm{CC}[\mathrm{C} @ @ \mathrm{H}](\mathrm{Nc} 1 \mathrm{ncnc} 2 \mathrm{sc} 3 \mathrm{c}(\mathrm{c} 12) \mathrm{CCN}(\mathrm{C}(=\mathrm{O}) / \mathrm{C}=\mathrm{C} / \mathrm{CN}(\mathrm{C}) \mathrm{C}) \mathrm{C} 3) \mathrm{c} 1 \mathrm{ccccc} 1$ & 12 & * \\
\hline 1091 & CCOc1cc2ncnc(C\#Cc3ncen3-c3ecces 3$) \mathrm{c} 2 \mathrm{cc} 1 \mathrm{OCC}$ & 12 & $*$ \\
\hline 1092 & $\mathrm{CN} / \mathrm{N}=\mathrm{C} / \mathrm{c} 1 \mathrm{c}(\mathrm{N}) \mathrm{ncnc} 1 \mathrm{Nc} 1 \mathrm{ccc} 2 \mathrm{c}(\mathrm{cnn} 2 \mathrm{Cc} 2 \mathrm{cccc}(\mathrm{F}) \mathrm{c} 2) \mathrm{c} 1$ & 12 & * \\
\hline 1093 & $\mathrm{OCC}(\mathrm{O}) \mathrm{Cn} 1 \mathrm{ncc} 2 \mathrm{cc} 3 \mathrm{c}(\mathrm{Nc} 4 \mathrm{cccc}(\mathrm{Br}) \mathrm{c} 4) \mathrm{ncnc} 3 \mathrm{cc} 21$ & 12 & * \\
\hline 1094 & $\mathrm{OCCN}(\mathrm{CCO}) \mathrm{c} 1 \mathrm{cc} 2 \mathrm{ncnc}(\mathrm{Nc} 3 \mathrm{cccc}(\mathrm{Br}) \mathrm{c} 3) \mathrm{c} 2 \mathrm{cn} 1$ & 12 & $*$ \\
\hline 1095 & $\mathrm{COC}(=\mathrm{O}) \mathrm{Nc} 1 \mathrm{ccc} 2 \mathrm{ncnc}(\mathrm{Nc} 3 \operatorname{cccc}(\mathrm{Br}) \mathrm{c} 3) \mathrm{c} 2 \mathrm{c} 1$ & 12 & $*$ \\
\hline 1096 & $\mathrm{CCNc} 1 \mathrm{ccc} 2 \mathrm{c}(\mathrm{Nc} 3 \mathrm{cccc}(\mathrm{Br}) \mathrm{c} 3) \mathrm{ncnc} 2 \mathrm{c} 1$ & 12 & $*$ \\
\hline 1097 & $\mathrm{CCN}(\mathrm{CC}) \mathrm{CC} \# \mathrm{CC}(=\mathrm{O}) \mathrm{Nc} 1 \mathrm{ccc} 2 \mathrm{ncnc}(\mathrm{Nc} 3 \mathrm{cccc}(\mathrm{Br}) \mathrm{c} 3) \mathrm{c} 2 \mathrm{c} 1$ & 12 & * \\
\hline 1098 & $\mathrm{CO} / \mathrm{N}=\mathrm{C} / \mathrm{c} 1 \mathrm{c}(\mathrm{N}) \mathrm{ncnc} 1 \mathrm{Nc} 1 \mathrm{ccc}(\mathrm{OCc} 2 \mathrm{ccc}(\mathrm{F}) \mathrm{c} 2) \mathrm{c}(\mathrm{Cl}) \mathrm{c} 1$ & 12 & * \\
\hline 1099 & $\mathrm{Nc} 1 \mathrm{ncnc}(\mathrm{Nc} 2 \mathrm{ccc} 3 \mathrm{c}(\mathrm{cnn} 3 \mathrm{Cc} 3 \mathrm{cccc}(\mathrm{F}) \mathrm{c} 3) \mathrm{c} 2) \mathrm{c} 1 / \mathrm{C}=\mathrm{N} / \mathrm{O}$ & 12 & $*$ \\
\hline 1100 & $\mathrm{C}[\mathrm{C} @ @ \mathrm{H}](\mathrm{Nc} 1 \mathrm{ncnc} 2[\mathrm{nH}] \mathrm{c}(-\mathrm{c} 3 \mathrm{ccc}(\mathrm{C \# N}) \mathrm{cc} 3) \mathrm{cc} 12) \mathrm{c} 1 \mathrm{ccccc} 1$ & 12 & * \\
\hline 1101 & $\mathrm{Cc} 1 \operatorname{cccc} 1 \mathrm{NC}(=\mathrm{O}) \mathrm{CSc} 1 \mathrm{nc} 2 \operatorname{cc} 3 \operatorname{ccccc} 3 \operatorname{cc} 2 \mathrm{c}(=\mathrm{O}) \mathrm{n} 1-\operatorname{coc} \operatorname{ccc}(\mathrm{S}(\mathrm{N})(=\mathrm{O})=\mathrm{O}) \mathrm{cc} 1$ & 12 & * \\
\hline 1102 & $\mathrm{C}=\mathrm{CC}(=\mathrm{O}) \mathrm{N}[\mathrm{C} @ \mathrm{H}] 1 \mathrm{CCCN}(\mathrm{c} 2 \mathrm{nc}(\mathrm{Nc} 3 \mathrm{cccc} 3) \mathrm{nc} 3 \mathrm{cnc}(\mathrm{Nc} 4 \mathrm{ccc}(\mathrm{N} 5 \mathrm{CCN}(\mathrm{C}) \mathrm{CC} 5) \mathrm{cn} 4) \mathrm{cc} 23) \mathrm{C} 1$ & 12 & $*$ \\
\hline 1103 & $\mathrm{C}=\mathrm{CC}(=\mathrm{O}) \mathrm{N} 1 \mathrm{CCc} 2 \mathrm{ncnc}(\mathrm{Nc} 3 \mathrm{ccc}(\mathrm{F}) \mathrm{c}(\mathrm{Cl}) \mathrm{c} 3) \mathrm{c} 2 \mathrm{C} 1$ & 12 & $*$ \\
\hline 1104 & $\mathrm{C}=\mathrm{CC}(=\mathrm{O}) \mathrm{NCCSc} 1 \mathrm{nc}(-\mathrm{c} 2 \operatorname{ccccc} 2) \mathrm{c}(-\mathrm{c} 2 \operatorname{ccnc}(\mathrm{Nc} 3 \operatorname{ccccc} 3) \mathrm{c} 2)[\mathrm{nH}] 1$ & 12 & * \\
\hline 1105 & $\mathrm{OCCN}(\mathrm{CCO}) \mathrm{c} 1 \mathrm{c}(\mathrm{Br}) \mathrm{cccc} 1 \mathrm{Nc} 1 \mathrm{ncnc} 2 \mathrm{ccncc} 12$ & 12.02 & $*$ \\
\hline 1106 & $\mathrm{C}=\mathrm{CC}(=\mathrm{O}) \mathrm{Nc} 1 \operatorname{cccc}(-\mathrm{n} 2 \mathrm{c}(=\mathrm{O}) \operatorname{cnc} 3 \operatorname{cnc}(\mathrm{Nc} 4 \operatorname{ccc}(\mathrm{C}(\mathrm{N})=\mathrm{O}) \operatorname{cc} 4) \mathrm{nc} 32) \mathrm{c} 1$ & 12.1 & 7.92 \\
\hline 1107 & $\mathrm{CC}(=\mathrm{O}) \mathrm{N} 1 \mathrm{CC}[\mathrm{C} @ \mathrm{H}](\mathrm{N} 2 \mathrm{C}(=\mathrm{O}) \mathrm{N}(\mathrm{c} 3 \operatorname{ccccc} 3 \mathrm{Cl}) \mathrm{Cc} 3 \mathrm{cnc}(\mathrm{Nc} 4 \mathrm{ccc}(\mathrm{N} 5 \mathrm{CCN}(\mathrm{C}) \mathrm{CC} 5) \mathrm{c}(\mathrm{C}) \mathrm{c} 4) \mathrm{nc} 32) \mathrm{C} 1$ & 12.1 & 7.92 \\
\hline 1108 & COc1cc2ncnc(Nc3ecc(F)c $(\mathrm{Cl}) \mathrm{c} 3) \mathrm{c} 2 \mathrm{cc} 1 \mathrm{OCCNCCN}$ & 12.1 & $*$ \\
\hline 1109 & $\mathrm{COc} 1 \mathrm{cc} 2 \mathrm{ncnc}(\mathrm{Nc} 3 \mathrm{ccc}(\mathrm{F}) \mathrm{c}(\mathrm{Cl}) \mathrm{c} 3) \mathrm{c} 2 \mathrm{cc} 1 \mathrm{NC}(=\mathrm{O}) / \mathrm{C}=\mathrm{C} / \mathrm{CN} 1 \mathrm{CCCCCC} 1$ & 12.13 & $*$ \\
\hline 1110 & $\mathrm{CCOc} 1 \mathrm{cc} 2 \mathrm{ncnc}(\mathrm{NC} 3=\mathrm{CC}(=\mathrm{O}) \mathrm{C}(\mathrm{OCc} 4 \mathrm{cccc}(\mathrm{Cl}) \mathrm{c} 4)=\mathrm{CC} 3=\mathrm{O}) \mathrm{c} 2 \mathrm{cc} 1 \mathrm{NC}(=\mathrm{O}) / \mathrm{C}=\mathrm{C} / \mathrm{CN}(\mathrm{C}) \mathrm{C}$ & 12.2 & 7.91 \\
\hline 1111 & $\mathrm{Cl} . \mathrm{O}=[\mathrm{N}+]([\mathrm{O}-]) \mathrm{c} 1 \mathrm{ccc} 2 \mathrm{sc} 3 \mathrm{c}(\mathrm{Nc} 4 \mathrm{cccc}(\mathrm{Br}) \mathrm{c} 4) \mathrm{ncnc} 3 \mathrm{c} 2 \mathrm{c} 1$ & 12.3 & $*$ \\
\hline 1112 & $\mathrm{CCOc} 1 \mathrm{cc} 2 \mathrm{ncc}(\mathrm{C \# N}) \mathrm{c}(\mathrm{Nc} 3 \mathrm{ccc}(\mathrm{OCc} 4 \mathrm{ccccn} 4) \mathrm{c}(\mathrm{Cl}) \mathrm{c} 3) \mathrm{c} 2 \mathrm{cc} 1 \mathrm{NC}(=\mathrm{O}) \mathrm{CCN}(\mathrm{C}) \mathrm{C}$ & 12.5 & 7.90 \\
\hline 1113 & $\mathrm{C}=\mathrm{CC}(=\mathrm{O}) \mathrm{Nc} 1 \mathrm{cccc}(-\mathrm{n} 2 \mathrm{c}(=\mathrm{O}) \operatorname{cnc} 3 \mathrm{cnc}(\mathrm{Nc} 4 \mathrm{ccc}(\mathrm{NC}(\mathrm{C})=\mathrm{O}) \mathrm{cc} 4) \mathrm{nc} 32) \mathrm{c} 1$ & 12.5 & 7.90 \\
\hline 1114 & $\mathrm{CN} 1 \mathrm{CCN}(\mathrm{Cc} 2 \mathrm{ccc}(-\mathrm{c} 3 \operatorname{ccc} 4 n \operatorname{ncn}(\mathrm{Nc} 5 \operatorname{ccc}(\mathrm{OCc} 6 \mathrm{ccc}(\mathrm{F}) \mathrm{c} 6) \mathrm{c}(\mathrm{Cl}) \mathrm{c} 5) \mathrm{c} 4 \mathrm{c} 3) \mathrm{o} 2) \mathrm{CC} 1 . \mathrm{Cc} 1 \mathrm{ccc}(\mathrm{S}(=\mathrm{O})(=\mathrm{O}) \mathrm{O}) \mathrm{cc} 1$ & 12.5 & $*$ \\
\hline 1115 & COc1 $\operatorname{ccc} 2 \mathrm{c} 1 \mathrm{sc} 1 \mathrm{c}(\mathrm{Nc} 3 \mathrm{cccc}(\mathrm{Br}) \mathrm{c} 3) \mathrm{ncnc} 12 . \mathrm{Cl}$ & 12.6 & $*$ \\
\hline 1116 & COc1cc2ncnc $(\mathrm{N}[\mathrm{C} @ \mathrm{H}](\mathrm{C}) \mathrm{c} 3 \mathrm{ccccc} 3) \mathrm{c} 2 \mathrm{cc} 1 \mathrm{OCCCCCCC}(=\mathrm{O}) \mathrm{NO}$ & 12.8 & 7.89 \\
\hline 1117 & $\mathrm{C}=\mathrm{CC}(=\mathrm{O}) \mathrm{Nc} 1 \operatorname{cccc}(-\mathrm{n} 2 \mathrm{c}(=\mathrm{O}) \mathrm{cnc} 3 \mathrm{cnc}(\mathrm{Nc} 4 \mathrm{ccccc} 4) \mathrm{nc} 32) \mathrm{c} 1$ & 12.8 & 7.89 \\
\hline 1118 & $\mathrm{CC}(=\mathrm{O}) \mathrm{Nc} 1 \mathrm{ccc}(\mathrm{C}(=\mathrm{O}) \mathrm{Nc} 2 \mathrm{ccc} 3 \mathrm{ncnc}(\mathrm{Nc} 4 \operatorname{ccc}(\mathrm{Br}) \mathrm{c} 4) \mathrm{c} 3 \mathrm{c} 2) \mathrm{cc} 1$ & 12.8 & $*$ \\
\hline 1119 & $\mathrm{CCOc} 1 \mathrm{cc} 2 \mathrm{ncnc}(\mathrm{Nc} 3 \operatorname{ccc}(\mathrm{Oc} 4 \mathrm{ccc}(\mathrm{C}) \mathrm{nc} 4) \mathrm{c}(\mathrm{Cl}) \mathrm{c} 3) \mathrm{c} 2 \mathrm{cc} 1 \mathrm{NC}(=\mathrm{O}) / \mathrm{C}(\mathrm{F})=\mathrm{C} / \mathrm{CN} 1 \mathrm{CCCCC} 1$ & 12.9 & 7.89 \\
\hline 1120 & $\mathrm{C}[\mathrm{C} @ @ \mathrm{H}](\mathrm{Nc} 1 \mathrm{ncnc} 2 \mathrm{oc}(-\mathrm{c} 3 \mathrm{ccc}(\mathrm{F}) \mathrm{cc} 3) \mathrm{cc} 12) \mathrm{c} 1 \mathrm{ccccc} 1$ & 13 & 7.89 \\
\hline
\end{tabular}




\begin{tabular}{|c|c|c|c|}
\hline 1121 & $\mathrm{C}=\mathrm{CC}(=\mathrm{O}) \mathrm{N} 1 \mathrm{CCC}[\mathrm{C} @ \mathrm{H}] 1 \mathrm{C}(=\mathrm{O}) \mathrm{Nc} 1 \mathrm{cc} 2 \mathrm{c}(\mathrm{Nc} 3 \mathrm{cccc}(\mathrm{Cl}) \mathrm{c} 3 \mathrm{~F}) \mathrm{ncnc} 2 \mathrm{cc} 1 \mathrm{OCCOC}$ & 13 & 7.89 \\
\hline 1122 & $\mathrm{Cc} 1 \mathrm{ncnc}(\mathrm{Nc} 2 \mathrm{ccc}(\mathrm{OCc} 3 \mathrm{cccc}(\mathrm{F}) \mathrm{c} 3) \mathrm{c}(\mathrm{Cl}) \mathrm{c} 2) \mathrm{c} 1 \mathrm{C} \# \mathrm{CCCN} 1 \mathrm{CCOCC} 1$ & 13 & 7.89 \\
\hline 1123 & COc1cccc(-c2cc3c(N[C@H](C)c4ccccs4)ncnc3s2)c1OC & 13 & 7.89 \\
\hline 1124 & C[C@@H](Nc1ncnc2sc(-c3ecc(CO)cc3F)cc12)c1ccccc1 & 13 & 7.89 \\
\hline 1125 & $\mathrm{O}=\mathrm{C}(\mathrm{Nc} 1 \mathrm{cc} 2 \mathrm{c}(\mathrm{Nc} 3 \mathrm{ccc}(\mathrm{F}) \mathrm{c}(\mathrm{Cl}) \mathrm{c} 3) n \mathrm{cnc} 2 \mathrm{cc} 1 \mathrm{OCCCN} 1 \mathrm{CCOCC} 1) \mathrm{c} 1 \mathrm{ccc}([\mathrm{N}+](=\mathrm{O})[\mathrm{O}-]) \mathrm{c} 1 \mathrm{~F}$ & 13 & 7.89 \\
\hline 1126 & $\mathrm{CN} 1 \mathrm{CCN}(\mathrm{CCOc} 2 \mathrm{cc} 3 \mathrm{ncnc}(\mathrm{Nc} 4 \mathrm{ccc}(\mathrm{F}) \mathrm{c}(\mathrm{Cl}) \mathrm{c} 4) \mathrm{c} 3 \mathrm{cc} 2 \mathrm{NC}(=\mathrm{O}) \mathrm{c} 2 \mathrm{cc}([\mathrm{N}+](=\mathrm{O})[\mathrm{O}-]) \operatorname{ccc} 2 \mathrm{~F}) \mathrm{CC} 1$ & 13 & 7.89 \\
\hline 1127 & $\mathrm{CS}(=\mathrm{O}) \mathrm{CCNCc} 1 \mathrm{ccc}(-\mathrm{c} 2 \mathrm{ccc} 3 \mathrm{ncnc}(\mathrm{Nc} 4 \mathrm{ccc}(\mathrm{OCc} 5 \mathrm{cccc}(\mathrm{F}) \mathrm{c} 5) \mathrm{c}(\mathrm{Cl}) \mathrm{c} 4) \mathrm{c} 3 \mathrm{c} 2) \mathrm{o} 1 . \mathrm{Cc} 1 \mathrm{ccc}(\mathrm{S}(=\mathrm{O})(=\mathrm{O}) \mathrm{O}) \mathrm{cc} 1$ & 13 & * \\
\hline 1128 & $\mathrm{COc} 1 \mathrm{cc} 2 \mathrm{ncnc}(\mathrm{C} \# \mathrm{CC}(\mathrm{C})(\mathrm{C}) \mathrm{Cc} 3 \mathrm{ccccc} 3) \mathrm{c} 2 \mathrm{cc} 1 \mathrm{OC}$ & 13 & $*$ \\
\hline 1129 & Fc1cc2ncnc(Ne3ecce(Br)c3)c2cn1 & 13 & $*$ \\
\hline 1130 & $\mathrm{CNc} 1 \mathrm{ncc} 2 \mathrm{ncnc}(\mathrm{Nc} 3 \operatorname{cccc} 3) \mathrm{c} 2 \mathrm{n} 1$ & 13 & $*$ \\
\hline 1131 & $\mathrm{CCN} 1 \mathrm{CCN}(\mathrm{C}(=\mathrm{O}) \mathrm{c} 2 \mathrm{cc}(\mathrm{C}) \mathrm{c}(/ \mathrm{C}=\mathrm{C} 3 \backslash \mathrm{C}(=\mathrm{O}) \mathrm{Nc} 4 \mathrm{ncnc}(\mathrm{Nc} 5 \mathrm{ccc}(\mathrm{F}) \mathrm{c}(\mathrm{Cl}) \mathrm{c} 5) \mathrm{c} 43)[\mathrm{nH}] 2) \mathrm{CC} 1$ & 13 & * \\
\hline 1132 & $\mathrm{CO} / \mathrm{N}=\mathrm{C} / \mathrm{c} 1 \mathrm{c}(\mathrm{N}) \mathrm{ncnc} 1 \mathrm{Nc} 1 \mathrm{ccc} 2 \mathrm{c}(\operatorname{ccn} 2 \mathrm{Cc} 2 \mathrm{cccc}(\mathrm{F}) \mathrm{c} 2) \mathrm{c} 1$ & 13 & * \\
\hline 1133 & $\mathrm{C}=\mathrm{CC}(=\mathrm{O}) \mathrm{Nc} 1 \mathrm{cccc}(-\mathrm{n} 2 \mathrm{c}(=\mathrm{O}) \mathrm{n}(\mathrm{CCC}) \mathrm{c}(=\mathrm{O}) \mathrm{c} 3 \mathrm{cnc}(\mathrm{Nc} 4 \mathrm{ccc}(\mathrm{N} 5 \mathrm{CCC}(\mathrm{N}(\mathrm{C}) \mathrm{C}) \mathrm{CC} 5) \mathrm{cc} 4 \mathrm{OC}) \mathrm{nc} 32) \mathrm{c} 1$ & 13 & * \\
\hline 1134 & $\mathrm{COCCOc} 1 \mathrm{cc} 2 \mathrm{ncnc}(\mathrm{Nc} 3 \mathrm{ccc}(\mathrm{F}) \mathrm{c}(\mathrm{Cl}) \mathrm{c} 3) \mathrm{c} 2 \mathrm{c} 2 \mathrm{c} 1 \mathrm{OCCO} 2$ & 13.1 & * \\
\hline 1135 & $\mathrm{Fc1c}(\mathrm{Br}) \mathrm{cccc} 1 \mathrm{Nc} 1 \mathrm{ncnc} 2 \mathrm{ccncc} 12$ & 13.18 & * \\
\hline 1136 & $\mathrm{CS}(=\mathrm{O})(=\mathrm{O}) \mathrm{C}[\mathrm{C} @ \mathrm{H}](\mathrm{N}) \mathrm{c} 1 \mathrm{ccc}(-\mathrm{c} 2 \mathrm{ccc} 3 \mathrm{ncnc}(\mathrm{Nc} 4 \mathrm{ccc}(\mathrm{OCc} 5 \mathrm{ccc}(\mathrm{F}) \mathrm{c} 5) \mathrm{c}(\mathrm{Cl}) \mathrm{c} 4) \mathrm{c} 3 \mathrm{c} 2) \mathrm{o} 1$ & 13.5 & * \\
\hline 1137 & $\mathrm{C}=\mathrm{C}=\mathrm{CC}(=\mathrm{O}) \mathrm{Nc} 1 \mathrm{cc}(\mathrm{Nc} 2 \mathrm{nccc}(\mathrm{C} 3=\mathrm{CN}(\mathrm{C}) \mathrm{C} 4 \mathrm{C}=\mathrm{CC}=\mathrm{CC} 34) \mathrm{n} 2) \mathrm{c}(\mathrm{OC}) \mathrm{cc} 1 \mathrm{~N} 1 \mathrm{CCOCC} 1$ & 13.5 & $*$ \\
\hline 1138 & $\mathrm{C}=\mathrm{C}=\mathrm{CC}(=\mathrm{O}) \mathrm{Nc} 1 \mathrm{cc}(\mathrm{Nc} 2 \mathrm{nccc}(-\mathrm{c} 3 \mathrm{cn}(\mathrm{C}) \mathrm{c} 4 \mathrm{cccc} 34) \mathrm{n} 2) \mathrm{c}(\mathrm{OC}) \mathrm{cc} 1 \mathrm{~N} 1 \mathrm{CCOCC} 1$ & 13.5 & * \\
\hline 1139 & COc1cc2ncnc $(\mathrm{Nc} 3 \mathrm{ccc}(\mathrm{F}) \mathrm{c}(\mathrm{Cl}) \mathrm{c} 3) \mathrm{c} 2 \mathrm{cc} 1 \mathrm{OCCCNCCN}$ & 13.6 & $*$ \\
\hline 1140 & Oc1 $1 \operatorname{cc}(-\mathrm{c} 2 \mathrm{nc}(-\mathrm{c} 3 \operatorname{ccccc} 3) \mathrm{c}(-\mathrm{c} 3 \operatorname{ccnc} 4[\mathrm{nH}] \mathrm{c}(-\mathrm{c} 5 \operatorname{ccccc} 5) \operatorname{cc} 34)[\mathrm{nH}] 2) \mathrm{cc} 1$ & 13.6 & * \\
\hline 1141 & $\mathrm{C}=\mathrm{CC}(=\mathrm{O}) \mathrm{Nc} 1 \operatorname{cccc}(-\mathrm{n} 2 \mathrm{c}(=\mathrm{O}) \operatorname{cnc} 3 \mathrm{cnc}(\mathrm{Nc} 4 \mathrm{ccc}(\mathrm{OC}) \mathrm{cc} 4) \mathrm{nc} 32) \mathrm{c} 1$ & 13.8 & 7.86 \\
\hline 1142 & $\mathrm{C}=\mathrm{C}=\mathrm{CC}(=\mathrm{O}) \mathrm{Nc} 1 \mathrm{cc}(\mathrm{Nc} 2 \mathrm{nccc}(\mathrm{C} 3=\mathrm{CN}(\mathrm{C}) \mathrm{C} 4 \mathrm{C}=\mathrm{CC}=\mathrm{CC} 34) \mathrm{n} 2) \mathrm{c}(\mathrm{OC}) \mathrm{cc} 1 \mathrm{OCCN} 1 \mathrm{CCN}(\mathrm{C}) \mathrm{CC} 1$ & 13.9 & * \\
\hline 1143 & $\mathrm{C}=\mathrm{C}=\mathrm{CC}(=\mathrm{O}) \mathrm{Nc} 1 \mathrm{cc}(\mathrm{Nc} 2 \mathrm{nccc}(-\mathrm{c} 3 \mathrm{cn}(\mathrm{C}) \mathrm{c} 4 \mathrm{cccc} 34) \mathrm{n} 2) \mathrm{c}(\mathrm{OC}) \mathrm{cc} 1 \mathrm{OCCN} 1 \mathrm{CCN}(\mathrm{C}) \mathrm{CC} 1$ & 13.9 & $*$ \\
\hline 1144 & COC[C@@H](Nc1ncnc2oc(-c3ccc(OC)cc3)cc12)c1cccc1 & 14 & 7.85 \\
\hline 1145 & $\mathrm{COc} 1 \mathrm{cc}(\mathrm{CO}) \mathrm{ccc} 1-\mathrm{c} 1 \mathrm{cc} 2 \mathrm{c}(\mathrm{Nc} 3 \mathrm{ccccc} 3) \mathrm{ncnc} 2 \mathrm{~s} 1$ & 14 & 7.85 \\
\hline 1146 & $\mathrm{O}=\mathrm{C}(\mathrm{Nc} 1 \mathrm{cc} 2 \mathrm{c}(\mathrm{Nc} 3 \operatorname{ccc}(\mathrm{F}) \mathrm{c}(\mathrm{Cl}) \mathrm{c} 3) \mathrm{ncnc} 2 \mathrm{cc} 1 \mathrm{OCCCN} 1 \mathrm{CCOCC} 1) \mathrm{c} 1 \mathrm{cccc}([\mathrm{N}+](=\mathrm{O})[\mathrm{O}-]) \mathrm{c} 1 \mathrm{Cl}$ & 14 & 7.85 \\
\hline 1147 & $\mathrm{O}=\mathrm{C}(/ \mathrm{C}=\mathrm{C} / \mathrm{CN} 1 \mathrm{CCCCC} 1) \mathrm{Nc} 1 \mathrm{cc} 2 \mathrm{c}(\mathrm{Nc} 3 \mathrm{ccc}(\mathrm{F}) \mathrm{c}(\mathrm{Cl}) \mathrm{c} 3) \mathrm{ncnc} 2 \mathrm{cn} 1$ & 14 & $*$ \\
\hline 1148 & $\operatorname{COc} 1 \mathrm{cc} 2 \mathrm{ncnc}(\mathrm{C} \# \mathrm{CCCc} 3 \operatorname{ccc} c 3) \mathrm{c} 2 \mathrm{cc} 1 \mathrm{OC}$ & 14 & * \\
\hline 1149 & $\mathrm{O}[\mathrm{C} @ \mathrm{H}] 1 \mathrm{CN}[\mathrm{C} @ \mathrm{H}](\mathrm{C} \# \mathrm{Cc} 2 \mathrm{cc} 3 n \mathrm{ncnc}(\mathrm{Nc} 4 \mathrm{ccc}(\mathrm{OCc} 5 \mathrm{cccc}(\mathrm{F}) \mathrm{c} 5) \mathrm{c}(\mathrm{Cl}) \mathrm{c} 4) \mathrm{c} 3 \mathrm{~s} 2) \mathrm{C} 1$ & 14 & $*$ \\
\hline 1150 & $\mathrm{OCC}(\mathrm{CO}) \mathrm{Nc} 1 \mathrm{cc} 2 \mathrm{ncnc}(\mathrm{Nc} 3 \mathrm{ccc}(\mathrm{Br}) \mathrm{c} 3) \mathrm{c} 2 \mathrm{cn} 1$ & 14 & $*$ \\
\hline 1151 & $\mathrm{COc} 1 \mathrm{cc} 2 \mathrm{c}(\mathrm{Nc} 3 \mathrm{ccc}(\mathrm{NC}(=\mathrm{O}) \mathrm{Nc} 4 \mathrm{cccc} 4) \mathrm{c}(\mathrm{Cl}) \mathrm{c} 3) \mathrm{ncnc} 2 \mathrm{cc} 1 \mathrm{OCCCN} 1 \mathrm{CCN}(\mathrm{C}) \mathrm{CC} 1$ & 14 & * \\
\hline 1152 & $\mathrm{CN}(\mathrm{C} / \mathrm{C}=\mathrm{C} / \mathrm{C}(=\mathrm{O}) \mathrm{Nc} 1 \mathrm{ccc} 2 \mathrm{ncnc}(\mathrm{Nc} 3 \operatorname{cccc}(\mathrm{Br}) \mathrm{c} 3) \mathrm{c} 2 \mathrm{c} 1) \mathrm{CCO}$ & 14 & * \\
\hline 1153 & $\mathrm{CN}(\mathrm{C}) \mathrm{N}=\mathrm{Nc} 1 \mathrm{ccc} 2 \mathrm{ncnc}(\mathrm{Nc} 3 \mathrm{cccc}(\mathrm{Cl}) \mathrm{c} 3) \mathrm{c} 2 \mathrm{c} 1$ & 14 & $*$ \\
\hline 1154 & $\mathrm{COCCO} / \mathrm{N}=\mathrm{C} / \mathrm{c} 1 \mathrm{c}(\mathrm{N}) \mathrm{ncnc} 1 \mathrm{Nc} 1 \mathrm{ccc} 2 \mathrm{c}(\mathrm{cnn} 2 \mathrm{Cc} 2 \mathrm{ccc}(\mathrm{F}) \mathrm{c} 2) \mathrm{c} 1$ & 14 & $*$ \\
\hline 1155 & $\mathrm{CC}(\mathrm{C}) \mathrm{O} / \mathrm{N}=\mathrm{C} / \mathrm{c} 1 \mathrm{c}(\mathrm{N}) \mathrm{ncnc} 1 \mathrm{Nc} 1 \mathrm{ccc} 2 \mathrm{c}(\mathrm{cnn} 2 \mathrm{Cc} 2 \mathrm{cccc}(\mathrm{F}) \mathrm{c} 2) \mathrm{c} 1$ & 14 & $*$ \\
\hline 1156 & C[C@@H](Nc1ncnc2[nH]c(-c3ecc(C\#N)cc3)cc12)c1ccc(F)cc1 & 14 & $*$ \\
\hline 1157 & $\mathrm{COc} 1 \mathrm{ccc}(-\mathrm{c} 2 \mathrm{cc} 3 \mathrm{c}(\mathrm{NC}(\mathrm{C}) \mathrm{c} 4 \mathrm{cccc}(\mathrm{C}) \mathrm{c} 4) \mathrm{ncnc} 3[\mathrm{nH}] 2) \mathrm{cc} 1$ & 14 & * \\
\hline 1158 & COc1ccc(-c2cc3c(N[C@H](C)c4ccc(C)cc4)ncnc3[nH]2)cc1 & 14 & $*$ \\
\hline 1159 & OCC\#Cc1 cec2ncnc(Ne3cce(F)c(Cl)c3)c2c1 & 14.1 & $*$ \\
\hline 1160 & $\mathrm{OCN}(\mathrm{CO}) \mathrm{c} 1 \mathrm{c}(\mathrm{Br}) \mathrm{ccc} 1 \mathrm{Nc} 1 \mathrm{ncnc} 2 \mathrm{ccncc} 12$ & 14.13 & $*$ \\
\hline 1161 & $\mathrm{C}=\mathrm{CC}(=\mathrm{O}) \mathrm{Nc} 1 \mathrm{cccc}(-\mathrm{n} 2 \mathrm{c}(=\mathrm{O}) \mathrm{cnc} 3 \mathrm{cnc}(\mathrm{Nc} 4 \mathrm{ccc}(\mathrm{N}(\mathrm{CC}) \mathrm{CC}) \mathrm{cc} 4) \mathrm{nc} 32) \mathrm{c} 1$ & 14.5 & 7.84 \\
\hline 1162 & $\mathrm{CCNC}(\mathrm{CS}(\mathrm{C})(=\mathrm{O})=\mathrm{O}) \mathrm{c} 1 \mathrm{ccc}(-\mathrm{c} 2 \mathrm{ccc} 3 \mathrm{ncnc}(\mathrm{Nc} 4 \mathrm{ccc}(\mathrm{OCc} 5 \operatorname{ccc}(\mathrm{F}) \mathrm{c} 5) \mathrm{c}(\mathrm{Cl}) \mathrm{c} 4) \mathrm{c} 3 \mathrm{c} 2) \mathrm{o} 1$ & 14.7 & $*$ \\
\hline 1163 & $\mathrm{C}=\mathrm{C}=\mathrm{CC}(=\mathrm{O}) \mathrm{Nc} 1 \mathrm{cc}(\mathrm{Nc} 2 \mathrm{ncc}(\mathrm{OCC}) \mathrm{c}(\mathrm{C} 3=\mathrm{CN}(\mathrm{C}) \mathrm{C} 4 \mathrm{C}=\mathrm{CC}=\mathrm{CC} 34) \mathrm{n} 2) \operatorname{ccc} 1 \mathrm{~N}(\mathrm{C}) \mathrm{CCN}(\mathrm{C}) \mathrm{C}$ & 14.7 & * \\
\hline
\end{tabular}




\begin{tabular}{|c|c|c|c|}
\hline 1164 & $\mathrm{C}=\mathrm{C}=\mathrm{CC}(=\mathrm{O}) \mathrm{Nc} 1 \mathrm{cc}(\mathrm{Nc} 2 \mathrm{nccc}(-\mathrm{c} 3 \mathrm{cn}(\mathrm{C}) \mathrm{c} 4 \mathrm{ccccc} 34) \mathrm{n} 2) \mathrm{c}(\mathrm{OCC}) \mathrm{cc} 1 \mathrm{~N}(\mathrm{C}) \mathrm{CCN}(\mathrm{C}) \mathrm{C}$ & 14.7 & $*$ \\
\hline 1165 & $\mathrm{COC}(=\mathrm{O}) \mathrm{N} 1 \mathrm{CCc} 2 \mathrm{ncnc}(\mathrm{Nc} 3 \mathrm{cccc}(\mathrm{Cl}) \mathrm{c} 3) \mathrm{c} 2 \mathrm{C} 1$ & 14.8 & 7.83 \\
\hline 1166 & 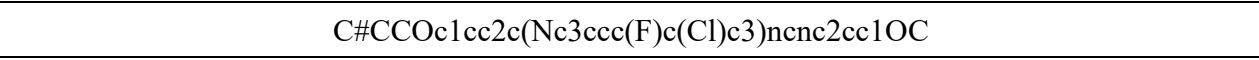 & 14.8 & $*$ \\
\hline 1167 & $\mathrm{O}=\mathrm{C}(\mathrm{Nc} 1 \mathrm{ccncc} 1) \mathrm{Nc} 1 \mathrm{cc}(-\mathrm{c} 2 \mathrm{cncnc} 2) \mathrm{cc}(\mathrm{C}(\mathrm{F})(\mathrm{F}) \mathrm{F}) \mathrm{c} 1$ & 14.83 & $*$ \\
\hline 1168 & $\mathrm{C} \# \mathrm{Cc} 1 \mathrm{cccc}(\mathrm{Nc} 2 \mathrm{ncnc} 3 \mathrm{cc}(\mathrm{OCCOC}) \mathrm{c}(\mathrm{OCCOC}) \mathrm{cc} 23) \mathrm{c} 1 . \mathrm{Cl}$ & 15 & 7.82 \\
\hline 1169 & $\mathrm{COc} 1 \mathrm{cc} 2 \mathrm{ncnc}(\mathrm{Nc} 3 \mathrm{ccc}(\mathrm{F}) \mathrm{c}(\mathrm{Cl}) \mathrm{c} 3) \mathrm{c} 2 \mathrm{cc} 1 \mathrm{OCCCN} 1 \mathrm{CCC} 2(\mathrm{COC} 2) \mathrm{C} 1$ & 15 & 7.82 \\
\hline 1170 & $\mathrm{CACc} 1 \mathrm{ccc}(\mathrm{Nc} 2 \mathrm{ncnc} 3 \mathrm{cc}(\mathrm{OC}) \mathrm{c}(\mathrm{OCCCCC}(=\mathrm{O}) \mathrm{NO}) \operatorname{cc} 23) \mathrm{c} 1$ & 15 & 7.82 \\
\hline 1171 & $\mathrm{CC} 1(\mathrm{C}) \mathrm{CC}(\mathrm{C}(=\mathrm{O}) \mathrm{Nc} 2 \mathrm{ccc} 3 \mathrm{ncnc}(\mathrm{Nc} 4 \mathrm{ccc}(\mathrm{F}) \mathrm{c}(\mathrm{Cl}) \mathrm{c} 4) \mathrm{c} 3 \mathrm{c} 2) \mathrm{CC}(\mathrm{C})(\mathrm{C}) \mathrm{N} 1[\mathrm{O}]$ & 15 & 7.82 \\
\hline 1172 & $\mathrm{CCOc} 1 \mathrm{cc} 2 \mathrm{ncc}(\mathrm{C \# N}) \mathrm{c}(\mathrm{Nc} 3 \mathrm{ccc}(\mathrm{OCc} 4 \mathrm{ccc} 5 \operatorname{ccccc} 5 \mathrm{c} 4) \mathrm{c}(\mathrm{Cl}) \mathrm{c} 3) \mathrm{c} 2 \mathrm{cc} 1 \mathrm{NC}(=\mathrm{O}) / \mathrm{C}=\mathrm{C} / \mathrm{CN}(\mathrm{C}) \mathrm{C}$ & 15 & 7.82 \\
\hline 1173 & $\mathrm{CCCCC} \# \mathrm{CC}(=\mathrm{O}) \mathrm{Nc} 1 \mathrm{cc} 2 \mathrm{c}(\mathrm{Nc} 3 \mathrm{ccc}(\mathrm{F}) \mathrm{c}(\mathrm{Cl}) \mathrm{c} 3) \mathrm{ncnc} 2 \mathrm{cn} 1$ & 15 & $*$ \\
\hline 1174 & $\mathrm{CCN}(\mathrm{CC}) \mathrm{CC} \# \mathrm{CC}(=\mathrm{O}) \mathrm{Nc} 1 \mathrm{cc} 2 \mathrm{c}(\mathrm{Nc} 3 \mathrm{ccc}(\mathrm{F}) \mathrm{c}(\mathrm{Cl}) \mathrm{c} 3) \mathrm{ncnc} 2 \mathrm{cn} 1$ & 15 & $*$ \\
\hline 1175 & $\mathrm{CS}(=\mathrm{O})(=\mathrm{O}) \mathrm{CCNC}(=\mathrm{O}) \mathrm{NC} 1 \mathrm{cccc}(\mathrm{C} \# \mathrm{Cc} 2 \mathrm{cncnc} 2 \mathrm{Nc} 2 \mathrm{ccc}(\mathrm{OCc} 3 \operatorname{ccc}(\mathrm{F}) \mathrm{c} 3) \mathrm{c}(\mathrm{Cl}) \mathrm{c} 2) \mathrm{n} 1$ & 15 & $*$ \\
\hline 1176 & $\mathrm{Nc} 1 \mathrm{ccccc} 1 \mathrm{NC}(=\mathrm{O}) \mathrm{CCc} 1 \mathrm{ccc}(-\mathrm{c} 2 \mathrm{ccc} 3 \mathrm{ncnc}(\mathrm{Nc} 4 \mathrm{ccc}(\mathrm{OCc} 5 \mathrm{cccc}(\mathrm{F}) \mathrm{c} 5) \mathrm{c}(\mathrm{Cl}) \mathrm{c} 4) \mathrm{c} 3 \mathrm{c} 2) \mathrm{cc} 1$ & 15 & $*$ \\
\hline 1177 & $\mathrm{C}=\mathrm{CC}(=\mathrm{O}) \mathrm{Nc} 1 \mathrm{cccc}(-\mathrm{n} 2 \mathrm{c}(=\mathrm{O}) \operatorname{ccc} 3 \mathrm{cnc}(\mathrm{Nc} 4 \mathrm{ccc}(\mathrm{N} 5 \mathrm{CCN}(\mathrm{C}) \mathrm{CC} 5) \mathrm{cc} 4 \mathrm{OC}) \mathrm{nc} 32) \mathrm{c} 1$ & 15 & $*$ \\
\hline 1178 & $\mathrm{Fc} 1 \mathrm{cccc}(\mathrm{COc} 2 \mathrm{ccc}(\mathrm{Nc} 3 \mathrm{ncnc} 4 \mathrm{sc}(-\mathrm{c} 5 \mathrm{ccco} 5) \mathrm{cc} 34) \mathrm{cc} 2 \mathrm{Cl}) \mathrm{c} 1$ & 15 & $*$ \\
\hline 1179 & $\mathrm{CCOc} 1 \mathrm{cc} 2 \mathrm{ncnc}(/ \mathrm{C}=\mathrm{C} / \mathrm{c} 3 \mathrm{cccc} 3) \mathrm{c} 2 \mathrm{cc} 1 \mathrm{OCC}$ & 15 & $*$ \\
\hline 1180 & $\mathrm{COc} 1 \mathrm{cc} 2 \mathrm{ncnc}(\mathrm{C} \# \mathrm{CCOc} 3 \mathrm{cccc} 3) \mathrm{c} 2 \mathrm{cc} 1 \mathrm{OC}$ & 15 & $*$ \\
\hline 1181 & $\mathrm{CS}(=\mathrm{O})(=\mathrm{O}) \mathrm{CC}(=\mathrm{O}) \mathrm{NCCn} 1 \mathrm{ccc} 2 \mathrm{ncnc}(\mathrm{Nc} 3 \operatorname{ccc}(\mathrm{Oc} 4 \operatorname{ccc}(\mathrm{C}(\mathrm{F})(\mathrm{F}) \mathrm{F}) \mathrm{c} 4) \mathrm{c}(\mathrm{Cl}) \mathrm{c} 3) \mathrm{c} 21$ & 15 & $*$ \\
\hline 1182 & $\mathrm{Brc} 1 \mathrm{cccc}(\mathrm{Nc} 2 \mathrm{ncnc} 3 \mathrm{cc} 4 \mathrm{c}(\mathrm{cc} 23) \mathrm{OCO} 4) \mathrm{c} 1$ & 15 & $*$ \\
\hline 1183 & $\mathrm{Nc} 1 \mathrm{cc} 2 \mathrm{ncnc}(\mathrm{Nc} 3 \operatorname{ccc}(\mathrm{C}(\mathrm{F})(\mathrm{F}) \mathrm{F}) \mathrm{c} 3) \mathrm{c} 2 \mathrm{cn} 1$ & 15 & $*$ \\
\hline 1184 & $\mathrm{COc} 1 \mathrm{cc} 2 \mathrm{ncnc}(\mathrm{Nc} 3 \operatorname{ccc}(\mathrm{Br}) \mathrm{c} 3) \mathrm{c} 2 \mathrm{cc} 1[\mathrm{~N}+](=\mathrm{O})[\mathrm{O}-]$ & 15 & $*$ \\
\hline 1185 & $\mathrm{COc} 1 \mathrm{cc} 2 \mathrm{c}(\mathrm{Nc} 3 \mathrm{ccc}(\mathrm{NC}(=\mathrm{O}) \mathrm{Nc} 4 \mathrm{ccccc} 4 \mathrm{C}) \mathrm{c}(\mathrm{Cl}) \mathrm{c} 3) \mathrm{ncnc} 2 \mathrm{cc} 1 \mathrm{OCCCN} 1 \mathrm{CCN}(\mathrm{C}) \mathrm{CC} 1$ & 15 & $*$ \\
\hline 1186 & OCCOCCn1 ccc2ncnc(Nc3ecc(Oc4cccc(C(F)(F)F)c4)c $(\mathrm{Cl}) \mathrm{c} 3) \mathrm{c} 21$ & 15 & $*$ \\
\hline 1187 & $\mathrm{CC}(\mathrm{C})[\mathrm{C} @ @ \mathrm{H}](\mathrm{Nc} 1 \mathrm{ncnc} 2[\mathrm{nH}] \mathrm{c}(-\mathrm{c} 3 \mathrm{cccc} 3) \mathrm{cc} 12) \mathrm{c} 1 \mathrm{ccccc} 1$ & 15 & $*$ \\
\hline 1188 & $\operatorname{COc} 1 \mathrm{cc} 2 \mathrm{ncnc}(\mathrm{Nc} 3 \operatorname{ccc}(\mathrm{OCc} 4 \mathrm{cccc}(\mathrm{F}) \mathrm{c} 4) \mathrm{c}(\mathrm{Cl}) \mathrm{c} 3) \mathrm{c} 2 \mathrm{cc} 1 \mathrm{OCCCCCCn} 1 \mathrm{ccnc} 1[\mathrm{~N}+](=\mathrm{O})[\mathrm{O}-]$ & 15.1 & 7.82 \\
\hline 1189 & $\mathrm{C}=\mathrm{CC}(=\mathrm{O}) \mathrm{Nc} 1 \mathrm{cccc}(-\mathrm{n} 2 \mathrm{c}(=\mathrm{O}) \mathrm{cnc} 3 \mathrm{cnc}(\mathrm{Nc} 4 \mathrm{ccc}(\mathrm{N} 5 \mathrm{CCCC} 5) \mathrm{cc} 4) \mathrm{nc} 32) \mathrm{c} 1$ & 15.3 & 7.82 \\
\hline 1190 & $\operatorname{Oc} 1 \mathrm{ccc}(\mathrm{C}=\mathrm{Nc} 2 \mathrm{ccc} 3 \mathrm{ncnc}(\mathrm{Nc} 4 \mathrm{ccc}(\mathrm{Br}) \mathrm{c} 4) \mathrm{c} 3 \mathrm{c} 2) \mathrm{cc} 1$ & 15.3 & $*$ \\
\hline 1191 & $\mathrm{COc} 1 \mathrm{cc} 2 \mathrm{ncnc}(\mathrm{Nc} 3 \mathrm{cc}(\mathrm{C}(=\mathrm{O}) \mathrm{NC} 45 \mathrm{CC} 6 \mathrm{CC}(\mathrm{CC}(\mathrm{C} 6) \mathrm{C} 4) \mathrm{C} 5) \mathrm{ccc} 3 \mathrm{C}) \mathrm{c} 2 \mathrm{cc} 1 \mathrm{OCCCN} 1 \mathrm{CCOCC} 1$ & 15.4 & 7.81 \\
\hline 1192 & $\mathrm{COc} 1 \mathrm{cc} 2 \mathrm{ncnc}(\mathrm{Nc} 3 \operatorname{ccc}(\mathrm{F}) \mathrm{c}(\mathrm{Cl}) \mathrm{c} 3) \mathrm{c} 2 \mathrm{cc} 1 \mathrm{~S}(=\mathrm{O})(=\mathrm{O}) \mathrm{CCCCCCC}(=\mathrm{O}) \mathrm{NO}$ & 15.4 & 7.81 \\
\hline 1193 & $\mathrm{O}=\mathrm{C}(\mathrm{Nc} 1 \mathrm{ccc}(\mathrm{F}) \mathrm{c}(\mathrm{Cl}) \mathrm{c} 1) \mathrm{c} 1 \mathrm{ccc}(\mathrm{OCCCN} 2 \mathrm{CCCCC} 2) \mathrm{cc} 1 \mathrm{O}$ & 15.4 & $*$ \\
\hline 1194 & $\mathrm{C}=\mathrm{CC}(=\mathrm{O}) \mathrm{Cc} 1 \mathrm{cc}(\mathrm{Nc} 2 \mathrm{ncc} 3 \mathrm{ncn}(-\mathrm{c} 4 \mathrm{ccc}(\mathrm{Cl}) \mathrm{cc} 4) \mathrm{c} 3 \mathrm{n} 2) \mathrm{c}(\mathrm{OC}) \mathrm{cc} 1 \mathrm{~N}(\mathrm{C}) \mathrm{CCN}(\mathrm{C}) \mathrm{C}$ & 15.6 & $*$ \\
\hline 1195 & $\mathrm{C} \# \mathrm{Cc} 1 \mathrm{cccc}(\mathrm{Nc} 2 \mathrm{ncnc} 3 \mathrm{ccc}(-\mathrm{c} 4 \mathrm{ccc}(\mathrm{CO}) \mathrm{o} 4) \mathrm{cc} 23) \mathrm{c} 1$ & 15.69 & $*$ \\
\hline 1196 & $\mathrm{C}=\mathrm{CC}(=\mathrm{O}) \mathrm{Nc} 1 \mathrm{cccc}(-\mathrm{n} 2 \mathrm{c}(=\mathrm{O}) \mathrm{cnc} 3 \mathrm{cnc}(\mathrm{Nc} 4 \mathrm{ccc}(\mathrm{N} 5 \mathrm{CCCCC} 5) \mathrm{cc} 4) \mathrm{nc} 32) \mathrm{c} 1$ & 15.7 & 7.80 \\
\hline 1197 & $\mathrm{CCC}(=\mathrm{O}) \mathrm{N} 1 \mathrm{CC}[\mathrm{C} @ \mathrm{H}](\mathrm{N} 2 \mathrm{C}(=\mathrm{O}) \mathrm{N}(\mathrm{c} 3 \operatorname{cccc} 3 \mathrm{Cl}) \mathrm{Cc} 3 \mathrm{cnc}(\mathrm{Nc} 4 \mathrm{ccc}(\mathrm{N} 5 \mathrm{CCN}(\mathrm{C}) \mathrm{CC} 5) \mathrm{c}(\mathrm{C}) \mathrm{c} 4) \mathrm{nc} 32) \mathrm{C} 1$ & 15.7 & 7.80 \\
\hline 1198 & $\mathrm{~S}=\mathrm{C}(\mathrm{Nc} 1 \mathrm{ccccc} 1) \mathrm{Nc} 1 \mathrm{ccc} 2 \mathrm{ncnc}(\mathrm{Nc} 3 \operatorname{ccc}(\mathrm{Br}) \mathrm{c} 3) \mathrm{c} 2 \mathrm{c} 1$ & 15.8 & $*$ \\
\hline 1199 & $\mathrm{~S}=\mathrm{C}(\mathrm{Nc} 1 \mathrm{ccc} 2 \mathrm{ncnc}(\mathrm{Nc} 3 \operatorname{ccc}(\mathrm{Br}) \mathrm{c} 3) \mathrm{c} 2 \mathrm{c} 1) \mathrm{Nc} 1 \mathrm{ccccc} 1 \mathrm{Cl}$ & 15.8 & $*$ \\
\hline 1200 & $\mathrm{COc} 1 \mathrm{cc} 2 \mathrm{ncnc}(\mathrm{Nc} 3 \mathrm{ccc}(\mathrm{F}) \mathrm{c}(\mathrm{Cl}) \mathrm{c} 3) \mathrm{c} 2 \mathrm{cc} 1 \mathrm{OCCN} 1 \mathrm{CC} 2(\mathrm{COC} 2) \mathrm{C} 1$ & 16 & 7.80 \\
\hline 1201 & $\mathrm{CCC}(=\mathrm{O}) \mathrm{Nc} 1 \mathrm{ccc} 2 \mathrm{nccc}(\mathrm{Nc} 3 \operatorname{cccc}(\mathrm{Br}) \mathrm{c} 3) \mathrm{c} 2 \mathrm{c} 1$ & 16 & 7.80 \\
\hline 1202 & $\mathrm{CCOc} 1 \mathrm{cc} 2 \mathrm{ncc}(\mathrm{CHN}) \mathrm{c}(\mathrm{Nc} 3 \mathrm{ccc}(\mathrm{OCc} 4 \mathrm{cccc} 4) \mathrm{c}(\mathrm{Cl}) \mathrm{c} 3) \mathrm{c} 2 \mathrm{cc} 1 \mathrm{NC}(=\mathrm{O}) / \mathrm{C}=\mathrm{C} / \mathrm{CN} 1 \mathrm{CCSCC} 1$ & 16 & 7.80 \\
\hline 1203 & $\mathrm{C \# Cc1} \operatorname{cccc}(\mathrm{Nc} 2 \mathrm{ncnc} 3 \mathrm{cc} 4 \mathrm{c}(\mathrm{cc} 23) \mathrm{N}(\mathrm{C}(=\mathrm{O}) / \mathrm{C}=\mathrm{C} / \mathrm{CN} 2 \mathrm{CCN}(\mathrm{C}) \mathrm{CC} 2) \mathrm{CCO} 4) \mathrm{c} 1$ & 16 & $*$ \\
\hline 1204 & $\mathrm{C}=\mathrm{CC}(=\mathrm{O}) \mathrm{Nc} 1 \mathrm{cc} 2 \mathrm{c}(\mathrm{Nc} 3 \mathrm{ccc}(\mathrm{F}) \mathrm{c}(\mathrm{Cl}) \mathrm{c} 3) \mathrm{ncnc} 2 \mathrm{~s} 1$ & 16 & $*$ \\
\hline 1205 & $\mathrm{C}=\mathrm{CC}(=\mathrm{O}) \mathrm{Nc} 1 \operatorname{cccc}(-\mathrm{n} 2 \mathrm{c}(=\mathrm{O}) \mathrm{c}(\mathrm{C}) \mathrm{cc} 3 \mathrm{cnc}(\mathrm{Nc} 4 \mathrm{ccc}(\mathrm{N} 5 \mathrm{CCN}(\mathrm{C}) \mathrm{CC} 5) \mathrm{cc} 4 \mathrm{OC}) \mathrm{nc} 32) \mathrm{c} 1$ & 16 & $*$ \\
\hline 1206 & $\mathrm{COCCOc} 1 \mathrm{cc} 2 \mathrm{ncnc}(\mathrm{Nc} 3 \operatorname{ccc} 4 \mathrm{c}(\operatorname{cnn} 4 \mathrm{Cc} 4 \mathrm{cccc} 4) \mathrm{c} 3) \mathrm{c} 2 \mathrm{cc} 1 \mathrm{NC}(=\mathrm{O}) / \mathrm{C}=\mathrm{C} / \mathrm{CN} 1 \mathrm{CCN}(\mathrm{C}) \mathrm{CC} 1$ & 16 & $*$ \\
\hline
\end{tabular}




\begin{tabular}{|c|c|c|c|}
\hline 1207 & $\mathrm{Nc} 1 \mathrm{ncnc}(\mathrm{Nc} 2 \mathrm{ccc} 3 \mathrm{c}(\mathrm{cnn} 3 \mathrm{Cc} 3 \mathrm{cccc}(\mathrm{F}) \mathrm{c} 3) \mathrm{c} 2) \mathrm{c} 1 / \mathrm{C}=\mathrm{N} / \mathrm{N} 1 \mathrm{CCOCC} 1$ & 16 & $*$ \\
\hline 1208 & $\mathrm{CN} 1 \mathrm{CCN}(/ \mathrm{N}=\mathrm{C} / \mathrm{c} 2 \mathrm{c}(\mathrm{N}) \mathrm{ncnc} 2 \mathrm{Nc} 2 \mathrm{ccc} 3 \mathrm{c}(\mathrm{cnn} 3 \mathrm{Cc} 3 \mathrm{ccc}(\mathrm{F}) \mathrm{c} 3) \mathrm{c} 2) \mathrm{CC} 1$ & 16 & $*$ \\
\hline 1209 & $\mathrm{CN}(\mathrm{CC}(=\mathrm{O}) \mathrm{O}) \mathrm{c} 1 \mathrm{cc} 2 \mathrm{ncnc}(\mathrm{Nc} 3 \mathrm{cccc}(\mathrm{Br}) \mathrm{c} 3) \mathrm{c} 2 \mathrm{cn} 1$ & 16 & $*$ \\
\hline 1210 & $\mathrm{CO} / \mathrm{N}=\mathrm{C} / \mathrm{c} 1 \mathrm{c}(\mathrm{N}) \mathrm{ncnc} 1 \mathrm{Nc} 1 \mathrm{ccc}(\mathrm{OCc} 2 \mathrm{cccc} 2) \mathrm{c}(\mathrm{Cl}) \mathrm{c} 1$ & 16 & $*$ \\
\hline 1211 & $\mathrm{C}=\mathrm{CC}(=\mathrm{O}) \mathrm{Nc} 1 \mathrm{cc}(\mathrm{Nc} 2 \mathrm{n}[\mathrm{nH}] \mathrm{c} 3 \mathrm{cc}(-\mathrm{c} 4 \mathrm{cccc}(\mathrm{C}(\mathrm{F})(\mathrm{F}) \mathrm{F}) \mathrm{c} 4) \operatorname{ccc} 23) \mathrm{c}(\mathrm{OC}) \mathrm{cc} 1 \mathrm{~N}(\mathrm{C}) \mathrm{CCN}(\mathrm{C}) \mathrm{C}$ & 16 & $*$ \\
\hline 1212 & $\mathrm{C}=\mathrm{CC}(=\mathrm{O}) \mathrm{NCc} 1 \mathrm{ccc}(\mathrm{Nc} 2 \mathrm{cc}(-\mathrm{c} 3[\mathrm{nH}] \mathrm{c}(\mathrm{SC}) \mathrm{nc} 3-\mathrm{c} 3 \mathrm{ccc}(\mathrm{F}) \mathrm{cc} 3) \mathrm{ccn} 2) \mathrm{c} 1$ & 16 & $*$ \\
\hline 1213 & $\mathrm{C}=\mathrm{CC}(=\mathrm{O}) \mathrm{NCCCSc} 1 \mathrm{nc}(-\mathrm{c} 2 \operatorname{ccc}(\mathrm{F}) \mathrm{cc} 2) \mathrm{c}(-\mathrm{c} 2 \operatorname{ccnc}(\mathrm{Nc} 3 \operatorname{ccccc} 3) \mathrm{c} 2)[\mathrm{nH}] 1$ & 16 & $*$ \\
\hline 1214 & $\mathrm{O}=[\mathrm{N}+]([\mathrm{O}-]) \mathrm{c} 1 \mathrm{ccc}(\mathrm{C}=\mathrm{Nc} 2 \mathrm{ccc} 3 \mathrm{ncnc}(\mathrm{Nc} 4 \mathrm{ccc}(\mathrm{Br}) \mathrm{c} 4) \mathrm{c} 3 \mathrm{c} 2) \mathrm{cc} 1$ & 16.2 & $*$ \\
\hline 1215 & $\mathrm{CN}(\mathrm{CC}(=\mathrm{O}) \mathrm{O}) \mathrm{c} 1 \mathrm{c}(\mathrm{Br}) \mathrm{cccc} 1 \mathrm{Nc} 1 \mathrm{ncnc} 2 \mathrm{ccncc} 12$ & 16.22 & $*$ \\
\hline 1216 & $\mathrm{C}=\mathrm{CC}(=\mathrm{O}) \mathrm{Nc} 1 \mathrm{cccc}(\mathrm{N} 2 \mathrm{C}(=\mathrm{O}) \mathrm{N}(\mathrm{C}) \mathrm{Cc} 3 \mathrm{cnc}(\mathrm{Nc} 4 \mathrm{ccc}(\mathrm{N} 5 \mathrm{CCOCC}) \mathrm{cc} 4 \mathrm{OC}) \mathrm{nc} 32) \mathrm{c} 1$ & 16.4 & 7.79 \\
\hline 1217 & $\mathrm{COc} 1 \mathrm{cc} 2 \mathrm{c}(\mathrm{Nc} 3 \operatorname{ccc}(\mathrm{OCc} 4 \mathrm{cccc}(\mathrm{F}) \mathrm{c} 4) \mathrm{c}(\mathrm{Cl}) \mathrm{c} 3) \mathrm{ncnc} 2 \mathrm{cc} 1 \mathrm{OCCCCCn} 1 \mathrm{ccnc} 1[\mathrm{~N}+](=\mathrm{O})[\mathrm{O}-]$ & 16.6 & 7.78 \\
\hline 1218 & $\mathrm{O}=\mathrm{C}(\mathrm{c} 1 \mathrm{cc} 2 \mathrm{cccc} 2[\mathrm{nH}] 1) \mathrm{c} 1 \mathrm{cc} 2 \mathrm{c}(\mathrm{Nc} 3 \operatorname{ccc}(\mathrm{Cl}) \mathrm{c} 3) \mathrm{ncnc} 2 \mathrm{~s} 1$ & 16.6 & $*$ \\
\hline 1219 & $\mathrm{CHCc} 1 \mathrm{ccc}(\mathrm{Nc} 2 \mathrm{ncnc} 3 \mathrm{cc}(\mathrm{OC} 4 \mathrm{CCOC} 4) \mathrm{c} 4 \mathrm{c}(\mathrm{c} 23) \mathrm{OCCO} 4) \mathrm{c} 1$ & 16.7 & $*$ \\
\hline 1220 & $\mathrm{C}=\mathrm{C}=\mathrm{CCOc} 1 \mathrm{cc} 2 \mathrm{c}(\mathrm{Nc} 3 \mathrm{ccc}(\mathrm{Cl}) \mathrm{c} 3) \mathrm{ncnc} 2 \mathrm{cc} 1 \mathrm{O}$ & 16.9 & $*$ \\
\hline 1221 & $\mathrm{Cc} 1 \mathrm{ncn} c(\mathrm{Nc} 2 \operatorname{ccc}(\mathrm{OCc} 3 \operatorname{ccc}(\mathrm{F}) \mathrm{c} 3) \mathrm{c}(\mathrm{Cl}) \mathrm{c} 2) \mathrm{c} 1 \mathrm{C}$ & 17 & 7.77 \\
\hline 1222 & $\mathrm{CCCCN}(\mathrm{CC} \# \mathrm{CC}(=\mathrm{O}) \mathrm{Nc} 1 \mathrm{cc} 2 \mathrm{c}(\mathrm{Nc} 3 \mathrm{ccc}(\mathrm{F}) \mathrm{c}(\mathrm{Cl}) \mathrm{c} 3) \mathrm{ncnc} 2 \mathrm{cn} 1) \mathrm{CCCC}$ & 17 & $*$ \\
\hline 1223 & $\mathrm{Fc} 1 \mathrm{cccc}(\mathrm{COc} 2 \mathrm{ccc}(\mathrm{Nc} 3 \mathrm{ncncc} 3 \mathrm{C} \# \mathrm{Cc} 3 \mathrm{ccc} \mathrm{n} 3) \mathrm{cc} 2 \mathrm{Cl}) \mathrm{c} 1$ & 17 & $*$ \\
\hline 1224 & $\mathrm{Cn} 1 \mathrm{ccnc} 1 \mathrm{~S}(=\mathrm{O})(=\mathrm{O}) \mathrm{CCNCc} 1 \mathrm{ccc}(-\mathrm{c} 2 \mathrm{ccc} 3 \mathrm{ncnc}(\mathrm{Nc} 4 \mathrm{ccc}(\mathrm{OCc} 5 \mathrm{cccc}(\mathrm{F}) \mathrm{c} 5) \mathrm{c}(\mathrm{C}(\mathrm{F})(\mathrm{F}) \mathrm{F}) \mathrm{c} 4) \mathrm{c} 3 \mathrm{c} 2) \mathrm{o} 1$ & 17 & $*$ \\
\hline 1225 & COc1 $1 \mathrm{cccc} 1-\mathrm{c} 1 \mathrm{cc} 2 \mathrm{c}(\mathrm{NCc} 3 \mathrm{ccccc} 3) \mathrm{ncnc} 2 \mathrm{~s} 1$ & 17 & $*$ \\
\hline 1226 & $\mathrm{CCC}(=\mathrm{O}) \mathrm{Nc} 1 \mathrm{cc} 2 \mathrm{c}(\mathrm{Nc} 3 \mathrm{ccc} 4 \mathrm{c}(\mathrm{cnn} 4 \mathrm{Cc} 4 \mathrm{ccccc} 4) \mathrm{c} 3) \mathrm{ncnc} 2 \mathrm{cc} 1 \mathrm{OC}$ & 17 & $*$ \\
\hline 1227 & $\mathrm{Cc} 1 \mathrm{cccc}(\mathrm{Nc} 2 \mathrm{ncnc} 3 \mathrm{cnc}(\mathrm{N}) \mathrm{nc} 23) \mathrm{c} 1$ & 17 & $*$ \\
\hline 1228 & $\mathrm{COc} 1 \mathrm{cc} 2 \mathrm{c}(\mathrm{Nc} 3 \mathrm{ccc}(\mathrm{NC}(=\mathrm{O}) \mathrm{Nc} 4 \mathrm{ccc}(\mathrm{Cl}) \mathrm{cc} 4) \mathrm{c}(\mathrm{Cl}) \mathrm{c} 3) \mathrm{ncnc} 2 \mathrm{cc} 1 \mathrm{OCCCN} 1 \mathrm{CCOCC} 1$ & 17 & $*$ \\
\hline 1229 & Br.Cc1 ccccc1C(C)Nc1ncnc2[nH]c(-c3ecc(O)cc3)cc12 & 17 & $*$ \\
\hline 1230 & $\mathrm{CC}(\mathrm{C})(\mathrm{C}) \mathrm{OC}(=\mathrm{O}) \mathrm{NCC}(=\mathrm{O}) \mathrm{Nc} 1 \mathrm{ccc} 2 \mathrm{ncnc}(\mathrm{Nc} 3 \mathrm{ccc}(\mathrm{F}) \mathrm{c}(\mathrm{Cl}) \mathrm{c} 3) \mathrm{c} 2 \mathrm{c} 1$ & 17 & $*$ \\
\hline 1231 & $\mathrm{C}=\mathrm{CC}(=\mathrm{O}) \mathrm{Nc} 1 \mathrm{cccc}(\mathrm{NC}(=\mathrm{O}) \mathrm{Nc} 2 \mathrm{ccnc}(\mathrm{Nc} 3 \operatorname{ccc}(\mathrm{N} 4 \mathrm{CCN}(\mathrm{C}) \mathrm{CC} 4) \operatorname{cc} 3 \mathrm{OC}) \mathrm{n} 2) \mathrm{c} 1$ & 17 & $*$ \\
\hline 1232 & $\mathrm{C}=\mathrm{CC}(=\mathrm{O}) \mathrm{Cc} 1 \mathrm{cc}(\mathrm{Nc} 2 \mathrm{ncc} 3 \mathrm{ncn}(-\mathrm{c} 4 \mathrm{ccc}(\mathrm{I}) \mathrm{cc} 4) \mathrm{c} 3 \mathrm{n} 2) \mathrm{c}(\mathrm{OC}) \mathrm{cc} 1 \mathrm{~N}(\mathrm{C}) \mathrm{CCN}(\mathrm{C}) \mathrm{C}$ & 17 & $*$ \\
\hline 1233 & $\mathrm{COc} 1 \mathrm{cc} 2 \mathrm{ncnc}(\mathrm{Nc} 3 \mathrm{ccc}(\mathrm{OCc} 4 \mathrm{cccc} 4) \mathrm{cc} 3) \mathrm{c} 2 \mathrm{cc} 1 \mathrm{OC}$ & 17 & $*$ \\
\hline 1234 & $\mathrm{COc} 1 \mathrm{cc} 2 \mathrm{ncnc}(\mathrm{Nc} 3 \mathrm{ccc}(\mathrm{OCc} 4 \mathrm{ccccc} 4 \mathrm{Br}) \mathrm{c}(\mathrm{Cl}) \mathrm{c} 3) \mathrm{c} 2 \mathrm{cc} 1 \mathrm{OC}$ & 17 & $*$ \\
\hline 1235 & $\mathrm{C}=\mathrm{CC}(=\mathrm{O}) \mathrm{Nc} 1 \mathrm{ccc}(\mathrm{OC}) \mathrm{c}(\mathrm{Nc} 2 \mathrm{cc}(-\mathrm{c} 3 \mathrm{cnc}(\mathrm{SC})[\mathrm{nH}] 3) \mathrm{ccn} 2) \mathrm{c} 1$ & 17 & $*$ \\
\hline 1236 & $\mathrm{CC} / \mathrm{C}=\mathrm{C} / \mathrm{C}(=\mathrm{O}) \mathrm{Nc} 1 \mathrm{cc} 2 \mathrm{c}(\mathrm{N} 3 \mathrm{CCc} 4 \mathrm{ccccc} 43) \mathrm{ncnc} 2 \mathrm{cc} 1 \mathrm{OC}$ & 17 & $*$ \\
\hline 1237 & $\mathrm{~S}=\mathrm{C}(\mathrm{NCc} 1 \mathrm{ccccc} 1) \mathrm{Nc} 1 \mathrm{ccc} 2 \mathrm{ncnc}(\mathrm{Nc} 3 \operatorname{ccc}(\mathrm{Br}) \mathrm{c} 3) \mathrm{c} 2 \mathrm{c} 1$ & 17.2 & $*$ \\
\hline 1238 & $\mathrm{CN}(\mathrm{C}) \mathrm{CCC}(=\mathrm{O}) \mathrm{N}(\mathrm{C}) \mathrm{c} 1 \mathrm{ccc} 2 \mathrm{ncnc}(\mathrm{Nc} 3 \mathrm{cccc}(\mathrm{Br}) \mathrm{c} 3) \mathrm{c} 2 \mathrm{c} 1$ & 17.4 & 7.76 \\
\hline 1239 & $\mathrm{O}=\mathrm{C}(\mathrm{Nc} 1 \mathrm{ccc} 2 \mathrm{ncnc}(\mathrm{Nc} 3 \mathrm{cccc}(\mathrm{Br}) \mathrm{c} 3) \mathrm{c} 2 \mathrm{c} 1) \mathrm{c} 1 \mathrm{ccncc} 1$ & 17.5 & $*$ \\
\hline 1240 & $\mathrm{CCC}(=\mathrm{O}) \mathrm{N} 1 \mathrm{CC}[\mathrm{C} @ \mathrm{H}](\mathrm{N} 2 \mathrm{C}(=\mathrm{O}) \mathrm{N}(\mathrm{c} 3 \mathrm{ccccc} 3 \mathrm{~F}) \mathrm{Cc} 3 \mathrm{cnc}(\mathrm{Nc} 4 \mathrm{ccc}(\mathrm{N} 5 \mathrm{CCN}(\mathrm{C}) \mathrm{CC} 5) \mathrm{c}(\mathrm{C}) \mathrm{c} 4) \mathrm{nc} 32) \mathrm{C} 1$ & 17.6 & 7.75 \\
\hline 1241 & $\mathrm{CS}(=\mathrm{O})(=\mathrm{O}) \mathrm{CC}(\mathrm{N}) \mathrm{c} 1 \mathrm{ccc}(-\mathrm{c} 2 \mathrm{ccc} 3 \mathrm{ncnc}(\mathrm{Nc} 4 \mathrm{ccc}(\mathrm{OCc} 5 \operatorname{cccc}(\mathrm{F}) \mathrm{c} 5) \mathrm{c}(\mathrm{Cl}) \mathrm{c} 4) \mathrm{c} 3 \mathrm{c} 2) \mathrm{o} 1$ & 17.6 & $*$ \\
\hline 1242 & $\mathrm{C}=\mathrm{CC}(=\mathrm{O}) \mathrm{NCc} 1 \mathrm{cccc}(-\mathrm{c} 2 \mathrm{nc}(-\mathrm{c} 3 \operatorname{ccc}(\mathrm{F}) \mathrm{cc} 3) \mathrm{c}(-\mathrm{c} 3 \mathrm{ccnc} 4[\mathrm{nH}] \mathrm{c}(-\mathrm{c} 5 \mathrm{cccc} 5) \mathrm{cc} 34)[\mathrm{nH}] 2) \mathrm{c} 1$ & 17.6 & $*$ \\
\hline 1243 & 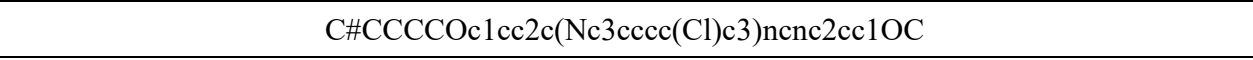 & 17.7 & * \\
\hline 1244 & $\mathrm{Brc} 1 \mathrm{cccc}(\mathrm{Nc} 2 \mathrm{ncnc} 3 \mathrm{cc} 4 \mathrm{c}(\mathrm{cc} 23) \mathrm{OCCO} 4) \mathrm{c} 1$ & 17.8 & $*$ \\
\hline 1245 & $\mathrm{Cc} 1 \mathrm{ncn} c(\mathrm{Nc} 2 \operatorname{ccc}(\mathrm{OCc} 3 \operatorname{ccc}(\mathrm{F}) \mathrm{c} 3) \mathrm{c}(\mathrm{Cl}) \mathrm{c} 2) \mathrm{c} 1 / \mathrm{C}=\mathrm{C}(\backslash \mathrm{F}) \mathrm{C}(=\mathrm{O}) \mathrm{NCCN} 1 \mathrm{CCOCC} 1$ & 18 & 7.74 \\
\hline 1246 & $\mathrm{CC}(\mathrm{C}) \mathrm{S}(=\mathrm{O})(=\mathrm{O}) \mathrm{CCNCc} 1 \mathrm{ccc}(-\mathrm{c} 2 \mathrm{ccc} 3 \mathrm{ncnc}(\mathrm{Nc} 4 \mathrm{ccc}(\mathrm{OCc} 5 \operatorname{cccc}(\mathrm{F}) \mathrm{c} 5) \mathrm{c}(\mathrm{Cl}) \mathrm{c} 4) \mathrm{c} 3 \mathrm{c} 2) \mathrm{o} 1$ & 18 & $*$ \\
\hline 1247 & $\mathrm{CS}(=\mathrm{O})(=\mathrm{O}) \mathrm{CCNCc} 1 \mathrm{ccc}(-\mathrm{c} 2 \mathrm{ccc} 3 \mathrm{ncnc}(\mathrm{Nc} 4 \operatorname{ccc}(\mathrm{OCc} 5 \operatorname{ccccc} 5) \mathrm{c}(\mathrm{Cl}) \mathrm{c} 4) \mathrm{c} 3 \mathrm{c} 2) \mathrm{o} 1$ & 18 & $*$ \\
\hline 1248 & $\mathrm{COc} 1 \mathrm{cc} 2 \mathrm{ncnc}(\mathrm{Nc} 3 \mathrm{ccc}(\mathrm{Cl}) \mathrm{c} 3 \mathrm{~F}) \mathrm{c} 2 \mathrm{cc} 1 \mathrm{OCCCN} 1 \mathrm{CCOCC} 1$ & 18 & $*$ \\
\hline 1249 & $\mathrm{O}=\mathrm{C}(/ \mathrm{C}=\mathrm{C} / \mathrm{c} 1 \operatorname{ccc}(-\mathrm{c} 2 \mathrm{ccc} 3 \mathrm{ncnc}(\mathrm{Nc} 4 \operatorname{ccc}(\mathrm{OCc} 5 \mathrm{cccc}(\mathrm{F}) \mathrm{c} 5) \mathrm{c}(\mathrm{Cl}) \mathrm{c} 4) \mathrm{c} 3 \mathrm{c} 2) \mathrm{c} 1) \mathrm{NO}$ & 18 & * \\
\hline
\end{tabular}




\begin{tabular}{|c|c|c|c|}
\hline 1250 & $\mathrm{O}=\mathrm{C}(/ \mathrm{C}=\mathrm{C} / \mathrm{c} 1 \mathrm{ccc}(-\mathrm{c} 2 \mathrm{ccc} 3 \mathrm{ncnc}(\mathrm{Nc} 4 \mathrm{ccc}(\mathrm{OCc} 5 \mathrm{cccc}(\mathrm{F}) \mathrm{c} 5) \mathrm{c}(\mathrm{Cl}) \mathrm{c} 4) \mathrm{c} 3 \mathrm{c} 2) \mathrm{cc} 1) \mathrm{NO}$ & 18 & * \\
\hline 1251 & $\mathrm{CSC} 1 \mathrm{CCN}(\mathrm{C} / \mathrm{C}=\mathrm{C} / \mathrm{C}(=\mathrm{O}) \mathrm{Nc} 2 \mathrm{cc} 3 \mathrm{c}(\mathrm{Nc} 4 \mathrm{ccc}(\mathrm{F}) \mathrm{c}(\mathrm{Cl}) \mathrm{c} 4) \mathrm{ncnc} 3 \mathrm{~s} 2) \mathrm{CC} 1$ & 18 & $*$ \\
\hline 1252 & $\mathrm{CHCc1ccc}(\mathrm{Nc} 2 \mathrm{ncnc} 3 \mathrm{se}(-\mathrm{c} 4 \mathrm{ccccc} 4 \mathrm{OC}) \mathrm{cc} 23) \mathrm{c} 1$ & 18 & * \\
\hline 1253 & $\mathrm{CCC} 1=\mathrm{C} 2 \mathrm{C}(\mathrm{Nc} 3 \operatorname{ccc} 4 \mathrm{c}(\operatorname{cnn} 4 \mathrm{Cc} 4 \mathrm{cccc} 4) \mathrm{c} 3)=\mathrm{NC}=\mathrm{NC} 2 \mathrm{~N}=\mathrm{C} 1 \mathrm{NC}(=\mathrm{O}) \mathrm{OCCN} 1 \mathrm{CCNCC} 1$ & 18 & $*$ \\
\hline 1254 & $\mathrm{CCC} 1=\mathrm{C} 2 \mathrm{C}(\mathrm{Nc} 3 \operatorname{ccc} 4 \mathrm{c}(\mathrm{cnn} 4 \mathrm{Cc} 4 \mathrm{ccccc} 4) \mathrm{c} 3)=\mathrm{NC}=\mathrm{NC} 2 \mathrm{~N}=\mathrm{C} 1 \mathrm{NC}(=\mathrm{O}) \mathrm{O}[\mathrm{C} @ \mathrm{H}] 1 \mathrm{CC}[\mathrm{C} @ \mathrm{H}](\mathrm{N}) \mathrm{CC} 1$ & 18 & $*$ \\
\hline 1255 & $\mathrm{CC}(\mathrm{C}(=\mathrm{O}) \mathrm{NCCn} 1 \mathrm{ccc} 2 \mathrm{ncnc}(\mathrm{Nc} 3 \operatorname{ccc}(\mathrm{Oc} 4 \operatorname{ccc}(\mathrm{C}(\mathrm{F})(\mathrm{F}) \mathrm{F}) \mathrm{c} 4) \mathrm{c}(\mathrm{Cl}) \mathrm{c} 3) \mathrm{c} 21) \mathrm{S}(\mathrm{C})(=\mathrm{O})=\mathrm{O}$ & 18 & $*$ \\
\hline 1256 & $\mathrm{Clc} 1 \mathrm{ccc} 2 \mathrm{ncnc}(\mathrm{Nc} 3 \operatorname{ccc}(\mathrm{Br}) \mathrm{c} 3) \mathrm{c} 2 \mathrm{n} 1$ & 18 & $*$ \\
\hline 1257 & $\mathrm{C} \# \mathrm{Cc} 1 \mathrm{cccc}(\mathrm{Nc} 2 \mathrm{ncnc} 3 \mathrm{c} 2 / \mathrm{C}(=\mathrm{C} / \mathrm{c} 2[\mathrm{nH}] \mathrm{c}(\mathrm{C}(=\mathrm{O}) \mathrm{NCCN} 4 \mathrm{CCOCC} 4) \mathrm{cc} 2 \mathrm{C}) \mathrm{C}(=\mathrm{O}) \mathrm{N} 3) \mathrm{c} 1$ & 18 & $*$ \\
\hline 1258 & $\mathrm{C}=\mathrm{CC}(=\mathrm{O}) \mathrm{Nc} 1 \mathrm{ccc}(\mathrm{NC}(=\mathrm{O}) \mathrm{Nc} 2 \mathrm{nc}(\mathrm{Nc} 3 \mathrm{ccc}(\mathrm{N} 4 \mathrm{CCC}(\mathrm{N} 5 \mathrm{CCOCC} 5) \mathrm{CC} 4) \mathrm{cc} 3 \mathrm{OC}) \mathrm{ncc} 2 \mathrm{C}(\mathrm{F})(\mathrm{F}) \mathrm{F}) \mathrm{c} 1$ & 18 & $*$ \\
\hline 1259 & $\mathrm{COc} 1 \mathrm{cc} 2 \mathrm{ncnc}(\mathrm{Nc} 3 \mathrm{ccc} 4[\mathrm{nH}] \mathrm{c}(\mathrm{Cc} 5 \mathrm{ccccc} 5) \mathrm{nc} 4 \mathrm{c} 3) \mathrm{c} 2 \mathrm{cc} 1 \mathrm{OC}$ & 18 & $*$ \\
\hline 1260 & $\mathrm{Clc} 1 \mathrm{cc}(\mathrm{Nc} 2 \mathrm{ncnc} 3 \mathrm{cc}[\mathrm{nH}] \mathrm{c} 23) \mathrm{ccc} 1 \mathrm{OCc} 1 \mathrm{ccc} n 1$ & 18 & * \\
\hline 1261 & $\mathrm{C}=\mathrm{CC}(=\mathrm{O}) \mathrm{N} 1 \mathrm{CCc} 2 \mathrm{ncnc}(\mathrm{Nc} 3 \operatorname{ccc}(\mathrm{Oc} 4 \mathrm{ccc}(\mathrm{C}(\mathrm{F})(\mathrm{F}) \mathrm{F}) \mathrm{c} 4) \mathrm{c}(\mathrm{Cl}) \mathrm{c} 3) \mathrm{c} 2 \mathrm{C} 1$ & 18 & $*$ \\
\hline 1262 & $\mathrm{Cc} 1 \operatorname{ccc}(\mathrm{Nc} 2 \operatorname{cc}(\mathrm{Oc} 3 \operatorname{ccc} 4[\mathrm{nH}] \operatorname{ccc} 4 \mathrm{c} 3) \operatorname{ncn} 2) \operatorname{cc} 1 \mathrm{~S}(\mathrm{~N})(=\mathrm{O})=\mathrm{O}$ & 18 & $*$ \\
\hline 1263 & $\mathrm{O}=\mathrm{C}(\mathrm{Nc} 1 \mathrm{ccncc} 1) \mathrm{Nc} 1 \mathrm{cc}(-\mathrm{c} 2 \mathrm{cncnc} 2) \operatorname{ccc} 1 \mathrm{OC}(\mathrm{F})(\mathrm{F}) \mathrm{F}$ & 18.04 & $*$ \\
\hline 1264 & $\mathrm{COc} 1 \mathrm{cc} 2 \mathrm{ncnc}(\mathrm{Nc} 3 \operatorname{ccc}(\mathrm{F}) \mathrm{c}(\mathrm{Cl}) \mathrm{c} 3) \mathrm{c} 2 \mathrm{cc} 1 \mathrm{NC}(=\mathrm{O}) / \mathrm{C}=\mathrm{C} / \mathrm{CN} 1 \mathrm{CCC}(\mathrm{F}) \mathrm{CC} 1$ & 18.08 & $*$ \\
\hline 1265 & $\mathrm{COc} 1 \mathrm{cc} 2 \mathrm{ncnc}(\mathrm{Nc} 3 \mathrm{ccc}(\mathrm{F}) \mathrm{c}(\mathrm{Cl}) \mathrm{c} 3) \mathrm{c} 2 \mathrm{cc} 1 \mathrm{OCCBr}$ & 18.1 & $*$ \\
\hline 1266 & $\mathrm{C}=\mathrm{CC}(=\mathrm{O}) \mathrm{Cc} 1 \mathrm{cc}(\mathrm{Nc} 2 \mathrm{ncc} 3 \mathrm{ncn}(-\mathrm{c} 4 \mathrm{ccc}(\mathrm{F}) \mathrm{cc} 4) \mathrm{c} 3 \mathrm{n} 2) \mathrm{c}(\mathrm{OC}) \mathrm{cc} 1 \mathrm{~N}(\mathrm{C}) \mathrm{CCN}(\mathrm{C}) \mathrm{C}$ & 18.2 & $*$ \\
\hline 1267 & Brc1 $1 \mathrm{ccc}(\mathrm{Nc} 2 \mathrm{ncnc} 3 \mathrm{cc}(\mathrm{OCCCN} 4 \mathrm{CCOCC} 4) \mathrm{c} 4 \mathrm{c}(\mathrm{c} 23) \mathrm{OCCO} 4) \mathrm{c} 1$ & 18.48 & $*$ \\
\hline 1268 & $\mathrm{O}=\mathrm{C}(\mathrm{c} 1 \mathrm{cc} 2 \mathrm{cccc} 2[\mathrm{nH}] 1) \mathrm{c} 1 \mathrm{cc} 2 \mathrm{c}(\mathrm{Nc} 3 \mathrm{ccc}(\mathrm{OCc} 4 \mathrm{ccc}(\mathrm{F}) \mathrm{c} 4) \mathrm{cc} 3 \mathrm{Cl}) \mathrm{ncnc} 2 \mathrm{~s} 1$ & 18.5 & $*$ \\
\hline 1269 & $\mathrm{CCOc} 1 \mathrm{cc} 2 \mathrm{ncnc}(\mathrm{NC} 3=\mathrm{CC}(=\mathrm{O}) \mathrm{C}(\mathrm{OCc} 4 \operatorname{cccc} 4)=\mathrm{CC} 3=\mathrm{O}) \mathrm{c} 2 \mathrm{cc} 1 \mathrm{NC}(=\mathrm{O}) / \mathrm{C}=\mathrm{C} / \mathrm{CN}(\mathrm{C}) \mathrm{C}$ & 18.7 & 7.73 \\
\hline 1270 & $\mathrm{CHC} 1 \mathrm{cccc}(\mathrm{Nc} 2 \mathrm{ncnc} 3 \operatorname{se}(\mathrm{C}(=\mathrm{O}) \mathrm{c} 4 \mathrm{cc} 5 \operatorname{cccc} 5[\mathrm{nH}] 4) \operatorname{cc} 23) \mathrm{c} 1$ & 18.7 & $*$ \\
\hline 1271 & $\mathrm{CS}(=\mathrm{O})(=\mathrm{O}) \mathrm{NCCNCc} 1 \mathrm{ccc}(-\mathrm{c} 2 \mathrm{ccc} 3 \mathrm{ncnc}(\mathrm{Nc} 4 \mathrm{ccc}(\mathrm{OCc} 5 \operatorname{ccc}(\mathrm{F}) \mathrm{c} 5) \mathrm{c}(\mathrm{Cl}) \mathrm{c} 4) \mathrm{c} 3 \mathrm{c} 2) \mathrm{o} 1 . \mathrm{Cc} 1 \mathrm{ccc}(\mathrm{S}(=\mathrm{O})(=\mathrm{O}) \mathrm{O}) \mathrm{cc} 1$ & 18.7 & $*$ \\
\hline 1272 & $\mathrm{C}=\mathrm{CC}(=\mathrm{O}) \mathrm{Nc} 1 \mathrm{ccc} 2 \mathrm{ncnc}(\mathrm{Nc} 3 \operatorname{ccccc} 3 \mathrm{CC}) \mathrm{c} 2 \mathrm{c} 1$ & 18.9 & $*$ \\
\hline 1273 & $\mathrm{C}=\mathrm{C}=\mathrm{CC}(=\mathrm{O}) \mathrm{Nc} 1 \mathrm{cc}(\mathrm{Nc} 2 \mathrm{nccc}(\mathrm{C} 3=\mathrm{CN}(\mathrm{C}) \mathrm{C} 4 \mathrm{C}=\mathrm{CC}=\mathrm{CC} 34) \mathrm{n} 2) \mathrm{c}(\mathrm{OC}) \mathrm{cc} 1 \mathrm{~N} 1 \mathrm{CCC}(\mathrm{N}(\mathrm{C}) \mathrm{C}) \mathrm{C} 1$ & 18.9 & $*$ \\
\hline 1274 & $\mathrm{C}=\mathrm{C}=\mathrm{CC}(=\mathrm{O}) \mathrm{Nc} 1 \mathrm{cc}(\mathrm{Nc} 2 \mathrm{nccc}(-\mathrm{c} 3 \mathrm{cn}(\mathrm{C}) \mathrm{c} 4 \operatorname{ccccc} 34) \mathrm{n} 2) \mathrm{c}(\mathrm{OC}) \mathrm{cc} 1 \mathrm{~N} 1 \mathrm{CCC}(\mathrm{N}(\mathrm{C}) \mathrm{C}) \mathrm{C} 1$ & 18.9 & $*$ \\
\hline 1275 & $\mathrm{O}=\mathrm{C}(\mathrm{CCOc} 1 \mathrm{ccccc} 1) \mathrm{Nc} 1 \mathrm{ccc} 2 \mathrm{ncnc}(\mathrm{Nc} 3 \mathrm{ccc}(\mathrm{Br}) \mathrm{c} 3) \mathrm{c} 2 \mathrm{c} 1$ & 19 & 7.72 \\
\hline 1276 & $\mathrm{O}=\mathrm{C}(\mathrm{CCl}) \mathrm{OCCn} 1 \mathrm{c}(=\mathrm{O}) \mathrm{oc} 2 \mathrm{cc} 3 \mathrm{ncnc}(\mathrm{Nc} 4 \mathrm{ccc}(\mathrm{N} 5 \mathrm{CCOCC} 5) \mathrm{c}(\mathrm{Cl}) \mathrm{c} 4) \mathrm{c} 3 \mathrm{cc} 21$ & 19 & 7.72 \\
\hline 1277 & $\mathrm{C} \# \mathrm{Cc} 1 \mathrm{cccc}(\mathrm{Nc} 2 \mathrm{ccnc} 3 \mathrm{cc}(\mathrm{OC}) \mathrm{c}(\mathrm{OC}) \mathrm{cc} 23) \mathrm{c} 1$ & 19 & 7.72 \\
\hline 1278 & $\mathrm{Cc} 1 \mathrm{ncnc}(\mathrm{Nc} 2 \operatorname{ccc}(\mathrm{OCc} 3 \operatorname{ccc}(\mathrm{F}) \mathrm{c} 3) \mathrm{c}(\mathrm{Cl}) \mathrm{c} 2) \mathrm{c} 1 / \mathrm{C}=\mathrm{C}(\mathrm{F}) \mathrm{C}(=\mathrm{O}) \mathrm{NCCS}(\mathrm{C})(=\mathrm{O})=\mathrm{O}$ & 19 & 7.72 \\
\hline 1279 & $\mathrm{C}[\mathrm{C} @ @ \mathrm{H}](\mathrm{Nc} 1 \mathrm{ncnc} 2 \mathrm{sc}(-\mathrm{c} 3 \mathrm{ccc}(\mathrm{C}(=\mathrm{O}) \mathrm{O}) \mathrm{cc} 3) \mathrm{cc} 12) \mathrm{c} 1 \mathrm{ccccc} 1$ & 19 & 7.72 \\
\hline 1280 & $\begin{array}{c}\mathrm{CS}(=\mathrm{O})(=\mathrm{O}) \mathrm{CCNCc} 1 \mathrm{ccc}(- \\
\mathrm{c} 2 \mathrm{ccc} 3 \mathrm{ncnc}(\mathrm{Nc} 4 \operatorname{ccc}(\mathrm{OCc} 5 \operatorname{cccc}(\mathrm{F}) \mathrm{c} 5) \mathrm{c}(\mathrm{Cl}) \mathrm{c} 4) \mathrm{c} 3 \mathrm{c} 2) \mathrm{o} 1 . \mathrm{Cc} 1 \mathrm{ccc}(\mathrm{S}(=\mathrm{O})(=\mathrm{O}) \mathrm{O}) \operatorname{cc} 1 . \mathrm{Cc} 1 \mathrm{ccc}(\mathrm{S}(=\mathrm{O})(=\mathrm{O}) \mathrm{O}) \mathrm{cc} 1 . \mathrm{O}\end{array}$ & 19 & 8.01 \\
\hline 1281 & $\mathrm{O}=\mathrm{S}(=\mathrm{O})(\mathrm{CCNCc} 1 \mathrm{ccc}(-\mathrm{c} 2 \mathrm{ccc} 3 \mathrm{ncnc}(\mathrm{Nc} 4 \mathrm{ccc}(\mathrm{OCc} 5 \mathrm{cccc}(\mathrm{F}) \mathrm{c} 5) \mathrm{c}(\mathrm{Cl}) \mathrm{c} 4) \mathrm{c} 3 \mathrm{c} 2) \mathrm{o} 1) \mathrm{c} 1 \mathrm{ccccc} 1$ & 19 & $*$ \\
\hline 1282 & $\mathrm{O}=\mathrm{S}(=\mathrm{O})(\mathrm{CCNCc} 1 \mathrm{ccc}(-\mathrm{c} 2 \mathrm{ccc} 3 \mathrm{ncnc}(\mathrm{Nc} 4 \mathrm{ccc}(\mathrm{OCc} 5 \operatorname{ccc}(\mathrm{F}) \mathrm{c} 5) \mathrm{c}(\mathrm{C}(\mathrm{F})(\mathrm{F}) \mathrm{F}) \mathrm{c} 4) \mathrm{c} 3 \mathrm{c} 2) \mathrm{o} 1) \mathrm{c} 1 \mathrm{ccc} n 1$ & 19 & $*$ \\
\hline 1283 & $\mathrm{COc} 1 \mathrm{ccccc} 1-\mathrm{c} 1 \mathrm{cc} 2 \mathrm{c}(\mathrm{NC}(\mathrm{C}) \mathrm{c} 3 \mathrm{ccccc} 3) \mathrm{ncnc} 2 \mathrm{~s} 1$ & 19 & $*$ \\
\hline 1284 & $\mathrm{CN} 1 \mathrm{CCN}(\mathrm{C} / \mathrm{C}=\mathrm{C} / \mathrm{C}(=\mathrm{O}) \mathrm{Nc} 2 \mathrm{cc} 3 \mathrm{c}(\mathrm{Nc} 4 \mathrm{ccc}(\mathrm{F}) \mathrm{c}(\mathrm{Cl}) \mathrm{c} 4) \mathrm{ncnc} 3 \mathrm{cn} 2) \mathrm{CC} 1$ & 19 & $*$ \\
\hline 1285 & $\mathrm{Clc} 1 \mathrm{cccc}(\mathrm{Nc} 2[\mathrm{nH}] \mathrm{cnc} 3 \mathrm{nnc}(-\mathrm{c} 4 \mathrm{ccccc} 4) \mathrm{c} 2-3) \mathrm{c} 1$ & 19 & $*$ \\
\hline 1286 & $\mathrm{Cc} 1 \mathrm{cncc}(\mathrm{Cn} 2 \mathrm{ncc} 3 \mathrm{cc}(\mathrm{Nc} 4 \mathrm{ncnn} 5 \mathrm{ccc}(\mathrm{CN} 6 \mathrm{CCC}(\mathrm{N}) \mathrm{CC} 6) \mathrm{c} 45) \operatorname{ccc} 32) \mathrm{c} 1$ & 19 & $*$ \\
\hline 1287 & $\mathrm{C}=\mathrm{CC}(=\mathrm{O}) \mathrm{N} 1 \mathrm{CCC}[\mathrm{C} @ \mathrm{H}] 1 \mathrm{CSc} 1 \mathrm{nc}(-\mathrm{c} 2 \mathrm{ccc}(\mathrm{F}) \mathrm{cc} 2) \mathrm{c}(-\mathrm{c} 2 \mathrm{ccnc}(\mathrm{Nc} 3 \operatorname{ccccc} 3) \mathrm{c} 2)[\mathrm{nH}] 1$ & 19 & $*$ \\
\hline 1288 & $\mathrm{O}=\mathrm{C}(\mathrm{Nc} 1 \mathrm{ccc}(\mathrm{Cl}) \mathrm{cc} 1) \mathrm{Nc} 1 \mathrm{ccc} 2 \mathrm{ncnc}(\mathrm{Nc} 3 \mathrm{cccc}(\mathrm{Br}) \mathrm{c} 3) \mathrm{c} 2 \mathrm{c} 1$ & 19.3 & * \\
\hline 1289 & $\mathrm{~S}=\mathrm{C}(\mathrm{Nc} 1 \mathrm{ccc}(\mathrm{Cl}) \mathrm{cc} 1) \mathrm{Nc} 1 \mathrm{ccc} 2 \mathrm{ncnc}(\mathrm{Nc} 3 \mathrm{cccc}(\mathrm{Br}) \mathrm{c} 3) \mathrm{c} 2 \mathrm{c} 1$ & 19.5 & $*$ \\
\hline 1290 & $\operatorname{COc} 1 \operatorname{ccc}(\mathrm{C}(=\mathrm{O}) \mathrm{Nc} 2 \operatorname{ccc} 3 \mathrm{ncnc}(\mathrm{Nc} 4 \operatorname{cccc}(\mathrm{Br}) \mathrm{c} 4) \mathrm{c} 3 \mathrm{c} 2) \operatorname{cc} 1 \mathrm{OC}$ & 19.5 & $*$ \\
\hline 1291 & $\mathrm{CN}(\mathrm{C}) \mathrm{c} 1 \mathrm{ccc} 2 \mathrm{sc} 3 \mathrm{c}(\mathrm{Nc} 4 \mathrm{ccc}(\mathrm{Br}) \mathrm{c} 4) \mathrm{ncnc} 3 \mathrm{c} 2 \mathrm{c} 1$ & 19.8 & $*$ \\
\hline
\end{tabular}




\begin{tabular}{|c|c|c|c|}
\hline 1292 & $\mathrm{O}=\mathrm{C}(\mathrm{Nc} 1 \mathrm{ccc} 2 \mathrm{ncnc}(\mathrm{Nc} 3 \mathrm{cccc}(\mathrm{Br}) \mathrm{c} 3) \mathrm{c} 2 \mathrm{c} 1) \mathrm{c} 1 \mathrm{ccc} \mathrm{c} 1$ & 19.8 & $*$ \\
\hline 1293 & $\mathrm{CN} 1 \mathrm{CCN}(\mathrm{c} 2 \mathrm{ccc}(\mathrm{Nc} 3 \mathrm{ncnc} 4 \mathrm{cc} 5 \mathrm{oc}(=\mathrm{O}) \mathrm{n}(\mathrm{CCOC}(=\mathrm{O}) \mathrm{CCl}) \mathrm{c} 5 \mathrm{cc} 34) \mathrm{cc} 2 \mathrm{Cl}) \mathrm{CC} 1$ & 20 & 7.70 \\
\hline 1294 & $\mathrm{CCOc} 1 \mathrm{cc} 2 \mathrm{ncc}(\mathrm{C \# N}) \mathrm{c}(\mathrm{Nc} 3 \mathrm{ccc}(\mathrm{OCc} 4 \mathrm{cccc} 4) \mathrm{c}(\mathrm{Cl}) \mathrm{c} 3) \mathrm{c} 2 \mathrm{cc} 1 \mathrm{NC}(=\mathrm{O}) / \mathrm{C}=\mathrm{C} / \mathrm{CN}(\mathrm{C}) \mathrm{CCO}$ & 20 & 7.70 \\
\hline 1295 & $\mathrm{CCOc} 1 \mathrm{cc} 2 \mathrm{ncc}(\mathrm{C \# N}) \mathrm{c}(\mathrm{Nc} 3 \mathrm{ccc}(\mathrm{OCc} 4 \mathrm{ccccc} 4) \mathrm{c}(\mathrm{Cl}) \mathrm{c} 3) \mathrm{c} 2 \mathrm{cc} 1 \mathrm{NC}(=\mathrm{O}) / \mathrm{C}=\mathrm{C} / \mathrm{CN} 1 \mathrm{CCOCC} 1$ & 20 & 7.70 \\
\hline 1296 & $\mathrm{COc} 1 \mathrm{cc}(\mathrm{C}=\mathrm{O}) \mathrm{ccc} 1-\mathrm{c} 1 \mathrm{cc} 2 \mathrm{c}(\mathrm{Nc} 3 \mathrm{cccc} 3) \mathrm{ncnc} 2 \mathrm{~s} 1$ & 20 & 7.70 \\
\hline 1297 & $\mathrm{COC}(=\mathrm{O}) \mathrm{c} 1 \mathrm{ccc}(-\mathrm{c} 2 \mathrm{cc} 3 \mathrm{c}(\mathrm{N}[\mathrm{C} @ \mathrm{H}](\mathrm{C}) \mathrm{c} 4 \mathrm{cccc} 4) \mathrm{ncnc} 3 \mathrm{~s} 2) \mathrm{c}(\mathrm{OC}) \mathrm{c} 1$ & 20 & 7.70 \\
\hline 1298 & $\mathrm{CS}(=\mathrm{O})(=\mathrm{O}) \mathrm{CCNCCCCOc} 1 \mathrm{ccc} 2 \mathrm{ncnc}(\mathrm{Nc} 3 \mathrm{ccc}(\mathrm{F}) \mathrm{c}(\mathrm{Cl}) \mathrm{c} 3) \mathrm{c} 2 \mathrm{c} 1$ & 20 & * \\
\hline 1299 & COc1cc2ncnc $(\mathrm{Nc} 3 \operatorname{ccc}(\mathrm{F}) \mathrm{c}(\mathrm{Cl}) \mathrm{c} 3) \mathrm{c} 2 \mathrm{cc} 1 \mathrm{CN} 1 \mathrm{CCC}[\mathrm{C} @ \mathrm{H}] 1 \mathrm{C}(\mathrm{N})=\mathrm{O}$ & 20 & $*$ \\
\hline 1300 & $\mathrm{COc} 1 \mathrm{cc} 2 \mathrm{ncnc}(\mathrm{Nc} 3 \operatorname{ccc}(\mathrm{Cl}) \mathrm{c} 3 \mathrm{~F}) \mathrm{c} 2 \mathrm{cc} 1 \mathrm{CN}(\mathrm{C}) \mathrm{CC}(\mathrm{N})=\mathrm{O}$ & 20 & $*$ \\
\hline 1301 & $\mathrm{COc} 1 \mathrm{cc} 2 \mathrm{ncnc}(\mathrm{Nc} 3 \mathrm{cccc}(\mathrm{Cl}) \mathrm{c} 3 \mathrm{~F}) \mathrm{c} 2 \mathrm{cc} 1 \mathrm{CN}(\mathrm{C}) \mathrm{C} 1 \mathrm{CCNC} 1=\mathrm{O}$ & 20 & $*$ \\
\hline 1302 & COc1cc2ncnc $(\mathrm{Nc} 3 \operatorname{ccc}(\mathrm{Cl}) \mathrm{c} 3 \mathrm{~F}) \mathrm{c} 2 \mathrm{cc} 1 \mathrm{CN}(\mathrm{C})[\mathrm{C} @ @ \mathrm{H}](\mathrm{CO}) \mathrm{C}(\mathrm{N})=\mathrm{O}$ & 20 & * \\
\hline 1303 & $\mathrm{COc} 1 \mathrm{cc} 2 \mathrm{ncnc}(\mathrm{Nc} 3 \operatorname{cccc}(\mathrm{Cl}) \mathrm{c} 3 \mathrm{~F}) \mathrm{c} 2 \mathrm{cc} 1 \mathrm{CN}(\mathrm{C}) \mathrm{Cl}(\mathrm{C}(\mathrm{N})=\mathrm{O}) \mathrm{CN}(\mathrm{C}) \mathrm{C} 1$ & 20 & * \\
\hline 1304 & $\mathrm{O}=\mathrm{C}(/ \mathrm{C}=\mathrm{C} / \mathrm{CNC} 1 \mathrm{CCOCC} 1) \mathrm{Nc} 1 \mathrm{cc} 2 \mathrm{c}(\mathrm{Nc} 3 \mathrm{ccc}(\mathrm{F}) \mathrm{c}(\mathrm{Cl}) \mathrm{c} 3) \mathrm{ncnc} 2 \mathrm{~s} 1$ & 20 & * \\
\hline 1305 & $\operatorname{CCOC}(=\mathrm{O}) \operatorname{CCCn} 1 \mathrm{c}(=\mathrm{O}) \mathrm{oc} 2 \mathrm{cc} 3 \mathrm{ncnc}(\mathrm{Nc} 4 \mathrm{ccc}(\mathrm{O}) \mathrm{cc} 4) \mathrm{c} 3 \mathrm{cc} 21$ & 20 & $*$ \\
\hline 1306 & $\mathrm{C}=\mathrm{CC}(=\mathrm{O}) \mathrm{Nc} 1 \mathrm{cccc}(-\mathrm{n} 2 \mathrm{c}(=\mathrm{O}) \mathrm{c}(-\mathrm{c} 3 \operatorname{cccc} 3) \mathrm{c}(\mathrm{C}) \mathrm{c} 3 \mathrm{cnc}(\mathrm{Nc} 4 \mathrm{ccc}(\mathrm{N} 5 \mathrm{CCN}(\mathrm{C}) \mathrm{CC} 5) \mathrm{cc} 4 \mathrm{OC}) \mathrm{nc} 32) \mathrm{c} 1$ & 20 & * \\
\hline 1307 & $\mathrm{C}=\mathrm{CC}(=\mathrm{O}) \mathrm{N} 1 \mathrm{CCc} 2 \mathrm{c}(\operatorname{sc} 3 n \mathrm{nnc}(\mathrm{N}[\mathrm{C} @ \mathrm{H}](\mathrm{C}) \mathrm{c} 4 \operatorname{ccccc} 4) \mathrm{c} 23) \mathrm{C} 1$ & 20 & * \\
\hline 1308 & $\mathrm{CCC} 1=\mathrm{C} 2 \mathrm{C}(\mathrm{Nc} 3 \operatorname{ccc} 4 \mathrm{c}(\operatorname{cnn} 4 \mathrm{Cc} 4 \mathrm{ccccc} 4) \mathrm{c} 3)=\mathrm{NC}=\mathrm{NC} 2 \mathrm{~N}=\mathrm{C} 1 \mathrm{NC}(=\mathrm{O}) \mathrm{O}[\mathrm{C} @ \mathrm{H}] 1 \mathrm{CC}[\mathrm{C} @ @](\mathrm{C})(\mathrm{N}) \mathrm{CC} 1$ & 20 & $*$ \\
\hline 1309 & $\mathrm{C}=\mathrm{CC}(=\mathrm{O}) \mathrm{N}(\mathrm{C}) \mathrm{c} 1 \mathrm{nc} 2 \mathrm{c}(\mathrm{Nc} 3 \mathrm{ccc}(\mathrm{F}) \mathrm{c}(\mathrm{Cl}) \mathrm{c} 3) \mathrm{ncnc} 2 \mathrm{cc} 1 \mathrm{OCCCN} 1 \mathrm{CCOCC} 1$ & 20 & $*$ \\
\hline 1310 & $\mathrm{CNc} 1 \mathrm{ccc} 2 \mathrm{ncnc}(\mathrm{Nc} 3 \mathrm{cccc}(\mathrm{Br}) \mathrm{c} 3) \mathrm{c} 2 \mathrm{n} 1$ & 20 & $*$ \\
\hline 1311 & $\mathrm{COc} 1 \mathrm{cc} 2 \mathrm{ncnc}(\mathrm{Oc} 3 \mathrm{ccc}(\mathrm{Cl}) \mathrm{c} 3) \mathrm{c} 2 \mathrm{cc} 1 \mathrm{OC}$ & 20 & * \\
\hline 1312 & COc1 $1 \mathrm{ccc} 2 \operatorname{sc} 3 \mathrm{c}(\mathrm{Nc} 4 \mathrm{cccc}(\mathrm{Br}) \mathrm{c} 4) \mathrm{ncnc} 3 \mathrm{c} 12 . \mathrm{Cl}$ & 20 & $*$ \\
\hline 1313 & $\mathrm{CCc} 1 \mathrm{c}(\mathrm{C}(=\mathrm{O}) \mathrm{O}) \mathrm{cn} 2 \mathrm{ncnc}(\mathrm{Nc} 3 \operatorname{ccc} 4 \mathrm{c}(\operatorname{cnn} 4 \mathrm{Cc} 4 \operatorname{ccccc} 4) \mathrm{c} 3) \mathrm{c} 12$ & 20 & * \\
\hline 1314 & $\mathrm{COc} 1 \mathrm{cc} 2 \mathrm{c}(\mathrm{Nc} 3 \mathrm{ccc}(\mathrm{NC}(=\mathrm{O}) \mathrm{c} 4 \mathrm{ccccc} 4 \mathrm{Cl}) \mathrm{cc} 3) \mathrm{ncnc} 2 \mathrm{cc} 1 \mathrm{OCCCN} 1 \mathrm{CCN}(\mathrm{C}) \mathrm{CC} 1$ & 20 & * \\
\hline 1315 & $\mathrm{O}=\mathrm{C}(\mathrm{C} \# \mathrm{CCN} 1 \mathrm{CCOCC} 1) \mathrm{Nc} 1 \mathrm{ccc} 2 \mathrm{ncnc}(\mathrm{Nc} 3 \mathrm{cccc}(\mathrm{Br}) \mathrm{c} 3) \mathrm{c} 2 \mathrm{c} 1$ & 20 & * \\
\hline 1316 & $\mathrm{CO} / \mathrm{N}=\mathrm{C} / \mathrm{c} 1 \mathrm{c}(\mathrm{N}) \mathrm{ncnc} 1 \mathrm{Nc} 1 \mathrm{ccc} 2 \mathrm{c}(\mathrm{cnn} 2 \mathrm{Cc} 2 \mathrm{cccc}(\mathrm{C \# N}) \mathrm{c} 2) \mathrm{c} 1$ & 20 & $*$ \\
\hline 1317 & C\#Cc1cccc(Nc2ncnn3ccc(COC[C@@H]4CNCCO4)c23)c1 & 20 & * \\
\hline 1318 & Cc1ccecc1Nc1ncnn2ecc(CN3CCC(N)CC3)c12 & 20 & * \\
\hline 1319 & $\mathrm{COc} 1 \mathrm{cc} 2 \mathrm{ncnc}(\mathrm{Oc} 3 \operatorname{ccc}(\mathrm{NC}(=\mathrm{S}) \mathrm{Nc} 4 \mathrm{ccc}(\mathrm{Cl}) \mathrm{c}(\mathrm{C}(\mathrm{F})(\mathrm{F}) \mathrm{F}) \mathrm{c} 4) \mathrm{c} 3) \mathrm{c} 2 \mathrm{cc} 1 \mathrm{OC}$ & 20 & * \\
\hline 1320 & $\operatorname{COc} 1 \mathrm{cc} 2 \mathrm{ncnc}(\mathrm{Sc} 3 \operatorname{ccc}(\mathrm{NC}(=\mathrm{S}) \mathrm{Nc} 4 \mathrm{cc}(\mathrm{C}(\mathrm{F})(\mathrm{F}) \mathrm{F}) \operatorname{cc}(\mathrm{C}(\mathrm{F})(\mathrm{F}) \mathrm{F}) \mathrm{c} 4) \mathrm{c} 3) \mathrm{c} 2 \mathrm{cc} 1 \mathrm{OC}$ & 20 & $*$ \\
\hline 1321 & $\mathrm{COc} 1 \mathrm{cc} 2 \mathrm{ncnc}(\mathrm{Nc} 3 \mathrm{ccc}(\mathrm{Br}) \mathrm{c}(\mathrm{O}) \mathrm{c} 3) \mathrm{c} 2 \mathrm{cc} 1 \mathrm{OC}$ & 20 & $*$ \\
\hline 1322 & $\mathrm{COc} 1 \mathrm{ccc}(\mathrm{Nc} 2 \mathrm{ncnc} 3 \mathrm{oc}(-\mathrm{c} 4 \mathrm{ccc}(\mathrm{N}) \mathrm{cc} 4) \mathrm{cc} 23) \mathrm{cc} 1 \mathrm{O}$ & 20 & $*$ \\
\hline 1323 & $\mathrm{Cc} 1 \mathrm{ccc}(\mathrm{Nc} 2 \mathrm{ncnc} 3 \mathrm{oc}(-\mathrm{c} 4 \mathrm{cccc}(\mathrm{N}) \mathrm{c} 4) \mathrm{cc} 23) \mathrm{cc} 1 \mathrm{O}$ & 20 & $*$ \\
\hline 1324 & $\mathrm{O}=[\mathrm{N}+]([\mathrm{O}-]) \mathrm{c} 1 \mathrm{ccc}(-\mathrm{c} 2 \mathrm{cc} 3 \mathrm{c}(\mathrm{Nc} 4 \mathrm{ccc}(\mathrm{Cl}) \mathrm{cc} 4 \mathrm{~F}) \mathrm{ncnc} 3 \mathrm{o} 2) \mathrm{cc} 1$ & 20 & $*$ \\
\hline 1325 & $\mathrm{Cc} 1 \mathrm{cccc}(\mathrm{Oc} 2 \mathrm{ccc}(\mathrm{Nc} 3 \mathrm{ncnc} 4 \mathrm{cc}[\mathrm{nH}] \mathrm{c} 34) \mathrm{cc} 2 \mathrm{Cl}) \mathrm{c} 1$ & 20 & $*$ \\
\hline 1326 & $\mathrm{Cc} 1 \mathrm{nc}(\mathrm{C}) \mathrm{c}(\mathrm{C}=\mathrm{C} 2 \mathrm{CN}(\mathrm{C}) \mathrm{CC}(=\mathrm{C} / \mathrm{c} 3 \mathrm{nc}(\mathrm{C}) \mathrm{c}(\mathrm{C}) \mathrm{nc} 3 \mathrm{C}) / \mathrm{C} 2=\mathrm{N} / \mathrm{O}) \mathrm{nc} 1 \mathrm{C}$ & 20 & $*$ \\
\hline 1327 & $\mathrm{COc} 1 \mathrm{cc}(\mathrm{Br}) \mathrm{c}(\mathrm{C}=\mathrm{C} 2 \mathrm{CN}(\mathrm{C}) \mathrm{CC}(=\mathrm{Cc} 3 \mathrm{nc}(\mathrm{C}) \mathrm{c}(\mathrm{C}) \mathrm{nc} 3 \mathrm{C}) \mathrm{C} 2=\mathrm{NO}) \mathrm{cc} 1 \mathrm{OC}$ & 20 & $*$ \\
\hline 1328 & $\mathrm{C}=\mathrm{CC}(=\mathrm{O}) \mathrm{Nc} 1 \mathrm{cccc}(-\mathrm{n} 2 \mathrm{c}(=\mathrm{O}) \mathrm{n}(\mathrm{C}(\mathrm{C}) \mathrm{C}) \mathrm{c}(=\mathrm{O}) \mathrm{c} 3 \mathrm{cnc}(\mathrm{Nc} 4 \mathrm{ccc}(\mathrm{N} 5 \mathrm{CCC}(\mathrm{N}(\mathrm{C}) \mathrm{C}) \mathrm{CC} 5) \mathrm{cc} 4 \mathrm{OC}) \mathrm{nc} 32) \mathrm{c} 1$ & 20 & $*$ \\
\hline 1329 & $\mathrm{Cc} 1 \mathrm{cccc}(\mathrm{NNc} 2 \mathrm{ncnc} 3[\mathrm{nH}] \operatorname{ccc} 23) \mathrm{c} 1$ & 20.01 & $*$ \\
\hline 1330 & $\mathrm{COc} 1 \mathrm{cc} 2 \mathrm{c}(\mathrm{Nc} 3 \operatorname{ccc}(\mathrm{OCc} 4 \mathrm{cccc}(\mathrm{F}) \mathrm{c} 4) \mathrm{c}(\mathrm{Cl}) \mathrm{c} 3) \mathrm{ncnc} 2 \mathrm{cc} 1 \mathrm{OCCOCCn} 1 \mathrm{ccnc} 1[\mathrm{~N}+](=\mathrm{O})[\mathrm{O}-]$ & 20.1 & 7.70 \\
\hline 1331 & Fc1cec(Nc2ncne3cc(OC4CCOC4)c4c(c23)OCCO4)ec1Cl & 20.5 & $*$ \\
\hline 1332 & $\mathrm{~S}=\mathrm{C}(\mathrm{Nc} 1 \mathrm{cccc}(\mathrm{Cl}) \mathrm{c} 1) \mathrm{Nc} 1 \mathrm{ccc} 2 \mathrm{ncnc}(\mathrm{Nc} 3 \operatorname{ccc}(\mathrm{Br}) \mathrm{c} 3) \mathrm{c} 2 \mathrm{c} 1$ & 20.6 & $*$ \\
\hline 1333 & $\mathrm{C} / \mathrm{C}=\mathrm{Clc1} \operatorname{ccc}(\mathrm{Nc} 2 \mathrm{ncnc} 3 \mathrm{cc}(\mathrm{OCCCN} 4 \mathrm{CCOCC} 4) \mathrm{c}(\mathrm{OCCCN} 4 \mathrm{CCOCC} 4) \mathrm{cc} 23) \mathrm{cc} 1$ & 20.7 & $*$ \\
\hline 1334 & $\mathrm{C} / \mathrm{C}=\mathrm{C} / \mathrm{c} 1 \mathrm{ccc}(\mathrm{Nc} 2 \mathrm{ncnc} 3 \mathrm{cc}(\mathrm{OCCCN} 4 \mathrm{CCOCC} 4) \mathrm{c}(\mathrm{OCCCN} 4 \mathrm{CCOCC} 4) \mathrm{cc} 23) \mathrm{cc} 1$ & 20.72 & * \\
\hline
\end{tabular}




\begin{tabular}{|c|c|c|c|}
\hline 1335 & OCc1 cce $(-\mathrm{c} 2 \mathrm{cc} 3 \mathrm{c}(\mathrm{Nc} 4 \mathrm{cccc} 4) \mathrm{ncnc} 3 \mathrm{~s} 2) \mathrm{cc} 1$ & 21 & 7.68 \\
\hline 1336 & $\mathrm{COc} 1 \mathrm{c}(\mathrm{C}=\mathrm{O}) \mathrm{cccc} 1-\mathrm{c} 1 \mathrm{cc} 2 \mathrm{c}(\mathrm{N}[\mathrm{C} @ \mathrm{H}](\mathrm{C}) \mathrm{c} 3 \operatorname{ccccc} 3) \mathrm{ncnc} 2 \mathrm{~s} 1$ & 21 & 7.68 \\
\hline 1337 & $\mathrm{CC}(=\mathrm{O}) \mathrm{N} 1 \mathrm{CCN}(\mathrm{CCCOc} 2 \mathrm{cc} 3 \mathrm{ncnc}(\mathrm{Nc} 4 \mathrm{ccc}(\mathrm{F}) \mathrm{c}(\mathrm{Cl}) \mathrm{c} 4) \mathrm{c} 3 \mathrm{cc} 2 \mathrm{NC}(=\mathrm{O}) \mathrm{c} 2 \mathrm{cc}([\mathrm{N}+](=\mathrm{O})[\mathrm{O}-]) \mathrm{ccc} 2 \mathrm{~F}) \mathrm{CC} 1$ & 21 & 7.68 \\
\hline 1338 & $\mathrm{NCc} 1 \mathrm{ccc}(\mathrm{C} \# \mathrm{Cc} 2 \mathrm{cncnc} 2 \mathrm{Nc} 2 \mathrm{ccc}(\mathrm{OCc} 3 \mathrm{cccc}(\mathrm{F}) \mathrm{c} 3) \mathrm{c}(\mathrm{Cl}) \mathrm{c} 2) \mathrm{n} 1$ & 21 & $*$ \\
\hline 1339 & $\operatorname{CCCS}(=\mathrm{O})(=\mathrm{O}) \mathrm{CCNCc} 1 \mathrm{ccc}(-\mathrm{c} 2 \mathrm{ccc} 3 \mathrm{ncnc}(\mathrm{Nc} 4 \operatorname{ccc}(\mathrm{OCc} 5 \operatorname{ccc}(\mathrm{F}) \mathrm{c} 5) \mathrm{c}(\mathrm{Cl}) \mathrm{c} 4) \mathrm{c} 3 \mathrm{c} 2) \mathrm{o} 1$ & 21 & $*$ \\
\hline 1340 & $\mathrm{CHCc} 1 \mathrm{cccc}(\mathrm{Nc} 2 \mathrm{ncnc} 3 \mathrm{cc}(\mathrm{OCCOC}) \mathrm{c} 4 \mathrm{c}(\mathrm{c} 23) \mathrm{OCCO} 4) \mathrm{c} 1$ & 21 & $*$ \\
\hline 1341 & $\mathrm{C}=\mathrm{C}(\mathrm{C}) \mathrm{C}(=\mathrm{O}) \mathrm{Nc} 1 \mathrm{cc} 2 \mathrm{c}(\mathrm{Nc} 3 \mathrm{ccc}(\mathrm{F}) \mathrm{c}(\mathrm{Cl}) \mathrm{c} 3) \mathrm{ncnc} 2 \mathrm{cc} 1 \mathrm{OCCCN} 1 \mathrm{CCOCC} 1$ & 21 & $*$ \\
\hline 1342 & $\mathrm{CCC}(=\mathrm{O}) \mathrm{Nc} 1 \mathrm{cc} 2 \mathrm{c}(\mathrm{Nc} 3 \operatorname{ccc} 4 \mathrm{c}(\operatorname{ccn} 4 \mathrm{Cc} 4 \mathrm{ccccc} 4) \mathrm{c} 3) \mathrm{ncnc} 2 \mathrm{cc} 1 \mathrm{OC}$ & 21 & $*$ \\
\hline 1343 & $\operatorname{CCOc} 1 \mathrm{cc} 2 \mathrm{ncnc}(\mathrm{Nc} 3 \operatorname{ccc}(\mathrm{NS}(=\mathrm{O})(=\mathrm{O}) \mathrm{c} 4 \mathrm{cccc} 4) \operatorname{cc} 3) \mathrm{c} 2 \mathrm{cc} 1 \mathrm{NC}(=\mathrm{O}) / \mathrm{C}=\mathrm{C} / \mathrm{CN} 1 \mathrm{CCCC} 1$ & 21 & $*$ \\
\hline 1344 & $\mathrm{O}=\mathrm{C}(/ \mathrm{C}=\mathrm{C} / \mathrm{CN} 1 \mathrm{CCOCC} 1) \mathrm{N} 1 \mathrm{CCc} 2 \mathrm{c}(\operatorname{sc} 3 n \mathrm{nnc}(\mathrm{N}[\mathrm{C} @ \mathrm{H}](\mathrm{CO}) \mathrm{c} 4 \mathrm{ccccc} 4) \mathrm{c} 23) \mathrm{C} 1$ & 21 & * \\
\hline 1345 & $\mathrm{CCC} 1=\mathrm{C} 2 \mathrm{C}(\mathrm{Nc} 3 \mathrm{ccc} 4 \mathrm{c}(\mathrm{cnn} 4 \mathrm{Cc} 4 \mathrm{ccccc} 4) \mathrm{c} 3)=\mathrm{NC}=\mathrm{NC} 2 \mathrm{~N}=\mathrm{C} 1 \mathrm{NC}(=\mathrm{O}) \mathrm{OC}[\mathrm{C} @ @ \mathrm{H}] 1 \mathrm{COCCN} 1$ & 21 & $*$ \\
\hline 1346 & $\mathrm{O}=\mathrm{C}(\mathrm{Nc} 1 \mathrm{cccc}(\mathrm{Nc} 2 \mathrm{cc}(\mathrm{Nc} 3 \operatorname{ccc}(\mathrm{C}(\mathrm{F})(\mathrm{F}) \mathrm{F}) \mathrm{c} 3) \mathrm{ncn} 2) \mathrm{c} 1) \mathrm{C} 1 \mathrm{CC} 1$ & 21 & $*$ \\
\hline 1347 & $\mathrm{CN}(\mathrm{C}) \mathrm{CCCn} 1 \mathrm{ccc} 2 \mathrm{cc} 3 \mathrm{c}(\mathrm{Nc} 4 \mathrm{cccc}(\mathrm{Br}) \mathrm{c} 4) \mathrm{ncnc} 3 \mathrm{cc} 21$ & 21 & $*$ \\
\hline 1348 & $\mathrm{COc} 1 \mathrm{cc}(\mathrm{OC} 2 \mathrm{CCN}(\mathrm{C}) \mathrm{CC} 2) \mathrm{c} 2 \mathrm{c}(\mathrm{Nc} 3 \mathrm{ccc}(\mathrm{F}) \mathrm{c}(\mathrm{Cl}) \mathrm{c} 3) \mathrm{ncnc} 2 \mathrm{c} 1$ & 21 & $*$ \\
\hline 1349 & $\mathrm{CC}(\mathrm{C})(\mathrm{C}) \mathrm{C}(=\mathrm{O}) \mathrm{NCCn} 1 \mathrm{ccc} 2 \mathrm{ncnc}(\mathrm{Nc} 3 \operatorname{ccc}(\mathrm{Oc} 4 \mathrm{cccc} 5 \operatorname{sncc} 45) \mathrm{c}(\mathrm{Cl}) \mathrm{c} 3) \mathrm{c} 21 . \mathrm{CS}(=\mathrm{O})(=\mathrm{O}) \mathrm{O}$ & 21 & * \\
\hline 1350 & $\mathrm{O}=\mathrm{C} 1 \mathrm{NCc} 2 \operatorname{ccc}(\mathrm{Oc} 3 \operatorname{ccc}(\mathrm{Nc} 4 \mathrm{ncnc} 5 \mathrm{ccn}(\mathrm{CCO}) \mathrm{c} 45) \mathrm{cc} 3 \mathrm{Cl}) \mathrm{c} 21$ & 21 & $*$ \\
\hline 1351 & $\begin{array}{c}\mathrm{Cc} 1 \mathrm{ccc}(\mathrm{S}(=\mathrm{O})(=\mathrm{O}) \mathrm{O}) \mathrm{cc} 1 . \mathrm{O}=\mathrm{S}(=\mathrm{O})(\mathrm{CCNCc} 1 \mathrm{ccc}(- \\
\mathrm{c} 2 \mathrm{ccc} 3 \mathrm{ncnc}(\mathrm{Nc} 4 \mathrm{ccc}(\mathrm{OCc} 5 \operatorname{cccc}(\mathrm{F}) \mathrm{c} 5) \mathrm{c}(\mathrm{Cl}) \mathrm{c} 4) \mathrm{c} 3 \mathrm{c} 2) \mathrm{o} 1) \mathrm{CC}(\mathrm{F})(\mathrm{F}) \mathrm{F}\end{array}$ & 21.1 & $*$ \\
\hline 1352 & $\mathrm{CN}(\mathrm{C}) \mathrm{CCOC}(=\mathrm{O}) \mathrm{N} 1 \mathrm{CCc} 2 \mathrm{ncnc}(\mathrm{Nc} 3 \operatorname{ccc}(\mathrm{C}(\mathrm{F})(\mathrm{F}) \mathrm{F}) \mathrm{c} 3) \mathrm{c} 2 \mathrm{C} 1$ & 21.4 & 7.67 \\
\hline 1353 & $\mathrm{Nc} 1 \mathrm{ccc}(-\mathrm{c} 2 \mathrm{cc} 3 \mathrm{c}(\mathrm{Nc} 4 \mathrm{ccc}(\mathrm{Oc} 5 \mathrm{cccc}(\mathrm{C}(\mathrm{F})(\mathrm{F}) \mathrm{F}) \mathrm{c} 5) \mathrm{c}(\mathrm{Cl}) \mathrm{c} 4) \mathrm{ncnc} 3 \mathrm{~s} 2) \mathrm{cc} 1$ & 21.4 & $*$ \\
\hline 1354 & Clc1 cecc $(\mathrm{Nc} 2 \mathrm{ncnc} 3 \mathrm{cc}(\mathrm{OCCCN} 4 \mathrm{CCOCC} 4) \mathrm{c} 4 \mathrm{c}(\mathrm{c} 23) \mathrm{OCCO} 4) \mathrm{c} 1$ & 21.95 & $*$ \\
\hline 1355 & $\mathrm{Cc} 1 \mathrm{ncnc}(\mathrm{Nc} 2 \mathrm{ccc}(\mathrm{OCc} 3 \operatorname{cccc}(\mathrm{F}) \mathrm{c} 3) \mathrm{c}(\mathrm{Cl}) \mathrm{c} 2) \mathrm{c} 1 \mathrm{C} \# \mathrm{Cc} 1 \mathrm{ccc}(\mathrm{CNCCS}(\mathrm{C})(=\mathrm{O})=\mathrm{O}) \mathrm{cc} 1$ & 22 & 7.66 \\
\hline 1356 & CC[C@@H](Nc1ncnc2oc(-c3ecc(OC)cc3)cc12)c1 ccccc1 & 22 & 7.66 \\
\hline 1357 & $\operatorname{COc} 1 \operatorname{ccc}(-\mathrm{c} 2 \mathrm{cc} 3 \mathrm{c}(\mathrm{NC}(\mathrm{CC}(\mathrm{N})=\mathrm{O}) \mathrm{c} 4 \mathrm{ccccc} 4) \operatorname{ncnc} 3 \mathrm{o} 2) \operatorname{cc} 1$ & 22 & 7.66 \\
\hline 1358 & $\mathrm{C} / \mathrm{C}=\mathrm{C} / \mathrm{C}(=\mathrm{O}) \mathrm{Nc} 1 \mathrm{cc} 2 \mathrm{c}(\mathrm{Nc} 3 \mathrm{ccc}(\mathrm{F}) \mathrm{c}(\mathrm{Cl}) \mathrm{c} 3) \mathrm{ncnc} 2 \mathrm{cc} 1 \mathrm{OCCCN} 1 \mathrm{CCOCC} 1$ & 22 & $*$ \\
\hline 1359 & $\mathrm{CCC} 1=\mathrm{C} 2 \mathrm{C}(\mathrm{Nc} 3 \mathrm{ccc} 4 \mathrm{c}(\mathrm{cnn} 4 \mathrm{Cc} 4 \mathrm{cccc}(\mathrm{F}) \mathrm{c} 4) \mathrm{c} 3)=\mathrm{NC}=\mathrm{NC} 2 \mathrm{~N}=\mathrm{C} 1 \mathrm{NC}(=\mathrm{O}) \mathrm{OC}[\mathrm{C} @ @ \mathrm{H}] 1 \mathrm{COCCN} 1$ & 22 & $*$ \\
\hline 1360 & Cc1c(NC(=O)OC[C@@H]2COCCN2)cn2ncnc(Nc3ecc4c(cnn4Cc4cccc(F)c4)c3)c12 & 22 & $*$ \\
\hline 1361 & $\mathrm{CN}(\mathrm{C}) \mathrm{CCn} 1 \mathrm{cnc} 2 \mathrm{cc} 3 \mathrm{c}(\mathrm{Nc} 4 \mathrm{cccc}(\mathrm{Br}) \mathrm{c} 4) \mathrm{ncnc} 3 \mathrm{cc} 21$ & 22 & $*$ \\
\hline 1362 & $\mathrm{O}=\mathrm{C} 1 \mathrm{Nc} 2 \mathrm{ncnc}(\mathrm{Nc} 3 \operatorname{ccc}(\mathrm{F}) \mathrm{c}(\mathrm{Cl}) \mathrm{c} 3) \mathrm{c} 2 / \mathrm{C} 1=\mathrm{C} / \mathrm{c} 1 \mathrm{ccc}(\mathrm{C}(=\mathrm{O}) \mathrm{NCCN} 2 \mathrm{CCOCC} 2)[\mathrm{nH}] 1$ & 22 & $*$ \\
\hline 1363 & $\mathrm{C}[\mathrm{C} @ @ \mathrm{H}](\mathrm{Oc} 1 \mathrm{cccc} 2 \mathrm{ncnc}(\mathrm{Nc} 3 \mathrm{ccc}(\mathrm{OCc} 4 \mathrm{ccc} n 4) \mathrm{c}(\mathrm{Cl}) \mathrm{c} 3) \mathrm{c} 12) \mathrm{C}(=\mathrm{O}) \mathrm{N}(\mathrm{C}) \mathrm{C}$ & 22 & $*$ \\
\hline 1364 & $\begin{array}{c}\mathrm{CCc} 1 \mathrm{cc}(\mathrm{Nc} 2 \mathrm{nccc}(-\mathrm{c} 3 \mathrm{c}(- \\
\mathrm{c} 4 \mathrm{cccc}(\mathrm{C}(=\mathrm{O}) \mathrm{Nc} 5 \mathrm{c}(\mathrm{F}) \operatorname{cccc} 5 \mathrm{~F}) \mathrm{c} 4) \mathrm{nc} 4 \mathrm{ccccn} 34) \mathrm{n} 2) \mathrm{c}(\mathrm{OC}) \operatorname{cc} 1 \mathrm{~N} 1 \mathrm{CCC}(\mathrm{N} 2 \mathrm{CCN}(\mathrm{S}(\mathrm{C})(=\mathrm{O})=\mathrm{O}) \mathrm{CC} 2) \mathrm{CC} 1\end{array}$ & 22 & $*$ \\
\hline 1365 & $\mathrm{O}=\mathrm{S}(=\mathrm{O})(\mathrm{Nc} 1 \mathrm{nccs} 1) \mathrm{c} 1 \mathrm{ccc}(\mathrm{NC}(=\mathrm{S}) \mathrm{Nc} 2 \operatorname{ccc} 3 \mathrm{ncnc}(\mathrm{Nc} 4 \operatorname{cccc}(\mathrm{Br}) \mathrm{c} 4) \mathrm{c} 3 \mathrm{c} 2) \mathrm{cc} 1$ & 22 & $*$ \\
\hline 1366 & $\operatorname{COc} 1 \mathrm{cc} 2 \mathrm{ncnc}(\mathrm{Nc} 3 \operatorname{ccc}(\mathrm{OCc} 4 \operatorname{cccc}(\mathrm{F}) \mathrm{c} 4) \mathrm{c}(\mathrm{Cl}) \mathrm{c} 3) \mathrm{c} 2 \mathrm{cc} 1 \mathrm{OCCCOP}(\mathrm{N})(=\mathrm{O}) \mathrm{N}(\mathrm{CCCl}) \mathrm{CCCl}$ & 22 & $*$ \\
\hline 1367 & $\operatorname{CCc} 1 \operatorname{ccc}(\mathrm{NC}(=\mathrm{O}) \operatorname{CSc} 2 \mathrm{nc} 3 \operatorname{cc} 4 \operatorname{ccccc} 4 \operatorname{cc} 3 \mathrm{c}(=\mathrm{O}) \mathrm{n} 2-\mathrm{c} 2 \operatorname{ccc}(\mathrm{S}(\mathrm{N})(=\mathrm{O})=\mathrm{O}) \operatorname{cc} 2) \mathrm{c} 1$ & 22 & $*$ \\
\hline 1368 & $\mathrm{Clc} 1 \mathrm{cccc}(\mathrm{Nc} 2 \mathrm{ncnc} 3 \mathrm{cc} 4 \mathrm{c}(\mathrm{cc} 23) \mathrm{OC}(\mathrm{CCN}(\mathrm{N} 2 \mathrm{CCOCC} 2) \mathrm{N} 2 \mathrm{CCOCC} 2) \mathrm{CO} 4) \mathrm{c} 1$ & 22 & $*$ \\
\hline 1369 & OCCNCCn1 ccc2ncnc(Nc3ecc(Oc4cecc(C(F)(F)F)c4)c(Cl)c3)c21 & 22 & * \\
\hline 1370 & $\mathrm{CCC}(=\mathrm{O}) \mathrm{Nc} 1 \mathrm{cccc}(\mathrm{Nc} 2 \mathrm{cc}(-\mathrm{c} 3[\mathrm{nH}] \mathrm{c}(\mathrm{SC}) \mathrm{nc} 3-\mathrm{c} 3 \operatorname{ccc}(\mathrm{F}) \mathrm{cc} 3) \mathrm{ccn} 2) \mathrm{c} 1$ & 22 & * \\
\hline 1371 & $\mathrm{C}=\mathrm{CC}(=\mathrm{O}) \mathrm{Nc} 1 \mathrm{cccc}(\mathrm{N} 2 \mathrm{C}(=\mathrm{O}) \mathrm{C}(\mathrm{C}) \mathrm{N}(\mathrm{C}) \mathrm{C}(=\mathrm{O}) \mathrm{c} 3 \mathrm{cnc}(\mathrm{Nc} 4 \mathrm{ccc}(\mathrm{N} 5 \mathrm{CCN}(\mathrm{C}) \mathrm{CC} 5) \mathrm{cc} 4 \mathrm{OC}) \mathrm{nc} 32) \mathrm{c} 1$ & 22.12 & 7.66 \\
\hline 1372 & $\mathrm{Cc} 1 \mathrm{cc}(\mathrm{Nc} 2 \mathrm{ncc} 3 \mathrm{c}(\mathrm{n} 2) \mathrm{N}([\mathrm{C} @ \mathrm{H}] 2 \mathrm{CCN}(\mathrm{C}(=\mathrm{O}) \mathrm{CC}(\mathrm{C}) \mathrm{C}) \mathrm{C} 2) \mathrm{C}(=\mathrm{O}) \mathrm{N}(\mathrm{c} 2 \mathrm{ccccc} 2 \mathrm{Cl}) \mathrm{C} 3) \operatorname{ccc} 1 \mathrm{~N} 1 \mathrm{CCN}(\mathrm{C}) \mathrm{CC} 1$ & 22.2 & 7.65 \\
\hline 1373 & $\mathrm{C}=\mathrm{C}=\mathrm{CC}(=\mathrm{O}) \mathrm{Nc} 1 \mathrm{cc}(\mathrm{Nc} 2 \mathrm{nccc}(-\mathrm{c} 3 \mathrm{cnn} 4 \mathrm{cccc} 34) \mathrm{n} 2) \mathrm{c}(\mathrm{OC}) \mathrm{cc} 1 \mathrm{~N}(\mathrm{C}) \mathrm{CCN}(\mathrm{C}) \mathrm{C}$ & 22.4 & $*$ \\
\hline 1374 & $\mathrm{C}=\mathrm{CC}(=\mathrm{O}) \mathrm{Cc} 1 \mathrm{cc}(\mathrm{Nc} 2 \mathrm{ncc} 3 \mathrm{nc}(\mathrm{Nc} 4 \mathrm{ccccc} 4) \mathrm{n}(\mathrm{C}) \mathrm{c} 3 \mathrm{n} 2) \mathrm{c}(\mathrm{OC}) \mathrm{cc} 1 \mathrm{~N}(\mathrm{C}) \mathrm{CCN}(\mathrm{C}) \mathrm{C}$ & 22.4 & $*$ \\
\hline 1375 & $\mathrm{Cc} 1 \operatorname{cccc}(\mathrm{NC}(=\mathrm{O}) \mathrm{c} 2 \mathrm{ccc}(\mathrm{OCCCN} 3 \mathrm{CCCCC} 3) \mathrm{cc} 2 \mathrm{O}) \mathrm{c} 1$ & 22.4 & $*$ \\
\hline
\end{tabular}




\begin{tabular}{|c|c|c|c|}
\hline 1376 & $\mathrm{COc} 1 \mathrm{cc} 2 \mathrm{ncnc}(\mathrm{Nc} 3 \mathrm{ccc}(\mathrm{F}) \mathrm{c}(\mathrm{Cl}) \mathrm{c} 3) \mathrm{c} 2 \mathrm{c} 2 \mathrm{c} 1 \mathrm{OCCO} 2$ & 22.5 & $*$ \\
\hline 1377 & $\mathrm{C}=\mathrm{C}=\mathrm{CC}(=\mathrm{O}) \mathrm{Nc} 1 \mathrm{cc}(\mathrm{Nc} 2 \mathrm{nccc}(\mathrm{C} 3=\mathrm{CN}(\mathrm{C}) \mathrm{C} 4 \mathrm{C}=\mathrm{CC}=\mathrm{CC} 34) \mathrm{n} 2) \operatorname{ccc} 1 \mathrm{~N}(\mathrm{C}) \mathrm{CCN}(\mathrm{C}) \mathrm{C}$ & 22.8 & $*$ \\
\hline 1378 & $\mathrm{C}=\mathrm{C}=\mathrm{CC}(=\mathrm{O}) \mathrm{Nc} 1 \mathrm{cc}(\mathrm{Nc} 2 \mathrm{nccc}(-\mathrm{c} 3 \mathrm{cn}(\mathrm{C}) \mathrm{c} 4 \mathrm{cccc} 34) \mathrm{n} 2) \operatorname{ccc} 1 \mathrm{~N}(\mathrm{C}) \mathrm{CCN}(\mathrm{C}) \mathrm{C}$ & 22.8 & $*$ \\
\hline 1379 & $\mathrm{CCOc} 1 \mathrm{cc} 2 \mathrm{ncc}(\mathrm{C \# N}) \mathrm{c}(\mathrm{Nc} 3 \operatorname{ccc}(\mathrm{OCc} 4 \mathrm{ccco} 4) \mathrm{c}(\mathrm{Cl}) \mathrm{c} 3) \mathrm{c} 2 \mathrm{cc} 1 \mathrm{NC}(=\mathrm{O}) / \mathrm{C}=\mathrm{C} / \mathrm{CN}(\mathrm{C}) \mathrm{C}$ & 23 & 7.64 \\
\hline 1380 & $\mathrm{CNC}(=\mathrm{O}) \mathrm{NCc} 1 \mathrm{cccc}(\mathrm{C \# Cc} 2 \mathrm{cncnc} 2 \mathrm{Nc} 2 \mathrm{ccc}(\mathrm{OCc} 3 \operatorname{ccc}(\mathrm{F}) \mathrm{c} 3) \mathrm{c}(\mathrm{Cl}) \mathrm{c} 2) \mathrm{n} 1$ & 23 & $*$ \\
\hline 1381 & COC[C@@H](Nc1ncnc2sc(-c3eccce3OC)cc12)c1 ccccc1 & 23 & $*$ \\
\hline 1382 & 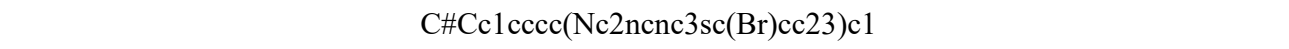 & 23 & $*$ \\
\hline 1383 & $\operatorname{CCOC}(=\mathrm{O}) \mathrm{C}(=\mathrm{CNc} 1 \mathrm{ccc} 2 \mathrm{ncnc}(\mathrm{Nc} 3 \operatorname{ccc}(\mathrm{Oc} 4 \operatorname{ccc}(\mathrm{C}(\mathrm{F})(\mathrm{F}) \mathrm{F}) \mathrm{c} 4) \mathrm{c}(\mathrm{Cl}) \mathrm{c} 3) \mathrm{c} 2 \mathrm{c} 1) \mathrm{C}(=\mathrm{O}) \mathrm{OCC}$ & 23 & $*$ \\
\hline 1384 & $\mathrm{CCOc} 1 \mathrm{cc} 2 \mathrm{ncnc}(\mathrm{Nc} 3 \operatorname{ccc} 4 \mathrm{c}(\operatorname{cnn} 4 \mathrm{Cc} 4 \mathrm{ccccc} 4) \mathrm{c} 3) \mathrm{c} 2 \mathrm{cc} 1 \mathrm{NC}(=\mathrm{O}) / \mathrm{C}=\mathrm{C} / \mathrm{CN} 1 \mathrm{CCN}(\mathrm{C}) \mathrm{CC} 1$ & 23 & $*$ \\
\hline 1385 & $\mathrm{CCOc} 1 \mathrm{cc} 2 \mathrm{ncnc}(\mathrm{Nc} 3 \mathrm{ccc}(\mathrm{OCc} 4 \mathrm{ccc}(\mathrm{F}) \mathrm{c} 4) \mathrm{c}(\mathrm{Cl}) \mathrm{c} 3) \mathrm{c} 2 \mathrm{cc} 1 \mathrm{NC}(=\mathrm{O}) / \mathrm{C}=\mathrm{C} / \mathrm{CN} 1 \mathrm{CCN}(\mathrm{C}) \mathrm{CC} 1$ & 23 & $*$ \\
\hline 1386 & $\mathrm{CCC} 1=\mathrm{C} 2 \mathrm{C}(\mathrm{Nc} 3 \operatorname{ccc} 4 \mathrm{c}(\operatorname{cnn} 4 \mathrm{Cc} 4 \mathrm{ccccc} 4) \mathrm{c} 3)=\mathrm{NC}=\mathrm{NC} 2 \mathrm{~N}=\mathrm{C} 1 \mathrm{NC}(=\mathrm{O}) \mathrm{OCC} 1 \mathrm{CCNCC} 1$ & 23 & $*$ \\
\hline 1387 & $\mathrm{Clc} 1 \mathrm{ccc}(\mathrm{Nc} 2 \mathrm{ncnc} 3 \operatorname{ccc} c 23) \mathrm{c} 1$ & 23 & $*$ \\
\hline 1388 & $\mathrm{CCCCN} 1 \mathrm{C}(=\mathrm{O}) \mathrm{CS} / \mathrm{C} 1=\mathrm{N} / \mathrm{Nc} 1 \mathrm{nncc} 2 \mathrm{ccccc} 12$ & 23 & $*$ \\
\hline 1389 & $\mathrm{Nc} 1 n \mathrm{nc} c(\mathrm{Nc} 2 \operatorname{ccc} 3 \mathrm{c}(\operatorname{cnn} 3 \mathrm{Cc} 3 \operatorname{ccc}(\mathrm{F}) \mathrm{c} 3) \mathrm{c} 2) \mathrm{c} 1 / \mathrm{C}=\mathrm{N} / \mathrm{OCc} 1 \mathrm{ccccc} 1$ & 23 & $*$ \\
\hline 1390 & $\mathrm{CO} / \mathrm{N}=\mathrm{C} / \mathrm{c} 1 \mathrm{c}(\mathrm{N}) \mathrm{ncnc} 1 \mathrm{Nc} 1 \mathrm{ccc} 2 \mathrm{c}(\mathrm{cnn} 2 \mathrm{Cc} 2 \operatorname{ccc}(\mathrm{Cl}) \mathrm{c} 2) \mathrm{c} 1$ & 23 & $*$ \\
\hline 1391 & $\mathrm{O}=\mathrm{S} 1 \mathrm{CCN}(\mathrm{Cc} 2 \mathrm{ccc}(-\mathrm{c} 3 \mathrm{cc} 4 \mathrm{c}(\mathrm{Nc} 5 \mathrm{ccc}(\mathrm{OCc} 6 \mathrm{cccc}(\mathrm{F}) \mathrm{c} 6) \mathrm{cc} 5) \mathrm{ncnc} 4 \mathrm{cn} 3) \mathrm{o} 2) \mathrm{CC} 1$ & 23 & $*$ \\
\hline 1392 & $\mathrm{Nc} 1 \operatorname{ccc}(-\mathrm{c} 2 \operatorname{ccc}(\mathrm{C}(=\mathrm{O}) \mathrm{Nc} 3 \operatorname{ccc}(\mathrm{Cl}) \mathrm{c} 3) \mathrm{c}(\mathrm{O}) \mathrm{c} 2) \mathrm{cc} 1$ & 23 & $*$ \\
\hline 1393 & $\mathrm{O}=\mathrm{C}(\mathrm{Nc} 1 \mathrm{ccc}([\mathrm{N}+](=\mathrm{O})[\mathrm{O}-]) \mathrm{cc} 1 \mathrm{Cl}) \mathrm{c} 1 \mathrm{ccc}(\mathrm{OCCCN} 2 \mathrm{CCCCC} 2) \operatorname{cc} 1 \mathrm{O}$ & 23 & $*$ \\
\hline 1394 & $\mathrm{O}=\mathrm{C}(\mathrm{CCNc} 1 \mathrm{ccc}(\mathrm{S}(=\mathrm{O})(=\mathrm{O}) \mathrm{Nc} 2 \mathrm{nccs} 2) \mathrm{cc} 1) \mathrm{Nc} 1 \mathrm{ccc} 2 \mathrm{ncnc}(\mathrm{Nc} 3 \operatorname{cccc}(\mathrm{Br}) \mathrm{c} 3) \mathrm{c} 2 \mathrm{c} 1$ & 23.1 & $*$ \\
\hline 1395 & $\mathrm{CCC}(=\mathrm{O}) \mathrm{N} 1 \mathrm{CC}[\mathrm{C} @ @ \mathrm{H}](\mathrm{N} 2 \mathrm{C}(=\mathrm{O}) \mathrm{N}(\mathrm{c} 3 \mathrm{ccccc} 3 \mathrm{Cl}) \mathrm{Cc} 3 \mathrm{cnc}(\mathrm{Nc} 4 \mathrm{ccc}(\mathrm{N} 5 \mathrm{CCN}(\mathrm{C}) \mathrm{CC} 5) \mathrm{c}(\mathrm{C}) \mathrm{c} 4) \mathrm{nc} 32) \mathrm{C} 1$ & 23.4 & 7.63 \\
\hline 1396 & $\mathrm{O}=\mathrm{C}(\mathrm{COc} 1 \mathrm{c}(\mathrm{F}) \mathrm{c}(\mathrm{F}) \mathrm{c}(\mathrm{F}) \mathrm{c}(\mathrm{F}) \mathrm{c} 1 \mathrm{~F}) \mathrm{Nc} 1 \mathrm{ccc} 2 \mathrm{ncnc}(\mathrm{Nc} 3 \mathrm{cccc}(\mathrm{Br}) \mathrm{c} 3) \mathrm{c} 2 \mathrm{c} 1$ & 23.6 & 7.63 \\
\hline 1397 & $\mathrm{C} \# \mathrm{Cc} 1 \mathrm{cccc}(\mathrm{Nc} 2 \mathrm{ncnc} 3 \mathrm{cc}(\mathrm{OC}(\mathrm{C}) \mathrm{C}) \mathrm{c} 4 \mathrm{c}(\mathrm{c} 23) \mathrm{OCCO} 4) \mathrm{c} 1$ & 23.7 & $*$ \\
\hline 1398 & $\mathrm{C}=\mathrm{C}=\mathrm{CCOc} 1 \mathrm{cc} 2 \mathrm{c}(\mathrm{Nc} 3 \mathrm{ccc}(\mathrm{F}) \mathrm{c}(\mathrm{Cl}) \mathrm{c} 3) \mathrm{ncnc} 2 \mathrm{cc} 1 \mathrm{O}$ & 23.8 & $*$ \\
\hline 1399 & $\mathrm{CS}(=\mathrm{O})(=\mathrm{O}) \mathrm{CCNCc} 1 \mathrm{ccc}(-\mathrm{c} 2 \mathrm{ccc} 3 \mathrm{ncnc}(\mathrm{Nc} 4 \mathrm{ccc}(\mathrm{F}) \mathrm{c}(\mathrm{Cl}) \mathrm{c} 4) \mathrm{c} 3 \mathrm{c} 2) \mathrm{o} 1$ & 23.99 & * \\
\hline 1400 & $\mathrm{Cc} 1 \mathrm{ncnc}(\mathrm{Nc} 2 \mathrm{ccc}(\mathrm{OCc} 3 \operatorname{cccc}(\mathrm{F}) \mathrm{c} 3) \mathrm{c}(\mathrm{Cl}) \mathrm{c} 2) \mathrm{c} 1 / \mathrm{C}=\mathrm{C} / \mathrm{c} 1 \mathrm{ccc}(\mathrm{CNC}(\mathrm{C}) \mathrm{C}) \mathrm{cc} 1$ & 24 & 7.62 \\
\hline 1401 & $\mathrm{COc} 1 \mathrm{cc} 2 \mathrm{ncnc}(\mathrm{Nc} 3 \operatorname{ccc}(\mathrm{F}) \mathrm{c}(\mathrm{Cl}) \mathrm{c} 3) \mathrm{c} 2 \mathrm{cc} 1 \mathrm{OCCCN} 1 \mathrm{CC} 2(\mathrm{C} 1) \mathrm{CS}(=\mathrm{O})(=\mathrm{O}) \mathrm{C} 2$ & 24 & 7.62 \\
\hline 1402 & $\mathrm{COc} 1 \mathrm{ccc}(-\mathrm{c} 2 \mathrm{cc} 3 \mathrm{c}(\mathrm{N}[\mathrm{C} @ \mathrm{H}](\mathrm{C}) \mathrm{c} 4 \mathrm{cccc}(\mathrm{F}) \mathrm{c} 4) \mathrm{ncnc} 3 \mathrm{o} 2) \mathrm{cc} 1$ & 24 & 7.62 \\
\hline 1403 & COc1ccc(-c2cc3c(N[C@H](C)c4ccccc4F)ncnc3o2)cc1 & 24 & 7.62 \\
\hline 1404 & $\mathrm{CCOc} 1 \mathrm{cc} 2 \mathrm{ncc}(\mathrm{C} \# \mathrm{~N}) \mathrm{c}(\mathrm{Nc} 3 \operatorname{ccc}(\mathrm{OCc} 4 \operatorname{ccccc} 4) \mathrm{c}(\mathrm{Cl}) \mathrm{c} 3) \mathrm{c} 2 \mathrm{cc} 1 \mathrm{NC}(=\mathrm{O}) / \mathrm{C}=\mathrm{C} / \mathrm{Cc} 1 \mathrm{c}[\mathrm{nH}] \mathrm{cn} 1$ & 24 & 7.62 \\
\hline 1405 & $\mathrm{COc} 1 \mathrm{cc} 2 \mathrm{ncc}(\mathrm{C \# N}) \mathrm{c}(\mathrm{Nc} 3 \operatorname{ccc}(\mathrm{OCc} 4 \mathrm{cccc} 4) \mathrm{c}(\mathrm{Cl}) \mathrm{c} 3) \mathrm{c} 2 \mathrm{cc} 1 \mathrm{NC}(=\mathrm{O}) / \mathrm{C}=\mathrm{C} / \mathrm{CN}(\mathrm{C}) \mathrm{C}$ & 24 & 7.62 \\
\hline 1406 & $\mathrm{CS}(=\mathrm{O})(=\mathrm{O}) \mathrm{c} 1 \mathrm{cccc}(\mathrm{C}(=\mathrm{O}) \mathrm{Nc} 2 \mathrm{cc} 3 \mathrm{c}(\mathrm{Nc} 4 \mathrm{ccc}(\mathrm{F}) \mathrm{c}(\mathrm{Cl}) \mathrm{c} 4) \mathrm{ncnc} 3 \mathrm{cc} 2 \mathrm{OCCCN} 2 \mathrm{CCOCC} 2) \mathrm{c} 1 \mathrm{~F}$ & 24 & 7.62 \\
\hline 1407 & $\mathrm{CS}(=\mathrm{O})(=\mathrm{O}) \mathrm{CCNCCCCOc} 1 \mathrm{ccc} 2 \mathrm{ncnc}(\mathrm{Nc} 3 \mathrm{ccc} 4 \mathrm{c}(\mathrm{cnn} 4 \mathrm{Cc} 4 \mathrm{cccc}(\mathrm{F}) \mathrm{c} 4) \mathrm{c} 3) \mathrm{c} 2 \mathrm{c} 1$ & 24 & $*$ \\
\hline 1408 & $\mathrm{CS}(=\mathrm{O})(=\mathrm{O}) \mathrm{CCNCc} 1 \mathrm{ccc}(-\mathrm{c} 2 \mathrm{ccc} 3 \mathrm{ncnc}(\mathrm{Nc} 4 \mathrm{ccc}(\mathrm{OCc} 5 \mathrm{cccc}(\mathrm{F}) \mathrm{c} 5) \mathrm{cc} 4) \mathrm{c} 3 \mathrm{c} 2) \mathrm{o} 1$ & 24 & $*$ \\
\hline 1409 & $\mathrm{O}=\mathrm{C}(\mathrm{c} 1 \mathrm{cc} 2 \mathrm{cc}(\mathrm{O}) \mathrm{ccc} 2[\mathrm{nH}] 1) \mathrm{c} 1 \mathrm{cc} 2 \mathrm{c}(\mathrm{Nc} 3 \operatorname{ccc}(\mathrm{F}) \mathrm{c}(\mathrm{Cl}) \mathrm{c} 3) \mathrm{ncnc} 2 \mathrm{~s} 1$ & 24 & $*$ \\
\hline 1410 & $\mathrm{CN}(\mathrm{C}) \mathrm{CCCNC}(=\mathrm{O}) \mathrm{Nc} 1 \mathrm{cc} 2 \mathrm{c}(\mathrm{Nc} 3 \mathrm{ccc}(\mathrm{F}) \mathrm{c}(\mathrm{Cl}) \mathrm{c} 3) \mathrm{ncnc} 2 \mathrm{cc} 1 \mathrm{O}[\mathrm{C} @ \mathrm{H}] 1 \mathrm{CCOC} 1$ & 24 & $*$ \\
\hline 1411 & $\mathrm{CN}(\mathrm{C}) \mathrm{C} / \mathrm{C}=\mathrm{C} / \mathrm{C}(=\mathrm{O}) \mathrm{Nc} 1 \mathrm{cc} 2 \mathrm{c}(\mathrm{Nc} 3 \mathrm{ccc}(\mathrm{F}) \mathrm{c}(\mathrm{Cl}) \mathrm{c} 3) \mathrm{ncnc} 2 \mathrm{~s} 1$ & 24 & $*$ \\
\hline 1412 & $\mathrm{Cc} 1 \mathrm{cccc}(\mathrm{Nc} 2 \mathrm{ncnc} 3 \operatorname{ccc}(\mathrm{N}=\mathrm{NN}(\mathrm{C}) \mathrm{C}) \mathrm{cc} 23) \mathrm{c} 1$ & 24 & $*$ \\
\hline 1413 & $\mathrm{CO} / \mathrm{N}=\mathrm{C} / \mathrm{c} 1 \mathrm{c}(\mathrm{N}) \mathrm{ncnc} 1 \mathrm{Nc} 1 \mathrm{cccc}(\mathrm{Br}) \mathrm{c} 1$ & 24 & * \\
\hline 1414 & $\mathrm{CN}(\mathrm{C}) \mathrm{CCCNN}(\mathrm{NCCCN}(\mathrm{C}) \mathrm{C}) \mathrm{C}(=\mathrm{O}) \mathrm{Nc} 1 \mathrm{cc} 2 \mathrm{c}(\mathrm{Nc} 3 \mathrm{ccc}(\mathrm{F}) \mathrm{c}(\mathrm{Cl}) \mathrm{c} 3) \mathrm{ncnc} 2 \mathrm{cc} 1 \mathrm{O}[\mathrm{C} @ \mathrm{H}] 1 \mathrm{CCOC} 1$ & 24 & $*$ \\
\hline 1415 & $\mathrm{C}=\mathrm{CC}(=\mathrm{O}) \mathrm{Nc} 1 \mathrm{cc}(\mathrm{C}(\mathrm{C}) \mathrm{C}) \mathrm{cc}(-\mathrm{n} 2 \mathrm{c}(=\mathrm{O}) \mathrm{cc}(\mathrm{C}) \mathrm{c} 3 \mathrm{cnc}(\mathrm{Nc} 4 \mathrm{ccc}(\mathrm{N} 5 \mathrm{CCN}(\mathrm{C}) \mathrm{CC} 5) \mathrm{cc} 4 \mathrm{OC}) \mathrm{nc} 32) \mathrm{c} 1$ & 24 & $*$ \\
\hline 1416 & $\mathrm{CSc} 1 \mathrm{nc}(-\mathrm{c} 2 \mathrm{ccc}(\mathrm{F}) \mathrm{cc} 2) \mathrm{c}(-\mathrm{c} 2 \mathrm{ccnc}(\mathrm{Nc} 3 \operatorname{ccccc} 3) \mathrm{c} 2)[\mathrm{nH}] 1$ & 24 & $*$ \\
\hline 1417 & $\mathrm{CC} \# \mathrm{Cc} 1 \mathrm{cc} 2 \mathrm{ncnc}(\mathrm{Nc} 3 \mathrm{ccc}(\mathrm{OCc} 4 \mathrm{cccc}(\mathrm{F}) \mathrm{c} 4) \mathrm{c}(\mathrm{Cl}) \mathrm{c} 3) \mathrm{c} 2 \mathrm{~s} 1$ & 24 & $*$ \\
\hline 1418 & $\mathrm{Fc} 1 \mathrm{ccc}(\mathrm{Nc} 2 \mathrm{ncnc} 3 \mathrm{cc}(\mathrm{OCC} 4 \mathrm{CCCO} 4) \mathrm{c} 4 \mathrm{c}(\mathrm{c} 23) \mathrm{OCCO} 4) \mathrm{cc} 1 \mathrm{Cl}$ & 24.1 & $*$ \\
\hline
\end{tabular}




\begin{tabular}{|c|c|c|c|}
\hline 1419 & $\mathrm{Nc} 1 \mathrm{cccc}(-\mathrm{c} 2 \mathrm{cc} 3 \mathrm{c}(-\mathrm{c} 4[\mathrm{nH}] \mathrm{c}(-\mathrm{c} 5 \mathrm{ccccc} 5) \mathrm{nc} 4-\mathrm{c} 4 \mathrm{ccc}(\mathrm{F}) \mathrm{cc} 4) \mathrm{ccnc} 3[\mathrm{nH}] 2) \mathrm{c} 1$ & 24.1 & * \\
\hline 1420 & $\mathrm{CCOc} 1 \mathrm{cc} 2 \mathrm{ncc}(\mathrm{CHN}) \mathrm{c}(\mathrm{Nc} 3 \mathrm{ccc}(\mathrm{OCc} 4 \mathrm{ccc} n 4) \mathrm{c}(\mathrm{Cl}) \mathrm{c} 3) \mathrm{c} 2 \mathrm{cc} 1 \mathrm{NC}(=\mathrm{O}) \mathrm{CCN} 1 \mathrm{CCCCC} 1$ & 24.8 & 7.61 \\
\hline 1421 & $\mathrm{COc} 1 \mathrm{cc}(\mathrm{NC}(=\mathrm{O}) \mathrm{Nc} 2 \mathrm{ccccn} 2) \mathrm{cc}(-\mathrm{c} 2 \mathrm{c}[\mathrm{nH}] \mathrm{cn} 2) \mathrm{c} 1 \mathrm{OC}$ & 24.81 & $*$ \\
\hline 1422 & $\mathrm{C}=\mathrm{CC}(=\mathrm{O}) \mathrm{Nc} 1 \mathrm{cccc}(\mathrm{N} 2 \mathrm{C}(=\mathrm{O}) \mathrm{C}(\mathrm{C}(\mathrm{C}) \mathrm{C}) \mathrm{N}(\mathrm{C}) \mathrm{C}(=\mathrm{O}) \mathrm{c} 3 \mathrm{cnc}(\mathrm{Nc} 4 \mathrm{ccc}(\mathrm{N} 5 \mathrm{CCN}(\mathrm{C}) \mathrm{CC} 5) \operatorname{cc} 4 \mathrm{OC}) \mathrm{nc} 32) \mathrm{c} 1$ & 24.83 & 7.61 \\
\hline 1423 & $\mathrm{CCOc} 1 \mathrm{cc} 2 \mathrm{ncnc}(\mathrm{NC} 3=\mathrm{CC}(=\mathrm{O}) \mathrm{C}(\mathrm{OCc} 4 \operatorname{ccc}(\mathrm{C}) \mathrm{c} 4)=\mathrm{CC} 3=\mathrm{O}) \mathrm{c} 2 \mathrm{cc} 1 \mathrm{NC}(=\mathrm{O}) / \mathrm{C}=\mathrm{C} / \mathrm{CN}(\mathrm{C}) \mathrm{C}$ & 24.9 & 7.60 \\
\hline 1424 & $\mathrm{Cc} 1 \mathrm{cc}(\mathrm{Nc} 2 \mathrm{ncc} 3 \mathrm{c}(\mathrm{n} 2) \mathrm{N}([\mathrm{C} @ \mathrm{H}] 2 \mathrm{CCN}(\mathrm{C}(=\mathrm{O}) \mathrm{C} 4 \mathrm{CCCCC} 4) \mathrm{C} 2) \mathrm{C}(=\mathrm{O}) \mathrm{N}(\mathrm{c} 2 \mathrm{cccc} 2 \mathrm{Cl}) \mathrm{C} 3) \operatorname{ccc} 1 \mathrm{~N} 1 \mathrm{CCN}(\mathrm{C}) \mathrm{CC} 1$ & 24.9 & 7.60 \\
\hline 1425 & $\mathrm{COc} 1 \mathrm{cc} 2 \mathrm{ncnc}(\mathrm{Nc} 3 \mathrm{ccc}(\mathrm{F}) \mathrm{c}(\mathrm{Cl}) \mathrm{c} 3) \mathrm{c} 2 \mathrm{cc} 1 \mathrm{OCCCN} 1 \mathrm{CC}(\mathrm{O}) \mathrm{C} 1$ & 25 & 7.60 \\
\hline 1426 & $\mathrm{COc} 1 \mathrm{cc} 2 \mathrm{ncnc}(\mathrm{Nc} 3 \operatorname{ccc}(\mathrm{Cl}) \mathrm{c} 3 \mathrm{~F}) \mathrm{c} 2 \mathrm{cc} 1 \mathrm{CN}(\mathrm{C}) \mathrm{C} 1(\mathrm{C}(\mathrm{N})=\mathrm{O}) \mathrm{CCN}(\mathrm{C}(\mathrm{C}) \mathrm{C}) \mathrm{CC} 1$ & 25 & $*$ \\
\hline 1427 & $\mathrm{O}=\mathrm{S}(=\mathrm{O})(\mathrm{CCOCc} 1 \mathrm{ccc}(-\mathrm{c} 2 \operatorname{ccc} 3 \mathrm{ncnc}(\mathrm{Nc} 4 \operatorname{ccc}(\mathrm{OCc} 5 \operatorname{ccc}(\mathrm{F}) \mathrm{c} 5) \mathrm{c}(\mathrm{Cl}) \mathrm{c} 4) \mathrm{c} 3 \mathrm{c} 2) \mathrm{o} 1) \mathrm{c} 1 \mathrm{ccccc} 1$ & 25 & $*$ \\
\hline 1428 & $\mathrm{CS}(=\mathrm{O})(=\mathrm{O}) \mathrm{CCNCc} 1 \mathrm{ccc}(-\mathrm{c} 2 \mathrm{ccc} 3 \mathrm{ncnc}(\mathrm{Nc} 4 \mathrm{ccc}(\mathrm{OCc} 5 \operatorname{ccccc} 5) \mathrm{c}(\mathrm{Br}) \mathrm{c} 4) \mathrm{c} 3 \mathrm{c} 2) \mathrm{o} 1$ & 25 & $*$ \\
\hline 1429 & $\mathrm{CN}(\mathrm{C}) \mathrm{C} / \mathrm{C}=\mathrm{C} / \mathrm{C}(=\mathrm{O}) \mathrm{Nc} 1 \mathrm{cc} 2 \mathrm{c}(\mathrm{Nc} 3 \operatorname{ccc}(\mathrm{OCc} 4 \mathrm{cccc}(\mathrm{F}) \mathrm{c} 4) \mathrm{c}(\mathrm{Cl}) \mathrm{c} 3) \mathrm{ncnc} 2 \mathrm{cn} 1$ & 25 & $*$ \\
\hline 1430 & $\mathrm{CS}(=\mathrm{O})(=\mathrm{O}) \mathrm{CCNCc} 1 \mathrm{ccc}(-\mathrm{c} 2 \mathrm{cc} 3 \mathrm{c}(\mathrm{Nc} 4 \mathrm{ccc}(\mathrm{OCc} 5 \mathrm{ccccc} 5) \operatorname{cc} 4) \mathrm{ncnc} 3 \mathrm{cn} 2) \mathrm{o} 1$ & 25 & $*$ \\
\hline 1431 & $\mathrm{COc} 1 \mathrm{cc} 2 \mathrm{ncnc}(\mathrm{Nc} 3 \mathrm{ccc}(\mathrm{F}) \mathrm{c} 3) \mathrm{c} 2 \mathrm{cc} 1 \mathrm{OC} . \mathrm{Cl}$ & 25 & $*$ \\
\hline 1432 & $\mathrm{Cc} 1[\mathrm{nH}] \mathrm{c} 2 \mathrm{ncnc}(\mathrm{Nc} 3 \mathrm{cccc}(\mathrm{Br}) \mathrm{c} 3) \mathrm{c} 2 \mathrm{c} 1 \mathrm{C}$ & 25 & $*$ \\
\hline 1433 & $\mathrm{O}=[\mathrm{N}+]([\mathrm{O}-]) \mathrm{c} 1 \mathrm{cc} 2 \mathrm{c}(\mathrm{Nc} 3 \mathrm{ccc}(\mathrm{Br}) \mathrm{c} 3) \mathrm{ncnc} 2 \mathrm{cc} 1 \mathrm{Cl}$ & 25 & $*$ \\
\hline 1434 & $\operatorname{Brc} 1 \operatorname{ccc}(\mathrm{Nc} 2 \mathrm{ncnc} 3 \operatorname{ccc}(\mathrm{NN}=\mathrm{NCc} 4 \operatorname{ccccc} 4) \mathrm{cc} 23) \mathrm{c} 1$ & 25 & $*$ \\
\hline 1435 & CSCCNCc1ccc(-c2 $\operatorname{ccc} 3 n c n c(N c 4 \operatorname{ccc}(\mathrm{OCc} 5 \operatorname{cccc}(\mathrm{F}) \mathrm{c} 5) \mathrm{c}(\mathrm{Cl}) \mathrm{c} 4) \mathrm{c} 3 \mathrm{c} 2)$ o1. $\mathrm{Cc} 1 \mathrm{ccc}(\mathrm{S}(=\mathrm{O})(=\mathrm{O}) \mathrm{O}) \mathrm{cc} 1$ & 25.1 & $*$ \\
\hline 1436 & $\mathrm{Fc} 1 \mathrm{ccc}(\mathrm{NC}(=\mathrm{S}) \mathrm{Nc} 2 \mathrm{ccc} 3 \mathrm{ncnc}(\mathrm{Nc} 4 \mathrm{cccc}(\mathrm{Br}) \mathrm{c} 4) \mathrm{c} 3 \mathrm{c} 2) \mathrm{cc} 1 \mathrm{Cl}$ & 25.3 & $*$ \\
\hline 1437 & $\mathrm{O}=\mathrm{C}(\mathrm{Nc} 1 \mathrm{ccc} 2 \mathrm{ncnc}(\mathrm{Nc} 3 \operatorname{ccc}(\mathrm{Br}) \mathrm{c} 3) \mathrm{c} 2 \mathrm{c} 1) \mathrm{N} 1 \mathrm{CCOCC} 1$ & 25.3 & $*$ \\
\hline 1438 & $\mathrm{C}=\mathrm{C}=\mathrm{CC}(=\mathrm{O}) \mathrm{Nc} 1 \mathrm{cc}(\mathrm{Nc} 2 \mathrm{nccc}(\mathrm{C} 3=\mathrm{CN}(\mathrm{C}) \mathrm{C} 4 \mathrm{C}=\mathrm{CC}=\mathrm{CC} 34) \mathrm{n} 2) \mathrm{c}(\mathrm{OC}) \mathrm{cc} 1 \mathrm{~N}(\mathrm{CC}) \mathrm{CCN}(\mathrm{C}) \mathrm{C}$ & 25.4 & $*$ \\
\hline 1439 & $\mathrm{C}=\mathrm{C}=\mathrm{CC}(=\mathrm{O}) \mathrm{Nc} 1 \mathrm{cc}(\mathrm{Nc} 2 \mathrm{nccc}(-\mathrm{c} 3 \mathrm{cn}(\mathrm{C}) \mathrm{c} 4 \mathrm{ccccc} 34) \mathrm{n} 2) \mathrm{c}(\mathrm{OC}) \mathrm{cc} 1 \mathrm{~N}(\mathrm{CC}) \mathrm{CCN}(\mathrm{C}) \mathrm{C}$ & 25.4 & $*$ \\
\hline 1440 & $\mathrm{Cc} 1 \mathrm{cc}(\mathrm{Nc} 2 \mathrm{ncc} 3 \mathrm{c}(\mathrm{n} 2) \mathrm{N}([\mathrm{C} @ \mathrm{H}] 2 \mathrm{CCN}(\mathrm{C}(=\mathrm{O}) \mathrm{C} 4 \mathrm{CCCC} 4) \mathrm{C} 2) \mathrm{C}(=\mathrm{O}) \mathrm{N}(\mathrm{c} 2 \operatorname{cccc} 2 \mathrm{Cl}) \mathrm{C} 3) \operatorname{ccc} 1 \mathrm{~N} 1 \mathrm{CCN}(\mathrm{C}) \mathrm{CC} 1$ & 25.5 & 7.59 \\
\hline 1441 & $\mathrm{O}=\mathrm{C} 1 \mathrm{~N}[\mathrm{C} @ \mathrm{H}](\mathrm{C}(=\mathrm{O}) \mathrm{Nc} 2 \mathrm{cc} 3 \mathrm{c}(\mathrm{Nc} 4 \mathrm{ccc}(\mathrm{F}) \mathrm{c}(\mathrm{Cl}) \mathrm{c} 4) \mathrm{ncnc} 3 \mathrm{cc} 2 \mathrm{OCCN} 2 \mathrm{CCCCC} 2) \mathrm{CO} 1$ & 25.53 & 7.59 \\
\hline 1442 & $\mathrm{Nc} 1 \mathrm{cc}(\mathrm{Br}) \mathrm{ccc} 1 \mathrm{Nc} 1 \mathrm{ncnc} 2 \mathrm{ccncc} 12$ & 25.7 & $*$ \\
\hline 1443 & $\mathrm{Fc} 1 \mathrm{ccc}(\mathrm{Nc} 2 \mathrm{ncnc} 3 \mathrm{cc}(\mathrm{OCCCN} 4 \mathrm{CCOCC} 4) \mathrm{c} 4 \mathrm{c}(\mathrm{c} 23) \mathrm{OCCO} 4) \mathrm{cc} 1 \mathrm{Cl}$ & 25.86 & $*$ \\
\hline 1444 & $\mathrm{C} \# \mathrm{CCOc} 1 \mathrm{cc} 2 \mathrm{c}(\mathrm{Nc} 3 \mathrm{cccc}(\mathrm{Cl}) \mathrm{c} 3) \mathrm{ncnc} 2 \mathrm{cc} 1 \mathrm{OC}$ & 25.9 & $*$ \\
\hline 1445 & $\mathrm{COc} 1 \mathrm{cc} 2 \mathrm{ncnc}(\mathrm{Nc} 3 \mathrm{ccc}(\mathrm{F}) \mathrm{c}(\mathrm{Cl}) \mathrm{c} 3) \mathrm{c} 2 \mathrm{cc} 1 \mathrm{OCCN} 1 \mathrm{CC}(\mathrm{O}) \mathrm{C} 1$ & 26 & 7.59 \\
\hline 1446 & $\mathrm{CCOc} 1 \mathrm{cc} 2 \mathrm{ncc}(\mathrm{C \# N}) \mathrm{c}(\mathrm{Nc} 3 \mathrm{ccc}(\mathrm{OCc} 4 \operatorname{ccccc} 4) \mathrm{c}(\mathrm{Cl}) \mathrm{c} 3) \mathrm{c} 2 \mathrm{cc} 1 \mathrm{NC}(=\mathrm{O}) / \mathrm{C}=\mathrm{C} / \mathrm{CN} 1 \mathrm{CCC} 1$ & 26 & 7.59 \\
\hline 1447 & $\mathrm{C}[\mathrm{C} @ @ \mathrm{H}](\mathrm{Nc} 1 \mathrm{ncnc} 2 \mathrm{sc}(-\mathrm{c} 3 \operatorname{cccc}(\mathrm{S}(\mathrm{C})(=\mathrm{O})=\mathrm{O}) \mathrm{c} 3) \mathrm{cc} 12) \mathrm{c} 1 \mathrm{ccccc} 1$ & 26 & 7.59 \\
\hline 1448 & $\mathrm{CS}(=\mathrm{O})(=\mathrm{O}) \mathrm{CCOCc} 1 \mathrm{ccc}(-\mathrm{c} 2 \operatorname{ccc} 3 \mathrm{ncnc}(\mathrm{Nc} 4 \mathrm{ccc}(\mathrm{OCc} 5 \operatorname{ccc}(\mathrm{F}) \mathrm{c} 5) \mathrm{c}(\mathrm{Cl}) \mathrm{c} 4) \mathrm{c} 3 \mathrm{c} 2) \mathrm{o} 1$ & 26 & $*$ \\
\hline 1449 & $\mathrm{Nc} 1 \mathrm{ccccc} 1 \mathrm{NC}(=\mathrm{O}) / \mathrm{C}=\mathrm{C} / \mathrm{c} 1 \mathrm{ccc}(-\mathrm{c} 2 \mathrm{ccc} 3 \mathrm{ncnc}(\mathrm{Nc} 4 \operatorname{ccc}(\mathrm{OCc} 5 \mathrm{cccc}(\mathrm{F}) \mathrm{c} 5) \mathrm{c}(\mathrm{Cl}) \mathrm{c} 4) \mathrm{c} 3 \mathrm{c} 2) \mathrm{o} 1$ & 26 & $*$ \\
\hline 1450 & $\mathrm{Cc} 1 \mathrm{ccc}(\mathrm{S}(=\mathrm{O})(=\mathrm{O}) \mathrm{O}) \mathrm{cc} 1 . \mathrm{Fc} 1 \mathrm{cccc}(\mathrm{COc} 2 \mathrm{ccc}(\mathrm{Nc} 3 \mathrm{ncnc} 4 \mathrm{ccc}(-\mathrm{c} 5 \mathrm{ccc}(\mathrm{CN} 6 \mathrm{CCOCC} 6) \mathrm{o}) \mathrm{cc} 34) \mathrm{cc} 2 \mathrm{Cl}) \mathrm{c} 1$ & 26 & $*$ \\
\hline 1451 & 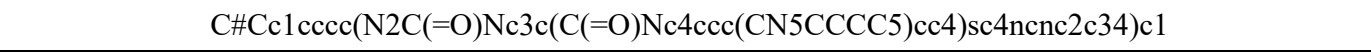 & 26 & * \\
\hline 1452 & $\operatorname{COCCn} 1 \mathrm{c}(=\mathrm{O}) \mathrm{oc} 2 \mathrm{cc} 3 \mathrm{ncnc}(\mathrm{Nc} 4 \mathrm{ccc}(\mathrm{F}) \mathrm{c}(\mathrm{F}) \mathrm{c} 4) \mathrm{c} 3 \mathrm{cc} 21$ & 26 & $*$ \\
\hline 1453 & COc1 $1 \mathrm{c} 2 \mathrm{ncnc}(\mathrm{CHCc} 3 \mathrm{cccc} 3-\mathrm{c} 3 \mathrm{cccc} 3) \mathrm{c} 2 \mathrm{cc} 1 \mathrm{OC}$ & 26 & $*$ \\
\hline 1454 & COC[C@@H]1CCCN1/N=C/c1c(N)ncnc1Nc1ccc2c(cnn2Cc2 $\operatorname{cccc}(\mathrm{F}) \mathrm{c} 2) \mathrm{c} 1$ & 26 & $*$ \\
\hline 1455 & $\mathrm{Clc} 1 \mathrm{cccc}(\mathrm{CNc} 2[\mathrm{nH}] \mathrm{nc} 3 \mathrm{ncnc}(\mathrm{Nc} 4 \mathrm{cccc}(\mathrm{Cl}) \mathrm{c} 4) \mathrm{c} 23) \mathrm{c} 1$ & 26 & $*$ \\
\hline 1456 & Oc1 $\operatorname{cccc}(-\mathrm{c} 2[\mathrm{nH}] \mathrm{nc} 3 \mathrm{ncnc}(\mathrm{Nc} 4 \mathrm{cccc}(\mathrm{Cl}) \mathrm{c} 4) \mathrm{c} 23) \mathrm{c} 1$ & 26 & $*$ \\
\hline 1457 & $\mathrm{ClCCNc} 1 \mathrm{ccc} 2 \mathrm{ncnc}(\mathrm{Nc} 3 \mathrm{cccc}(\mathrm{Cl}) \mathrm{c} 3) \mathrm{c} 2 \mathrm{c} 1$ & 26 & $*$ \\
\hline 1458 & $\mathrm{O}[\mathrm{C} @ \mathrm{H}] 1 \mathrm{CNCCN}(\mathrm{Cc} 2 \mathrm{ccn} 3 \mathrm{ncnc}(\mathrm{Nc} 4 \mathrm{ccc} 5 \mathrm{c}(\mathrm{cnn} 5 \mathrm{Cc} 5 \mathrm{cccc}(\mathrm{F}) \mathrm{c} 5) \mathrm{c} 4) \mathrm{c} 23) \mathrm{C} 1$ & 26 & $*$ \\
\hline 1459 & Br.Oc1 $1 \mathrm{ccc}(-\mathrm{c} 2 \mathrm{cc} 3 \mathrm{c}(\mathrm{NCc} 4 \mathrm{ccc}(\mathrm{F}) \mathrm{cc} 4) \mathrm{ncnc} 3[\mathrm{nH}] 2) \mathrm{cc} 1$ & 26 & $*$ \\
\hline 1460 & $\mathrm{NP}(=\mathrm{O})(\mathrm{OCCCC}(=\mathrm{O}) \mathrm{Nc} 1 \mathrm{ccc} 2 \mathrm{ncnc}(\mathrm{Nc} 3 \operatorname{ccc}(\mathrm{OCc} 4 \mathrm{cccc}(\mathrm{F}) \mathrm{c} 4) \mathrm{c}(\mathrm{Cl}) \mathrm{c} 3) \mathrm{c} 2 \mathrm{c} 1) \mathrm{N}(\mathrm{CCCl}) \mathrm{CCCl}$ & 26 & $*$ \\
\hline 1461 & $\mathrm{C}=\mathrm{CC}(=\mathrm{O}) \mathrm{Nc} 1 \mathrm{cc}(\mathrm{F}) \mathrm{cc}(-\mathrm{n} 2 \mathrm{c}(=\mathrm{O}) \mathrm{cc}(\mathrm{C}) \mathrm{c} 3 \mathrm{cnc}(\mathrm{Nc} 4 \mathrm{ccc}(\mathrm{N} 5 \mathrm{CCN}(\mathrm{C}) \mathrm{CC} 5) \mathrm{cc} 4 \mathrm{OC}) \mathrm{nc} 32) \mathrm{c} 1$ & 26 & $*$ \\
\hline
\end{tabular}




\begin{tabular}{|c|c|c|c|}
\hline 1462 & $\mathrm{NS}(=\mathrm{O})(=\mathrm{O}) \mathrm{c} 1 \operatorname{ccc}(-\mathrm{n} 2 \mathrm{c}(\mathrm{SCC}(=\mathrm{O}) \mathrm{Nc} 3 \operatorname{ccc} \mathrm{c} 3 \mathrm{~F}) \mathrm{nc} 3 \operatorname{cc} 4 \operatorname{ccc} c 4 \mathrm{cc} 3 \mathrm{c} 2=\mathrm{O}) \mathrm{cc} 1$ & 26 & $*$ \\
\hline 1463 & $\mathrm{Cc} 1 n n c(-\mathrm{c} 2 \mathrm{ccc} 3 \mathrm{ncnc}(\mathrm{Nc} 4 \mathrm{ccc} 5 \mathrm{c}(\mathrm{cnn} 5 \mathrm{Cc} 5 \mathrm{cccc}(\mathrm{F}) \mathrm{c} 5) \mathrm{c} 4) \mathrm{c} 3 \mathrm{c} 2) \mathrm{o} 1$ & 26 & $*$ \\
\hline 1464 & $\mathrm{C}=\mathrm{CC}(=\mathrm{O}) \mathrm{Nc} 1 \mathrm{cc}(\mathrm{Nc} 2 \mathrm{n}[\mathrm{nH}] \mathrm{c} 3 \mathrm{cc}(-\mathrm{c} 4 \mathrm{ccc}(\mathrm{F}) \mathrm{cc} 4) \operatorname{ccc} 23) \mathrm{c}(\mathrm{OC}) \mathrm{cc} 1 \mathrm{~N}(\mathrm{C}) \mathrm{CCN}(\mathrm{C}) \mathrm{C}$ & 26 & * \\
\hline 1465 & $\mathrm{COc} 1 \mathrm{cccc}(\mathrm{Nc} 2 \mathrm{cc}(\mathrm{Nc} 3 \mathrm{cc}(\mathrm{OC}) \mathrm{ccc} 3 \mathrm{OC}) \mathrm{ncn} 2) \mathrm{c} 1$ & 26 & $*$ \\
\hline 1466 & $\mathrm{COC}(=\mathrm{O}) \mathrm{N} 1 \mathrm{CCc} 2 \mathrm{ncnc}(\mathrm{Nc} 3 \operatorname{ccc}(\mathrm{Oc} 4 \operatorname{cccc}(\mathrm{C}(\mathrm{F})(\mathrm{F}) \mathrm{F}) \mathrm{c} 4) \mathrm{c}(\mathrm{Cl}) \mathrm{c} 3) \mathrm{c} 2 \mathrm{C} 1$ & 26.2 & 7.58 \\
\hline 1467 & $\mathrm{O}=\mathrm{C}(\mathrm{Nc} 1 \mathrm{ccc} n 1) \mathrm{Nc} 1 \mathrm{cc}(-\mathrm{c} 2 \mathrm{cncnc} 2) \operatorname{ccc} 1 \mathrm{OC}(\mathrm{F})(\mathrm{F}) \mathrm{F}$ & 26.56 & $*$ \\
\hline 1468 & $\mathrm{Cc} 1 \mathrm{cc}(\mathrm{Nc} 2 \mathrm{ncc} 3 \mathrm{c}(\mathrm{n} 2) \mathrm{N}([\mathrm{C} @ \mathrm{H}] 2 \mathrm{CCN}(\mathrm{C}(=\mathrm{O}) \mathrm{CN}(\mathrm{C}) \mathrm{C}) \mathrm{C} 2) \mathrm{C}(=\mathrm{O}) \mathrm{N}(\mathrm{c} 2 \operatorname{ccccc} 2 \mathrm{Cl}) \mathrm{C} 3) \operatorname{ccc} 1 \mathrm{~N} 1 \mathrm{CCN}(\mathrm{C}) \mathrm{CC} 1$ & 26.6 & 7.58 \\
\hline 1469 & $\mathrm{COc} 1 \mathrm{cc} 2 \mathrm{ncnc}(\mathrm{Nc} 3 \mathrm{ccc}(\mathrm{F}) \mathrm{c}(\mathrm{Cl}) \mathrm{c} 3) \mathrm{c} 2 \mathrm{cc} 1 \mathrm{NC}(=\mathrm{O}) / \mathrm{C}=\mathrm{C} / \mathrm{CN}(\mathrm{C}) \mathrm{C} 1 \mathrm{CC} 1$ & 26.9 & $*$ \\
\hline 1470 & $\mathrm{~S}=\mathrm{C}(\mathrm{Nc} 1 \mathrm{ccc} 2 \mathrm{ncnc}(\mathrm{Nc} 3 \mathrm{cccc}(\mathrm{Br}) \mathrm{c} 3) \mathrm{c} 2 \mathrm{c} 1) \mathrm{N} 1 \mathrm{CCOCC} 1$ & 26.9 & * \\
\hline 1471 & $\mathrm{C} \# \mathrm{Cc} 1 \mathrm{cccc}(\mathrm{Nc} 2 \mathrm{ncnc} 3 \mathrm{cc}(\mathrm{OCCOC}(=\mathrm{O}) \mathrm{Cc} 4 \mathrm{c}(\mathrm{C}) \mathrm{n}(\mathrm{C}(=\mathrm{O}) \mathrm{c} 5 \mathrm{ccc}(\mathrm{Cl}) \mathrm{cc} 5) \mathrm{c} 5 \mathrm{ccc}(\mathrm{OC}) \mathrm{cc} 45) \mathrm{c}(\mathrm{OCCOC}) \mathrm{cc} 23) \mathrm{c} 1$ & 27 & 7.57 \\
\hline 1472 & 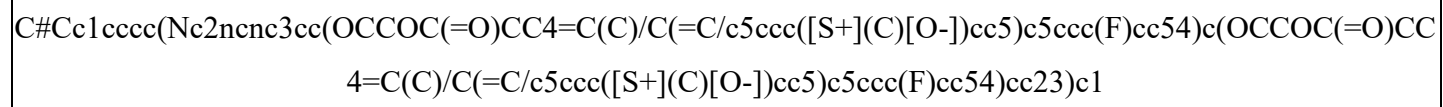 & 27 & 7.57 \\
\hline 1473 & $\mathrm{COc} 1 \mathrm{ccc}(-\mathrm{c} 2 \mathrm{cc} 3 \mathrm{c}(\mathrm{N}[\mathrm{C} @ \mathrm{H}](\mathrm{C}) \mathrm{c} 4 \mathrm{ccc}(\mathrm{F}) \mathrm{cc} 4) \mathrm{ncnc} 3 \mathrm{o} 2) \mathrm{cc} 1$ & 27 & 7.57 \\
\hline 1474 & $\mathrm{O}=\mathrm{C}(\mathrm{Nc} 1 \mathrm{cc} 2 \mathrm{c}(\mathrm{Nc} 3 \mathrm{ccc}(\mathrm{F}) \mathrm{c}(\mathrm{Cl}) \mathrm{c} 3) \mathrm{ncnc} 2 \mathrm{cc} 1 \mathrm{OCCCN} 1 \mathrm{CCOCC} 1) \mathrm{c} 1 \mathrm{ccccc} 1$ & 27 & 7.57 \\
\hline 1475 & $\mathrm{CS}(=\mathrm{O})(=\mathrm{O}) \mathrm{CCNCCCCOc} 1 \mathrm{ccc} 2 \mathrm{ncnc}(\mathrm{Nc} 3 \mathrm{ccc}(\mathrm{OCc} 4 \mathrm{cccc}(\mathrm{F}) \mathrm{c} 4) \mathrm{c}(\mathrm{Cl}) \mathrm{c} 3) \mathrm{c} 2 \mathrm{c} 1$ & 27 & $*$ \\
\hline 1476 & $\mathrm{CS}(=\mathrm{O})(=\mathrm{O}) \mathrm{CCNCc} 1 \mathrm{ccc}(-\mathrm{c} 2 \operatorname{ccc} 3 \mathrm{ncnc}(\mathrm{Nc} 4 \mathrm{ccc}(\mathrm{OCc} 5 \operatorname{ccc} c 5) \operatorname{cc} 4) \mathrm{c} 3 \mathrm{c} 2) \mathrm{o} 1$ & 27 & $*$ \\
\hline 1477 & $\mathrm{CS}(=\mathrm{O})(=\mathrm{O}) \mathrm{CCN}(\mathrm{CC} \# \mathrm{~N}) \mathrm{Cc} 1 \mathrm{ccc}(-\mathrm{c} 2 \operatorname{ccc} 3 \mathrm{ncnc}(\mathrm{Nc} 4 \operatorname{ccc}(\mathrm{OCc} 5 \operatorname{cccc}(\mathrm{F}) \mathrm{c} 5) \mathrm{c}(\mathrm{Cl}) \mathrm{c} 4) \mathrm{c} 3 \mathrm{c} 2) \mathrm{o} 1$ & 27 & $*$ \\
\hline 1478 & $\mathrm{O}=\mathrm{C}(\mathrm{NCCO}) \mathrm{Nc} 1 \mathrm{cc} 2 \mathrm{c}(\mathrm{Nc} 3 \mathrm{ccc}(\mathrm{F}) \mathrm{c}(\mathrm{Cl}) \mathrm{c} 3) \mathrm{ncnc} 2 \mathrm{cc} 1 \mathrm{O}[\mathrm{C} @ \mathrm{H}] 1 \mathrm{CCOC} 1$ & 27 & $*$ \\
\hline 1479 & COc1 1cccc1-c1cc2c(N[C@H](C)c3ecc(F)cc3)ncnc2s1 & 27 & $*$ \\
\hline 1480 & $\mathrm{c} 1 \mathrm{ccc}(-\mathrm{c} 2 \mathrm{cccc}(\mathrm{Nc} 3 \mathrm{ncnc} 4 \mathrm{cc} 5 \mathrm{c}(\mathrm{cc} 34) \mathrm{OCCCO}) \mathrm{c} 2) \mathrm{cc} 1$ & 27 & $*$ \\
\hline 1481 & $\mathrm{C}=\mathrm{CC}(=\mathrm{O}) \mathrm{Nc} 1 \mathrm{ccc} 2 \mathrm{ncnc}(\mathrm{Nc} 3 \mathrm{ccc}(\mathrm{OCCN}(\mathrm{C}) \mathrm{C}) \mathrm{c}(\mathrm{Br}) \mathrm{c} 3) \mathrm{c} 2 \mathrm{c} 1$ & 27 & * \\
\hline 1482 & $\operatorname{Brc} 1 \operatorname{ccc}(\mathrm{Nc} 2 \mathrm{ncnc} 3 \operatorname{ccccc} 23) \mathrm{c} 1$ & 27 & $*$ \\
\hline 1483 & $\mathrm{COc} 1 \mathrm{cc} 2 \mathrm{ncnc}(\mathrm{NC} 3 \mathrm{CC} 3 \mathrm{c} 3 \mathrm{cccc} 3) \mathrm{c} 2 \mathrm{cc} 1 \mathrm{OCCCN}(\mathrm{C}) \mathrm{C}$ & 27 & * \\
\hline 1484 & c1ccc2ncnec2c1 & 27 & * \\
\hline 1485 & $\mathrm{Cc} 1[\mathrm{nH}] \mathrm{c} 2 \mathrm{ncnc}(\mathrm{Nc} 3 \operatorname{cccc}(\mathrm{Cl}) \mathrm{c} 3) \mathrm{c} 2 \mathrm{c} 1 \mathrm{C}$ & 27 & $*$ \\
\hline 1486 & Cl.c1 ccc(-c2 $\mathrm{cccc}(\mathrm{Nc} 3 \mathrm{ncnc} 4 \mathrm{cc} 5 \mathrm{c}(\mathrm{cc} 34) \mathrm{OCCCO}) \mathrm{c} 2) \mathrm{cc} 1$ & 27 & $*$ \\
\hline 1487 & $\mathrm{C}[\mathrm{C} @ @ \mathrm{H}](\mathrm{Nc} 1 \mathrm{ncnc} 2[\mathrm{nH}] \mathrm{c}(-\mathrm{c} 3 \mathrm{ccc}(\mathrm{F}) \mathrm{cc} 3) \mathrm{cc} 12) \mathrm{c} 1 \mathrm{ccc}(\mathrm{F}) \mathrm{cc} 1$ & 27 & $*$ \\
\hline 1488 & $\mathrm{O}=\mathrm{C}(\mathrm{Nc} 1 \mathrm{cc} 2 \mathrm{c}(\mathrm{Nc} 3 \mathrm{ccc}(\mathrm{F}) \mathrm{c}(\mathrm{Cl}) \mathrm{c} 3) n \mathrm{cnc} 2 \mathrm{cc} 1 \mathrm{O}[\mathrm{C} @ \mathrm{H}] 1 \mathrm{CCOC} 1) \mathrm{N}(\mathrm{NCO}) \mathrm{NCCO}$ & 27 & $*$ \\
\hline 1489 & $\mathrm{NP}(=\mathrm{O})(\mathrm{OCCCCOc} 1 \mathrm{ccc} 2 \mathrm{ncnc}(\mathrm{Nc} 3 \operatorname{ccc}(\mathrm{OCc} 4 \mathrm{cccc}(\mathrm{F}) \mathrm{c} 4) \mathrm{c}(\mathrm{Cl}) \mathrm{c} 3) \mathrm{c} 2 \mathrm{c} 1) \mathrm{N}(\mathrm{CCCl}) \mathrm{CCCl}$ & 27 & $*$ \\
\hline 1490 & Clc1 $\operatorname{ccccc} 1 O c 1 \mathrm{ccc}(\mathrm{Nc} 2 \mathrm{ncnc} 3 \mathrm{cc}[\mathrm{nH}] \mathrm{c} 23) \mathrm{cc} 1 \mathrm{Cl}$ & 27 & $*$ \\
\hline 1491 & Cl.Cn1 ccc2ncnc(Ne3ecc $(\mathrm{Oc} 4 \mathrm{cccc}(\mathrm{C}(\mathrm{F})(\mathrm{F}) \mathrm{F}) \mathrm{c} 4) \mathrm{c}(\mathrm{Cl}) \mathrm{c} 3) \mathrm{c} 21$ & 27 & $*$ \\
\hline 1492 & $\mathrm{CCOC}(=\mathrm{O}) \mathrm{CCCC}(=\mathrm{O}) \mathrm{Nc} 1 \mathrm{cc}(\mathrm{Nc} 2 \mathrm{cccc}(\mathrm{Cl}) \mathrm{c} 2) \mathrm{ncn} 1$ & 27 & $*$ \\
\hline 1493 & $\mathrm{O}=\mathrm{C}(\mathrm{O}) \mathrm{CCCC}(=\mathrm{O}) \mathrm{Nc} 1 \mathrm{cc}(\mathrm{Nc} 2 \mathrm{cccc}(\mathrm{Cl}) \mathrm{c} 2) \mathrm{ncn} 1$ & 27 & $*$ \\
\hline 1494 & $\mathrm{CCC}(=\mathrm{O}) \mathrm{Nc} 1 \mathrm{cccc}(-\mathrm{c} 2 \mathrm{cc} 3 \mathrm{c}(-\mathrm{c} 4[\mathrm{nH}] \mathrm{c}(-\mathrm{c} 5 \mathrm{ccccc} 5) \mathrm{nc} 4-\mathrm{c} 4 \mathrm{ccc}(\mathrm{F}) \mathrm{cc} 4) \mathrm{ccnc} 3[\mathrm{nH}] 2) \mathrm{c} 1$ & 27.2 & $*$ \\
\hline 1495 & $\mathrm{CHCc1} 1 \mathrm{ccc}(\mathrm{Nc} 2 \mathrm{ncnc} 3 \mathrm{cc}(\mathrm{OCC} 4 \mathrm{CCCO} 4) \mathrm{c} 4 \mathrm{c}(\mathrm{c} 23) \mathrm{OCCO} 4) \mathrm{c} 1$ & 27.3 & $*$ \\
\hline 1496 & $\mathrm{CCC}(=\mathrm{O}) \mathrm{N} 1 \mathrm{CC}[\mathrm{C} @ \mathrm{H}](\mathrm{N} 2 \mathrm{C}(=\mathrm{O}) \mathrm{N}(\mathrm{c} 3 \operatorname{ccccc} 3 \mathrm{OC}) \mathrm{Cc} 3 \mathrm{cnc}(\mathrm{Nc} 4 \mathrm{ccc}(\mathrm{N} 5 \mathrm{CCN}(\mathrm{C}) \mathrm{CC} 5) \mathrm{c}(\mathrm{C}) \mathrm{c} 4) \mathrm{nc} 32) \mathrm{C} 1$ & 27.4 & 7.56 \\
\hline 1497 & $\mathrm{C}=\mathrm{C}=\mathrm{CC}(=\mathrm{O}) \mathrm{Nc} 1 \mathrm{cc}(\mathrm{Nc} 2 \mathrm{nccc}(\mathrm{C} 3=\mathrm{CN}(\mathrm{C}) \mathrm{C} 4 \mathrm{C}=\mathrm{CC}=\mathrm{CC} 34) \mathrm{n} 2) \mathrm{c}(\mathrm{OC}) \mathrm{cc} 1 \mathrm{~N}(\mathrm{C}) \mathrm{CCN}(\mathrm{C}) \mathrm{C}$ & 27.9 & $*$ \\
\hline 1498 & $\mathrm{C}=\mathrm{C}=\mathrm{CC}(=\mathrm{O}) \mathrm{Nc} 1 \mathrm{cc}(\mathrm{Nc} 2 \mathrm{nccc}(-\mathrm{c} 3 \mathrm{cn}(\mathrm{C}) \mathrm{c} 4 \mathrm{ccccc} 34) \mathrm{n} 2) \mathrm{c}(\mathrm{OC}) \mathrm{cc} 1 \mathrm{~N}(\mathrm{C}) \mathrm{CCN}(\mathrm{C}) \mathrm{C}$ & 27.9 & $*$ \\
\hline 1499 & COC[C@@H](Nc1ncnc2oc(-c3ecccc3)cc12)c1ccecc1 & 28 & 7.55 \\
\hline 1500 & $\mathrm{C} / \mathrm{C}(=\mathrm{Clc} 1 \mathrm{c}(\mathrm{C}) \mathrm{ncnc} 1 \mathrm{Nc} 1 \mathrm{ccc}(\mathrm{OCc} 2 \mathrm{cccc}(\mathrm{F}) \mathrm{c} 2) \mathrm{c}(\mathrm{Cl}) \mathrm{c} 1) \mathrm{C}(=\mathrm{O}) \mathrm{NCCN} 1 \mathrm{CCOCC} 1$ & 28 & 7.55 \\
\hline 1501 & $\mathrm{O}=\mathrm{C}(\mathrm{Nc} 1 \mathrm{cc} 2 \mathrm{c}(\mathrm{Nc} 3 \mathrm{ccc}(\mathrm{OCc} 4 \mathrm{cccc}(\mathrm{F}) \mathrm{c} 4) \mathrm{c}(\mathrm{Cl}) \mathrm{c} 3) \mathrm{ncnc} 2 \mathrm{cc} 1 \mathrm{OCCCN} 1 \mathrm{CCOCC} 1) \mathrm{c} 1 \mathrm{cc}([\mathrm{N}+](=\mathrm{O})[\mathrm{O}-]) \mathrm{ccc} 1 \mathrm{~F}$ & 28 & 7.55 \\
\hline 1502 & $\begin{array}{c}\operatorname{CCOC}(=\mathrm{O}) \mathrm{N} 1 \mathrm{CCN}(\mathrm{Cc} 2 \mathrm{ccc}(- \\
\mathrm{c} 3 \operatorname{ccc} 4 n \mathrm{nnc}(\mathrm{Nc} 5 \operatorname{ccc}(\mathrm{OCc} 6 \operatorname{ccc}(\mathrm{F}) \mathrm{c} 6) \mathrm{c}(\mathrm{Cl}) \mathrm{c} 5) \mathrm{c} 4 \mathrm{c} 3) \mathrm{o} 2) \mathrm{CC} 1 . \mathrm{Cc} 1 \mathrm{ccc}(\mathrm{S}(=\mathrm{O})(=\mathrm{O}) \mathrm{O}) \mathrm{cc} 1\end{array}$ & 28 & $*$ \\
\hline
\end{tabular}




\begin{tabular}{|c|c|c|c|}
\hline 1503 & $\mathrm{O}=\mathrm{C}(/ \mathrm{C}=\mathrm{C} / \mathrm{CN} 1 \mathrm{CCC}(\mathrm{F})(\mathrm{F}) \mathrm{C} 1) \mathrm{Nc} 1 \mathrm{cc} 2 \mathrm{c}(\mathrm{Nc} 3 \mathrm{ccc}(\mathrm{F}) \mathrm{c}(\mathrm{Cl}) \mathrm{c} 3) \mathrm{ncnc} 2 \mathrm{~s} 1$ & 28 & * \\
\hline 1504 & $\mathrm{CN}(\mathrm{C}) \mathrm{C}(=\mathrm{O}) \mathrm{O}[\mathrm{C} @ \mathrm{H}] 1 \mathrm{CN}[\mathrm{C} @ \mathrm{H}](\mathrm{C} \# \mathrm{Cc} 2 \mathrm{cc} 3 \mathrm{ncnc}(\mathrm{Nc} 4 \mathrm{ccc}(\mathrm{OCc} 5 \mathrm{cccc}(\mathrm{F}) \mathrm{c} 5) \mathrm{c}(\mathrm{Cl}) \mathrm{c} 4) \mathrm{c} 3 \mathrm{~s} 2) \mathrm{C} 1$ & 28 & * \\
\hline 1505 & $\mathrm{CCC} 1=\mathrm{C} 2 \mathrm{C}(\mathrm{Nc} 3 \mathrm{ccc} 4 \mathrm{c}(\mathrm{cnn} 4 \mathrm{Cc} 4 \mathrm{ccccc} 4) \mathrm{c} 3)=\mathrm{NC}=\mathrm{NC} 2 \mathrm{~N}=\mathrm{C} 1 \mathrm{NC}(=\mathrm{O}) \mathrm{OCCN} 1 \mathrm{CCCCC} 1$ & 28 & $*$ \\
\hline 1506 & $\mathrm{CC}(=\mathrm{O}) \mathrm{Nc} 1 \mathrm{cc} 2 \mathrm{ncnc}(\mathrm{Nc} 3 \operatorname{cccc}(\mathrm{Br}) \mathrm{c} 3) \mathrm{c} 2 \mathrm{cc} 1[\mathrm{~N}+](=\mathrm{O})[\mathrm{O}-]$ & 28 & $*$ \\
\hline 1507 & $\begin{array}{c}\mathrm{CC} 1(\mathrm{C})[\mathrm{C} @ @ \mathrm{H}](\mathrm{O}[\mathrm{C} @ @ \mathrm{H}] 2 \mathrm{O}[\mathrm{C} @ \mathrm{H}](\mathrm{C}(=\mathrm{O}) \mathrm{O})[\mathrm{C} @ @ \mathrm{H}](\mathrm{O})[\mathrm{C} @ \mathrm{H}](\mathrm{O})[\mathrm{C} @ \mathrm{H}] 2 \mathrm{O}) \mathrm{CC}[\mathrm{C} @ @] 2(\mathrm{C})[\mathrm{C} @ \mathrm{H}] 1 \mathrm{CC} \\
[\mathrm{C} @] 1(\mathrm{C})[\mathrm{C} @ @ \mathrm{H}] 2 \mathrm{C}=\mathrm{O}) \mathrm{C}=\mathrm{C} 2[\mathrm{C} @ @ \mathrm{H}] 3 \mathrm{C}[\mathrm{C} @ @](\mathrm{C})(\mathrm{C}=\mathrm{O}) \mathrm{O}) \mathrm{CC}[\mathrm{C} @] 3(\mathrm{C}) \mathrm{C}[\mathrm{C} @] 21 \mathrm{C}\end{array}$ & 28 & $*$ \\
\hline 1508 & $\mathrm{C}=\mathrm{CC}(=\mathrm{O}) \mathrm{Nc} 1 \mathrm{cccc}(-\mathrm{n} 2 \mathrm{c}(=\mathrm{O}) \mathrm{c}(=\mathrm{O}) \mathrm{n}(\mathrm{C}(\mathrm{C}) \mathrm{C}) \mathrm{c} 3 \mathrm{cnc}(\mathrm{Nc} 4 \mathrm{ccc}(\mathrm{N} 5 \mathrm{CCC}(\mathrm{N} 6 \mathrm{CCN}(\mathrm{C}) \mathrm{CC} 6) \mathrm{CC} 5) \mathrm{cc} 4 \mathrm{OC}) \mathrm{nc} 32) \mathrm{c} 1$ & 28 & $*$ \\
\hline 1509 & $\mathrm{C}=\mathrm{CC}(=\mathrm{O}) \mathrm{N} 1 \mathrm{CCC}[\mathrm{C} @ @ \mathrm{H}] 1 \mathrm{CSc} 1 \mathrm{nc}(-\mathrm{c} 2 \mathrm{ccc}(\mathrm{F}) \mathrm{cc} 2) \mathrm{c}(-\mathrm{c} 2 \mathrm{ccnc}(\mathrm{Nc} 3 \mathrm{ccccc} 3) \mathrm{c} 2)[\mathrm{nH}] 1$ & 28 & * \\
\hline 1510 & c1 cnc2cce(Nc3ncnc4ccc(-c5enn(C6CCNCC6)c5)cc34)cc2c1 & 28.2 & 7.55 \\
\hline 1511 & $\mathrm{COCC} 1 \mathrm{CO} 2 \mathrm{cc} 3 \mathrm{ncnc}(\mathrm{Nc} 4 \mathrm{cccc}(\mathrm{I}) \mathrm{c} 4) \mathrm{c} 3 \mathrm{cc} 2 \mathrm{O} 1$ & 28.2 & * \\
\hline 1512 & OCCNCC1COc2 $1 \mathrm{cc} 3 \mathrm{ncnc}(\mathrm{Nc} 4 \mathrm{cccc}(\mathrm{Br}) \mathrm{c} 4) \mathrm{c} 3 \mathrm{cc} 2 \mathrm{O} 1$ & 28.2 & $*$ \\
\hline 1513 & $\mathrm{COc} 1 \mathrm{cc} 2 \mathrm{ncnc}(\mathrm{Nc} 3 \mathrm{ccc}(\mathrm{Br}) \mathrm{cc} 3 \mathrm{~F}) \mathrm{c} 2 \mathrm{cc} 1 \mathrm{OCCCN} 1 \mathrm{CCNCCNCC} 1$ & 28.2 & $*$ \\
\hline 1514 & $\mathrm{~S}=\mathrm{C}(\mathrm{NCc} 1 \mathrm{ccc}(\mathrm{Cl}) \mathrm{cc} 1) \mathrm{Nc} 1 \mathrm{ccc} 2 \mathrm{ncnc}(\mathrm{Nc} 3 \mathrm{cccc}(\mathrm{Br}) \mathrm{c} 3) \mathrm{c} 2 \mathrm{c} 1$ & 28.3 & $*$ \\
\hline 1515 & $\operatorname{COc} 1 \mathrm{cc} 2 \mathrm{ncnc}(\mathrm{Nc} 3 \operatorname{ccc}(\mathrm{OCc} 4 \mathrm{cccc}(\mathrm{F}) \mathrm{c} 4) \mathrm{c}(\mathrm{Cl}) \mathrm{c} 3) \mathrm{c} 2 \mathrm{cc} 1 \mathrm{OCCCCn} 1 \mathrm{ccnc} 1[\mathrm{~N}+](=\mathrm{O})[\mathrm{O}-]$ & 28.5 & 7.55 \\
\hline 1516 & $\mathrm{C}=\mathrm{C}=\mathrm{CCCCOc} 1 \mathrm{cc} 2 \mathrm{c}(\mathrm{Nc} 3 \mathrm{cccc}(\mathrm{Cl}) \mathrm{c} 3) \mathrm{ncnc} 2 \mathrm{cc} 1 \mathrm{O}$ & 28.5 & $*$ \\
\hline 1517 & $\mathrm{Cc} 1 \mathrm{cc}(\mathrm{Nc} 2 \mathrm{ncc} 3 \mathrm{c}(\mathrm{n} 2) \mathrm{N}([\mathrm{C} @ \mathrm{H}] 2 \mathrm{CCN}(\mathrm{C}(=\mathrm{O}) \mathrm{C} 4 \mathrm{CC} 4) \mathrm{C} 2) \mathrm{C}(=\mathrm{O}) \mathrm{N}(\mathrm{c} 2 \mathrm{ccccc} 2 \mathrm{Cl}) \mathrm{C} 3) \mathrm{ccc} 1 \mathrm{~N} 1 \mathrm{CCN}(\mathrm{C}) \mathrm{CC} 1$ & 28.7 & 7.54 \\
\hline 1518 & $\mathrm{CS}(=\mathrm{O})(=\mathrm{O}) \operatorname{CCNC}(\mathrm{CS}(\mathrm{C})(=\mathrm{O})=\mathrm{O}) \mathrm{c} 1 \mathrm{ccc}(-\mathrm{c} 2 \mathrm{ccc} 3 \mathrm{ncnc}(\mathrm{Nc} 4 \mathrm{ccc}(\mathrm{OCc} 5 \operatorname{cccc}(\mathrm{F}) \mathrm{c} 5) \mathrm{c}(\mathrm{Cl}) \mathrm{c} 4) \mathrm{c} 3 \mathrm{c} 2) \mathrm{o} 1$ & 28.7 & * \\
\hline 1519 & $\mathrm{CACc} 1 \mathrm{cc}(\mathrm{Nc} 2 \mathrm{ncnc} 3 \mathrm{cc}(\mathrm{OC}) \mathrm{c}(\mathrm{OCCCCCCC}(=\mathrm{O}) \mathrm{NO}) \mathrm{cc} 23) \mathrm{ccc} 1 \mathrm{~F}$ & 28.8 & 7.54 \\
\hline 1520 & $\mathrm{C} \# \mathrm{Cc} 1 \mathrm{cccc}(\mathrm{Nc} 2 \mathrm{ncnc} 3 \mathrm{cc}(\mathrm{OC}) \mathrm{c}(\mathrm{OC}) \mathrm{cc} 23) \mathrm{c} 1$ & 28.8 & $*$ \\
\hline 1521 & $\mathrm{COC}[\mathrm{C} @ \mathrm{H}] 1 \mathrm{Oc} 2 \mathrm{cc} 3 \mathrm{ncnc}(\mathrm{Nc4} 4 \mathrm{ccc}(\mathrm{Br}) \mathrm{c} 4) \mathrm{c} 3 \mathrm{cc} 2 \mathrm{O}[\mathrm{C} @ @ \mathrm{H}] 1 \mathrm{COC}$ & 28.89 & * \\
\hline 1522 & $\mathrm{CN} 1 \mathrm{CCN}(\mathrm{CCOC}(=\mathrm{O}) \mathrm{N} 2 \mathrm{CCc} 3 \operatorname{ncnc}(\mathrm{Nc} 4 \mathrm{cccc}(\mathrm{C}(\mathrm{F})(\mathrm{F}) \mathrm{F}) \mathrm{c} 4) \mathrm{c} 3 \mathrm{C} 2) \mathrm{CC} 1$ & 28.9 & 7.54 \\
\hline 1523 & $\mathrm{CCCC}(=\mathrm{O}) \mathrm{N} 1 \mathrm{CC}[\mathrm{C} @ \mathrm{H}](\mathrm{N} 2 \mathrm{C}(=\mathrm{O}) \mathrm{N}(\mathrm{c} 3 \mathrm{ccccc} 3 \mathrm{Cl}) \mathrm{Cc} 3 \mathrm{cnc}(\mathrm{Nc} 4 \mathrm{ccc}(\mathrm{N} 5 \mathrm{CCN}(\mathrm{C}) \mathrm{CC} 5) \mathrm{c}(\mathrm{C}) \mathrm{c} 4) \mathrm{nc} 32) \mathrm{C} 1$ & 28.9 & 7.54 \\
\hline 1524 & $\mathrm{C}=\mathrm{Cc} 1 \mathrm{ccc}(-\mathrm{c} 2 \mathrm{cc} 3 \mathrm{c}(\mathrm{N}[\mathrm{C} @ \mathrm{H}](\mathrm{C}) \mathrm{c} 4 \mathrm{ccccc} 4) \mathrm{ncnc} 3 \mathrm{o} 2) \mathrm{cc} 1$ & 29 & 7.54 \\
\hline 1525 & $\mathrm{Nc} 1 \mathrm{ccc} 2 \mathrm{ncnc}(\mathrm{Nc} 3 \mathrm{ccc}(\mathrm{F}) \mathrm{c}(\mathrm{Cl}) \mathrm{c} 3) \mathrm{c} 2 \mathrm{c} 1$ & 29 & 7.54 \\
\hline 1526 & $\mathrm{O}=\mathrm{C}(\mathrm{Nc} 1 \mathrm{cc} 2 \mathrm{c}(\mathrm{Nc} 3 \mathrm{ccc}(\mathrm{F}) \mathrm{c}(\mathrm{Cl}) \mathrm{c} 3) \mathrm{ncnc} 2 \mathrm{cc} 1 \mathrm{OCCCN} 1 \mathrm{CCOCC} 1) \mathrm{c} 1 \mathrm{cccc}(\mathrm{F}) \mathrm{c} 1 \mathrm{~F}$ & 29 & 7.54 \\
\hline 1527 & $\mathrm{Nc} 1 \operatorname{ccccc} 1 \mathrm{NC}(=\mathrm{O}) / \mathrm{C}=\mathrm{C} / \mathrm{c} 1 \mathrm{ccc}(-\mathrm{c} 2 \mathrm{ccc} 3 \mathrm{ncnc}(\mathrm{Nc} 4 \mathrm{ccc}(\mathrm{OCc} 5 \operatorname{cccc}(\mathrm{F}) \mathrm{c} 5) \mathrm{c}(\mathrm{Cl}) \mathrm{c} 4) \mathrm{c} 3 \mathrm{c} 2) \mathrm{cc} 1$ & 29 & * \\
\hline 1528 & $\mathrm{CN}(\mathrm{C}) \mathrm{CCCC}(=\mathrm{O}) \mathrm{Nc} 1 \mathrm{cccc}(-\mathrm{c} 2 \mathrm{c}(-\mathrm{c} 3 \mathrm{ccccc} 3) \mathrm{oc} 3 \mathrm{ncnc}(\mathrm{N}[\mathrm{C} @ \mathrm{H}](\mathrm{CO}) \mathrm{c} 4 \mathrm{ccccc} 4) \mathrm{c} 23) \mathrm{c} 1$ & 29 & $*$ \\
\hline 1529 & $\mathrm{O}=\mathrm{C}(/ \mathrm{C}=\mathrm{C} / \mathrm{CN} 1 \mathrm{CCS}(=\mathrm{O})(=\mathrm{O}) \mathrm{CC} 1) \mathrm{Nc} 1 \mathrm{cc} 2 \mathrm{c}(\mathrm{Nc} 3 \mathrm{ccc}(\mathrm{F}) \mathrm{c}(\mathrm{Cl}) \mathrm{c} 3) \mathrm{ncnc} 2 \mathrm{~s} 1$ & 29 & * \\
\hline 1530 & $\mathrm{CCNC}(=\mathrm{O}) \mathrm{Nc} 1 \mathrm{ccc} 2 \mathrm{ncnc}(\mathrm{Nc} 3 \operatorname{ccc}(\mathrm{Oc} 4 \operatorname{cccc}(\mathrm{C}(\mathrm{F})(\mathrm{F}) \mathrm{F}) \mathrm{c} 4) \mathrm{c}(\mathrm{Cl}) \mathrm{c} 3) \mathrm{c} 2 \mathrm{c} 1$ & 29 & * \\
\hline 1531 & $\mathrm{CCC} 1=\mathrm{C} 2 \mathrm{C}(\mathrm{Nc} 3 \mathrm{ccc} 4 \mathrm{c}(\mathrm{cnn} 4 \mathrm{Cc} 4 \mathrm{ccccc} 4) \mathrm{c} 3)=\mathrm{NC}=\mathrm{NC} 2 \mathrm{~N}=\mathrm{C} 1 \mathrm{NC}(=\mathrm{O}) \mathrm{OCC} 1 \mathrm{CCCNC} 1$ & 29 & * \\
\hline 1532 & $\operatorname{Brc1} 1 \mathrm{ccc}(\mathrm{Nc} 2 \mathrm{ncnc} 3 \mathrm{ccc} 4[\mathrm{nH}] \mathrm{cnc} 4 \mathrm{c} 23) \mathrm{c} 1$ & 29 & $*$ \\
\hline 1533 & $\mathrm{CC}(=0) \mathrm{Nc} 1 \mathrm{cc} 2 \mathrm{ncnc}(\mathrm{Nc} 3 \operatorname{cccc}(\mathrm{Br}) \mathrm{c} 3) \mathrm{c} 2 \mathrm{cn} 1$ & 29 & $*$ \\
\hline 1534 & $\mathrm{Clc} 1 \mathrm{cccc}(\mathrm{Nc} 2[\mathrm{nH}] \mathrm{cnc} 3 \mathrm{nc} 4 \mathrm{c}(\mathrm{c} 2-3) \mathrm{CCCC} 4) \mathrm{c} 1$ & 29 & * \\
\hline 1535 & $\mathrm{CN}(\mathrm{C}) \mathrm{c} 1 \mathrm{ccc}(\mathrm{Nc} 2[\mathrm{nH}] \mathrm{nc} 3 \mathrm{ncnc}(\mathrm{Nc} 4 \mathrm{cccc}(\mathrm{Cl}) \mathrm{c} 4) \mathrm{c} 23) \mathrm{cc} 1$ & 29 & * \\
\hline 1536 & $\mathrm{Cc} 1 \mathrm{cc}(\mathrm{C}(=\mathrm{O}) \mathrm{O})[\mathrm{nH}] \mathrm{c} 1 / \mathrm{C}=\mathrm{C} 1 \backslash \mathrm{C}(=\mathrm{O}) \mathrm{Nc} 2 \mathrm{ncnc}(\mathrm{Nc} 3 \mathrm{ccc}(\mathrm{F}) \mathrm{c}(\mathrm{Cl}) \mathrm{c} 3) \mathrm{c} 21$ & 29 & * \\
\hline 1537 & C[C@@H](Nc1ncnc2[nH]c(-c3ecc(Br)cc3)cc12)c1 ccc(F)cc1 & 29 & $*$ \\
\hline 1538 & Brc1 cccc(Nc2ncnc3ccc4nc[nH]c4c23)c1 & 29 & * \\
\hline 1539 & 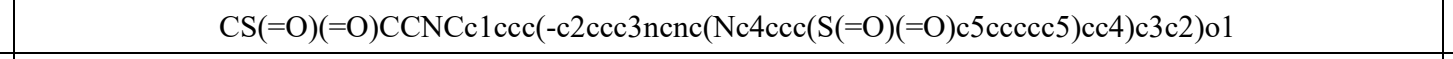 & 29 & $*$ \\
\hline 1540 & $\mathrm{CC}(\mathrm{C}) \mathrm{Oc} 1 \mathrm{cc} 2 \mathrm{ncnc}(\mathrm{Nc} 3 \mathrm{ccc}(\mathrm{F}) \mathrm{c}(\mathrm{Cl}) \mathrm{c} 3) \mathrm{c} 2 \mathrm{c} 2 \mathrm{c} 1 \mathrm{OCCO} 2$ & 29.1 & * \\
\hline 1541 & $\mathrm{C}=\mathrm{C}=\mathrm{CC}(=\mathrm{O}) \mathrm{Nc} 1 \mathrm{cc}(\mathrm{Nc} 2 \mathrm{nccc}(\mathrm{C} 3=\mathrm{CN}(\mathrm{C}) \mathrm{C} 4 \mathrm{C}=\mathrm{CC}=\mathrm{CC} 34) \mathrm{n} 2) \mathrm{c}(\mathrm{OC}) \mathrm{cc} 1 \mathrm{O}[\mathrm{C} @ \mathrm{H}] 1 \mathrm{CCOC} 1$ & 29.1 & $*$ \\
\hline 1542 & $\mathrm{C}=\mathrm{C}=\mathrm{CC}(=\mathrm{O}) \mathrm{Nc} 1 \mathrm{cc}(\mathrm{Nc} 2 \mathrm{nccc}(-\mathrm{c} 3 \mathrm{cn}(\mathrm{C}) \mathrm{c} 4 \mathrm{ccccc} 34) \mathrm{n} 2) \mathrm{c}(\mathrm{OC}) \mathrm{cc} 1 \mathrm{O}[\mathrm{C} @ \mathrm{H}] 1 \mathrm{CCOC} 1$ & 29.1 & * \\
\hline 1543 & Fc1 $1 \mathrm{ccc}(-\mathrm{c} 2 \mathrm{nc}(\mathrm{Nc} 3 \mathrm{cc}(\mathrm{Br}) \mathrm{cc} 4 \mathrm{cc}(-\mathrm{c} 5 \mathrm{cccc}(\mathrm{Cl}) \mathrm{c} 5) \mathrm{oc} 34) \mathrm{c} 3 \mathrm{cc}(\mathrm{Br}) \mathrm{ccc} 3 \mathrm{n} 2) \mathrm{cc} 1$ & 29.3 & $*$ \\
\hline 1544 & $\mathrm{Cc} 1 \mathrm{cc}(\mathrm{Nc} 2 \mathrm{ncc} 3 \mathrm{c}(\mathrm{n} 2) \mathrm{N}([\mathrm{C} @ \mathrm{H}] 2 \mathrm{CCN}(\mathrm{C}(=\mathrm{O}) \mathrm{C}(\mathrm{C})(\mathrm{C}) \mathrm{C}) \mathrm{C} 2) \mathrm{C}(=\mathrm{O}) \mathrm{N}(\mathrm{c} 2 \mathrm{ccccc} 2 \mathrm{Cl}) \mathrm{C} 3) \operatorname{ccc} 1 \mathrm{~N} 1 \mathrm{CCN}(\mathrm{C}) \mathrm{CC} 1$ & 29.4 & 7.53 \\
\hline
\end{tabular}




\begin{tabular}{|c|c|c|c|}
\hline 1545 & $\mathrm{C}=\mathrm{CC}(=\mathrm{O}) \mathrm{Nc} 1 \mathrm{ccc}(\mathrm{N} 2 \mathrm{C}(=\mathrm{O}) \mathrm{N}(\mathrm{C}) \mathrm{Cc} 3 \mathrm{cnc}(\mathrm{Nc} 4 \mathrm{ccc}(\mathrm{N} 5 \mathrm{CCCCC} 5) \mathrm{cc} 4 \mathrm{OC}) \mathrm{nc} 32) \mathrm{c} 1$ & 29.5 & 7.53 \\
\hline 1546 & $\mathrm{CC}(=\mathrm{O}) \mathrm{Nc} 1 \mathrm{c}(\mathrm{Br}) \mathrm{cccc} 1 \mathrm{Nc} 1 \mathrm{ncnc} 2 \mathrm{ccncc} 12$ & 29.51 & $*$ \\
\hline 1547 & $\mathrm{C}=\mathrm{C}=\mathrm{CC}(=\mathrm{O}) \mathrm{Nc} 1 \mathrm{cc}(\mathrm{Nc} 2 \mathrm{nccc}(-\mathrm{c} 3 \mathrm{cn}(\mathrm{C}) \mathrm{c} 4 \mathrm{cccc} 34) \mathrm{n} 2) \mathrm{c}(\mathrm{C}) \mathrm{cc} 1 \mathrm{~N}(\mathrm{C}) \mathrm{CCN}(\mathrm{C}) \mathrm{C}$ & 29.9 & $*$ \\
\hline 1548 & $\mathrm{Cc} 1 \mathrm{ncnc}(\mathrm{Nc} 2 \mathrm{ccc}(\mathrm{OCc} 3 \mathrm{cccc}(\mathrm{F}) \mathrm{c} 3) \mathrm{c}(\mathrm{Cl}) \mathrm{c} 2) \mathrm{c} 1 \mathrm{C} \# \mathrm{Cc} 1 \mathrm{ccc}(\mathrm{CN} 2 \mathrm{CCCC} 2) \mathrm{s} 1$ & 30 & 7.52 \\
\hline 1549 & $\mathrm{Cc} 1 \mathrm{ccc}(\mathrm{C}(=\mathrm{O}) \mathrm{Nc} 2 \operatorname{ccc}(\mathrm{CN} 3 \mathrm{CCN}(\mathrm{C}) \mathrm{CC} 3) \mathrm{c}(\mathrm{C}(\mathrm{F})(\mathrm{F}) \mathrm{F}) \mathrm{c} 2) \mathrm{cc} 1 \mathrm{NC}(=\mathrm{O}) \mathrm{c} 1 \mathrm{cnc} 2[\mathrm{nH}] \mathrm{ncc} 2 \mathrm{c} 1$ & 30 & 7.52 \\
\hline 1550 & $\mathrm{CACc} 1 \mathrm{ccc}(\mathrm{Nc} 2 \mathrm{ccnc} 3 \mathrm{cc}(\mathrm{OCCOC}) \mathrm{c}(\mathrm{OCCOC}) \mathrm{cc} 23) \mathrm{c} 1$ & 30 & 7.52 \\
\hline 1551 & $\mathrm{CCOc} 1 \mathrm{cc} 2 \mathrm{ncc}(\mathrm{C} \# \mathrm{~N}) \mathrm{c}(\mathrm{Nc} 3 \mathrm{ccc}(\mathrm{OCc} 4 \mathrm{ccccc} 4) \mathrm{c}(\mathrm{Cl}) \mathrm{c} 3) \mathrm{c} 2 \mathrm{cc} 1 \mathrm{NC}(=\mathrm{O}) / \mathrm{C}=\mathrm{C} / \mathrm{CN}(\mathrm{C}(\mathrm{C}) \mathrm{C}) \mathrm{C}(\mathrm{C}) \mathrm{C}$ & 30 & 7.52 \\
\hline 1552 & $\mathrm{O}=\mathrm{C}(\mathrm{O}[\mathrm{C} @ \mathrm{H}] 1 \mathrm{CN}[\mathrm{C} @ \mathrm{H}](\mathrm{C} \# \mathrm{Cc} 2 \mathrm{cc} 3 \mathrm{ncnc}(\mathrm{Nc} 4 \mathrm{ccc} 5 \mathrm{c}(\mathrm{cnn} 5 \mathrm{Cc} 5 \mathrm{cccc}(\mathrm{F}) \mathrm{c} 5) \mathrm{c} 4) \mathrm{c} 3 \mathrm{~s} 2) \mathrm{C} 1) \mathrm{N} 1 \mathrm{CCOCC} 1$ & 30 & 7.52 \\
\hline 1553 & $\mathrm{O}=\mathrm{C}(\mathrm{Nc} 1 \mathrm{cc} 2 \mathrm{c}(\mathrm{Nc} 3 \mathrm{ccc}(\mathrm{F}) \mathrm{c}(\mathrm{Cl}) \mathrm{c} 3) \mathrm{ncnc} 2 \mathrm{cc} 1 \mathrm{OCCCN} 1 \mathrm{CCOCC} 1) \mathrm{c} 1 \mathrm{cccc}(\mathrm{C}(\mathrm{F})(\mathrm{F}) \mathrm{F}) \mathrm{c} 1 \mathrm{~F}$ & 30 & 7.52 \\
\hline 1554 & $\mathrm{Nc} 1 \mathrm{ccc}(\mathrm{C} \# \mathrm{Cc} 2 \mathrm{cncnc} 2 \mathrm{Nc} 2 \mathrm{ccc}(\mathrm{OCc} 3 \operatorname{cccc}(\mathrm{F}) \mathrm{c} 3) \mathrm{c}(\mathrm{Cl}) \mathrm{c} 2) \mathrm{cc} 1$ & 30 & * \\
\hline 1555 & $\mathrm{COc} 1 \mathrm{cc} 2 \mathrm{ncnc}(\mathrm{Nc} 3 \mathrm{cccc}(\mathrm{Cl}) \mathrm{c} 3 \mathrm{~F}) \mathrm{c} 2 \mathrm{cc} 1 \mathrm{CN} 1 \mathrm{CCC}[\mathrm{C} @ \mathrm{H}] 1 \mathrm{C}(\mathrm{N})=\mathrm{O}$ & 30 & * \\
\hline 1556 & $\mathrm{COc} 1 \mathrm{cc} 2 \mathrm{ncnc}(\mathrm{Nc} 3 \operatorname{ccc}(\mathrm{Cl}) \mathrm{c} 3 \mathrm{~F}) \mathrm{c} 2 \mathrm{cc} 1 \mathrm{CN} 1 \mathrm{CCN}(\mathrm{C}) \mathrm{CC} 1 \mathrm{C}(\mathrm{N})=\mathrm{O}$ & 30 & $*$ \\
\hline 1557 & $\mathrm{CNC}(=\mathrm{O})[\mathrm{C} @ @ \mathrm{H}](\mathrm{C}) \mathrm{N}(\mathrm{C}) \mathrm{Cc} 1 \mathrm{cc} 2 \mathrm{c}(\mathrm{Nc} 3 \mathrm{ccc}(\mathrm{Cl}) \mathrm{c} 3 \mathrm{~F}) \mathrm{ncnc} 2 \mathrm{cc} 1 \mathrm{OC}$ & 30 & $*$ \\
\hline 1558 & $\mathrm{COC}[\mathrm{C} @ @ \mathrm{H}](\mathrm{C}(\mathrm{N})=\mathrm{O}) \mathrm{N}(\mathrm{C}) \mathrm{Cc} 1 \mathrm{cc} 2 \mathrm{c}(\mathrm{Nc} 3 \mathrm{cccc}(\mathrm{Cl}) \mathrm{c} 3 \mathrm{~F}) \mathrm{ncnc} 2 \mathrm{cc} 1 \mathrm{OC}$ & 30 & $*$ \\
\hline 1559 & $\mathrm{CCC} 1=\mathrm{C} 2 \mathrm{C}(\mathrm{Nc} 3 \operatorname{ccc} 4 \mathrm{c}(\operatorname{cnn} 4 \mathrm{Cc} 4 \operatorname{ccccc} 4) \mathrm{c} 3)=\mathrm{NC}=\mathrm{NC} 2 \mathrm{~N}=\mathrm{C} 1 \mathrm{NC}(=\mathrm{O}) \mathrm{OCC} 1 \mathrm{CCCCN} 1$ & 30 & $*$ \\
\hline 1560 & $\mathrm{Nc} 1 n \mathrm{ncn}(\mathrm{Nc} 2 \mathrm{ccc} 3 \mathrm{c}(\mathrm{cnn} 3 \mathrm{Cc} 3 \mathrm{cccc}(\mathrm{F}) \mathrm{c} 3) \mathrm{c} 2) \mathrm{c} 1 / \mathrm{C}=\mathrm{N} / \mathrm{N} 1 \mathrm{CCCCC} 1$ & 30 & $*$ \\
\hline 1561 & $\mathrm{O}=\mathrm{C}(\mathrm{OCCCc} 1 \mathrm{cccc} 1) \mathrm{c} 1 \mathrm{cc}(\mathrm{NCc} 2 \mathrm{cc}(\mathrm{O}) \mathrm{ccc} 2 \mathrm{O}) \mathrm{ccc} 1 \mathrm{O}$ & 30 & $*$ \\
\hline 1562 & COc1cce2ncnec2 1 & 30 & $*$ \\
\hline 1563 & $\mathrm{COc} 1 \mathrm{cc} 2 \mathrm{ncnc}(\mathrm{Nc} 3 \mathrm{ccc}(\mathrm{Cl}) \mathrm{c} 3) \mathrm{c} 2 \mathrm{cc} 1 \mathrm{OC} . \mathrm{Cl}$ & 30 & $*$ \\
\hline 1564 & $\mathrm{COc} 1 \mathrm{ccc}(\mathrm{Nc} 2[\mathrm{nH}] \mathrm{nc} 3 \mathrm{ncnc}(\mathrm{Nc} 4 \mathrm{cccc}(\mathrm{Cl}) \mathrm{c} 4) \mathrm{c} 23) \mathrm{cc} 1$ & 30 & $*$ \\
\hline 1565 & $\operatorname{COc} 1 \operatorname{ccc}(\mathrm{Nc} 2 \mathrm{ncc} 3 \mathrm{cc}(-\mathrm{c} 4 \mathrm{c}(\mathrm{Cl}) \operatorname{cccc} 4 \mathrm{Cl}) \mathrm{c}(=\mathrm{O}) \mathrm{n}(\mathrm{C}) \mathrm{c} 3 \mathrm{n} 2) \mathrm{c} 1$ & 30 & $*$ \\
\hline 1566 & $\mathrm{Fc} 1 \mathrm{ccc}(\mathrm{Nc} 2 \mathrm{ncnc} 3 \operatorname{ccc} c 23) \mathrm{cc} 1 \mathrm{Cl}$ & 30 & $*$ \\
\hline 1567 & $\mathrm{O}=\mathrm{C}(\mathrm{O}) \mathrm{COCc} 1 \mathrm{ccn} 2 \mathrm{ncnc}(\mathrm{Nc} 3 \mathrm{ccc} 4 \mathrm{c}(\mathrm{cnn} 4 \mathrm{Cc} 4 \mathrm{cccc}(\mathrm{F}) \mathrm{c} 4) \mathrm{c} 3) \mathrm{c} 12$ & 30 & $*$ \\
\hline 1568 & $\mathrm{c} 1 \mathrm{cc}(\mathrm{Nc} 2 \mathrm{ccc} 3[\mathrm{nH}] \mathrm{ccc} 3 \mathrm{c} 2) \mathrm{c} 2 \mathrm{sc}(-\mathrm{c} 3 \mathrm{ccc}(\mathrm{CN} 4 \mathrm{CCOCC} 4) \mathrm{cc} 3) \mathrm{cc} 2 \mathrm{n} 1$ & 30 & $*$ \\
\hline 1569 & $\mathrm{Nc} 1 \mathrm{ccc}(-\mathrm{c} 2 \mathrm{cc} 3 \mathrm{c}(\mathrm{Nc} 4 \mathrm{cccc}(\mathrm{N}) \mathrm{c} 4) \mathrm{ncnc} 3 \mathrm{o} 2) \mathrm{cc} 1$ & 30 & $*$ \\
\hline 1570 & $\mathrm{COc} 1 \mathrm{cc} 2 \mathrm{ncnc}(\mathrm{Nc} 3 \operatorname{ccc}(\mathrm{Cl}) \mathrm{c} 3 \mathrm{~F}) \mathrm{c} 2 \mathrm{cc} 1 \mathrm{CNC}(=\mathrm{O}) \mathrm{C} 1 \mathrm{CN}(\mathrm{C}) \mathrm{CCN} 1 \mathrm{C}$ & 30 & $*$ \\
\hline 1571 & $\mathrm{C}=\mathrm{CC}(=\mathrm{O}) \mathrm{Nc} 1 \mathrm{cc}(\mathrm{Nc} 2 \mathrm{n}[\mathrm{nH}] \mathrm{c} 3 \mathrm{cc}(-\mathrm{c} 4 \mathrm{ccncc} 4) \mathrm{ccc} 23) \mathrm{c}(\mathrm{OC}) \mathrm{cc} 1 \mathrm{~N}(\mathrm{C}) \mathrm{CCN}(\mathrm{C}) \mathrm{C}$ & 30 & $*$ \\
\hline 1572 & $\mathrm{CN}(\mathrm{C})[\mathrm{C} @ @ \mathrm{H}](\mathrm{CS}(\mathrm{C})(=\mathrm{O})=\mathrm{O}) \mathrm{c} 1 \mathrm{ccc}(-\mathrm{c} 2 \mathrm{ccc} 3 \mathrm{ncnc}(\mathrm{Nc} 4 \mathrm{ccc}(\mathrm{OCc} 5 \mathrm{ccc}(\mathrm{F}) \mathrm{c} 5) \mathrm{c}(\mathrm{Cl}) \mathrm{c} 4) \mathrm{c} 3 \mathrm{c} 2) \mathrm{o} 1$ & 30.4 & $*$ \\
\hline 1573 & $\mathrm{C}=\mathrm{C}=\mathrm{CC}(=\mathrm{O}) \mathrm{Nc} 1 \mathrm{cc}(\mathrm{Nc} 2 \mathrm{nccc}(\mathrm{C} 3=\mathrm{CN}(\mathrm{C}) \mathrm{C} 4 \mathrm{C}=\mathrm{CC}=\mathrm{CC} 34) \mathrm{n} 2) \mathrm{c}(\mathrm{OC}) \mathrm{cc} 1 \mathrm{OCCN} 1 \mathrm{CCOCC} 1$ & 30.4 & * \\
\hline 1574 & Oc1 $1 \operatorname{ccc}(-\mathrm{c} 2 \mathrm{nc}(-\mathrm{c} 3 \operatorname{ccc}(\mathrm{F}) \mathrm{cc} 3) \mathrm{c}(-\mathrm{c} 3 \operatorname{ccnc} 4[\mathrm{nH}] \mathrm{c}(-\mathrm{c} 5 \operatorname{ccccc} 5) \operatorname{cc} 34)[\mathrm{nH}] 2) \mathrm{c} 1$ & 30.4 & $*$ \\
\hline 1575 & $\mathrm{C}=\mathrm{C}=\mathrm{CC}(=\mathrm{O}) \mathrm{Nc} 1 \mathrm{cc}(\mathrm{Nc} 2 \mathrm{nccc}(-\mathrm{c} 3 \mathrm{cn}(\mathrm{C}) \mathrm{c} 4 \mathrm{cccc} 34) \mathrm{n} 2) \mathrm{c}(\mathrm{OC}) \mathrm{cc} 1 \mathrm{OCCN} 1 \mathrm{CCOCC} 1$ & 30.4 & $*$ \\
\hline 1576 & $\mathrm{COc} 1 \mathrm{cc} 2 \mathrm{c}(\mathrm{Nc} 3 \mathrm{ccc}(\mathrm{OCc} 4 \mathrm{cccc}(\mathrm{F}) \mathrm{c} 4) \mathrm{c}(\mathrm{Cl}) \mathrm{c} 3) \mathrm{ncnc} 2 \mathrm{cc} 1 \mathrm{OCCCn} 1 \mathrm{ccnc} 1[\mathrm{~N}+](=\mathrm{O})[\mathrm{O}-]$ & 30.5 & 7.52 \\
\hline 1577 & $\mathrm{COc} 1 \operatorname{ccc}(\mathrm{CNC}(=\mathrm{O}) \mathrm{c} 2 \operatorname{cccc} 2 \mathrm{NC}(=\mathrm{O}) \mathrm{c} 2 \operatorname{ccco} 2) \mathrm{cc} 1$ & 30.5 & $*$ \\
\hline 1578 & $\mathrm{C}=\mathrm{C}=\mathrm{CC}(=\mathrm{O}) \mathrm{Nc} 1 \mathrm{cc}(\mathrm{Nc} 2 \mathrm{nccc}(\mathrm{C} 3=\mathrm{CN}(\mathrm{C}) \mathrm{C} 4 \mathrm{C}=\mathrm{C}(\mathrm{Cl}) \mathrm{C}=\mathrm{CC} 34) \mathrm{n} 2) \mathrm{c}(\mathrm{OC}) \mathrm{cc} 1 \mathrm{~N}(\mathrm{C}) \mathrm{CCN}(\mathrm{C}) \mathrm{C}$ & 30.6 & $*$ \\
\hline 1579 & $\mathrm{C}=\mathrm{C}=\mathrm{CC}(=\mathrm{O}) \mathrm{Nc} 1 \mathrm{cc}(\mathrm{Nc} 2 \mathrm{nccc}(-\mathrm{c} 3 \operatorname{cn}(\mathrm{C}) \mathrm{c} 4 \mathrm{cc}(\mathrm{Cl}) \mathrm{ccc} 34) \mathrm{n} 2) \mathrm{c}(\mathrm{OC}) \operatorname{cc} 1 \mathrm{~N}(\mathrm{C}) \mathrm{CCN}(\mathrm{C}) \mathrm{C}$ & 30.6 & $*$ \\
\hline 1580 & $\begin{array}{c}\mathrm{C} \# \mathrm{Cc} 1 \mathrm{cccc}(\mathrm{Nc} 2 \mathrm{ncnc} 3 \mathrm{cc}(\mathrm{OCCOC}(=\mathrm{O}) \mathrm{CC} 4=\mathrm{C}(\mathrm{C}) / \mathrm{C}(=\mathrm{C} \backslash \mathrm{c} 5 \mathrm{ccc}([\mathrm{S}+](\mathrm{C})[\mathrm{O}-]) \mathrm{cc} 5) \mathrm{c} 5 \mathrm{ccc}(\mathrm{F}) \mathrm{cc} 54) \mathrm{c}(\mathrm{OCCOC}) \mathrm{cc} 23) \mathrm{c} \\
1\end{array}$ & 31 & 7.51 \\
\hline 1581 & $\mathrm{CC} 1(\mathrm{C}) \mathrm{CC}(\mathrm{C}(=\mathrm{O}) \mathrm{Nc} 2 \mathrm{ccc} 3 \mathrm{ncnc}(\mathrm{Nc} 4 \mathrm{cccc}(\mathrm{Br}) \mathrm{c} 4) \mathrm{c} 3 \mathrm{c} 2) \mathrm{CC}(\mathrm{C})(\mathrm{C}) \mathrm{N} 1[\mathrm{O}]$ & 31 & 7.51 \\
\hline 1582 & $\mathrm{CCOc} 1 \mathrm{cc} 2 \mathrm{ncc}(\mathrm{C \# N}) \mathrm{c}(\mathrm{Nc} 3 \operatorname{ccc}(\mathrm{OCc} 4 \mathrm{ccccc} 4 \mathrm{OC}) \mathrm{c}(\mathrm{Cl}) \mathrm{c} 3) \mathrm{c} 2 \mathrm{cc} 1 \mathrm{NC}(=\mathrm{O}) / \mathrm{C}=\mathrm{C} / \mathrm{CN}(\mathrm{C}) \mathrm{C}$ & 31 & 7.51 \\
\hline 1583 & $\mathrm{CCOc} 1 \mathrm{cc} 2 \mathrm{ncc}(\mathrm{C \# N}) \mathrm{c}(\mathrm{Nc} 3 \mathrm{ccc}(\mathrm{OCc} 4 \mathrm{ccccc} 4) \mathrm{c}(\mathrm{Cl}) \mathrm{c} 3) \mathrm{c} 2 \mathrm{cc} 1 \mathrm{NC}(=\mathrm{O}) / \mathrm{C}=\mathrm{C} / \mathrm{CN} 1 \mathrm{CCCCC} 1$ & 31 & 7.51 \\
\hline 1584 & $\operatorname{COC}(=\mathrm{O}) \mathrm{CCCC}(=\mathrm{O}) \mathrm{Nc} 1 \mathrm{cccc}(\mathrm{C} \# \mathrm{Cc} 2 \mathrm{cncnc} 2 \mathrm{Nc} 2 \operatorname{ccc}(\mathrm{OCc} 3 \operatorname{cccc}(\mathrm{F}) \mathrm{c} 3) \mathrm{c}(\mathrm{Cl}) \mathrm{c} 2) \mathrm{c} 1$ & 31 & $*$ \\
\hline 1585 & $\operatorname{CCNC}(=\mathrm{O}) \mathrm{Nc} 1 \mathrm{ccc}(\mathrm{C}(=\mathrm{O}) \mathrm{Nc} 2 \mathrm{ccc} 3 \mathrm{ncnc}(\mathrm{Nc} 4 \mathrm{ccc}(\mathrm{F}) \mathrm{c}(\mathrm{Cl}) \mathrm{c} 4) \mathrm{c} 3 \mathrm{c} 2) \mathrm{cc} 1$ & 31 & $*$ \\
\hline 1586 & $\mathrm{COC}[\mathrm{C} @ \mathrm{H}] 1 \mathrm{CCCN} 1 / \mathrm{N}=\mathrm{C} / \mathrm{c} 1 \mathrm{c}(\mathrm{N}) \mathrm{ncnc} 1 \mathrm{Nc} 1 \mathrm{ccc} 2 \mathrm{c}(\mathrm{cnn} 2 \mathrm{Cc} 2 \mathrm{cccc}(\mathrm{F}) \mathrm{c} 2) \mathrm{c} 1$ & 31 & $*$ \\
\hline
\end{tabular}




\begin{tabular}{|c|c|c|c|}
\hline 1587 & $\operatorname{CCS}(=\mathrm{O})(=\mathrm{O}) \mathrm{CC}(=\mathrm{O}) \mathrm{NCCn} 1 \mathrm{ccc} 2 \mathrm{ncnc}(\mathrm{Nc} 3 \operatorname{ccc}(\mathrm{Oc} 4 \operatorname{ccc}(\mathrm{C}(\mathrm{F})(\mathrm{F}) \mathrm{F}) \mathrm{c} 4) \mathrm{c}(\mathrm{Cl}) \mathrm{c} 3) \mathrm{c} 21$ & 31 & $*$ \\
\hline 1588 & $\operatorname{Brc} 1 \operatorname{ccc}(\mathrm{Nc} 2[\mathrm{nH}] \mathrm{cnc} 3 \mathrm{nc} 4 \mathrm{ccccc} 4 \mathrm{c} 2-3) \mathrm{c} 1$ & 31 & $*$ \\
\hline 1589 & $\operatorname{Brc} 1 \operatorname{ccc}(\mathrm{Nc} 2 \mathrm{ncnc} 3[\mathrm{nH}] \mathrm{c} 4 \mathrm{ccccc} 4 \mathrm{c} 23) \mathrm{c} 1$ & 31 & * \\
\hline 1590 & $\mathrm{O}=\mathrm{S}(\mathrm{CCO}) \mathrm{CCn} 1 \mathrm{ccc} 2 \mathrm{ncnc}(\mathrm{Nc} 3 \operatorname{ccc}(\mathrm{Oc} 4 \mathrm{cccc}(\mathrm{C}(\mathrm{F})(\mathrm{F}) \mathrm{F}) \mathrm{c} 4) \mathrm{c}(\mathrm{Cl}) \mathrm{c} 3) \mathrm{c} 21$ & 31 & $*$ \\
\hline 1591 & $\mathrm{COc} 1 \mathrm{ccc}(\mathrm{Nc} 2 \mathrm{cc}(\mathrm{Oc} 3 \operatorname{ccc} 4[\mathrm{nH}] \operatorname{ccc} 4 \mathrm{c} 3) \mathrm{ncn} 2) \mathrm{cc} 1 \mathrm{~N} 1 \mathrm{CCOCC} 1$ & 31 & $*$ \\
\hline 1592 & Fc1 $1 \mathrm{ccc}(-\mathrm{c} 2 \mathrm{nc}(\mathrm{Nc} 3 \mathrm{cc}(\mathrm{Br}) \mathrm{cc} 4 \mathrm{cc}(-\mathrm{c} 5 \mathrm{ccc}(\mathrm{OC}(\mathrm{F})(\mathrm{F}) \mathrm{F}) \mathrm{cc} 5) \mathrm{oc} 34) \mathrm{c} 3 \mathrm{cc}(\mathrm{Br}) \mathrm{ccc} 3 \mathrm{n} 2) \mathrm{cc} 1$ & 31.1 & * \\
\hline 1593 & $\mathrm{O}=\mathrm{C}(\mathrm{Nc} 1 \mathrm{ccccc} 1 \mathrm{C}(=\mathrm{O}) \mathrm{N} / \mathrm{N}=\mathrm{C} / \mathrm{c} 1 \operatorname{ccc}(\mathrm{O}) \operatorname{cc} 1 \mathrm{O}) \mathrm{c} 1 \mathrm{ccco} 1$ & 31.2 & $*$ \\
\hline 1594 & $\begin{array}{c}\text { COc1ccc }(- \\
\mathrm{c} 2 \mathrm{c} 3 \mathrm{c} 4 \mathrm{cc}(\mathrm{OCCCN}(\mathrm{C}) \mathrm{C}) \mathrm{c}(\mathrm{OCCCN}(\mathrm{C}) \mathrm{C}) \mathrm{cc} 4 \mathrm{oc}(=\mathrm{O}) \mathrm{c} 3 \mathrm{n} 3 \operatorname{ccc} 4 \mathrm{cc}(\mathrm{O}) \mathrm{c}(\mathrm{OC}) \mathrm{cc} 4 \mathrm{c} 23) \mathrm{cc} 1 \mathrm{O} . \mathrm{O}=\mathrm{C}(\mathrm{O}) \mathrm{C}(\mathrm{F})(\mathrm{F}) \mathrm{F}\end{array}$ & 31.8 & $*$ \\
\hline 1595 & $\mathrm{Fc} 1 \mathrm{ccc}(\mathrm{Nc} 2 \mathrm{ncnc} 3 \mathrm{ccc}(-\mathrm{c} 4 \mathrm{cnn}(\mathrm{C} 5 \mathrm{CCNCC} 5) \mathrm{c} 4) \mathrm{cc} 23) \mathrm{cc} 1 \mathrm{Cl}$ & 31.9 & 7.50 \\
\hline 1596 & $\mathrm{C \# Cc1} \operatorname{cccc}(\mathrm{Nc} 2 \mathrm{ncnc} 3 \mathrm{cc}(\mathrm{OCCOC}(=\mathrm{O}) \mathrm{c} 4 \mathrm{ccc}(\mathrm{C}(=\mathrm{O}) \mathrm{Nc} 5 \operatorname{ccc} 6 \mathrm{c}(\mathrm{c} 5) \mathrm{C}(\mathrm{C})(\mathrm{C}) \mathrm{CCC} 6(\mathrm{C}) \mathrm{C}) \mathrm{cc} 4) \mathrm{c}(\mathrm{OCCOC}) \mathrm{cc} 23) \mathrm{c} 1$ & 32 & 7.49 \\
\hline 1597 & $\mathrm{COc} 1 \mathrm{cc} 2 \mathrm{ncc}(\mathrm{C \# N}) \mathrm{c}(\mathrm{Nc} 3 \operatorname{ccc}(\mathrm{Sc} 4 \mathrm{ncc}(-\mathrm{c} 5 \operatorname{ccccc} 5) \mathrm{s} 4) \mathrm{c}(\mathrm{Cl}) \mathrm{c} 3) \mathrm{c} 2 \mathrm{cc} 1 \mathrm{NC}(=\mathrm{O}) / \mathrm{C}=\mathrm{C} / \mathrm{CN}(\mathrm{C}) \mathrm{C}$ & 32 & 7.49 \\
\hline 1598 & $\mathrm{Nc} 1 \mathrm{nccc}(\mathrm{C} \# \mathrm{Cc} 2 \mathrm{cncnc} 2 \mathrm{Nc} 2 \mathrm{ccc}(\mathrm{OCc} 3 \mathrm{cccc}(\mathrm{F}) \mathrm{c} 3) \mathrm{c}(\mathrm{Cl}) \mathrm{c} 2) \mathrm{n} 1$ & 32 & $*$ \\
\hline 1599 & $\mathrm{CCN}(\mathrm{CC}) \mathrm{CCCNC}(=\mathrm{O}) \mathrm{Nc} 1 \mathrm{cc} 2 \mathrm{c}(\mathrm{Nc} 3 \mathrm{ccc}(\mathrm{F}) \mathrm{c}(\mathrm{Cl}) \mathrm{c} 3) \mathrm{ncnc} 2 \mathrm{cc} 1 \mathrm{O}[\mathrm{C} @ \mathrm{H}] 1 \mathrm{CCOC} 1$ & 32 & * \\
\hline 1600 & $\mathrm{CCNC}(=\mathrm{O}) \mathrm{O}[\mathrm{C} @ \mathrm{H}] 1 \mathrm{CN}[\mathrm{C} @ @ \mathrm{H}](\mathrm{C} \# \mathrm{Cc} 2 \mathrm{cc} 3 \mathrm{ncnc}(\mathrm{Nc} 4 \mathrm{ccc}(\mathrm{OCc} 5 \mathrm{cccc}(\mathrm{F}) \mathrm{c} 5) \mathrm{c}(\mathrm{Cl}) \mathrm{c} 4) \mathrm{c} 3 \mathrm{~s} 2) \mathrm{C} 1$ & 32 & * \\
\hline 1601 & $\mathrm{CCNC}(=\mathrm{O}) \mathrm{O}[\mathrm{C} @ \mathrm{H}] 1 \mathrm{CN}[\mathrm{C} @ \mathrm{H}](\mathrm{C} \# \mathrm{Cc} 2 \mathrm{cc} 3 \mathrm{ncnc}(\mathrm{Nc} 4 \mathrm{ccc}(\mathrm{OCc} 5 \mathrm{cccc}(\mathrm{F}) \mathrm{c} 5) \mathrm{c}(\mathrm{Cl}) \mathrm{c} 4) \mathrm{c} 3 \mathrm{~s} 2) \mathrm{C} 1$ & 32 & $*$ \\
\hline 1602 & $\mathrm{CN}(\mathrm{C}) \mathrm{c} 1 \mathrm{ccc} 2 \mathrm{ncnc}(\mathrm{Nc} 3 \operatorname{cccc}(\mathrm{Br}) \mathrm{c} 3) \mathrm{c} 2 \mathrm{n} 1$ & 32 & $*$ \\
\hline 1603 & $\mathrm{NC} 1 \mathrm{CCN}(\mathrm{Cc} 2 \mathrm{ccn} 3 \mathrm{ncnc}(\mathrm{Nc} 4 \mathrm{ccc}(\mathrm{OCc} 5 \mathrm{cnccn} 5) \mathrm{c}(\mathrm{Cl}) \mathrm{c} 4) \mathrm{c} 23) \mathrm{CC} 1$ & 32 & * \\
\hline 1604 & $\mathrm{Fc} 1 \mathrm{cccc}(\mathrm{COc} 2 \mathrm{ccc}(\mathrm{Nc} 3 \mathrm{ncnc} 4 \mathrm{nn} 5 \mathrm{ccccc} 5 \mathrm{c} 34) \mathrm{cc} 2 \mathrm{Cl}) \mathrm{c} 1$ & 32 & * \\
\hline 1605 & $\mathrm{CC}(\mathrm{C}) \mathrm{CO} / \mathrm{N}=\mathrm{C} / \mathrm{c} 1 \mathrm{c}(\mathrm{N}) \mathrm{ncnc} 1 \mathrm{Nc} 1 \mathrm{ccc} 2 \mathrm{c}(\mathrm{cnn} 2 \mathrm{Cc} 2 \mathrm{cccc}(\mathrm{F}) \mathrm{c} 2) \mathrm{c} 1$ & 32 & $*$ \\
\hline 1606 & $\mathrm{CCN}(\mathrm{CC}) \mathrm{CCCNN}(\mathrm{NCCCN}(\mathrm{CC}) \mathrm{CC}) \mathrm{C}(=\mathrm{O}) \mathrm{Nc} 1 \mathrm{cc} 2 \mathrm{c}(\mathrm{Nc} 3 \mathrm{ccc}(\mathrm{F}) \mathrm{c}(\mathrm{Cl}) \mathrm{c} 3) \mathrm{ncnc} 2 \mathrm{cc} 1 \mathrm{O}[\mathrm{C} @ \mathrm{H}] 1 \mathrm{CCOC} 1$ & 32 & $*$ \\
\hline 1607 & $\mathrm{O}=\mathrm{C}(\mathrm{CN} 1 \mathrm{CCCC} 1) \mathrm{Nc} 1 \mathrm{ccc} 2 \mathrm{ncnc}(\mathrm{Nc} 3 \mathrm{ccc}(\mathrm{Cl}) \mathrm{cc} 3) \mathrm{c} 2 \mathrm{c} 1$ & 32 & $*$ \\
\hline 1608 & $\mathrm{CN} 1 \mathrm{CCN}(\mathrm{CC}(=\mathrm{O}) \mathrm{Nc} 2 \mathrm{ccc} 3 \mathrm{ncnc}(\mathrm{Nc} 4 \mathrm{cccc}(\mathrm{Br}) \mathrm{c} 4) \mathrm{c} 3 \mathrm{c} 2) \mathrm{CC} 1$ & 32 & $*$ \\
\hline 1609 & $\mathrm{O}=\mathrm{C}(\mathrm{Nc} 1 \mathrm{cccc}(\mathrm{Cl}) \mathrm{c} 1) \mathrm{c} 1 \mathrm{c}(\mathrm{O}) \operatorname{cc}(\mathrm{O}) \mathrm{cc} 1 \mathrm{O}$ & 32 & * \\
\hline 1610 & $\mathrm{C}=\mathrm{CC}(=\mathrm{O}) \mathrm{Nc} 1 \mathrm{ccc}(\mathrm{OC}) \mathrm{c}(\mathrm{Nc} 2 \mathrm{cc}(-\mathrm{c} 3[\mathrm{nH}] \mathrm{c}(\mathrm{SC}) \mathrm{nc} 3 \mathrm{C}) \mathrm{ccn} 2) \mathrm{c} 1$ & 32 & $*$ \\
\hline 1611 & $\mathrm{c} 1 \mathrm{ccc} 2 \mathrm{c}(\mathrm{c} 1) \mathrm{CCN} 2 \mathrm{c} 1 \mathrm{ncnc} 2 \mathrm{cc} 3 \mathrm{c}(\mathrm{cc} 12) \mathrm{ncn} 3 \mathrm{CCN} 1 \mathrm{CCCC} 1$ & 32 & $*$ \\
\hline 1612 & $\mathrm{C} \# \mathrm{Cc} 1 \mathrm{cccc}(\mathrm{Nc} 2 \mathrm{ncnc} 3 \mathrm{cc}(\mathrm{O}[\mathrm{C} @ \mathrm{H}] 4 \mathrm{CCOC} 4) \mathrm{c}(\mathrm{NC}(=\mathrm{O}) \mathrm{C}=\mathrm{C}) \mathrm{cc} 23) \mathrm{c} 1$ & 32.2 & $*$ \\
\hline 1613 & $\mathrm{O}=\mathrm{C}(\mathrm{Nc} 1 \mathrm{ccc} 2 \mathrm{ncnc}(\mathrm{Nc} 3 \mathrm{cccc}(\mathrm{Cl}) \mathrm{c} 3) \mathrm{c} 2 \mathrm{c} 1) \mathrm{C} 1 \mathrm{CCC} 2(\mathrm{CC} 1) \mathrm{OOC} 1(\mathrm{O} 2) \mathrm{C} 2 \mathrm{CC} 3 \mathrm{CC}(\mathrm{C} 2) \mathrm{CC} 1 \mathrm{C} 3$ & 32.35 & $*$ \\
\hline 1614 & $\mathrm{C}=\mathrm{CCCCCOc} 1 \mathrm{cc} 2 \mathrm{c}(\mathrm{Nc} 3 \mathrm{ccc}(\mathrm{F}) \mathrm{c}(\mathrm{Cl}) \mathrm{c} 3) \mathrm{ncnc} 2 \mathrm{cc} 1 \mathrm{OC}$ & 32.6 & $*$ \\
\hline 1615 & 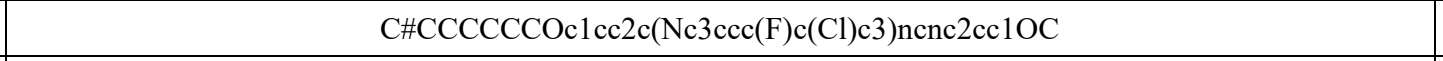 & 32.7 & $*$ \\
\hline 1616 & $\mathrm{Cc} 1 \mathrm{ccc}(\mathrm{C}(=\mathrm{O}) \mathrm{Nc} 2 \mathrm{ccc}(\mathrm{CN} 3 \mathrm{CCN}(\mathrm{C}) \mathrm{CC} 3) \mathrm{c}(\mathrm{C}(\mathrm{F})(\mathrm{F}) \mathrm{F}) \mathrm{c} 2) \mathrm{cc} 1 \mathrm{NC}(=\mathrm{O}) \mathrm{c} 1 \mathrm{cnc}(\mathrm{NC} 2 \mathrm{CCCC} 2) \mathrm{nc} 1$ & 33 & 7.48 \\
\hline 1617 & 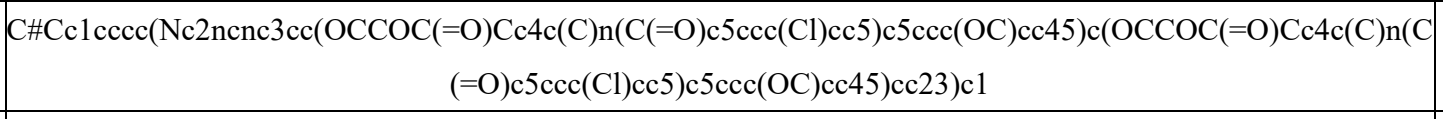 & 33 & 7.48 \\
\hline 1618 & $\mathrm{O}=\mathrm{C}(\mathrm{O}[\mathrm{C} @ \mathrm{H}] 1 \mathrm{CN}[\mathrm{C} @ \mathrm{H}](\mathrm{C} \# \mathrm{Cc} 2 \mathrm{cc} 3 \mathrm{ncnc}(\mathrm{Nc} 4 \mathrm{ccc} 5 \mathrm{c}(\mathrm{cnn} 5 \mathrm{Cc} 5 \mathrm{cc}(\mathrm{F}) \mathrm{ccc} 5 \mathrm{~F}) \mathrm{c} 4) \mathrm{c} 3 \mathrm{~s} 2) \mathrm{C} 1) \mathrm{N} 1 \mathrm{CCOCC} 1$ & 33 & 7.48 \\
\hline 1619 & $\mathrm{OCc} 1 \mathrm{ccc}(\mathrm{C \# Cc} 2 \mathrm{cncnc} 2 \mathrm{Nc} 2 \operatorname{ccc}(\mathrm{OCc} 3 \operatorname{ccc}(\mathrm{F}) \mathrm{c} 3) \mathrm{c}(\mathrm{Cl}) \mathrm{c} 2) \mathrm{o} 1$ & 33 & $*$ \\
\hline 1620 & $\mathrm{Nc} 1 \mathrm{ccccc} 1 \mathrm{NC}(=\mathrm{O}) \mathrm{c} 1 \mathrm{ccc}(\mathrm{COc} 2 \mathrm{ccc} 3 \mathrm{ncnc}(\mathrm{Nc} 4 \mathrm{cccc}(\mathrm{Br}) \mathrm{c} 4) \mathrm{c} 3 \mathrm{c} 2) \mathrm{cc} 1$ & 33 & $*$ \\
\hline 1621 & COc1cc2ncnc(C\#C[C@@] $(\mathrm{C})(\mathrm{Cc} 3 \operatorname{cccc} 3) \mathrm{N} 3 \mathrm{CCC}(\mathrm{C}(=\mathrm{O}) \mathrm{O}) \mathrm{CC} 3) \mathrm{c} 2 \mathrm{cc} 1 \mathrm{OC}$ & 33 & $*$ \\
\hline 1622 & Fc1 $1 \mathrm{ccc}(\mathrm{Cn} 2 \mathrm{ncc} 3 \mathrm{cc}(\mathrm{Nc} 4 \mathrm{ncnn} 5 \mathrm{ccc}(\mathrm{CN} 6 \mathrm{CCCNCC} 6) \mathrm{c} 45) \operatorname{ccc} 32) \mathrm{c} 1$ & 33 & * \\
\hline 1623 & $\mathrm{CC}(\mathrm{C})(\mathrm{C}) \mathrm{NC}(=\mathrm{O}) \mathrm{c} 1 \mathrm{cccc}(\mathrm{Oc} 2 \mathrm{ccc}(\mathrm{Nc} 3 \mathrm{ncnc} 4 \mathrm{ccn}(\mathrm{CCO}) \mathrm{c} 34) \mathrm{cc} 2 \mathrm{Cl}) \mathrm{c} 1$ & 33 & * \\
\hline 1624 & $\mathrm{CO} / \mathrm{N}=\mathrm{C} / \mathrm{c} 1 \mathrm{c}(\mathrm{N}) \mathrm{ncnc} 1 \mathrm{Nc} 1 \mathrm{ccc}(\mathrm{OCc} 2 \mathrm{cc}(\mathrm{F}) \mathrm{cc}(\mathrm{F}) \mathrm{c} 2) \mathrm{c}(\mathrm{Cl}) \mathrm{c} 1$ & 33 & $*$ \\
\hline 1625 & $\mathrm{Nc} 1 \mathrm{ccc}(-\mathrm{c} 2 \mathrm{nn}(\mathrm{C} 3 \mathrm{CCCC} 3) \mathrm{c} 3 \mathrm{ncnc}(\mathrm{N}) \mathrm{c} 23) \mathrm{cc} 1 \mathrm{O}$ & 33 & $*$ \\
\hline 1626 & $\mathrm{C}[\mathrm{C} @ @ \mathrm{H}](\mathrm{Nc} 1 \mathrm{ncnc} 2[\mathrm{nH}] \mathrm{c}(-\mathrm{c} 3 \mathrm{ccccc} 3) \mathrm{cc} 12) \mathrm{c} 1 \mathrm{ccc}(\mathrm{F}) \mathrm{cc} 1$ & 33 & $*$ \\
\hline 1627 & OCCCCCn1 ccc2ncnc(Nc3ecc(Oc4cecc(C(F)(F)F)c4)c $(\mathrm{Cl}) \mathrm{c} 3) \mathrm{c} 21$ & 33 & $*$ \\
\hline
\end{tabular}




\begin{tabular}{|c|c|c|c|}
\hline 1628 & $\mathrm{COc} 1 \mathrm{cc} 2 \mathrm{ncnc}(\mathrm{C \# CC}(\mathrm{C})(\mathrm{Cc} 3 \operatorname{ccccc} 3) \mathrm{N} 3 \mathrm{CCC}(\mathrm{C}(=\mathrm{O}) \mathrm{O}) \mathrm{CC} 3) \mathrm{c} 2 \mathrm{cc} 1 \mathrm{OC}$ & 33 & $*$ \\
\hline 1629 & $\mathrm{COc} 1 \mathrm{cc}(\mathrm{Nc} 2 \mathrm{nccc}(\mathrm{N}(\mathrm{C}) \mathrm{c} 3 \mathrm{ccc} 4[\mathrm{nH}] \operatorname{ccc} 4 \mathrm{c} 3) \mathrm{n} 2) \mathrm{cc}(\mathrm{N} 2 \mathrm{CCOCC} 2) \mathrm{c} 1$ & 33 & $*$ \\
\hline 1630 & $\mathrm{C}=\mathrm{CC}(=\mathrm{O}) \mathrm{Nc} 1 \mathrm{cc}(\mathrm{Nc} 2 \mathrm{n}[\mathrm{nH}] \mathrm{c} 3 \operatorname{ccc}(-\mathrm{c} 4 \mathrm{ccc} 5 \mathrm{cccc} 45) \operatorname{cc} 23) \mathrm{c}(\mathrm{OC}) \mathrm{cc} 1 \mathrm{~N}(\mathrm{C}) \mathrm{CCN}(\mathrm{C}) \mathrm{C}$ & 33 & $*$ \\
\hline 1631 & $\mathrm{CCC}(=\mathrm{O}) \mathrm{NCCSc} 1 \mathrm{nc}(-\mathrm{c} 2 \mathrm{ccc}(\mathrm{F}) \mathrm{cc} 2) \mathrm{c}(-\mathrm{c} 2 \mathrm{ccnc}(\mathrm{Nc} 3 \operatorname{cccc} 3) \mathrm{c} 2)[\mathrm{nH}] 1$ & 33 & * \\
\hline 1632 & $\mathrm{CCC} / \mathrm{C}=\mathrm{C} / \mathrm{C}(=\mathrm{O}) \mathrm{Nc} 1 \mathrm{cc} 2 \mathrm{c}(\mathrm{N} 3 \mathrm{CCC} 4 \mathrm{ccccc} 43) \mathrm{ncnc} 2 \mathrm{cc} 1 \mathrm{OC}$ & 33 & $*$ \\
\hline 1633 & $\mathrm{C}=\mathrm{CC}(=\mathrm{O}) \mathrm{Nc} 1 \mathrm{cc}(\mathrm{Cl}) \mathrm{cc}(-\mathrm{n} 2 \mathrm{c}(=\mathrm{O}) \mathrm{cc}(\mathrm{C}) \mathrm{c} 3 \mathrm{cnc}(\mathrm{Nc} 4 \mathrm{ccc}(\mathrm{N} 5 \mathrm{CCN}(\mathrm{C}) \mathrm{CC} 5) \mathrm{cc} 4 \mathrm{OC}) \mathrm{nc} 32) \mathrm{c} 1$ & 33.1 & $*$ \\
\hline 1634 & $\mathrm{C}=\mathrm{CC}(=\mathrm{O}) \mathrm{NCc} 1 \mathrm{cccc}(-\mathrm{c} 2 \mathrm{cc} 3 \mathrm{c}(-\mathrm{c} 4[\mathrm{nH}] \mathrm{c}(-\mathrm{c} 5 \mathrm{cccc} 5) \mathrm{nc} 4-\mathrm{c} 4 \mathrm{ccc}(\mathrm{F}) \mathrm{cc} 4) \mathrm{ccnc} 3[\mathrm{nH}] 2) \mathrm{c} 1$ & 33.2 & $*$ \\
\hline 1635 & $\mathrm{C}=\mathrm{CC}(=\mathrm{O}) \mathrm{Nc} 1 \mathrm{ccc}(\mathrm{N} 2 \mathrm{C}(=\mathrm{O}) \mathrm{C}(\mathrm{Cc} 3 \operatorname{ccc}(\mathrm{OC}) \mathrm{cc} 3) \mathrm{N}(\mathrm{C}) \mathrm{C}(=\mathrm{O}) \mathrm{c} 3 \mathrm{cnc}(\mathrm{Nc} 4 \mathrm{ccc}(\mathrm{N} 5 \mathrm{CCN}(\mathrm{C}) \mathrm{CC} 5) \mathrm{cc} 4 \mathrm{OC}) \mathrm{nc} 32) \mathrm{c} 1$ & 33.95 & 7.47 \\
\hline 1636 & $\mathrm{COc} 1 \mathrm{cc} 2 \mathrm{ncnc}(\mathrm{Nc} 3 \mathrm{ccc}(\mathrm{F}) \mathrm{c}(\mathrm{Cl}) \mathrm{c} 3) \mathrm{c} 2 \mathrm{cc} 1 \mathrm{OCCCN} 1 \mathrm{CC}(\mathrm{OC}) \mathrm{C} 1$ & 34 & 7.47 \\
\hline 1637 & $\mathrm{C \# Cc1} \operatorname{cccc}(\mathrm{Nc} 2 \mathrm{ncnc} 3 \operatorname{cc}(\mathrm{OCCOC}(=\mathrm{O}) \mathrm{c} 4 \operatorname{ccccc} 4 \mathrm{OC}(\mathrm{C})=\mathrm{O}) \mathrm{c}(\mathrm{OCCOC}(=\mathrm{O}) \mathrm{c} 4 \operatorname{ccccc} 4 \mathrm{OC}(\mathrm{C})=\mathrm{O}) \operatorname{cc} 23) \mathrm{c} 1$ & 34 & 7.47 \\
\hline 1638 & $\mathrm{Cc} 1 \mathrm{ncnc}(\mathrm{Nc} 2 \mathrm{ccc}(\mathrm{OCc} 3 \mathrm{cccc}(\mathrm{F}) \mathrm{c} 3) \mathrm{c}(\mathrm{Cl}) \mathrm{c} 2) \mathrm{c} 1 \mathrm{C} \# \mathrm{CCCCN} 1 \mathrm{CCOCC} 1$ & 34 & 7.47 \\
\hline 1639 & $\mathrm{CCOc} 1 \mathrm{cc} 2 \mathrm{ncc}(\mathrm{CHN}) \mathrm{c}(\mathrm{Nc} 3 \operatorname{ccc}(\mathrm{NCc} 4 \operatorname{ccc} 5 \operatorname{cccc} 45) \mathrm{c}(\mathrm{Cl}) \mathrm{c} 3) \mathrm{c} 2 \mathrm{cc} 1 \mathrm{NC}(=\mathrm{O}) / \mathrm{C}=\mathrm{C} / \mathrm{CN}(\mathrm{C}) \mathrm{C}$ & 34 & 7.47 \\
\hline 1640 & $\mathrm{CCOc} 1 \mathrm{cc} 2 \mathrm{ncc}(\mathrm{C \# N}) \mathrm{c}(\mathrm{Nc} 3 \operatorname{ccc}(\mathrm{OCc} 4 \mathrm{cccc}(\mathrm{F}) \mathrm{c} 4) \mathrm{c}(\mathrm{Cl}) \mathrm{c} 3) \mathrm{c} 2 \mathrm{cc} 1 \mathrm{NC}(=\mathrm{O}) / \mathrm{C}=\mathrm{C} / \mathrm{CN}(\mathrm{C}) \mathrm{C}$ & 34 & 7.47 \\
\hline 1641 & $\mathrm{CN}(\mathrm{C}) \mathrm{CCCCC}(=\mathrm{O}) \mathrm{Nc} 1 \mathrm{cccc}(-\mathrm{c} 2 \mathrm{c}(-\mathrm{c} 3 \operatorname{ccccc} 3) \mathrm{oc} 3 \mathrm{ncnc}(\mathrm{N}[\mathrm{C} @ \mathrm{H}](\mathrm{CO}) \mathrm{c} 4 \operatorname{ccccc} 4) \mathrm{c} 23) \mathrm{c} 1$ & 34 & $*$ \\
\hline 1642 & $\mathrm{CC}(\mathrm{C}) \mathrm{N} 1 \mathrm{CCN}(\mathrm{C} / \mathrm{C}=\mathrm{C} / \mathrm{C}(=\mathrm{O}) \mathrm{Nc} 2 \mathrm{cc} 3 \mathrm{c}(\mathrm{Nc} 4 \mathrm{ccc}(\mathrm{F}) \mathrm{c}(\mathrm{Cl}) \mathrm{c} 4) \mathrm{ncnc} 3 \mathrm{~s} 2) \mathrm{CC} 1$ & 34 & $*$ \\
\hline 1643 & $\operatorname{Brc} 1 \operatorname{ccc}(\mathrm{Nc} 2 \mathrm{ncnc} 3 \mathrm{cccnc} 23) \mathrm{c} 1$ & 34 & $*$ \\
\hline 1644 & OCCn1 ccc2ncnc(Nc3ecc(Oc4cccc(C(F)(F)F)c4)c(Cl)c3)c21 & 34 & $*$ \\
\hline 1645 & $\mathrm{NC} 1 \mathrm{CCN}(\mathrm{Cc} 2 \mathrm{ccn} 3 \mathrm{ncnc}(\mathrm{Nc} 4 \mathrm{cc}(\mathrm{Cl}) \mathrm{cc}(\mathrm{Cl}) \mathrm{c} 4) \mathrm{c} 23) \mathrm{CC} 1$ & 34 & $*$ \\
\hline 1646 & $\mathrm{C}=\mathrm{CC}(=\mathrm{O}) \mathrm{Nc} 1 \mathrm{cccc}(-\mathrm{n} 2 \mathrm{c}(=\mathrm{O}) \mathrm{n}(\mathrm{C}(\mathrm{C}) \mathrm{C}) \mathrm{c}(=\mathrm{O}) \mathrm{c} 3 \mathrm{cnc}(\mathrm{Nc} 4 \mathrm{ccc}(\mathrm{N} 5 \mathrm{CCN}(\mathrm{C}) \mathrm{CC} 5) \mathrm{c}(\mathrm{C}) \mathrm{c} 4) \mathrm{nc} 32) \mathrm{c} 1$ & 34 & $*$ \\
\hline 1647 & $\mathrm{C} \# \mathrm{Cc} 1 \mathrm{cccc}(\mathrm{Nc} 2 \mathrm{ncnc} 3 \mathrm{ccc}(-\mathrm{c} 4 \mathrm{ccc}(\mathrm{CNCCS}(\mathrm{C})(=\mathrm{O})=\mathrm{O}) \mathrm{o} 4) \operatorname{cc} 23) \mathrm{c} 1$ & 34.16 & $*$ \\
\hline 1648 & $\mathrm{O}=\mathrm{C}(\mathrm{Nc} 1 \mathrm{cccc}(\mathrm{C}(\mathrm{F})(\mathrm{F}) \mathrm{F}) \mathrm{c} 1) \mathrm{c} 1 \mathrm{ccc}(\mathrm{OCCCN} 2 \mathrm{CCOCC} 2) \mathrm{cc} 1 \mathrm{O}$ & 34.6 & $*$ \\
\hline 1649 & $\mathrm{CNC}(\mathrm{CS}(\mathrm{C})(=\mathrm{O})=\mathrm{O}) \mathrm{c} 1 \mathrm{ccc}(-\mathrm{c} 2 \mathrm{ccc} 3 \mathrm{ncnc}(\mathrm{Nc} 4 \operatorname{ccc}(\mathrm{OCc} 5 \operatorname{cccc}(\mathrm{F}) \mathrm{c} 5) \mathrm{c}(\mathrm{Cl}) \mathrm{c} 4) \mathrm{c} 3 \mathrm{c} 2) \mathrm{o} 1$ & 34.8 & $*$ \\
\hline 1650 & $\operatorname{CCCCCCCCCCCCCCCCNC}(=\mathrm{O}) \operatorname{COc} 1 \mathrm{cc}(\mathrm{O}) \mathrm{c} 2 \mathrm{c}(=\mathrm{O}) \operatorname{cc}(-\mathrm{c} 3 \operatorname{ccccc} 3) \mathrm{oc} 2 \mathrm{c} 1$ & 35 & 7.46 \\
\hline 1651 & $\mathrm{CCN} 1 \mathrm{CCN}(\mathrm{C} / \mathrm{C}=\mathrm{C} / \mathrm{C}(=\mathrm{O}) \mathrm{Nc} 2 \mathrm{cc} 3 \mathrm{c}(\mathrm{Nc} 4 \mathrm{ccc}(\mathrm{F}) \mathrm{c}(\mathrm{Cl}) \mathrm{c} 4) \mathrm{ncnc} 3 \mathrm{~s} 2) \mathrm{CC} 1$ & 35 & $*$ \\
\hline 1652 & $\mathrm{CCNC}(=\mathrm{O}) \mathrm{Nc} 1 \mathrm{ccc} 2 \mathrm{ncnc}(\mathrm{Nc} 3 \operatorname{ccc}(\mathrm{OCc} 4 \mathrm{cccc}(\mathrm{F}) \mathrm{c} 4) \mathrm{c}(\mathrm{Cl}) \mathrm{c} 3) \mathrm{c} 2 \mathrm{c} 1$ & 35 & $*$ \\
\hline 1653 & $\mathrm{COc} 1 \mathrm{cc} 2 \mathrm{ncnc}(\mathrm{Nc} 3 \mathrm{ccc}(\mathrm{F}) \mathrm{c}(\mathrm{Cl}) \mathrm{c} 3) \mathrm{c} 2 \mathrm{cc} 1 \mathrm{OCCN}(\mathrm{CCO}) \mathrm{CCO}$ & 35 & $*$ \\
\hline 1654 & $\operatorname{Brc} 1 \mathrm{cccc}(\mathrm{Nc} 2 \mathrm{ncnc} 3 \mathrm{ccncc} 23) \mathrm{c} 1$ & 35 & $*$ \\
\hline 1655 & $\mathrm{CN}(\mathrm{C}) \mathrm{CCNc} 1 \mathrm{ncc} 2 \mathrm{ncnc}(\mathrm{Nc} 3 \operatorname{cccc}(\mathrm{Br}) \mathrm{c} 3) \mathrm{c} 2 \mathrm{n} 1$ & 35 & $*$ \\
\hline 1656 & Brc1ecce(Nc2ncnc3scce23)c1 & 35 & $*$ \\
\hline 1657 & $\mathrm{NCC} 1 \mathrm{CCN}(\mathrm{Cc} 2 \mathrm{ccn} 3 \mathrm{ncnc}(\mathrm{Nc} 4 \mathrm{ccc} 5 \mathrm{c}(\mathrm{cnn} 5 \mathrm{Cc} 5 \mathrm{cccc}(\mathrm{F}) \mathrm{c} 5) \mathrm{c} 4) \mathrm{c} 23) \mathrm{CC} 1$ & 35 & $*$ \\
\hline 1658 & $\mathrm{NC} 1 \mathrm{CCN}(\mathrm{Cc} 2 \mathrm{ccn} 3 \mathrm{ncnc}(\mathrm{Nc} 4 \mathrm{ccc} 5 \mathrm{c}(\mathrm{cnn} 5 \mathrm{Cc} 5 \mathrm{cccc}(\mathrm{F}) \mathrm{c} 5) \mathrm{c} 4) \mathrm{c} 23) \mathrm{CC} 1$ & 35 & $*$ \\
\hline 1659 & $\mathrm{CN}(\mathrm{CCOc} 1 \mathrm{cccc} 2 \mathrm{ncnc}(\mathrm{Nc} 3 \mathrm{ccc}(\mathrm{OCc} 4 \mathrm{ccc} \mathrm{n} 4) \mathrm{c}(\mathrm{Cl}) \mathrm{c} 3) \mathrm{c} 12) \mathrm{C}(=\mathrm{O}) \mathrm{CO}$ & 35 & $*$ \\
\hline 1660 & $\mathrm{Clc} 1 \mathrm{cccc}(\mathrm{Oc} 2 \mathrm{ccc}(\mathrm{Nc} 3 \mathrm{ncnc} 4 \mathrm{cc}[\mathrm{nH}] \mathrm{c} 34) \mathrm{cc} 2 \mathrm{Cl}) \mathrm{c} 1$ & 35 & $*$ \\
\hline 1661 & $\mathrm{CN}(\mathrm{c} 1 \mathrm{ccc} 2[\mathrm{nH}] \mathrm{ccc} 2 \mathrm{c} 1) \mathrm{c} 1 \mathrm{cc}(\mathrm{Nc} 2 \mathrm{ccc}(\mathrm{N} 3 \mathrm{CCOCC} 3) \mathrm{cc} 2) \mathrm{ncn} 1$ & 35 & $*$ \\
\hline 1662 & $\mathrm{O}=\mathrm{C}(\mathrm{Nc} 1 \mathrm{cccc}(\mathrm{C}(\mathrm{F})(\mathrm{F}) \mathrm{F}) \mathrm{c} 1) \mathrm{c} 1 \mathrm{ccc}(\mathrm{OCCCN} 2 \mathrm{CCCCC} 2) \operatorname{cc} 1 \mathrm{O}$ & 35.2 & $*$ \\
\hline 1663 & $\mathrm{~S}=\mathrm{C}(\mathrm{Nc} 1 \mathrm{ccc}(\mathrm{Br}) \mathrm{cc} 1) \mathrm{Nc} 1 \mathrm{ccc} 2 \mathrm{ncnc}(\mathrm{Nc} 3 \mathrm{cccc}(\mathrm{Br}) \mathrm{c} 3) \mathrm{c} 2 \mathrm{c} 1$ & 35.4 & $*$ \\
\hline 1664 & $\mathrm{COc} 1 \mathrm{cc} 2 \mathrm{c}(\mathrm{Nc} 3 \mathrm{ccc}(\mathrm{OCc} 4 \mathrm{cccc}(\mathrm{F}) \mathrm{c} 4) \mathrm{c}(\mathrm{Cl}) \mathrm{c} 3) \mathrm{ncnc} 2 \mathrm{cc} 1 \mathrm{OCCCCCCn} 1 \mathrm{ccnc} 1[\mathrm{~N}+](=\mathrm{O})[\mathrm{O}-]$ & 35.5 & 7.45 \\
\hline 1665 & $\mathrm{COCC} 1 \mathrm{COc} 2 \mathrm{cc} 3 \mathrm{ncnc}(\mathrm{Nc} 4 \mathrm{ccc}(\mathrm{Br}) \mathrm{c} 4) \mathrm{c} 3 \mathrm{cc} 2 \mathrm{O} 1$ & 35.5 & $*$ \\
\hline 1666 & $\mathrm{CCC}(=\mathrm{O}) \mathrm{N} 1 \mathrm{CC}[\mathrm{C} @ \mathrm{H}](\mathrm{N} 2 \mathrm{C}(=\mathrm{O}) \mathrm{N}(\mathrm{c} 3 \mathrm{cccc}(\mathrm{F}) \mathrm{c} 3) \mathrm{Cc} 3 \mathrm{cnc}(\mathrm{Nc} 4 \mathrm{ccc}(\mathrm{N} 5 \mathrm{CCN}(\mathrm{C}) \mathrm{CC} 5) \mathrm{c}(\mathrm{C}) \mathrm{c} 4) \mathrm{nc} 32) \mathrm{C} 1$ & 35.8 & 7.45 \\
\hline 1667 & $\mathrm{COc} 1 \mathrm{cc} 2 \mathrm{ncnc}(\mathrm{Nc} 3 \mathrm{ccc}(\mathrm{F}) \mathrm{c}(\mathrm{Cl}) \mathrm{c} 3) \mathrm{c} 2 \mathrm{cc} 1 \mathrm{OCCCN} 1 \mathrm{CC} 2(\mathrm{CCO} 2) \mathrm{C} 1$ & 36 & 7.44 \\
\hline 1668 & OC[C@@H](Nc1ncnc2sc(Br)cc12)c1ccccc1 & 36 & * \\
\hline 1669 & $\mathrm{CCC}(=\mathrm{O}) \mathrm{Nc} 1 \mathrm{cc} 2 \mathrm{c}(\mathrm{Nc} 3 \mathrm{ccc}(\mathrm{OCc} 4 \mathrm{cccc} 4) \mathrm{cc} 3) \mathrm{ncnc} 2 \mathrm{cc} 1 \mathrm{OC}$ & 36 & $*$ \\
\hline 1670 & $\mathrm{CCOc} 1 \mathrm{cc} 2 \mathrm{ncnc}(\mathrm{Nc} 3 \operatorname{ccc} 4 \mathrm{c}(\operatorname{ccn} 4 \mathrm{~S}(=\mathrm{O})(=\mathrm{O}) \mathrm{c} 4 \mathrm{cccc} 4) \mathrm{c} 3) \mathrm{c} 2 \mathrm{cc} 1 \mathrm{NC}(=\mathrm{O}) / \mathrm{C}=\mathrm{C} / \mathrm{CN} 1 \mathrm{CCCC} 1$ & 36 & $*$ \\
\hline
\end{tabular}




\begin{tabular}{|c|c|c|c|}
\hline 1671 & $\mathrm{O}=\mathrm{C}(\mathrm{NCCO}) \mathrm{C} 1=\mathrm{Cc} 2 \mathrm{c}(\mathrm{ncnc} 2 \mathrm{Nc} 2 \mathrm{ccc}(\mathrm{Oc} 3 \mathrm{ccc} 4 \mathrm{sec} 34) \mathrm{c}(\mathrm{Cl}) \mathrm{c} 2) \mathrm{NCC} 1$ & 36 & $*$ \\
\hline 1672 & $\mathrm{CN}(\mathrm{CCO}) \mathrm{c} 1 \mathrm{cc} 2 \mathrm{c}(\mathrm{Nc} 3 \mathrm{ccc} 4 \mathrm{c}(\mathrm{cnn} 4 \mathrm{Cc} 4 \mathrm{ccccc} 4) \mathrm{c} 3) \mathrm{ncnc} 2 \mathrm{cn} 1$ & 36 & $*$ \\
\hline 1673 & $\mathrm{NC} 1 \mathrm{CCN}(\mathrm{Cc} 2 \mathrm{ccn} 3 \mathrm{nenc}(\mathrm{Nc} 4 \mathrm{ccc}(\mathrm{OCc} 5 \operatorname{ccc} \mathrm{n} 5) \mathrm{c}(\mathrm{Cl}) \mathrm{c} 4) \mathrm{c} 23) \mathrm{CC} 1$ & 36 & $*$ \\
\hline 1674 & $\mathrm{Cn} 1 \mathrm{ncc} 2 \mathrm{c}(\mathrm{Oc} 3 \mathrm{ccc}(\mathrm{Nc} 4 \mathrm{ncnc} 5 \mathrm{ccn}(\mathrm{CCO}) \mathrm{c} 45) \mathrm{cc} 3 \mathrm{Cl}) \operatorname{ccc} 21$ & 36 & $*$ \\
\hline 1675 & $\mathrm{COc} 1 \mathrm{ccc}(\mathrm{N} 2 \mathrm{C}(=\mathrm{O}) \mathrm{CS} / \mathrm{C} 2=\mathrm{N} / \mathrm{Nc} 2 \mathrm{nncc} 3 \operatorname{cccc} 23) \mathrm{cc} 1$ & 36 & $*$ \\
\hline 1676 & $\mathrm{C}=\mathrm{CC}(=\mathrm{O}) \mathrm{Nc} 1 \mathrm{ccc}(\mathrm{NC}(=\mathrm{O}) \mathrm{Nc} 2 \mathrm{ccnc}(\mathrm{Nc} 3 \operatorname{ccc}(\mathrm{N} 4 \mathrm{CCC}(\mathrm{N}(\mathrm{CC}) \mathrm{CC}) \mathrm{CC} 4) \operatorname{cc} 3 \mathrm{OC}) \mathrm{n} 2) \mathrm{c} 1$ & 36 & $*$ \\
\hline 1677 & $\mathrm{CN} 1 \mathrm{CCN}(\mathrm{N}(\mathrm{CCC} 2 \mathrm{COc} 3 \mathrm{cc} 4 \mathrm{ncnc}(\mathrm{Nc} 5 \mathrm{cccc}(\mathrm{Br}) \mathrm{c} 5) \mathrm{c} 4 \mathrm{cc} 3 \mathrm{O} 2) \mathrm{N} 2 \mathrm{CCN}(\mathrm{C}) \mathrm{CC} 2) \mathrm{CC} 1$ & 36 & $*$ \\
\hline 1678 & $\operatorname{COCCOc} 1 \mathrm{cc} 2 \mathrm{ncnc}(\mathrm{Nc} 3 \mathrm{ccc}(\mathrm{Cl}) \mathrm{c}([\mathrm{N}+](=\mathrm{O})[\mathrm{O}-]) \mathrm{c} 3) \mathrm{c} 2 \mathrm{c} 2 \mathrm{c} 1 \mathrm{OCCO} 2$ & 36.2 & $*$ \\
\hline 1679 & $\mathrm{Cc} 1 \operatorname{ccc}(\mathrm{Nc} 2 \mathrm{ncnc} 3 \operatorname{ccc}(\mathrm{NC}(=\mathrm{S}) \mathrm{NCc} 4 \operatorname{ccccc} 4) \operatorname{cc} 23) \mathrm{c} 1$ & 36.8 & $*$ \\
\hline 1680 & $\mathrm{C}=\mathrm{CC}(=\mathrm{O}) \mathrm{Nc} 1 \mathrm{cc}(-\mathrm{n} 2 \mathrm{c}(=\mathrm{O}) \mathrm{cc}(\mathrm{C}) \mathrm{c} 3 \mathrm{cnc}(\mathrm{Nc} 4 \mathrm{ccc}(\mathrm{N} 5 \mathrm{CCN}(\mathrm{C}) \mathrm{CC} 5) \mathrm{cc} 4 \mathrm{OC}) \mathrm{nc} 32) \mathrm{ccc} 1 \mathrm{C}$ & 36.9 & $*$ \\
\hline 1681 & $\mathrm{C}=\mathrm{CC}(=\mathrm{O}) \mathrm{Nc} 1 \mathrm{cccc}(\mathrm{Oc} 2 \mathrm{cc}(\mathrm{Nc} 3 \operatorname{ccc}(\mathrm{OCc} 4 \mathrm{ccc}(\mathrm{F}) \mathrm{c} 4) \mathrm{c}(\mathrm{Cl}) \mathrm{c} 3) \mathrm{ncn} 2) \mathrm{c} 1$ & 37 & 7.43 \\
\hline 1682 & $\mathrm{O}=\mathrm{C}(/ \mathrm{C}=\mathrm{C} / \mathrm{CN} 1 \mathrm{CCCC} 1) \mathrm{Nc} 1 \mathrm{cc} 2 \mathrm{c}(\mathrm{Nc} 3 \mathrm{ccc}(\mathrm{OCc} 4 \mathrm{cccc}(\mathrm{F}) \mathrm{c} 4) \mathrm{c}(\mathrm{Cl}) \mathrm{c} 3) \mathrm{ncnc} 2 \mathrm{cn} 1$ & 37 & $*$ \\
\hline 1683 & $\mathrm{CCC} 1=\mathrm{C} 2 \mathrm{C}(\mathrm{Nc} 3 \operatorname{ccc} 4 \mathrm{c}(\operatorname{cnn} 4 \mathrm{Cc} 4 \mathrm{cccc} 4) \mathrm{c} 3)=\mathrm{NC}=\mathrm{NC} 2 \mathrm{~N}=\mathrm{C} 1 \mathrm{NC}(=\mathrm{O}) \mathrm{OCCC} 1 \mathrm{CCNCC} 1$ & 37 & $*$ \\
\hline 1684 & $\mathrm{O}=[\mathrm{N}+]([\mathrm{O}-]) \mathrm{c} 1 \mathrm{cccc}(-\mathrm{c} 2[\mathrm{nH}] \mathrm{nc} 3 \mathrm{ncnc}(\mathrm{Nc} 4 \operatorname{ccc}(\mathrm{Cl}) \mathrm{c} 4) \mathrm{c} 23) \mathrm{c} 1$ & 37 & $*$ \\
\hline 1685 & $\mathrm{CN}(\mathrm{C}) \mathrm{CCNN}=\mathrm{Nc} 1 \mathrm{ccc} 2 \mathrm{ncnc}(\mathrm{Nc} 3 \mathrm{cccc}(\mathrm{Cl}) \mathrm{c} 3) \mathrm{c} 2 \mathrm{c} 1$ & 37 & $*$ \\
\hline 1686 & $\mathrm{O}=\mathrm{C}(\mathrm{CN} 1 \mathrm{CCCCC} 1) \mathrm{Nc} 1 \mathrm{ccc} 2 \mathrm{ncnc}(\mathrm{Nc} 3 \operatorname{ccc}(\mathrm{Br}) \mathrm{c} 3) \mathrm{c} 2 \mathrm{c} 1$ & 37 & $*$ \\
\hline 1687 & $\mathrm{CN}(\mathrm{C}) \mathrm{CCN} / \mathrm{N}=\mathrm{N} / \mathrm{c} 1 \mathrm{ccc} 2 \mathrm{ncnc}(\mathrm{Nc} 3 \operatorname{ccc}(\mathrm{Cl}) \mathrm{c} 3) \mathrm{c} 2 \mathrm{c} 1 .[\mathrm{H}+]$ & 37 & $*$ \\
\hline 1688 & $\operatorname{COc} 1 \operatorname{ccc}(\mathrm{Nc} 2 \mathrm{cc}(\mathrm{NC}(=\mathrm{O}) \mathrm{CCCC}(=\mathrm{O}) \mathrm{O}) \mathrm{ncn} 2) \mathrm{c} 1$ & 37 & $*$ \\
\hline 1689 & $\mathrm{CN}(\mathrm{C}) \mathrm{C} / \mathrm{C}=\mathrm{C} / \mathrm{C}(=\mathrm{O}) \mathrm{Nc} 1 \mathrm{ccc} 2 \mathrm{ncc}(\mathrm{C} \# \mathrm{~N}) \mathrm{c}(\mathrm{Nc} 3 \mathrm{cccc}(\mathrm{Br}) \mathrm{c} 3) \mathrm{c} 2 \mathrm{c} 1$ & 37.2 & 6.82 \\
\hline 1690 & $\mathrm{C}=\mathrm{CC}(=\mathrm{O}) \mathrm{Nc} 1 \operatorname{ccc}(\mathrm{N} 2 \mathrm{C}(=\mathrm{O}) \mathrm{C}(\mathrm{Cc} 3 \operatorname{ccc}(\mathrm{Cl}) \operatorname{cc} 3) \mathrm{N}(\mathrm{C}) \mathrm{C}(=\mathrm{O}) \mathrm{c} 3 \mathrm{cnc}(\mathrm{Nc} 4 \operatorname{ccc}(\mathrm{N} 5 \mathrm{CCN}(\mathrm{C}) \mathrm{CC} 5) \operatorname{cc} 4 \mathrm{OC}) \mathrm{nc} 32) \mathrm{c} 1$ & 37.37 & 7.43 \\
\hline 1691 & $\mathrm{CCOc} 1 \mathrm{cc} 2 \mathrm{ncc}(\mathrm{C \# N}) \mathrm{c}(\mathrm{Nc} 3 \operatorname{ccc}(\mathrm{OCc} 4 \mathrm{ccc} n 4) \mathrm{c}(\mathrm{Cl}) \mathrm{c} 3) \mathrm{c} 2 \mathrm{cc} 1 \mathrm{NC}(=\mathrm{O}) \mathrm{CCN} 1 \mathrm{CCOCC} 1$ & 37.5 & 7.43 \\
\hline 1692 & $\mathrm{CCOc} 1 \mathrm{cc} 2 \mathrm{ncnc}(\mathrm{Nc} 3 \mathrm{ccc}(\mathrm{OCC} 4 \mathrm{CC} 4) \mathrm{c}(\mathrm{Cl}) \mathrm{c} 3) \mathrm{c} 2 \mathrm{cc} 1 \mathrm{NC}(=\mathrm{O})[\mathrm{C} @ @ \mathrm{H}] 1 \mathrm{COC}(=\mathrm{O}) \mathrm{N} 1$ & 37.81 & 7.42 \\
\hline 1693 & $\mathrm{Cc} 1 \mathrm{ncnc}(\mathrm{Nc} 2 \mathrm{ccc}(\mathrm{OCc} 3 \operatorname{ccc}(\mathrm{F}) \mathrm{c} 3) \mathrm{c}(\mathrm{Cl}) \mathrm{c} 2) \mathrm{c} 1 \mathrm{C} \# \mathrm{C} / \mathrm{C}=\mathrm{N} / \mathrm{OCCN} 1 \mathrm{CCOCC} 1$ & 38 & 7.42 \\
\hline 1694 & $\mathrm{O}=\mathrm{C}(/ \mathrm{C}=\mathrm{C} / \mathrm{CN} 1 \mathrm{CC}(\mathrm{O}) \mathrm{C} 1) \mathrm{Nc} 1 \mathrm{cc} 2 \mathrm{c}(\mathrm{Nc} 3 \mathrm{ccc}(\mathrm{F}) \mathrm{c}(\mathrm{Cl}) \mathrm{c} 3) \mathrm{ncnc} 2 \mathrm{~s} 1$ & 38 & $*$ \\
\hline 1695 & C[C@@H](Nc1ncnc2sc(Br)cc12)c1cccc1 & 38 & $*$ \\
\hline 1696 & $\operatorname{CCOc} 1 \mathrm{cc} 2 \mathrm{ncnc}(\mathrm{Nc} 3 \operatorname{ccc} 4 \mathrm{c}(\operatorname{ccn} 4 \mathrm{~S}(=\mathrm{O})(=\mathrm{O}) \mathrm{c} 4 \operatorname{ccccc} 4) \mathrm{c} 3) \mathrm{c} 2 \mathrm{cc} 1 \mathrm{NC}(=\mathrm{O}) / \mathrm{C}=\mathrm{C} / \mathrm{CN}(\mathrm{C}) \mathrm{C}$ & 38 & $*$ \\
\hline 1697 & $\mathrm{O}=\mathrm{C}(\mathrm{NCCO}) \mathrm{C} 1=\mathrm{Cc} 2 \mathrm{c}(\mathrm{ncnc} 2 \mathrm{Nc} 2 \mathrm{ccc}(\mathrm{Oc} 3 \operatorname{ccc}(\mathrm{C}(\mathrm{F})(\mathrm{F}) \mathrm{F}) \mathrm{c} 3) \mathrm{c}(\mathrm{Cl}) \mathrm{c} 2) \mathrm{NCC} 1$ & 38 & $*$ \\
\hline 1698 & $\mathrm{COc} 1 \mathrm{cc}(\mathrm{O}) \mathrm{c} 2 \mathrm{c}(\mathrm{O}) \mathrm{c}(-\mathrm{c} 3 \mathrm{cccc}(\mathrm{Cl}) \mathrm{c} 3) \mathrm{cnc} 2 \mathrm{c} 1$ & 38 & $*$ \\
\hline 1699 & $\mathrm{NC} 1 \mathrm{CCN}(\mathrm{Cc} 2 \mathrm{ccn} 3 \mathrm{ncnc}(\mathrm{Nc} 4 \mathrm{ccc}(\mathrm{OCc} 5 \mathrm{cccc}(\mathrm{F}) \mathrm{c} 5) \mathrm{c}(\mathrm{Cl}) \mathrm{c} 4) \mathrm{c} 23) \mathrm{CC} 1$ & 38 & $*$ \\
\hline 1700 & $\mathrm{CN}(\mathrm{C}) \mathrm{CCN}=\mathrm{NNc} 1 \mathrm{ccc} 2 \mathrm{ncnc}(\mathrm{Nc} 3 \mathrm{cccc}(\mathrm{Br}) \mathrm{c} 3) \mathrm{c} 2 \mathrm{c} 1$ & 38 & * \\
\hline 1701 & $\mathrm{Cc} 1 \mathrm{cc} 2 \mathrm{ncnc}(\mathrm{Nc} 3 \mathrm{ccc}(\mathrm{Oc} 4 \mathrm{ccc}(\mathrm{C}(\mathrm{F})(\mathrm{F}) \mathrm{F}) \mathrm{c} 4) \mathrm{c}(\mathrm{Cl}) \mathrm{c} 3) \mathrm{c} 2 \mathrm{n} 1 \mathrm{CCOCCO}$ & 38 & $*$ \\
\hline 1702 & $\operatorname{COc} 1 \mathrm{cc} 2 \mathrm{ncnc}(\mathrm{Nc} 3 \operatorname{ccc}(\mathrm{OCc} 4 \mathrm{cccc}(\mathrm{F}) \mathrm{c} 4) \mathrm{c}(\mathrm{Cl}) \mathrm{c} 3) \mathrm{c} 2 \mathrm{cc} 1 \mathrm{OCCCn} 1 \mathrm{ccnc} 1[\mathrm{~N}+](=\mathrm{O})[\mathrm{O}-]$ & 38.3 & 7.42 \\
\hline 1703 & $\mathrm{C}=\mathrm{C}=\mathrm{Cc} 1 \mathrm{cccc}(\mathrm{Nc} 2 \mathrm{ncnc} 3 \mathrm{cc}(\mathrm{OC}) \mathrm{c}(\mathrm{OC}) \mathrm{cc} 23) \mathrm{c} 1$ & 38.7 & $*$ \\
\hline 1704 & $\mathrm{C}=\mathrm{CC}(=\mathrm{O}) \mathrm{Nc} 1 \mathrm{cccc}(\mathrm{Oc} 2 \mathrm{nc}(\mathrm{Nc} 3 \mathrm{ccc}(\mathrm{N} 4 \mathrm{CCN}(\mathrm{C}(\mathrm{C})=\mathrm{O}) \mathrm{CC} 4) \mathrm{cc} 3 \mathrm{OC}(\mathrm{F}) \mathrm{F}) \mathrm{ncc} 2 \mathrm{SC}) \mathrm{c} 1$ & 38.8 & $*$ \\
\hline 1705 & $\begin{array}{c}\mathrm{C}=\mathrm{CC}(=\mathrm{O}) \mathrm{Nc} 1 \mathrm{cccc}(\mathrm{Oc} 2 \mathrm{nc}(\mathrm{Nc} 3 \operatorname{ccc}(\mathrm{N} 4 \mathrm{CCN}(\mathrm{CC}(=\mathrm{O}) \mathrm{N} 5 \mathrm{CCN}(\mathrm{CCOc} 6 \mathrm{no}[\mathrm{n}+]([\mathrm{O}-]) \mathrm{c} 6 \mathrm{~S}(=\mathrm{O})(=\mathrm{O}) \mathrm{c} 6 \mathrm{ccccc} 6) \mathrm{CC} 5) \mathrm{C} \\
\mathrm{C} 4) \mathrm{cc} 3 \mathrm{OC}) \mathrm{ncc} 2 \mathrm{Cl}) \mathrm{c} 1\end{array}$ & 39 & 7.41 \\
\hline 1706 & $\mathrm{O}=\mathrm{C}(\mathrm{Nc} 1 \mathrm{cc} 2 \mathrm{c}(\mathrm{Nc} 3 \operatorname{ccc}(\mathrm{OCc} 4 \mathrm{ccc} n 4) \mathrm{c}(\mathrm{Cl}) \mathrm{c} 3) \operatorname{ncn} 2 \mathrm{cc} 1 \mathrm{OCCCN} 1 \mathrm{CCOCC} 1) \mathrm{c} 1 \mathrm{cc}([\mathrm{N}+](=\mathrm{O})[\mathrm{O}-]) \operatorname{ccc} 1 \mathrm{~F}$ & 39 & 7.41 \\
\hline 1707 & COc1cc2ncnc(Nc3ecce(Br)c3)c2cn1 & 39 & $*$ \\
\hline 1708 & $\mathrm{CN}=\mathrm{NNc} 1 \mathrm{ccc} 2 \mathrm{ncnc}(\mathrm{Nc} 3 \mathrm{cccc}(\mathrm{Br}) \mathrm{c} 3) \mathrm{c} 2 \mathrm{c} 1$ & 39 & $*$ \\
\hline 1709 & $\mathrm{CCOc} 1 \mathrm{cc} 2 \mathrm{ncnc}(\mathrm{Nc} 3 \operatorname{ccc}(\mathrm{Oc} 4 \mathrm{ccc}(\mathrm{C}) \mathrm{nc} 4) \mathrm{c}(\mathrm{Cl}) \mathrm{c} 3) \mathrm{c} 2 \mathrm{cc} 1 \mathrm{NC}(=\mathrm{O}) / \mathrm{C}(\mathrm{F})=\mathrm{C} \backslash \mathrm{CN} 1 \mathrm{CCCCC} 1$ & 39.2 & 7.41 \\
\hline 1710 & $\mathrm{CC}(\mathrm{C}) \mathrm{NC}(\mathrm{CS}(\mathrm{C})(=\mathrm{O})=\mathrm{O}) \mathrm{c} 1 \mathrm{ccc}(-\mathrm{c} 2 \mathrm{ccc} 3 \mathrm{ncnc}(\mathrm{Nc} 4 \mathrm{ccc}(\mathrm{OCc} 5 \mathrm{cccc}(\mathrm{F}) \mathrm{c} 5) \mathrm{c}(\mathrm{Cl}) \mathrm{c} 4) \mathrm{c} 3 \mathrm{c} 2) \mathrm{o} 1$ & 39.2 & $*$ \\
\hline 1711 & $\mathrm{COc} 1 \mathrm{c}(\mathrm{Br}) \operatorname{cccc} 1 \mathrm{Nc} 1 \mathrm{ncnc} 2 \mathrm{ccncc} 12$ & 39.81 & $*$ \\
\hline 1712 & $\mathrm{CCCCN}(\mathrm{CC} \# \mathrm{CC}(=\mathrm{O}) \mathrm{Nc} 1 \mathrm{ccc} 2 \mathrm{ncnc}(\mathrm{Nc} 3 \mathrm{ccc}(\mathrm{F}) \mathrm{c}(\mathrm{Cl}) \mathrm{c} 3) \mathrm{c} 2 \mathrm{c} 1) \mathrm{CCCC}$ & 40 & $*$ \\
\hline
\end{tabular}




\begin{tabular}{|c|c|c|c|}
\hline 1713 & OCc1 $\operatorname{ccc}(\mathrm{C} \# \mathrm{Cc} 2 \mathrm{cncnc} 2 \mathrm{Nc} 2 \mathrm{ccc}(\mathrm{OCc} 3 \mathrm{cccc}(\mathrm{F}) \mathrm{c} 3) \mathrm{c}(\mathrm{Cl}) \mathrm{c} 2) \mathrm{n} 1$ & 40 & $*$ \\
\hline 1714 & COc1cc2ncnc(Nc3ecce $(\mathrm{Cl}) \mathrm{c} 3 \mathrm{~F}) \mathrm{c} 2 \mathrm{cc} 1 \mathrm{CN}(\mathrm{C})[\mathrm{C} @ \mathrm{H}](\mathrm{C}) \mathrm{C}(=\mathrm{O}) \mathrm{N}(\mathrm{C}) \mathrm{C}$ & 40 & $*$ \\
\hline 1715 & CCN1CCN(Cc2ccc(-c3cc4c(N[C@@H](C)c5cccc5)ncnc4[nH]3)cc2)CC1 & 40 & * \\
\hline 1716 & $\mathrm{O}=\mathrm{C}(\mathrm{CCl}) \mathrm{Nc} 1 \mathrm{cc} 2 \mathrm{c}(\mathrm{Nc} 3 \mathrm{ccc}(\mathrm{F}) \mathrm{c}(\mathrm{Cl}) \mathrm{c} 3) \mathrm{ncnc} 2 \mathrm{~s} 1$ & 40 & $*$ \\
\hline 1717 & $\mathrm{CN}(\mathrm{C}) \mathrm{C}(=\mathrm{O}) \mathrm{O}[\mathrm{C} @ @ \mathrm{H}] 1 \mathrm{CN}[\mathrm{C} @ @ \mathrm{H}](\mathrm{C} \# \mathrm{Cc} 2 \mathrm{cc} 3 \mathrm{ncnc}(\mathrm{Nc} 4 \mathrm{ccc}(\mathrm{OCc} 5 \mathrm{cccc}(\mathrm{F}) \mathrm{c} 5) \mathrm{c}(\mathrm{Cl}) \mathrm{c} 4) \mathrm{c} 3 \mathrm{~s} 2) \mathrm{C} 1$ & 40 & * \\
\hline 1718 & O=C(O[C@@H]1CN[C@@H](C\#Cc2cc3ncnc(Nc4ccc(OCc5cccc(F)c5)c(Cl)c4)c3s2)C1)N1CCOCC1 & 40 & $*$ \\
\hline 1719 & $\mathrm{CS}(=\mathrm{O})(=\mathrm{O}) \mathrm{CCNC}(=\mathrm{O}) \mathrm{O}[\mathrm{C} @ \mathrm{H}] 1 \mathrm{CN}[\mathrm{C} @ \mathrm{H}](\mathrm{CHC} 2 \mathrm{cc} 3 \mathrm{ncnc}(\mathrm{Nc} 4 \mathrm{ccc}(\mathrm{OCc} 5 \mathrm{cccc}(\mathrm{F}) \mathrm{c} 5) \mathrm{c}(\mathrm{Cl}) \mathrm{c} 4) \mathrm{c} 3 \mathrm{~s} 2) \mathrm{C} 1$ & 40 & $*$ \\
\hline 1720 & $\mathrm{NC}(=\mathrm{O}) \mathrm{O}[\mathrm{C} @ \mathrm{H}] 1 \mathrm{CN}[\mathrm{C} @ \mathrm{H}](\mathrm{C} \# \mathrm{Cc} 2 \mathrm{cc} 3 \mathrm{ncnc}(\mathrm{Nc} 4 \mathrm{ccc}(\mathrm{OCc} 5 \mathrm{ccc}(\mathrm{F}) \mathrm{c} 5) \mathrm{c}(\mathrm{Cl}) \mathrm{c} 4) \mathrm{c} 3 \mathrm{~s} 2) \mathrm{C} 1$ & 40 & $*$ \\
\hline 1721 & $\mathrm{Nc} 1 \mathrm{ccc} 2 \mathrm{ncnc}(\mathrm{Nc} 3 \operatorname{cccc}(\mathrm{Br}) \mathrm{c} 3) \mathrm{c} 2 \mathrm{c} 1$ & 40 & $*$ \\
\hline 1722 & $\mathrm{Clc} 1 \mathrm{cc} 2 \mathrm{c}(\mathrm{Nc} 3 \mathrm{cccc}(\mathrm{Br}) \mathrm{c} 3) \mathrm{ncnc} 2 \mathrm{cn} 1$ & 40 & $*$ \\
\hline 1723 & $\mathrm{CN}(\mathrm{C}) \mathrm{CCn} 1 \mathrm{ncc} 2 \mathrm{cc} 3 \mathrm{c}(\mathrm{Nc} 4 \mathrm{cccc}(\mathrm{Br}) \mathrm{c} 4) \mathrm{ncnc} 3 \mathrm{cc} 21$ & 40 & $*$ \\
\hline 1724 & $\mathrm{CN}(\mathrm{C}) \mathrm{CCN}(\mathrm{C}) \mathrm{c} 1 \mathrm{cc} 2 \mathrm{ncnc}(\mathrm{Nc} 3 \mathrm{cccc}(\mathrm{Br}) \mathrm{c} 3) \mathrm{c} 2 \mathrm{cn} 1$ & 40 & $*$ \\
\hline 1725 & $\mathrm{Cc} 1 \mathrm{cccc}(\mathrm{Nc} 2 \mathrm{ncnc} 3 \mathrm{cc}(\mathrm{N}) \mathrm{ncc} 23) \mathrm{c} 1$ & 40 & $*$ \\
\hline 1726 & $\mathrm{Nc} 1 \mathrm{cc} 2 \mathrm{ncnc}(\mathrm{Nc} 3 \operatorname{cccc}([\mathrm{N}+](=\mathrm{O})[\mathrm{O}-]) \mathrm{c} 3) \mathrm{c} 2 \mathrm{cn} 1$ & 40 & $*$ \\
\hline 1727 & $\mathrm{CC}(=\mathrm{O}) \mathrm{Nc} 1 \mathrm{ccc} 2 \mathrm{c}(\mathrm{Nc} 3 \mathrm{cccc}(\mathrm{Br}) \mathrm{c} 3) \mathrm{ncnc} 2 \mathrm{c} 1$ & 40 & * \\
\hline 1728 & $\mathrm{Brc} 1 \mathrm{cccc}(\mathrm{Nc} 2 \mathrm{ncnc} 3 \mathrm{c} 2 \mathrm{sc} 2 \mathrm{ncsc} 23) \mathrm{c} 1 . \mathrm{CO}$ & 40 & * \\
\hline 1729 & $\mathrm{CCc} 1 \mathrm{c}(\mathrm{NC}(=\mathrm{O}) \mathrm{OCCn} 2 \mathrm{ccnc} 2) \mathrm{cn} 2 \mathrm{ncnc}(\mathrm{Nc} 3 \operatorname{ccc} 4 \mathrm{c}(\mathrm{cnn} 4 \mathrm{Cc} 4 \mathrm{ccccc} 4) \mathrm{c} 3) \mathrm{c} 12$ & 40 & $*$ \\
\hline 1730 & $\mathrm{CCc} 1 \mathrm{c}(\mathrm{C}(=\mathrm{O}) \mathrm{NCCCn} 2 \mathrm{ccnc} 2) \mathrm{cn} 2 \mathrm{ncnc}(\mathrm{Nc} 3 \mathrm{ccc} 4 \mathrm{c}(\mathrm{cnn} 4 \mathrm{Cc} 4 \mathrm{ccccc} 4) \mathrm{c} 3) \mathrm{c} 12$ & 40 & * \\
\hline 1731 & $\mathrm{COc} 1 \mathrm{cn} 2 \mathrm{ncnc}(\mathrm{Nc} 3 \mathrm{ccc} 4 \mathrm{c}(\mathrm{cnn} 4 \mathrm{Cc} 4 \mathrm{cccc}(\mathrm{F}) \mathrm{c} 4) \mathrm{c} 3) \mathrm{c} 2 \mathrm{c} 1 \mathrm{CN} 1 \mathrm{CCC}(\mathrm{N}) \mathrm{CC} 1$ & 40 & $*$ \\
\hline 1732 & $\mathrm{COc} 1 \mathrm{cc} 2 \mathrm{ncnc}(\mathrm{Oc} 3 \operatorname{ccc}(\mathrm{NC}(=\mathrm{S}) \mathrm{Nc} 4 \mathrm{ccc}(\mathrm{F}) \mathrm{c}(\mathrm{C}(\mathrm{F})(\mathrm{F}) \mathrm{F}) \mathrm{c} 4) \mathrm{c} 3) \mathrm{c} 2 \mathrm{cc} 1 \mathrm{OC}$ & 40 & $*$ \\
\hline 1733 & $\operatorname{Brc} 1 \mathrm{cccc}(\mathrm{Nc} 2 \mathrm{ncnc} 3 \mathrm{c} 2 \mathrm{sc} 2 \mathrm{ncsc} 23) \mathrm{c} 1$ & 40 & $*$ \\
\hline 1734 & $\mathrm{COc} 1 \mathrm{cc} 2 \mathrm{ncnc}(\mathrm{Nc} 3 \mathrm{ccc}(\mathrm{C}) \mathrm{c}(\mathrm{O}) \mathrm{c} 3) \mathrm{c} 2 \mathrm{cc} 1 \mathrm{OC}$ & 40 & $*$ \\
\hline 1735 & $\mathrm{Cc} 1 \mathrm{ccc}(\mathrm{Nc} 2 \mathrm{ncnc} 3 \mathrm{oc}(-\mathrm{c} 4 \mathrm{ccc}(\mathrm{N}) \mathrm{cc} 4) \mathrm{cc} 23) \mathrm{cc} 1 \mathrm{O}$ & 40 & $*$ \\
\hline 1736 & $\mathrm{O}=\mathrm{S}(=\mathrm{O})(\mathrm{CCO}) \mathrm{CCn} 1 \mathrm{ccc} 2 \mathrm{ncnc}(\mathrm{Nc} 3 \operatorname{ccc}(\mathrm{Oc} 4 \operatorname{cccc}(\mathrm{C}(\mathrm{F})(\mathrm{F}) \mathrm{F}) \mathrm{c} 4) \mathrm{c}(\mathrm{Cl}) \mathrm{c} 3) \mathrm{c} 21$ & 40 & $*$ \\
\hline 1737 & $\mathrm{Cc} 1 \mathrm{nc}(\mathrm{C}) \mathrm{c}(\mathrm{C}=\mathrm{C} 2 \mathrm{CN}(\mathrm{C}) \mathrm{CC}(=\mathrm{Cc} 3 \mathrm{nc}(\mathrm{C}) \mathrm{c}(\mathrm{C}) \mathrm{nc} 3 \mathrm{C}) \mathrm{C} 2=\mathrm{O}) \mathrm{nc} 1 \mathrm{C}$ & 40 & * \\
\hline 1738 & $\mathrm{CN} 1 \mathrm{CC}(=\mathrm{Cc} 2 \operatorname{ccc}(\mathrm{N}(\mathrm{C}) \mathrm{C}) \operatorname{cc} 2[\mathrm{~N}+](=\mathrm{O})[\mathrm{O}-]) \mathrm{C}(=\mathrm{N} / \mathrm{O}) / \mathrm{C}(=\mathrm{C} / \mathrm{c} 2 \operatorname{ccc}(\mathrm{N}(\mathrm{C}) \mathrm{C}) \mathrm{cc} 2[\mathrm{~N}+](=\mathrm{O})[\mathrm{O}-]) \mathrm{C} 1$ & 40 & $*$ \\
\hline 1739 & 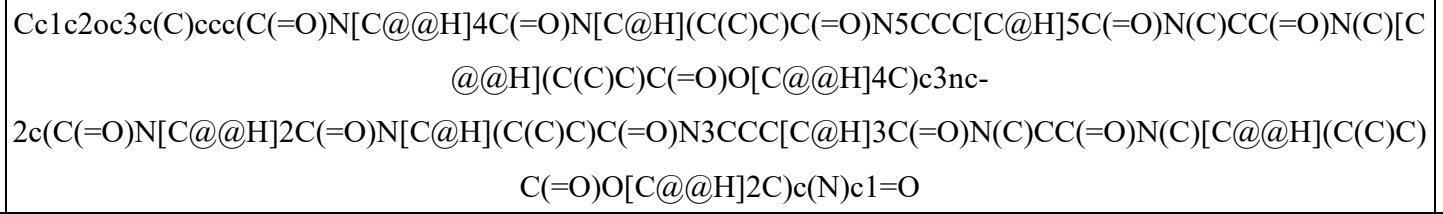 & 40 & $*$ \\
\hline 1740 & Clc1 $1 \mathrm{cc}(-\mathrm{c} 2 \mathrm{nc}(\mathrm{Nc} 3 \mathrm{cc}(\mathrm{Br}) \mathrm{cc} 4 \mathrm{cc}(-\mathrm{c} 5 \mathrm{ccccc} 5) \mathrm{oc} 34) \mathrm{c} 3 \mathrm{cc}(\mathrm{Br}) \operatorname{ccc} 3 \mathrm{n} 2) \mathrm{cc} 1$ & 40.4 & $*$ \\
\hline 1741 & Fc1 $1 \mathrm{cc}(-\mathrm{c} 2 \mathrm{nc}(\mathrm{Nc} 3 \mathrm{cc}(\mathrm{Br}) \mathrm{cc} 4 \mathrm{cc}(-\mathrm{c} 5 \mathrm{cccc}(\mathrm{Cl}) \mathrm{c} 5)[\mathrm{nH}] \mathrm{c} 34) \mathrm{c} 3 \mathrm{ccccc} 3 \mathrm{n} 2) \mathrm{cc} 1$ & 40.7 & $*$ \\
\hline 1742 & $\mathrm{CN}(\mathrm{C}) \mathrm{CCN}(\mathrm{C}) \mathrm{c} 1 \mathrm{c}(\mathrm{Br}) \mathrm{cccc} 1 \mathrm{Nc} 1 \mathrm{ncnc} 2 \mathrm{ccncc} 12$ & 40.74 & * \\
\hline 1743 & $\mathrm{Nc} 1 \mathrm{c}(\mathrm{Nc} 2 \mathrm{ncnc} 3 \mathrm{ccncc} 23) \operatorname{cccc} 1[\mathrm{~N}+](=\mathrm{O})[\mathrm{O}-]$ & 40.74 & * \\
\hline 1744 & Cc1ccec(Nc2ncnc3ecncc23)c1N & 40.74 & $*$ \\
\hline 1745 & $\mathrm{COc} 1 \mathrm{cc} 2 \mathrm{ncc}(\mathrm{C \# N}) \mathrm{c}(\mathrm{Nc} 3 \operatorname{ccc}(\mathrm{Sc} 4 \mathrm{nccn} 4 \mathrm{C}) \mathrm{c}(\mathrm{Cl}) \mathrm{c} 3) \mathrm{c} 2 \mathrm{cc} 1 \mathrm{NC}(=\mathrm{O}) / \mathrm{C}=\mathrm{C} / \mathrm{CN}(\mathrm{C}) \mathrm{C}$ & 41 & 7.39 \\
\hline 1746 & $\mathrm{C}[\mathrm{C} @ @ \mathrm{H}](\mathrm{Nc} 1 \mathrm{ncnc} 2 \mathrm{sc}(-\mathrm{c} 3 \operatorname{ccc}(\mathrm{S}(\mathrm{C})(=\mathrm{O})=\mathrm{O}) \mathrm{cc} 3) \mathrm{cc} 12) \mathrm{c} 1 \mathrm{ccccc} 1$ & 41 & 7.39 \\
\hline 1747 & $\mathrm{CS}(=\mathrm{O})(=\mathrm{O}) \mathrm{CCNC}(=\mathrm{O}) \mathrm{Nc} 1 \mathrm{cc} 2 \mathrm{c}(\mathrm{Nc} 3 \mathrm{ccc}(\mathrm{F}) \mathrm{c}(\mathrm{Cl}) \mathrm{c} 3) \mathrm{ncnc} 2 \mathrm{cc} 1 \mathrm{O}[\mathrm{C} @ \mathrm{H}] 1 \mathrm{CCOC} 1$ & 41 & $*$ \\
\hline 1748 & $\mathrm{CN}(\mathrm{C}) \mathrm{C} / \mathrm{C}=\mathrm{C} / \mathrm{C}(=\mathrm{O}) \mathrm{Nc} 1 \mathrm{cc} 2 \mathrm{c}(\mathrm{Nc} 3 \mathrm{ccc} 4 \mathrm{c}(\mathrm{cnn} 4 \mathrm{Cc} 4 \mathrm{ccccc} 4) \mathrm{c} 3) \mathrm{ncnc} 2 \mathrm{cn} 1$ & 41 & $*$ \\
\hline 1749 & $\mathrm{CN}(\mathrm{C}) \mathrm{CCn} 1 \mathrm{ccc} 2 \mathrm{cc} 3 \mathrm{c}(\mathrm{Nc} 4 \mathrm{cccc}(\mathrm{Br}) \mathrm{c} 4) \mathrm{ncnc} 3 \mathrm{cc} 21$ & 41 & $*$ \\
\hline 1750 & $\mathrm{Cc} 1 \mathrm{cc}(\mathrm{C}) \mathrm{c}(/ \mathrm{C}=\mathrm{C} 2 \backslash \mathrm{C}(=\mathrm{O}) \mathrm{Nc} 3 \mathrm{ncnc}(\mathrm{Nc} 4 \mathrm{ccc}(\mathrm{F}) \mathrm{c}(\mathrm{Cl}) \mathrm{c} 4) \mathrm{c} 32)[\mathrm{nH}] 1$ & 41 & $*$ \\
\hline 1751 & $\mathrm{CS}(=\mathrm{O})(=\mathrm{O}) \mathrm{CCNN}(\mathrm{NCS}(\mathrm{C})(=\mathrm{O})=\mathrm{O}) \mathrm{C}(=\mathrm{O}) \mathrm{Nc} 1 \mathrm{cc} 2 \mathrm{c}(\mathrm{Nc} 3 \mathrm{ccc}(\mathrm{F}) \mathrm{c}(\mathrm{Cl}) \mathrm{c} 3) \mathrm{ncnc} 2 \mathrm{cc} 1 \mathrm{O}[\mathrm{C} @ \mathrm{H}] 1 \mathrm{CCOC} 1$ & 41 & * \\
\hline 1752 & $\mathrm{C}=\mathrm{CC}(=\mathrm{O}) \mathrm{Cc} 1 \mathrm{cc}(\mathrm{Nc} 2 \mathrm{ncc} 3 \mathrm{nc}(\mathrm{Nc} 4 \mathrm{ccccc} 4) \mathrm{n}(\mathrm{C}(\mathrm{C}) \mathrm{C}) \mathrm{c} 3 \mathrm{n} 2) \mathrm{c}(\mathrm{OC}) \mathrm{cc} 1 \mathrm{~N}(\mathrm{C}) \mathrm{CCN}(\mathrm{C}) \mathrm{C}$ & 41 & $*$ \\
\hline
\end{tabular}




\begin{tabular}{|c|c|c|c|}
\hline 1753 & $\mathrm{COc} 1 \mathrm{cc}(\mathrm{Nc} 2 \mathrm{nccc}(\mathrm{Nc} 3 \mathrm{ccc} 4[\mathrm{nH}] \mathrm{ccc} 4 \mathrm{c} 3) \mathrm{n} 2) \mathrm{cc}(\mathrm{N} 2 \mathrm{CCOCC} 2) \mathrm{c} 1$ & 41 & $*$ \\
\hline 1754 & $\begin{array}{c}\mathrm{C}=\mathrm{CC}(=\mathrm{O}) \mathrm{Nc} 1 \mathrm{cccc}(\mathrm{Oc} 2 \mathrm{nc}(\mathrm{Nc} 3 \operatorname{ccc}(\mathrm{N} 4 \mathrm{CCN}(\mathrm{CC}(=\mathrm{O}) \mathrm{N} 5 \mathrm{CCC}(\mathrm{Oc} 6 \mathrm{no}[\mathrm{n}+]([\mathrm{O}-]) \mathrm{c} 6 \mathrm{~S}(=\mathrm{O})(=\mathrm{O}) \mathrm{c} 6 \mathrm{ccccc} 6) \mathrm{CC} 5) \mathrm{CC} 4) \\
\operatorname{cc} 3 \mathrm{OC}) \mathrm{ncc} 2 \mathrm{Cl}) \mathrm{c} 1\end{array}$ & 42 & 7.38 \\
\hline 1755 & $\operatorname{COc} 1 \mathrm{cc} 2 \mathrm{ncc}(\mathrm{C \# N}) \mathrm{c}(\mathrm{Nc} 3 \operatorname{ccc}(\mathrm{Sc} 4 \mathrm{nccs} 4) \mathrm{c}(\mathrm{Cl}) \mathrm{c} 3) \mathrm{c} 2 \mathrm{cc} 1 \mathrm{NC}(=\mathrm{O}) / \mathrm{C}=\mathrm{C} / \mathrm{CN}(\mathrm{C}) \mathrm{C}$ & 42 & 7.38 \\
\hline 1756 & $\mathrm{Fc} 1 \mathrm{ccc}(\mathrm{COc} 2 \mathrm{ccc}(\mathrm{Nc} 3 \mathrm{ncncc} 3 \mathrm{C} \# \mathrm{Cc} 3 \mathrm{cc}[\mathrm{nH}] \mathrm{n} 3) \mathrm{cc} 2 \mathrm{Cl}) \mathrm{c} 1$ & 42 & $*$ \\
\hline 1757 & $\mathrm{Nc} 1 \mathrm{cccc}(\mathrm{C} \# \mathrm{Cc} 2 \mathrm{cncnc} 2 \mathrm{Nc} 2 \mathrm{ccc}(\mathrm{OCc} 3 \mathrm{ccc}(\mathrm{F}) \mathrm{c} 3) \mathrm{c}(\mathrm{Cl}) \mathrm{c} 2) \mathrm{c} 1$ & 42 & $*$ \\
\hline 1758 & $\mathrm{c} 1 \mathrm{ccc}(-\mathrm{c} 2 \mathrm{cccc}(\mathrm{Nc} 3 \mathrm{ncnc} 4 \mathrm{cc} 5 \mathrm{c}(\mathrm{cc} 34) \mathrm{OCCO}) \mathrm{c} 2) \mathrm{cc} 1$ & 42 & $*$ \\
\hline 1759 & $\mathrm{O}=\mathrm{C} 1 \mathrm{CS} / \mathrm{C}(=\mathrm{N} / \mathrm{Nc} 2 \mathrm{nncc} 3 \operatorname{cccc} 23) \mathrm{N} 1 \mathrm{c} 1 \mathrm{ccc}(\mathrm{Cl}) \mathrm{cc} 1$ & 42 & $*$ \\
\hline 1760 & $\mathrm{C}=\mathrm{C}=\mathrm{CC}(=\mathrm{O}) \mathrm{Nc} 1 \mathrm{cc}(\mathrm{Nc} 2 \mathrm{nccc}(\mathrm{C} 3=\mathrm{CN}(\mathrm{C}) \mathrm{C} 4 \mathrm{C}=\mathrm{CC}=\mathrm{CC} 34) \mathrm{n} 2) \mathrm{c}(\mathrm{OC}) \mathrm{cc} 1 \mathrm{~N}(\mathrm{C}) \mathrm{CCN} 1 \mathrm{CCOCC} 1$ & 42 & $*$ \\
\hline 1761 & $\mathrm{Brc} 1 \mathrm{cccc}(\mathrm{Nc} 2 \mathrm{ncnc} 3 \mathrm{cc} 4 \mathrm{c}(\mathrm{cc} 23) \mathrm{OC}(\mathrm{CCN}(\mathrm{N} 2 \mathrm{CCOCC} 2) \mathrm{N} 2 \mathrm{CCOCC} 2) \mathrm{CO} 4) \mathrm{c} 1$ & 42 & $*$ \\
\hline 1762 & $\mathrm{C}=\mathrm{C}=\mathrm{CC}(=\mathrm{O}) \mathrm{Nc} 1 \mathrm{cc}(\mathrm{Nc} 2 \mathrm{nccc}(-\mathrm{c} 3 \mathrm{cn}(\mathrm{C}) \mathrm{c} 4 \mathrm{cccc} 34) \mathrm{n} 2) \mathrm{c}(\mathrm{OC}) \mathrm{cc} 1 \mathrm{~N}(\mathrm{C}) \mathrm{CCN} 1 \mathrm{CCOCC} 1$ & 42 & $*$ \\
\hline 1763 & COc1ccc(-c2cc3c(N[C@H](C)c4ccc(Br)cc4)ncnc3[nH]2)cc1 & 42 & $*$ \\
\hline 1764 & $\mathrm{Cc} 1 \mathrm{ccc}(\mathrm{C}(=\mathrm{O}) \mathrm{Nc} 2 \operatorname{ccc}(\mathrm{CN} 3 \mathrm{CCN}(\mathrm{C}) \mathrm{CC} 3) \mathrm{c}(\mathrm{C}(\mathrm{F})(\mathrm{F}) \mathrm{F}) \mathrm{c} 2) \mathrm{cc} 1 \mathrm{NC}(=\mathrm{O}) \mathrm{c} 1 \mathrm{cnc}(\mathrm{N}) \mathrm{nc} 1$ & 43 & 7.37 \\
\hline 1765 & $\mathrm{Cc} 1 \mathrm{ccc}(\mathrm{C}(=\mathrm{O}) \mathrm{Nc} 2 \mathrm{ccc}(\mathrm{CN} 3 \mathrm{CCN}(\mathrm{C}) \mathrm{CC} 3) \mathrm{c}(\mathrm{C}(\mathrm{F})(\mathrm{F}) \mathrm{F}) \mathrm{c} 2) \mathrm{cc} 1 \mathrm{NC}(=\mathrm{O}) \mathrm{c} 1 \mathrm{cnc}(\mathrm{NC}(\mathrm{C}) \mathrm{C}) \mathrm{nc} 1$ & 43 & 7.37 \\
\hline 1766 & $\mathrm{O}=\mathrm{C}(\mathrm{Nc} 1 \mathrm{cc} 2 \mathrm{c}(\mathrm{Nc} 3 \mathrm{ccc}(\mathrm{F}) \mathrm{c}(\mathrm{Cl}) \mathrm{c} 3) \mathrm{ncnc} 2 \mathrm{cc} 1 \mathrm{OCCCN} 1 \mathrm{CCOCC} 1) \mathrm{c} 1 \mathrm{cc}(\mathrm{F}) \mathrm{ccc} 1[\mathrm{~N}+](=\mathrm{O})[\mathrm{O}-]$ & 43 & 7.37 \\
\hline 1767 & $\mathrm{CS}(=\mathrm{O})(=\mathrm{O}) \mathrm{CCNCc} 1 \mathrm{ccc}(-\mathrm{c} 2 \mathrm{ccc} 3 \mathrm{ncnc}(\mathrm{Nc} 4 \mathrm{ccc}(\mathrm{OCc} 5 \operatorname{cccc}(\mathrm{Br}) \mathrm{c} 5) \mathrm{cc} 4) \mathrm{c} 3 \mathrm{c} 2) \mathrm{o} 1$ & 43 & $*$ \\
\hline 1768 & $\mathrm{Cc} 1 \mathrm{ccc}(\mathrm{Nc} 2 \mathrm{nccc}(\mathrm{N}(\mathrm{C}) \mathrm{c} 3 \operatorname{ccc} 4[\mathrm{nH}] \operatorname{ccc} 4 \mathrm{c} 3) \mathrm{n} 2) \operatorname{cc} 1 \mathrm{~S}(\mathrm{~N})(=\mathrm{O})=\mathrm{O}$ & 43 & $*$ \\
\hline 1769 & $\mathrm{C}=\mathrm{CC}(=\mathrm{O}) \mathrm{Nc} 1 \mathrm{cccc}(-\mathrm{c} 2 \mathrm{cc} 3 \mathrm{c}(-\mathrm{c} 4[\mathrm{nH}] \mathrm{c}(-\mathrm{c} 5 \mathrm{cccc} 5) \mathrm{nc} 4-\mathrm{c} 4 \mathrm{ccc}(\mathrm{F}) \mathrm{cc} 4) \mathrm{ccnc} 3[\mathrm{nH}] 2) \mathrm{c} 1$ & 43.2 & $*$ \\
\hline 1770 & $\mathrm{FC}(\mathrm{F})(\mathrm{F}) \mathrm{c} 1 \mathrm{cccc}(\mathrm{Nc} 2 \mathrm{ncnc} 3[\mathrm{nH}] \mathrm{ccc} 23) \mathrm{c} 1$ & 43.57 & $*$ \\
\hline 1771 & $\mathrm{O}=\mathrm{C}(\mathrm{c} 1 \mathrm{cc} 2 \mathrm{cccc} 2[\mathrm{nH}] 1) \mathrm{c} 1 \mathrm{cc} 2 \mathrm{c}(\mathrm{Nc} 3 \mathrm{ccc}(\mathrm{F}) \mathrm{cc} 3) \mathrm{ncnc} 2 \mathrm{~s} 1$ & 43.7 & $*$ \\
\hline 1772 & $\mathrm{C}=\mathrm{CC}(=\mathrm{O}) \mathrm{Nc} 1 \mathrm{ccc} 2 \mathrm{ncnc}(\mathrm{Nc} 3 \operatorname{ccc}(\mathrm{S}(=\mathrm{O})(=\mathrm{O}) \mathrm{Nc} 4 \mathrm{nccs} 4) \mathrm{cc} 3) \mathrm{c} 2 \mathrm{c} 1$ & 43.7 & $*$ \\
\hline 1773 & $\operatorname{COCCOc} 1 \mathrm{cc} 2 \mathrm{ncnc}(\mathrm{Nc} 3 \mathrm{ccc}(\mathrm{F}) \mathrm{c}([\mathrm{N}+](=\mathrm{O})[\mathrm{O}-]) \mathrm{c} 3) \mathrm{c} 2 \mathrm{c} 2 \mathrm{c} 1 \mathrm{OCCO} 2$ & 43.8 & $*$ \\
\hline 1774 & $\mathrm{Cc} 1 \mathrm{ccc}(\mathrm{C}(=\mathrm{O}) \mathrm{Nc} 2 \operatorname{ccc}(\mathrm{CN} 3 \mathrm{CCN}(\mathrm{C}) \mathrm{CC} 3) \mathrm{c}(\mathrm{C}(\mathrm{F})(\mathrm{F}) \mathrm{F}) \mathrm{c} 2) \mathrm{cc} 1 \mathrm{NC}(=\mathrm{O}) \mathrm{c} 1 \mathrm{cnc}(\mathrm{NC} 2 \mathrm{CC} 2) \mathrm{nc} 1$ & 44 & 7.36 \\
\hline 1775 & C[C@@H](Nc1ncnc2oc(-c3ccc(C\#N)cc3)cc12)c1 ccccc1 & 44 & 7.36 \\
\hline 1776 & $\mathrm{O}=\mathrm{C}(\mathrm{Nc} 1 \mathrm{cc} 2 \mathrm{c}(\mathrm{Nc} 3 \operatorname{ccc}(\mathrm{F}) \mathrm{c}(\mathrm{Cl}) \mathrm{c} 3) \mathrm{ncnc} 2 \mathrm{cc} 1 \mathrm{~F}) \mathrm{c} 1 \mathrm{cc}([\mathrm{N}+](=\mathrm{O})[\mathrm{O}-]) \operatorname{ccc} 1 \mathrm{~F}$ & 44 & 7.36 \\
\hline 1777 & $\mathrm{CC}(\mathrm{C}) \mathrm{N}(\mathrm{CC} \# \mathrm{CC}(=\mathrm{O}) \mathrm{Nc} 1 \mathrm{cc} 2 \mathrm{c}(\mathrm{Nc} 3 \mathrm{ccc}(\mathrm{F}) \mathrm{c}(\mathrm{Cl}) \mathrm{c} 3) \mathrm{ncnc} 2 \mathrm{cn} 1) \mathrm{C}(\mathrm{C}) \mathrm{C}$ & 44 & $*$ \\
\hline 1778 & $\mathrm{CCC} 1=\mathrm{C} 2 \mathrm{C}(\mathrm{Nc} 3 \operatorname{ccc} 4 \mathrm{c}(\operatorname{cnn} 4 \mathrm{Cc} 4 \mathrm{ccccc} 4) \mathrm{c} 3)=\mathrm{NC}=\mathrm{NC} 2 \mathrm{~N}=\mathrm{C} 1 \mathrm{NC}(=\mathrm{O}) \mathrm{OCCn} 1 \mathrm{ccnc} 1$ & 44 & $*$ \\
\hline 1779 & $\mathrm{COC}(=\mathrm{O}) \mathrm{C} 1=\mathrm{Cc} 2 \mathrm{c}(\mathrm{ncnc} 2 \mathrm{Nc} 2 \operatorname{ccc}(\mathrm{Oc} 3 \operatorname{ccc} 4 \operatorname{scc} 34) \mathrm{c}(\mathrm{Cl}) \mathrm{c} 2) \mathrm{NCC} 1$ & 44 & $*$ \\
\hline 1780 & $\operatorname{Brc} 1 \mathrm{ccc}(\mathrm{Nc} 2 \mathrm{ncnc} 3 \mathrm{cc} 4 \mathrm{ncsc} 4 \mathrm{cc} 23) \mathrm{c} 1$ & 44 & $*$ \\
\hline 1781 & $\mathrm{Fc} 1 \mathrm{ccc} 2 \mathrm{ncnc}(\mathrm{Nc} 3 \operatorname{cccc}(\mathrm{Br}) \mathrm{c} 3) \mathrm{c} 2 \mathrm{n} 1$ & 44 & $*$ \\
\hline 1782 & $\mathrm{CCN}(\mathrm{CC}) \mathrm{CCOc} 1 \mathrm{ccc}(\mathrm{Nc} 2 \mathrm{ncc} 3 \mathrm{cc}(-\mathrm{c} 4 \mathrm{c}(\mathrm{Cl}) \operatorname{cccc} 4 \mathrm{Cl}) \mathrm{c}(=\mathrm{O}) \mathrm{n}(\mathrm{C}) \mathrm{c} 3 \mathrm{n} 2) \mathrm{cc} 1$ & 44 & $*$ \\
\hline 1783 & $\mathrm{CO} / \mathrm{N}=\mathrm{C} / \mathrm{c} 1 \mathrm{c}(\mathrm{N}) \mathrm{ncnc} 1 \mathrm{Nc} 1 \mathrm{ccc} 2 \mathrm{c}(\mathrm{cnn} 2 \mathrm{Cc} 2 \mathrm{cccc} 2) \mathrm{c} 1$ & 44 & $*$ \\
\hline 1784 & OCCCe1nc(-c2 $\operatorname{ccc}(\mathrm{F}) \mathrm{cc} 2) \mathrm{c}(-\mathrm{c} 2 \mathrm{ccnc} 3[\mathrm{nH}] \operatorname{ccc} 23)[\mathrm{nH}] 1$ & 44 & $*$ \\
\hline 1785 & OCCSCCn $1 \operatorname{ccc} 2 n c n c(N c 3 \operatorname{ccc}(\mathrm{Oc} 4 \operatorname{ccc}(\mathrm{C}(\mathrm{F})(\mathrm{F}) \mathrm{F}) \mathrm{c} 4) \mathrm{c}(\mathrm{Cl}) \mathrm{c} 3) \mathrm{c} 21$ & 44 & $*$ \\
\hline 1786 & $\mathrm{Cn} 1 \mathrm{cc}(-\mathrm{c} 2 \mathrm{ccc} 3 \mathrm{n} \operatorname{cnc}(\mathrm{Nc} 4 \mathrm{ccc} 5 \mathrm{ncccc} 5 \mathrm{c} 4) \mathrm{c} 3 \mathrm{c} 2) \mathrm{cn} 1$ & 44.1 & 7.36 \\
\hline 1787 & $\mathrm{C}=\mathrm{CS}(=\mathrm{O})(=\mathrm{O}) \mathrm{Nc} 1 \mathrm{cc} 2 \mathrm{c}(\mathrm{Nc} 3 \operatorname{ccc}(\mathrm{OCc} 4 \mathrm{ccccc} 4) \mathrm{c}(\mathrm{Cl}) \mathrm{c} 3) \mathrm{c}(\mathrm{C \# N}) \mathrm{cnc} 2 \mathrm{cc} 1 \mathrm{OCC}$ & 45 & 7.35 \\
\hline 1788 & $\mathrm{CCOc} 1 \mathrm{cc} 2 \mathrm{ncc}(\mathrm{C} \# \mathrm{~N}) \mathrm{c}(\mathrm{Nc} 3 \operatorname{ccc}(\mathrm{NCc} 4 \operatorname{ccccc} 4) \mathrm{c}(\mathrm{Cl}) \mathrm{c} 3) \mathrm{c} 2 \mathrm{cc} 1 \mathrm{NC}(=\mathrm{O}) / \mathrm{C}=\mathrm{C} / \mathrm{CN}(\mathrm{C}) \mathrm{C}$ & 45 & 7.35 \\
\hline 1789 & $\mathrm{Cc} 1 \mathrm{ncnc}(\mathrm{Nc} 2 \mathrm{ccc}(\mathrm{OCc} 3 \operatorname{ccc}(\mathrm{F}) \mathrm{c} 3) \mathrm{c}(\mathrm{Cl}) \mathrm{c} 2) \mathrm{c} 1 \mathrm{C} \# \mathrm{Cc} 1 \mathrm{ccc}(\mathrm{CNCCS}(\mathrm{C})(=\mathrm{O})=\mathrm{O}) \mathrm{o} 1$ & 45 & 7.35 \\
\hline 1790 & $\mathrm{C}=\mathrm{CC}(=\mathrm{O}) \mathrm{Nc} 1 \mathrm{ccc} 2 \mathrm{ncnc}(\mathrm{Nc} 3 \operatorname{ccc}(\mathrm{CN}(\mathrm{C}) \mathrm{C}) \mathrm{c}(\mathrm{Br}) \mathrm{c} 3) \mathrm{c} 2 \mathrm{c} 1$ & 45 & $*$ \\
\hline 1791 & $\mathrm{CN}(\mathrm{C}) \mathrm{CCNc} 1 \mathrm{cc} 2 \mathrm{ncnc}(\mathrm{Nc} 3 \mathrm{cccc}(\mathrm{Br}) \mathrm{c} 3) \mathrm{c} 2 \mathrm{cn} 1$ & 45 & $*$ \\
\hline 1792 & OCCNCc1cen2nenc(Nc3ecc4c(enn4Cc4cece(F)c4)c3)c12 & 45 & $*$ \\
\hline 1793 & $\mathrm{O}=\mathrm{C} 1 \mathrm{CS} / \mathrm{C}(=\mathrm{N} / \mathrm{Nc} 2 \mathrm{nncc} 3 \operatorname{ccc} c 23) \mathrm{N} 1 \mathrm{c} 1 \mathrm{ccccc} 1$ & 45 & $*$ \\
\hline 1794 & Br.Oc1ece(-c2 $2 \mathrm{cc} 3 \mathrm{c}(\mathrm{NCc} 4 \mathrm{cccc} 4 \mathrm{~F}) \mathrm{ncnc} 3[\mathrm{nH}] 2) \mathrm{cc} 1$ & 45 & $*$ \\
\hline
\end{tabular}




\begin{tabular}{|c|c|c|c|}
\hline 1795 & $\mathrm{C}=\mathrm{CC}(=\mathrm{O}) \mathrm{Nc} 1 \mathrm{cccc}(\mathrm{NC}(=\mathrm{O}) \mathrm{Nc} 2 \mathrm{ccnc}(\mathrm{Nc} 3 \operatorname{ccc}(\mathrm{N} 4 \mathrm{CCC}(\mathrm{N}(\mathrm{C}) \mathrm{C}) \mathrm{CC} 4) \mathrm{cc} 3 \mathrm{OC}) \mathrm{n} 2) \mathrm{c} 1$ & 45 & $*$ \\
\hline 1796 & $\mathrm{C}=\mathrm{CC}(=\mathrm{O}) \mathrm{NCCSc} 1 \mathrm{nc}(-\mathrm{c} 2 \mathrm{ccc}(\mathrm{F}) \mathrm{c}(\mathrm{C}(\mathrm{F})(\mathrm{F}) \mathrm{F}) \mathrm{c} 2) \mathrm{c}(-\mathrm{c} 2 \mathrm{ccnc}(\mathrm{Nc} 3 \operatorname{cccc} 3) \mathrm{c} 2)[\mathrm{nH}] 1$ & 45 & $*$ \\
\hline 1797 & $\mathrm{COc} 1 \mathrm{cc} 2 \mathrm{ncnc}(\mathrm{Nc} 3 \operatorname{ccc}(\mathrm{F}) \mathrm{c}(\mathrm{Cl}) \mathrm{c} 3) \mathrm{c} 2 \mathrm{cc} 1 \mathrm{NC}(=\mathrm{O}) / \mathrm{C}=\mathrm{C} / \mathrm{CN} 1 \mathrm{CCCC}(\mathrm{F}) \mathrm{C} 1$ & 45.34 & $*$ \\
\hline 1798 & $\mathrm{COc} 1 \mathrm{cc} 2 \mathrm{ncnc}(\mathrm{N} 3 \mathrm{CCc} 4 \operatorname{cccc} 43) \mathrm{c} 2 \mathrm{cc} 1 \mathrm{NC}(=\mathrm{O}) / \mathrm{C}=\mathrm{C} / \mathrm{CN} 1 \mathrm{CCCCC} 1$ & 45.4 & $*$ \\
\hline 1799 & $\mathrm{O}=\mathrm{C}(\mathrm{Nc} 1 \mathrm{cccc}(\mathrm{Br}) \mathrm{c} 1) \mathrm{c} 1 \mathrm{ccc}(\mathrm{OCCCN} 2 \mathrm{CCCCC} 2) \mathrm{cc} 1 \mathrm{O}$ & 45.7 & $*$ \\
\hline 1800 & $\mathrm{CN}(\mathrm{C}) \mathrm{CCNc} 1 \mathrm{c}(\mathrm{Br}) \mathrm{ccc} 1 \mathrm{Nc} 1 \mathrm{ncnc} 2 \mathrm{ccncc} 12$ & 45.71 & $*$ \\
\hline 1801 & $\mathrm{C}=\mathrm{CC}(=\mathrm{O}) \mathrm{N} 1 \mathrm{CCc} 2 \mathrm{c}(\operatorname{sc} 3 \mathrm{ncnc}(\mathrm{N}[\mathrm{C} @ \mathrm{H}](\mathrm{CC}) \mathrm{c} 4 \operatorname{ccccc} 4) \mathrm{c} 23) \mathrm{C} 1$ & 46 & $*$ \\
\hline 1802 & $\operatorname{Brc} 1 \mathrm{ccc}(\mathrm{Nc} 2[\mathrm{nH}] \mathrm{cnc} 3 \mathrm{nc} 4 \mathrm{c}(\mathrm{c} 2-3) \mathrm{CCCC} 4) \mathrm{c} 1$ & 46 & $*$ \\
\hline 1803 & $\mathrm{C}=\mathrm{CC}(=\mathrm{O}) \mathrm{Nc} 1 \mathrm{cc}(\mathrm{Nc} 2 \mathrm{ncc}(\mathrm{F}) \mathrm{c}(\mathrm{Nc} 3 \operatorname{cccc} 3 \mathrm{~S}(=\mathrm{O})(=\mathrm{O}) \mathrm{C}(\mathrm{C}) \mathrm{C}) \mathrm{n} 2) \mathrm{c}(\mathrm{OC}) \mathrm{cc} 1 \mathrm{~N}(\mathrm{C}) \mathrm{CCN}(\mathrm{C}) \mathrm{C}$ & 46 & $*$ \\
\hline 1804 & $\mathrm{C}=\mathrm{CC}(=\mathrm{O}) \mathrm{Nc} 1 \mathrm{ccc}(\mathrm{Oc} 2 \mathrm{nc}(\mathrm{Nc} 3 \mathrm{ccc}(\mathrm{N} 4 \mathrm{CCN}(\mathrm{C}(=\mathrm{O}) \mathrm{CC}) \mathrm{CC} 4) \operatorname{cc} 3 \mathrm{OC}(\mathrm{F}) \mathrm{F}) \mathrm{ncc} 2 \mathrm{SC}) \mathrm{c} 1$ & 46.4 & $*$ \\
\hline 1805 & $\mathrm{C}=\mathrm{CC}(=\mathrm{O}) \mathrm{Nc} 1 \mathrm{cc}(-\mathrm{n} 2 \mathrm{c}(=\mathrm{O}) \mathrm{cc}(\mathrm{C}) \mathrm{c} 3 \mathrm{cnc}(\mathrm{Nc} 4 \mathrm{ccc}(\mathrm{N} 5 \mathrm{CCN}(\mathrm{C}) \mathrm{CC} 5) \mathrm{nc} 4) \mathrm{nc} 32) \mathrm{cc}(\mathrm{C}(\mathrm{F})(\mathrm{F}) \mathrm{F}) \mathrm{c} 1$ & 46.8 & $*$ \\
\hline 1806 & $\mathrm{Cc} 1 \mathrm{ccc}(\mathrm{C}(=\mathrm{O}) \mathrm{Nc} 2 \operatorname{ccc}(\mathrm{CN} 3 \mathrm{CCN}(\mathrm{C}) \mathrm{CC} 3) \mathrm{c}(\mathrm{C}(\mathrm{F})(\mathrm{F}) \mathrm{F}) \mathrm{c} 2) \operatorname{cc} 1 \mathrm{NC}(=\mathrm{O}) \mathrm{c} 1 \mathrm{cnc}(\mathrm{NC} 2 \mathrm{CCCCC} 2) \mathrm{nc} 1$ & 47 & 7.33 \\
\hline 1807 & $\mathrm{CC}(\mathrm{C})(\mathrm{C}(=\mathrm{O}) \mathrm{NCCn} 1 \mathrm{ccc} 2 \mathrm{ncnc}(\mathrm{Nc} 3 \operatorname{ccc}(\mathrm{Oc} 4 \operatorname{ccc}(\mathrm{C}(\mathrm{F})(\mathrm{F}) \mathrm{F}) \mathrm{c} 4) \mathrm{c}(\mathrm{Cl}) \mathrm{c} 3) \mathrm{c} 21) \mathrm{S}(\mathrm{C})(=\mathrm{O})=\mathrm{O}$ & 47 & $*$ \\
\hline 1808 & $\mathrm{CS}(=\mathrm{O})(=\mathrm{O}) \mathrm{CCNC}(=\mathrm{O}) \mathrm{C} 1=\mathrm{Cc} 2 \mathrm{c}(\mathrm{ncnc} 2 \mathrm{Nc} 2 \mathrm{ccc}(\mathrm{Oc} 3 \operatorname{ccc} 4 \operatorname{secc} 34) \mathrm{c}(\mathrm{Cl}) \mathrm{c} 2) \mathrm{NCC} 1$ & 47 & $*$ \\
\hline 1809 & $\mathrm{Nc} 1 \mathrm{ccc} 2 \mathrm{sc} 3 \mathrm{c}(\mathrm{Nc} 4 \mathrm{ccc}(\mathrm{C}(\mathrm{F})(\mathrm{F}) \mathrm{F}) \mathrm{c} 4) \mathrm{ncnc} 3 \mathrm{c} 2 \mathrm{c} 1$ & 47 & $*$ \\
\hline 1810 & $\mathrm{NC} 1 \mathrm{CCN}(\mathrm{Cc} 2 \mathrm{ccn} 3 \mathrm{ncnc}(\mathrm{Nc} 4 \mathrm{ccc} 5 \mathrm{c}(\mathrm{cnn} 5 \mathrm{Cc} 5 \mathrm{ccc} \mathrm{cn} 5) \mathrm{c} 4) \mathrm{c} 23) \mathrm{CC} 1$ & 47 & $*$ \\
\hline 1811 & $\mathrm{CCN} 1 \mathrm{C}(=\mathrm{O}) \mathrm{CS} / \mathrm{C} 1=\mathrm{N} / \mathrm{Nc} 1 \mathrm{nncc} 2 \operatorname{ccccc} 12$ & 47 & $*$ \\
\hline 1812 & $\mathrm{COc} 1 \mathrm{cccc} 1 \mathrm{CO} / \mathrm{N}=\mathrm{C} / \mathrm{c} 1 \mathrm{c}(\mathrm{N}) \mathrm{ncnc} 1 \mathrm{Nc} 1 \mathrm{ccc} 2 \mathrm{c}(\mathrm{cnn} 2 \mathrm{Cc} 2 \mathrm{cccc}(\mathrm{F}) \mathrm{c} 2) \mathrm{c} 1$ & 47 & $*$ \\
\hline 1813 & $\operatorname{COc} 1 \operatorname{ccc}(-\mathrm{c} 2 \mathrm{cc} 3 \mathrm{c}(\mathrm{N}[\mathrm{C} @ \mathrm{H}](\mathrm{C}) \mathrm{c} 4 \operatorname{ccc}([\mathrm{N}+](=\mathrm{O})[\mathrm{O}-]) \mathrm{cc} 4) \mathrm{ncnc} 3[\mathrm{nH}] 2) \mathrm{cc} 1$ & 47 & $*$ \\
\hline 1814 & $\operatorname{COc} 1 \mathrm{ccc}(-\mathrm{c} 2 \mathrm{c} 3 \mathrm{c} 4 \mathrm{cc}(\mathrm{OC}) \mathrm{c}(\mathrm{OCCCNC}(=\mathrm{N}) \mathrm{N}) \mathrm{cc} 4 \mathrm{oc}(=\mathrm{O}) \mathrm{c} 3 \mathrm{n} 3 \mathrm{ccc} 4 \mathrm{cc}(\mathrm{O}) \mathrm{c}(\mathrm{OC}) \mathrm{cc} 4 \mathrm{c} 23) \mathrm{cc} 1 \mathrm{O} . \mathrm{O}=\mathrm{C}(\mathrm{O}) \mathrm{C}(\mathrm{F})(\mathrm{F}) \mathrm{F}$ & 47 & $*$ \\
\hline 1815 & $\mathrm{Nc} 1 \mathrm{cnc}(\mathrm{C} \# \mathrm{Cc} 2 \mathrm{cc} 3 \mathrm{ncnc}(\mathrm{Nc} 4 \mathrm{ccc}(\mathrm{OCc} 5 \mathrm{cccc}(\mathrm{F}) \mathrm{c} 5) \mathrm{c}(\mathrm{Cl}) \mathrm{c} 4) \mathrm{c} 3 \mathrm{~s} 2) \mathrm{cn} 1$ & 47 & $*$ \\
\hline 1816 & $\mathrm{C}=\mathrm{CC}(=\mathrm{O}) \mathrm{Nc} 1 \mathrm{cccc}(-\mathrm{n} 2 \mathrm{c}(=\mathrm{O}) \mathrm{cnc} 3 \mathrm{cnc}(\mathrm{Nc} 4 \mathrm{ccc}(\mathrm{Cl}) \mathrm{cc} 4) \mathrm{nc} 32) \mathrm{c} 1$ & 47.1 & 7.33 \\
\hline 1817 & $\mathrm{CS}(=\mathrm{O})(=\mathrm{O}) \mathrm{Nc} 1 \mathrm{ccc}(-\mathrm{c} 2 \mathrm{cc} 3 \mathrm{c}(\mathrm{Nc} 4 \mathrm{ccc}(\mathrm{Oc} 5 \mathrm{cccc}(\mathrm{C}(\mathrm{F})(\mathrm{F}) \mathrm{F}) \mathrm{c} 5) \mathrm{c}(\mathrm{Cl}) \mathrm{c} 4) \mathrm{ncnc} 3 \mathrm{~s} 2) \mathrm{cc} 1$ & 47.1 & * \\
\hline 1818 & $\mathrm{CCOc} 1 \mathrm{cc} 2 \mathrm{ncnc}(\mathrm{NC} 3=\mathrm{CC}(=\mathrm{O}) \mathrm{C}(\mathrm{OCc} 4 \operatorname{cccs} 4)=\mathrm{CC} 3=\mathrm{O}) \mathrm{c} 2 \mathrm{cc} 1 \mathrm{NC}(=\mathrm{O}) / \mathrm{C}=\mathrm{C} / \mathrm{CN}(\mathrm{C}) \mathrm{C}$ & 47.5 & 7.32 \\
\hline 1819 & $\mathrm{CC}(=\mathrm{O}) \mathrm{Nc} 1 \mathrm{ccc}(-\mathrm{c} 2 \mathrm{cc} 3 \mathrm{c}(\mathrm{Nc} 4 \mathrm{ccc}(\mathrm{Oc} 5 \mathrm{ccc}(\mathrm{C}(\mathrm{F})(\mathrm{F}) \mathrm{F}) \mathrm{c} 5) \mathrm{c}(\mathrm{Cl}) \mathrm{c} 4) \mathrm{ncnc} 3 \mathrm{~s} 2) \mathrm{cc} 1$ & 47.7 & $*$ \\
\hline 1820 & $\mathrm{COc} 1 \mathrm{ccc}(-\mathrm{c} 2 \mathrm{c} 3 \mathrm{c} 4 \mathrm{cc}(\mathrm{O}) \mathrm{c}(\mathrm{OCCCN}(\mathrm{C}) \mathrm{C}) \mathrm{cc} 4 \mathrm{oc}(=\mathrm{O}) \mathrm{c} 3 \mathrm{n} 3 \operatorname{ccc} 4 \mathrm{cc}(\mathrm{O}) \mathrm{c}(\mathrm{OC}) \mathrm{cc} 4 \mathrm{c} 23) \mathrm{cc} 1 \mathrm{O} . \mathrm{O}=\mathrm{C}(\mathrm{O}) \mathrm{C}(\mathrm{F})(\mathrm{F}) \mathrm{F}$ & 47.8 & $*$ \\
\hline 1821 & $\mathrm{N \# CCC}(=\mathrm{O}) \mathrm{Nc} 1 \mathrm{cccc}(\mathrm{Oc} 2 \mathrm{cc}(\mathrm{Nc} 3 \operatorname{ccc}(\mathrm{OCc} 4 \mathrm{ccc}(\mathrm{F}) \mathrm{c} 4) \mathrm{c}(\mathrm{Cl}) \mathrm{c} 3) \mathrm{ncn} 2) \mathrm{c} 1$ & 48 & 7.32 \\
\hline 1822 & $\mathrm{COc} 1 \mathrm{cc} 2 \mathrm{ncnc}(\mathrm{Nc} 3 \mathrm{ccc}(\mathrm{F}) \mathrm{c}(\mathrm{Cl}) \mathrm{c} 3) \mathrm{c} 2 \mathrm{cc} 1 \mathrm{OCCCN} 1 \mathrm{CC} 2(\mathrm{CSC} 2) \mathrm{C} 1$ & 48 & 7.32 \\
\hline 1823 & $\operatorname{CCCCCCCCCCCCCCCCOC}(=0) \operatorname{COc} 1 \mathrm{cc}(\mathrm{O}) \mathrm{c} 2 \mathrm{c}(=\mathrm{O}) \operatorname{cc}(-\mathrm{c} 3 \operatorname{ccccc} 3) \mathrm{oc} 2 \mathrm{c} 1$ & 48 & 7.32 \\
\hline 1824 & OCc1 $\operatorname{ccc}(-\mathrm{c} 2 \mathrm{cc} 3 \mathrm{c}(\mathrm{NCc} 4 \mathrm{cccc} 4) \mathrm{ncnc} 3 \mathrm{~s} 2) \mathrm{cc} 1$ & 48 & 7.32 \\
\hline 1825 & $\mathrm{CN}(\mathrm{C}) \mathrm{CC}(=\mathrm{O}) \mathrm{Nc} 1 \mathrm{cccc}(-\mathrm{c} 2 \mathrm{c}(-\mathrm{c} 3 \operatorname{ccccc} 3) \mathrm{oc} 3 \mathrm{ncnc}(\mathrm{N}[\mathrm{C} @ \mathrm{H}](\mathrm{CO}) \mathrm{c} 4 \mathrm{ccccc} 4) \mathrm{c} 23) \mathrm{c} 1$ & 48 & $*$ \\
\hline 1826 & CN[C@@H]1C[C@H]2O[C@@](C)([C@@H]1OC)n1c3cccc3c3c4c(c5c6ccccc6n2c5c31)C(=O)NC4 & 48 & $*$ \\
\hline 1827 & $\mathrm{Cl} . \mathrm{O}=[\mathrm{N}+]([\mathrm{O}-]) \mathrm{c} 1 \mathrm{ccc} 2 \mathrm{c}(\mathrm{c} 1) \mathrm{sc} 1 \mathrm{c}(\mathrm{Nc} 3 \mathrm{cccc}(\mathrm{Br}) \mathrm{c} 3) \mathrm{ncnc} 12$ & 48 & $*$ \\
\hline 1828 & $\mathrm{OCCNC} 1 \mathrm{CCN}(\mathrm{Cc} 2 \mathrm{ccn} 3 \mathrm{ncnc}(\mathrm{Nc} 4 \mathrm{ccc} 5 \mathrm{c}(\mathrm{cnn} 5 \mathrm{Cc} 5 \mathrm{cccc}(\mathrm{F}) \mathrm{c} 5) \mathrm{c} 4) \mathrm{c} 23) \mathrm{CC} 1$ & 48 & $*$ \\
\hline 1829 & $\mathrm{Fc} 1 \mathrm{cccc}(\mathrm{COc} 2 \mathrm{ccc}(\mathrm{Nc} 3 \mathrm{ncnn} 4 \mathrm{ccc}(\mathrm{CN} 5 \mathrm{CCCNCC} 5) \mathrm{c} 34) \mathrm{cc} 2 \mathrm{Cl}) \mathrm{c} 1$ & 48 & $*$ \\
\hline 1830 & $\mathrm{CO} / \mathrm{N}=\mathrm{C} / \mathrm{c} 1 \mathrm{c}(\mathrm{N}) \mathrm{ncnc} 1 \mathrm{Nc} 1 \mathrm{ccc} 2[\mathrm{nH}] \mathrm{c}(\mathrm{Cc} 3 \operatorname{ccc}(\mathrm{F}) \mathrm{c} 3) \mathrm{nc} 2 \mathrm{c} 1$ & 48 & $*$ \\
\hline 1831 & $\mathrm{C}=\mathrm{CC}(=\mathrm{O}) \mathrm{Nc} 1 \mathrm{cc}(\mathrm{Nc} 2 \mathrm{n}[\mathrm{nH}] \mathrm{c} 3 \mathrm{cc}(-\mathrm{c} 4 \mathrm{cccc}(\mathrm{N}(\mathrm{C}) \mathrm{C}) \mathrm{c} 4) \operatorname{ccc} 23) \mathrm{c}(\mathrm{OC}) \mathrm{cc} 1 \mathrm{~N}(\mathrm{C}) \mathrm{CCN}(\mathrm{C}) \mathrm{C}$ & 48 & $*$ \\
\hline 1832 & $\operatorname{CCOC}(=\mathrm{O}) \mathrm{c} 1 \mathrm{ccc}(\mathrm{Nc} 2 \mathrm{cc}(\mathrm{NC}(=\mathrm{O}) \mathrm{CCCC}(=\mathrm{O}) \mathrm{O}) \mathrm{ncn} 2) \mathrm{cc} 1$ & 48 & * \\
\hline 1833 & $\operatorname{COc} 1 \mathrm{cc}(\mathrm{NC}(=\mathrm{O}) \mathrm{Nc} 2 \mathrm{ccc} n 2) \mathrm{cc}(-\mathrm{c} 2 \mathrm{cccnc} 2) \mathrm{c} 1 \mathrm{OC}$ & 48.81 & $*$ \\
\hline 1834 & $\mathrm{~S}=\mathrm{C}(\mathrm{Nc} 1 \mathrm{ccc} 2 \mathrm{ncnc}(\mathrm{Nc} 3 \mathrm{cccc}(\mathrm{Br}) \mathrm{c} 3) \mathrm{c} 2 \mathrm{c} 1) \mathrm{Nc} 1 \mathrm{ccc}(\mathrm{Cl}) \mathrm{cc} 1 \mathrm{Cl}$ & 48.9 & $*$ \\
\hline 1835 & $\mathrm{Nc} 1 \mathrm{ccccc} 1 \mathrm{NC}(=\mathrm{O}) / \mathrm{C}=\mathrm{C} / \mathrm{c} 1 \mathrm{cccc}(-\mathrm{c} 2 \mathrm{ccc} 3 \mathrm{ncnc}(\mathrm{Nc} 4 \mathrm{ccc}(\mathrm{OCc} 5 \mathrm{cccc}(\mathrm{F}) \mathrm{c} 5) \mathrm{c}(\mathrm{Cl}) \mathrm{c} 4) \mathrm{c} 3 \mathrm{c} 2) \mathrm{c} 1$ & 49 & $*$ \\
\hline 1836 & $\mathrm{COc} 1 \mathrm{cc} 2 \mathrm{ncnc}(\mathrm{Nc} 3 \mathrm{ccc}(\mathrm{F}) \mathrm{c}(\mathrm{Cl}) \mathrm{c} 3) \mathrm{c} 2 \mathrm{cc} 1 \mathrm{OCCCN}(\mathrm{C}) \mathrm{C}$ & 49 & $*$ \\
\hline 1837 & $\operatorname{COc} 1 \operatorname{ccc}(/ \mathrm{N}=\mathrm{C} / \mathrm{c} 2 \mathrm{c}(\mathrm{N}) \mathrm{ncnc} 2 \mathrm{Nc} 2 \mathrm{ccc} 3 \mathrm{c}(\operatorname{cnn} 3 \mathrm{Cc} 3 \operatorname{ccc}(\mathrm{F}) \mathrm{c} 3) \mathrm{c} 2) \mathrm{cc} 1$ & 49 & $*$ \\
\hline
\end{tabular}




\begin{tabular}{|c|c|c|c|}
\hline 1838 & $\mathrm{C}=\mathrm{CC}(=\mathrm{O}) \mathrm{Nc} 1 \mathrm{cccc}(\mathrm{NC}(=\mathrm{O}) \mathrm{Nc} 2 \mathrm{ccnc}(\mathrm{Nc} 3 \operatorname{ccc}(\mathrm{N}(\mathrm{C}) \mathrm{CCN}(\mathrm{C}) \mathrm{C}) \mathrm{cc} 3 \mathrm{OC}) \mathrm{n} 2) \mathrm{c} 1$ & 49 & $*$ \\
\hline 1839 & OCCOCCn1 cec2nenc(Ne3ecc $(\mathrm{Oc} 4 \operatorname{cccc}(\mathrm{OC}(\mathrm{F})(\mathrm{F}) \mathrm{F}) \mathrm{c} 4) \mathrm{c}(\mathrm{Cl}) \mathrm{c} 3) \mathrm{c} 21$ & 49 & $*$ \\
\hline 1840 & $\mathrm{Cc} 1 \mathrm{ccc}(\mathrm{NC}(/ \mathrm{C}=\mathrm{C} / \mathrm{c} 2 \mathrm{ccccc} 2) \mathrm{n} 2 \mathrm{c}(-\mathrm{c} 3 \mathrm{cc}(\mathrm{CCn} 4 \mathrm{c}(-\mathrm{c} 5 \mathrm{cccc} 5) \mathrm{nc} 5 \mathrm{ccccc} 5 \mathrm{c} 4=\mathrm{O}) \operatorname{ccc} 3 \mathrm{Cl}) \mathrm{nc} 3 \operatorname{ccccc} 32) \mathrm{cc} 1$ & 49 & $*$ \\
\hline 1841 & $\mathrm{CN} 1 \mathrm{CCN}(\mathrm{c} 2 \mathrm{ccc}(\mathrm{Nc} 3 \mathrm{nccc}(\mathrm{Nc} 4 \mathrm{ccc} 5[\mathrm{nH}] \mathrm{ccc} 5 \mathrm{c} 4) \mathrm{n} 3) \mathrm{cc} 2) \mathrm{CC} 1$ & 49 & $*$ \\
\hline 1842 & Oc1 $1 \mathrm{ccc}(-\mathrm{c} 2 \mathrm{nc}(-\mathrm{c} 3 \mathrm{ccc}(\mathrm{F}) \mathrm{cc} 3) \mathrm{c}(-\mathrm{c} 3 \mathrm{ccnc} 4[\mathrm{nH}] \mathrm{c}(-\mathrm{c} 5 \mathrm{ccccc} 5) \mathrm{cc} 34)[\mathrm{nH}] 2) \mathrm{cc} 1$ & 49.2 & $*$ \\
\hline 1843 & $\begin{array}{c}\mathrm{O}=\mathrm{C} 1 \mathrm{OC}[\mathrm{C} @ \mathrm{H}] 2 \mathrm{OC}(=\mathrm{O}) \mathrm{c} 3 \mathrm{cc}(\mathrm{O}) \mathrm{c}(\mathrm{O}) \mathrm{c}(\mathrm{O}) \mathrm{c} 3-\mathrm{c} 3 \mathrm{c}(\mathrm{O}) \mathrm{c}(\mathrm{O}) \mathrm{c}(\mathrm{O}) \mathrm{c} 4 \mathrm{c} 3 \mathrm{C}(=\mathrm{O}) \mathrm{O}[\mathrm{C} @ \mathrm{H}]([\mathrm{C} @ \mathrm{H}] 3 \mathrm{OC}(=\mathrm{O}) \mathrm{c} 5 \mathrm{c}- \\
4 \mathrm{c}(\mathrm{O}) \mathrm{c}(\mathrm{O}) \mathrm{c}(\mathrm{O}) \mathrm{c} 5[\mathrm{C} @ \mathrm{H}] 3 \mathrm{O})[\mathrm{C} @ @ \mathrm{H}] 2 \mathrm{OC}(=\mathrm{O}) \mathrm{c} 2 \mathrm{cc}(\mathrm{O}) \mathrm{c}(\mathrm{O}) \mathrm{c}(\mathrm{O}) \mathrm{c} 2-\mathrm{c} 2 \mathrm{c} 1 \mathrm{cc}(\mathrm{O}) \mathrm{c}(\mathrm{O}) \mathrm{c} 2 \mathrm{O}\end{array}$ & 49.9 & $*$ \\
\hline 1844 & $\mathrm{Clc} 1 \mathrm{ccc}(\mathrm{C} 2=\mathrm{NN}(\mathrm{c} 3 \operatorname{cccc} 3) \mathrm{C}(\mathrm{c} 3 \operatorname{ccc} 4 \mathrm{cccc} 4 \mathrm{c} 3) \mathrm{C} 2) \mathrm{cc} 1 \mathrm{Cl}$ & 50 & 7.30 \\
\hline 1845 & $\mathrm{CN}(\mathrm{C}) \mathrm{CCOc} 1 \mathrm{cc} 2 \mathrm{ncnc}(\mathrm{Nc} 3 \mathrm{ccc}(\mathrm{F}) \mathrm{c}(\mathrm{Cl}) \mathrm{c} 3) \mathrm{c} 2 \mathrm{cc} 1 \mathrm{NC}(=\mathrm{O}) \mathrm{c} 1 \mathrm{cc}([\mathrm{N}+](=\mathrm{O})[\mathrm{O}-]) \operatorname{ccc} 1 \mathrm{~F}$ & 50 & 7.30 \\
\hline 1846 & $\mathrm{CS}(=\mathrm{O})(=\mathrm{O}) \mathrm{CCC}(=\mathrm{O}) \mathrm{Nc} 1 \mathrm{cccc}(\mathrm{C} \# \mathrm{Cc} 2 \mathrm{cncnc} 2 \mathrm{Nc} 2 \mathrm{ccc}(\mathrm{OCc} 3 \operatorname{ccc}(\mathrm{F}) \mathrm{c} 3) \mathrm{c}(\mathrm{Cl}) \mathrm{c} 2) \mathrm{c} 1$ & 50 & * \\
\hline 1847 & $\mathrm{CNC}(=\mathrm{O})[\mathrm{C} @ \mathrm{H}] 1 \mathrm{CCCN} 1 \mathrm{Cc} 1 \mathrm{cc} 2 \mathrm{c}(\mathrm{Nc} 3 \mathrm{cccc}(\mathrm{Cl}) \mathrm{c} 3 \mathrm{~F}) \mathrm{ncnc} 2 \mathrm{cc} 1 \mathrm{OC}$ & 50 & $*$ \\
\hline 1848 & $\mathrm{COc} 1 \mathrm{cc} 2 \mathrm{ncnc}(\mathrm{Nc} 3 \operatorname{ccc}(\mathrm{Cl}) \mathrm{c} 3 \mathrm{~F}) \mathrm{c} 2 \mathrm{cc} 1 \mathrm{CN} 1 \mathrm{CCOCC} 1 \mathrm{C}(\mathrm{N})=\mathrm{O}$ & 50 & $*$ \\
\hline 1849 & $\mathrm{COc} 1 \mathrm{cc} 2 \mathrm{ncnc}(\mathrm{Nc} 3 \operatorname{ccc}(\mathrm{Cl}) \mathrm{c} 3 \mathrm{~F}) \mathrm{c} 2 \mathrm{cc} 1 \mathrm{CN} 1 \mathrm{CC}(\mathrm{C}(\mathrm{N})=\mathrm{O}) \mathrm{C} 1$ & 50 & $*$ \\
\hline 1850 & COc1cc2ncnc $(\mathrm{Nc} 3 \operatorname{ccc}(\mathrm{Cl}) \mathrm{c} 3 \mathrm{~F}) \mathrm{c} 2 \mathrm{cc} 1 \mathrm{CN}(\mathrm{C})[\mathrm{C} @ @ \mathrm{H}](\mathrm{CN}(\mathrm{C}) \mathrm{C}) \mathrm{C}(\mathrm{N})=\mathrm{O}$ & 50 & * \\
\hline 1851 & $\mathrm{O}=\mathrm{S}(=\mathrm{O})(\mathrm{CCCCNCc} 1 \mathrm{ccc}(-\mathrm{c} 2 \mathrm{ccc} 3 \mathrm{ncnc}(\mathrm{Nc} 4 \mathrm{ccc}(\mathrm{OCc} 5 \mathrm{ccccc} 5) \mathrm{c}(\mathrm{Cl}) \mathrm{c} 4) \mathrm{c} 3 \mathrm{c} 2) \mathrm{o} 1) \mathrm{c} 1 \mathrm{ccccc} 1$ & 50 & $*$ \\
\hline 1852 & $\mathrm{CNC}(=\mathrm{O}) \mathrm{O}[\mathrm{C} @ \mathrm{H}] 1 \mathrm{CN}[\mathrm{C} @ \mathrm{H}](\mathrm{CHCc} 2 \mathrm{cc} 3 \mathrm{ncnc}(\mathrm{Nc} 4 \mathrm{ccc}(\mathrm{OCc} 5 \mathrm{ccc}(\mathrm{F}) \mathrm{c} 5) \mathrm{c}(\mathrm{Cl}) \mathrm{c} 4) \mathrm{c} 3 \mathrm{~s} 2) \mathrm{C} 1$ & 50 & * \\
\hline 1853 & $\mathrm{O}=\mathrm{C}(\mathrm{O}[\mathrm{C} @ \mathrm{H}] 1 \mathrm{CN}[\mathrm{C} @ @ \mathrm{H}](\mathrm{C} \# \mathrm{Cc} 2 \mathrm{cc} 3 \mathrm{ncnc}(\mathrm{Nc} 4 \mathrm{ccc}(\mathrm{OCc} 5 \mathrm{cccc}(\mathrm{F}) \mathrm{c} 5) \mathrm{c}(\mathrm{Cl}) \mathrm{c} 4) \mathrm{c} 3 \mathrm{~s} 2) \mathrm{C} 1) \mathrm{N} 1 \mathrm{CCOCC} 1$ & 50 & $*$ \\
\hline 1854 & $\mathrm{CCN}(\mathrm{C}) \mathrm{C}(=\mathrm{O}) \mathrm{O}[\mathrm{C} @ \mathrm{H}] 1 \mathrm{CN}[\mathrm{C} @ \mathrm{H}](\mathrm{C} \# \mathrm{Cc} 2 \mathrm{cc} 3 \mathrm{ncnc}(\mathrm{Nc} 4 \mathrm{ccc}(\mathrm{OCc} 5 \mathrm{cccc}(\mathrm{F}) \mathrm{c} 5) \mathrm{c}(\mathrm{Cl}) \mathrm{c} 4) \mathrm{c} 3 \mathrm{~s} 2) \mathrm{C} 1$ & 50 & $*$ \\
\hline 1855 & $\mathrm{CCNC}(=\mathrm{O}) \mathrm{O}[\mathrm{C} @ @ \mathrm{H}] 1 \mathrm{CN}[\mathrm{C} @ @ \mathrm{H}](\mathrm{C} \# \mathrm{Cc} 2 \mathrm{cc} 3 \mathrm{ncnc}(\mathrm{Nc} 4 \mathrm{ccc}(\mathrm{OCc} 5 \mathrm{ccc}(\mathrm{F}) \mathrm{c} 5) \mathrm{c}(\mathrm{Cl}) \mathrm{c} 4) \mathrm{c} 3 \mathrm{~s} 2) \mathrm{C} 1$ & 50 & $*$ \\
\hline 1856 & $\mathrm{CCS}(=\mathrm{O})(=\mathrm{O}) \mathrm{N}[\mathrm{C} @ \mathrm{H}] 1 \mathrm{CN}[\mathrm{C} @ \mathrm{H}](\mathrm{CHCc} 2 \mathrm{cc} 3 \mathrm{ncnc}(\mathrm{Nc} 4 \mathrm{ccc}(\mathrm{OCc} 5 \mathrm{ccc}(\mathrm{F}) \mathrm{c5}) \mathrm{c}(\mathrm{Cl}) \mathrm{c} 4) \mathrm{c} 3 \mathrm{~s} 2) \mathrm{C} 1$ & 50 & $*$ \\
\hline 1857 & $\mathrm{O}=\mathrm{C}(\mathrm{O}[\mathrm{C} @ \mathrm{H}] 1 \mathrm{CN}[\mathrm{C} @ \mathrm{H}](\mathrm{C} \# \mathrm{Cc} 2 \mathrm{cc} 3 \mathrm{ncnc}(\mathrm{Nc} 4 \mathrm{ccc}(\mathrm{OCc} 5 \mathrm{ccc} n 5) \mathrm{c}(\mathrm{Cl}) \mathrm{c} 4) \mathrm{c} 3 \mathrm{~s} 2) \mathrm{C} 1) \mathrm{N} 1 \mathrm{CCOCC} 1$ & 50 & $*$ \\
\hline 1858 & $\mathrm{O}=\mathrm{C}(\mathrm{NOCc} 1 \mathrm{ccccc} 1) \mathrm{c} 1 \mathrm{cc}(\mathrm{NCc} 2 \mathrm{cc}(\mathrm{O}) \mathrm{ccc} 2 \mathrm{O}) \mathrm{ccc} 1 \mathrm{O}$ & 50 & $*$ \\
\hline 1859 & Cl.Clc1 $\operatorname{ccc}(\mathrm{Nc} 2 \mathrm{ncnc} 3 \operatorname{cccc} 23) \mathrm{c} 1$ & 50 & $*$ \\
\hline 1860 & COc1cc2ncne(Nc3ecccs)c2cc1OC.Cl & 50 & $*$ \\
\hline 1861 & $\mathrm{CCOC}(=\mathrm{O}) \mathrm{c} 1 \mathrm{cn} 2 \mathrm{ncnc}(\mathrm{Nc} 3 \mathrm{ccc} 4[\mathrm{nH}] \mathrm{ncc} 4 \mathrm{c} 3) \mathrm{c} 2 \mathrm{c} 1 \mathrm{CC}$ & 50 & * \\
\hline 1862 & $\mathrm{CC} 1(\mathrm{~N}) \mathrm{CCN}(\mathrm{Cc} 2 \mathrm{ccn} 3 \mathrm{ncnc}(\mathrm{Nc} 4 \mathrm{ccc} 5 \mathrm{c}(\mathrm{cnn} 5 \mathrm{Cc} 5 \mathrm{cccc}(\mathrm{F}) \mathrm{c} 5) \mathrm{c} 4) \mathrm{c} 23) \mathrm{CC} 1$ & 50 & $*$ \\
\hline 1863 & $\mathrm{~N}[\mathrm{C} @ \mathrm{H}] 1 \mathrm{CCN}(\mathrm{Cc} 2 \mathrm{ccn} 3 \mathrm{ncnc}(\mathrm{Nc} 4 \mathrm{ccc} 5 \mathrm{c}(\mathrm{cnn} 5 \mathrm{Cc} 5 \mathrm{ccc}(\mathrm{F}) \mathrm{c} 5) \mathrm{c} 4) \mathrm{c} 23) \mathrm{C} 1$ & 50 & * \\
\hline 1864 & 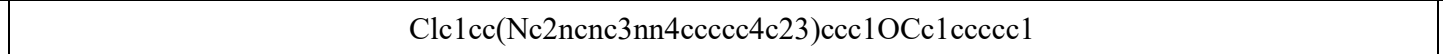 & 50 & * \\
\hline 1865 & $\mathrm{COc} 1 \mathrm{cc} 2 \mathrm{ncnc}(\mathrm{Oc} 3 \mathrm{cccc}(\mathrm{NC}(=\mathrm{S}) \mathrm{Nc} 4 \mathrm{ccc}(\mathrm{Br}) \mathrm{c}(\mathrm{C}(\mathrm{F})(\mathrm{F}) \mathrm{F}) \mathrm{c} 4) \mathrm{c} 3) \mathrm{c} 2 \mathrm{cc} 1 \mathrm{OC}$ & 50 & * \\
\hline 1866 & $\mathrm{COc} 1 \mathrm{cc}(\mathrm{Nc} 2 \mathrm{ncnc} 3 \mathrm{cc}(\mathrm{OC}) \mathrm{c}(\mathrm{OC}) \mathrm{cc} 23) \mathrm{ccc} 1 \mathrm{Br}$ & 50 & $*$ \\
\hline 1867 & $\mathrm{Nc} 1 \mathrm{cccc}(-\mathrm{c} 2 \mathrm{cc} 3 \mathrm{c}(\mathrm{Nc} 4 \mathrm{cc}(\mathrm{Cl}) \mathrm{cc}(\mathrm{Cl}) \mathrm{c} 4) \mathrm{ncnc} 3 \mathrm{o} 2) \mathrm{c} 1$ & 50 & $*$ \\
\hline 1868 & $\mathrm{CC}(\mathrm{C})(\mathrm{O}) \mathrm{C}(=\mathrm{O}) \mathrm{NCCn} 1 \mathrm{ccc} 2 \mathrm{ncnc}(\mathrm{Nc} 3 \operatorname{ccc}(\mathrm{Oc} 4 \operatorname{cccc}(\mathrm{C}(\mathrm{F})(\mathrm{F}) \mathrm{F}) \mathrm{c} 4) \mathrm{c}(\mathrm{Cl}) \mathrm{c} 3) \mathrm{c} 21$ & 50 & * \\
\hline 1869 & Cl.Cn1cce2nenc(Nc3ecc(Oc4cecc $(\mathrm{OC}(\mathrm{F})(\mathrm{F}) \mathrm{F}) \mathrm{c} 4) \mathrm{c}(\mathrm{Cl}) \mathrm{c} 3) \mathrm{c} 21$ & 50 & $*$ \\
\hline 1870 & $\mathrm{COc} 1 \mathrm{cc} 2 \mathrm{ncnc}(\mathrm{Nc} 3 \operatorname{ccc}(\mathrm{Cl}) \mathrm{c} 3 \mathrm{~F}) \mathrm{c} 2 \mathrm{cc} 1 \mathrm{CNC}(=\mathrm{O}) \mathrm{C} 1 \mathrm{COCCN} 1 \mathrm{C}$ & 50 & $*$ \\
\hline 1871 & $\mathrm{COc} 1 \mathrm{cc} 2 \mathrm{ncnc}(\mathrm{Nc} 3 \operatorname{ccc}(\mathrm{Cl}) \mathrm{c} 3 \mathrm{~F}) \mathrm{c} 2 \mathrm{cc} 1 \mathrm{CNC}(=\mathrm{O}) \mathrm{C} 1 \mathrm{CN}(\mathrm{C}) \mathrm{C} 1$ & 50 & $*$ \\
\hline 1872 & $\mathrm{CCOC}(\mathrm{OCC}) \mathrm{c} 1 \mathrm{ccc}(\mathrm{C}=\mathrm{C} 2 \mathrm{CN}(\mathrm{C}) \mathrm{CC}(=\mathrm{Clc} 3 \operatorname{ccc}(\mathrm{C}(\mathrm{OCC}) \mathrm{OCC}) \mathrm{cc} 3) / \mathrm{C} 2=\mathrm{N} \backslash \mathrm{O}) \mathrm{cc} 1$ & 50 & $*$ \\
\hline 1873 & Fc1ece(Nc2ncne3cec(C\#CCN4CCOCC4)cc23)cc1Cl & 50.3 & $*$ \\
\hline 1874 & $\mathrm{C}=\mathrm{CC}(=\mathrm{O}) \mathrm{Nc} 1 \mathrm{cc}(\mathrm{Nc} 2 \mathrm{nccc}(\mathrm{NC}(=\mathrm{O}) \mathrm{c} 3 \operatorname{cccc}(\mathrm{OC}) \mathrm{c} 3) \mathrm{n} 2) \mathrm{c}(\mathrm{OC}) \mathrm{cc} 1 \mathrm{~N} 1 \mathrm{CCC}(\mathrm{C}(\mathrm{N})=\mathrm{O}) \mathrm{CC} 1$ & 50.5 & $*$ \\
\hline 1875 & $\mathrm{C}=\mathrm{CC}(=\mathrm{O}) \mathrm{Nc} 1 \mathrm{cc} 2 \mathrm{c}(\mathrm{Nc} 3 \mathrm{ccc}(\mathrm{OCc} 4 \mathrm{ccc} n 4) \mathrm{c}(\mathrm{Cl}) \mathrm{c} 3) \mathrm{c}(\mathrm{C \# N}) \mathrm{cnc} 2 \mathrm{cc} 1 \mathrm{OCC}$ & 50.7 & 7.29 \\
\hline 1876 & $\mathrm{O}=\mathrm{C}(\mathrm{Nc} 1 \mathrm{cc} 2 \mathrm{c}(\mathrm{Nc} 3 \mathrm{ccc}(\mathrm{F}) \mathrm{c}(\mathrm{Cl}) \mathrm{c} 3) \mathrm{ncnc} 2 \mathrm{cc} 1 \mathrm{OCCCN} 1 \mathrm{CCOCC} 1) \mathrm{c} 1 \mathrm{ccc}([\mathrm{N}+](=\mathrm{O})[\mathrm{O}-]) \mathrm{c} 1$ & 50.9 & 7.29 \\
\hline 1877 & $\begin{array}{c}\mathrm{C}=\mathrm{CC}(=\mathrm{O}) \mathrm{Nc} 1 \mathrm{cccc}(\mathrm{Oc} 2 \mathrm{nc}(\mathrm{Nc} 3 \operatorname{ccc}(\mathrm{N} 4 \mathrm{CCN}(\mathrm{CC}(=\mathrm{O}) \mathrm{NCCOc} 5 \mathrm{no}[\mathrm{n}+]([\mathrm{O}-]) \mathrm{c} 5 \mathrm{~S}(=\mathrm{O})(=\mathrm{O}) \mathrm{c} 5 \mathrm{ccccc} 5) \mathrm{CC} 4) \operatorname{cc} 3 \mathrm{OC}) \mathrm{n} \\
\operatorname{cc} 2 \mathrm{Cl}) \mathrm{c} 1\end{array}$ & 51 & 7.29 \\
\hline 1878 & $\mathrm{CCOc} 1 \mathrm{cc} 2 \mathrm{ncc}(\mathrm{C} \# \mathrm{~N}) \mathrm{c}(\mathrm{Nc} 3 \mathrm{ccc}(\mathrm{OCc} 4 \mathrm{ccc}(\mathrm{Cl}) \mathrm{cc} 4) \mathrm{c}(\mathrm{Cl}) \mathrm{c} 3) \mathrm{c} 2 \mathrm{cc} 1 \mathrm{NC}(=\mathrm{O}) / \mathrm{C}=\mathrm{C} / \mathrm{CN}(\mathrm{C}) \mathrm{C}$ & 51 & 7.29 \\
\hline
\end{tabular}




\begin{tabular}{|c|c|c|c|}
\hline 1879 & $\mathrm{COc} 1 \mathrm{cc} 2 \mathrm{ncnc}(\mathrm{Nc} 3 \mathrm{cc}(\mathrm{Cl}) \mathrm{ccc} 3 \mathrm{~F}) \mathrm{c} 2 \mathrm{cc} 1 \mathrm{OCCCN} 1 \mathrm{CCOCC} 1$ & 51 & $*$ \\
\hline 1880 & $\operatorname{Brc} 1 \operatorname{ccc}(\mathrm{Nc} 2 \mathrm{ncnc} 3 \mathrm{cnccc} 23) \mathrm{c} 1$ & 51 & $*$ \\
\hline 1881 & $\mathrm{O}=\mathrm{C} 1 \mathrm{CS} / \mathrm{C}(=\mathrm{N} / \mathrm{Nc} 2 \mathrm{nncc} 3 \operatorname{cccc} 23) \mathrm{N} 1$ & 51 & * \\
\hline 1882 & $\mathrm{COc} 1 \mathrm{cc} 2 \mathrm{c}(\mathrm{Nc} 3 \mathrm{ccc}(\mathrm{NC}(=\mathrm{O}) \mathrm{Nc} 4 \mathrm{ccc}(\mathrm{C}) \mathrm{c}(\mathrm{C}) \mathrm{c} 4) \mathrm{c}(\mathrm{Cl}) \mathrm{c} 3) \mathrm{ncnc} 2 \mathrm{cc} 1 \mathrm{OCCCN} 1 \mathrm{CCOCC} 1$ & 51 & $*$ \\
\hline 1883 & $\mathrm{~N} \# \mathrm{Cc} 1 \mathrm{cccc} 1 \mathrm{Oc} 1 \mathrm{ccc}(\mathrm{Nc} 2 \mathrm{ncnc} 3 \mathrm{cc}[\mathrm{nH}] \mathrm{c} 23) \mathrm{cc} 1 \mathrm{Cl}$ & 51 & $*$ \\
\hline 1884 & $\operatorname{COc} 1 \operatorname{ccc}(-n 2 \mathrm{c}(-\mathrm{c} 3 \operatorname{ccc} c 3) \mathrm{c}(-\mathrm{c} 3 \operatorname{ccc} c 3) \mathrm{c} 3 \operatorname{cc} 4 \mathrm{c}(\mathrm{cc} 3 \mathrm{c} 2=\mathrm{O}) \mathrm{C}(\mathrm{c} 2 \operatorname{ccc} c 2) \mathrm{NC}(=\mathrm{O}) \mathrm{N} 4) \mathrm{cc} 1$ & 51 & $*$ \\
\hline 1885 & $\mathrm{COc} 1 \mathrm{cc} 2 \mathrm{ncnc}(\mathrm{Nc} 3 \operatorname{ccc}(\mathrm{OCc} 4 \mathrm{ccc}(\mathrm{F}) \mathrm{c} 4) \mathrm{c}(\mathrm{Cl}) \mathrm{c} 3) \mathrm{c} 2 \mathrm{cc} 1 \mathrm{OCCCCCn} 1 \mathrm{ccnc} 1[\mathrm{~N}+](=\mathrm{O})[\mathrm{O}-]$ & 51.2 & 7.29 \\
\hline 1886 & $\begin{array}{c}\mathrm{C}=\mathrm{CC}(=\mathrm{O}) \mathrm{Nc} 1 \mathrm{cccc}(\mathrm{Oc} 2 \mathrm{nc}(\mathrm{Nc} 3 \operatorname{ccc}(\mathrm{N} 4 \mathrm{CCN}(\mathrm{CC}(=\mathrm{O}) \mathrm{OCC} \# \mathrm{CCOc} 5 \mathrm{no}[\mathrm{n}+]([\mathrm{O}-]) \mathrm{c} 5 \mathrm{~S}(=\mathrm{O})(=\mathrm{O}) \mathrm{c} 5 \mathrm{ccccc} 5) \mathrm{CC} 4) \mathrm{cc} 3 \\
\mathrm{OC}) \mathrm{ncc} 2 \mathrm{Cl}) \mathrm{c} 1\end{array}$ & 52 & 7.28 \\
\hline 1887 & $\mathrm{COc} 1 \mathrm{cc} 2 \mathrm{ncnc}(\mathrm{Nc} 3 \mathrm{ccc}(\mathrm{F}) \mathrm{c}(\mathrm{Cl}) \mathrm{c} 3) \mathrm{c} 2 \mathrm{cc} 1 \mathrm{OCCN} 1 \mathrm{CC} 2(\mathrm{CSC} 2) \mathrm{C} 1$ & 52 & 7.28 \\
\hline 1888 & $\mathrm{Nc} 1 n \mathrm{nc}(\mathrm{Nc} 2 \mathrm{ccc} 3 \mathrm{c}(\operatorname{cnn} 3 \mathrm{Cc} 3 \operatorname{ccc}(\mathrm{F}) \mathrm{c} 3) \mathrm{c} 2) \mathrm{c} 1 / \mathrm{C}=\mathrm{N} / \mathrm{NCC}(\mathrm{F})(\mathrm{F}) \mathrm{F}$ & 52 & $*$ \\
\hline 1889 & $\mathrm{CNc} 1 \mathrm{ccc} 2 \mathrm{c}(\mathrm{Nc} 3 \operatorname{ccc}(\mathrm{Br}) \mathrm{c} 3) \mathrm{ncnc} 2 \mathrm{n} 1$ & 52 & $*$ \\
\hline 1890 & $\mathrm{CCCCNC}(=\mathrm{S}) \mathrm{NNc} 1 \mathrm{nncc} 2 \operatorname{ccccc} 12$ & 52 & $*$ \\
\hline 1891 & Br.Oc1cec(-c2ec3ec(NCc4cece(F)c4)ncnc3[nH]2)cc1 & 52 & $*$ \\
\hline 1892 & OCCC1COc2ce3ncnc( $\mathrm{Nc} 4 \mathrm{cccc}(\mathrm{Cl}) \mathrm{c} 4) \mathrm{c} 3 \mathrm{cc} 2 \mathrm{O} 1$ & 52 & * \\
\hline 1893 & $\mathrm{Brc} 1 \mathrm{cccc}(\mathrm{Nc} 2 \mathrm{ncnc} 3 \mathrm{cc} 4 \mathrm{c}(\mathrm{cc} 23) \mathrm{OC}(\mathrm{CCN}(\mathrm{N} 2 \mathrm{CCCCC} 2) \mathrm{N} 2 \mathrm{CCCCC} 2) \mathrm{CO} 4) \mathrm{c} 1$ & 52 & $*$ \\
\hline 1894 & $\mathrm{Fc} 1 \mathrm{ccc}(-\mathrm{c} 2 \mathrm{nc}(\mathrm{Nc} 3 \mathrm{cc}(\mathrm{Br}) \mathrm{cc} 4 \mathrm{cc}(-\mathrm{c} 5 \mathrm{ccc}(\mathrm{F}) \mathrm{cc} 5) \mathrm{oc} 34) \mathrm{c} 3 \mathrm{cc}(\mathrm{Br}) \mathrm{ccc} 3 \mathrm{n} 2) \mathrm{cc} 1$ & 52.2 & $*$ \\
\hline 1895 & $\mathrm{Fc} 1 \mathrm{ccc}(-\mathrm{c} 2 \mathrm{nc}(\mathrm{Nc} 3 \mathrm{cc}(\mathrm{Br}) \mathrm{cc} 4 \mathrm{cc}(-\mathrm{c} 5 \mathrm{ccc}(\mathrm{F}) \mathrm{cc} 5)[\mathrm{nH}] \mathrm{c} 34) \mathrm{c} 3 \mathrm{ccccc} 3 \mathrm{n} 2) \mathrm{cc} 1$ & 52.5 & $*$ \\
\hline 1896 & $\mathrm{CCCN1CC}[\mathrm{C} @ \mathrm{H}](\mathrm{N} 2 \mathrm{C}(=\mathrm{O}) \mathrm{N}(\mathrm{c} 3 \mathrm{cccc} 3 \mathrm{Cl}) \mathrm{Cc} 3 \mathrm{cnc}(\mathrm{Nc} 4 \mathrm{ccc}(\mathrm{N} 5 \mathrm{CCN}(\mathrm{C}) \mathrm{CC} 5) \mathrm{c}(\mathrm{C}) \mathrm{c} 4) \mathrm{nc} 32) \mathrm{C} 1$ & 52.8 & 7.28 \\
\hline 1897 & $\mathrm{O}=\mathrm{C}(\mathrm{Nc} 1 \mathrm{cc} 2 \mathrm{c}(\mathrm{Nc} 3 \operatorname{ccc}(\mathrm{F}) \mathrm{c}(\mathrm{F}) \mathrm{c} 3) \mathrm{ncnc} 2 \mathrm{cc} 1 \mathrm{OCCCN} 1 \mathrm{CCOCC} 1) \mathrm{c} 1 \mathrm{cc}([\mathrm{N}+](=\mathrm{O})[\mathrm{O}-]) \mathrm{ccc} 1 \mathrm{~F}$ & 53 & 7.28 \\
\hline 1898 & $\mathrm{Fc} 1 \mathrm{ccc}(\mathrm{Nc} 2 \mathrm{ncnc} 3 \mathrm{sc}(\mathrm{Br}) \mathrm{cc} 23) \mathrm{cc} 1 \mathrm{Cl}$ & 53 & $*$ \\
\hline 1899 & $\operatorname{CCOC}(=\mathrm{O}) \operatorname{CCCn} 1 \mathrm{c}(=\mathrm{O}) \mathrm{oc} 2 \mathrm{cc} 3 \mathrm{ncnc}(\mathrm{Nc} 4 \operatorname{ccc}(\mathrm{OCc} 5 \operatorname{ccc}(\mathrm{Cl}) \mathrm{cc} 5) \mathrm{c}(\mathrm{Cl}) \mathrm{c} 4) \mathrm{c} 3 \mathrm{cc} 21$ & 53 & $*$ \\
\hline 1900 & $\mathrm{CCOc} 1 \mathrm{cc} 2 \mathrm{ncc}(\mathrm{C \# N}) \mathrm{c}(\mathrm{Nc} 3 \operatorname{ccc}(\mathrm{OCc} 4 \mathrm{cccc} 4) \mathrm{c}(\mathrm{Cl}) \mathrm{c} 3) \mathrm{c} 2 \mathrm{cc} 1 \mathrm{NC}(=\mathrm{O}) / \mathrm{C}=\mathrm{C} / \mathrm{CN}(\mathrm{C}) \mathrm{C}$ & 53 & $*$ \\
\hline 1901 & $\mathrm{CC}(\mathrm{C}) \mathrm{S}(=\mathrm{O})(=\mathrm{O}) \mathrm{CC}(=\mathrm{O}) \mathrm{NCCn} 1 \mathrm{ccc} 2 \mathrm{ncnc}(\mathrm{Nc} 3 \operatorname{ccc}(\mathrm{Oc} 4 \mathrm{cccc}(\mathrm{C}(\mathrm{F})(\mathrm{F}) \mathrm{F}) \mathrm{c} 4) \mathrm{c}(\mathrm{Cl}) \mathrm{c} 3) \mathrm{c} 21$ & 53 & $*$ \\
\hline 1902 & $\mathrm{Nc} 1 \mathrm{ccc} 2 \mathrm{ncnc}(\mathrm{Nc} 3 \operatorname{ccc}(\mathrm{Br}) \mathrm{c} 3) \mathrm{c} 2 \mathrm{n} 1$ & 53 & $*$ \\
\hline 1903 & $\mathrm{O}=\mathrm{C}(\mathrm{O}) \mathrm{Cn} 1 \mathrm{ncc} 2 \mathrm{cc} 3 \mathrm{c}(\mathrm{Nc} 4 \mathrm{cccc}(\mathrm{Br}) \mathrm{c} 4) \mathrm{ncnc} 3 \mathrm{cc} 21$ & 53 & $*$ \\
\hline 1904 & $\mathrm{Nc} 1 \mathrm{cc} 2 \mathrm{ncnc}(\mathrm{Nc} 3 \operatorname{cccc}(\mathrm{Br}) \mathrm{c} 3) \mathrm{c} 2 \mathrm{cc} 1[\mathrm{~N}+](=\mathrm{O})[\mathrm{O}-]$ & 53 & $*$ \\
\hline 1905 & $\operatorname{COc} 1 \operatorname{ccc}(\mathrm{NC}(=\mathrm{S}) \mathrm{NNc} 2 \mathrm{nncc} 3 \operatorname{ccccc} 23) \mathrm{cc} 1$ & 53 & $*$ \\
\hline 1906 & $\mathrm{COc} 1 \mathrm{cc}(\mathrm{Nc} 2 \mathrm{c}(\mathrm{CHN}) \mathrm{cnc} 3 \mathrm{cc}(\mathrm{OCCCN} 4 \mathrm{CCN}(\mathrm{C}) \mathrm{CC} 4) \mathrm{c}(\mathrm{OC}) \mathrm{cc} 23) \mathrm{c}(\mathrm{Cl}) \mathrm{cc} 1 \mathrm{Cl}$ & 53 & $*$ \\
\hline 1907 & $\mathrm{O}=\mathrm{C}(\mathrm{O}) \mathrm{CCCC}(=\mathrm{O}) \mathrm{Ne} 1 \mathrm{cc}(\mathrm{N} 2 \mathrm{CCOCC} 2) \mathrm{ncn} 1$ & 53 & $*$ \\
\hline 1908 & $\mathrm{O}=\mathrm{C} 1 \mathrm{COc} 2 \mathrm{cc} 3 \mathrm{ncnc}(\mathrm{Nc} 4 \mathrm{ccc}(\mathrm{F}) \mathrm{c}(\mathrm{Cl}) \mathrm{c} 4) \mathrm{c} 3 \mathrm{cc} 2 \mathrm{~N} 1 \mathrm{CCCN} 1 \mathrm{CCOCC} 1$ & 53.1 & $*$ \\
\hline 1909 & $\mathrm{C}=\mathrm{CC}(=\mathrm{O}) \mathrm{Nc} 1 \mathrm{ccc} 2 \mathrm{ncnc}(\mathrm{Nc} 3 \operatorname{ccc}(\mathrm{S}(=\mathrm{O})(=\mathrm{O}) \mathrm{NC}(=\mathrm{N}) \mathrm{N}) \operatorname{cc} 3) \mathrm{c} 2 \mathrm{c} 1$ & 53.3 & $*$ \\
\hline 1910 & $\mathrm{C}=\mathrm{CC}(=\mathrm{O}) \mathrm{Nc} 1 \mathrm{ccc} 2 \mathrm{ncnc}(\mathrm{Nc} 3 \mathrm{ccc}(\mathrm{OC}) \mathrm{cc} 3 \mathrm{OC}) \mathrm{c} 2 \mathrm{c} 1$ & 53.6 & $*$ \\
\hline 1911 & $\mathrm{Fc} 1 \mathrm{cccc}(\mathrm{COc} 2 \mathrm{ccc}(\mathrm{Nc} 3 \mathrm{ncnc} 4 \mathrm{sc}(-\mathrm{c} 5 \mathrm{ccc}(\mathrm{CNCc} 6 \mathrm{ccccc} 6) \mathrm{o} 5) \mathrm{cc} 34) \mathrm{cc} 2 \mathrm{Cl}) \mathrm{c} 1$ & 54 & $*$ \\
\hline 1912 & $\mathrm{O}=\mathrm{C}(\mathrm{O}) \mathrm{c} 1 \mathrm{ccc}(\mathrm{S}(=\mathrm{O})(=\mathrm{O}) \mathrm{Oc} 2 \operatorname{ccc}(/ \mathrm{C}=\mathrm{C} /[\mathrm{N}+](=\mathrm{O})[\mathrm{O}-]) \operatorname{cc} 2) \operatorname{cc} 1 \mathrm{O}$ & 54 & $*$ \\
\hline 1913 & $\operatorname{COc} 1 \operatorname{ccc}(\mathrm{NC}(=\mathrm{O}) / \mathrm{C}=\mathrm{C} / \mathrm{CN}(\mathrm{C}) \mathrm{C}) \mathrm{cc} 1 \mathrm{Nc} 1 \mathrm{nccc}(\mathrm{Nc} 2 \operatorname{ccc} 3 \operatorname{ccccc} 3 \mathrm{c} 2) \mathrm{n} 1$ & 54 & $*$ \\
\hline 1914 & $\mathrm{C}=\mathrm{CC}(=\mathrm{O}) \mathrm{Nc} 1 \mathrm{cc}(\mathrm{Nc} 2 \mathrm{ncc}(\mathrm{I}) \mathrm{c}(\mathrm{Nc} 3 \operatorname{ccccc} 3 \mathrm{P}(\mathrm{C})(\mathrm{C})=\mathrm{O}) \mathrm{n} 2) \mathrm{c}(\mathrm{OC}) \operatorname{cc} 1 \mathrm{~N}(\mathrm{C}) \mathrm{CCN}(\mathrm{C}) \mathrm{C}$ & 54 & $*$ \\
\hline 1915 & $\mathrm{Cc} 1 \mathrm{ncnc}(\mathrm{Nc} 2 \mathrm{ccc}(\mathrm{OCc} 3 \operatorname{ccc}(\mathrm{F}) \mathrm{c} 3) \mathrm{c}(\mathrm{Cl}) \mathrm{c} 2) \mathrm{c} 1 \mathrm{C} \# \mathrm{Cc} 1 \mathrm{ccc}(\mathrm{CN}(\mathrm{C}) \mathrm{C}) \mathrm{c} 1$ & 55 & 7.26 \\
\hline 1916 & COc1cccc1-c1cc2c(N[C@H](C)c3eccs3)ncnc2s1 & 55 & $*$ \\
\hline 1917 & Brc1ccce(Nc2ncnc3ec4c(cc23)OCCOCCO4)c1 & 55 & $*$ \\
\hline 1918 & $\mathrm{COc} 1 \mathrm{ccc} 2 \mathrm{ncnc}(\mathrm{Ne} 3 \mathrm{cccc} 3) \mathrm{c} 2 \mathrm{c} 1$ & 55 & $*$ \\
\hline 1919 & $\mathrm{Cc} 1 \mathrm{ccc}(\mathrm{Nc} 2 \mathrm{nccc}(\mathrm{N}(\mathrm{C}) \mathrm{c} 3 \operatorname{ccc} 4[\mathrm{nH}] \operatorname{cc}(\mathrm{C}) \mathrm{c} 4 \mathrm{c} 3) \mathrm{n} 2) \operatorname{cc} 1 \mathrm{~S}(\mathrm{~N})(=\mathrm{O})=\mathrm{O}$ & 55 & $*$ \\
\hline 1920 & NCCCSc1nc(-c2 $\operatorname{ccc}(\mathrm{F}) \mathrm{cc} 2) \mathrm{c}(-\mathrm{c} 2 \mathrm{ccnc}(\mathrm{Nc} 3 \mathrm{ccccc} 3) \mathrm{c} 2)[\mathrm{nH}] 1$ & 55 & $*$ \\
\hline
\end{tabular}




\begin{tabular}{|c|c|c|c|}
\hline 1921 & $\mathrm{~S}=\mathrm{C}(\mathrm{Nc} 1 \mathrm{cncc}(\mathrm{Cl}) \mathrm{c} 1) \mathrm{Nc} 1 \mathrm{ccc} 2 \mathrm{ncnc}(\mathrm{Nc} 3 \mathrm{cccc}(\mathrm{Cl}) \mathrm{c} 3) \mathrm{c} 2 \mathrm{c} 1$ & 55.5 & $*$ \\
\hline 1922 & $\mathrm{CC}[\mathrm{C} @ \mathrm{H}](\mathrm{C})[\mathrm{C} @ @ \mathrm{H}](\mathrm{NC}(=\mathrm{O}) \mathrm{OC}(\mathrm{C})(\mathrm{C}) \mathrm{C}) \mathrm{C}(=\mathrm{O}) \mathrm{Nc} 1 \mathrm{ccc} 2 \mathrm{ncnc}(\mathrm{Nc} 3 \mathrm{ccc}(\mathrm{F}) \mathrm{c}(\mathrm{Cl}) \mathrm{c} 3) \mathrm{c} 2 \mathrm{c} 1$ & 55.5 & * \\
\hline 1923 & $\mathrm{COc} 1 \mathrm{cc} 2 \mathrm{ncnc}(\mathrm{Nc} 3 \mathrm{ccc}(\mathrm{F}) \mathrm{c}(\mathrm{Cl}) \mathrm{c} 3) \mathrm{c} 2 \mathrm{cc} 1 \mathrm{OCCCN} 1 \mathrm{CC} 2(\mathrm{COC} 2) \mathrm{C} 1$ & 56 & 7.25 \\
\hline 1924 & C[C@@H](Nc1ncnc2oc(-c3ecc(Br)cc3)cc12)c1ccccc1 & 56 & 7.25 \\
\hline 1925 & $\mathrm{CC}(\mathrm{C})(\mathrm{C}) \mathrm{S}(=\mathrm{O})(=\mathrm{O}) \mathrm{CC}(=\mathrm{O}) \mathrm{NCCn} 1 \mathrm{ccc} 2 \mathrm{ncnc}(\mathrm{Nc} 3 \operatorname{ccc}(\mathrm{Oc} 4 \operatorname{cccc}(\mathrm{C}(\mathrm{F})(\mathrm{F}) \mathrm{F}) \mathrm{c} 4) \mathrm{c}(\mathrm{Cl}) \mathrm{c} 3) \mathrm{c} 21$ & 56 & * \\
\hline 1926 & $\mathrm{COc} 1 \mathrm{cc} 2 \mathrm{ncnc}(\mathrm{NCc} 3 \mathrm{cccc} 3) \mathrm{c} 2 \mathrm{cc} 1 \mathrm{O}$ & 56 & $*$ \\
\hline 1927 & Fc1 $\operatorname{ccc}(\mathrm{Nc} 2 \mathrm{ncnc} 3 \operatorname{ccccc} 23) \mathrm{c} 1$ & 56 & $*$ \\
\hline 1928 & $\mathrm{O}=\mathrm{C}(\mathrm{N} / \mathrm{N}=\mathrm{C} / \mathrm{c} 1 \mathrm{ccc}(\mathrm{O}) \mathrm{cc} 1) \mathrm{Nc} 1 \mathrm{cc} 2 \mathrm{c}(\mathrm{Nc} 3 \mathrm{ccc}(\mathrm{F}) \mathrm{c}(\mathrm{Cl}) \mathrm{c} 3) \mathrm{ncnc} 2 \mathrm{cc} 1 \mathrm{O}[\mathrm{C} @ \mathrm{H}] 1 \mathrm{CCOC} 1$ & 56 & $*$ \\
\hline 1929 & $\mathrm{COc} 1 \mathrm{ccc}(\mathrm{Nc} 2 \mathrm{nccc}(\mathrm{Nc} 3 \mathrm{ccc} 4[\mathrm{nH}] \mathrm{ccc} 4 \mathrm{c} 3) \mathrm{n} 2) \mathrm{cc} 1 \mathrm{~N} 1 \mathrm{CCOCC} 1$ & 56 & $*$ \\
\hline 1930 & $\mathrm{CS}(=\mathrm{O})(=\mathrm{O}) \mathrm{c} 1 \mathrm{ccc}(\mathrm{F}) \mathrm{c}(\mathrm{C}(=\mathrm{O}) \mathrm{Nc} 2 \mathrm{cc} 3 \mathrm{c}(\mathrm{Nc} 4 \mathrm{ccc}(\mathrm{F}) \mathrm{c}(\mathrm{Cl}) \mathrm{c} 4) \mathrm{ncn}$ 3 $\mathrm{cc} 2 \mathrm{OCCCN} 2 \mathrm{CCOCC} 2) \mathrm{c} 1$ & 57 & 7.24 \\
\hline 1931 & $\mathrm{O}=\mathrm{C}(/ \mathrm{C}=\mathrm{C} / \mathrm{CN} 1 \mathrm{CCCC} 1) \mathrm{Nc} 1 \mathrm{cc} 2 \mathrm{c}(\mathrm{Nc} 3 \operatorname{ccc} 4 \mathrm{c}(\operatorname{cnn} 4 \mathrm{Cc} 4 \mathrm{ccccc} 4) \mathrm{c} 3) \mathrm{ncnc} 2 \mathrm{cn} 1$ & 57 & $*$ \\
\hline 1932 & $\mathrm{CCN}(\mathrm{CC}) \mathrm{CCCOc} 1 \mathrm{cc} 2 \mathrm{c}(\mathrm{Nc} 3 \mathrm{ccc}(\mathrm{F}) \mathrm{c}(\mathrm{Cl}) \mathrm{c} 3) \mathrm{ncnc} 2 \mathrm{cc} 1 \mathrm{OC}$ & 57 & $*$ \\
\hline 1933 & $\mathrm{O}=\mathrm{C}(\mathrm{C} \# \mathrm{CCN} 1 \mathrm{CCCCC} 1) \mathrm{Nc} 1 \mathrm{ccc} 2 \mathrm{ncnc}(\mathrm{Nc} 3 \mathrm{cccc}(\mathrm{Br}) \mathrm{c} 3) \mathrm{c} 2 \mathrm{c} 1$ & 57 & $*$ \\
\hline 1934 & $\begin{array}{l}\text { COc1cc(N2CCC }(\mathrm{N} 3 \mathrm{CCN}(\mathrm{S}(\mathrm{C})(=\mathrm{O})=\mathrm{O}) \mathrm{CC} 3) \mathrm{CC} 2) \operatorname{ccc} 1 \mathrm{Nc} 1 \mathrm{nccc}(-\mathrm{c} 2 \mathrm{c}(- \\
\mathrm{c} 3 \operatorname{ccc}(\mathrm{C}(=\mathrm{O}) \mathrm{Nc} 4 \mathrm{c}(\mathrm{F}) \mathrm{cccc} 4 \mathrm{~F}) \mathrm{c} 3) \mathrm{nc} 3 \mathrm{ccc} n 23) \mathrm{n} 1\end{array}$ & 57 & $*$ \\
\hline 1935 & $\mathrm{CO} / \mathrm{N}=\mathrm{C} / \mathrm{c} 1 \mathrm{c}(\mathrm{N}) \mathrm{ncnc} 1 \mathrm{Nc} 1 \mathrm{ccc} 2 \mathrm{c}(\mathrm{c} 1) \mathrm{CCN} 2 \mathrm{Cc} 1 \mathrm{cccc}(\mathrm{F}) \mathrm{c} 1$ & 57 & $*$ \\
\hline 1936 & $\mathrm{C}=\mathrm{CC}(=\mathrm{O}) \mathrm{Nc} 1 \mathrm{cc}(\mathrm{Br}) \operatorname{cc}(-\mathrm{n} 2 \mathrm{c}(=\mathrm{O}) \mathrm{cc}(\mathrm{C}) \mathrm{c} 3 \mathrm{cnc}(\mathrm{Nc} 4 \mathrm{ccc}(\mathrm{N} 5 \mathrm{CCN}(\mathrm{C}) \mathrm{CC} 5) \mathrm{cc} 4 \mathrm{OC}) \mathrm{nc} 32) \mathrm{c} 1$ & 57 & $*$ \\
\hline 1937 & $\operatorname{COc} 1 \mathrm{cc}(\mathrm{O}) \mathrm{c}(\mathrm{C}(=\mathrm{O}) \mathrm{Nc} 2 \mathrm{cccc}(\mathrm{Cl}) \mathrm{c} 2) \mathrm{cc} 1 \mathrm{O}$ & 57 & $*$ \\
\hline 1938 & $\mathrm{C}=\mathrm{CC}(=\mathrm{O}) \mathrm{Nc} 1 \mathrm{ccc}(\mathrm{OC}) \mathrm{c}(\mathrm{Nc} 2 \mathrm{cc}(-\mathrm{c} 3[\mathrm{nH}] \mathrm{c}(\mathrm{SC}) \mathrm{nc} 3 \mathrm{C}(\mathrm{C})(\mathrm{C}) \mathrm{C}) \mathrm{ccn} 2) \mathrm{c} 1$ & 57 & $*$ \\
\hline 1939 & 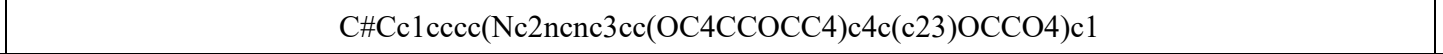 & 57.8 & $*$ \\
\hline 1940 & COc1cccc1Cc1nc2ccc(-c3nn([C@H]4CC[C@H](C5CCN(C)CC5)CC4)c4ncnc(N)c34)cc2[nH]1 & 58 & * \\
\hline 1941 & COCCCN1CCC $([\mathrm{C} @ \mathrm{H}] 2 \mathrm{CC}[\mathrm{C} @ \mathrm{H}](\mathrm{n} 3 \mathrm{nc}(-\mathrm{c} 4 \mathrm{ccc} 5 \mathrm{nc}(\mathrm{Cc} 6 \mathrm{ccccc} 6 \mathrm{Cl})[\mathrm{nH}] \mathrm{c5c} 4) \mathrm{c} 4 \mathrm{c}(\mathrm{N}) \mathrm{ncnc} 43) \mathrm{CC} 2) \mathrm{CC} 1$ & 58 & $*$ \\
\hline 1942 & CC $(=\mathrm{O}) \mathrm{N} 1 \mathrm{CCC}[\mathrm{C} @ @ \mathrm{H}] 1 \mathrm{C} \# \mathrm{Cc} 1 \mathrm{cc} 2 \mathrm{ncnc}(\mathrm{Nc} 3 \mathrm{ccc}(\mathrm{OCc} 4 \mathrm{cccc}(\mathrm{F}) \mathrm{c} 4) \mathrm{c}(\mathrm{Cl}) \mathrm{c} 3) \mathrm{c} 2 \mathrm{~s} 1$ & 58 & * \\
\hline 1943 & COc1 $1 \mathrm{ccc} 2 \mathrm{c}(\mathrm{NCc} 3 \mathrm{ccccc} 3) \mathrm{ncnc} 2 \mathrm{c} 1$ & 58 & * \\
\hline 1944 & $\mathrm{c} 1 \mathrm{ccc}(\mathrm{Nc} 2 \mathrm{nc}[\mathrm{nH}] \mathrm{c} 3 \mathrm{nnc}(\mathrm{Nc} 4 \mathrm{ccccc} 4) \mathrm{c} 2-3) \mathrm{cc} 1$ & 58 & $*$ \\
\hline 1945 & $\mathrm{Cl} . \mathrm{O}=[\mathrm{N}+]([\mathrm{O}-]) \mathrm{c} 1 \mathrm{ccc} 2 \mathrm{sc} 3 \mathrm{c}(\mathrm{Nc} 4 \mathrm{ccccc} 4) \mathrm{ncnc} 3 \mathrm{c} 2 \mathrm{c} 1$ & 58 & $*$ \\
\hline 1946 & $\mathrm{Clc} 1 \mathrm{cccc}(\mathrm{Nc} 2 \mathrm{ncnc} 3 \mathrm{cc} 4 \mathrm{c}(\mathrm{cc} 23) \mathrm{OC}(\mathrm{CCN}(\mathrm{N} 2 \mathrm{CCCCC} 2) \mathrm{N} 2 \mathrm{CCCCC} 2) \mathrm{CO} 4) \mathrm{c} 1$ & 58 & $*$ \\
\hline 1947 & $\mathrm{Fc} 1 \mathrm{ccc}(\mathrm{Nc} 2 \mathrm{ncnc} 3 \mathrm{cc}(\mathrm{OC} 4 \mathrm{CCOCC} 4) \mathrm{c} 4 \mathrm{c}(\mathrm{c} 23) \mathrm{OCCO} 4) \mathrm{cc} 1 \mathrm{Cl}$ & 58.8 & $*$ \\
\hline 1948 & $\begin{array}{c}\mathrm{C}=\mathrm{CC}(=\mathrm{O}) \mathrm{Nc} 1 \mathrm{cccc}(\mathrm{Oc} 2 \mathrm{nc}(\mathrm{Nc} 3 \operatorname{ccc}(\mathrm{N} 4 \mathrm{CCN}(\mathrm{CC}(=\mathrm{O}) \mathrm{NCCCOc} 5 \mathrm{no}[\mathrm{n}+]([\mathrm{O}-]) \mathrm{c} 5 \mathrm{~S}(=\mathrm{O})(=\mathrm{O}) \mathrm{c} 5 \mathrm{ccccc} 5) \mathrm{CC} 4) \operatorname{cc} 3 \mathrm{OC} \\
) \mathrm{ncc} 2 \mathrm{Cl}) \mathrm{c} 1\end{array}$ & 59 & 7.23 \\
\hline 1949 & $\begin{array}{c}\mathrm{C}=\mathrm{CC}(=\mathrm{O}) \mathrm{Nc} 1 \mathrm{ccc}(\mathrm{Oc} 2 \mathrm{nc}(\mathrm{Nc} 3 \operatorname{ccc}(\mathrm{N} 4 \mathrm{CCN}(\mathrm{CC}(=\mathrm{O}) \mathrm{OCCO} 5 \mathrm{no}[\mathrm{n}+]([\mathrm{O}-]) \mathrm{c} 5 \mathrm{~S}(=\mathrm{O})(=\mathrm{O}) \mathrm{c} 5 \operatorname{ccccc} 5) \mathrm{CC} 4) \operatorname{cc} 3 \mathrm{OC}) \mathrm{n} \\
\operatorname{cc} 2 \mathrm{Cl}) \mathrm{c} 1\end{array}$ & 59 & 7.23 \\
\hline 1950 & $\mathrm{C}[\mathrm{C} @ @ \mathrm{H}](\mathrm{Nc} 1 \mathrm{ncnc} 2 \mathrm{sc}(-\mathrm{c} 3 \mathrm{ccc}(\mathrm{C}=\mathrm{O}) \mathrm{cc} 3 \mathrm{~F}) \mathrm{cc} 12) \mathrm{c} 1 \mathrm{ccccc} 1$ & 59 & 7.23 \\
\hline 1951 & COc1cc2ncnc(Nc3ecc(OCc4cecen4)c(C)c3)c2cc1OC & 59 & $*$ \\
\hline 1952 & $\mathrm{COCOCC} \# \mathrm{CC}(=\mathrm{O}) \mathrm{Nc} 1 \mathrm{ccc} 2 \mathrm{ncnc}(\mathrm{Nc} 3 \mathrm{cccc}(\mathrm{Br}) \mathrm{c} 3) \mathrm{c} 2 \mathrm{c} 1$ & 59 & $*$ \\
\hline 1953 & $\operatorname{COc} 1 \operatorname{ccc}(\mathrm{Nc} 2 \mathrm{ncc} 3 \mathrm{ncc}(=\mathrm{O}) \mathrm{n}(-\mathrm{c} 4 \mathrm{ccc}(\mathrm{NC}(=\mathrm{O}) / \mathrm{C}=\mathrm{C} / \mathrm{CN}(\mathrm{C}) \mathrm{C}) \mathrm{cc} 4) \mathrm{c} 3 \mathrm{n} 2) \mathrm{cc} 1$ & 59.1 & 7.23 \\
\hline 1954 & $\begin{array}{c}\mathrm{O}=\mathrm{C} 1 \mathrm{OC}[\mathrm{C} @ \mathrm{H}] 2 \mathrm{OC}(=\mathrm{O}) \mathrm{c} 3 \mathrm{cc}(\mathrm{O}) \mathrm{c}(\mathrm{O}) \mathrm{c}(\mathrm{O}) \mathrm{c} 3-\mathrm{c} 3 \mathrm{c}(\mathrm{O}) \mathrm{c}(\mathrm{O}) \mathrm{c}(\mathrm{O}) \mathrm{c} 4 \mathrm{c} 3 \mathrm{C}(=\mathrm{O}) \mathrm{O}[\mathrm{C} @ \mathrm{H}]([\mathrm{C} @ \mathrm{H}] 3 \mathrm{OC}(=\mathrm{O}) \mathrm{c} 5 \mathrm{c}- \\
4 \mathrm{c}(\mathrm{O}) \mathrm{c}(\mathrm{O}) \mathrm{c}(\mathrm{O}) \mathrm{c} 5[\mathrm{C} @ @ \mathrm{H}] 3[\mathrm{C} @] 3(\mathrm{O}) \mathrm{OC}[\mathrm{C} @ @ \mathrm{H}](\mathrm{O})[\mathrm{C} @ \mathrm{H}](\mathrm{O})[\mathrm{C} @ \mathrm{H}] 3 \mathrm{O})[\mathrm{C} @ @ \mathrm{H}] 2 \mathrm{OC}(=\mathrm{O}) \mathrm{c} 2 \mathrm{cc}(\mathrm{O}) \mathrm{c}(\mathrm{O}) \mathrm{c}(\mathrm{O} \\
) \mathrm{c} 2-\mathrm{c} 2 \mathrm{c} 1 \mathrm{cc}(\mathrm{O}) \mathrm{c}(\mathrm{O}) \mathrm{c} 2 \mathrm{O}\end{array}$ & 59.2 & $*$ \\
\hline 1955 & $\mathrm{O}=\mathrm{C}(\mathrm{Nc} 1 \operatorname{ccccc} 1 \mathrm{C}(=\mathrm{O}) \mathrm{N} / \mathrm{N}=\mathrm{C} / \mathrm{c} 1 \operatorname{ccccc} 1) \mathrm{c} 1 \mathrm{ccco} 1$ & 59.3 & $*$ \\
\hline 1956 & $\begin{array}{c}\mathrm{CS}(=\mathrm{O})(=\mathrm{O}) \mathrm{N} 1 \mathrm{CCN}(\mathrm{Cc} 2 \mathrm{ccc}(- \\
\mathrm{c} 3 \operatorname{ccc} 4 \mathrm{ncnc}(\mathrm{Nc} 5 \operatorname{ccc}(\mathrm{OCc} 6 \mathrm{cccc}(\mathrm{F}) \mathrm{c} 6) \mathrm{c}(\mathrm{Cl}) \mathrm{c} 5) \mathrm{c} 4 \mathrm{c} 3) \mathrm{o} 2) \mathrm{CC} 1 . \mathrm{Cc} 1 \mathrm{ccc}(\mathrm{S}(=\mathrm{O})(=\mathrm{O}) \mathrm{O}) \mathrm{cc} 1\end{array}$ & 59.9 & $*$ \\
\hline 1957 & $\mathrm{Cc} 1 \mathrm{ccc}(\mathrm{C} 2=\mathrm{NN}(\mathrm{c} 3 \operatorname{ccc} c 3) \mathrm{C}(\mathrm{c} 3 \operatorname{ccc} 4 \operatorname{ccc} c \mathrm{c} 43) \mathrm{C} 2) \mathrm{cc} 1$ & 60 & 7.22 \\
\hline
\end{tabular}




\begin{tabular}{|c|c|c|c|}
\hline 1958 & $\mathrm{Cc} 1 \mathrm{ccc}(\mathrm{C} 2=\mathrm{NN}(\mathrm{c} 3 \mathrm{nc}(-\mathrm{c} 4 \mathrm{ccc}(\mathrm{Cl}) \mathrm{cc} 4) \operatorname{cs} 3) \mathrm{C}(\mathrm{c} 3 \mathrm{ccc}(\mathrm{F}) \mathrm{cc} 3) \mathrm{C} 2) \mathrm{cc} 1 \mathrm{C}$ & 60 & 7.22 \\
\hline 1959 & $\mathrm{CC}(=\mathrm{O}) \mathrm{NCc} 1 \mathrm{cccc}(\mathrm{C} \# \mathrm{Cc} 2 \mathrm{cncnc} 2 \mathrm{Nc} 2 \operatorname{ccc}(\mathrm{OCc} 3 \operatorname{ccc}(\mathrm{F}) \mathrm{c} 3) \mathrm{c}(\mathrm{Cl}) \mathrm{c} 2) \mathrm{c} 1$ & 60 & $*$ \\
\hline 1960 & $\mathrm{CCOc} 1 \mathrm{cc} 2 \mathrm{ncnc}(\mathrm{Nc} 3 \operatorname{ccc}(\mathrm{OCc} 4 \mathrm{ccc}(\mathrm{F}) \mathrm{c} 4) \mathrm{c}(\mathrm{Cl}) \mathrm{c} 3) \mathrm{c} 2 \mathrm{cc} 1 \mathrm{NC}(=\mathrm{O}) / \mathrm{C}=\mathrm{C} / \mathrm{CN} 1 \mathrm{CCCC} 1$ & 60 & $*$ \\
\hline 1961 & $\mathrm{CCOC}(=\mathrm{O}) \mathrm{N}[\mathrm{C} @ \mathrm{H}] 1 \mathrm{CN}[\mathrm{C} @ \mathrm{H}](\mathrm{C} \# \mathrm{Cc} 2 \mathrm{cc} 3 \mathrm{ncnc}(\mathrm{Nc} 4 \mathrm{ccc}(\mathrm{OCc} 5 \mathrm{ccc}(\mathrm{F}) \mathrm{c} 5) \mathrm{c}(\mathrm{Cl}) \mathrm{c} 4) \mathrm{c} 3 \mathrm{~s} 2) \mathrm{C} 1$ & 60 & $*$ \\
\hline 1962 & $\mathrm{O}=\mathrm{C}(\mathrm{Nc} 1 \mathrm{ccc} 2 \mathrm{ncnc}(\mathrm{Nc} 3 \operatorname{ccc}(\mathrm{Br}) \mathrm{c} 3) \mathrm{c} 2 \mathrm{c} 1) \mathrm{C} 1 \mathrm{CCSS} 1$ & 60 & $*$ \\
\hline 1963 & $\operatorname{CCOC}(=\mathrm{O}) \mathrm{c} 1 \mathrm{cn} 2 \mathrm{ncnc}(\mathrm{Nc} 3 \operatorname{ccc}(\mathrm{Br}) \mathrm{c} 3) \mathrm{c} 2 \mathrm{c} 1 \mathrm{CC}$ & 60 & $*$ \\
\hline 1964 & N[C@@H]1CCN(Cc2ccn3ncnc(Nc4ccc5c(cnn5Cc5cccc(F)c5)c4)c23)C1 & 60 & * \\
\hline 1965 & $\mathrm{NS}(=\mathrm{O})(=\mathrm{O}) \operatorname{c} 1 \operatorname{ccc}(-\mathrm{n} 2 \mathrm{c}(\mathrm{SCC}(=\mathrm{O}) \mathrm{Nc} 3 \operatorname{ccc}([\mathrm{N}+](=\mathrm{O})[\mathrm{O}-]) \operatorname{cc} 3[\mathrm{~N}+](=\mathrm{O})[\mathrm{O}-]) \mathrm{nc} 3 \operatorname{cc} 4 \operatorname{ccccc} 4 \mathrm{cc} 3 \mathrm{c} 2=\mathrm{O}) \operatorname{cc} 1$ & 60 & $*$ \\
\hline 1966 & $\mathrm{Nc} 1 \mathrm{cccc}(-\mathrm{c} 2 \mathrm{nc} 3 \mathrm{c}(\mathrm{Nc} 4 \mathrm{cccc}(\mathrm{Cl}) \mathrm{c} 4) \mathrm{ncnc} 3 \mathrm{o} 2) \mathrm{c} 1$ & 60 & * \\
\hline 1967 & $\mathrm{COc} 1 \mathrm{cc}(\mathrm{Br}) \mathrm{c}(\mathrm{C}=\mathrm{C} 2 \mathrm{CN}(\mathrm{C}) \mathrm{CC}(=\mathrm{Cc} 3 \mathrm{nc}(\mathrm{C}) \mathrm{c}(\mathrm{C}) \mathrm{nc} 3 \mathrm{C}) \mathrm{C} 2=\mathrm{O}) \mathrm{cc} 1 \mathrm{OC}$ & 60 & $*$ \\
\hline 1968 & $\mathrm{Fc} 1 \mathrm{cc}(\mathrm{F}) \mathrm{cc}(\mathrm{NC}(=\mathrm{S}) \mathrm{Nc} 2 \mathrm{ccc} 3 \mathrm{ncnc}(\mathrm{Nc} 4 \mathrm{cccc}(\mathrm{Cl}) \mathrm{c} 4) \mathrm{c} 3 \mathrm{c} 2) \mathrm{c} 1$ & 60.1 & * \\
\hline 1969 & $\mathrm{C}=\mathrm{CC}(=\mathrm{O}) \mathrm{Oc} 1 \mathrm{ccc}(-\mathrm{n} 2 \mathrm{c}(=\mathrm{O}) \mathrm{cnc} 3 \mathrm{cnc}(\mathrm{Nc} 4 \mathrm{ccc}(\mathrm{OC}) \mathrm{cc} 4) \mathrm{nc} 32) \mathrm{cc} 1$ & 60.4 & 7.22 \\
\hline 1970 & $\mathrm{FC}(\mathrm{F})(\mathrm{F}) \mathrm{c} 1 \mathrm{cccc}(\mathrm{NC}(=\mathrm{S}) \mathrm{Nc} 2 \mathrm{ccc} 3 \mathrm{ncnc}(\mathrm{Nc} 4 \mathrm{cccc}(\mathrm{Br}) \mathrm{c} 4) \mathrm{c} 3 \mathrm{c} 2) \mathrm{c} 1$ & 60.7 & $*$ \\
\hline 1971 & $\mathrm{Nc} 1 \mathrm{cc}(\mathrm{Nc} 2 \mathrm{cccc}(\mathrm{Oc} 3 \mathrm{cc}(\mathrm{Nc} 4 \mathrm{ccc}(\mathrm{OCc} 5 \mathrm{ccc}(\mathrm{F}) \mathrm{c} 5) \mathrm{c}(\mathrm{Cl}) \mathrm{c} 4) \mathrm{ncn} 3) \mathrm{c} 2) \mathrm{ncn} 1$ & 61 & 7.21 \\
\hline 1972 & $\mathrm{O}=\mathrm{c} 1 \mathrm{oc} 2 \mathrm{cc} 3 \mathrm{ncnc}(\mathrm{Nc} 4 \mathrm{ccc}(\mathrm{OCc} 5 \mathrm{ccc}(\mathrm{Cl}) \mathrm{cc} 5) \mathrm{c}(\mathrm{Cl}) \mathrm{c} 4) \mathrm{c} 3 \mathrm{cc} 2 \mathrm{n} 1 \mathrm{CCCN} 1 \mathrm{CCOCC} 1$ & 61 & $*$ \\
\hline 1973 & $\mathrm{NC}(=\mathrm{O}) \mathrm{Nc} 1 \mathrm{ccc} 2 \mathrm{ncnc}(\mathrm{Nc} 3 \mathrm{ccc}(\mathrm{Cl}) \mathrm{cc} 3) \mathrm{c} 2 \mathrm{c} 1$ & 61 & $*$ \\
\hline 1974 & $\mathrm{CCC}(=\mathrm{O}) \mathrm{Nc} 1 \mathrm{cc} 2 \mathrm{c}(\mathrm{Nc} 3 \mathrm{ccc} 4 \mathrm{c}(\mathrm{ccn} 4 \mathrm{Cc} 4 \mathrm{ccc} \operatorname{cn} 4) \mathrm{c} 3) \mathrm{ncnc} 2 \mathrm{cc} 1 \mathrm{OC}$ & 61 & $*$ \\
\hline 1975 & $\mathrm{COCCN}(\mathrm{CCOC}) \mathrm{CCOc} 1 \mathrm{cc} 2 \mathrm{c}(\mathrm{Nc} 3 \mathrm{ccc}(\mathrm{F}) \mathrm{c}(\mathrm{Cl}) \mathrm{c} 3) \mathrm{ncnc} 2 \mathrm{cc} 1 \mathrm{OC}$ & 61 & $*$ \\
\hline 1976 & Fc1ccec(Cn2ncc3ec(Nc4ncnn5ccc(COC[C@@H]6CNCCO6)c45)ccc32)c1 & 61 & $*$ \\
\hline 1977 & $\mathrm{Fc} 1 \mathrm{ccccc} 1 \mathrm{Oc} 1 \mathrm{ccc}(\mathrm{Nc} 2 \mathrm{ncnc} 3 \mathrm{cc}[\mathrm{nH}] \mathrm{c} 23) \mathrm{cc} 1 \mathrm{Cl}$ & 61 & $*$ \\
\hline 1978 & $\mathrm{CS}(=\mathrm{O})(=\mathrm{O}) \mathrm{O} . \mathrm{O}=\mathrm{C}(\mathrm{CCO}) \mathrm{NCCn} 1 \mathrm{ccc} 2 \mathrm{ncnc}(\mathrm{Nc} 3 \operatorname{ccc}(\mathrm{Oc} 4 \operatorname{ccc}(\mathrm{C}(\mathrm{F})(\mathrm{F}) \mathrm{F}) \mathrm{c} 4) \mathrm{c}(\mathrm{Cl}) \mathrm{c} 3) \mathrm{c} 21$ & 61 & $*$ \\
\hline 1979 & $\mathrm{FC}(\mathrm{F})(\mathrm{F}) \mathrm{Oc} 1 \mathrm{ccc}(-\mathrm{c} 2 \mathrm{cc} 3 \mathrm{cc}(\mathrm{Br}) \mathrm{cc}(\mathrm{Nc} 4 \mathrm{nc}(-\mathrm{c} 5 \mathrm{ccc}(\mathrm{Cl}) \mathrm{cc} 5) \mathrm{nc} 5 \mathrm{ccc}(\mathrm{Br}) \mathrm{cc} 45) \mathrm{c} 3 \mathrm{o} 2) \mathrm{cc} 1$ & 61.5 & $*$ \\
\hline 1980 & $\begin{array}{c}\mathrm{O}=\mathrm{C} 1 \mathrm{OC}[\mathrm{C} @ \mathrm{H}] 2 \mathrm{OC}(=\mathrm{O}) \mathrm{c} 3 \mathrm{cc}(\mathrm{O}) \mathrm{c}(\mathrm{O}) \mathrm{c}(\mathrm{O}) \mathrm{c} 3-\mathrm{c} 3 \mathrm{c}(\mathrm{O}) \mathrm{c}(\mathrm{O}) \mathrm{c}(\mathrm{O}) \mathrm{c} 4 \mathrm{c} 3 \mathrm{C}(=\mathrm{O}) \mathrm{O}[\mathrm{C} @ \mathrm{H}]([\mathrm{C} @ \mathrm{H}] 3 \mathrm{OC}(=\mathrm{O}) \mathrm{c} 5 \mathrm{c}- \\
4 \mathrm{c}(\mathrm{O}) \mathrm{c}(\mathrm{O}) \mathrm{c}(\mathrm{O}) \mathrm{c} 5[\mathrm{C} @ @ \mathrm{H}] 3 \mathrm{O})[\mathrm{C} @ @ \mathrm{H}] 2 \mathrm{OC}(=\mathrm{O}) \mathrm{c} 2 \mathrm{cc}(\mathrm{O}) \mathrm{c}(\mathrm{O}) \mathrm{c}(\mathrm{O}) \mathrm{c} 2-\mathrm{c} 2 \mathrm{c} 1 \mathrm{cc}(\mathrm{O}) \mathrm{c}(\mathrm{O}) \mathrm{c} 2 \mathrm{O}\end{array}$ & 61.8 & $*$ \\
\hline 1981 & $\mathrm{O}=\mathrm{C}(\mathrm{Nc} 1 \mathrm{ccc} 2 \mathrm{ncnc}(\mathrm{Nc} 3 \operatorname{cccc}(\mathrm{Br}) \mathrm{c} 3) \mathrm{c} 2 \mathrm{c} 1) \mathrm{c} 1 \mathrm{ccc}([\mathrm{N}+](=\mathrm{O})[\mathrm{O}-]) \mathrm{cc} 1$ & 61.8 & $*$ \\
\hline 1982 & $\operatorname{COCCN}(\mathrm{C}) \mathrm{C} / \mathrm{C}=\mathrm{C} / \mathrm{C}(=\mathrm{O}) \mathrm{Nc} 1 \mathrm{ccc} 2 \mathrm{ncnc}(\mathrm{Nc} 3 \operatorname{cccc}(\mathrm{Br}) \mathrm{c} 3) \mathrm{c} 2 \mathrm{c} 1$ & 62 & $*$ \\
\hline 1983 & $\mathrm{CCCN}(\mathrm{CC} \# \mathrm{CC}(=\mathrm{O}) \mathrm{Nc} 1 \mathrm{ccc} 2 \mathrm{ncnc}(\mathrm{Nc} 3 \mathrm{cccc}(\mathrm{Br}) \mathrm{c} 3) \mathrm{c} 2 \mathrm{c} 1) \mathrm{CCC}$ & 62 & $*$ \\
\hline 1984 & Br.C[C@@H](Nc1ncnc2[nH]c(-c3ecc(O)cc3)cc12)c1ccc(Br)cc1 & 62 & $*$ \\
\hline 1985 & $\mathrm{Brc} 1 \mathrm{cccc}(\mathrm{Nc} 2 \mathrm{ncnc} 3 \mathrm{cc} 4 \mathrm{c}(\mathrm{cc} 23) \mathrm{OC}(\mathrm{CCN}(\mathrm{N} 2 \mathrm{CCCC} 2) \mathrm{N} 2 \mathrm{CCCC} 2) \mathrm{CO} 4) \mathrm{c} 1$ & 62 & $*$ \\
\hline 1986 & $\operatorname{COc} 1 \operatorname{ccc}(\mathrm{NC}(\mathrm{c} 2 \mathrm{ccccc} 2) \mathrm{n} 2 \mathrm{c}(-\mathrm{c} 3 \mathrm{cc}(\mathrm{CCn} 4 \mathrm{c}(-\mathrm{c} 5 \operatorname{ccccc} 5) \mathrm{nc} 5 \operatorname{ccccc} 5 \mathrm{c} 4=\mathrm{O}) \mathrm{ccc} 3 \mathrm{Cl}) \mathrm{nc} 3 \operatorname{ccccc} 32) \mathrm{cc} 1$ & 62 & $*$ \\
\hline 1987 & $\mathrm{Nc} 1 \mathrm{ccccc} 1 \mathrm{C} \# \mathrm{Cc} 1 \mathrm{cncnc} 1 \mathrm{Nc} 1 \mathrm{ccc}(\mathrm{OCc} 2 \mathrm{cccc}(\mathrm{F}) \mathrm{c} 2) \mathrm{c}(\mathrm{Cl}) \mathrm{c} 1$ & 63 & $*$ \\
\hline 1988 & $\mathrm{CCN}(\mathrm{CC}) \mathrm{C}(=\mathrm{O}) \mathrm{O}[\mathrm{C} @ \mathrm{H}] 1 \mathrm{CN}[\mathrm{C} @ \mathrm{H}](\mathrm{C} \# \mathrm{Cc} 2 \mathrm{cc} 3 \mathrm{ncnc}(\mathrm{Nc} 4 \mathrm{ccc}(\mathrm{OCc} 5 \mathrm{cccc}(\mathrm{F}) \mathrm{c} 5) \mathrm{c}(\mathrm{Cl}) \mathrm{c} 4) \mathrm{c} 3 \mathrm{~s} 2) \mathrm{C} 1$ & 63 & $*$ \\
\hline 1989 & $\mathrm{O}=\mathrm{C}(\mathrm{O}[\mathrm{C} @ \mathrm{H}] 1 \mathrm{CN}[\mathrm{C} @ \mathrm{H}](\mathrm{C \# Cc} 2 \mathrm{cc} 3 \mathrm{ncnc}(\mathrm{Nc} 4 \mathrm{ccc}(\mathrm{OCc} 5 \mathrm{cccc}(\mathrm{F}) \mathrm{c} 5) \mathrm{c}(\mathrm{Cl}) \mathrm{c} 4) \mathrm{c} 3 \mathrm{~s} 2) \mathrm{C} 1) \mathrm{N} 1 \mathrm{CCNCC} 1$ & 63 & $*$ \\
\hline 1990 & $\mathrm{CCC}(=\mathrm{O}) \mathrm{O}[\mathrm{C} @ \mathrm{H}] 1 \mathrm{CN}[\mathrm{C} @ \mathrm{H}](\mathrm{C \# Cc} 2 \mathrm{cc} 3 \mathrm{ncnc}(\mathrm{Nc} 4 \operatorname{ccc}(\mathrm{OCc} 5 \operatorname{cccc}(\mathrm{F}) \mathrm{c} 5) \mathrm{c}(\mathrm{Cl}) \mathrm{c} 4) \mathrm{c} 3 \mathrm{~s} 2) \mathrm{C} 1$ & 63 & $*$ \\
\hline 1991 & $\mathrm{CNC} 1 \mathrm{CCN}(\mathrm{Cc} 2 \mathrm{ccn} 3 \mathrm{ncnc}(\mathrm{Ne} 4 \mathrm{ccc} 5 \mathrm{c}(\mathrm{cnn} 5 \mathrm{Cc} 5 \mathrm{cccc}(\mathrm{F}) \mathrm{c} 5) \mathrm{c} 4) \mathrm{c} 23) \mathrm{CC} 1$ & 63 & $*$ \\
\hline 1992 & $\mathrm{C}[\mathrm{C} @ @ \mathrm{H}](\mathrm{Nc} 1 \mathrm{ncnc} 2[\mathrm{nH}] \mathrm{c}(-\mathrm{c} 3 \mathrm{ccc}(\mathrm{Br}) \mathrm{cc} 3) \mathrm{cc} 12) \mathrm{c} 1 \mathrm{ccccc} 1$ & 63 & $*$ \\
\hline 1993 & Ic1 $1 \mathrm{ccc}(\mathrm{Nc} 2 \mathrm{ncnc} 3 \mathrm{cc} 4 \mathrm{c}(\mathrm{cc} 23) \mathrm{OCCO} 4) \mathrm{c} 1$ & 63 & $*$ \\
\hline 1994 & $\mathrm{O}=\mathrm{C} 1 \mathrm{COc} 2 \mathrm{cc} 3 \mathrm{ncnc}(\mathrm{Nc} 4 \mathrm{cccc}(\mathrm{Cl}) \mathrm{c} 4) \mathrm{c} 3 \mathrm{cc} 2 \mathrm{~N} 1 \mathrm{CCCN} 1 \mathrm{CCOCC} 1$ & 63.1 & $*$ \\
\hline 1995 & Brc1 $\operatorname{cccc}(\mathrm{Nc} 2 \mathrm{ncnc} 3 \mathrm{cc} 4 \mathrm{c}(\mathrm{cc} 23) \mathrm{OC}(\mathrm{CN} 2 \mathrm{CCOCC} 2) \mathrm{CO} 4) \mathrm{c} 1$ & 63.1 & $*$ \\
\hline 1996 & $\mathrm{c} 1 \mathrm{ccc}(\mathrm{Cc} 2 \mathrm{ccc}(\mathrm{Nc} 3 \mathrm{ncnc} 4[\mathrm{nH}] \operatorname{ccc} 34) \mathrm{cc} 2) \mathrm{cc} 1$ & 63.29 & $*$ \\
\hline 1997 & $\mathrm{COc} 1 \mathrm{cc} 2 \mathrm{ncnc}(\mathrm{Nc} 3 \mathrm{ccc}(\mathrm{F}) \mathrm{c}(\mathrm{Cl}) \mathrm{c} 3) \mathrm{c} 2 \mathrm{cc} 1 \mathrm{OCCO}$ & 63.4 & $*$ \\
\hline 1998 & Oc1 $\operatorname{cccc}(\mathrm{Nc} 2 \mathrm{ncnc} 3 \operatorname{ccc}(\mathrm{NC}(=\mathrm{S}) \mathrm{NCc} 4 \operatorname{ccccc} 4) \operatorname{cc} 23) \mathrm{c} 1$ & 63.6 & $*$ \\
\hline 1999 & $\mathrm{O}=\mathrm{C}(\mathrm{Nc} 1 \mathrm{cccc}(\mathrm{Cl}) \mathrm{c} 1) \mathrm{c} 1 \mathrm{ccc}(\mathrm{OCCCN} 2 \mathrm{CCCCC} 2) \mathrm{cc} 1 \mathrm{O}$ & 63.9 & $*$ \\
\hline
\end{tabular}




\begin{tabular}{|c|c|c|c|}
\hline 2000 & $\mathrm{CCOc} 1 \mathrm{cc} 2 \mathrm{ncc}(\mathrm{CHN}) \mathrm{c}(\mathrm{Nc} 3 \operatorname{ccc}(\mathrm{OCc} 4 \mathrm{ccc}(\mathrm{F}) \mathrm{cc} 4) \mathrm{c}(\mathrm{Cl}) \mathrm{c} 3) \mathrm{c} 2 \mathrm{cc} 1 \mathrm{NC}(=\mathrm{O}) / \mathrm{C}=\mathrm{C} / \mathrm{CN}(\mathrm{C}) \mathrm{C}$ & 64 & 7.19 \\
\hline 2001 & $\operatorname{COC}(=\mathrm{O}) \mathrm{Cn} 1 \mathrm{cc}(-\mathrm{c} 2 \mathrm{cccc}(\mathrm{Cl}) \mathrm{c} 2) \mathrm{c}(=\mathrm{O}) \mathrm{c} 2 \mathrm{c}(\mathrm{O}) \mathrm{cc}(\mathrm{OC}) \mathrm{cc} 21$ & 64 & $*$ \\
\hline 2002 & $\mathrm{~S}=\mathrm{C}(\mathrm{NNc} 1 \mathrm{nncc} 2 \mathrm{ccccc} 12) \mathrm{Nc} 1 \mathrm{ccc}(\mathrm{Cl}) \mathrm{cc} 1$ & 64 & $*$ \\
\hline 2003 & NCCCOCc1 cen2ncnc(Nc3ecc4c(cnn4Cc4ccce(F)c4)c3)c12 & 64 & $*$ \\
\hline 2004 & $\mathrm{Brc} 1 \mathrm{ccc}(\mathrm{Nc} 2 \mathrm{ncnc} 3 \mathrm{ccc}(\mathrm{NN}=\mathrm{NCCN} 4 \mathrm{CCOCC} 4) \mathrm{cc} 23) \mathrm{c} 1$ & 64 & $*$ \\
\hline 2005 & $\operatorname{COc} 1 \mathrm{cc}(\mathrm{O}) \mathrm{c}(\mathrm{C}(=\mathrm{O}) \mathrm{Nc} 2 \operatorname{cccc}(\mathrm{Cl}) \mathrm{c} 2) \mathrm{cc} 1 \mathrm{OC}$ & 64 & $*$ \\
\hline 2006 & $\mathrm{CN} 1 \mathrm{CCN}(\mathrm{N}(\mathrm{CCC} 2 \mathrm{COc} 3 \mathrm{cc} 4 \mathrm{ncnc}(\mathrm{Nc} 5 \mathrm{cccc}(\mathrm{Cl}) \mathrm{c} 5) \mathrm{c} 4 \mathrm{cc} 3 \mathrm{O} 2) \mathrm{N} 2 \mathrm{CCN}(\mathrm{C}) \mathrm{CC} 2) \mathrm{CC} 1$ & 64 & $*$ \\
\hline 2007 & $\mathrm{C}[\mathrm{C} @ \mathrm{H}](\mathrm{N}) \mathrm{C} \# \mathrm{Cc} 1 \mathrm{cc} 2 \mathrm{ncnc}(\mathrm{Nc} 3 \mathrm{ccc}(\mathrm{OCc} 4 \mathrm{cccc}(\mathrm{F}) \mathrm{c} 4) \mathrm{c}(\mathrm{Cl}) \mathrm{c} 3) \mathrm{c} 2 \mathrm{~s} 1$ & 64 & $*$ \\
\hline 2008 & $\mathrm{O}=\mathrm{C}(\mathrm{O}[\mathrm{C} @ \mathrm{H}] 1 \mathrm{CN}[\mathrm{C} @ \mathrm{H}](\mathrm{CHCc} 2 \mathrm{cc} 3 \mathrm{ncnc}(\mathrm{Nc} 4 \mathrm{ccc}(\mathrm{OCc} 5 \mathrm{cccc}(\mathrm{F}) \mathrm{c} 5) \mathrm{c}(\mathrm{Cl}) \mathrm{c} 4) \mathrm{c} 3 \mathrm{~s} 2) \mathrm{C} 1) \mathrm{N} 1 \mathrm{CCOCC} 1$ & 65 & 7.14 \\
\hline 2009 & $\mathrm{O}=\mathrm{C}(\mathrm{COc} 1 \mathrm{cccc} 1) \mathrm{Nc} 1 \mathrm{ccc}(\mathrm{Oc} 2 \mathrm{cc}(\mathrm{Nc} 3 \mathrm{ccc}(\mathrm{OCc} 4 \mathrm{cccc}(\mathrm{F}) \mathrm{c} 4) \mathrm{c}(\mathrm{Cl}) \mathrm{c} 3) \mathrm{ncn} 2) \mathrm{c} 1$ & 65 & 7.19 \\
\hline 2010 & $\mathrm{Cc} 1 n \mathrm{nnc}(\mathrm{Nc} 2 \mathrm{ccc}(\mathrm{OCc} 3 \operatorname{ccc}(\mathrm{F}) \mathrm{c} 3) \mathrm{c}(\mathrm{Cl}) \mathrm{c} 2) \mathrm{c} 1 / \mathrm{C}=\mathrm{N} / \mathrm{OCCCN} 1 \mathrm{CCOCC} 1$ & 65 & 7.19 \\
\hline 2011 & $\mathrm{CC} 1(\mathrm{C}) \mathrm{CC}(\mathrm{C}(=\mathrm{O}) \mathrm{Nc} 2 \mathrm{ccc} 3 \mathrm{ncnc}(\mathrm{Nc} 4 \mathrm{cccc}(\mathrm{Cl}) \mathrm{c} 4) \mathrm{c} 3 \mathrm{c} 2) \mathrm{CC}(\mathrm{C})(\mathrm{C}) \mathrm{N} 1[\mathrm{O}]$ & 65 & 7.19 \\
\hline 2012 & $\mathrm{CCC}(=\mathrm{O}) \mathrm{Nc} 1 \mathrm{cc} 2 \mathrm{c}(\mathrm{Nc} 3 \mathrm{ccc}(\mathrm{Oc} 4 \mathrm{ccccc} 4) \mathrm{cc} 3) \mathrm{ncnc} 2 \mathrm{cc} 1 \mathrm{OC}$ & 65 & $*$ \\
\hline 2013 & $\mathrm{CCC}(=\mathrm{O}) \mathrm{Nc} 1 \mathrm{cc} 2 \mathrm{c}(\mathrm{Nc} 3 \operatorname{ccc}(\mathrm{NS}(=\mathrm{O})(=\mathrm{O}) \mathrm{c} 4 \mathrm{cccc} 4) \mathrm{cc} 3) \mathrm{ncnc} 2 \mathrm{cc} 1 \mathrm{OC}$ & 65 & $*$ \\
\hline 2014 & $\mathrm{~S}=\mathrm{C}(\mathrm{NNc} 1 \mathrm{nncc} 2 \mathrm{ccccc} 12) \mathrm{Nc} 1 \mathrm{ccc} c 1$ & 65 & $*$ \\
\hline 2015 & $\operatorname{COCC} 1 \mathrm{CCCN} 1 \mathrm{CC} \# \mathrm{CC}(=\mathrm{O}) \mathrm{Nc} 1 \mathrm{ccc} 2 \mathrm{ncnc}(\mathrm{Nc} 3 \mathrm{ccc}(\mathrm{Br}) \mathrm{c} 3) \mathrm{c} 2 \mathrm{c} 1$ & 65 & $*$ \\
\hline 2016 & $\operatorname{COCCOCC\# CC(}(=\mathrm{O}) \mathrm{Nc} 1 \mathrm{ccc} 2 \mathrm{ncnc}(\mathrm{Nc} 3 \operatorname{cccc}(\mathrm{Br}) \mathrm{c} 3) \mathrm{c} 2 \mathrm{c} 1$ & 65 & $*$ \\
\hline 2017 & $\mathrm{CCN} 1 \mathrm{CCN}(\mathrm{CC} \# \mathrm{CC}(=\mathrm{O}) \mathrm{Nc} 2 \mathrm{ccc} 3 \mathrm{ncnc}(\mathrm{Nc} 4 \mathrm{cccc}(\mathrm{Br}) \mathrm{c} 4) \mathrm{c} 3 \mathrm{c} 2) \mathrm{CC} 1$ & 65 & $*$ \\
\hline 2018 & OCCn1 cnc2ce3c(N4CCe $5 \operatorname{ccccc} 54) n c n c 3 c c 21$ & 65 & $*$ \\
\hline 2019 & $\mathrm{C}=\mathrm{CC}(=\mathrm{O}) \mathrm{Nc} 1 \mathrm{cc}(\mathrm{Nc} 2 \mathrm{ncc}(\mathrm{Cl}) \mathrm{c}(\mathrm{Nc} 3 \operatorname{cccc} 3 \mathrm{P}(\mathrm{C})(\mathrm{C})=\mathrm{O}) \mathrm{n} 2) \mathrm{c}(\mathrm{OC}) \mathrm{cc} 1 \mathrm{~N}(\mathrm{C}) \mathrm{CCN}(\mathrm{C}) \mathrm{C}$ & 65 & $*$ \\
\hline 2020 & $\mathrm{C}=\mathrm{C}=\mathrm{CCCCCOc} 1 \mathrm{cc} 2 \mathrm{c}(\mathrm{Nc} 3 \mathrm{ccc}(\mathrm{F}) \mathrm{c}(\mathrm{Cl}) \mathrm{c} 3) \mathrm{ncnc} 2 \mathrm{cc} 1 \mathrm{O}$ & 65.5 & $*$ \\
\hline 2021 & $\mathrm{COc} 1 \mathrm{cc} 2 \mathrm{ncnc}(\mathrm{Nc} 3 \mathrm{ccc}(\mathrm{F}) \mathrm{c}(\mathrm{Cl}) \mathrm{c} 3) \mathrm{c} 2 \mathrm{cc} 1 \mathrm{OCCn} 1 \mathrm{ccnc} 1$ & 66 & $*$ \\
\hline 2022 & $\mathrm{COc} 1 \mathrm{cccc} 1 \mathrm{Nc} 1 \mathrm{ncc} 2 \mathrm{cc}(-\mathrm{c} 3 \mathrm{c}(\mathrm{Cl}) \mathrm{cccc} 3 \mathrm{Cl}) \mathrm{c}(=\mathrm{O}) \mathrm{n}(\mathrm{C}) \mathrm{c} 2 \mathrm{n} 1$ & 66 & $*$ \\
\hline 2023 & $\mathrm{CN} 1 \mathrm{CCN}(\mathrm{CCCOc} 2 \mathrm{cc}(\mathrm{OC} 3 \mathrm{CCOCC} 3) \mathrm{c} 3 \mathrm{c}(\mathrm{Nc} 4 \mathrm{ccc}(\mathrm{F}) \mathrm{c}(\mathrm{Cl}) \mathrm{c} 4) \mathrm{ncnc} 3 \mathrm{c} 2) \mathrm{CC} 1$ & 66 & $*$ \\
\hline 2024 & $\mathrm{C}=\mathrm{CC}(=\mathrm{O}) \mathrm{Nc} 1 \mathrm{cc}(-\mathrm{n} 2 \mathrm{c}(=\mathrm{O}) \mathrm{cc}(\mathrm{C}) \mathrm{c} 3 \mathrm{cnc}(\mathrm{Nc} 4 \mathrm{ccc}(\mathrm{N} 5 \mathrm{CCN}(\mathrm{C}) \mathrm{C}(\mathrm{C}) \mathrm{C} 5) \mathrm{cc} 4 \mathrm{OC}) \mathrm{nc} 32) \mathrm{cc}(\mathrm{C}(\mathrm{F})(\mathrm{F}) \mathrm{F}) \mathrm{c} 1$ & 66 & $*$ \\
\hline 2025 & $\mathrm{CCN}(\mathrm{CC}) \mathrm{N}(\mathrm{CCC} 1 \mathrm{COc} 2 \mathrm{cc} 3 \mathrm{ncnc}(\mathrm{Nc} 4 \mathrm{cccc}(\mathrm{Cl}) \mathrm{c} 4) \mathrm{c} 3 \mathrm{cc} 2 \mathrm{O} 1) \mathrm{N}(\mathrm{CC}) \mathrm{CC}$ & 66 & $*$ \\
\hline 2026 & $\mathrm{Fc} 1 \mathrm{ccc}(\mathrm{Nc} 2 \mathrm{ncnc} 3 \mathrm{cc} 4 \mathrm{c}(\mathrm{cc} 23) \mathrm{OC}(\mathrm{CCN}(\mathrm{N} 2 \mathrm{CCOCC} 2) \mathrm{N} 2 \mathrm{CCOCC} 2) \mathrm{CO} 4) \mathrm{cc} 1 \mathrm{Cl}$ & 66 & $*$ \\
\hline 2027 & $\mathrm{Fc} 1 \mathrm{ccc}(\mathrm{Nc} 2 \mathrm{ncnc} 3 \mathrm{cc} 4 \mathrm{c}(\mathrm{cc} 23) \mathrm{OC}(\mathrm{CCN}(\mathrm{N} 2 \mathrm{CCCCC} 2) \mathrm{N} 2 \mathrm{CCCCC} 2) \mathrm{CO} 4) \mathrm{cc} 1 \mathrm{Cl}$ & 66 & $*$ \\
\hline 2028 & $\operatorname{COc} 1 \operatorname{ccc}(-\mathrm{c} 2 \mathrm{cc}(\mathrm{NC}(=\mathrm{O}) \mathrm{Nc} 3 \operatorname{ccc} \mathrm{n} 3) \mathrm{cc}(\mathrm{OC}) \mathrm{c} 2 \mathrm{OC}) \mathrm{cn} 1$ & 66.59 & $*$ \\
\hline 2029 & $\mathrm{Cc} 1 \mathrm{ccc}(\mathrm{Nc} 2 \mathrm{ncnc} 3 \mathrm{cc} 4 \mathrm{oc}(=\mathrm{O}) \mathrm{n}(\mathrm{CCCN} 5 \mathrm{CCOCC} 5) \mathrm{c} 4 \mathrm{cc} 23) \mathrm{cc} 1$ & 67 & $*$ \\
\hline 2030 & $\mathrm{CCC}(=\mathrm{O}) \mathrm{Nc} 1 \mathrm{cc} 2 \mathrm{c}(\mathrm{Nc} 3 \mathrm{ccc}(\mathrm{OCc} 4 \mathrm{cccc}(\mathrm{F}) \mathrm{c} 4) \mathrm{c}(\mathrm{Cl}) \mathrm{c} 3) \mathrm{ncnc} 2 \mathrm{cc} 1 \mathrm{OC}$ & 67 & $*$ \\
\hline 2031 & $\mathrm{COc} 1 \mathrm{cc} 2 \mathrm{ncnc}(\mathrm{Nc} 3 \mathrm{ccc}(\mathrm{F}) \mathrm{c}(\mathrm{Cl}) \mathrm{c} 3) \mathrm{c} 2 \mathrm{cc} 1 \mathrm{OC}[\mathrm{C} @ \mathrm{H}](\mathrm{O}) \mathrm{CN} 1 \mathrm{CCOCC} 1$ & 67 & $*$ \\
\hline 2032 & $\mathrm{Nc} 1 \mathrm{ncnc} 2 \mathrm{c} 1 \mathrm{c}(-\mathrm{c} 1 \mathrm{ccc}(\mathrm{Cl}) \mathrm{c}(\mathrm{O}) \mathrm{c} 1) \mathrm{nn} 2 \mathrm{C} 1 \mathrm{CCCC} 1$ & 67 & * \\
\hline 2033 & $\mathrm{FC}(\mathrm{F})(\mathrm{F}) \mathrm{c} 1 \mathrm{cccc}(\mathrm{Oc} 2 \mathrm{ccc}(\mathrm{Nc} 3 \mathrm{ncnc} 4 \mathrm{cc}[\mathrm{nH}] \mathrm{c} 34) \mathrm{cc} 2 \mathrm{Cl}) \mathrm{c} 1$ & 67 & $*$ \\
\hline 2034 & $\mathrm{Cc} 1 \mathrm{ncnc}(\mathrm{Nc} 2 \mathrm{ccc}(\mathrm{OCc} 3 \operatorname{ccc}(\mathrm{F}) \mathrm{c} 3) \mathrm{c}(\mathrm{Cl}) \mathrm{c} 2) \mathrm{c} 1 / \mathrm{C}=\mathrm{N} / \mathrm{OCCN} 1 \mathrm{CCOCC} 1$ & 68 & 7.17 \\
\hline 2035 & $\mathrm{CCOc} 1 \mathrm{cc} 2 \mathrm{ncc}(\mathrm{CHN}) \mathrm{c}(\mathrm{Nc} 3 \operatorname{ccc}(\mathrm{OCc} 4 \operatorname{ccccc} 4) \mathrm{c}(\mathrm{Cl}) \mathrm{c} 3) \mathrm{c} 2 \mathrm{cc} 1 \mathrm{NC}(=\mathrm{O}) / \mathrm{C}=\mathrm{C} / \mathrm{CN}(\mathrm{C}) \mathrm{CCOC}$ & 68 & 7.17 \\
\hline 2036 & $\mathrm{COc} 1 \mathrm{cc} 2 \mathrm{ncnc}(\mathrm{Nc} 3 \operatorname{ccc}(\mathrm{F}) \mathrm{c}(\mathrm{Cl}) \mathrm{c} 3) \mathrm{c} 2 \mathrm{cc} 1 \mathrm{NC}(=\mathrm{O}) \mathrm{c} 1 \mathrm{cc}([\mathrm{N}+](=\mathrm{O})[\mathrm{O}-]) \mathrm{ccc} 1 \mathrm{~F}$ & 68 & 7.17 \\
\hline 2037 & $\mathrm{COc} 1 \mathrm{ccc} 2 \mathrm{ncnc}(\mathrm{Nc} 3 \mathrm{ccc}(\mathrm{OCc} 4 \mathrm{ccccc} 4) \mathrm{cc} 3) \mathrm{c} 2 \mathrm{c} 1$ & 68 & $*$ \\
\hline 2038 & $\mathrm{O}=\mathrm{C}(\mathrm{NCCN} 1 \mathrm{CCCC} 1) \mathrm{Nc} 1 \mathrm{cc} 2 \mathrm{c}(\mathrm{Nc} 3 \mathrm{ccc}(\mathrm{F}) \mathrm{c}(\mathrm{Cl}) \mathrm{c} 3) \mathrm{ncnc} 2 \mathrm{cc} 1 \mathrm{O}[\mathrm{C} @ \mathrm{H}] 1 \mathrm{CCOC} 1$ & 68 & $*$ \\
\hline 2039 & $\mathrm{CN}(\mathrm{C}) \mathrm{Cc} 1 \mathrm{ccc}(-\mathrm{c} 2 \mathrm{cc} 3 \mathrm{c}(\mathrm{Nc} 4 \mathrm{ccc}(\mathrm{OCc} 5 \mathrm{cccc}(\mathrm{F}) \mathrm{c} 5) \mathrm{c}(\mathrm{Cl}) \mathrm{c} 4) \mathrm{ncnc} 3 \mathrm{~s} 2)[\mathrm{nH}] 1$ & 68 & $*$ \\
\hline 2040 & Fc1 $\operatorname{cccc}(\mathrm{COc} 2 \mathrm{ccc}(\mathrm{Nc} 3 \mathrm{ncnc} 4 \mathrm{cc}(-\mathrm{c} 5 \mathrm{ccc}[\mathrm{nH}] 5) \mathrm{sc} 34) \mathrm{cc} 2 \mathrm{Cl}) \mathrm{c} 1$ & 68 & $*$ \\
\hline 2041 & $\mathrm{CNc} 1 \mathrm{cc} 2 \mathrm{ncnc}(\mathrm{Nc} 3 \operatorname{cccc}(\mathrm{Br}) \mathrm{c} 3) \mathrm{c} 2 \mathrm{cc} 1[\mathrm{~N}+](=\mathrm{O})[\mathrm{O}-]$ & 68 & $*$ \\
\hline 2042 & $\mathrm{OC} 1 \mathrm{CCN}(\mathrm{Cc} 2 \mathrm{ccn} 3 \mathrm{nenc}(\mathrm{Nc} 4 \mathrm{ccc} 5 \mathrm{c}(\operatorname{cnn} 5 \mathrm{Cc} 5 \mathrm{cccc}(\mathrm{F}) \mathrm{c} 5) \mathrm{c} 4) \mathrm{c} 23) \mathrm{CC} 1$ & 68 & $*$ \\
\hline
\end{tabular}




\begin{tabular}{|c|c|c|c|}
\hline 2043 & $\mathrm{O}=\mathrm{C}(/ \mathrm{C}=\mathrm{C} / \mathrm{CN} 1 \mathrm{CCC}(\mathrm{N} 2 \mathrm{CCCCC} 2) \mathrm{CC} 1) \mathrm{Nc} 1 \mathrm{ccc} 2 \mathrm{ncnc}(\mathrm{Nc} 3 \mathrm{ccc}(\mathrm{Br}) \mathrm{c} 3) \mathrm{c} 2 \mathrm{c} 1$ & 68 & $*$ \\
\hline 2044 & $\mathrm{C}[\mathrm{C} @ \mathrm{H}](\mathrm{c} 1 \mathrm{cccc}(\mathrm{F}) \mathrm{c} 1) \mathrm{n} 1 \mathrm{ncc} 2 \mathrm{cc}(\mathrm{Nc} 3 \mathrm{ncnn} 4 \mathrm{ccc}(\mathrm{COC}[\mathrm{C} @ @ \mathrm{H}] 5 \mathrm{CNCCO}) \mathrm{c} 34) \mathrm{ccc} 21$ & 68 & $*$ \\
\hline 2045 & $\operatorname{clccc}(-\mathrm{c} 2 \mathrm{cc} 3 \mathrm{ncnc}(\mathrm{Nc} 4 \mathrm{ccc} 5[\mathrm{nH}] \mathrm{ccc} 5 \mathrm{c} 4) \mathrm{c} 3 \mathrm{~s} 2) \mathrm{cc} 1$ & 68 & $*$ \\
\hline 2046 & $\mathrm{O}=\mathrm{C}(\mathrm{Nc} 1 \mathrm{cc} 2 \mathrm{c}(\mathrm{Nc} 3 \mathrm{ccc}(\mathrm{F}) \mathrm{c}(\mathrm{Cl}) \mathrm{c} 3) \mathrm{ncnc} 2 \mathrm{cc} 1 \mathrm{O}[\mathrm{C} @ \mathrm{H}] 1 \mathrm{CCOC} 1) \mathrm{N}(\mathrm{NCCN} 1 \mathrm{CCCC} 1) \mathrm{NCN} 1 \mathrm{CCCC} 1$ & 68 & * \\
\hline 2047 & $\mathrm{C}=\mathrm{CC}(=\mathrm{O}) \mathrm{Nc} 1 \mathrm{cccc}(-\mathrm{n} 2 \mathrm{c}(=\mathrm{O}) \mathrm{c}(=\mathrm{O}) \mathrm{n}(\mathrm{C}(\mathrm{C}) \mathrm{C}) \mathrm{c} 3 \mathrm{cnc}(\mathrm{Nc} 4 \mathrm{ccc}(\mathrm{OCCN}(\mathrm{C}) \mathrm{C}) \mathrm{cc} 4 \mathrm{OC}) \mathrm{nc} 32) \mathrm{c} 1$ & 68 & $*$ \\
\hline 2048 & $\mathrm{COc} 1 \mathrm{ccc}(\mathrm{OC}) \mathrm{c}(\mathrm{Nc} 2 \mathrm{cc}(\mathrm{NC}(=\mathrm{O}) \mathrm{CCCC}(=\mathrm{O}) \mathrm{O}) \mathrm{ncn} 2) \mathrm{c} 1$ & 68 & $*$ \\
\hline 2049 & $\mathrm{C}[\mathrm{C} @ \mathrm{H}](\mathrm{N}) \mathrm{C} \# \mathrm{Cc} 1 \mathrm{cc} 2 \mathrm{c}(\mathrm{Nc} 3 \mathrm{ccc}(\mathrm{OCc} 4 \mathrm{cccc}(\mathrm{F}) \mathrm{c} 4) \mathrm{c}(\mathrm{Cl}) \mathrm{c} 3) \mathrm{ncnc} 2 \mathrm{~s} 1$ & 69 & $*$ \\
\hline 2050 & $\mathrm{CCOc} 1 \mathrm{cc} 2 \mathrm{ncnc}(\mathrm{Nc} 3 \operatorname{ccc}(\mathrm{NS}(=\mathrm{O})(=\mathrm{O}) \mathrm{c} 4 \mathrm{cccc} 4) \mathrm{cc} 3) \mathrm{c} 2 \mathrm{cc} 1 \mathrm{NC}(=\mathrm{O}) / \mathrm{C}=\mathrm{C} / \mathrm{CN} 1 \mathrm{CCOCC} 1$ & 69 & $*$ \\
\hline 2051 & $\mathrm{COc} 1 \mathrm{cc} 2 \mathrm{ncnc}(\mathrm{Nc} 3 \mathrm{ccc}(\mathrm{F}) \mathrm{c}(\mathrm{Cl}) \mathrm{c} 3) \mathrm{c} 2 \mathrm{cc} 1 \mathrm{OCCNC}(\mathrm{C})(\mathrm{CO}) \mathrm{CO}$ & 69 & $*$ \\
\hline 2052 & $\begin{array}{c}\mathrm{CC} 1(\mathrm{C})[\mathrm{C} @ @ \mathrm{H}](\mathrm{O}[\mathrm{C} @ @ \mathrm{H}] 2 \mathrm{O}[\mathrm{C} @ \mathrm{H}](\mathrm{C}=\mathrm{O}) \mathrm{O})[\mathrm{C} @ @ \mathrm{H}](\mathrm{O})[\mathrm{C} @ \mathrm{H}](\mathrm{O})[\mathrm{C} @ \mathrm{H}] 2 \mathrm{O}) \mathrm{CC}[\mathrm{C} @ @] 2(\mathrm{C})[\mathrm{C} @ \mathrm{H}] 1 \mathrm{CC} \\
{[\mathrm{C} @] 1(\mathrm{C})[\mathrm{C} @ @ \mathrm{H}] 2 \mathrm{C}(=\mathrm{O}) \mathrm{C}=\mathrm{C} 2[\mathrm{C} @ \mathrm{H}] 3 \mathrm{C}[\mathrm{C} @ @](\mathrm{C})(\mathrm{C}(=\mathrm{O}) \mathrm{O}) \mathrm{CC}[\mathrm{C} @] 3(\mathrm{C}) \mathrm{CC}[\mathrm{C} @] 21 \mathrm{C}}\end{array}$ & 69 & $*$ \\
\hline 2053 & $\operatorname{COc} 1 \operatorname{ccc}(\mathrm{C} 2 \mathrm{CC}(\mathrm{c} 3 \operatorname{ccc}(\mathrm{C}) \mathrm{c}(\mathrm{C}) \mathrm{c} 3)=\mathrm{NN} 2 \mathrm{C}(\mathrm{N})=\mathrm{S}) \mathrm{cc} 1$ & 70 & 7.15 \\
\hline 2054 & $\mathrm{COc} 1 \mathrm{cc} 2 \mathrm{ncnc}(\mathrm{Nc} 3 \operatorname{ccc}(\mathrm{Cl}) \mathrm{c} 3 \mathrm{~F}) \mathrm{c} 2 \mathrm{cc} 1 \mathrm{CN} 1 \mathrm{CCC} 1 \mathrm{C}(\mathrm{N})=\mathrm{O}$ & 70 & $*$ \\
\hline 2055 & $\mathrm{O}=\mathrm{C}(\mathrm{Oc} 1 \mathrm{ccccc} 1) \mathrm{c} 1 \mathrm{cc}(\mathrm{NCc} 2 \mathrm{cc}(\mathrm{O}) \mathrm{ccc} 2 \mathrm{O}) \mathrm{ccc} 1 \mathrm{O}$ & 70 & $*$ \\
\hline 2056 & $\mathrm{Nc} 1 \mathrm{cc} 2 \mathrm{ncnc}(\mathrm{Nc} 3 \mathrm{ccc}(\mathrm{O}) \mathrm{c} 3) \mathrm{c} 2 \mathrm{cn} 1$ & 70 & $*$ \\
\hline 2057 & $\mathrm{CCc} 1 \mathrm{c}(\mathrm{C}(=\mathrm{O}) \mathrm{NC}) \mathrm{cn} 2 \mathrm{ncnc}(\mathrm{Nc} 3 \mathrm{ccc} 4 \mathrm{c}(\operatorname{cnn} 4 \mathrm{Cc} 4 \mathrm{ccccc} 4) \mathrm{c} 3) \mathrm{c} 12$ & 70 & $*$ \\
\hline 2058 & $\mathrm{NC} 1 \mathrm{CCN}(\mathrm{Cc} 2 \mathrm{ccn} 3 \mathrm{ncnc}(\mathrm{Nc} 4 \mathrm{ccc}(\mathrm{OCc} 5 \mathrm{cccc}[\mathrm{n}+] 5[\mathrm{O}-]) \mathrm{c}(\mathrm{Cl}) \mathrm{c} 4) \mathrm{c} 23) \mathrm{CC} 1$ & 70 & $*$ \\
\hline 2059 & $\mathrm{CO} / \mathrm{N}=\mathrm{C} / \mathrm{c} 1 \mathrm{c}(\mathrm{N}) \mathrm{ncnc} 1 \mathrm{Nc} 1 \mathrm{ccc}(\mathrm{F}) \mathrm{c}(\mathrm{Cl}) \mathrm{cl}$ & 70 & $*$ \\
\hline 2060 & $\mathrm{COc} 1 \mathrm{ccc}(\mathrm{Nc} 2 \mathrm{ncnn} 3 \mathrm{ccc}(\mathrm{CN} 4 \mathrm{CCC}(\mathrm{N}) \mathrm{CC} 4) \mathrm{c} 23) \mathrm{cc} 1 \mathrm{Cl}$ & 70 & $*$ \\
\hline 2061 & $\mathrm{COc} 1 \mathrm{cc} 2 \mathrm{ncnc}(\mathrm{Sc} 3 \operatorname{ccc}(\mathrm{NC}(=\mathrm{S}) \mathrm{Nc} 4 \operatorname{ccc}(\mathrm{C}(\mathrm{F})(\mathrm{F}) \mathrm{F}) \mathrm{c} 4) \mathrm{c} 3) \mathrm{c} 2 \mathrm{cc} 1 \mathrm{OC}$ & 70 & $*$ \\
\hline 2062 & $\mathrm{CN} / \mathrm{N}=\mathrm{N} / \mathrm{c} 1 \mathrm{ccc} 2 \mathrm{ncnc}(\mathrm{Nc} 3 \operatorname{cccc}(\mathrm{Br}) \mathrm{c} 3) \mathrm{c} 2 \mathrm{c} 1$ & 70 & $*$ \\
\hline 2063 & $\mathrm{Nc} 1 \mathrm{ccc}(-\mathrm{c} 2 \mathrm{nc} 3 \mathrm{c}(\mathrm{Nc} 4 \mathrm{cccc}(\mathrm{O}) \mathrm{c} 4) \mathrm{ncnc} 3 \mathrm{o} 2) \mathrm{cc} 1$ & 70 & $*$ \\
\hline 2064 & $\mathrm{Clc} 1 \mathrm{cccc}(\mathrm{Nc} 2 \mathrm{ncnc} 3 \mathrm{cc} 4 \mathrm{c}(\mathrm{cc} 23) \mathrm{OC}(\mathrm{CCN}(\mathrm{N} 2 \mathrm{CCCC} 2) \mathrm{N} 2 \mathrm{CCCC} 2) \mathrm{CO} 4) \mathrm{c} 1$ & 70 & $*$ \\
\hline 2065 & $\mathrm{COc} 1 \mathrm{cc} 2 \mathrm{ncnc}(\mathrm{Nc} 3 \operatorname{cccc}(\mathrm{Cl}) \mathrm{c} 3 \mathrm{~F}) \mathrm{c} 2 \mathrm{cc} 1 \mathrm{CNC}(=\mathrm{O}) \mathrm{C} 1 \mathrm{CCN} 1 \mathrm{C}$ & 70 & $*$ \\
\hline 2066 & $\mathrm{O}=\mathrm{C}(\mathrm{O}) \mathrm{CCCC}(=\mathrm{O}) \mathrm{Nc} 1 \mathrm{cc}(\mathrm{Nc} 2 \mathrm{cccc}(\mathrm{Br}) \mathrm{c} 2) \mathrm{ncn} 1$ & 70 & $*$ \\
\hline 2067 & $\mathrm{Nc} 1 \mathrm{c}(\mathrm{O}) \mathrm{cccc} 1 \mathrm{Nc} 1 \mathrm{ncnc} 2 \mathrm{ccncc} 12$ & 70.79 & $*$ \\
\hline 2068 & $\mathrm{CACc} 1 \mathrm{cc} 2 \mathrm{c}(\mathrm{Nc} 3 \mathrm{ccc}(\mathrm{OCc} 4 \mathrm{cccc}(\mathrm{F}) \mathrm{c} 4) \mathrm{c}(\mathrm{Cl}) \mathrm{c} 3) \mathrm{ncnc} 2 \mathrm{~s} 1$ & 71 & $*$ \\
\hline 2069 & COc1cc2ncnc(Nc3ecc(F)c(Cl)c3)c2cc1OCCCN1CCCC1 & 71 & $*$ \\
\hline 2070 & $\mathrm{ClCCN}(\mathrm{CCNN}=\mathrm{Nc} 1 \mathrm{ccc} 2 \mathrm{ncnc}(\mathrm{Nc} 3 \operatorname{ccc}(\mathrm{Cl}) \mathrm{c} 3) \mathrm{c} 2 \mathrm{c} 1) \mathrm{Cc} 1 \mathrm{ccccc} 1$ & 71 & $*$ \\
\hline 2071 & $\mathrm{C}=\mathrm{CCN}(\mathrm{C}) \mathrm{CC} \# \mathrm{CC}(=\mathrm{O}) \mathrm{Nc} 1 \mathrm{ccc} 2 \mathrm{ncnc}(\mathrm{Nc} 3 \operatorname{cccc}(\mathrm{Br}) \mathrm{c} 3) \mathrm{c} 2 \mathrm{c} 1$ & 71 & $*$ \\
\hline 2072 & $\mathrm{COCCN}=\mathrm{NNc} 1 \mathrm{ccc} 2 \mathrm{ncnc}(\mathrm{Nc} 3 \mathrm{cccc}(\mathrm{Br}) \mathrm{c} 3) \mathrm{c} 2 \mathrm{c} 1$ & 71 & $*$ \\
\hline 2073 & $\mathrm{O}=\mathrm{C}(\mathrm{CN} 1 \mathrm{CCCC} 1) \mathrm{Nc} 1 \mathrm{ccc} 2 \mathrm{ncnc}(\mathrm{Nc} 3 \mathrm{ccc}(\mathrm{OCc} 4 \mathrm{cccc}(\mathrm{F}) \mathrm{c} 4) \mathrm{cc} 3) \mathrm{c} 2 \mathrm{c} 1$ & 71 & $*$ \\
\hline 2074 & $\mathrm{O}=\mathrm{C}(\mathrm{Nc} 1 \mathrm{cccc}(\mathrm{Cl}) \mathrm{c} 1) \mathrm{c} 1 \mathrm{ccc}(\mathrm{O}) \mathrm{cc} 1 \mathrm{O}$ & 71 & $*$ \\
\hline 2075 & $\begin{array}{c}\mathrm{O}=\mathrm{C} 1 \mathrm{OC}[\mathrm{C} @ \mathrm{H}] 2 \mathrm{OC}(=\mathrm{O}) \mathrm{c} 3 \mathrm{cc}(\mathrm{O}) \mathrm{c}(\mathrm{O}) \mathrm{c}(\mathrm{O}) \mathrm{c} 3-\mathrm{c} 3 \mathrm{c}(\mathrm{O}) \mathrm{c}(\mathrm{O}) \mathrm{c}(\mathrm{O}) \mathrm{c} 4 \mathrm{c} 3 \mathrm{C}(=\mathrm{O}) \mathrm{O}[\mathrm{C} @ \mathrm{H}]([\mathrm{C} @ \mathrm{H}] 3 \mathrm{OC}(=\mathrm{O}) \mathrm{c5c}- \\
4 \mathrm{c}(\mathrm{O}) \mathrm{c}(\mathrm{O}) \mathrm{c}(\mathrm{O}) \mathrm{c} 5[\mathrm{C} @ @ \mathrm{H}] 3[\mathrm{C} @] 3(\mathrm{O}) \mathrm{OC}[\mathrm{C} @ @ \mathrm{H}](\mathrm{O})[\mathrm{C} @ \mathrm{H}](\mathrm{O})[\mathrm{C} @ @ \mathrm{H}] 3 \mathrm{O})[\mathrm{C} @ @ \mathrm{H}] 2 \mathrm{OC}(=\mathrm{O}) \mathrm{c} 2 \mathrm{cc}(\mathrm{O}) \mathrm{c}(\mathrm{O}) \mathrm{c}( \\
\mathrm{O}) \mathrm{c} 2-\mathrm{c} 2 \mathrm{c} 1 \mathrm{cc}(\mathrm{O}) \mathrm{c}(\mathrm{O}) \mathrm{c} 2 \mathrm{O}\end{array}$ & 71.2 & $*$ \\
\hline 2076 & $\mathrm{CCC}(=\mathrm{O}) \mathrm{N} 1 \mathrm{CC}[\mathrm{C} @ \mathrm{H}](\mathrm{N} 2 \mathrm{C}(=\mathrm{O}) \mathrm{N}(\mathrm{c} 3 \mathrm{ccc}(\mathrm{F}) \mathrm{cc} 3) \mathrm{Cc} 3 \mathrm{cnc}(\mathrm{Nc} 4 \mathrm{ccc}(\mathrm{N} 5 \mathrm{CCN}(\mathrm{C}) \mathrm{CC} 5) \mathrm{c}(\mathrm{C}) \mathrm{c} 4) \mathrm{nc} 32) \mathrm{C} 1$ & 71.6 & 7.15 \\
\hline 2077 & $\mathrm{O}=\mathrm{C}(\mathrm{Nc} 1 \mathrm{nccs} 1) \mathrm{Nc} 1 \mathrm{cc}(-\mathrm{c} 2 \mathrm{cncnc} 2) \operatorname{ccc} 1 \mathrm{OC}(\mathrm{F})(\mathrm{F}) \mathrm{F}$ & 71.71 & $*$ \\
\hline 2078 & $\mathrm{O}=\mathrm{C}(\mathrm{Nc} 1 \mathrm{cc}(-\mathrm{c} 2 \mathrm{cncnc} 2) \mathrm{cc}(\mathrm{C}(\mathrm{F})(\mathrm{F}) \mathrm{F}) \mathrm{c} 1) \mathrm{Nc} 1 \mathrm{nccs} 1$ & 71.82 & * \\
\hline 2079 & $\mathrm{CACc} 1 \mathrm{cccc}(\mathrm{Nc} 2 \mathrm{ncnc} 3 \mathrm{cc}(\mathrm{OCCOC}(=\mathrm{O}) \mathrm{C}(\mathrm{C}) \mathrm{c} 4 \mathrm{ccc} 5 \mathrm{cc}(\mathrm{OC}) \mathrm{ccc} 5 \mathrm{c} 4) \mathrm{c}(\mathrm{OCCOC}) \mathrm{cc} 23) \mathrm{c} 1$ & 72 & 7.14 \\
\hline 2080 & $\mathrm{COc} 1 \mathrm{cc} 2 \mathrm{ncnc}(\mathrm{NCc} 3 \mathrm{ccc}(\mathrm{Cl}) \mathrm{c}(\mathrm{F}) \mathrm{c} 3) \mathrm{c} 2 \mathrm{cc} 1 \mathrm{OCCCCCCC}(=\mathrm{O}) \mathrm{NO}$ & 72 & 7.14 \\
\hline 2081 & $\mathrm{COc} 1 \mathrm{cc} 2 \mathrm{ncc}(\mathrm{C \# N}) \mathrm{c}(\mathrm{Nc} 3 \mathrm{ccc}(\mathrm{NCc} 4 \mathrm{cccnc} 4) \mathrm{c}(\mathrm{Cl}) \mathrm{c} 3) \mathrm{c} 2 \mathrm{cc} 1 \mathrm{NC}(=\mathrm{O}) / \mathrm{C}=\mathrm{C} / \mathrm{CN}(\mathrm{C}) \mathrm{C}$ & 72 & 7.14 \\
\hline 2082 & $\operatorname{Brc} 1 \operatorname{ccc}(\mathrm{Nc} 2[\mathrm{nH}] \mathrm{cnc} 3 \mathrm{c} 4 \mathrm{cccc} 4 \mathrm{nc} 2-3) \mathrm{c} 1 . \mathrm{Cl}$ & 72 & $*$ \\
\hline
\end{tabular}




\begin{tabular}{|c|c|c|c|}
\hline 2083 & $\mathrm{Brc} 1 \mathrm{ccc}(\mathrm{Nc} 2 \mathrm{ncnc} 3 \mathrm{c} 2[\mathrm{nH}] \mathrm{c} 2 \mathrm{ccccc} 23) \mathrm{c} 1 . \mathrm{Cl}$ & 72 & $*$ \\
\hline 2084 & $\mathrm{CN} 1 \mathrm{CCN}(\mathrm{N}(\mathrm{CCC} 2 \mathrm{COc} 3 \mathrm{cc} 4 \mathrm{ncnc}(\mathrm{Nc} 5 \mathrm{ccc}(\mathrm{F}) \mathrm{c}(\mathrm{Cl}) \mathrm{c} 5) \mathrm{c} 4 \mathrm{cc} 3 \mathrm{O} 2) \mathrm{N} 2 \mathrm{CCN}(\mathrm{C}) \mathrm{CC} 2) \mathrm{CC} 1$ & 72 & $*$ \\
\hline 2085 & $\mathrm{Cc} 1 \mathrm{ccc}(\mathrm{NC}(\mathrm{c} 2 \mathrm{ccccc} 2) \mathrm{n} 2 \mathrm{c}(-\mathrm{c} 3 \mathrm{cc}(\mathrm{CCn} 4 \mathrm{c}(-\mathrm{c} 5 \operatorname{ccc} c 5) \mathrm{nc} 5 \operatorname{ccc} \mathrm{c} 5 \mathrm{c} 4=\mathrm{O}) \operatorname{ccc} 3 \mathrm{Cl}) \mathrm{nc} 3 \operatorname{cccc} 32) \mathrm{cc} 1$ & 72 & $*$ \\
\hline 2086 & $\mathrm{CN}(\mathrm{C}) \mathrm{c} 1 \mathrm{nc} 2 \mathrm{cc} 3 \mathrm{c}(\mathrm{N} 4 \mathrm{CCc} 5 \mathrm{cccc} 54) \mathrm{ncnc} 3 \mathrm{cc} 2 \mathrm{o} 1$ & 72 & $*$ \\
\hline 2087 & $\mathrm{COc} 1 \mathrm{cc} 2 \mathrm{ncnc}(\mathrm{N} 3 \mathrm{CCCc} 4 \mathrm{cccc} 43) \mathrm{c} 2 \mathrm{cc} 1 \mathrm{NC}(=\mathrm{O}) / \mathrm{C}=\mathrm{C} / \mathrm{CN}(\mathrm{C}) \mathrm{C}$ & 72 & $*$ \\
\hline 2088 & $\mathrm{C}=\mathrm{CC}(=\mathrm{O}) \mathrm{Nc} 1 \mathrm{cc} 2 \mathrm{c}(\mathrm{Nc} 3 \mathrm{ccc}(\mathrm{OCc} 4 \mathrm{cccc}(\mathrm{F}) \mathrm{c} 4) \mathrm{cc} 3) \mathrm{ncnc} 2 \mathrm{cc} 1 \mathrm{O}[\mathrm{C} @ \mathrm{H}] 1 \mathrm{CCOC} 1$ & 72.2 & $*$ \\
\hline 2089 & $\begin{array}{c}\mathrm{C}=\mathrm{CC}(=\mathrm{O}) \mathrm{Nc} 1 \mathrm{cccc}(\mathrm{Oc} 2 \mathrm{nc}(\mathrm{Nc} 3 \operatorname{ccc}(\mathrm{N} 4 \mathrm{CCN}(\mathrm{CC}(=\mathrm{O}) \mathrm{NCC}(\mathrm{C}) \mathrm{Oc} 5 \mathrm{no}[\mathrm{n}+]([\mathrm{O}-]) \mathrm{c} 5 \mathrm{~S}(=\mathrm{O})(=\mathrm{O}) \mathrm{c} 5 \mathrm{ccccc} 5) \mathrm{CC} 4) \operatorname{cc} 3 \mathrm{O} \\
\mathrm{C}) \mathrm{ncc} 2 \mathrm{Cl}) \mathrm{c} 1\end{array}$ & 73 & 7.14 \\
\hline 2090 & $\mathrm{CCN}(\mathrm{CC}) \mathrm{C} / \mathrm{C}=\mathrm{C} / \mathrm{C}(=\mathrm{O}) \mathrm{Nc} 1 \mathrm{ccc} 2 \mathrm{ncnc}(\mathrm{Nc} 3 \mathrm{cccc}(\mathrm{Br}) \mathrm{c} 3) \mathrm{c} 2 \mathrm{c} 1$ & 73 & $*$ \\
\hline 2091 & Fc1 $1 \mathrm{ccc}(\mathrm{Cn} 2 \mathrm{ncc} 3 \mathrm{cc}(\mathrm{Nc} 4 \mathrm{ncnn} 5 \mathrm{ccc}(\mathrm{COC} 6 \mathrm{CCNCC} 6) \mathrm{c} 45) \mathrm{ccc} 32) \mathrm{c} 1$ & 73 & $*$ \\
\hline 2092 & $\mathrm{Cc} 1 \mathrm{ncnc}(\mathrm{Nc} 2 \mathrm{ccc}(\mathrm{OCc} 3 \mathrm{ccc}(\mathrm{F}) \mathrm{c} 3) \mathrm{c}(\mathrm{Cl}) \mathrm{c} 2) \mathrm{c} 1 \mathrm{C} \# \mathrm{Cc} 1 \mathrm{ncc}(\mathrm{CN} 2 \mathrm{CCCC} 2) \mathrm{s} 1$ & 74 & 7.13 \\
\hline 2093 & $\mathrm{COc} 1 \mathrm{ccc}(-\mathrm{c} 2 \mathrm{cc} 3 \mathrm{c}(\mathrm{NCc} 4 \mathrm{cccc} 4) \mathrm{ncnc} 3 \mathrm{o} 2) \mathrm{cc} 1$ & 74 & 7.13 \\
\hline 2094 & $\mathrm{CS}(=\mathrm{O})(=\mathrm{O}) \mathrm{CCNCCCCOc} 1 \mathrm{ccc} 2 \mathrm{ncnc}(\mathrm{Nc} 3 \operatorname{ccc}(\mathrm{OCc} 4 \mathrm{cccc} 4) \mathrm{cc} 3) \mathrm{c} 2 \mathrm{c} 1$ & 74 & $*$ \\
\hline 2095 & $\mathrm{O}=\mathrm{C}(\mathrm{NCCCCOc} 1 \mathrm{ccc} 2 \mathrm{ncnc}(\mathrm{Nc} 3 \mathrm{ccc}(\mathrm{OCc} 4 \mathrm{ccccc} 4) \mathrm{cc} 3) \mathrm{c} 2 \mathrm{c} 1) \mathrm{C}(\mathrm{F})(\mathrm{F}) \mathrm{F}$ & 74 & $*$ \\
\hline 2096 & $\mathrm{Fc} 1 \mathrm{cccc}(\mathrm{COc} 2 \mathrm{ccc}(\mathrm{Nc} 3 \mathrm{ncncc} 3 \mathrm{C} \# \mathrm{Cc} 3 \mathrm{ccc} n \mathrm{c} 3) \mathrm{cc} 2 \mathrm{Cl}) \mathrm{c} 1$ & 74 & $*$ \\
\hline 2097 & $\mathrm{O}=\mathrm{C}(/ \mathrm{C}=\mathrm{C} / \mathrm{CN} 1 \mathrm{CCOCC} 1) \mathrm{Nc} 1 \mathrm{ccc} 2 \mathrm{ncnc}(\mathrm{Nc} 3 \operatorname{ccc}(\mathrm{Br}) \mathrm{c} 3) \mathrm{c} 2 \mathrm{c} 1$ & 74 & $*$ \\
\hline 2098 & $\operatorname{COCCOc} 1 \mathrm{cc} 2 \mathrm{ncnc}(\mathrm{Nc} 3 \operatorname{ccc}(\mathrm{C}) \mathrm{c}([\mathrm{N}+](=\mathrm{O})[\mathrm{O}-]) \mathrm{c} 3) \mathrm{c} 2 \mathrm{c} 2 \mathrm{c} 1 \mathrm{OCCO} 2$ & 74.6 & $*$ \\
\hline 2099 & $\mathrm{C}=\mathrm{C}(\mathrm{CN} 1 \mathrm{CCOCC} 1) \mathrm{C}(=\mathrm{O}) \mathrm{Nc} 1 \mathrm{cc} 2 \mathrm{c}(\mathrm{Nc} 3 \operatorname{ccc}(\mathrm{OCc} 4 \mathrm{cccc} 4) \mathrm{c}(\mathrm{Cl}) \mathrm{c} 3) \mathrm{c}(\mathrm{C} \# \mathrm{~N}) \mathrm{cnc} 2 \mathrm{cc} 1 \mathrm{OCC}$ & 75 & 7.12 \\
\hline 2100 & $\mathrm{CS}(=\mathrm{O})(=\mathrm{O}) \mathrm{CCNC}(=\mathrm{O}) \mathrm{C} 1=\mathrm{Cc} 2 \mathrm{c}(\mathrm{ncnc} 2 \mathrm{Nc} 2 \operatorname{ccc}(\mathrm{Oc} 3 \operatorname{ccc}(\mathrm{C}(\mathrm{F})(\mathrm{F}) \mathrm{F}) \mathrm{c} 3) \mathrm{c}(\mathrm{Cl}) \mathrm{c} 2) \mathrm{NCC} 1$ & 75 & $*$ \\
\hline 2101 & $\mathrm{COc} 1 \mathrm{cc} 2 \mathrm{c}(\mathrm{Nc} 3 \mathrm{ccc}(\mathrm{Cl}) \mathrm{cc} 3 \mathrm{~F}) \mathrm{ncnc} 2 \mathrm{cc} 1 \mathrm{OCCCN} 1 \mathrm{CCN}(\mathrm{C}) \mathrm{CC} 1 . \mathrm{Cl}$ & 75 & $*$ \\
\hline 2102 & $\mathrm{NP}(=\mathrm{O})(\mathrm{OCCCOc} 1 \mathrm{ccc} 2 \mathrm{ncnc}(\mathrm{Nc} 3 \mathrm{ccc}(\mathrm{OCc} 4 \mathrm{ccc}(\mathrm{F}) \mathrm{c} 4) \mathrm{c}(\mathrm{Cl}) \mathrm{c} 3) \mathrm{c} 2 \mathrm{c} 1) \mathrm{N}(\mathrm{CCCl}) \mathrm{CCCl}$ & 75 & $*$ \\
\hline 2103 & $\mathrm{OCc} 1 \mathrm{nc}(\mathrm{C} \# \mathrm{Cc} 2 \mathrm{cncnc} 2 \mathrm{Nc} 2 \mathrm{ccc}(\mathrm{OCc} 3 \mathrm{cccc}(\mathrm{F}) \mathrm{c} 3) \mathrm{c}(\mathrm{Cl}) \mathrm{c} 2) \mathrm{cs} 1$ & 76 & $*$ \\
\hline 2104 & $\mathrm{CCN}=\mathrm{C}(\mathrm{S}) \mathrm{NNc} 1 \mathrm{nncc} 2 \operatorname{cccc} 12$ & 76 & $*$ \\
\hline 2105 & $\mathrm{C}=\mathrm{CC}(=\mathrm{O}) \mathrm{Nc} 1 \mathrm{ccc} 2 \mathrm{ncnc}(\mathrm{Nc} 3 \operatorname{ccc}(\mathrm{S}(\mathrm{N})(=\mathrm{O})=\mathrm{O}) \mathrm{cc} 3) \mathrm{c} 2 \mathrm{c} 1$ & 76.5 & $*$ \\
\hline 2106 & $\mathrm{O}=\mathrm{C}(\mathrm{CBr}) \mathrm{OCCn} 1 \mathrm{c}(=\mathrm{O}) \mathrm{oc} 2 \mathrm{cc} 3 \mathrm{ncnc}(\mathrm{Nc} 4 \mathrm{ccc}(\mathrm{OCc} 5 \mathrm{ccc}(\mathrm{F}) \mathrm{c} 5) \mathrm{c}(\mathrm{Cl}) \mathrm{c} 4) \mathrm{c} 3 \mathrm{cc} 21$ & 77 & 7.11 \\
\hline 2107 & $\mathrm{Fc} 1 \mathrm{cccc}(\mathrm{COc} 2 \mathrm{ccc}(\mathrm{Nc} 3 \mathrm{ncncc} 3 \mathrm{C} \# \mathrm{Cc} 3 \mathrm{nccc} 3) \mathrm{cc} 2 \mathrm{Cl}) \mathrm{c} 1$ & 77 & $*$ \\
\hline 2108 & $\mathrm{CCC} 1=\mathrm{C} 2 \mathrm{C}(\mathrm{Nc} 3 \operatorname{ccc} 4 \mathrm{c}(\operatorname{cnn} 4 \mathrm{Cc} 4 \mathrm{cccc} 4) \mathrm{c} 3)=\mathrm{NC}=\mathrm{NC} 2 \mathrm{~N}=\mathrm{C} 1 \mathrm{NC}(=\mathrm{O}) \mathrm{OCCN} 1 \mathrm{CCOCC} 1$ & 77 & $*$ \\
\hline 2109 & $\mathrm{NC}(=\mathrm{S}) \mathrm{NNc} 1 \mathrm{nncc} 2 \mathrm{ccccc} 12$ & 77 & $*$ \\
\hline 2110 & COc1ccc(-c2cc3c(N[C@@H](C)c4ccccs)ncnc3[nH]2)cc1 & 77 & $*$ \\
\hline 2111 & $\mathrm{C}=\mathrm{CC}(=\mathrm{O}) \mathrm{Nc} 1 \operatorname{ccc}(\mathrm{N} 2 \mathrm{C}(=\mathrm{O}) \mathrm{C}(\mathrm{c} 3 \operatorname{ccccc} 3) \mathrm{N}(\mathrm{C}) \mathrm{C}(=\mathrm{O}) \mathrm{c} 3 \operatorname{cnc}(\mathrm{Nc} 4 \operatorname{ccc}(\mathrm{N} 5 \mathrm{CCN}(\mathrm{C}) \mathrm{CC} 5) \operatorname{cc} 4 \mathrm{OC}) \mathrm{nc} 32) \mathrm{c} 1$ & 77.19 & 7.11 \\
\hline 2112 & $\mathrm{CS}(=\mathrm{O})(=\mathrm{O}) \mathrm{CC}(\mathrm{NC} 1 \mathrm{CCCCC} 1) \mathrm{c} 1 \mathrm{ccc}(-\mathrm{c} 2 \mathrm{ccc} 3 \mathrm{ncnc}(\mathrm{Nc} 4 \mathrm{ccc}(\mathrm{OCc} 5 \mathrm{cccc}(\mathrm{F}) \mathrm{c} 5) \mathrm{c}(\mathrm{Cl}) \mathrm{c} 4) \mathrm{c} 3 \mathrm{c} 2) \mathrm{o} 1$ & 77.2 & $*$ \\
\hline 2113 & $\mathrm{Fc} 1 \mathrm{ccc}(\mathrm{Nc} 2 \mathrm{ncnc} 3 \mathrm{cc} 4 \mathrm{c}(\mathrm{cc} 23) \mathrm{OCCO} 4) \mathrm{cc} 1$ & 77.6 & * \\
\hline 2114 & $\mathrm{CCOc} 1 \mathrm{cc} 2 \mathrm{ncc}(\mathrm{C \# N}) \mathrm{c}(\mathrm{Nc} 3 \operatorname{ccc}(\mathrm{OCc} 4 \mathrm{cccc} 4) \mathrm{c}(\mathrm{Cl}) \mathrm{c} 3) \mathrm{c} 2 \mathrm{cc} 1 \mathrm{NC}(=\mathrm{O}) / \mathrm{C}=\mathrm{C} / \mathrm{CN} 1 \mathrm{CCCC} 1$ & 78 & 7.11 \\
\hline 2115 & $\mathrm{O}=\mathrm{c} 1 \mathrm{oc} 2 \mathrm{cc} 3 \mathrm{ncnc}(\mathrm{Nc} 4 \mathrm{ccc}(\mathrm{F}) \mathrm{c}(\mathrm{Cl}) \mathrm{c} 4) \mathrm{c} 3 \mathrm{cc} 2 \mathrm{n} 1 \mathrm{CCCN} 1 \mathrm{CCOCC} 1$ & 78 & $*$ \\
\hline 2116 & $\mathrm{CACc} 1 \operatorname{ccc}(\mathrm{Nc} 2 \mathrm{ncnc} 3 \operatorname{ccc}(\mathrm{OCc} 4 \mathrm{ccc}(\mathrm{C}(=\mathrm{O}) \mathrm{Nc} 5 \operatorname{ccccc} 5 \mathrm{~N}) \mathrm{cc} 4) \operatorname{cc} 23) \mathrm{c} 1$ & 78 & $*$ \\
\hline 2117 & $\mathrm{COc} 1 \mathrm{cc} 2 \mathrm{c}(\mathrm{Nc} 3 \mathrm{ccc}(\mathrm{NC}(=\mathrm{O}) \mathrm{Nc} 4 \mathrm{ccc}(\mathrm{F}) \mathrm{c}(\mathrm{Cl}) \mathrm{c} 4) \mathrm{c}(\mathrm{Cl}) \mathrm{c} 3) \mathrm{ncnc} 2 \mathrm{cc} 1 \mathrm{OCCCN} 1 \mathrm{CCN}(\mathrm{C}) \mathrm{CC} 1$ & 78 & $*$ \\
\hline 2118 & $\mathrm{O}=\mathrm{C}(\mathrm{Nc} 1 \mathrm{cc}(-\mathrm{c} 2 \mathrm{cccnc} 2) \mathrm{cc}(\mathrm{C}(\mathrm{F})(\mathrm{F}) \mathrm{F}) \mathrm{c} 1) \mathrm{Nc} 1 \mathrm{nccs} 1$ & 78.17 & $*$ \\
\hline 2119 & $\mathrm{Cc} 1 \mathrm{ncnc}(\mathrm{Nc} 2 \mathrm{ccc}(\mathrm{OCc} 3 \operatorname{ccc}(\mathrm{F}) \mathrm{c} 3) \mathrm{c}(\mathrm{Cl}) \mathrm{c} 2) \mathrm{c} 1 \mathrm{C} \# \mathrm{Cc} 1 \mathrm{ccc}(\mathrm{CN} 2 \mathrm{CCCC} 2) \mathrm{o} 1$ & 79 & 7.10 \\
\hline 2120 & $\mathrm{C}=\mathrm{CCOc} 1 \mathrm{ccc} 2 \mathrm{ncnc}(\mathrm{Nc} 3 \mathrm{ccc}(\mathrm{OCc} 4 \mathrm{ccccc} 4) \mathrm{cc} 3) \mathrm{c} 2 \mathrm{c} 1$ & 79 & $*$ \\
\hline 2121 & $\mathrm{Fc} 1 \mathrm{cccc}(\mathrm{COc} 2 \mathrm{ccc}(\mathrm{Nc} 3 \mathrm{ncncc} 3 \mathrm{C} \# \mathrm{Cc} 3 \mathrm{ccccc} 3) \mathrm{cc} 2 \mathrm{Cl}) \mathrm{c} 1$ & 79 & $*$ \\
\hline 2122 & $\mathrm{CNC}(=\mathrm{O}) \mathrm{c} 1 \mathrm{cccc}(\mathrm{C \# C} 2 \mathrm{cncnc} 2 \mathrm{Nc} 2 \operatorname{ccc}(\mathrm{OCc} 3 \operatorname{cccc}(\mathrm{F}) \mathrm{c} 3) \mathrm{c}(\mathrm{Cl}) \mathrm{c} 2) \mathrm{c} 1$ & 79 & $*$ \\
\hline 2123 & $\mathrm{CCC}(=\mathrm{O}) \mathrm{Nc} 1 \mathrm{cc} 2 \mathrm{c}(\mathrm{Nc} 3 \mathrm{ccc} 4[\mathrm{nH}] \mathrm{ncc} 4 \mathrm{c} 3) \mathrm{ncnc} 2 \mathrm{cc} 1 \mathrm{OC}$ & 79 & $*$ \\
\hline 2124 & COc1cc2ncne( $(\mathrm{Nc} 3 \operatorname{ccc}(\mathrm{F}) \mathrm{c}(\mathrm{Cl}) \mathrm{c} 3) \mathrm{c} 2 \mathrm{cc} 1 \mathrm{OCCCN} 1 \mathrm{CCCCC} 1$ & 79 & $*$ \\
\hline
\end{tabular}




\begin{tabular}{|c|c|c|c|}
\hline 2125 & $\mathrm{CN}(\mathrm{C}) \mathrm{C}(=\mathrm{O}) \mathrm{O}[\mathrm{C} @ @ \mathrm{H}] 1 \mathrm{CN}[\mathrm{C} @ \mathrm{H}](\mathrm{C \# Cc} 2 \mathrm{cc} 3 n \mathrm{ncnc}(\mathrm{Nc} 4 \mathrm{ccc}(\mathrm{OCc} 5 \mathrm{cccc}(\mathrm{F}) \mathrm{c} 5) \mathrm{c}(\mathrm{Cl}) \mathrm{c} 4) \mathrm{c} 3 \mathrm{~s} 2) \mathrm{C} 1$ & 79 & * \\
\hline 2126 & $\mathrm{CN}(\mathrm{C}) \mathrm{C}(=\mathrm{O}) \mathrm{O}[\mathrm{C} @ \mathrm{H}] 1 \mathrm{CN}[\mathrm{C} @ @ \mathrm{H}](\mathrm{C} \# \mathrm{Cc} 2 \mathrm{cc} 3 n \mathrm{ncnc}(\mathrm{Nc} 4 \mathrm{ccc}(\mathrm{OCc} 5 \mathrm{cccc}(\mathrm{F}) \mathrm{c} 5) \mathrm{c}(\mathrm{Cl}) \mathrm{c} 4) \mathrm{c} 3 \mathrm{~s} 2) \mathrm{C} 1$ & 79 & $*$ \\
\hline 2127 & $\mathrm{O}=\mathrm{C}(\mathrm{O}[\mathrm{C} @ @ \mathrm{H}] 1 \mathrm{CN}[\mathrm{C} @ \mathrm{H}](\mathrm{C \# Cc} 2 \mathrm{cc} 3 \mathrm{ncnc}(\mathrm{Nc} 4 \mathrm{ccc}(\mathrm{OCc} 5 \mathrm{ccc}(\mathrm{F}) \mathrm{c} 5) \mathrm{c}(\mathrm{Cl}) \mathrm{c} 4) \mathrm{c} 3 \mathrm{~s} 2) \mathrm{C} 1) \mathrm{N} 1 \mathrm{CCOCC} 1$ & 79 & $*$ \\
\hline 2128 & $\mathrm{C}=\mathrm{CC}(=\mathrm{O}) \mathrm{Nc} 1 \mathrm{cccc}(-\mathrm{n} 2 \mathrm{c}(=\mathrm{O}) \mathrm{n}(\mathrm{C}(\mathrm{C}) \mathrm{C}) \mathrm{c}(=\mathrm{O}) \mathrm{c} 3 \mathrm{cnc}(\mathrm{Nc} 4 \mathrm{ccc}(\mathrm{N} 5 \mathrm{CCN}(\mathrm{C}) \mathrm{CC} 5) \mathrm{cc} 4 \mathrm{OC}) \mathrm{nc} 32) \mathrm{c} 1$ & 79 & $*$ \\
\hline 2129 & $\mathrm{Oc} 1 \mathrm{ccc}(\mathrm{CN}(\mathrm{Cc} 2 \operatorname{cccc}(\mathrm{Cl}) \mathrm{c} 2 \mathrm{O}) \mathrm{C}(=\mathrm{S}) \mathrm{Nc} 2 \mathrm{cccc} 2) \mathrm{cc} 1$ & 80 & 7.10 \\
\hline 2130 & $\operatorname{COc} 1 \operatorname{ccc}(\mathrm{NC}(=\mathrm{O}) \mathrm{c} 2 \mathrm{ccc}(\mathrm{N}(\mathrm{CCCl}) \mathrm{CCCl}) \mathrm{cc} 2) \mathrm{cc} 1$ & 80 & 7.10 \\
\hline 2131 & $\mathrm{O}=\mathrm{C}(\mathrm{O}[\mathrm{C} @ \mathrm{H}] 1 \mathrm{CN}[\mathrm{C} @ \mathrm{H}](\mathrm{C} \# \mathrm{Cc} 2 \mathrm{cc} 3 \mathrm{ncnc}(\mathrm{Nc} 4 \mathrm{ccc} 5 \mathrm{c}(\operatorname{cnn} 5 \mathrm{Cc} 5 \mathrm{ccccc} 5) \mathrm{c} 4) \mathrm{c} 3 \mathrm{~s} 2) \mathrm{C} 1) \mathrm{N} 1 \mathrm{CCOCC} 1$ & 80 & 7.10 \\
\hline 2132 & $\mathrm{COc} 1 \mathrm{cc} 2 \mathrm{ncnc}(\mathrm{Nc} 3 \operatorname{ccc}(\mathrm{Cl}) \mathrm{c} 3 \mathrm{~F}) \mathrm{c} 2 \mathrm{cc} 1 \mathrm{CN} 1 \mathrm{CC}[\mathrm{C} @ \mathrm{H}](\mathrm{C}(\mathrm{N})=\mathrm{O}) \mathrm{C} 1$ & 80 & $*$ \\
\hline 2133 & $\mathrm{CS}(=\mathrm{O})(=\mathrm{O}) \mathrm{CCNCc} 1 \mathrm{ccc}(-\mathrm{c} 2 \mathrm{ccc} 3 \mathrm{ncnc}(\mathrm{Nc} 4 \mathrm{ccc}(\mathrm{OCc} 5 \operatorname{ccc}(\mathrm{F}) \mathrm{c} 5) \mathrm{c}(\mathrm{C}(\mathrm{F})(\mathrm{F}) \mathrm{F}) \mathrm{c} 4) \mathrm{c} 3 \mathrm{c} 2) \mathrm{o} 1$ & 80 & $*$ \\
\hline 2134 & Brc1cc2c(Nc3eccec3)ncnc2s1 & 80 & $*$ \\
\hline 2135 & $\mathrm{COc} 1 \mathrm{cc} 2 \mathrm{ncnc}(\mathrm{C} \# \mathrm{CC}(\mathrm{C})(\mathrm{C}) \mathrm{N}(\mathrm{C}) \mathrm{c} 3 \mathrm{cccc} 3) \mathrm{c} 2 \mathrm{cc} 1 \mathrm{OC}$ & 80 & $*$ \\
\hline 2136 & $\mathrm{O}=\mathrm{C}(\mathrm{OCc} 1 \mathrm{ccccc} 1) \mathrm{c} 1 \mathrm{cc}(\mathrm{NCc} 2 \mathrm{cc}(\mathrm{O}) \operatorname{ccc} 2 \mathrm{O}) \mathrm{ccc} 1 \mathrm{O}$ & 80 & $*$ \\
\hline 2137 & Ic1 $1 \operatorname{ccc}(\mathrm{Nc} 2 \mathrm{ncnc} 3 \operatorname{ccc} c 23) \mathrm{c} 1$ & 80 & $*$ \\
\hline 2138 & $\mathrm{Cn} 1 \mathrm{c}(=\mathrm{O}) \mathrm{c}(-\mathrm{c} 2 \mathrm{c}(\mathrm{Cl}) \mathrm{cccc} 2 \mathrm{Cl}) \mathrm{cc} 2 \mathrm{cnc}(\mathrm{Nc} 3 \mathrm{ccc}(\mathrm{CCCC}(=\mathrm{O}) \mathrm{O}) \mathrm{cc} 3) \mathrm{nc} 21$ & 80 & $*$ \\
\hline 2139 & $\mathrm{COc} 1 \mathrm{ccc} 2 \mathrm{c}(\mathrm{c} 1) \operatorname{sc} 1 \mathrm{c}(\mathrm{Nc} 3 \mathrm{cccc}(\mathrm{Br}) \mathrm{c} 3) \mathrm{ncnc} 12$ & 80 & $*$ \\
\hline 2140 & $\mathrm{C}=\mathrm{CC}(=\mathrm{O}) \mathrm{Nc} 1 \mathrm{cc} 2 \mathrm{c}(\mathrm{Nc} 3 \mathrm{ccc}(\mathrm{F}) \mathrm{c}(\mathrm{Cl}) \mathrm{c} 3) \mathrm{c}(\mathrm{C} \# \mathrm{~N}) \mathrm{cnc} 2 \mathrm{cc} 1 \mathrm{OCCCN} 1 \mathrm{CCOCC} 1$ & 80 & $*$ \\
\hline 2141 & $\mathrm{C}=\mathrm{CC}(=\mathrm{O}) \mathrm{Nc} 1 \mathrm{cccc}(\mathrm{NC}(=\mathrm{O}) \mathrm{Nc} 2 \mathrm{ccnc}(\mathrm{Nc} 3 \mathrm{ccc}(\mathrm{N} 4 \mathrm{CCC}(\mathrm{N} 5 \mathrm{CCN}(\mathrm{C}) \mathrm{CC} 5) \mathrm{CC} 4) \mathrm{cc} 3 \mathrm{OC}) \mathrm{n} 2) \mathrm{c} 1$ & 80 & $*$ \\
\hline 2142 & $\mathrm{CS}(=\mathrm{O})(=\mathrm{O}) \mathrm{O}[\mathrm{C} @ \mathrm{H}] 1 \mathrm{CN}[\mathrm{C} @ \mathrm{H}](\mathrm{C} \# \mathrm{Cc} 2 \mathrm{cc} 3 \mathrm{ncnc}(\mathrm{Nc} 4 \mathrm{ccc}(\mathrm{OCc} 5 \mathrm{cccc}(\mathrm{F}) \mathrm{c} 5) \mathrm{c}(\mathrm{Cl}) \mathrm{c} 4) \mathrm{c} 3 \mathrm{~s} 2) \mathrm{C} 1$ & 81 & * \\
\hline 2143 & $\mathrm{Cc} 1 \mathrm{ccn} 2 \mathrm{ncnc}(\mathrm{Nc} 3 \mathrm{ccc} 4 \mathrm{c}(\mathrm{cnn} 4 \mathrm{Cc} 4 \mathrm{ccc}(\mathrm{F}) \mathrm{c} 4) \mathrm{c} 3) \mathrm{c} 12$ & 81 & $*$ \\
\hline 2144 & 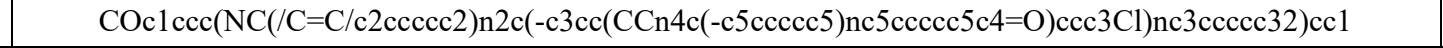 & 81 & $*$ \\
\hline 2145 & $\begin{array}{c}\mathrm{CC} 1(\mathrm{C})[\mathrm{C} @ @ \mathrm{H}](\mathrm{O}[\mathrm{C} @ \mathrm{H}] 2 \mathrm{O}[\mathrm{C} @ \mathrm{H}](\mathrm{C}=\mathrm{O}) \mathrm{O})[\mathrm{C} @ @ \mathrm{H}](\mathrm{O})[\mathrm{C} @ \mathrm{H}](\mathrm{O})[\mathrm{C} @ \mathrm{H}] 2 \mathrm{O}[\mathrm{C} @ @ \mathrm{H}] 2 \mathrm{O}[\mathrm{C} @ \mathrm{H}](\mathrm{C}(=\mathrm{O}) \mathrm{O})[ \\
\mathrm{C} @ \mathrm{H}](\mathrm{O})[\mathrm{C} @ \mathrm{H}](\mathrm{O})[\mathrm{C} @ \mathrm{H}] 2 \mathrm{O}) \mathrm{CC}[\mathrm{C} @ @] 2(\mathrm{C})[\mathrm{C} @ \mathrm{H}] 1 \mathrm{CC}[\mathrm{C} @] 1(\mathrm{C})[\mathrm{C} @ @ \mathrm{H}] 2 \mathrm{C}(=\mathrm{O}) \mathrm{C}=\mathrm{C} 2[\mathrm{C} @ @ \mathrm{H}] 3 \mathrm{C}[\mathrm{C} @ \\
@](\mathrm{C})(\mathrm{C}(=\mathrm{O}) \mathrm{O}) \mathrm{CC}[\mathrm{C} @] 3(\mathrm{C}) \mathrm{CC}[\mathrm{C} @] 21 \mathrm{C}\end{array}$ & 81 & $*$ \\
\hline 2146 & $\mathrm{C}=\mathrm{CC}(=\mathrm{O}) \mathrm{Nc} 1 \mathrm{cccc}(-\mathrm{n} 2 \mathrm{c}(=\mathrm{O}) \mathrm{c}(=\mathrm{O}) \mathrm{n}(\mathrm{CC}) \mathrm{c} 3 \mathrm{cnc}(\mathrm{Nc} 4 \mathrm{ccc}(\mathrm{N} 5 \mathrm{CCN}(\mathrm{C}) \mathrm{CC} 5) \mathrm{cc} 4 \mathrm{OC}) \mathrm{nc} 32) \mathrm{c} 1$ & 81 & $*$ \\
\hline 2147 & $\operatorname{COc} 1 \operatorname{ccc}(\mathrm{Nc} 2 \mathrm{cc}(\mathrm{NC}(=\mathrm{O}) \mathrm{c} 3 \operatorname{ccccc} 3) \mathrm{ncn} 2) \mathrm{cc} 1$ & 81 & $*$ \\
\hline 2148 & $\mathrm{CCOc} 1 \mathrm{cc} 2 \mathrm{ncc}(\mathrm{C} \# \mathrm{~N}) \mathrm{c}(\mathrm{Nc} 3 \operatorname{ccc} 4 \mathrm{c}(\operatorname{ccn} 4 \mathrm{~S}(=\mathrm{O})(=\mathrm{O}) \mathrm{c} 4 \mathrm{ccccc} 4) \mathrm{c} 3) \mathrm{c} 2 \mathrm{cc} 1 \mathrm{NC}(=\mathrm{O}) / \mathrm{C}=\mathrm{C} / \mathrm{CN}(\mathrm{C}) \mathrm{C}$ & 82 & 7.09 \\
\hline 2149 & $\mathrm{O}=\mathrm{C}(\mathrm{NCCN} 1 \mathrm{CCOCC} 1) \mathrm{Nc} 1 \mathrm{cc} 2 \mathrm{c}(\mathrm{Nc} 3 \mathrm{ccc}(\mathrm{F}) \mathrm{c}(\mathrm{Cl}) \mathrm{c} 3) \mathrm{ncnc} 2 \mathrm{cc} 1 \mathrm{O}[\mathrm{C} @ \mathrm{H}] 1 \mathrm{CCOC} 1$ & 82 & * \\
\hline 2150 & $\mathrm{CCOc} 1 \mathrm{cc} 2 \mathrm{ncnc}(\mathrm{Nc} 3 \operatorname{ccc}(\mathrm{NS}(=\mathrm{O})(=\mathrm{O}) \mathrm{c} 4 \mathrm{ccccc} 4) \operatorname{cc} 3) \mathrm{c} 2 \mathrm{cc} 1 \mathrm{NC}(=\mathrm{O}) / \mathrm{C}=\mathrm{C} / \mathrm{CN} 1 \mathrm{CCN}(\mathrm{C}) \mathrm{CC} 1$ & 82 & $*$ \\
\hline 2151 & $\mathrm{C}=\mathrm{CC}(=\mathrm{O}) \mathrm{Nc} 1 \mathrm{ccc}(-\mathrm{c} 2 \mathrm{c}(-\mathrm{c} 3 \operatorname{ccccc} 3) \mathrm{oc} 3 \mathrm{ncnc}(\mathrm{N}[\mathrm{C} @ \mathrm{H}](\mathrm{CO}) \mathrm{c} 4 \mathrm{ccccc} 4) \mathrm{c} 23) \mathrm{cc} 1$ & 82 & $*$ \\
\hline 2152 & Clc1ncc2nenc(Nc3ecce(Br)c3)c2n1 & 82 & $*$ \\
\hline 2153 & $\operatorname{COc} 1 \mathrm{cc} 2 \mathrm{ncnc}(\mathrm{Nc} 3 \operatorname{cccc}(\mathrm{NC}(=\mathrm{O}) \mathrm{Nc} 4 \mathrm{ccc}(\mathrm{Cl}) \mathrm{c}(\mathrm{C}(\mathrm{F})(\mathrm{F}) \mathrm{F}) \mathrm{c} 4) \mathrm{c} 3) \mathrm{c} 2 \mathrm{cc} 1 \mathrm{OCCCN} 1 \mathrm{CCOCC} 1$ & 82 & $*$ \\
\hline 2154 & $\mathrm{O}=\mathrm{C}(\mathrm{Nc} 1 \mathrm{cc} 2 \mathrm{c}(\mathrm{Nc} 3 \mathrm{ccc}(\mathrm{F}) \mathrm{c}(\mathrm{Cl}) \mathrm{c} 3) \mathrm{ncnc} 2 \mathrm{cc} 1 \mathrm{O}[\mathrm{C} @ \mathrm{H}] 1 \mathrm{CCOC} 1) \mathrm{N}(\mathrm{NCCN} 1 \mathrm{CCOCC} 1) \mathrm{NCN} 1 \mathrm{CCOCC} 1$ & 82 & $*$ \\
\hline 2155 & $\mathrm{C}=\mathrm{CC}(=\mathrm{O}) \mathrm{Nc} 1 \mathrm{cccc}(-\mathrm{n} 2 \mathrm{c}(=\mathrm{O}) \mathrm{n}(\mathrm{C}) \mathrm{c}(=\mathrm{O}) \mathrm{c} 3 \mathrm{cnc}(\mathrm{Nc} 4 \operatorname{ccccc} 4) \mathrm{nc} 32) \mathrm{c} 1$ & 82 & $*$ \\
\hline 2156 & $\mathrm{CC}(\mathrm{C}) \mathrm{Oc} 1 \mathrm{cc} 2 \mathrm{ncnc}(\mathrm{Nc} 3 \mathrm{ccc}(\mathrm{F}) \mathrm{c}([\mathrm{N}+](=\mathrm{O})[\mathrm{O}-]) \mathrm{c} 3) \mathrm{c} 2 \mathrm{c} 2 \mathrm{c} 1 \mathrm{OCCO} 2$ & 82.5 & $*$ \\
\hline 2157 & $\mathrm{OCC}(\mathrm{Nc} 1 \mathrm{ncnc} 2 \mathrm{sc}(\mathrm{Br}) \mathrm{cc} 12) \mathrm{c} 1 \mathrm{ccccc} 1$ & 83 & $*$ \\
\hline 2158 & Fc1 $1 \mathrm{ccc}(\mathrm{Cn} 2 \mathrm{ncc} 3 \mathrm{cc}(\mathrm{Nc} 4 \mathrm{ncnn} 5 \mathrm{ccc}(\mathrm{COC}[\mathrm{C} @ \mathrm{H}] 6 \mathrm{CNCCO}) \mathrm{c} 45) \mathrm{ccc} 32) \mathrm{c} 1$ & 83 & $*$ \\
\hline 2159 & $\mathrm{O}=\mathrm{C}(\mathrm{Nc} 1 \mathrm{ccc} 2 \mathrm{ncnc}(\mathrm{Nc} 3 \mathrm{cccc}(\mathrm{Cl}) \mathrm{c} 3) \mathrm{c} 2 \mathrm{c} 1) \mathrm{C} 1 \mathrm{CCC} 2(\mathrm{CC} 1) \mathrm{OOC} 1(\mathrm{CCCCC} 1) \mathrm{OO} 2$ & 83.82 & $*$ \\
\hline 2160 & Fc1ccec(Nc2ncnc3ec(OCCCN4CCOCC4)c4c(c23)OCCO4)c1 & 83.88 & $*$ \\
\hline 2161 & $\mathrm{COc} 1 \mathrm{cc} 2 \mathrm{ncnc}(\mathrm{NC} 3 \mathrm{CC} 3 \mathrm{c} 3 \mathrm{cccc} 3) \mathrm{c} 2 \mathrm{cc} 1 \mathrm{OC}(\mathrm{C})=\mathrm{O}$ & 84 & * \\
\hline 2162 & $\mathrm{CN}(\mathrm{C}) \mathrm{c} 1 \mathrm{ccc} 2 \mathrm{ncnc}(\mathrm{Nc} 3 \mathrm{cccc}(\mathrm{Br}) \mathrm{c} 3) \mathrm{c} 2 \mathrm{c} 1$ & 84 & $*$ \\
\hline 2163 & Clc1 $\operatorname{ccc}(\mathrm{Nc} 2[\mathrm{nH}] \mathrm{nc} 3 \mathrm{ncnc}(\mathrm{Nc} 4 \mathrm{ccccc} 4) \mathrm{c} 23) \mathrm{c} 1$ & 84 & $*$ \\
\hline 2164 & $\mathrm{O}=\mathrm{S}(=\mathrm{O})(\mathrm{Nc} 1 \mathrm{ccc} \mathrm{c} 1) \mathrm{c} 1 \mathrm{ccc}(\mathrm{Nc} 2 \mathrm{nncc} 3 \operatorname{ccc} c \mathrm{2} 23) \mathrm{cc} 1$ & 84 & $*$ \\
\hline 2165 & $\mathrm{COc} 1 \mathrm{cc}(-\mathrm{c} 2 \mathrm{nn}(\mathrm{C} 3 \mathrm{CCCC} 3) \mathrm{c} 3 n \mathrm{nnc}(\mathrm{N}) \mathrm{c} 23) \mathrm{ccc} 1 \mathrm{~N}$ & 84 & $*$ \\
\hline
\end{tabular}




\begin{tabular}{|c|c|c|c|}
\hline 2166 & $\mathrm{O}=\mathrm{C}(\mathrm{CCCCCCOc} 1 \mathrm{ccc} 2 \mathrm{ncnc}(\mathrm{Nc} 3 \mathrm{ccc}(\mathrm{F}) \mathrm{c}(\mathrm{Cl}) \mathrm{c} 3) \mathrm{c} 2 \mathrm{c} 1) \mathrm{NO}$ & 84.2 & 7.07 \\
\hline 2167 & $\mathrm{O}=\mathrm{C}(\mathrm{Nc} 1 \mathrm{ccc}([\mathrm{N}+](=\mathrm{O})[\mathrm{O}-]) \mathrm{cc} 1 \mathrm{Cl}) \mathrm{c} 1 \mathrm{ccc}(\mathrm{OCCCN} 2 \mathrm{CCOCC} 2) \operatorname{cc} 1 \mathrm{O}$ & 84.8 & $*$ \\
\hline 2168 & $\mathrm{Clc} 1 \mathrm{ccc}(\mathrm{Nc} 2 \mathrm{ncnc} 3[\mathrm{nH}] \mathrm{ccc} 23) \mathrm{cc} 1$ & 84.92 & $*$ \\
\hline 2169 & $\mathrm{Cc} 1 \mathrm{ccc}(\mathrm{Br}) \mathrm{c} 2 \mathrm{c}(\mathrm{C \# N}) \mathrm{cc}(\mathrm{C}(=\mathrm{O}) \mathrm{C} 3 \mathrm{CC} 3) \mathrm{n} 12$ & 85 & 7.07 \\
\hline 2170 & 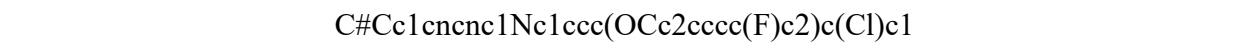 & 85 & $*$ \\
\hline 2171 & $\operatorname{CCCN}(\operatorname{CCS}(\mathrm{C})(=\mathrm{O})=\mathrm{O}) \operatorname{Cc} 1 \mathrm{ccc}(-\mathrm{c} 2 \mathrm{ccc} 3 \mathrm{ncnc}(\mathrm{Nc} 4 \mathrm{ccc}(\mathrm{OCc} 5 \operatorname{ccc}(\mathrm{F}) \mathrm{c} 5) \mathrm{c}(\mathrm{Cl}) \mathrm{c} 4) \mathrm{c} 3 \mathrm{c} 2) \mathrm{o} 1$ & 85 & $*$ \\
\hline 2172 & $\mathrm{Brc} 1 \mathrm{cccc}(\mathrm{Nc} 2 \mathrm{ncnc} 3 \mathrm{cc} 4 \mathrm{c}(\mathrm{cc} 23) \mathrm{OCCCO} 4) \mathrm{c} 1$ & 85 & $*$ \\
\hline 2173 & $\mathrm{Cc} 1 \mathrm{cncc}(\mathrm{COc} 2 \mathrm{ccc}(\mathrm{Nc} 3 \mathrm{ncnn} 4 \mathrm{ccc}(\mathrm{CN} 5 \mathrm{CCC}(\mathrm{N}) \mathrm{CC} 5) \mathrm{c} 34) \mathrm{cc} 2 \mathrm{Cl}) \mathrm{c} 1$ & 85 & $*$ \\
\hline 2174 & $\mathrm{COC}[\mathrm{C} @ \mathrm{H}] 1 \mathrm{CCCN} 1 \mathrm{C} / \mathrm{C}=\mathrm{C} / \mathrm{C}(=\mathrm{O}) \mathrm{Nc} 1 \mathrm{ccc} 2 \mathrm{ncnc}(\mathrm{Nc} 3 \operatorname{ccc}(\mathrm{Br}) \mathrm{c} 3) \mathrm{c} 2 \mathrm{c} 1$ & 85 & $*$ \\
\hline 2175 & $\mathrm{CC}(\mathrm{C}) \mathrm{N}(\mathrm{C}) \mathrm{CC} \# \mathrm{CC}(=\mathrm{O}) \mathrm{Nc} 1 \mathrm{ccc} 2 \mathrm{ncnc}(\mathrm{Nc} 3 \mathrm{ccc}(\mathrm{Br}) \mathrm{c} 3) \mathrm{c} 2 \mathrm{c} 1$ & 85 & $*$ \\
\hline 2176 & $\mathrm{Nc} 1 \mathrm{ncnc} 2 \mathrm{c} 1 \mathrm{c}(-\mathrm{c} 1 \mathrm{ccc} 3 \mathrm{cc}[\mathrm{nH}] \mathrm{c} 3 \mathrm{c} 1) \mathrm{nn} 2 \mathrm{C} 1 \mathrm{CCCC} 1$ & 85 & $*$ \\
\hline 2177 & $\mathrm{O}=\mathrm{C} 1 \mathrm{NCc} 2 \mathrm{cc} 3 \mathrm{c}(=\mathrm{O}) \mathrm{n}(-\mathrm{c} 4 \mathrm{ccc}(\mathrm{Cl}) \mathrm{cc} 4) \mathrm{c}(-\mathrm{c} 4 \operatorname{cccc} 4) \mathrm{c}(-\mathrm{c} 4 \mathrm{cccc} 4) \mathrm{c} 3 \mathrm{cc} 2 \mathrm{~N} 1$ & 85 & $*$ \\
\hline 2178 & $\mathrm{NS}(=\mathrm{O})(=\mathrm{O}) \operatorname{c} 1 \operatorname{ccc}(\mathrm{NC}(=\mathrm{O}) \operatorname{coc} \operatorname{ccc} 2 \mathrm{NC}(=\mathrm{O}) \mathrm{c} 2 \operatorname{ccco} 2) \operatorname{cc} 1$ & 85.4 & $*$ \\
\hline 2179 & $\mathrm{O}=\mathrm{C}(\mathrm{Nc} 1 \mathrm{cccc}(\mathrm{Br}) \mathrm{c} 1) \mathrm{c} 1 \mathrm{ccc}(\mathrm{OCCCN} 2 \mathrm{CCOCC} 2) \mathrm{cc} 1 \mathrm{O}$ & 85.8 & $*$ \\
\hline 2180 & $\mathrm{Cc} 1 \mathrm{ncnc}(\mathrm{Nc} 2 \mathrm{ccc}(\mathrm{OCc} 3 \operatorname{ccc}(\mathrm{F}) \mathrm{c} 3) \mathrm{c}(\mathrm{Cl}) \mathrm{c} 2) \mathrm{c} 1 \mathrm{C} \# \mathrm{CCOc} 1 \mathrm{ccc}(\mathrm{CNC}(\mathrm{C}) \mathrm{C}) \mathrm{cc} 1$ & 86 & 7.07 \\
\hline 2181 & $\mathrm{O}=\mathrm{C}(\mathrm{C} \# \mathrm{CCN} 1 \mathrm{CCOCC} 1) \mathrm{Nc} 1 \mathrm{ccc} 2 \mathrm{ncnc}(\mathrm{Nc} 3 \mathrm{ccc}(\mathrm{F}) \mathrm{c}(\mathrm{Cl}) \mathrm{c} 3) \mathrm{c} 2 \mathrm{c} 1$ & 86 & $*$ \\
\hline 2182 & $\mathrm{CCC}(=\mathrm{O}) \mathrm{Nc} 1 \mathrm{cc} 2 \mathrm{c}(\mathrm{Nc} 3 \mathrm{ccc} 4 \mathrm{c}(\operatorname{ccn} 4 \mathrm{Cc} 4 \mathrm{ccco} 4) \mathrm{c} 3) \mathrm{ncnc} 2 \mathrm{cc} 1 \mathrm{OC}$ & 86 & $*$ \\
\hline 2183 & $\mathrm{CCC}(=\mathrm{O}) \mathrm{Nc} 1 \mathrm{cc} 2 \mathrm{c}(\mathrm{N}[\mathrm{C} @ \mathrm{H}](\mathrm{C}) \mathrm{c} 3 \mathrm{cccc} 3) \mathrm{ncnc} 2 \mathrm{cc} 1 \mathrm{OC}$ & 86 & $*$ \\
\hline 2184 & $\mathrm{O}=\mathrm{S}(=\mathrm{O})(\mathrm{Nc} 1 \mathrm{nccc} 1) \mathrm{c} 1 \mathrm{ccc}(\mathrm{Nc} 2 \mathrm{nncc} 3 \operatorname{cccc} 23) \mathrm{cc} 1$ & 86 & $*$ \\
\hline 2185 & $\mathrm{Cc} 1 \mathrm{ccn} 2 \mathrm{ncnc}(\mathrm{Nc} 3 \operatorname{ccc} 4 \mathrm{c}(\operatorname{cnn} 4 \mathrm{Cc} 4 \mathrm{ccccc} 4) \mathrm{c} 3) \mathrm{c} 12$ & 86 & $*$ \\
\hline 2186 & $\mathrm{C}=\mathrm{CC}(=\mathrm{O}) \mathrm{Nc} 1 \mathrm{cccc}(\mathrm{NC}(=\mathrm{O}) \mathrm{Nc} 2 \mathrm{ccnc}(\mathrm{Nc} 3 \mathrm{ccc}(\mathrm{N} 4 \mathrm{CCC}(\mathrm{N} 5 \mathrm{CCOCC}) \mathrm{CC} 4) \mathrm{cc} 3 \mathrm{OC}) \mathrm{n} 2) \mathrm{c} 1$ & 86 & * \\
\hline 2187 & $\mathrm{COc} 1 \mathrm{cc} 2 \mathrm{ncnc}(\mathrm{Nc} 3 \mathrm{ccc}(\mathrm{F}) \mathrm{c}(\mathrm{Cl}) \mathrm{c} 3) \mathrm{c} 2 \mathrm{cc} 1 \mathrm{OCCN} 1 \mathrm{CCCC} 1$ & 87 & $*$ \\
\hline 2188 & $\mathrm{C}=\mathrm{CC}(=\mathrm{O}) \mathrm{Nc} 1 \mathrm{cccc}(\mathrm{Oc} 2 \mathrm{nc}(\mathrm{Nc} 3 \operatorname{ccc}(/ \mathrm{C}=\mathrm{C} / \mathrm{c} 4 \mathrm{cc}(\mathrm{C}) \mathrm{cc}(\mathrm{C}) \mathrm{c} 4) \mathrm{cc} 3) \mathrm{ncc} 2 \mathrm{Cl}) \mathrm{c} 1$ & 87 & $*$ \\
\hline 2189 & 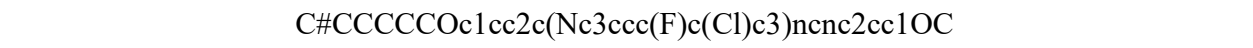 & 87.1 & $*$ \\
\hline 2190 & $\mathrm{C}=\mathrm{CC}(=\mathrm{O}) \mathrm{Nc} 1 \mathrm{ccc}(\mathrm{Oc} 2 \mathrm{nc}(\mathrm{Nc} 3 \operatorname{ccc}(\mathrm{N} 4 \mathrm{CCN}(\mathrm{C}(\mathrm{C})=\mathrm{O}) \mathrm{CC} 4) \mathrm{cc} 3 \mathrm{OC}) \mathrm{ncc} 2 \mathrm{SC}) \mathrm{c} 1$ & 87.5 & $*$ \\
\hline 2191 & $\mathrm{O}=\mathrm{S}(=\mathrm{O})(\mathrm{Nc} 1 \mathrm{nccs} 1) \mathrm{c} 1 \mathrm{ccc}(\mathrm{Nc} 2 \mathrm{nncc} 3 \mathrm{ccccc} 23) \mathrm{cc} 1$ & 88 & $*$ \\
\hline 2192 & $\mathrm{CC}(\mathrm{C}) \mathrm{n} 1 \mathrm{nc}(-\mathrm{c} 2 \mathrm{ccc} 3 \mathrm{cc}(\mathrm{O}) \mathrm{ccc} 3 \mathrm{c} 2) \mathrm{c} 2 \mathrm{c}(\mathrm{N}) \mathrm{ncnc} 21$ & 88 & $*$ \\
\hline 2193 & $\mathrm{Fc} 1 \mathrm{ccc}(\mathrm{Nc} 2 \mathrm{ncnc} 3 \mathrm{ccc}(\mathrm{C} \# \mathrm{CCN} 4 \mathrm{CCCCC} 4) \mathrm{cc} 23) \mathrm{cc} 1 \mathrm{Cl}$ & 88.7 & $*$ \\
\hline 2194 & $\mathrm{CN} 1 \mathrm{CCN}(\mathrm{C} / \mathrm{C}=\mathrm{C} / \mathrm{C}(=\mathrm{O}) \mathrm{N} 2 \mathrm{CCc} 3 \mathrm{c}(\mathrm{sc} 4 \mathrm{ncnc}(\mathrm{N}[\mathrm{C} @ \mathrm{H}](\mathrm{CO}) \mathrm{c} 5 \mathrm{ccccc} 5) \mathrm{c} 34) \mathrm{C} 2) \mathrm{CC} 1$ & 89 & * \\
\hline 2195 & $\mathrm{CCC}(=\mathrm{O}) \mathrm{ON}[\mathrm{C} @ \mathrm{H}](\mathrm{CS}(\mathrm{C})(=\mathrm{O})=\mathrm{O}) \mathrm{c} 1 \mathrm{ccc}(-\mathrm{c} 2 \mathrm{ccc} 3 \mathrm{ncnc}(\mathrm{Nc} 4 \mathrm{ccc}(\mathrm{OCc} 5 \mathrm{cccc}(\mathrm{F}) \mathrm{c} 5) \mathrm{c}(\mathrm{Cl}) \mathrm{c} 4) \mathrm{c} 3 \mathrm{c} 2) \mathrm{o} 1$ & 89.6 & $*$ \\
\hline 2196 & $\mathrm{O}=\mathrm{C} 1 \mathrm{CO} 2 \mathrm{cc} 3 \mathrm{ncnc}(\mathrm{Nc} 4 \mathrm{ccc}(\mathrm{Br}) \mathrm{c} 4) \mathrm{c} 3 \mathrm{cc} 2 \mathrm{~N} 1 \mathrm{CCCN} 1 \mathrm{CCOCC} 1$ & 89.6 & $*$ \\
\hline 2197 & $\operatorname{CCOC}(=\mathrm{O}) \mathrm{C} 1=\mathrm{C}(\mathrm{N}) \mathrm{N}(\mathrm{c} 2 \mathrm{cccnc} 2) \mathrm{C} 2=\mathrm{C}(\mathrm{C}(=\mathrm{O}) \mathrm{CCC} 2) \mathrm{C} 1 \mathrm{c} 1 \mathrm{cc} 2 \operatorname{ccccc} 2 \mathrm{n} 2 \mathrm{nnnc} 12$ & 90 & 7.05 \\
\hline 2198 & $\mathrm{O}=\mathrm{C} 1 \mathrm{CSC}(\mathrm{N} / \mathrm{N}=\mathrm{C} / \mathrm{c} 2 \mathrm{cc}(\mathrm{Br}) \operatorname{ccc} 2 \mathrm{O})=\mathrm{N} 1$ & 90 & 7.05 \\
\hline 2199 & $\mathrm{O}=\mathrm{C}(\mathrm{Nc} 1 \mathrm{cccc} 2 \mathrm{ccccc} 12) \mathrm{c} 1 \mathrm{ccc}(\mathrm{N}(\mathrm{CCCl}) \mathrm{CCCl}) \mathrm{cc} 1$ & 90 & 7.05 \\
\hline 2200 & $\mathrm{O}=\mathrm{C}(\mathrm{NS}(=\mathrm{O})(=\mathrm{O}) \mathrm{c} 1 \mathrm{ccc}(\mathrm{Cl}) \mathrm{cc} 1) \mathrm{c} 1 \mathrm{cncc}(\mathrm{Br}) \mathrm{c} 1$ & 90 & 7.05 \\
\hline 2201 & $\mathrm{COc} 1 \mathrm{cc} 2 \mathrm{ncc}(\mathrm{C \# N}) \mathrm{c}(\mathrm{Nc} 3 \operatorname{cccc}(\mathrm{Br}) \mathrm{c} 3) \mathrm{c} 2 \mathrm{cc} 1 \mathrm{NC}(=\mathrm{O}) \mathrm{C} \# \mathrm{CCN}(\mathrm{C}) \mathrm{C}$ & 90 & 7.05 \\
\hline 2202 & $\mathrm{CS}(=\mathrm{O})(=\mathrm{O}) \mathrm{CCN}(\mathrm{Cc} 1 \mathrm{ccccc} 1) \mathrm{Cc} 1 \mathrm{ccc}(-\mathrm{c} 2 \mathrm{ccc} 3 \mathrm{ncnc}(\mathrm{Nc} 4 \mathrm{ccc}(\mathrm{OCc} 5 \mathrm{ccc}(\mathrm{F}) \mathrm{c} 5) \mathrm{c}(\mathrm{Cl}) \mathrm{c} 4) \mathrm{c} 3 \mathrm{c} 2) \mathrm{o} 1$ & 90 & * \\
\hline 2203 & $\mathrm{O}=\mathrm{C}(\mathrm{O}[\mathrm{C} @ \mathrm{H}] 1 \mathrm{CN}[\mathrm{C} @ \mathrm{H}](\mathrm{C} \# \mathrm{Cc} 2 \mathrm{cc} 3 \mathrm{ncnc}(\mathrm{Nc} 4 \mathrm{ccc} 5 \mathrm{c}(\operatorname{ccn} 5 \mathrm{Cc} 5 \mathrm{cccc} 5) \mathrm{c} 4) \mathrm{c} 3 \mathrm{~s} 2) \mathrm{C} 1) \mathrm{N} 1 \mathrm{CCOCC} 1$ & 90 & $*$ \\
\hline 2204 & $\mathrm{O}=\mathrm{C}(\mathrm{Oc} 1 \mathrm{cccc}(\mathrm{O}) \mathrm{c} 1) \mathrm{c} 1 \mathrm{cc}(\mathrm{NCc} 2 \mathrm{cc}(\mathrm{O}) \mathrm{ccc} 2 \mathrm{O}) \operatorname{ccc} 1 \mathrm{O}$ & 90 & $*$ \\
\hline 2205 & $\mathrm{O}=\mathrm{C}(\mathrm{Oc} 1 \mathrm{ccc} 2 \mathrm{ccccc} 2 \mathrm{c} 1) \mathrm{c} 1 \mathrm{cc}(\mathrm{NCc} 2 \mathrm{cc}(\mathrm{O}) \operatorname{ccc} 2 \mathrm{O}) \mathrm{ccc} 1 \mathrm{O}$ & 90 & $*$ \\
\hline 2206 & $\mathrm{Nc} 1 \mathrm{cc} 2 \mathrm{ncnc}(\mathrm{Nc} 3 \mathrm{ccc}(\mathrm{Br}) \mathrm{cc} 3) \mathrm{c} 2 \mathrm{cn} 1$ & 90 & $*$ \\
\hline 2207 & $\mathrm{Cn} 1 \mathrm{c}(=\mathrm{O}) \mathrm{c}(-\mathrm{c} 2 \mathrm{c}(\mathrm{Cl}) \mathrm{cccc} 2 \mathrm{Cl}) \mathrm{cc} 2 \mathrm{cnc}(\mathrm{Nc} 3 \operatorname{ccc}(\mathrm{CO}) \mathrm{c} 3) \mathrm{nc} 21$ & 90 & $*$ \\
\hline 2208 & $\mathrm{COc} 1 \mathrm{cc} 2 \mathrm{c}(\mathrm{Nc} 3 \mathrm{ccc}(\mathrm{Cl}) \mathrm{cc} 3 \mathrm{~F}) \mathrm{ncnc} 2 \mathrm{cc} 1 \mathrm{OC} / \mathrm{C}=\mathrm{C} / \mathrm{CN} 1 \mathrm{CCCC} 1 . \mathrm{Cl}$ & 90 & $*$ \\
\hline
\end{tabular}




\begin{tabular}{|c|c|c|c|}
\hline 2209 & $\operatorname{CCOC}(=\mathrm{O}) \mathrm{c} 1 \mathrm{cn} 2 \mathrm{ncnc}(\mathrm{Nc} 3 \mathrm{ccc}(\mathrm{F}) \mathrm{c}(\mathrm{Cl}) \mathrm{c} 3) \mathrm{c} 2 \mathrm{c} 1 \mathrm{CC}$ & 90 & $*$ \\
\hline 2210 & $\mathrm{Fc} 1 \mathrm{cccc}(\mathrm{Cn} 2 \mathrm{ncc} 3 \mathrm{cc}(\mathrm{Nc} 4 \mathrm{ncnn} 5 \mathrm{ccc}(\mathrm{CN} 6 \mathrm{CCNCC} 6) \mathrm{c} 45) \operatorname{ccc} 32) \mathrm{c} 1$ & 90 & $*$ \\
\hline 2211 & $\mathrm{CCCN}(\mathrm{C} / \mathrm{C}=\mathrm{C} / \mathrm{C}(=\mathrm{O}) \mathrm{Nc} 1 \mathrm{ccc} 2 \mathrm{ncnc}(\mathrm{Nc} 3 \operatorname{ccc}(\mathrm{Br}) \mathrm{c} 3) \mathrm{c} 2 \mathrm{c} 1) \mathrm{CCC}$ & 90 & $*$ \\
\hline 2212 & NCCOCc1 cen2ncnc(Nc3ecc4c( $\operatorname{cnn} 4 \mathrm{Cc} 4 \mathrm{cccc}(\mathrm{F}) \mathrm{c} 4) \mathrm{c} 3) \mathrm{c} 12$ & 90 & $*$ \\
\hline 2213 & $\mathrm{COc} 1 \mathrm{ccc}(/ \mathrm{C}=\mathrm{C} / \mathrm{C}(=\mathrm{O}) \mathrm{c} 2 \mathrm{cc}(\mathrm{Br}) \operatorname{cc} 3 \operatorname{cc}(-\mathrm{c} 4 \mathrm{ccc}(\mathrm{F}) \mathrm{cc} 4) \mathrm{oc} 23) \mathrm{cc} 1$ & 90 & $*$ \\
\hline 2214 & $\mathrm{COc} 1 \mathrm{cc} 2 \mathrm{c}(\mathrm{Oc} 3 \mathrm{ccc}(\mathrm{NC}(=\mathrm{O}) \mathrm{c} 4 \mathrm{cc}(-\mathrm{c} 5 \mathrm{ccc}(\mathrm{C}) \mathrm{cc} 5) \mathrm{ccn} 4) \mathrm{cc} 3 \mathrm{~F}) \mathrm{ccn} 2 \mathrm{cc} 1 \mathrm{OCCCN} 1 \mathrm{CCN}(\mathrm{C}) \mathrm{CC} 1$ & 90.05 & $*$ \\
\hline 2215 & Clc1 $1 \mathrm{cc}(-\mathrm{c} 2 \mathrm{nc}(\mathrm{Nc} 3 \mathrm{cc}(\mathrm{Br}) \mathrm{cc} 4 \mathrm{cc}(-\mathrm{c} 5 \mathrm{cccc}(\mathrm{Cl}) \mathrm{c} 5) \mathrm{oc} 34) \mathrm{c} 3 \mathrm{cc}(\mathrm{Br}) \mathrm{ccc} 3 \mathrm{n} 2) \mathrm{cc} 1$ & 90.2 & $*$ \\
\hline 2216 & $\mathrm{O}=\mathrm{C}(\mathrm{Nc} 1 \mathrm{ccc} \mathrm{n} 1) \mathrm{Nc} 1 \mathrm{cc}(-\mathrm{c} 2 \mathrm{ccc} n \mathrm{c} 2) \operatorname{ccc} 1 \mathrm{OC}(\mathrm{F})(\mathrm{F}) \mathrm{F}$ & 90.57 & $*$ \\
\hline 2217 & $\mathrm{CCOc} 1 \mathrm{cc} 2 \mathrm{ncnc}(\mathrm{NC} 3=\mathrm{CC}(=\mathrm{O}) \mathrm{C}(\mathrm{OCc} 4 \mathrm{ccc} n 4)=\mathrm{CC} 3=\mathrm{O}) \mathrm{c} 2 \mathrm{cc} 1 \mathrm{NC}(=\mathrm{O}) / \mathrm{C}=\mathrm{C} / \mathrm{CN}(\mathrm{C}) \mathrm{C}$ & 90.8 & 7.04 \\
\hline 2218 & $\mathrm{CC}(=\mathrm{O}) \mathrm{Nc} 1 \mathrm{cccc}(\mathrm{C \# C} 2 \mathrm{cncnc} 2 \mathrm{Nc} 2 \mathrm{ccc}(\mathrm{OCc} 3 \operatorname{cccc}(\mathrm{F}) \mathrm{c} 3) \mathrm{c}(\mathrm{Cl}) \mathrm{c} 2) \mathrm{n} 1$ & 91 & $*$ \\
\hline 2219 & $\mathrm{CS}(=\mathrm{O})(=\mathrm{O}) \mathrm{CCNCc} 1 \mathrm{ccc}(-\mathrm{c} 2 \mathrm{ccc} 3 \mathrm{ncnc}(\mathrm{Nc} 4 \mathrm{ccc}(\mathrm{OCc} 5 \operatorname{ccc}(\mathrm{C}(\mathrm{F})(\mathrm{F}) \mathrm{F}) \mathrm{c} 5) \mathrm{cc} 4) \mathrm{c} 3 \mathrm{c} 2) \mathrm{o} 1$ & 91 & $*$ \\
\hline 2220 & $\mathrm{COCCOc} 1 \mathrm{cc} 2 \mathrm{ncnc}(\mathrm{Nc} 3 \operatorname{ccc}(\mathrm{OCc} 4 \operatorname{ccc}(\mathrm{F}) \mathrm{c} 4) \mathrm{cc} 3) \mathrm{c} 2 \mathrm{cc} 1 \mathrm{NC}(=\mathrm{O}) / \mathrm{C}=\mathrm{C} / \mathrm{CN}(\mathrm{C}) \mathrm{C}$ & 91 & $*$ \\
\hline 2221 & $\mathrm{C}=\mathrm{CS}(=\mathrm{O})(=\mathrm{O}) \mathrm{N} 1 \mathrm{CCc} 2 \mathrm{c}(\mathrm{sc} 3 \mathrm{ncnc}(\mathrm{N}[\mathrm{C} @ \mathrm{H}](\mathrm{CO}) \mathrm{c} 4 \mathrm{ccccc} 4) \mathrm{c} 23) \mathrm{C} 1$ & 91 & $*$ \\
\hline 2222 & $\mathrm{COC}(=\mathrm{O}) \mathrm{c} 1 \mathrm{ccc} 2 \mathrm{oc} 3 \mathrm{cnnn}(\mathrm{Nc} 4 \mathrm{ccc}(\mathrm{C}) \mathrm{cc} 4) \mathrm{c} 3 \mathrm{c} 2 \mathrm{c} 1$ & 91.2 & 7.04 \\
\hline 2223 & $\mathrm{O}=\mathrm{C}(\mathrm{NCCN} 1 \mathrm{CCOCC} 1) \mathrm{Nc} 1 \mathrm{ccc}(-\mathrm{c} 2 \mathrm{cc} 3 \mathrm{c}(\mathrm{Nc} 4 \mathrm{ccc}(\mathrm{Oc} 5 \mathrm{cccc}(\mathrm{C}(\mathrm{F})(\mathrm{F}) \mathrm{F}) \mathrm{c} 5) \mathrm{c}(\mathrm{Cl}) \mathrm{c} 4) \mathrm{ncnc} 3 \mathrm{~s} 2) \mathrm{cc} 1$ & 91.7 & $*$ \\
\hline \multirow[t]{3}{*}{2224} & $\mathrm{CC} 1(\mathrm{C})[\mathrm{C} @ @ \mathrm{H}](\mathrm{O}[\mathrm{C} @ \mathrm{H}] 2 \mathrm{O}[\mathrm{C} @ \mathrm{H}](\mathrm{C}(=\mathrm{O}) \mathrm{O})[\mathrm{C} @ @ \mathrm{H}](\mathrm{O})[\mathrm{C} @ \mathrm{H}](\mathrm{O})[\mathrm{C} @ \mathrm{H}] 2 \mathrm{O}[\mathrm{C} @ @ \mathrm{H}] 2 \mathrm{O}[\mathrm{C} @ \mathrm{H}](\mathrm{C}=\mathrm{O}) \mathrm{O})[$ & \multirow[t]{3}{*}{92} & \multirow[t]{3}{*}{$*$} \\
\hline & C@@H](O)[C@H](O)[C@H]2O)CC[C@@]2(C)[C@H]1CC[C@]1(C)[C@@H]2C(=O)C=C2[C@H]3C[C@@ & & \\
\hline & ]$(\mathrm{C})(\mathrm{C}(=\mathrm{O}) \mathrm{O}) \mathrm{CC}[\mathrm{C} @] 3(\mathrm{C}) \mathrm{CC}[\mathrm{C} @] 21 \mathrm{C}$ & & \\
\hline 2225 & $\mathrm{CCCCC}(=\mathrm{O}) \mathrm{ON}[\mathrm{C} @ \mathrm{H}](\mathrm{CS}(\mathrm{C})(=\mathrm{O})=\mathrm{O}) \mathrm{c} 1 \mathrm{ccc}(-\mathrm{c} 2 \mathrm{ccc} 3 \mathrm{ncnc}(\mathrm{Nc} 4 \mathrm{ccc}(\mathrm{OCc} 5 \operatorname{cccc}(\mathrm{F}) \mathrm{c} 5) \mathrm{c}(\mathrm{Cl}) \mathrm{c} 4) \mathrm{c} 3 \mathrm{c} 2) \mathrm{o} 1$ & 92.8 & $*$ \\
\hline 2226 & c1 $1 \mathrm{ccc}(\mathrm{CNc} 2 \mathrm{ncnc} 3 \mathrm{oc}(-\mathrm{c} 4 \mathrm{cccc} 4) \mathrm{cc} 23) \mathrm{cc} 1$ & 93 & 7.03 \\
\hline 2227 & $\operatorname{CS}(=\mathrm{O})(=\mathrm{O}) \mathrm{CCNCCCCOc} 1 \mathrm{ccc} 2 \mathrm{ncnc}(\mathrm{Nc} 3 \operatorname{ccc}(\mathrm{S}(=\mathrm{O})(=\mathrm{O}) \mathrm{c} 4 \mathrm{cccc} 4) \operatorname{cc} 3) \mathrm{c} 2 \mathrm{c} 1$ & 93 & $*$ \\
\hline 2228 & $\mathrm{CN}(\mathrm{C}) \mathrm{CCCN}(\mathrm{C}) \mathrm{C} / \mathrm{C}=\mathrm{C} / \mathrm{C}(=\mathrm{O}) \mathrm{Nc} 1 \mathrm{cc} 2 \mathrm{c}(\mathrm{Nc} 3 \mathrm{ccc}(\mathrm{F}) \mathrm{c}(\mathrm{Cl}) \mathrm{c} 3) \mathrm{ncnc} 2 \mathrm{~s} 1$ & 93 & $*$ \\
\hline 2229 & $\mathrm{CCN}(\mathrm{CC}) \mathrm{CCOc} 1 \mathrm{cc} 2 \mathrm{c}(\mathrm{Nc} 3 \mathrm{ccc}(\mathrm{F}) \mathrm{c}(\mathrm{Cl}) \mathrm{c} 3) \mathrm{ncnc} 2 \mathrm{cc} 1 \mathrm{OC}$ & 93 & $*$ \\
\hline 2230 & $\mathrm{c} 1 \mathrm{ccc} 2 \mathrm{c}(\mathrm{c} 1) \mathrm{CCCN} 2 \mathrm{c} 1 \mathrm{ncn} 2 \mathrm{cc} 3 \mathrm{oc}(\mathrm{N} 4 \mathrm{CCCCC} 4) \mathrm{nc} 3 \mathrm{cc} 12$ & 93 & $*$ \\
\hline 2231 & Ic1 $1 \mathrm{ccc}(\mathrm{Nc} 2 \mathrm{ncnc} 3 \mathrm{cc} 4 \mathrm{c}(\mathrm{cc} 23) \mathrm{OC}(\mathrm{CN} 2 \mathrm{CCOCC} 2) \mathrm{CO} 4) \mathrm{c} 1$ & 93.3 & $*$ \\
\hline 2232 & Ic1 $1 \mathrm{ccc}(\mathrm{Nc} 2 \mathrm{ncnc} 3 \mathrm{cc} 4 \mathrm{c}(\mathrm{cc} 23) \mathrm{OC}(\mathrm{CNCCN} 2 \mathrm{CCOCC} 2) \mathrm{CO} 4) \mathrm{c} 1$ & 93.3 & $*$ \\
\hline 2233 & $\mathrm{O}=\mathrm{S}(=\mathrm{O})(\mathrm{CCO}) \mathrm{c} 1 \mathrm{cc} 2 \mathrm{c}(\mathrm{Nc} 3 \mathrm{cccc}(\mathrm{Br}) \mathrm{c} 3) \mathrm{ncnc} 2 \mathrm{cn} 1$ & 93.5 & $*$ \\
\hline 2234 & $\mathrm{Cc} 1 \mathrm{ncnc}(\mathrm{Nc} 2 \mathrm{ccc}(\mathrm{OCc} 3 \operatorname{ccc}(\mathrm{F}) \mathrm{c} 3) \mathrm{c}(\mathrm{Cl}) \mathrm{c} 2) \mathrm{c} 1 / \mathrm{C}=\mathrm{C} / \mathrm{c} 1 \mathrm{ccc}(\mathrm{CNCCS}(\mathrm{C})(=\mathrm{O})=\mathrm{O}) \mathrm{cc} 1$ & 94 & 7.03 \\
\hline 2235 & $\mathrm{COc} 1 \mathrm{cc} 2 \mathrm{ncnc}(\mathrm{Nc} 3 \mathrm{ccc}(\mathrm{F}) \mathrm{c}(\mathrm{Cl}) \mathrm{c} 3) \mathrm{c} 2 \mathrm{cc} 1 \mathrm{OCCN} 1 \mathrm{CC}(\mathrm{OC}) \mathrm{C} 1$ & 94 & 7.03 \\
\hline 2236 & $\mathrm{CCC}(=\mathrm{O}) \mathrm{Nc} 1 \mathrm{cc} 2 \mathrm{c}(\mathrm{Nc} 3 \mathrm{ccc} 4 \mathrm{c}(\mathrm{cnn} 4 \mathrm{Cc} 4 \mathrm{ccc} n 4) \mathrm{c} 3) \mathrm{ncnc} 2 \mathrm{cc} 1 \mathrm{OC}$ & 94 & $*$ \\
\hline 2237 & $\mathrm{CN}(\mathrm{C}) \mathrm{c} 1 \mathrm{ccc}(\mathrm{Nc} 2 \mathrm{ncnc} 3 \mathrm{cc}(-\mathrm{c} 4 \mathrm{ccccc} 4) \mathrm{sc} 23) \mathrm{cc} 1$ & 94 & $*$ \\
\hline 2238 & $\operatorname{COc} 1 \operatorname{ccc}(\mathrm{NC}(=\mathrm{O}) / \mathrm{C}=\mathrm{C} / \mathrm{CN}(\mathrm{C}) \mathrm{C}) \mathrm{cc} 1 \mathrm{Nc} 1 \mathrm{ncc}(\mathrm{Cl}) \mathrm{c}(\mathrm{N}(\mathrm{C}) \mathrm{c} 2 \operatorname{ccc} 3 \operatorname{ccccc} 3 \mathrm{c} 2) \mathrm{n} 1$ & 94 & $*$ \\
\hline 2239 & $\mathrm{CC}(\mathrm{O}) \mathrm{C} \# \mathrm{Cc} 1 \mathrm{ccc} 2 \mathrm{ncnc}(\mathrm{Nc} 3 \mathrm{ccc}(\mathrm{F}) \mathrm{c}(\mathrm{Cl}) \mathrm{c} 3) \mathrm{c} 2 \mathrm{c} 1$ & 94.5 & $*$ \\
\hline 2240 & $\mathrm{O}=\mathrm{C}(\mathrm{Nc} 1 \mathrm{ccc} 2 \mathrm{ncnc}(\mathrm{Nc} 3 \mathrm{cccc}(\mathrm{Cl}) \mathrm{c} 3) \mathrm{c} 2 \mathrm{c} 1) \mathrm{C} 1 \mathrm{CCC} 2(\mathrm{CC} 1) \mathrm{OCC} 1(\mathrm{OO} 2) \mathrm{C} 2 \mathrm{CC} 3 \mathrm{CC}(\mathrm{C} 2) \mathrm{CC} 1 \mathrm{C} 3$ & 94.72 & $*$ \\
\hline 2241 & $\mathrm{Cn} 1 \mathrm{cnc}(-\mathrm{c} 2 \mathrm{ccc}(\mathrm{OC}(\mathrm{F})(\mathrm{F}) \mathrm{F}) \mathrm{c}(\mathrm{NC}(=\mathrm{O}) \mathrm{Nc} 3 \mathrm{ccncc} 3) \mathrm{c} 2) \mathrm{c} 1$ & 94.82 & * \\
\hline 2242 & COc1cc2ncnc $(\mathrm{Nc} 3 \mathrm{ccc}(\mathrm{F}) \mathrm{c}(\mathrm{Cl}) \mathrm{c} 3) \mathrm{c} 2 \mathrm{cc} 1 \mathrm{OC}[\mathrm{C} @ @ \mathrm{H}](\mathrm{O}) \mathrm{CN} 1 \mathrm{CCOCC} 1$ & 95 & $*$ \\
\hline 2243 & $\mathrm{O}=\mathrm{c} 1 \mathrm{c}(-\mathrm{c} 2 \mathrm{cccc}(\mathrm{Cl}) \mathrm{c} 2) \operatorname{coc} 2 \mathrm{cc}(\mathrm{O}) \mathrm{cc}(\mathrm{O}) \mathrm{c} 12$ & 95 & $*$ \\
\hline 2244 & $\mathrm{O}=\mathrm{C}(\mathrm{C} \# \mathrm{CCN} 1 \mathrm{CCSCC} 1) \mathrm{Nc} 1 \mathrm{ccc} 2 \mathrm{ncnc}(\mathrm{Nc} 3 \mathrm{cccc}(\mathrm{Br}) \mathrm{c} 3) \mathrm{c} 2 \mathrm{c} 1$ & 95 & $*$ \\
\hline 2245 & Br.Cc1 $1 \operatorname{ccc}(\mathrm{C}(\mathrm{C}) \mathrm{Nc} 2 \mathrm{ncnc} 3[\mathrm{nH}] \mathrm{c}(-\mathrm{c} 4 \mathrm{ccc}(\mathrm{O}) \mathrm{cc} 4) \mathrm{cc} 23) \mathrm{c} 1$ & 95 & $*$ \\
\hline 2246 & $\mathrm{CS}(=\mathrm{O})(=\mathrm{O}) \mathrm{CCNCc} 1 \mathrm{ccc}(-\mathrm{c} 2 \mathrm{cc} 3 \mathrm{c}(\mathrm{Nc} 4 \mathrm{ccc}(\mathrm{OCc} 5 \mathrm{ccc}(\mathrm{F}) \mathrm{c} 5) \mathrm{c}(\mathrm{Cl}) \mathrm{c} 4) \mathrm{ncnc} 3 \mathrm{~s} 2) \mathrm{s} 1$ & 96 & $*$ \\
\hline 2247 & $\mathrm{Clc} 1 \mathrm{cccc}(\mathrm{Nc} 2[\mathrm{nH}] \mathrm{cnc} 3 \mathrm{nc}(-\mathrm{c} 4 \mathrm{ccccc} 4) \mathrm{c}(-\mathrm{c} 4 \mathrm{cccc} 4) \mathrm{c} 2-3) \mathrm{c} 1$ & 96 & $*$ \\
\hline 2248 & $\mathrm{COc} 1 \mathrm{ccc}(-\mathrm{c} 2[\mathrm{nH}] \mathrm{nc} 3 \mathrm{ncnc}(\mathrm{Nc} 4 \mathrm{cccc}(\mathrm{Cl}) \mathrm{c} 4) \mathrm{c} 23) \mathrm{cc} 1$ & 96 & $*$ \\
\hline 2249 & $\mathrm{C}=\mathrm{C}=\mathrm{Cc} 1 \mathrm{ccc}(\mathrm{Nc} 2 \mathrm{ncnc} 3 \mathrm{cc}(\mathrm{OCCOC}) \mathrm{c}(\mathrm{OCCOC}) \mathrm{cc} 23) \mathrm{c} 1$ & 96 & $*$ \\
\hline
\end{tabular}




\begin{tabular}{|c|c|c|c|}
\hline 2250 & $\mathrm{C}=\mathrm{CC}(=\mathrm{O}) \mathrm{Nc} 1 \mathrm{cccc}(-\mathrm{n} 2 \mathrm{c}(=\mathrm{O}) \mathrm{cc}(-\mathrm{c} 3 \mathrm{cccc} 3) \mathrm{c} 3 \mathrm{cnc}(\mathrm{Nc} 4 \mathrm{ccc}(\mathrm{N} 5 \mathrm{CCN}(\mathrm{C}) \mathrm{CC} 5) \mathrm{cc} 4 \mathrm{OC}) \mathrm{nc} 32) \mathrm{c} 1$ & 97 & $*$ \\
\hline 2251 & $\mathrm{CC}(\mathrm{C}) \mathrm{N}(\mathrm{CC} \# \mathrm{CC}(=\mathrm{O}) \mathrm{Nc} 1 \mathrm{ccc} 2 \mathrm{ncnc}(\mathrm{Nc} 3 \mathrm{cccc}(\mathrm{Br}) \mathrm{c} 3) \mathrm{c} 2 \mathrm{c} 1) \mathrm{C}(\mathrm{C}) \mathrm{C}$ & 97 & $*$ \\
\hline 2252 & $\mathrm{O}=\mathrm{C}(\mathrm{CO}) \mathrm{N} 1 \mathrm{CCC}[\mathrm{C} @ @ \mathrm{H}] 1 \mathrm{COc} 1 \mathrm{ccc} 2 \mathrm{ncnc}(\mathrm{Nc} 3 \mathrm{ccc}(\mathrm{OCc} 4 \mathrm{ccc} \mathrm{c} 4) \mathrm{c}(\mathrm{Cl}) \mathrm{c} 3) \mathrm{c} 12$ & 97 & $*$ \\
\hline 2253 & $\mathrm{C}=\mathrm{CC}(=\mathrm{O}) \mathrm{Nc} 1 \mathrm{cccc}(-\mathrm{n} 2 \mathrm{c}(=\mathrm{O}) \mathrm{cc}(\mathrm{C}) \mathrm{c} 3 \mathrm{cnc}(\mathrm{Nc} 4 \mathrm{ccc}(\mathrm{N} 5 \mathrm{CC}(\mathrm{C}) \mathrm{N}(\mathrm{C}) \mathrm{C}(\mathrm{C}) \mathrm{C} 5) \mathrm{cc} 4 \mathrm{OC}) \mathrm{nc} 32) \mathrm{c} 1$ & 97 & $*$ \\
\hline 2254 & $\mathrm{C}=\mathrm{CC}(=\mathrm{O}) \mathrm{Nc} 1 \mathrm{cc}(-\mathrm{n} 2 \mathrm{c}(=\mathrm{O}) \mathrm{cc}(\mathrm{C}) \mathrm{c} 3 \mathrm{cnc}(\mathrm{Nc} 4 \mathrm{ccc}(\mathrm{N} 5 \mathrm{CC}(\mathrm{C}) \mathrm{N}(\mathrm{C}) \mathrm{C}(\mathrm{C}) \mathrm{C} 5) \mathrm{cc} 4 \mathrm{OC}) \mathrm{nc} 32) \mathrm{cc}(\mathrm{C}(\mathrm{F})(\mathrm{F}) \mathrm{F}) \mathrm{c} 1$ & 97 & $*$ \\
\hline 2255 & $\mathrm{C}=\mathrm{CC}(=\mathrm{O}) \mathrm{Nc} 1 \mathrm{cc}(\mathrm{Nc} 2 \mathrm{n}[\mathrm{nH}] \mathrm{c} 3 \mathrm{cc}(-\mathrm{c} 4 \mathrm{cccnc} 4) \operatorname{ccc} 23) \mathrm{c}(\mathrm{OC}) \mathrm{cc} 1 \mathrm{~N}(\mathrm{C}) \mathrm{CCN}(\mathrm{C}) \mathrm{C}$ & 97 & * \\
\hline 2256 & $\mathrm{FC}(\mathrm{F})(\mathrm{F}) \mathrm{c} 1 \mathrm{cccc}(\mathrm{Nc} 2 \mathrm{ncnc} 3 \mathrm{cc}(\mathrm{OCCCN} 4 \mathrm{CCOCC} 4) \mathrm{c} 4 \mathrm{c}(\mathrm{c} 23) \mathrm{OCCO} 4) \mathrm{c} 1$ & 97.18 & * \\
\hline 2257 & $\mathrm{O}=\mathrm{C}(\mathrm{Nc} 1 \mathrm{ccncc} 1) \mathrm{Nc} 1 \mathrm{cc}(-\mathrm{c} 2 \mathrm{cccnc} 2) \operatorname{ccc} 1 \mathrm{OC}(\mathrm{F})(\mathrm{F}) \mathrm{F}$ & 97.22 & $*$ \\
\hline 2258 & $\mathrm{Cc} 1 \mathrm{ncnc}(\mathrm{Nc} 2 \mathrm{ccc}(\mathrm{OCc} 3 \operatorname{ccc}(\mathrm{F}) \mathrm{c} 3) \mathrm{c}(\mathrm{Cl}) \mathrm{c} 2) \mathrm{c} 1 / \mathrm{C}=\mathrm{C} / \mathrm{c} 1 \mathrm{ccc}(\mathrm{CNC} 2 \mathrm{CC} 2) \mathrm{cc} 1$ & 98 & 7.01 \\
\hline 2259 & $\mathrm{CCOc} 1 \mathrm{cc} 2 \mathrm{ncc}(\mathrm{C \# N}) \mathrm{c}(\mathrm{Nc} 3 \operatorname{ccc}(\mathrm{OCc} 4 \mathrm{cccc} 4) \mathrm{c}(\mathrm{Cl}) \mathrm{c} 3) \mathrm{c} 2 \mathrm{cc} 1 \mathrm{NC}(=\mathrm{O}) / \mathrm{C}=\mathrm{C} / \mathrm{CN}(\mathrm{CC}(\mathrm{C}) \mathrm{O}) \mathrm{CC}(\mathrm{C}) \mathrm{O}$ & 98 & 7.01 \\
\hline 2260 & Brc1 $\operatorname{ccc}(\mathrm{Nc} 2 \mathrm{ncnc} 3 \mathrm{ccc}(\mathrm{NCc} 4 \mathrm{ccc} 5 \mathrm{c}(\mathrm{c} 4) \mathrm{OCCCO}) \mathrm{cc} 23) \mathrm{c} 1$ & 98 & 7.01 \\
\hline 2261 & Oc1 $1 \mathrm{cc} 2 \mathrm{ncnc}(\mathrm{Nc} 3 \operatorname{ccc}(\mathrm{OCc} 4 \mathrm{cccc} 4) \mathrm{cc} 3) \mathrm{c} 2 \mathrm{c} 1$ & 98 & $*$ \\
\hline 2262 & $\mathrm{C}=\mathrm{CC}(=\mathrm{O}) \mathrm{Nc} 1 \mathrm{cccc}(-\mathrm{n} 2 \mathrm{c}(=\mathrm{O}) \mathrm{cc}(\mathrm{C}(\mathrm{C}) \mathrm{C}) \mathrm{c} 3 \mathrm{cnc}(\mathrm{Nc} 4 \mathrm{ccc}(\mathrm{N} 5 \mathrm{CCN}(\mathrm{C}) \mathrm{CC} 5) \mathrm{cc} 4 \mathrm{OC}) \mathrm{nc} 32) \mathrm{c} 1$ & 98 & $*$ \\
\hline 2263 & $\mathrm{CCOc} 1 \mathrm{cc} 2 \mathrm{ncnc}(\mathrm{Nc} 3 \operatorname{ccc}(\mathrm{OCc} 4 \mathrm{ccc} n 4) \mathrm{cc} 3) \mathrm{c} 2 \mathrm{cc} 1 \mathrm{NC}(=\mathrm{O}) / \mathrm{C}=\mathrm{C} / \mathrm{CN} 1 \mathrm{CCCC} 1$ & 98 & $*$ \\
\hline 2264 & $\mathrm{COc} 1 \mathrm{cc} 2 \mathrm{ncnc}(\mathrm{Nc} 3 \mathrm{ccc}(\mathrm{F}) \mathrm{c}(\mathrm{Cl}) \mathrm{c} 3) \mathrm{c} 2 \mathrm{cc} 1 \mathrm{OCCN} 1 \mathrm{CCCCC} 1$ & 98 & $*$ \\
\hline 2265 & $\mathrm{O}=\mathrm{C}(\mathrm{CN} 1 \mathrm{CCOCC} 1) \mathrm{Nc} 1 \mathrm{ccc} 2 \mathrm{ncnc}(\mathrm{Nc} 3 \operatorname{cccc}(\mathrm{Br}) \mathrm{c} 3) \mathrm{c} 2 \mathrm{c} 1$ & 98 & $*$ \\
\hline 2266 & $\begin{array}{c}\mathrm{C}=\mathrm{CC}(=\mathrm{O}) \mathrm{Nc} 1 \mathrm{cccc}(\mathrm{Oc} 2 \mathrm{nc}(\mathrm{Nc} 3 \operatorname{ccc}(\mathrm{N} 4 \mathrm{CCN}(\mathrm{CC}(=\mathrm{O}) \mathrm{OCCCOc} 5 \mathrm{no}[\mathrm{n}+]([\mathrm{O}-]) \mathrm{c} 5 \mathrm{~S}(=\mathrm{O})(=\mathrm{O}) \mathrm{c} 5 \mathrm{cccc} 5) \mathrm{CC} 4) \operatorname{cc} 3 \mathrm{OC} \\
) \mathrm{ncc} 2 \mathrm{Cl}) \mathrm{c} 1\end{array}$ & 99 & 7.00 \\
\hline 2267 & $\mathrm{CCc} 1 \mathrm{ccc}(\mathrm{C}(=\mathrm{O}) \mathrm{Nc} 2 \operatorname{ccc}(\mathrm{CN} 3 \mathrm{CCN}(\mathrm{C}) \mathrm{CC} 3) \mathrm{c}(\mathrm{C}(\mathrm{F})(\mathrm{F}) \mathrm{F}) \mathrm{c} 2) \mathrm{cc} 1 \mathrm{NC}(=\mathrm{O}) \mathrm{c} 1 \mathrm{cnc} 2[\mathrm{nH}] \operatorname{ccc} 2 \mathrm{c} 1$ & 99 & 7.00 \\
\hline 2268 & $\mathrm{NC}(=\mathrm{O}) \mathrm{Nc} 1 \mathrm{ccc} 2 \mathrm{ncnc}(\mathrm{Nc} 3 \mathrm{ccc}(\mathrm{OCc} 4 \mathrm{cccc}(\mathrm{F}) \mathrm{c} 4) \mathrm{c}(\mathrm{Cl}) \mathrm{c} 3) \mathrm{c} 2 \mathrm{c} 1$ & 99 & 8.69 \\
\hline 2269 & $\mathrm{Cc} 1 \mathrm{c}(\mathrm{OCC}(\mathrm{F})(\mathrm{F}) \mathrm{F}) \mathrm{ccnc} 1 \mathrm{COc} 1 \mathrm{cccc}(\mathrm{Nc} 2 \mathrm{ncnc} 3 \mathrm{cc} 4 \mathrm{oc}(=\mathrm{O}) \mathrm{n}(\mathrm{CCCN} 5 \mathrm{CCOCC} 5) \mathrm{c} 4 \mathrm{cc} 23) \mathrm{c} 1$ & 99 & $*$ \\
\hline 2270 & $\mathrm{O}=\mathrm{C} 1 \mathrm{CO} 2 \mathrm{cc} 3 \mathrm{ncnc}(\mathrm{Nc} 4 \mathrm{cccc}(\mathrm{Br}) \mathrm{c} 4) \mathrm{c} 3 \mathrm{cc} 2 \mathrm{~N} 1 \mathrm{CCCN} 1 \mathrm{CCCCC} 1$ & 99 & $*$ \\
\hline 2271 & $\mathrm{O}=\mathrm{C}(\mathrm{O}[\mathrm{C} @ \mathrm{H}] 1 \mathrm{CN}[\mathrm{C} @ \mathrm{H}](\mathrm{C} \# \mathrm{Cc} 2 \mathrm{cc} 3 \mathrm{ncnc}(\mathrm{Nc} 4 \mathrm{ccc}(\mathrm{OCc} 5 \mathrm{cccc}(\mathrm{F}) \mathrm{c} 5) \mathrm{c}(\mathrm{Cl}) \mathrm{c} 4) \mathrm{c} 3 \mathrm{~s} 2) \mathrm{C} 1) \mathrm{N} 1 \mathrm{CCCC} 1$ & 99 & $*$ \\
\hline 2272 & $\mathrm{O}=\mathrm{C}(\mathrm{Nc} 1 \mathrm{cccc}(\mathrm{Nc} 2 \mathrm{ncnc} 3 \mathrm{cc}(\mathrm{OCCCN} 4 \mathrm{CCN}(\mathrm{CCO}) \mathrm{CC} 4) \operatorname{ccc} 23) \mathrm{c} 1) \mathrm{Nc} 1 \mathrm{ccc}(\mathrm{Cl}) \mathrm{c}(\mathrm{C}(\mathrm{F})(\mathrm{F}) \mathrm{F}) \mathrm{c} 1$ & 99 & $*$ \\
\hline 2273 & $\mathrm{Fc} 1 \mathrm{cc}(\mathrm{Br}) \mathrm{ccc} 1 \mathrm{Nc} 1 \mathrm{ncnc} 2 \mathrm{cc} 3 \mathrm{c}(\mathrm{cc} 12) \mathrm{OC}(\mathrm{CCN}(\mathrm{N} 1 \mathrm{CCOCC} 1) \mathrm{N} 1 \mathrm{CCOCC} 1) \mathrm{CO} 3$ & 99 & $*$ \\
\hline 2274 & $\operatorname{COc} 1 \mathrm{cc} 2 \mathrm{ncnc}(\mathrm{NCc} 3 \operatorname{cccc} 3) \mathrm{c} 2 \mathrm{cc} 1 \mathrm{OCCCCCCC}(=\mathrm{O}) \mathrm{NO}$ & 99.4 & 7.00 \\
\hline 2275 & $\operatorname{COc} 1 \operatorname{ccc}(\mathrm{C} 2=\mathrm{NN}(\mathrm{c} 3 \operatorname{ccc} c 3) \mathrm{C}(\mathrm{c} 3 \operatorname{ccc} 4 \operatorname{ccc} c \mathrm{c} 34) \mathrm{C} 2) \operatorname{cc} 1$ & 100 & 7.00 \\
\hline 2276 & $\mathrm{CCOc} 1 \mathrm{cc} 2 \mathrm{ncc}(\mathrm{C} \# \mathrm{~N}) \mathrm{c}(\mathrm{Nc} 3 \operatorname{ccc} 4 \mathrm{c}(\operatorname{ccn} 4 \mathrm{Cc} 4 \operatorname{ccccc} 4) \mathrm{c} 3) \mathrm{c} 2 \mathrm{cc} 1 \mathrm{NC}(=\mathrm{O}) / \mathrm{C}=\mathrm{C} / \mathrm{CN}(\mathrm{C}) \mathrm{C}$ & 100 & 7.00 \\
\hline 2277 & $\mathrm{CCOc} 1 \mathrm{cc} 2 \mathrm{ncc}(\mathrm{C \# N}) \mathrm{c}(\mathrm{Nc} 3 \operatorname{ccc}(\mathrm{O}[\mathrm{C} @ \mathrm{H}](\mathrm{C}) \mathrm{c} 4 \mathrm{ccccc} 4) \mathrm{c}(\mathrm{Cl}) \mathrm{c} 3) \mathrm{c} 2 \mathrm{cc} 1 \mathrm{NC}(=\mathrm{O}) / \mathrm{C}=\mathrm{C} / \mathrm{CN}(\mathrm{C}) \mathrm{C}$ & 100 & 7.00 \\
\hline 2278 & $\operatorname{COc} 1 \mathrm{cc}(\mathrm{Nc} 2 \mathrm{ncnc} 3 \operatorname{ccc}(-\mathrm{c} 4 \operatorname{ccc}(\mathrm{CNCCS}(\mathrm{C})(=\mathrm{O})=\mathrm{O}) \mathrm{o} 4) \operatorname{cc} 23) \operatorname{ccc} 1 \mathrm{OCc} 1 \mathrm{cccc}(\mathrm{F}) \mathrm{c} 1$ & 100 & * \\
\hline 2279 & $\mathrm{COc} 1 \mathrm{cc} 2 \mathrm{ncnc}(\mathrm{Nc} 3 \mathrm{ccc}(\mathrm{F}) \mathrm{c}(\mathrm{Cl}) \mathrm{c} 3) \mathrm{c} 2 \mathrm{cc} 1 \mathrm{OCCNC}(\mathrm{C})(\mathrm{C}) \mathrm{C}$ & 100 & * \\
\hline 2280 & $\mathrm{CC}(\mathrm{C})(\mathrm{C}) \mathrm{ONC}(=\mathrm{O}) \mathrm{c} 1 \mathrm{cc}(\mathrm{NCc} 2 \mathrm{cc}(\mathrm{O}) \mathrm{ccc} 2 \mathrm{O}) \mathrm{ccc} 1 \mathrm{O}$ & 100 & $*$ \\
\hline 2281 & $\mathrm{CC}(=\mathrm{O}) \mathrm{Nc} 1 \mathrm{cc} 2 \mathrm{ncnc}(\mathrm{NCc} 3 \mathrm{cccc} 3) \mathrm{c} 2 \mathrm{cn} 1$ & 100 & $*$ \\
\hline 2282 & $\mathrm{COc} 1 \mathrm{cc} 2 \mathrm{ncnc}(\mathrm{Nc} 3 \operatorname{ccc}(\mathrm{O}) \mathrm{cc} 3) \mathrm{c} 2 \mathrm{cc} 1 \mathrm{OC} . \mathrm{Cl}$ & 100 & $*$ \\
\hline 2283 & $\mathrm{COc} 1 \mathrm{ccc} 2 \mathrm{ncnc}(\mathrm{Nc} 3 \mathrm{cc}(\mathrm{OC}) \mathrm{c}(\mathrm{OC}) \mathrm{c}(\mathrm{OC}) \mathrm{c} 3) \mathrm{c} 2 \mathrm{c} 1 . \mathrm{Cl}$ & 100 & $*$ \\
\hline 2284 & $\mathrm{Nc} 1 \mathrm{ccc} 2 \mathrm{c}(\mathrm{Nc} 3 \operatorname{ccc} c \mathrm{3}) \mathrm{ncnc} 2 \mathrm{c} 1$ & 100 & $*$ \\
\hline 2285 & $\mathrm{COc} 1 \mathrm{cc} 2 \mathrm{ncnc}(\mathrm{N}(\mathrm{C}) \mathrm{c} 3 \mathrm{cccc}(\mathrm{Cl}) \mathrm{c} 3) \mathrm{c} 2 \mathrm{cc} 1 \mathrm{OC} . \mathrm{Cl}$ & 100 & $*$ \\
\hline 2286 & COc1cc2c(Nc3ecc(Br)cc3F)ncnc2cc1OC[C@H]1CCCN(C)C1 & 100 & $*$ \\
\hline 2287 & COc1cc2c(Nc3ccc(Cl)cc3F)ncnc2cc1OC[C@@H]1CCCN(C)C1 & 100 & * \\
\hline 2288 & $\mathrm{COc} 1 \mathrm{cc} 2 \mathrm{c}(\mathrm{Nc} 3 \mathrm{ccc}(\mathrm{Cl}) \mathrm{cc} 3 \mathrm{~F}) \mathrm{ncnc} 2 \mathrm{cc} 1 \mathrm{OCCCN} 1 \mathrm{CCOCC} 1$ & 100 & $*$ \\
\hline 2289 & $\mathrm{COc} 1 \mathrm{cc} 2 \mathrm{c}(\mathrm{Nc} 3 \mathrm{cc}(\mathrm{O}) \mathrm{c}(\mathrm{Cl}) \mathrm{cc} 3 \mathrm{~F}) \mathrm{ncnc} 2 \mathrm{cc} 1 \mathrm{OCC} 1 \mathrm{CCN}(\mathrm{C}) \mathrm{CC} 1 . \mathrm{Cl}$ & 100 & $*$ \\
\hline 2290 & $\mathrm{COc} 1 \mathrm{cc} 2 \mathrm{c}(\mathrm{Nc} 3 \mathrm{ccc}(\mathrm{Cl}) \mathrm{cc} 3 \mathrm{~F}) \mathrm{ncn} 2 \mathrm{cc} 1 \mathrm{OCCCN} 1 \mathrm{CCCC} 1 . \mathrm{Cl}$ & 100 & $*$ \\
\hline 2291 & $\mathrm{COc} 1 \mathrm{cc} 2 \mathrm{c}(\mathrm{Nc} 3 \mathrm{ccc}(\mathrm{Br}) \mathrm{cc} 3 \mathrm{~F}) \mathrm{ncnc} 2 \mathrm{cc} 1 \mathrm{OC} / \mathrm{C}=\mathrm{C} / \mathrm{CN} 1 \mathrm{CCCC} 1 . \mathrm{Cl}$ & 100 & $*$ \\
\hline
\end{tabular}




\begin{tabular}{|c|c|c|c|}
\hline 2292 & $\mathrm{COCCOc} 1 \mathrm{cc} 2 \mathrm{ncnc}(\mathrm{Nc} 3 \mathrm{ccc}(\mathrm{Cl}) \mathrm{cc} 3 \mathrm{~F}) \mathrm{c} 2 \mathrm{cc} 1 \mathrm{OC}$ & 100 & $*$ \\
\hline 2293 & $\mathrm{COc} 1 \mathrm{cc} 2 \mathrm{c}(\mathrm{Nc} 3 \mathrm{ccc}(\mathrm{Br}) \mathrm{cc} 3 \mathrm{~F}) \mathrm{ncnc} 2 \mathrm{cc} 1 \mathrm{OCCCN} 1 \mathrm{CCN}(\mathrm{C}) \mathrm{CC} 1 . \mathrm{Cl}$ & 100 & $*$ \\
\hline 2294 & $\mathrm{Cc} 1 \mathrm{ccn} 2 \mathrm{ncnc}(\mathrm{Nc} 3 \mathrm{ccc}(\mathrm{F}) \mathrm{c}(\mathrm{Cl}) \mathrm{c} 3) \mathrm{c} 12$ & 100 & $*$ \\
\hline 2295 & $\mathrm{CN}(\mathrm{C}) \mathrm{C} 1 \mathrm{CCN}(\mathrm{Cc} 2 \mathrm{ccn} 3 \mathrm{ncnc}(\mathrm{Nc} 4 \mathrm{ccc} 5 \mathrm{c}(\mathrm{cnn} 5 \mathrm{Cc} 5 \mathrm{cccc}(\mathrm{F}) \mathrm{c} 5) \mathrm{c} 4) \mathrm{c} 23) \mathrm{CC} 1$ & 100 & $*$ \\
\hline 2296 & $\mathrm{CN}=\mathrm{NNc} 1 \mathrm{ccc} 2 \mathrm{ncnc}(\mathrm{Nc} 3 \mathrm{ccc}(\mathrm{Cl}) \mathrm{c} 3) \mathrm{c} 2 \mathrm{c} 1$ & 100 & $*$ \\
\hline 2297 & $\mathrm{Cc} 1 \mathrm{cc} 2 \mathrm{cc}(\mathrm{Nc} 3 \mathrm{ncnc} 4 \mathrm{cc}(-\mathrm{c} 5 \mathrm{ccccc} 5) \operatorname{sc} 34) \mathrm{ccc} 2[\mathrm{nH}] 1$ & 100 & $*$ \\
\hline 2298 & $\mathrm{C} / \mathrm{C}=\mathrm{C} \backslash \mathrm{C}(=\mathrm{O}) \mathrm{Nc} 1 \mathrm{cccc}(\mathrm{Nc} 2 \mathrm{ncnc} 3 \mathrm{cc}(\mathrm{OC}) \mathrm{c}(\mathrm{OCCCN} 4 \mathrm{CCOCC} 4) \mathrm{cc} 23) \mathrm{c} 1$ & 100 & $*$ \\
\hline 2299 & $\operatorname{COc} 1 \operatorname{ccc}(\mathrm{Nc} 2 \mathrm{ncnc} 3 \mathrm{oc}(-\mathrm{c} 4 \mathrm{ccc}([\mathrm{N}+](=\mathrm{O})[\mathrm{O}-]) \operatorname{cc} 4) \operatorname{cc} 23) \operatorname{cc} 1 \mathrm{O}$ & 100 & $*$ \\
\hline 2300 & $\mathrm{OCCN}(\mathrm{CCO}) \mathrm{N}(\mathrm{CCC} 1 \mathrm{CO} 2 \mathrm{cc} 3 \mathrm{ncnc}(\mathrm{Nc} 4 \mathrm{cccc}(\mathrm{Br}) \mathrm{c} 4) \mathrm{c} 3 \mathrm{cc} 2 \mathrm{O} 1) \mathrm{N}(\mathrm{CCO}) \mathrm{CCO}$ & 100 & $*$ \\
\hline 2301 & $\mathrm{C}=\mathrm{CC}(=\mathrm{O}) \mathrm{Nc} 1 \mathrm{cc} 2 \mathrm{c}(\mathrm{Nc} 3 \mathrm{ccc}(\mathrm{OCc} 4 \mathrm{ccc} n 4) \mathrm{cc} 3) \mathrm{ncnc} 2 \mathrm{cc} 1 \mathrm{O}[\mathrm{C} @ \mathrm{H}] 1 \mathrm{CCOC} 1$ & 100.1 & $*$ \\
\hline 2302 & $\begin{array}{c}\mathrm{C}=\mathrm{CC}(=\mathrm{O}) \mathrm{Nc} 1 \mathrm{cccc}(\mathrm{Oc} 2 \mathrm{nc}(\mathrm{Nc} 3 \operatorname{ccc}(\mathrm{N} 4 \mathrm{CCN}(\mathrm{CC}(=\mathrm{O}) \mathrm{OCCOCCOc} 5 \mathrm{no}[\mathrm{n}+]([\mathrm{O}-]) \mathrm{c} 5 \mathrm{~S}(=\mathrm{O})(=\mathrm{O}) \mathrm{c} 5 \mathrm{ccccc} 5) \mathrm{CC} 4) \mathrm{cc} 3 \\
\mathrm{OC}) \mathrm{ncc} 2 \mathrm{Cl}) \mathrm{c} 1\end{array}$ & 101 & 7.00 \\
\hline 2303 & $\mathrm{C}=\mathrm{CC}(=\mathrm{O}) \mathrm{Nc} 1 \mathrm{cc} 2 \mathrm{c}(\mathrm{Nc} 3 \mathrm{ccc}(\mathrm{OCc} 4 \mathrm{ccc}(\mathrm{F}) \mathrm{c} 4) \mathrm{c}(\mathrm{Cl}) \mathrm{c} 3) \mathrm{ncnc} 2 \mathrm{cc} 1 \mathrm{OCCOC}$ & 102.2 & $*$ \\
\hline 2304 & $\operatorname{COCCOc} 1 \mathrm{cc} 2 \mathrm{ncnc}(\mathrm{Nc} 3 \operatorname{ccc}(\mathrm{NC}(=\mathrm{O}) / \mathrm{C}=\mathrm{C} / \mathrm{CN}(\mathrm{C}) \mathrm{C}) \mathrm{c}(\mathrm{C}(\mathrm{F})(\mathrm{F}) \mathrm{F}) \mathrm{c} 3) \mathrm{c} 2 \mathrm{cc} 1 \mathrm{NC}(=\mathrm{O}) / \mathrm{C}=\mathrm{C} / \mathrm{CN}(\mathrm{C}) \mathrm{C}$ & 102.3 & $*$ \\
\hline 2305 & $\mathrm{CC}(\mathrm{C}) \mathrm{Oc} 1 \mathrm{cc} 2 \mathrm{ncnc}(\mathrm{Nc} 3 \mathrm{ccc}(\mathrm{Cl}) \mathrm{c}([\mathrm{N}+](=\mathrm{O})[\mathrm{O}-]) \mathrm{c} 3) \mathrm{c} 2 \mathrm{c} 2 \mathrm{c} 1 \mathrm{OCCO} 2$ & 102.6 & $*$ \\
\hline 2306 & $\operatorname{COc} 1 \operatorname{ccc}(-\mathrm{c} 2 \operatorname{ccc}(\mathrm{OC}(\mathrm{F})(\mathrm{F}) \mathrm{F}) \mathrm{c}(\mathrm{NC}(=\mathrm{O}) \mathrm{Nc} 3 \operatorname{ccncc} 3) \mathrm{c} 2) \mathrm{cn} 1$ & 102.93 & $*$ \\
\hline 2307 & $\mathrm{CS}(=\mathrm{O})(=\mathrm{O}) \mathrm{CCNCCCOc} 1 \mathrm{ccc} 2 \mathrm{ncnc}(\mathrm{Nc} 3 \operatorname{ccc}(\mathrm{OCc} 4 \mathrm{ccccc} 4) \mathrm{cc} 3) \mathrm{c} 2 \mathrm{c} 1$ & 104 & $*$ \\
\hline 2308 & $\mathrm{CO} / \mathrm{N}=\mathrm{C} / \mathrm{c} 1 \mathrm{c}(\mathrm{N}) \mathrm{ncnc} 1 \mathrm{Nc} 1 \mathrm{ccc} 2 \mathrm{c}(\mathrm{cnn} 2 \mathrm{Cc} 2 \mathrm{ccc}(\mathrm{F}) \mathrm{cc} 2) \mathrm{c} 1$ & 104 & $*$ \\
\hline 2309 & $\mathrm{C}=\mathrm{CC}(=\mathrm{O}) \mathrm{Nc} 1 \mathrm{cc} 2 \mathrm{c}(\mathrm{Nc} 3 \mathrm{ccc}(\mathrm{Cl}) \mathrm{c}(\mathrm{C}(\mathrm{F})(\mathrm{F}) \mathrm{F}) \mathrm{c} 3) \mathrm{ncn} 2 \mathrm{cc} 1 \mathrm{O}[\mathrm{C} @ \mathrm{H}] 1 \mathrm{CCOC} 1$ & 104.7 & $*$ \\
\hline 2310 & $\mathrm{Nc} 1 \mathrm{cccc} 2 \mathrm{c}(\mathrm{Nc} 3 \mathrm{cccc}(\mathrm{Br}) \mathrm{c} 3) \mathrm{ncnc} 12$ & 105 & $*$ \\
\hline 2311 & $\mathrm{CCCCOc} 1 \mathrm{cc} 2 \mathrm{ncnc}(\mathrm{Nc} 3 \mathrm{ccc}(\mathrm{Br}) \mathrm{c} 3) \mathrm{c} 2 \mathrm{cc} 1 \mathrm{OCCCC}$ & 105 & $*$ \\
\hline 2312 & $\mathrm{C} / \mathrm{C}=\mathrm{C} \backslash \mathrm{C}(=\mathrm{O}) \mathrm{Nc} 1 \mathrm{ccccc} 1 \mathrm{Nc} 1 \mathrm{ncnc} 2 \mathrm{cc}(\mathrm{OC}) \mathrm{c}(\mathrm{OCCCN} 3 \mathrm{CCOCC} 3) \mathrm{cc} 12$ & 105 & $*$ \\
\hline 2313 & COc1ccc(-c2cc3c(N[C@H](C)c4ccccc4OC)ncnc3[nH]2)cc1 & 105 & $*$ \\
\hline 2314 & $\mathrm{COc} 1 \mathrm{cc} 2 \mathrm{ncnc}(\mathrm{Nc} 3 \mathrm{cc}(\mathrm{Cl}) \mathrm{ccc} 3 \mathrm{~F}) \mathrm{c} 2 \mathrm{cc} 1 \mathrm{OC} 1 \mathrm{CCN}(\mathrm{C}) \mathrm{CC} 1$ & 106 & $*$ \\
\hline 2315 & $\mathrm{CCCCCCOc} 1 \mathrm{cc} 2 \mathrm{c}(\mathrm{Nc} 3 \mathrm{ccc}(\mathrm{F}) \mathrm{c}(\mathrm{Cl}) \mathrm{c} 3) \mathrm{ncnc} 2 \mathrm{cc} 1 \mathrm{OC}$ & 106 & $*$ \\
\hline 2316 & $\mathrm{O}=\mathrm{C}(/ \mathrm{C}=\mathrm{C} / \mathrm{CN} 1 \mathrm{CCCCC} 1) \mathrm{Nc} 1 \mathrm{ccc} 2 \mathrm{ncnc}(\mathrm{Nc} 3 \operatorname{ccc}(\mathrm{Br}) \mathrm{c} 3) \mathrm{c} 2 \mathrm{c} 1$ & 106 & $*$ \\
\hline 2317 & $\mathrm{C}=\mathrm{CC}(=\mathrm{O}) \mathrm{Nc} 1 \mathrm{cc}(\mathrm{Nc} 2 \mathrm{ncc}(\mathrm{F}) \mathrm{c}(\mathrm{Nc} 3 \operatorname{cccc} 3 \mathrm{P}(\mathrm{C})(\mathrm{C})=\mathrm{O}) \mathrm{n} 2) \mathrm{c}(\mathrm{OC}) \mathrm{cc} 1 \mathrm{~N}(\mathrm{C}) \mathrm{CCN}(\mathrm{C}) \mathrm{C}$ & 106 & $*$ \\
\hline 2318 & $\mathrm{C}=\mathrm{C}(\mathrm{CN} 1 \mathrm{CCOCC} 1) \mathrm{C}(=\mathrm{O}) \mathrm{Nc} 1 \mathrm{ccc} 2 \mathrm{ncnc}(\mathrm{Nc} 3 \operatorname{cccc}(\mathrm{Br}) \mathrm{c} 3) \mathrm{c} 2 \mathrm{c} 1$ & 107 & $*$ \\
\hline 2319 & $\mathrm{CC}(=\mathrm{O}) \mathrm{Nc} 1 \mathrm{cccc}(\mathrm{Oc} 2 \mathrm{cc}(\mathrm{Nc} 3 \operatorname{ccc}(\mathrm{OCc} 4 \operatorname{ccc}(\mathrm{F}) \mathrm{c} 4) \mathrm{c}(\mathrm{Cl}) \mathrm{c} 3) \mathrm{ncn} 2) \mathrm{c} 1$ & 108 & 6.97 \\
\hline 2320 & COc1 $1 \mathrm{cccc} 1-\mathrm{c} 1 \mathrm{cc} 2 \mathrm{c}(\mathrm{NCc} 3 \mathrm{ccncc} 3) \mathrm{ncnc} 2 \mathrm{~s} 1$ & 108 & $*$ \\
\hline 2321 & $\mathrm{C}=\mathrm{CC}(=\mathrm{O}) \mathrm{Nc} 1 \mathrm{cc}(\mathrm{Nc} 2 \mathrm{nccc}(\mathrm{NC}(=\mathrm{O}) \mathrm{c} 3 \operatorname{ccc}(\mathrm{C}(\mathrm{F})(\mathrm{F}) \mathrm{F}) \mathrm{cc} 3) \mathrm{n} 2) \mathrm{c}(\mathrm{OC}) \mathrm{cc} 1 \mathrm{~N}(\mathrm{C}) \mathrm{CCN}(\mathrm{C}) \mathrm{C}$ & 108.7 & $*$ \\
\hline 2322 & Fc1ecce(COc2cec(Nc3ncnc4sc(C\#CC5CCCN5)cc34)cc2Cl)c1 & 109 & $*$ \\
\hline 2323 & Fc1cccc(COc2ccc(Nc3ncnc4cc(C\#C[C@@H]5CCCN5)sc34)cc2Cl)c1 & 109 & $*$ \\
\hline 2324 & N\#CCCSc1nc(-c2ecc(F)cc2)c(-c2cenc(Nc3eccec3)c2)[nH]1 & 109 & $*$ \\
\hline 2325 & Fc1 $1 \mathrm{ccc}(\mathrm{COc} 2 \mathrm{ccc}(\mathrm{Nc} 3 \mathrm{ncnc} 4 \mathrm{sc}(\mathrm{C} \# \mathrm{C}[\mathrm{C} @ \mathrm{H}] 5 \mathrm{CCCN} 5) \mathrm{cc} 34) \mathrm{cc} 2 \mathrm{Cl}) \mathrm{c} 1$ & 109 & $*$ \\
\hline 2326 & $\mathrm{O}=\mathrm{C}(/ \mathrm{C}=\mathrm{C} / \mathrm{CN} 1 \mathrm{CC}[\mathrm{S}+]([\mathrm{O}-]) \mathrm{CC} 1) \mathrm{Nc} 1 \mathrm{cc} 2 \mathrm{c}(\mathrm{Nc} 3 \mathrm{ccc}(\mathrm{F}) \mathrm{c}(\mathrm{Cl}) \mathrm{c} 3) \operatorname{ncnc} 2 \mathrm{cc} 1 \mathrm{O}[\mathrm{C} @ \mathrm{H}] 1 \mathrm{CCOC} 1$ & 109.4 & $*$ \\
\hline 2327 & $\mathrm{Clc} 1 \mathrm{ccc}(\mathrm{C} 2=\mathrm{NN}(\mathrm{c} 3 \operatorname{cccc} 3) \mathrm{C}(\mathrm{c} 3 \operatorname{ccc} 4 \operatorname{ccccc} 4 \mathrm{c} 3) \mathrm{C} 2) \mathrm{cc} 1$ & 110 & 6.96 \\
\hline 2328 & $\mathrm{CCOc} 1 \mathrm{cc} 2 \mathrm{ncc}(\mathrm{C \# N}) \mathrm{c}(\mathrm{Nc} 3 \operatorname{ccc}(\mathrm{OCc} 4 \mathrm{ccc}(\mathrm{F}) \mathrm{cc} 4 \mathrm{~F}) \mathrm{c}(\mathrm{Cl}) \mathrm{c} 3) \mathrm{c} 2 \mathrm{cc} 1 \mathrm{NC}(=\mathrm{O}) / \mathrm{C}=\mathrm{C} / \mathrm{CN}(\mathrm{C}) \mathrm{C}$ & 110 & 6.96 \\
\hline 2329 & $\mathrm{CS}(=\mathrm{O})(=\mathrm{O}) \mathrm{Nc} 1 \mathrm{cccc}(\mathrm{C} \# \mathrm{Cc} 2 \mathrm{cncnc} 2 \mathrm{Nc} 2 \operatorname{ccc}(\mathrm{OCc} 3 \operatorname{ccc}(\mathrm{F}) \mathrm{c} 3) \mathrm{c}(\mathrm{Cl}) \mathrm{c} 2) \mathrm{c} 1$ & 110 & $*$ \\
\hline 2330 & $\mathrm{COC}(=\mathrm{O}) \mathrm{C} 1=\mathrm{Cc} 2 \mathrm{c}(\mathrm{ncnc} 2 \mathrm{Nc} 2 \operatorname{ccc}(\mathrm{Oc} 3 \operatorname{cccc}(\mathrm{C}(\mathrm{F})(\mathrm{F}) \mathrm{F}) \mathrm{c} 3) \mathrm{c}(\mathrm{Cl}) \mathrm{c} 2) \mathrm{NCC} 1$ & 110 & * \\
\hline 2331 & $\mathrm{O}=\mathrm{C}(\mathrm{Oc} 1 \mathrm{cccc} 2 \mathrm{cccc} 12) \mathrm{c} 1 \mathrm{cc}(\mathrm{NCc} 2 \mathrm{cc}(\mathrm{O}) \mathrm{ccc} 2 \mathrm{O}) \mathrm{ccc} 1 \mathrm{O}$ & 110 & $*$ \\
\hline 2332 & $\mathrm{Cc} 1 \mathrm{ccc}(\mathrm{Nc} 2[\mathrm{nH}] \mathrm{cnc} 3 \mathrm{nc} 4 \mathrm{c}(\mathrm{c} 2-3) \mathrm{CCCC} 4) \mathrm{cc} 1$ & 110 & $*$ \\
\hline 2333 & $\mathrm{O}=\mathrm{C}(\mathrm{CO}) \mathrm{NC} 1 \mathrm{CCN}(\mathrm{Cc} 2 \mathrm{ccn} 3 \mathrm{ncnc}(\mathrm{Nc} 4 \mathrm{ccc} 5 \mathrm{c}(\operatorname{cnn} 5 \mathrm{Cc} 5 \mathrm{cccc}(\mathrm{F}) \mathrm{c} 5) \mathrm{c} 4) \mathrm{c} 23) \mathrm{CC} 1$ & 110 & $*$ \\
\hline
\end{tabular}




\begin{tabular}{|c|c|c|c|}
\hline 2334 & Fc1 $1 \mathrm{ccc}(\mathrm{Cn} 2 \mathrm{ncc} 3 \mathrm{cc}(\mathrm{Ne} 4 \mathrm{ncnn} 5 \mathrm{ccc}(\mathrm{CNC} 6 \mathrm{CCNCC} 6) \mathrm{c} 45) \operatorname{ccc} 32) \mathrm{c} 1$ & 110 & $*$ \\
\hline 2335 & $\mathrm{CN}(\mathrm{CCO}) \mathrm{Cc} 1 \mathrm{ccn} 2 \mathrm{ncnc}(\mathrm{Nc} 3 \mathrm{ccc} 4 \mathrm{c}(\mathrm{cnn} 4 \mathrm{Cc} 4 \mathrm{cccc}(\mathrm{F}) \mathrm{c} 4) \mathrm{c} 3) \mathrm{c} 12$ & 110 & $*$ \\
\hline 2336 & $\mathrm{NS}(=\mathrm{O})(=\mathrm{O}) \mathrm{c} 1 \mathrm{ccc}(-\mathrm{n} 2 \mathrm{c}(\mathrm{SCC}(=\mathrm{O}) \mathrm{Nc} 3 \operatorname{cnc} 4 \mathrm{cccc} 4 \mathrm{c} 3) \mathrm{nc} 3 \operatorname{cc} 4 \operatorname{ccc} c \mathrm{cc} 3 \mathrm{c} 2=\mathrm{O}) \mathrm{cc} 1$ & 110 & * \\
\hline 2337 & $\mathrm{COc} 1 \mathrm{cc} 2 \mathrm{c}(\mathrm{Nc} 3 \mathrm{ccc}(\mathrm{NC}(=\mathrm{O}) \mathrm{c} 4 \mathrm{ccccc} 4) \mathrm{cc} 3) \mathrm{ncn} 2 \mathrm{cc} 1 \mathrm{OCCCN} 1 \mathrm{CCOCC} 1$ & 110 & $*$ \\
\hline 2338 & $\mathrm{CN}(\mathrm{CO}) / \mathrm{N}=\mathrm{N} / \mathrm{c} 1 \mathrm{ccc} 2 \mathrm{ncnc}(\mathrm{Nc} 3 \mathrm{ccc}(\mathrm{Br}) \mathrm{c} 3) \mathrm{c} 2 \mathrm{c} 1$ & 110 & * \\
\hline 2339 & Clc1 $1 \mathrm{c}(\mathrm{Nc} 2 \mathrm{ncnc} 3 \mathrm{cc}[\mathrm{nH}] \mathrm{c} 23) \mathrm{ccc} 1 \mathrm{Oc} 1 \mathrm{cccc} 1$ & 110 & $*$ \\
\hline 2340 & OCCn1 $1 \mathrm{cc} 2 \mathrm{ncnc}(\mathrm{Nc} 3 \mathrm{ccc}(\mathrm{Oc} 4 \mathrm{cccc}(\mathrm{OC}(\mathrm{F})(\mathrm{F}) \mathrm{F}) \mathrm{c} 4) \mathrm{c}(\mathrm{Cl}) \mathrm{c} 3) \mathrm{c} 21$ & 110 & * \\
\hline 2341 & $\mathrm{CCCCCCC}(=\mathrm{O}) \mathrm{ON}[\mathrm{C} @ \mathrm{H}](\mathrm{CS}(\mathrm{C})(=\mathrm{O})=\mathrm{O}) \mathrm{c} 1 \mathrm{ccc}(-\mathrm{c} 2 \mathrm{ccc} 3 \mathrm{ncnc}(\mathrm{Nc} 4 \mathrm{ccc}(\mathrm{OCc} 5 \mathrm{cccc}(\mathrm{F}) \mathrm{c} 5) \mathrm{c}(\mathrm{Cl}) \mathrm{c} 4) \mathrm{c} 3 \mathrm{c} 2) \mathrm{o} 1$ & 110.2 & * \\
\hline 2342 & $\mathrm{c} 1 \mathrm{ccc}(\mathrm{Oc} 2 \mathrm{ccc}(\mathrm{Nc} 3 \mathrm{ncnc} 4[\mathrm{nH}] \mathrm{ccc} 34) \mathrm{cc} 2) \mathrm{cc} 1$ & 110.97 & $*$ \\
\hline 2343 & $\mathrm{CCOc} 1 \mathrm{cc} 2 \mathrm{ncc}(\mathrm{CHN}) \mathrm{c}(\mathrm{Nc} 3 \operatorname{ccc}(\mathrm{OCc} 4 \operatorname{ccc}(\mathrm{C}) \mathrm{c} 4) \mathrm{c}(\mathrm{Cl}) \mathrm{c} 3) \mathrm{c} 2 \mathrm{cc} 1 \mathrm{NC}(=\mathrm{O}) / \mathrm{C}=\mathrm{C} / \mathrm{CN}(\mathrm{C}) \mathrm{C}$ & 111 & 6.95 \\
\hline 2344 & $\mathrm{C}=\mathrm{CC}(=\mathrm{O}) \mathrm{Nc} 1 \mathrm{cccc}(-\mathrm{n} 2 \mathrm{c}(=\mathrm{O}) \mathrm{n}(\mathrm{CC}) \mathrm{c}(=\mathrm{O}) \mathrm{c} 3 \mathrm{cnc}(\mathrm{Nc} 4 \mathrm{ccc}(\mathrm{N} 5 \mathrm{CCC}(\mathrm{N}(\mathrm{C}) \mathrm{C}) \mathrm{CC} 5) \mathrm{cc} 4 \mathrm{OC}) \mathrm{nc} 32) \mathrm{c} 1$ & 111 & * \\
\hline 2345 & Fc1 $1 \mathrm{ccc}(-\mathrm{c} 2 \mathrm{nc}(\mathrm{Nc} 3 \mathrm{cc}(\mathrm{Br}) \mathrm{cc} 4 \mathrm{cc}(-\mathrm{c} 5 \mathrm{ccccc} 5) \mathrm{oc} 34) \mathrm{c} 3 \mathrm{cc}(\mathrm{Br}) \mathrm{ccc} 3 \mathrm{n} 2) \mathrm{cc} 1$ & 111.3 & * \\
\hline 2346 & $\mathrm{O}=\mathrm{C}(\mathrm{Nc} 1 \mathrm{ccc}(-\mathrm{c} 2 \mathrm{cc} 3 \mathrm{c}(\mathrm{Nc} 4 \mathrm{ccc}(\mathrm{Oc} 5 \mathrm{ccc}(\mathrm{C}(\mathrm{F})(\mathrm{F}) \mathrm{F}) \mathrm{c} 5) \mathrm{c}(\mathrm{Cl}) \mathrm{c} 4) \mathrm{ncnc} 3 \mathrm{~s} 2) \mathrm{cc} 1) \mathrm{NC} 1 \mathrm{CC} 1$ & 112 & $*$ \\
\hline 2347 & $\mathrm{COc} 1 \mathrm{cc} 2 \mathrm{c}(\mathrm{Nc} 3 \mathrm{ccc}(\mathrm{Br}) \mathrm{cc} 3 \mathrm{~F}) \mathrm{ncnc} 2 \mathrm{cc} 1 \mathrm{OCC} 1 \mathrm{CCN}(\mathrm{C}) \mathrm{CC} 1$ & 112.4 & 6.95 \\
\hline 2348 & $\mathrm{Fc} 1 \mathrm{c}(\mathrm{NC}(=\mathrm{S}) \mathrm{Nc} 2 \mathrm{ccc} 3 \mathrm{ncnc}(\mathrm{Nc} 4 \mathrm{cccc}(\mathrm{Br}) \mathrm{c} 4) \mathrm{c} 3 \mathrm{c} 2) \operatorname{ccc} 1 \mathrm{C}(\mathrm{F})(\mathrm{F}) \mathrm{F}$ & 112.4 & $*$ \\
\hline 2349 & COc1cc2ncnc(Nc3ec(Br)ce(Br)c3)c2cc1OC & 113 & * \\
\hline 2350 & $\mathrm{Nc} 1 \mathrm{c}(-\mathrm{c} 2 \mathrm{ccc}(\mathrm{F}) \mathrm{cc} 2) \mathrm{c}(-\mathrm{c} 2 \mathrm{ccncc} 2) \mathrm{nn} 1-\mathrm{c} 1 \mathrm{c}(\mathrm{Cl}) \mathrm{cc}(\mathrm{Cl}) \mathrm{cc} 1 \mathrm{Cl}$ & 113 & $*$ \\
\hline 2351 & $\mathrm{Cc} 1 \mathrm{ncnc}(\mathrm{Nc} 2 \mathrm{ccc}(\mathrm{OCc} 3 \operatorname{ccc}(\mathrm{F}) \mathrm{c} 3) \mathrm{c}(\mathrm{Cl}) \mathrm{c} 2) \mathrm{c} 1 / \mathrm{C}=\mathrm{C} / \mathrm{C}(=\mathrm{O}) \mathrm{NCCN} 1 \mathrm{CCOCC} 1$ & 114 & 6.94 \\
\hline 2352 & $\mathrm{COCCN} 1 \mathrm{CCC}(\mathrm{Oc} 2 \mathrm{cc} 3 \mathrm{c}(\mathrm{Nc} 4 \mathrm{cc}(\mathrm{Cl}) \mathrm{ccc} 4 \mathrm{~F}) \mathrm{ncnc} 3 \mathrm{cc} 2 \mathrm{OC}) \mathrm{CC} 1$ & 114 & $*$ \\
\hline 2353 & $\mathrm{C}=\mathrm{CC}(=\mathrm{O}) \mathrm{Nc} 1 \mathrm{cccc}(-\mathrm{n} 2 \mathrm{c}(=\mathrm{O}) \mathrm{cc}(\mathrm{CC}) \mathrm{c} 3 \mathrm{cnc}(\mathrm{Nc} 4 \mathrm{ccc}(\mathrm{N} 5 \mathrm{CCN}(\mathrm{C}) \mathrm{CC} 5) \mathrm{cc} 4 \mathrm{OC}) \mathrm{nc} 32) \mathrm{c} 1$ & 114 & * \\
\hline 2354 & OCCCC\#Cc1 cec2ncnc(Nc3ecc(F)c(Cl)c3)c2c1 & 114.2 & * \\
\hline 2355 & $\mathrm{CN}(\mathrm{C}) \mathrm{C} / \mathrm{C}=\mathrm{C} / \mathrm{C}(=\mathrm{O}) \mathrm{Nc} 1 \mathrm{cccc}(-\mathrm{n} 2 \mathrm{c}(=\mathrm{O}) \mathrm{cnc} 3 \mathrm{cnc}(\mathrm{Nc} 4 \mathrm{ccccc} 4) \mathrm{nc} 32) \mathrm{c} 1$ & 115 & 6.94 \\
\hline 2356 & $\mathrm{Fc} 1 \mathrm{cccc}(\mathrm{COc} 2 \mathrm{ccc}(\mathrm{Nc} 3 \mathrm{ncnc} 4 \mathrm{sc}(-\mathrm{c} 5 \mathrm{ccc}[\mathrm{nH}] 5) \mathrm{cc} 34) \mathrm{cc} 2 \mathrm{Cl}) \mathrm{c} 1$ & 115 & $*$ \\
\hline 2357 & $\mathrm{CCO}[\mathrm{C} @ \mathrm{H}] 1 \mathrm{CN}[\mathrm{C} @ \mathrm{H}](\mathrm{C} \# \mathrm{Cc} 2 \mathrm{cc} 3 \mathrm{ncnc}(\mathrm{Nc} 4 \mathrm{ccc}(\mathrm{OCc} 5 \mathrm{cccc}(\mathrm{F}) \mathrm{c} 5) \mathrm{c}(\mathrm{Cl}) \mathrm{c} 4) \mathrm{c} 3 \mathrm{~s} 2) \mathrm{C} 1$ & 115 & * \\
\hline 2358 & $\mathrm{CN} 1 \mathrm{CCC}=\mathrm{C}(\mathrm{C}(=\mathrm{O}) \mathrm{Nc} 2 \mathrm{ccc} 3 \mathrm{ncnc}(\mathrm{Nc} 4 \mathrm{cccc}(\mathrm{Br}) \mathrm{c} 4) \mathrm{c} 3 \mathrm{c} 2) \mathrm{C} 1$ & 115 & * \\
\hline 2359 & $\mathrm{C}=\mathrm{CC}(=\mathrm{O}) \mathrm{Nc} 1 \mathrm{cc} 2 \mathrm{c}(\mathrm{Nc} 3 \mathrm{ccc}(\mathrm{NC}(=\mathrm{O}) \mathrm{C}=\mathrm{C}) \mathrm{c}(\mathrm{C}(\mathrm{F})(\mathrm{F}) \mathrm{F}) \mathrm{c} 3) \mathrm{ncnc} 2 \mathrm{cc} 1 \mathrm{OCCOC}$ & 115.1 & $*$ \\
\hline 2360 & $\mathrm{O}=\mathrm{C} 1 \mathrm{COc} 2 \mathrm{cc} 3 \mathrm{ncnc}(\mathrm{Nc} 4 \mathrm{cccc}(\mathrm{Cl}) \mathrm{c} 4) \mathrm{c} 3 \mathrm{cc} 2 \mathrm{~N} 1 \mathrm{CCCN} 1 \mathrm{CCCCC} 1$ & 115.9 & * \\
\hline 2361 & $\mathrm{CCC}(=\mathrm{O}) \mathrm{Nc} 1 \mathrm{cc} 2 \mathrm{c}(\mathrm{Nc} 3 \operatorname{ccc}(\mathrm{OCc} 4 \mathrm{ccc} \operatorname{cn} 4) \mathrm{cc} 3) \mathrm{ncnc} 2 \mathrm{cc} 1 \mathrm{OC}$ & 116 & $*$ \\
\hline 2362 & $\mathrm{Cc} 1 \mathrm{nc}(\mathrm{Nc} 2 \mathrm{cccc}(\mathrm{Br}) \mathrm{c} 2) \mathrm{c} 2 \mathrm{cc}(\mathrm{NCCN} 3 \mathrm{CCOCC} 3) \mathrm{ncc} 2 \mathrm{n} 1$ & 117 & $*$ \\
\hline 2363 & Fc1 $1 \mathrm{cc}(\mathrm{Nc} 2 \mathrm{ncnn} 3 \mathrm{ccc} 23) \mathrm{cc} 1 \mathrm{Cl}$ & 118 & $*$ \\
\hline 2364 & $\mathrm{C}=\mathrm{CC}(=\mathrm{O}) \mathrm{Nc} 1 \mathrm{cccc}(-\mathrm{n} 2 \mathrm{c}(=\mathrm{O}) \mathrm{n}(\mathrm{C}(\mathrm{C}) \mathrm{C}) \mathrm{c}(=\mathrm{O}) \mathrm{c} 3 \mathrm{cnc}(\mathrm{Nc} 4 \mathrm{ccc}(\mathrm{N} 5 \mathrm{CCN}(\mathrm{C}) \mathrm{CC} 5) \mathrm{c}(\mathrm{OC}) \mathrm{c} 4) \mathrm{nc} 32) \mathrm{c} 1$ & 119 & $*$ \\
\hline 2365 & $\mathrm{COc} 1 \mathrm{ccc}(\mathrm{C} 2=\mathrm{NN}(\mathrm{c} 3 \operatorname{cccc} 3) \mathrm{C}(\mathrm{c} 3 \operatorname{ccc} 4 \operatorname{ccccc} 4 \mathrm{c} 3) \mathrm{C} 2) \mathrm{cc} 1$ & 120 & 6.92 \\
\hline 2366 & $\operatorname{COc} 1 \operatorname{ccc}(\mathrm{Oc} 2 \mathrm{nc} 3 \operatorname{ccc}(\mathrm{C}) \mathrm{cc} 3 \mathrm{cc} 2 / \mathrm{C}=\mathrm{N} / \mathrm{NC}(=\mathrm{O}) \mathrm{Cn} 2 \mathrm{c}([\mathrm{N}+](=\mathrm{O})[\mathrm{O}-]) \mathrm{cnc} 2 \mathrm{C}) \mathrm{cc} 1$ & 120 & 6.92 \\
\hline 2367 & $\mathrm{CNc} 1 \mathrm{ncc}(\mathrm{C}(=\mathrm{O}) \mathrm{Nc} 2 \mathrm{cc}(\mathrm{C}(=\mathrm{O}) \mathrm{Nc} 3 \operatorname{ccc}(\mathrm{CN} 4 \mathrm{CCN}(\mathrm{C}) \mathrm{CC} 4) \mathrm{c}(\mathrm{C}(\mathrm{F})(\mathrm{F}) \mathrm{F}) \mathrm{c} 3) \operatorname{ccc} 2 \mathrm{C}) \mathrm{cn} 1$ & 120 & 6.92 \\
\hline 2368 & $\mathrm{Cc} 1 \mathrm{ccc}(\mathrm{C} 2=\mathrm{NN}(\mathrm{C} 3=\mathrm{NC}(=\mathrm{O}) \mathrm{CS} 3) \mathrm{C}(\mathrm{c} 3 \operatorname{ccc} 4 \operatorname{ccccc} 4 \mathrm{c} 3) \mathrm{C} 2) \operatorname{cc} 1 \mathrm{C}$ & 120 & 6.92 \\
\hline 2369 & $\mathrm{Oc} 1 \mathrm{ccc}(\mathrm{CN}(\mathrm{Cc} 2 \operatorname{ccc}(\mathrm{Br}) \mathrm{c} 2 \mathrm{O}) \mathrm{C}(=\mathrm{S}) \mathrm{Nc} 2 \mathrm{cccc} 2) \mathrm{cc} 1$ & 120 & 6.92 \\
\hline 2370 & $\mathrm{Cc} 1 \mathrm{ncnc}(\mathrm{Nc} 2 \mathrm{ccc}(\mathrm{OCc} 3 \operatorname{cccc}(\mathrm{F}) \mathrm{c} 3) \mathrm{c}(\mathrm{Cl}) \mathrm{c} 2) \mathrm{c} 1 / \mathrm{C}=\mathrm{C} / \mathrm{c} 1 \mathrm{ccc}(\mathrm{CN} 2 \mathrm{CCOCC} 2) \mathrm{cc} 1$ & 120 & 6.92 \\
\hline 2371 & $\mathrm{O}=\mathrm{C}(/ \mathrm{C}=\mathrm{C} / \mathrm{c} 1 \operatorname{cccc}([\mathrm{N}+](=\mathrm{O})[\mathrm{O}-]) \mathrm{c} 1) \mathrm{Nc} 1 \mathrm{ccc} 2 \mathrm{ncnc}(\mathrm{Nc} 3 \operatorname{cccc}(\mathrm{Br}) \mathrm{c} 3) \mathrm{c} 2 \mathrm{c} 1$ & 120 & 6.92 \\
\hline 2372 & $\mathrm{O}=\mathrm{C}(\mathrm{O}[\mathrm{C} @ \mathrm{H}] 1 \mathrm{CN}[\mathrm{C} @ \mathrm{H}](\mathrm{C \# Cc} 2 \mathrm{cc} 3 \mathrm{ncnc}(\mathrm{Nc} 4 \mathrm{ccc}(\mathrm{OCc} 5 \mathrm{cscn} 5) \mathrm{c}(\mathrm{Cl}) \mathrm{c} 4) \mathrm{c} 3 \mathrm{~s} 2) \mathrm{C} 1) \mathrm{N} 1 \mathrm{CCOCC} 1$ & 120 & 6.92 \\
\hline 2373 & CC(c1cccc(F)c1)n1ncc2cc(Nc3ncnc4cc(C\#C[C@@H]5C[C@@H](OC(=O)N6CCOCC6)CN5)sc34)ccc21 & 120 & 6.92 \\
\hline 2374 & $\mathrm{COc} 1 \mathrm{cc} 2 \mathrm{ncnc}(\mathrm{Nc} 3 \operatorname{ccc}(\mathrm{Cl}) \mathrm{c} 3 \mathrm{~F}) \mathrm{c} 2 \mathrm{cc} 1 \mathrm{CN}(\mathrm{CCN}(\mathrm{C}) \mathrm{C})[\mathrm{C} @ @ \mathrm{H}](\mathrm{C}) \mathrm{C}(\mathrm{N})=\mathrm{O}$ & 120 & $*$ \\
\hline 2375 & $\mathrm{O}=\mathrm{c} 1 \mathrm{oc} 2 \mathrm{cc} 3 \mathrm{ncnc}(\mathrm{Nc} 4 \mathrm{ccc} 5[\mathrm{nH}] \mathrm{ncc} 5 \mathrm{c} 4) \mathrm{c} 3 \mathrm{cc} 2 \mathrm{n} 1 \mathrm{CCCN} 1 \mathrm{CCOCC} 1$ & 120 & $*$ \\
\hline 2376 & $\mathrm{C}=\mathrm{CC}(=\mathrm{O}) \mathrm{Nc} 1 \mathrm{cccc}(-\mathrm{n} 2 \mathrm{c}(=\mathrm{O}) \mathrm{cc}(\mathrm{C} 3 \mathrm{CC} 3) \mathrm{c} 3 \mathrm{cnc}(\mathrm{Nc} 4 \mathrm{ccc}(\mathrm{N} 5 \mathrm{CCN}(\mathrm{C}) \mathrm{CC} 5) \mathrm{cc} 4 \mathrm{OC}) \mathrm{nc} 32) \mathrm{c} 1$ & 120 & * \\
\hline
\end{tabular}




\begin{tabular}{|c|c|c|c|}
\hline 2377 & $\mathrm{Brc} 1 \mathrm{cccc}(\mathrm{Nc} 2 \mathrm{ncnc} 3 \mathrm{cc} 4 \mathrm{c}(\mathrm{cc} 23) \mathrm{Oc} 2 \mathrm{cccc} 2 \mathrm{O} 4) \mathrm{c} 1$ & 120 & $*$ \\
\hline 2378 & $\mathrm{CS}(=\mathrm{O})(=\mathrm{O}) \mathrm{N} 1 \mathrm{CCC}[\mathrm{C} @ @ \mathrm{H}] 1 \mathrm{C} \# \mathrm{Cc} 1 \mathrm{cc} 2 \mathrm{ncnc}(\mathrm{Nc} 3 \mathrm{ccc}(\mathrm{OCc} 4 \mathrm{ccc}(\mathrm{F}) \mathrm{c} 4) \mathrm{c}(\mathrm{Cl}) \mathrm{c} 3) \mathrm{c} 2 \mathrm{~s} 1$ & 120 & $*$ \\
\hline 2379 & $\mathrm{CN}(\mathrm{C}) \mathrm{c} 1 \mathrm{ccc} 2 \mathrm{ncncc} 2 \mathrm{c} 1$ & 120 & $*$ \\
\hline 2380 & $\mathrm{Nc} 1 \mathrm{cc} 2 \mathrm{ncnc}(\mathrm{Nc} 3 \operatorname{ccc}(\mathrm{Cl}) \mathrm{c} 3) \mathrm{c} 2 \mathrm{cn} 1$ & 120 & $*$ \\
\hline 2381 & $\mathrm{COc} 1 \mathrm{ccc} 2 \mathrm{c}(\mathrm{Nc} 3 \mathrm{cccc} 3) \mathrm{ncnc} 2 \mathrm{c} 1$ & 120 & $*$ \\
\hline 2382 & $\mathrm{CCc} 1 \mathrm{c}(\mathrm{C}(\mathrm{N})=\mathrm{O}) \mathrm{cn} 2 \mathrm{ncnc}(\mathrm{Nc} 3 \operatorname{ccc} 4 \mathrm{c}(\mathrm{cnn} 4 \mathrm{Cc} 4 \mathrm{cccc} 4) \mathrm{c} 3) \mathrm{c} 12$ & 120 & $*$ \\
\hline 2383 & $\operatorname{CCOC}(=O) \operatorname{c} 1 \mathrm{cc} 2 \mathrm{c}(\mathrm{Nc} 3 \operatorname{ccc} 4 \mathrm{c}(\operatorname{cnn} 4 \mathrm{Cc} 4 \mathrm{ccccc} 4) \mathrm{c} 3) \mathrm{ncnn} 2 \mathrm{c} 1$ & 120 & $*$ \\
\hline 2384 & OCc1 cen $2 n c n c(N c 3 \operatorname{ccc} 4 \mathrm{c}(\operatorname{cnn} 4 \mathrm{Cc} 4 \mathrm{cccc}(\mathrm{F}) \mathrm{c} 4) \mathrm{c} 3) \mathrm{c} 12$ & 120 & $*$ \\
\hline 2385 & $\mathrm{C}[\mathrm{C} @ \mathrm{H}](\mathrm{c} 1 \mathrm{ccccc} 1) \mathrm{n} 1 \mathrm{ncc} 2 \mathrm{cc}(\mathrm{Nc} 3 \mathrm{ncnn} 4 \mathrm{ccc}(\mathrm{COC}[\mathrm{C} @ @ \mathrm{H}] 5 \mathrm{CNCCO}) \mathrm{c} 34) \mathrm{ccc} 21$ & 120 & $*$ \\
\hline 2386 & $\mathrm{~S}=\mathrm{C}(\mathrm{Nc} 1 \mathrm{ccc} 2 \mathrm{ncnc}(\mathrm{Nc} 3 \mathrm{cccc}(\mathrm{Cl}) \mathrm{c} 3) \mathrm{c} 2 \mathrm{c} 1) \mathrm{Nc} 1 \mathrm{ncc}(\mathrm{Cl}) \mathrm{s} 1$ & 120 & $*$ \\
\hline 2387 & $\mathrm{Cc} 1 \mathrm{nnc}(\mathrm{NC}(=\mathrm{S}) \mathrm{Nc} 2 \mathrm{ccc} 3 \mathrm{ncnc}(\mathrm{Nc} 4 \mathrm{cccc}(\mathrm{Cl}) \mathrm{c} 4) \mathrm{c} 3 \mathrm{c} 2) \mathrm{s} 1$ & 120 & $*$ \\
\hline 2388 & $\mathrm{~N} \# \mathrm{CC} 1=\mathrm{C}(\mathrm{c} 2 \mathrm{ccccc} 2) \mathrm{Nc} 2 \mathrm{c}(\mathrm{c}(-\mathrm{c} 3 \operatorname{ccc} 3) \mathrm{nn} 2-\mathrm{c} 2 \mathrm{cccc} 2) \mathrm{C} 12 \mathrm{C}(=\mathrm{O}) \mathrm{Nc} 1 \mathrm{ccc}(\mathrm{Br}) \mathrm{cc} 12$ & 120 & $*$ \\
\hline 2389 & $\mathrm{Nc} 1 \mathrm{ccc}(\mathrm{C}(=\mathrm{O}) \mathrm{Nc} 2 \operatorname{ccc}(\mathrm{Cl}) \mathrm{c} 2) \mathrm{c}(\mathrm{O}) \mathrm{c} 1$ & 120 & $*$ \\
\hline 2390 & $\mathrm{CN} 1 \mathrm{CCN}(\mathrm{N}(\mathrm{CCC} 2 \mathrm{COc} 3 \mathrm{cc} 4 \mathrm{ncnc}(\mathrm{Nc} 5 \mathrm{ccc}(\mathrm{Br}) \mathrm{cc} 5 \mathrm{~F}) \mathrm{c} 4 \mathrm{cc} 3 \mathrm{O} 2) \mathrm{N} 2 \mathrm{CCN}(\mathrm{C}) \mathrm{CC} 2) \mathrm{CC} 1$ & 120 & $*$ \\
\hline 2391 & $\mathrm{CCN}(\mathrm{CC}) \mathrm{N}(\mathrm{CCC} 1 \mathrm{COc} 2 \mathrm{cc} 3 \mathrm{ncnc}(\mathrm{Nc} 4 \mathrm{ccc}(\mathrm{Br}) \mathrm{cc} 4 \mathrm{~F}) \mathrm{c} 3 \mathrm{cc} 2 \mathrm{O} 1) \mathrm{N}(\mathrm{CC}) \mathrm{CC}$ & 120 & $*$ \\
\hline 2392 & OCCC1COc2cc3ncnc(Nc4ccc(Br)ce4F)c3cc2O1 & 120 & $*$ \\
\hline 2393 & $\begin{array}{c}\mathrm{CN}(\mathrm{CCN}(\mathrm{CCN} 1 \mathrm{CCOCC} 1) \mathrm{CCN}(\mathrm{C}) / \mathrm{N}=\mathrm{N} / \mathrm{c} 1 \mathrm{ccc} 2 \mathrm{ncnc}(\mathrm{Nc} 3 \mathrm{cccc}(\mathrm{Br}) \mathrm{c} 3) \mathrm{c} 2 \mathrm{c} 1) / \mathrm{N}=\mathrm{N} / \mathrm{c} 1 \mathrm{ccc} 2 \mathrm{ncnc}(\mathrm{Nc} 3 \mathrm{cccc}(\mathrm{Br}) \mathrm{c} 3) \mathrm{c} 2 \\
\mathrm{c} 1\end{array}$ & 120 & $*$ \\
\hline 2394 & $\begin{array}{c}\mathrm{Cc} 1 \mathrm{nc}(\mathrm{Nc} 2 \mathrm{ncc}(\mathrm{C}(=\mathrm{O}) \mathrm{Nc} 3 \mathrm{c}(\mathrm{C}) \mathrm{cccc} 3 \mathrm{Cl}) \mathrm{s} 2) \mathrm{cc}(\mathrm{N} 2 \mathrm{CCN}(\mathrm{CCOC}(=\mathrm{O}) \mathrm{CCC}(=\mathrm{O}) \mathrm{OCCN}(\mathrm{C}) \mathrm{Cc} 3 \operatorname{ccc}(\mathrm{C}(=\mathrm{O}) \mathrm{Nc} 4 \mathrm{ccc} 5 \mathrm{ncn} \\
\mathrm{c}(\mathrm{Nc} 6 \mathrm{cccc}(\mathrm{Cl}) \mathrm{c} 6) \mathrm{c} 5 \mathrm{c} 4) \mathrm{cc} 3) \mathrm{CC} 2) \mathrm{n} 1\end{array}$ & 120 & $*$ \\
\hline 2395 & $\mathrm{O}=\mathrm{C}(/ \mathrm{C}=\mathrm{C} / \mathrm{c} 1 \mathrm{ccc}(\mathrm{OC}(\mathrm{F})(\mathrm{F}) \mathrm{F}) \mathrm{cc} 1) \mathrm{c} 1 \mathrm{cc}(\mathrm{Br}) \operatorname{cc} 2 \mathrm{cc}(-\mathrm{c} 3 \operatorname{ccc}(\mathrm{F}) \mathrm{c} 3) \mathrm{oc} 12$ & 120 & $*$ \\
\hline 2396 & $\mathrm{Nc} 1 \mathrm{c}(\mathrm{Cl}) \mathrm{cccc} 1 \mathrm{Nc} 1 \mathrm{ncnc} 2 \mathrm{ccncc} 12$ & 120.23 & $*$ \\
\hline 2397 & $\mathrm{COc} 1 \mathrm{ccc} 2 \mathrm{ncnc}(\mathrm{Nc} 3 \mathrm{cccc} 3) \mathrm{c} 2 \mathrm{c} 1 . \mathrm{Cl}$ & 120.23 & $*$ \\
\hline 2398 & $\mathrm{CCNCc} 1 \mathrm{ccc}(-\mathrm{c} 2 \mathrm{cc} 3 \mathrm{c}(\mathrm{Nc} 4 \mathrm{ccc}(\mathrm{OCc} 5 \mathrm{cccc}(\mathrm{F}) \mathrm{c} 5) \mathrm{c}(\mathrm{Cl}) \mathrm{c} 4) \mathrm{ncnc} 3 \mathrm{~s} 2)[\mathrm{nH}] 1$ & 121 & $*$ \\
\hline 2399 & $\mathrm{C}=\mathrm{CC}(=\mathrm{O}) \mathrm{Nc} 1 \mathrm{cccc}(-\mathrm{n} 2 \mathrm{c}(=\mathrm{O}) \mathrm{n}(\mathrm{C}(\mathrm{C}) \mathrm{C}) \mathrm{c}(=\mathrm{O}) \mathrm{c} 3 \mathrm{cnc}(\mathrm{Nc} 4 \mathrm{ccc}(\mathrm{N}(\mathrm{C}) \mathrm{CCN}(\mathrm{C}) \mathrm{C}) \mathrm{cc} 4 \mathrm{OC}) \mathrm{nc} 32) \mathrm{c} 1$ & 121 & $*$ \\
\hline 2400 & $\mathrm{O}=\mathrm{C}(\mathrm{Nc} 1 \mathrm{nccs} 1) \mathrm{Nc} 1 \mathrm{cc}(-\mathrm{c} 2 \mathrm{cccnc} 2) \operatorname{ccc} 1 \mathrm{OC}(\mathrm{F})(\mathrm{F}) \mathrm{F}$ & 121.09 & $*$ \\
\hline 2401 & $\mathrm{C}=\mathrm{CC}(=\mathrm{O}) \mathrm{Nc} 1 \mathrm{cc} 2 \mathrm{c}(\mathrm{Nc} 3 \mathrm{ccc}(\mathrm{Br}) \mathrm{cc} 3 \mathrm{~F}) \mathrm{ncnc} 2 \mathrm{cc} 1 \mathrm{O}[\mathrm{C} @ \mathrm{H}] 1 \mathrm{CCOC} 1$ & 121.1 & $*$ \\
\hline 2402 & $\operatorname{CCOc} 1 \operatorname{cc} 2 n \operatorname{nc}(\mathrm{Nc} 3 \operatorname{ccc} 4 \mathrm{c}(\operatorname{ccn} 4 \mathrm{~S}(=\mathrm{O})(=\mathrm{O}) \mathrm{c} 4 \operatorname{ccc} c 4) \mathrm{c} 3) \mathrm{c} 2 \mathrm{cc} 1 \mathrm{NC}(=\mathrm{O}) / \mathrm{C}=\mathrm{C} / \mathrm{CN} 1 \mathrm{CCOCC} 1$ & 122 & $*$ \\
\hline 2403 & $\mathrm{Fc} 1 \mathrm{cc}(\mathrm{Br}) \mathrm{ccc} 1 \mathrm{Nc} 1 \mathrm{ncnc} 2 \mathrm{cc} 3 \mathrm{c}(\mathrm{cc} 12) \mathrm{OC}(\mathrm{CCN}(\mathrm{N} 1 \mathrm{CCCCC} 1) \mathrm{N} 1 \mathrm{CCCCC} 1) \mathrm{CO} 3$ & 122 & $*$ \\
\hline 2404 & $\mathrm{Fc} 1 \mathrm{ccc}(-\mathrm{c} 2 \mathrm{nc}(\mathrm{Nc} 3 \mathrm{cc}(\mathrm{Br}) \mathrm{cc} 4 \mathrm{cc}(-\mathrm{c} 5 \mathrm{ccc}(\mathrm{F}) \mathrm{c} 5) \mathrm{oc} 34) \mathrm{c} 3 \mathrm{cc}(\mathrm{Br}) \mathrm{ccc} 3 \mathrm{n} 2) \mathrm{cc} 1$ & 122.5 & $*$ \\
\hline 2405 & $\mathrm{CN} 1 \mathrm{CCN}(\mathrm{C} / \mathrm{C}=\mathrm{C} / \mathrm{C}(=\mathrm{O}) \mathrm{Nc} 2 \mathrm{cc} 3 \mathrm{c}(\mathrm{Nc} 4 \mathrm{ccc}(\mathrm{F}) \mathrm{c}(\mathrm{Cl}) \mathrm{c} 4) \mathrm{ncnc} 3 \mathrm{~s} 2) \mathrm{CC} 1$ & 124 & $*$ \\
\hline 2406 & $\mathrm{Fc} 1 \mathrm{cc} 2 \mathrm{c}(\mathrm{Nc} 3 \mathrm{cccc}(\mathrm{Br}) \mathrm{c} 3) \mathrm{ncnc} 2 \mathrm{cn} 1$ & 124 & $*$ \\
\hline 2407 & $\mathrm{O}=\mathrm{C}(\mathrm{CO}) \mathrm{NCCn} 1 \mathrm{ccc} 2 \mathrm{ncnc}(\mathrm{Nc} 3 \operatorname{ccc}(\mathrm{Oc} 4 \mathrm{ccc}(\mathrm{C}(\mathrm{F})(\mathrm{F}) \mathrm{F}) \mathrm{c} 4) \mathrm{c}(\mathrm{Cl}) \mathrm{c} 3) \mathrm{c} 21$ & 124 & $*$ \\
\hline 2408 & $\mathrm{CCOc} 1 \mathrm{cc} 2 \mathrm{ncc}(\mathrm{C \# N}) \mathrm{c}(\mathrm{Nc} 3 \operatorname{ccc}(\mathrm{Sc} 4 \mathrm{nc}(-\mathrm{c} 5 \mathrm{cccc} 5) \operatorname{cs} 4) \mathrm{c}(\mathrm{Cl}) \mathrm{c} 3) \mathrm{c} 2 \mathrm{cc} 1 \mathrm{NC}(=\mathrm{O}) / \mathrm{C}=\mathrm{C} / \mathrm{CN}(\mathrm{C}) \mathrm{C}$ & 125 & 6.90 \\
\hline 2409 & $\mathrm{CCNC}(=\mathrm{O}) \mathrm{O}[\mathrm{C} @ @ \mathrm{H}] 1 \mathrm{CN}[\mathrm{C} @ \mathrm{H}](\mathrm{C} \# \mathrm{Cc} 2 \mathrm{cc} 3 \mathrm{ncnc}(\mathrm{Nc} 4 \mathrm{ccc}(\mathrm{OCc} 5 \mathrm{ccc}(\mathrm{F}) \mathrm{c} 5) \mathrm{c}(\mathrm{Cl}) \mathrm{c} 4) \mathrm{c} 3 \mathrm{~s} 2) \mathrm{C} 1$ & 125 & $*$ \\
\hline 2410 & $\mathrm{~N} \# \mathrm{CC}(\mathrm{C \# N})=\mathrm{C}(\mathrm{N}) / \mathrm{C}(\mathrm{CHN})=\mathrm{C} / \mathrm{c} 1 \mathrm{ccc}(\mathrm{O}) \mathrm{cc} 1$ & 125 & $*$ \\
\hline 2411 & $\mathrm{COc} 1 \mathrm{ccc}(\mathrm{OC}) \mathrm{c}(\mathrm{Nc} 2 \mathrm{cc}(\mathrm{NCCc} 3 \mathrm{cccs} 3) \mathrm{ncn} 2) \mathrm{c} 1$ & 125 & $*$ \\
\hline 2412 & $\mathrm{C}=\mathrm{CC}(=\mathrm{O}) \mathrm{Nc} 1 \mathrm{cc}(\mathrm{Nc} 2 \mathrm{nccc}(\mathrm{NC}(=\mathrm{O}) \mathrm{c} 3 \operatorname{ccc}(\mathrm{C}(\mathrm{F})(\mathrm{F}) \mathrm{F}) \operatorname{cc} 3) \mathrm{n} 2) \mathrm{c}(\mathrm{OC}) \operatorname{cc} 1 \mathrm{~N} 1 \mathrm{CCC}(\mathrm{C}(\mathrm{N})=\mathrm{O}) \mathrm{CC} 1$ & 125.1 & $*$ \\
\hline 2413 & $\operatorname{Brc} 1 \mathrm{ccc}(\mathrm{Nc} 2 \mathrm{ncnc} 3[\mathrm{nH}] \mathrm{ccc} 23) \mathrm{cc} 1$ & 125.33 & $*$ \\
\hline 2414 & COc1cc2ncnc(N[C@@H](C)c3ccc(F)cc3)c2cc1OCCCCCCC $(=\mathrm{O}) \mathrm{NO}$ & 125.6 & 6.90 \\
\hline 2415 & $\mathrm{Fc} 1 \mathrm{ccc}(-\mathrm{c} 2 \mathrm{cc} 3 \mathrm{cc}(\mathrm{Br}) \mathrm{cc}(\mathrm{Nc} 4 \mathrm{nc}(-\mathrm{c} 5 \mathrm{ccc}(\mathrm{Cl}) \mathrm{cc} 5) \mathrm{nc} 5 \mathrm{ccc}(\mathrm{Br}) \mathrm{cc} 45) \mathrm{c} 3 \mathrm{o} 2) \mathrm{cc} 1$ & 125.7 & $*$ \\
\hline 2416 & $\mathrm{COc} 1 \mathrm{cc} 2 \mathrm{ncnc}(\mathrm{Nc} 3 \mathrm{cccc}(\mathrm{SC}) \mathrm{c} 3) \mathrm{c} 2 \mathrm{cc} 1 \mathrm{OC}$ & 126.7 & $*$ \\
\hline 2417 & $\mathrm{COc} 1 \mathrm{cc} 2 \mathrm{ncnc}(\mathrm{Nc} 3 \mathrm{cccc}(-\mathrm{c} 4 \mathrm{cccc} 4) \mathrm{c} 3) \mathrm{c} 2 \mathrm{cc} 1 \mathrm{OC}$ & 126.7 & $*$ \\
\hline
\end{tabular}




\begin{tabular}{|c|c|c|c|}
\hline 2418 & $\mathrm{C} \# \mathrm{Cc} 1 \mathrm{ccc} 2 \mathrm{ncnc}(\mathrm{Nc} 3 \mathrm{ccc}(\mathrm{F}) \mathrm{c}(\mathrm{Cl}) \mathrm{c} 3) \mathrm{c} 2 \mathrm{c} 1$ & 126.9 & $*$ \\
\hline 2419 & $\mathrm{CCC}(=\mathrm{O}) \mathrm{Nc} 1 \mathrm{cc} 2 \mathrm{c}(\mathrm{Nc} 3 \operatorname{ccc} 4 \mathrm{c}(\operatorname{ccn} 4 \mathrm{~S}(=\mathrm{O})(=\mathrm{O}) \operatorname{c} 4 \operatorname{ccc} c 4) \mathrm{c} 3) \mathrm{ncn} \operatorname{coc} 1 \mathrm{OC}$ & 127 & $*$ \\
\hline 2420 & $\mathrm{CN} 1 \mathrm{CCN}(\mathrm{c} 2 \mathrm{ccc}(\mathrm{Nc} 3 \mathrm{nc}(\mathrm{Nc} 4 \mathrm{ccc} 5[\mathrm{nH}] \mathrm{ccc} 5 \mathrm{c} 4) \mathrm{c} 4 \mathrm{cn}[\mathrm{nH}] \mathrm{c} 4 \mathrm{n} 3) \mathrm{cc} 2) \mathrm{CC} 1$ & 127 & $*$ \\
\hline 2421 & $\mathrm{C}=\mathrm{CC}(=\mathrm{O}) \mathrm{Nc} 1 \mathrm{cc}(\mathrm{Nc} 2 \mathrm{nccc}(\mathrm{NC}(=\mathrm{O}) \mathrm{c} 3 \operatorname{ccccc} 3) \mathrm{n} 2) \mathrm{c}(\mathrm{OC}) \operatorname{cc} 1 \mathrm{~N}(\mathrm{C}) \mathrm{C}$ & 127.2 & $*$ \\
\hline 2422 & $\mathrm{O}=\mathrm{C}(\mathrm{Nc} 1 \mathrm{ccc} 2 \mathrm{ncnc}(\mathrm{Nc} 3 \mathrm{cccc}(\mathrm{Cl}) \mathrm{c} 3) \mathrm{c} 2 \mathrm{c} 1) \mathrm{C} 1 \mathrm{CCC} 2(\mathrm{CC} 1) \mathrm{OCC} 1(\mathrm{O} 2) \mathrm{C} 2 \mathrm{CC} 3 \mathrm{CC}(\mathrm{C} 2) \mathrm{CC} 1 \mathrm{C} 3$ & 127.8 & $*$ \\
\hline 2423 & $\mathrm{COc} 1 \mathrm{cc} 2 \mathrm{ncnc}(\mathrm{Nc} 3 \mathrm{cccc} 3 \mathrm{Br}) \mathrm{c} 2 \mathrm{cc} 1 \mathrm{OC}$ & 128 & $*$ \\
\hline 2424 & $\mathrm{C}=\mathrm{CC}(=\mathrm{O}) \mathrm{Nc} 1 \mathrm{cc}(\mathrm{Nc} 2 \mathrm{nccc}(\mathrm{NC}(=\mathrm{O}) \mathrm{c} 3 \mathrm{ccc}(\mathrm{OC}) \mathrm{c}(\mathrm{OC}) \mathrm{c} 3) \mathrm{n} 2) \mathrm{c}(\mathrm{OC}) \mathrm{cc} 1 \mathrm{~N} 1 \mathrm{CCC}(\mathrm{C}(\mathrm{N})=\mathrm{O}) \mathrm{CC} 1$ & 128 & $*$ \\
\hline 2425 & $\mathrm{CCOC}(=\mathrm{O}) / \mathrm{C}=\mathrm{C} / \mathrm{C}(=\mathrm{O}) \mathrm{Nc} 1 \mathrm{cccc}(\mathrm{Oc} 2 \mathrm{cc}(\mathrm{Nc} 3 \operatorname{ccc}(\mathrm{OCc} 4 \mathrm{cccc}(\mathrm{F}) \mathrm{c} 4) \mathrm{c}(\mathrm{Cl}) \mathrm{c} 3) \mathrm{ncn} 2) \mathrm{c} 1$ & 129 & 6.89 \\
\hline 2426 & $\mathrm{COc} 1 \mathrm{cc}(\mathrm{N} 2 \mathrm{CCN}(\mathrm{C}) \mathrm{CC} 2) \operatorname{ccc} 1 \mathrm{Nc} 1 \mathrm{ncc}(\mathrm{Cl}) \mathrm{c}(\mathrm{Oc} 2 \operatorname{ccc}(\mathrm{COc} 3 \mathrm{no}[\mathrm{n}+]([\mathrm{O}-]) \mathrm{c} 3 \mathrm{~S}(=\mathrm{O})(=\mathrm{O}) \mathrm{c} 3 \operatorname{ccccc} 3) \mathrm{c} 2) \mathrm{n} 1$ & 130 & 6.89 \\
\hline 2427 & $\mathrm{CCNc} 1 \mathrm{ncc}(\mathrm{C}(=\mathrm{O}) \mathrm{Nc} 2 \mathrm{cc}(\mathrm{C}(=\mathrm{O}) \mathrm{Nc} 3 \operatorname{ccc}(\mathrm{CN} 4 \mathrm{CCN}(\mathrm{C}) \mathrm{CC} 4) \mathrm{c}(\mathrm{C}(\mathrm{F})(\mathrm{F}) \mathrm{F}) \mathrm{c} 3) \operatorname{ccc} 2 \mathrm{C}) \mathrm{cn} 1$ & 130 & 6.89 \\
\hline 2428 & $\mathrm{Cc} 1 \mathrm{ccc}(\mathrm{C} 2=\mathrm{NN}(\mathrm{C}(\mathrm{N})=\mathrm{S}) \mathrm{C}(\mathrm{c} 3 \operatorname{ccc}(\mathrm{O}) \mathrm{cc} 3) \mathrm{C} 2) \operatorname{cc} 1 \mathrm{C}$ & 130 & 6.89 \\
\hline 2429 & $\mathrm{COc} 1 \mathrm{cc} 2 \mathrm{ncc}(\mathrm{C} \# \mathrm{~N}) \mathrm{c}(\mathrm{Nc} 3 \operatorname{ccc} 4 \mathrm{c}(\operatorname{cnn} 4 \mathrm{Cc} 4 \mathrm{ccccc} 4) \mathrm{c} 3) \mathrm{c} 2 \mathrm{cc} 1 \mathrm{NC}(=\mathrm{O}) / \mathrm{C}=\mathrm{C} / \mathrm{CN}(\mathrm{C}) \mathrm{C}$ & 130 & 6.89 \\
\hline 2430 & $\mathrm{CCCN}(\mathrm{CC} \# \mathrm{CC}(=\mathrm{O}) \mathrm{Nc} 1 \mathrm{ccc} 2 \mathrm{ncc}(\mathrm{CHN}) \mathrm{c}(\mathrm{Nc} 3 \operatorname{ccc}(\mathrm{Br}) \mathrm{c} 3) \mathrm{c} 2 \mathrm{c} 1) \mathrm{CCC}$ & 130 & 6.89 \\
\hline 2431 & $\operatorname{CCOC}(=\mathrm{O}) \operatorname{CCCn} 1 \mathrm{c}(=\mathrm{O}) \mathrm{oc} 2 \mathrm{cc} 3 \mathrm{ncnc}(\mathrm{Nc} 4 \mathrm{ccc} 5[\mathrm{nH}] \mathrm{ncc} 5 \mathrm{c} 4) \mathrm{c} 3 \mathrm{cc} 21$ & 130 & $*$ \\
\hline 2432 & $\mathrm{CCN}(\mathrm{CC})[\mathrm{C} @ @](\mathrm{C})(\mathrm{CCc} 1 \mathrm{ncnc} 2 \mathrm{cc}(\mathrm{OC}) \mathrm{c}(\mathrm{OC}) \mathrm{cc} 12) \mathrm{Cc} 1 \mathrm{ccccc} 1$ & 130 & $*$ \\
\hline 2433 & COCCN1CCC[C@@H]1C\#Cc1cc2ncnc(Nc3ccc(OCc4cccc(F)c4)c (Cl)c3)c2s1 & 130 & $*$ \\
\hline 2434 & $\mathrm{O}=\mathrm{C}(\mathrm{OCCc} 1 \mathrm{cccc} 1) \mathrm{c} 1 \mathrm{cc}(\mathrm{NCc} 2 \mathrm{cc}(\mathrm{O}) \mathrm{ccc} 2 \mathrm{O}) \operatorname{ccc} 1 \mathrm{O}$ & 130 & $*$ \\
\hline 2435 & $\mathrm{COc} 1 \mathrm{cccc}(\mathrm{Nc} 2 \mathrm{ncnc} 3 \mathrm{cc}(\mathrm{N}) \mathrm{ncc} 23) \mathrm{c} 1$ & 130 & $*$ \\
\hline 2436 & Clc1 $1 \mathrm{ccc}(\mathrm{Nc} 2[\mathrm{nH}] \mathrm{nc} 3 \mathrm{ncnc}(\mathrm{Nc} 4 \mathrm{cccc}(\mathrm{Br}) \mathrm{c} 4) \mathrm{c} 23) \mathrm{c} 1$ & 130 & $*$ \\
\hline 2437 & $\mathrm{Cc} 1 \mathrm{cccc}(\mathrm{Nc} 2[\mathrm{nH}] \mathrm{cnc} 3 \mathrm{nnc}(\mathrm{Nc} 4 \operatorname{cccc}(\mathrm{Cl}) \mathrm{c} 4) \mathrm{c} 2-3) \mathrm{c} 1$ & 130 & $*$ \\
\hline 2438 & $\mathrm{CN} 1 \mathrm{CCCN}(\mathrm{Cc} 2 \mathrm{ccn} 3 \mathrm{ncnc}(\mathrm{Nc} 4 \mathrm{ccc} 5 \mathrm{c}(\mathrm{cnn} 5 \mathrm{Cc} 5 \mathrm{cccc}(\mathrm{F}) \mathrm{c} 5) \mathrm{c} 4) \mathrm{c} 23) \mathrm{CC} 1$ & 130 & * \\
\hline 2439 & $\mathrm{CC} 1 \mathrm{CNCCN}(\mathrm{Cc} 2 \mathrm{ccn} 3 \mathrm{ncnc}(\mathrm{Nc} 4 \mathrm{ccc} 5 \mathrm{c}(\mathrm{cnn} 5 \mathrm{Cc} 5 \mathrm{cccc}(\mathrm{F}) \mathrm{c} 5) \mathrm{c} 4) \mathrm{c} 23) \mathrm{C} 1$ & 130 & $*$ \\
\hline 2440 & $\mathrm{COc} 1 \mathrm{cc} 2 \mathrm{c}(\mathrm{Nc} 3 \operatorname{ccc}(\mathrm{NC}(=\mathrm{O}) \mathrm{c} 4 \mathrm{cccc} 4) \mathrm{cc} 3) \mathrm{ncnc} 2 \mathrm{cc} 1 \mathrm{OCCCN} 1 \mathrm{CCN}(\mathrm{C}) \mathrm{CC} 1$ & 130 & $*$ \\
\hline 2441 & $\mathrm{Cc} 1 \mathrm{cc}(\mathrm{NS}(=\mathrm{O})(=\mathrm{O}) \operatorname{c} 2 \mathrm{ccc}(\mathrm{Nc} 3 \mathrm{nncc} 4 \operatorname{ccccc} 34) \operatorname{cc} 2) \mathrm{no} 1$ & 130 & $*$ \\
\hline 2442 & $\mathrm{Fc} 1 \mathrm{cccc}(\mathrm{Cn} 2 \mathrm{ncc} 3 \mathrm{cc}(\mathrm{Nc} 4 \mathrm{ncnn} 5 \mathrm{ccc}(\mathrm{COCC} 6 \mathrm{CCNCC} 6) \mathrm{c} 45) \mathrm{ccc} 32) \mathrm{c} 1$ & 130 & $*$ \\
\hline 2443 & $\mathrm{FC}(\mathrm{F})(\mathrm{F}) \mathrm{c} 1 \mathrm{nnc}(\mathrm{NC}(=\mathrm{S}) \mathrm{Nc} 2 \mathrm{ccc} 3 \mathrm{ncnc}(\mathrm{Nc} 4 \mathrm{cccc}(\mathrm{Cl}) \mathrm{c} 4) \mathrm{c} 3 \mathrm{c} 2) \mathrm{s} 1$ & 130 & $*$ \\
\hline 2444 & $\mathrm{CC}(=\mathrm{O}) \mathrm{OCN}(\mathrm{C}) / \mathrm{N}=\mathrm{N} / \mathrm{c} 1 \mathrm{ccc} 2 \mathrm{ncnc}(\mathrm{Nc} 3 \operatorname{ccc}(\mathrm{Br}) \mathrm{c} 3) \mathrm{c} 2 \mathrm{c} 1$ & 130 & $*$ \\
\hline 2445 & $\mathrm{CCN}(\mathrm{CC}) \mathrm{C}(\mathrm{C})(\mathrm{CCc} 1 \mathrm{ncnc} 2 \mathrm{cc}(\mathrm{OC}) \mathrm{c}(\mathrm{OC}) \mathrm{cc} 12) \mathrm{Cc} 1 \mathrm{cccc} 1$ & 130 & $*$ \\
\hline 2446 & COc1 $1 \mathrm{cc} 2 \mathrm{ncnc}(-\mathrm{c} 3 \mathrm{c}[\mathrm{nH}] \mathrm{c} 4 \mathrm{ccc}(\mathrm{Br}) \mathrm{cc} 34) \mathrm{c} 2 \mathrm{cc} 1 \mathrm{OC}$ & 131 & $*$ \\
\hline 2447 & $\mathrm{COC}[\mathrm{C} @ @ \mathrm{H}] 1 \mathrm{CCCN} 1 \mathrm{C} / \mathrm{C}=\mathrm{C} / \mathrm{C}(=\mathrm{O}) \mathrm{Nc} 1 \mathrm{ccc} 2 \mathrm{ncnc}(\mathrm{Nc} 3 \operatorname{ccc}(\mathrm{Br}) \mathrm{c} 3) \mathrm{c} 2 \mathrm{c} 1$ & 131 & $*$ \\
\hline 2448 & $\mathrm{COc} 1 \mathrm{ccc}(\mathrm{NC}(=\mathrm{O}) / \mathrm{C}=\mathrm{C} / \mathrm{CN}(\mathrm{C}) \mathrm{C}) \mathrm{cc} 1 \mathrm{Nc} 1 \mathrm{ncc}(\mathrm{F}) \mathrm{c}(\mathrm{Nc} 2 \operatorname{ccc} 3 \operatorname{cccc} 3 \mathrm{c} 2) \mathrm{n} 1$ & 131 & $*$ \\
\hline 2449 & $\mathrm{O}=\mathrm{C}(\mathrm{Nc} 1 \mathrm{cc}(\mathrm{N} 2 \mathrm{CCOCC} 2) \mathrm{ncn} 1) \mathrm{c} 1 \mathrm{ccc}(\mathrm{F}) \mathrm{cc} 1$ & 131 & $*$ \\
\hline 2450 & $\operatorname{COc} 1 \mathrm{cc}(\mathrm{NC}(=\mathrm{O}) \mathrm{Nc} 2 \mathrm{ccncc} 2) \operatorname{cc}(-\mathrm{c} 2 \mathrm{cccn} \operatorname{c} 2) \mathrm{c} 1 \mathrm{OC}$ & 131.09 & * \\
\hline 2451 & COc1ccec(Nc2ncnc3cence23)c1N & 131.83 & $*$ \\
\hline 2452 & $\mathrm{COc} 1 \mathrm{cc} 2 \mathrm{ncnc}(\mathrm{Nc} 3 \mathrm{ccc}(\mathrm{Oc} 4 \mathrm{cccc} 4) \mathrm{cc} 3) \mathrm{c} 2 \mathrm{cc} 1 \mathrm{NC}(=\mathrm{O}) / \mathrm{C}=\mathrm{C} / \mathrm{CN} 1 \mathrm{CCCCC} 1$ & 132 & $*$ \\
\hline 2453 & Cl.Cn $1 \mathrm{c} 2 \mathrm{ccccc} 2 \mathrm{c} 2 \mathrm{ncnc}(\mathrm{Nc} 3 \operatorname{ccc}(\mathrm{Br}) \mathrm{c} 3) \mathrm{c} 21$ & 132 & $*$ \\
\hline 2454 & $\mathrm{O}=\mathrm{C} 1 \mathrm{Nc} 2 \mathrm{cc} 3 \mathrm{c}(-\mathrm{c} 4 \mathrm{ccccc} 4) \mathrm{c}(-\mathrm{c} 4 \operatorname{ccccc} 4) \mathrm{n}(-\mathrm{c} 4 \operatorname{ccc}(\mathrm{Cl}) \operatorname{cc} 4) \mathrm{c}(=\mathrm{O}) \mathrm{c} 3 \mathrm{cc} 2 \mathrm{C}(\mathrm{c} 2 \operatorname{ccccc} 2) \mathrm{N} 1$ & 132 & $*$ \\
\hline 2455 & $\mathrm{COC}(=\mathrm{O}) \mathrm{c} 1 \mathrm{ccc} 2 \mathrm{oc} 3 \mathrm{cnnc}(\mathrm{Nc} 4 \mathrm{ccccc} 4 \mathrm{C}) \mathrm{c} 3 \mathrm{c} 2 \mathrm{c} 1$ & 132.5 & 6.88 \\
\hline 2456 & $\mathrm{Fc} 1 \mathrm{cccc}(-\mathrm{c} 2 \mathrm{cc} 3 \mathrm{cc}(\mathrm{Br}) \mathrm{cc}(\mathrm{Nc} 4 \mathrm{nc}(-\mathrm{c} 5 \mathrm{ccc}(\mathrm{Cl}) \mathrm{cc} 5) \mathrm{nc} 5 \mathrm{ccc}(\mathrm{Br}) \mathrm{cc} 45) \mathrm{c} 3 \mathrm{o} 2) \mathrm{c} 1$ & 132.9 & $*$ \\
\hline 2457 & $\mathrm{~S}=\mathrm{C}(\mathrm{Nc} 1 \mathrm{ccc}(\mathrm{Cl}) \mathrm{c}(\mathrm{Cl}) \mathrm{c} 1) \mathrm{Nc} 1 \mathrm{ccc} 2 \mathrm{ncnc}(\mathrm{Nc} 3 \operatorname{ccc}(\mathrm{Br}) \mathrm{c} 3) \mathrm{c} 2 \mathrm{c} 1$ & 133.1 & $*$ \\
\hline 2458 & $\mathrm{CN}(\mathrm{C}) \mathrm{C} / \mathrm{C}=\mathrm{C} / \mathrm{C}(=\mathrm{O}) \mathrm{Nc} 1 \mathrm{cc} 2 \mathrm{c}(\mathrm{Nc} 3 \operatorname{ccc}(\mathrm{OCc} 4 \mathrm{ccc}(\mathrm{F}) \mathrm{c} 4) \mathrm{cc} 3) \mathrm{ncnc} 2 \mathrm{cc} 1 \mathrm{O}[\mathrm{C} @ \mathrm{H}] 1 \mathrm{CCOC} 1$ & 133.9 & $*$ \\
\hline 2459 & $\mathrm{C}=\mathrm{CC}(=\mathrm{O}) \mathrm{Nc} 1 \mathrm{cc}(\mathrm{Nc} 2 \mathrm{nccc}(\mathrm{NC}(=\mathrm{O}) \mathrm{c} 3 \operatorname{ccc} 4 \operatorname{ccc} c 34) \mathrm{n} 2) \mathrm{c}(\mathrm{OC}) \operatorname{cc} 1 \mathrm{~N} 1 \mathrm{CCN}(\mathrm{C}) \mathrm{CC} 1$ & 133.9 & $*$ \\
\hline 2460 & $\mathrm{C}=\mathrm{CC}(=\mathrm{O}) \mathrm{Nc} 1 \mathrm{cc} 2 \mathrm{c}(\mathrm{Nc} 3 \mathrm{ccc}(\mathrm{OCc} 4 \mathrm{ccc} n 4) \mathrm{c}(\mathrm{Cl}) \mathrm{c} 3) \mathrm{ncnc} 2 \mathrm{cc} 1 \mathrm{O}[\mathrm{C} @ \mathrm{H}] 1 \mathrm{CCOC} 1$ & 134.9 & * \\
\hline
\end{tabular}




\begin{tabular}{|c|c|c|c|}
\hline 2461 & $\mathrm{CCC}(=\mathrm{O}) \mathrm{Nc} 1 \mathrm{cc} 2 \mathrm{c}(\mathrm{NCc} 3 \mathrm{cccc} 3) \mathrm{ncnc} 2 \mathrm{cc} 1 \mathrm{OC}$ & 136 & $*$ \\
\hline 2462 & $\mathrm{CCN} 1 \mathrm{CCC}(\mathrm{Nc} 2 \mathrm{ccc} 3 \mathrm{c}(\mathrm{c} 2) \mathrm{C}(=\mathrm{C}(\mathrm{c} 2 \mathrm{ccc}(\mathrm{Cl}) \mathrm{cc} 2) \mathrm{c} 2 \mathrm{ncc}[\mathrm{nH}] 2) \mathrm{C}(=\mathrm{O}) \mathrm{N} 3) \mathrm{CC} 1$ & 137 & $*$ \\
\hline 2463 & $\mathrm{FC}(\mathrm{F})(\mathrm{F}) \mathrm{c} 1 \mathrm{csc}(\mathrm{NC}(=\mathrm{S}) \mathrm{Nc} 2 \mathrm{ccc} 3 \mathrm{ncnc}(\mathrm{Nc} 4 \mathrm{cccc}(\mathrm{Cl}) \mathrm{c} 4) \mathrm{c} 3 \mathrm{c} 2) \mathrm{n} 1$ & 137 & $*$ \\
\hline 2464 & $\mathrm{C}=\mathrm{CC}(=\mathrm{O}) \mathrm{Nc} 1 \mathrm{cccc}(-\mathrm{n} 2 \mathrm{c}(=\mathrm{O}) \mathrm{n}(\mathrm{C}) \mathrm{c}(=\mathrm{O}) \mathrm{c} 3 \mathrm{cnc}(\mathrm{Nc} 4 \mathrm{ccc}(\mathrm{N} 5 \mathrm{CCC}(\mathrm{N}(\mathrm{C}) \mathrm{C}) \mathrm{CC} 5) \mathrm{cc} 4 \mathrm{OC}) \mathrm{nc} 32) \mathrm{c} 1$ & 137 & $*$ \\
\hline 2465 & $\mathrm{O}=\mathrm{C} 1 \mathrm{COc} 2 \mathrm{cc} 3 \mathrm{ncnc}(\mathrm{Nc} 4 \mathrm{ccc}(\mathrm{F}) \mathrm{c}(\mathrm{Cl}) \mathrm{c} 4) \mathrm{c} 3 \mathrm{cc} 2 \mathrm{~N} 1 \mathrm{CCCN} 1 \mathrm{CCCCC} 1$ & 137.9 & $*$ \\
\hline 2466 & $\mathrm{CS}(=\mathrm{O})(=\mathrm{O}) \mathrm{CCNCc} 1 \mathrm{ccc}(-\mathrm{c} 2 \mathrm{cc} 3 \mathrm{c}(\mathrm{Nc} 4 \mathrm{ccc}(\mathrm{OCc} 5 \mathrm{ccc}(\mathrm{F}) \mathrm{c} 5) \mathrm{c}(\mathrm{Cl}) \mathrm{c} 4) \mathrm{ncnc} 3 \mathrm{~s} 2)[\mathrm{nH}] 1$ & 138 & $*$ \\
\hline 2467 & $\mathrm{CCN}(\mathrm{CC}) \mathrm{CCN}(\mathrm{C}) \mathrm{C} / \mathrm{C}=\mathrm{C} / \mathrm{C}(=\mathrm{O}) \mathrm{Nc} 1 \mathrm{cc} 2 \mathrm{c}(\mathrm{Nc} 3 \mathrm{ccc}(\mathrm{F}) \mathrm{c}(\mathrm{Cl}) \mathrm{c} 3) \mathrm{ncnc} 2 \mathrm{~s} 1$ & 139 & $*$ \\
\hline 2468 & $\mathrm{CHCc} 1 \mathrm{cccc}(\mathrm{Nc} 2 \mathrm{ncnc} 3 \mathrm{cc} 4 \mathrm{c}(\mathrm{cc} 23) \mathrm{N}(\mathrm{CCCN} 2 \mathrm{CCOCC} 2) \mathrm{C}(=\mathrm{O}) \mathrm{CO} 4) \mathrm{c} 1$ & 139 & $*$ \\
\hline 2469 & $\mathrm{COc} 1 \mathrm{cccc} 2 \mathrm{ncnc}(\mathrm{Nc} 3 \operatorname{ccc}(\mathrm{Br}) \mathrm{c} 3) \mathrm{c} 12$ & 139 & $*$ \\
\hline 2470 & $\mathrm{Clc} 1 \mathrm{ccc}(\mathrm{C} 2=\mathrm{NN}(\mathrm{c} 3 \operatorname{ccc} c 3) \mathrm{C}(\mathrm{c} 3 \operatorname{ccc} 4 \operatorname{ccccc} 34) \mathrm{C} 2) \mathrm{cc} 1 \mathrm{Cl}$ & 140 & 6.85 \\
\hline 2471 & $\mathrm{CCOc} 1 \mathrm{cc} 2 \mathrm{ncc}(\mathrm{CHN}) \mathrm{c}(\mathrm{Nc} 3 \mathrm{ccc}(\mathrm{OCc} 4 \mathrm{cc}(\mathrm{F}) \mathrm{cc}(\mathrm{F}) \mathrm{c} 4) \mathrm{c}(\mathrm{Cl}) \mathrm{c} 3) \mathrm{c} 2 \mathrm{cc} 1 \mathrm{NC}(=\mathrm{O}) / \mathrm{C}=\mathrm{C} / \mathrm{CN}(\mathrm{C}) \mathrm{C}$ & 140 & 6.85 \\
\hline 2472 & $\mathrm{O}=\mathrm{c} 1 \mathrm{oc} 2 \mathrm{cc} 3 \mathrm{ncnc}(\mathrm{Nc} 4 \mathrm{ccc}(\mathrm{OCc} 5 \mathrm{ccccc} 5) \mathrm{cc} 4) \mathrm{c} 3 \mathrm{cc} 2 \mathrm{n} 1 \mathrm{CCCN} 1 \mathrm{CCOCC} 1$ & 140 & $*$ \\
\hline 2473 & $\operatorname{CCOC}(=\mathrm{O}) \mathrm{CCCn} 1 \mathrm{c}(=\mathrm{O}) \mathrm{oc} 2 \mathrm{cc} 3 \mathrm{ncnc}(\mathrm{Nc} 4 \mathrm{ccc}(\mathrm{F}) \mathrm{c}(\mathrm{F}) \mathrm{c} 4) \mathrm{c} 3 \mathrm{cc} 21$ & 140 & $*$ \\
\hline 2474 & $\mathrm{CCOc} 1 \mathrm{cc} 2 \mathrm{ncnc}(/ \mathrm{C}=\mathrm{C} / \mathrm{CCC} 3 \mathrm{cccc} 3) \mathrm{c} 2 \mathrm{cc} 1 \mathrm{OCC}$ & 140 & $*$ \\
\hline 2475 & COC $(=\mathrm{O}) \mathrm{N} 1 \mathrm{CCC}[\mathrm{C} @ @ \mathrm{H}] 1 \mathrm{C} \# \mathrm{Cc} 1 \mathrm{cc} 2 \mathrm{ncnc}(\mathrm{Nc} 3 \mathrm{ccc}(\mathrm{OCc} 4 \mathrm{ccc}(\mathrm{F}) \mathrm{c} 4) \mathrm{c}(\mathrm{Cl}) \mathrm{c} 3) \mathrm{c} 2 \mathrm{~s} 1$ & 140 & $*$ \\
\hline 2476 & $\mathrm{CN} 1 \mathrm{CCC}(\mathrm{Oc} 2 \mathrm{cccc} 3 \mathrm{ncnc}(\mathrm{Nc} 4 \mathrm{ccc}(\mathrm{OCc} 5 \mathrm{ccc} n 5) \mathrm{c}(\mathrm{Cl}) \mathrm{c} 4) \mathrm{c} 23) \mathrm{CC} 1$ & 140 & $*$ \\
\hline 2477 & $\mathrm{NC}(=\mathrm{O}) \mathrm{C} 1 \mathrm{CCN}(\mathrm{Cc} 2 \mathrm{ccn} 3 \mathrm{ncnc}(\mathrm{Nc} 4 \mathrm{ccc} 5 \mathrm{c}(\operatorname{cnn} 5 \mathrm{Cc} 5 \mathrm{cccc}(\mathrm{F}) \mathrm{c} 5) \mathrm{c} 4) \mathrm{c} 23) \mathrm{CC} 1$ & 140 & $*$ \\
\hline 2478 & $\mathrm{NS}(=\mathrm{O})(=\mathrm{O}) \mathrm{c} 1 \mathrm{ccc}(\mathrm{Nc} 2 \mathrm{nncc} 3 \operatorname{cccc} 23) \mathrm{cc} 1$ & 140 & $*$ \\
\hline 2479 & $\mathrm{NC}(=\mathrm{O}) \mathrm{COCc} 1 \mathrm{ccn} 2 \mathrm{ncnc}(\mathrm{Nc} 3 \operatorname{ccc} 4 \mathrm{c}(\operatorname{cnn} 4 \mathrm{Cc} 4 \mathrm{cccc}(\mathrm{F}) \mathrm{c} 4) \mathrm{c} 3) \mathrm{c} 12$ & 140 & $*$ \\
\hline 2480 & $\mathrm{Cc} 1 \mathrm{cc} 2 \mathrm{cc}(\mathrm{Nc} 3 \mathrm{ccnc} 4 \mathrm{cc}(-\mathrm{c} 5 \mathrm{ccc}(\mathrm{CN}(\mathrm{C}) \mathrm{CCO}) \operatorname{cc} 5) \operatorname{sc} 34) \operatorname{ccc} 2[\mathrm{nH}] 1$ & 140 & $*$ \\
\hline 2481 & $\mathrm{CC}(\mathrm{C}) \mathrm{C}[\mathrm{C} @ @ \mathrm{H}](\mathrm{NC}(=\mathrm{O}) \mathrm{OC}(\mathrm{C})(\mathrm{C}) \mathrm{C}) \mathrm{C}(=\mathrm{O}) \mathrm{Nc} 1 \mathrm{ccc} 2 \mathrm{ncnc}(\mathrm{Nc} 3 \mathrm{ccc}(\mathrm{F}) \mathrm{c}(\mathrm{Cl}) \mathrm{c} 3) \mathrm{c} 2 \mathrm{c} 1$ & 140 & $*$ \\
\hline 2482 & $\mathrm{COc} 1 \mathrm{cc} 2 \mathrm{ncnc}(\mathrm{Oc} 3 \operatorname{ccc}(\mathrm{NC}(=\mathrm{S}) \mathrm{Nc} 4 \mathrm{ccc}(\mathrm{C}(\mathrm{F})(\mathrm{F}) \mathrm{F}) \mathrm{c} 4) \mathrm{c} 3) \mathrm{c} 2 \mathrm{cc} 1 \mathrm{OC}$ & 140 & $*$ \\
\hline 2483 & $\operatorname{COc} 1 \operatorname{ccc}(-n 2 c(-\mathrm{c} 3 \operatorname{ccc} c 3) \mathrm{c}(-\mathrm{c} 3 \operatorname{ccc} c 3) \mathrm{c} 3 \operatorname{cc} 4 \mathrm{c}(\operatorname{cc} 3 \mathrm{c} 2=\mathrm{O}) \mathrm{CNC}(=\mathrm{O}) \mathrm{N} 4) \mathrm{cc} 1$ & 140 & $*$ \\
\hline 2484 & $\mathrm{COc} 1 \mathrm{cc} 2 \mathrm{ncnc}(\mathrm{Nc} 3 \operatorname{ccc}(\mathrm{F}) \mathrm{c}(\mathrm{Cl}) \mathrm{c} 3) \mathrm{c} 2 \mathrm{cc} 1 \mathrm{NC}(=\mathrm{O}) / \mathrm{C}=\mathrm{C} / \mathrm{CNC} 1 \mathrm{CC}(\mathrm{F})(\mathrm{F}) \mathrm{C} 1$ & 141 & $*$ \\
\hline 2485 & $\mathrm{CCOC}(=\mathrm{O}) \mathrm{O}[\mathrm{C} @ \mathrm{H}] 1 \mathrm{CN}[\mathrm{C} @ \mathrm{H}](\mathrm{C} \# \mathrm{Cc} 2 \mathrm{cc} 3 \mathrm{ncnc}(\mathrm{Nc} 4 \mathrm{ccc}(\mathrm{OCc} 5 \mathrm{ccc}(\mathrm{F}) \mathrm{c} 5) \mathrm{c}(\mathrm{Cl}) \mathrm{c} 4) \mathrm{c} 3 \mathrm{~s} 2) \mathrm{C} 1$ & 141 & $*$ \\
\hline 2486 & $\mathrm{Cc} 1 \mathrm{cccc}(\mathrm{NC}(=\mathrm{O}) \mathrm{c} 2 \mathrm{ccc}(\mathrm{OCCCN} 3 \mathrm{CCOCC} 3) \mathrm{cc} 2 \mathrm{O}) \mathrm{c} 1$ & 142.1 & $*$ \\
\hline 2487 & $\mathrm{C}=\mathrm{CC}(=\mathrm{O}) \mathrm{Nc} 1 \mathrm{ccccc} 1 \mathrm{Nc} 1 \mathrm{nc}(\mathrm{Nc} 2 \mathrm{ccc}(\mathrm{OCC}(=\mathrm{O}) \mathrm{N} 3 \mathrm{CCOCC} 3) \mathrm{cc} 2) \mathrm{ncc} 1 \mathrm{Cl}$ & 142.9 & * \\
\hline 2488 & $\mathrm{C}=\mathrm{CC}(=\mathrm{O}) \mathrm{Nc} 1 \mathrm{cccc}(\mathrm{NC}(=\mathrm{O}) \mathrm{Nc} 2 \operatorname{ccnc}(\mathrm{Nc} 3 \operatorname{ccc}(\mathrm{N} 4 \mathrm{CCN}(\mathrm{C}) \mathrm{CC} 4) \mathrm{cc} 3) \mathrm{n} 2) \mathrm{c} 1$ & 143 & $*$ \\
\hline 2489 & $\mathrm{CCC}(=\mathrm{O}) \mathrm{N} 1 \mathrm{CC}[\mathrm{C} @ \mathrm{H}](\mathrm{N} 2 \mathrm{C}(=\mathrm{O}) \mathrm{N}(\mathrm{c} 3 \mathrm{cccc}(\mathrm{Cl}) \mathrm{c} 3) \mathrm{Cc} 3 \mathrm{cnc}(\mathrm{Nc} 4 \mathrm{ccc}(\mathrm{N} 5 \mathrm{CCN}(\mathrm{C}) \mathrm{CC} 5) \mathrm{c}(\mathrm{C}) \mathrm{c} 4) \mathrm{nc} 32) \mathrm{C} 1$ & 144 & 6.84 \\
\hline 2490 & $\mathrm{~S}=\mathrm{C}(\mathrm{Nc} 1 \mathrm{cc}(\mathrm{Cl}) \mathrm{cc}(\mathrm{Cl}) \mathrm{c} 1) \mathrm{Nc} 1 \mathrm{ccc} 2 \mathrm{ncnc}(\mathrm{Nc} 3 \operatorname{ccc}(\mathrm{Br}) \mathrm{c} 3) \mathrm{c} 2 \mathrm{c} 1$ & 146.3 & $*$ \\
\hline 2491 & $\mathrm{Nc} 1 \mathrm{nc}(\mathrm{Nc} 2 \mathrm{cccc}(\mathrm{Br}) \mathrm{c} 2) \mathrm{c} 2 \mathrm{c}(\mathrm{n} 1)[\mathrm{nH}] \mathrm{c} 1 \mathrm{cccc} 12$ & 147 & $*$ \\
\hline 2492 & $\mathrm{CN}(\mathrm{C}) \mathrm{C} / \mathrm{C}=\mathrm{C} / \mathrm{C}(=\mathrm{O}) \mathrm{Nc} 1 \mathrm{cc} 2 \mathrm{c}(\mathrm{Nc} 3 \mathrm{ccc}(\mathrm{F}) \mathrm{c}(\mathrm{C \# N}) \mathrm{c} 3) \mathrm{ncnc} 2 \mathrm{cc} 1 \mathrm{O}[\mathrm{C} @ \mathrm{H}] 1 \mathrm{CCOC} 1$ & 147.4 & $*$ \\
\hline 2493 & $\mathrm{C}=\mathrm{CC}(=\mathrm{O}) \mathrm{Nc} 1 \mathrm{cc}(\mathrm{Nc} 2 \mathrm{nccc}(\mathrm{NC}(=\mathrm{O}) \mathrm{c} 3 \operatorname{cccc}(\mathrm{OC}) \mathrm{c} 3) \mathrm{n} 2) \mathrm{c}(\mathrm{OC}) \mathrm{cc} 1 \mathrm{~N} 1 \mathrm{CCN}(\mathrm{C}) \mathrm{CC} 1$ & 147.4 & * \\
\hline 2494 & $\mathrm{CCC}(=\mathrm{O}) \mathrm{N} 1 \mathrm{CC}[\mathrm{C} @ \mathrm{H}](\mathrm{N} 2 \mathrm{C}(=\mathrm{O}) \mathrm{N}(\mathrm{c} 3 \mathrm{cc}(\mathrm{OC}) \mathrm{ccc} 3 \mathrm{~F}) \mathrm{Cc} 3 \mathrm{cnc}(\mathrm{Nc} 4 \mathrm{ccc}(\mathrm{N} 5 \mathrm{CCN}(\mathrm{C}(\mathrm{C})=\mathrm{O}) \mathrm{CC} 5) \mathrm{c}(\mathrm{C}) \mathrm{c} 4) \mathrm{nc} 32) \mathrm{C} 1$ & 148 & 6.83 \\
\hline 2495 & $\mathrm{COc} 1 \mathrm{cc} 2 \mathrm{ncnc}(\mathrm{Nc} 3 \operatorname{ccc}(\mathrm{Cc} 4 \mathrm{ccc} n 4) \operatorname{cc} 3) \mathrm{c} 2 \mathrm{cc} 1 \mathrm{NC}(=\mathrm{O}) / \mathrm{C}=\mathrm{C} / \mathrm{CN} 1 \mathrm{CCCC} 1$ & 148 & $*$ \\
\hline 2496 & $\mathrm{C}=\mathrm{CC}(=\mathrm{O}) \mathrm{Nc} 1 \mathrm{cc}(\mathrm{Nc} 2 \mathrm{nccc}(\mathrm{NC}(=\mathrm{O}) \mathrm{c} 3 \mathrm{ccc}(\mathrm{OC}) \mathrm{c}(\mathrm{OC}) \mathrm{c} 3) \mathrm{n} 2) \mathrm{c}(\mathrm{OC}) \mathrm{cc} 1 \mathrm{~N}(\mathrm{C}) \mathrm{C}$ & 148.8 & $*$ \\
\hline 2497 & $\mathrm{CN}(\mathrm{C}) \mathrm{C} / \mathrm{C}=\mathrm{C} / \mathrm{C}(=\mathrm{O}) \mathrm{N} 1 \mathrm{CCc} 2 \mathrm{c}(\operatorname{sc} 3 n \mathrm{ncnc}(\mathrm{N}[\mathrm{C} @ \mathrm{H}](\mathrm{CO}) \mathrm{Cc} 4 \operatorname{ccccc} 4) \mathrm{c} 23) \mathrm{C} 1$ & 149 & $*$ \\
\hline 2498 & $\mathrm{C}=\mathrm{CC}(=\mathrm{O}) \mathrm{Nc} 1 \mathrm{cc}(\mathrm{Nc} 2 \mathrm{nccc}(\mathrm{Nc} 3 \operatorname{ccccc} 3 \mathrm{P}(\mathrm{C})(\mathrm{C})=\mathrm{O}) \mathrm{n} 2) \mathrm{c}(\mathrm{OC}) \mathrm{cc} 1 \mathrm{~N}(\mathrm{C}) \mathrm{CCN}(\mathrm{C}) \mathrm{C}$ & 149 & $*$ \\
\hline 2499 & $\mathrm{COc} 1 \mathrm{cc} 2 \mathrm{c}(\mathrm{cc} 1 \mathrm{OC}) \mathrm{Nc} 1 \mathrm{ncnc}(\mathrm{N}[\mathrm{C} @ \mathrm{H}](\mathrm{C}) \mathrm{c} 3 \mathrm{ccccc} 3) \mathrm{c} 1 \mathrm{NC} 2$ & 150 & 6.82 \\
\hline 2500 & $\operatorname{COCC} 1 \mathrm{CCCN} 1 \mathrm{CC} \# \mathrm{CC}(=\mathrm{O}) \mathrm{Nc} 1 \mathrm{ccc} 2 \mathrm{ncc}(\mathrm{C} \# \mathrm{~N}) \mathrm{c}(\mathrm{Nc} 3 \operatorname{cccc}(\mathrm{Br}) \mathrm{c} 3) \mathrm{c} 2 \mathrm{c} 1$ & 150 & 6.82 \\
\hline 2501 & $\mathrm{COC}[\mathrm{C} @ @ \mathrm{H}] 1 \mathrm{CCCN} 1 \mathrm{CC} \# \mathrm{CC}(=\mathrm{O}) \mathrm{Nc} 1 \mathrm{ccc} 2 \mathrm{ncc}(\mathrm{C \# N}) \mathrm{c}(\mathrm{Nc} 3 \operatorname{cccc}(\mathrm{Br}) \mathrm{c} 3) \mathrm{c} 2 \mathrm{c} 1$ & 150 & 6.82 \\
\hline 2502 & $\mathrm{O}=\mathrm{C}(\mathrm{O}[\mathrm{C} @ \mathrm{H}] 1 \mathrm{CN}[\mathrm{C} @ \mathrm{H}](\mathrm{C} \# \mathrm{Cc} 2 \mathrm{cc} 3 \mathrm{ncnc}(\mathrm{Nc} 4 \mathrm{ccc} 5 \mathrm{c}(\operatorname{ccn} 5 \mathrm{~S}(=\mathrm{O})(=\mathrm{O}) \mathrm{c} 5 \mathrm{ccsc} 5) \mathrm{c} 4) \mathrm{c} 3 \mathrm{~s} 2) \mathrm{C} 1) \mathrm{N} 1 \mathrm{CCOCC} 1$ & 150 & 6.82 \\
\hline 2503 & $\mathrm{COc} 1 \mathrm{cc} 2 \mathrm{ncnc}(\mathrm{Nc} 3 \operatorname{ccc}(\mathrm{Cl}) \mathrm{c} 3 \mathrm{~F}) \mathrm{c} 2 \mathrm{cc} 1 \mathrm{CN}[\mathrm{C} @ \mathrm{H}](\mathrm{C}) \mathrm{C}(\mathrm{N})=\mathrm{O}$ & 150 & $*$ \\
\hline
\end{tabular}




\begin{tabular}{|c|c|c|c|}
\hline 2504 & $\mathrm{C}[\mathrm{C} @ @ \mathrm{H}](\mathrm{Nc} 1 \mathrm{ncnc} 2 \mathrm{sc}(\mathrm{Br}) \mathrm{cc} 12) \mathrm{c} 1 \mathrm{ccc}(\mathrm{F}) \mathrm{cc} 1$ & 150 & $*$ \\
\hline 2505 & $\mathrm{Cc} 1 \mathrm{ccc}(\mathrm{S}(=\mathrm{O})(=\mathrm{O}) \mathrm{N} 2 \mathrm{CCO} 3 \mathrm{cc} 4 \mathrm{ncnc}(\mathrm{Nc} 5 \mathrm{cccc}(\mathrm{Br}) \mathrm{c} 5) \mathrm{c} 4 \mathrm{cc} 3 \mathrm{OCC} 2) \mathrm{cc} 1$ & 150 & $*$ \\
\hline 2506 & $\mathrm{CN} 1 \mathrm{CCN}(\mathrm{CCCNc} 2 \mathrm{ncc} 3 \mathrm{cc}(-\mathrm{c} 4 \mathrm{c}(\mathrm{Cl}) \operatorname{cccc} 4 \mathrm{Cl}) \mathrm{c}(\mathrm{NC}(=\mathrm{O}) \mathrm{NC}(\mathrm{C})(\mathrm{C}) \mathrm{C}) \mathrm{nc} 3 \mathrm{n} 2) \mathrm{CC} 1$ & 150 & * \\
\hline 2507 & $\mathrm{Cn} 1 \mathrm{c}(=\mathrm{O}) \mathrm{c}(-\mathrm{c} 2 \mathrm{c}(\mathrm{Cl}) \mathrm{ccc} 2 \mathrm{Cl}) \mathrm{cc} 2 \mathrm{cnc}(\mathrm{Nc} 3 \mathrm{cccc}(\mathrm{O}) \mathrm{c} 3) \mathrm{nc} 21$ & 150 & $*$ \\
\hline 2508 & $\mathrm{NC} 1 \mathrm{CCN}(\mathrm{Cc} 2 \mathrm{ccn} 3 \mathrm{ncnc}(\mathrm{Nc} 4 \mathrm{ccc}(\mathrm{OCc} 5 \mathrm{cccnc} 5) \mathrm{c}(\mathrm{Cl}) \mathrm{c} 4) \mathrm{c} 23) \mathrm{CC} 1$ & 150 & $*$ \\
\hline 2509 & $\mathrm{COc} 1 \mathrm{cc} 2 \mathrm{c}(\mathrm{Nc} 3 \mathrm{ccc}(\mathrm{NC}(=\mathrm{O}) \mathrm{c} 4 \mathrm{cccc}(\mathrm{Cl}) \mathrm{c} 4) \mathrm{cc} 3) \mathrm{ncnc} 2 \mathrm{cc} 1 \mathrm{OCCCN} 1 \mathrm{CCN}(\mathrm{C}) \mathrm{CC} 1$ & 150 & $*$ \\
\hline 2510 & Cc1nnc(-c2en3ncnc(Nc4cnc5[nH]ccc5c4)c3c2C(C)C)o1 & 150 & $*$ \\
\hline 2511 & $\mathrm{CN}(\mathrm{C}) \mathrm{C} / \mathrm{C}=\mathrm{C} / \mathrm{C}(=\mathrm{O}) \mathrm{Nc} 1 \mathrm{ccc} 2 \mathrm{c}(\mathrm{C \# N}) \mathrm{cnc}(\mathrm{Nc} 3 \operatorname{ccc}(\mathrm{Br}) \mathrm{c} 3) \mathrm{c} 2 \mathrm{c} 1$ & 150 & $*$ \\
\hline 2512 & Nc1ncce(-c2c(-c3ecc(F)cc3)ncn2C2CCCCC2)n1 & 150 & $*$ \\
\hline 2513 & $\mathrm{N \# CC1}=\mathrm{C}(\mathrm{c} 2 \operatorname{ccccc} 2) \mathrm{Nc} 2 \mathrm{c}(\mathrm{c}(-\mathrm{c} 3 \operatorname{ccc} 3) n n 2-\mathrm{c} 2 \operatorname{cccc} 2) \mathrm{C} 12 \mathrm{C}(=\mathrm{O}) \mathrm{Nc} 1 \mathrm{ccc}(\mathrm{Cl}) \operatorname{cc} 12$ & 150 & $*$ \\
\hline 2514 & $\begin{array}{c}\mathrm{CN}(\mathrm{CCN}(\mathrm{CCN} 1 \mathrm{CCOCC} 1) \mathrm{CCN}(\mathrm{C}) / \mathrm{N}=\mathrm{N} / \mathrm{c} 1 \mathrm{ccc} 2 \mathrm{ncnc}(\mathrm{Nc} 3 \mathrm{cccc}(\mathrm{Cl}) \mathrm{c} 3) \mathrm{c} 2 \mathrm{c} 1) / \mathrm{N}=\mathrm{N} / \mathrm{c} 1 \mathrm{ccc} 2 \mathrm{ncnc}(\mathrm{Nc} 3 \mathrm{cccc}(\mathrm{Cl}) \mathrm{c} 3) \mathrm{c} 2 \\
\mathrm{c} 1\end{array}$ & 150 & * \\
\hline 2515 & $\mathrm{~N} \# \mathrm{Cc} 1 \mathrm{cccc}(\mathrm{Oc} 2 \mathrm{ccc}(\mathrm{Nc} 3 \mathrm{ncnc} 4 \mathrm{cc}[\mathrm{nH}] \mathrm{c} 34) \mathrm{cc} 2 \mathrm{Cl}) \mathrm{c} 1$ & 150 & $*$ \\
\hline 2516 & $\mathrm{Fc} 1 \mathrm{cccc}(\mathrm{Oc} 2 \mathrm{ccc}(\mathrm{Nc} 3 \mathrm{ncnc} 4 \mathrm{cc}[\mathrm{nH}] \mathrm{c} 34) \mathrm{cc} 2 \mathrm{Cl}) \mathrm{c} 1$ & 150 & $*$ \\
\hline 2517 & $\mathrm{FC}(\mathrm{F})(\mathrm{F}) \mathrm{c} 1 \mathrm{ccccc} 1 \mathrm{Oc} 1 \mathrm{ccc}(\mathrm{Nc} 2 \mathrm{ncnc} 3 \mathrm{cc}[\mathrm{nH}] \mathrm{c} 23) \mathrm{cc} 1 \mathrm{Cl}$ & 150 & $*$ \\
\hline 2518 & $\operatorname{COc} 1 \operatorname{ccc}(-\mathrm{c} 2 \mathrm{cc} 3 \operatorname{cc}(\mathrm{Br}) \operatorname{cc}(\mathrm{C}(=\mathrm{O}) / \mathrm{C}=\mathrm{C} / \mathrm{c} 4 \mathrm{ccc}(\mathrm{F}) \mathrm{cc} 4) \mathrm{c} 3 \mathrm{o} 2) \mathrm{cc} 1$ & 150 & $*$ \\
\hline 2519 & $\mathrm{CCOc} 1 \mathrm{cc} 2 \mathrm{ncc}(\mathrm{C} \# \mathrm{~N}) \mathrm{c}(\mathrm{Nc} 3 \operatorname{ccc}(\mathrm{OCc} 4 \operatorname{ccccc} 4) \mathrm{c}(\mathrm{Cl}) \mathrm{c} 3) \mathrm{c} 2 \mathrm{cc} 1 \mathrm{NC}(=\mathrm{O}) / \mathrm{C}=\mathrm{C} / \mathrm{CN} 1 \mathrm{CCCC} 1 \mathrm{COC}$ & 151 & 6.82 \\
\hline 2520 & $\mathrm{Cc} 1 \mathrm{cc} 2 \mathrm{c}(\mathrm{Nc} 3 \mathrm{ccc}(\mathrm{F}) \mathrm{c}(\mathrm{Cl}) \mathrm{c} 3) \mathrm{ncnn} 2 \mathrm{c} 1$ & 151 & $*$ \\
\hline 2521 & $\mathrm{C}=\mathrm{CC}(=\mathrm{O}) \mathrm{Nc} 1 \mathrm{cc}(\mathrm{Nc} 2 \mathrm{ncc}(\mathrm{Cl}) \mathrm{c}(\mathrm{Nc} 3 \operatorname{cccc} 3 \mathrm{~S}(=\mathrm{O})(=\mathrm{O}) \mathrm{C}(\mathrm{C}) \mathrm{C}) \mathrm{n} 2) \mathrm{c}(\mathrm{OC}) \operatorname{cc} 1 \mathrm{~N}(\mathrm{C}) \mathrm{CCN}(\mathrm{C}) \mathrm{C}$ & 151 & * \\
\hline 2522 & $\mathrm{CC}(\mathrm{C})(\mathrm{O}) \mathrm{C} \# \mathrm{Cc} 1 \mathrm{ccc} 2 \mathrm{ncnc}(\mathrm{Nc} 3 \mathrm{ccc}(\mathrm{F}) \mathrm{c}(\mathrm{Cl}) \mathrm{c} 3) \mathrm{c} 2 \mathrm{c} 1$ & 151.5 & $*$ \\
\hline 2523 & $\mathrm{COc} 1 \mathrm{cc} 2 \mathrm{ncnc}(\mathrm{N}(\mathrm{C}) \mathrm{c} 3 \operatorname{cccc}(\mathrm{Br}) \mathrm{c} 3) \mathrm{c} 2 \mathrm{cc} 1 \mathrm{OC}$ & 152 & $*$ \\
\hline 2524 & $\mathrm{O}=\mathrm{C} 1 \mathrm{NCc} 2 \mathrm{cc} 3 \mathrm{c}(=\mathrm{O}) \mathrm{n}(-\mathrm{c} 4 \operatorname{ccccc} 4) \mathrm{c}(-\mathrm{c} 4 \mathrm{ccccc} 4) \mathrm{c}(-\mathrm{c} 4 \operatorname{ccccc} 4) \mathrm{c} 3 \operatorname{cc} 2 \mathrm{~N} 1$ & 152 & $*$ \\
\hline 2525 & $\mathrm{C}=\mathrm{CC}(=\mathrm{O}) \mathrm{Nc} 1 \mathrm{cc}(\mathrm{Nc} 2 \mathrm{nccc}(\mathrm{NC}(=\mathrm{O}) \mathrm{c} 3 \operatorname{ccc}(\mathrm{C}(\mathrm{F})(\mathrm{F}) \mathrm{F}) \mathrm{cc} 3) \mathrm{n} 2) \mathrm{c}(\mathrm{OC}) \mathrm{cc} 1 \mathrm{~N} 1 \mathrm{CCN}(\mathrm{C}) \mathrm{CC} 1$ & 152.2 & $*$ \\
\hline 2526 & $\mathrm{CCC}(=\mathrm{O}) \mathrm{N} 1 \mathrm{CC}[\mathrm{C} @ \mathrm{H}](\mathrm{N} 2 \mathrm{C}(=\mathrm{O}) \mathrm{N}(\mathrm{c} 3 \mathrm{ccc}(\mathrm{OC}) \mathrm{cc} 3) \mathrm{Cc} 3 \mathrm{cnc}(\mathrm{Nc} 4 \mathrm{ccc}(\mathrm{N} 5 \mathrm{CCN}(\mathrm{C}) \mathrm{CC} 5) \mathrm{c}(\mathrm{C}) \mathrm{c} 4) \mathrm{nc} 32) \mathrm{C} 1$ & 153 & 6.82 \\
\hline 2527 & COc1cccc1-c1cc2c(N[C@H](C)c3eccen3)ncnc2s1 & 153 & $*$ \\
\hline 2528 & $\mathrm{C}=\mathrm{CC}(=\mathrm{O}) \mathrm{Nc} 1 \mathrm{cc}(\mathrm{Nc} 2 \mathrm{nccc}(\mathrm{NC}(=\mathrm{O}) \mathrm{c} 3 \operatorname{cccc}(\mathrm{OC}) \mathrm{c} 3) \mathrm{n} 2) \mathrm{c}(\mathrm{OC}) \mathrm{cc} 1 \mathrm{~N}(\mathrm{C}) \mathrm{CCN}(\mathrm{C}) \mathrm{C}$ & 153.5 & $*$ \\
\hline 2529 & $\mathrm{C}=\mathrm{CC}(=\mathrm{O}) \mathrm{Nc} 1 \mathrm{cccc}(\mathrm{Oc} 2 \mathrm{nc}(\mathrm{Nc} 3 \operatorname{ccc}(\mathrm{N} 4 \mathrm{CCN}(\mathrm{C}(=\mathrm{O}) \mathrm{CC}) \mathrm{CC} 4) \operatorname{cc} 3 \mathrm{OC}) \mathrm{ncc} 2 \mathrm{SC}) \mathrm{c} 1$ & 153.7 & $*$ \\
\hline 2530 & $\mathrm{CCN} 1 \mathrm{CCN}(\mathrm{C}(=\mathrm{O}) / \mathrm{C}(\mathrm{F})=\mathrm{C} / \mathrm{c} 2 \mathrm{c}(\mathrm{C}) \mathrm{ncn} \operatorname{coN} 2 \operatorname{ccc}(\mathrm{OCc} 3 \operatorname{cccc}(\mathrm{F}) \mathrm{c} 3) \mathrm{c}(\mathrm{Cl}) \mathrm{c} 2) \mathrm{CC} 1$ & 156 & 6.81 \\
\hline 2531 & $\mathrm{CC}(\mathrm{Nc} 1 \mathrm{ncnc} 2 \mathrm{sc}(\mathrm{Br}) \mathrm{cc} 12) \mathrm{c} 1 \mathrm{ccccc} 1$ & 156 & $*$ \\
\hline 2532 & $\mathrm{C}=\mathrm{CC}(=\mathrm{O}) \mathrm{Nc} 1 \mathrm{cc}(\mathrm{Nc} 2 \mathrm{nccc}(\mathrm{NC}(=\mathrm{O}) \mathrm{c} 3 \operatorname{ccccc} 3) \mathrm{n} 2) \mathrm{c}(\mathrm{OC}) \operatorname{cc} 1 \mathrm{~N} 1 \mathrm{CCN}(\mathrm{C}) \mathrm{CC} 1$ & 156.5 & * \\
\hline 2533 & $\mathrm{C}=\mathrm{CC}(=\mathrm{O}) \mathrm{Nc} 1 \mathrm{cc}(\mathrm{Nc} 2 \mathrm{nccc}(\mathrm{NC}(=\mathrm{O}) \mathrm{c} 3 \operatorname{ccc}(\mathrm{OC}) \mathrm{c}(\mathrm{OC}) \mathrm{c} 3) \mathrm{n} 2) \mathrm{c}(\mathrm{OC}) \mathrm{cc} 1 \mathrm{~N} 1 \mathrm{CCN}(\mathrm{C}) \mathrm{CC} 1$ & 157.5 & $*$ \\
\hline 2534 & $\mathrm{COc} 1 \mathrm{cc} 2 \mathrm{ncnc}(\mathrm{Nc} 3 \mathrm{ccc}(\mathrm{F}) \mathrm{c}(\mathrm{Cl}) \mathrm{c} 3) \mathrm{c} 2 \mathrm{cc} 1 \mathrm{OCCN} 1 \mathrm{CC} 2(\mathrm{C} 1) \mathrm{CS}(=\mathrm{O})(=\mathrm{O}) \mathrm{C} 2$ & 158 & 6.80 \\
\hline 2535 & $\mathrm{Cl} . \mathrm{O}=[\mathrm{N}+]([\mathrm{O}-]) \mathrm{c} 1 \mathrm{cccc} 2 \mathrm{c} 1 \mathrm{sc} 1 \mathrm{c}(\mathrm{Nc} 3 \mathrm{cccc}(\mathrm{Br}) \mathrm{c} 3) \mathrm{ncnc} 12$ & 158 & $*$ \\
\hline 2536 & $\mathrm{CC}(\mathrm{C}) \mathrm{n} 1 \mathrm{nc}(-\mathrm{c} 2 \mathrm{ccc}(\mathrm{Cl}) \mathrm{c}(\mathrm{O}) \mathrm{c} 2) \mathrm{c} 2 \mathrm{c}(\mathrm{N}) \mathrm{ncnc} 21$ & 158 & $*$ \\
\hline 2537 & $\mathrm{C}=\mathrm{CC}(=\mathrm{O}) \mathrm{Nc} 1 \mathrm{cccc}(\mathrm{NC}(=\mathrm{O}) \mathrm{Nc} 2 \operatorname{ccnc}(\mathrm{Nc} 3 \operatorname{ccc}(\mathrm{N} 4 \mathrm{CCN}(\mathrm{CCF}) \mathrm{CC} 4) \operatorname{cc} 3 \mathrm{OC}) \mathrm{n} 2) \mathrm{c} 1$ & 158 & $*$ \\
\hline 2538 & $\mathrm{COC}(=\mathrm{O}) \mathrm{c} 1 \mathrm{ccc} 2 \mathrm{oc} 3 \mathrm{cnn} c(\mathrm{NCc} 4 \operatorname{ccccc} 4) \mathrm{c} 3 \mathrm{c} 2 \mathrm{c} 1$ & 158.5 & 6.80 \\
\hline 2539 & $\mathrm{CN}(\mathrm{C}) \mathrm{c} 1 \mathrm{cc} 2 \mathrm{ncnc}(\mathrm{Nc} 3 \mathrm{cccc}(\mathrm{Br}) \mathrm{c} 3) \mathrm{c} 2 \mathrm{cc} 1 \mathrm{~N}$ & 159 & $*$ \\
\hline 2540 & $\mathrm{COCCOc} 1 \mathrm{cc} 2 \mathrm{ncnc}(\mathrm{Nc} 3 \mathrm{cccc}(\mathrm{OC}) \mathrm{c} 3) \mathrm{c} 2 \mathrm{c} 2 \mathrm{c} 1 \mathrm{OCCO} 2$ & 159.9 & $*$ \\
\hline 2541 & $\operatorname{COc} 1 \operatorname{ccc}(\mathrm{C} 2=\mathrm{NN}(\mathrm{C}(\mathrm{N})=\mathrm{S}) \mathrm{C}(\mathrm{c} 3 \operatorname{cccc} 4 \operatorname{ccccc} 34) \mathrm{C} 2) \mathrm{cc} 1$ & 160 & 6.80 \\
\hline 2542 & $\mathrm{CC}(\mathrm{C}) \mathrm{c} 1 \mathrm{ccc}(\mathrm{C}(=\mathrm{O}) \mathrm{Nc} 2 \operatorname{ccc}(\mathrm{CN} 3 \mathrm{CCN}(\mathrm{C}) \mathrm{CC} 3) \mathrm{c}(\mathrm{C}(\mathrm{F})(\mathrm{F}) \mathrm{F}) \mathrm{c} 2) \mathrm{cc} 1 \mathrm{NC}(=\mathrm{O}) \mathrm{c} 1 \mathrm{cnc} 2[\mathrm{nH}] \operatorname{ccc} 2 \mathrm{c} 1$ & 160 & 6.80 \\
\hline 2543 & $\mathrm{O}=\mathrm{C}(\mathrm{CBr}) \mathrm{OCCn} 1 \mathrm{c}(=\mathrm{O}) \mathrm{oc} 2 \mathrm{cc} 3 \mathrm{ncnc}(\mathrm{Nc} 4 \operatorname{ccc}(\mathrm{Oc} 5 \operatorname{cccc}(\mathrm{C}(\mathrm{F})(\mathrm{F}) \mathrm{F}) \mathrm{c} 5) \mathrm{c}(\mathrm{Cl}) \mathrm{c} 4) \mathrm{c} 3 \mathrm{cc} 21$ & 160 & 6.80 \\
\hline 2544 & $\mathrm{CS}(=\mathrm{O})(=\mathrm{O}) \mathrm{CCNCc} 1 \mathrm{ccc}(-\mathrm{c} 2 \mathrm{ccc} 3 \mathrm{ncnc}(\mathrm{Nc} 4 \mathrm{ccc}(\mathrm{OCc} 5 \operatorname{ccccc} 5) \mathrm{c}(\mathrm{C}(\mathrm{F})(\mathrm{F}) \mathrm{F}) \mathrm{c} 4) \mathrm{c} 3 \mathrm{c} 2) \mathrm{o} 1$ & 160 & $*$ \\
\hline 2545 & $\operatorname{CCOC}(=O) \operatorname{CCCn} 1 \mathrm{c}(=\mathrm{O}) \mathrm{oc} 2 \mathrm{cc} 3 \mathrm{ncnc}(\mathrm{Nc} 4 \operatorname{ccc}(\mathrm{OC}(\mathrm{C}) \mathrm{C}) \mathrm{cc} 4) \mathrm{c} 3 \mathrm{cc} 21$ & 160 & $*$ \\
\hline
\end{tabular}




\begin{tabular}{|c|c|c|c|}
\hline 2546 & $\mathrm{Nc} 1[\mathrm{nH}] \mathrm{cnc} 2 \mathrm{nnc}(\mathrm{Nc} 3 \mathrm{cccc}(\mathrm{Cl}) \mathrm{c} 3) \mathrm{c} 1-2$ & 160 & $*$ \\
\hline 2547 & NCCCCOCc1 cen2ncnc $(\mathrm{Nc} 3 \operatorname{ccc} 4 \mathrm{c}(\mathrm{cnn} 4 \mathrm{Cc} 4 \mathrm{cccc}(\mathrm{F}) \mathrm{c} 4) \mathrm{c} 3) \mathrm{c} 12$ & 160 & $*$ \\
\hline 2548 & $\mathrm{COc} 1 \mathrm{cc} 2 \mathrm{ncc}(\mathrm{CHN}) \mathrm{c}(\mathrm{Nc} 3 \mathrm{ccc}(\mathrm{F}) \mathrm{c}(\mathrm{C}(\mathrm{F})(\mathrm{F}) \mathrm{F}) \mathrm{c} 3) \mathrm{c} 2 \mathrm{cc} 1 \mathrm{OC} . \mathrm{Cl}$ & 160 & $*$ \\
\hline 2549 & $\mathrm{Cc} 1 \mathrm{ccc}(\mathrm{Nc} 2 \mathrm{ncnc} 3 \mathrm{cc} 4 \mathrm{c}(\mathrm{cc} 23) \mathrm{N}(\mathrm{CCCN} 2 \mathrm{CCOCC} 2) \mathrm{C}(=\mathrm{O}) \mathrm{CO} 4) \mathrm{cc} 1 \mathrm{Cl}$ & 162.7 & $*$ \\
\hline 2550 & $\mathrm{CCOc} 1 \mathrm{cc} 2 \mathrm{ncc}(\mathrm{C \# N}) \mathrm{c}(\mathrm{Nc} 3 \mathrm{cc}(\mathrm{Cl}) \mathrm{c}(\mathrm{OCc} 4 \mathrm{cccc} 4) \mathrm{c}(\mathrm{Cl}) \mathrm{c} 3) \mathrm{c} 2 \mathrm{cc} 1 \mathrm{NC}(=\mathrm{O}) / \mathrm{C}=\mathrm{C} / \mathrm{CN}(\mathrm{C}) \mathrm{C}$ & 163 & 6.79 \\
\hline 2551 & $\mathrm{CCOc} 1 \mathrm{cc} 2 \mathrm{ncnc}(\mathrm{Nc} 3 \operatorname{ccc}(\mathrm{OCc} 4 \mathrm{cccc} n 4) \mathrm{cc} 3) \mathrm{c} 2 \mathrm{cc} 1 \mathrm{NC}(=\mathrm{O}) / \mathrm{C}=\mathrm{C} / \mathrm{CN} 1 \mathrm{CCN}(\mathrm{C}) \mathrm{CC} 1$ & 164 & $*$ \\
\hline 2552 & $\mathrm{C}=\mathrm{CC}(=\mathrm{O}) \mathrm{NCc} 1 \mathrm{cn}(\mathrm{Cc} 2 \mathrm{cccc}(\mathrm{Nc} 3 \mathrm{cc}(-\mathrm{c} 4[\mathrm{nH}] \mathrm{c}(\mathrm{SC}) \mathrm{nc} 4-\mathrm{c} 4 \mathrm{ccc}(\mathrm{F}) \mathrm{cc} 4) \mathrm{ccn} 3) \mathrm{c} 2) \mathrm{nn} 1$ & 164 & $*$ \\
\hline 2553 & $\mathrm{CCOc} 1 \mathrm{cc} 2 \mathrm{ncc}(\mathrm{C \# N}) \mathrm{c}(\mathrm{Nc} 3 \operatorname{ccc}(\mathrm{OCCc} 4 \mathrm{ccccc} 4) \mathrm{c}(\mathrm{Cl}) \mathrm{c} 3) \mathrm{c} 2 \mathrm{cc} 1 \mathrm{NC}(=\mathrm{O}) / \mathrm{C}=\mathrm{C} / \mathrm{CN}(\mathrm{C}) \mathrm{C}$ & 165 & 6.78 \\
\hline 2554 & $\mathrm{O}=\mathrm{C}(\mathrm{NCCN} 1 \mathrm{CCCCC} 1) \mathrm{Nc} 1 \mathrm{cc} 2 \mathrm{c}(\mathrm{Nc} 3 \mathrm{ccc}(\mathrm{F}) \mathrm{c}(\mathrm{Cl}) \mathrm{c} 3) \mathrm{ncnc} 2 \mathrm{cc} 1 \mathrm{O}[\mathrm{C} @ \mathrm{H}] 1 \mathrm{CCOC} 1$ & 165 & * \\
\hline 2555 & $\mathrm{CCN}(\mathrm{CCO}) \mathrm{CCCOc} 1 \mathrm{ccc} 2 \mathrm{c}(\mathrm{Nc} 3 \operatorname{ccc}(\mathrm{NC}(=\mathrm{O}) \mathrm{Nc} 4 \mathrm{ccc}(\mathrm{F}) \mathrm{c}(\mathrm{Cl}) \mathrm{c} 4) \mathrm{c} 3) \mathrm{ncnc} 2 \mathrm{c} 1$ & 165 & $*$ \\
\hline 2556 & $\mathrm{O}=\mathrm{C}(\mathrm{Nc} 1 \mathrm{cc} 2 \mathrm{c}(\mathrm{Nc} 3 \mathrm{ccc}(\mathrm{F}) \mathrm{c}(\mathrm{Cl}) \mathrm{c} 3) \mathrm{ncnc} 2 \mathrm{cc} 1 \mathrm{O}[\mathrm{C} @ \mathrm{H}] 1 \mathrm{CCOC} 1) \mathrm{N}(\mathrm{NCCN} 1 \mathrm{CCCCC} 1) \mathrm{NCN} 1 \mathrm{CCCCC} 1$ & 165 & $*$ \\
\hline 2557 & $\mathrm{Cn} 1 \mathrm{cnc}(-\mathrm{c} 2 \mathrm{cc}(\mathrm{NC}(=\mathrm{O}) \mathrm{Nc} 3 \mathrm{ccncc} 3) \mathrm{cc}(\mathrm{C}(\mathrm{F})(\mathrm{F}) \mathrm{F}) \mathrm{c} 2) \mathrm{c} 1$ & 165.6 & $*$ \\
\hline 2558 & $\mathrm{C}=\mathrm{CC}(=\mathrm{O}) \mathrm{Nc} 1 \mathrm{cc}(-\mathrm{n} 2 \mathrm{c}(=\mathrm{O}) \mathrm{cc}(\mathrm{C}) \mathrm{c} 3 \mathrm{cnc}(\mathrm{Nc} 4 \mathrm{cnn}(\mathrm{C} 5 \mathrm{CCN}(\mathrm{C}) \mathrm{CC} 5) \mathrm{c} 4) \mathrm{nc} 32) \mathrm{cc}(\mathrm{C}(\mathrm{F})(\mathrm{F}) \mathrm{F}) \mathrm{c} 1$ & 166.2 & $*$ \\
\hline 2559 & $\mathrm{CCOc} 1 \mathrm{cc} 2 \mathrm{ncnc}(\mathrm{NC} 3=\mathrm{CC}(=\mathrm{O}) \mathrm{C}(\mathrm{OCc} 4 \mathrm{ccc}(\mathrm{F}) \mathrm{c}(\mathrm{F}) \mathrm{c} 4)=\mathrm{CC} 3=\mathrm{O}) \mathrm{c} 2 \mathrm{cc} 1 \mathrm{NC}(=\mathrm{O}) / \mathrm{C}=\mathrm{C} / \mathrm{CN}(\mathrm{C}) \mathrm{C}$ & 166.7 & 6.78 \\
\hline 2560 & $\mathrm{C}=\mathrm{CC}(=\mathrm{O}) \mathrm{Nc} 1 \mathrm{cc} 2 \mathrm{c}(\mathrm{Nc} 3 \mathrm{ccc}(\mathrm{F}) \mathrm{c}(\mathrm{C \# N}) \mathrm{c} 3) n \mathrm{cnc} 2 \mathrm{cc} 1 \mathrm{O}[\mathrm{C} @ \mathrm{H}] 1 \mathrm{CCOC} 1$ & 167.3 & $*$ \\
\hline 2561 & $\mathrm{N \# Cc1} \operatorname{cccc}(\mathrm{Oc} 2 \mathrm{ccc}(\mathrm{Nc} 3 \mathrm{ncnc} 4 \mathrm{cc}(\mathrm{OCCCN} 5 \mathrm{CCOCC} 5) \mathrm{c}(\mathrm{NC}(=\mathrm{O}) \mathrm{c} 5 \mathrm{cc}([\mathrm{N}+](=\mathrm{O})[\mathrm{O}-]) \operatorname{ccc} 5 \mathrm{~F}) \mathrm{cc} 34) \mathrm{cc} 2 \mathrm{Cl}) \mathrm{c} 1$ & 169 & 6.77 \\
\hline 2562 & $\mathrm{C}=\mathrm{CC}(=\mathrm{O}) \mathrm{Nc} 1 \mathrm{cccc}(-\mathrm{n} 2 \mathrm{c}(=\mathrm{O}) \mathrm{cc}(\mathrm{C}) \mathrm{c} 3 \mathrm{cnc}(\mathrm{Nc} 4 \mathrm{ccc}(\mathrm{N} 5 \mathrm{CCN}(\mathrm{C}) \mathrm{C}(\mathrm{C}) \mathrm{C} 5) \mathrm{cc} 4 \mathrm{OC}) \mathrm{nc} 32) \mathrm{c} 1$ & 169.2 & $*$ \\
\hline 2563 & $\mathrm{O}=\mathrm{C}(\mathrm{Nc} 1 \mathrm{ccc} 2 \mathrm{ncnc}(\mathrm{Nc} 3 \mathrm{ccc}(\mathrm{Cl}) \mathrm{c} 3) \mathrm{c} 2 \mathrm{c} 1) \mathrm{C} 1 \mathrm{CCC} 2(\mathrm{CC} 1) \mathrm{OCC} 1(\mathrm{CO} 2) \mathrm{C} 2 \mathrm{CC} 3 \mathrm{CC}(\mathrm{C} 2) \mathrm{CC} 1 \mathrm{C} 3$ & 169.4 & $*$ \\
\hline 2564 & $\mathrm{COc} 1 \mathrm{cc} 2 \mathrm{ncnc}(\mathrm{Nc} 3 \operatorname{cccc}(\mathrm{Cl}) \mathrm{c} 3 \mathrm{~F}) \mathrm{c} 2 \mathrm{cc} 1 \mathrm{CN} 1 \mathrm{CCC}[\mathrm{C} @ \mathrm{H}] 1 \mathrm{CC}(\mathrm{N})=\mathrm{O}$ & 170 & $*$ \\
\hline 2565 & $\mathrm{COc} 1 \mathrm{ccccc} 1-\mathrm{c} 1 \mathrm{cc} 2 \mathrm{c}(\mathrm{NCc} 3 \mathrm{ccc} 3) \mathrm{ncnc} 2 \mathrm{~s} 1$ & 170 & $*$ \\
\hline 2566 & $\mathrm{C}=\mathrm{CC}(=\mathrm{O}) \mathrm{Nc} 1 \mathrm{cccc}(-\mathrm{n} 2 \mathrm{c}(=\mathrm{O}) \mathrm{cc}(\mathrm{C}) \mathrm{c} 3 \mathrm{cnc}(\mathrm{Nc} 4 \mathrm{ccc}(\mathrm{N} 5 \mathrm{CCN}(\mathrm{C}) \mathrm{CC} 5) \mathrm{cc} 4 \mathrm{OCC}) \mathrm{nc} 32) \mathrm{c} 1$ & 170 & $*$ \\
\hline 2567 & $\mathrm{COc} 1 \mathrm{cc} 2 \mathrm{ncnc}(\mathrm{NCc} 3 \operatorname{ccc}(\mathrm{C}) \mathrm{c} 3) \mathrm{c} 2 \mathrm{cc} 1 \mathrm{OC}$ & 170 & $*$ \\
\hline 2568 & $\mathrm{Cc} 1[\mathrm{nH}] \mathrm{c} 2 \mathrm{ncnc}(\mathrm{Nc} 3 \mathrm{cc}(\mathrm{Cl}) \mathrm{cc}(\mathrm{Cl}) \mathrm{c} 3) \mathrm{c} 2 \mathrm{c} 1 \mathrm{C}$ & 170 & * \\
\hline 2569 & $\operatorname{COc} 1 \mathrm{cc}(\mathrm{O}) \mathrm{c} 2 \mathrm{c}(=\mathrm{O}) \mathrm{c}(-\mathrm{c} 3 \mathrm{ccc}(\mathrm{Cl}) \mathrm{c} 3) \mathrm{cn}(\mathrm{C}) \mathrm{c} 2 \mathrm{c} 1$ & 170 & $*$ \\
\hline 2570 & $\mathrm{Cc} 1 \mathrm{cc}(\mathrm{C}(=\mathrm{O}) \mathrm{N} 2 \mathrm{CCOCC} 2)[\mathrm{nH}] \mathrm{c} 1 / \mathrm{C}=\mathrm{C} 1 \backslash \mathrm{C}(=\mathrm{O}) \mathrm{Nc} 2 \mathrm{ncnc}(\mathrm{Nc} 3 \mathrm{ccc}(\mathrm{F}) \mathrm{c}(\mathrm{Cl}) \mathrm{c} 3) \mathrm{c} 21$ & 170 & $*$ \\
\hline 2571 & $\mathrm{CCc} 1 \mathrm{c}(\mathrm{C}(=\mathrm{O}) \mathrm{OCCCn} 2 \mathrm{ccnc} 2) \mathrm{cn} 2 \mathrm{ncnc}(\mathrm{Nc} 3 \mathrm{ccc} 4 \mathrm{c}(\mathrm{cnn} 4 \mathrm{Cc} 4 \mathrm{ccccc} 4) \mathrm{c} 3) \mathrm{c} 12$ & 170 & $*$ \\
\hline 2572 & $\mathrm{CN} 1 \mathrm{CCN}(\mathrm{Cc} 2 \mathrm{ccn} 3 \mathrm{ncnc}(\mathrm{Nc} 4 \mathrm{ccc} 5 \mathrm{c}(\mathrm{cnn} 5 \mathrm{Cc} 5 \mathrm{cccc}(\mathrm{F}) \mathrm{c} 5) \mathrm{c} 4) \mathrm{c} 23) \mathrm{CC} 1$ & 170 & $*$ \\
\hline 2573 & $\mathrm{NC}(=\mathrm{O}) \mathrm{CN} 1 \mathrm{CCC}(\mathrm{n} 2 \mathrm{cc}(-\mathrm{c} 3 \mathrm{cccc}(\mathrm{O}) \mathrm{c} 3) \mathrm{c} 3 \mathrm{c}(\mathrm{N}) \mathrm{ncnc} 32) \mathrm{CC} 1$ & 170 & $*$ \\
\hline 2574 & $\operatorname{COc} 1 \mathrm{cc}(-\mathrm{c} 2 \mathrm{nn}(\mathrm{C}(\mathrm{C}) \mathrm{C}) \mathrm{c} 3 \mathrm{ncnc}(\mathrm{N}) \mathrm{c} 23) \mathrm{ccc} 1 \mathrm{NC}(=\mathrm{O}) \mathrm{OC}(\mathrm{C})(\mathrm{C}) \mathrm{C}$ & 170 & $*$ \\
\hline 2575 & $\mathrm{CCNc} 1 \mathrm{cc}(\mathrm{Nc} 2 \mathrm{cccc}(\mathrm{Cl}) \mathrm{c} 2) \mathrm{ncn} 1$ & 170 & $*$ \\
\hline 2576 & $\mathrm{O}=\mathrm{C}(/ \mathrm{C}=\mathrm{C} / \mathrm{c} 1 \mathrm{ccc}(\mathrm{F}) \mathrm{cc} 1) \mathrm{c} 1 \mathrm{cc}(\mathrm{Br}) \operatorname{cc} 2 \mathrm{cc}(-\mathrm{c} 3 \mathrm{ccccc} 3) \mathrm{oc} 12$ & 170 & $*$ \\
\hline 2577 & $\mathrm{O}=\mathrm{C}(/ \mathrm{C}=\mathrm{C} / \mathrm{c} 1 \mathrm{ccccc} 1) \mathrm{c} 1 \mathrm{cc}(\mathrm{Br}) \mathrm{cc} 2 \mathrm{cc}(-\mathrm{c} 3 \operatorname{cccc}(\mathrm{Cl}) \mathrm{c} 3) \mathrm{oc} 12$ & 170 & $*$ \\
\hline 2578 & $\mathrm{O}=\mathrm{C}(\mathrm{Nc} 1 \mathrm{cc} 2 \mathrm{c}(\mathrm{Nc} 3 \mathrm{ccc}(\mathrm{OCC} 4 \mathrm{CC} 4) \mathrm{c}(\mathrm{Cl}) \mathrm{c} 3) \mathrm{ncnc} 2 \mathrm{cc} 1 \mathrm{OCCCN} 1 \mathrm{CCOCC} 1) \mathrm{c} 1 \mathrm{cc}([\mathrm{N}+](=\mathrm{O})[\mathrm{O}-]) \mathrm{ccc} 1 \mathrm{~F}$ & 172 & 6.76 \\
\hline 2579 & $\mathrm{C}=\mathrm{CC}(=\mathrm{O}) \mathrm{Nc} 1 \mathrm{cc}(\mathrm{Nc} 2 \mathrm{ncc}(\mathrm{F}) \mathrm{c}(\mathrm{Nc} 3 \operatorname{cccc} 3 \mathrm{~S}(=\mathrm{O})(=\mathrm{O}) \mathrm{N}(\mathrm{C}) \mathrm{C}) \mathrm{n} 2) \mathrm{c}(\mathrm{OC}) \mathrm{cc} 1 \mathrm{~N}(\mathrm{C}) \mathrm{CCN}(\mathrm{C}) \mathrm{C}$ & 172 & $*$ \\
\hline 2580 & COc1 $1 \mathrm{ccc} 1-\mathrm{c} 1 \mathrm{cc} 2 \mathrm{c}(\mathrm{Ne} 3 \mathrm{cccc} 3) \mathrm{ncnc} 2 \mathrm{~s} 1$ & 173 & $*$ \\
\hline 2581 & $\mathrm{COc} 1 \mathrm{ccc}(\mathrm{NC}(=\mathrm{O}) / \mathrm{C}=\mathrm{C} / \mathrm{CN}(\mathrm{C}) \mathrm{C}) \mathrm{cc} 1 \mathrm{Nc} 1 \mathrm{ncc}(\mathrm{C} \# \mathrm{~N}) \mathrm{c}(\mathrm{Nc} 2 \operatorname{ccc} 3 \operatorname{ccccc} 3 \mathrm{c} 2) \mathrm{n} 1$ & 173 & $*$ \\
\hline 2582 & $\mathrm{C}=\mathrm{CC}(=\mathrm{O}) \mathrm{Nc} 1 \mathrm{cccc}(\mathrm{Oc} 2 \mathrm{nc}(\mathrm{Nc} 3 \mathrm{ccc}(\mathrm{N} 4 \mathrm{CCN}(\mathrm{C}(=\mathrm{O}) \mathrm{C}(\mathrm{C}) \mathrm{C}) \mathrm{CC} 4) \mathrm{cc} 3 \mathrm{OC}) \mathrm{ncc} 2 \mathrm{SC}) \mathrm{c} 1$ & 173.6 & $*$ \\
\hline 2583 & $\begin{array}{c}\mathrm{C}=\mathrm{CC}(=\mathrm{O}) \mathrm{Nc} 1 \mathrm{cccc}(\mathrm{Oc} 2 \mathrm{nc}(\mathrm{Nc} 3 \operatorname{ccc}(\mathrm{N} 4 \mathrm{CCN}(\mathrm{CC}(=\mathrm{O}) \mathrm{OCCCCOc} 5 \mathrm{no}[\mathrm{n}+]([\mathrm{O}-]) \mathrm{c} 5 \mathrm{~S}(=\mathrm{O})(=\mathrm{O}) \mathrm{c} 5 \operatorname{ccccc} 5) \mathrm{CC} 4) \operatorname{cc} 3 \mathrm{O} \\
\mathrm{C}) \mathrm{ncc} 2 \mathrm{Cl}) \mathrm{c} 1\end{array}$ & 174 & 6.76 \\
\hline 2584 & $\mathrm{CCC}(=\mathrm{O}) \mathrm{Nc} 1 \mathrm{cc} 2 \mathrm{c}(\mathrm{Nc} 3 \mathrm{ccc} 4 \mathrm{c}(\mathrm{c} 3) \mathrm{CCN} 4 \mathrm{Cc} 3 \mathrm{cccc} 3) \mathrm{ncnc} 2 \mathrm{cc} 1 \mathrm{OC}$ & 175 & * \\
\hline 2585 & $\mathrm{CC}(\mathrm{C}) \mathrm{n} 1 \mathrm{nc}(-\mathrm{c} 2 \mathrm{ccc} 3[\mathrm{nH}] \mathrm{ccc} 3 \mathrm{c} 2) \mathrm{c} 2 \mathrm{c}(\mathrm{N}) \mathrm{ncnc} 21$ & 176 & $*$ \\
\hline 2586 & $\mathrm{c} 1 \mathrm{cc}(\mathrm{Nc} 2 \mathrm{ccc} 3[\mathrm{nH}] \operatorname{ccc} 3 \mathrm{c} 2) \mathrm{nc}(\mathrm{Nc} 2 \mathrm{ccc}(\mathrm{OCCCCN} 3 \mathrm{CCOCC} 3) \mathrm{cc} 2) \mathrm{n} 1$ & 178 & $*$ \\
\hline 2587 & $\mathrm{CC}(=\mathrm{O}) \mathrm{Nc} 1 \mathrm{ccc}(-\mathrm{c} 2 \mathrm{c}(-\mathrm{c} 3 \mathrm{cccc} 3) \mathrm{oc} 3 \mathrm{ncnc}(\mathrm{N}[\mathrm{C} @ \mathrm{H}](\mathrm{CO}) \mathrm{c} 4 \mathrm{ccccc} 4) \mathrm{c} 23) \mathrm{cc} 1$ & 179 & $*$ \\
\hline
\end{tabular}




\begin{tabular}{|c|c|c|c|}
\hline 2588 & $\mathrm{CC}(\mathrm{C}) \mathrm{n} 1 \mathrm{nc}(-\mathrm{c} 2 \mathrm{ccc} 3 \mathrm{c}(\operatorname{ccn} 3 \mathrm{C}(=\mathrm{O}) \mathrm{OC}(\mathrm{C})(\mathrm{C}) \mathrm{C}) \mathrm{c} 2) \mathrm{c} 2 \mathrm{c}(\mathrm{N}) \mathrm{ncnc} 21$ & 179 & $*$ \\
\hline 2589 & $\mathrm{Cc} 1 \mathrm{ccc}(\mathrm{Oc} 2 \mathrm{nc} 3 \operatorname{ccc}(\mathrm{C}) \operatorname{cc} 3 \mathrm{cc} 2 / \mathrm{C}=\mathrm{N} / \mathrm{NC}(=\mathrm{O}) \mathrm{Cn} 2 \mathrm{c}([\mathrm{N}+](=\mathrm{O})[\mathrm{O}-]) \mathrm{cnc} 2 \mathrm{C}) \mathrm{cc} 1$ & 180 & 6.74 \\
\hline 2590 & 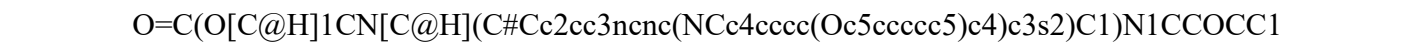 & 180 & 6.74 \\
\hline 2591 & $\mathrm{O}=\mathrm{C}(/ \mathrm{C}=\mathrm{C} / \mathrm{CN} 1 \mathrm{CCCC} 1) \mathrm{Nc} 1 \mathrm{cc} 2 \mathrm{c}(\mathrm{Nc} 3 \mathrm{ccc}(\mathrm{Oc} 4 \mathrm{cccc} 4) \mathrm{cc} 3) \mathrm{ncnc} 2 \mathrm{cn} 1$ & 180 & $*$ \\
\hline 2592 & $\mathrm{C}=\mathrm{C}(\mathrm{CN}(\mathrm{C}) \mathrm{C}) \mathrm{C}(=\mathrm{O}) \mathrm{c} 1 \mathrm{ccc}(\mathrm{OCc} 2 \mathrm{cccc} 2) \mathrm{cc} 1 . \mathrm{Cl}$ & 180 & $*$ \\
\hline 2593 & $\mathrm{Cc} 1[\mathrm{nH}] \mathrm{c}(/ \mathrm{C}=\mathrm{C} 2 \backslash \mathrm{C}(=\mathrm{O}) \mathrm{Nc} 3 \mathrm{ncnc}(\mathrm{Nc} 4 \mathrm{ccc}(\mathrm{F}) \mathrm{c}(\mathrm{Cl}) \mathrm{c} 4) \mathrm{c} 32) \mathrm{c}(\mathrm{C}) \mathrm{c} 1 \mathrm{CCC}(=\mathrm{O}) \mathrm{O}$ & 180 & $*$ \\
\hline 2594 & $\mathrm{C}[\mathrm{C} @ @ \mathrm{H}](\mathrm{Oc} 1 \mathrm{cccc} 2 \mathrm{ncnc}(\mathrm{Nc} 3 \mathrm{ccc} 4 \mathrm{c}(\mathrm{cnn} 4 \mathrm{Cc} 4 \mathrm{ccc} n 4) \mathrm{c} 3) \mathrm{c} 12) \mathrm{C}(=\mathrm{O}) \mathrm{N}(\mathrm{C}) \mathrm{C}$ & 180 & $*$ \\
\hline 2595 & $\mathrm{COc} 1 \mathrm{cc} 2 \mathrm{ncc}(\mathrm{C \# N}) \mathrm{c}(\mathrm{Nc} 3 \mathrm{ccc}(\mathrm{Cl}) \mathrm{c} 3) \mathrm{c} 2 \mathrm{cc} 1 \mathrm{OC}$ & 180 & $*$ \\
\hline 2596 & $\mathrm{c} 1 \mathrm{cc}(\mathrm{Nc} 2 \mathrm{nccc}(\mathrm{Nc} 3 \mathrm{ccc} 4[\mathrm{nH}] \operatorname{ccc} 4 \mathrm{c} 3) \mathrm{n} 2) \mathrm{cc}(\mathrm{N} 2 \mathrm{CCOCC} 2) \mathrm{c} 1$ & 180 & $*$ \\
\hline 2597 & $\mathrm{C}=\mathrm{CC}(=\mathrm{O}) \mathrm{Nc} 1 \mathrm{cccc}(-\mathrm{n} 2 \mathrm{c}(=\mathrm{O}) \mathrm{n}(\mathrm{C}) \mathrm{c}(=\mathrm{O}) \mathrm{c} 3 \mathrm{cnc}(\mathrm{Nc} 4 \mathrm{ccc}(\mathrm{N} 5 \mathrm{CCN}(\mathrm{C}(\mathrm{C})=\mathrm{O}) \mathrm{CC} 5) \mathrm{cc} 4 \mathrm{OC}) \mathrm{nc} 32) \mathrm{c} 1$ & 180 & $*$ \\
\hline 2598 & $\mathrm{C}=\mathrm{CC}(=\mathrm{O}) \mathrm{Nc} 1 \mathrm{cc}(\mathrm{Nc} 2 \mathrm{nccc}(\mathrm{NC}(=\mathrm{O}) \mathrm{c} 3 \operatorname{ccccc} 3) \mathrm{n} 2) \mathrm{c}(\mathrm{OC}) \operatorname{cc} 1 \mathrm{~N} 1 \mathrm{CCC}(\mathrm{C}(\mathrm{N})=\mathrm{O}) \mathrm{CC} 1$ & 180.6 & $*$ \\
\hline 2599 & $\mathrm{C}=\mathrm{CC}(=\mathrm{O}) \mathrm{Nc} 1 \mathrm{cc}(-\mathrm{n} 2 \mathrm{c}(=\mathrm{O}) \mathrm{cc}(\mathrm{C}) \mathrm{c} 3 \mathrm{cnc}(\mathrm{Nc} 4 \mathrm{ccc}(\mathrm{N} 5 \mathrm{CCN}(\mathrm{C}) \mathrm{CC} 5) \mathrm{cc} 4 \mathrm{OC}) \mathrm{nc} 32) \mathrm{cc}(\mathrm{C}(\mathrm{F})(\mathrm{F}) \mathrm{F}) \mathrm{c} 1$ & 181.9 & $*$ \\
\hline 2600 & $\mathrm{COc} 1 \mathrm{cccc} 1-\mathrm{c} 1 \mathrm{cc} 2 \mathrm{c}(\mathrm{NCc} 3 \mathrm{ccc} n 3) \mathrm{ncnc} 2 \mathrm{~s} 1$ & 183 & $*$ \\
\hline 2601 & CC[C@@H](Nc1ncnc2sc(Br)cc12)c1cccc1 & 183 & $*$ \\
\hline 2602 & $\mathrm{C}=\mathrm{CC}(=\mathrm{O}) \mathrm{Nc} 1 \operatorname{ccc}(\mathrm{NC}(=\mathrm{O}) \mathrm{Nc} 2 \operatorname{ccnc}(\mathrm{Nc} 3 \operatorname{ccc}(\mathrm{N}(\mathrm{CC}) \mathrm{CC}) \operatorname{cc} 3 \mathrm{OC}) \mathrm{n} 2) \mathrm{c} 1$ & 183 & $*$ \\
\hline 2603 & $\mathrm{Fc} 1 \mathrm{ccc}(-\mathrm{c} 2 \mathrm{nc}(\mathrm{SCCN} 3 \mathrm{CCOCC} 3)[\mathrm{nH}] \mathrm{c} 2-\mathrm{c} 2 \mathrm{ccnc}(\mathrm{Nc} 3 \mathrm{cccc} 3) \mathrm{c} 2) \mathrm{cc} 1$ & 183 & $*$ \\
\hline 2604 & $\mathrm{O}=\mathrm{C}(\mathrm{CBr}) \mathrm{OCCn} 1 \mathrm{c}(=\mathrm{O}) \mathrm{oc} 2 \mathrm{cc} 3 \mathrm{ncnc}(\mathrm{Nc} 4 \mathrm{ccc}(\mathrm{N} 5 \mathrm{CCCCC} 5) \mathrm{c}(\mathrm{Cl}) \mathrm{c} 4) \mathrm{c} 3 \mathrm{cc} 21$ & 184 & 6.74 \\
\hline 2605 & $\mathrm{Cc} 1 \mathrm{ccc}(\mathrm{Nc} 2 \mathrm{ncnc} 3 \mathrm{cc}(\mathrm{OC}(\mathrm{C}) \mathrm{C}) \mathrm{c} 4 \mathrm{c}(\mathrm{c} 23) \mathrm{OCCO} 4) \operatorname{cc} 1[\mathrm{~N}+](=\mathrm{O})[\mathrm{O}-]$ & 184.5 & $*$ \\
\hline 2606 & $\mathrm{COc} 1 \mathrm{cc} 2 \mathrm{ncc}(\mathrm{C \# N}) \mathrm{c}(\mathrm{Nc} 3 \operatorname{ccc}(\mathrm{OCc} 4 \operatorname{cccc} 4) \operatorname{cc} 3) \mathrm{c} 2 \mathrm{cc} 1 \mathrm{NC}(=\mathrm{O}) / \mathrm{C}=\mathrm{C} / \mathrm{CN}(\mathrm{C}) \mathrm{C}$ & 185 & 6.73 \\
\hline 2607 & $\mathrm{Cc} 1 \mathrm{ccc}(-\mathrm{n} 2 \mathrm{c}(-\mathrm{c} 3 \operatorname{ccc} c 3) \mathrm{c}(-\mathrm{c} 3 \operatorname{ccc} c 3) \mathrm{c} 3 \operatorname{cc} 4 \mathrm{c}(\mathrm{cc} 3 \mathrm{c} 2=\mathrm{O}) \mathrm{C}(\mathrm{c} 2 \operatorname{ccc} c 2) \mathrm{NC}(=\mathrm{O}) \mathrm{N} 4) \mathrm{cc} 1$ & 185 & $*$ \\
\hline 2608 & $\mathrm{CC}(=\mathrm{O}) \mathrm{CCCSc} 1 \mathrm{nc}(-\mathrm{c} 2 \mathrm{ccc}(\mathrm{F}) \mathrm{cc} 2) \mathrm{c}(-\mathrm{c} 2 \mathrm{ccnc}(\mathrm{Nc} 3 \mathrm{ccccc} 3) \mathrm{c} 2)[\mathrm{nH}] 1$ & 185 & * \\
\hline 2609 & OCCC\#Cc1 ccc2ncnc(Nc3ccc(F)c(Cl)c3)c2c1 & 185.8 & $*$ \\
\hline 2610 & $\mathrm{Cc} 1 \mathrm{cccc}(\mathrm{Nc} 2 \mathrm{ncnc} 3 \mathrm{cc} 4 \mathrm{c}(\mathrm{cc} 23) \mathrm{N}(\mathrm{CCCN} 2 \mathrm{CCOCC} 2) \mathrm{C}(=\mathrm{O}) \mathrm{CO} 4) \mathrm{c} 1$ & 186.9 & $*$ \\
\hline 2611 & $\mathrm{COc} 1 \mathrm{cc}(\mathrm{OC} 2 \mathrm{CCOC} 2) \mathrm{c} 2 \mathrm{c}(\mathrm{Nc} 3 \mathrm{ccc}(\mathrm{F}) \mathrm{c}(\mathrm{Cl}) \mathrm{c} 3) \mathrm{ncnc} 2 \mathrm{c} 1$ & 187 & $*$ \\
\hline 2612 & $\mathrm{C}=\mathrm{CC}(=\mathrm{O}) \mathrm{Nc} 1 \mathrm{cc}(\mathrm{Nc} 2 \mathrm{nccc}(\mathrm{NC}(=\mathrm{O}) \mathrm{c} 3 \mathrm{ccc}(\mathrm{OC}) \mathrm{c}(\mathrm{OC}) \mathrm{c} 3) \mathrm{n} 2) \mathrm{c}(\mathrm{OC}) \mathrm{cc} 1 \mathrm{~N}(\mathrm{C}) \mathrm{CCN}(\mathrm{C}) \mathrm{C}$ & 187.2 & $*$ \\
\hline 2613 & $\mathrm{CCOc} 1 \mathrm{cc} 2 \mathrm{ncc}(\mathrm{C} \# \mathrm{~N}) \mathrm{c}(\mathrm{Nc} 3 \mathrm{ccc}(\mathrm{OCc} 4 \mathrm{nc} 5 \mathrm{ccccc} 5 \mathrm{~s} 4) \mathrm{c}(\mathrm{Cl}) \mathrm{c} 3) \mathrm{c} 2 \mathrm{cc} 1 \mathrm{NC}(=\mathrm{O}) / \mathrm{C}=\mathrm{C} / \mathrm{CN}(\mathrm{C}) \mathrm{C}$ & 188 & 6.73 \\
\hline 2614 & $\mathrm{CCN}(\mathrm{CCO}) \mathrm{CCCOc} 1 \mathrm{ccc} 2 \mathrm{c}(\mathrm{Nc} 3 \operatorname{ccc}(\mathrm{NC}(=\mathrm{O}) \mathrm{Nc} 4 \mathrm{ccc}(\mathrm{Cl}) \mathrm{c}(\mathrm{C}(\mathrm{F})(\mathrm{F}) \mathrm{F}) \mathrm{c} 4) \mathrm{c} 3) \mathrm{ncnc} 2 \mathrm{c} 1$ & 188 & $*$ \\
\hline 2615 & $\mathrm{O}=\mathrm{C}(\mathrm{Nc} 1 \mathrm{ccncc} 1) \mathrm{Nc} 1 \mathrm{cc}(-\mathrm{c} 2 \mathrm{cccnc} 2) \mathrm{cc}(\mathrm{C}(\mathrm{F})(\mathrm{F}) \mathrm{F}) \mathrm{c} 1$ & 189.49 & $*$ \\
\hline 2616 & $\mathrm{Cc} 1 \mathrm{ncnc}(\mathrm{Nc} 2 \mathrm{ccc}(\mathrm{OCc} 3 \operatorname{cccc}(\mathrm{F}) \mathrm{c} 3) \mathrm{c}(\mathrm{Cl}) \mathrm{c} 2) \mathrm{c} 1 \mathrm{C} \# \mathrm{Cc} 1 \mathrm{ccc}(\mathrm{CN} 2 \mathrm{CCCC} 2) \mathrm{c}(\mathrm{F}) \mathrm{c} 1$ & 190 & 6.72 \\
\hline 2617 & $\mathrm{COc} 1 \mathrm{cc} 2 \mathrm{ncnc}(\mathrm{Nc} 3 \mathrm{ccc}(\mathrm{F}) \mathrm{c}(\mathrm{Cl}) \mathrm{c} 3) \mathrm{c} 2 \mathrm{cc} 1 \mathrm{OCCN} 1 \mathrm{CC} 2(\mathrm{CCO} 2) \mathrm{C} 1$ & 190 & 6.72 \\
\hline 2618 & $\mathrm{O}=\mathrm{C}(/ \mathrm{C}=\mathrm{C} / \mathrm{c} 1 \operatorname{cccc}([\mathrm{N}+](=\mathrm{O})[\mathrm{O}-]) \mathrm{c} 1) \mathrm{Nc} 1 \mathrm{ccc} 2 \mathrm{ncnc}(\mathrm{Nc} 3 \operatorname{cccc}(\mathrm{Cl}) \mathrm{c} 3) \mathrm{c} 2 \mathrm{c} 1$ & 190 & 6.72 \\
\hline 2619 & $\mathrm{Cc} 1 \mathrm{ccc}(\mathrm{C} 2=\mathrm{NN}(\mathrm{c} 3 \mathrm{nc}(-\mathrm{c} 4 \mathrm{ccc}(\mathrm{Cl}) \operatorname{cc} 4) \operatorname{cs} 3) \mathrm{C}(\mathrm{c} 3 \mathrm{ccc}(\mathrm{Cl}) \mathrm{cc} 3) \mathrm{C} 2) \mathrm{cc} 1 \mathrm{C}$ & 190 & 6.72 \\
\hline 2620 & $\mathrm{COc} 1 \mathrm{cc} 2 \mathrm{ncc}(\mathrm{CHN}) \mathrm{c}(\mathrm{Nc} 3 \mathrm{cccc}(\mathrm{Br}) \mathrm{c} 3) \mathrm{c} 2 \mathrm{cc} 1 \mathrm{OC}$ & 190 & 6.72 \\
\hline 2621 & $\mathrm{C} \# \mathrm{Cc} 1 \mathrm{cccc}(\mathrm{Nc} 2 \mathrm{ncnc} 3 \mathrm{cc} 4 \mathrm{oc}(=\mathrm{O}) \mathrm{n}(\mathrm{CCOC}) \mathrm{c} 4 \mathrm{cc} 23) \mathrm{c} 1$ & 190 & $*$ \\
\hline 2622 & $\mathrm{O}=\mathrm{C}(\mathrm{O}[\mathrm{C} @ \mathrm{H}] 1 \mathrm{CN}[\mathrm{C} @ \mathrm{H}](\mathrm{C} \# \mathrm{Cc} 2 \mathrm{cc} 3 \mathrm{ncnc}(\mathrm{Nc} 4 \mathrm{ccc}(\mathrm{Oc} 5 \mathrm{ccc} n 5) \mathrm{c}(\mathrm{Cl}) \mathrm{c} 4) \mathrm{c} 3 \mathrm{~s} 2) \mathrm{C} 1) \mathrm{N} 1 \mathrm{CCOCC} 1$ & 190 & $*$ \\
\hline 2623 & $\mathrm{Cn} 1 \mathrm{c}(=\mathrm{O}) \mathrm{c}(-\mathrm{c} 2 \mathrm{c}(\mathrm{Cl}) \operatorname{cccc} 2 \mathrm{Cl}) \mathrm{cc} 2 \mathrm{cnc}(\mathrm{Nc} 3 \operatorname{ccc}(\mathrm{C}(=\mathrm{O}) \mathrm{O}) \mathrm{c} 3) \mathrm{nc} 21$ & 190 & $*$ \\
\hline 2624 & $\mathrm{COc} 1 \mathrm{cn} 2 \mathrm{ncnc}(\mathrm{Nc} 3 \mathrm{ccc} 4 \mathrm{c}(\mathrm{cnn} 4 \mathrm{Cc} 4 \mathrm{cccc}(\mathrm{F}) \mathrm{c} 4) \mathrm{c} 3) \mathrm{c} 2 \mathrm{c} 1 \mathrm{CN} 1 \mathrm{CCCNCC} 1$ & 190 & $*$ \\
\hline 2625 & $\mathrm{NC} 1 \mathrm{CCN}(\mathrm{Cc} 2 \mathrm{ccn} 3 \mathrm{ncnc}(\mathrm{Ne} 4 \mathrm{ccc} 5 \mathrm{c}(\mathrm{cnn} 5 \mathrm{Cc} 5 \mathrm{cccnc} 5) \mathrm{c} 4) \mathrm{c} 23) \mathrm{CC} 1$ & 190 & * \\
\hline 2626 & $\mathrm{COC} 1 \mathrm{CNCCN}(\mathrm{Cc} 2 \mathrm{ccn} 3 \mathrm{nenc}(\mathrm{Ne} 4 \mathrm{ccc} 5 \mathrm{c}(\mathrm{cnn} 5 \mathrm{Cc} 5 \mathrm{cccc}(\mathrm{F}) \mathrm{c} 5) \mathrm{c} 4) \mathrm{c} 23) \mathrm{C} 1$ & 190 & $*$ \\
\hline 2627 & Fc1 $1 \mathrm{ccc}(\mathrm{Cn} 2 \mathrm{ncc} 3 \mathrm{cc}(\mathrm{Nc} 4 \mathrm{ncnn} 5 \mathrm{ccc}(\mathrm{COC}[\mathrm{C} @ \mathrm{H}] 6 \mathrm{CCCNC} 6) \mathrm{c} 45) \mathrm{ccc} 32) \mathrm{c} 1$ & 190 & * \\
\hline 2628 & $\mathrm{CC}(\mathrm{C})(\mathrm{N}) \mathrm{c} 1 \mathrm{cc}(\mathrm{C}(=\mathrm{O}) \mathrm{N}[\mathrm{C} @ @ \mathrm{H}] 2 \mathrm{CCc} 3 \operatorname{ccc}(\mathrm{Oc} 4 \mathrm{ccnc} 5 \mathrm{c} 4 \mathrm{CCC}(=\mathrm{O}) \mathrm{N} 5) \mathrm{cc} 3 \mathrm{C} 2) \mathrm{cc}(\mathrm{C}(\mathrm{F})(\mathrm{F}) \mathrm{F}) \mathrm{c} 1$ & 190 & $*$ \\
\hline 2629 & $\mathrm{COc} 1 \mathrm{ccc}(\mathrm{C}(\mathrm{Nc} 2 \mathrm{ccc}(\mathrm{C}) \mathrm{cc} 2) \mathrm{n} 2 \mathrm{c}(-\mathrm{c} 3 \mathrm{cc}(\mathrm{CCn} 4 \mathrm{c}(-\mathrm{c} 5 \mathrm{ccccc} 5) \mathrm{nc} 5 \mathrm{ccccc} 5 \mathrm{c} 4=\mathrm{O}) \operatorname{ccc} 3 \mathrm{Cl}) \mathrm{nc} 3 \operatorname{cccc} 32) \mathrm{cc} 1$ & 190 & * \\
\hline 2630 & $\mathrm{COc} 1 \mathrm{ccc}(-\mathrm{c} 2 \mathrm{c} 3 \mathrm{c} 4 \mathrm{cc}(\mathrm{OCCN}(\mathrm{C}) \mathrm{C}) \mathrm{c}(\mathrm{OCCN}(\mathrm{C}) \mathrm{C}) \mathrm{cc} 4 \mathrm{oc}(=\mathrm{O}) \mathrm{c} 3 \mathrm{n} 3 \mathrm{ccc} 4 \mathrm{cc}(\mathrm{O}) \mathrm{c}(\mathrm{OC}) \mathrm{cc} 4 \mathrm{c} 23) \mathrm{cc} 1 \mathrm{O} . \mathrm{O}=\mathrm{C}(\mathrm{O}) \mathrm{C}(\mathrm{F})(\mathrm{F}) \mathrm{F}$ & 190.6 & $*$ \\
\hline
\end{tabular}




\begin{tabular}{|c|c|c|c|}
\hline 2631 & $\mathrm{c} 1 \mathrm{ccc}(\mathrm{CNc} 2 \mathrm{ncnc} 3 \mathrm{c} 2 \mathrm{sc} 2 \mathrm{cccc} 23) \mathrm{cc} 1$ & 191 & $*$ \\
\hline 2632 & $\mathrm{C}[\mathrm{C} @ @ \mathrm{H}](\mathrm{CN}(\mathrm{C}) \mathrm{C}(=\mathrm{O}) \mathrm{CO}) \mathrm{Oc} 1 \mathrm{ccc} 2 \mathrm{ncnc}(\mathrm{Nc} 3 \mathrm{ccc}(\mathrm{OCc} 4 \mathrm{ccc} n 4) \mathrm{c}(\mathrm{Cl}) \mathrm{c} 3) \mathrm{c} 12$ & 191 & $*$ \\
\hline 2633 & $\mathrm{COc} 1 \mathrm{cc} 2 \mathrm{c}(\mathrm{Nc} 3 \mathrm{ccc}(\mathrm{NC}(=\mathrm{O}) \mathrm{Nc} 4 \mathrm{cccc} 4) \mathrm{cc} 3) \mathrm{ncnc} 2 \mathrm{cc} 1 \mathrm{OCCCN} 1 \mathrm{CCN}(\mathrm{C}) \mathrm{CC} 1$ & 194 & $*$ \\
\hline 2634 & $\mathrm{COC}[\mathrm{C} @ @ \mathrm{H}] 1 \mathrm{CCCN} 1 \mathrm{C} / \mathrm{C}=\mathrm{C} \mid \mathrm{C}(=\mathrm{O}) \mathrm{Nc} 1 \mathrm{ccc} 2 \mathrm{ncnc}(\mathrm{Nc} 3 \operatorname{cccc}(\mathrm{Br}) \mathrm{c} 3) \mathrm{c} 2 \mathrm{c} 1$ & 194 & $*$ \\
\hline 2635 & $\mathrm{CCOc} 1 \mathrm{cc} 2 \mathrm{ncc}(\mathrm{CHN}) \mathrm{c}(\mathrm{Nc} 3 \operatorname{ccc}(\mathrm{OCc} 4 \operatorname{ccc}(\mathrm{CHN}) \mathrm{c} 4) \mathrm{c}(\mathrm{Cl}) \mathrm{c} 3) \mathrm{c} 2 \mathrm{cc} 1 \mathrm{NC}(=\mathrm{O}) / \mathrm{C}=\mathrm{C} / \mathrm{CN}(\mathrm{C}) \mathrm{C}$ & 195 & 6.71 \\
\hline 2636 & $\mathrm{C}=\mathrm{CC}(=\mathrm{O}) \mathrm{Nc} 1 \mathrm{cc} 2 \mathrm{c}(\mathrm{Nc} 3 \mathrm{ccc}(\mathrm{F}) \mathrm{c}(\mathrm{C \# N}) \mathrm{c} 3) \mathrm{ncnc} 2 \mathrm{cc} 1 \mathrm{OCCOC}$ & 195.8 & $*$ \\
\hline 2637 & $\mathrm{O}=\mathrm{C}(\mathrm{Nc} 1 \mathrm{cccc}(\mathrm{Cl}) \mathrm{c} 1) \mathrm{c} 1 \mathrm{ccc}(\mathrm{OCCCN} 2 \mathrm{CCOCC} 2) \mathrm{cc} 1 \mathrm{O}$ & 195.8 & $*$ \\
\hline 2638 & $\operatorname{COCCCNC}(=\mathrm{O}) \mathrm{Nc} 1 \mathrm{cc} 2 \mathrm{c}(\mathrm{Nc} 3 \mathrm{ccc}(\mathrm{F}) \mathrm{c}(\mathrm{Cl}) \mathrm{c} 3) \mathrm{ncnc} 2 \mathrm{cc} 1 \mathrm{O}[\mathrm{C} @ \mathrm{H}] 1 \mathrm{CCOC} 1$ & 197 & $*$ \\
\hline 2639 & $\mathrm{COCCCNN}(\mathrm{NCCCOC}) \mathrm{C}(=\mathrm{O}) \mathrm{Nc} 1 \mathrm{cc} 2 \mathrm{c}(\mathrm{Nc} 3 \mathrm{ccc}(\mathrm{F}) \mathrm{c}(\mathrm{Cl}) \mathrm{c} 3) \mathrm{ncnc} 2 \mathrm{cc} 1 \mathrm{O}[\mathrm{C} @ \mathrm{H}] 1 \mathrm{CCOC} 1$ & 197 & $*$ \\
\hline 2640 & C[C@@H](Nc1ncnc2[nH]c(-c3ecccc3O)cc12)c1ccccc1 & 198 & $*$ \\
\hline 2641 & $\mathrm{Cc} 1 \mathrm{ccc}(\mathrm{C} 2=\mathrm{NN}(\mathrm{c} 3 \operatorname{ccc} c 3) \mathrm{C}(\mathrm{c} 3 \operatorname{ccc} 4 \operatorname{ccc} c 34) \mathrm{C} 2) \mathrm{cc} 1$ & 200 & 6.70 \\
\hline 2642 & $\operatorname{CCOC}(=\mathrm{O}) \mathrm{C} 1=\mathrm{C}(\mathrm{N}) \mathrm{N}(\mathrm{c} 2 \mathrm{cccnc} 2) \mathrm{C} 2=\mathrm{C}(\mathrm{C}(=\mathrm{O}) \mathrm{CCC} 2) \mathrm{C} 1 \mathrm{c} 1 \mathrm{cc} 2 \mathrm{cc}(\mathrm{OC}) \operatorname{ccc} 2 \mathrm{n} 2 \mathrm{nnnc} 12$ & 200 & 6.70 \\
\hline 2643 & $\mathrm{COc} 1 \mathrm{cc} 2 \mathrm{c}(\mathrm{cc} 1 \mathrm{OC}) \mathrm{Nc} 1 \mathrm{ncnc}(\mathrm{NCc} 3 \mathrm{cccc} 3) \mathrm{c} 1 \mathrm{NC} 2$ & 200 & 6.70 \\
\hline 2644 & $\mathrm{Nc} 1 \mathrm{ccc} 2 \mathrm{ncnc}(\mathrm{Nc} 3 \mathrm{cccc}(\mathrm{Cl}) \mathrm{c} 3) \mathrm{c} 2 \mathrm{c} 1$ & 200 & 7.02 \\
\hline 2645 & $\mathrm{CCN}(\mathrm{CC})[\mathrm{C} @ @](\mathrm{C})(\mathrm{C} \# \mathrm{Cc} 1 \mathrm{ncnc} 2 \mathrm{cc}(\mathrm{OC}) \mathrm{c}(\mathrm{OC}) \mathrm{cc} 12) \mathrm{Cc} 1 \mathrm{ccncc} 1$ & 200 & $*$ \\
\hline 2646 & $\mathrm{C}=\mathrm{CC}(=\mathrm{O}) \mathrm{Nc} 1 \mathrm{cccc}(\mathrm{Oc} 2 \mathrm{nc}(\mathrm{Nc} 3 \mathrm{ccc}(\mathrm{N} 4 \mathrm{CCN}(\mathrm{C}(\mathrm{C})=\mathrm{O}) \mathrm{CC} 4) \operatorname{cc} 3 \mathrm{OC}) \mathrm{ncc} 2 \mathrm{C}(\mathrm{F})(\mathrm{F}) \mathrm{F}) \mathrm{c} 1$ & 200 & $*$ \\
\hline 2647 & $\mathrm{COc} 1 \mathrm{ccc} 2 \mathrm{ncnc}(\mathrm{NCc} 3 \operatorname{ccc} c 3) \mathrm{c} 2 \mathrm{c} 1$ & 200 & * \\
\hline 2648 & COc1cc2ncnc(Nc3nccc $4 \operatorname{ccccc} 34) \mathrm{c} 2 \mathrm{cc} 1 \mathrm{OC}$ & 200 & $*$ \\
\hline 2649 & $\mathrm{Cc} 1[\mathrm{nH}] \mathrm{c} 2 \mathrm{ncnc}(\mathrm{Nc} 3 \mathrm{cccc}(\mathrm{CHN}) \mathrm{c} 3) \mathrm{c} 2 \mathrm{c} 1 \mathrm{C}$ & 200 & $*$ \\
\hline 2650 & $\mathrm{CCn} 1 \mathrm{c}(=\mathrm{O}) \mathrm{c}(-\mathrm{c} 2 \mathrm{c}(\mathrm{Cl}) \mathrm{ccc} 2 \mathrm{Cl}) \mathrm{cc} 2 \mathrm{cnc}(\mathrm{Nc} 3 \mathrm{ccccc} 3) \mathrm{nc} 21$ & 200 & $*$ \\
\hline 2651 & $\mathrm{CCN}(\mathrm{CC}) \mathrm{CCNC}(=\mathrm{O}) \mathrm{c} 1 \mathrm{c}(\mathrm{C})[\mathrm{nH}] \mathrm{c}(/ \mathrm{C}=\mathrm{C} 2 \backslash \mathrm{C}(=\mathrm{O}) \mathrm{Nc} 3 \mathrm{ncnc}(\mathrm{Nc} 4 \mathrm{ccc}(\mathrm{F}) \mathrm{c}(\mathrm{Cl}) \mathrm{c} 4) \mathrm{c} 32) \mathrm{c} 1 \mathrm{C}$ & 200 & * \\
\hline 2652 & COc1cc2c(Nc3ccc(Br)cc3F)ncnc2cc1OC[C@@H]1CCCN(C)C1 & 200 & $*$ \\
\hline 2653 & $\mathrm{COc} 1 \mathrm{cc} 2 \mathrm{c}(\mathrm{Nc} 3 \mathrm{ccc}(\mathrm{Cl}) \mathrm{cc} 3 \mathrm{~F}) \mathrm{ncnc} 2 \mathrm{cc} 1 \mathrm{OCCN} 1 \mathrm{CCN}(\mathrm{C}) \mathrm{CC} 1$ & 200 & $*$ \\
\hline 2654 & $\mathrm{COc} 1 \mathrm{cc} 2 \mathrm{c}(\mathrm{Nc} 3 \mathrm{ccc}(\mathrm{Br}) \mathrm{cc} 3 \mathrm{~F}) \mathrm{ncnc} 2 \mathrm{cc} 1 \mathrm{OCCC} 1 \mathrm{CCN}(\mathrm{C}) \mathrm{CC} 1$ & 200 & $*$ \\
\hline 2655 & $\mathrm{COc} 1 \mathrm{cc} 2 \mathrm{c}(\mathrm{Nc} 3 \mathrm{ccc}(\mathrm{Br}) \mathrm{cc} 3 \mathrm{~F}) \mathrm{ncnc} 2 \mathrm{cc} 1 \mathrm{OCCC} 1 \mathrm{CCNCC} 1$ & 200 & $*$ \\
\hline 2656 & $\mathrm{Cc} 1 \mathrm{ccc}(\mathrm{Nc} 2 \mathrm{ncnn} 3 \mathrm{cc}(\mathrm{C}) \mathrm{c}(\mathrm{C}) \mathrm{c} 23) \mathrm{cc} 1 \mathrm{O}$ & 200 & $*$ \\
\hline 2657 & $\mathrm{CCc} 1 \mathrm{c}(\mathrm{C}(=\mathrm{O}) \mathrm{N}(\mathrm{C}) \mathrm{C}) \mathrm{cn} 2 \mathrm{ncnc}(\mathrm{Nc} 3 \mathrm{ccc} 4 \mathrm{c}(\mathrm{cnn} 4 \mathrm{Cc} 4 \mathrm{ccccc} 4) \mathrm{c} 3) \mathrm{c} 12$ & 200 & $*$ \\
\hline 2658 & $\operatorname{CCOC}(=\mathrm{O}) \mathrm{c} 1 \mathrm{cn} 2 \mathrm{ncnc}(\mathrm{Nc} 3 \operatorname{ccc} 4 \mathrm{c}(\operatorname{cnn} 4 \mathrm{Cc} 4 \operatorname{ccccc} 4) \mathrm{c} 3) \mathrm{c} 2 \mathrm{c} 1 \mathrm{C}$ & 200 & $*$ \\
\hline 2659 & $\operatorname{CCOC}(=\mathrm{O}) \mathrm{c} 1 \mathrm{cn} 2 \mathrm{ncnc}(\mathrm{NCc} 3 \operatorname{cccc} 3) \mathrm{c} 2 \mathrm{c} 1 \mathrm{CC}$ & 200 & $*$ \\
\hline 2660 & $\mathrm{CCOC}(=\mathrm{O}) \mathrm{c} 1 \mathrm{cn} 2 \mathrm{ncnc}(\mathrm{Nc} 3 \mathrm{ccc} 4 \mathrm{c}(\mathrm{cnn} 4 \mathrm{Cc} 4 \mathrm{ccccc} 4) \mathrm{c} 3) \mathrm{c} 2 \mathrm{c} 1 \mathrm{C}(\mathrm{C}) \mathrm{C}$ & 200 & $*$ \\
\hline 2661 & $\mathrm{CS}(=\mathrm{O})(=\mathrm{O}) \mathrm{CCNC} 1 \mathrm{CCN}(\mathrm{Cc} 2 \mathrm{ccn} 3 \mathrm{ncnc}(\mathrm{Nc} 4 \mathrm{ccc} 5 \mathrm{c}(\operatorname{cnn} 5 \mathrm{Cc} 5 \mathrm{ccc}(\mathrm{F}) \mathrm{c} 5) \mathrm{c} 4) \mathrm{c} 23) \mathrm{CC} 1$ & 200 & $*$ \\
\hline 2662 & $\mathrm{Fc} 1 \mathrm{ccc}(\mathrm{Nc} 2 \mathrm{ncnc} 3 \mathrm{nn} 4 \mathrm{ccccc} 4 \mathrm{c} 23) \mathrm{cc} 1 \mathrm{Cl}$ & 200 & $*$ \\
\hline 2663 & $\mathrm{O}[\mathrm{C} @ @ \mathrm{H}] 1 \mathrm{CNCCN}(\mathrm{Cc} 2 \mathrm{ccn} 3 \mathrm{ncnc}(\mathrm{Nc} 4 \mathrm{ccc} 5 \mathrm{c}(\mathrm{cnn} 5 \mathrm{Cc} 5 \mathrm{cccc}(\mathrm{F}) \mathrm{c} 5) \mathrm{c} 4) \mathrm{c} 23) \mathrm{C} 1$ & 200 & $*$ \\
\hline 2664 & $\mathrm{Cc} 1 \mathrm{ccn} 2 \mathrm{ncnc}(\mathrm{Nc} 3 \mathrm{ccc} 4 \mathrm{c}(\mathrm{cnn} 4 \mathrm{Cc} 4 \mathrm{ccccn} 4) \mathrm{c} 3) \mathrm{c} 12$ & 200 & $*$ \\
\hline 2665 & $\mathrm{CN}=\mathrm{NNc} 1 \mathrm{ccc} 2 \mathrm{ncnc}(\mathrm{Nc} 3 \mathrm{cccc}(\mathrm{C}) \mathrm{c} 3) \mathrm{c} 2 \mathrm{c} 1$ & 200 & $*$ \\
\hline 2666 & $\mathrm{CN} / \mathrm{N}=\mathrm{N} / \mathrm{c} 1 \mathrm{ccc} 2 \mathrm{ncnc}(\mathrm{Nc} 3 \operatorname{ccc}(\mathrm{C}) \mathrm{c} 3) \mathrm{c} 2 \mathrm{c} 1$ & 200 & $*$ \\
\hline 2667 & $\mathrm{Nc} 1 \mathrm{cccc}(-\mathrm{c} 2 \mathrm{nc} 3 \mathrm{c}(\mathrm{Nc} 4 \mathrm{cccc}(\mathrm{O}) \mathrm{c} 4) \mathrm{ncnc} 3 \mathrm{o} 2) \mathrm{c} 1$ & 200 & $*$ \\
\hline 2668 & Nc1 cce(-c2nc3c(Nc4ccc(O)cc4)ncnc3o2)cc1 & 200 & $*$ \\
\hline 2669 & Cl.Nc1 cec(-c2nc3c(Nc4cccc $(\mathrm{Cl}) \mathrm{c} 4) \mathrm{ncnc} 3 \mathrm{o} 2) \mathrm{cc} 1$ & 200 & $*$ \\
\hline 2670 & $\mathrm{CCN}(\mathrm{CC}) \mathrm{C}(\mathrm{C})(\mathrm{C} \# \mathrm{Cc} 1 \mathrm{ncnc} 2 \mathrm{cc}(\mathrm{OC}) \mathrm{c}(\mathrm{OC}) \mathrm{cc} 12) \mathrm{Cc} 1 \mathrm{ccncc} 1$ & 200 & $*$ \\
\hline 2671 & $\mathrm{CN}(\mathrm{c} 1 \mathrm{ccc} 2[\mathrm{nH}] \operatorname{ccc} 2 \mathrm{c} 1) \mathrm{c} 1 \mathrm{ccnc}(\mathrm{Nc} 2 \mathrm{ccc}(\mathrm{OCCCCN} 3 \mathrm{CCOCC} 3) \mathrm{cc} 2) \mathrm{n} 1$ & 200 & $*$ \\
\hline 2672 & $\mathrm{COCCOc} 1 \mathrm{cc} 2 \mathrm{ncnc}(\mathrm{Nc} 3 \mathrm{ccc}(\mathrm{F}) \mathrm{cc} 3) \mathrm{c} 2 \mathrm{c} 2 \mathrm{c} 1 \mathrm{OCCO} 2$ & 200.3 & $*$ \\
\hline 2673 & $\operatorname{COc} 1 \mathrm{cc}(\mathrm{N} 2 \mathrm{CCN}(\mathrm{C}) \mathrm{CC} 2) \operatorname{ccc} 1 \mathrm{Nc} 1 \mathrm{ncc}(\mathrm{Cl}) \mathrm{c}(\mathrm{Oc} 2 \mathrm{cccc}(\mathrm{NC}(=\mathrm{O}) \mathrm{CCN} 3 \mathrm{CCN}(\mathrm{CCOc} 4 \mathrm{no}[\mathrm{n}+]([\mathrm{O}-]) \mathrm{c} 4 \mathrm{~S}(=\mathrm{O})(=\mathrm{O}) \mathrm{c} 4 \mathrm{ccc}$ & 201 & 6.70 \\
\hline
\end{tabular}




\begin{tabular}{|c|c|c|c|}
\hline & cc4)(C3)c2)n1 & & \\
\hline 2674 & $\mathrm{CN}(\mathrm{C}) \mathrm{C} / \mathrm{C}=\mathrm{C} / \mathrm{C}(=\mathrm{O}) \mathrm{Nc} 1 \mathrm{cc} 2 \mathrm{c}(\mathrm{Nc} 3 \mathrm{ccc}(\mathrm{Oc} 4 \mathrm{ccccc} 4) \mathrm{cc} 3) \mathrm{ncnc} 2 \mathrm{cn} 1$ & 201 & $*$ \\
\hline 2675 & $\mathrm{Nc} 1 \mathrm{cccc}(-\mathrm{c} 2 \mathrm{c}(-\mathrm{c} 3 \operatorname{ccccc} 3) \mathrm{oc} 3 \mathrm{ncnc}(\mathrm{N}[\mathrm{C} @ \mathrm{H}](\mathrm{CO}) \mathrm{c} 4 \operatorname{ccccc} 4) \mathrm{c} 23) \mathrm{c} 1$ & 203 & $*$ \\
\hline 2676 & $\mathrm{CN}(\mathrm{C}) \mathrm{CCn} 1 \mathrm{cnc} 2 \mathrm{c}(\mathrm{Cl}) \mathrm{c} 3 \mathrm{c}(\mathrm{Nc} 4 \mathrm{cccc}(\mathrm{Br}) \mathrm{c} 4) \mathrm{ncnc} 3 \mathrm{cc} 21$ & 203 & $*$ \\
\hline 2677 & $\mathrm{O}=\mathrm{C}(/ \mathrm{C}=\mathrm{C} / \mathrm{CN} 1 \mathrm{CCSCC} 1) \mathrm{Nc} 1 \mathrm{ccc} 2 \mathrm{ncnc}(\mathrm{Nc} 3 \operatorname{ccc}(\mathrm{Br}) \mathrm{c} 3) \mathrm{c} 2 \mathrm{c} 1$ & 203 & $*$ \\
\hline 2678 & $\mathrm{C}=\mathrm{CC}(=\mathrm{O}) \mathrm{Nc} 1 \mathrm{cc}(\mathrm{Nc} 2 \mathrm{ncc}(\mathrm{Cl}) \mathrm{c}(\mathrm{Nc} 3 \operatorname{cccc} 3 \mathrm{~S}(=\mathrm{O})(=\mathrm{O}) \mathrm{N}(\mathrm{C}) \mathrm{C}) \mathrm{n} 2) \mathrm{c}(\mathrm{OC}) \operatorname{cc} 1 \mathrm{~N}(\mathrm{C}) \mathrm{CCN}(\mathrm{C}) \mathrm{C}$ & 204 & $*$ \\
\hline 2679 & $\mathrm{CCC}(=\mathrm{O}) \mathrm{Nc} 1 \mathrm{cc} 2 \mathrm{c}(\mathrm{Nc} 3 \mathrm{ccc}(\mathrm{Cc} 4 \mathrm{ccc} n 4) \mathrm{cc} 3) \mathrm{ncnc} 2 \mathrm{cc} 1 \mathrm{OC}$ & 205 & $*$ \\
\hline 2680 & $\mathrm{COc} 1 \mathrm{cc} 2 \mathrm{ncnc}(\mathrm{Nc} 3 \mathrm{ccc}(\mathrm{C} \# \mathrm{CC}(\mathrm{C})(\mathrm{C}) \mathrm{O}) \mathrm{c} 3) \mathrm{c} 2 \mathrm{cc} 1 \mathrm{OC}$ & 205.8 & $*$ \\
\hline 2681 & $\mathrm{CC}(\mathrm{C}) \mathrm{n} 1 \mathrm{nc}(-\mathrm{c} 2 \mathrm{ccc} 3 \mathrm{c}(\mathrm{N}) \mathrm{n}[\mathrm{nH}] \mathrm{c} 3 \mathrm{c} 2) \mathrm{c} 2 \mathrm{c}(\mathrm{N}) \mathrm{ncnc} 21$ & 207 & $*$ \\
\hline 2682 & $\mathrm{C}=\mathrm{CC}(=\mathrm{O}) \mathrm{Nc} 1 \mathrm{cc}(\mathrm{C}) \mathrm{cc}(-\mathrm{n} 2 \mathrm{c}(=\mathrm{O}) \mathrm{cc}(\mathrm{C}) \mathrm{c} 3 \mathrm{cnc}(\mathrm{Nc} 4 \mathrm{ccc}(\mathrm{N} 5 \mathrm{CCN}(\mathrm{C}) \mathrm{CC} 5) \mathrm{cc} 4 \mathrm{OC}) \mathrm{nc} 32) \mathrm{c} 1$ & 208.4 & $*$ \\
\hline 2683 & $\mathrm{CCC}(=\mathrm{O}) \mathrm{N} 1 \mathrm{CC}[\mathrm{C} @ \mathrm{H}](\mathrm{N} 2 \mathrm{C}(=\mathrm{O}) \mathrm{N}(\mathrm{c} 3 \mathrm{cc}(\mathrm{OC}) \mathrm{ccc} 3 \mathrm{~F}) \mathrm{Cc} 3 \mathrm{cnc}(\mathrm{Nc} 4 \mathrm{ccc}(\mathrm{N} 5 \mathrm{CCCN}(\mathrm{C}) \mathrm{CC} 5) \mathrm{c}(\mathrm{C}) \mathrm{c} 4) \mathrm{nc} 32) \mathrm{C} 1$ & 209 & 6.68 \\
\hline 2684 & $\mathrm{COc} 1 \mathrm{cc} 2 \mathrm{ncnc}(-\mathrm{c} 3 \mathrm{c}[\mathrm{nH}] \mathrm{c} 4 \mathrm{cc}(\mathrm{F}) \mathrm{c}(\mathrm{Cl}) \mathrm{cc} 34) \mathrm{c} 2 \mathrm{cc} 1 \mathrm{OC}$ & 209 & * \\
\hline 2685 & $\mathrm{NC}(=\mathrm{S}) \mathrm{N} 1 \mathrm{~N}=\mathrm{C}(\mathrm{c} 2 \mathrm{ccc}(\mathrm{Cl}) \mathrm{c}(\mathrm{Cl}) \mathrm{c} 2) \mathrm{CC} 1 \mathrm{c} 1 \mathrm{cccc} 2 \mathrm{cccc} 12$ & 210 & 6.68 \\
\hline 2686 & $\mathrm{Cc} 1 \mathrm{ncc}([\mathrm{N}+](=\mathrm{O})[\mathrm{O}-]) \mathrm{n} 1 \mathrm{C} / \mathrm{C}(=\mathrm{N} / \mathrm{NC}(=\mathrm{O}) \mathrm{c} 1 \mathrm{ccc}(\mathrm{O}) \operatorname{cc} 1) \mathrm{c} 1 \mathrm{ccc}(\mathrm{Br}) \mathrm{cc} 1$ & 210 & 6.68 \\
\hline 2687 & $\mathrm{COc} 1 \mathrm{cc} 2 \mathrm{ncc}(\mathrm{C \# N}) \mathrm{c}(\mathrm{Nc} 3 \operatorname{ccc}(\mathrm{NCNc} 4 \mathrm{cccc} 4) \mathrm{c}(\mathrm{Cl}) \mathrm{c} 3) \mathrm{c} 2 \mathrm{cc} 1 \mathrm{NC}(=\mathrm{O}) / \mathrm{C}=\mathrm{C} / \mathrm{CN}(\mathrm{C}) \mathrm{C}$ & 210 & 6.68 \\
\hline 2688 & $\mathrm{C}=\mathrm{CC}(=\mathrm{O}) \mathrm{Nc} 1 \mathrm{cccc}(-\mathrm{n} 2 \mathrm{c}(=\mathrm{O}) \mathrm{cc}(\mathrm{N}(\mathrm{C}) \mathrm{C}) \mathrm{c} 3 \mathrm{cnc}(\mathrm{Nc} 4 \mathrm{ccc}(\mathrm{N} 5 \mathrm{CCN}(\mathrm{C}) \mathrm{CC} 5) \mathrm{cc} 4 \mathrm{OC}) \mathrm{nc} 32) \mathrm{c} 1$ & 210 & $*$ \\
\hline 2689 & $\mathrm{C}=\mathrm{CC}(=\mathrm{O}) \mathrm{Nc} 1 \mathrm{cc}(\mathrm{Nc} 2 \mathrm{nccc}(-\mathrm{c} 3 \mathrm{cn}(\mathrm{C}) \mathrm{c} 4 \mathrm{cccc} 34) \mathrm{n} 2) \mathrm{c}(\mathrm{OC}) \mathrm{cc} 1 \mathrm{~N}(\mathrm{C}) \mathrm{CCN}(\mathrm{C}) \mathrm{C}$ & 210 & $*$ \\
\hline 2690 & $\mathrm{CN} 1 \mathrm{CCN}(\mathrm{CCCCNc} 2 \mathrm{ncc} 3 \mathrm{cc}(-\mathrm{c} 4 \mathrm{c}(\mathrm{Cl}) \mathrm{cccc} 4 \mathrm{Cl}) \mathrm{c}(=\mathrm{O}) \mathrm{n}(\mathrm{C}) \mathrm{c} 3 \mathrm{n} 2) \mathrm{CC} 1$ & 210 & $*$ \\
\hline 2691 & $\mathrm{Cc} 1 \mathrm{cc}(/ \mathrm{C}=\mathrm{C} 2 \backslash \mathrm{C}(=\mathrm{O}) \mathrm{Nc} 3 \mathrm{ncnc}(\mathrm{Nc} 4 \mathrm{ccc}(\mathrm{F}) \mathrm{c}(\mathrm{Cl}) \mathrm{c} 4) \mathrm{c} 32)[\mathrm{nH}] \mathrm{c} 1 \mathrm{C}(=\mathrm{O}) \mathrm{N} 1 \mathrm{CCN}(\mathrm{C}) \mathrm{CC} 1$ & 210 & $*$ \\
\hline 2692 & $\mathrm{CCc} 1 \mathrm{c}(\mathrm{NC}(=\mathrm{O}) \mathrm{OCc} 2 \operatorname{cccc} 2) \operatorname{cn} 2 \mathrm{ncnc}(\mathrm{Nc} 3 \operatorname{ccc} 4 \mathrm{c}(\operatorname{cnn} 4 \mathrm{Cc} 4 \mathrm{ccccc} 4) \mathrm{c} 3) \mathrm{c} 12$ & 210 & $*$ \\
\hline 2693 & $\mathrm{CS}(=\mathrm{O})(=\mathrm{O}) \mathrm{N} 1 \mathrm{CCCN}(\mathrm{Cc} 2 \mathrm{ccn} 3 \mathrm{ncnc}(\mathrm{Nc} 4 \mathrm{ccc} 5 \mathrm{c}(\operatorname{cnn} 5 \mathrm{Cc} 5 \mathrm{ccc}(\mathrm{F}) \mathrm{c} 5) \mathrm{c} 4) \mathrm{c} 23) \mathrm{CC} 1$ & 210 & $*$ \\
\hline 2694 & $\mathrm{Fc} 1 \mathrm{cccc}(\mathrm{Cn} 2 \mathrm{ncc} 3 \mathrm{cc}(\mathrm{Nc} 4 \mathrm{ncnn} 5 \mathrm{ccc}(\mathrm{COCC} 6 \mathrm{CNCCOC}) \mathrm{c} 45) \mathrm{ccc} 32) \mathrm{c} 1$ & 210 & $*$ \\
\hline 2695 & $\mathrm{Cc} 1 \mathrm{ccn} 2 \mathrm{ncnc}(\mathrm{Nc} 3 \mathrm{ccc} 4[\mathrm{nH}] \mathrm{ncc} 4 \mathrm{c} 3) \mathrm{c} 12$ & 210 & $*$ \\
\hline 2696 & $\mathrm{FC}(\mathrm{F})(\mathrm{F}) \mathrm{Oc} 1 \mathrm{ccccc} 1 \mathrm{Oc} 1 \mathrm{ccc}(\mathrm{Nc} 2 \mathrm{ncnc} 3 \mathrm{cc}[\mathrm{nH}] \mathrm{c} 23) \mathrm{cc} 1 \mathrm{Cl}$ & 210 & $*$ \\
\hline 2697 & $\mathrm{CN}(\mathrm{CCn} 1 \mathrm{ccc} 2 \mathrm{ncnc}(\mathrm{Nc} 3 \operatorname{ccc}(\mathrm{Oc} 4 \operatorname{ccc}(\mathrm{C}(\mathrm{F})(\mathrm{F}) \mathrm{F}) \mathrm{c} 4) \mathrm{c}(\mathrm{Cl}) \mathrm{c} 3) \mathrm{c} 21) \mathrm{C}(=\mathrm{O}) \mathrm{CO}$ & 210 & $*$ \\
\hline 2698 & $\mathrm{c} 1 \mathrm{cc}(\mathrm{Nc} 2 \mathrm{ccc} 3[\mathrm{nH}] \mathrm{ccc} 3 \mathrm{c} 2) \mathrm{nc}(\mathrm{Nc} 2 \mathrm{ccc}(\mathrm{OCCN} 3 \mathrm{CCOCC} 3) \mathrm{cc} 2) \mathrm{n} 1$ & 210 & $*$ \\
\hline 2699 & $\mathrm{C} \# \mathrm{Cc} 1 \mathrm{cccc}(\mathrm{Nc} 2 \mathrm{ncnc} 3 \mathrm{cc} 4 \mathrm{c}(\mathrm{cc} 23) \mathrm{N}(\mathrm{CCCN} 2 \mathrm{CCCCC} 2) \mathrm{C}(=\mathrm{O}) \mathrm{CO} 4) \mathrm{c} 1$ & 211.4 & $*$ \\
\hline 2700 & $\mathrm{COc} 1 \mathrm{cc} 2 \mathrm{c}(\mathrm{Nc} 3 \mathrm{ccc}(\mathrm{NC}(=\mathrm{O}) \mathrm{Nc} 4 \mathrm{cccc} 4) \mathrm{c}(\mathrm{Cl}) \mathrm{c} 3) \mathrm{ncnc} 2 \mathrm{cc} 1 \mathrm{OCCN} 1 \mathrm{CCCCC} 1$ & 212 & $*$ \\
\hline 2701 & $\mathrm{COc} 1 \mathrm{cc} 2 \mathrm{ncc}(\mathrm{C \# N}) \mathrm{c}(\mathrm{Nc} 3 \operatorname{ccc}(\mathrm{Cc} 4 \mathrm{nc}(-\mathrm{c} 5 \mathrm{cccc} 5) \mathrm{cs} 4) \mathrm{c}(\mathrm{Cl}) \mathrm{c} 3) \mathrm{c} 2 \mathrm{cc} 1 \mathrm{NC}(=\mathrm{O}) / \mathrm{C}=\mathrm{C} / \mathrm{CN}(\mathrm{C}) \mathrm{C}$ & 214 & 6.67 \\
\hline 2702 & $\mathrm{O}=\mathrm{C}(/ \mathrm{C}=\mathrm{C} / \mathrm{N} 1 \mathrm{CCOCC} 1) \mathrm{Nc} 1 \mathrm{ccc} 2 \mathrm{ncnc}(\mathrm{Nc} 3 \operatorname{ccc}(\mathrm{Br}) \mathrm{c} 3) \mathrm{c} 2 \mathrm{c} 1$ & 215 & $*$ \\
\hline 2703 & Fc1 $1 \mathrm{ccc}(-\mathrm{c} 2 \mathrm{nc}(-\mathrm{c} 3 \operatorname{ccccc} 3)[\mathrm{nH}] \mathrm{c} 2-\mathrm{c} 2 \mathrm{ccnc} 3[\mathrm{nH}] \mathrm{c}(-\mathrm{c} 4 \mathrm{ccccc} 4) \mathrm{cc} 23) \mathrm{cc} 1$ & 215 & $*$ \\
\hline 2704 & $\mathrm{COc} 1 \mathrm{ccc}(-\mathrm{c} 2 \mathrm{c} 3 \mathrm{c} 4 \mathrm{cc}(\mathrm{OC}) \mathrm{c}(\mathrm{OCCCN}(\mathrm{C}) \mathrm{C}) \mathrm{cc} 4 \mathrm{oc}(=\mathrm{O}) \mathrm{c} 3 \mathrm{n} 3 \mathrm{ccc} 4 \mathrm{cc}(\mathrm{O}) \mathrm{c}(\mathrm{OC}) \mathrm{cc} 4 \mathrm{c} 23) \mathrm{cc} 1 \mathrm{O} . \mathrm{O}=\mathrm{C}(\mathrm{O}) \mathrm{C}(\mathrm{F})(\mathrm{F}) \mathrm{F}$ & 215.4 & $*$ \\
\hline 2705 & Clc1 $1 \mathrm{ccc}(\mathrm{Nc} 2 \mathrm{ncnc} 3 \mathrm{ccc}(\mathrm{NCc} 4 \mathrm{ccc} 5 \mathrm{c}(\mathrm{c} 4) \mathrm{OCCCO}) \mathrm{cc} 23) \mathrm{c} 1$ & 216 & 6.67 \\
\hline 2706 & $\begin{array}{c}\mathrm{CCC}(=\mathrm{O}) \mathrm{N} 1 \mathrm{CC}[\mathrm{C} @ \mathrm{H}](\mathrm{N} 2 \mathrm{C}(=\mathrm{O}) \mathrm{N}(\mathrm{c} 3 \mathrm{cc}(\mathrm{OC}) \mathrm{ccc} 3 \mathrm{~F}) \mathrm{Cc} 3 \mathrm{cnc}(\mathrm{Nc} 4 \mathrm{ccc}(\mathrm{N} 5 \mathrm{C}[\mathrm{C} @ @ \mathrm{H}] 6 \mathrm{CN}(\mathrm{C}) \mathrm{C}[\mathrm{C} @ \mathrm{H}] 6 \mathrm{C} 5) \mathrm{c}(\mathrm{C}) \\
\mathrm{c} 4) \mathrm{nc} 32) \mathrm{C} 1\end{array}$ & 216 & 6.67 \\
\hline 2707 & $\mathrm{C}=\mathrm{CC}(=\mathrm{O}) \mathrm{Nc} 1 \mathrm{cccc}(\mathrm{Nc} 2 \mathrm{nc}(\mathrm{Nc} 3 \operatorname{ccc}(/ \mathrm{C}=\mathrm{C} / \mathrm{c} 4 \mathrm{cc}(\mathrm{OC}) \mathrm{cc}(\mathrm{OC}) \mathrm{c} 4) \mathrm{cc} 3) \mathrm{ncc} 2 \mathrm{Cl}) \mathrm{c} 1$ & 216.1 & $*$ \\
\hline 2708 & $\mathrm{C}=\mathrm{CC}(=\mathrm{O}) \mathrm{N} 1 \mathrm{CCC}(\mathrm{Sc} 2 \mathrm{nc}(-\mathrm{c} 3 \mathrm{ccc}(\mathrm{F}) \mathrm{cc} 3) \mathrm{c}(-\mathrm{c} 3 \mathrm{ccnc}(\mathrm{Nc} 4 \mathrm{ccccc} 4) \mathrm{c} 3)[\mathrm{nH}] 2) \mathrm{C} 1$ & 217 & $*$ \\
\hline 2709 & $\mathrm{CCC}(=\mathrm{O}) \mathrm{N} 1 \mathrm{CC}[\mathrm{C} @ \mathrm{H}](\mathrm{N} 2 \mathrm{C}(=\mathrm{O}) \mathrm{N}(\mathrm{c} 3 \mathrm{cc}(\mathrm{OC}) \mathrm{ccc} 3 \mathrm{~F}) \mathrm{Cc} 3 \mathrm{cnc}(\mathrm{Nc} 4 \mathrm{ccc}(\mathrm{N} 5 \mathrm{CC} 6(\mathrm{CCN}(\mathrm{C}) \mathrm{CC} 6) \mathrm{C} 5) \mathrm{c}(\mathrm{C}) \mathrm{c} 4) \mathrm{nc} 32) \mathrm{C} 1$ & 218 & 6.66 \\
\hline 2710 & $\mathrm{CC}(=\mathrm{O}) \mathrm{Nc} 1 \mathrm{cccc}(-\mathrm{c} 2 \mathrm{c}(-\mathrm{c} 3 \mathrm{ccccc} 3) \mathrm{oc} 3 \mathrm{ncnc}(\mathrm{N}[\mathrm{C} @ \mathrm{H}](\mathrm{CO}) \mathrm{c} 4 \mathrm{cccc} 4) \mathrm{c} 23) \mathrm{c} 1$ & 218 & $*$ \\
\hline 2711 & $\mathrm{COc} 1 \mathrm{cccc} 1-\mathrm{c} 1 \mathrm{cc} 2 \mathrm{c}(\mathrm{Nc} 3 \mathrm{ccc}(\mathrm{OCc} 4 \mathrm{cccc}(\mathrm{F}) \mathrm{c} 4) \mathrm{c}(\mathrm{Cl}) \mathrm{c} 3) \mathrm{ncnc} 2 \mathrm{~s} 1$ & 220 & $*$ \\
\hline 2712 & $\mathrm{Nc} 1 \mathrm{nc}(\mathrm{N}) \mathrm{c} 2 \mathrm{c}(\mathrm{Nc} 3 \mathrm{cccc}(\mathrm{Cl}) \mathrm{c} 3)[\mathrm{nH}] \mathrm{nc} 2 \mathrm{n} 1$ & 220 & $*$ \\
\hline 2713 & $\mathrm{COc} 1 \mathrm{ccc}(\mathrm{Nc} 2 \mathrm{ncc} 3 \mathrm{cc}(-\mathrm{c} 4 \mathrm{c}(\mathrm{Cl}) \mathrm{cccc} 4 \mathrm{Cl}) \mathrm{c}(=\mathrm{O}) \mathrm{n}(\mathrm{C}) \mathrm{c} 3 \mathrm{n} 2) \mathrm{cc} 1$ & 220 & $*$ \\
\hline 2714 & $\mathrm{Cn} 1 \mathrm{c}(=\mathrm{O}) \mathrm{c}(-\mathrm{c} 2 \mathrm{c}(\mathrm{Cl}) \operatorname{ccc} 2 \mathrm{Cl}) \mathrm{cc} 2 \mathrm{cnc}(\mathrm{Nc} 3 \operatorname{ccc}(\mathrm{CC}(=\mathrm{O}) \mathrm{O}) \mathrm{cc} 3) \mathrm{nc} 21$ & 220 & $*$ \\
\hline
\end{tabular}




\begin{tabular}{|c|c|c|c|}
\hline 2715 & $\mathrm{O}=\mathrm{C}(\mathrm{O}) \mathrm{C} 1 \mathrm{CCN}(\mathrm{Cc} 2 \mathrm{ccn} 3 \mathrm{ncnc}(\mathrm{Nc} 4 \mathrm{ccc} 5 \mathrm{c}(\operatorname{cnn} 5 \mathrm{Cc} 5 \mathrm{ccc}(\mathrm{F}) \mathrm{c} 5) \mathrm{c} 4) \mathrm{c} 23) \mathrm{CC} 1$ & 220 & $*$ \\
\hline 2716 & $\mathrm{CC}(\mathrm{C}) \mathrm{n} 1 \mathrm{nc}(-\mathrm{c} 2 \mathrm{ccc} 3 \mathrm{cc}[\mathrm{nH}] \mathrm{c} 3 \mathrm{c} 2) \mathrm{c} 2 \mathrm{c}(\mathrm{N}) \mathrm{ncnc} 21$ & 220 & $*$ \\
\hline 2717 & $\mathrm{O}=\mathrm{C}(\mathrm{Nc} 1 \mathrm{cccc}(\mathrm{Cl}) \mathrm{c} 1) \mathrm{c} 1 \mathrm{cc}(\mathrm{O}) \mathrm{ccc} 1 \mathrm{O}$ & 220 & $*$ \\
\hline 2718 & $\mathrm{FC}(\mathrm{F})(\mathrm{F}) \mathrm{Oc} 1 \mathrm{cccc}(\mathrm{Oc} 2 \mathrm{ccc}(\mathrm{Nc} 3 \mathrm{ncnc} 4 \mathrm{cc}[\mathrm{nH}] \mathrm{c} 34) \mathrm{cc} 2 \mathrm{Cl}) \mathrm{c} 1$ & 220 & $*$ \\
\hline 2719 & $\mathrm{CCOc} 1 \mathrm{cc} 2 \mathrm{ncc}(\mathrm{C} \# \mathrm{~N}) \mathrm{c}(\mathrm{Nc} 3 \operatorname{ccc}(\mathrm{OCc} 4 \mathrm{ccccc} 4) \mathrm{c}(\mathrm{Cl}) \mathrm{c} 3) \mathrm{c} 2 \mathrm{cc} 1 \mathrm{NC}(=\mathrm{O}) / \mathrm{C}=\mathrm{C} / \mathrm{CN} 1 \mathrm{CCC}(\mathrm{O}) \mathrm{CC} 1$ & 221 & 6.66 \\
\hline 2720 & $\mathrm{C}=\mathrm{C}(\mathrm{CN}(\mathrm{C}) \mathrm{C}) \mathrm{C}(=\mathrm{O}) \mathrm{Nc} 1 \mathrm{cc} 2 \mathrm{c}(\mathrm{Nc} 3 \operatorname{ccc}(\mathrm{OCc} 4 \mathrm{ccccc} 4) \mathrm{c}(\mathrm{Cl}) \mathrm{c} 3) \mathrm{c}(\mathrm{C \# N}) \mathrm{cnc} 2 \mathrm{cc} 1 \mathrm{OCC}$ & 223 & 6.65 \\
\hline 2721 & $\mathrm{C}=\mathrm{CC}(=\mathrm{O}) \mathrm{Nc} 1 \mathrm{cccc}(-\mathrm{n} 2 \mathrm{c}(=\mathrm{O}) \mathrm{c}(=\mathrm{O}) \mathrm{n}(\mathrm{C}(\mathrm{C}) \mathrm{C}) \mathrm{c} 3 \mathrm{cnc}(\mathrm{Nc} 4 \mathrm{ccc}(\mathrm{N}(\mathrm{C}) \mathrm{CCN}(\mathrm{C}) \mathrm{C}) \mathrm{cc} 4 \mathrm{OC}) \mathrm{nc} 32) \mathrm{c} 1$ & 223 & $*$ \\
\hline 2722 & $\mathrm{C} / \mathrm{C}=\mathrm{C} \backslash \mathrm{C}(=\mathrm{O}) \mathrm{Nc} 1 \mathrm{cccc} 1 \mathrm{Nc} 1 \mathrm{ncnc} 2 \mathrm{cc}(\mathrm{OCCCOC}) \mathrm{c}(\mathrm{OCCCOC}) \mathrm{cc} 12$ & 223.6 & $*$ \\
\hline 2723 & $\begin{array}{c}\mathrm{CCC}(=\mathrm{O}) \mathrm{N} 1 \mathrm{CC}[\mathrm{C} @ \mathrm{H}](\mathrm{N} 2 \mathrm{C}(=\mathrm{O}) \mathrm{N}(\mathrm{c} 3 \mathrm{cc}(\mathrm{OC}) \mathrm{ccc} 3 \mathrm{~F}) \mathrm{Cc} 3 \mathrm{cnc}(\mathrm{Nc} 4 \mathrm{ccc}(\mathrm{N} 5 \mathrm{CCC} 6(\mathrm{CCN}(\mathrm{C}) \mathrm{CC} 6) \mathrm{CC} 5) \mathrm{c}(\mathrm{C}) \mathrm{c} 4) \mathrm{nc} 32) \\
\mathrm{C} 1\end{array}$ & 224.5 & 6.65 \\
\hline 2724 & $\mathrm{COc} 1 \mathrm{ccc} 2 \mathrm{ncnc}(\mathrm{Nc} 3 \mathrm{ccc}(\mathrm{F}) \mathrm{c}(\mathrm{Cl}) \mathrm{c} 3) \mathrm{c} 2 \mathrm{c} 1 \mathrm{OC} 1 \mathrm{CCN}(\mathrm{C}) \mathrm{CC} 1$ & 225 & $*$ \\
\hline 2725 & $\mathrm{C}=\mathrm{CC}(=\mathrm{O}) \mathrm{Nc} 1 \operatorname{ccc}(\mathrm{NC}(=\mathrm{O}) \mathrm{Nc} 2 \mathrm{ccnc}(\mathrm{Nc} 3 \operatorname{ccc}(\mathrm{N} 4 \mathrm{CCOCC} 4) \mathrm{cc} 3 \mathrm{OC}) \mathrm{n} 2) \mathrm{c} 1$ & 225 & $*$ \\
\hline 2726 & $\operatorname{COc} 1 \operatorname{ccc}(\mathrm{NC}(=\mathrm{O}) / \mathrm{C}=\mathrm{C} / \mathrm{CN}(\mathrm{C}) \mathrm{C}) \mathrm{cc} 1 \mathrm{Nc} 1 \mathrm{ncc}(\mathrm{C}) \mathrm{c}(\mathrm{Nc} 2 \operatorname{ccc} 3 \operatorname{cccc} 3 \mathrm{c} 2) \mathrm{n} 1$ & 225 & $*$ \\
\hline 2727 & $\operatorname{COc} 1 \operatorname{ccc}(\mathrm{NC}(=\mathrm{O}) / \mathrm{C}=\mathrm{C} / \mathrm{CN}(\mathrm{C}) \mathrm{C}) \mathrm{cc} 1 \mathrm{Nc} 1 \mathrm{ncc}(\mathrm{OC}) \mathrm{c}(\mathrm{Nc} 2 \operatorname{ccc} 3 \operatorname{ccccc} 3 \mathrm{c} 2) \mathrm{n} 1$ & 225 & $*$ \\
\hline 2728 & $\mathrm{CCNC}(=\mathrm{O}) \mathrm{Nc} 1 \mathrm{ccc} 2 \mathrm{ncnc}(\mathrm{Nc} 3 \mathrm{ccc}(\mathrm{OCc} 4 \mathrm{ccc} \mathrm{n} 4) \mathrm{c}(\mathrm{Cl}) \mathrm{c} 3) \mathrm{c} 2 \mathrm{c} 1$ & 227 & $*$ \\
\hline 2729 & $\mathrm{C}=\mathrm{CC}(=\mathrm{O}) \mathrm{Nc} 1 \mathrm{cccc}(-\mathrm{n} 2 \mathrm{c}(=\mathrm{O}) \mathrm{n}(\mathrm{C}(\mathrm{C}) \mathrm{C}) \mathrm{c}(=\mathrm{O}) \mathrm{c} 3 \mathrm{cnc}(\mathrm{Nc} 4 \mathrm{ccc}(\mathrm{OCCN}(\mathrm{C}) \mathrm{C}) \mathrm{cc} 4 \mathrm{OC}) \mathrm{nc} 32) \mathrm{c} 1$ & 227 & $*$ \\
\hline 2730 & $\mathrm{O}=\mathrm{C}(\mathrm{O}[\mathrm{C} @ \mathrm{H}] 1 \mathrm{CN}[\mathrm{C} @ \mathrm{H}](\mathrm{C} \# \mathrm{Cc} 2 \mathrm{cc} 3 \mathrm{ncnc}(\mathrm{Nc} 4 \mathrm{ccc} 5 \mathrm{c}(\mathrm{cnn} 5 \mathrm{~S}(=\mathrm{O})(=\mathrm{O}) \mathrm{c} 5 \operatorname{cccc}(\mathrm{F}) \mathrm{c} 5) \mathrm{c} 4) \mathrm{c} 3 \mathrm{~s} 2) \mathrm{C} 1) \mathrm{N} 1 \mathrm{CCOCC} 1$ & 230 & 6.64 \\
\hline 2731 & $\operatorname{CCOC}(=\mathrm{O}) \mathrm{c} 1 \mathrm{ccc}(\mathrm{O}) \mathrm{c}(\mathrm{Nc} 2 \mathrm{ncnc} 3 \mathrm{cc} 4 \mathrm{oc}(=\mathrm{O}) \mathrm{n}(\mathrm{CCCN} 5 \mathrm{CCOCC} 5) \mathrm{c} 4 \mathrm{cc} 23) \mathrm{c} 1$ & 230 & $*$ \\
\hline 2732 & $\mathrm{Nc} 1 \mathrm{cc} 2 \mathrm{ncnc}(\mathrm{NCc} 3 \operatorname{ccc} c 3 \mathrm{~N}) \mathrm{c} 2 \mathrm{cn} 1$ & 230 & $*$ \\
\hline 2733 & $\mathrm{C}=\mathrm{C}(\mathrm{CN}(\mathrm{C}) \mathrm{C}) \mathrm{C}(=\mathrm{O}) \mathrm{c} 1 \operatorname{ccc}(\mathrm{OS}(=\mathrm{O})(=\mathrm{O}) \mathrm{c} 2 \operatorname{ccc}(\mathrm{C}(=\mathrm{O}) \mathrm{O}) \mathrm{cc} 2) \mathrm{cc} 1$ & 230 & $*$ \\
\hline 2734 & $\mathrm{Cc} 1[\mathrm{nH}] \mathrm{c} 2 \mathrm{ncnc}(\mathrm{Nc} 3 \mathrm{cccc}(\mathrm{Cl}) \mathrm{c} 3) \mathrm{c} 2 \mathrm{c} 1-\mathrm{c} 1 \mathrm{cccc} 1$ & 230 & $*$ \\
\hline 2735 & $\mathrm{COc} 1 \mathrm{cc}(\mathrm{Nc} 2 \mathrm{c}(\mathrm{C \# N}) \mathrm{cnc} 3 \mathrm{cc}(-\mathrm{c} 4 \operatorname{coc}(\mathrm{CN} 5 \mathrm{CCN}(\mathrm{C}) \mathrm{CC} 5) \mathrm{c} 4) \mathrm{c}(\mathrm{OC}) \mathrm{cc} 23) \mathrm{c}(\mathrm{Cl}) \mathrm{cc} 1 \mathrm{Cl}$ & 230 & $*$ \\
\hline 2736 & $\mathrm{COc} 1 \mathrm{cc} 2 \mathrm{c}(\mathrm{Nc} 3 \mathrm{ccc}(\mathrm{NC}(=\mathrm{O}) \mathrm{c} 4 \mathrm{cccc}(\mathrm{Cl}) \mathrm{c} 4) \mathrm{cc} 3) \mathrm{ncn} 2 \mathrm{cc} 1 \mathrm{OCCCN} 1 \mathrm{CCOCC} 1$ & 230 & $*$ \\
\hline 2737 & $\mathrm{COc} 1 \mathrm{cc} 2 \mathrm{ncc}(\mathrm{C \# N}) \mathrm{c}(\mathrm{Nc} 3 \mathrm{ccc}(\mathrm{C}(\mathrm{C}) \mathrm{C}) \mathrm{cc} 3) \mathrm{c} 2 \mathrm{cc} 1 \mathrm{OC}$ & 230 & $*$ \\
\hline 2738 & 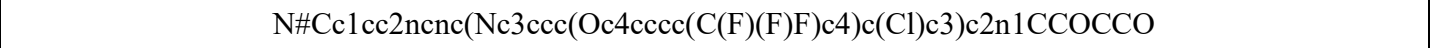 & 230 & $*$ \\
\hline 2739 & $\mathrm{CHCCNC}(=\mathrm{O}) \mathrm{Nc} 1 \mathrm{cc} 2 \mathrm{c}(\mathrm{Nc} 3 \mathrm{ccc}(\mathrm{F}) \mathrm{c}(\mathrm{Cl}) \mathrm{c} 3) \mathrm{ncnc} 2 \mathrm{cc} 1 \mathrm{O}[\mathrm{C} @ \mathrm{H}] 1 \mathrm{CCOC} 1$ & 232 & $*$ \\
\hline 2740 & $\mathrm{C} \# \mathrm{CCNN}(\mathrm{NCC} \# \mathrm{C}) \mathrm{C}(=\mathrm{O}) \mathrm{Nc} 1 \mathrm{cc} 2 \mathrm{c}(\mathrm{Nc} 3 \mathrm{ccc}(\mathrm{F}) \mathrm{c}(\mathrm{Cl}) \mathrm{c} 3) \mathrm{ncnc} 2 \mathrm{cc} 1 \mathrm{O}[\mathrm{C} @ \mathrm{H}] 1 \mathrm{CCOC} 1$ & 232 & $*$ \\
\hline 2741 & $\mathrm{CCOC}(\mathrm{C}) \mathrm{Oc} 1 \mathrm{cc} 2 \mathrm{ncnc}(\mathrm{Nc} 3 \mathrm{ccc}(\mathrm{F}) \mathrm{c}([\mathrm{N}+](=\mathrm{O})[\mathrm{O}-]) \mathrm{c} 3) \mathrm{c} 2 \mathrm{c} 2 \mathrm{c} 1 \mathrm{OCCO} 2$ & 232.3 & * \\
\hline 2742 & $\mathrm{CN} 1 \mathrm{CCN}(\mathrm{C}(=\mathrm{O}) \mathrm{c} 2 \mathrm{ccc}(-\mathrm{c} 3 \operatorname{ccc} 4 \mathrm{ncnc}(\mathrm{Nc} 5 \operatorname{ccc}(\mathrm{OCc} 6 \operatorname{ccc}(\mathrm{F}) \mathrm{c} 6) \mathrm{c}(\mathrm{Cl}) \mathrm{c} 5) \mathrm{c} 4 \mathrm{c} 3) \mathrm{o} 2) \mathrm{CC} 1 . \mathrm{Cc} 1 \mathrm{ccc}(\mathrm{S}(=\mathrm{O})(=\mathrm{O}) \mathrm{O}) \mathrm{cc} 1$ & 232.4 & $*$ \\
\hline 2743 & $\mathrm{COc} 1 \mathrm{cc} 2 \mathrm{c}(\mathrm{Nc} 3 \operatorname{ccc}(\mathrm{NC}(=\mathrm{O}) \mathrm{Nc} 4 \mathrm{ccc}(\mathrm{Cl}) \mathrm{cc} 4) \mathrm{cc} 3) \mathrm{ncnc} 2 \mathrm{cc} 1 \mathrm{OCCCN} 1 \mathrm{CCN}(\mathrm{C}) \mathrm{CC} 1$ & 235 & $*$ \\
\hline 2744 & Nc1ncnc2c1c(-c1ece(Br)c(O)c1)nn2C1CCCC1 & 236 & $*$ \\
\hline 2745 & $\mathrm{CCOc} 1 \mathrm{cc} 2 \mathrm{ncc}(\mathrm{C \# N}) \mathrm{c}(\mathrm{Nc} 3 \mathrm{ccc}(\mathrm{OCc} 4 \mathrm{ccnc} 5 \mathrm{ccccc} 45) \mathrm{c}(\mathrm{Cl}) \mathrm{c} 3) \mathrm{c} 2 \mathrm{cc} 1 \mathrm{NC}(=\mathrm{O}) / \mathrm{C}=\mathrm{C} / \mathrm{CN}(\mathrm{C}) \mathrm{C}$ & 238 & 6.62 \\
\hline 2746 & $\operatorname{Brc} 1 \operatorname{ccc}(\mathrm{Nc} 2 \mathrm{ncnc} 3 \operatorname{ccc}(\mathrm{NN}=\mathrm{NCc} 4 \mathrm{ccc} n 4) \operatorname{cc} 23) \mathrm{c} 1$ & 238 & $*$ \\
\hline 2747 & $\mathrm{O}=\mathrm{C} 1 \mathrm{Nc} 2 \operatorname{cc} 3 \mathrm{c}(-\mathrm{c} 4 \operatorname{ccc} c 4) \mathrm{c}(-\mathrm{c} 4 \mathrm{cccc} 4) \mathrm{n}(-\mathrm{c} 4 \operatorname{ccc} c 4) \mathrm{c}(=\mathrm{O}) \mathrm{c} 3 \mathrm{cc} 2 \mathrm{C}(\mathrm{c} 2 \operatorname{ccc} c 2) \mathrm{N} 1$ & 238 & $*$ \\
\hline 2748 & COc1ccc(N2Cc3cnc(Nc4ccccc4)nc3N([C@@H]3CC[C@@H](O)C3)C2=O)cc1 & 239 & $*$ \\
\hline 2749 & $\mathrm{Cc} 1 \mathrm{ccc}(\mathrm{C} 2=\mathrm{NN}(\mathrm{C} 3=\mathrm{NC}(=\mathrm{O}) \mathrm{CS} 3) \mathrm{C}(\mathrm{c} 3 \operatorname{ccc}(\mathrm{Br}) \mathrm{cc} 3) \mathrm{C} 2) \mathrm{cc} 1$ & 240 & 6.62 \\
\hline 2750 & $\mathrm{c} 1 \mathrm{ccc}(\mathrm{C} 2=\mathrm{NN}(\mathrm{c} 3 \operatorname{ccccc} 3) \mathrm{C}(\mathrm{c} 3 \operatorname{ccc} 4 \mathrm{cccc} 4 \mathrm{c} 3) \mathrm{C} 2) \mathrm{cc} 1$ & 240 & 6.62 \\
\hline 2751 & $\operatorname{COc} 1 \mathrm{cc}(\mathrm{N} 2 \mathrm{CCC}(\mathrm{O}) \mathrm{CC} 2) \operatorname{ccc} 1 \mathrm{Nc} 1 \mathrm{ncc}(\mathrm{Cl}) \mathrm{c}(\mathrm{Oc} 2 \operatorname{ccc}(\mathrm{COc} 3 \mathrm{no}[\mathrm{n}+]([\mathrm{O}-]) \mathrm{c} 3 \mathrm{~S}(=\mathrm{O})(=\mathrm{O}) \mathrm{c} 3 \operatorname{cccc} 3) \mathrm{c} 2) \mathrm{n} 1$ & 240 & 6.62 \\
\hline 2752 & $\mathrm{O}=\mathrm{C}(\mathrm{CCl}) \mathrm{OCCn} 1 \mathrm{c}(=\mathrm{O}) \mathrm{oc} 2 \mathrm{cc} 3 \mathrm{ncnc}(\mathrm{Nc} 4 \mathrm{ccc}(\mathrm{N} 5 \mathrm{CCCCC} 5) \mathrm{c}(\mathrm{Cl}) \mathrm{c} 4) \mathrm{c} 3 \mathrm{cc} 21$ & 240 & 6.62 \\
\hline 2753 & Cc1ncnc(Nc2 $\operatorname{ccc}(\mathrm{OCc} 3 \operatorname{cccc}(\mathrm{F}) \mathrm{c} 3) \mathrm{c}(\mathrm{Cl}) \mathrm{c} 2) \mathrm{c} 1 \mathrm{C} \# \mathrm{Cc} 1 \mathrm{ccc}(\mathrm{CN} 2 \mathrm{CCOCC} 2) \mathrm{cc} 1$ & 240 & 6.62 \\
\hline 2754 & 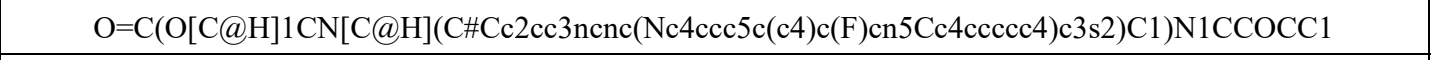 & 240 & 6.62 \\
\hline 2755 & $\mathrm{O}=\mathrm{C}(\mathrm{O}[\mathrm{C} @ \mathrm{H}] 1 \mathrm{CN}[\mathrm{C} @ \mathrm{H}](\mathrm{C} \# \mathrm{Cc} 2 \mathrm{cc} 3 \mathrm{ncnc}(\mathrm{Nc} 4 \mathrm{ccc}(\mathrm{Cc} 5 \mathrm{ccccc} 5) \mathrm{cc} 4) \mathrm{c} 3 \mathrm{~s} 2) \mathrm{C} 1) \mathrm{N} 1 \mathrm{CCOCC} 1$ & 240 & 6.62 \\
\hline 2756 & $\mathrm{C}=\mathrm{CC}(=\mathrm{O}) \mathrm{Nc} 1 \mathrm{cccc}(-\mathrm{n} 2 \mathrm{c}(=\mathrm{O}) \mathrm{cc}(\mathrm{C}) \mathrm{c} 3 \mathrm{cnc}(\mathrm{Nc} 4 \mathrm{ccc}(\mathrm{N} 5 \mathrm{CCN}(\mathrm{C}) \mathrm{CC} 5) \mathrm{cc} 4 \mathrm{OC}) \mathrm{nc} 32) \mathrm{c} 1$ & 240 & $*$ \\
\hline
\end{tabular}




\begin{tabular}{|c|c|c|c|}
\hline 2757 & $\mathrm{Nc} 1 \mathrm{cc} 2 \mathrm{ncnc}(\mathrm{Nc} 3 \mathrm{cccc} 3 \mathrm{Br}) \mathrm{c} 2 \mathrm{cn} 1$ & 240 & $*$ \\
\hline 2758 & $\mathrm{CCN}(\mathrm{CC}) \mathrm{CCCCNc} 1 \mathrm{ncc} 2 \mathrm{cc}(-\mathrm{c} 3 \mathrm{c}(\mathrm{Cl}) \mathrm{cccc} 3 \mathrm{Cl}) \mathrm{c}(\mathrm{NC}(=\mathrm{O}) \mathrm{NC}(\mathrm{C})(\mathrm{C}) \mathrm{C}) \mathrm{nc} 2 \mathrm{n} 1$ & 240 & $*$ \\
\hline 2759 & $\mathrm{O}=\mathrm{C} 1 \mathrm{CCN}(\mathrm{Cc} 2 \mathrm{ccn} 3 \mathrm{ncnc}(\mathrm{Nc} 4 \mathrm{ccc} 5 \mathrm{c}(\mathrm{cnn} 5 \mathrm{Cc} 5 \mathrm{ccc}(\mathrm{F}) \mathrm{c} 5) \mathrm{c} 4) \mathrm{c} 23) \mathrm{CCN} 1$ & 240 & * \\
\hline 2760 & $\mathrm{NS}(=\mathrm{O})(=\mathrm{O}) \mathrm{c} 1 \mathrm{ccc}(-\mathrm{n} 2 \mathrm{c}(\mathrm{SCC}(=\mathrm{O}) \mathrm{Nc} 3 \mathrm{cc}(\mathrm{Cl}) \mathrm{c}(\mathrm{Cl}) \mathrm{cc} 3 \mathrm{Cl}) \mathrm{nc} 3 \mathrm{cc} 4 \mathrm{ccccc} 4 \mathrm{cc} 3 \mathrm{c} 2=\mathrm{O}) \mathrm{cc} 1$ & 240 & $*$ \\
\hline 2761 & $\mathrm{COc} 1 \mathrm{ccc}(\mathrm{O}) \mathrm{c}(\mathrm{C}(=\mathrm{O}) \mathrm{Nc} 2 \mathrm{cccc}(\mathrm{Cl}) \mathrm{c} 2) \mathrm{c} 1$ & 240 & $*$ \\
\hline 2762 & $\operatorname{c1cc}(\mathrm{Nc} 2 \mathrm{ccc} 3[\mathrm{nH}] \operatorname{ccc} 3 \mathrm{c} 2) \mathrm{nc}(\mathrm{Nc} 2 \mathrm{ccc}(\mathrm{N} 3 \mathrm{CCOCC} 3) \mathrm{cc} 2) \mathrm{n} 1$ & 240 & * \\
\hline 2763 & $\mathrm{C}=\mathrm{CC}(=\mathrm{O}) \mathrm{Nc} 1 \mathrm{cccc}(-\mathrm{n} 2 \mathrm{c}(=\mathrm{O}) \mathrm{n}(\mathrm{C}(\mathrm{C}) \mathrm{C}) \mathrm{c}(=\mathrm{O}) \mathrm{c} 3 \mathrm{cnc}(\mathrm{Nc} 4 \mathrm{ccc}(\mathrm{N} 5 \mathrm{CCC}(\mathrm{N} 6 \mathrm{CCN}(\mathrm{C}) \mathrm{CC} 6) \mathrm{CC} 5) \mathrm{cc} 4 \mathrm{OC}) \mathrm{nc} 32) \mathrm{c} 1$ & 240 & $*$ \\
\hline 2764 & $\operatorname{Brc} 1 \mathrm{cc} 2 \mathrm{c}(\mathrm{NCc} 3 \operatorname{ccc} c 3) n \mathrm{cnc} 2 \mathrm{~s} 1$ & 241 & * \\
\hline 2765 & $\mathrm{C}=\mathrm{CC}(=\mathrm{O}) \mathrm{Nc} 1 \mathrm{cc}(\mathrm{Nc} 2 \mathrm{ncc}(\mathrm{I}) \mathrm{c}(\mathrm{Nc} 3 \operatorname{ccccc} 3 \mathrm{~S}(=\mathrm{O})(=\mathrm{O}) \mathrm{N}(\mathrm{C}) \mathrm{C}) \mathrm{n} 2) \mathrm{c}(\mathrm{OC}) \operatorname{cc} 1 \mathrm{~N}(\mathrm{C}) \mathrm{CCN}(\mathrm{C}) \mathrm{C}$ & 244 & * \\
\hline 2766 & $\mathrm{O}=\mathrm{C} 1 \mathrm{CO} 2 \mathrm{cc} 3 \mathrm{ncnc}(\mathrm{Nc} 4 \mathrm{cccc}(\mathrm{F}) \mathrm{c} 4) \mathrm{c} 3 \mathrm{cc} 2 \mathrm{~N} 1 \mathrm{CCCN} 1 \mathrm{CCOCC} 1$ & 245.1 & $*$ \\
\hline 2767 & $\mathrm{Nc} 1 \mathrm{ccccc} 1 \mathrm{Nc} 1 \mathrm{ncnc} 2 \mathrm{cc}(\mathrm{Br}) \mathrm{ncc} 12$ & 245.47 & $*$ \\
\hline 2768 & $\mathrm{CCOc} 1 \mathrm{cc} 2 \mathrm{ncc}(\mathrm{CHN}) \mathrm{c}(\mathrm{Nc} 3 \mathrm{ccc}(\mathrm{OCc} 4 \mathrm{ccccc} 4) \mathrm{c}(\mathrm{Cl}) \mathrm{c} 3) \mathrm{c} 2 \mathrm{cc} 1 \mathrm{NC}(=\mathrm{O}) / \mathrm{C}=\mathrm{C} / \mathrm{CN} 1 \mathrm{C}(\mathrm{C}) \mathrm{CCCC} 1 \mathrm{C}$ & 247 & 6.61 \\
\hline 2769 & $\mathrm{COCC}(\mathrm{C}) \mathrm{Oc} 1 \mathrm{cc} 2 \mathrm{ncnc}(\mathrm{Nc} 3 \mathrm{ccc}(\mathrm{F}) \mathrm{c}(\mathrm{Cl}) \mathrm{c} 3) \mathrm{c} 2 \mathrm{c} 2 \mathrm{c} 1 \mathrm{OCCO} 2$ & 247.2 & $*$ \\
\hline 2770 & $\mathrm{C}=\mathrm{CC}(=\mathrm{O}) \mathrm{Nc} 1 \mathrm{ccc}(\mathrm{Oc} 2 \mathrm{nc}(\mathrm{Nc} 3 \operatorname{ccc}(\mathrm{N} 4 \mathrm{CCN}(\mathrm{C}(=\mathrm{O}) \mathrm{C}(\mathrm{F})(\mathrm{F}) \mathrm{F}) \mathrm{CC} 4) \mathrm{cc} 3 \mathrm{OC}) \mathrm{ncc} 2 \mathrm{SC}) \mathrm{c} 1$ & 247.8 & $*$ \\
\hline 2771 & $\mathrm{CC}(\mathrm{C}) \mathrm{n} 1 \mathrm{nc}(-\mathrm{c} 2 \mathrm{cc}(\mathrm{O}) \mathrm{cc}(\mathrm{Br}) \mathrm{c} 2) \mathrm{c} 2 \mathrm{c}(\mathrm{N}) \mathrm{ncnc} 21$ & 249 & $*$ \\
\hline 2772 & $\mathrm{COc} 1 \mathrm{ccc}(-\mathrm{c} 2 \mathrm{c} 3 \mathrm{c} 4 \mathrm{cc}(\mathrm{O}) \mathrm{c}(\mathrm{OC}) \mathrm{cc} 4 \mathrm{oc}(=\mathrm{O}) \mathrm{c} 3 \mathrm{n} 3 \mathrm{ccc} 4 \mathrm{cc}(\mathrm{O}) \mathrm{c}(\mathrm{OC}) \mathrm{cc} 4 \mathrm{c} 23) \mathrm{cc} 1 \mathrm{O}$ & 249.1 & $*$ \\
\hline 2773 & $\mathrm{CCOc} 1 \mathrm{cc} 2 \mathrm{ncc}(\mathrm{C \# N}) \mathrm{c}(\mathrm{Nc} 3 \operatorname{ccc}(\mathrm{N}(\mathrm{C}) \mathrm{Cc} 4 \operatorname{ccccc} 4) \mathrm{c}(\mathrm{Cl}) \mathrm{c} 3) \mathrm{c} 2 \mathrm{cc} 1 \mathrm{NC}(=\mathrm{O}) / \mathrm{C}=\mathrm{C} / \mathrm{CN}(\mathrm{C}) \mathrm{C}$ & 250 & 6.60 \\
\hline 2774 & $\mathrm{CC}(\mathrm{C}) \mathrm{N}(\mathrm{CC} \# \mathrm{CC}(=\mathrm{O}) \mathrm{Nc} 1 \mathrm{ccc} 2 \mathrm{ncc}(\mathrm{C \# N}) \mathrm{c}(\mathrm{Nc} 3 \operatorname{cccc}(\mathrm{Br}) \mathrm{c} 3) \mathrm{c} 2 \mathrm{c} 1) \mathrm{C}(\mathrm{C}) \mathrm{C}$ & 250 & 6.60 \\
\hline 2775 & $\mathrm{COc} 1 \mathrm{ccc}(\mathrm{Nc} 2 \mathrm{ncnc} 3 \mathrm{cc}(\mathrm{OC}) \mathrm{c}(\mathrm{OC}) \mathrm{cc} 23) \mathrm{cc} 1 . \mathrm{Cl}$ & 250 & $*$ \\
\hline 2776 & $\mathrm{Nc} 1 \mathrm{cc} 2 \mathrm{ncnc}(\mathrm{Nc} 3 \mathrm{ccccc} 3) \mathrm{c} 2 \mathrm{cn} 1$ & 250 & $*$ \\
\hline 2777 & $\mathrm{COc} 1 \mathrm{ccc}(\mathrm{Nc} 2 \mathrm{ncc} 3 \mathrm{cc}(-\mathrm{c} 4 \mathrm{c}(\mathrm{Cl}) \operatorname{ccc} 4 \mathrm{Cl}) \mathrm{c}(=\mathrm{O}) \mathrm{n}(\mathrm{C}) \mathrm{c} 3 \mathrm{n} 2) \mathrm{cc} 1 \mathrm{C}$ & 250 & $*$ \\
\hline 2778 & $\mathrm{CN}(\mathrm{C}) / \mathrm{C}=\mathrm{C} / \mathrm{C}(=\mathrm{O}) \mathrm{Nc} 1 \mathrm{ccc} 2 \mathrm{ncnc}(\mathrm{Nc} 3 \mathrm{cccc}(\mathrm{Br}) \mathrm{c} 3) \mathrm{c} 2 \mathrm{c} 1$ & 250 & $*$ \\
\hline 2779 & $\mathrm{Cc} 1 \mathrm{ccn} 2 \mathrm{ncnc}(\mathrm{Nc} 3 \mathrm{ccc}(\mathrm{OCc} 4 \mathrm{cccc}(\mathrm{F}) \mathrm{c} 4) \mathrm{c}(\mathrm{Cl}) \mathrm{c} 3) \mathrm{c} 12$ & 250 & $*$ \\
\hline 2780 & $\mathrm{Cc} 1 \mathrm{cc} 2 \mathrm{cc}(\mathrm{Nc} 3 \mathrm{ccnc} 4 \mathrm{cc}(-\mathrm{c} 5 \mathrm{ccc}(\mathrm{CNCCN} 6 \mathrm{CCNCC} 6) \mathrm{cc} 5) \operatorname{sc} 34) \operatorname{ccc} 2[\mathrm{nH}] 1$ & 250 & $*$ \\
\hline 2781 & Ne1ccec1Nc1nenc2cence12 & 251.19 & $*$ \\
\hline 2782 & $\operatorname{COc} 1 \operatorname{ccc}(\mathrm{NC}(=\mathrm{O}) / \mathrm{C}=\mathrm{C} / \mathrm{CN}(\mathrm{C}) \mathrm{C}) \operatorname{cc} 1 \mathrm{Nc} 1 \mathrm{ncc}(\mathrm{Br}) \mathrm{c}(\mathrm{Nc} 2 \operatorname{ccc} 3 \operatorname{ccccc} 3 \mathrm{c} 2) \mathrm{n} 1$ & 254 & * \\
\hline 2783 & $\mathrm{c} 1 \mathrm{ccc}(\mathrm{Nc} 2 \mathrm{ncnc} 3[\mathrm{nH}] \operatorname{ccc} 23) \mathrm{cc} 1$ & 254.13 & $*$ \\
\hline 2784 & $\mathrm{CCOc} 1 \mathrm{cc} 2 \mathrm{ncc}(\mathrm{C \# N}) \mathrm{c}(\mathrm{Nc} 3 \operatorname{ccc}(\mathrm{OCc} 4 \mathrm{ccccc} 4) \mathrm{c}(\mathrm{Cl}) \mathrm{c} 3) \mathrm{c} 2 \mathrm{cc} 1 \mathrm{NC}(=\mathrm{O}) / \mathrm{C}=\mathrm{C} / \mathrm{c} 1 \mathrm{cn}(\mathrm{C}) \mathrm{cn} 1$ & 255 & 6.59 \\
\hline 2785 & $\mathrm{CCC}(=\mathrm{O}) \mathrm{N} 1 \mathrm{CC}[\mathrm{C} @ \mathrm{H}](\mathrm{N} 2 \mathrm{C}(=\mathrm{O}) \mathrm{N}(\mathrm{c} 3 \mathrm{cccc}(\mathrm{OC}(\mathrm{F}) \mathrm{F}) \mathrm{c} 3) \mathrm{Cc} 3 \mathrm{cnc}(\mathrm{Nc} 4 \mathrm{ccc}(\mathrm{N} 5 \mathrm{CCN}(\mathrm{C}) \mathrm{CC} 5) \mathrm{c}(\mathrm{C}) \mathrm{c} 4) \mathrm{nc} 32) \mathrm{C} 1$ & 257 & 6.59 \\
\hline 2786 & $\mathrm{Fc} 1 \mathrm{cccc}(\mathrm{COc} 2 \mathrm{ccc}(\mathrm{Nc} 3 \mathrm{ncnc} 4 \mathrm{sc}(\mathrm{Br}) \mathrm{cc} 34) \mathrm{cc} 2 \mathrm{Cl}) \mathrm{c} 1$ & 257 & $*$ \\
\hline 2787 & OC[C@@H](Nc1ncnc2oc(-c3eccc3)c(-c3ccc4c(c3)OCO4)c12)c1ccccc1 & 258 & $*$ \\
\hline 2788 & $\mathrm{CC} \# \mathrm{CC}(=\mathrm{O}) \mathrm{Nc} 1 \mathrm{ccc} 2 \mathrm{ncc}(\mathrm{C} \# \mathrm{~N}) \mathrm{c}(\mathrm{Nc} 3 \operatorname{cccc}(\mathrm{Br}) \mathrm{c} 3) \mathrm{c} 2 \mathrm{c} 1$ & 258.9 & 6.21 \\
\hline 2789 & $\mathrm{Nc} 1 \mathrm{cc} 2 \mathrm{ncnc}(\mathrm{Nc} 3 \mathrm{cccc}(\mathrm{I}) \mathrm{c} 3) \mathrm{c} 2 \mathrm{cn} 1$ & 260 & $*$ \\
\hline 2790 & $\mathrm{Cn} 1 \mathrm{c}(=\mathrm{O}) \mathrm{c}(-\mathrm{c} 2 \mathrm{c}(\mathrm{Cl}) \mathrm{ccc} 2 \mathrm{Cl}) \mathrm{cc} 2 \mathrm{cnc}(\mathrm{Nc} 3 \mathrm{ccccc} 3) \mathrm{nc} 21$ & 260 & $*$ \\
\hline 2791 & $\mathrm{Nc} 1 \mathrm{ncnc} 2 \mathrm{c} 1 \mathrm{c}(-\mathrm{c} 1 \mathrm{cnc} 3[\mathrm{nH}] \mathrm{ccc} 3 \mathrm{c} 1) \mathrm{nn} 2 \mathrm{C} 1 \mathrm{CCCC} 1$ & 260 & $*$ \\
\hline 2792 & $\mathrm{COc} 1 \operatorname{ccc}(\mathrm{NC}(=\mathrm{O}) / \mathrm{C}=\mathrm{C} / \mathrm{CN}(\mathrm{C}) \mathrm{C}) \operatorname{cc} 1 \mathrm{Nc} 1 \mathrm{ncc}(\mathrm{Cl}) \mathrm{c}(\mathrm{Nc} 2 \operatorname{ccc} 3 \operatorname{ccccc} 3 \mathrm{c} 2) \mathrm{n} 1$ & 260 & $*$ \\
\hline 2793 & $\mathrm{COC}[\mathrm{C} @ @ \mathrm{H}](\mathrm{Nc} 1 \mathrm{ncnc} 2 \mathrm{sc}(\mathrm{Br}) \mathrm{cc} 12) \mathrm{c} 1 \mathrm{ccccc} 1$ & 262 & $*$ \\
\hline 2794 & $\mathrm{CS}(=\mathrm{O})(=\mathrm{O}) \mathrm{CCN}(\mathrm{CCCCOc} 1 \mathrm{ccc} 2 \mathrm{ncnc}(\mathrm{Nc} 3 \mathrm{ccc}(\mathrm{OCc} 4 \mathrm{ccccc} 4) \mathrm{cc} 3) \mathrm{c} 2 \mathrm{c} 1) \mathrm{C}(=\mathrm{O}) \mathrm{C}(\mathrm{F})(\mathrm{F}) \mathrm{F}$ & 263 & * \\
\hline 2795 & $\mathrm{COc} 1 \mathrm{ccc} 2 \mathrm{c}(\mathrm{Nc} 3 \operatorname{ccc}(\mathrm{Br}) \mathrm{c} 3) \mathrm{ncnc} 2 \mathrm{n} 1$ & 263 & $*$ \\
\hline 2796 & $\mathrm{c} 1 \mathrm{ccc}(\mathrm{Nc} 2[\mathrm{nH}] \mathrm{cnc} 3 \mathrm{nc} 4 \mathrm{ccccc} 4 \mathrm{c} 2-3) \mathrm{cc} 1$ & 264 & * \\
\hline 2797 & $\mathrm{c} 1 \mathrm{ccc}(\mathrm{Nc} 2 \mathrm{ncnc} 3[\mathrm{nH}] \mathrm{c} 4 \mathrm{ccccc} 4 \mathrm{c} 23) \mathrm{cc} 1$ & 264 & * \\
\hline 2798 & $\mathrm{O}=\mathrm{C}(\mathrm{Nc} 1 \mathrm{cc} 2 \mathrm{c}(\mathrm{Nc} 3 \mathrm{ccc}(\mathrm{F}) \mathrm{c}(\mathrm{Cl}) \mathrm{c} 3) \mathrm{ncnc} 2 \mathrm{cc} 1 \mathrm{O}[\mathrm{C} @ \mathrm{H}] 1 \mathrm{CCOC} 1) \mathrm{N} 1 \mathrm{CCC}(\mathrm{N} 2 \mathrm{CCCC} 2) \mathrm{CC} 1$ & 265 & * \\
\hline 2799 & $\mathrm{O}=\mathrm{C}(\mathrm{Nc} 1 \mathrm{cc} 2 \mathrm{c}(\mathrm{Nc} 3 \mathrm{ccc}(\mathrm{F}) \mathrm{c}(\mathrm{Cl}) \mathrm{c} 3) \mathrm{ncnc} 2 \mathrm{cc} 1 \mathrm{O}[\mathrm{C} @ \mathrm{H}] 1 \mathrm{CCOC} 1) \mathrm{N}(\mathrm{N} 1 \mathrm{CCC}(\mathrm{N} 2 \mathrm{CCCC} 2) \mathrm{CC} 1) \mathrm{N} 1 \mathrm{CCC}(\mathrm{N} 2 \mathrm{CCCC} 2)$ & 265 & * \\
\hline
\end{tabular}




\begin{tabular}{|c|c|c|c|}
\hline & $\mathrm{CC} 1$ & & \\
\hline 2800 & $\mathrm{CSc} 1 \mathrm{nc}(-\mathrm{c} 2 \mathrm{ccc}(\mathrm{F}) \mathrm{cc} 2) \mathrm{c}(-\mathrm{c} 2 \mathrm{ccnc}(\mathrm{Nc} 3 \operatorname{cc}(\mathrm{F}) \mathrm{cc}([\mathrm{N}+](=\mathrm{O})[\mathrm{O}-]) \mathrm{c} 3) \mathrm{c} 2)[\mathrm{nH}] 1$ & 265 & $*$ \\
\hline 2801 & $\mathrm{CO} / \mathrm{N}=\mathrm{C} / \mathrm{c} 1 \mathrm{c}(\mathrm{N}) \mathrm{ncnc} 1 \mathrm{Nc} 1 \mathrm{ccc} 2 \mathrm{c}(\mathrm{cnn} 2 \mathrm{Cc} 2 \mathrm{cccc}(\mathrm{OC}) \mathrm{c} 2) \mathrm{c} 1$ & 267 & $*$ \\
\hline 2802 & $\operatorname{COc} 1 \mathrm{cc} 2 \mathrm{ncnc}(\mathrm{NCc} 3 \mathrm{ccc}(\mathrm{F}) \mathrm{cc} 3) \mathrm{c} 2 \mathrm{cc} 1 \mathrm{OCCCCCCC}(=\mathrm{O}) \mathrm{NO}$ & 268 & 6.57 \\
\hline 2803 & $\mathrm{C} / \mathrm{C}=\mathrm{C} \backslash \mathrm{C}(=\mathrm{O}) \mathrm{Nc} 1 \mathrm{ccc} 2 \mathrm{ncnc}(\mathrm{Nc} 3 \mathrm{cccc}(\mathrm{Br}) \mathrm{c} 3) \mathrm{c} 2 \mathrm{c} 1$ & 269 & $*$ \\
\hline 2804 & $\mathrm{COc} 1 \mathrm{ccc}(\mathrm{Oc} 2 \mathrm{nc} 3 \mathrm{ccccc} 3 \mathrm{cc} 2 / \mathrm{C}=\mathrm{N} / \mathrm{NC}(=\mathrm{O}) \mathrm{Cn} 2 \mathrm{c}([\mathrm{N}+](=\mathrm{O})[\mathrm{O}-]) \operatorname{cnc} 2 \mathrm{C}) \mathrm{cc} 1$ & 270 & 6.57 \\
\hline 2805 & $\mathrm{Cc} 1 \mathrm{ncnc}(\mathrm{Nc} 2 \mathrm{ccc}(\mathrm{OCc} 3 \mathrm{cccc}(\mathrm{F}) \mathrm{c} 3) \mathrm{c}(\mathrm{Cl}) \mathrm{c} 2) \mathrm{c} 1 \mathrm{C} \# \mathrm{CCCNC} 1 \mathrm{ccccc} 1$ & 270 & 6.57 \\
\hline 2806 & $\mathrm{C}=\mathrm{CC}(=\mathrm{O}) \mathrm{Nc} 1 \mathrm{cccc}(-\mathrm{n} 2 \mathrm{c}(=\mathrm{O}) \mathrm{cc}(\mathrm{C}) \mathrm{c} 3 \mathrm{cnc}(\mathrm{Nc} 4 \mathrm{ccc}(\mathrm{N} 5 \mathrm{CCN}(\mathrm{C}) \mathrm{CC} 5) \mathrm{cc} 4 \mathrm{OCCC}) \mathrm{nc} 32) \mathrm{c} 1$ & 270 & $*$ \\
\hline 2807 & $\mathrm{CC}(\mathrm{C})(\mathrm{C}) \mathrm{OC}(=\mathrm{O}) \mathrm{Nc} 1 \mathrm{ccc}(-\mathrm{c} 2[\mathrm{nH}] \mathrm{nc} 3 \mathrm{ncnc}(\mathrm{Nc} 4 \mathrm{cccc}(\mathrm{Cl}) \mathrm{c} 4) \mathrm{c} 23) \mathrm{cc} 1$ & 270 & * \\
\hline 2808 & $\mathrm{COc} 1 \mathrm{ccc}(-\mathrm{c} 2 \mathrm{nn}(\mathrm{C} 3 \mathrm{CCC}(\mathrm{C}) \mathrm{C} 3) \mathrm{c} 3 n \mathrm{nnc}(\mathrm{N}) \mathrm{c} 23) \mathrm{cc} 1 \mathrm{O}$ & 270 & $*$ \\
\hline 2809 & COc1 $1 \mathrm{ccc}(-\mathrm{c} 2 \mathrm{cc} 3 \mathrm{c}(\mathrm{NC}(\mathrm{C}) \mathrm{c} 4 \mathrm{ccc}(\mathrm{C}(\mathrm{F})(\mathrm{F}) \mathrm{F}) \mathrm{cc} 4) \mathrm{ncnc} 3[\mathrm{nH}] 2) \mathrm{cc} 1$ & 270 & $*$ \\
\hline 2810 & $\mathrm{C}=\mathrm{CC}(=\mathrm{O}) \mathrm{Nc} 1 \mathrm{ccc}(\mathrm{Oc} 2 \mathrm{nc}(\mathrm{Nc} 3 \mathrm{ccc}(\mathrm{N} 4 \mathrm{CCN}(\mathrm{C}) \mathrm{CC} 4) \mathrm{cc} 3 \mathrm{OC}) \mathrm{ncc} 2 \mathrm{SC}) \mathrm{c} 1$ & 271.6 & $*$ \\
\hline 2811 & $\operatorname{Brc} 1 \mathrm{cccc}(\mathrm{Nc} 2 \mathrm{ncnc} 3 \mathrm{c} 2 \mathrm{ccc} 2[\mathrm{nH}] \mathrm{cnc} 23) \mathrm{c} 1$ & 272 & $*$ \\
\hline 2812 & $\operatorname{Brc} 1 \mathrm{cccc}(\mathrm{Nc} 2 \mathrm{ncnc} 3 \mathrm{c} 2 \mathrm{ccc} 2 \mathrm{nc}[\mathrm{nH}] \mathrm{c} 23) \mathrm{c} 1$ & 272 & $*$ \\
\hline 2813 & $\mathrm{C}=\mathrm{CC}(=\mathrm{O}) \mathrm{Nc} 1 \mathrm{ccc}(\mathrm{NC}(=\mathrm{O}) \mathrm{Nc} 2 \mathrm{ccnc}(\mathrm{Nc} 3 \operatorname{ccc}(\mathrm{N} 4 \mathrm{CCCCC} 4) \mathrm{cc} 3 \mathrm{OC}) \mathrm{n} 2) \mathrm{c} 1$ & 273 & $*$ \\
\hline 2814 & $\mathrm{COc} 1 \mathrm{cccc} 1-\mathrm{c} 1 \mathrm{cc} 2 \mathrm{c}(\mathrm{NCc} 3 \mathrm{ccc} n \mathrm{c} 3) \mathrm{ncnc} 2 \mathrm{~s} 1$ & 275 & $*$ \\
\hline 2815 & $\mathrm{C}[\mathrm{C} @ @ \mathrm{H}](\mathrm{Nc} 1 \mathrm{ncnc} 2 \mathrm{sc}(-\mathrm{c} 3 \operatorname{cccc} 3 \mathrm{C}(\mathrm{N})=\mathrm{O}) \mathrm{cc} 12) \mathrm{c} 1 \mathrm{ccccc} 1$ & 276 & 6.56 \\
\hline 2816 & $\mathrm{CCOc} 1 \mathrm{cc} 2 \mathrm{ncc}(\mathrm{C} \# \mathrm{~N}) \mathrm{c}(\mathrm{Nc} 3 \mathrm{ccc}(\mathrm{OCc} 4 \mathrm{cccs} 4) \mathrm{c}(\mathrm{Cl}) \mathrm{c} 3) \mathrm{c} 2 \mathrm{cc} 1 \mathrm{NC}(=\mathrm{O}) / \mathrm{C}=\mathrm{C} / \mathrm{CN}(\mathrm{C}) \mathrm{C}$ & 277 & 6.56 \\
\hline 2817 & 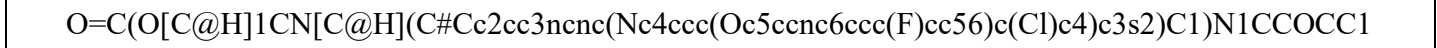 & 280 & 6.55 \\
\hline 2818 & $\mathrm{CN} 1 \mathrm{CCC}(\mathrm{Oc} 2 \mathrm{cccc} 3 \mathrm{ncnc}(\mathrm{Nc} 4 \mathrm{ccc}(\mathrm{OCc} 5 \operatorname{cscn} 5) \mathrm{c}(\mathrm{Cl}) \mathrm{c} 4) \mathrm{c} 23) \mathrm{CC} 1$ & 280 & $*$ \\
\hline 2819 & $\mathrm{CN}(\mathrm{C}) \mathrm{CCN}(\mathrm{C}) \mathrm{C}(=\mathrm{O}) \mathrm{Nc} 1 \mathrm{cc} 2 \mathrm{c}(\mathrm{Nc} 3 \mathrm{ccc}(\mathrm{F}) \mathrm{c}(\mathrm{Cl}) \mathrm{c} 3) \mathrm{ncnc} 2 \mathrm{cc} 1 \mathrm{O}[\mathrm{C} @ \mathrm{H}] 1 \mathrm{CCOC} 1$ & 281 & $*$ \\
\hline 2820 & $\mathrm{CN}(\mathrm{C}) \mathrm{CCN}(\mathrm{C}) \mathrm{N}(\mathrm{C}(=\mathrm{O}) \mathrm{Nc} 1 \mathrm{cc} 2 \mathrm{c}(\mathrm{Nc} 3 \mathrm{ccc}(\mathrm{F}) \mathrm{c}(\mathrm{Cl}) \mathrm{c} 3) n \mathrm{ncnc} 2 \mathrm{cc} 1 \mathrm{O}[\mathrm{C} @ \mathrm{H}] 1 \mathrm{CCOC} 1) \mathrm{N}(\mathrm{C}) \mathrm{CCN}(\mathrm{C}) \mathrm{C}$ & 281 & $*$ \\
\hline 2821 & $\mathrm{CCOc} 1 \mathrm{cc} 2 \mathrm{ncc}(\mathrm{C \# N}) \mathrm{c}(\mathrm{Nc} 3 \mathrm{ccc}(\mathrm{OCc} 4 \mathrm{ccccc} 4) \mathrm{c}(\mathrm{Cl}) \mathrm{c} 3) \mathrm{c} 2 \mathrm{cc} 1 \mathrm{NC}(=\mathrm{O}) / \mathrm{C}=\mathrm{C} / \mathrm{CN} 1 \mathrm{CCC}(\mathrm{O})(\mathrm{O}) \mathrm{CC} 1$ & 282 & 6.55 \\
\hline 2822 & $\mathrm{CCOc} 1 \mathrm{cc} 2 \mathrm{ncnc}(\mathrm{NC} 3=\mathrm{CC}(=\mathrm{O}) \mathrm{C}(\mathrm{OC}(\mathrm{CF}) \mathrm{CF})=\mathrm{CC} 3=\mathrm{O}) \mathrm{c} 2 \mathrm{cc} 1 \mathrm{NC}(=\mathrm{O}) / \mathrm{C}=\mathrm{C} / \mathrm{CN}(\mathrm{C}) \mathrm{C}$ & 283.3 & 6.55 \\
\hline 2823 & $\mathrm{CCOc} 1 \mathrm{cc} 2 \mathrm{ncc}(\mathrm{CHN}) \mathrm{c}(\mathrm{Nc} 3 \mathrm{ccc}(\mathrm{OCC} 4 \mathrm{CCCCC} 4) \mathrm{c}(\mathrm{Cl}) \mathrm{c} 3) \mathrm{c} 2 \mathrm{cc} 1 \mathrm{NC}(=\mathrm{O}) / \mathrm{C}=\mathrm{C} / \mathrm{CN}(\mathrm{C}) \mathrm{C}$ & 285 & 6.55 \\
\hline 2824 & $\mathrm{COc} 1 \mathrm{cc} 2 \mathrm{ncnc}(\mathrm{Nc} 3 \mathrm{ccc}(\mathrm{NC}(=\mathrm{O}) \mathrm{Nc} 4 \mathrm{ccc}(\mathrm{Cl}) \mathrm{c}(\mathrm{C}(\mathrm{F})(\mathrm{F}) \mathrm{F}) \mathrm{c} 4) \mathrm{cc} 3) \mathrm{c} 2 \mathrm{cc} 1 \mathrm{OCCCN} 1 \mathrm{CCOCC} 1$ & 285 & $*$ \\
\hline 2825 & $\mathrm{CCC}(=\mathrm{O}) \mathrm{N} 1 \mathrm{CC}[\mathrm{C} @ \mathrm{H}](\mathrm{N} 2 \mathrm{C}(=\mathrm{O}) \mathrm{N}(\mathrm{c} 3 \mathrm{cc}(\mathrm{OC}) \mathrm{ccc} 3 \mathrm{~F}) \mathrm{Cc} 3 \mathrm{cnc}(\mathrm{Nc} 4 \mathrm{ccc}(\mathrm{N} 5 \mathrm{CCC}(\mathrm{N}(\mathrm{C}) \mathrm{C}) \mathrm{CC} 5) \mathrm{c}(\mathrm{C}) \mathrm{c} 4) \mathrm{nc} 32) \mathrm{C} 1$ & 286 & 6.54 \\
\hline 2826 & $\mathrm{COc} 1 \mathrm{ccc}(\mathrm{OC}) \mathrm{c}(\mathrm{Nc} 2 \mathrm{cc}(\mathrm{Nc} 3 \mathrm{ccc}(\mathrm{N} 4 \mathrm{CCN}(\mathrm{C}) \mathrm{CC} 4) \mathrm{cc} 3) \mathrm{ncn} 2) \mathrm{c} 1$ & 288 & $*$ \\
\hline 2827 & $\mathrm{COc} 1 \mathrm{cccc}(\mathrm{Oc} 2 \mathrm{ccc}(\mathrm{Nc} 3 \mathrm{ncnc} 4 \mathrm{cc}[\mathrm{nH}] \mathrm{c} 34) \mathrm{cc} 2 \mathrm{Cl}) \mathrm{c} 1$ & 290 & $*$ \\
\hline 2828 & $\mathrm{COc} 1 \mathrm{cc}(\mathrm{NC}(=\mathrm{O}) \mathrm{Nc} 2 \mathrm{ccncc} 2) \mathrm{cc}(-\mathrm{c} 2 \mathrm{cncnc} 2) \mathrm{c} 1 \mathrm{OC}$ & 290.46 & * \\
\hline 2829 & $\begin{array}{c}\mathrm{C}=\mathrm{CC}(=\mathrm{O}) \mathrm{Nc} 1 \mathrm{cccc}(\mathrm{Oc} 2 \mathrm{nc}(\mathrm{Nc} 3 \mathrm{ccc}(\mathrm{N} 4 \mathrm{CCN}(\mathrm{CC}(=\mathrm{O}) \mathrm{OCCCCCCOc} 5 \mathrm{no}[\mathrm{n}+]([\mathrm{O}-]) \mathrm{c} 5 \mathrm{~S}(=\mathrm{O})(=\mathrm{O}) \mathrm{c} 5 \mathrm{ccccc} 5) \mathrm{CC} 4) \mathrm{cc} \\
3 \mathrm{OC}) \mathrm{ncc} 2 \mathrm{Cl}) \mathrm{c} 1\end{array}$ & 292 & 6.53 \\
\hline 2830 & $\mathrm{COc} 1 \mathrm{ccc}(-\mathrm{c} 2 \mathrm{cn}(\mathrm{C} 3 \mathrm{CCN}(\mathrm{CCN}(\mathrm{C}) \mathrm{CCO}) \mathrm{CC} 3) \mathrm{c} 3 n \mathrm{ncnc}(\mathrm{N}) \mathrm{c} 23) \mathrm{c} 1$ & 295 & $*$ \\
\hline 2831 & $\mathrm{COc} 1 \mathrm{ccc}(\mathrm{NC}(=\mathrm{O}) / \mathrm{C}=\mathrm{C} / \mathrm{CN}(\mathrm{C}) \mathrm{C}) \operatorname{cc} 1 \mathrm{Nc} 1 \mathrm{ncc}(\mathrm{Cl}) \mathrm{c}(\mathrm{Nc} 2 \mathrm{ccc} 3[\mathrm{nH}] \mathrm{ccc} 3 \mathrm{c} 2) \mathrm{n} 1$ & 295 & $*$ \\
\hline 2832 & $\mathrm{CCC}(=\mathrm{O}) \mathrm{N} 1 \mathrm{CC}[\mathrm{C} @ \mathrm{H}](\mathrm{N} 2 \mathrm{C}(=\mathrm{O}) \mathrm{N}(\mathrm{c} 3 \mathrm{cc}(\mathrm{OC}) \mathrm{ccc} 3 \mathrm{~F}) \mathrm{Cc} 3 \mathrm{cnc}(\mathrm{Nc} 4 \mathrm{ccc}(\mathrm{N} 5 \mathrm{CCC} 6(\mathrm{CCN}(\mathrm{C}) \mathrm{C} 6) \mathrm{C} 5) \mathrm{c}(\mathrm{C}) \mathrm{c} 4) \mathrm{nc} 32) \mathrm{C} 1$ & 295.7 & 6.53 \\
\hline 2833 & $\mathrm{Fc} 1 \mathrm{ccc}(\mathrm{C} 2=\mathrm{NN}(\mathrm{c} 3 \operatorname{ccccc} 3) \mathrm{C}(\mathrm{c} 3 \operatorname{ccc} 4 \operatorname{ccccc} 4 \mathrm{c} 3) \mathrm{C} 2) \mathrm{cc} 1$ & 300 & 6.52 \\
\hline 2834 & $\mathrm{O}=\mathrm{C}(\mathrm{CBr}) \mathrm{OCCn} 1 \mathrm{c}(=\mathrm{O}) \mathrm{oc} 2 \mathrm{cc} 3 \mathrm{ncnc}(\mathrm{Nc} 4 \mathrm{ccc}(\mathrm{F}) \mathrm{c}(\mathrm{F}) \mathrm{c} 4) \mathrm{c} 3 \mathrm{cc} 21$ & 300 & 6.52 \\
\hline 2835 & $\mathrm{COc} 1 \mathrm{cc} 2 \mathrm{c}(\mathrm{cc} 1 \mathrm{OC}) \mathrm{Oc} 1 \mathrm{ncnc}(\mathrm{Nc} 3 \mathrm{cccc}(\mathrm{Br}) \mathrm{c} 3) \mathrm{c} 1 \mathrm{NC} 2$ & 300 & 6.52 \\
\hline 2836 & $\mathrm{COc} 1 \mathrm{cc} 2 \mathrm{c}(\mathrm{cc} 1 \mathrm{OC}) \mathrm{Oc} 1 \mathrm{ncnc}(\mathrm{Nc} 3 \mathrm{cccc}(\mathrm{Cl}) \mathrm{c} 3 \mathrm{~F}) \mathrm{c} 1 \mathrm{NC} 2$ & 300 & 6.52 \\
\hline 2837 & $\mathrm{COc} 1 \mathrm{cc} 2 \mathrm{c}(\mathrm{cc} 1 \mathrm{OC}) \mathrm{Nc} 1 \mathrm{ncnc}(\mathrm{NCc} 3 \mathrm{ccc}(\mathrm{F}) \mathrm{c}(\mathrm{Cl}) \mathrm{c} 3) \mathrm{c} 1 \mathrm{NC} 2$ & 300 & 6.52 \\
\hline 2838 & $\operatorname{CONC}(=\mathrm{O}) \mathrm{c} 1 \mathrm{cc}(\mathrm{NCc} 2 \mathrm{cc}(\mathrm{O}) \operatorname{ccc} 2 \mathrm{O}) \operatorname{ccc} 1 \mathrm{O}$ & 300 & $*$ \\
\hline 2839 & $\mathrm{O}=\mathrm{C} 1 \mathrm{NC}(=\mathrm{O}) \mathrm{c} 2 \mathrm{cc}(\mathrm{Nc} 3 \operatorname{ccc} \mathrm{c} 3) \mathrm{c}(\mathrm{Nc} 3 \mathrm{cccc} 3) \mathrm{cc} 21$ & 300 & $*$ \\
\hline 2840 & COc1cc2ncnc(NC3CC3c3ecces3)c2cc1OCCN1CCOCC1 & 300 & * \\
\hline
\end{tabular}




\begin{tabular}{|c|c|c|c|}
\hline 2841 & $\operatorname{CCOC}(=\mathrm{O}) \mathrm{C} 1 \mathrm{CCN}(\mathrm{CCC}(=\mathrm{O}) \operatorname{c} 2 \operatorname{ccc}(\mathrm{OCc} 3 \operatorname{ccccc} 3) \operatorname{cc} 2) \mathrm{CC} 1 . \mathrm{Cl}$ & 300 & $*$ \\
\hline 2842 & $\mathrm{COc} 1 \mathrm{cc} 2 \mathrm{c}(\mathrm{Nc} 3 \mathrm{ccc}(\mathrm{Cl}) \mathrm{cc} 3 \mathrm{~F}) \mathrm{ncnc} 2 \mathrm{cc} 1 \mathrm{OCC} 1 \mathrm{CCN}(\mathrm{C}) \mathrm{CC} 1 . \mathrm{Cl}$ & 300 & $*$ \\
\hline 2843 & $\mathrm{COc} 1 \mathrm{cc} 2 \mathrm{c}(\mathrm{Nc} 3 \mathrm{ccc}(\mathrm{Cl}) \mathrm{cc} 3 \mathrm{~F}) \mathrm{ncnc} 2 \mathrm{cc} 1 \mathrm{OCCC} 1 \mathrm{CCN}(\mathrm{C}) \mathrm{CC} 1$ & 300 & $*$ \\
\hline 2844 & $\mathrm{COc} 1 \mathrm{cc} 2 \mathrm{c}(\mathrm{Nc} 3 \mathrm{ccc}(\mathrm{Cl}) \mathrm{cc} 3 \mathrm{~F}) \mathrm{ncnc} 2 \mathrm{cc} 1 \mathrm{OCC} 1 \mathrm{CCNCC} 1 . \mathrm{Cl}$ & 300 & $*$ \\
\hline 2845 & $\mathrm{COc} 1 \mathrm{cc} 2 \mathrm{c}(\mathrm{Nc} 3 \mathrm{cc}(\mathrm{O}) \mathrm{c}(\mathrm{C}) \mathrm{cc} 3 \mathrm{~F}) \mathrm{ncn} 2 \mathrm{cc} 1 \mathrm{OCC} 1 \mathrm{CCN}(\mathrm{C}) \mathrm{CC} 1 . \mathrm{Cl}$ & 300 & $*$ \\
\hline 2846 & $\mathrm{COc} 1 \mathrm{cc} 2 \mathrm{c}(\mathrm{Nc} 3 \mathrm{c}(\mathrm{F}) \mathrm{cc}(\mathrm{Br}) \mathrm{cc} 3 \mathrm{~F}) \mathrm{ncnc} 2 \mathrm{cc} 1 \mathrm{OCC} 1 \mathrm{CCN}(\mathrm{C}) \mathrm{CC} 1$ & 300 & $*$ \\
\hline 2847 & $\mathrm{COc} 1 \mathrm{cc} 2 \mathrm{c}(\mathrm{Nc} 3 \mathrm{ccc}(\mathrm{Cl}) \mathrm{cc} 3 \mathrm{~F}) \mathrm{ncn} 2 \mathrm{cc} 1 \mathrm{OCCN}(\mathrm{C}) \mathrm{c} 1 \mathrm{ccncc} 1$ & 300 & $*$ \\
\hline 2848 & $\mathrm{COc} 1 \mathrm{cc} 2 \mathrm{c}(\mathrm{Nc} 3 \operatorname{ccc}(\mathrm{NC}(=\mathrm{O}) \mathrm{c} 4 \operatorname{ccc}(\mathrm{Cl}) \mathrm{c} 4) \mathrm{cc} 3) \mathrm{ncnc} 2 \mathrm{cc} 1 \mathrm{OCCN} 1 \mathrm{CCCCC} 1$ & 300 & $*$ \\
\hline 2849 & $\mathrm{CCC}(=\mathrm{O}) \mathrm{N} 1 \mathrm{CC}[\mathrm{C} @ \mathrm{H}](\mathrm{N} 2 \mathrm{C}(=\mathrm{O}) \mathrm{N}(\mathrm{c} 3 \mathrm{cc}(\mathrm{OC}) \mathrm{ccc} 3 \mathrm{~F}) \mathrm{Cc} 3 \mathrm{cnc}(\mathrm{Nc} 4 \mathrm{ccc}(\mathrm{N} 5 \mathrm{CCN}(\mathrm{C} 6 \mathrm{COC} 6) \mathrm{CC} 5) \mathrm{c}(\mathrm{C}) \mathrm{c} 4) \mathrm{nc} 32) \mathrm{C} 1$ & 302 & 6.52 \\
\hline 2850 & $\mathrm{O}=\mathrm{C}(\mathrm{Nc} 1 \mathrm{cc} 2 \mathrm{c}(\mathrm{Nc} 3 \mathrm{ccc}(\mathrm{F}) \mathrm{c}(\mathrm{Cl}) \mathrm{c} 3) \mathrm{ncnc} 2 \mathrm{cc} 1 \mathrm{O}[\mathrm{C} @ \mathrm{H}] 1 \mathrm{CCOC} 1) \mathrm{N} 1 \mathrm{CCC}(\mathrm{CCO}) \mathrm{CC} 1$ & 304 & * \\
\hline 2851 & $\mathrm{CN}(\mathrm{C}) \mathrm{C} / \mathrm{C}=\mathrm{C} / \mathrm{C}(=\mathrm{O}) \mathrm{Nc} 1 \mathrm{cc} 2 \mathrm{c}(\mathrm{Nc} 3 \mathrm{ccc}(\mathrm{Cc} 4 \mathrm{ccc} n 4) \mathrm{cc} 3) \mathrm{ncnc} 2 \mathrm{cn} 1$ & 304 & $*$ \\
\hline 2852 & $\mathrm{CS}(=\mathrm{O})(=\mathrm{O}) \mathrm{CCNCc} 1 \mathrm{cc}(-\mathrm{c} 2 \mathrm{cc} 3 \mathrm{c}(\mathrm{Nc} 4 \mathrm{ccc}(\mathrm{OCc} 5 \mathrm{ccc}(\mathrm{F}) \mathrm{c} 5) \mathrm{c}(\mathrm{Cl}) \mathrm{c} 4) \mathrm{ncnc} 3 \mathrm{~s} 2) \mathrm{cs} 1$ & 304 & $*$ \\
\hline 2853 & $\mathrm{O}=\mathrm{C}(\mathrm{Nc} 1 \mathrm{cc} 2 \mathrm{c}(\mathrm{Nc} 3 \mathrm{ccc}(\mathrm{F}) \mathrm{c}(\mathrm{Cl}) \mathrm{c} 3) \mathrm{ncnc} 2 \mathrm{cc} 1 \mathrm{O}[\mathrm{C} @ \mathrm{H}] 1 \mathrm{CCOC} 1) \mathrm{N}(\mathrm{N} 1 \mathrm{CCC}(\mathrm{CCO}) \mathrm{CC} 1) \mathrm{N} 1 \mathrm{CCC}(\mathrm{CCO}) \mathrm{CC} 1$ & 304 & $*$ \\
\hline 2854 & $\mathrm{CO} / \mathrm{N}=\mathrm{C} / \mathrm{c} 1 \mathrm{c}(\mathrm{N}) \mathrm{ncnc} 1 \mathrm{Nc} 1 \mathrm{ccc} 2[\mathrm{nH}] \mathrm{ncc} 2 \mathrm{c} 1$ & 306 & $*$ \\
\hline 2855 & $\mathrm{C}=\mathrm{CC}(=\mathrm{O}) \mathrm{Nc} 1 \mathrm{cc}(\mathrm{Nc} 2 \mathrm{nccc}(\mathrm{Nc} 3 \operatorname{ccccc} 3 \mathrm{~S}(=\mathrm{O})(=\mathrm{O}) \mathrm{N}(\mathrm{C}) \mathrm{C}) \mathrm{n} 2) \mathrm{c}(\mathrm{OC}) \operatorname{cc} 1 \mathrm{~N}(\mathrm{C}) \mathrm{CCN}(\mathrm{C}) \mathrm{C}$ & 307 & $*$ \\
\hline 2856 & COc1cc2ncnc $(\mathrm{Nc} 3 \operatorname{ccc}(\mathrm{F}) \mathrm{c}(\mathrm{Cl}) \mathrm{c} 3) \mathrm{c} 2 \mathrm{cc} 1 \mathrm{OCCNC}(\mathrm{C}) \mathrm{C}$ & 310 & $*$ \\
\hline 2857 & $\mathrm{O}=\mathrm{C}(\mathrm{O}) \mathrm{c} 1 \mathrm{ccc}(\mathrm{S}(=\mathrm{O})(=\mathrm{O}) \mathrm{Oc} 2 \operatorname{ccc}(/ \mathrm{C}=\mathrm{C} /[\mathrm{N}+](=\mathrm{O})[\mathrm{O}-]) \operatorname{cc} 2) \mathrm{c}(\mathrm{O}) \mathrm{c} 1$ & 310 & $*$ \\
\hline 2858 & $\mathrm{c} 1 \mathrm{ccc}(\mathrm{Nc} 2 \mathrm{ncnc} 3[\mathrm{nH}] \mathrm{c} 4 \mathrm{c}(\mathrm{c} 23) \mathrm{CCCC} 4) \mathrm{cc} 1$ & 310 & $*$ \\
\hline 2859 & COCCNCCN1CCC(n2ce(-c3ecce(OC)c3)c3c(N)ncnc32)CC1 & 310 & $*$ \\
\hline 2860 & $\operatorname{COc} 1 \operatorname{ccc}(\mathrm{C} 2=\mathrm{C}(\mathrm{C} \# \mathrm{~N}) \mathrm{C} 3(\mathrm{C}(=\mathrm{O}) \mathrm{Nc} 4 \mathrm{ccc}(\mathrm{Br}) \operatorname{cc} 43) \mathrm{c} 3 \mathrm{c}(-\mathrm{c} 4 \operatorname{cccs} 4) \mathrm{nn}(-\mathrm{c} 4 \mathrm{ccccc} 4) \mathrm{c} 3 \mathrm{~N} 2) \mathrm{cc} 1$ & 310 & $*$ \\
\hline 2861 & $\operatorname{CCOC}(=\mathrm{O}) \mathrm{c} 1 \mathrm{c}(\mathrm{C}) \mathrm{cn} 2 \mathrm{ncnc}(\mathrm{Nc} 3 \operatorname{ccc} 4 \mathrm{c}(\mathrm{cnn} 4 \mathrm{Cc} 4 \mathrm{cccc}(\mathrm{F}) \mathrm{c} 4) \mathrm{c} 3) \mathrm{c} 12$ & 310 & $*$ \\
\hline 2862 & $\mathrm{Cn} 1 \mathrm{cnc}(-\mathrm{c} 2 \mathrm{cc}(\mathrm{NC}(=\mathrm{O}) \mathrm{Nc} 3 \mathrm{nccs} 3) \mathrm{cc}(\mathrm{C}(\mathrm{F})(\mathrm{F}) \mathrm{F}) \mathrm{c} 2) \mathrm{c} 1$ & 310.76 & $*$ \\
\hline 2863 & $\mathrm{C}=\mathrm{CC}(=\mathrm{O}) \mathrm{Nc} 1 \mathrm{cc}(\mathrm{Nc} 2 \mathrm{n}[\mathrm{nH}] \mathrm{c} 3 \mathrm{cc}(-\mathrm{c} 4 \mathrm{ccc} 5 \mathrm{cccc} 5 \mathrm{c} 4) \operatorname{ccc} 23) \mathrm{c}(\mathrm{OC}) \mathrm{cc} 1 \mathrm{~N}(\mathrm{C}) \mathrm{CCN}(\mathrm{C}) \mathrm{C}$ & 312 & $*$ \\
\hline 2864 & $\mathrm{CC}(\mathrm{C}) \mathrm{Oc} 1 \mathrm{cc} 2 \mathrm{ncnc}(\mathrm{Nc} 3 \mathrm{ccc}(\mathrm{F}) \mathrm{c}(\mathrm{C \# N}) \mathrm{c} 3) \mathrm{c} 2 \mathrm{c} 2 \mathrm{c} 1 \mathrm{OCCO} 2$ & 313.6 & * \\
\hline 2865 & $\mathrm{C}=\mathrm{CC}(=\mathrm{O}) \mathrm{Nc} 1 \mathrm{cccc}(-\mathrm{n} 2 \mathrm{c}(=\mathrm{O}) \mathrm{n}(\mathrm{C}) \mathrm{c}(=\mathrm{O}) \mathrm{c} 3 \mathrm{cnc}(\mathrm{Nc} 4 \mathrm{ccc}(\mathrm{N} 5 \mathrm{CCSCC} 5) \mathrm{cc} 4 \mathrm{OC}) \mathrm{nc} 32) \mathrm{c} 1$ & 314 & $*$ \\
\hline 2866 & $\operatorname{CCCCCCCCCCCCCCNC}(=\mathrm{O}) \operatorname{COc} 1 \mathrm{cc}(\mathrm{O}) \mathrm{c} 2 \mathrm{c}(=\mathrm{O}) \mathrm{cc}(-\mathrm{c} 3 \operatorname{cccc} 3) \mathrm{oc} 2 \mathrm{c} 1$ & 316 & 6.50 \\
\hline 2867 & $\operatorname{COc} 1 \mathrm{cc}(\mathrm{NC}(=\mathrm{O}) \mathrm{Nc} 2 \mathrm{nccs} 2) \mathrm{cc}(-\mathrm{c} 2 \mathrm{ccc} n \mathrm{c} 2) \mathrm{c} 1 \mathrm{OC}$ & 317.12 & $*$ \\
\hline 2868 & $\mathrm{C}=\mathrm{CC}(=\mathrm{O}) \mathrm{Nc} 1 \mathrm{cc}(\mathrm{Nc} 2 \mathrm{nccc}(\mathrm{NC}(=\mathrm{O}) \mathrm{c} 3 \operatorname{ccccc} 3) \mathrm{n} 2) \mathrm{c}(\mathrm{OC}) \operatorname{cc} 1 \mathrm{~N}(\mathrm{C}) \mathrm{CCN}(\mathrm{C}) \mathrm{C}$ & 317.6 & $*$ \\
\hline 2869 & Nc1ncnc2c1c(-c1ecc(F)c(O)c1)nn2C1CCCC1 & 318 & $*$ \\
\hline 2870 & $\mathrm{Fc} 1 \mathrm{cccc}(\mathrm{COc} 2 \mathrm{ccc}(\mathrm{Nc} 3 \mathrm{ccncn} 3) \mathrm{cc} 2 \mathrm{Cl}) \mathrm{c} 1$ & 320 & 6.04 \\
\hline 2871 & COc1 $\operatorname{ccc}(-\mathrm{c} 2 \mathrm{nnnc}(-\mathrm{n} 3 \mathrm{c}(-\mathrm{c} 4 \mathrm{ccccc} 4) \mathrm{nc} 4 \mathrm{cc}(\mathrm{Cl}) \mathrm{ccc} 4 \mathrm{c} 3=\mathrm{O}) \mathrm{s} 2) \mathrm{cc} 1$ & 320 & 6.49 \\
\hline 2872 & $\operatorname{c1ccc}(\mathrm{CNc} 2 \mathrm{ncnc} 3 \operatorname{ccccc} 23) \mathrm{cc} 1$ & 320 & $*$ \\
\hline 2873 & $\mathrm{O}=\mathrm{c} 1[\mathrm{nH}] \mathrm{cc}(\mathrm{F}) \mathrm{c}(=\mathrm{O})[\mathrm{nH}] 1$ & 320 & $*$ \\
\hline 2874 & $\mathrm{O}=\mathrm{c} \operatorname{lnc}(\mathrm{O}) \mathrm{c}(\mathrm{F}) \mathrm{c}[\mathrm{nH}] 1$ & 320 & * \\
\hline 2875 & $\mathrm{CCOc} 1 \mathrm{cc} 2 \mathrm{ncc}(\mathrm{C \# N}) \mathrm{c}(\mathrm{Nc} 3 \operatorname{ccc}(\mathrm{OCc} 4 \mathrm{cccc} 4) \mathrm{c}(\mathrm{Cl}) \mathrm{c} 3) \mathrm{c} 2 \mathrm{cc} 1 \mathrm{NC}(=\mathrm{O}) / \mathrm{C}=\mathrm{C} / \mathrm{CN} 1 \mathrm{CCOCCOCCOCC} 1$ & 321 & 6.49 \\
\hline 2876 & $\mathrm{CN}(\mathrm{C}) \mathrm{c} 1 \mathrm{ccc} 2 \mathrm{c}(\mathrm{Nc} 3 \operatorname{ccc}(\mathrm{Br}) \mathrm{c} 3) \mathrm{ncnc} 2 \mathrm{n} 1$ & 324 & $*$ \\
\hline 2877 & $\mathrm{Nc} 1 \mathrm{ncnc} 2 \mathrm{c} 1 \mathrm{c}(-\mathrm{c} 1 \mathrm{ccc}(\mathrm{Br}) \mathrm{c}(\mathrm{O}) \mathrm{c} 1) \mathrm{nn} 2 \mathrm{C} 1 \mathrm{CCC} 1$ & 324 & $*$ \\
\hline 2878 & $\mathrm{Clc} 1 \mathrm{ccc}(\mathrm{Nc} 2 \mathrm{cc}(\mathrm{Nc} 3 \operatorname{cccc}(\mathrm{Cl}) \mathrm{n} 3) \mathrm{ncn} 2) \mathrm{cc} 1$ & 324 & * \\
\hline 2879 & $\mathrm{CN} 1 \mathrm{CCN}(\mathrm{c} 2 \mathrm{ccc}(\mathrm{Nc} 3 \mathrm{ncc}(\mathrm{Br}) \mathrm{c}(\mathrm{Nc} 4 \mathrm{ccc} 5 \mathrm{c}(\mathrm{ccn} 5 \mathrm{Cc} 5 \mathrm{cccc}(\mathrm{F}) \mathrm{c} 5) \mathrm{c} 4) \mathrm{n} 3) \mathrm{cc} 2) \mathrm{CC} 1$ & 325 & $*$ \\
\hline 2880 & $\mathrm{O}=\mathrm{C}(\mathrm{CO}) \mathrm{N} 1 \mathrm{CCC}[\mathrm{C} @ \mathrm{H}] 1 \mathrm{COc} 1 \mathrm{cccc} 2 \mathrm{ncnc}(\mathrm{Nc} 3 \mathrm{ccc}(\mathrm{OCc} 4 \mathrm{ccc} n 4) \mathrm{c}(\mathrm{Cl}) \mathrm{c} 3) \mathrm{c} 12$ & 327 & $*$ \\
\hline 2881 & $\mathrm{O}=\mathrm{C}(\mathrm{CCl}) \mathrm{OCCn} 1 \mathrm{c}(=\mathrm{O}) \mathrm{oc} 2 \mathrm{cc} 3 \mathrm{ncnc}(\mathrm{Nc} 4 \mathrm{ccc}(\mathrm{F}) \mathrm{c}(\mathrm{Cl}) \mathrm{c} 4) \mathrm{c} 3 \mathrm{cc} 21$ & 330 & 6.48 \\
\hline 2882 & $\operatorname{COCOC} \# \mathrm{CC}(=\mathrm{O}) \mathrm{Nc} 1 \mathrm{ccc} 2 \mathrm{ncc}(\mathrm{C} \# \mathrm{~N}) \mathrm{c}(\mathrm{Nc} 3 \operatorname{cccc}(\mathrm{Br}) \mathrm{c} 3) \mathrm{c} 2 \mathrm{c} 1$ & 330 & 6.48 \\
\hline 2883 & $\operatorname{COCOCC\# CC}(=\mathrm{O}) \mathrm{Nc} 1 \mathrm{ccc} 2 \mathrm{ncc}(\mathrm{C} \# \mathrm{~N}) \mathrm{c}(\mathrm{Nc} 3 \mathrm{cccc}(\mathrm{Br}) \mathrm{c} 3) \mathrm{c} 2 \mathrm{c} 1$ & 330 & 6.48 \\
\hline
\end{tabular}




\begin{tabular}{|c|c|c|c|}
\hline 2884 & $\mathrm{Clc} 1 \mathrm{cccc}(\mathrm{Nc} 2 \mathrm{nc}[\mathrm{nH}] \mathrm{c} 3 \mathrm{nnc}(\mathrm{Nc} 4 \mathrm{cccc}(\mathrm{Cl}) \mathrm{c} 4) \mathrm{c} 2-3) \mathrm{c} 1$ & 330 & $*$ \\
\hline 2885 & $\operatorname{COc} 1 \mathrm{cc}(\mathrm{Nc} 2 \mathrm{ncc} 3 \mathrm{cc}(-\mathrm{c} 4 \mathrm{c}(\mathrm{Cl}) \operatorname{ccc} 4 \mathrm{Cl}) \mathrm{c}(=\mathrm{O}) \mathrm{n}(\mathrm{C}) \mathrm{c} 3 \mathrm{n} 2) \mathrm{cc}(\mathrm{OC}) \mathrm{c} 1$ & 330 & $*$ \\
\hline 2886 & $\mathrm{O}=\mathrm{C}(\mathrm{Nc} 1 \mathrm{cc} 2 \mathrm{c}(\mathrm{Nc} 3 \mathrm{ccc}(\mathrm{F}) \mathrm{c}(\mathrm{Cl}) \mathrm{c} 3) \mathrm{ncnc} 2 \mathrm{cc} 1 \mathrm{O}[\mathrm{C} @ \mathrm{H}] 1 \mathrm{CCOC} 1) \mathrm{N} 1 \mathrm{CCN}(\mathrm{CCO}) \mathrm{CC} 1$ & 331 & $*$ \\
\hline 2887 & $\mathrm{Fc} 1 \mathrm{ccc}(\mathrm{Nc} 2 \mathrm{ncnc} 3 \mathrm{ccc}(\mathrm{CHC} 4 \mathrm{ccccc} 4) \mathrm{cc} 23) \mathrm{cc} 1 \mathrm{Cl}$ & 331 & * \\
\hline 2888 & $\mathrm{O}=\mathrm{C}(\mathrm{Nc} 1 \mathrm{cc} 2 \mathrm{c}(\mathrm{Nc} 3 \mathrm{ccc}(\mathrm{F}) \mathrm{c}(\mathrm{Cl}) \mathrm{c} 3) n \mathrm{nc} 2 \mathrm{cc} 1 \mathrm{O}[\mathrm{C} @ \mathrm{H}] 1 \mathrm{CCOC} 1) \mathrm{N}(\mathrm{N} 1 \mathrm{CCN}(\mathrm{CCO}) \mathrm{CC} 1) \mathrm{N} 1 \mathrm{CCN}(\mathrm{CCO}) \mathrm{CC} 1$ & 331 & $*$ \\
\hline 2889 & $\mathrm{COc} 1 \mathrm{cc} 2 \mathrm{ncnc}(-\mathrm{c} 3 \mathrm{c}[\mathrm{nH}] \mathrm{c} 4 \mathrm{cc}(\mathrm{F}) \mathrm{c}(\mathrm{Cl}) \mathrm{cc} 34) \mathrm{c} 2 \mathrm{cc} 1 \mathrm{OCCCN} 1 \mathrm{CCOCC} 1$ & 333 & $*$ \\
\hline 2890 & $\mathrm{CN}=\mathrm{NNc} 1 \mathrm{ccc} 2 \mathrm{ncnc}(\mathrm{NCc} 3 \operatorname{ccccc} 3) \mathrm{c} 2 \mathrm{c} 1$ & 335 & $*$ \\
\hline 2891 & $\mathrm{COc} 1 \mathrm{ccc}(\mathrm{OC}) \mathrm{c}(\mathrm{Nc} 2 \mathrm{cc}(\mathrm{Nc} 3 \mathrm{ccc}(\mathrm{F}) \mathrm{cc} 3) \mathrm{ncn} 2) \mathrm{c} 1$ & 336 & $*$ \\
\hline 2892 & $\mathrm{Cc} 1 \mathrm{ccc}(\mathrm{C} 2 \mathrm{CC}(\mathrm{c} 3 \operatorname{ccc}(\mathrm{C}) \mathrm{c}(\mathrm{C}) \mathrm{c} 3)=\mathrm{NN} 2 \mathrm{C}(\mathrm{N})=\mathrm{S}) \mathrm{cc} 1$ & 340 & 6.47 \\
\hline 2893 & $\mathrm{CCOc} 1 \mathrm{cc} 2 \mathrm{ncc}(\mathrm{C \# N}) \mathrm{c}(\mathrm{Nc} 3 \operatorname{ccc} 4 \mathrm{c}(\mathrm{c} 3) \mathrm{CCN} 4 \mathrm{Cc} 3 \operatorname{ccc} c 3) \mathrm{c} 2 \mathrm{cc} 1 \mathrm{NC}(=\mathrm{O}) / \mathrm{C}=\mathrm{C} / \mathrm{CN}(\mathrm{C}) \mathrm{C}$ & 340 & 6.47 \\
\hline 2894 & $\operatorname{COCCn} 1 \mathrm{c}(=\mathrm{O}) \mathrm{oc} 2 \mathrm{cc} 3 \mathrm{ncnc}(\mathrm{Nc} 4 \mathrm{ccc}(\mathrm{OCc} 5 \mathrm{nccc}(\mathrm{OCC}(\mathrm{F})(\mathrm{F}) \mathrm{F}) \mathrm{c} 5 \mathrm{C}) \mathrm{cc} 4) \mathrm{c} 3 \mathrm{cc} 21$ & 340 & $*$ \\
\hline 2895 & $\mathrm{COCc} 1 \mathrm{ccn} 2 \mathrm{ncnc}(\mathrm{Nc} 3 \mathrm{ccc} 4 \mathrm{c}(\mathrm{cnn} 4 \mathrm{Cc} 4 \mathrm{cccc}(\mathrm{F}) \mathrm{c} 4) \mathrm{c} 3) \mathrm{c} 12$ & 340 & $*$ \\
\hline 2896 & $\mathrm{CCOc} 1 \mathrm{cc} 2 \mathrm{ncc}(\mathrm{C} \# \mathrm{~N}) \mathrm{c}(\mathrm{Nc} 3 \operatorname{ccc}(\mathrm{OCc} 4 \mathrm{cccnc} 4) \mathrm{c}(\mathrm{Cl}) \mathrm{c} 3) \mathrm{c} 2 \mathrm{cc} 1 \mathrm{NC}(=\mathrm{O}) / \mathrm{C}=\mathrm{C} / \mathrm{CN}(\mathrm{C}) \mathrm{C}$ & 341 & 6.47 \\
\hline 2897 & $\mathrm{C}=\mathrm{CC}(=\mathrm{O}) \mathrm{Nc} 1 \mathrm{cccc}(-\mathrm{n} 2 \mathrm{c}(=\mathrm{O}) \mathrm{n}(\mathrm{C}) \mathrm{c}(=\mathrm{O}) \mathrm{c} 3 \mathrm{cnc}(\mathrm{Nc} 4 \mathrm{ccc}(\mathrm{N} 5 \mathrm{CCOCC} 5) \mathrm{cc} 4 \mathrm{OC}) \mathrm{nc} 32) \mathrm{c} 1$ & 341 & $*$ \\
\hline 2898 & $\operatorname{COc} 1 \mathrm{cc} 2 \mathrm{ncc}(\mathrm{C}(=\mathrm{O}) \mathrm{NC} 3 \mathrm{CC}(\mathrm{C})(\mathrm{C}) \mathrm{N}([\mathrm{O}]) \mathrm{C}(\mathrm{C})(\mathrm{C}) \mathrm{C} 3) \mathrm{c}(\mathrm{Nc} 3 \mathrm{ccc}(\mathrm{Br}) \mathrm{c} 3) \mathrm{c} 2 \mathrm{cc} 1 \mathrm{OC}$ & 342 & 6.47 \\
\hline 2899 & $\mathrm{CCOc} 1 \mathrm{cc} 2 \mathrm{ncc}(\mathrm{C \# N}) \mathrm{c}(\mathrm{Nc} 3 \operatorname{ccc}(\mathrm{OCc} 4 \operatorname{ccccc} 4) \mathrm{c}(\mathrm{Cl}) \mathrm{c} 3) \mathrm{c} 2 \mathrm{cc} 1 \mathrm{NC}(=\mathrm{O}) / \mathrm{C}=\mathrm{C} / \mathrm{CN} 1 \mathrm{CC} 1 \mathrm{C}(=\mathrm{O}) \mathrm{OC}$ & 343 & 6.46 \\
\hline 2900 & $\mathrm{CCC}(=\mathrm{O}) \mathrm{Nc} 1 \mathrm{cc} 2 \mathrm{c}(\mathrm{Nc} 3 \mathrm{ccc}(\mathrm{C}(\mathrm{O}) \mathrm{c} 4 \mathrm{cccc} 4) \mathrm{cc} 3) \mathrm{ncnc} 2 \mathrm{cc} 1 \mathrm{OC}$ & 343 & $*$ \\
\hline 2901 & $\mathrm{c} 1 \mathrm{ccc}(\mathrm{Nc} 2 \mathrm{ncnc} 3 \mathrm{ccccc} 23) \mathrm{cc} 1$ & 344 & $*$ \\
\hline 2902 & $\mathrm{CCOc} 1 \mathrm{cc} 2 \mathrm{ncc}(\mathrm{CHN}) \mathrm{c}(\mathrm{Nc} 3 \operatorname{ccc}(\mathrm{OCc} 4 \mathrm{ccccc} 4) \mathrm{cc} 3) \mathrm{c} 2 \mathrm{cc} 1 \mathrm{NC}(=\mathrm{O}) / \mathrm{C}=\mathrm{C} / \mathrm{CN}(\mathrm{C}) \mathrm{C}$ & 345 & 6.46 \\
\hline 2903 & $\mathrm{Cc} 1 \mathrm{ccc}(\mathrm{Nc} 2 \mathrm{ncnn} 3 \mathrm{ccc}(\mathrm{C}) \mathrm{c} 23) \mathrm{cc} 1 \mathrm{O}$ & 346 & $*$ \\
\hline 2904 & $\mathrm{CCOc} 1 \mathrm{cc} 2 \mathrm{ncnc}(\mathrm{NC} 3=\mathrm{CC}(=\mathrm{O}) \mathrm{C}(\mathrm{OCc} 4 \operatorname{cccc}(\mathrm{OC}) \mathrm{c} 4)=\mathrm{CC} 3=\mathrm{O}) \mathrm{c} 2 \mathrm{cc} 1 \mathrm{NC}(=\mathrm{O}) / \mathrm{C}=\mathrm{C} / \mathrm{CN}(\mathrm{C}) \mathrm{C}$ & 346.9 & 6.46 \\
\hline 2905 & $\mathrm{COc} 1 \mathrm{ccc} 2 \mathrm{ncnc}(\mathrm{Nc} 3 \operatorname{ccc}(\mathrm{Br}) \mathrm{c} 3) \mathrm{c} 2 \mathrm{c} 1$ & 348 & $*$ \\
\hline 2906 & $\mathrm{C}=\mathrm{CC}(=\mathrm{O}) \mathrm{Nc} 1 \operatorname{ccc}(\mathrm{NC}(=\mathrm{O}) \mathrm{Nc} 2 \mathrm{ccnc}(\mathrm{Nc} 3 \operatorname{ccc}(\mathrm{OC}) \operatorname{cc} 3 \mathrm{OC}) \mathrm{n} 2) \mathrm{c} 1$ & 348 & * \\
\hline 2907 & $\mathrm{CCc} 1 \mathrm{ccc}(\mathrm{Nc} 2 \mathrm{ncnc} 3 \mathrm{cc}(\mathrm{OCCOC}) \mathrm{c}(\mathrm{OCCOC}) \mathrm{cc} 23) \mathrm{c} 1$ & 348.7 & $*$ \\
\hline 2908 & $\mathrm{NC}(=\mathrm{S}) \mathrm{N} 1 \mathrm{~N}=\mathrm{C}(\mathrm{c} 2 \mathrm{ccc}(\mathrm{Br}) \mathrm{cc} 2) \mathrm{CC} 1 \mathrm{c} 1 \mathrm{ccc} 2 \mathrm{ccccc} 2 \mathrm{c} 1$ & 350 & 6.46 \\
\hline 2909 & $\mathrm{C}=\mathrm{CC}(=\mathrm{O}) \mathrm{N} 1 \mathrm{CCN}(\mathrm{c} 2 \mathrm{ccc}(\mathrm{Nc} 3 \mathrm{ncc}(\mathrm{Cl}) \mathrm{c}(\mathrm{Oc} 4 \mathrm{cccc}(\mathrm{COc} 5 \mathrm{no}[\mathrm{n}+]([\mathrm{O}-]) \mathrm{c} 5 \mathrm{~S}(=\mathrm{O})(=\mathrm{O}) \mathrm{c} 5 \operatorname{ccccc} 5) \mathrm{c} 4) \mathrm{n} 3) \mathrm{c}(\mathrm{OC}) \mathrm{c} 2) \mathrm{CC} 1$ & 350 & 6.46 \\
\hline 2910 & $\mathrm{Cc} 1 \operatorname{ccc}(\mathrm{C}(/ \mathrm{C}=\mathrm{C} / \mathrm{c} 2 \operatorname{ccccc} 2)=\mathrm{N} \backslash \mathrm{NC}(\mathrm{N})=\mathrm{S}) \operatorname{cc} 1$ & 350 & 6.46 \\
\hline 2911 & $\mathrm{C}=\mathrm{CC}(=\mathrm{O}) \mathrm{Nc} 1 \mathrm{cccc}(\mathrm{Nc} 2 \mathrm{nc}(\mathrm{Nc} 3 \operatorname{ccc}(\mathrm{N} 4 \mathrm{CCN}(\mathrm{C}(\mathrm{C})=\mathrm{O}) \mathrm{CC} 4) \operatorname{cc} 3 \mathrm{OC}) \mathrm{ncc} 2 \mathrm{C}(\mathrm{F})(\mathrm{F}) \mathrm{F}) \mathrm{c} 1$ & 350 & $*$ \\
\hline 2912 & $\mathrm{COc} 1 \mathrm{ccc}(\mathrm{Nc} 2 \mathrm{ncnc} 3 \mathrm{cc}(\mathrm{OC}) \mathrm{c}(\mathrm{OC}) \mathrm{cc} 23) \mathrm{cc} 1 \mathrm{OC} . \mathrm{Cl}$ & 350 & $*$ \\
\hline 2913 & $\mathrm{O}=\mathrm{C} 1 \mathrm{CN}(\mathrm{Cc} 2 \mathrm{ccn} 3 \mathrm{ncnc}(\mathrm{Nc} 4 \mathrm{ccc} 5 \mathrm{c}(\mathrm{cnn} 5 \mathrm{Cc} 5 \mathrm{cccc}(\mathrm{F}) \mathrm{c} 5) \mathrm{c} 4) \mathrm{c} 23) \mathrm{CCN} 1$ & 350 & $*$ \\
\hline 2914 & $\operatorname{COc} 1 \operatorname{cccc}(-\mathrm{c} 2 \mathrm{cn}(\mathrm{C} 3 \mathrm{CCN}(\mathrm{CC}(\mathrm{N})=\mathrm{O}) \mathrm{CC} 3) \mathrm{c} 3 \operatorname{ncnc}(\mathrm{N}) \mathrm{c} 23) \mathrm{c} 1$ & 350 & $*$ \\
\hline 2915 & $\mathrm{~N} \# \mathrm{Cc} 1 \mathrm{cnc} 2 \mathrm{cc}(\mathrm{O}) \mathrm{c}(\mathrm{O}) \mathrm{cc} 2 \mathrm{c} 1 \mathrm{Nc} 1 \mathrm{cccc}(\mathrm{Br}) \mathrm{c} 1$ & 350 & $*$ \\
\hline 2916 & $\mathrm{CCOC}(\mathrm{C}) \mathrm{Oc} 1 \mathrm{cc} 2 \mathrm{ncnc}(\mathrm{Nc} 3 \mathrm{ccc}(\mathrm{F}) \mathrm{c}(\mathrm{C} \# \mathrm{~N}) \mathrm{c} 3) \mathrm{c} 2 \mathrm{c} 2 \mathrm{c} 1 \mathrm{OCCO} 2$ & 351.8 & $*$ \\
\hline 2917 & OC[C@@H](Nc1ncnc2oc(-c3ecccc3)c(-c3ccoc3)c12)c1ccccc1 & 352 & $*$ \\
\hline 2918 & $\mathrm{O}=\mathrm{C} 1 \mathrm{COc} 2 \mathrm{cc} 3 \mathrm{ncnc}(\mathrm{Nc} 4 \mathrm{ccc}(\mathrm{Cl}) \mathrm{cc} 4) \mathrm{c} 3 \mathrm{cc} 2 \mathrm{~N} 1 \mathrm{CCCN} 1 \mathrm{CCOCC} 1$ & 353.7 & $*$ \\
\hline 2919 & $\mathrm{O}=[\mathrm{N}+]([\mathrm{O}-]) \mathrm{c} 1 \mathrm{cccc} 2 \mathrm{ncnc}(\mathrm{Nc} 3 \operatorname{ccc}(\mathrm{Br}) \mathrm{c} 3) \mathrm{c} 12$ & 355 & $*$ \\
\hline 2920 & $\mathrm{COCCOc} 1 \mathrm{cc} 2 \mathrm{ncnc}(\mathrm{Nc} 3 \operatorname{ccc}(\mathrm{F}) \mathrm{c}(\mathrm{Cl}) \mathrm{c} 3) \mathrm{c} 2 \mathrm{cc} 1 \mathrm{NC}(=\mathrm{O}) / \mathrm{C}=\mathrm{C} / \mathrm{CN} 1 \mathrm{CC}[\mathrm{S}+]([\mathrm{O}-]) \mathrm{CC} 1$ & 356.6 & $*$ \\
\hline 2921 & $\mathrm{CCOc} 1 \mathrm{cc} 2 \mathrm{ncc}(\mathrm{C \# N}) \mathrm{c}(\mathrm{Nc} 3 \operatorname{ccc}(\mathrm{OCc} 4 \mathrm{ccccc} 4) \mathrm{c}(\mathrm{Cl}) \mathrm{c} 3) \mathrm{c} 2 \mathrm{cc} 1 \mathrm{NC}(=\mathrm{O}) / \mathrm{C}=\mathrm{C} / \mathrm{CN} 1 \mathrm{CCN}(\mathrm{C}) \mathrm{CC} 1$ & 360 & 6.44 \\
\hline 2922 & $\mathrm{CCC}(=\mathrm{O}) \mathrm{N} 1 \mathrm{CC}[\mathrm{C} @ \mathrm{H}](\mathrm{N} 2 \mathrm{C}(=\mathrm{O}) \mathrm{N}(\mathrm{c} 3 \mathrm{cc}(\mathrm{OC}) \mathrm{ccc} 3 \mathrm{Cl}) \mathrm{Cc} 3 \mathrm{cnc}(\mathrm{Nc} 4 \mathrm{ccc}(\mathrm{N} 5 \mathrm{CCN}(\mathrm{C} 6 \mathrm{COC} 6) \mathrm{CC} 5) \mathrm{c}(\mathrm{C}) \mathrm{c} 4) \mathrm{nc} 32) \mathrm{C} 1$ & 360 & 6.44 \\
\hline 2923 & $\mathrm{COc} 1 \mathrm{cc} 2 \mathrm{ncnc}(\mathrm{Nc} 3 \operatorname{ccc}(\mathrm{Cl}) \mathrm{c} 3 \mathrm{~F}) \mathrm{c} 2 \mathrm{cc} 1 \mathrm{CN} 1 \mathrm{CCCC} 1$ & 360 & $*$ \\
\hline 2924 & $\mathrm{CC}(\mathrm{COC}(=\mathrm{O}) \mathrm{c} 1 \mathrm{cc}(\mathrm{NCc} 2 \operatorname{cc}(\mathrm{O}) \operatorname{ccc} 2 \mathrm{O}) \operatorname{ccc} 1 \mathrm{O}) \mathrm{Cc} 1 \mathrm{ccccc} 1$ & 360 & $*$ \\
\hline 2925 & $\mathrm{CN}(\mathrm{C}) \mathrm{CCC}(=\mathrm{O}) \mathrm{c} 1 \mathrm{ccc}(\mathrm{OCc} 2 \mathrm{ccccc} 2) \mathrm{c}(\mathrm{O}) \mathrm{c} 1 . \mathrm{Cl}$ & 360 & $*$ \\
\hline 2926 & $\mathrm{FC}(\mathrm{F})(\mathrm{F}) \mathrm{c} 1 \mathrm{cccc}(\mathrm{Nc} 2[\mathrm{nH}] \mathrm{cnc} 3 \mathrm{nc} 4 \mathrm{c}(\mathrm{c} 2-3) \mathrm{CCCC} 4) \mathrm{c} 1$ & 360 & $*$ \\
\hline
\end{tabular}




\begin{tabular}{|c|c|c|c|}
\hline 2927 & $\mathrm{Cn} 1 \mathrm{ncc} 2 \mathrm{cc}(\mathrm{Nc} 3 \mathrm{ncnn} 4 \mathrm{ccc}(\mathrm{CN} 5 \mathrm{CCC}(\mathrm{N}) \mathrm{CC} 5) \mathrm{c} 34) \operatorname{ccc} 21$ & 360 & * \\
\hline 2928 & $\mathrm{~N} \# \mathrm{CC} 1=\mathrm{C}(\mathrm{c} 2 \mathrm{ccc}(\mathrm{Cl}) \mathrm{cc} 2) \mathrm{Nc} 2 \mathrm{c}(\mathrm{c}(-\mathrm{c} 3 \operatorname{ccc} 3) \mathrm{nn} 2-\mathrm{c} 2 \mathrm{cccc} 2) \mathrm{C} 12 \mathrm{C}(=\mathrm{O}) \mathrm{Nc} 1 \mathrm{ccccc} 12$ & 360 & $*$ \\
\hline 2929 & $\mathrm{COc} 1 \mathrm{cc} 2 \mathrm{ncc}(\mathrm{CHN}) \mathrm{c}(\mathrm{Nc} 3 \mathrm{cccc} 3 \mathrm{C}(\mathrm{C}) \mathrm{C}) \mathrm{c} 2 \mathrm{cc} 1 \mathrm{OC}$ & 360 & $*$ \\
\hline 2930 & $\operatorname{COc} 1 \operatorname{ccc}(\mathrm{C}(=\mathrm{O}) \mathrm{Nc} 2 \operatorname{ccc}(\mathrm{Cl}) \mathrm{c} 2) \mathrm{c}(\mathrm{O}) \mathrm{c} 1$ & 360 & $*$ \\
\hline 2931 & $\mathrm{CCOc} 1 \mathrm{ccc}(\mathrm{NC}(=\mathrm{O}) / \mathrm{C}=\mathrm{C} / \mathrm{c} 2 \mathrm{ccc} 3 \mathrm{c}(\mathrm{c} 2) \mathrm{OCCCCO} 3) \mathrm{cc} 1$ & 360 & $*$ \\
\hline 2932 & $\mathrm{CCOc} 1 \mathrm{cc} 2 \mathrm{ncc}(\mathrm{C \# N}) \mathrm{c}(\mathrm{Nc} 3 \mathrm{cc}(\mathrm{Cl}) \mathrm{c}(\mathrm{OCc} 4 \mathrm{cccc}(\mathrm{F}) \mathrm{c} 4) \mathrm{c}(\mathrm{Cl}) \mathrm{c} 3) \mathrm{c} 2 \mathrm{cc} 1 \mathrm{NC}(=\mathrm{O}) / \mathrm{C}=\mathrm{C} / \mathrm{CN}(\mathrm{C}) \mathrm{C}$ & 362 & 6.44 \\
\hline 2933 & $\mathrm{CCC}(=\mathrm{O}) \mathrm{N} 1 \mathrm{CC}[\mathrm{C} @ \mathrm{H}](\mathrm{N} 2 \mathrm{C}(=\mathrm{O}) \mathrm{N}(\mathrm{c} 3 \mathrm{cc}(\mathrm{OC}) \mathrm{ccc} 3 \mathrm{~F}) \mathrm{Cc} 3 \mathrm{cnc}(\mathrm{Nc} 4 \mathrm{ccc}(\mathrm{N} 5 \mathrm{CCN}(\mathrm{C}) \mathrm{CC} 5) \mathrm{c}(\mathrm{C}) \mathrm{c} 4) \mathrm{nc} 32) \mathrm{C} 1$ & 362 & 6.44 \\
\hline 2934 & $\operatorname{COc} 1 \mathrm{cc}(\mathrm{NC}(=\mathrm{O}) \mathrm{Nc} 2 \mathrm{nccs} 2) \operatorname{cc}(-\mathrm{c} 2 \mathrm{cn}(\mathrm{C}) \mathrm{cn} 2) \mathrm{c} 1 \mathrm{OC}$ & 362 & $*$ \\
\hline 2935 & $\mathrm{CCOC}(\mathrm{C}) \mathrm{Oc} 1 \mathrm{cc} 2 \mathrm{ncnc}(\mathrm{Nc} 3 \operatorname{ccc}(\mathrm{C}) \mathrm{c}([\mathrm{N}+](=\mathrm{O})[\mathrm{O}-]) \mathrm{c} 3) \mathrm{c} 2 \mathrm{c} 2 \mathrm{c} 1 \mathrm{OCCO} 2$ & 363.3 & $*$ \\
\hline 2936 & $\mathrm{O}=\mathrm{C}(\mathrm{Nc} 1 \mathrm{cc} 2 \mathrm{c}(\mathrm{Nc} 3 \mathrm{ccc}(\mathrm{F}) \mathrm{c}(\mathrm{Cl}) \mathrm{c} 3) n \mathrm{ncn} 2 \mathrm{cc} 1 \mathrm{OCCCN} 1 \mathrm{CCOCC} 1) \mathrm{c} 1 \mathrm{cc}(\mathrm{F}) \mathrm{cc}(\mathrm{F}) \mathrm{c} 1 \mathrm{~F}$ & 365 & 6.44 \\
\hline 2937 & $\mathrm{CCC}(=\mathrm{O}) \mathrm{N} 1 \mathrm{CC}[\mathrm{C} @ \mathrm{H}](\mathrm{N} 2 \mathrm{C}(=\mathrm{O}) \mathrm{N}(\mathrm{c} 3 \operatorname{cccc}(\mathrm{C}) \mathrm{c} 3) \mathrm{Cc} 3 \mathrm{cnc}(\mathrm{Nc} 4 \mathrm{ccc}(\mathrm{N} 5 \mathrm{CCN}(\mathrm{C}) \mathrm{CC} 5) \mathrm{c}(\mathrm{C}) \mathrm{c} 4) \mathrm{nc} 32) \mathrm{C} 1$ & 365 & 6.44 \\
\hline 2938 & $\mathrm{CCC}(=\mathrm{O}) \mathrm{N} 1 \mathrm{CC}[\mathrm{C} @ \mathrm{H}](\mathrm{N} 2 \mathrm{C}(=\mathrm{O}) \mathrm{N}(\mathrm{c} 3 \mathrm{cc}(\mathrm{OC}) \mathrm{ccc} 3 \mathrm{~F}) \mathrm{Cc} 3 \mathrm{cnc}(\mathrm{Nc} 4 \mathrm{ccc}(\mathrm{N} 5 \mathrm{CCN}(\mathrm{C}) \mathrm{CC} 5) \mathrm{c}(\mathrm{C}(\mathrm{C}) \mathrm{C}) \mathrm{c} 4) \mathrm{nc} 32) \mathrm{C} 1$ & 365 & 6.44 \\
\hline 2939 & $\mathrm{CCN}(\mathrm{CC}) \mathrm{CCNC}(=\mathrm{O}) \mathrm{Nc} 1 \mathrm{cc} 2 \mathrm{c}(\mathrm{Nc} 3 \mathrm{ccc}(\mathrm{F}) \mathrm{c}(\mathrm{Cl}) \mathrm{c} 3) \mathrm{ncnc} 2 \mathrm{cc} 1 \mathrm{O}[\mathrm{C} @ \mathrm{H}] 1 \mathrm{CCOC} 1$ & 365 & $*$ \\
\hline 2940 & COc1ccc(N2Cc3enc(Nc4cccc4)nc3N([C@H]3CC[C@H](O)C3)C2=O)cc1 & 365 & $*$ \\
\hline 2941 & $\mathrm{CCN}(\mathrm{CC}) \mathrm{CCNN}(\mathrm{NCN}(\mathrm{CC}) \mathrm{CC}) \mathrm{C}(=\mathrm{O}) \mathrm{Nc} 1 \mathrm{cc} 2 \mathrm{c}(\mathrm{Nc} 3 \mathrm{ccc}(\mathrm{F}) \mathrm{c}(\mathrm{Cl}) \mathrm{c} 3) \mathrm{ncnc} 2 \mathrm{cc} 1 \mathrm{O}[\mathrm{C} @ \mathrm{H}] 1 \mathrm{CCOC} 1$ & 365 & $*$ \\
\hline 2942 & $\mathrm{CC} 1 \mathrm{CCC}(\mathrm{n} 2 \mathrm{nc}(-\mathrm{c} 3 \mathrm{ccc}(\mathrm{F}) \mathrm{c}(\mathrm{O}) \mathrm{c} 3) \mathrm{c} 3 \mathrm{c}(\mathrm{N}) \mathrm{ncnc} 32) \mathrm{C} 1$ & 366 & $*$ \\
\hline 2943 & $\operatorname{CCOC}(=\mathrm{O}) \mathrm{CNc} 1 \mathrm{cccc}(\mathrm{Oc} 2 \mathrm{cc}(\mathrm{Nc} 3 \operatorname{ccc}(\mathrm{OCc} 4 \operatorname{ccc}(\mathrm{F}) \mathrm{c} 4) \mathrm{c}(\mathrm{Cl}) \mathrm{c} 3) \mathrm{ncn} 2) \mathrm{c} 1$ & 370 & 6.43 \\
\hline 2944 & $\mathrm{Cc} 1 \mathrm{ccc}(\mathrm{C} 2=\mathrm{NN}(\mathrm{c} 3 \mathrm{nc}(-\mathrm{c} 4 \mathrm{ccc}(\mathrm{Cl}) \mathrm{cc} 4) \operatorname{cs} 3) \mathrm{C}(\mathrm{c} 3 \mathrm{ccc}(\mathrm{Br}) \mathrm{cc} 3) \mathrm{C} 2) \mathrm{cc} 1 \mathrm{C}$ & 370 & 6.43 \\
\hline 2945 & $\mathrm{COc} 1 \mathrm{cc} 2 \mathrm{nccc}(\mathrm{Nc} 3 \mathrm{cccc}(\mathrm{Br}) \mathrm{c} 3) \mathrm{c} 2 \mathrm{cc} 1 \mathrm{OC}$ & 370 & $*$ \\
\hline 2946 & $\mathrm{Nc} 1 \mathrm{cnc}(\mathrm{C} \# \mathrm{Cc} 2 \mathrm{cc} 3 \mathrm{c}(\mathrm{Nc} 4 \mathrm{ccc}(\mathrm{OCc} 5 \mathrm{cccc}(\mathrm{F}) \mathrm{c} 5) \mathrm{c}(\mathrm{Cl}) \mathrm{c} 4) \mathrm{ncnc} 3 \mathrm{~s} 2) \mathrm{cn} 1$ & 372 & $*$ \\
\hline 2947 & $\mathrm{CCC}(=\mathrm{O}) \mathrm{N} 1 \mathrm{CC}[\mathrm{C} @ \mathrm{H}](\mathrm{N} 2 \mathrm{C}(=\mathrm{O}) \mathrm{N}(\mathrm{c} 3 \mathrm{cc}(\mathrm{OC}) \mathrm{ccc} 3 \mathrm{Cl}) \mathrm{Cc} 3 \mathrm{cnc}(\mathrm{Nc} 4 \mathrm{ccc}(\mathrm{N} 5 \mathrm{CCN}(\mathrm{C}) \mathrm{CC} 5) \mathrm{c}(\mathrm{C}) \mathrm{c} 4) \mathrm{nc} 32) \mathrm{C} 1$ & 373 & 6.43 \\
\hline 2948 & $\mathrm{C}=\mathrm{CC}(=\mathrm{O}) \mathrm{Nc} 1 \mathrm{ccc}(-\mathrm{n} 2 \mathrm{c}(=\mathrm{O}) \mathrm{cnc} 3 \mathrm{cnc}(\mathrm{Nc} 4 \mathrm{ccc}(\mathrm{Cl}) \mathrm{cc} 4) \mathrm{nc} 32) \mathrm{cc} 1$ & 373.5 & 6.43 \\
\hline 2949 & $\mathrm{CN}(\mathrm{C}) \mathrm{CCOc} 1 \mathrm{ccc}(\mathrm{Nc} 2 \mathrm{ncnc} 3 \mathrm{cc}(\mathrm{OCCCN} 4 \mathrm{CCOCC} 4) \mathrm{c}(\mathrm{NC}(=\mathrm{O}) \mathrm{c} 4 \mathrm{cc}([\mathrm{N}+](=\mathrm{O})[\mathrm{O}-]) \operatorname{ccc} 4 \mathrm{~F}) \mathrm{cc} 23) \mathrm{cc} 1 \mathrm{Cl}$ & 374 & 6.43 \\
\hline 2950 & $\mathrm{C}=\mathrm{CC}(=\mathrm{O}) \mathrm{Nc} 1 \mathrm{cnc} 2 \mathrm{ncc}(\mathrm{C \# N}) \mathrm{c}(\mathrm{Nc} 3 \mathrm{cccc}(\mathrm{Br}) \mathrm{c} 3) \mathrm{c} 2 \mathrm{c} 1$ & 374.8 & 6.43 \\
\hline 2951 & $\mathrm{CCC}(=\mathrm{O}) \mathrm{N} 1 \mathrm{CC}[\mathrm{C} @ \mathrm{H}](\mathrm{N} 2 \mathrm{C}(=\mathrm{O}) \mathrm{N}(\mathrm{c} 3 \mathrm{ccc}(\mathrm{C}) \mathrm{cc} 3) \mathrm{Cc} 3 \mathrm{cnc}(\mathrm{Nc} 4 \mathrm{ccc}(\mathrm{N} 5 \mathrm{CCN}(\mathrm{C}) \mathrm{CC} 5) \mathrm{c}(\mathrm{C}) \mathrm{c} 4) \mathrm{nc} 32) \mathrm{C} 1$ & 377 & 6.42 \\
\hline 2952 & $\mathrm{O}=\mathrm{C}(\mathrm{Nc} 1 \mathrm{ccc} 2 \mathrm{ncnc}(\mathrm{Nc} 3 \mathrm{ccc}(\mathrm{Cl}) \mathrm{c} 3) \mathrm{c} 2 \mathrm{c} 1) \mathrm{C} 1 \mathrm{CCC} 2(\mathrm{CC} 1) \mathrm{OOC} 1(\mathrm{OO} 2) \mathrm{C} 2 \mathrm{CC} 3 \mathrm{CC}(\mathrm{C} 2) \mathrm{CC} 1 \mathrm{C} 3$ & 379.7 & $*$ \\
\hline 2953 & $\mathrm{CCOc} 1 \mathrm{cc} 2 \mathrm{ncc}(\mathrm{C \# N}) \mathrm{c}(\mathrm{Nc} 3 \operatorname{ccc}(\mathrm{O}[\mathrm{C} @ @ \mathrm{H}] 4 \mathrm{CCc} 5 \mathrm{cccc} 54) \mathrm{c}(\mathrm{Cl}) \mathrm{c} 3) \mathrm{c} 2 \mathrm{cc} 1 \mathrm{NC}(=\mathrm{O}) / \mathrm{C}=\mathrm{C} / \mathrm{CN}(\mathrm{C}) \mathrm{C}$ & 380 & 6.42 \\
\hline 2954 & $\mathrm{COc} 1 \mathrm{cc} 2 \mathrm{ncnc}(\mathrm{Nc} 3 \mathrm{ccc}(\mathrm{F}) \mathrm{c}(\mathrm{Cl}) \mathrm{c} 3) \mathrm{c} 2 \mathrm{cc} 1 \mathrm{OC}$ & 380 & $*$ \\
\hline 2955 & $\mathrm{COc} 1 \mathrm{ccc}(\mathrm{Nc} 2 \mathrm{ncnc} 3 \mathrm{cc} 4 \mathrm{oc}(=\mathrm{O}) \mathrm{n}(\mathrm{CCCN} 5 \mathrm{CCOCC} 5) \mathrm{c} 4 \mathrm{cc} 23) \mathrm{cc} 1$ & 380 & $*$ \\
\hline 2956 & $\mathrm{C} \# \mathrm{Cc} 1 \mathrm{cccc}(\mathrm{Nc} 2 \mathrm{ncnc} 3 \mathrm{cc} 4 \mathrm{oc}(=\mathrm{O}) \mathrm{n}(\mathrm{CCCN} 5 \mathrm{CCOCC} 5) \mathrm{c} 4 \mathrm{cc} 23) \mathrm{c} 1$ & 380 & $*$ \\
\hline 2957 & $\mathrm{Cc} 1 \mathrm{cccc}(\mathrm{Nc} 2 \mathrm{ncnc} 3 \mathrm{cnc}(\mathrm{Cl}) \mathrm{nc} 23) \mathrm{c} 1$ & 380 & $*$ \\
\hline 2958 & $\mathrm{CC}(=\mathrm{O}) \mathrm{NC} 1 \mathrm{CCN}(\mathrm{Cc} 2 \operatorname{ccn} 3 \mathrm{ncnc}(\mathrm{Nc} 4 \mathrm{ccc} 5 \mathrm{c}(\operatorname{cnn} 5 \mathrm{Cc} 5 \operatorname{ccc}(\mathrm{F}) \mathrm{c} 5) \mathrm{c} 4) \mathrm{c} 23) \mathrm{CC} 1$ & 380 & $*$ \\
\hline 2959 & $\mathrm{Cn} 1 \mathrm{c}(=\mathrm{O}) \mathrm{c}(-\mathrm{c} 2 \mathrm{c}(\mathrm{Cl}) \mathrm{cccc} 2 \mathrm{Cl}) \mathrm{cc} 2 \mathrm{cnc}(\mathrm{Nc} 3 \mathrm{ccc}(\mathrm{F}) \mathrm{cc} 3) \mathrm{nc} 21$ & 380 & $*$ \\
\hline 2960 & $\mathrm{CCN}(\mathrm{CC}) \mathrm{CCOc} 1 \mathrm{ccc}(\mathrm{Nc} 2 \mathrm{cc}(\mathrm{NC}(=\mathrm{O}) \mathrm{Nc} 3 \mathrm{c}(\mathrm{Cl}) \mathrm{cccc} 3 \mathrm{Cl}) \mathrm{ncn} 2) \mathrm{cc} 1$ & 380 & $*$ \\
\hline 2961 & $\mathrm{CC}(\mathrm{C}) \mathrm{n} 1 \mathrm{nc}(-\mathrm{c} 2 \mathrm{cnc} 3[\mathrm{nH}] \mathrm{ccc} 3 \mathrm{c} 2) \mathrm{c} 2 \mathrm{c}(\mathrm{N}) \mathrm{ncnc} 21$ & 380 & $*$ \\
\hline 2962 & $\mathrm{O}[\mathrm{C} @ \mathrm{H}] 1 \mathrm{CC}[\mathrm{C} @ \mathrm{H}](\mathrm{Nc} 2 \mathrm{ncc} 3 \mathrm{nc}(\mathrm{Nc} 4 \mathrm{c}(\mathrm{F}) \mathrm{cc}(\mathrm{F}) \mathrm{cc} 4 \mathrm{~F}) \mathrm{n}([\mathrm{C} @ \mathrm{H}] 4 \mathrm{CCOC} 4) \mathrm{c} 3 \mathrm{n} 2) \mathrm{CC} 1$ & 380 & $*$ \\
\hline 2963 & $\mathrm{CCC}(=\mathrm{O}) \mathrm{N} 1 \mathrm{CC}[\mathrm{C} @ \mathrm{H}](\mathrm{N} 2 \mathrm{C}(=\mathrm{O}) \mathrm{N}(\mathrm{c} 3 \mathrm{ccc}(\mathrm{Cl}) \mathrm{cc} 3) \mathrm{Cc} 3 \mathrm{cnc}(\mathrm{Nc} 4 \mathrm{ccc}(\mathrm{N} 5 \mathrm{CCN}(\mathrm{C}) \mathrm{CC} 5) \mathrm{c}(\mathrm{C}) \mathrm{c} 4) \mathrm{nc} 32) \mathrm{C} 1$ & 383 & 6.42 \\
\hline 2964 & $\mathrm{CCC}(=\mathrm{O}) \mathrm{Nc} 1 \mathrm{cc} 2 \mathrm{c}(\mathrm{Nc} 3 \mathrm{ccc}(\mathrm{NCc} 4 \mathrm{ccccc} 4) \mathrm{cc} 3) \mathrm{ncnc} 2 \mathrm{cc} 1 \mathrm{OC}$ & 383 & * \\
\hline 2965 & $\mathrm{Nc} 1 \mathrm{nc}(\mathrm{Nc} 2 \mathrm{cccc}(\mathrm{Br}) \mathrm{c} 2) \mathrm{c} 2 \mathrm{cc}[\mathrm{nH}] \mathrm{c} 2 \mathrm{n} 1$ & 383.7 & $*$ \\
\hline 2966 & $\mathrm{C}=\mathrm{CC}(=\mathrm{O}) \mathrm{Nc} 1 \mathrm{cccc}(\mathrm{Nc} 2 \mathrm{nc}(\mathrm{Nc} 3 \operatorname{ccc}(/ \mathrm{C}=\mathrm{C} / \mathrm{c} 4 \mathrm{ccc}(\mathrm{C}) \mathrm{cc} 4 \mathrm{C}) \mathrm{cc} 3) \mathrm{ncc} 2 \mathrm{~F}) \mathrm{c} 1$ & 386.7 & $*$ \\
\hline 2967 & $\mathrm{C}=\mathrm{CC}(=\mathrm{O}) \mathrm{Nc} 1 \mathrm{cc}(\mathrm{Nc} 2 \mathrm{n}[\mathrm{nH}] \mathrm{c} 3 \mathrm{cc}(-\mathrm{c} 4 \mathrm{ccc}(\mathrm{N}(\mathrm{C}) \mathrm{C}) \mathrm{cc} 4) \operatorname{ccc} 23) \mathrm{c}(\mathrm{OC}) \mathrm{cc} 1 \mathrm{~N}(\mathrm{C}) \mathrm{CCN}(\mathrm{C}) \mathrm{C}$ & 387 & $*$ \\
\hline 2968 & $\mathrm{COCCOc} 1 \mathrm{cc} 2 \mathrm{ncnc}(\mathrm{Nc} 3 \mathrm{ccc}(\mathrm{F}) \mathrm{c}(\mathrm{CHN}) \mathrm{c} 3) \mathrm{c} 2 \mathrm{c} 2 \mathrm{c} 1 \mathrm{OCCO} 2$ & 387.8 & $*$ \\
\hline 2969 & $\mathrm{CCC}(=\mathrm{O}) \mathrm{Nc} 1 \mathrm{cc} 2 \mathrm{c}(\mathrm{Nc} 3 \mathrm{ccc}(\mathrm{Cc} 4 \mathrm{ccncc} 4) \mathrm{cc} 3) \mathrm{ncnc} 2 \mathrm{cc} 1 \mathrm{OC}$ & 388 & * \\
\hline
\end{tabular}




\begin{tabular}{|c|c|c|c|}
\hline 2970 & $\operatorname{Cn} 1 n c(-c 2 c c c 3 \operatorname{ccc} c 3 c 2) c 2 c(N) n c n c 21$ & 388 & $*$ \\
\hline 2971 & $\mathrm{C}=\mathrm{CC}(=\mathrm{O}) \mathrm{Nc} 1 \mathrm{cccc}(\mathrm{Nc} 2 \mathrm{nc}(\mathrm{Nc} 3 \operatorname{ccc}(/ \mathrm{C}=\mathrm{C} / \mathrm{c} 4 \mathrm{cc}(\mathrm{Cl}) \mathrm{cc}(\mathrm{Cl}) \mathrm{c} 4) \mathrm{cc} 3) \mathrm{ncc} 2 \mathrm{~F}) \mathrm{c} 1$ & 388.1 & $*$ \\
\hline 2972 & $\mathrm{C}=\mathrm{CC}(=\mathrm{O}) \mathrm{Nc} 1 \mathrm{ccc}(\mathrm{Oc} 2 \mathrm{nc}(\mathrm{Nc} 3 \mathrm{ccc}(\mathrm{N} 4 \mathrm{CCCN}(\mathrm{C}(\mathrm{C})=\mathrm{O}) \mathrm{CC} 4) \operatorname{cc} 3 \mathrm{OC}) \mathrm{ncc} 2 \mathrm{SC}) \mathrm{c} 1$ & 389.4 & $*$ \\
\hline 2973 & $\operatorname{Cc} \operatorname{lncc}([\mathrm{N}+](=\mathrm{O})[\mathrm{O}-]) \mathrm{n} 1 \mathrm{CC}(=\mathrm{O}) \mathrm{NS}(=\mathrm{O})(=\mathrm{O}) \mathrm{c} 1 \mathrm{ccc}(\mathrm{F}) \mathrm{cc} 1$ & 390 & 6.41 \\
\hline 2974 & $\begin{array}{c}\mathrm{C \# C} 1 \mathrm{cccc}(\mathrm{Nc} 2 \mathrm{ncnc} 3 \mathrm{cc}(\mathrm{OCCOC}(=\mathrm{O}) \mathrm{C}(\mathrm{C}) \mathrm{c} 4 \mathrm{ccc} 5 \mathrm{cc}(\mathrm{OC}) \operatorname{ccc} 5 \mathrm{c} 4) \mathrm{c}(\mathrm{OCCOC}(=\mathrm{O}) \mathrm{C}(\mathrm{C}) \mathrm{c} 4 \mathrm{ccc} 5 \mathrm{cc}(\mathrm{OC}) \mathrm{ccc} 5 \mathrm{c} 4) \mathrm{cc} 23) \\
\mathrm{c} 1\end{array}$ & 390 & 6.41 \\
\hline 2975 & $\mathrm{Cc} 1 \mathrm{ccc}(\mathrm{Oc} 2 \mathrm{ccc}(\mathrm{Nc} 3 \mathrm{ncnc} 4 \mathrm{cc}(\mathrm{OCCCN} 5 \mathrm{CCOCC} 5) \mathrm{c}(\mathrm{NC}(=\mathrm{O}) \mathrm{c} 5 \mathrm{cc}([\mathrm{N}+](=\mathrm{O})[\mathrm{O}-]) \operatorname{ccc} 5 \mathrm{~F}) \mathrm{cc} 34) \operatorname{cc} 2 \mathrm{Cl}) \mathrm{cn} 1$ & 390 & 6.41 \\
\hline 2976 & $\mathrm{COc} 1 \mathrm{cc} 2 \mathrm{ncnc}(\mathrm{NC} 3 \mathrm{CC} 3 \mathrm{c} 3 \mathrm{ccccc} 3) \mathrm{c} 2 \mathrm{cc} 1 \mathrm{O}$ & 390 & $*$ \\
\hline 2977 & $\mathrm{Cc} 1 \mathrm{cc}(\mathrm{Nc} 2 \mathrm{ncc} 3 \mathrm{cc}(-\mathrm{c} 4 \mathrm{c}(\mathrm{Cl}) \operatorname{ccc} 4 \mathrm{Cl}) \mathrm{c}(=\mathrm{O}) \mathrm{n}(\mathrm{C}) \mathrm{c} 3 \mathrm{n} 2) \operatorname{ccc} 1 \mathrm{~F}$ & 390 & $*$ \\
\hline 2978 & $\mathrm{CC}(\mathrm{C})(\mathrm{C}) \mathrm{OC}(=\mathrm{O}) \mathrm{n} 1 \mathrm{ccc} 2 \mathrm{cc}(-\mathrm{c} 3 \mathrm{nn}(\mathrm{C} 4 \mathrm{CCCC} 4) \mathrm{c} 4 \mathrm{ncnc}(\mathrm{N}) \mathrm{c} 34) \operatorname{ccc} 21$ & 391 & $*$ \\
\hline 2979 & OC[C@@H](Nc1ncnc2oc(-c3ecccc3)c(-c3ccccc3)c12)c1 ccccc1 & 393 & $*$ \\
\hline 2980 & $\mathrm{CN} 1 \mathrm{CCN}(\mathrm{c} 2 \mathrm{ccc}(\mathrm{Nc} 3 \mathrm{ncc}(\mathrm{Br}) \mathrm{c}(\mathrm{Nc} 4 \mathrm{ccc} 5[\mathrm{nH}] \mathrm{ncc} 5 \mathrm{c} 4) \mathrm{n} 3) \mathrm{cc} 2) \mathrm{CC} 1$ & 393 & $*$ \\
\hline 2981 & $\mathrm{CC} / \mathrm{C}=\mathrm{C} \backslash \mathrm{C}(=\mathrm{O}) \mathrm{Nc} 1 \mathrm{cccc}(\mathrm{Nc} 2 \mathrm{ncnc} 3 \mathrm{cc}(\mathrm{OC}) \mathrm{c}(\mathrm{OCCCN} 4 \mathrm{CCOCC} 4) \mathrm{cc} 23) \mathrm{c} 1$ & 393.9 & $*$ \\
\hline 2982 & $\mathrm{C}=\mathrm{CC}(=\mathrm{O}) \mathrm{Nc} 1 \mathrm{ccc}(-\mathrm{n} 2 \mathrm{c}(=\mathrm{O}) \mathrm{cnc} 3 \mathrm{cnc}(\mathrm{Nc} 4 \mathrm{ccc}(\mathrm{N} 5 \mathrm{CCN}(\mathrm{C}) \mathrm{CC} 5) \mathrm{cc} 4 \mathrm{OC}) \mathrm{nc} 32) \mathrm{cc} 1$ & 395 & 6.40 \\
\hline 2983 & c1 ccc(-c2c(-c3ecc(OCCN4CCCC4)cc3)oc3ncne(NCCN4CCNCC4)c23)cc1 & 397 & $*$ \\
\hline 2984 & $\operatorname{COc} 1 \mathrm{cc}(/ \mathrm{C}=\mathrm{C}(\backslash \mathrm{C} \# \mathrm{~N}) \mathrm{C}(\mathrm{N})=\mathrm{O}) \operatorname{cc}(\mathrm{CSc} 2 \operatorname{cccc} 2) \mathrm{c} 1 \mathrm{O}$ & 398.11 & $*$ \\
\hline 2985 & $\mathrm{COc} 1 \mathrm{cc}(/ \mathrm{C}=\mathrm{C} 2 \backslash \mathrm{CCC} / \mathrm{C}(=\mathrm{C} \backslash \mathrm{c} 3 \mathrm{ccc}(\mathrm{O}) \mathrm{c}(\mathrm{O}) \mathrm{c} 3) \mathrm{C} 2=\mathrm{O}) \mathrm{cc}(\mathrm{OC}) \mathrm{c} 1$ & 400 & 6.38 \\
\hline 2986 & $\mathrm{COc} 1 \mathrm{cc} 2 \mathrm{ncc}(\mathrm{C \# N}) \mathrm{c}(\mathrm{Nc} 3 \operatorname{ccc}(\mathrm{NCc} 4 \mathrm{ccccc} 4) \mathrm{c}(\mathrm{Cl}) \mathrm{c} 3) \mathrm{c} 2 \mathrm{cc} 1 \mathrm{NC}(=\mathrm{O}) / \mathrm{C}=\mathrm{C} / \mathrm{CN}(\mathrm{C}) \mathrm{C}$ & 400 & 6.40 \\
\hline 2987 & $\mathrm{CCOc} 1 \mathrm{cc} 2 \mathrm{ncc}(\mathrm{C \# N}) \mathrm{c}(\mathrm{Nc} 3 \operatorname{ccc}(\mathrm{O}[\mathrm{C} @ \mathrm{H}] 4 \mathrm{CCc} 5 \mathrm{ccccc} 54) \mathrm{c}(\mathrm{Cl}) \mathrm{c} 3) \mathrm{c} 2 \mathrm{cc} 1 \mathrm{NC}(=\mathrm{O}) / \mathrm{C}=\mathrm{C} / \mathrm{CN}(\mathrm{C}) \mathrm{C}$ & 400 & 6.40 \\
\hline 2988 & Cc1cc(Oc2ccc(Nc3ncnc4cc(C\#C[C@@H]5C[C@@H](OC(=O)N6CCOCC6)CN5)sc34)cc2Cl)no1 & 400 & 6.40 \\
\hline 2989 & $\mathrm{O}=\mathrm{C}(\mathrm{OCCCCc} 1 \mathrm{cccc} 1) \mathrm{c} 1 \mathrm{cc}(\mathrm{NCc} 2 \mathrm{cc}(\mathrm{O}) \operatorname{ccc} 2 \mathrm{O}) \mathrm{ccc} 1 \mathrm{O}$ & 400 & $*$ \\
\hline 2990 & $\mathrm{CC}(\mathrm{CCOC}(=\mathrm{O}) \mathrm{c} 1 \mathrm{cc}(\mathrm{NCc} 2 \mathrm{cc}(\mathrm{O}) \mathrm{ccc} 2 \mathrm{O}) \mathrm{ccc} 1 \mathrm{O}) \mathrm{c} 1 \mathrm{ccccc} 1$ & 400 & $*$ \\
\hline 2991 & $\operatorname{CCOC}(=\mathrm{O}) \operatorname{c} 1 \operatorname{cc}(\mathrm{NCc} 2 \operatorname{cc}(\mathrm{O}) \operatorname{ccc} 2 \mathrm{O}) \operatorname{ccc} 1 \mathrm{O}$ & 400 & $*$ \\
\hline 2992 & $\mathrm{O}=\mathrm{C}(\mathrm{NO}) \mathrm{c} 1 \mathrm{cc}(\mathrm{NCc} 2 \mathrm{cc}(\mathrm{O}) \mathrm{ccc} 2 \mathrm{O}) \mathrm{ccc} 1 \mathrm{O}$ & 400 & $*$ \\
\hline 2993 & $\mathrm{CNC}(=\mathrm{O}) \operatorname{c} 1 \operatorname{ccc}(\mathrm{S}(=\mathrm{O})(=\mathrm{O}) \mathrm{Oc} 2 \operatorname{ccc}(/ \mathrm{C}=\mathrm{C} /[\mathrm{N}+](=\mathrm{O})[\mathrm{O}-]) \operatorname{cc} 2) \operatorname{cc} 1$ & 400 & $*$ \\
\hline 2994 & $\mathrm{COc} 1 \mathrm{cc} 2 \mathrm{c}(\mathrm{Nc} 3 \mathrm{ccc}(\mathrm{Cl}) \mathrm{cc} 3 \mathrm{~F}) \mathrm{ncnc} 2 \mathrm{cc} 1 \mathrm{OCCN} 1 \mathrm{CCOCC} 1$ & 400 & $*$ \\
\hline 2995 & COc1cc2c(Nc3ecc(Br)cc3F)ncnc2cc1OCCn1 cenn 1 & 400 & $*$ \\
\hline 2996 & $\mathrm{NC}(=\mathrm{O}) \mathrm{CN} 1 \mathrm{CCC}(\mathrm{n} 2 \mathrm{cc}(-\mathrm{c} 3 \operatorname{cccc}(\mathrm{O}) \mathrm{c} 3) \mathrm{c} 3 \mathrm{c}(\mathrm{N}) \mathrm{ncnc} 32) \mathrm{C} 1$ & 400 & $*$ \\
\hline 2997 & C[C@@H](c1cccc(F)c1)n1ncc2cc(Nc3ncnn4ccc(COC[C@@H]5CNCCO5)c34)ccc21 & 400 & $*$ \\
\hline 2998 & $\begin{array}{c}\mathrm{Cc} 1 \mathrm{nc}(\mathrm{Nc} 2 \mathrm{ncc}(\mathrm{C}(=\mathrm{O}) \mathrm{Nc} 3 \mathrm{c}(\mathrm{C}) \mathrm{cccc} 3 \mathrm{Cl}) \mathrm{s} 2) \mathrm{cc}(\mathrm{N} 2 \mathrm{CCN}(\mathrm{CCOC}(=\mathrm{O}) \mathrm{CCC}(=\mathrm{O}) \mathrm{Nc} 3 \operatorname{ccc} 4 \mathrm{ncnc}(\mathrm{Nc} 5 \mathrm{ccc}(\mathrm{Cl}) \mathrm{c} 5) \mathrm{c} 4 \mathrm{c} 3) \mathrm{C} \\
\mathrm{C} 2) \mathrm{n} 1\end{array}$ & 400 & $*$ \\
\hline 2999 & $\operatorname{COc} 1 \operatorname{ccc}(\mathrm{NC}(=\mathrm{O}) / \mathrm{C}=\mathrm{C} / \mathrm{CN}(\mathrm{C}) \mathrm{C}) \mathrm{cc} 1 \mathrm{Nc} 1 \mathrm{ncc}(\mathrm{Cl}) \mathrm{c}(\mathrm{Nc} 2 \mathrm{ccc}(\mathrm{Cl}) \mathrm{c}(\mathrm{Cl}) \mathrm{c} 2) \mathrm{n} 1$ & 400 & $*$ \\
\hline 3000 & $\mathrm{CCOc} 1 \mathrm{cc} 2 \mathrm{ncc}(\mathrm{C \# N}) \mathrm{c}(\mathrm{Nc} 3 \operatorname{ccc}(\mathrm{OCc} 4 \operatorname{cccc} 4 \mathrm{~F}) \mathrm{c}(\mathrm{Cl}) \mathrm{c} 3) \mathrm{c} 2 \mathrm{cc} 1 \mathrm{NC}(=\mathrm{O}) / \mathrm{C}=\mathrm{C} / \mathrm{CN}(\mathrm{C}) \mathrm{C}$ & 401 & 6.40 \\
\hline 3001 & $\mathrm{COc} 1 \mathrm{cc} 2 \mathrm{ncnc}(\mathrm{Nc} 3 \operatorname{ccc}(\mathrm{CHCCCO}) \mathrm{c} 3) \mathrm{c} 2 \mathrm{cc} 1 \mathrm{OC}$ & 402.1 & $*$ \\
\hline 3002 & $\operatorname{COc} 1 \mathrm{cc} 2 \mathrm{ncc}(\mathrm{CHN}) \mathrm{c}(\mathrm{Nc} 3 \operatorname{ccc}(\mathrm{Sc} 4 \mathrm{ncccn} 4) \mathrm{c}(\mathrm{Cl}) \mathrm{c} 3) \mathrm{c} 2 \mathrm{cc} 1 \mathrm{NC}(=\mathrm{O}) / \mathrm{C}=\mathrm{C} / \mathrm{CN}(\mathrm{C}) \mathrm{C}$ & 403 & 6.39 \\
\hline 3003 & $\mathrm{COC}(=\mathrm{O}) / \mathrm{C}=\mathrm{C} / \mathrm{CNC}(=\mathrm{O}) \mathrm{Nc} 1 \mathrm{cc} 2 \mathrm{c}(\mathrm{Nc} 3 \mathrm{ccc}(\mathrm{F}) \mathrm{c}(\mathrm{Cl}) \mathrm{c} 3) \mathrm{ncnc} 2 \mathrm{cc} 1 \mathrm{O}[\mathrm{C} @ \mathrm{H}] 1 \mathrm{CCOC} 1$ & 404 & * \\
\hline 3004 & $\mathrm{COC}(=\mathrm{O}) / \mathrm{C}=\mathrm{C} \backslash \mathrm{CNN}(\mathrm{NC} / \mathrm{C}=\mathrm{C} \backslash \mathrm{C}(=\mathrm{O}) \mathrm{OC}) \mathrm{C}(=\mathrm{O}) \mathrm{Nc} 1 \mathrm{cc} 2 \mathrm{c}(\mathrm{Nc} 3 \mathrm{ccc}(\mathrm{F}) \mathrm{c}(\mathrm{Cl}) \mathrm{c} 3) \mathrm{ncnc} 2 \mathrm{cc} 1 \mathrm{O}[\mathrm{C} @ \mathrm{H}] 1 \mathrm{CCOC} 1$ & 404 & * \\
\hline 3005 & $\mathrm{O}=\mathrm{C}(/ \mathrm{C}=\mathrm{C} / \mathrm{CN} 1 \mathrm{CCCC} 1) \mathrm{Nc} 1 \mathrm{cc} 2 \mathrm{c}(\mathrm{Nc} 3 \mathrm{ccc}(\mathrm{Cc} 4 \mathrm{ccc} \mathrm{n} 4) \mathrm{cc} 3) \mathrm{ncnc} 2 \mathrm{cn} 1$ & 405 & * \\
\hline 3006 & $\mathrm{CN} 1 \mathrm{CCN}(\mathrm{c} 2 \mathrm{ccc}(\mathrm{Nc} 3 \mathrm{ncc}(\mathrm{Br}) \mathrm{c}(\mathrm{Nc} 4 \mathrm{ccc} 5 \mathrm{nccnc} 5 \mathrm{c} 4) \mathrm{n} 3) \mathrm{cc} 2) \mathrm{CC} 1$ & 408 & $*$ \\
\hline 3007 & $\mathrm{COC}(=\mathrm{O}) \mathrm{c} 1 \mathrm{cccc}(\mathrm{Nc} 2 \mathrm{ncnc} 3 \mathrm{ccc}(-\mathrm{c} 4 \mathrm{cnc}(\mathrm{OC}) \mathrm{c}(\mathrm{NS}(\mathrm{C})(=\mathrm{O})=\mathrm{O}) \mathrm{c} 4) \mathrm{cc} 23) \mathrm{c} 1$ & 409 & $*$ \\
\hline 3008 & $\mathrm{C}=\mathrm{CC}(=\mathrm{O}) \mathrm{Nc} 1 \mathrm{cccc}(\mathrm{Oc} 2 \mathrm{nc}(\mathrm{Nc} 3 \mathrm{ccc}(\mathrm{N} 4 \mathrm{CCN}(\mathrm{C}(=\mathrm{O}) \mathrm{C}(\mathrm{C})(\mathrm{C}) \mathrm{C}) \mathrm{CC} 4) \mathrm{cc} 3 \mathrm{OC}) \mathrm{ncc} 2 \mathrm{SC}) \mathrm{c} 1$ & 409.7 & $*$ \\
\hline 3009 & $\mathrm{NC}(=\mathrm{S}) \mathrm{N} / \mathrm{N}=\mathrm{C}(/ \mathrm{C}=\mathrm{C} / \mathrm{c} 1 \operatorname{ccc} 2 \operatorname{ccccc} 12) \mathrm{c} 1 \operatorname{ccccc} 1$ & 410 & 6.39 \\
\hline 3010 & $\mathrm{Cc} 1 \mathrm{c}(\mathrm{C}(=\mathrm{O}) \mathrm{N} 2 \mathrm{CCN}(\mathrm{C}) \mathrm{CC} 2) \mathrm{c}[\mathrm{nH}] \mathrm{c} 1 / \mathrm{C}=\mathrm{C} 1 \backslash \mathrm{C}(=\mathrm{O}) \mathrm{Nc} 2 \mathrm{ncnc}(\mathrm{Nc} 3 \mathrm{ccc}(\mathrm{F}) \mathrm{c}(\mathrm{Cl}) \mathrm{c} 3) \mathrm{c} 21$ & 410 & $*$ \\
\hline
\end{tabular}




\begin{tabular}{|c|c|c|c|}
\hline 3011 & $\mathrm{CNC}(=\mathrm{O}) \mathrm{c} 1 \mathrm{nc}(-\mathrm{c} 2 \operatorname{ccc}(\mathrm{Cl}) \mathrm{c}(\mathrm{S}(=\mathrm{O})(=\mathrm{O}) \mathrm{Nc} 3 \operatorname{cccc}(\mathrm{F}) \mathrm{c} 3 \mathrm{C}) \mathrm{c} 2) \mathrm{cnc} 1 \mathrm{~N}$ & 410 & * \\
\hline 3012 & $\mathrm{COc} 1 \mathrm{cc} 2 \mathrm{ncnc}(\mathrm{Nc} 3 \mathrm{ccc}(\mathrm{CHN}) \mathrm{c} 3) \mathrm{c} 2 \mathrm{cc} 1 \mathrm{OC}$ & 412.8 & $*$ \\
\hline 3013 & $\mathrm{CCC}(=\mathrm{O}) \mathrm{N} 1 \mathrm{CC}[\mathrm{C} @ \mathrm{H}](\mathrm{N} 2 \mathrm{C}(=\mathrm{O}) \mathrm{N}(\mathrm{c} 3 \mathrm{ccc}(\mathrm{OC}) \mathrm{c} 3 \mathrm{Cl}) \mathrm{Cc} 3 \mathrm{cnc}(\mathrm{Nc} 4 \mathrm{ccc}(\mathrm{N} 5 \mathrm{CCN}(\mathrm{C}) \mathrm{CC} 5) \mathrm{c}(\mathrm{C}) \mathrm{c} 4) \mathrm{nc} 32) \mathrm{C} 1$ & 413 & 6.38 \\
\hline 3014 & C[C@@H](Nc1ncnc2sc(Br)cc12)c1 cccs1 & 415 & $*$ \\
\hline 3015 & $\mathrm{Cc} 1 \mathrm{ccc}(\mathrm{Nc} 2 \mathrm{ncnc} 3 \mathrm{cc}(\mathrm{OC}(\mathrm{C}) \mathrm{C}) \mathrm{c} 4 \mathrm{c}(\mathrm{c} 23) \mathrm{OCCO} 4) \mathrm{cc} 1 \mathrm{C} \# \mathrm{~N}$ & 416.1 & $*$ \\
\hline 3016 & $\mathrm{CCC}(=\mathrm{O}) \mathrm{N} 1 \mathrm{CC}[\mathrm{C} @ \mathrm{H}](\mathrm{N} 2 \mathrm{C}(=\mathrm{O}) \mathrm{N}(\mathrm{c} 3 \operatorname{cccc}(\mathrm{OC}) \mathrm{c} 3) \mathrm{Cc} 3 \mathrm{cnc}(\mathrm{Nc} 4 \mathrm{ccc}(\mathrm{N} 5 \mathrm{CCN}(\mathrm{C}) \mathrm{CC} 5) \mathrm{c}(\mathrm{C}) \mathrm{c} 4) \mathrm{nc} 32) \mathrm{C} 1$ & 417 & 6.38 \\
\hline 3017 & $\mathrm{C}[\mathrm{C} @ \mathrm{H}](\mathrm{Nc} 1[\mathrm{nH}] \mathrm{cnc} 2 \mathrm{c} 3 \mathrm{ccccc} 3 \mathrm{nc} 1-2) \mathrm{c} 1 \mathrm{cccc} 1 . \mathrm{Cl}$ & 419 & $*$ \\
\hline 3018 & $\mathrm{C}[\mathrm{C} @ @ \mathrm{H}](\mathrm{Nc} 1 \mathrm{ncnc} 2 \mathrm{c} 1[\mathrm{nH}] \mathrm{c} 1 \mathrm{ccccc} 12) \mathrm{c} 1 \mathrm{ccccc} 1 . \mathrm{Cl}$ & 419 & $*$ \\
\hline 3019 & $\mathrm{Cc} 1 \mathrm{ccc} 2 \mathrm{nc}(\mathrm{Oc} 3 \operatorname{ccc}(\mathrm{F}) \mathrm{cc} 3) \mathrm{c}(/ \mathrm{C}=\mathrm{N} / \mathrm{NC}(=\mathrm{O}) \mathrm{Cn} 3 \mathrm{c}([\mathrm{N}+](=\mathrm{O})[\mathrm{O}-]) \operatorname{cnc} 3 \mathrm{C}) \mathrm{cc} 2 \mathrm{c} 1$ & 420 & 6.38 \\
\hline 3020 & $\mathrm{O}=\mathrm{C}(\mathrm{Nn} 1 \mathrm{c}(-\mathrm{c} 2 \mathrm{ccccc} 2) \mathrm{nc} 2 \mathrm{ccccc} 2 \mathrm{c} 1=\mathrm{O}) \mathrm{c} 1 \mathrm{ccc}(\mathrm{Br}) \mathrm{cc} 1$ & 420 & 6.38 \\
\hline 3021 & Oc1 ccce $(\mathrm{Nc} 2[\mathrm{nH}] \mathrm{cnc} 3 \mathrm{nc} 4 \mathrm{c}(\mathrm{c} 2-3) \mathrm{CCCC} 4) \mathrm{c} 1$ & 420 & * \\
\hline 3022 & $\mathrm{CCOc} 1 \mathrm{cc} 2 \mathrm{ncc}(\mathrm{C \# N}) \mathrm{c}(\mathrm{Nc} 3 \mathrm{cccc}(\mathrm{Br}) \mathrm{c} 3) \mathrm{c} 2 \mathrm{cc} 1 \mathrm{OCC}$ & 420 & * \\
\hline 3023 & OCCOCCn1 cec2ncnc(Nc3enc(Oc4cect $(\mathrm{C}(\mathrm{F})(\mathrm{F}) \mathrm{F}) \mathrm{c} 4) \mathrm{c}(\mathrm{Cl}) \mathrm{c} 3) \mathrm{c} 21$ & 420 & $*$ \\
\hline 3024 & $\mathrm{CCC}(=\mathrm{O}) \mathrm{N} 1 \mathrm{CC}[\mathrm{C} @ \mathrm{H}](\mathrm{N} 2 \mathrm{C}(=\mathrm{O}) \mathrm{N}(\mathrm{c} 3 \mathrm{cccc}(\mathrm{OC}) \mathrm{c} 3 \mathrm{~F}) \mathrm{Cc} 3 \mathrm{cnc}(\mathrm{Nc} 4 \mathrm{ccc}(\mathrm{N} 5 \mathrm{CCN}(\mathrm{C}) \mathrm{CC} 5) \mathrm{c}(\mathrm{C}) \mathrm{c} 4) \mathrm{nc} 32) \mathrm{C} 1$ & 421 & 6.38 \\
\hline 3025 & $\mathrm{CCC}(=\mathrm{O}) \mathrm{Nc} 1 \mathrm{cc} 2 \mathrm{c}(\mathrm{Nc} 3 \mathrm{ccc} 4 \mathrm{c}(\operatorname{ccn} 4 \mathrm{CC}(\mathrm{C}) \mathrm{C}) \mathrm{c} 3) \mathrm{ncnc} 2 \mathrm{cc} 1 \mathrm{OC}$ & 421 & $*$ \\
\hline 3026 & $\mathrm{COc} 1 \mathrm{cc} 2 \mathrm{ncc}(\mathrm{C}(=\mathrm{O}) \mathrm{NC} 3 \mathrm{CC}(\mathrm{C})(\mathrm{C}) \mathrm{N}([\mathrm{O}]) \mathrm{C}(\mathrm{C})(\mathrm{C}) \mathrm{C} 3) \mathrm{c}(\mathrm{Nc} 3 \mathrm{ccc}(\mathrm{F}) \mathrm{c}(\mathrm{Cl}) \mathrm{c} 3) \mathrm{c} 2 \mathrm{cc} 1 \mathrm{OC}$ & 422 & 6.37 \\
\hline 3027 & $\mathrm{Cc} 1 \mathrm{ncc}([\mathrm{N}+](=\mathrm{O})[\mathrm{O}-]) \mathrm{n} 1 \mathrm{C} / \mathrm{C}(=\mathrm{N} / \mathrm{NC}(=\mathrm{O}) \mathrm{c} 1 \mathrm{ccc}(\mathrm{N}) \mathrm{cc} 1) \mathrm{c} 1 \mathrm{ccc}(\mathrm{Br}) \mathrm{cc} 1$ & 430 & 6.37 \\
\hline 3028 & $\mathrm{COc} 1 \mathrm{cc} 2 \mathrm{ncnc}(\mathrm{NNc} 3 \mathrm{ccc}(\mathrm{F}) \mathrm{c}(\mathrm{Cl}) \mathrm{c} 3) \mathrm{c} 2 \mathrm{cc} 1 \mathrm{OC}$ & 430 & $*$ \\
\hline 3029 & $\mathrm{COc} 1 \mathrm{cn} 2 \mathrm{ncnc}(\mathrm{Nc} 3 \mathrm{ccc} 4 \mathrm{c}(\mathrm{cnn} 4 \mathrm{Cc} 4 \mathrm{cccc}(\mathrm{F}) \mathrm{c} 4) \mathrm{c} 3) \mathrm{c} 2 \mathrm{c} 1 \mathrm{COC}[\mathrm{C} @ @ \mathrm{H}] 1 \mathrm{CNCCO} 1$ & 430 & $*$ \\
\hline 3030 & $\mathrm{~N} \# \mathrm{CC} 1=\mathrm{C}(\mathrm{c} 2 \mathrm{ccccc} 2) \mathrm{Nc} 2 \mathrm{c}(\mathrm{c}(-\mathrm{c} 3 \operatorname{ccc} 3) \mathrm{nn} 2-\mathrm{c} 2 \mathrm{cccc} 2) \mathrm{C} 12 \mathrm{C}(=\mathrm{O}) \mathrm{Nc} 1 \mathrm{ccccc} 12$ & 430 & $*$ \\
\hline 3031 & OC[C@@H](Nc1ncnc2oc(-c3ecccc3)c(-c3ccco3)c12)c1 ccccc1 & 434 & $*$ \\
\hline 3032 & $\mathrm{O}=\mathrm{C} 1 \mathrm{COc} 2 \mathrm{cc} 3 \mathrm{ncnc}(\mathrm{Nc} 4 \mathrm{ccc}(\mathrm{F}) \mathrm{cc} 4) \mathrm{c} 3 \mathrm{cc} 2 \mathrm{~N} 1 \mathrm{CCCN} 1 \mathrm{CCOCC} 1$ & 434.1 & $*$ \\
\hline 3033 & $\mathrm{COc} 1 \mathrm{ccc}(-\mathrm{c} 2 \mathrm{nn}(\mathrm{C} 3 \mathrm{CCCC} 3) \mathrm{c} 3 \mathrm{ncnc}(\mathrm{N}) \mathrm{c} 23) \mathrm{cc} 1 \mathrm{O}$ & 437 & $*$ \\
\hline 3034 & $\mathrm{Nc} 1 \mathrm{cccc} 2 \mathrm{ncnc}(\mathrm{Nc} 3 \operatorname{cccc}(\mathrm{Br}) \mathrm{c} 3) \mathrm{c} 12$ & 439 & $*$ \\
\hline 3035 & $\operatorname{CCOC}(=\mathrm{O}) \mathrm{c} 1 \mathrm{ccc}(\mathrm{O}) \mathrm{c}(\mathrm{Nc} 2 \mathrm{ncnc} 3 \mathrm{cc} 4 \mathrm{oc}(=\mathrm{O}) \mathrm{n}(\mathrm{CCOC}) \mathrm{c} 4 \mathrm{cc} 23) \mathrm{c} 1$ & 440 & $*$ \\
\hline 3036 & $\mathrm{COc} 1 \mathrm{ccc} 2 \mathrm{ncnc}(\mathrm{Nc} 3 \mathrm{ccc}(\mathrm{OCc} 4 \mathrm{ccc} n 4) \mathrm{c}(\mathrm{Cl}) \mathrm{c} 3) \mathrm{c} 12$ & 440 & $*$ \\
\hline 3037 & $\operatorname{COc} 1 \operatorname{ccc}(-\mathrm{c} 2 \mathrm{cn}(\mathrm{C} 3 \mathrm{CCN}(\mathrm{CC}(\mathrm{N})=\mathrm{O}) \mathrm{C} 3) \mathrm{c} 3 \operatorname{ncnc}(\mathrm{N}) \mathrm{c} 23) \mathrm{c} 1$ & 440 & $*$ \\
\hline 3038 & $\mathrm{COc} 1 \mathrm{cc} 2 \mathrm{sc} 3 \mathrm{c}(\mathrm{Nc} 4 \mathrm{cccc}(\mathrm{Br}) \mathrm{c} 4) \mathrm{ncnc} 3 \mathrm{c} 2 \mathrm{cc} 1 \mathrm{OC} . \mathrm{Cl}$ & 444 & $*$ \\
\hline 3039 & $\mathrm{C}=\mathrm{CC}(=\mathrm{O}) \mathrm{Nc} 1 \mathrm{cc}(-\mathrm{n} 2 \mathrm{c}(=\mathrm{O}) \mathrm{cc}(\mathrm{C}) \mathrm{c} 3 \mathrm{cnc}(\mathrm{Nc} 4 \mathrm{cnn}(\mathrm{CCN}(\mathrm{C}) \mathrm{C}) \mathrm{c} 4) \mathrm{nc} 32) \mathrm{cc}(\mathrm{C}(\mathrm{F})(\mathrm{F}) \mathrm{F}) \mathrm{c} 1$ & 444.7 & $*$ \\
\hline 3040 & $\mathrm{CCOc} 1 \mathrm{cc} 2 \mathrm{ncc}(\mathrm{C \# N}) \mathrm{c}(\mathrm{Nc} 3 \operatorname{ccc}(\mathrm{Oc} 4 \mathrm{cccc} 4) \mathrm{c}(\mathrm{Cl}) \mathrm{c} 3) \mathrm{c} 2 \mathrm{cc} 1 \mathrm{NC}(=\mathrm{O}) / \mathrm{C}=\mathrm{C} / \mathrm{CN}(\mathrm{C}) \mathrm{C}$ & 445 & 6.35 \\
\hline 3041 & $\mathrm{~N} \# \mathrm{CC}(\mathrm{C \# N})=\mathrm{CNc} 1 \mathrm{ccc} 2 \mathrm{ncnc}(\mathrm{Nc} 3 \mathrm{ccc}(\mathrm{OCc} 4 \mathrm{ccc}(\mathrm{F}) \mathrm{c} 4) \mathrm{c}(\mathrm{Cl}) \mathrm{c} 3) \mathrm{c} 2 \mathrm{c} 1$ & 445 & $*$ \\
\hline 3042 & $\mathrm{C}=\mathrm{CC}(=\mathrm{O}) \mathrm{Nc} 1 \mathrm{cccc}(\mathrm{Nc} 2 \mathrm{nc}(\mathrm{Nc} 3 \mathrm{ccc}(\mathrm{CN} 4 \mathrm{CCOCC} 4) \mathrm{cc} 3) \mathrm{ncc} 2 \mathrm{Cl}) \mathrm{c} 1$ & 448.7 & $*$ \\
\hline 3043 & $\mathrm{Cc} 1 \operatorname{ccc}(\mathrm{NC}(=\mathrm{O}) / \mathrm{C}=\mathrm{C} / \mathrm{CN}(\mathrm{C}) \mathrm{C}) \operatorname{cc} 1 \mathrm{C}(=\mathrm{O}) \mathrm{Nc} 1 \operatorname{ccc}(\mathrm{OCc} 2 \operatorname{ccc}(\mathrm{F}) \mathrm{c} 2) \mathrm{c}(\mathrm{Cl}) \mathrm{c} 1$ & 450 & 6.35 \\
\hline 3044 & COc1cc2ncnc(Nc3ecce(Cl)c3F)c2cc1CN1CCC[C@@H]1C $(=\mathrm{O}) \mathrm{N}(\mathrm{C}) \mathrm{C}$ & 450 & $*$ \\
\hline 3045 & $\mathrm{CC}(\mathrm{C})(\mathrm{C}) \mathrm{NC}(=\mathrm{O}) \mathrm{Nc} 1 \mathrm{nc} 2 \mathrm{nc}(\mathrm{N}) \mathrm{ncc} 2 \mathrm{cc} 1-\mathrm{c} 1 \mathrm{c}(\mathrm{Cl}) \mathrm{ccc} 1 \mathrm{Cl}$ & 450 & $*$ \\
\hline 3046 & $\mathrm{CCN}(\mathrm{CC}) \mathrm{CCNC}(=\mathrm{O}) \mathrm{c} 1 \mathrm{cc}(\mathrm{C}) \mathrm{c}(\mathrm{C}=\mathrm{C} 2 \backslash \mathrm{C}(=\mathrm{O}) \mathrm{Nc} 3 \mathrm{ncnc}(\mathrm{Nc} 4 \mathrm{ccc}(\mathrm{Cl}) \mathrm{cc} 4 \mathrm{~F}) \mathrm{c} 32)[\mathrm{nH}] 1$ & 450 & $*$ \\
\hline 3047 & $\mathrm{COc} 1 \mathrm{cc} 2 \mathrm{c}(\mathrm{Nc} 3 \mathrm{c}(\mathrm{F}) \mathrm{cc}(\mathrm{Br}) \mathrm{cc} 3 \mathrm{~F}) \mathrm{ncnc} 2 \mathrm{cc} 1 \mathrm{OCC} 1 \mathrm{CCNCC} 1$ & 450 & $*$ \\
\hline 3048 & $\mathrm{COc} 1 \mathrm{cc} 2 \mathrm{c}(\mathrm{Nc} 3 \mathrm{c}(\mathrm{F}) \mathrm{cc}(\mathrm{Cl}) \mathrm{cc} 3 \mathrm{~F}) \mathrm{ncnc} 2 \mathrm{cc} 1 \mathrm{OCC} 1 \mathrm{CCN}(\mathrm{C}) \mathrm{CC} 1$ & 450 & $*$ \\
\hline 3049 & Br.Cc1ccc $([\mathrm{C} @ @ \mathrm{H}](\mathrm{C}) \mathrm{Nc} 2 \mathrm{ncnc} 3[\mathrm{nH}] \mathrm{c}(-\mathrm{c} 4 \mathrm{ccc}(\mathrm{O}) \mathrm{cc} 4) \mathrm{cc} 23) \mathrm{cc} 1$ & 450 & $*$ \\
\hline 3050 & OC[C@@H](Nc1ncnc2oc(-c3ccccs)c(Br)c12)c1 ccccc1 & 452 & $*$ \\
\hline 3051 & $\mathrm{CC} / \mathrm{C}=\mathrm{C} \backslash \mathrm{C}(=\mathrm{O}) \mathrm{Nc} 1 \mathrm{ccccc} 1 \mathrm{Nc} 1 \mathrm{ncnc} 2 \mathrm{cc}(\mathrm{OC}) \mathrm{c}(\mathrm{OCCCN} 3 \mathrm{CCOCC} 3) \mathrm{cc} 12$ & 452.4 & $*$ \\
\hline 3052 & $\mathrm{COc} 1 \mathrm{ccc}(-\mathrm{c} 2 \mathrm{cc}(\mathrm{NC}(=\mathrm{O}) \mathrm{Nc} 3 \mathrm{ccncc} 3) \mathrm{cc}(\mathrm{OC}) \mathrm{c} 2 \mathrm{OC}) \mathrm{cn} 1$ & 455.17 & $*$ \\
\hline 3053 & $\mathrm{Cc} 1 \mathrm{cccc}(\mathrm{Nc} 2 \mathrm{ncnc} 3 \mathrm{cc} 4 \mathrm{c}(\mathrm{cc} 23) \mathrm{N}(\mathrm{CCCN} 2 \mathrm{CCCCC} 2) \mathrm{C}(=\mathrm{O}) \mathrm{CO} 4) \mathrm{c} 1$ & 456.2 & $*$ \\
\hline
\end{tabular}




\begin{tabular}{|c|c|c|c|}
\hline 3054 & Clc1 $1 \mathrm{ccc}(\mathrm{Nc} 2 \mathrm{nnc}(\mathrm{Cc} 3 \mathrm{ccncc} 3) \mathrm{c} 3 \operatorname{ccccc} 23) \mathrm{cc} 1$ & 457.7 & 6.34 \\
\hline 3055 & $\mathrm{O}=\mathrm{C}(\mathrm{CBr}) \mathrm{OCCn} 1 \mathrm{c}(=\mathrm{O}) \mathrm{oc} 2 \mathrm{cc} 3 \mathrm{ncnc}(\mathrm{Nc} 4 \mathrm{ccc}(\mathrm{F}) \mathrm{c}(\mathrm{Cl}) \mathrm{c} 4) \mathrm{c} 3 \mathrm{cc} 21$ & 460 & 6.34 \\
\hline 3056 & $\mathrm{Cc} 1 \mathrm{ncnc}(\mathrm{Nc} 2 \operatorname{ccc}(\mathrm{OCc} 3 \operatorname{ccc}(\mathrm{F}) \mathrm{c} 3) \mathrm{c}(\mathrm{Cl}) \mathrm{c} 2) \mathrm{c} 1 / \mathrm{C}=\mathrm{C} / \mathrm{c} 1 \mathrm{ccc}(\mathrm{CNCCS}(\mathrm{C})(=\mathrm{O})=\mathrm{O}) \mathrm{o} 1$ & 460 & 6.34 \\
\hline 3057 & $\mathrm{COc} 1 \mathrm{cc} 2 \mathrm{ncnc}(\mathrm{Nc} 3 \mathrm{cccc}(\mathrm{Cl}) \mathrm{c} 3) \mathrm{c} 2 \mathrm{cc} 1 \mathrm{~B}(\mathrm{O}) \mathrm{O}$ & 460 & $*$ \\
\hline 3058 & $\mathrm{O}=\mathrm{C} 1 \mathrm{COc} 2 \mathrm{cc} 3 \mathrm{ncnc}(\mathrm{Nc} 4 \mathrm{ccc}(\mathrm{F}) \mathrm{c} 4) \mathrm{c} 3 \mathrm{cc} 2 \mathrm{~N} 1 \mathrm{CCCN} 1 \mathrm{CCCCC} 1$ & 460 & $*$ \\
\hline 3059 & $\operatorname{c1} 1 \mathrm{ccc}(\mathrm{CNc} 2[\mathrm{nH}] \mathrm{cnc} 3 \mathrm{c} 4 \mathrm{ccccc} 4 \mathrm{nc} 2-3) \mathrm{cc} 1$ & 460 & $*$ \\
\hline 3060 & $\mathrm{Cl} . \mathrm{O}=[\mathrm{N}+]([\mathrm{O}-]) \mathrm{c} 1 \mathrm{ccc} 2 \mathrm{sc} 3 \mathrm{c}(\mathrm{Nc} 4 \mathrm{ccc}(\mathrm{C}(\mathrm{F})(\mathrm{F}) \mathrm{F}) \mathrm{c} 4) \mathrm{ncnc} 3 \mathrm{c} 2 \mathrm{c} 1$ & 460 & $*$ \\
\hline 3061 & $\mathrm{CC}(\mathrm{C}) \mathrm{S}(=\mathrm{O})(=\mathrm{O}) \mathrm{c} 1 \mathrm{cccc} 1 \mathrm{Nc} 1 \mathrm{nc}(\mathrm{N} / \mathrm{N}=\mathrm{C} / \mathrm{c} 2 \operatorname{cccc}(\mathrm{C}(\mathrm{F})(\mathrm{F}) \mathrm{F}) \mathrm{c} 2) \mathrm{ncc} 1 \mathrm{Cl}$ & 460 & $*$ \\
\hline 3062 & $\mathrm{COC}(=\mathrm{O}) \mathrm{COCc} 1 \mathrm{ccn} 2 \mathrm{ncnc}(\mathrm{Nc} 3 \operatorname{ccc} 4 \mathrm{c}(\operatorname{cnn} 4 \mathrm{Cc} 4 \operatorname{cccc}(\mathrm{F}) \mathrm{c} 4) \mathrm{c} 3) \mathrm{c} 12$ & 460 & $*$ \\
\hline 3063 & $\mathrm{c} 1 \mathrm{ccc}(\mathrm{CNc} 2 \mathrm{ncnc} 3 \mathrm{c} 2[\mathrm{nH}] \mathrm{c} 2 \mathrm{ccccc} 23) \mathrm{cc} 1$ & 460 & $*$ \\
\hline 3064 & $\mathrm{C}=\mathrm{CC}(=\mathrm{O}) \mathrm{Nc} 1 \mathrm{cccc}(\mathrm{NC}(=\mathrm{O}) \mathrm{Nc} 2 \mathrm{ccnc}(\mathrm{Nc} 3 \operatorname{ccc}(\mathrm{N}(\mathrm{C}) \mathrm{C}) \mathrm{cc} 3) \mathrm{n} 2) \mathrm{c} 1$ & 462 & $*$ \\
\hline 3065 & $\mathrm{COc} 1 \mathrm{cc} 2 \mathrm{nc}(\mathrm{N}) \mathrm{nc}(\mathrm{Nc} 3 \mathrm{cccc}(\mathrm{Br}) \mathrm{c} 3) \mathrm{c} 2 \mathrm{cc} 1 \mathrm{OC}$ & 463 & * \\
\hline 3066 & $\operatorname{CCCCCCCCCCCCCCCCCCNC}(=\mathrm{O}) \operatorname{COc} 1 \mathrm{cc}(\mathrm{O}) \mathrm{c} 2 \mathrm{c}(=\mathrm{O}) \mathrm{cc}(-\mathrm{c} 3 \operatorname{ccccc} 3) \mathrm{oc} 2 \mathrm{c} 1$ & 464 & 6.33 \\
\hline 3067 & $\mathrm{CN} 1 \mathrm{CCN}(\mathrm{C}(=\mathrm{O}) \mathrm{Nc} 2 \mathrm{cc} 3 \mathrm{c}(\mathrm{Nc} 4 \mathrm{ccc}(\mathrm{F}) \mathrm{c}(\mathrm{Cl}) \mathrm{c} 4) \mathrm{ncnc} 3 \mathrm{cc} 2 \mathrm{O}[\mathrm{C} @ \mathrm{H}] 2 \mathrm{CCOC} 2) \mathrm{CC} 1$ & 464 & $*$ \\
\hline 3068 & $\mathrm{CN}(\mathrm{C}) \mathrm{CCCN}(\mathrm{C}) \mathrm{C}(=\mathrm{O}) \mathrm{Nc} 1 \mathrm{cc} 2 \mathrm{c}(\mathrm{Nc} 3 \mathrm{ccc}(\mathrm{F}) \mathrm{c}(\mathrm{Cl}) \mathrm{c} 3) \mathrm{ncnc} 2 \mathrm{cc} 1 \mathrm{O}[\mathrm{C} @ \mathrm{H}] 1 \mathrm{CCOC} 1$ & 464 & $*$ \\
\hline 3069 & $\mathrm{CN}(\mathrm{C}) \mathrm{CCCN}(\mathrm{C}) \mathrm{N}(\mathrm{C}(=\mathrm{O}) \mathrm{Nc} 1 \mathrm{cc} 2 \mathrm{c}(\mathrm{Nc} 3 \mathrm{ccc}(\mathrm{F}) \mathrm{c}(\mathrm{Cl}) \mathrm{c} 3) \mathrm{ncnc} 2 \mathrm{cc} 1 \mathrm{O}[\mathrm{C} @ \mathrm{H}] 1 \mathrm{CCOC} 1) \mathrm{N}(\mathrm{C}) \mathrm{CCCN}(\mathrm{C}) \mathrm{C}$ & 464 & * \\
\hline 3070 & $\mathrm{CN} 1 \mathrm{CCN}(\mathrm{N}(\mathrm{C}(=\mathrm{O}) \mathrm{Nc} 2 \mathrm{cc} 3 \mathrm{c}(\mathrm{Nc} 4 \mathrm{ccc}(\mathrm{F}) \mathrm{c}(\mathrm{Cl}) \mathrm{c} 4) \mathrm{ncnc} 3 \mathrm{cc} 2 \mathrm{O}[\mathrm{C} @ \mathrm{H}] 2 \mathrm{CCOC} 2) \mathrm{N} 2 \mathrm{CCN}(\mathrm{C}) \mathrm{CC} 2) \mathrm{CC} 1$ & 464 & $*$ \\
\hline 3071 & $\mathrm{CCC}(=\mathrm{O}) \mathrm{N} 1 \mathrm{CC}[\mathrm{C} @ \mathrm{H}](\mathrm{N} 2 \mathrm{C}(=\mathrm{O}) \mathrm{N}(\mathrm{c} 3 \mathrm{cc}(\mathrm{OC}) \mathrm{ccc} 3 \mathrm{~F}) \mathrm{Cc} 3 \mathrm{cnc}(\mathrm{Nc} 4 \mathrm{ccc}(\mathrm{N} 5 \mathrm{CCCCC} 5) \mathrm{c}(\mathrm{C}) \mathrm{c} 4) \mathrm{nc} 32) \mathrm{C} 1$ & 467 & 6.33 \\
\hline 3072 & $\mathrm{COCCn} 1 \mathrm{c}(=\mathrm{O}) \mathrm{oc} 2 \mathrm{cc} 3 \mathrm{ncnc}(\mathrm{Nc} 4 \mathrm{ccc}(\mathrm{F}) \mathrm{c}(\mathrm{Cl}) \mathrm{c} 4) \mathrm{c} 3 \mathrm{cc} 21$ & 470 & $*$ \\
\hline 3073 & $\mathrm{C}=\mathrm{C}(\mathrm{CN}(\mathrm{C}) \mathrm{C}) \mathrm{C}(=\mathrm{O}) \mathrm{c} 1 \mathrm{ccc}(\mathrm{OS}(=\mathrm{O})(=\mathrm{O}) \mathrm{c} 2 \operatorname{ccc}(\mathrm{C}(=\mathrm{O}) \mathrm{O}) \mathrm{c}(\mathrm{O}) \mathrm{c} 2) \mathrm{cc} 1$ & 470 & $*$ \\
\hline 3074 & $\operatorname{CCOC}(=\mathrm{O}) \mathrm{c} 1 \mathrm{cn} 2 \mathrm{ncnc}(\mathrm{Nc} 3 \mathrm{ccc} 4 \mathrm{c}(\operatorname{cnn} 4 \mathrm{Cc} 4 \mathrm{cccc}(\mathrm{F}) \mathrm{c} 4) \mathrm{c} 3) \mathrm{c} 2 \mathrm{c} 1 \mathrm{C}$ & 470 & $*$ \\
\hline 3075 & Clc1ecce1Nc1ncnc2[nH]ccc12 & 470.67 & $*$ \\
\hline 3076 & COCCOc1cc2ncnc(-c3c[nH]c4cc(F)c $(\mathrm{Cl}) \mathrm{cc} 34) \mathrm{c} 2 \mathrm{cc} 1 \mathrm{OCCOC}$ & 472 & $*$ \\
\hline 3077 & $\mathrm{C}=\mathrm{CC}(=\mathrm{O}) \mathrm{Nc} 1 \mathrm{cc}(\mathrm{CC}) \mathrm{cc}(-\mathrm{n} 2 \mathrm{c}(=\mathrm{O}) \mathrm{cc}(\mathrm{C}) \mathrm{c} 3 \mathrm{cnc}(\mathrm{Nc} 4 \mathrm{ccc}(\mathrm{N} 5 \mathrm{CCN}(\mathrm{C}) \mathrm{CC} 5) \mathrm{cc} 4 \mathrm{OC}) \mathrm{nc} 32) \mathrm{c} 1$ & 472.1 & $*$ \\
\hline 3078 & $\mathrm{Nc} 1 \mathrm{cccc}(\mathrm{Oc} 2 \mathrm{cc}(\mathrm{Nc} 3 \operatorname{ccc}(\mathrm{OCc} 4 \mathrm{cccc}(\mathrm{F}) \mathrm{c} 4) \mathrm{c}(\mathrm{Cl}) \mathrm{c} 3) \mathrm{ncn} 2) \mathrm{c} 1$ & 473 & 6.33 \\
\hline 3079 & 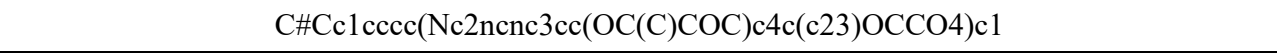 & 473.6 & $*$ \\
\hline 3080 & $\mathrm{C}=\mathrm{CC}(=\mathrm{O}) \mathrm{Nc} 1 \mathrm{cccc}(-\mathrm{n} 2 \mathrm{c}(=\mathrm{O}) \mathrm{c}(=\mathrm{O}) \mathrm{n}(\mathrm{C}) \mathrm{c} 3 \mathrm{cnc}(\mathrm{Nc} 4 \mathrm{ccc}(\mathrm{N} 5 \mathrm{CCN}(\mathrm{C}) \mathrm{CC} 5) \mathrm{cc} 4 \mathrm{OC}) \mathrm{nc} 32) \mathrm{c} 1$ & 474 & $*$ \\
\hline 3081 & $\operatorname{COc} 1 \operatorname{ccc}(-\mathrm{c} 2 \mathrm{cc}(\mathrm{NC}(=\mathrm{O}) \mathrm{Nc} 3 \mathrm{nccs} 3) \operatorname{cc}(\mathrm{C}(\mathrm{F})(\mathrm{F}) \mathrm{F}) \mathrm{c} 2) \mathrm{cn} 1$ & 476.66 & $*$ \\
\hline 3082 & $\operatorname{COCCNC}(=\mathrm{O}) \mathrm{Nc} 1 \mathrm{cc} 2 \mathrm{c}(\mathrm{Nc} 3 \mathrm{ccc}(\mathrm{F}) \mathrm{c}(\mathrm{Cl}) \mathrm{c} 3) \mathrm{ncnc} 2 \mathrm{cc} 1 \mathrm{O}[\mathrm{C} @ \mathrm{H}] 1 \mathrm{CCOC} 1$ & 479 & $*$ \\
\hline 3083 & $\operatorname{COCCNN}(\mathrm{NCOC}) \mathrm{C}(=\mathrm{O}) \mathrm{Nc} 1 \mathrm{cc} 2 \mathrm{c}(\mathrm{Nc} 3 \mathrm{ccc}(\mathrm{F}) \mathrm{c}(\mathrm{Cl}) \mathrm{c} 3) \mathrm{ncnc} 2 \mathrm{cc} 1 \mathrm{O}[\mathrm{C} @ \mathrm{H}] 1 \mathrm{CCOC} 1$ & 479 & $*$ \\
\hline 3084 & $\mathrm{CC}(\mathrm{C})(\mathrm{C}) \mathrm{n} 1 \mathrm{nc}(-\mathrm{c} 2 \mathrm{ccc}(\mathrm{Cl}) \mathrm{cc} 2) \mathrm{c} 2 \mathrm{c}(\mathrm{N}) \mathrm{ncnc} 21$ & 480 & $*$ \\
\hline 3085 & $\mathrm{Cc} 1 \mathrm{ccc}(\mathrm{Nc} 2 \mathrm{ncc} 3 \mathrm{cc}(-\mathrm{c} 4 \mathrm{c}(\mathrm{Cl}) \operatorname{cccc} 4 \mathrm{Cl}) \mathrm{c}(=\mathrm{O}) \mathrm{n}(\mathrm{C}) \mathrm{c} 3 \mathrm{n} 2) \mathrm{cc} 1$ & 480 & $*$ \\
\hline 3086 & $\mathrm{CN}(\mathrm{C}) \mathrm{N}=\mathrm{Nc} 1 \mathrm{ccc} 2 \mathrm{ncnc}(\mathrm{NCc} 3 \mathrm{ccccc} 3) \mathrm{c} 2 \mathrm{c} 1$ & 482 & $*$ \\
\hline 3087 & $\operatorname{Brc} 1 \operatorname{ccc}(\mathrm{C} 2=\mathrm{NN}(\mathrm{c} 3 \operatorname{ccccc} 3) \mathrm{C}(\mathrm{c} 3 \operatorname{cccc} 4 \operatorname{ccccc} 34) \mathrm{C} 2) \mathrm{cc} 1$ & 490 & 6.31 \\
\hline 3088 & $\mathrm{COc} 1 \mathrm{cc} 2 \mathrm{ncnc}(\mathrm{Nc} 3 \operatorname{cccc}(\mathrm{Cl}) \mathrm{c} 3) \mathrm{c} 2 \mathrm{cc} 1 \mathrm{~B} 1 \mathrm{OC}(\mathrm{C})(\mathrm{C}) \mathrm{C}(\mathrm{C})(\mathrm{C}) \mathrm{O} 1$ & 490 & $*$ \\
\hline 3089 & $\mathrm{CCn} 1 \mathrm{c}(=\mathrm{O}) \mathrm{c}(-\mathrm{c} 2 \mathrm{c}(\mathrm{Cl}) \mathrm{cccc} 2 \mathrm{Cl}) \mathrm{cc} 2 \mathrm{cnc}(\mathrm{Nc} 3 \mathrm{ccncc} 3) \mathrm{nc} 21$ & 490 & $*$ \\
\hline 3090 & $\operatorname{COc} 1 \mathrm{cc} 2 \mathrm{ncnc}(\mathrm{Nc} 3 \mathrm{cc}(\mathrm{NC}(=\mathrm{O}) \mathrm{c} 4 \mathrm{ccccc} 4) \mathrm{c}(\mathrm{F}) \mathrm{cc} 3 \mathrm{~F}) \mathrm{c} 2 \mathrm{cc} 1 \mathrm{OC}$ & 490 & $*$ \\
\hline 3091 & $\mathrm{CCc} 1 \mathrm{c}(\mathrm{CO}) \mathrm{cn} 2 \mathrm{ncnc}(\mathrm{Nc} 3 \mathrm{ccc} 4 \mathrm{c}(\mathrm{cnn} 4 \mathrm{Cc} 4 \mathrm{ccccc} 4) \mathrm{c} 3) \mathrm{c} 12$ & 490 & * \\
\hline 3092 & COCCOCc1 cen2nenc $(\mathrm{Nc} 3 \operatorname{ccc} 4 \mathrm{c}(\mathrm{cnn} 4 \mathrm{Cc} 4 \mathrm{cccc}(\mathrm{F}) \mathrm{c} 4) \mathrm{c} 3) \mathrm{c} 12$ & 490 & $*$ \\
\hline 3093 & $\mathrm{~N} \# \mathrm{Cc} 1 \mathrm{c}(-\mathrm{c} 2 \mathrm{ccc} 3 \operatorname{ncc}(\mathrm{C}(\mathrm{N})=\mathrm{O}) \mathrm{c}(\mathrm{Nc} 4 \mathrm{cccc}(\mathrm{Br}) \mathrm{c} 4) \mathrm{c} 3 \mathrm{c} 2) \csc 1 \mathrm{~N}$ & 490 & $*$ \\
\hline 3094 & $\mathrm{C}=\mathrm{CC}(=\mathrm{O}) \mathrm{Nc} 1 \mathrm{ccccc} 1 \mathrm{Nc} 1 \mathrm{nc}(\mathrm{Nc} 2 \mathrm{ccc}(\mathrm{OCCN} 3 \mathrm{CCOCC} 3) \mathrm{cc} 2) \mathrm{ncc} 1 \mathrm{Cl}$ & 491 & $*$ \\
\hline 3095 & $\mathrm{COc} 1 \mathrm{ccc}(-\mathrm{c} 2 \mathrm{ccc}(\mathrm{OC}(\mathrm{F})(\mathrm{F}) \mathrm{F}) \mathrm{c}(\mathrm{NC}(=\mathrm{O}) \mathrm{Nc} 3 \mathrm{nccs} 3) \mathrm{c} 2) \mathrm{cn} 1$ & 495.3 & $*$ \\
\hline 3096 & $\mathrm{C} / \mathrm{C}=\mathrm{C} \backslash \mathrm{C}(=\mathrm{O}) \mathrm{Nc} 1 \mathrm{ccc}(\mathrm{Nc} 2 \mathrm{ncnc} 3 \mathrm{cc}(\mathrm{OCCCOC}) \mathrm{c}(\mathrm{OCCCOC}) \mathrm{cc} 23) \mathrm{cc} 1$ & 497.5 & $*$ \\
\hline
\end{tabular}




\begin{tabular}{|c|c|c|c|}
\hline 3097 & $\mathrm{CCOc} 1 \mathrm{cc} 2 \mathrm{ncc}(\mathrm{CHN}) \mathrm{c}(\mathrm{Nc} 3 \mathrm{ccc}(\mathrm{OCc} 4 \mathrm{nccn} 4 \mathrm{C}) \mathrm{c}(\mathrm{Cl}) \mathrm{c} 3) \mathrm{c} 2 \mathrm{cc} 1 \mathrm{NC}(=\mathrm{O}) / \mathrm{C}=\mathrm{C} / \mathrm{CN}(\mathrm{C}) \mathrm{C}$ & 500 & 6.30 \\
\hline 3098 & $\mathrm{COc} 1 \mathrm{cc} 2 \mathrm{c}(\mathrm{cc} 1 \mathrm{OC}) \mathrm{Oc} 1 \mathrm{ncnc}(\mathrm{Nc} 3 \mathrm{ccc} 4 \mathrm{ccccc} 4 \mathrm{c} 3) \mathrm{c} 1 \mathrm{NC} 2$ & 500 & 6.30 \\
\hline 3099 & $\mathrm{Cc} 1 \mathrm{ccc} 2[\mathrm{nH}] \mathrm{c}(\mathrm{C}(=\mathrm{O}) \mathrm{NC}(\mathrm{CO}) \mathrm{Cc} 3 \operatorname{ccccc} 3) \mathrm{c}(\mathrm{Cl}) \mathrm{c} 2 \mathrm{c} 1$ & 500 & 6.30 \\
\hline 3100 & $\mathrm{~N} \# \mathrm{CC}(\mathrm{CHN})=\mathrm{C} 1 \mathrm{CCc} 2 \mathrm{cc}(\mathrm{O}) \mathrm{c}(\mathrm{O}) \mathrm{cc} 21$ & 500 & $*$ \\
\hline 3101 & $\mathrm{COc} 1 \mathrm{cc} 2 \mathrm{ncnc}(\mathrm{Nc} 3 \mathrm{cc}(\mathrm{OC}) \mathrm{c}(\mathrm{OC}) \mathrm{c}(\mathrm{OC}) \mathrm{c} 3) \mathrm{c} 2 \mathrm{cc} 1 \mathrm{OC} . \mathrm{Cl}$ & 500 & $*$ \\
\hline 3102 & $\mathrm{~N} \# \mathrm{CC}(\mathrm{C \# N})=\mathrm{C}(\mathrm{N}) / \mathrm{C}(\mathrm{C} \# \mathrm{~N})=\mathrm{C} / \mathrm{c} 1 \mathrm{cc}(\mathrm{O}) \mathrm{c}(\mathrm{O}) \mathrm{c}(\mathrm{Br}) \mathrm{c} 1$ & 500 & $*$ \\
\hline 3103 & $\begin{array}{c}\operatorname{COc} 1 \mathrm{cc}(/ \mathrm{C}=\mathrm{C} /[\mathrm{N}+](=\mathrm{O})[\mathrm{O}-]) \operatorname{ccc} 1 \mathrm{OS}(=\mathrm{O})(=\mathrm{O}) \mathrm{c} 1 \mathrm{ccc}(\mathrm{C}(=\mathrm{O}) \mathrm{OC}[\mathrm{C} @ \mathrm{H}] 2 \mathrm{O}[\mathrm{C} @ @ \mathrm{H}](\mathrm{n} 3 \mathrm{cnc} 4 \mathrm{c}(\mathrm{N}) \mathrm{ncnc} 43)[\mathrm{C} @ \mathrm{H}]( \\
\mathrm{O})[\mathrm{C} @ @ \mathrm{H}] 2 \mathrm{O}) \mathrm{cc} 1\end{array}$ & 500 & * \\
\hline 3104 & $\mathrm{Cc} 1 \mathrm{nc} 2 \mathrm{nc}[\mathrm{nH}] \mathrm{c}(\mathrm{N}(\mathrm{C}) \mathrm{c} 3 \mathrm{cccc}(\mathrm{Cl}) \mathrm{c} 3) \mathrm{c}-2 \mathrm{c} 1 \mathrm{C}$ & 500 & $*$ \\
\hline 3105 & $\mathrm{COc} 1 \mathrm{cc} 2 \mathrm{c}(\mathrm{Nc} 3 \mathrm{ccc}(\mathrm{Br}) \mathrm{cc} 3 \mathrm{~F}) \mathrm{ncnc} 2 \mathrm{cc} 1 \mathrm{OCC} 1 \mathrm{CCN}(\mathrm{C}) \mathrm{CC} 1 . \mathrm{Cl}$ & 500 & $*$ \\
\hline 3106 & $\mathrm{COc} 1 \mathrm{cc} 2 \mathrm{c}(\mathrm{Nc} 3 \mathrm{c}(\mathrm{F}) \mathrm{cc}(\mathrm{Cl}) \mathrm{cc} 3 \mathrm{~F}) \mathrm{ncnc} 2 \mathrm{cc} 1 \mathrm{OCC} 1 \mathrm{CCNCC} 1$ & 500 & $*$ \\
\hline 3107 & $\mathrm{COc} 1 \mathrm{cc} 2 \mathrm{c}(\mathrm{Nc} 3 \mathrm{ccc}(\mathrm{C}) \mathrm{cc} 3 \mathrm{~F}) \mathrm{ncnc} 2 \mathrm{cc} 1 \mathrm{OCC} 1 \mathrm{CCNCC} 1$ & 500 & $*$ \\
\hline 3108 & $\mathrm{Fc} 1 \mathrm{cccc}(\mathrm{Cn} 2 \mathrm{ncc} 3 \mathrm{cc}(\mathrm{Nc} 4 \mathrm{ncnn} 5 \mathrm{ccc}(\mathrm{CN} 6 \mathrm{CCCC} 6) \mathrm{c} 45) \mathrm{ccc} 32) \mathrm{c} 1$ & 500 & $*$ \\
\hline 3109 & $\mathrm{COc} 1 \mathrm{cc} 2 \mathrm{c}(\mathrm{Nc} 3 \operatorname{ccc}(\mathrm{NC}(=\mathrm{O}) \mathrm{Nc} 4 \operatorname{cccc}(\mathrm{Cl}) \mathrm{c} 4) \mathrm{cc} 3) \operatorname{ncnc} 2 \mathrm{cc} 1 \mathrm{OCCCN} 1 \mathrm{CCN}(\mathrm{C}) \mathrm{CC} 1$ & 500 & $*$ \\
\hline 3110 & $\mathrm{CN}(\mathrm{C}) \mathrm{C}(=\mathrm{O}) \mathrm{CN} 1 \mathrm{CCC}(\mathrm{n} 2 \mathrm{cc}(-\mathrm{c} 3 \mathrm{cccc}(\mathrm{O}) \mathrm{c} 3) \mathrm{c} 3 \mathrm{c}(\mathrm{N}) \mathrm{ncnc} 32) \mathrm{CC} 1$ & 500 & * \\
\hline 3111 & c1ccc(Cn2ncc3ec(Nc4ncnn5ccc(COC[C@@H]6CNCCO6)c45)ccc32)nc1 & 500 & $*$ \\
\hline 3112 & $\mathrm{Cc} 1 \mathrm{cc} 2 \mathrm{cc}(\mathrm{Nc} 3 \mathrm{ccnc} 4 \mathrm{cc}(-\mathrm{c} 5 \mathrm{ccc}(\mathrm{CNCCCO}) \mathrm{cc} 5) \operatorname{sc} 34) \mathrm{ccc} 2[\mathrm{nH}] 1$ & 500 & $*$ \\
\hline 3113 & $\mathrm{C}=\mathrm{CC}(=\mathrm{O}) \mathrm{Nc} 1 \mathrm{cccc}(\mathrm{Nc} 2 \mathrm{nc}(\mathrm{Nc} 3 \mathrm{ccc}(\mathrm{CN} 4 \mathrm{CCOCC} 4) \mathrm{cc} 3) \mathrm{ncc} 2 \mathrm{~F}) \mathrm{c} 1$ & 500 & $*$ \\
\hline 3114 & $\mathrm{COc} 1 \mathrm{cc} 2 \mathrm{c}(\mathrm{Nc} 3 \mathrm{ccc}(\mathrm{NC}(=\mathrm{O}) \mathrm{Nc} 4 \mathrm{cccc} 4 \mathrm{C}) \mathrm{cc} 3) \mathrm{ncn} 2 \mathrm{cc} 1 \mathrm{OCCCN} 1 \mathrm{CCN}(\mathrm{C}) \mathrm{CC} 1$ & 502 & $*$ \\
\hline 3115 & $\operatorname{COCCOc} 1 \mathrm{ccc}(\mathrm{Nc} 2 \mathrm{ncnc} 3 \mathrm{cc}(\mathrm{OCCCN} 4 \mathrm{CCOCC} 4) \mathrm{c}(\mathrm{NC}(=\mathrm{O}) \mathrm{c} 4 \mathrm{cc}([\mathrm{N}+](=\mathrm{O})[\mathrm{O}-]) \mathrm{ccc} 4 \mathrm{~F}) \mathrm{cc} 23) \mathrm{cc} 1 \mathrm{Cl}$ & 503 & 6.30 \\
\hline 3116 & $\mathrm{CCN}(\mathrm{CC}) \mathrm{CCN}(\mathrm{C}) \mathrm{C}(=\mathrm{O}) \mathrm{Nc} 1 \mathrm{cc} 2 \mathrm{c}(\mathrm{Nc} 3 \mathrm{ccc}(\mathrm{F}) \mathrm{c}(\mathrm{Cl}) \mathrm{c} 3) \mathrm{ncnc} 2 \mathrm{cc} 1 \mathrm{O}[\mathrm{C} @ \mathrm{H}] 1 \mathrm{CCOC} 1$ & 505 & $*$ \\
\hline 3117 & $\mathrm{CCN}(\mathrm{CC}) \mathrm{CCN}(\mathrm{C}) \mathrm{N}(\mathrm{C}(=\mathrm{O}) \mathrm{Nc} 1 \mathrm{cc} 2 \mathrm{c}(\mathrm{Nc} 3 \mathrm{ccc}(\mathrm{F}) \mathrm{c}(\mathrm{Cl}) \mathrm{c} 3) \mathrm{ncnc} 2 \mathrm{cc} 1 \mathrm{O}[\mathrm{C} @ \mathrm{H}] 1 \mathrm{CCOC} 1) \mathrm{N}(\mathrm{C}) \mathrm{CCN}(\mathrm{CC}) \mathrm{CC}$ & 505 & $*$ \\
\hline 3118 & $\mathrm{C}=\mathrm{CC}(=\mathrm{O}) \mathrm{Nc} 1 \mathrm{ccc}(\mathrm{Nc} 2 \mathrm{nc}(\mathrm{Nc} 3 \mathrm{ccc}(\mathrm{Cn} 4 \mathrm{ccnc} 4) \operatorname{cc} 3 \mathrm{OC}) \mathrm{ncc} 2 \mathrm{Cl}) \mathrm{c} 1$ & 506 & $*$ \\
\hline 3119 & $\mathrm{CCC}(=\mathrm{O}) \mathrm{Nc} 1 \mathrm{cc} 2 \mathrm{c}(\mathrm{Nc} 3 \mathrm{ccc}(\mathrm{Oc} 4 \mathrm{ccc} 5 \mathrm{c}(\mathrm{c} 4) \mathrm{OCO} 5) \mathrm{cc} 3) \mathrm{ncnc} 2 \mathrm{cc} 1 \mathrm{OC}$ & 509 & $*$ \\
\hline 3120 & $\mathrm{CCOC}(=\mathrm{O}) \mathrm{C} 1=\mathrm{C}(\mathrm{N}) \mathrm{N}(\mathrm{c} 2 \mathrm{cccnc} 2) \mathrm{C} 2=\mathrm{C}(\mathrm{C}(=\mathrm{O}) \mathrm{CC}(\mathrm{C})(\mathrm{C}) \mathrm{C} 2) \mathrm{C} 1 \mathrm{c} 1 \mathrm{c}(\mathrm{C}) \mathrm{nn}(-\mathrm{c} 2 \mathrm{ccc}(\mathrm{C}) \mathrm{cc} 2) \mathrm{c} 1 \mathrm{Cl}$ & 510 & 6.29 \\
\hline 3121 & $\mathrm{O}=\mathrm{C}(\mathrm{CCl}) \mathrm{OCCn} 1 \mathrm{c}(=\mathrm{O}) \mathrm{oc} 2 \mathrm{cc} 3 \mathrm{ncnc}(\mathrm{Nc} 4 \operatorname{ccc}(\mathrm{Oc} 5 \operatorname{cccc}(\mathrm{C}(\mathrm{F})(\mathrm{F}) \mathrm{F}) \mathrm{c} 5) \mathrm{c}(\mathrm{Cl}) \mathrm{c} 4) \mathrm{c} 3 \mathrm{cc} 21$ & 510 & 6.29 \\
\hline 3122 & $\mathrm{COc} 1 \mathrm{cc} 2 \mathrm{ncnc}(\mathrm{Nc} 3 \mathrm{ccc}(\mathrm{F}) \mathrm{c}(\mathrm{Cl}) \mathrm{c} 3) \mathrm{c} 2 \mathrm{cc} 1 \mathrm{~B}(\mathrm{O}) \mathrm{O}$ & 510 & $*$ \\
\hline 3123 & $\mathrm{Cn} 1 \mathrm{c}(=\mathrm{O}) \mathrm{c}(-\mathrm{c} 2 \mathrm{c}(\mathrm{Cl}) \mathrm{cccc} 2 \mathrm{Cl}) \mathrm{cc} 2 \mathrm{cnc}(\mathrm{Nc} 3 \mathrm{cccnc} 3) \mathrm{nc} 21$ & 510 & * \\
\hline 3124 & $\mathrm{Cc} 1 \mathrm{ccc}(\mathrm{Nc} 2 \mathrm{ncnn} 3 \operatorname{ccc} 23) \mathrm{cc} 1 \mathrm{O}$ & 510 & $*$ \\
\hline 3125 & $\mathrm{O}=\mathrm{C} 1 \mathrm{NCc} 2 \mathrm{cc}(\mathrm{Oc} 3 \operatorname{ccc}(\mathrm{Nc} 4 \mathrm{ncnc} 5 \mathrm{ccn}(\mathrm{CCO}) \mathrm{c} 45) \mathrm{cc} 3 \mathrm{Cl}) \operatorname{ccc} 21$ & 510 & * \\
\hline 3126 & $\mathrm{COc} 1 \mathrm{ccc} 2 \mathrm{cc}(-\mathrm{c} 3 \mathrm{nn}(\mathrm{C}(\mathrm{C}) \mathrm{C}) \mathrm{c} 4 \mathrm{ncnc}(\mathrm{N}) \mathrm{c} 34) \mathrm{ccc} 2 \mathrm{c} 1 . \mathrm{Cl}$ & 510 & $*$ \\
\hline 3127 & $\mathrm{Cc} 1 \mathrm{ccc}(\mathrm{C} 2=\mathrm{C}(\mathrm{C \# N}) \mathrm{C} 3(\mathrm{C}(=\mathrm{O}) \mathrm{Nc} 4 \mathrm{ccc}(\mathrm{Br}) \mathrm{cc} 43) \mathrm{c} 3 \mathrm{c}(-\mathrm{c} 4 \operatorname{ccc} 4) \mathrm{nn}(-\mathrm{c} 4 \mathrm{ccccc} 4) \mathrm{c} 3 \mathrm{~N} 2) \operatorname{cc} 1$ & 510 & $*$ \\
\hline 3128 & $\mathrm{CN}(\mathrm{C}) \mathrm{C} / \mathrm{C}=\mathrm{C} / \mathrm{C}(=\mathrm{O}) \mathrm{Nc} 1 \mathrm{cc} 2 \mathrm{c}(\mathrm{Nc} 3 \mathrm{ccc}(\mathrm{OCc} 4 \mathrm{cccc}(\mathrm{F}) \mathrm{c} 4) \mathrm{c}(\mathrm{Cl}) \mathrm{c} 3) \mathrm{ncnc} 2 \mathrm{cc} 1 \mathrm{O}[\mathrm{C} @ \mathrm{H}] 1 \mathrm{CCOC} 1$ & 510.2 & $*$ \\
\hline 3129 & $\mathrm{CCC}(=\mathrm{O}) \mathrm{N} 1 \mathrm{CC}[\mathrm{C} @ \mathrm{H}](\mathrm{N} 2 \mathrm{C}(=\mathrm{O}) \mathrm{N}(\mathrm{c} 3 \mathrm{cc}(\mathrm{OC}) \mathrm{ccc} 3 \mathrm{~F}) \mathrm{Cc} 3 \mathrm{cnc}(\mathrm{Nc} 4 \mathrm{ccc}(\mathrm{N} 5 \mathrm{CCN}(\mathrm{C}) \mathrm{CC} 5) \mathrm{c}(\mathrm{CC}) \mathrm{c} 4) \mathrm{nc} 32) \mathrm{C} 1$ & 518 & 6.29 \\
\hline 3130 & $\mathrm{O}=\mathrm{C} 1 \mathrm{CO} 2 \mathrm{cc} 3 \mathrm{ncnc}(\mathrm{Ne} 4 \mathrm{ccccc} 4) \mathrm{c} 3 \mathrm{cc} 2 \mathrm{~N} 1 \mathrm{CCCN} 1 \mathrm{CCOCC} 1$ & 518.6 & $*$ \\
\hline 3131 & $\mathrm{CCOc} 1 \mathrm{cc} 2 \mathrm{ncc}(\mathrm{C \# N}) \mathrm{c}(\mathrm{Nc} 3 \operatorname{ccc}(\mathrm{Cn} 4 \mathrm{ccnc} 4) \mathrm{c}(\mathrm{Cl}) \mathrm{c} 3) \mathrm{c} 2 \mathrm{cc} 1 \mathrm{NC}(=\mathrm{O}) / \mathrm{C}=\mathrm{C} / \mathrm{CN}(\mathrm{C}) \mathrm{C}$ & 519 & 6.28 \\
\hline 3132 & $\mathrm{CCC}(=\mathrm{O}) \mathrm{Nc} 1 \mathrm{cc} 2 \mathrm{c}(\mathrm{Nc} 3 \mathrm{ccc} 4 \mathrm{c}(\mathrm{c} 3) \mathrm{CCN} 4 \mathrm{Cc} 3 \mathrm{ccc} n 3) \mathrm{ncnc} 2 \mathrm{cc} 1 \mathrm{OC}$ & 519 & $*$ \\
\hline 3133 & $\mathrm{Cc} 1 \mathrm{ccc}(\mathrm{C} 2=\mathrm{NN}(\mathrm{C}(\mathrm{N})=\mathrm{S}) \mathrm{C}(\mathrm{c} 3 \operatorname{ccc} 4 \mathrm{cccc} 4 \mathrm{c} 3) \mathrm{C} 2) \mathrm{cc} 1$ & 520 & 6.28 \\
\hline 3134 & $\mathrm{COc} 1 \mathrm{cc} 2 \mathrm{ncnc}(\mathrm{Nc} 3 \operatorname{ccc}(\mathrm{F}) \mathrm{c}(\mathrm{Cl}) \mathrm{c} 3) \mathrm{c} 2 \mathrm{cc} 1 \mathrm{~B} 1 \mathrm{OC}(\mathrm{C})(\mathrm{C}) \mathrm{C}(\mathrm{C})(\mathrm{C}) \mathrm{O} 1$ & 520 & $*$ \\
\hline 3135 & $\mathrm{O}=\mathrm{C} 1 \mathrm{CCN}(\mathrm{C} / \mathrm{C}=\mathrm{C} / \mathrm{C}(=\mathrm{O}) \mathrm{Nc} 2 \mathrm{cc} 3 \mathrm{c}(\mathrm{Nc} 4 \mathrm{ccc}(\mathrm{F}) \mathrm{c}(\mathrm{Cl}) \mathrm{c} 4) \mathrm{ncnc} 3 \mathrm{cc} 2 \mathrm{O}[\mathrm{C} @ \mathrm{H}] 2 \mathrm{CCOC} 2) \mathrm{CC} 1$ & 520.2 & $*$ \\
\hline 3136 & $\mathrm{CCC}(=\mathrm{O}) \mathrm{Nc} 1 \mathrm{cc} 2 \mathrm{c}(\mathrm{Nc} 3 \operatorname{ccc}(\mathrm{NS}(=\mathrm{O})(=\mathrm{O}) \mathrm{c} 4 \mathrm{ccccc} 4) \mathrm{nc} 3) \mathrm{ncnc} 2 \mathrm{cc} 1 \mathrm{OC}$ & 522 & $*$ \\
\hline 3137 & $\mathrm{COc} 1 \mathrm{ccc}(/ \mathrm{C}=\mathrm{C} / \mathrm{C}(=\mathrm{O}) \mathrm{Nc} 2 \operatorname{cccc}(\mathrm{Oc} 3 \mathrm{cc}(\mathrm{Nc} 4 \operatorname{ccc}(\mathrm{OCc} 5 \operatorname{ccc}(\mathrm{F}) \mathrm{c} 5) \mathrm{c}(\mathrm{Cl}) \mathrm{c} 4) \mathrm{ncn} 3) \mathrm{c} 2) \mathrm{cc} 1 \mathrm{OC}$ & 523 & 6.28 \\
\hline 3138 & $\mathrm{COc} 1 \mathrm{cc}(\mathrm{N} 2 \mathrm{CCN}(\mathrm{C}) \mathrm{CC} 2) \operatorname{ccc} 1 \mathrm{Nc} 1 \mathrm{ncc}(\mathrm{Cl}) \mathrm{c}(\mathrm{Oc} 2 \mathrm{ccc}(\mathrm{NC}(=\mathrm{O}) \mathrm{CCN} 3 \mathrm{CCCC} 3) \mathrm{c} 2) \mathrm{n} 1$ & 525 & 6.28 \\
\hline
\end{tabular}




\begin{tabular}{|c|c|c|c|}
\hline 3139 & $\mathrm{C}=\mathrm{CC}(=\mathrm{O}) \mathrm{NCc} 1 \mathrm{cccc}(-\mathrm{c} 2 \mathrm{cc} 3 \operatorname{ccc} n \mathrm{c} 3[\mathrm{nH}] 2) \mathrm{c} 1$ & 525 & $*$ \\
\hline 3140 & $\mathrm{COc} 1 \mathrm{cc} 2 \mathrm{c}(\mathrm{Oc} 3 \mathrm{ccc}(\mathrm{NC}(=\mathrm{O}) \mathrm{c} 4 \mathrm{cn}(-\mathrm{c} 5 \mathrm{cccc} 5 \mathrm{Cl}) \mathrm{nn} 4) \mathrm{cc} 3 \mathrm{~F}) \mathrm{ccn} \operatorname{coc} 1 \mathrm{OCCCN} 1 \mathrm{CCCCC} 1$ & 529.4 & 6.28 \\
\hline 3141 & $\mathrm{NC}(=\mathrm{S}) \mathrm{N} 1 \mathrm{~N}=\mathrm{C}(\mathrm{c} 2 \mathrm{ccc}(\mathrm{Cl}) \mathrm{cc} 2) \mathrm{CC} 1 \mathrm{c} 1 \mathrm{ccc} 2 \mathrm{ccccc} 2 \mathrm{c} 1$ & 530 & 6.28 \\
\hline 3142 & $\mathrm{O}=\mathrm{c} 1 \mathrm{c} 2 \mathrm{ccc}(\mathrm{Cl}) \mathrm{cc} 2 \mathrm{nc}(-\mathrm{c} 2 \mathrm{cccc} 2) \mathrm{n} 1-\mathrm{c} 1 \mathrm{nnn}(\mathrm{C} 2 \mathrm{CC} 2) \mathrm{s} 1$ & 530 & 6.28 \\
\hline 3143 & NCCCn $1 \mathrm{ccc} 2 \mathrm{c}(-\mathrm{c} 3 \mathrm{ccnc}(\mathrm{Nc} 4 \mathrm{cccc}(\mathrm{OC}(\mathrm{F})(\mathrm{F}) \mathrm{C}(\mathrm{F}) \mathrm{F}) \mathrm{c} 4) \mathrm{n} 3) \operatorname{ccc} 21$ & 530 & $*$ \\
\hline 3144 & $\mathrm{NC} 1 \mathrm{CCN}(\mathrm{Cc} 2 \mathrm{ccn} 3 \mathrm{ncnc}(\mathrm{Nc} 4 \mathrm{ccc} 5 \mathrm{c}(\mathrm{cnn} 5 \mathrm{Cc} 5 \mathrm{ccncc} 5) \mathrm{c} 4) \mathrm{c} 23) \mathrm{CC} 1$ & 530 & * \\
\hline 3145 & $\mathrm{CCC}(=\mathrm{O}) \mathrm{Nc} 1 \mathrm{cc} 2 \mathrm{c}(\mathrm{Nc} 3 \mathrm{ccc}(\mathrm{Oc} 4 \mathrm{cccnc} 4) \mathrm{cc} 3) \mathrm{ncnc} 2 \mathrm{cc} 1 \mathrm{OC}$ & 531 & $*$ \\
\hline 3146 & COc1cc2ncnc(-c3c[nH]c4cc(F)c(C)cc34)c2cc1OC & 533 & $*$ \\
\hline 3147 & $\mathrm{C}[\mathrm{C} @ \mathrm{H}](\mathrm{Nc} 1 \mathrm{ncnc} 2 \mathrm{c} 1 \mathrm{sc} 1 \mathrm{ccccc} 12) \mathrm{c} 1 \mathrm{ccccc} 1$ & 538 & $*$ \\
\hline 3148 & $\mathrm{C}[\mathrm{C} @ @ \mathrm{H}](\mathrm{Nc} 1 \mathrm{ncnc} 2 \mathrm{c} 1 \mathrm{sc} 1 \mathrm{ccccc} 12) \mathrm{c} 1 \mathrm{ccccc} 1$ & 538 & $*$ \\
\hline 3149 & $\mathrm{Cn} 1 \mathrm{ccc} 2 \mathrm{cc}(-\mathrm{c} 3 \mathrm{nn}(\mathrm{C} 4 \mathrm{CCCC} 4) \mathrm{c} 4 \mathrm{ncnc}(\mathrm{N}) \mathrm{c} 34) \mathrm{ccc} 21$ & 539 & * \\
\hline 3150 & $\mathrm{C}=\mathrm{CC}(=\mathrm{O}) \mathrm{Nc} 1 \mathrm{cccc}(\mathrm{Nc} 2 \mathrm{nc}(\mathrm{Nc} 3 \operatorname{ccc}(/ \mathrm{C}=\mathrm{C} / \mathrm{c} 4 \mathrm{cc}(\mathrm{C}) \mathrm{cc}(\mathrm{C}) \mathrm{c} 4) \mathrm{cc} 3) \mathrm{ncc} 2 \mathrm{~F}) \mathrm{c} 1$ & 539.2 & $*$ \\
\hline 3151 & $\mathrm{O}=[\mathrm{N}+]([\mathrm{O}-]) \mathrm{c} 1 \mathrm{ccc} 2 \mathrm{c}(\mathrm{Nc} 3 \mathrm{ccc}(\mathrm{I}) \mathrm{c} 3) \mathrm{ncnc} 2 \mathrm{c} 1$ & 540 & $*$ \\
\hline 3152 & $\mathrm{Nc} 1 \mathrm{ncnc} 2 \mathrm{c} 1 \mathrm{c}(-\mathrm{c} 1 \mathrm{cnc} 3 \mathrm{cccc} 3 \mathrm{c} 1) \mathrm{nn} 2 \mathrm{C} 1 \mathrm{CCCC} 1$ & 540 & $*$ \\
\hline 3153 & $\mathrm{O}=\mathrm{C}(\mathrm{CN} 1 \mathrm{CCC}(\mathrm{CCO}) \mathrm{CC} 1) \mathrm{Nc} 1 \mathrm{cc} 2 \mathrm{c}(\mathrm{Nc} 3 \mathrm{ccc}(\mathrm{F}) \mathrm{c}(\mathrm{Cl}) \mathrm{c} 3) \mathrm{ncnc} 2 \mathrm{~s} 1$ & 542 & $*$ \\
\hline 3154 & $\mathrm{O}=\mathrm{C}(\mathrm{Nc} 1 \mathrm{cc} 2 \mathrm{c}(\mathrm{Nc} 3 \mathrm{ccc}(\mathrm{F}) \mathrm{c}(\mathrm{Cl}) \mathrm{c} 3) \mathrm{ncnc} 2 \mathrm{cc} 1 \mathrm{O}[\mathrm{C} @ \mathrm{H}] 1 \mathrm{CCOC} 1) \mathrm{N} 1 \mathrm{CC}(\mathrm{O}) \mathrm{C} 1$ & 543 & $*$ \\
\hline 3155 & $\mathrm{NC}(=\mathrm{O}) \mathrm{Nc} 1 \mathrm{ccc} 2 \mathrm{ncnc}(\mathrm{Nc} 3 \mathrm{ccc}(\mathrm{Oc} 4 \mathrm{ccc}(\mathrm{Cl}) \mathrm{c}(\mathrm{Cl}) \mathrm{c} 4) \mathrm{c}(\mathrm{Cl}) \mathrm{c} 3) \mathrm{c} 2 \mathrm{c} 1$ & 543 & $*$ \\
\hline 3156 & $\mathrm{O}=\mathrm{C}(\mathrm{Nc} 1 \mathrm{cc} 2 \mathrm{c}(\mathrm{Nc} 3 \mathrm{ccc}(\mathrm{F}) \mathrm{c}(\mathrm{Cl}) \mathrm{c} 3) \mathrm{ncnc} 2 \mathrm{cc} 1 \mathrm{O}[\mathrm{C} @ \mathrm{H}] 1 \mathrm{CCOC} 1) \mathrm{N}(\mathrm{N} 1 \mathrm{CC}(\mathrm{O}) \mathrm{C} 1) \mathrm{N} 1 \mathrm{CC}(\mathrm{O}) \mathrm{C} 1$ & 543 & $*$ \\
\hline 3157 & $\mathrm{COC}(\mathrm{CCNC}(=\mathrm{O}) \mathrm{Nc} 1 \mathrm{cc} 2 \mathrm{c}(\mathrm{Nc} 3 \mathrm{ccc}(\mathrm{F}) \mathrm{c}(\mathrm{Cl}) \mathrm{c} 3) \mathrm{ncnc} 2 \mathrm{cc} 1 \mathrm{O}[\mathrm{C} @ \mathrm{H}] 1 \mathrm{CCOC} 1) \mathrm{OC}$ & 544 & $*$ \\
\hline 3158 & $\mathrm{COC}(\mathrm{CCNN}(\mathrm{NCCC}(\mathrm{OC}) \mathrm{OC}) \mathrm{C}(=\mathrm{O}) \mathrm{Nc} 1 \mathrm{cc} 2 \mathrm{c}(\mathrm{Nc} 3 \mathrm{ccc}(\mathrm{F}) \mathrm{c}(\mathrm{Cl}) \mathrm{c} 3) \mathrm{ncnc} 2 \mathrm{cc} 1 \mathrm{O}[\mathrm{C} @ \mathrm{H}] 1 \mathrm{CCOC} 1) \mathrm{OC}$ & 544 & $*$ \\
\hline 3159 & COc1ccc(N2Cc3cnc(Nc4ccc(F)cc4)nc3N([C@@H]3CC[C@@H](O)C3)C2=O)cc1 & 545 & $*$ \\
\hline 3160 & $\mathrm{C}=\mathrm{CC}(=\mathrm{O}) \mathrm{Nc} 1 \mathrm{cc}(-\mathrm{n} 2 \mathrm{c}(=\mathrm{O}) \mathrm{cc}(\mathrm{C}) \mathrm{c} 3 \mathrm{cnc}(\mathrm{Nc} 4 \mathrm{nc} 5 \mathrm{c}(\mathrm{s} 4) \mathrm{CN}(\mathrm{C}) \mathrm{CC} 5) \mathrm{nc} 32) \mathrm{cc}(\mathrm{C}(\mathrm{F})(\mathrm{F}) \mathrm{F}) \mathrm{c} 1$ & 549.6 & $*$ \\
\hline 3161 & $\mathrm{Cc} 1 \mathrm{ccc}(\mathrm{C}(=\mathrm{O}) \mathrm{Nc} 2 \operatorname{ccc}(\mathrm{CN} 3 \mathrm{CCN}(\mathrm{C}) \mathrm{CC} 3) \mathrm{c}(\mathrm{C}(\mathrm{F})(\mathrm{F}) \mathrm{F}) \mathrm{c} 2) \operatorname{cc} 1 \mathrm{NC}(=\mathrm{O}) \mathrm{c} 1 \mathrm{cccnc} 1$ & 550 & 6.26 \\
\hline 3162 & $\mathrm{~N} \# \mathrm{Cc} 1 \mathrm{cnc} 2 \mathrm{ccc}(\mathrm{NC}(=\mathrm{O}) \mathrm{C} \# \mathrm{CCN} 3 \mathrm{CCSCC} 3) \mathrm{cc} 2 \mathrm{c} 1 \mathrm{Nc} 1 \mathrm{cccc}(\mathrm{Br}) \mathrm{c} 1$ & 550 & 6.26 \\
\hline 3163 & $\mathrm{Cc} 1[\mathrm{nH}] \mathrm{c} 2 \mathrm{ncnc}(\mathrm{Nc} 3 \mathrm{cccc}(\mathrm{F}) \mathrm{c} 3) \mathrm{c} 2 \mathrm{c} 1 \mathrm{C}$ & 550 & $*$ \\
\hline 3164 & $\mathrm{CC}(\mathrm{C}) \mathrm{n} 1 \mathrm{nc}(-\mathrm{c} 2 \mathrm{ccc}(\mathrm{Br}) \mathrm{c}(\mathrm{O}) \mathrm{c} 2) \mathrm{c} 2 \mathrm{c}(\mathrm{N}) \mathrm{ncnc} 21$ & 550 & $*$ \\
\hline 3165 & $\mathrm{CN} 1 \mathrm{CCN}(\mathrm{c} 2 \mathrm{ccc}(\mathrm{Nc} 3 \mathrm{ncc}(\mathrm{Cl}) \mathrm{c}(\mathrm{Nc} 4 \mathrm{ccc} 5[\mathrm{nH}] \operatorname{ccc} 5 \mathrm{c} 4) \mathrm{n} 3) \mathrm{cc} 2) \mathrm{CC} 1$ & 557 & $*$ \\
\hline 3166 & $\mathrm{O}=\mathrm{C} 1 \mathrm{CSC}(\mathrm{N} / \mathrm{N}=\mathrm{C} / \mathrm{c} 2 \mathrm{cc}(\mathrm{Cl}) \operatorname{ccc} 2 \mathrm{O})=\mathrm{N} 1$ & 560 & 6.25 \\
\hline 3167 & $\mathrm{Oc} 1 \operatorname{ccc}(\mathrm{CN}(\mathrm{Cc} 2 \operatorname{cc}(\mathrm{Cl}) \operatorname{cc}(\mathrm{Cl}) \mathrm{c} 2 \mathrm{O}) \mathrm{C}(=\mathrm{S}) \mathrm{Nc} 2 \operatorname{ccccc} 2) \operatorname{cc} 1$ & 560 & 6.25 \\
\hline 3168 & $\mathrm{C}=\mathrm{C}(\mathrm{CN}(\mathrm{C}) \mathrm{C}) \mathrm{C}(=\mathrm{O}) \mathrm{Nc} 1 \mathrm{cc} 2 \mathrm{c}(\mathrm{Nc} 3 \mathrm{ccc}(\mathrm{F}) \mathrm{c}(\mathrm{Cl}) \mathrm{c} 3) \mathrm{c}(\mathrm{C \# N}) \mathrm{cnc} 2 \mathrm{cc} 1 \mathrm{OCC}$ & 560 & 6.25 \\
\hline 3169 & $\operatorname{COCCn} 1 \mathrm{c}(=\mathrm{O}) \mathrm{oc} 2 \mathrm{cc} 3 \mathrm{ncnc}(\mathrm{Nc} 4 \operatorname{cccc}(\mathrm{C}(\mathrm{C})=\mathrm{O}) \mathrm{c} 4) \mathrm{c} 3 \mathrm{cc} 21$ & 560 & $*$ \\
\hline 3170 & $\mathrm{Cc} 1[\mathrm{nH}] \mathrm{c} 2 \mathrm{ncnc}(\mathrm{Nc} 3 \mathrm{ccc}(\mathrm{F}) \mathrm{cc} 3) \mathrm{c} 2 \mathrm{c} 1 \mathrm{C}$ & 560 & $*$ \\
\hline 3171 & Fc1cccc(COc2ccc(Nc3ncnn4ccc(COC[C@@H]5CNCCO5)c34)cc2Cl)c1 & 560 & * \\
\hline 3172 & $\mathrm{CCN} 1 \mathrm{CCC}(=\mathrm{O}) / \mathrm{C}(=\mathrm{C} / \mathrm{c} 2 \mathrm{ccc}(\mathrm{CC} 3 \mathrm{CCCC} 3) \mathrm{cc} 2) \mathrm{C} 1$ & 560 & $*$ \\
\hline 3173 & $\mathrm{C}=\mathrm{CC}(=\mathrm{O}) \mathrm{Nc} 1 \mathrm{cc} 2 \mathrm{c}(\mathrm{Nc} 3 \mathrm{ccc}(\mathrm{OCc} 4 \mathrm{cccc}(\mathrm{F}) \mathrm{c} 4) \mathrm{c}(\mathrm{Cl}) \mathrm{c} 3) \mathrm{ncnc} 2 \mathrm{cc} 1 \mathrm{O}[\mathrm{C} @ \mathrm{H}] 1 \mathrm{CCOC} 1$ & 560.4 & $*$ \\
\hline 3174 & $\mathrm{Clc} 1 \mathrm{cccc}(\mathrm{Nc} 2 \mathrm{ncnc} 3 \operatorname{ccc}(\mathrm{NCc} 4 \mathrm{ccc} 5 \mathrm{c}(\mathrm{c} 4) \mathrm{OCO} 5) \mathrm{cc} 23) \mathrm{c} 1$ & 570 & 6.24 \\
\hline 3175 & $\mathrm{O}=\mathrm{c} 1 \mathrm{loc} 2 \mathrm{cc} 3 \mathrm{ncnc}(\mathrm{Nc} 4 \mathrm{ccc}(\mathrm{F}) \mathrm{c}(\mathrm{F}) \mathrm{c} 4) \mathrm{c} 3 \mathrm{cc} 2 \mathrm{n} 1 \mathrm{CCCN} 1 \mathrm{CCOCC} 1$ & 570 & * \\
\hline 3176 & $\mathrm{CC} 1(\mathrm{C}) \mathrm{OB}(\mathrm{c} 2 \mathrm{ccc} 3 \mathrm{ncnc}(\mathrm{Nc} 4 \mathrm{ccc}(\mathrm{F}) \mathrm{c}(\mathrm{Cl}) \mathrm{c} 4) \mathrm{c} 3 \mathrm{c} 2) \mathrm{OC} 1(\mathrm{C}) \mathrm{C}$ & 570 & $*$ \\
\hline 3177 & $\mathrm{Cc} 1 \mathrm{cccc}(\mathrm{Nc} 2[\mathrm{nH}] \mathrm{cnc} 3 \mathrm{nc}(\mathrm{C}) \mathrm{c}(\mathrm{C}) \mathrm{c} 2-3) \mathrm{c} 1$ & 570 & $*$ \\
\hline 3178 & $\mathrm{CC}(\mathrm{C}) \mathrm{S}(=\mathrm{O})(=\mathrm{O}) \mathrm{c} 1 \operatorname{ccccc} 1 \mathrm{Nc} 1 \mathrm{nc}(\mathrm{N} / \mathrm{N}=\mathrm{C} / \mathrm{c} 2 \operatorname{ccc}(\mathrm{F}) \mathrm{cc} 2) \mathrm{ncc} 1 \mathrm{Cl}$ & 570 & $*$ \\
\hline 3179 & Nc1ncnc2c1c(-c1 cec3[nH]ncc3c1)nn2C1CCCC1 & 571 & $*$ \\
\hline 3180 & $\mathrm{COCCOc} 1 \mathrm{cc} 2 \mathrm{ncnc}(\mathrm{Nc} 3 \operatorname{ccc}(\mathrm{Cl}) \mathrm{c}(\mathrm{C}(\mathrm{F})(\mathrm{F}) \mathrm{F}) \mathrm{c} 3) \mathrm{c} 2 \mathrm{cc} 1 \mathrm{NC}(=\mathrm{O}) / \mathrm{C}=\mathrm{C} / \mathrm{CN}(\mathrm{C}) \mathrm{C}$ & 573.6 & $*$ \\
\hline 3181 & $\mathrm{CCOc} 1 \mathrm{cc} 2 \mathrm{ncc}(\mathrm{C} \# \mathrm{~N}) \mathrm{c}(\mathrm{Nc} 3 \operatorname{ccc}(\mathrm{OCc} 4 \mathrm{ccc}(\mathrm{OCc} 5 \operatorname{ccccc} 5) \operatorname{cc} 4) \mathrm{c}(\mathrm{Cl}) \mathrm{c} 3) \mathrm{c} 2 \mathrm{cc} 1 \mathrm{NC}(=\mathrm{O}) / \mathrm{C}=\mathrm{C} / \mathrm{CN}(\mathrm{C}) \mathrm{C}$ & 574 & 6.24 \\
\hline
\end{tabular}




\begin{tabular}{|c|c|c|c|}
\hline 3182 & $\mathrm{Nc} 1 \mathrm{ccc} 2 \mathrm{ncnc}(\mathrm{Nc} 3 \operatorname{ccc}(\mathrm{C}(\mathrm{F})(\mathrm{F}) \mathrm{F}) \mathrm{c} 3) \mathrm{c} 2 \mathrm{c} 1$ & 574 & $*$ \\
\hline 3183 & $\mathrm{Cc} 1 \mathrm{ccc}(\mathrm{C}(=\mathrm{O}) \mathrm{Nc} 2 \operatorname{ccc}(\mathrm{CN} 3 \mathrm{CCN}(\mathrm{C}) \mathrm{CC} 3) \mathrm{c}(\mathrm{C}(\mathrm{F})(\mathrm{F}) \mathrm{F}) \mathrm{c} 2) \operatorname{cc} 1 \mathrm{NC}(=\mathrm{O}) \mathrm{c} 1 \mathrm{ccc} n 1$ & 575 & 6.24 \\
\hline 3184 & Nc1ncnc2c1c(-c1ccc3occe3c1)nn2C1CCCC1 & 575 & $*$ \\
\hline 3185 & $\mathrm{CC}(\mathrm{C}) \mathrm{n} 1 \mathrm{nc}(-\mathrm{c} 2 \mathrm{cc}(\mathrm{O}) \mathrm{cc}(\mathrm{F}) \mathrm{c} 2) \mathrm{c} 2 \mathrm{c}(\mathrm{N}) \mathrm{ncnc} 21$ & 576 & * \\
\hline 3186 & $\mathrm{FC}(\mathrm{F})(\mathrm{F}) \mathrm{c} 1 \mathrm{cccc}(\mathrm{Nc} 2 \mathrm{ncnc} 3 \operatorname{ccccc} 23) \mathrm{c} 1$ & 577 & $*$ \\
\hline 3187 & $\mathrm{Nc} 1 \mathrm{cc} 2 \mathrm{ncnc}(\mathrm{NCc} 3 \operatorname{cccc} 3) \mathrm{c} 2 \mathrm{cn} 1$ & 578 & $*$ \\
\hline 3188 & $\mathrm{CC}(=\mathrm{O}) \mathrm{N}(\mathrm{C}) / \mathrm{N}=\mathrm{N} / \mathrm{c} 1 \mathrm{ccc} 2 \mathrm{ncnc}(\mathrm{Nc} 3 \operatorname{ccc}(\mathrm{C}) \mathrm{c} 3) \mathrm{c} 2 \mathrm{c} 1$ & 578 & $*$ \\
\hline 3189 & $\mathrm{CC}(\mathrm{C}) \mathrm{n} 1 \mathrm{nc}(-\mathrm{c} 2 \mathrm{cccc}(\mathrm{C}(=\mathrm{O}) \mathrm{NC} 3=\mathrm{NCCS} 3) \mathrm{c} 2) \mathrm{c} 2 \mathrm{c}(\mathrm{N}) \mathrm{ncnc} 21$ & 579 & $*$ \\
\hline 3190 & $\mathrm{Cc} 1 \operatorname{ccc}(\mathrm{NC}(=\mathrm{O}) \mathrm{c} 2 \operatorname{ccc}(\mathrm{N}(\mathrm{CCCl}) \mathrm{CCCl}) \mathrm{cc} 2) \mathrm{cc} 1$ & 580 & 6.24 \\
\hline 3191 & $\mathrm{O}=\mathrm{C}(\mathrm{Nc} 1 \mathrm{ccc}(\mathrm{Oc} 2 \mathrm{ccnc} 3[\mathrm{nH}] \operatorname{ccc} 23) \mathrm{c}(\mathrm{F}) \mathrm{c} 1) \mathrm{c} 1 \mathrm{nnn}(-\mathrm{c} 2 \mathrm{ccc}(\mathrm{F}) \mathrm{cc} 2) \mathrm{c} 1 \mathrm{C}(\mathrm{F})(\mathrm{F}) \mathrm{F}$ & 582.17 & $*$ \\
\hline 3192 & $\mathrm{COc} 1 \operatorname{ccc}(/ \mathrm{C}=\mathrm{N} / \mathrm{Nc} 2 \mathrm{ncc}(\mathrm{Cl}) \mathrm{c}(\mathrm{Nc} 3 \operatorname{ccccc} 3 \mathrm{~S}(=\mathrm{O})(=\mathrm{O}) \mathrm{C}(\mathrm{C}) \mathrm{C}) \mathrm{n} 2) \mathrm{cc} 1$ & 587 & $*$ \\
\hline 3193 & $\mathrm{COc} 1 \mathrm{cc} 2 \mathrm{c}(\mathrm{NCc} 3 \mathrm{cccc} 3) \mathrm{ncnc} 2 \mathrm{cc} 1 \mathrm{O}$ & 588 & $*$ \\
\hline 3194 & OC[C@@H](Nc1ncnc2oc(-c3eccc3)c(Cl)c12)c1 ccccc1 & 589 & $*$ \\
\hline 3195 & $\mathrm{Cc} 1 \mathrm{ncnc}(\mathrm{Nc} 2 \mathrm{ccc}(\mathrm{OCc} 3 \operatorname{ccc}(\mathrm{F}) \mathrm{c} 3) \mathrm{c}(\mathrm{Cl}) \mathrm{c} 2) \mathrm{c} 1-\mathrm{c} 1 \mathrm{cccc}(\mathrm{CN} 2 \mathrm{CCOCC} 2) \mathrm{c} 1$ & 590 & 6.23 \\
\hline 3196 & $\mathrm{NC}(=\mathrm{S}) \mathrm{N} / \mathrm{N}=\mathrm{C}(/ \mathrm{C}=\mathrm{C} / \mathrm{c} 1 \mathrm{ccccc} 1) \mathrm{c} 1 \mathrm{ccc}(\mathrm{Cl}) \mathrm{cc} 1$ & 590 & 6.23 \\
\hline 3197 & $\mathrm{CC} 1(\mathrm{C}) \mathrm{OB}(\mathrm{c} 2 \mathrm{ccc} 3 \mathrm{ncnc}(\mathrm{Nc} 4 \mathrm{cccc}(\mathrm{Cl}) \mathrm{c} 4) \mathrm{c} 3 \mathrm{c} 2) \mathrm{OC} 1(\mathrm{C}) \mathrm{C}$ & 590 & $*$ \\
\hline 3198 & $\mathrm{Cc} 1 \mathrm{cc}(-\mathrm{c} 2 \mathrm{cnc}(\mathrm{Nc} 3 \mathrm{cc}(\mathrm{Cl}) \mathrm{cc}(\mathrm{Cl}) \mathrm{c} 3) \mathrm{nc} 2 \mathrm{NC} 2 \mathrm{CCC}(\mathrm{N}(\mathrm{C}) \mathrm{C}) \mathrm{CC} 2) \mathrm{on} 1$ & 590 & $*$ \\
\hline 3199 & $\mathrm{Fc} 1 \mathrm{ccc}(\mathrm{Oc} 2 \mathrm{ncnc} 3 \mathrm{ccccc} 23) \mathrm{cc} 1 \mathrm{Cl}$ & 590 & $*$ \\
\hline 3200 & $\mathrm{~N} \# \mathrm{Cc} 1 \mathrm{ccc}(\mathrm{Oc} 2 \mathrm{ccc}(\mathrm{Nc} 3 \mathrm{ncnc} 4 \mathrm{cc}[\mathrm{nH}] \mathrm{c} 34) \mathrm{cc} 2 \mathrm{Cl}) \mathrm{cc} 1$ & 590 & $*$ \\
\hline 3201 & $\mathrm{C}=\mathrm{CC}(=\mathrm{O}) \mathrm{Nc} 1 \mathrm{ccccc} 1 \mathrm{Nc} 1 \mathrm{nc}(\mathrm{Nc} 2 \mathrm{ccc}(\mathrm{NC}(=\mathrm{O}) \mathrm{CN} 3 \mathrm{CCOCC} 3) \mathrm{cc} 2) \mathrm{ncc} 1 \mathrm{Cl}$ & 592.1 & * \\
\hline 3202 & $\mathrm{CCC}(=\mathrm{O}) \mathrm{Nc} 1 \mathrm{cc} 2 \mathrm{c}(\mathrm{Nc} 3 \operatorname{ccc}(\mathrm{NS}(=\mathrm{O})(=\mathrm{O}) \mathrm{c} 4 \mathrm{cccc} 4) \mathrm{c}(\mathrm{F}) \mathrm{c} 3) \mathrm{ncnc} 2 \mathrm{cc} 1 \mathrm{OC}$ & 593 & * \\
\hline 3203 & $\mathrm{CC}(\mathrm{C}) \mathrm{S}(=\mathrm{O})(=\mathrm{O}) \mathrm{c} 1 \mathrm{ccccc} 1 \mathrm{Nc} 1 \mathrm{nc}(\mathrm{N} / \mathrm{N}=\mathrm{C} / \mathrm{c} 2 \mathrm{ccc}(\mathrm{C}(\mathrm{F})(\mathrm{F}) \mathrm{F}) \mathrm{cc} 2) \mathrm{ncc} 1 \mathrm{Cl}$ & 593 & $*$ \\
\hline 3204 & $\mathrm{Cc} 1 \mathrm{ccc}(\mathrm{Nc} 2 \mathrm{ncnc} 3 \mathrm{cc} 4 \mathrm{c}(\mathrm{cc} 23) \mathrm{N}(\mathrm{CCCN} 2 \mathrm{CCOCC} 2) \mathrm{C}(=\mathrm{O}) \mathrm{CO} 4) \mathrm{cc} 1$ & 594.5 & $*$ \\
\hline 3205 & $\mathrm{COc} 1 \mathrm{ccc}(-\mathrm{c} 2 \mathrm{c} 3 \mathrm{c} 4 \mathrm{cc}(\mathrm{OC}) \mathrm{c}(\mathrm{OCCN}(\mathrm{C}) \mathrm{C}) \mathrm{cc} 4 \mathrm{oc}(=\mathrm{O}) \mathrm{c} 3 \mathrm{n} 3 \mathrm{ccc} 4 \mathrm{cc}(\mathrm{O}) \mathrm{c}(\mathrm{OC}) \mathrm{cc} 4 \mathrm{c} 23) \mathrm{cc} 1 \mathrm{O} . \mathrm{O}=\mathrm{C}(\mathrm{O}) \mathrm{C}(\mathrm{F})(\mathrm{F}) \mathrm{F}$ & 595.4 & $*$ \\
\hline 3206 & $\mathrm{Cc} 1 \mathrm{ccc}(\mathrm{NC}(=\mathrm{O}) \mathrm{c} 2 \mathrm{ccc}(\mathrm{CN} 3 \mathrm{CCN}(\mathrm{C}) \mathrm{CC} 3) \mathrm{cc} 2) \mathrm{cc} 1 \mathrm{C}(=\mathrm{O}) \mathrm{Nc} 1 \mathrm{ccc}(\mathrm{OCc} 2 \mathrm{cccc}(\mathrm{F}) \mathrm{c} 2) \mathrm{c}(\mathrm{Cl}) \mathrm{c} 1$ & 600 & 6.22 \\
\hline 3207 & $\mathrm{CCC}(=\mathrm{O}) \mathrm{N} 1 \mathrm{CC}[\mathrm{C} @ \mathrm{H}](\mathrm{N} 2 \mathrm{C}(=\mathrm{O}) \mathrm{N}(\mathrm{c} 3 \mathrm{cc}(\mathrm{OC}) \mathrm{ccc} 3 \mathrm{~F}) \mathrm{Cc} 3 \mathrm{cnc}(\mathrm{Nc} 4 \mathrm{ccc}(\mathrm{N} 5 \mathrm{CCN}(\mathrm{C}) \mathrm{CC} 5) \mathrm{c}(\mathrm{OC}) \mathrm{c} 4) \mathrm{nc} 32) \mathrm{C} 1$ & 600 & 6.22 \\
\hline 3208 & OCCN1CCN(Cc2 $\operatorname{ccc}(-\mathrm{c} 3 \mathrm{cc} 4 \mathrm{c}(\mathrm{N}[\mathrm{C} @ \mathrm{H}](\mathrm{CO}) \mathrm{c} 5 \mathrm{ccccc} 5) \mathrm{ncnc} 4 \mathrm{~s} 3) \mathrm{cc} 2) \mathrm{CC} 1$ & 600 & $*$ \\
\hline 3209 & OC[C@@H](Nc1ncnc2sc(-c3ecc(CN4CCNCC4)cc3)cc12)c1ccccc1 & 600 & $*$ \\
\hline 3210 & $\mathrm{COc} 1 \mathrm{cc} 2 \mathrm{ncnc}(\mathrm{Nc} 3 \mathrm{ccc} 4 \mathrm{c}(\mathrm{c} 3) \mathrm{CCC} 4) \mathrm{c} 2 \mathrm{cc} 1 \mathrm{OC} . \mathrm{Cl}$ & 600 & * \\
\hline 3211 & 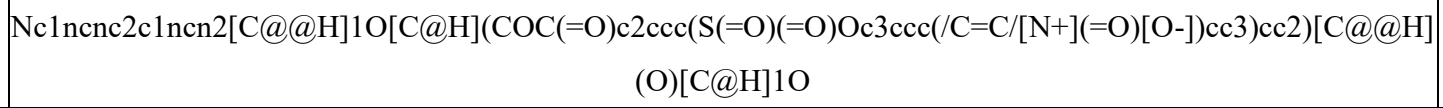 & 600 & $*$ \\
\hline 3212 & $\begin{aligned} \mathrm{O}= & \mathrm{C}(\mathrm{NCCc} 1 \mathrm{ccc}(\mathrm{O}) \mathrm{c}(\mathrm{Br}) \mathrm{c} 1) / \mathrm{C}(\mathrm{Cc} 1 \mathrm{cc}(\mathrm{Br}) \mathrm{c}(\mathrm{O}) \mathrm{c}(\mathrm{Oc} 2 \mathrm{ccc}(\mathrm{CCNC}(=\mathrm{O}) / \mathrm{C}(\mathrm{Cc} 3 \mathrm{cc}(\mathrm{Br}) \mathrm{c}(\mathrm{O}) \mathrm{c}(- \\
& \mathrm{c} 4 \mathrm{cc}(\mathrm{C} / \mathrm{C}(=\mathrm{N} \backslash \mathrm{O}) \mathrm{C}(=\mathrm{O}) \mathrm{NCC} 5 \mathrm{ccc}(\mathrm{O}) \mathrm{c}(\mathrm{Br}) \mathrm{c} 5) \mathrm{cc}(\mathrm{Br}) \mathrm{c} 4 \mathrm{O}) \mathrm{c} 3)=\mathrm{N} / \mathrm{O}) \mathrm{cc} 2 \mathrm{Br}) \mathrm{c} 1)=\mathrm{N} / \mathrm{O}\end{aligned}$ & 600 & $*$ \\
\hline 3213 & $\mathrm{c} 1 \mathrm{nc}(\mathrm{Nc} 2 \operatorname{ccc} 3[\mathrm{nH}] \operatorname{ccc} 3 \mathrm{c} 2) \mathrm{c} 2 \operatorname{secc} 2 \mathrm{n} 1$ & 600 & $*$ \\
\hline 3214 & $\begin{array}{c}\mathrm{Cc} 1 \mathrm{nc}(\mathrm{Nc} 2 \mathrm{ncc}(\mathrm{C}(=\mathrm{O}) \mathrm{Nc} 3 \mathrm{c}(\mathrm{C}) \mathrm{cccc} 3 \mathrm{Cl}) \mathrm{s} 2) \mathrm{cc}(\mathrm{N} 2 \mathrm{CCN}(\mathrm{CCOC}(=\mathrm{O}) \mathrm{c} 3 \mathrm{cnc}(\mathrm{C}(=\mathrm{O}) \mathrm{Nc} 4 \mathrm{ccc} 5 \mathrm{ncnc}(\mathrm{Nc} 6 \mathrm{cccc}(\mathrm{Cl}) \mathrm{c} 6) \mathrm{c} 5 \mathrm{c} \\
4) \mathrm{cn} 3) \mathrm{CC} 2) \mathrm{n} 1\end{array}$ & 600 & $*$ \\
\hline 3215 & $\operatorname{COc} 1 \operatorname{ccc}(/ \mathrm{C}=\mathrm{N} / \mathrm{Nc} 2 \mathrm{ncc}(\mathrm{Cl}) \mathrm{c}(\mathrm{Nc} 3 \operatorname{ccccc} 3 \mathrm{~S}(=\mathrm{O})(=\mathrm{O}) \mathrm{C}(\mathrm{C}) \mathrm{C}) \mathrm{n} 2) \mathrm{c} 1$ & 601 & $*$ \\
\hline 3216 & $\mathrm{c} 1 \mathrm{ccc}(\mathrm{CNc} 2 \mathrm{ncnc} 3 \mathrm{cccnc} 23) \mathrm{cc} 1$ & 603 & $*$ \\
\hline 3217 & $\mathrm{C}=\mathrm{CC}(=\mathrm{O}) \mathrm{Nc} 1 \mathrm{cccc}(\mathrm{Nc} 2 \mathrm{nc}(\mathrm{Nc} 3 \mathrm{ccc}(/ \mathrm{C}=\mathrm{C} / \mathrm{c} 4 \mathrm{cc}(\mathrm{C}) \mathrm{cc}(\mathrm{C}) \mathrm{c} 4) \mathrm{cc} 3) \mathrm{ncc} 2 \mathrm{Cl}) \mathrm{c} 1$ & 606.5 & $*$ \\
\hline 3218 & $\mathrm{Cc} 1 \mathrm{cccc}(\mathrm{C}) \mathrm{c} 1-\mathrm{c} 1 \mathrm{cc} 2 \mathrm{cnc}(\mathrm{N}) \mathrm{nc} 2 \mathrm{nc} 1 \mathrm{NC}(=\mathrm{O}) \mathrm{NC}(\mathrm{C})(\mathrm{C}) \mathrm{C}$ & 610 & $*$ \\
\hline 3219 & $\mathrm{CCOC}(=\mathrm{O}) \mathrm{c} 1 \mathrm{cn} 2 \mathrm{ncnc}(\mathrm{Nc} 3 \mathrm{ccc}(\mathrm{Oc} 4 \mathrm{ccccc} 4) \mathrm{cc} 3) \mathrm{c} 2 \mathrm{c} 1 \mathrm{CC}$ & 610 & $*$ \\
\hline 3220 & $\mathrm{CC}(\mathrm{C}) \mathrm{n} 1 \mathrm{nc}(-\mathrm{c} 2 \mathrm{ccc} 3 \mathrm{ncccc} 3 \mathrm{c} 2) \mathrm{c} 2 \mathrm{c}(\mathrm{N}) \mathrm{ncnc} 21$ & 610 & $*$ \\
\hline 3221 & $\mathrm{Fc} 1 \mathrm{cc}(\mathrm{Nc} 2 \mathrm{nccc}(\mathrm{Nc} 3 \mathrm{ccc} 4[\mathrm{nH}] \mathrm{ccc} 4 \mathrm{c} 3) \mathrm{n} 2) \mathrm{cc}(\mathrm{N} 2 \mathrm{CCOCC} 2) \mathrm{c} 1$ & 610 & $*$ \\
\hline
\end{tabular}




\begin{tabular}{|c|c|c|c|}
\hline 3222 & $\mathrm{COC}(=\mathrm{O}) \mathrm{CNC}(=\mathrm{O}) \mathrm{c} 1 \mathrm{ccc}(\mathrm{Nc} 2 \mathrm{ncnc} 3 \mathrm{cc}(\mathrm{OCCCN} 4 \mathrm{CCN}(\mathrm{C}) \mathrm{CC} 4) \mathrm{c}(\mathrm{OC}) \mathrm{cc} 23) \mathrm{cc} 1$ & 611 & $*$ \\
\hline 3223 & COc1cc2ncnc(N[C@@H](C)c3ecc(Cl)cc3)c2cc1OCCCCCCC $(=\mathrm{O}) \mathrm{NO}$ & 614 & 6.21 \\
\hline 3224 & $\mathrm{COc} 1 \mathrm{ccc}(\mathrm{NC}(=\mathrm{O}) / \mathrm{C}=\mathrm{C} / \mathrm{CN}(\mathrm{C}) \mathrm{C}) \mathrm{cc} 1 \mathrm{Nc} 1 \mathrm{ncc}(\mathrm{Cl}) \mathrm{c}(\mathrm{Nc} 2 \mathrm{ccc} 3 \mathrm{ncccc} 3 \mathrm{c} 2) \mathrm{n} 1$ & 615 & $*$ \\
\hline 3225 & $\operatorname{Cc} 1 n \operatorname{cc}([\mathrm{N}+](=\mathrm{O})[\mathrm{O}-]) \operatorname{n} 1 \mathrm{CCOC}(=\mathrm{O}) / \mathrm{C}=\mathrm{C} / \mathrm{c} 1 \mathrm{ccc}(-\mathrm{c} 2 \operatorname{ccccc} 2) \operatorname{cc} 1$ & 620 & 6.21 \\
\hline 3226 & $\mathrm{CN}(\mathrm{C}) \mathrm{CCCOCc} 1 \mathrm{ccn} 2 \mathrm{ncnc}(\mathrm{Nc} 3 \mathrm{ccc} 4 \mathrm{c}(\mathrm{cnn} 4 \mathrm{Cc} 4 \mathrm{cccc}(\mathrm{F}) \mathrm{c} 4) \mathrm{c} 3) \mathrm{c} 12$ & 620 & $*$ \\
\hline 3227 & $\mathrm{COc} 1 \mathrm{cc} 2 \mathrm{ncc}(\mathrm{C \# N}) \mathrm{c}(\mathrm{Nc} 3 \mathrm{ccc}(\mathrm{Br}) \mathrm{c}(\mathrm{C}) \mathrm{c} 3) \mathrm{c} 2 \mathrm{cc} 1 \mathrm{OC}$ & 620 & $*$ \\
\hline 3228 & $\mathrm{COc} 1 \mathrm{cc} 2 \mathrm{ncc}(\mathrm{C}(=\mathrm{O}) \mathrm{NC} 3 \mathrm{CC}(\mathrm{C})(\mathrm{C}) \mathrm{N}([\mathrm{O}]) \mathrm{C}(\mathrm{C})(\mathrm{C}) \mathrm{C} 3) \mathrm{c}(\mathrm{Nc} 3 \mathrm{ccc}(\mathrm{Cl}) \mathrm{c} 3) \mathrm{c} 2 \mathrm{cc} 1 \mathrm{OC}$ & 623 & 6.21 \\
\hline 3229 & $\mathrm{O}=\mathrm{C}(\mathrm{Cc} 1 \mathrm{cc}(\mathrm{F}) \mathrm{c}(\mathrm{F}) \mathrm{cc} 1 \mathrm{~F}) \mathrm{Nc} 1 \mathrm{cccc}(\mathrm{Oc} 2 \mathrm{cc}(\mathrm{Nc} 3 \mathrm{ccc}(\mathrm{OCc} 4 \mathrm{ccc}(\mathrm{F}) \mathrm{c} 4) \mathrm{c}(\mathrm{Cl}) \mathrm{c} 3) \mathrm{ncn} 2) \mathrm{c} 1$ & 627 & 6.20 \\
\hline 3230 & COc1cccc1-c1cc2c(N[C@@H](CO)c3ccccs3)ncnc2s1 & 629 & $*$ \\
\hline 3231 & $\mathrm{Cc} 1 \mathrm{ccc}(\mathrm{C} 2=\mathrm{NN}(\mathrm{c} 3 \mathrm{nc}(-\mathrm{c} 4 \operatorname{ccc}(\mathrm{Cl}) \operatorname{cc} 4) \operatorname{cs} 3) \mathrm{C}(\mathrm{c} 3 \operatorname{ccc}([\mathrm{N}+](=\mathrm{O})[\mathrm{O}-]) \operatorname{cc} 3) \mathrm{C} 2) \operatorname{cc} 1 \mathrm{C}$ & 630 & 6.20 \\
\hline 3232 & $\mathrm{Brc} 1 \mathrm{ccc}(\mathrm{Nc} 2 \mathrm{ncnc} 3 \mathrm{ccc}(\mathrm{NCc} 4 \mathrm{ccc} 5 \mathrm{c}(\mathrm{c} 4) \mathrm{OCO} 5) \mathrm{cc} 23) \mathrm{c} 1$ & 630 & 6.20 \\
\hline 3233 & $\mathrm{O}=\mathrm{C}(\mathrm{O}[\mathrm{C} @ \mathrm{H}] 1 \mathrm{CN}[\mathrm{C} @ \mathrm{H}](\mathrm{C \# Cc} 2 \mathrm{cc} 3 \mathrm{ncnc}(\mathrm{Nc} 4 \mathrm{ccc}(\mathrm{Sc} 5 \mathrm{cccc}(\mathrm{F}) \mathrm{c} 5) \mathrm{c}(\mathrm{Cl}) \mathrm{c} 4) \mathrm{c} 3 \mathrm{~s} 2) \mathrm{C} 1) \mathrm{N} 1 \mathrm{CCOCC} 1$ & 630 & 6.20 \\
\hline 3234 & $\operatorname{COc} 1 \operatorname{ccc}(\mathrm{NC}(=\mathrm{O}) \mathrm{c} 2 \mathrm{cc}(\mathrm{I}) \operatorname{ccc} 2 \mathrm{O}) \mathrm{cc} 1$ & 630 & $*$ \\
\hline 3235 & $\mathrm{CN}(\mathrm{C}) \mathrm{CCNC}(=\mathrm{O}) \mathrm{Nc} 1 \mathrm{cc} 2 \mathrm{c}(\mathrm{Nc} 3 \mathrm{ccc}(\mathrm{F}) \mathrm{c}(\mathrm{Cl}) \mathrm{c} 3) \mathrm{ncnc} 2 \mathrm{cc} 1 \mathrm{O}[\mathrm{C} @ \mathrm{H}] 1 \mathrm{CCOC} 1$ & 635 & $*$ \\
\hline 3236 & $\mathrm{CN}(\mathrm{C}) \mathrm{CCNN}(\mathrm{NCN}(\mathrm{C}) \mathrm{C}) \mathrm{C}(=\mathrm{O}) \mathrm{Nc} 1 \mathrm{cc} 2 \mathrm{c}(\mathrm{Nc} 3 \mathrm{ccc}(\mathrm{F}) \mathrm{c}(\mathrm{Cl}) \mathrm{c} 3) n \mathrm{ncn} 2 \mathrm{cc} 1 \mathrm{O}[\mathrm{C} @ \mathrm{H}] 1 \mathrm{CCOC} 1$ & 635 & $*$ \\
\hline 3237 & $\mathrm{COc} 1 \mathrm{cc}(\mathrm{N} 2 \mathrm{CCN}(\mathrm{C}) \mathrm{CC} 2) \operatorname{ccc} 1 \mathrm{Nc} 1 \mathrm{ncc}(\mathrm{Cl}) \mathrm{c}(\mathrm{Oc} 2 \mathrm{cccc}(\mathrm{NC}(=\mathrm{O}) \mathrm{CCN}(\mathrm{C}) \mathrm{C}) \mathrm{c} 2) \mathrm{n} 1$ & 638 & 6.20 \\
\hline 3238 & $\mathrm{CC}(\mathrm{C}) \mathrm{n} 1 \mathrm{nc}(-\mathrm{c} 2 \mathrm{ccc} 3 \mathrm{c}(\mathrm{C}=\mathrm{O}) \mathrm{c}[\mathrm{nH}] \mathrm{c} 3 \mathrm{c} 2) \mathrm{c} 2 \mathrm{c}(\mathrm{N}) \mathrm{ncnc} 21$ & 638 & $*$ \\
\hline 3239 & $\mathrm{CCc} 1 \mathrm{ncnc}(\mathrm{Nc} 2 \mathrm{ccc}(\mathrm{OCc} 3 \mathrm{ccc}(\mathrm{F}) \mathrm{c} 3) \mathrm{c}(\mathrm{Cl}) \mathrm{c} 2) \mathrm{c} 1 \mathrm{C}$ & 640 & 6.19 \\
\hline 3240 & Fc1cccc(Cn2ncc3ec(Nc4ncnn5ccc(COC[C@@H]6COCCN6)c45)ccc32)c1 & 640 & $*$ \\
\hline 3241 & $\mathrm{CN} 1 \mathrm{C}(=\mathrm{O}) \mathrm{c} 2 \operatorname{ccc}(\mathrm{NC}(=\mathrm{O}) \mathrm{CSc} 3 \mathrm{nc} 4 \operatorname{cc} 5 \operatorname{ccc} c 5 \operatorname{cc} 4 \mathrm{c}(=\mathrm{O}) \mathrm{n} 3-\mathrm{c} 3 \operatorname{ccc}(\mathrm{S}(\mathrm{N})(=\mathrm{O})=\mathrm{O}) \operatorname{cc} 3) \operatorname{cc} 2 \mathrm{C} 1=\mathrm{O}$ & 640 & $*$ \\
\hline 3242 & $\mathrm{C}=\mathrm{CC}(=\mathrm{O}) \mathrm{Nc} 1 \mathrm{cccc}(\mathrm{NC}(=\mathrm{O}) \mathrm{Nc} 2 \mathrm{nc}(\mathrm{Nc} 3 \mathrm{ccc}(\mathrm{N} 4 \mathrm{CCC}(\mathrm{N} 5 \mathrm{CCOCC} 5) \mathrm{CC} 4) \mathrm{cc} 3 \mathrm{OC}) \mathrm{ncc} 2 \mathrm{Cl}) \mathrm{c} 1$ & 641 & * \\
\hline 3243 & $\mathrm{C}=\mathrm{CC}(=\mathrm{O}) \mathrm{Nc} 1 \mathrm{cccc}(\mathrm{NC}(=\mathrm{O}) \mathrm{Nc} 2 \mathrm{ccnc}(\mathrm{Nc} 3 \mathrm{ccc}(\mathrm{N} 4 \mathrm{CCOCC} 4) \mathrm{cc} 3) \mathrm{n} 2) \mathrm{c} 1$ & 644 & $*$ \\
\hline 3244 & $\mathrm{~N} \# \mathrm{C} / \mathrm{C}(=\mathrm{C} \backslash \mathrm{c} 1 \mathrm{cc}(\mathrm{O}) \mathrm{c}(\mathrm{O}) \mathrm{c}(\mathrm{CSC} 2 \mathrm{ccccc} 2) \mathrm{c} 1) \mathrm{C}(\mathrm{N})=\mathrm{O}$ & 645.65 & $*$ \\
\hline 3245 & $\mathrm{Cc} 1 \mathrm{ncnc}(\mathrm{Nc} 2 \mathrm{ccc}(\mathrm{OCc} 3 \operatorname{ccc}(\mathrm{F}) \mathrm{c} 3) \mathrm{c}(\mathrm{Cl}) \mathrm{c} 2) \mathrm{c} 1 \mathrm{C} \# \mathrm{Cc} 1 \mathrm{cccc} 1$ & 650 & 6.19 \\
\hline 3246 & $\mathrm{Cc} 1 \mathrm{ccc}(\mathrm{C} 2=\mathrm{NN}(\mathrm{C} 3=\mathrm{NC}(\mathrm{c} 4 \mathrm{ccccc} 4) \mathrm{CS} 3) \mathrm{C}(\mathrm{c} 3 \operatorname{ccc} 4 \operatorname{ccccc} 4 \mathrm{c} 3) \mathrm{C} 2) \mathrm{cc} 1 \mathrm{C}$ & 650 & 6.19 \\
\hline 3247 & $\mathrm{CCOc} 1 \mathrm{cc} 2 \mathrm{ncc}(\mathrm{C \# N}) \mathrm{c}(\mathrm{Nc} 3 \mathrm{ccc}(\mathrm{Oc} 4 \mathrm{ccncc} 4) \mathrm{c}(\mathrm{Cl}) \mathrm{c} 3) \mathrm{c} 2 \mathrm{cc} 1 \mathrm{NC}(=\mathrm{O}) / \mathrm{C}=\mathrm{C} / \mathrm{CN}(\mathrm{C}) \mathrm{C}$ & 650 & 6.19 \\
\hline 3248 & $\mathrm{CN}(\mathrm{C}) \mathrm{C} / \mathrm{C}=\mathrm{C} / \mathrm{C}(=\mathrm{O}) \mathrm{Nc} 1 \mathrm{ccc} 2 \mathrm{ncc}(\mathrm{C \# N}) \mathrm{c}(\mathrm{Nc} 3 \mathrm{ccc}(\mathrm{F}) \mathrm{c}(\mathrm{Cl}) \mathrm{c} 3) \mathrm{c} 2 \mathrm{c} 1$ & 650 & 6.19 \\
\hline 3249 & $\mathrm{OB}(\mathrm{O}) \mathrm{c} 1 \mathrm{ccc} 2 \mathrm{ncnc}(\mathrm{Nc} 3 \mathrm{cccc}(\mathrm{Cl}) \mathrm{c} 3) \mathrm{c} 2 \mathrm{c} 1$ & 650 & $*$ \\
\hline 3250 & $\operatorname{COc} 1 \operatorname{cc} 2 n \operatorname{ccc}(\mathrm{Oc} 3 \operatorname{ccc}(\mathrm{NC}(=\mathrm{O}) \mathrm{c} 4 \operatorname{ccc}(\mathrm{C}(\mathrm{C})(\mathrm{C}) \mathrm{C}) \operatorname{cc} 4) \mathrm{c} 3) \mathrm{c} 2 \mathrm{cc} 1 \mathrm{OC}$ & 650 & $*$ \\
\hline 3251 & $\mathrm{Cc} 1 \mathrm{cc} 2 \mathrm{c}(\mathrm{Nc} 3 \operatorname{ccc}(\mathrm{C}) \mathrm{c}(\mathrm{O}) \mathrm{c} 3) \mathrm{ncnn} 2 \mathrm{c} 1$ & 654 & $*$ \\
\hline 3252 & $\mathrm{Cc} 1 \mathrm{cc} 2 \mathrm{cc}(\mathrm{Nc} 3 \mathrm{ccnc} 4 \mathrm{cc}(-\mathrm{c} 5 \mathrm{ccc}(\mathrm{CNCCOCCO}) \mathrm{cc} 5) \operatorname{sc} 34) \operatorname{ccc} 2[\mathrm{nH}] 1$ & 657 & $*$ \\
\hline 3253 & $\mathrm{NC}(=\mathrm{S}) \mathrm{N} 1 \mathrm{~N}=\mathrm{C}(\mathrm{c} 2 \operatorname{ccc}(\mathrm{Cl}) \mathrm{c}(\mathrm{Cl}) \mathrm{c} 2) \mathrm{CC} 1 \mathrm{c} 1 \mathrm{ccc} 2 \operatorname{ccccc} 2 \mathrm{c} 1$ & 660 & 6.18 \\
\hline 3254 & $\mathrm{CN}(\mathrm{C}) \mathrm{C} / \mathrm{C}=\mathrm{C} / \mathrm{C}(=\mathrm{O}) \mathrm{Nc} 1 \mathrm{ccc}(-\mathrm{c} 2 \mathrm{cncc}(\mathrm{CHN}) \mathrm{c} 2 \mathrm{Nc} 2 \operatorname{ccc}(\mathrm{OCc} 3 \operatorname{cccc}(\mathrm{F}) \mathrm{c} 3) \mathrm{c}(\mathrm{Cl}) \mathrm{c} 2) \mathrm{cc} 1$ & 660 & 6.18 \\
\hline 3255 & $\operatorname{CCOC}(=\mathrm{O}) \mathrm{CCCn} 1 \mathrm{c}(=\mathrm{O}) \mathrm{oc} 2 \mathrm{cc} 3 \mathrm{ncnc}(\mathrm{Nc} 4 \mathrm{ccc}(\mathrm{C}(=\mathrm{O}) \mathrm{OCc} 5 \mathrm{ccc}(\mathrm{Cl}) \mathrm{cc} 5) \mathrm{cc} 4) \mathrm{c} 3 \mathrm{cc} 21$ & 660 & $*$ \\
\hline 3256 & $\mathrm{COc} 1 \mathrm{cc} 2 \mathrm{ncnc}(\mathrm{Nc} 3 \mathrm{cc} 4 \mathrm{ccccc} 4 \mathrm{cn} 3) \mathrm{c} 2 \mathrm{cc} 1 \mathrm{OC}$ & 660 & $*$ \\
\hline 3257 & CCOc1cc2ncnc $(\mathrm{C} \# \mathrm{C}[\mathrm{C} @](\mathrm{C})(\mathrm{Cc} 3 \operatorname{cccc} 3) \mathrm{N} 3 \mathrm{CCC}(\mathrm{C}(=\mathrm{O}) \mathrm{O}) \mathrm{CC} 3) \mathrm{c} 2 \mathrm{cc} 1 \mathrm{OCC}$ & 662 & $*$ \\
\hline 3258 & $\operatorname{CCOC}(=\mathrm{O}) \mathrm{C} 1 \mathrm{CCN}([\mathrm{C} @](\mathrm{C})(\mathrm{C} \# \mathrm{Cc} 2 \mathrm{ncnc} 3 \mathrm{cc}(\mathrm{OCC}) \mathrm{c}(\mathrm{OCC}) \mathrm{cc} 23) \mathrm{Cc} 2 \mathrm{ccccc} 2) \mathrm{CC} 1$ & 662 & $*$ \\
\hline 3259 & $\mathrm{Cc} 1 \mathrm{ccc}(-\mathrm{c} 2 \mathrm{nn}(\mathrm{C}(\mathrm{C}) \mathrm{C}) \mathrm{c} 3 \mathrm{ncnc}(\mathrm{N}) \mathrm{c} 23) \mathrm{cc} 1 \mathrm{O}$ & 663 & $*$ \\
\hline 3260 & $\mathrm{Cc} 1 \mathrm{ccc}(\mathrm{Nc} 2 \mathrm{ncnc} 3[\mathrm{nH}] \mathrm{ccc} 23) \mathrm{cc} 1$ & 667.13 & $*$ \\
\hline 3261 & $\mathrm{COc} 1 \mathrm{cc} 2 \mathrm{c}(\mathrm{Nc} 3 \operatorname{ccc}(\mathrm{NC}(=\mathrm{O}) \mathrm{Nc} 4 \mathrm{ccc}(\mathrm{C}) \mathrm{c}(\mathrm{C}) \mathrm{c} 4) \mathrm{cc} 3) \mathrm{ncn} 2 \mathrm{cc} 1 \mathrm{OCCCN} 1 \mathrm{CCN}(\mathrm{C}) \mathrm{CC} 1$ & 668 & $*$ \\
\hline 3262 & $\mathrm{Oc} 1 \mathrm{c}(\mathrm{Cl}) \operatorname{ccc} 1 \mathrm{CN}(\mathrm{Cc} 1 \mathrm{ccc}(\mathrm{F}) \mathrm{cc} 1) \mathrm{C}(=\mathrm{S}) \mathrm{Nc} 1 \mathrm{ccccc} 1$ & 670 & 6.17 \\
\hline 3263 & $\mathrm{COc} 1 \mathrm{ccc}(\mathrm{Nc} 2 \mathrm{ncnc} 3 \mathrm{cc}(\mathrm{N}) \mathrm{ncc} 23) \mathrm{cc} 1$ & 670 & $*$ \\
\hline 3264 & $\mathrm{C}=\mathrm{C}(\mathrm{CN}(\mathrm{C}) \mathrm{C}) \mathrm{C}(=\mathrm{O}) \mathrm{c} 1 \mathrm{ccc}(\mathrm{OCc} 2 \mathrm{cccc} 2) \mathrm{c}(\mathrm{O}) \mathrm{c} 1 . \mathrm{Cl}$ & 670 & $*$ \\
\hline
\end{tabular}




\begin{tabular}{|c|c|c|c|}
\hline 3265 & $\mathrm{Cn} 1 \mathrm{c}(=\mathrm{O}) \mathrm{c}(-\mathrm{c} 2 \mathrm{c}(\mathrm{Cl}) \mathrm{ccc} 2 \mathrm{Cl}) \mathrm{cc} 2 \mathrm{cnc}(\mathrm{Nc} 3 \mathrm{cccc}(\mathrm{Br}) \mathrm{c} 3) \mathrm{nc} 21$ & 670 & $*$ \\
\hline 3266 & $\mathrm{COCCOc} 1 \mathrm{cc}(\mathrm{OC} 2 \mathrm{CCOCC} 2) \mathrm{c} 2 \mathrm{c}(\mathrm{Nc} 3 \mathrm{ccc}(\mathrm{F}) \mathrm{c}(\mathrm{Cl}) \mathrm{c} 3) \mathrm{ncnc} 2 \mathrm{c} 1$ & 671 & $*$ \\
\hline 3267 & $\mathrm{CCC}(=\mathrm{O}) \mathrm{Nc} 1 \mathrm{cccc}(-\mathrm{c} 2 \mathrm{c}[\mathrm{nH}] \mathrm{c} 3 \mathrm{nccc}(-\mathrm{c} 4[\mathrm{nH}] \mathrm{c}(\mathrm{CCCO}) \mathrm{nc} 4-\mathrm{c} 4 \mathrm{ccc}(\mathrm{F}) \mathrm{cc} 4) \mathrm{c} 23) \mathrm{c} 1$ & 673 & $*$ \\
\hline 3268 & $\mathrm{C}=\mathrm{CC}(=\mathrm{O}) \mathrm{Nc} 1 \mathrm{cccc}(-\mathrm{c} 2 \mathrm{c}[\mathrm{nH}] \mathrm{c} 3 \mathrm{nccc}(-\mathrm{c} 4[\mathrm{nH}] \mathrm{c}(\mathrm{CCCO}) \mathrm{nc} 4 \mathrm{C} 4 \mathrm{CC} 4) \mathrm{c} 23) \mathrm{c} 1$ & 673 & $*$ \\
\hline 3269 & $\operatorname{COc} 1 \mathrm{ccc}(\mathrm{Nc} 2 \mathrm{ncnc} 3 \mathrm{ccncc} 23) \mathrm{c}(\mathrm{N}) \mathrm{c} 1$ & 676.08 & $*$ \\
\hline 3270 & $\mathrm{Clc} 1 \mathrm{ccc}(\mathrm{C} 2=\mathrm{NN}(\mathrm{c} 3 \operatorname{cccc} 3) \mathrm{C}(\mathrm{c} 3 \operatorname{ccc} 4 \operatorname{ccc} c 34) \mathrm{C} 2) \mathrm{cc} 1$ & 680 & 6.17 \\
\hline 3271 & $\mathrm{CN} 1 \mathrm{CCN}(\mathrm{Cc} 2 \mathrm{ccc}(\mathrm{NC}(=\mathrm{O}) \mathrm{c} 3 \operatorname{cccc}(\mathrm{NC}(=\mathrm{O}) \mathrm{c} 4 \mathrm{cnc} 5[\mathrm{nH}] \operatorname{ccc} 5 \mathrm{c} 4) \mathrm{c} 3) \mathrm{cc} 2 \mathrm{C}(\mathrm{F})(\mathrm{F}) \mathrm{F}) \mathrm{CC} 1$ & 680 & 6.17 \\
\hline 3272 & $\mathrm{O}=\mathrm{C}(\mathrm{O}[\mathrm{C} @ \mathrm{H}] 1 \mathrm{CN}[\mathrm{C} @ \mathrm{H}](\mathrm{C} \# \mathrm{Cc} 2 \mathrm{cc} 3 \mathrm{ncnc}(\mathrm{Nc} 4 \mathrm{ccc} 5 \mathrm{c}(\mathrm{ccn} 5 \mathrm{Cc} 5 \mathrm{cscn} 5) \mathrm{c} 4) \mathrm{c} 3 \mathrm{~s} 2) \mathrm{C} 1) \mathrm{N} 1 \mathrm{CCOCC} 1$ & 680 & 6.17 \\
\hline 3273 & $\mathrm{C}=\mathrm{CC}(=\mathrm{O}) \mathrm{Nc} 1 \mathrm{cccc}(-\mathrm{c} 2 \mathrm{c}[\mathrm{nH}] \mathrm{c} 3 \mathrm{nccc}(-\mathrm{c} 4[\mathrm{nH}] \mathrm{c}(\mathrm{CCCO}) \mathrm{nc} 4 \mathrm{C}(\mathrm{F})(\mathrm{F}) \mathrm{F}) \mathrm{c} 23) \mathrm{c} 1$ & 680 & $*$ \\
\hline 3274 & $\mathrm{Fc} 1 \mathrm{ccc} 2 \mathrm{c}(\mathrm{Nc} 3 \operatorname{ccc}(\mathrm{Br}) \mathrm{c} 3) \mathrm{ncnc} 2 \mathrm{n} 1$ & 684 & * \\
\hline 3275 & Brc1 ccec(Nc2ncnc3ncece23)c1 & 688 & $*$ \\
\hline 3276 & $\mathrm{CN} 1 \mathrm{CCC}(\mathrm{Oc} 2 \mathrm{ccc} 3 \mathrm{ncnc}(\mathrm{Nc} 4 \mathrm{ccc}(\mathrm{OCc} 5 \mathrm{cnc} \mathrm{n} 5) \mathrm{c}(\mathrm{Cl}) \mathrm{c} 4) \mathrm{c} 23) \mathrm{CC} 1$ & 690 & $*$ \\
\hline 3277 & $\mathrm{O}=\mathrm{c} 1 \mathrm{oc} 2 \mathrm{c}(\mathrm{O}) \mathrm{c}(\mathrm{O}) \mathrm{cc} 3 \mathrm{c}(=\mathrm{O}) \mathrm{oc} 4 \mathrm{c}(\mathrm{O}) \mathrm{c}(\mathrm{O}) \mathrm{cc} 1 \mathrm{c} 4 \mathrm{c} 23$ & 690 & $*$ \\
\hline 3278 & $\mathrm{COc} 1 \mathrm{cc} 2 \mathrm{c}(\mathrm{Nc} 3 \mathrm{ccc}(\mathrm{NC}(=\mathrm{O}) \mathrm{c} 4 \mathrm{ccc}(\mathrm{C}) \mathrm{cc} 4) \mathrm{cc} 3) \mathrm{ncnc} 2 \mathrm{cc} 1 \mathrm{OCCCN} 1 \mathrm{CCN}(\mathrm{C}) \mathrm{CC} 1$ & 690 & $*$ \\
\hline 3279 & $\mathrm{COc} 1 \mathrm{cc} 2 \mathrm{c}(\mathrm{Oc} 3 \mathrm{ccc}(\mathrm{NC}(=\mathrm{O}) \mathrm{c} 4 \mathrm{cn}(-\mathrm{c} 5 \mathrm{cccc} 5 \mathrm{OC}) \mathrm{cn} 4) \mathrm{cc} 3 \mathrm{~F}) \mathrm{ccn} \mathrm{c} 2 \mathrm{cc} 1 \mathrm{OCCCN} 1 \mathrm{CCN}(\mathrm{C}) \mathrm{CC} 1$ & 690 & $*$ \\
\hline 3280 & C[C@@H](c1cccc1)n1ncc2cc(Nc3ncnn4ccc(COC[C@@H]5CNCCO5)c34)ccc21 & 690 & $*$ \\
\hline 3281 & $\operatorname{CCCCCCCCCCCCCCCCCCOC~}(=0) \operatorname{COc} 1 \mathrm{cc}(\mathrm{O}) \mathrm{c} 2 \mathrm{c}(=\mathrm{O}) \mathrm{cc}(-\mathrm{c} 3 \operatorname{ccccc} 3) \mathrm{oc} 2 \mathrm{c} 1$ & 692 & 6.16 \\
\hline 3282 & $\operatorname{CCOC}(=\mathrm{O}) \mathrm{N} 1 \mathrm{CCN}(\mathrm{CCC}(=\mathrm{O}) \mathrm{Nc} 2 \operatorname{cccc}(\mathrm{Oc} 3 \mathrm{nc}(\mathrm{Nc} 4 \mathrm{ccc}(\mathrm{N} 5 \mathrm{CCN}(\mathrm{C}) \mathrm{CC} 5) \mathrm{cc} 4 \mathrm{OC}) \mathrm{ncc} 3 \mathrm{Cl}) \mathrm{c} 2) \mathrm{CC} 1$ & 698 & 6.16 \\
\hline 3283 & $\mathrm{O}=\mathrm{C}(\mathrm{Nc} 1 \mathrm{cc} 2 \mathrm{c}(\mathrm{Nc} 3 \mathrm{ccc}(\mathrm{F}) \mathrm{c}(\mathrm{Cl}) \mathrm{c} 3) \mathrm{ncnc} 2 \mathrm{cc} 1 \mathrm{O}[\mathrm{C} @ \mathrm{H}] 1 \mathrm{CCOC} 1) \mathrm{N} 1 \mathrm{CCC}(\mathrm{F}) \mathrm{CC} 1$ & 699 & $*$ \\
\hline 3284 & $\mathrm{O}=\mathrm{C}(\mathrm{Nc} 1 \mathrm{cc} 2 \mathrm{c}(\mathrm{Nc} 3 \mathrm{ccc}(\mathrm{F}) \mathrm{c}(\mathrm{Cl}) \mathrm{c} 3) \mathrm{ncnc} 2 \mathrm{cc} 1 \mathrm{O}[\mathrm{C} @ \mathrm{H}] 1 \mathrm{CCOC} 1) \mathrm{N}(\mathrm{N} 1 \mathrm{CCC}(\mathrm{F}) \mathrm{CC} 1) \mathrm{N} 1 \mathrm{CCC}(\mathrm{F}) \mathrm{CC} 1$ & 699 & $*$ \\
\hline 3285 & $\mathrm{NC}(=\mathrm{S}) \mathrm{N} / \mathrm{N}=\mathrm{C}(/ \mathrm{C}=\mathrm{C} / \mathrm{c} 1 \mathrm{ccc}(\mathrm{OCc} 2 \mathrm{cccc} 2) \mathrm{cc} 1) \mathrm{c} 1 \mathrm{ccccc} 1$ & 700 & 6.15 \\
\hline 3286 & $\mathrm{COc} 1 \mathrm{cc} 2 \mathrm{c}(\mathrm{cc} 1 \mathrm{OC}) \mathrm{Oc} 1 \mathrm{ncnc}(\mathrm{Oc} 3 \mathrm{ccc}(\mathrm{Br}) \mathrm{c} 3) \mathrm{c} 1 \mathrm{NC} 2$ & 700 & 6.15 \\
\hline 3287 & $\mathrm{~N} \# \mathrm{C} / \mathrm{C}(=\mathrm{C} \backslash \mathrm{c} 1 \mathrm{ccc}(\mathrm{O}) \mathrm{c}(\mathrm{O}) \mathrm{c} 1) \mathrm{C}(=\mathrm{O}) \mathrm{NCCC} 1 \mathrm{cccc} 1$ & 700 & $*$ \\
\hline 3288 & $\mathrm{CC}(\mathrm{C})(\mathrm{C}) \mathrm{CCOC}(=\mathrm{O}) \mathrm{c} 1 \mathrm{cc}(\mathrm{NCc} 2 \mathrm{cc}(\mathrm{O}) \operatorname{ccc} 2 \mathrm{O}) \mathrm{ccc} 1 \mathrm{O}$ & 700 & $*$ \\
\hline 3289 & $\mathrm{O}=\mathrm{C} 1 \mathrm{NC}(=\mathrm{O}) \mathrm{c} 2 \mathrm{cc}(\mathrm{Nc} 3 \operatorname{ccc}(\mathrm{F}) \mathrm{cc} 3) \mathrm{c}(\mathrm{Nc} 3 \operatorname{ccc}(\mathrm{F}) \mathrm{cc} 3) \mathrm{cc} 21$ & 700 & $*$ \\
\hline 3290 & $\mathrm{C}=\mathrm{C}(\mathrm{CN}(\mathrm{C}) \mathrm{C}) \mathrm{C}(=\mathrm{O}) \mathrm{c} 1 \mathrm{ccc}(\mathrm{OS}(=\mathrm{O})(=\mathrm{O}) \mathrm{c} 2 \operatorname{ccc}(\mathrm{C}(=\mathrm{O}) \mathrm{N}(\mathrm{C}) \mathrm{C}) \mathrm{cc} 2) \mathrm{cc} 1 . \mathrm{Cl}$ & 700 & $*$ \\
\hline 3291 & $\operatorname{CCOC}(=\mathrm{O}) \mathrm{CCCc} 1 \mathrm{ccc}(\mathrm{Nc} 2 \mathrm{ncc} 3 \operatorname{cc}(-\mathrm{c} 4 \mathrm{c}(\mathrm{Cl}) \operatorname{ccc} 4 \mathrm{Cl}) \mathrm{c}(=\mathrm{O}) \mathrm{n}(\mathrm{C}) \mathrm{c} 3 \mathrm{n} 2) \mathrm{cc} 1$ & 700 & $*$ \\
\hline 3292 & $\mathrm{CCOc} 1 \mathrm{ccc} 2 \mathrm{cc}(-\mathrm{c} 3 \mathrm{nn}(\mathrm{C}(\mathrm{C}) \mathrm{C}) \mathrm{c} 4 \mathrm{nncnc}(\mathrm{N}) \mathrm{c} 34) \mathrm{ccc} 2 \mathrm{c} 1 . \mathrm{Cl}$ & 700 & $*$ \\
\hline 3293 & $\mathrm{Cc} 1 \mathrm{ccc}(\mathrm{NC}(=\mathrm{O}) \mathrm{c} 2 \operatorname{ccc}(\mathrm{CN} 3 \mathrm{CCN}(\mathrm{C}) \mathrm{CC} 3) \mathrm{cc} 2) \mathrm{cc} 1-\mathrm{c} 1 \mathrm{ccc} 2 \mathrm{ccncc} 2 \mathrm{c} 1$ & 700 & $*$ \\
\hline 3294 & $\mathrm{CN}(\mathrm{C}) \mathrm{c} 1 \mathrm{ccc}(\mathrm{C}=\mathrm{C} 2 \mathrm{CNCC}(=\mathrm{C} \backslash \mathrm{c} 3 \operatorname{ccc}(\mathrm{N}(\mathrm{C}) \mathrm{C}) \mathrm{cc} 3[\mathrm{~N}+](=\mathrm{O})[\mathrm{O}-]) / \mathrm{C} 2=\mathrm{N} \backslash \mathrm{O}) \mathrm{c}([\mathrm{N}+](=\mathrm{O})[\mathrm{O}-]) \mathrm{c} 1$ & 700 & $*$ \\
\hline 3295 & $\operatorname{COc} 1 \operatorname{cc}(/ \mathrm{C}=\mathrm{C}(\backslash \mathrm{CHN}) \mathrm{C}(\mathrm{N})=\mathrm{O}) \operatorname{cc}(\mathrm{CSc} 2 \operatorname{ccccc} 2 \mathrm{C}(=\mathrm{O}) \mathrm{O}) \mathrm{c} 1 \mathrm{O}$ & 707.95 & $*$ \\
\hline 3296 & $\operatorname{Brc} 1 \operatorname{ccc}(\mathrm{C} 2=\mathrm{NN}(\mathrm{c} 3 \operatorname{ccccc} 3) \mathrm{C}(\mathrm{c} 3 \operatorname{ccc} 4 \operatorname{ccccc} 4 \mathrm{c} 3) \mathrm{C} 2) \mathrm{cc} 1$ & 710 & 6.15 \\
\hline 3297 & $\mathrm{O}=\mathrm{C} 1 \mathrm{NC}(=\mathrm{O}) \mathrm{N}(\mathrm{CCc} 2 \operatorname{ccccc} 2) / \mathrm{C} 1=\mathrm{C} / \mathrm{c} 1 \mathrm{ccc}(\mathrm{O}) \mathrm{cc} 1$ & 710 & $*$ \\
\hline 3298 & $\mathrm{CC}(=\mathrm{O}) \mathrm{N} 1 \mathrm{CCN}(\mathrm{Cc} 2 \mathrm{ccn} 3 \mathrm{ncnc}(\mathrm{Nc} 4 \mathrm{ccc} 5 \mathrm{c}(\mathrm{cnn} 5 \mathrm{Cc} 5 \mathrm{cccc}(\mathrm{F}) \mathrm{c} 5) \mathrm{c} 4) \mathrm{c} 23) \mathrm{CC} 1$ & 710 & $*$ \\
\hline 3299 & $\mathrm{Fc} 1 \mathrm{ccc}(-\mathrm{c} 2 \mathrm{nc}(-\mathrm{c} 3 \operatorname{ccccc} 3)[\mathrm{nH}] \mathrm{c} 2-\mathrm{c} 2 \mathrm{ccnc} 3[\mathrm{nH}] \operatorname{ccc} 23) \mathrm{cc} 1$ & 712 & $*$ \\
\hline 3300 & $\mathrm{CCC}(=\mathrm{O}) \mathrm{Nc} 1 \mathrm{cc} 2 \mathrm{c}(\mathrm{Nc} 3 \mathrm{ccc} 4 \mathrm{c}(\mathrm{ccn} 4 \mathrm{Cc} 4 \mathrm{cccnc} 4) \mathrm{c} 3) \mathrm{ncnc} 2 \mathrm{cc} 1 \mathrm{OC}$ & 714 & $*$ \\
\hline 3301 & $\mathrm{CCC}(=\mathrm{O}) \mathrm{N} 1 \mathrm{CC}[\mathrm{C} @ \mathrm{H}](\mathrm{N} 2 \mathrm{C}(=\mathrm{O}) \mathrm{N}(\mathrm{c} 3 \mathrm{cc}(\mathrm{OC}) \mathrm{ccc} 3 \mathrm{~F}) \mathrm{Cc} 3 \mathrm{cnc}(\mathrm{Nc} 4 \mathrm{ccc}(\mathrm{N} 5 \mathrm{CCN}(\mathrm{C}) \mathrm{C}(\mathrm{C}) \mathrm{C} 5) \mathrm{c}(\mathrm{C}) \mathrm{c} 4) \mathrm{nc} 32) \mathrm{C} 1$ & 715 & 6.15 \\
\hline 3302 & 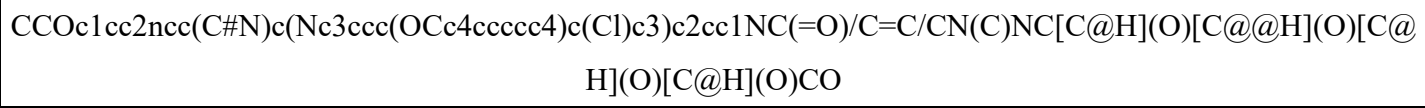 & 719 & 6.14 \\
\hline 3303 & OC[C@@H](Nc1ncnc2sc3c(c12)CCCC3)c1ccccc1 & 720 & $*$ \\
\hline 3304 & $\mathrm{COc} 1 \mathrm{cc}(\mathrm{Nc} 2 \mathrm{c}(\mathrm{C} \# \mathrm{~N}) \mathrm{cnc} 3 \mathrm{cc}(\mathrm{C \# CCCN} 4 \mathrm{CCN}(\mathrm{C}) \mathrm{CC} 4) \mathrm{c}(\mathrm{OC}) \mathrm{cc} 23) \mathrm{c}(\mathrm{Cl}) \mathrm{cc} 1 \mathrm{Cl}$ & 720 & $*$ \\
\hline 3305 & $\mathrm{O}=\mathrm{C}(\mathrm{COc} 1 \mathrm{cc}(\mathrm{F}) \mathrm{c}(\mathrm{F}) \mathrm{c}(\mathrm{F}) \mathrm{c} 1) \mathrm{Nc} 1 \mathrm{cccc}(\mathrm{Oc} 2 \mathrm{cc}(\mathrm{Nc} 3 \mathrm{ccc}(\mathrm{OCc} 4 \mathrm{cccc}(\mathrm{F}) \mathrm{c} 4) \mathrm{c}(\mathrm{Cl}) \mathrm{c} 3) \mathrm{ncn} 2) \mathrm{c} 1$ & 721 & 6.14 \\
\hline 3306 & $\mathrm{O}=\mathrm{C}(\mathrm{Nc} 1 \mathrm{cc} 2 \mathrm{c}(\mathrm{Nc} 3 \operatorname{ccc}(\mathrm{F}) \mathrm{cc} 3) n \mathrm{nc} \operatorname{coc} 1 \mathrm{OCCCN} 1 \mathrm{CCOCC} 1) \mathrm{c} 1 \mathrm{cc}([\mathrm{N}+](=\mathrm{O})[\mathrm{O}-]) \operatorname{ccc} 1 \mathrm{~F}$ & 722 & 6.14 \\
\hline
\end{tabular}




\begin{tabular}{|c|c|c|c|}
\hline 3307 & $\mathrm{CC}(=\mathrm{O}) \mathrm{Nc} 1 \mathrm{ccc} 2 \mathrm{c}(\mathrm{c} 1) \mathrm{C}(\mathrm{c} 1 \mathrm{ccccc} 1 \mathrm{Cl})=\mathrm{Nc} 1 \mathrm{c}[\mathrm{nH}] \mathrm{nc} 1 \mathrm{~N} 2$ & 726 & $*$ \\
\hline 3308 & $\mathrm{COc} 1 \mathrm{cc} 2 \mathrm{ncnc}(\mathrm{N}=\mathrm{Nc} 3 \mathrm{ccc}(\mathrm{F}) \mathrm{c}(\mathrm{Cl}) \mathrm{c} 3) \mathrm{c} 2 \mathrm{cc} 1 \mathrm{OC}$ & 730 & $*$ \\
\hline 3309 & $\mathrm{COc} 1 \mathrm{cc} 2 \mathrm{c}(\mathrm{Nc} 3 \operatorname{ccc}(\mathrm{NC}(=\mathrm{O}) \mathrm{c} 4 \mathrm{ccccc} 4 \mathrm{Cl}) \mathrm{cc} 3) \mathrm{ncnc} 2 \mathrm{cc} 1 \mathrm{OCc} 1 \mathrm{cccc} 1$ & 730 & $*$ \\
\hline 3310 & $\mathrm{C}=\mathrm{CC}(=\mathrm{O}) \mathrm{Nc} 1 \mathrm{ccc}(\mathrm{Oc} 2 \mathrm{nc}(\mathrm{Nc} 3 \operatorname{ccc}(\mathrm{N} 4 \mathrm{CCN}(\mathrm{S}(\mathrm{C})(=\mathrm{O})=\mathrm{O}) \mathrm{CC} 4) \operatorname{cc} 3 \mathrm{OC}) \mathrm{ncc} 2 \mathrm{SC}) \mathrm{c} 1$ & 730.5 & $*$ \\
\hline 3311 & $\mathrm{COc} 1 \mathrm{ccc}(-\mathrm{c} 2 \mathrm{cc} 3 \mathrm{c}(\mathrm{NCc} 4 \mathrm{cccc}(\mathrm{F}) \mathrm{c} 4) \mathrm{ncnc} 3[\mathrm{nH}] 2) \mathrm{cc} 1$ & 731 & $*$ \\
\hline 3312 & $\operatorname{Brc} 1 \mathrm{ccc}(\mathrm{Nc} 2 \mathrm{ncnc} 3 \mathrm{c} 2 \mathrm{sc} 2 \mathrm{nccc} 23) \mathrm{c} 1$ & 732 & $*$ \\
\hline 3313 & $\mathrm{Nc} 1 \mathrm{ncnc} 2 \mathrm{c} 1 \mathrm{c}(-\mathrm{c} 1 \mathrm{ccc} 3[\mathrm{nH}] \mathrm{ccc} 3 \mathrm{c} 1) \mathrm{nn} 2 \mathrm{C} 1 \mathrm{CCCC} 1$ & 734 & $*$ \\
\hline 3314 & $\mathrm{CNC}(=\mathrm{O}) \mathrm{c} 1 \mathrm{ncc}(\mathrm{C} \# \mathrm{Cc} 2 \mathrm{cc}(\mathrm{C}(=\mathrm{O}) \mathrm{Nc} 3 \operatorname{ccc}(\mathrm{CN} 4 \mathrm{CCN}(\mathrm{CCO}) \mathrm{CC} 4) \mathrm{c}(\mathrm{C}(\mathrm{F})(\mathrm{F}) \mathrm{F}) \mathrm{c} 3) \operatorname{ccc} 2 \mathrm{C}) \mathrm{n} 1 \mathrm{C}$ & 736 & $*$ \\
\hline 3315 & $\mathrm{CNC}(=\mathrm{O}) \mathrm{c} 1 \mathrm{nc}(-\mathrm{c} 2 \mathrm{ccc}(\mathrm{Cl}) \mathrm{c}(\mathrm{S}(=\mathrm{O})(=\mathrm{O}) \mathrm{Nc} 3 \operatorname{ccc}(\mathrm{F}) \mathrm{c} 3 \mathrm{~F}) \mathrm{c} 2) \mathrm{cnc} 1 \mathrm{~N}$ & 739 & $*$ \\
\hline 3316 & $\operatorname{Brc} 1 \mathrm{cccc}(\mathrm{Nc} 2 \mathrm{ncnc} 3 \mathrm{c} 2 \mathrm{oc} 2 \mathrm{cccc} 23) \mathrm{c} 1$ & 740 & $*$ \\
\hline 3317 & $\operatorname{COC}(=\mathrm{O}) \mathrm{CN} 1 \mathrm{CCC}(\mathrm{n} 2 \mathrm{cc}(-\mathrm{c} 3 \mathrm{cccc}(\mathrm{O}) \mathrm{c} 3) \mathrm{c} 3 \mathrm{c}(\mathrm{N}) \mathrm{ncnc} 32) \mathrm{C} 1$ & 740 & $*$ \\
\hline 3318 & $\operatorname{COc} 1 \operatorname{cc}(\mathrm{N} 2 \mathrm{CCN}(\mathrm{C}) \mathrm{CC} 2) \operatorname{ccc} 1 \mathrm{Nc} 1 \mathrm{nccc}(\mathrm{Oc} 2 \operatorname{ccc}([\mathrm{N}+](=\mathrm{O})[\mathrm{O}-]) \mathrm{c} 2) \mathrm{n} 1$ & 740 & $*$ \\
\hline 3319 & $\mathrm{COc} 1 \mathrm{cc} 2 \mathrm{ncc}(\mathrm{CHN}) \mathrm{c}(\mathrm{Nc} 3 \mathrm{cccc}(\mathrm{F}) \mathrm{c} 3) \mathrm{c} 2 \mathrm{cc} 1 \mathrm{OC}$ & 740 & $*$ \\
\hline 3320 & $\mathrm{Cn} 1 \mathrm{c} 2 \mathrm{ccccc} 2 \mathrm{c} 2 \mathrm{c}(\mathrm{Nc} 3 \operatorname{cccc}(\mathrm{Br}) \mathrm{c} 3) \mathrm{ncn} \mathrm{c} 21$ & 742 & $*$ \\
\hline 3321 & $\mathrm{CCC}(=\mathrm{O}) \mathrm{Nc} 1 \mathrm{cc} 2 \mathrm{c}(\mathrm{Nc} 3 \operatorname{ccc}(\mathrm{CCc} 4 \mathrm{ccccc} 4) \mathrm{cc} 3) \mathrm{ncnc} 2 \mathrm{cc} 1 \mathrm{OC}$ & 747 & $*$ \\
\hline 3322 & $\mathrm{CC}(\mathrm{C}) \mathrm{c} 1 \mathrm{ccc}(\mathrm{NC}(=\mathrm{O}) \mathrm{c} 2 \mathrm{ccc}(\mathrm{N}(\mathrm{CCCl}) \mathrm{CCCl}) \mathrm{cc} 2) \mathrm{cc} 1$ & 750 & 6.12 \\
\hline 3323 & $\operatorname{COc} 1 \operatorname{ccc}(-\mathrm{c} 2 \mathrm{cn}(\mathrm{C} 3 \mathrm{CCN}(\mathrm{CC}(=\mathrm{O}) \mathrm{N}(\mathrm{C}) \mathrm{C}) \mathrm{CC} 3) \mathrm{c} 3 \operatorname{ncnc}(\mathrm{N}) \mathrm{c} 23) \mathrm{c} 1$ & 750 & $*$ \\
\hline 3324 & $\mathrm{Nc} 1 \mathrm{ccc}(\mathrm{Oc} 2 \mathrm{ccn}(\mathrm{Nc} 3 \operatorname{ccc} c 3 \mathrm{O}) \mathrm{n} 2) \mathrm{c} 1$ & 750 & $*$ \\
\hline 3325 & $\mathrm{Nc} 1 \mathrm{ncnc} 2 \mathrm{c} 1 \mathrm{c}(-\mathrm{c} 1 \mathrm{cc}(\mathrm{O}) \mathrm{cc}(\mathrm{F}) \mathrm{c} 1) \mathrm{nn} 2 \mathrm{C} 1 \mathrm{CCCC} 1$ & 751 & $*$ \\
\hline 3326 & $\mathrm{Cc} 1 \mathrm{oc} 2 \mathrm{ncnc}(\mathrm{Nc} 3 \operatorname{ccc}(\mathrm{Br}) \mathrm{c} 3) \mathrm{c} 2 \mathrm{c} 1 \mathrm{C}(=\mathrm{O}) \mathrm{O}$ & 752 & $*$ \\
\hline 3327 & $\operatorname{Brc} 1 \operatorname{ccc}(\mathrm{Oc} 2 \mathrm{ncnc} 3 \operatorname{ccc} c 23) \mathrm{c} 1$ & 756 & $*$ \\
\hline 3328 & $\mathrm{COc} 1 \mathrm{cc} 2 \mathrm{c}(\mathrm{Nc} 3 \mathrm{ccc}(\mathrm{NC}(=\mathrm{O}) \mathrm{c} 4 \mathrm{ccc}(\mathrm{C}) \mathrm{cc} 4) \mathrm{cc} 3) \mathrm{ncnc} 2 \mathrm{cc} 1 \mathrm{OCCCN} 1 \mathrm{CCOCC} 1$ & 760 & $*$ \\
\hline 3329 & $\mathrm{Nc} 1 \mathrm{ncnc} 2 \mathrm{c} 1 \mathrm{c}(-\mathrm{c} 1 \mathrm{ccc} 3 \mathrm{cn}[\mathrm{nH}] \mathrm{c} 3 \mathrm{c} 1) \mathrm{nn} 2 \mathrm{C} 1 \mathrm{CCCC} 1$ & 760 & $*$ \\
\hline 3330 & $\mathrm{COc} 1 \mathrm{cc} 2 \mathrm{ncc}(\mathrm{C \# N}) \mathrm{c}(\mathrm{Nc} 3 \mathrm{cccc}(\mathrm{SC}) \mathrm{c} 3) \mathrm{c} 2 \mathrm{cc} 1 \mathrm{OC} . \mathrm{Cl}$ & 760 & $*$ \\
\hline 3331 & $\mathrm{COC}(=\mathrm{O}) \mathrm{CNC}(=\mathrm{O}) \mathrm{c} 1 \mathrm{ccc}(\mathrm{Nc} 2 \mathrm{ncnc} 3 \mathrm{cc}(\mathrm{OCCCN} 4 \mathrm{CCOCC} 4) \mathrm{c}(\mathrm{OC}) \mathrm{cc} 23) \mathrm{cc} 1$ & 763 & $*$ \\
\hline 3332 & $\mathrm{C}=\mathrm{CC}(=\mathrm{O}) \mathrm{Nc} 1 \mathrm{ccccc} 1 \mathrm{Nc} 1 \mathrm{nc}(\mathrm{Nc} 2 \mathrm{ccc}(\mathrm{OCCCN} 3 \mathrm{CCOCC} 3) \mathrm{cc} 2) \mathrm{ncc} 1 \mathrm{Cl}$ & 766.6 & $*$ \\
\hline 3333 & $\mathrm{CCOc} 1 \mathrm{cc} 2 \mathrm{ncc}(\mathrm{C \# N}) \mathrm{c}(\mathrm{Nc} 3 \mathrm{ccc}(\mathrm{OCc} 4 \operatorname{ccccc} 4) \mathrm{c}(\mathrm{C} \# \mathrm{~N}) \mathrm{c} 3) \mathrm{c} 2 \mathrm{cc} 1 \mathrm{NC}(=\mathrm{O}) / \mathrm{C}=\mathrm{C} / \mathrm{CN}(\mathrm{C}) \mathrm{C}$ & 768 & 6.11 \\
\hline 3334 & $\mathrm{CCOc} 1 \mathrm{ccc}(-\mathrm{c} 2 \mathrm{nn}(\mathrm{C} 3 \mathrm{CCCC} 3) \mathrm{c} 3 \mathrm{ncnc}(\mathrm{N}) \mathrm{c} 23) \mathrm{cc} 1 \mathrm{O}$ & 768 & $*$ \\
\hline 3335 & $\mathrm{CCOc} 1 \mathrm{cc} 2 \mathrm{ncc}(\mathrm{C \# N}) \mathrm{c}(\mathrm{Nc} 3 \operatorname{ccc}(\mathrm{O}[\mathrm{C} @ @ \mathrm{H}](\mathrm{C}) \mathrm{c} 4 \operatorname{ccccc} 4) \mathrm{c}(\mathrm{Cl}) \mathrm{c} 3) \mathrm{c} 2 \mathrm{cc} 1 \mathrm{NC}(=\mathrm{O}) / \mathrm{C}=\mathrm{C} / \mathrm{CN}(\mathrm{C}) \mathrm{C}$ & 770 & 6.11 \\
\hline 3336 & $\mathrm{COc} 1 \mathrm{cc} 2 \mathrm{ncc}(\mathrm{C \# N}) \mathrm{c}(\mathrm{Nc} 3 \mathrm{ccc}(-\mathrm{n} 4 \mathrm{ccnc} 4) \mathrm{c}(\mathrm{Cl}) \mathrm{c} 3) \mathrm{c} 2 \mathrm{cc} 1 \mathrm{NC}(=\mathrm{O}) / \mathrm{C}=\mathrm{C} / \mathrm{CN}(\mathrm{C}) \mathrm{C}$ & 770 & 6.11 \\
\hline 3337 & $\mathrm{O}=\mathrm{C}(\mathrm{CN} 1 \mathrm{CCN}(\mathrm{CCO}) \mathrm{CC} 1) \mathrm{Nc} 1 \mathrm{cc} 2 \mathrm{c}(\mathrm{Nc} 3 \mathrm{ccc}(\mathrm{F}) \mathrm{c}(\mathrm{Cl}) \mathrm{c} 3) \mathrm{ncnc} 2 \mathrm{~s} 1$ & 770 & $*$ \\
\hline 3338 & $\mathrm{Nc} 1 \mathrm{ccc} 2 \mathrm{ncnc}(\mathrm{Nc} 3 \mathrm{ccccc} 3) \mathrm{c} 2 \mathrm{c} 1$ & 770 & $*$ \\
\hline 3339 & $\mathrm{Nc} 1 \mathrm{ncnc} 2 \mathrm{c} 1 \mathrm{c}(-\mathrm{c} 1 \mathrm{ccc}(\mathrm{F}) \mathrm{c}(\mathrm{O}) \mathrm{c} 1) \mathrm{nn} 2 \mathrm{C} 1 \mathrm{CCCCCC} 1$ & 775 & $*$ \\
\hline 3340 & $\operatorname{COc} 1 \operatorname{ccc}(\mathrm{OC}) \mathrm{c}(\mathrm{Nc} 2 \mathrm{cc}(\mathrm{Nc} 3 \operatorname{ccc}(\mathrm{S}(\mathrm{N})(=\mathrm{O})=\mathrm{O}) \operatorname{cc} 3) \mathrm{ncn} 2) \mathrm{c} 1$ & 779 & $*$ \\
\hline 3341 & $\operatorname{CCOC}(=\mathrm{O}) \operatorname{CCCn} 1 \mathrm{c}(=\mathrm{O}) \mathrm{oc} 2 \mathrm{cc} 3 \mathrm{ncnc}(\mathrm{Nc} 4 \mathrm{ccc}(\mathrm{OCc} 5 \mathrm{nccc}(\mathrm{OCC}(\mathrm{F})(\mathrm{F}) \mathrm{F}) \mathrm{c} 5 \mathrm{C}) \mathrm{cc} 4) \mathrm{c} 3 \mathrm{cc} 21$ & 780 & $*$ \\
\hline 3342 & $\mathrm{O}=\mathrm{C}(\mathrm{O}) / \mathrm{C}=\mathrm{C} / \mathrm{c} 1 \mathrm{cc}(\mathrm{CO}) \mathrm{ccc} 1 \mathrm{CO}$ & 780 & $*$ \\
\hline 3343 & $\mathrm{COc} 1 \mathrm{cc} 2 \mathrm{ncnc}(\mathrm{Nc} 3 \mathrm{cnc} 4 \mathrm{cccc} 4 \mathrm{n} 3) \mathrm{c} 2 \mathrm{cc} 1 \mathrm{OC}$ & 780 & $*$ \\
\hline 3344 & $\mathrm{O}=\mathrm{C} 1 \mathrm{CNCCN}(\mathrm{Cc} 2 \mathrm{ccn} 3 \mathrm{ncnc}(\mathrm{Nc} 4 \mathrm{ccc} 5 \mathrm{c}(\mathrm{cnn} 5 \mathrm{Cc} 5 \mathrm{cccc}(\mathrm{F}) \mathrm{c} 5) \mathrm{c} 4) \mathrm{c} 23) \mathrm{C} 1$ & 780 & $*$ \\
\hline 3345 & $\mathrm{Clc} 1 \mathrm{cccc}(\mathrm{Nc} 2 \mathrm{ncnc} 3 \mathrm{ccc}(\mathrm{NCc} 4 \mathrm{ccc} 5 \mathrm{c}(\mathrm{c} 4) \mathrm{OCCO} 5) \mathrm{cc} 23) \mathrm{c} 1$ & 790 & 6.10 \\
\hline 3346 & $\mathrm{COc} 1 \mathrm{cc} 2 \mathrm{ncc}(\mathrm{C \# N}) \mathrm{c}(\mathrm{Nc} 3 \operatorname{ccc}(\mathrm{Br}) \mathrm{c} 3) \mathrm{c} 2 \mathrm{cc} 1 \mathrm{NC}(=\mathrm{O}) / \mathrm{C}=\mathrm{C} / \mathrm{CN}(\mathrm{C}) \mathrm{C}$ & 790 & 6.10 \\
\hline 3347 & $\mathrm{COCC} \# \mathrm{CC}(=\mathrm{O}) \mathrm{Nc} 1 \mathrm{cc} 2 \mathrm{c}(\mathrm{Nc} 3 \mathrm{cccc}(\mathrm{Br}) \mathrm{c} 3) \mathrm{c}(\mathrm{C \# N}) \mathrm{cnc} 2 \mathrm{cc} 1 \mathrm{OC}$ & 790 & 6.10 \\
\hline 3348 & $\mathrm{CN} 1 \mathrm{CCC}(\mathrm{O})(\mathrm{c} 2 \mathrm{nc}(-\mathrm{c} 3 \mathrm{ccc}(\mathrm{F}) \mathrm{cc} 3) \mathrm{c}(-\mathrm{c} 3 \mathrm{ccncc} 3) \mathrm{o} 2) \mathrm{CC} 1$ & 797 & $*$ \\
\hline 3349 & $\mathrm{CN}(\mathrm{C}) \mathrm{CCCC}(=\mathrm{O}) \mathrm{Nc} 1 \mathrm{cc} 2 \mathrm{c}(\mathrm{Nc} 3 \mathrm{ccc}(\mathrm{F}) \mathrm{c}(\mathrm{Cl}) \mathrm{c} 3) \mathrm{ncnc} 2 \mathrm{~s} 1$ & 799 & $*$ \\
\hline
\end{tabular}




\begin{tabular}{|c|c|c|c|}
\hline 3350 & $\mathrm{CCOc} 1 \mathrm{cc} 2 \mathrm{ncnc}(\mathrm{NC} 3=\mathrm{CC}(=\mathrm{O}) \mathrm{C}(\mathrm{OC})=\mathrm{CC} 3=\mathrm{O}) \mathrm{c} 2 \mathrm{cc} 1 \mathrm{NC}(=\mathrm{O}) / \mathrm{C}=\mathrm{C} / \mathrm{CN}(\mathrm{C}) \mathrm{C}$ & 799.3 & 6.10 \\
\hline 3351 & $\mathrm{COc} 1 \mathrm{ccc}(\mathrm{CNc} 2 \mathrm{ncnc} 3 \mathrm{c} 2 \mathrm{NCc} 2 \mathrm{cc}(\mathrm{OC}) \mathrm{c}(\mathrm{OC}) \mathrm{cc} 2 \mathrm{~N} 3) \mathrm{c} 1$ & 800 & 6.10 \\
\hline 3352 & $\mathrm{CCOc} 1 \mathrm{cc}(\mathrm{N}) \mathrm{c}(\mathrm{C}(=\mathrm{O}) \mathrm{Nc} 2 \mathrm{ccc}(\mathrm{F}) \mathrm{c}(\mathrm{Cl}) \mathrm{c} 2) \mathrm{cc} 1 \mathrm{NC}(=\mathrm{O}) \mathrm{c} 1 \mathrm{ccc}(\mathrm{CN} 2 \mathrm{CCN}(\mathrm{C}) \mathrm{CC} 2) \mathrm{cc} 1$ & 800 & 6.10 \\
\hline 3353 & $\mathrm{CCOc} 1 \mathrm{cc}(\mathrm{N}) \mathrm{c}(\mathrm{C}(=\mathrm{O}) \mathrm{Nc} 2 \mathrm{ccc}(\mathrm{OCc} 3 \operatorname{ccc} n 3) \mathrm{c}(\mathrm{Cl}) \mathrm{c} 2) \mathrm{cc} 1 \mathrm{NC}(=\mathrm{O}) / \mathrm{C}=\mathrm{C} / \mathrm{CN}(\mathrm{C}) \mathrm{C}$ & 800 & 6.10 \\
\hline 3354 & $\mathrm{O}=\mathrm{C}(\mathrm{NC}(\mathrm{CO}) \mathrm{Cc} 1 \mathrm{cccc} 1) \mathrm{c} 1 \mathrm{cc} 2 \mathrm{cc}(\mathrm{Cl}) \operatorname{ccc} 2[\mathrm{nH}] 1$ & 800 & 6.10 \\
\hline 3355 & $\operatorname{CCCCOC}(=\mathrm{O}) \mathrm{Nc} 1 \mathrm{ccc}(\mathrm{Nc} 2 \mathrm{ncnc} 3 \mathrm{cc}(\mathrm{OC}) \mathrm{c}(\mathrm{OC}) \mathrm{cc} 23) \mathrm{cc} 1 . \mathrm{Cl}$ & 800 & $*$ \\
\hline 3356 & $\mathrm{OB}(\mathrm{O}) \mathrm{c} 1 \mathrm{ccc} 2 \mathrm{ncnc}(\mathrm{Nc} 3 \mathrm{ccc}(\mathrm{F}) \mathrm{c}(\mathrm{Cl}) \mathrm{c} 3) \mathrm{c} 2 \mathrm{c} 1$ & 800 & $*$ \\
\hline 3357 & $\operatorname{CCCCOC}(=\mathrm{O}) \mathrm{Nc} 1 \mathrm{ccc}(\mathrm{Nc} 2 \mathrm{ncnc} 3 \mathrm{cc}(\mathrm{OC}) \mathrm{c}(\mathrm{OC}) \mathrm{cc} 23) \mathrm{cc} 1$ & 800 & $*$ \\
\hline 3358 & Nc1ncnc2c1c(-c1eccec1)nn2-c1 cecce1 & 800 & $*$ \\
\hline 3359 & $\mathrm{COc} 1 \mathrm{cc} 2 \mathrm{c}(\mathrm{Nc} 3 \mathrm{ccc}(\mathrm{C \# N}) \mathrm{cc} 3 \mathrm{~F}) \mathrm{ncnc} 2 \mathrm{cc} 1 \mathrm{OC} / \mathrm{C}=\mathrm{C} / \mathrm{CN} 1 \mathrm{CCCC} 1$ & 800 & $*$ \\
\hline 3360 & $\mathrm{COc} 1 \mathrm{cc} 2 \mathrm{c}(\mathrm{Nc} 3 \mathrm{ncc}(\mathrm{CC}(=\mathrm{O}) \mathrm{Nc} 4 \mathrm{ccc}(\mathrm{F}) \mathrm{c} 4) \mathrm{s} 3) \mathrm{ncnc} 2 \mathrm{cc} 1 \mathrm{OCCCN} 1 \mathrm{CCC}(\mathrm{CO}) \mathrm{CC} 1$ & 800 & $*$ \\
\hline 3361 & $\operatorname{COC}(=\mathrm{O}) \mathrm{CN} 1 \mathrm{CCC}(\mathrm{n} 2 \mathrm{cc}(-\mathrm{c} 3 \mathrm{cccc}(\mathrm{O}) \mathrm{c} 3) \mathrm{c} 3 \mathrm{c}(\mathrm{N}) \mathrm{ncnc} 32) \mathrm{CC} 1$ & 800 & $*$ \\
\hline 3362 & $\mathrm{C}=\mathrm{CC}(=\mathrm{O}) \mathrm{Nc} 1 \mathrm{cc} 2 \mathrm{c}(\mathrm{Nc} 3 \operatorname{ccc}(\mathrm{Br}) \mathrm{c} 3) \mathrm{c}(\mathrm{C \# N}) \mathrm{cnc} 2 \mathrm{cc} 1 \mathrm{OC}$ & 810 & 6.09 \\
\hline 3363 & $\mathrm{O}=[\mathrm{N}+]([\mathrm{O}-]) \mathrm{c} 1 \mathrm{ccc} 2 \mathrm{c}(\mathrm{Nc} 3 \mathrm{ccc}(\mathrm{Cl}) \mathrm{c} 3) \mathrm{ncnc} 2 \mathrm{c} 1$ & 810 & $*$ \\
\hline 3364 & c1cncc(Cn2ncc3cc(Nc4ncnn5ccc(COC[C@@H]6CNCCO6)c45)ccc32)c1 & 810 & $*$ \\
\hline 3365 & $\mathrm{CCOC}(=\mathrm{O}) \mathrm{C}(=\mathrm{CNc} 1 \mathrm{ccc} 2 \mathrm{ncnc}(\mathrm{Nc} 3 \operatorname{ccc}(\mathrm{OCc} 4 \mathrm{cccc}(\mathrm{F}) \mathrm{c} 4) \mathrm{c}(\mathrm{Cl}) \mathrm{c} 3) \mathrm{c} 2 \mathrm{c} 1) \mathrm{C}(=\mathrm{O}) \mathrm{OCC}$ & 812 & $*$ \\
\hline 3366 & $\mathrm{COc} 1 \mathrm{cc} 2 \mathrm{c}(\mathrm{Nc} 3 \mathrm{ccc}(\mathrm{NC}(=\mathrm{O}) \mathrm{Nc} 4 \mathrm{ccc}(\mathrm{C}) \mathrm{c}(\mathrm{C}) \mathrm{c} 4) \mathrm{c}(\mathrm{Cl}) \mathrm{c} 3) \mathrm{ncnc} 2 \mathrm{cc} 1 \mathrm{OCCN} 1 \mathrm{CCCCC} 1$ & 817 & $*$ \\
\hline 3367 & $\mathrm{COc} 1 \mathrm{ccc}(\mathrm{C} 2 \mathrm{CC}(\mathrm{c} 3 \mathrm{ccc}(\mathrm{C}) \mathrm{c}(\mathrm{C}) \mathrm{c} 3)=\mathrm{NN} 2 \mathrm{c} 2 \mathrm{nc}(-\mathrm{c} 3 \mathrm{ccc}(\mathrm{Cl}) \mathrm{cc} 3) \mathrm{cs} 2) \mathrm{cc} 1$ & 820 & 6.09 \\
\hline 3368 & $\mathrm{O}=[\mathrm{N}+]([\mathrm{O}-]) \mathrm{c} 1 \mathrm{cccc}(-\mathrm{c} 2 \mathrm{c}(-\mathrm{c} 3 \operatorname{ccccc} 3) \operatorname{oc} 3 \mathrm{ncnc}(\mathrm{N}[\mathrm{C} @ \mathrm{H}](\mathrm{CO}) \mathrm{c} 4 \mathrm{cccc} 4) \mathrm{c} 23) \mathrm{c} 1$ & 820 & $*$ \\
\hline 3369 & COc1cc2ncnc(Ne3nnc4cecce $4 n 3) c 2 c c 1 O C$ & 820 & $*$ \\
\hline 3370 & $\mathrm{COc} 1 \mathrm{cc} 2 \mathrm{ncnc}(\mathrm{N} 3 \mathrm{CCc} 4 \mathrm{cccc} 43) \mathrm{c} 2 \mathrm{cc} 1 \mathrm{OC}$ & 820 & $*$ \\
\hline 3371 & $\mathrm{Cc} 1 \mathrm{cccc}(\mathrm{Nc} 2[\mathrm{nH}] \mathrm{cnc} 3 \mathrm{nc} 4 \mathrm{c}(\mathrm{c} 2-3) \mathrm{CCCC} 4) \mathrm{c} 1$ & 820 & $*$ \\
\hline 3372 & $\mathrm{COc} 1 \mathrm{cc} 2 \mathrm{ncc}(\mathrm{CHN}) \mathrm{c}(\mathrm{Nc} 3 \operatorname{ccc}(\mathrm{N}) \mathrm{c} 3) \mathrm{c} 2 \mathrm{cc} 1 \mathrm{OC}$ & 820 & $*$ \\
\hline 3373 & $\mathrm{O}=\mathrm{C}(\mathrm{Nc} 1 \mathrm{cccc}(\mathrm{Cl}) \mathrm{c} 1) \mathrm{c} 1 \mathrm{ccc}(\mathrm{O}) \mathrm{c}(\mathrm{O}) \mathrm{c} 1 \mathrm{O}$ & 820 & $*$ \\
\hline 3374 & $\mathrm{O}=\mathrm{C}(/ \mathrm{C}=\mathrm{C} / \mathrm{c} 1 \mathrm{ccc}(\mathrm{F}) \mathrm{cc} 1) \mathrm{Nc} 1 \mathrm{cccc}(\mathrm{Oc} 2 \mathrm{cc}(\mathrm{Nc} 3 \operatorname{ccc}(\mathrm{OCc} 4 \mathrm{ccc}(\mathrm{F}) \mathrm{c} 4) \mathrm{c}(\mathrm{Cl}) \mathrm{c} 3) \mathrm{ncn} 2) \mathrm{c} 1$ & 821 & 6.09 \\
\hline 3375 & $\mathrm{O}=\mathrm{C} 1 \mathrm{CO} 2 \mathrm{cc} 3 \mathrm{ncnc}(\mathrm{Nc} 4 \mathrm{ccc}(\mathrm{Br}) \mathrm{cc} 4) \mathrm{c} 3 \mathrm{cc} 2 \mathrm{~N} 1 \mathrm{CCCN} 1 \mathrm{CCOCC} 1$ & 823.9 & $*$ \\
\hline 3376 & $\mathrm{O}=\mathrm{C} 1 \mathrm{COc} 2 \mathrm{cc} 3 \mathrm{ncnc}(\mathrm{Nc} 4 \mathrm{ccc}(\mathrm{C}(\mathrm{F})(\mathrm{F}) \mathrm{F}) \mathrm{c} 4) \mathrm{c} 3 \mathrm{cc} 2 \mathrm{~N} 1 \mathrm{CCCN} 1 \mathrm{CCOCC} 1$ & 829.2 & $*$ \\
\hline 3377 & $\mathrm{Cc} 1 \mathrm{ccc}(\mathrm{C} 2=\mathrm{NN}(\mathrm{C}(\mathrm{N})=\mathrm{S}) \mathrm{C}(\mathrm{c} 3 \operatorname{ccc}(\mathrm{F}) \operatorname{cc} 3) \mathrm{C} 2) \operatorname{cc} 1 \mathrm{C}$ & 830 & 6.08 \\
\hline 3378 & $\mathrm{CN}(\mathrm{CCCOc} 1 \mathrm{ccc} 2 \mathrm{ncnc}(\mathrm{Nc} 3 \operatorname{ccc}(\mathrm{OCc} 4 \mathrm{cccc} 4) \operatorname{cc} 3) \mathrm{c} 2 \mathrm{c} 1) \mathrm{CCS}(\mathrm{C})(=\mathrm{O})=\mathrm{O}$ & 830 & $*$ \\
\hline 3379 & $\operatorname{COC}(=\mathrm{O}) \mathrm{CN} 1 \mathrm{CCC}(\mathrm{n} 2 \mathrm{cc}(-\mathrm{c} 3 \mathrm{cccc}(\mathrm{OC}) \mathrm{c} 3) \mathrm{c} 3 \mathrm{c}(\mathrm{N}) \mathrm{ncnc} 32) \mathrm{C} 1$ & 830 & $*$ \\
\hline 3380 & $\mathrm{Nc} 1 \mathrm{cc} 2 \mathrm{ncnc}(\mathrm{Nc} 3 \mathrm{cccc}(\mathrm{F}) \mathrm{c} 3) \mathrm{c} 2 \mathrm{cn} 1$ & 840 & $*$ \\
\hline 3381 & $\mathrm{COc} 1 \mathrm{cc} 2 \mathrm{ncc}(\mathrm{CHN}) \mathrm{c}(\mathrm{Nc} 3 \mathrm{cccc}(\mathrm{Br}) \mathrm{c} 3 \mathrm{C}) \mathrm{c} 2 \mathrm{cc} 1 \mathrm{OC}$ & 840 & $*$ \\
\hline 3382 & $\mathrm{COc} 1 \mathrm{ccc}(\mathrm{Nc} 2 \mathrm{ncnc} 3 \operatorname{ccc} \mathrm{c} 23) \mathrm{c} 1$ & 842 & $*$ \\
\hline 3383 & $\mathrm{COc} 1 \mathrm{ccc}(-\mathrm{c} 2 \mathrm{c} 3 \mathrm{c} 4 \mathrm{cc}(\mathrm{OCCN}(\mathrm{C}) \mathrm{C}) \mathrm{c}(\mathrm{OC}) \mathrm{cc} 4 \mathrm{oc}(=\mathrm{O}) \mathrm{c} 3 \mathrm{n} 3 \mathrm{ccc} 4 \mathrm{cc}(\mathrm{O}) \mathrm{c}(\mathrm{OC}) \mathrm{cc} 4 \mathrm{c} 23) \mathrm{cc} 1 \mathrm{O} . \mathrm{O}=\mathrm{C}(\mathrm{O}) \mathrm{C}(\mathrm{F})(\mathrm{F}) \mathrm{F}$ & 842.3 & * \\
\hline 3384 & $\mathrm{COc} 1 \mathrm{ccc}(\mathrm{NC}(=\mathrm{O}) / \mathrm{C}=\mathrm{C} / \mathrm{CN}(\mathrm{C}) \mathrm{C}) \mathrm{cc} 1 \mathrm{Nc} 1 \mathrm{ncc}(\mathrm{Cl}) \mathrm{c}(\mathrm{Nc} 2 \mathrm{cnc} 3 \mathrm{ccccc} 3 \mathrm{c} 2) \mathrm{n} 1$ & 848 & $*$ \\
\hline 3385 & $\mathrm{CCOc} 1 \mathrm{cc}([\mathrm{N}+](=\mathrm{O})[\mathrm{O}-]) \mathrm{c}(\mathrm{C}(=\mathrm{O}) \mathrm{Nc} 2 \operatorname{ccc}(\mathrm{OCc} 3 \operatorname{ccc} n 3) \mathrm{c}(\mathrm{Cl}) \mathrm{c} 2) \mathrm{cc} 1 \mathrm{NC}(=\mathrm{O}) / \mathrm{C}=\mathrm{C} / \mathrm{CN}(\mathrm{C}) \mathrm{C}$ & 850 & 6.07 \\
\hline 3386 & $\mathrm{O}=\mathrm{C}(\mathrm{CCc} 1 \mathrm{c}(\mathrm{SSc} 2[\mathrm{nH}] \mathrm{c} 3 \operatorname{cccc} 3 \mathrm{c} 2 \mathrm{CCC}(=\mathrm{O}) \mathrm{NCc} 2 \operatorname{cccc} 2)[\mathrm{nH}] \mathrm{c} 2 \operatorname{ccccc} 12) \mathrm{NCc} 1 \operatorname{ccccc} 1$ & 850 & * \\
\hline 3387 & $\mathrm{C} \# \mathrm{Cc} 1 \mathrm{cccc}(\mathrm{Nc} 2 \mathrm{c}(\mathrm{C \# N}) \mathrm{cnc} 3 \mathrm{cc}(\mathrm{OCCOC}) \mathrm{c}(\mathrm{OCCOC}) \mathrm{cc} 23) \mathrm{c} 1$ & 850 & $*$ \\
\hline 3388 & $\mathrm{COc} 1 \mathrm{cc} 2 \mathrm{ncc}(\mathrm{C \# N}) \mathrm{c}(\mathrm{Nc} 3 \mathrm{cccc}(\mathrm{N}(\mathrm{C}) \mathrm{C}) \mathrm{c} 3) \mathrm{c} 2 \mathrm{cc} 1 \mathrm{OC} . \mathrm{Cl}$ & 850 & $*$ \\
\hline 3389 & $\mathrm{COc} 1 \operatorname{ccc}(\mathrm{NC}(=\mathrm{O}) / \mathrm{C}=\mathrm{C} / \mathrm{c} 2 \mathrm{ccc} 3 \mathrm{c}(\mathrm{c} 2) \mathrm{OCCCCO} 3) \mathrm{cc} 1$ & 850 & $*$ \\
\hline 3390 & $\mathrm{Nc} 1 \mathrm{c}(\mathrm{F}) \mathrm{cccc} 1 \mathrm{Nc} 1 \mathrm{ncnc} 2 \mathrm{ccncc} 12$ & 851.14 & $*$ \\
\hline 3391 & $\mathrm{COc} 1 \mathrm{cc}(\mathrm{Nc} 2 \mathrm{nccc}(\mathrm{Nc} 3 \mathrm{cnc} 4 \mathrm{ccccc} 4 \mathrm{c} 3) \mathrm{n} 2) \mathrm{cc}(\mathrm{OC}) \mathrm{c} 1 \mathrm{OC}$ & 853 & $*$ \\
\hline 3392 & $\mathrm{CN} 1 \mathrm{CCN}(\mathrm{C} / \mathrm{C}=\mathrm{C} / \mathrm{C}(=\mathrm{O}) \mathrm{Nc} 2 \mathrm{cc} 3 \mathrm{c}(\mathrm{Nc} 4 \mathrm{ccc}(\mathrm{Cc} 5 \mathrm{ccc} n 5) \operatorname{cc} 4) n \mathrm{cnc} 3 \mathrm{cn} 2) \mathrm{CC} 1$ & 857 & $*$ \\
\hline
\end{tabular}




\begin{tabular}{|c|c|c|c|}
\hline 3393 & $\mathrm{O}=\mathrm{C}(\mathrm{Nc} 1 \mathrm{cc} 2 \mathrm{c}(\mathrm{Nc} 3 \mathrm{ccc}(\mathrm{F}) \mathrm{c}(\mathrm{Cl}) \mathrm{c} 3) \mathrm{ncnc} 2 \mathrm{cc} 1 \mathrm{O}[\mathrm{C} @ \mathrm{H}] 1 \mathrm{CCOC} 1) \mathrm{N} 1 \mathrm{CCC}(\mathrm{F})(\mathrm{F}) \mathrm{CC} 1$ & 859 & * \\
\hline 3394 & $\mathrm{O}=\mathrm{C}(\mathrm{Nc} 1 \mathrm{cc} 2 \mathrm{c}(\mathrm{Nc} 3 \mathrm{ccc}(\mathrm{F}) \mathrm{c}(\mathrm{Cl}) \mathrm{c} 3) \mathrm{ncnc} 2 \mathrm{cc} 1 \mathrm{O}[\mathrm{C} @ \mathrm{H}] 1 \mathrm{CCOC} 1) \mathrm{N}(\mathrm{N} 1 \mathrm{CCC}(\mathrm{F})(\mathrm{F}) \mathrm{CC} 1) \mathrm{N} 1 \mathrm{CCC}(\mathrm{F})(\mathrm{F}) \mathrm{CC} 1$ & 859 & $*$ \\
\hline 3395 & $\mathrm{COc} 1 \mathrm{ccc}(\mathrm{Nc} 2[\mathrm{nH}] \mathrm{cnc} 3 \mathrm{nc} 4 \mathrm{c}(\mathrm{c} 2-3) \mathrm{CCCC} 4) \mathrm{c} 1$ & 860 & $*$ \\
\hline 3396 & $\mathrm{C}=\mathrm{CC}(=\mathrm{O}) \mathrm{Nc} 1 \mathrm{cc}(\mathrm{Nc} 2 \mathrm{ncc}(\mathrm{I}) \mathrm{c}(\mathrm{Nc} 3 \operatorname{cccc} 3 \mathrm{~S}(=\mathrm{O})(=\mathrm{O}) \mathrm{C}(\mathrm{C}) \mathrm{C}) \mathrm{n} 2) \mathrm{c}(\mathrm{OC}) \mathrm{cc} 1 \mathrm{~N}(\mathrm{C}) \mathrm{CCN}(\mathrm{C}) \mathrm{C}$ & 865 & * \\
\hline 3397 & $\mathrm{C}=\mathrm{C}=\mathrm{Cc} 1 \mathrm{ccc}(\mathrm{Nc} 2 \mathrm{ncnc} 3 \mathrm{cc}(\mathrm{OC}) \mathrm{c}(\mathrm{OC}) \mathrm{cc} 23) \mathrm{cc} 1$ & 865.2 & * \\
\hline 3398 & $\mathrm{CC}(\mathrm{C})(\mathrm{C}) \mathrm{c} 1 \mathrm{ccc}(\mathrm{Nc} 2 \mathrm{ncnc} 3 \mathrm{cc} 4 \mathrm{oc}(=\mathrm{O}) \mathrm{n}(\mathrm{CCOC}(=\mathrm{O}) \mathrm{CBr}) \mathrm{c} 4 \mathrm{cc} 23) \mathrm{cc} 1$ & 870 & 6.06 \\
\hline 3399 & $\operatorname{Oc} 1 \operatorname{ccc}(\mathrm{CN}(\mathrm{Cc} 2 \operatorname{cc}(\mathrm{Br}) \operatorname{cc}(\mathrm{Br}) \mathrm{c} 2 \mathrm{O}) \mathrm{C}(=\mathrm{S}) \mathrm{Nc} 2 \operatorname{ccccc} 2) \operatorname{cc} 1$ & 870 & 6.06 \\
\hline 3400 & Oc1cce $(\mathrm{CNc} 2 \mathrm{ccc} 3 \mathrm{ncnc}(\mathrm{Nc} 4 \mathrm{cccc}(\mathrm{Br}) \mathrm{c} 4) \mathrm{c} 3 \mathrm{c} 2) \mathrm{cc} 1$ & 870 & 6.06 \\
\hline 3401 & Clc1 $\operatorname{cccc}(\mathrm{Nc} 2[\mathrm{nH}] \mathrm{nc} 3 \mathrm{ncnc}(\mathrm{NCc} 4 \operatorname{ccccc} 4) \mathrm{c} 23) \mathrm{c} 1$ & 870 & $*$ \\
\hline 3402 & $\mathrm{COc} 1 \mathrm{cc} 2 \mathrm{ncc}(\mathrm{CHN}) \mathrm{c}(\mathrm{Nc} 3 \operatorname{ccc}([\mathrm{N}+](=\mathrm{O})[\mathrm{O}-]) \mathrm{c} 3) \mathrm{c} 2 \mathrm{cc} 1 \mathrm{OC}$ & 870 & * \\
\hline 3403 & $\mathrm{COc} 1 \mathrm{cc}(\mathrm{OC} 2 \mathrm{CCN}(\mathrm{C}(\mathrm{C})=\mathrm{O}) \mathrm{CC} 2) \mathrm{c} 2 \mathrm{c}(\mathrm{Nc} 3 \mathrm{ccc}(\mathrm{F}) \mathrm{c}(\mathrm{Cl}) \mathrm{c} 3) \mathrm{ncnc} 2 \mathrm{c} 1$ & 873 & $*$ \\
\hline 3404 & $\mathrm{CCN}(\mathrm{CC}) \mathrm{CCC}(=\mathrm{O}) \mathrm{Nc} 1 \mathrm{ccc}(\mathrm{Oc} 2 \mathrm{nc}(\mathrm{Nc} 3 \mathrm{ccc}(\mathrm{N} 4 \mathrm{CCN}(\mathrm{C}) \mathrm{CC} 4) \mathrm{cc} 3 \mathrm{OC}) \mathrm{ncc} 2 \mathrm{Cl}) \mathrm{c} 1$ & 877 & 6.06 \\
\hline 3405 & $\begin{array}{c}\mathrm{C \# C} 1 \mathrm{cccc}(\mathrm{Nc} 2 \mathrm{ncnc} 3 \mathrm{cc}(\mathrm{OCCOC}(=\mathrm{O}) \mathrm{c} 4 \mathrm{ccc}(\mathrm{C}(=\mathrm{O}) \mathrm{Nc} 5 \mathrm{ccc} 6 \mathrm{c}(\mathrm{c} 5) \mathrm{C}(\mathrm{C})(\mathrm{C}) \mathrm{CCC} 6(\mathrm{C}) \mathrm{C}) \mathrm{cc} 4) \mathrm{c}(\mathrm{OCCOC}(=\mathrm{O}) \mathrm{c} 4 \mathrm{ccc}( \\
\mathrm{C}(=\mathrm{O}) \mathrm{Nc} 5 \mathrm{ccc} 6 \mathrm{c}(\mathrm{c} 5) \mathrm{C}(\mathrm{C})(\mathrm{C}) \mathrm{CCC} 6(\mathrm{C}) \mathrm{C}) \mathrm{cc} 4) \mathrm{cc} 23) \mathrm{c} 1\end{array}$ & 880 & 6.06 \\
\hline 3406 & $\mathrm{CC}(\mathrm{C}) \mathrm{Nc} 1 \mathrm{ncn} n 2 \mathrm{ccc}(\mathrm{CN} 3 \mathrm{CCC}(\mathrm{N}) \mathrm{CC} 3) \mathrm{c} 12$ & 880 & $*$ \\
\hline 3407 & $\mathrm{~S}=\mathrm{C}=\mathrm{Nc} 1 \mathrm{ccc} 2 \mathrm{ncnc}(\mathrm{Nc} 3 \mathrm{cccc}(\mathrm{Br}) \mathrm{c} 3) \mathrm{c} 2 \mathrm{c} 1$ & 880 & $*$ \\
\hline 3408 & $\mathrm{CCC}(=\mathrm{O}) \mathrm{Nc} 1 \mathrm{cc} 2 \mathrm{c}(\mathrm{Nc} 3 \operatorname{ccc}(\mathrm{Oc} 4 \mathrm{cccc}(\mathrm{F}) \mathrm{c} 4) \mathrm{cc} 3) \mathrm{ncnc} 2 \mathrm{cc} 1 \mathrm{OC}$ & 881 & $*$ \\
\hline 3409 & $\mathrm{O}=\mathrm{C}(\mathrm{Nc} 1 \mathrm{cc} 2 \mathrm{c}(\mathrm{Nc} 3 \mathrm{ccc}(\mathrm{F}) \mathrm{c}(\mathrm{Cl}) \mathrm{c} 3) \mathrm{ncnc} 2 \mathrm{cc} 1 \mathrm{O}[\mathrm{C} @ \mathrm{H}] 1 \mathrm{CCOC} 1) \mathrm{N} 1 \mathrm{CCCC}(\mathrm{F})(\mathrm{F}) \mathrm{C} 1$ & 884 & $*$ \\
\hline 3410 & $\mathrm{O}=\mathrm{C}(\mathrm{Nc} 1 \mathrm{cc} 2 \mathrm{c}(\mathrm{Nc} 3 \mathrm{ccc}(\mathrm{F}) \mathrm{c}(\mathrm{Cl}) \mathrm{c} 3) n \mathrm{cnc} 2 \mathrm{cc} 1 \mathrm{O}[\mathrm{C} @ \mathrm{H}] 1 \mathrm{CCOC} 1) \mathrm{N}(\mathrm{N} 1 \mathrm{CCCC}(\mathrm{F})(\mathrm{F}) \mathrm{C} 1) \mathrm{N} 1 \mathrm{CCCC}(\mathrm{F})(\mathrm{F}) \mathrm{C} 1$ & 884 & $*$ \\
\hline 3411 & $\begin{array}{c}\mathrm{CCC}(=\mathrm{O}) \mathrm{N} 1 \mathrm{CC}[\mathrm{C} @ \mathrm{H}](\mathrm{N} 2 \mathrm{C}(=\mathrm{O}) \mathrm{N}(\mathrm{c} 3 \mathrm{cc}(\mathrm{OC}) \mathrm{ccc} 3 \mathrm{~F}) \mathrm{Cc} 3 \mathrm{cnc}(\mathrm{Nc} 4 \mathrm{ccc}(\mathrm{N} 5 \mathrm{C}[\mathrm{C} @ \mathrm{H}](\mathrm{C}) \mathrm{N}(\mathrm{C})[\mathrm{C} @ \mathrm{H}](\mathrm{C}) \mathrm{C} 5) \mathrm{c}(\mathrm{C}) \mathrm{c} 4) \mathrm{n} \\
\mathrm{c} 32) \mathrm{C} 1\end{array}$ & 888.2 & 6.05 \\
\hline 3412 & $\mathrm{CCC}(=\mathrm{O}) \mathrm{N} 1 \mathrm{CC}[\mathrm{C} @ \mathrm{H}](\mathrm{N} 2 \mathrm{C}(=\mathrm{O}) \mathrm{N}(\mathrm{c} 3 \mathrm{cccc}(\mathrm{OC}(\mathrm{F})(\mathrm{F}) \mathrm{F}) \mathrm{c} 3) \mathrm{Cc} 3 \mathrm{cnc}(\mathrm{Nc} 4 \mathrm{ccc}(\mathrm{N} 5 \mathrm{CCN}(\mathrm{C}) \mathrm{CC} 5) \mathrm{c}(\mathrm{C}) \mathrm{c} 4) \mathrm{nc} 32) \mathrm{C} 1$ & 889 & 6.05 \\
\hline 3413 & $\mathrm{O}=\mathrm{C} 1 \mathrm{NCc} 2 \mathrm{c}(\mathrm{Oc} 3 \mathrm{ccc}(\mathrm{Nc} 4 \mathrm{ncnc} 5 \mathrm{ccn}(\mathrm{CCO}) \mathrm{c} 45) \mathrm{cc} 3 \mathrm{Cl}) \operatorname{ccc} 21$ & 890 & $*$ \\
\hline 3414 & $\mathrm{COc} 1 \mathrm{cc}(/ \mathrm{C}=\mathrm{C}(\mathrm{CHN}) \mathrm{C}(\mathrm{N})=\mathrm{O}) \operatorname{cc}(\mathrm{CSCc} 2 \operatorname{ccccc} 2) \mathrm{c} 1 \mathrm{O}$ & 891.25 & $*$ \\
\hline 3415 & $\mathrm{CCCCCOc} 1 \mathrm{ccc}(\mathrm{Nc} 2 \mathrm{c}(\mathrm{C \# N}) \mathrm{cnc} 3 \mathrm{cc}(\mathrm{OCC}) \mathrm{c}(\mathrm{NC}(=\mathrm{O}) / \mathrm{C}=\mathrm{C} / \mathrm{CN}(\mathrm{C}) \mathrm{C}) \mathrm{cc} 23) \mathrm{cc} 1 \mathrm{Cl}$ & 894 & 6.05 \\
\hline 3416 & $\mathrm{O}=[\mathrm{N}+]([\mathrm{O}-]) \mathrm{c} 1 \mathrm{ccc} 2 \mathrm{ncnc}(\mathrm{Nc} 3 \mathrm{cccc}(\mathrm{Br}) \mathrm{c} 3) \mathrm{c} 2 \mathrm{c} 1$ & 897 & $*$ \\
\hline 3417 & $\mathrm{CC}(\mathrm{C}) \mathrm{S}(=\mathrm{O})(=\mathrm{O}) \mathrm{c} 1 \mathrm{ccccc} 1 \mathrm{Nc} 1 \mathrm{nc}(\mathrm{N} / \mathrm{N}=\mathrm{C} / \mathrm{c} 2 \operatorname{ccc}(\mathrm{OC}(\mathrm{F})(\mathrm{F}) \mathrm{F}) \mathrm{cc} 2) \mathrm{ncc} 1 \mathrm{Cl}$ & 898 & $*$ \\
\hline 3418 & $\mathrm{CCOc} 1 \mathrm{cc}([\mathrm{N}+](=\mathrm{O})[\mathrm{O}-]) \mathrm{c}(\mathrm{C}(=\mathrm{O}) \mathrm{Nc} 2 \operatorname{ccc}(\mathrm{OCc} 3 \operatorname{ccc} n 3) \mathrm{c}(\mathrm{Cl}) \mathrm{c} 2) \operatorname{cc} 1 \mathrm{NC}(=\mathrm{O}) \mathrm{c} 1 \mathrm{ccc}(\mathrm{CN} 2 \mathrm{CCN}(\mathrm{C}) \mathrm{CC} 2) \mathrm{cc} 1$ & 900 & 6.05 \\
\hline 3419 & $\mathrm{CCc} 1 \mathrm{ccc} 2[\mathrm{nH}] \mathrm{c}(\mathrm{C}(=\mathrm{O}) \mathrm{NC}(\mathrm{CO}) \mathrm{Cc} 3 \operatorname{ccccc} 3) \mathrm{c}(\mathrm{C}(\mathrm{F})(\mathrm{F}) \mathrm{F}) \mathrm{c} 2 \mathrm{c} 1$ & 900 & 6.05 \\
\hline 3420 & $\mathrm{CCOC}(=\mathrm{O}) \mathrm{Nc} 1 \mathrm{cc}(\mathrm{Nc} 2 \mathrm{ncnc} 3 \mathrm{cc}(\mathrm{OC}) \mathrm{c}(\mathrm{OC}) \mathrm{cc} 23) \mathrm{ccc} 1 \mathrm{Cl} . \mathrm{Cl}$ & 900 & * \\
\hline 3421 & $\operatorname{CCCOC}(=\mathrm{O}) \mathrm{Nc} 1 \mathrm{ccc}(\mathrm{Nc} 2 \mathrm{ncnc} 3 \mathrm{cc}(\mathrm{OC}) \mathrm{c}(\mathrm{OC}) \mathrm{cc} 23) \mathrm{cc} 1 \mathrm{C} . \mathrm{Cl}$ & 900 & $*$ \\
\hline 3422 & $\mathrm{CCOC}(=\mathrm{O}) \mathrm{Nc} 1 \mathrm{ccc}(\mathrm{Nc} 2 \mathrm{ncnc} 3 \mathrm{cc}(\mathrm{OC}) \mathrm{c}(\mathrm{OC}) \mathrm{cc} 23) \mathrm{cc} 1 \mathrm{C} . \mathrm{Cl}$ & 900 & $*$ \\
\hline 3423 & $\operatorname{CCOC}(=\mathrm{O}) \mathrm{Nc} 1 \mathrm{cc}(\mathrm{Nc} 2 \mathrm{ncnc} 3 \mathrm{cc}(\mathrm{OC}) \mathrm{c}(\mathrm{OC}) \mathrm{cc} 23) \operatorname{ccc} 1 \mathrm{Cl}$ & 900 & * \\
\hline 3424 & $\mathrm{CCOC}(=\mathrm{O}) \mathrm{Nc} 1 \mathrm{ccc}(\mathrm{Nc} 2 \mathrm{ncnc} 3 \mathrm{cc}(\mathrm{OC}) \mathrm{c}(\mathrm{OC}) \mathrm{cc} 23) \mathrm{cc} 1 \mathrm{C}$ & 900 & * \\
\hline 3425 & $\operatorname{CCCOC}(=\mathrm{O}) \mathrm{Nc} 1 \mathrm{ccc}(\mathrm{Nc} 2 \mathrm{ncnc} 3 \mathrm{cc}(\mathrm{OC}) \mathrm{c}(\mathrm{OC}) \mathrm{cc} 23) \mathrm{cc} 1 \mathrm{C}$ & 900 & $*$ \\
\hline 3426 & $\mathrm{COc} 1 \mathrm{cc} 2 \mathrm{nc}(\mathrm{Cl}) \mathrm{nc}(\mathrm{Nc} 3 \operatorname{ccc}(\mathrm{C}(\mathrm{N})=\mathrm{O}) \mathrm{cc} 3) \mathrm{c} 2 \mathrm{cc} 1 \mathrm{OC}$ & 900 & $*$ \\
\hline 3427 & $\operatorname{CCCCCCNC}(=\mathrm{O}) \mathrm{c} 1 \mathrm{cc}(\mathrm{NCc} 2 \mathrm{cc}(\mathrm{O}) \operatorname{ccc} 2 \mathrm{O}) \operatorname{ccc} 1 \mathrm{O}$ & 900 & * \\
\hline 3428 & $\mathrm{Clc} 1 \mathrm{ccc} 2 \mathrm{c}(\mathrm{c} 1 \mathrm{Nc} 1 \mathrm{ncnc} 3 \mathrm{cc}(\mathrm{OCCCN} 4 \mathrm{CCCC} 4) \mathrm{cc}(\mathrm{OC} 4 \mathrm{CCOCC} 4) \mathrm{c} 13) \mathrm{OCO} 2$ & 900 & * \\
\hline 3429 & $\mathrm{C} \# \mathrm{Cc} 1 \operatorname{cccc}(\mathrm{NC}(=\mathrm{O}) \mathrm{c} 2 \mathrm{cc}(\mathrm{OCCCCCCC}(=\mathrm{O}) \mathrm{NO}) \operatorname{ccc} 2 \mathrm{O}) \mathrm{c} 1$ & 900 & $*$ \\
\hline 3430 & $\mathrm{Cc} 1 \mathrm{cc}(\mathrm{Nc} 2 \mathrm{ncc}(\mathrm{Cl}) \mathrm{c}(\mathrm{Nc} 3 \operatorname{ccccc} 3 \mathrm{~S}(=\mathrm{O})(=\mathrm{O}) \mathrm{C}(\mathrm{C}) \mathrm{C}) \mathrm{n} 2) \mathrm{c}(\mathrm{OC}(\mathrm{C}) \mathrm{C}) \operatorname{cc} 1 \mathrm{C} 1 \mathrm{CCNCC} 1$ & 900 & $*$ \\
\hline 3431 & $\mathrm{C}=\mathrm{CC}(=\mathrm{O}) \mathrm{Nc} 1 \mathrm{cc}(\mathrm{Nc} 2 \mathrm{cc}[\mathrm{nH}] \mathrm{n} 2) \mathrm{nc}(-\mathrm{c} 2 \mathrm{ccccc} 2) \mathrm{n} 1$ & 900 & $*$ \\
\hline 3432 & $\mathrm{C}=\mathrm{CC}(=\mathrm{O}) \mathrm{Nc} 1 \mathrm{ccccc} 1 \mathrm{Oc} 1 \mathrm{nc}(\mathrm{Nc} 2 \mathrm{cc}(\mathrm{C})[\mathrm{nH}] \mathrm{n} 2) \operatorname{cc}(\mathrm{N} 2 \mathrm{CCN}(\mathrm{C}) \mathrm{CC} 2) \mathrm{n} 1$ & 900 & $*$ \\
\hline 3433 & $\mathrm{COc} 1 \mathrm{cccc}(-\mathrm{c} 2 \mathrm{cn}(\mathrm{C} 3 \mathrm{CCN}(\mathrm{CCO}) \mathrm{CC} 3) \mathrm{c} 3 \mathrm{ncnc}(\mathrm{N}) \mathrm{c} 23) \mathrm{c} 1$ & 900 & $*$ \\
\hline
\end{tabular}




\begin{tabular}{|c|c|c|c|}
\hline 3434 & $\mathrm{O}=\mathrm{c} 1 \mathrm{c}(\mathrm{O}) \mathrm{c}(-\mathrm{c} 2 \mathrm{ccc}(\mathrm{O}) \mathrm{c}(\mathrm{O}) \mathrm{c} 2) \mathrm{oc} 2 \mathrm{cc}(\mathrm{O}) \mathrm{cc}(\mathrm{O}) \mathrm{c} 12$ & 900 & $*$ \\
\hline 3435 & $\mathrm{COc} 1 \mathrm{ccc}(\mathrm{Nc} 2 \mathrm{ncnc} 3 \mathrm{oc}(-\mathrm{c} 4 \mathrm{cccc}(\mathrm{N}) \mathrm{c} 4) \mathrm{nc} 23) \mathrm{cc} 1 \mathrm{O}$ & 900 & $*$ \\
\hline 3436 & $\begin{array}{c}\mathrm{Cc} 1 \mathrm{nc}(\mathrm{Nc} 2 \mathrm{ncc}(\mathrm{C}(=\mathrm{O}) \mathrm{Nc} 3 \mathrm{c}(\mathrm{C}) \mathrm{cccc} 3 \mathrm{Cl}) \mathrm{s} 2) \mathrm{cc}(\mathrm{N} 2 \mathrm{CCN}(\mathrm{CCOC}(=\mathrm{O}) \mathrm{OCCN} 3 \mathrm{CCN}(\mathrm{N}=\mathrm{Nc} 4 \mathrm{ccc} 5 \mathrm{ncnc}(\mathrm{Cc} 6 \mathrm{cccc}(\mathrm{Br}) \mathrm{c} 6) \\
\mathrm{c} 5 \mathrm{c} 4) \mathrm{CC} 3) \mathrm{CC} 2) \mathrm{n} 1\end{array}$ & 900 & $*$ \\
\hline 3437 & $\mathrm{CCOC}(\mathrm{OCC}) \mathrm{c} 1 \mathrm{ccc}(\mathrm{C}=\mathrm{C} 2 \mathrm{CNCC}(=\mathrm{C} \backslash \mathrm{c} 3 \operatorname{ccc}(\mathrm{C}(\mathrm{OCC}) \mathrm{OCC}) \mathrm{cc} 3) / \mathrm{C} 2=\mathrm{N} \backslash \mathrm{O}) \mathrm{cc} 1$ & 900 & $*$ \\
\hline 3438 & $\mathrm{Cc} 1 \mathrm{loc} 2 \mathrm{ncnc}(\mathrm{Nc} 3 \operatorname{ccc}(\mathrm{Cl}) \mathrm{c} 3) \mathrm{c} 2 \mathrm{c} 1 \mathrm{C}(=\mathrm{O}) \mathrm{O}$ & 901 & $*$ \\
\hline 3439 & $\mathrm{COc} 1 \mathrm{cc}(\mathrm{Nc} 2 \mathrm{cc}(\mathrm{Nc} 3 \mathrm{ccc}(\mathrm{Cl}) \mathrm{cc} 3) \mathrm{ncn} 2) \mathrm{cc}(\mathrm{OC}) \mathrm{c} 1 \mathrm{OC}$ & 901 & $*$ \\
\hline 3440 & $\mathrm{COc} 1 \mathrm{cc}(-\mathrm{c} 2 \mathrm{nn}(\mathrm{C}(\mathrm{C}) \mathrm{C}) \mathrm{c} 3 \mathrm{ncnc}(\mathrm{N}) \mathrm{c} 23) \mathrm{ccc} 1 \mathrm{O}$ & 908 & $*$ \\
\hline 3441 & $\operatorname{CCOC}(=\mathrm{O}) \mathrm{C} 1=\mathrm{C}(\mathrm{N}) \mathrm{N}(\mathrm{c} 2 \mathrm{cccnc} 2) \mathrm{C} 2=\mathrm{C}(\mathrm{C}(=\mathrm{O}) \mathrm{CCC} 2) \mathrm{C} 1 \mathrm{c} 1 \mathrm{c}(\mathrm{C}) \mathrm{nn}(-\mathrm{c} 2 \mathrm{ccc}(\mathrm{C}) \mathrm{cc} 2) \mathrm{c} 1 \mathrm{Cl}$ & 910 & 6.04 \\
\hline 3442 & $\mathrm{CC} \# \mathrm{CC}(=\mathrm{O}) \mathrm{Nc} 1 \mathrm{cc} 2 \mathrm{c}(\mathrm{Nc} 3 \mathrm{cccc}(\mathrm{Br}) \mathrm{c} 3) \mathrm{c}(\mathrm{C \# N}) \mathrm{cnc} 2 \mathrm{cc} 1 \mathrm{OC}$ & 910 & 6.04 \\
\hline 3443 & $\mathrm{Cc} 1 \mathrm{cccc}(\mathrm{Nc} 2 \mathrm{ncnc} 3 \operatorname{ccc} c 23) \mathrm{c} 1$ & 910 & $*$ \\
\hline 3444 & COc1cc2ncnc(NC3CCc4cecc 43$) \mathrm{c} 2 \mathrm{cc} 1 \mathrm{OC}$ & 910 & $*$ \\
\hline 3445 & $\mathrm{Cn} 1 \mathrm{c}(=\mathrm{O}) \mathrm{c}(-\mathrm{c} 2 \mathrm{c}(\mathrm{Cl}) \mathrm{cccc} 2 \mathrm{Cl}) \mathrm{cc} 2 \mathrm{cnc}(\mathrm{Nc} 3 \mathrm{ccncc} 3) \mathrm{nc} 21$ & 910 & $*$ \\
\hline 3446 & $\mathrm{Clc} 1 \mathrm{cccc}(\mathrm{Nc} 2 \mathrm{ncnc} 3 \mathrm{ccc}(\mathrm{NCc} 4 \mathrm{ccc} 5 \mathrm{c}(\mathrm{c} 4) \mathrm{OCCCCO} 5) \mathrm{cc} 23) \mathrm{c} 1$ & 920 & 6.04 \\
\hline 3447 & $\mathrm{O}=\mathrm{C}(\mathrm{Nc} 1 \mathrm{ccccc} 1 \mathrm{Br}) \mathrm{c} 1 \mathrm{cc}(\mathrm{I}) \mathrm{ccc} 1 \mathrm{O}$ & 920 & $*$ \\
\hline 3448 & $\operatorname{COc} 1 \mathrm{cc} 2 \mathrm{ncnc}(\mathrm{Nc} 3 \operatorname{cccc}(\mathrm{C} \# \mathrm{Cc} 4 \mathrm{ccccc} 4) \mathrm{c} 3) \mathrm{c} 2 \mathrm{cc} 1 \mathrm{OC}$ & 921 & $*$ \\
\hline 3449 & $\mathrm{CC}(\mathrm{C}) \mathrm{n} 1 \mathrm{nc}(-\mathrm{c} 2 \mathrm{ccc}(\mathrm{O}) \mathrm{cc} 2) \mathrm{c} 2 \mathrm{c}(\mathrm{N}) \mathrm{ncnc} 21$ & 922 & $*$ \\
\hline 3450 & $\mathrm{C}=\mathrm{CC}(=\mathrm{O}) \mathrm{Nc} 1 \mathrm{cccc}(\mathrm{N} 2 \mathrm{C}(=\mathrm{O}) \mathrm{N}(\mathrm{C}) \mathrm{Cc} 3 \mathrm{cnc}(\mathrm{NC}) \mathrm{nc} 32) \mathrm{c} 1$ & 929 & 6.03 \\
\hline 3451 & $\operatorname{COCCOCC\# CC~}(=\mathrm{O}) \mathrm{Nc} 1 \mathrm{ccc} 2 \mathrm{ncc}(\mathrm{C} \# \mathrm{~N}) \mathrm{c}(\mathrm{Nc} 3 \mathrm{cccc}(\mathrm{Br}) \mathrm{c} 3) \mathrm{c} 2 \mathrm{c} 1$ & 930 & 6.03 \\
\hline 3452 & $\mathrm{~N} \# \mathrm{C} / \mathrm{C}(=\mathrm{Clc} 1 \mathrm{ccc}(\mathrm{O}) \mathrm{c}(\mathrm{O}) \mathrm{c} 1) \mathrm{C}(=\mathrm{O}) \mathrm{NCCc} 1 \mathrm{cccc} 1$ & 930 & $*$ \\
\hline 3453 & $\operatorname{COCCN}(\mathrm{C}) \mathrm{CCN} 1 \mathrm{CCC}(\mathrm{n} 2 \mathrm{cc}(-\mathrm{c} 3 \mathrm{cccc}(\mathrm{OC}) \mathrm{c} 3) \mathrm{c} 3 \mathrm{c}(\mathrm{N}) \mathrm{ncnc} 32) \mathrm{CC} 1$ & 930 & $*$ \\
\hline 3454 & $\mathrm{CC}(\mathrm{C}) \mathrm{n} 1 \mathrm{nc}(-\mathrm{c} 2 \mathrm{ccc} 3[\mathrm{nH}] \mathrm{c}(=\mathrm{O})[\mathrm{nH}] \mathrm{c} 3 \mathrm{c} 2) \mathrm{c} 2 \mathrm{c}(\mathrm{N}) \mathrm{ncnc} 21$ & 937 & * \\
\hline 3455 & $\mathrm{NC}(=\mathrm{S}) \mathrm{N} 1 \mathrm{~N}=\mathrm{C}(\mathrm{c} 2 \mathrm{ccc}(\mathrm{Cl}) \mathrm{cc} 2) \mathrm{CC} 1 \mathrm{c} 1 \mathrm{cccc} 2 \mathrm{ccccc} 12$ & 940 & 6.03 \\
\hline 3456 & $\mathrm{O}=\mathrm{C}(\mathrm{Nc} 1 \mathrm{ccc}(\mathrm{Br}) \mathrm{cc} 1) \mathrm{c} 1 \mathrm{ccc}(\mathrm{N}(\mathrm{CCCl}) \mathrm{CCCl}) \mathrm{cc} 1$ & 940 & 6.03 \\
\hline 3457 & $\mathrm{O}=\mathrm{C}(/ \mathrm{C}=\mathrm{C} / \mathrm{c} 1 \operatorname{cccc} 1[\mathrm{~N}+](=\mathrm{O})[\mathrm{O}-]) \mathrm{Nc} 1 \operatorname{ccc} 2 \mathrm{ncnc}(\mathrm{Nc} 3 \operatorname{ccc}(\mathrm{Cl}) \mathrm{c} 3) \mathrm{c} 2 \mathrm{c} 1$ & 940 & 6.03 \\
\hline 3458 & $\mathrm{Nc} 1 \mathrm{ccc} 2 \mathrm{c}(\mathrm{Nc} 3 \mathrm{cccc}(\mathrm{Br}) \mathrm{c} 3) \mathrm{ncnc} 2 \mathrm{n} 1$ & 940 & $*$ \\
\hline 3459 & $\mathrm{COc} 1 \mathrm{cc}(/ \mathrm{C}=\mathrm{C}(\backslash \mathrm{C} \# \mathrm{~N}) \mathrm{S}(=\mathrm{O})(=\mathrm{O}) / \mathrm{C}(\mathrm{C} \# \mathrm{~N})=\mathrm{C} / \mathrm{c} 2 \mathrm{cc}(\mathrm{O}) \mathrm{c}(\mathrm{O}) \mathrm{c}(\mathrm{OC}) \mathrm{c} 2) \mathrm{cc}(\mathrm{O}) \mathrm{c} 1 \mathrm{O}$ & 940 & $*$ \\
\hline 3460 & $\mathrm{CCOCc} 1 \mathrm{cn} 2 \mathrm{ncnc}(\mathrm{Nc} 3 \mathrm{ccc} 4 \mathrm{c}(\operatorname{cnn} 4 \mathrm{Cc} 4 \mathrm{ccccc} 4) \mathrm{c} 3) \mathrm{c} 2 \mathrm{c} 1 \mathrm{CC}$ & 950 & $*$ \\
\hline 3461 & $\mathrm{CCCc} 1 \mathrm{c}(\mathrm{C}(=\mathrm{O}) \mathrm{OCC}) \mathrm{cn} 2 \mathrm{ncnc}(\mathrm{Nc} 3 \operatorname{ccc} 4 \mathrm{c}(\operatorname{cnn} 4 \mathrm{Cc} 4 \operatorname{ccccc} 4) \mathrm{c} 3) \mathrm{c} 12$ & 950 & $*$ \\
\hline 3462 & $\mathrm{Cc} 1 \mathrm{cccc}(\mathrm{Nc} 2 \mathrm{ncnc} 3 \operatorname{ccc}(/ \mathrm{N}=\mathrm{N} / \mathrm{N}(\mathrm{C}) \mathrm{CCN}(\mathrm{CCN} 4 \mathrm{CCOCC} 4) \mathrm{CCN}(\mathrm{C}) / \mathrm{N}=\mathrm{N} / \mathrm{c} 4 \mathrm{ccc} 5 \mathrm{ncnc}(\mathrm{Nc} 6 \mathrm{cccc}(\mathrm{C}) \mathrm{c} 6) \mathrm{c} 5 \mathrm{c} 4) \mathrm{cc} 23) \mathrm{c} 1$ & 950 & $*$ \\
\hline 3463 & $\mathrm{Cc} 1 \mathrm{oc} 2 \mathrm{ncnc}(\mathrm{Nc} 3 \operatorname{ccc}(\mathrm{OCc} 4 \mathrm{cccc}(\mathrm{F}) \mathrm{c} 4) \mathrm{c}(\mathrm{Cl}) \mathrm{c} 3) \mathrm{c} 2 \mathrm{c} 1 \mathrm{C}(=\mathrm{O}) \mathrm{NCCO}$ & 951 & $*$ \\
\hline 3464 & $\mathrm{CC}(\mathrm{C}) \mathrm{n} 1 \mathrm{nc}(-\mathrm{c} 2 \mathrm{cccc}(\mathrm{O}) \mathrm{c} 2) \mathrm{c} 2 \mathrm{c}(\mathrm{N}) \mathrm{ncnc} 21$ & 954 & $*$ \\
\hline 3465 & $\mathrm{Cc} 1 \mathrm{cc}(\mathrm{O}) \mathrm{ccc} 1-\mathrm{c} 1 \mathrm{nn}(\mathrm{C}(\mathrm{C}) \mathrm{C}) \mathrm{c} 2 \mathrm{ncnc}(\mathrm{N}) \mathrm{c} 12$ & 954 & $*$ \\
\hline 3466 & $\mathrm{CC}(\mathrm{C}) \mathrm{n} 1 \mathrm{nc}(-\mathrm{c} 2 \mathrm{ccc} 3 \mathrm{c}(\mathrm{ccn} 3 \mathrm{C}) \mathrm{c} 2) \mathrm{c} 2 \mathrm{c}(\mathrm{N}) \mathrm{ncnc} 21$ & 955 & $*$ \\
\hline 3467 & $\mathrm{O}=\mathrm{C}(\mathrm{Nc} 1 \operatorname{ccccc} 1) \mathrm{N}(\mathrm{Cc} 1 \operatorname{ccc}(\mathrm{O}) \operatorname{cc} 1) \mathrm{Cc} 1 \operatorname{ccc}(\mathrm{Cl}) \mathrm{c} 1 \mathrm{O}$ & 960 & 6.02 \\
\hline 3468 & $\operatorname{COCC} \# \mathrm{CC}(=\mathrm{O}) \mathrm{Nc} 1 \mathrm{ccc} 2 \mathrm{ncc}(\mathrm{C \# N}) \mathrm{c}(\mathrm{Nc} 3 \operatorname{cccc}(\mathrm{Br}) \mathrm{c} 3) \mathrm{c} 2 \mathrm{c} 1$ & 960 & 6.02 \\
\hline 3469 & $\mathrm{O}=\mathrm{C} 1 \mathrm{Cc} 2 \mathrm{cc}(\mathrm{Oc} 3 \mathrm{ccc}(\mathrm{Nc} 4 \mathrm{ncnc} 5 \mathrm{ccn}(\mathrm{CCO}) \mathrm{c} 45) \mathrm{cc} 3 \mathrm{Cl}) \operatorname{ccc} 2 \mathrm{~N} 1$ & 960 & $*$ \\
\hline 3470 & $\mathrm{C}=\mathrm{CC}(=\mathrm{O}) \mathrm{Nc} 1 \mathrm{cccc}(\mathrm{Nc} 2 \mathrm{nc}(\mathrm{Nc} 3 \operatorname{ccc}(\mathrm{OCCN} 4 \mathrm{CCOCC} 4) \operatorname{cc} 3) \mathrm{ncc} 2 \mathrm{Cl}) \mathrm{c} 1$ & 961.3 & * \\
\hline 3471 & $\mathrm{CC}(\mathrm{C}) \mathrm{n} 1 \mathrm{nc}(-\mathrm{c} 2 \mathrm{ccc} 3 \mathrm{occc} 3 \mathrm{c} 2) \mathrm{c} 2 \mathrm{c}(\mathrm{N}) \mathrm{ncnc} 21$ & 964 & $*$ \\
\hline 3472 & $\mathrm{Cc} 1 \mathrm{cccc}(\mathrm{C}) \mathrm{c} 1-\mathrm{c} 1 \mathrm{cc}(\mathrm{C}) \mathrm{c} 2 \mathrm{nc}(\mathrm{Nc} 3 \mathrm{ccc}(\mathrm{OCCN} 4 \mathrm{CCCC} 4) \mathrm{cc} 3) \mathrm{nnc} 2 \mathrm{c} 1$ & 965 & * \\
\hline 3473 & $\mathrm{O}=\mathrm{C}(\mathrm{Nc} 1 \mathrm{cc} 2 \mathrm{c}(\mathrm{Nc} 3 \mathrm{ccc}(\mathrm{F}) \mathrm{c}(\mathrm{Cl}) \mathrm{c} 3) \mathrm{ncnc} 2 \mathrm{cc} 1 \mathrm{O}[\mathrm{C} @ \mathrm{H}] 1 \mathrm{CCOC} 1) \mathrm{N} 1 \mathrm{CC}(\mathrm{F}) \mathrm{C} 1$ & 967 & * \\
\hline 3474 & $\mathrm{O}=\mathrm{C}(\mathrm{Nc} 1 \mathrm{cc} 2 \mathrm{c}(\mathrm{Nc} 3 \mathrm{ccc}(\mathrm{F}) \mathrm{c}(\mathrm{Cl}) \mathrm{c} 3) \mathrm{ncnc} 2 \mathrm{cc} 1 \mathrm{O}[\mathrm{C} @ \mathrm{H}] 1 \mathrm{CCOC} 1) \mathrm{N}(\mathrm{N} 1 \mathrm{CC}(\mathrm{F}) \mathrm{C} 1) \mathrm{N} 1 \mathrm{CC}(\mathrm{F}) \mathrm{C} 1$ & 967 & $*$ \\
\hline 3475 & $\mathrm{O}=\mathrm{C} 1 \mathrm{CSC}(\mathrm{N} / \mathrm{N}=\mathrm{C} / \mathrm{c} 2 \mathrm{cc}(\mathrm{F}) \operatorname{ccc} 2 \mathrm{O})=\mathrm{N} 1$ & 970 & 6.01 \\
\hline
\end{tabular}




\begin{tabular}{|c|c|c|c|}
\hline 3476 & $\mathrm{Cc} 1 \mathrm{ccc}(\mathrm{C} 2=\mathrm{NN}(\mathrm{c} 3 \mathrm{nc}(-\mathrm{c} 4 \mathrm{ccc}(\mathrm{Cl}) \mathrm{cc} 4) \operatorname{cs} 3) \mathrm{C}(\mathrm{c} 3 \operatorname{ccc}(\mathrm{O}) \operatorname{cc} 3) \mathrm{C} 2) \operatorname{cc} 1 \mathrm{C}$ & 970 & 6.01 \\
\hline 3477 & $\mathrm{C}=\mathrm{CC}(=\mathrm{O}) \mathrm{Nc} 1 \mathrm{cccc}(-\mathrm{n} 2 \mathrm{c}(=\mathrm{O}) \mathrm{cc}(\mathrm{CCC}) \mathrm{c} 3 \mathrm{cnc}(\mathrm{Nc} 4 \mathrm{ccc}(\mathrm{N} 5 \mathrm{CCN}(\mathrm{C}) \mathrm{CC} 5) \mathrm{cc} 4 \mathrm{OC}) \mathrm{nc} 32) \mathrm{c} 1$ & 970 & $*$ \\
\hline 3478 & $\mathrm{COc} 1 \mathrm{ccc}(\mathrm{N}(\mathrm{CCNN}=\mathrm{Nc} 2 \mathrm{ccc} 3 \mathrm{ncnc}(\mathrm{Nc} 4 \mathrm{cccc}(\mathrm{Cl}) \mathrm{c} 4) \mathrm{c} 3 \mathrm{c} 2) \mathrm{CC}(\mathrm{C}) \mathrm{Cl}) \mathrm{cc} 1$ & 970 & $*$ \\
\hline 3479 & $\mathrm{O}=\mathrm{C}(\mathrm{Cc} 1 \mathrm{nc} 2 \operatorname{cccc} 2[\mathrm{nH}] 1) \mathrm{N} 1 \mathrm{~N}=\mathrm{C}(\mathrm{c} 2 \operatorname{ccc}(\mathrm{Cl}) \mathrm{cc} 2) \mathrm{CC} 1 \mathrm{c} 1 \mathrm{ccc}(\mathrm{Cl}) \mathrm{cc} 1$ & 970 & $*$ \\
\hline 3480 & $\mathrm{C}=\mathrm{CC}(=\mathrm{O}) \mathrm{Nc} 1 \operatorname{ccc}(\mathrm{NC}(=\mathrm{O}) \mathrm{Nc} 2 \operatorname{ccnc}(\mathrm{Nc} 3 \operatorname{ccc}(\mathrm{C}(=\mathrm{O}) \mathrm{N} 4 \mathrm{CCN}(\mathrm{C}) \mathrm{CC} 4) \operatorname{cc} 3 \mathrm{OC}) \mathrm{n} 2) \mathrm{c} 1$ & 972 & $*$ \\
\hline 3481 & $\mathrm{COc} 1 \mathrm{ccc} 2 \mathrm{c}(\mathrm{Nc} 3 \operatorname{ccc}(\mathrm{Br}) \mathrm{c} 3) \mathrm{ncnc} 12$ & 974 & $*$ \\
\hline 3482 & $\operatorname{COc} 1 \operatorname{ccc}(\mathrm{NC}(=\mathrm{O}) / \mathrm{C}=\mathrm{C} / \mathrm{CN}(\mathrm{C}) \mathrm{C}) \operatorname{cc} 1 \mathrm{Nc} 1 \mathrm{ncc}(\mathrm{Cl}) \mathrm{c}(\mathrm{Nc} 2 \operatorname{ccc}(\mathrm{Cl}) \mathrm{cc} 2) \mathrm{n} 1$ & 976 & $*$ \\
\hline 3483 & $\mathrm{Oc} 1 \mathrm{c}(\mathrm{Br}) \operatorname{ccc} 1 \mathrm{CN}(\mathrm{Cc} 1 \mathrm{ccc}(\mathrm{F}) \mathrm{cc} 1) \mathrm{C}(=\mathrm{S}) \mathrm{Nc} 1 \mathrm{ccccc} 1$ & 980 & 6.01 \\
\hline 3484 & $\mathrm{C}=\mathrm{CC}(=\mathrm{O}) \mathrm{Nc} 1 \mathrm{ccc}(\mathrm{Nc} 2 \mathrm{cc}(\mathrm{Nc} 3 \operatorname{ccc}(\mathrm{SCC}(=\mathrm{O}) \mathrm{N} 4 \mathrm{CCOCC} 4) \operatorname{cc} 3) \operatorname{ccc} 2 \mathrm{Cl}) \mathrm{c} 1$ & 980 & $*$ \\
\hline 3485 & $\mathrm{CCOc} 1 \mathrm{cc} 2 \mathrm{ncc}(\mathrm{CHN}) \mathrm{c}(\mathrm{Nc} 3 \mathrm{ccc}(\mathrm{F}) \mathrm{c}(\mathrm{Cl}) \mathrm{c} 3) \mathrm{c} 2 \mathrm{cc} 1 \mathrm{OCC}$ & 980 & $*$ \\
\hline 3486 & $\mathrm{C}=\mathrm{CC}(=\mathrm{O}) \mathrm{Nc} 1 \mathrm{cccc}(\mathrm{Nc} 2 \mathrm{nc}(\mathrm{Nc} 3 \operatorname{ccc}(\mathrm{Cn} 4 \mathrm{ccnc} 4) \mathrm{cc} 3) \mathrm{ncc} 2 \mathrm{~F}) \mathrm{c} 1$ & 987 & $*$ \\
\hline 3487 & $\mathrm{Nc} 1 \mathrm{ccc} 2 \mathrm{c}(\mathrm{c} 1) \mathrm{C}(\mathrm{c} 1 \mathrm{cccc} 1 \mathrm{Cl})=\mathrm{Nc} 1 \mathrm{c}[\mathrm{nH}] \mathrm{nc} 1 \mathrm{~N} 2$ & 989 & $*$ \\
\hline 3488 & $\mathrm{CCOc} 1 \mathrm{cc} 2 \mathrm{ncc}(\mathrm{C \# N}) \mathrm{c}(\mathrm{Nc} 3 \operatorname{ccc}(\mathrm{OCc} 4 \mathrm{cccc} 4) \mathrm{c}(\mathrm{Cl}) \mathrm{c} 3) \mathrm{c} 2 \mathrm{cc} 1 \mathrm{NC}(=\mathrm{O}) / \mathrm{C}=\mathrm{C} / \mathrm{c} 1 \mathrm{ccc} 2 \mathrm{cccnc} 12$ & 990 & 6.00 \\
\hline 3489 & $\mathrm{O}=\mathrm{c} 1 \mathrm{oc} 2 \mathrm{cc} 3 \mathrm{ncnc}(\mathrm{Nc} 4 \mathrm{ccc}(\mathrm{OCc} 5 \mathrm{ccc}(\mathrm{Cl}) \mathrm{cc} 5) \mathrm{cc} 4) \mathrm{c} 3 \mathrm{cc} 2 \mathrm{n} 1 \mathrm{CCCN} 1 \mathrm{CCOCC} 1$ & 990 & $*$ \\
\hline 3490 & $\mathrm{C}=\mathrm{CC}(=\mathrm{O}) \mathrm{Nc} 1 \mathrm{ccc}(\mathrm{Nc} 2 \mathrm{cc}(\mathrm{Nc} 3 \operatorname{ccc}(\mathrm{S}(=\mathrm{O}) \mathrm{CC}(=\mathrm{O}) \mathrm{N} 4 \mathrm{CCOCC} 4) \operatorname{cc} 3) \operatorname{ccc} 2 \mathrm{Cl}) \mathrm{c} 1$ & 992.9 & $*$ \\
\hline 3491 & $\mathrm{C}=\mathrm{CC}(=\mathrm{O}) \mathrm{Nc} 1 \mathrm{cccc}(\mathrm{Oc} 2 \mathrm{nc}(\mathrm{Nc} 3 \operatorname{ccc}(\mathrm{CC}(=\mathrm{O}) \mathrm{N} 4 \mathrm{CCOCC} 4) \mathrm{cc} 3) \mathrm{ncc} 2 \mathrm{Cl}) \mathrm{c} 1$ & 996 & $*$ \\
\hline 3492 & $\mathrm{C}=\mathrm{CC}(=\mathrm{O}) \mathrm{Nc} 1 \mathrm{cccc}(\mathrm{Nc} 2 \mathrm{nc}(\mathrm{Nc} 3 \operatorname{ccc}(/ \mathrm{C}=\mathrm{C} / \mathrm{c} 4 \operatorname{ccc}(\mathrm{C}) \mathrm{cc} 4 \mathrm{C}) \mathrm{cc} 3) \mathrm{ncc} 2 \mathrm{Cl}) \mathrm{c} 1$ & 996.1 & $*$ \\
\hline 3493 & $\mathrm{COc} 1 \mathrm{cc} 2 \mathrm{c}(\mathrm{cc} 1 \mathrm{OC}) \mathrm{Oc} 1 \mathrm{ncnc}(\mathrm{Sc} 3 \operatorname{ccc}(\mathrm{Cl}) \mathrm{c} 3) \mathrm{c} 1 \mathrm{NC} 2$ & 1000 & 6.00 \\
\hline 3494 & $\mathrm{CCOc} 1 \mathrm{cc}(\mathrm{N}) \mathrm{c}(\mathrm{C}(=\mathrm{O}) \mathrm{Nc} 2 \mathrm{ccc}(\mathrm{OCc} 3 \operatorname{ccc} n 3) \mathrm{c}(\mathrm{Cl}) \mathrm{c} 2) \mathrm{cc} 1 \mathrm{NC}(=\mathrm{O}) \mathrm{c} 1 \mathrm{ccc}(\mathrm{CN} 2 \mathrm{CCN}(\mathrm{C}) \mathrm{CC} 2) \mathrm{cc} 1$ & 1000 & 6.00 \\
\hline 3495 & $\mathrm{CCCOC}(=\mathrm{O}) \mathrm{Nc} 1 \mathrm{ccc}(\mathrm{Nc} 2 \mathrm{ncnc} 3 \mathrm{cc}(\mathrm{OC}) \mathrm{c}(\mathrm{OC}) \mathrm{cc} 23) \mathrm{cc} 1 \mathrm{Cl} . \mathrm{Cl}$ & 1000 & $*$ \\
\hline 3496 & $\mathrm{CCOC}(=\mathrm{O}) \mathrm{Nc} 1 \mathrm{ccc}(\mathrm{Nc} 2 \mathrm{ncnc} 3 \mathrm{cc}(\mathrm{OC}) \mathrm{c}(\mathrm{OC}) \mathrm{cc} 23) \mathrm{cc} 1 \mathrm{Cl} . \mathrm{Cl}$ & 1000 & $*$ \\
\hline 3497 & $\operatorname{CCCOC}(=\mathrm{O}) \mathrm{Nc} 1 \mathrm{ccc}(\mathrm{Nc} 2 \mathrm{ncnc} 3 \mathrm{cc}(\mathrm{OC}) \mathrm{c}(\mathrm{OC}) \mathrm{cc} 23) \mathrm{cc} 1 \mathrm{Cl}$ & 1000 & $*$ \\
\hline 3498 & $\operatorname{CCOC}(=\mathrm{O}) \mathrm{Nc} 1 \mathrm{ccc}(\mathrm{Nc} 2 \mathrm{ncnc} 3 \mathrm{cc}(\mathrm{OC}) \mathrm{c}(\mathrm{OC}) \mathrm{cc} 23) \mathrm{cc} 1 \mathrm{Cl}$ & 1000 & $*$ \\
\hline 3499 & $\mathrm{C}=\mathrm{CC}(=\mathrm{O}) \mathrm{Nc} 1 \mathrm{cccc}(\mathrm{Nc} 2 \mathrm{nc}(\mathrm{Nc} 3 \operatorname{ccc}(\mathrm{Cn} 4 \mathrm{ccnc} 4) \mathrm{cc} 3) \mathrm{ncc} 2 \mathrm{Cl}) \mathrm{c} 1$ & 1000 & $*$ \\
\hline 3500 & $\mathrm{CN} 1 \mathrm{C}(=\mathrm{S}) \mathrm{C}(\mathrm{C}(=\mathrm{O}) \mathrm{Nc} 2 \operatorname{ccccc} 2) \mathrm{c} 2 \operatorname{ccccc} 21$ & 1000 & $*$ \\
\hline 3501 & $\mathrm{CC}(\mathrm{C})(\mathrm{C}) \mathrm{OC}(=\mathrm{O}) \mathrm{c} 1 \mathrm{cc}(\mathrm{NCc} 2 \mathrm{cc}(\mathrm{O}) \operatorname{ccc} 2 \mathrm{O}) \operatorname{ccc} 1 \mathrm{O}$ & 1000 & $*$ \\
\hline 3502 & $\mathrm{CC}(\mathrm{C}) \mathrm{c} 1 \mathrm{ccc}(\mathrm{COC}(=\mathrm{O}) \mathrm{c} 2 \mathrm{cc}(\mathrm{NCc} 3 \mathrm{cc}(\mathrm{O}) \mathrm{ccc} 3 \mathrm{O}) \mathrm{ccc} 2 \mathrm{O}) \mathrm{cc} 1$ & 1000 & $*$ \\
\hline 3503 & $\mathrm{O}=\mathrm{C}(\mathrm{Cc} 1 \mathrm{cc}(\mathrm{NCc} 2 \mathrm{cc}(\mathrm{O}) \operatorname{ccc} 2 \mathrm{O}) \operatorname{ccc} 1 \mathrm{O}) \mathrm{NOCc} 1 \mathrm{ccccc} 1$ & 1000 & $*$ \\
\hline 3504 & $\mathrm{O}=[\mathrm{N}+]([\mathrm{O}-]) \mathrm{c} 1 \mathrm{ccc} 2 \mathrm{c}(\mathrm{Nc} 3 \mathrm{cccc}(\mathrm{Br}) \mathrm{c} 3) \mathrm{ncnc} 2 \mathrm{c} 1$ & 1000 & $*$ \\
\hline 3505 & $\mathrm{O}=\mathrm{C}(\mathrm{O}) \mathrm{c} 1 \operatorname{ccc}(\mathrm{S}(=\mathrm{O})(=\mathrm{O}) \mathrm{Oc} 2 \operatorname{ccc}(/ \mathrm{C}=\mathrm{C} /[\mathrm{N}+](=\mathrm{O})[\mathrm{O}-]) \operatorname{cc} 2) \operatorname{cc} 1$ & 1000 & $*$ \\
\hline 3506 & $\mathrm{Nc} 1 \mathrm{cc} 2 \mathrm{ncnc}(\mathrm{NCc} 3 \operatorname{ccc}(\mathrm{Br}) \mathrm{c} 3) \mathrm{c} 2 \mathrm{cn} 1$ & 1000 & $*$ \\
\hline 3507 & $\mathrm{Cn} 1 \mathrm{c}(=\mathrm{O}) \mathrm{c}(-\mathrm{c} 2 \mathrm{c}(\mathrm{Cl}) \mathrm{cccc} 2 \mathrm{Cl}) \mathrm{cc} 2 \mathrm{cnc}(\mathrm{NCCCCCC}(=\mathrm{O}) \mathrm{O}) \mathrm{nc} 21$ & 1000 & $*$ \\
\hline 3508 & $\mathrm{CCN}(\mathrm{CC}) \mathrm{CCCCNc} 1 \mathrm{ncc} 2 \mathrm{cc}(-\mathrm{c} 3 \mathrm{c}(\mathrm{Cl}) \operatorname{cccc} 3 \mathrm{Cl}) \mathrm{c}(\mathrm{NC}(=\mathrm{O}) \mathrm{Nc} 3 \operatorname{ccccc} 3) \mathrm{nc} 2 \mathrm{n} 1$ & 1000 & $*$ \\
\hline 3509 & $\mathrm{COc} 1 \mathrm{cc} 2 \mathrm{c}(\mathrm{Nc} 3 \mathrm{ccc}(\mathrm{C}) \mathrm{cc} 3 \mathrm{~F}) \mathrm{ncn}$ 2 $2 \mathrm{cc} 1 \mathrm{OCC} 1 \mathrm{CCN}(\mathrm{C}) \mathrm{CC} 1$ & 1000 & $*$ \\
\hline 3510 & $\mathrm{COc} 1 \mathrm{cc} 2 \mathrm{ncnc}(\mathrm{Nc} 3 \operatorname{ccc}(\mathrm{Cl}) \mathrm{c}(\mathrm{NC}(=\mathrm{O}) \mathrm{c} 4 \operatorname{cccc}(\mathrm{N}(\mathrm{C}) \mathrm{C}) \mathrm{c} 4) \mathrm{c} 3) \mathrm{c} 2 \mathrm{cc} 1 \mathrm{OC}$ & 1000 & $*$ \\
\hline 3511 & $\operatorname{COc} 1 \mathrm{cc}(/ \mathrm{C}=\mathrm{C}(\backslash \mathrm{C \# N}) \mathrm{C}(\mathrm{N})=\mathrm{O}) \operatorname{cc}(\mathrm{CSCc} 2 \operatorname{cccc} 2 \mathrm{Cl}) \mathrm{c} 1 \mathrm{O}$ & 1000 & $*$ \\
\hline 3512 & $\mathrm{Cc} 1 \mathrm{cccc}(\mathrm{Nc} 2 \mathrm{ncnc} 3 \operatorname{ccc}(\mathrm{N}) \mathrm{cc} 23) \mathrm{c} 1$ & 1000 & $*$ \\
\hline 3513 & $\mathrm{Cc} 1 \mathrm{cc} 2 \mathrm{cc}(\mathrm{Nc} 3 \mathrm{ccnc} 4 \mathrm{cc}(-\mathrm{c} 5 \mathrm{ccc}(\mathrm{CNCCO}) \mathrm{cc} 5) \operatorname{sc} 34) \operatorname{ccc} 2[\mathrm{nH}] 1$ & 1000 & * \\
\hline 3514 & $\mathrm{CC}(\mathrm{C}) \mathrm{n} 1 \mathrm{nc}(-\mathrm{c} 2 \mathrm{cnc} 3 \mathrm{ccccc} 3 \mathrm{c} 2) \mathrm{c} 2 \mathrm{c}(\mathrm{N}) \mathrm{ncnc} 21$ & 1000 & $*$ \\
\hline 3515 & Clc1 $1 \mathrm{ccc}(\mathrm{Nc} 2 \mathrm{ncnc} 3 \mathrm{c} 2 \mathrm{sc} 2 \mathrm{nccc} 23) \mathrm{c} 1$ & 1000 & $*$ \\
\hline 3516 & $\mathrm{Nc} 1 \mathrm{ccc}(-\mathrm{c} 2 \mathrm{ccc}(\mathrm{C}(=\mathrm{O}) \mathrm{Nc} 3 \operatorname{cccc}(\mathrm{O}) \mathrm{c} 3) \mathrm{c}(\mathrm{O}) \mathrm{c} 2) \mathrm{cc} 1$ & 1000 & * \\
\hline 3517 & $\mathrm{CCOC}(=\mathrm{O}) \mathrm{c} 1 \mathrm{c}(\mathrm{OC}) \mathrm{cn} 2 \mathrm{ncnc}(\mathrm{Nc} 3 \mathrm{ccc} 4 \mathrm{c}(\mathrm{cnn} 4 \mathrm{Cc} 4 \mathrm{cccc}(\mathrm{F}) \mathrm{c} 4) \mathrm{c} 3) \mathrm{c} 12$ & 1000 & * \\
\hline 3518 & $\mathrm{C}=\mathrm{CC}(=\mathrm{O}) \mathrm{Nc} 1 \mathrm{ccc}(\mathrm{N} 2 \mathrm{C}(=\mathrm{O}) \mathrm{C} 3 \mathrm{CCCN} 3 \mathrm{C}(=\mathrm{O}) \mathrm{c} 3 \mathrm{cnc}(\mathrm{Nc} 4 \mathrm{ccc}(\mathrm{N} 5 \mathrm{CCN}(\mathrm{C}) \mathrm{CC} 5) \mathrm{cc} 4 \mathrm{OC}) \mathrm{nc} 32) \mathrm{c} 1$ & 1000 & $*$ \\
\hline
\end{tabular}




\begin{tabular}{|c|c|c|c|}
\hline 3519 & $\mathrm{CN} 1 \mathrm{CCN}(\mathrm{c} 2 \mathrm{ccc}(\mathrm{Nc} 3 \mathrm{ncc}(\mathrm{F}) \mathrm{c}(\mathrm{Nc} 4 \mathrm{ccc} 5[\mathrm{nH}] \operatorname{ccc} 5 \mathrm{c} 4) \mathrm{n} 3) \mathrm{cc} 2) \mathrm{CC} 1$ & 1000 & $*$ \\
\hline 3520 & $\mathrm{Cc} 1 \mathrm{cnc}(\mathrm{Nc} 2 \mathrm{ccc}(\mathrm{N} 3 \mathrm{CCN}(\mathrm{C}) \mathrm{CC} 3) \mathrm{cc} 2) \mathrm{nc} 1 \mathrm{Nc} 1 \mathrm{ccc} 2[\mathrm{nH}] \operatorname{ccc} 2 \mathrm{c} 1$ & 1000 & $*$ \\
\hline 3521 & $\mathrm{CN} 1 \mathrm{CCN}(\mathrm{c} 2 \mathrm{ccc}(\mathrm{Nc} 3 \mathrm{ncc}(\mathrm{Br}) \mathrm{c}(\mathrm{Nc} 4 \mathrm{ccc} 5[\mathrm{nH}] \operatorname{ccc} 5 \mathrm{c} 4) \mathrm{n} 3) \mathrm{cc} 2) \mathrm{CC} 1$ & 1000 & $*$ \\
\hline 3522 & $\mathrm{CN} 1 \mathrm{CCN}(\mathrm{c} 2 \mathrm{ccc}(\mathrm{Nc} 3 \mathrm{ncc}(\mathrm{C}(\mathrm{F})(\mathrm{F}) \mathrm{F}) \mathrm{c}(\mathrm{Nc} 4 \mathrm{ccc} 5[\mathrm{nH}] \mathrm{ccc} 5 \mathrm{c} 4) \mathrm{n} 3) \mathrm{cc} 2) \mathrm{CC} 1$ & 1000 & $*$ \\
\hline 3523 & $\mathrm{CN} 1 \mathrm{CCN}(\mathrm{c} 2 \operatorname{ccc}(\mathrm{Nc} 3 \mathrm{ncc}([\mathrm{N}+](=\mathrm{O})[\mathrm{O}-]) \mathrm{c}(\mathrm{Nc} 4 \mathrm{ccc} 5[\mathrm{nH}] \operatorname{ccc} 5 \mathrm{c} 4) \mathrm{n} 3) \mathrm{cc} 2) \mathrm{CC} 1$ & 1000 & $*$ \\
\hline 3524 & $\mathrm{COc} 1 \mathrm{cnc}(\mathrm{Nc} 2 \mathrm{ccc}(\mathrm{N} 3 \mathrm{CCN}(\mathrm{C}) \mathrm{CC} 3) \mathrm{cc} 2) \mathrm{nc} 1 \mathrm{Nc} 1 \mathrm{ccc} 2[\mathrm{nH}] \operatorname{ccc} 2 \mathrm{c} 1$ & 1000 & $*$ \\
\hline 3525 & COc1cec $(-\mathrm{c} 2 \mathrm{c} 3 \mathrm{c} 4 \mathrm{cc}(\mathrm{OC}) \mathrm{c}(\mathrm{O}) \mathrm{cc} 4 \mathrm{oc}(=\mathrm{O}) \mathrm{c} 3 \mathrm{n} 3 \mathrm{ccc} 4 \mathrm{cc}(\mathrm{O}) \mathrm{c}(\mathrm{OC}) \mathrm{cc} 4 \mathrm{c} 23) \mathrm{cc} 1 \mathrm{O}$ & 1000 & $*$ \\
\hline 3526 & $\mathrm{COc} 1 \mathrm{ccc}(-\mathrm{c} 2 \mathrm{c} 3 \mathrm{c} 4 \mathrm{cc}(\mathrm{OC}) \mathrm{c}(\mathrm{OC}) \mathrm{cc} 4 \mathrm{oc}(=\mathrm{O}) \mathrm{c} 3 \mathrm{n} 3 \operatorname{ccc} 4 \mathrm{cc}(\mathrm{O}) \mathrm{c}(\mathrm{OC}) \mathrm{cc} 4 \mathrm{c} 23) \mathrm{cc} 1 \mathrm{O}$ & 1000 & $*$ \\
\hline 3527 & $\begin{array}{c}\text { COc1 } 1 \mathrm{ccc}(- \\
\mathrm{c} 2 \mathrm{c} 3 \mathrm{c} 4 \mathrm{cc}(\mathrm{OCCCN} 5 \mathrm{CCOCC} 5) \mathrm{c}(\mathrm{OCCCN} 5 \mathrm{CCOCC} 5) \mathrm{cc} 4 \mathrm{oc}(=\mathrm{O}) \mathrm{c} 3 \mathrm{n} 3 \mathrm{ccc} 4 \mathrm{cc}(\mathrm{O}) \mathrm{c}(\mathrm{OC}) \mathrm{cc} 4 \mathrm{c} 23) \mathrm{cc} 1 \mathrm{O} . \mathrm{CS}(=\mathrm{O})(=\mathrm{O}) \mathrm{O}\end{array}$ & 1000 & $*$ \\
\hline 3528 & $\mathrm{COc} 1 \mathrm{ccc}(-\mathrm{c} 2 \mathrm{c} 3 \mathrm{c} 4 \mathrm{cc}(\mathrm{OC}) \mathrm{c}(\mathrm{OCCNC}(=\mathrm{N}) \mathrm{N}) \mathrm{cc} 4 \mathrm{oc}(=\mathrm{O}) \mathrm{c} 3 \mathrm{n} 3 \mathrm{ccc} 4 \mathrm{cc}(\mathrm{O}) \mathrm{c}(\mathrm{OC}) \mathrm{cc} 4 \mathrm{c} 23) \mathrm{cc} 1 \mathrm{O} . \mathrm{O}=\mathrm{C}(\mathrm{O}) \mathrm{C}(\mathrm{F})(\mathrm{F}) \mathrm{F}$ & 1000 & $*$ \\
\hline 3529 & $\mathrm{C}=\mathrm{CC}(=\mathrm{O}) \mathrm{Nc} 1 \mathrm{cccc}(\mathrm{N} 2 \mathrm{C}(=\mathrm{O}) \mathrm{N}(\mathrm{C}) \mathrm{Cc} 3 \mathrm{cnc}(\mathrm{Nc} 4 \mathrm{ccc}(\mathrm{N} 5 \mathrm{CCN}(\mathrm{C}) \mathrm{CC} 5) \mathrm{cc} 4 \mathrm{~F}) \mathrm{nc} 32) \mathrm{c} 1$ & 1000 & $*$ \\
\hline 3530 & $\mathrm{COc} 1 \mathrm{cc}(\mathrm{N} 2 \mathrm{CCN}(\mathrm{C}) \mathrm{CC} 2) \operatorname{ccc} 1 \mathrm{Nc} 1 \mathrm{ncc} 2 \mathrm{c}(\mathrm{n} 1) \mathrm{N}(\mathrm{c} 1 \mathrm{cccc}(\mathrm{N}) \mathrm{c} 1) \mathrm{C}(=\mathrm{O}) \mathrm{N}(\mathrm{C}) \mathrm{C} 2$ & 1000 & $*$ \\
\hline 3531 & Br.CC(Nc1ncnc2[nH]c(-c3ecc(O)cc3)cc12)c1 cccc2 $\operatorname{ccccc} 12$ & 1008 & $*$ \\
\hline 3532 & $\operatorname{CCCCCCCCCCCCCCOC}(=\mathrm{O}) \operatorname{COc} 1 \mathrm{cc}(\mathrm{O}) \mathrm{c} 2 \mathrm{c}(=\mathrm{O}) \mathrm{cc}(-\mathrm{c} 3 \operatorname{ccccc} 3) \mathrm{oc} 2 \mathrm{c} 1$ & 1010 & 6.00 \\
\hline 3533 & $\mathrm{C}=\mathrm{CC}(=\mathrm{O}) \mathrm{Nc} 1 \mathrm{cccc}(\mathrm{Oc} 2 \mathrm{cc}(\mathrm{Nc} 3 \mathrm{ccc}(\mathrm{SCCCN} 4 \mathrm{CCOCC} 4) \operatorname{cc} 3) \operatorname{ccc} 2 \mathrm{Cl}) \mathrm{c} 1$ & 1012 & $*$ \\
\hline 3534 & $\mathrm{O}=\mathrm{C}(/ \mathrm{C}=\mathrm{C} / \mathrm{c} 1 \operatorname{ccccc} 1[\mathrm{~N}+](=\mathrm{O})[\mathrm{O}-]) \mathrm{Nc} 1 \mathrm{ccc} 2 \mathrm{ncnc}(\mathrm{Nc} 3 \operatorname{ccc}(\mathrm{Br}) \mathrm{c} 3) \mathrm{c} 2 \mathrm{c} 1$ & 1020 & 5.99 \\
\hline 3535 & $\mathrm{Brc} 1 \mathrm{ccc}(\mathrm{Nc} 2 \mathrm{ncnc} 3 \mathrm{ccc}(\mathrm{NCc} 4 \mathrm{ccc} 5 \mathrm{c}(\mathrm{c} 4) \mathrm{OCCO} 5) \mathrm{cc} 23) \mathrm{c} 1$ & 1020 & 5.99 \\
\hline 3536 & $\mathrm{CCOC}(=\mathrm{O}) \mathrm{C}(=\mathrm{CNc} 1 \mathrm{ccc} 2 \mathrm{ncnc}(\mathrm{Nc} 3 \operatorname{ccc}(\mathrm{OCc} 4 \operatorname{ccc} n 4) \mathrm{c}(\mathrm{Cl}) \mathrm{c} 3) \mathrm{c} 2 \mathrm{c} 1) \mathrm{C}(=\mathrm{O}) \mathrm{OCC}$ & 1020 & $*$ \\
\hline 3537 & $\mathrm{CC}(\mathrm{C})[\mathrm{C} @ @ \mathrm{H}](\mathrm{NC}(=\mathrm{O}) \mathrm{OC}(\mathrm{C})(\mathrm{C}) \mathrm{C}) \mathrm{C}(=\mathrm{O}) \mathrm{Nc} 1 \mathrm{ccc} 2 \mathrm{ncnc}(\mathrm{Nc} 3 \mathrm{ccc}(\mathrm{F}) \mathrm{c}(\mathrm{Cl}) \mathrm{c} 3) \mathrm{c} 2 \mathrm{c} 1$ & 1021 & $*$ \\
\hline 3538 & $\mathrm{CC}(\mathrm{C}) \mathrm{Nc} 1 \mathrm{ncn} 2 \mathrm{oc}(-\mathrm{c} 3 \mathrm{ccc}(\mathrm{OCCN} 4 \mathrm{CCCC} 4) \mathrm{cc} 3) \mathrm{c}(-\mathrm{c} 3 \mathrm{cccc} 3) \mathrm{c} 12$ & 1029 & $*$ \\
\hline 3539 & $\mathrm{CCOC}(=\mathrm{O}) \mathrm{C} 1=\mathrm{C}(\mathrm{N}) \mathrm{N}(\mathrm{c} 2 \mathrm{cccnc} 2) \mathrm{C} 2=\mathrm{C}(\mathrm{C}(=\mathrm{O}) \mathrm{CC}(\mathrm{C})(\mathrm{C}) \mathrm{C} 2) \mathrm{C} 1 \mathrm{c} 1 \mathrm{c}(\mathrm{C}) \mathrm{nn}(-\mathrm{c} 2 \mathrm{ccc}(\mathrm{Cl}) \mathrm{cc} 2) \mathrm{c} 1 \mathrm{Cl}$ & 1030 & 5.99 \\
\hline 3540 & $\mathrm{C}=\mathrm{CC}(=\mathrm{O}) \mathrm{Nc} 1 \mathrm{ccc}(\mathrm{Nc} 2 \mathrm{cc}(\mathrm{Nc} 3 \operatorname{ccc}(\mathrm{S}(=\mathrm{O}) \mathrm{CCCN} 4 \mathrm{CCOCC} 4) \operatorname{cc} 3) \operatorname{ccc} 2 \mathrm{Cl}) \mathrm{c} 1$ & 1035 & $*$ \\
\hline 3541 & $\mathrm{C}=\mathrm{CC}(=\mathrm{O}) \mathrm{Nc} 1 \mathrm{cccc}(\mathrm{Nc} 2 \mathrm{nc}(\mathrm{Nc} 3 \mathrm{ccc}(/ \mathrm{C}=\mathrm{C} / \mathrm{c} 4 \mathrm{cc}(\mathrm{Cl}) \mathrm{cc}(\mathrm{Cl}) \mathrm{c} 4) \mathrm{cc} 3) \mathrm{ncc} 2 \mathrm{Cl}) \mathrm{c} 1$ & 1037 & $*$ \\
\hline 3542 & $\mathrm{COc} 1 \mathrm{ccc}(\mathrm{C} 2=\mathrm{NN}(\mathrm{C}(\mathrm{N})=\mathrm{S}) \mathrm{C}(\mathrm{c} 3 \operatorname{ccc} 4 \operatorname{ccccc} 4 \mathrm{c} 3) \mathrm{C} 2) \mathrm{cc} 1$ & 1040 & 5.98 \\
\hline 3543 & $\mathrm{Cc} 1 \mathrm{ccc}(\mathrm{C} 2 \mathrm{CC}(\mathrm{c} 3 \operatorname{ccc}(\mathrm{C}) \mathrm{c}(\mathrm{C}) \mathrm{c} 3)=\mathrm{NN} 2 \mathrm{c} 2 \mathrm{nc}(-\mathrm{c} 3 \mathrm{ccc}(\mathrm{Cl}) \mathrm{cc} 3) \operatorname{cs} 2) \mathrm{cc} 1$ & 1040 & 5.98 \\
\hline 3544 & $\mathrm{COCCNC} / \mathrm{C}=\mathrm{C} / \mathrm{C}(=\mathrm{O}) \mathrm{Nc} 1 \mathrm{cc} 2 \mathrm{c}(\mathrm{Nc} 3 \mathrm{ccc}(\mathrm{F}) \mathrm{c}(\mathrm{Cl}) \mathrm{c} 3) \mathrm{ncnc} 2 \mathrm{~s} 1$ & 1040 & $*$ \\
\hline 3545 & $\mathrm{COc} 1 \mathrm{cc} 2 \mathrm{ncc}(\mathrm{C \# N}) \mathrm{c}(\mathrm{Nc} 3 \mathrm{ccc}(\mathrm{F}) \mathrm{c}(\mathrm{Cl}) \mathrm{c} 3) \mathrm{c} 2 \mathrm{cc} 1 \mathrm{OCCCN} 1 \mathrm{CCOCC} 1$ & 1040 & $*$ \\
\hline 3546 & $\mathrm{CC}(\mathrm{C}) \mathrm{n} 1 \mathrm{nc}(-\mathrm{c} 2 \mathrm{ccc}(\mathrm{O}) \mathrm{c}(\mathrm{F}) \mathrm{c} 2) \mathrm{c} 2 \mathrm{c}(\mathrm{N}) \mathrm{ncnc} 21$ & 1040 & $*$ \\
\hline 3547 & $\mathrm{O}=\mathrm{C}(\mathrm{O}[\mathrm{C} @ \mathrm{H}] 1 \mathrm{CN}[\mathrm{C} @ \mathrm{H}](\mathrm{C} \# \mathrm{Cc} 2 \mathrm{cc} 3 \mathrm{ncnc}(\mathrm{Nc} 4 \mathrm{ccc} 5 \mathrm{c}(\mathrm{Oc} 6 \mathrm{ccccn} 6) \operatorname{ccc} 5 \mathrm{c} 4) \mathrm{c} 3 \mathrm{~s} 2) \mathrm{C} 1) \mathrm{N} 1 \mathrm{CCOCC} 1$ & 1050 & 5.98 \\
\hline 3548 & $\operatorname{COc} 1 \operatorname{ccc}(\mathrm{CNC}(=\mathrm{O}) \operatorname{CSc} 2 \mathrm{nc} 3 \operatorname{cc} 4 \operatorname{ccc} c \operatorname{ccc} 3 \mathrm{c}(=\mathrm{O}) \mathrm{n} 2-\mathrm{c} 2 \operatorname{ccc}(\mathrm{S}(\mathrm{N})(=\mathrm{O})=\mathrm{O}) \operatorname{cc} 2) \mathrm{c} 1 \mathrm{OC}$ & 1050 & $*$ \\
\hline 3549 & $\mathrm{Fc} 1 \mathrm{ccc}(\mathrm{C} 2=\mathrm{NN}(\mathrm{c} 3 \mathrm{ccccc} 3) \mathrm{C}(\mathrm{c} 3 \mathrm{cccc} 4 \mathrm{ccccc} 34) \mathrm{C} 2) \mathrm{cc} 1$ & 1070 & 5.97 \\
\hline 3550 & $\mathrm{O}=\mathrm{C}(\mathrm{Nc} 1 \mathrm{ccccc} 1) \mathrm{N}(\mathrm{Cc} 1 \mathrm{ccc}(\mathrm{O}) \mathrm{cc} 1) \mathrm{Cc} 1 \mathrm{ccc}(\mathrm{Br}) \mathrm{c} 1 \mathrm{O}$ & 1070 & 5.97 \\
\hline 3551 & $\mathrm{Cc} 1 \mathrm{ccc}(\mathrm{C} 2=\mathrm{NN}(\mathrm{C} 3=\mathrm{NC}(=\mathrm{O}) \mathrm{CS} 3) \mathrm{C}(\mathrm{c} 3 \operatorname{ccccc} 3) \mathrm{C} 2) \mathrm{cc} 1$ & 1080 & 5.97 \\
\hline 3552 & $\mathrm{Cc} 1[\mathrm{nH}] \mathrm{c} 2 \mathrm{ncnc}(\mathrm{NCc} 3 \mathrm{cccc} 3) \mathrm{c} 2 \mathrm{c} 1 \mathrm{C}$ & 1080 & $*$ \\
\hline 3553 & $\operatorname{COc} 1 \mathrm{cc}(\mathrm{N} 2 \mathrm{CCN}(\mathrm{C}) \mathrm{CC} 2) \operatorname{ccc} 1 \mathrm{Nc} 1 \mathrm{ncc}(\mathrm{Cl}) \mathrm{c}(\mathrm{Oc} 2 \operatorname{ccc}(\mathrm{COc} 3 \mathrm{no}[\mathrm{n}+]([\mathrm{O}-]) \mathrm{c} 3 \mathrm{~S}(=\mathrm{O})(=\mathrm{O}) \mathrm{c} 3 \operatorname{ccccc} 3) \mathrm{cc} 2) \mathrm{n} 1$ & 1090 & 5.96 \\
\hline 3554 & OC[C@@H](Nc1ncnc2sc3c(c12)CCC3)c1 ccccc1 & 1090 & $*$ \\
\hline 3555 & $\mathrm{COC}(=\mathrm{O}) \mathrm{C} 1=\mathrm{C}(\mathrm{N}) \mathrm{N}(\mathrm{c} 2 \mathrm{ccc} n \mathrm{c} 2) \mathrm{C} 2=\mathrm{C}(\mathrm{C}(=\mathrm{O}) \mathrm{CCC} 2) \mathrm{C} 1 \mathrm{c} 1 \mathrm{cc} 2 \mathrm{cccc} 2 \mathrm{n} 2 \mathrm{nnnn} 12$ & 1100 & 5.96 \\
\hline 3556 & $\mathrm{Cc} 1 \mathrm{cc}(\mathrm{Nc} 2 \mathrm{ccc}(\mathrm{OCc} 3 \operatorname{ccc}(\mathrm{F}) \mathrm{c} 3) \mathrm{c}(\mathrm{Cl}) \mathrm{c} 2) \mathrm{ncn} 1$ & 1100 & 5.96 \\
\hline 3557 & $\mathrm{COc} 1 \mathrm{cc} 2 \mathrm{c}(\mathrm{cc} 1 \mathrm{OC}) \mathrm{Oc} 1 \mathrm{ncnc}(\mathrm{Nc} 3 \mathrm{cc}(\mathrm{Cl}) \mathrm{ccc} 3 \mathrm{~F}) \mathrm{c} 1 \mathrm{NC} 2$ & 1100 & 5.96 \\
\hline 3558 & $\mathrm{C}=\mathrm{CC}(=\mathrm{O}) \mathrm{Nc} 1 \mathrm{ccc}(-\mathrm{n} 2 \mathrm{c}(=\mathrm{O}) \mathrm{cnc} 3 \mathrm{cnc}(\mathrm{Nc} 4 \mathrm{ccc}(\mathrm{N} 5 \mathrm{CCN}(\mathrm{C}) \mathrm{CC} 5) \mathrm{cc} 4) \mathrm{nc} 32) \mathrm{cc} 1$ & 1100 & 5.96 \\
\hline 3559 & $\mathrm{CCC}(=\mathrm{O}) \mathrm{N} 1 \mathrm{CC}[\mathrm{C} @ \mathrm{H}](\mathrm{N} 2 \mathrm{C}(=\mathrm{O}) \mathrm{N}(\mathrm{c} 3 \mathrm{cc}(\mathrm{OC}) \mathrm{ccc} 3 \mathrm{~F}) \mathrm{Cc} 3 \mathrm{cnc}(\mathrm{Nc} 4 \mathrm{ccc}(\mathrm{N} 5 \mathrm{CCN}(\mathrm{C}) \mathrm{CC} 5) \mathrm{cc} 4) \mathrm{nc} 32) \mathrm{C} 1$ & 1100 & 5.96 \\
\hline 3560 & $\mathrm{CCN}(\mathrm{CC})[\mathrm{C} @ @](\mathrm{C})(\mathrm{C} \# \mathrm{Cc} 1 \mathrm{ncnc} 2 \mathrm{cc}(\mathrm{OC}) \mathrm{c}(\mathrm{OC}) \mathrm{cc} 12) \mathrm{CC} 1 \mathrm{CCCCC} 1$ & 1100 & $*$ \\
\hline
\end{tabular}




\begin{tabular}{|c|c|c|c|}
\hline 3561 & $\mathrm{~N} \# \mathrm{C} / \mathrm{C}(=\mathrm{Clc} 1 \mathrm{ccc}(\mathrm{O}) \mathrm{c}(\mathrm{O}) \mathrm{c} 1) \mathrm{C}(=\mathrm{O}) \mathrm{Nc} 1 \mathrm{ccccc} 1 \mathrm{Cl}$ & 1100 & $*$ \\
\hline 3562 & $\mathrm{~N} \# \mathrm{C} / \mathrm{C}(=\mathrm{Clc} 1 \mathrm{ccc}(\mathrm{O}) \mathrm{c}(\mathrm{O}) \mathrm{c} 1) \mathrm{C}(=\mathrm{O}) \mathrm{NCCCCc} 1 \mathrm{ccccc} 1$ & 1100 & $*$ \\
\hline 3563 & $\mathrm{C}=\mathrm{C}(\mathrm{CN} 1 \mathrm{CCCCC} 1) \mathrm{C}(=\mathrm{O}) \mathrm{c} 1 \mathrm{ccc}(\mathrm{OCc} 2 \mathrm{cccc} 2) \mathrm{cc} 1 . \mathrm{Cl}$ & 1100 & $*$ \\
\hline 3564 & $\mathrm{C}=\mathrm{C}(\mathrm{CN} 1 \mathrm{CCOCC} 1) \mathrm{C}(=\mathrm{O}) \mathrm{c} 1 \mathrm{ccc}(\mathrm{OCc} 2 \mathrm{cccc} 2) \mathrm{cc} 1 . \mathrm{Cl}$ & 1100 & $*$ \\
\hline 3565 & $\mathrm{CCc} 1 \mathrm{c}(\mathrm{CC}(\mathrm{N})=\mathrm{O}) \mathrm{cn} 2 \mathrm{ncnc}(\mathrm{Nc} 3 \operatorname{ccc} 4 \mathrm{c}(\mathrm{cnn} 4 \mathrm{Cc} 4 \mathrm{ccccc} 4) \mathrm{c} 3) \mathrm{c} 12$ & 1100 & $*$ \\
\hline 3566 & $\mathrm{O}=\mathrm{C}(\mathrm{CCCCCC}(=\mathrm{O}) \mathrm{Nc} 1 \mathrm{ccc}(\mathrm{O}) \mathrm{c}(\mathrm{C}(=\mathrm{O}) \mathrm{Nc} 2 \mathrm{ccc}(\mathrm{OCc} 3 \operatorname{ccc}(\mathrm{F}) \mathrm{c} 3) \mathrm{c}(\mathrm{Cl}) \mathrm{c} 2) \mathrm{c} 1) \mathrm{NO}$ & 1100 & $*$ \\
\hline 3567 & $\mathrm{C}=\mathrm{CC}(=\mathrm{O}) \mathrm{Nc} 1 \mathrm{cccc}(-\mathrm{c} 2 \mathrm{nc}(\mathrm{Nc} 3 \mathrm{cc}[\mathrm{nH}] \mathrm{n} 3) \mathrm{c} 3 \operatorname{ccccc} 3 \mathrm{n} 2) \mathrm{c} 1$ & 1100 & $*$ \\
\hline 3568 & $\mathrm{Cc} 1 \mathrm{ccc}(\mathrm{Oc} 2 \operatorname{ccc}(\mathrm{Nc} 3 n \operatorname{cnc} 4 \operatorname{ccc}(\mathrm{O}[\mathrm{C} @ \mathrm{H}](\mathrm{C}) \mathrm{C}(=\mathrm{O}) \mathrm{N}(\mathrm{C}) \mathrm{C}) \mathrm{c} 34) \mathrm{cc} 2 \mathrm{C}) \mathrm{cn} 1$ & 1100 & * \\
\hline 3569 & $\mathrm{CC}(\mathrm{C}) \mathrm{n} 1 \mathrm{nc}(-\mathrm{c} 2 \mathrm{ccc} 3[\mathrm{nH}] \mathrm{ncc} 3 \mathrm{c} 2) \mathrm{c} 2 \mathrm{c}(\mathrm{N}) \mathrm{ncnc} 21$ & 1100 & $*$ \\
\hline 3570 & $\mathrm{COCCOc} 1 \mathrm{cc} 2 \mathrm{ncc}(\mathrm{C \# N}) \mathrm{c}(\mathrm{Nc} 3 \mathrm{cccc}(\mathrm{Br}) \mathrm{c} 3) \mathrm{c} 2 \mathrm{cc} 1 \mathrm{OCCOC}$ & 1100 & $*$ \\
\hline 3571 & 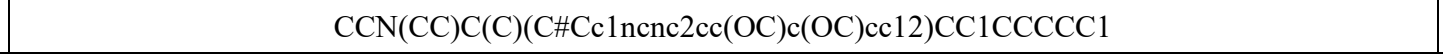 & 1100 & $*$ \\
\hline 3572 & $\begin{array}{c}\mathrm{Cc} 1 \mathrm{nc}(\mathrm{Nc} 2 \mathrm{ncc}(\mathrm{C}(=\mathrm{O}) \mathrm{Nc} 3 \mathrm{c}(\mathrm{C}) \mathrm{cccc} 3 \mathrm{Cl}) \mathrm{s} 2) \mathrm{cc}(\mathrm{N} 2 \mathrm{CCN}(\mathrm{CCOC}(=\mathrm{O}) \mathrm{OCCN} 3 \mathrm{CCN}(\mathrm{CCNc} 4 \mathrm{ccc} 5 \mathrm{ncnc}(\mathrm{Nc} 6 \mathrm{cccc}(\mathrm{Br}) \mathrm{c} 6 \\
) \mathrm{c} 5 \mathrm{c} 4) \mathrm{CC} 3) \mathrm{CC} 2) \mathrm{n} 1\end{array}$ & 1100 & * \\
\hline 3573 & $\mathrm{Cc} 1 \mathrm{nc}(\mathrm{C}) \mathrm{c}(\mathrm{C}=\mathrm{C} 2 \mathrm{CC}(\mathrm{C}) \mathrm{CC}(=\mathrm{Cc} 3 \mathrm{nc}(\mathrm{C}) \mathrm{c}(\mathrm{C}) \mathrm{nc} 3 \mathrm{C}) \mathrm{C} 2=\mathrm{O}) \mathrm{nc} 1 \mathrm{C}$ & 1100 & $*$ \\
\hline 3574 & $\mathrm{CN} 1 \mathrm{CCN}(\mathrm{c} 2 \mathrm{ccc}(\mathrm{Nc} 3 \mathrm{ncc}(\mathrm{Br}) \mathrm{c}(\mathrm{Nc} 4 \mathrm{ccc} 5 \mathrm{cn}[\mathrm{nH}] \mathrm{c} 5 \mathrm{c} 4) \mathrm{n} 3) \mathrm{cc} 2) \mathrm{CC} 1$ & 1100 & $*$ \\
\hline 3575 & $\operatorname{COc} 1 \operatorname{ccc}(\mathrm{C}(=\mathrm{O}) \mathrm{Nc} 2 \mathrm{ccc}(\mathrm{Nc} 3 \mathrm{ncnc} 4 \mathrm{cc}(\mathrm{OCCCN} 5 \mathrm{CCN}(\mathrm{C}) \mathrm{CC} 5) \mathrm{c}(\mathrm{OC}) \mathrm{cc} 34) \mathrm{cc} 2) \mathrm{cc} 1$ & 1110 & $*$ \\
\hline 3576 & $\mathrm{Cc} 1 \mathrm{ccc} 2 \mathrm{nc}(/ \mathrm{C}=\mathrm{C} / \mathrm{c} 3 \operatorname{ccc}(\mathrm{N}(\mathrm{C}) \mathrm{C}) \mathrm{cc} 3) \mathrm{cc}(-\mathrm{c} 3 \mathrm{nnc}(\mathrm{N}) \mathrm{s} 3) \mathrm{c} 2 \mathrm{c} 1$ & 1110 & $*$ \\
\hline 3577 & $\mathrm{O}=\mathrm{C}(\mathrm{Nc} 1 \mathrm{ccccc} 1) \mathrm{N}(\mathrm{Cc} 1 \mathrm{ccc}(\mathrm{O}) \mathrm{cc} 1) \mathrm{Cc} 1 \mathrm{cc}(\mathrm{Br}) \operatorname{cc}(\mathrm{Br}) \mathrm{c} 1 \mathrm{O}$ & 1120 & 5.95 \\
\hline 3578 & $\mathrm{C} \# \mathrm{Cc} 1 \mathrm{ccc}(\mathrm{NC}(=\mathrm{O}) \mathrm{c} 2 \mathrm{cc}(\mathrm{NC}(=\mathrm{O}) \mathrm{CCCCCC}(=\mathrm{O}) \mathrm{NO}) \mathrm{c}(\mathrm{OC}) \mathrm{cc} 2 \mathrm{O}) \mathrm{c} 1$ & 1120 & $*$ \\
\hline 3579 & $\mathrm{COc} 1 \mathrm{cccc}(-\mathrm{c} 2 \mathrm{cn}(\mathrm{C} 3 \mathrm{CCNC} 3) \mathrm{c} 3 \mathrm{ncnc}(\mathrm{N}) \mathrm{c} 23) \mathrm{c} 1$ & 1120 & $*$ \\
\hline 3580 & $\mathrm{CO} / \mathrm{N}=\mathrm{C} / \mathrm{c} 1 \mathrm{c}(\mathrm{N}) \mathrm{ncnc} 1 \mathrm{NCc} 1 \mathrm{ccc}(\mathrm{F}) \mathrm{c}(\mathrm{Cl}) \mathrm{c} 1$ & 1123 & $*$ \\
\hline 3581 & $\mathrm{O}=\mathrm{C}(/ \mathrm{C}=\mathrm{C} / \mathrm{Cn} 1 \mathrm{cccn} 1) \mathrm{Nc} 1 \mathrm{ccc} 2 \mathrm{ncnc}(\mathrm{Nc} 3 \operatorname{cccc}(\mathrm{Br}) \mathrm{c} 3) \mathrm{c} 2 \mathrm{c} 1$ & 1124 & $*$ \\
\hline 3582 & $\mathrm{COC} / \mathrm{C}=\mathrm{C} / \mathrm{C}(=\mathrm{O}) \mathrm{Nc} 1 \mathrm{ccc} 2 \mathrm{ncnc}(\mathrm{Nc} 3 \operatorname{ccc}(\mathrm{Br}) \mathrm{c} 3) \mathrm{c} 2 \mathrm{c} 1$ & 1132 & $*$ \\
\hline 3583 & Brc1 $1 \mathrm{ccc}(\mathrm{Nc} 2 \mathrm{ncnc} 3 \mathrm{ccc}(\mathrm{NCc} 4 \mathrm{ccc} 5 \mathrm{c}(\mathrm{c} 4) \mathrm{OCCCCO}) \mathrm{cc} 23) \mathrm{c} 1$ & 1140 & 5.94 \\
\hline 3584 & $\mathrm{Nc} 1 \mathrm{ncnc} 2 \mathrm{c} 1 \mathrm{c}(-\mathrm{c} 1 \mathrm{ccc}(\mathrm{Cl}) \mathrm{c}(\mathrm{O}) \mathrm{c} 1) \mathrm{nn} 2 \mathrm{C} 1 \mathrm{CCC} 1$ & 1150 & $*$ \\
\hline 3585 & $\mathrm{Cc} 1 \mathrm{ccc}(\mathrm{C} 2=\mathrm{NN}(\mathrm{C} 3=\mathrm{NC}(=\mathrm{O}) \mathrm{CS} 3) \mathrm{C}(\mathrm{c} 3 \operatorname{ccc}(\mathrm{C}) \mathrm{cc} 3) \mathrm{C} 2) \mathrm{cc} 1$ & 1160 & 5.94 \\
\hline 3586 & $\mathrm{CCOc} 1 \mathrm{ccc}(-\mathrm{c} 2 \mathrm{nn}(\mathrm{C} 3 \mathrm{CCCCC} 3) \mathrm{c} 3 \mathrm{ncnc}(\mathrm{N}) \mathrm{c} 23) \mathrm{cc} 1 \mathrm{OC}$ & 1160 & $*$ \\
\hline 3587 & $\operatorname{COc} 1 \mathrm{cc}(\mathrm{O}) \mathrm{c} 2 \mathrm{c}(\mathrm{c} 1) \mathrm{CCN}(\mathrm{c} 1 \mathrm{ccc}(\mathrm{C}(=\mathrm{O}) \mathrm{N} 3 \mathrm{CCCCC} 3) \mathrm{c} 1) \mathrm{C} 2=\mathrm{O}$ & 1180 & $*$ \\
\hline 3588 & $\operatorname{Cc} 1 \operatorname{ccc}(\mathrm{C}(=\mathrm{O}) \mathrm{NS}(=\mathrm{O})(=\mathrm{O}) \operatorname{c} 2 \operatorname{ccc}(\mathrm{Cl}) \operatorname{cc} 2) \mathrm{c}(\mathrm{Cl}) \mathrm{n} 1$ & 1190 & 5.92 \\
\hline 3589 & $\mathrm{C}=\mathrm{C}(\mathrm{CNc} 1 \mathrm{cc} 2 \mathrm{c}(\mathrm{Nc} 3 \operatorname{ccc}(\mathrm{OCc} 4 \mathrm{ccccc} 4) \mathrm{c}(\mathrm{Cl}) \mathrm{c} 3) \mathrm{c}(\mathrm{C \# N}) \mathrm{cnc} 2 \mathrm{cc} 1 \mathrm{OCC}) \mathrm{C}(=\mathrm{O}) \mathrm{O}$ & 1191 & 5.92 \\
\hline 3590 & $\mathrm{CN}(\mathrm{C}) \mathrm{CCCNC} / \mathrm{C}=\mathrm{C} / \mathrm{C}(=\mathrm{O}) \mathrm{Nc} 1 \mathrm{cc} 2 \mathrm{c}(\mathrm{Nc} 3 \operatorname{ccc}(\mathrm{F}) \mathrm{c}(\mathrm{Cl}) \mathrm{c} 3) \mathrm{ncnc} 2 \mathrm{~s} 1$ & 1196 & $*$ \\
\hline 3591 & $\mathrm{Fc} 1 \mathrm{cccc}(\mathrm{COc} 2 \mathrm{ccc}(\mathrm{Nc} 3 \mathrm{cc}(-\mathrm{c} 4 \mathrm{ccccc} 4) \mathrm{ncn} 3) \mathrm{cc} 2 \mathrm{Cl}) \mathrm{c} 1$ & 1200 & 5.92 \\
\hline 3592 & $\mathrm{COc} 1 \mathrm{cc} 2 \mathrm{c}(\mathrm{cc} 1 \mathrm{OC}) \mathrm{Oc} 1 \mathrm{ncnc}(\mathrm{Nc} 3 \mathrm{ccc}(\mathrm{F}) \mathrm{c}(\mathrm{Cl}) \mathrm{c} 3) \mathrm{c} 1 \mathrm{NC} 2$ & 1200 & 5.92 \\
\hline 3593 & $\mathrm{COc} 1 \mathrm{cc} 2 \mathrm{c}(\mathrm{cc} 1 \mathrm{OC}) \mathrm{Oc} 1 \mathrm{ncnc}(\mathrm{Nc} 3 \mathrm{ccc} 4 \mathrm{c}[\mathrm{nH}] \mathrm{nc} 4 \mathrm{c} 3) \mathrm{c} 1 \mathrm{NC} 2$ & 1200 & 5.92 \\
\hline 3594 & $\mathrm{COc} 1 \mathrm{cc} 2 \mathrm{c}(\mathrm{cc} 1 \mathrm{OC}) \mathrm{Oc} 1 \mathrm{ncnc}(\mathrm{Oc} 3 \operatorname{cccc}(\mathrm{Cl}) \mathrm{c} 3 \mathrm{~F}) \mathrm{c} 1 \mathrm{NC} 2$ & 1200 & 5.92 \\
\hline 3595 & $\mathrm{CCOc} 1 \operatorname{ccc}(\mathrm{C}(=\mathrm{O}) \mathrm{Nc} 2 \operatorname{ccc}(\mathrm{OCc} 3 \operatorname{ccc} \operatorname{con} 3) \mathrm{c}(\mathrm{Cl}) \mathrm{c} 2) \operatorname{cc} 1 \mathrm{NC}(=\mathrm{O}) / \mathrm{C}=\mathrm{C} / \mathrm{CN}(\mathrm{C}) \mathrm{C}$ & 1200 & 5.92 \\
\hline 3596 & $\mathrm{CCC}(=\mathrm{O}) \mathrm{N} 1 \mathrm{CC}[\mathrm{C} @ \mathrm{H}](\mathrm{N} 2 \mathrm{C}(=\mathrm{O}) \mathrm{N}(\mathrm{c} 3 \mathrm{cc}(\mathrm{OC}) \mathrm{ccc} 3 \mathrm{~F}) \mathrm{Cc} 3 \mathrm{cnc}(\mathrm{Nc} 4 \mathrm{ccc}(\mathrm{N} 5 \mathrm{CCN}(\mathrm{C}) \mathrm{CC} 5) \mathrm{c}(\mathrm{Cl}) \mathrm{c} 4) \mathrm{nc} 32) \mathrm{C} 1$ & 1200 & 5.92 \\
\hline 3597 & 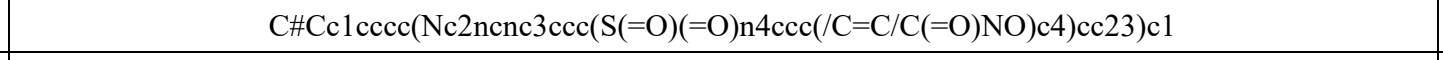 & 1200 & $*$ \\
\hline 3598 & $\mathrm{CCOC}(=\mathrm{O}) \mathrm{CCCn} 1 \mathrm{c}(=\mathrm{O}) \operatorname{oc} 2 \mathrm{cc} 3 \operatorname{ncnc}(\mathrm{Nc} 4 \mathrm{ccc}(\mathrm{Cl}) \mathrm{cc} 4) \mathrm{c} 3 \mathrm{cc} 21$ & 1200 & $*$ \\
\hline 3599 & 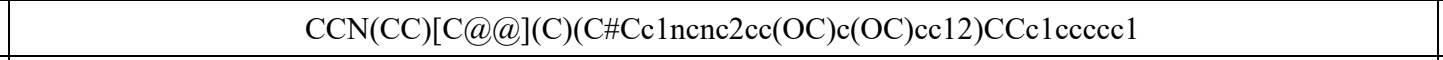 & 1200 & * \\
\hline 3600 & $\mathrm{O}=\mathrm{C}(\mathrm{OCC} 1 \mathrm{CCCCC} 1) \mathrm{c} 1 \mathrm{cc}(\mathrm{NCc} 2 \mathrm{cc}(\mathrm{O}) \mathrm{ccc} 2 \mathrm{O}) \mathrm{ccc} 1 \mathrm{O}$ & 1200 & $*$ \\
\hline 3601 & $\operatorname{COc} 1 \mathrm{cc}(/ \mathrm{C}=\mathrm{C}(\backslash \mathrm{C} \# \mathrm{~N}) \mathrm{C}(\mathrm{N})=\mathrm{C}(\mathrm{C \# N}) \mathrm{C \# N}) \operatorname{cc}(\mathrm{O}) \mathrm{c} 1 \mathrm{O}$ & 1200 & $*$ \\
\hline 3602 & $\mathrm{COc} 1 \mathrm{ccc}(\mathrm{Nc} 2[\mathrm{nH}] \mathrm{cnc} 3 \mathrm{nc}(\mathrm{C}) \mathrm{c}(\mathrm{C}) \mathrm{c} 2-3) \mathrm{c} 1$ & 1200 & $*$ \\
\hline
\end{tabular}




\begin{tabular}{|c|c|c|c|}
\hline 3603 & $\mathrm{CC}(\mathrm{C}) \mathrm{n} 1 \mathrm{nc}(-\mathrm{c} 2 \mathrm{cc}(\mathrm{F}) \mathrm{c} 3 \mathrm{cn}[\mathrm{nH}] \mathrm{c} 3 \mathrm{c} 2) \mathrm{c} 2 \mathrm{c}(\mathrm{N}) \mathrm{ncnc} 21$ & 1200 & $*$ \\
\hline 3604 & $\mathrm{Cc} 1 \mathrm{ccc}(\mathrm{O}) \mathrm{c}(\mathrm{C}(=\mathrm{O}) \mathrm{Nc} 2 \operatorname{cccc}(\mathrm{Cl}) \mathrm{c} 2) \mathrm{c} 1$ & 1200 & $*$ \\
\hline 3605 & $\mathrm{CCN}(\mathrm{CC}) \mathrm{C}(\mathrm{C})(\mathrm{CHCc} 1 \mathrm{ncnc} 2 \mathrm{cc}(\mathrm{OC}) \mathrm{c}(\mathrm{OC}) \mathrm{cc} 12) \mathrm{CCc} 1 \mathrm{ccccc} 1$ & 1200 & $*$ \\
\hline 3606 & $\mathrm{O}=[\mathrm{N}+]([\mathrm{O}-]) \mathrm{c} 1 \mathrm{cccc}(\mathrm{Oc} 2 \mathrm{cc}(\mathrm{Nc} 3 \operatorname{ccc}(\mathrm{OCc} 4 \mathrm{ccc}(\mathrm{F}) \mathrm{c} 4) \mathrm{c}(\mathrm{Cl}) \mathrm{c} 3) \mathrm{ncn} 2) \mathrm{c} 1$ & 1204 & 5.92 \\
\hline 3607 & $\mathrm{O}=\mathrm{C}(/ \mathrm{C}=\mathrm{C} / \mathrm{c} 1 \mathrm{ccc}(\mathrm{Cl}) \mathrm{cc} 1) \mathrm{Nc} 1 \mathrm{ccc} 2 \mathrm{ncnc}(\mathrm{Nc} 3 \operatorname{ccc}(\mathrm{Br}) \mathrm{c} 3) \mathrm{c} 2 \mathrm{c} 1$ & 1210 & 5.92 \\
\hline 3608 & $\mathrm{COc} 1 \mathrm{cc} 2 \mathrm{c}(\mathrm{c}(\mathrm{OC}) \mathrm{c} 1) \mathrm{C}(=\mathrm{O}) \mathrm{N}(\mathrm{c} 1 \operatorname{cccc}(\mathrm{C}(=\mathrm{O}) \mathrm{N} 3 \mathrm{CCCCC} 3) \mathrm{c} 1) \mathrm{CC} 2$ & 1230 & $*$ \\
\hline 3609 & $\mathrm{Cc} 1 \mathrm{ccccc} 1 \mathrm{Nc} 1 \mathrm{ncnc} 2[\mathrm{nH}] \mathrm{ccc} 12$ & 1230 & $*$ \\
\hline 3610 & $\mathrm{O}=\mathrm{C} 1 \mathrm{CSC}(\mathrm{N} / \mathrm{N}=\mathrm{C} / \mathrm{c} 2 \mathrm{cc}(\mathrm{Br}) \mathrm{cc}(\mathrm{Br}) \mathrm{c} 2 \mathrm{O})=\mathrm{N} 1$ & 1240 & 5.91 \\
\hline 3611 & $\mathrm{Nc} 1 \mathrm{cc} 2 \mathrm{ncnc}(\mathrm{Nc} 3 \operatorname{cccc} 3[\mathrm{~N}+](=\mathrm{O})[\mathrm{O}-]) \mathrm{c} 2 \mathrm{cn} 1$ & 1250 & $*$ \\
\hline 3612 & $\mathrm{Cc} 1[\mathrm{nH}] \mathrm{c} 2 \mathrm{ncnc}(\mathrm{Nc} 3 \operatorname{cccc}(\mathrm{O}) \mathrm{c} 3) \mathrm{c} 2 \mathrm{c} 1 \mathrm{C}$ & 1250 & $*$ \\
\hline 3613 & $\mathrm{Cc} 1 \mathrm{cc} 2 \mathrm{cc}(\mathrm{Nc} 3 \mathrm{ccnc} 4 \mathrm{cc}(-\mathrm{c} 5 \mathrm{ccc}(\mathrm{CN} 6 \mathrm{CCOCC} 6) \operatorname{cc} 5) \operatorname{sc} 34) \operatorname{ccc} 2[\mathrm{nH}] 1$ & 1250 & $*$ \\
\hline 3614 & $\mathrm{NS}(=\mathrm{O})(=\mathrm{O}) \mathrm{c} 1 \mathrm{ccc}(-\mathrm{n} 2 \mathrm{c}(\mathrm{SCC}(=\mathrm{O}) \mathrm{Nc} 3 \mathrm{ccc}(\mathrm{N} 4 \mathrm{CCOCC} 4) \mathrm{cc} 3) \mathrm{nc} 3 \mathrm{cc} 4 \mathrm{cccc} 4 \mathrm{cc} 3 \mathrm{c} 2=\mathrm{O}) \mathrm{cc} 1$ & 1250 & $*$ \\
\hline 3615 & $\mathrm{COc} 1 \mathrm{ccc}(\mathrm{C} 2=\mathrm{NN}(\mathrm{C} 3=\mathrm{NC}(=\mathrm{O}) \mathrm{CS} 3) \mathrm{C}(\mathrm{c} 3 \operatorname{ccc}(\mathrm{Br}) \mathrm{cc} 3) \mathrm{C} 2) \mathrm{cc} 1$ & 1260 & 5.90 \\
\hline 3616 & $\mathrm{CCNC}(=\mathrm{O}) \mathrm{Nc} 1 \mathrm{nc} 2 \mathrm{nc}(\mathrm{NCCCCN}(\mathrm{CC}) \mathrm{CC}) \mathrm{ncc} 2 \mathrm{cc} 1-\mathrm{c} 1 \mathrm{c}(\mathrm{Cl}) \mathrm{cccc} 1 \mathrm{Cl}$ & 1260 & $*$ \\
\hline 3617 & $\mathrm{O}=\mathrm{C}(\mathrm{Nc} 1 \mathrm{cccc}(\mathrm{Br}) \mathrm{c} 1) \mathrm{Nc} 1 \mathrm{ccc}(\mathrm{Oc} 2 \mathrm{ncnc} 3 \mathrm{sc} 4 \mathrm{c}(\mathrm{c} 23) \mathrm{CCCC} 4) \mathrm{cc} 1 \mathrm{Cl}$ & 1260 & $*$ \\
\hline 3618 & $\operatorname{Cc} 1 n \operatorname{cc}([\mathrm{N}+](=\mathrm{O})[\mathrm{O}-]) \mathrm{n} 1 \mathrm{CCOC}(=\mathrm{O}) / \mathrm{C}=\mathrm{C} / \mathrm{c} 1 \mathrm{ccc}(\mathrm{OCc} 2 \operatorname{ccccc} 2) \operatorname{cc} 1$ & 1270 & 5.90 \\
\hline 3619 & $\operatorname{CCCCCCCCCCCCNC}(=\mathrm{O}) \operatorname{COc} 1 \mathrm{cc}(\mathrm{O}) \mathrm{c} 2 \mathrm{c}(=\mathrm{O}) \operatorname{cc}(-\mathrm{c} 3 \operatorname{ccccc} 3) \mathrm{oc} 2 \mathrm{c} 1$ & 1270 & 5.90 \\
\hline 3620 & $\mathrm{CC \# CC}(=\mathrm{O}) \mathrm{N} 1 \mathrm{CCc} 2 \mathrm{c}(\mathrm{sc} 3 \mathrm{ncnc}(\mathrm{N}[\mathrm{C} @ \mathrm{H}](\mathrm{CO}) \mathrm{c} 4 \mathrm{ccccc} 4) \mathrm{c} 23) \mathrm{C} 1$ & 1270 & $*$ \\
\hline 3621 & $\operatorname{COc} 1 \mathrm{cc}(\mathrm{O}) \mathrm{c} 2 \mathrm{c}(=\mathrm{O}) \mathrm{c}(-\mathrm{c} 3 \mathrm{ccc}(\mathrm{Cl}) \mathrm{c} 3) \operatorname{coc} 2 \mathrm{c} 1$ & 1270 & $*$ \\
\hline 3622 & $\mathrm{CCN}(\mathrm{CC}) \mathrm{CCNC}(=\mathrm{O}) \mathrm{c} 1[\mathrm{nH}] \mathrm{c} 2 \mathrm{cnnn}(\mathrm{Nc} 3 \operatorname{ccc}(\mathrm{OCc} 4 \mathrm{cccc}(\mathrm{F}) \mathrm{c} 4) \mathrm{c}(\mathrm{Cl}) \mathrm{c} 3) \mathrm{c} 2 \mathrm{c} 1 \mathrm{C}$ & 1280 & 5.89 \\
\hline 3623 & $\mathrm{O}=\mathrm{C}(\mathrm{Nc} 1 \mathrm{ccc} 2 \mathrm{ncnc}(\mathrm{Nc} 3 \mathrm{cccc}(\mathrm{Cl}) \mathrm{c} 3) \mathrm{c} 2 \mathrm{c} 1) \mathrm{c} 1 \mathrm{ccc} 2 \mathrm{c} 1 \mathrm{OCCO} 2$ & 1290 & 5.89 \\
\hline 3624 & $\operatorname{Cn} 1 \mathrm{c} 2 \operatorname{ccc} c \cos 2 \operatorname{ccc}(\mathrm{NC}(=\mathrm{O}) \operatorname{CSc} 3 n \operatorname{coc} 5 \operatorname{ccc} \cos 5 \operatorname{cc} 4 \mathrm{c}(=\mathrm{O}) \mathrm{n} 3-\mathrm{c} 3 \operatorname{ccc}(\mathrm{S}(\mathrm{N})(=\mathrm{O})=\mathrm{O}) \operatorname{cc} 3) \operatorname{cc} 21$ & 1290 & * \\
\hline 3625 & $\mathrm{COC}(=\mathrm{O}) \mathrm{C} 1=\mathrm{C}(\mathrm{N}) \mathrm{N}(\mathrm{c} 2 \mathrm{cccnc} 2) \mathrm{C} 2=\mathrm{C}(\mathrm{C}(=\mathrm{O}) \mathrm{CCC} 2) \mathrm{C} 1 \mathrm{c} 1 \mathrm{cc} 2 \mathrm{cc}(\mathrm{OC}) \mathrm{ccc} 2 \mathrm{n} 2 \mathrm{nnnn} 12$ & 1300 & 5.89 \\
\hline 3626 & $\mathrm{COc} 1 \mathrm{cc} 2 \mathrm{c}(\mathrm{cc} 1 \mathrm{OC}) \mathrm{Oc} 1 \mathrm{ncnc}(\mathrm{Sc} 3 \mathrm{cccc}(\mathrm{Br}) \mathrm{c} 3) \mathrm{c} 1 \mathrm{NC} 2$ & 1300 & 5.89 \\
\hline 3627 & $\mathrm{CCC}(=\mathrm{O}) \mathrm{N} 1 \mathrm{CC}[\mathrm{C} @ \mathrm{H}](\mathrm{N} 2 \mathrm{C}(=\mathrm{O}) \mathrm{N}(\mathrm{c} 3 \mathrm{cc}(\mathrm{OC}) \mathrm{ccc} 3 \mathrm{~F}) \mathrm{Cc} 3 \mathrm{cnc}(\mathrm{Nc} 4 \mathrm{ccc}(\mathrm{N} 5 \mathrm{CCN}(\mathrm{C}) \mathrm{CC} 5) \mathrm{c}(\mathrm{F}) \mathrm{c} 4) \mathrm{nc} 32) \mathrm{C} 1$ & 1300 & 5.89 \\
\hline 3628 & $\mathrm{CCC}(=\mathrm{O}) \mathrm{N} 1 \mathrm{CC}[\mathrm{C} @ \mathrm{H}](\mathrm{N} 2 \mathrm{C}(=\mathrm{O}) \mathrm{N}(\mathrm{c} 3 \mathrm{cc}(\mathrm{OC}) \mathrm{ccc} 3 \mathrm{~F}) \mathrm{Cc} 3 \mathrm{cnc}(\mathrm{Nc} 4 \mathrm{ccc}(\mathrm{N}(\mathrm{C}) \mathrm{CCN}(\mathrm{C}) \mathrm{C}) \mathrm{c}(\mathrm{C}) \mathrm{c} 4) \mathrm{nc} 32) \mathrm{C} 1$ & 1300 & 5.89 \\
\hline 3629 & $\mathrm{C} \# \mathrm{Cc} 1 \operatorname{ccc}(\mathrm{Nc} 2 \mathrm{ncnc} 3 \operatorname{ccc}(\mathrm{S}(=\mathrm{O})(=\mathrm{O}) \mathrm{n} 4 \mathrm{ccc}(/ \mathrm{C}=\mathrm{C} / \mathrm{C}(=\mathrm{O}) \mathrm{Nc} 5 \operatorname{ccc} c 5 \mathrm{~N}) \mathrm{c} 4) \operatorname{cc} 23) \mathrm{c} 1$ & 1300 & $*$ \\
\hline 3630 & $\operatorname{COCCn} 1 \mathrm{c}(=\mathrm{O}) \mathrm{oc} 2 \mathrm{cc} 3 \mathrm{ncnc}(\mathrm{Nc} 4 \mathrm{ccc}(\mathrm{OCc} 5 \mathrm{ccc}(\mathrm{Cl}) \mathrm{cc} 5) \mathrm{c}(\mathrm{Cl}) \mathrm{c} 4) \mathrm{c} 3 \mathrm{cc} 21$ & 1300 & $*$ \\
\hline 3631 & $\mathrm{~N} \# \mathrm{C} / \mathrm{C}(=\mathrm{C} \mid \mathrm{c} 1 \mathrm{ccc}(\mathrm{O}) \mathrm{c}(\mathrm{O}) \mathrm{c} 1) \mathrm{C}(=\mathrm{O}) \mathrm{c} 1 \mathrm{ccccc} 1$ & 1300 & $*$ \\
\hline 3632 & $\mathrm{O}=\mathrm{C}(\mathrm{OC} / \mathrm{C}=\mathrm{C} / \mathrm{c} 1 \mathrm{cccc} 1) \mathrm{c} 1 \mathrm{cc}(\mathrm{NCc} 2 \mathrm{cc}(\mathrm{O}) \mathrm{ccc} 2 \mathrm{O}) \operatorname{ccc} 1 \mathrm{O}$ & 1300 & $*$ \\
\hline 3633 & $\mathrm{CC}(\mathrm{C})(\mathrm{C}) \mathrm{NC}(=\mathrm{O}) \operatorname{c} 1 \operatorname{ccc}(\mathrm{S}(=\mathrm{O})(=\mathrm{O}) \mathrm{Oc} 2 \operatorname{ccc}(/ \mathrm{C}=\mathrm{C} /[\mathrm{N}+](=\mathrm{O})[\mathrm{O}-]) \operatorname{cc} 2) \mathrm{cc} 1$ & 1300 & $*$ \\
\hline 3634 & $\mathrm{N \# C/C}(=\mathrm{C} \mid \mathrm{c} 1 \mathrm{ccc}(\mathrm{O}) \mathrm{c}(\mathrm{O}) \mathrm{c} 1) \mathrm{C}(=\mathrm{O}) \mathrm{NCCCCCCCCCCNC}(=\mathrm{O}) / \mathrm{C}(\mathrm{C \# N})=\mathrm{C} / \mathrm{c} 1 \mathrm{ccc}(\mathrm{O}) \mathrm{c}(\mathrm{O}) \mathrm{c} 1$ & 1300 & $*$ \\
\hline 3635 & $\operatorname{COc} 1 \operatorname{ccc}(\mathrm{Nc} 2 \mathrm{ncc} 3 \mathrm{cc}(-\mathrm{c} 4 \mathrm{c}(\mathrm{Cl}) \operatorname{ccc} 4 \mathrm{Cl}) \mathrm{c}(=\mathrm{O}) \mathrm{n}(\mathrm{C}) \mathrm{c} 3 \mathrm{n} 2) \mathrm{cn} 1$ & 1300 & $*$ \\
\hline 3636 & $\begin{array}{c}\mathrm{O}=\mathrm{C}(\mathrm{NCCc} 1 \mathrm{ccc}(\mathrm{O}) \mathrm{c}(\mathrm{Br}) \mathrm{c} 1) / \mathrm{C}(\mathrm{Cc} 1 \mathrm{cc}(\mathrm{Br}) \mathrm{c}(\mathrm{O}) \mathrm{c}(- \\
\mathrm{c} 2 \mathrm{cc}(\mathrm{C} / \mathrm{C}(=\mathrm{N} / \mathrm{O}) \mathrm{C}(=\mathrm{O}) \mathrm{NCC} 3 \operatorname{ccc}(\mathrm{O}) \mathrm{c}(\mathrm{Br}) \mathrm{c} 3) \mathrm{cc}(\mathrm{Br}) \mathrm{c} 2 \mathrm{O}) \mathrm{c} 1)=\mathrm{N} \backslash \mathrm{O}\end{array}$ & 1300 & $*$ \\
\hline 3637 & $\mathrm{CN} 1 \mathrm{CCN}(\mathrm{CCC}(=\mathrm{O}) \mathrm{Nc} 2 \mathrm{ccc} 3 \mathrm{c}(\mathrm{C} \# \mathrm{~N}) \mathrm{cnc}(\mathrm{Nc} 4 \mathrm{cccc}(\mathrm{Br}) \mathrm{c} 4) \mathrm{c} 3 \mathrm{c} 2) \mathrm{CC} 1$ & 1300 & $*$ \\
\hline 3638 & $\operatorname{COc} 1 \operatorname{ccc}(\mathrm{NC}(=\mathrm{O}) / \mathrm{C}=\mathrm{C} / \mathrm{CN}(\mathrm{C}) \mathrm{C}) \mathrm{cc} 1 \mathrm{Nc} 1 \mathrm{ncc}(\mathrm{Cl}) \mathrm{c}(\mathrm{Nc} 2 \operatorname{cccc}(\mathrm{Cl}) \mathrm{c} 2) \mathrm{n} 1$ & 1300 & $*$ \\
\hline 3639 & $\mathrm{CN} 1 \mathrm{CCN}(\mathrm{c} 2 \mathrm{ccc}(\mathrm{Nc} 3 \mathrm{ncc}(\mathrm{Br}) \mathrm{c}(\mathrm{Nc} 4 \mathrm{ccc} 5 \mathrm{ccn}(\mathrm{C}) \mathrm{c} 5 \mathrm{c} 4) \mathrm{n} 3) \mathrm{cc} 2) \mathrm{CC} 1$ & 1300 & $*$ \\
\hline 3640 & $\mathrm{~N} \# \mathrm{C} / \mathrm{C}(=\mathrm{C} \mid \mathrm{c} 1 \mathrm{ccc}(\mathrm{O}) \mathrm{c}(\mathrm{O}) \mathrm{c} 1) \mathrm{C}(\mathrm{N})=\mathrm{S}$ & 1310 & $*$ \\
\hline 3641 & $\mathrm{Cc} 1 \operatorname{ccc}(\mathrm{C} 2=\mathrm{NN}(\mathrm{C} 3=\mathrm{NC}(=\mathrm{O}) \mathrm{CS} 3) \mathrm{C}(\mathrm{c} 3 \operatorname{ccc} 4 \operatorname{ccccc} 34) \mathrm{C} 2) \operatorname{cc} 1 \mathrm{C}$ & 1320 & 5.88 \\
\hline 3642 & $\mathrm{Cc} 1 \mathrm{ccc}(\mathrm{C}(=\mathrm{O}) \mathrm{Nc} 2 \operatorname{ccc}(\mathrm{CN} 3 \mathrm{CCN}(\mathrm{C}) \mathrm{CC} 3) \mathrm{c}(\mathrm{C}(\mathrm{F})(\mathrm{F}) \mathrm{F}) \mathrm{c} 2) \operatorname{cc} 1 \mathrm{NC}(=\mathrm{O}) \mathrm{c} 1 \mathrm{ccc}(\mathrm{O}) \mathrm{nc} 1$ & 1330 & 5.88 \\
\hline 3643 & $\mathrm{Fc} 1 \mathrm{ccc}(\mathrm{Nc} 2 \mathrm{ncnc} 3 \mathrm{sc} 4 \mathrm{c}(\mathrm{c} 23) \mathrm{CCCC} 4) \mathrm{cc} 1 \mathrm{Cl}$ & 1330 & $*$ \\
\hline 3644 & $\mathrm{COc} 1 \mathrm{cc} 2 \mathrm{c}(\mathrm{Nc} 3 \mathrm{ccc}(\mathrm{NC}(=\mathrm{O}) \mathrm{c} 4 \mathrm{ccc}(\mathrm{Cl}) \mathrm{cc} 4) \mathrm{cc} 3) \mathrm{ncnc} 2 \mathrm{cc} 1 \mathrm{OCCCN} 1 \mathrm{CCN}(\mathrm{C}) \mathrm{CC} 1$ & 1330 & $*$ \\
\hline
\end{tabular}




\begin{tabular}{|c|c|c|c|}
\hline 3645 & $\mathrm{COc} 1 \mathrm{ccc}(\mathrm{NC}(=\mathrm{O}) / \mathrm{C}=\mathrm{C} / \mathrm{CN}(\mathrm{C}) \mathrm{C}) \operatorname{cc} 1 \mathrm{Nc} 1 \mathrm{ncc}(\mathrm{Cl}) \mathrm{c}(\mathrm{Nc} 2 \mathrm{ccccc} 2) \mathrm{n} 1$ & 1330 & $*$ \\
\hline 3646 & $\mathrm{Oc} 1 \mathrm{c}(\mathrm{Cl}) \mathrm{cc}(\mathrm{Cl}) \mathrm{cc} 1 \mathrm{CN}(\mathrm{Cc} 1 \mathrm{ccc}(\mathrm{F}) \mathrm{cc} 1) \mathrm{C}(=\mathrm{S}) \mathrm{Nc} 1 \mathrm{ccccc} 1$ & 1340 & 5.87 \\
\hline 3647 & $\mathrm{O}=\mathrm{C} 1 \mathrm{CSC}(\mathrm{N} 2 \mathrm{~N}=\mathrm{C}(\mathrm{c} 3 \operatorname{cccc} 3) \mathrm{CC} 2 \mathrm{c} 2 \mathrm{ccc}(\mathrm{Br}) \mathrm{cc} 2)=\mathrm{N} 1$ & 1350 & 5.87 \\
\hline 3648 & $\operatorname{CCCCCCCCCCCCCCCCCCCCNC}(=0) \operatorname{COc} 1 \mathrm{cc}(\mathrm{O}) \mathrm{c} 2 \mathrm{c}(=\mathrm{O}) \mathrm{cc}(-\mathrm{c} 3 \mathrm{ccccc} 3) \mathrm{oc} 2 \mathrm{c} 1$ & 1350 & 5.87 \\
\hline 3649 & $\mathrm{COc} 1 \mathrm{cc} 2 \mathrm{c}(\mathrm{Nc} 3 \mathrm{ccc}(\mathrm{NC}(=\mathrm{O}) \mathrm{c} 4 \mathrm{ccc}(\mathrm{Cl}) \mathrm{cc} 4) \mathrm{cc} 3) \mathrm{ncn} 2 \mathrm{cc} 1 \mathrm{OCCCN} 1 \mathrm{CCOCC} 1$ & 1350 & $*$ \\
\hline 3650 & $\mathrm{Cc} 1 \mathrm{ccc}(\mathrm{C} 2=\mathrm{NN}(\mathrm{C}(\mathrm{N})=\mathrm{S}) \mathrm{C}(\mathrm{c} 3 \operatorname{ccc}(\mathrm{Cl}) \mathrm{cc} 3) \mathrm{C} 2) \operatorname{cc} 1 \mathrm{C}$ & 1360 & 5.87 \\
\hline 3651 & $\mathrm{CCNC}(=\mathrm{O}) \mathrm{Nc} 1 \mathrm{nc} 2 \mathrm{nc}(\mathrm{N}) \mathrm{ncc} 2 \mathrm{cc} 1-\mathrm{c} 1 \mathrm{c}(\mathrm{Cl}) \mathrm{cccc} 1 \mathrm{Cl}$ & 1360 & * \\
\hline 3652 & OCCCNc1 $\operatorname{cncc}(-\mathrm{c} 2 \mathrm{cncc}(\mathrm{Nc} 3 \mathrm{cccc}(\mathrm{Cl}) \mathrm{c} 3) \mathrm{n} 2) \mathrm{c} 1$ & 1360 & $*$ \\
\hline 3653 & $\mathrm{COc} 1 \mathrm{cc} 2 \mathrm{ncnc}(\mathrm{Nc} 3 \mathrm{ccc}(\mathrm{C \# CCCCO}) \mathrm{c} 3) \mathrm{c} 2 \mathrm{cc} 1 \mathrm{OC}$ & 1362.6 & $*$ \\
\hline 3654 & $\mathrm{COc} 1 \mathrm{ccc} 2 \mathrm{ncnc}(\mathrm{Nc} 3 \mathrm{cccc}(\mathrm{Br}) \mathrm{c} 3) \mathrm{c} 2 \mathrm{c} 1 \mathrm{OC}$ & 1370 & * \\
\hline 3655 & $\mathrm{Cc} 1 \mathrm{c} 2 \operatorname{ccc}(\mathrm{N}(\mathrm{C}) \mathrm{c} 3 \operatorname{ccnc}(\mathrm{Nc} 4 \operatorname{ccc}(\mathrm{S}(=\mathrm{O})(=\mathrm{O}) \mathrm{NC}(=\mathrm{N}) \mathrm{N}) \operatorname{cc} 4) \mathrm{n} 3) \operatorname{cc} 2 \mathrm{nn} 1 \mathrm{C}$ & 1370 & * \\
\hline 3656 & Brc1cc2c(NCc3eccs3)ncnc2s1 & 1374 & * \\
\hline 3657 & $\operatorname{COc} 1 \mathrm{cc}(\mathrm{O}) \mathrm{c} 2 \mathrm{c}(=\mathrm{O}) \mathrm{n}(-\mathrm{c} 3 \operatorname{ccc}(\mathrm{C}(=\mathrm{O}) \mathrm{N} 4 \mathrm{CCCCC} 4) \mathrm{c} 3) \operatorname{ccc} 2 \mathrm{c} 1$ & 1380 & * \\
\hline 3658 & $\mathrm{COc} 1 \mathrm{cc}(\mathrm{OC} 2 \mathrm{CCOCC} 2) \mathrm{c} 2 \mathrm{c}(\mathrm{Nc} 3 \mathrm{ccc}(\mathrm{F}) \mathrm{c}(\mathrm{Cl}) \mathrm{c} 3) \mathrm{ncnc} 2 \mathrm{c} 1$ & 1384 & $*$ \\
\hline 3659 & CCOc1cec(Nc2ncnc3cc4oc $(=\mathrm{O}) \mathrm{n}(\mathrm{CCCN} 5 \mathrm{CCOCC} 5) \mathrm{c} 4 \mathrm{cc} 23) \mathrm{cc} 1$ & 1400 & * \\
\hline 3660 & $\mathrm{CC}(\mathrm{C})(\mathrm{C}) \mathrm{OC}(=\mathrm{O}) \mathrm{NCCNC}(=\mathrm{O}) \mathrm{c} 1 \mathrm{ccc}(\mathrm{S}(=\mathrm{O})(=\mathrm{O}) \mathrm{Oc} 2 \mathrm{ccc}(/ \mathrm{C}=\mathrm{C} /[\mathrm{N}+](=\mathrm{O})[\mathrm{O}-]) \operatorname{cc} 2) \operatorname{cc} 1$ & 1400 & $*$ \\
\hline 3661 & $\mathrm{CCN}(\mathrm{CC}) \mathrm{CCCNc} 1 \mathrm{ncc} 2 \mathrm{cc}(-\mathrm{c} 3 \mathrm{c}(\mathrm{Cl}) \mathrm{cccc} 3 \mathrm{Cl}) \mathrm{c}(=\mathrm{O}) \mathrm{n}(\mathrm{C}) \mathrm{c} 2 \mathrm{n} 1$ & 1400 & $*$ \\
\hline 3662 & $\mathrm{CCOc} 1 \mathrm{ccc}(-\mathrm{c} 2 \mathrm{nn}(\mathrm{C} 3 \mathrm{CCCC} 3) \mathrm{c} 3 \mathrm{ncnc}(\mathrm{N}) \mathrm{c} 23) \mathrm{cc} 1 \mathrm{OC}$ & 1400 & $*$ \\
\hline 3663 & $\mathrm{COc} 1 \mathrm{cccc}(-\mathrm{c} 2 \mathrm{nn}(\mathrm{C}(\mathrm{C}) \mathrm{C}) \mathrm{c} 3 \mathrm{ncnc}(\mathrm{N}) \mathrm{c} 23) \mathrm{c} 1$ & 1400 & * \\
\hline 3664 & Nc1ncnc2c1c(-c1ccc(Cl)c(O)c1)nn2[C@@H]1CCOC1 & 1400 & * \\
\hline 3665 & $\mathrm{CC}(\mathrm{C}) \mathrm{n} 1 \mathrm{nc}(-\mathrm{c} 2 \mathrm{ccc}(\mathrm{F}) \mathrm{c}(\mathrm{O}) \mathrm{c} 2) \mathrm{c} 2 \mathrm{c}(\mathrm{N}) \mathrm{ncnc} 21$ & 1400 & $*$ \\
\hline 3666 & Nc1ncnc2c1c(-c1cce3[nH]c(=O)ccc3c1)nn2C1CCCC1 & 1400 & * \\
\hline 3667 & Nc1ncnc2c1c(-c1ecce3[nH]ccc13)nn2C1CCCC1 & 1400 & * \\
\hline 3668 & $\mathrm{CN}(\mathrm{C}) \mathrm{C} / \mathrm{C}=\mathrm{C} / \mathrm{C}(=\mathrm{O}) \mathrm{Nc} 1 \mathrm{ccc}(\mathrm{F}) \mathrm{c}(\mathrm{Nc} 2 \mathrm{ncc}(\mathrm{Cl}) \mathrm{c}(\mathrm{Nc} 3 \operatorname{ccc} 4 \operatorname{ccccc} 4 \mathrm{c} 3) \mathrm{n} 2) \mathrm{c} 1$ & 1400 & * \\
\hline 3669 & $\mathrm{CN} 1 \mathrm{CCN}(\mathrm{c} 2 \mathrm{ccc}(\mathrm{Nc} 3 \mathrm{ncc}(\mathrm{Br}) \mathrm{c}(\mathrm{Nc} 4 \mathrm{ccc} 5 \mathrm{cc}[\mathrm{nH}] \mathrm{c5c} 4) \mathrm{n} 3) \mathrm{cc} 2) \mathrm{CC} 1$ & 1400 & * \\
\hline 3670 & $\mathrm{Cc} 1 \mathrm{cc}(\mathrm{C}(=\mathrm{O}) \mathrm{N} 2 \mathrm{CCOCC} 2)[\mathrm{nH}] \mathrm{c} 1 / \mathrm{C}=\mathrm{C} 1 \backslash \mathrm{C}(=\mathrm{O}) \mathrm{Nc} 2 \mathrm{ncnc}(\mathrm{Nc} 3 \mathrm{ccc} 4 \mathrm{c}(\mathrm{c} 3) \mathrm{CCC} 4) \mathrm{c} 21$ & 1410 & * \\
\hline 3671 & $\mathrm{O}=\mathrm{C}(\mathrm{CCCCCC}(=\mathrm{O}) \mathrm{Nc} 1 \mathrm{ccc}(\mathrm{O}) \mathrm{c}(\mathrm{C}(=\mathrm{O}) \mathrm{Nc} 2 \operatorname{cccc}(\mathrm{F}) \mathrm{c} 2) \mathrm{c} 1) \mathrm{NO}$ & 1410 & * \\
\hline 3672 & $\mathrm{O}=\mathrm{C}(\mathrm{CCCCCC}(=\mathrm{O}) \mathrm{Nc} 1 \mathrm{ccc}(\mathrm{O}) \mathrm{c}(\mathrm{C}(=\mathrm{O}) \mathrm{Nc} 2 \mathrm{ccc}(\mathrm{Cl}) \mathrm{c}(\mathrm{C}(\mathrm{F})(\mathrm{F}) \mathrm{F}) \mathrm{c} 2) \mathrm{c} 1) \mathrm{NO}$ & 1410 & $*$ \\
\hline 3673 & COc1cc2ncc(C\#N)c(Nc3ecce(C(F)(F)F)c3)c2cc1OC & 1450 & $*$ \\
\hline 3674 & $\mathrm{O}=\mathrm{C} 1 \mathrm{CSC}(\mathrm{N} / \mathrm{N}=\mathrm{C} / \mathrm{c} 2 \mathrm{cc}(\mathrm{Cl}) \mathrm{cc}(\mathrm{Cl}) \mathrm{c} 2 \mathrm{O})=\mathrm{N} 1$ & 1460 & 5.84 \\
\hline 3675 & $\mathrm{CCOC}(=\mathrm{O}) \mathrm{C}(=\mathrm{CNC}(=\mathrm{O}) \mathrm{Nc} 1 \mathrm{ccc}(\mathrm{C}(=\mathrm{O}) \mathrm{Nc} 2 \mathrm{ccc} 3 \operatorname{ncnc}(\mathrm{Nc} 4 \mathrm{ccc}(\mathrm{F}) \mathrm{c}(\mathrm{Cl}) \mathrm{c} 4) \mathrm{c} 3 \mathrm{c} 2) \mathrm{cc} 1) \mathrm{C}(=\mathrm{O}) \mathrm{OCC}$ & 1460 & $*$ \\
\hline 3676 & $\mathrm{c} 1 \mathrm{ccc}(\mathrm{CNc} 2 \mathrm{ncnc} 3 \mathrm{ccncc} 23) \mathrm{cc} 1$ & 1460 & $*$ \\
\hline 3677 & $\mathrm{CCOc} 1 \mathrm{ccc}(\mathrm{NC}(=\mathrm{O}) / \mathrm{C}=\mathrm{C} / \mathrm{CN}(\mathrm{C}) \mathrm{C}) \mathrm{cc} 1 \mathrm{Nc} 1 \mathrm{ncc}(\mathrm{Cl}) \mathrm{c}(\mathrm{Nc} 2 \mathrm{ccc} 3 \operatorname{ccccc} 3 \mathrm{c} 2) \mathrm{n} 1$ & 1460 & $*$ \\
\hline 3678 & $\mathrm{COC}(=\mathrm{O}) \mathrm{CN} 1 \mathrm{CCC}(\mathrm{n} 2 \mathrm{cc}(-\mathrm{c} 3 \mathrm{cccc}(\mathrm{OC}) \mathrm{c} 3) \mathrm{c} 3 \mathrm{c}(\mathrm{N}) \mathrm{ncnc} 32) \mathrm{CC} 1$ & 1470 & $*$ \\
\hline 3679 & $\mathrm{COc} 1 \mathrm{cc} 2 \mathrm{ncc}(\mathrm{CHN}) \mathrm{c}(\mathrm{Nc} 3 \mathrm{ccc}(\mathrm{C}) \mathrm{c}(\mathrm{Cl}) \mathrm{c} 3) \mathrm{c} 2 \mathrm{cc} 1 \mathrm{OC} . \mathrm{Cl}$ & 1480 & $*$ \\
\hline 3680 & $\mathrm{O}=\mathrm{C}(\mathrm{Nc} 1 \mathrm{ccc}(\mathrm{Cl}) \mathrm{cc} 1) \mathrm{c} 1 \mathrm{ccc}(\mathrm{N}(\mathrm{CCCl}) \mathrm{CCCl}) \mathrm{cc} 1$ & 1490 & 5.83 \\
\hline 3681 & $\mathrm{COc} 1 \mathrm{cc}(/ \mathrm{C}=\mathrm{C} 2 \backslash \mathrm{CCC} / \mathrm{C}(=\mathrm{C} \backslash \mathrm{c} 3 \operatorname{ccccc} 3 \mathrm{Cl}) \mathrm{C} 2=\mathrm{O}) \operatorname{cc}(\mathrm{OC}) \mathrm{c} 1$ & 1500 & 5.46 \\
\hline 3682 & $\mathrm{Clc} 1 \mathrm{cccc}(\mathrm{Nc} 2 \mathrm{ncnc} 3 \mathrm{ccc}(\mathrm{NCc} 4 \mathrm{ccc}(\mathrm{Br}) \mathrm{s} 4) \mathrm{cc} 23) \mathrm{c} 1$ & 1500 & 5.82 \\
\hline 3683 & $\mathrm{COc} 1 \mathrm{cc} 2 \mathrm{c}(\mathrm{cc} 1 \mathrm{OC}) \mathrm{Nc} 1 \mathrm{ncnc}(\mathrm{Nc} 3 \mathrm{cccc}(\mathrm{Br}) \mathrm{c} 3) \mathrm{c} 1 \mathrm{NC} 2$ & 1500 & 5.82 \\
\hline 3684 & $\mathrm{Cc} 1 \mathrm{ncc}(\mathrm{C \# N}) \mathrm{c}(\mathrm{Nc} 2 \operatorname{ccc}(\mathrm{OCc} 3 \operatorname{ccc} n 3) \mathrm{c}(\mathrm{Cl}) \mathrm{c} 2) \mathrm{c} 1 \mathrm{C} \# \mathrm{Cc} 1 \mathrm{ccc}(\mathrm{CNCCS}(\mathrm{C})(=\mathrm{O})=\mathrm{O}) \mathrm{o} 1$ & 1500 & 5.82 \\
\hline 3685 & $\mathrm{CCOc} 1 \mathrm{cc}(\mathrm{N}) \mathrm{c}(\mathrm{C}(=\mathrm{O}) \mathrm{Nc} 2 \operatorname{ccc}(\mathrm{OCc} 3 \operatorname{ccc}(\mathrm{F}) \mathrm{c} 3) \mathrm{c}(\mathrm{Cl}) \mathrm{c} 2) \mathrm{cc} 1 \mathrm{NC}(=\mathrm{O}) / \mathrm{C}=\mathrm{C} / \mathrm{CN}(\mathrm{C}) \mathrm{C}$ & 1500 & 5.82 \\
\hline 3686 & $\mathrm{COc} 1 \mathrm{ccc}(-\mathrm{c} 2 \mathrm{nc} 3 \mathrm{sc}(-\mathrm{c} 4 \mathrm{ccc}(\mathrm{Cl}) \mathrm{cc} 4) \mathrm{cn} 3 \mathrm{n} 2) \mathrm{cc} 1$ & 1500 & 5.82 \\
\hline 3687 & $\operatorname{CCOC}(=O) \operatorname{CCCn} 1 \mathrm{c}(=\mathrm{O}) \operatorname{oc} 2 \mathrm{cc} 3 \mathrm{ncnc}(\mathrm{Nc} 4 \mathrm{cc}(\mathrm{C}) \mathrm{cc}(\mathrm{C}) \mathrm{c} 4) \mathrm{c} 3 \mathrm{cc} 21$ & 1500 & * \\
\hline
\end{tabular}




\begin{tabular}{|c|c|c|c|}
\hline 3688 & $\operatorname{COC}(=\mathrm{O}) \operatorname{c} 1 \operatorname{ccc}(\mathrm{S}(=\mathrm{O})(=\mathrm{O}) \mathrm{Oc} 2 \operatorname{ccc}(/ \mathrm{C}=\mathrm{C} /[\mathrm{N}+](=\mathrm{O})[\mathrm{O}-]) \operatorname{cc} 2) \operatorname{cc} 1$ & 1500 & $*$ \\
\hline 3689 & $\mathrm{Cc} 1 \mathrm{cccc} 2 \mathrm{c}(\mathrm{CCC}(=\mathrm{O}) \mathrm{O}) \mathrm{c}(\mathrm{SSc} 3[\mathrm{nH}] \mathrm{c} 4 \mathrm{c}(\mathrm{C}) \operatorname{ccc} 4 \mathrm{c} 3 \mathrm{CCC}(=\mathrm{O}) \mathrm{O})[\mathrm{nH}] \mathrm{c} 12$ & 1500 & $*$ \\
\hline 3690 & $\mathrm{Cl} . \mathrm{O}=\mathrm{C}(\mathrm{CCN} 1 \mathrm{CCOCC} 1) \mathrm{c} 1 \mathrm{ccc}(\mathrm{OCc} 2 \mathrm{ccccc} 2) \mathrm{cc} 1$ & 1500 & $*$ \\
\hline 3691 & $\mathrm{C}=\mathrm{C}(\mathrm{CN} 1 \mathrm{CCNCC} 1) \mathrm{C}(=\mathrm{O}) \mathrm{c} 1 \mathrm{ccc}(\mathrm{OCc} 2 \mathrm{cccc} 2) \mathrm{cc} 1 . \mathrm{Cl}$ & 1500 & $*$ \\
\hline 3692 & $\mathrm{CN}(\mathrm{C}) \mathrm{CCC}(=\mathrm{O}) \mathrm{c} 1 \mathrm{ccc}(\mathrm{OCc} 2 \operatorname{ccccc} 2) \mathrm{cc} 1 . \mathrm{Cl}$ & 1500 & $*$ \\
\hline 3693 & $\begin{array}{c}\mathrm{O}=\mathrm{C} 1 \mathrm{~N} / \mathrm{C}=\mathrm{C} \backslash \mathrm{c} 2 \mathrm{ccc}(\mathrm{c}(\mathrm{Br}) \mathrm{c} 2) \mathrm{Oc} 2 \mathrm{cc}(\mathrm{cc}(\mathrm{Br}) \mathrm{c} 2 \mathrm{O}) \mathrm{CCNC}(=\mathrm{O}) / \mathrm{C}(=\mathrm{N} / \mathrm{O}) \mathrm{Cc} 2 \mathrm{ccc}(\mathrm{c}(\mathrm{Br}) \mathrm{c} 2) \mathrm{Oc} 2 \mathrm{cc}(\operatorname{cc}(\mathrm{Br}) \mathrm{c} 2 \mathrm{O}) \mathrm{C} / \mathrm{C} 1=\mathrm{N} \backslash \\
\mathrm{O}\end{array}$ & 1500 & $*$ \\
\hline 3694 & $\mathrm{Cc} 1 \mathrm{c}(\mathrm{Cl}) \operatorname{ccc} 1 \mathrm{NC}(=\mathrm{O}) \mathrm{c} 1 \operatorname{cccc} 1 \mathrm{O}$ & 1500 & $*$ \\
\hline 3695 & $\mathrm{Cc} 1 \mathrm{ncc}([\mathrm{N}+](=\mathrm{O})[\mathrm{O}-]) \mathrm{n} 1 \mathrm{CC}(=\mathrm{O}) \mathrm{NS}(=\mathrm{O})(=\mathrm{O}) \mathrm{c} 1 \mathrm{ccc}(\mathrm{Cl}) \mathrm{cc} 1$ & 1510 & 5.82 \\
\hline 3696 & $\mathrm{Nc} 1 \mathrm{ccccc} 1-\mathrm{c} 1 \mathrm{nnn}(\mathrm{SCc} 2 \mathrm{cccc} 2) \mathrm{o} 1$ & 1510 & 5.82 \\
\hline 3697 & $\mathrm{CCOC}(=\mathrm{O}) \mathrm{C}(\mathrm{Cc} 1 \mathrm{ccccc} 1) \mathrm{NC}(=\mathrm{O}) / \mathrm{C}(\mathrm{C} \# \mathrm{~N})=\mathrm{C} / \mathrm{c} 1 \mathrm{ccc}(\mathrm{O}) \mathrm{c}(\mathrm{O}) \mathrm{c} 1$ & 1530 & $*$ \\
\hline 3698 & $\mathrm{Nc} 1 \mathrm{ncn} 2 \mathrm{c} 1 \mathrm{c}(-\mathrm{c} 1 \mathrm{cccc}(\mathrm{O}) \mathrm{c} 1) \mathrm{cn} 2 \mathrm{C} 1 \mathrm{CCNC} 1$ & 1530 & $*$ \\
\hline 3699 & $\mathrm{~N} \# \mathrm{C} / \mathrm{C}(=\mathrm{C} \backslash \mathrm{c} 1 \mathrm{ccc}(\mathrm{O}) \mathrm{c}(\mathrm{O}) \mathrm{c} 1) \mathrm{C}(=\mathrm{O}) \mathrm{c} 1 \mathrm{cccc} 1 \mathrm{Cl}$ & 1540 & $*$ \\
\hline 3700 & $\mathrm{Nc} 1 \mathrm{cccc}(\mathrm{Nc} 2 \mathrm{ncnc} 3 \mathrm{cc}(\mathrm{N}) \mathrm{ncc} 23) \mathrm{c} 1$ & 1550 & $*$ \\
\hline 3701 & $\operatorname{COc} 1 \mathrm{cc}(\mathrm{O}) \mathrm{c}(\mathrm{C}(=\mathrm{O}) \mathrm{Nc} 2 \mathrm{ccc}(\mathrm{F}) \mathrm{c}(\mathrm{Cl}) \mathrm{c} 2) \operatorname{cc} 1 \mathrm{NC}(=\mathrm{O}) \mathrm{CCCCCC}(=\mathrm{O}) \mathrm{NO}$ & 1560 & $*$ \\
\hline 3702 & $\operatorname{COc} 1 \operatorname{ccc}(\mathrm{NC}(=\mathrm{O}) / \mathrm{C}=\mathrm{C} / \mathrm{CN}(\mathrm{C}) \mathrm{C}) \operatorname{cc} 1 \mathrm{Nc} 1 \mathrm{ncc}(\mathrm{Cl}) \mathrm{c}(\mathrm{Nc} 2 \operatorname{ccc} 3 \operatorname{cccc} 23) \mathrm{n} 1$ & 1560 & $*$ \\
\hline 3703 & $\mathrm{CCOc} 1 \mathrm{cc} 2 \mathrm{ncc}(\mathrm{C \# N}) \mathrm{c}(\mathrm{Nc} 3 \operatorname{ccc}(\mathrm{OCc} 4 \mathrm{ccccc} 4) \mathrm{c}(\mathrm{Cl}) \mathrm{c} 3) \mathrm{c} 2 \mathrm{cc} 1 \mathrm{NC}(=\mathrm{O}) / \mathrm{C}=\mathrm{C} / \mathrm{c} 1 \mathrm{ccccc} 1 \mathrm{~N}(\mathrm{C}) \mathrm{C}$ & 1569 & 5.80 \\
\hline 3704 & $\mathrm{NC}(=\mathrm{S}) \mathrm{N} / \mathrm{N}=\mathrm{C}(/ \mathrm{C}=\mathrm{C} / \mathrm{c} 1 \mathrm{ccc}([\mathrm{N}+](=\mathrm{O})[\mathrm{O}-]) \operatorname{cc} 1) \mathrm{c} 1 \mathrm{ccccc} 1$ & 1570 & 5.80 \\
\hline 3705 & $\mathrm{Nc} 1 \mathrm{ncnc} 2 \mathrm{c} 1 \mathrm{c}(-\mathrm{c} 1 \mathrm{ccc}(\mathrm{Cl}) \mathrm{c}(\mathrm{O}) \mathrm{c} 1) \mathrm{nn} 2[\mathrm{C} @ \mathrm{H}] 1 \mathrm{CCOC} 1$ & 1580 & $*$ \\
\hline 3706 & $\mathrm{O}=\mathrm{C}(\mathrm{Nc} 1 \mathrm{cc} 2 \mathrm{c}(\mathrm{Nc} 3 \mathrm{ccc}(\mathrm{F}) \mathrm{c}(\mathrm{Cl}) \mathrm{c} 3) \mathrm{ncnc} 2 \mathrm{cc} 1 \mathrm{O}[\mathrm{C} @ \mathrm{H}] 1 \mathrm{CCOC} 1) \mathrm{N} 1 \mathrm{CCC}(\mathrm{F})(\mathrm{F}) \mathrm{C} 1$ & 1581 & $*$ \\
\hline 3707 & $\mathrm{O}=\mathrm{C}(\mathrm{Nc} 1 \mathrm{cc} 2 \mathrm{c}(\mathrm{Nc} 3 \mathrm{ccc}(\mathrm{F}) \mathrm{c}(\mathrm{Cl}) \mathrm{c} 3) \mathrm{ncnc} 2 \mathrm{cc} 1 \mathrm{O}[\mathrm{C} @ \mathrm{H}] 1 \mathrm{CCOC} 1) \mathrm{N}(\mathrm{N} 1 \mathrm{CCC}(\mathrm{F})(\mathrm{F}) \mathrm{C} 1) \mathrm{N} 1 \mathrm{CCC}(\mathrm{F})(\mathrm{F}) \mathrm{C} 1$ & 1581 & $*$ \\
\hline 3708 & $\operatorname{CCCCCCCCCCCCCCCCCCCCOC~}(=0) \operatorname{COc} 1 \mathrm{cc}(\mathrm{O}) \mathrm{c} 2 \mathrm{c}(=\mathrm{O}) \operatorname{cc}(-\mathrm{c} 3 \operatorname{ccccc} 3) \mathrm{oc} 2 \mathrm{c} 1$ & 1589 & 5.80 \\
\hline 3709 & $\mathrm{COc} 1 \mathrm{cc}(/ \mathrm{C}=\mathrm{C} 2 \backslash \mathrm{CCC} / \mathrm{C}(=\mathrm{C} \backslash \mathrm{c} 3 \operatorname{ccccc} 3) \mathrm{C} 2=\mathrm{O}) \mathrm{cc}(\mathrm{OC}) \mathrm{c} 1$ & 1600 & 5.34 \\
\hline 3710 & $\mathrm{COc} 1 \mathrm{cc} 2 \mathrm{c}(\mathrm{cc} 1 \mathrm{OC}) \mathrm{Sc} 1 \mathrm{ncnc}(\mathrm{Sc} 3 \mathrm{cccc}(\mathrm{Br}) \mathrm{c} 3) \mathrm{c} 1 \mathrm{NC} 2$ & 1600 & 5.80 \\
\hline 3711 & $\mathrm{CCOc} 1 \mathrm{cc} 2 \mathrm{ncc}(\mathrm{C \# N}) \mathrm{c}(\mathrm{Nc} 3 \operatorname{ccc}(\mathrm{Br}) \mathrm{c} 3) \mathrm{c} 2 \mathrm{cc} 1 \mathrm{NC}(=\mathrm{O}) / \mathrm{C}=\mathrm{C} / \mathrm{CN}(\mathrm{C}) \mathrm{C}$ & 1600 & 5.80 \\
\hline 3712 & $\mathrm{CCC}(=\mathrm{O}) \mathrm{N} 1 \mathrm{CC}[\mathrm{C} @ \mathrm{H}](\mathrm{N} 2 \mathrm{C}(=\mathrm{O}) \mathrm{N}(\mathrm{c} 3 \mathrm{cc}(\mathrm{OC}) \mathrm{ccc} 3 \mathrm{~F}) \mathrm{Cc} 3 \mathrm{cnc}(\mathrm{Nc} 4 \mathrm{ccc}(\mathrm{N} 5 \mathrm{CCN}(\mathrm{C}) \mathrm{CC} 5) \mathrm{cc} 4 \mathrm{OC}) \mathrm{nc} 32) \mathrm{C} 1$ & 1600 & 5.80 \\
\hline 3713 & $\mathrm{~N} \# \mathrm{C} / \mathrm{C}(=\mathrm{Clc} 1 \mathrm{ccc}(\mathrm{O}) \mathrm{c}(\mathrm{O}) \mathrm{c} 1) \mathrm{C}(=\mathrm{O}) \mathrm{NC} 1 \mathrm{CCCCC} 1$ & 1600 & $*$ \\
\hline 3714 & $\mathrm{CCc} 1 \mathrm{c}(\mathrm{CC}(=\mathrm{O}) \mathrm{O}) \mathrm{cn} 2 \mathrm{ncnc}(\mathrm{Nc} 3 \mathrm{ccc} 4 \mathrm{c}(\operatorname{cnn} 4 \mathrm{Cc} 4 \mathrm{ccccc} 4) \mathrm{c} 3) \mathrm{c} 12$ & 1600 & $*$ \\
\hline 3715 & $\mathrm{c} 1 \mathrm{ccc}(-\mathrm{c} 2 \mathrm{cc} 3 \mathrm{ncnc}(\mathrm{Nc} 4 \mathrm{ccc} 5[\mathrm{nH}] \mathrm{ncc} 5 \mathrm{c} 4) \mathrm{c} 3 \mathrm{~s} 2) \mathrm{cc} 1$ & 1600 & $*$ \\
\hline 3716 & $\mathrm{CCOC}(=\mathrm{O}) \mathrm{C} 1=\mathrm{C}(\mathrm{C}) \mathrm{OC}(\mathrm{N})=\mathrm{C}(\mathrm{C} \# \mathrm{~N}) \mathrm{C} 1 \mathrm{c} 1 \mathrm{ccc}(\mathrm{OC} 2 \mathrm{CCCC} 2) \mathrm{cc} 1$ & 1600 & * \\
\hline 3717 & $\mathrm{CN}(\mathrm{C}) \mathrm{c} 1 \mathrm{ccc}(\mathrm{C}=\mathrm{C} 2 \mathrm{COCC}(=\mathrm{C} \backslash \mathrm{c} 3 \operatorname{ccc}(\mathrm{N}(\mathrm{C}) \mathrm{C}) \mathrm{cc} 3[\mathrm{~N}+](=\mathrm{O})[\mathrm{O}-]) / \mathrm{C} 2=\mathrm{N} \backslash \mathrm{O}) \mathrm{c}([\mathrm{N}+](=\mathrm{O})[\mathrm{O}-]) \mathrm{c} 1$ & 1600 & $*$ \\
\hline 3718 & $\mathrm{C} / \mathrm{C}=\mathrm{C} / \mathrm{C}(=\mathrm{O}) \mathrm{Nc} 1 \mathrm{ccc} 2 \mathrm{ncc}(\mathrm{C \# N}) \mathrm{c}(\mathrm{Nc} 3 \operatorname{cccc}(\mathrm{Br}) \mathrm{c} 3) \mathrm{c} 2 \mathrm{c} 1$ & 1620 & 5.79 \\
\hline 3719 & $\mathrm{O}=\mathrm{C}(\mathrm{O}) \mathrm{CCC} 1 \mathrm{C}(\mathrm{S})=\mathrm{Nc} 2 \operatorname{cccc} 21$ & 1620 & $*$ \\
\hline 3720 & $\mathrm{Cc} 1 \mathrm{ccc}(\mathrm{O}) \mathrm{cc} 1-\mathrm{n} 1 \mathrm{c}(=\mathrm{O}) \mathrm{c} 2 \mathrm{c}(\mathrm{c} 3 \mathrm{c}(\mathrm{N}) \mathrm{ncnc} 31) \mathrm{CCCC} 2$ & 1620 & $*$ \\
\hline 3721 & $\mathrm{O}=\mathrm{C}(\mathrm{Nc} 1 \mathrm{ccc} 2 \mathrm{ncnc}(\mathrm{Nc} 3 \operatorname{ccc}(\mathrm{Br}) \mathrm{c} 3) \mathrm{c} 2 \mathrm{c} 1) \mathrm{c} 1 \mathrm{cccc} 2 \mathrm{c} 1 \mathrm{OCCO} 2$ & 1630 & 5.79 \\
\hline 3722 & $\mathrm{CNS}(=\mathrm{O})(=\mathrm{O}) \mathrm{c} 1 \mathrm{ccc}(\mathrm{Nc} 2 \mathrm{nc}(\mathrm{Cl}) \mathrm{nc} 3 \mathrm{cc}(\mathrm{OC}) \mathrm{c}(\mathrm{OC}) \mathrm{cc} 23) \mathrm{cc} 1$ & 1630 & $*$ \\
\hline 3723 & $\mathrm{Fc} 1 \mathrm{cc}(\mathrm{Nc} 2 \mathrm{nccc}(\mathrm{Nc} 3 \operatorname{ccc} 4[\mathrm{nH}] \mathrm{ccc} 4 \mathrm{c} 3) \mathrm{n} 2) \operatorname{ccc} 1 \mathrm{~N} 1 \mathrm{CCOCC} 1$ & 1630 & $*$ \\
\hline 3724 & $\mathrm{Clc} 1 \mathrm{ccc}(\mathrm{CNc} 2 \mathrm{ccc} 3 \mathrm{ncnc}(\mathrm{Nc} 4 \mathrm{cccc}(\mathrm{Br}) \mathrm{c} 4) \mathrm{c} 3 \mathrm{c} 2) \mathrm{cc} 1$ & 1640 & 5.79 \\
\hline 3725 & $\mathrm{Fc} 1 \mathrm{ccc}(\mathrm{Nc} 2 \mathrm{ncnc} 3 \mathrm{ccc}(\mathrm{C} \# \mathrm{Cc} 4 \mathrm{cccs} 4) \mathrm{cc} 23) \mathrm{cc} 1 \mathrm{Cl}$ & 1640.6 & $*$ \\
\hline 3726 & COc1cc2ncne(Ne3ecce(C\#CCO)c3)c2cc1OC & 1643.6 & $*$ \\
\hline 3727 & $\mathrm{O}=\mathrm{C}(\mathrm{O}[\mathrm{C} @ \mathrm{H}] 1 \mathrm{CN}[\mathrm{C} @ \mathrm{H}](\mathrm{C} \# \mathrm{Cc} 2 \mathrm{cc} 3 \mathrm{ncnc}(\mathrm{Nc} 4 \mathrm{ccc}(\mathrm{Sc} 5 \mathrm{ccccn} 5) \mathrm{cc} 4) \mathrm{c} 3 \mathrm{~s} 2) \mathrm{C} 1) \mathrm{N} 1 \mathrm{CCOCC} 1$ & 1650 & 5.78 \\
\hline 3728 & $\mathrm{Cc} 1 \mathrm{ccc}(\mathrm{C} 2=\mathrm{NN}(\mathrm{C} 3=\mathrm{NC}(=\mathrm{O}) \mathrm{CS} 3) \mathrm{C}(\mathrm{c} 3 \operatorname{ccc}(\mathrm{Cl}) \mathrm{cc} 3) \mathrm{C} 2) \mathrm{cc} 1$ & 1660 & 5.78 \\
\hline 3729 & $\mathrm{Nc} 1 \mathrm{cc} 2 \mathrm{ncnc}(\mathrm{NCc} 3 \operatorname{ccc} c 3 \mathrm{Br}) \mathrm{c} 2 \mathrm{cn} 1$ & 1670 & $*$ \\
\hline
\end{tabular}




\begin{tabular}{|c|c|c|c|}
\hline 3730 & $\mathrm{CCC}(\mathrm{C}) \mathrm{n} 1 \mathrm{nc}(-\mathrm{c} 2 \mathrm{ccc}(\mathrm{C}) \mathrm{c}(\mathrm{O}) \mathrm{c} 2) \mathrm{c} 2 \mathrm{c}(\mathrm{N}) \mathrm{ncnc} 21$ & 1670 & $*$ \\
\hline 3731 & $\mathrm{O}=\mathrm{C}(/ \mathrm{C}=\mathrm{C} / \mathrm{c} 1 \mathrm{ccccc} 1) \mathrm{Nc} 1 \operatorname{ccc}(\mathrm{Oc} 2 \mathrm{cc}(\mathrm{Nc} 3 \operatorname{ccc}(\mathrm{OCc} 4 \operatorname{ccc}(\mathrm{F}) \mathrm{c} 4) \mathrm{c}(\mathrm{Cl}) \mathrm{c} 3) \mathrm{ncn} 2) \mathrm{c} 1$ & 1671 & 5.78 \\
\hline 3732 & $\mathrm{O}=\mathrm{c} 1 \mathrm{c} 2 \mathrm{ccc}(\mathrm{Cl}) \mathrm{cc} 2 \mathrm{nc}(-\mathrm{c} 2 \mathrm{ccccc} 2) \mathrm{n} 1-\mathrm{c} 1 \mathrm{nnn}(-\mathrm{c} 2 \mathrm{cccc} 2) \mathrm{s} 1$ & 1680 & 5.77 \\
\hline 3733 & $\mathrm{COc} 1 \mathrm{cc}(\mathrm{C} 2=\mathrm{C}(\mathrm{c} 3 \mathrm{c}[\mathrm{nH}] \mathrm{c} 4 \mathrm{ccc}(\mathrm{I}) \mathrm{cc} 34) \mathrm{C}(=\mathrm{O}) \mathrm{NC} 2=\mathrm{O}) \mathrm{cc}(\mathrm{OC}) \mathrm{c} 1 \mathrm{OC}$ & 1688 & $*$ \\
\hline 3734 & $\operatorname{COc} 1 \mathrm{cc}(/ \mathrm{C}=\mathrm{C}(\backslash \mathrm{C} \# \mathrm{~N}) \mathrm{C}(\mathrm{N})=\mathrm{O}) \operatorname{cc}(\mathrm{CSc} 2 \operatorname{cccc} 3 \operatorname{cccc} 23) \mathrm{c} 1 \mathrm{O}$ & 1698.24 & $*$ \\
\hline 3735 & $\mathrm{COc} 1 \mathrm{cc}(-\mathrm{c} 2 \mathrm{nc} 3 \mathrm{sc}(-\mathrm{c} 4 \mathrm{ccc}(\mathrm{Cl}) \mathrm{cc} 4) \mathrm{cn} 3 \mathrm{n} 2) \mathrm{cc}(\mathrm{OC}) \mathrm{c} 1 \mathrm{OC}$ & 1700 & 5.77 \\
\hline 3736 & $\mathrm{CC} 1=\mathrm{C} 2 \mathrm{C}=\mathrm{C}(\mathrm{Cl}) \mathrm{C}=\mathrm{CC} 2 \mathrm{~N} 2 \mathrm{C}=\mathrm{C}(\mathrm{Cc} 3 \operatorname{ccccc} 3) \mathrm{NC}(=\mathrm{O}) \mathrm{C} 12$ & 1700 & 5.77 \\
\hline 3737 & $\mathrm{O}=\mathrm{c} 1 \mathrm{oc} 2 \mathrm{cc} 3 \mathrm{ncnc}(\mathrm{Ne} 4 \mathrm{ccc}(\mathrm{OCc} 5 \mathrm{ccc} \mathrm{n} 5) \mathrm{cc} 4) \mathrm{c} 3 \mathrm{cc} 2 \mathrm{n} 1 \mathrm{CCCN} 1 \mathrm{CCOCC} 1$ & 1700 & $*$ \\
\hline 3738 & $\operatorname{COc} 1 \operatorname{ccc}(\mathrm{CCNC}(=\mathrm{O}) / \mathrm{C}(\mathrm{C} \# \mathrm{~N})=\mathrm{C} / \mathrm{c} 2 \operatorname{ccc}(\mathrm{O}) \mathrm{c}(\mathrm{O}) \mathrm{c} 2) \operatorname{cc} 1 \mathrm{OC}$ & 1700 & $*$ \\
\hline 3739 & $\mathrm{COc} 1 \mathrm{ccc}(\mathrm{NC}(=\mathrm{O}) / \mathrm{C}(\mathrm{C \# N})=\mathrm{C} / \mathrm{c} 2 \operatorname{ccc}(\mathrm{O}) \mathrm{c}(\mathrm{O}) \mathrm{c} 2) \mathrm{c}(\mathrm{OC}) \mathrm{c} 1$ & 1700 & $*$ \\
\hline 3740 & $\mathrm{C}=\mathrm{CC}(=\mathrm{O}) \mathrm{Nc} 1 \mathrm{cccc}(\mathrm{Oc} 2 \mathrm{nc}(\mathrm{Nc} 3 \mathrm{n}[\mathrm{nH}] \mathrm{c} 4 \mathrm{ccccc} 34) \operatorname{cc}(\mathrm{N} 3 \mathrm{CCN}(\mathrm{C}) \mathrm{CC} 3) \mathrm{n} 2) \mathrm{c} 1$ & 1700 & $*$ \\
\hline 3741 & $\mathrm{Cc} 1 \mathrm{cc}(\mathrm{Nc} 2 \mathrm{cc}(\mathrm{N} 3 \mathrm{CCN}(\mathrm{C}) \mathrm{CC} 3) \mathrm{nc}(\mathrm{Oc} 3 \operatorname{ccc}(\mathrm{NC}(=\mathrm{O}) / \mathrm{C}=\mathrm{C} / \mathrm{CN}(\mathrm{C}) \mathrm{C}) \mathrm{cc} 3) \mathrm{n} 2) \mathrm{n}[\mathrm{nH}] 1$ & 1700 & $*$ \\
\hline 3742 & $\mathrm{COc} 1 \mathrm{cc} 2 \mathrm{c}(\mathrm{Oc} 3 \mathrm{ccc}(-\mathrm{c} 4 \mathrm{cnc}(\mathrm{Cc} 5 \mathrm{ccccc} 5) \mathrm{n}(\mathrm{C}) \mathrm{c} 4=\mathrm{O}) \mathrm{cc} 3 \mathrm{~F}) \mathrm{ccn} 2 \mathrm{cc} 1 \mathrm{OCCCN} 1 \mathrm{CCOCC} 1$ & 1700 & $*$ \\
\hline 3743 & $\mathrm{COc} 1 \mathrm{cc} 2 \mathrm{c}(\mathrm{Oc} 3 \mathrm{ccc}(-\mathrm{c} 4 \mathrm{cnc}(\mathrm{Nc} 5 \mathrm{ccc}(\mathrm{F}) \mathrm{cc} 5) \mathrm{n}(\mathrm{C}) \mathrm{c} 4=\mathrm{O}) \mathrm{cc} 3 \mathrm{~F}) \mathrm{ccnc} 2 \mathrm{cc} 1 \mathrm{OCCCN} 1 \mathrm{CCOCC} 1$ & 1700 & $*$ \\
\hline 3744 & $\operatorname{COc} 1 \operatorname{ccc}(\mathrm{C} 2=\mathrm{NN}(\mathrm{C}(=\mathrm{O}) \mathrm{Cc} 3 \mathrm{nc} 4 \operatorname{ccccc} 4[\mathrm{nH}] 3) \mathrm{C}(\mathrm{c} 3 \operatorname{ccc}(\mathrm{Cl}) \operatorname{cc} 3) \mathrm{C} 2) \mathrm{cc} 1$ & 1700 & $*$ \\
\hline 3745 & $\mathrm{CC}(=\mathrm{O}) \mathrm{Nc} 1 \mathrm{ccc}(\mathrm{C}(=\mathrm{O}) \mathrm{Nc} 2 \operatorname{ccc}(\mathrm{Cl}) \mathrm{c} 2) \mathrm{c}(\mathrm{O}) \mathrm{c} 1$ & 1700 & $*$ \\
\hline 3746 & $\mathrm{COc} 1 \mathrm{cc}(\mathrm{Nc} 2 \mathrm{nccc}(-\mathrm{c} 3 \mathrm{ccc}(\mathrm{N} 4 \mathrm{CCNCC} 4) \mathrm{nc} 3) \mathrm{n} 2) \mathrm{cc}(\mathrm{OC}) \mathrm{c} 1 \mathrm{OC}$ & 1704 & $*$ \\
\hline 3747 & $\mathrm{O}=\mathrm{C}(\mathrm{Nc} 1 \mathrm{cc} 2 \mathrm{c}(\mathrm{Nc} 3 \mathrm{ccc}(\mathrm{F}) \mathrm{c}(\mathrm{Cl}) \mathrm{c} 3) \mathrm{ncnc} 2 \mathrm{cc} 1 \mathrm{O}[\mathrm{C} @ \mathrm{H}] 1 \mathrm{CCOC} 1) \mathrm{N} 1 \mathrm{CCC} 2(\mathrm{CC} 1) \mathrm{OCCO} 2$ & 1715 & $*$ \\
\hline 3748 & $\mathrm{O}=\mathrm{C}(\mathrm{Nc} 1 \mathrm{cc} 2 \mathrm{c}(\mathrm{Nc} 3 \mathrm{ccc}(\mathrm{F}) \mathrm{c}(\mathrm{Cl}) \mathrm{c} 3) \mathrm{ncnc} 2 \mathrm{cc} 1 \mathrm{O}[\mathrm{C} @ \mathrm{H}] 1 \mathrm{CCOC} 1) \mathrm{N}(\mathrm{N} 1 \mathrm{CCC} 2(\mathrm{CC} 1) \mathrm{OCCO} 2) \mathrm{N} 1 \mathrm{CCC} 2(\mathrm{CC} 1) \mathrm{OCCO} 2$ & 1715 & $*$ \\
\hline 3749 & $\mathrm{O}=\mathrm{C} 1 \mathrm{CSC}(\mathrm{N} / \mathrm{N}=\mathrm{C} / \mathrm{c} 2 \operatorname{ccc}(\mathrm{Br}) \operatorname{cc} 2)=\mathrm{N} 1$ & 1720 & 5.76 \\
\hline 3750 & $\mathrm{O}=\mathrm{C}(\mathrm{Nc} 1 \mathrm{ccc}(\mathrm{F}) \mathrm{cc} 1) \mathrm{c} 1 \mathrm{ccc}(\mathrm{N}(\mathrm{CCCl}) \mathrm{CCCl}) \mathrm{cc} 1$ & 1720 & 5.76 \\
\hline 3751 & $\operatorname{CCCCCCCCCCCCOC}(=\mathrm{O}) \operatorname{COc} 1 \mathrm{cc}(\mathrm{O}) \mathrm{c} 2 \mathrm{c}(=\mathrm{O}) \mathrm{cc}(-\mathrm{c} 3 \operatorname{ccccc} 3) \mathrm{oc} 2 \mathrm{c} 1$ & 1720 & 5.76 \\
\hline 3752 & $\mathrm{Cc} 1 \mathrm{ccc}(\mathrm{C} 2=\mathrm{NN}(\mathrm{c} 3 \mathrm{nc}(-\mathrm{c} 4 \mathrm{ccccc} 4) \operatorname{cs} 3) \mathrm{C}(\mathrm{c} 3 \mathrm{ccc}(\mathrm{F}) \mathrm{cc} 3) \mathrm{C} 2) \operatorname{cc} 1 \mathrm{C}$ & 1730 & 5.76 \\
\hline 3753 & $\mathrm{CC}(=\mathrm{O}) \mathrm{c} 1 \mathrm{ccc} 2 \mathrm{ncc}(\mathrm{C}(\mathrm{N})=\mathrm{O}) \mathrm{c}(\mathrm{Nc} 3 \operatorname{ccc}(\mathrm{OCc} 4 \operatorname{cccc} 4) \operatorname{cc} 3) \mathrm{c} 2 \mathrm{c} 1$ & 1730 & $*$ \\
\hline 3754 & $\operatorname{COc} 1 \mathrm{cc}(/ \mathrm{C}=\mathrm{C}(\backslash \mathrm{C} \# \mathrm{~N}) \mathrm{C}(\mathrm{N})=\mathrm{O}) \operatorname{cc}(\mathrm{CSc} 2 \operatorname{ccc}(\mathrm{C}) \operatorname{cc} 2) \mathrm{c} 1 \mathrm{O}$ & 1737.8 & $*$ \\
\hline 3755 & $\operatorname{Oc} 1 \mathrm{c}(\mathrm{Br}) \operatorname{cc}(\mathrm{Br}) \operatorname{cc} 1 \mathrm{CN}(\mathrm{Cc} 1 \mathrm{ccc}(\mathrm{F}) \mathrm{cc} 1) \mathrm{C}(=\mathrm{S}) \mathrm{Nc} 1 \mathrm{ccccc} 1$ & 1760 & 5.75 \\
\hline 3756 & $\mathrm{Nc} 1 \mathrm{ncnc} 2 \mathrm{c} 1 \mathrm{c}(-\mathrm{c} 1 \mathrm{ccc}(\mathrm{O}) \mathrm{c} 1 \mathrm{~F}) \mathrm{nn} 2 \mathrm{C} 1 \mathrm{CCCC} 1$ & 1770 & $*$ \\
\hline 3757 & $\mathrm{CN}(\mathrm{C}) \mathrm{c} 1 \mathrm{cccc}(\mathrm{Nc} 2 \mathrm{ncnc} 3 \mathrm{cc}(\mathrm{N}) \mathrm{ncc} 23) \mathrm{c} 1$ & 1790 & $*$ \\
\hline 3758 & Oc1 $1 \mathrm{ccc}(-\mathrm{c} 2 \mathrm{nc}(-\mathrm{c} 3 \mathrm{ccco} 3) \mathrm{c}(-\mathrm{c} 3 \mathrm{ccnc} 4[\mathrm{nH}] \mathrm{c}(-\mathrm{c} 5 \mathrm{ccccc} 5) \mathrm{cc} 34)[\mathrm{nH}] 2) \mathrm{cc} 1$ & 1790 & $*$ \\
\hline 3759 & $\mathrm{COc} 1 \mathrm{cc} 2 \mathrm{ncc}(\mathrm{CHN}) \mathrm{c}(\mathrm{Nc} 3 \mathrm{ccc}(\mathrm{C}) \mathrm{c}(\mathrm{Br}) \mathrm{c} 3) \mathrm{c} 2 \mathrm{cc} 1 \mathrm{OC}$ & 1790 & $*$ \\
\hline 3760 & $\mathrm{C}=\mathrm{CCOC}(=\mathrm{O}) \mathrm{Nc} 1 \mathrm{cc} 2 \mathrm{c}(\mathrm{Nc} 3 \mathrm{ccc}(\mathrm{F}) \mathrm{c}(\mathrm{Cl}) \mathrm{c} 3) \mathrm{ncnc} 2 \mathrm{~s} 1$ & 1792 & $*$ \\
\hline 3761 & $\operatorname{COC}(=\mathrm{O}) \operatorname{c} 1 \operatorname{ccc}(\mathrm{S}(=\mathrm{O})(=\mathrm{O}) \mathrm{Oc} 2 \mathrm{ccc}(/ \mathrm{C}=\mathrm{C} /[\mathrm{N}+](=\mathrm{O})[\mathrm{O}-]) \operatorname{cc} 2) \operatorname{cc} 1 \mathrm{O}$ & 1800 & $*$ \\
\hline 3762 & $\mathrm{Cl} . \mathrm{O}=\mathrm{C}(\mathrm{CCN} 1 \mathrm{CCCCC} 1) \mathrm{c} 1 \mathrm{ccc}(\mathrm{OCc} 2 \mathrm{cccc} 2) \mathrm{cc} 1$ & 1800 & $*$ \\
\hline 3763 & $\mathrm{N \# C/C}(=\mathrm{C} \mid \mathrm{c} 1 \operatorname{ccc}(\mathrm{O}) \mathrm{c}(\mathrm{O}) \mathrm{c} 1) \mathrm{C}(=\mathrm{O}) \mathrm{NCC} 1 \mathrm{CCCC}(\mathrm{CNC}(=\mathrm{O}) / \mathrm{C}(\mathrm{C \# N})=\mathrm{C} / \mathrm{c} 2 \operatorname{ccc}(\mathrm{O}) \mathrm{c}(\mathrm{O}) \mathrm{c} 2) \mathrm{C} 1$ & 1800 & $*$ \\
\hline 3764 & $\mathrm{FC}(\mathrm{F}) \mathrm{C}(\mathrm{F})(\mathrm{F}) \mathrm{Oc} 1 \mathrm{cccc}(\mathrm{Nc} 2 \mathrm{nccc}(-\mathrm{c} 3 \mathrm{c}[\mathrm{nH}] \mathrm{c} 4 \mathrm{ccccc} 34) \mathrm{n} 2) \mathrm{c} 1$ & 1800 & $*$ \\
\hline 3765 & $\mathrm{COc} 1 \mathrm{ccc}(\mathrm{Nc} 2 \mathrm{ncnc} 3 \operatorname{cccc}(\mathrm{OC} 4 \mathrm{CCN}(\mathrm{C}) \mathrm{CC} 4) \mathrm{c} 23) \mathrm{cc} 1 \mathrm{Cl}$ & 1800 & $*$ \\
\hline 3766 & $\mathrm{CC}(\mathrm{C})(\mathrm{C}) \mathrm{c} 1 \mathrm{ccc}(\mathrm{OC}[\mathrm{C} @ @ \mathrm{H}](\mathrm{Cn} 2 \mathrm{ccnc} 2[\mathrm{~N}+](=\mathrm{O})[\mathrm{O}-]) \mathrm{OC}(=\mathrm{O}) \mathrm{c} 2 \mathrm{ccc}(\mathrm{NC}=\mathrm{C} 3 \mathrm{C}(=\mathrm{O}) \mathrm{C}=\mathrm{CC} 3=\mathrm{O}) \mathrm{cc} 2) \mathrm{cc} 1$ & 1800 & $*$ \\
\hline 3767 & $\mathrm{O}=\mathrm{C}(\mathrm{CCCCCC}(=\mathrm{O}) \mathrm{Nc} 1 \mathrm{ccc}(\mathrm{O}) \mathrm{c}(\mathrm{C}(=\mathrm{O}) \mathrm{Nc} 2 \mathrm{ccc}(\mathrm{Cl}) \mathrm{c}(\mathrm{Cl}) \mathrm{c} 2) \mathrm{c} 1) \mathrm{NO}$ & 1800 & $*$ \\
\hline 3768 & $\mathrm{Cc} 1 \mathrm{ccn} 2 \mathrm{ncnc}(\mathrm{Nc} 3 \mathrm{ccc} 4 \mathrm{c}(\mathrm{cnn} 4 \mathrm{Cc} 4 \mathrm{cccnc} 4) \mathrm{c} 3) \mathrm{c} 12$ & 1800 & $*$ \\
\hline 3769 & $\mathrm{CC}(\mathrm{C}) \mathrm{CC}(\mathrm{C}) \mathrm{NC}(=\mathrm{O}) \mathrm{CSc} 1 \mathrm{nc} 2 \operatorname{cc} 3 \operatorname{ccccc} 3 \operatorname{cc} 2 \mathrm{c}(=\mathrm{O}) \mathrm{n} 1-\mathrm{c} 1 \operatorname{ccc}(\mathrm{S}(\mathrm{N})(=\mathrm{O})=\mathrm{O}) \mathrm{cc} 1$ & 1810 & $*$ \\
\hline 3770 & $\mathrm{CN}(\mathrm{C}) \mathrm{c} 1 \mathrm{cccc}(\mathrm{Nc} 2 \mathrm{ncnc} 3 \mathrm{ccncc} 23) \mathrm{c} 1 \mathrm{~N}$ & 1819.7 & $*$ \\
\hline 3771 & $\mathrm{Cc} 1 \mathrm{ccc}(\mathrm{C} 2=\mathrm{NN}(\mathrm{c} 3 \mathrm{nc}(-\mathrm{c} 4 \mathrm{ccccc} 4) \mathrm{cs} 3) \mathrm{C}(\mathrm{c} 3 \mathrm{ccc}(\mathrm{Br}) \mathrm{cc} 3) \mathrm{C} 2) \mathrm{cc} 1 \mathrm{C}$ & 1840 & 5.74 \\
\hline 3772 & $\mathrm{O}=\mathrm{C}(\mathrm{Nc} 1 \mathrm{cccc} 1) \mathrm{N}(\mathrm{Cc} 1 \mathrm{ccc}(\mathrm{O}) \mathrm{cc} 1) \mathrm{Cc} 1 \mathrm{cc}(\mathrm{Cl}) \mathrm{cc}(\mathrm{Cl}) \mathrm{c} 1 \mathrm{O}$ & 1860 & 5.73 \\
\hline
\end{tabular}




\begin{tabular}{|c|c|c|c|}
\hline 3773 & COc1cccc1-c1cc2c(N[C@@H](C)c3ccccs3)ncnc2s1 & 1860 & $*$ \\
\hline 3774 & $\mathrm{Oc} 1 \mathrm{ccc}(\mathrm{CNc} 2 \mathrm{ccc} 3 \mathrm{ncnc}(\mathrm{Nc} 4 \mathrm{cccc}(\mathrm{Cl}) \mathrm{c} 4) \mathrm{c} 3 \mathrm{c} 2) \mathrm{cc} 1$ & 1870 & 5.73 \\
\hline 3775 & $\mathrm{Cc} 1 \mathrm{ncc}([\mathrm{N}+](=\mathrm{O})[\mathrm{O}-]) \mathrm{n} 1 \mathrm{C} / \mathrm{C}(=\mathrm{N} / \mathrm{NC}(=\mathrm{O}) \operatorname{c} 1 \operatorname{ccccc} 1 \mathrm{~N}) \operatorname{clccc}(\mathrm{Br}) \operatorname{cc} 1$ & 1890 & 5.72 \\
\hline 3776 & $\operatorname{COc} 1 \operatorname{cc}(/ \mathrm{C}=\mathrm{C} 2 \backslash \mathrm{CCC} / \mathrm{C}(=\mathrm{C} \backslash \mathrm{c} 3 \operatorname{ccc}(\mathrm{S}(\mathrm{C})(=\mathrm{O})=\mathrm{O}) \operatorname{cc} 3) \mathrm{C} 2=\mathrm{O}) \operatorname{cc}(\mathrm{OC}) \mathrm{c} 1$ & 1900 & 5.71 \\
\hline 3777 & $\mathrm{Cc} 1[\mathrm{nH}] \mathrm{c} 2 \mathrm{ncnc}(\mathrm{Nc} 3 \operatorname{cccc} 3) \mathrm{c} 2 \mathrm{c} 1 \mathrm{C}$ & 1900 & $*$ \\
\hline 3778 & $\mathrm{Cc} 1[\mathrm{nH}] \mathrm{c} 2 \mathrm{ncnc}(\mathrm{Nc} 3 \operatorname{ccc}(\mathrm{C}(\mathrm{F})(\mathrm{F}) \mathrm{F}) \mathrm{c} 3) \mathrm{c} 2 \mathrm{c} 1 \mathrm{C}$ & 1900 & $*$ \\
\hline 3779 & $\mathrm{Cc} 1 \mathrm{ccc}(\mathrm{Oc} 2 \mathrm{ccc}(\mathrm{Nc} 3 \mathrm{ncnc} 4 \mathrm{cc}[\mathrm{nH}] \mathrm{c} 34) \mathrm{cc} 2 \mathrm{C}) \mathrm{cn} 1$ & 1900 & $*$ \\
\hline 3780 & $\mathrm{COc} 1 \mathrm{cc}(\mathrm{Br}) \mathrm{c}(\mathrm{C}=\mathrm{C} 2 \mathrm{CC}(\mathrm{C}) \mathrm{CC}(=\mathrm{Cc} 3 \mathrm{nc}(\mathrm{C}) \mathrm{c}(\mathrm{C}) \mathrm{nc} 3 \mathrm{C}) \mathrm{C} 2=\mathrm{O}) \mathrm{cc} 1 \mathrm{OC}$ & 1900 & $*$ \\
\hline 3781 & $\operatorname{CCOC}(\mathrm{OCC}) \mathrm{c} 1 \operatorname{ccc}(\mathrm{C}=\mathrm{C} 2 \mathrm{COCC}(=\mathrm{C} \backslash \mathrm{c} 3 \operatorname{ccc}(\mathrm{C}(\mathrm{OCC}) \mathrm{OCC}) \mathrm{cc} 3) / \mathrm{C} 2=\mathrm{N} \backslash \mathrm{O}) \mathrm{cc} 1$ & 1900 & $*$ \\
\hline 3782 & $\mathrm{CCN}(\mathrm{CC}) \mathrm{C} / \mathrm{C}=\mathrm{C} / \mathrm{C}(=\mathrm{O}) \mathrm{Nc} 1 \mathrm{cc} 2 \mathrm{c}(\mathrm{Nc} 3 \mathrm{ccc}(\mathrm{F}) \mathrm{c}(\mathrm{Cl}) \mathrm{c} 3) \mathrm{c}(\mathrm{C \# N}) \mathrm{cnc} 2 \mathrm{cc} 1 \mathrm{OC}$ & 1910 & 5.72 \\
\hline 3783 & $\mathrm{Cc} 1 \mathrm{ccc}(\mathrm{C}(=\mathrm{O}) \mathrm{Nc} 2 \operatorname{ccc}(\mathrm{CN} 3 \mathrm{CCN}(\mathrm{C}) \mathrm{CC} 3) \mathrm{c}(\mathrm{C}(\mathrm{F})(\mathrm{F}) \mathrm{F}) \mathrm{c} 2) \operatorname{cc} 1 \mathrm{NC}(=\mathrm{O}) \mathrm{c} 1 \mathrm{cncnc} 1$ & 1920 & 5.72 \\
\hline 3784 & $\mathrm{Cc} 1 \mathrm{ccc}(\mathrm{C} 2=\mathrm{NN}(\mathrm{c} 3 \mathrm{nc}(-\mathrm{c} 4 \mathrm{cccc} 4) \operatorname{cs} 3) \mathrm{C}(\mathrm{c} 3 \mathrm{ccc}(\mathrm{O}) \mathrm{cc} 3) \mathrm{C} 2) \mathrm{cc} 1 \mathrm{C}$ & 1920 & 5.72 \\
\hline 3785 & $\mathrm{Cc} 1 \mathrm{ccc}(-\mathrm{c} 2 \mathrm{nc} 3 \operatorname{cc}(\mathrm{NC}(=\mathrm{O}) \mathrm{CCl}) \operatorname{ccc} 3[\mathrm{nH}] 2) \mathrm{cc} 1$ & 1929 & $*$ \\
\hline 3786 & $\mathrm{O}=\mathrm{C} 1 \mathrm{CSC}(\mathrm{N} / \mathrm{N}=\mathrm{C} / \mathrm{c} 2 \operatorname{ccc}(\mathrm{Cl}) \mathrm{cc} 2)=\mathrm{N} 1$ & 1940 & 5.71 \\
\hline 3787 & $\mathrm{Nc} 1 \mathrm{cc} 2 \mathrm{ncnc}(\mathrm{NCc} 3 \operatorname{ccc}(\mathrm{C}(\mathrm{F})(\mathrm{F}) \mathrm{F}) \mathrm{c} 3) \mathrm{c} 2 \mathrm{cn} 1$ & 1950 & $*$ \\
\hline 3788 & $\mathrm{O}=\mathrm{C}(\mathrm{Nc} 1 \mathrm{ccccc} 1) \mathrm{N}(\mathrm{Cc} 1 \mathrm{ccc}(\mathrm{F}) \mathrm{cc} 1) \mathrm{Cc} 1 \mathrm{ccc}(\mathrm{Cl}) \mathrm{c} 1 \mathrm{O}$ & 1980 & 5.70 \\
\hline 3789 & $\mathrm{COc} 1 \mathrm{cc}(/ \mathrm{C}=\mathrm{C} 2 \backslash \mathrm{CCC} / \mathrm{C}(=\mathrm{C} \backslash \mathrm{c} 3 \mathrm{cc}(\mathrm{OC}) \mathrm{cc}(\mathrm{OC}) \mathrm{c} 3) \mathrm{C} 2=\mathrm{O}) \mathrm{cc}(\mathrm{OC}) \mathrm{c} 1$ & 2000 & 5.69 \\
\hline 3790 & $\mathrm{CCOc} 1 \operatorname{cc}([\mathrm{N}+](=\mathrm{O})[\mathrm{O}-]) \mathrm{c}(\mathrm{C}(=\mathrm{O}) \mathrm{Nc} 2 \operatorname{ccc}(\mathrm{OCc} 3 \operatorname{ccc}(\mathrm{F}) \mathrm{c} 3) \mathrm{c}(\mathrm{Cl}) \mathrm{c} 2) \operatorname{cc} 1 \mathrm{NC}(=\mathrm{O}) / \mathrm{C}=\mathrm{C} / \mathrm{CN}(\mathrm{C}) \mathrm{C}$ & 2000 & 5.70 \\
\hline 3791 & $\mathrm{COc} 1 \operatorname{ccc}(\mathrm{Nc} 2 \mathrm{cc} 3 \mathrm{c}(\mathrm{cc} 2 \mathrm{Nc} 2 \operatorname{cccc} 2) \mathrm{C}(=\mathrm{O}) \mathrm{NC} 3=\mathrm{O}) \mathrm{cc} 1$ & 2000 & $*$ \\
\hline 3792 & $\mathrm{CN}(\mathrm{C}) \mathrm{c} 1 \mathrm{cc} 2 \mathrm{ncnc}(\mathrm{Nc} 3 \operatorname{cccc}(\mathrm{Br}) \mathrm{c} 3) \mathrm{c} 2 \mathrm{cc} 1[\mathrm{~N}+](=\mathrm{O})[\mathrm{O}-]$ & 2000 & $*$ \\
\hline 3793 & $\mathrm{CN}(\mathrm{c} 1 \mathrm{ccccc} 1) \mathrm{c} 1[\mathrm{nH}] \mathrm{cnc} 2 \mathrm{ncnc} 1-2$ & 2000 & $*$ \\
\hline 3794 & CCn1cnc2c(Nc3eccc(Cl)c3)nc(N[C@@H]3CCCC[C@@H]3N)nc21 & 2000 & $*$ \\
\hline 3795 & $\mathrm{COc} 1 \mathrm{cc}(\mathrm{Nc} 2 \mathrm{c}(\mathrm{CHN}) \mathrm{cnc} 3 \mathrm{cc}(-\mathrm{c} 4 \mathrm{ccc}(\mathrm{CN} 5 \mathrm{CCN}(\mathrm{C}) \mathrm{CC} 5) \mathrm{cn} 4) \mathrm{sc} 23) \mathrm{c}(\mathrm{Cl}) \mathrm{cc} 1 \mathrm{Cl}$ & 2000 & $*$ \\
\hline 3796 & $\begin{array}{c}\mathrm{O}=\mathrm{C} 1 \mathrm{NCCc} 2 \mathrm{cc}(\mathrm{Br}) \mathrm{c}(\mathrm{O}) \mathrm{c}(\mathrm{c} 2) \mathrm{Oc} 2 \mathrm{c}(\mathrm{Br}) \mathrm{cc}(\mathrm{cc} 2 \mathrm{Br}) \mathrm{CCNC}(=\mathrm{O}) / \mathrm{C}(=\mathrm{N} / \mathrm{O}) \mathrm{Cc} 2 \mathrm{cc}(\mathrm{Br}) \mathrm{c}(\mathrm{O}) \mathrm{c}(\mathrm{c} 2) \mathrm{Oc} 2 \mathrm{c}(\mathrm{Br}) \mathrm{cc}(\mathrm{cc} 2 \mathrm{Br}) \mathrm{C} / \mathrm{C} \\
1=\mathrm{N} \backslash \mathrm{O}\end{array}$ & 2000 & $*$ \\
\hline 3797 & $\mathrm{Cc} 1 \mathrm{cc}(\mathrm{Nc} 2 \mathrm{cc}(\mathrm{N} 3 \mathrm{CCN}(\mathrm{C}) \mathrm{CC} 3) \mathrm{nc}(\mathrm{Oc} 3 \operatorname{ccc}(\mathrm{NC}(=\mathrm{O}) / \mathrm{C}=\mathrm{C} / \mathrm{C}(\mathrm{F})(\mathrm{F}) \mathrm{F}) \operatorname{cc} 3) \mathrm{n} 2) \mathrm{n}[\mathrm{nH}] 1$ & 2000 & $*$ \\
\hline 3798 & $\mathrm{Cc} 1 \mathrm{ccc}(\mathrm{Oc} 2 \mathrm{ccc}(\mathrm{Nc} 3 \mathrm{ncnc} 4 \operatorname{ccc}(\mathrm{O}[\mathrm{C} @ \mathrm{H}](\mathrm{C}) \mathrm{C}(=\mathrm{O}) \mathrm{N}(\mathrm{C}) \mathrm{CCO}) \mathrm{c} 34) \mathrm{cc} 2 \mathrm{C}) \mathrm{cn} 1$ & 2000 & $*$ \\
\hline 3799 & $\mathrm{CN}(\mathrm{C}) \mathrm{c} 1 \operatorname{ccc}(\mathrm{C}=\mathrm{C} 2 \mathrm{CCCC}(=\mathrm{C} \backslash \mathrm{c} 3 \operatorname{ccc}(\mathrm{N}(\mathrm{C}) \mathrm{C}) \operatorname{cc} 3[\mathrm{~N}+](=\mathrm{O})[\mathrm{O}-]) / \mathrm{C} 2=\mathrm{N} \backslash \mathrm{O}) \mathrm{c}([\mathrm{N}+](=\mathrm{O})[\mathrm{O}-]) \mathrm{c} 1$ & 2000 & $*$ \\
\hline 3800 & $\mathrm{Cc} 1 \mathrm{ccc}(\mathrm{C} 2=\mathrm{NN}(\mathrm{C} 3=\mathrm{NC}(=\mathrm{O}) \mathrm{CS} 3) \mathrm{C}(\mathrm{c} 3 \operatorname{ccc}(\mathrm{F}) \mathrm{cc} 3) \mathrm{C} 2) \mathrm{cc} 1$ & 2010 & 5.70 \\
\hline 3801 & $\mathrm{Nc} 1 \mathrm{ncnc} 2 \mathrm{c} 1 \mathrm{c}(-\mathrm{c} 1 \mathrm{ccc}(\mathrm{Cl}) \mathrm{c}(\mathrm{O}) \mathrm{c} 1) \mathrm{nn} 2 \mathrm{CC} 1 \mathrm{CCNC} 1$ & 2010 & * \\
\hline 3802 & $\mathrm{O}=\mathrm{C} 1 \mathrm{CSC}(\mathrm{N} 2 \mathrm{~N}=\mathrm{C}(\mathrm{c} 3 \operatorname{ccc}(\mathrm{Br}) \mathrm{cc} 3) \mathrm{CC} 2 \mathrm{c} 2 \mathrm{ccc}(\mathrm{Br}) \mathrm{cc} 2)=\mathrm{N} 1$ & 2030 & 5.69 \\
\hline 3803 & $\mathrm{c} 1 \mathrm{ccc}(\mathrm{CNc} 2 \mathrm{ncnc} 3 \mathrm{cnccc} 23) \mathrm{cc} 1$ & 2030 & $*$ \\
\hline 3804 & $\mathrm{Cc} 1 \operatorname{ccc}(\mathrm{Nc} 2 \mathrm{nccc}(\mathrm{Oc} 3 \operatorname{ccc} 4[\mathrm{nH}] \operatorname{ccc} 4 \mathrm{c} 3) \mathrm{n} 2) \operatorname{cc} 1 \mathrm{~S}(\mathrm{~N})(=\mathrm{O})=\mathrm{O}$ & 2042 & $*$ \\
\hline 3805 & $\mathrm{CN}(\mathrm{C}) \mathrm{C} / \mathrm{C}=\mathrm{C} / \mathrm{C}(=\mathrm{O}) \mathrm{Nc} 1 \mathrm{cnc} 2 \mathrm{ncc}(\mathrm{C \# N}) \mathrm{c}(\mathrm{Nc} 3 \mathrm{cccc}(\mathrm{Br}) \mathrm{c} 3) \mathrm{c} 2 \mathrm{c} 1$ & 2043.6 & 5.69 \\
\hline 3806 & $\mathrm{Cc} 1 \mathrm{ccc}(\mathrm{C} 2=\mathrm{NN}(\mathrm{C}(\mathrm{N})=\mathrm{S}) \mathrm{C}(\mathrm{c} 3 \operatorname{ccc} 4 \operatorname{ccccc} 34) \mathrm{C} 2) \mathrm{cc} 1$ & 2060 & 5.69 \\
\hline 3807 & $\operatorname{COc} 1 \operatorname{ccc}(\mathrm{NC}(=\mathrm{O}) / \mathrm{C}=\mathrm{C} / \mathrm{CN}(\mathrm{C}) \mathrm{C}) \operatorname{cc} 1 \mathrm{Nc} 1 \operatorname{lnc}(\mathrm{C}(\mathrm{F})(\mathrm{F}) \mathrm{F}) \mathrm{c}(\mathrm{Nc} 2 \operatorname{ccc} 3 \operatorname{ccccc} 3 \mathrm{c} 2) \mathrm{n} 1$ & 2070 & $*$ \\
\hline 3808 & $\mathrm{C}[\mathrm{C} @ @ \mathrm{H}](\mathrm{Nc} 1 \mathrm{ncnc} 2 \mathrm{sc}(\mathrm{Br}) \mathrm{cc} 12) \mathrm{c} 1 \mathrm{ccc} n 1$ & 2079 & $*$ \\
\hline 3809 & $\mathrm{NC}(=\mathrm{S}) \mathrm{N} / \mathrm{N}=\mathrm{C}(/ \mathrm{C}=\mathrm{C} / \mathrm{c} 1 \mathrm{cccc}(\mathrm{F}) \mathrm{c} 1) \mathrm{c} 1 \mathrm{ccccc} 1$ & 2080 & 5.68 \\
\hline 3810 & $\mathrm{O}=\mathrm{C}(\mathrm{NS}(=\mathrm{O})(=\mathrm{O}) \mathrm{c} 1 \mathrm{ccc}(\mathrm{Br}) \mathrm{cc} 1) \mathrm{c} 1 \mathrm{cncc}(\mathrm{Br}) \mathrm{c} 1$ & 2080 & 5.68 \\
\hline 3811 & $\operatorname{CCOC}(=\mathrm{O}) \mathrm{C} 1=\mathrm{C}(\mathrm{N}) \mathrm{N}(\mathrm{c} 2 \mathrm{cccnc} 2) \mathrm{C} 2=\mathrm{C}(\mathrm{C}(=\mathrm{O}) \mathrm{CCC} 2) \mathrm{C} 1 \mathrm{c} 1 \mathrm{c}(\mathrm{C}) \mathrm{nn}(-\mathrm{c} 2 \operatorname{ccccc} 2) \mathrm{c} 1 \mathrm{Cl}$ & 2090 & 5.68 \\
\hline 3812 & $\mathrm{Nc} 1 \mathrm{ncnn} 2 \operatorname{ccc}(\mathrm{C}(=\mathrm{O}) \mathrm{Nc} 3 \operatorname{ccc}(\mathrm{NC}(=\mathrm{O}) \mathrm{Nc} 4 \operatorname{cccc}(\mathrm{F}) \mathrm{c} 4) \operatorname{cc} 3) \mathrm{c} 12$ & 2090 & $*$ \\
\hline 3813 & $\mathrm{COc} 1 \mathrm{cc}(/ \mathrm{C}=\mathrm{C} 2 \backslash \mathrm{CCC} / \mathrm{C}(=\mathrm{C} \backslash \mathrm{c} 3 \operatorname{cccc} 3 \mathrm{~F}) \mathrm{C} 2=\mathrm{O}) \operatorname{cc}(\mathrm{OC}) \mathrm{c} 1$ & 2100 & 5.67 \\
\hline 3814 & $\mathrm{N \# C/C}(=\mathrm{C} \mid \mathrm{c} 1 \operatorname{ccc}(\mathrm{O}) \mathrm{c}(\mathrm{O}) \mathrm{c} 1) \mathrm{C}(=\mathrm{O}) \mathrm{N} 1 \mathrm{CCc} 2 \operatorname{cccc} 21$ & 2100 & $*$ \\
\hline
\end{tabular}




\begin{tabular}{|c|c|c|c|}
\hline 3815 & $\mathrm{Cc} 1 \mathrm{ccc}(\mathrm{SCC}(\mathrm{CN}(\mathrm{C}) \mathrm{C}) \mathrm{C}(=\mathrm{O}) \mathrm{c} 2 \mathrm{ccc}(\mathrm{OCc} 3 \operatorname{cccc} 3) \operatorname{cc} 2) \operatorname{cc} 1 \mathrm{C} . \mathrm{Cl}$ & 2100 & $*$ \\
\hline 3816 & $\mathrm{Cc} 1 \mathrm{ccc}(\mathrm{Nc} 2[\mathrm{nH}] \mathrm{cnc} 3 \mathrm{nc}(\mathrm{C}) \mathrm{c}(\mathrm{C}) \mathrm{c} 2-3) \mathrm{cc} 1$ & 2100 & $*$ \\
\hline 3817 & $\mathrm{CN} 1 \mathrm{CCC}(\mathrm{Oc} 2 \mathrm{cccc} 3 \mathrm{ncnc}(\mathrm{Nc} 4 \mathrm{ccc}(\mathrm{OCc} 5 \mathrm{ccc} n 5) \mathrm{cc} 4) \mathrm{c} 23) \mathrm{CC} 1$ & 2100 & $*$ \\
\hline 3818 & C[C@@H]1CN(c2nc(C(F)(F)F)no2)CCN1c1ncc $(\mathrm{OCc} 2 \mathrm{ccc}(\mathrm{CS}(\mathrm{C})(=\mathrm{O})=\mathrm{O}) \mathrm{cc} 2 \mathrm{~F}) \mathrm{cn} 1$ & 2100 & $*$ \\
\hline 3819 & $\mathrm{COc} 1 \mathrm{cccc}(-\mathrm{c} 2 \mathrm{cn}(\mathrm{C} 3 \mathrm{CCN}(\mathrm{C}(=\mathrm{O}) \mathrm{OC}(\mathrm{C})(\mathrm{C}) \mathrm{C}) \mathrm{C} 3) \mathrm{c} 3 n \mathrm{nnc}(\mathrm{N}) \mathrm{c} 23) \mathrm{c} 1$ & 2100 & $*$ \\
\hline 3820 & Nc1ncnc2c1c(-c1cce3nccec3c1)nn2C1CCCC1 & 2100 & $*$ \\
\hline 3821 & $\mathrm{NCCn} 1 \mathrm{c}(-\mathrm{c} 2 \mathrm{ccccc} 2) \mathrm{nc} 2 \mathrm{cc}(\mathrm{Cl}) \mathrm{ccc} 2 \mathrm{c} 1=\mathrm{O}$ & 2110 & 5.68 \\
\hline 3822 & Cl.c1 $1 \mathrm{cc}(\mathrm{Nc} 2[\mathrm{nH}] \mathrm{cnc} 3 \mathrm{c} 4 \mathrm{cccc} 4 \mathrm{nc} 2-3) \mathrm{cc} 1$ & 2110 & $*$ \\
\hline 3823 & Cl.c1 $1 \mathrm{ccc}(\mathrm{Nc} 2 \mathrm{ncnc} 3 \mathrm{c} 2[\mathrm{nH}] \mathrm{c} 2 \mathrm{cccc} 23) \mathrm{cc} 1$ & 2110 & $*$ \\
\hline 3824 & $\operatorname{COc} 1 \mathrm{cc}(\mathrm{OC}) \mathrm{c} 2 \mathrm{c}(=\mathrm{O}) \mathrm{n}(-\mathrm{c} 3 \operatorname{ccc}(\mathrm{C}(=\mathrm{O}) \mathrm{N} 4 \mathrm{CCCCC} 4) \mathrm{c} 3) \operatorname{ccc} 2 \mathrm{c} 1$ & 2120 & $*$ \\
\hline 3825 & $\mathrm{CC}(\mathrm{C}) \mathrm{n} 1 \mathrm{nc}(-\mathrm{c} 2 \mathrm{ccc}(\mathrm{N}) \mathrm{c}(\mathrm{O}) \mathrm{c} 2) \mathrm{c} 2 \mathrm{c}(\mathrm{N}) \mathrm{ncnc} 21$ & 2120 & $*$ \\
\hline 3826 & $\operatorname{CCCCCCCCCCNC}(=\mathrm{O}) \operatorname{COc} 1 \mathrm{cc}(\mathrm{O}) \mathrm{c} 2 \mathrm{c}(=\mathrm{O}) \mathrm{cc}(-\mathrm{c} 3 \operatorname{ccccc} 3) \mathrm{oc} 2 \mathrm{c} 1$ & 2140 & 5.67 \\
\hline 3827 & $\mathrm{COc} 1 \mathrm{cc}(\mathrm{Nc} 2 \mathrm{nccc}(-\mathrm{c} 3 \mathrm{ccc}(\mathrm{Cl}) \mathrm{cc} 3) \mathrm{n} 2) \mathrm{cc}(\mathrm{OC}) \mathrm{c} 1 \mathrm{OC}$ & 2145 & $*$ \\
\hline 3828 & $\mathrm{O}=\mathrm{C}(/ \mathrm{C}=\mathrm{C} / \mathrm{CN} 1 \mathrm{CC} 2(\mathrm{CCOCC} 2) \mathrm{C} 1) \mathrm{Nc} 1 \mathrm{cc} 2 \mathrm{c}(\mathrm{Nc} 3 \mathrm{ccc}(\mathrm{F}) \mathrm{c}(\mathrm{Cl}) \mathrm{c} 3) \mathrm{ncnc} 2 \mathrm{~s} 1$ & 2159 & $*$ \\
\hline 3829 & $\mathrm{Cc} 1 \mathrm{ccc}(\mathrm{C} 2=\mathrm{NOC}(\mathrm{c} 3 \operatorname{ccc}(\mathrm{OC} 4 \mathrm{CCCC} 4) \mathrm{cc} 3) \mathrm{C} 2) \mathrm{cc} 1$ & 2160 & $*$ \\
\hline 3830 & $\mathrm{Cc} 1 \mathrm{ncc}([\mathrm{N}+](=\mathrm{O})[\mathrm{O}-]) \mathrm{n} 1 \mathrm{CC}(=\mathrm{O}) \mathrm{NS}(=\mathrm{O})(=\mathrm{O}) \mathrm{c} 1 \mathrm{ccc}(\mathrm{Br}) \operatorname{cc} 1$ & 2170 & 5.66 \\
\hline 3831 & $\mathrm{Cc} 1 \operatorname{ccc}(\mathrm{C} 2=\mathrm{NN}(\mathrm{C}(\mathrm{N})=\mathrm{S}) \mathrm{C}(\mathrm{c} 3 \operatorname{ccc}(\mathrm{Br}) \operatorname{cc} 3) \mathrm{C} 2) \operatorname{cc} 1 \mathrm{C}$ & 2170 & 5.66 \\
\hline 3832 & $\mathrm{NC}(=\mathrm{S}) \mathrm{N} / \mathrm{N}=\mathrm{C}(/ \mathrm{C}=\mathrm{C} / \mathrm{c} 1 \mathrm{ccc}(\mathrm{F}) \mathrm{cc} 1) \mathrm{c} 1 \mathrm{ccc}(\mathrm{Br}) \mathrm{cc} 1$ & 2170 & 5.66 \\
\hline 3833 & $\mathrm{O}=\mathrm{C} 1 \mathrm{CSC}(\mathrm{N} / \mathrm{N}=\mathrm{C} / \mathrm{c} 2 \operatorname{ccc}(\mathrm{F}) \mathrm{cc} 2)=\mathrm{N} 1$ & 2180 & 5.66 \\
\hline 3834 & $\mathrm{O}=\mathrm{C}(/ \mathrm{C}=\mathrm{C} / \mathrm{c} 1 \mathrm{ccc} 2 \mathrm{c}(\mathrm{c} 1) \mathrm{OCCCCO} 2) \mathrm{NCc} 1 \mathrm{ccccc} 1 \mathrm{~F}$ & 2180 & $*$ \\
\hline 3835 & $\mathrm{COc} 1 \mathrm{ccc}(-\mathrm{c} 2 \mathrm{nn}(\mathrm{C}(\mathrm{C}) \mathrm{C}) \mathrm{c} 3 \mathrm{ncnc}(\mathrm{N}) \mathrm{c} 23) \mathrm{cc} 1 \mathrm{O}$ & 2190 & * \\
\hline 3836 & $\mathrm{COc} 1 \mathrm{cc}(/ \mathrm{C}=\mathrm{C} 2 \backslash \mathrm{CCC} / \mathrm{C}(=\mathrm{C} \backslash \mathrm{c} 3 \operatorname{cccc}(\mathrm{Cl}) \mathrm{c} 3) \mathrm{C} 2=\mathrm{O}) \mathrm{cc}(\mathrm{OC}) \mathrm{c} 1$ & 2200 & $*$ \\
\hline 3837 & $\mathrm{COc} 1 \mathrm{cc} 2 \mathrm{ncnc}(\mathrm{Nc} 3 \mathrm{ccc}(\mathrm{Cl}) \mathrm{c}(\mathrm{NC}(=\mathrm{O}) \mathrm{c} 4 \mathrm{cccc} 4) \mathrm{c} 3) \mathrm{c} 2 \mathrm{cc} 1 \mathrm{OC}$ & 2200 & $*$ \\
\hline 3838 & $\mathrm{ClCCN}(\mathrm{CCNN}=\mathrm{Nc} 1 \mathrm{ccc} 2 \mathrm{ncnc}(\mathrm{Nc} 3 \operatorname{ccc}(\mathrm{Cl}) \mathrm{c} 3) \mathrm{c} 2 \mathrm{c} 1) \mathrm{c} 1 \mathrm{ccc}(\mathrm{Cl}) \mathrm{cc} 1$ & 2200 & $*$ \\
\hline 3839 & $\operatorname{CCCC}(\mathrm{Cc} 1 \operatorname{coc} 2 \mathrm{nc}(\mathrm{N}) \mathrm{nc}(\mathrm{N}) \mathrm{c} 12) \mathrm{c} 1 \mathrm{ccccc} 1 \mathrm{OC}$ & 2200 & $*$ \\
\hline 3840 & $\mathrm{CC}(\mathrm{C})(\mathrm{C}) \mathrm{OC}(=\mathrm{O}) \mathrm{N} 1 \mathrm{CCC}(\mathrm{n} 2 \mathrm{cc}(-\mathrm{c} 3 \operatorname{ccc}(\mathrm{O}) \mathrm{c} 3) \mathrm{c} 3 \mathrm{c}(\mathrm{N}) \mathrm{ncnc} 32) \mathrm{C} 1$ & 2200 & $*$ \\
\hline 3841 & 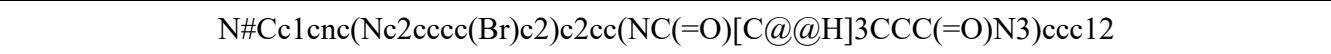 & 2200 & $*$ \\
\hline 3842 & $\operatorname{COc} 1 \mathrm{cc} 2 \mathrm{ncc}(\mathrm{CHN}) \mathrm{c}(\mathrm{Nc} 3 \operatorname{ccc}(\mathrm{N}=[\mathrm{N}+]=[\mathrm{N}-]) \mathrm{c} 3) \mathrm{c} 2 \mathrm{cc} 1 \mathrm{OC}$ & 2210 & $*$ \\
\hline 3843 & $\mathrm{O}=\mathrm{C}(\mathrm{CCCCCC}(=\mathrm{O}) \mathrm{Nc} 1 \mathrm{ccc}(\mathrm{O}) \mathrm{c}(\mathrm{C}(=\mathrm{O}) \mathrm{Nc} 2 \mathrm{ccc}(\mathrm{F}) \mathrm{c}(\mathrm{F}) \mathrm{c} 2) \mathrm{c} 1) \mathrm{NO}$ & 2220 & $*$ \\
\hline 3844 & $\mathrm{Cc} 1 \mathrm{ccc}(\mathrm{NC}(=\mathrm{O}) / \mathrm{C}=\mathrm{C} / \mathrm{CN}(\mathrm{C}) \mathrm{C}) \mathrm{cc} 1 \mathrm{Nc} 1 \mathrm{ncc}(\mathrm{Cl}) \mathrm{c}(\mathrm{Nc} 2 \mathrm{ccc} 3 \operatorname{cccc} 3 \mathrm{c} 2) \mathrm{n} 1$ & 2220 & $*$ \\
\hline 3845 & $\mathrm{NC}(=\mathrm{S}) \mathrm{N} 1 \mathrm{~N}=\mathrm{C}(\mathrm{c} 2 \operatorname{cccc} 2) \mathrm{CC} 1 \mathrm{c} 1 \operatorname{ccc} 2 \operatorname{ccccc} 12$ & 2230 & 5.65 \\
\hline 3846 & $\mathrm{CN}(\mathrm{C}) \mathrm{c} 1 \mathrm{ccc}(/ \mathrm{C}=\mathrm{C} / \mathrm{c} 2 \mathrm{cc}(\mathrm{C}(=\mathrm{O}) \mathrm{O}) \mathrm{c} 3 \mathrm{cc}(\mathrm{Br}) \operatorname{ccc} 3 \mathrm{n} 2) \mathrm{cc} 1$ & 2230 & $*$ \\
\hline 3847 & $\mathrm{O}=\mathrm{C}(\mathrm{Nc} 1 \mathrm{cccc} 1) \mathrm{N}(\mathrm{Cc} 1 \mathrm{ccc}(\mathrm{F}) \mathrm{cc} 1) \mathrm{Cc} 1 \mathrm{cccc}(\mathrm{Br}) \mathrm{c} 1 \mathrm{O}$ & 2240 & 5.65 \\
\hline 3848 & $\mathrm{Cc} 1 \mathrm{c}(\mathrm{C}(=\mathrm{O}) \mathrm{c} 2 \mathrm{ccc}(\mathrm{Cl}) \mathrm{cc} 2) \mathrm{c} 2 \mathrm{ccc}(\mathrm{OC}(\mathrm{F})(\mathrm{F}) \mathrm{F}) \mathrm{cc} 2 \mathrm{n} 1 \mathrm{Cc} 1 \mathrm{ccc}(\mathrm{O}[\mathrm{C} @ \mathrm{H}](\mathrm{C}) \mathrm{C}(=\mathrm{O}) \mathrm{O}) \mathrm{c} 1$ & 2240 & $*$ \\
\hline 3849 & $\mathrm{Cn} 1 \mathrm{ccc} 2 \mathrm{cc}(\mathrm{Nc} 3 \mathrm{ccnc}(\mathrm{Nc} 4 \mathrm{ccc}(\mathrm{N} 5 \mathrm{CCOCC} 5) \mathrm{cc} 4) \mathrm{n} 3) \mathrm{ccc} 21$ & 2240 & $*$ \\
\hline 3850 & $\mathrm{C} \# \mathrm{Cc} 1 \mathrm{cccc}(\mathrm{NC}(=\mathrm{O}) \mathrm{c} 2 \mathrm{cc}(\mathrm{NC}(=\mathrm{O}) \mathrm{CCCCCCC}(=\mathrm{O}) \mathrm{NO}) \operatorname{ccc} 2 \mathrm{O}) \mathrm{c} 1$ & 2250 & $*$ \\
\hline 3851 & $\mathrm{O}=\mathrm{C} 1 \mathrm{CSC}(\mathrm{N} 2 \mathrm{~N}=\mathrm{C}(\mathrm{c} 3 \operatorname{ccc}(\mathrm{Cl}) \mathrm{cc} 3) \mathrm{CC} 2 \mathrm{c} 2 \mathrm{ccc}(\mathrm{Br}) \mathrm{cc} 2)=\mathrm{N} 1$ & 2280 & 5.64 \\
\hline 3852 & $\operatorname{COc} 1 \mathrm{cc}(\mathrm{N} 2 \mathrm{CCN}(\mathrm{C}) \mathrm{CC} 2) \operatorname{ccc} 1 \mathrm{Nc} 1 \mathrm{ncc}(\mathrm{Cl}) \mathrm{c}(\mathrm{Oc} 2 \operatorname{ccc}(\mathrm{CCCO} 3 \mathrm{no}[\mathrm{n}+]([\mathrm{O}-]) \mathrm{c} 3 \mathrm{~S}(=\mathrm{O})(=\mathrm{O}) \mathrm{c} 3 \operatorname{ccccc} 3) \mathrm{cc} 2) \mathrm{n} 1$ & 2280 & 5.64 \\
\hline 3853 & $\mathrm{~N} \# \mathrm{Cc} 1 \mathrm{cnc} 2 \mathrm{ccc}(\mathrm{NC}(=\mathrm{O}) / \mathrm{C}=\mathrm{C} / \mathrm{CN} 3 \mathrm{CCOCC} 3) \mathrm{cc} 2 \mathrm{c} 1 \mathrm{Nc} 1 \mathrm{ccc}(\mathrm{F}) \mathrm{c}(\mathrm{Cl}) \mathrm{c} 1$ & 2290 & 5.64 \\
\hline 3854 & $\mathrm{c} 1 \mathrm{ccc} 2 \mathrm{ncc}(\mathrm{Nc} 3 \mathrm{ccnc}(\mathrm{Nc} 4 \mathrm{ccc}(\mathrm{OCCCN} 5 \mathrm{CCCCC} 5) \mathrm{cc} 4) \mathrm{n} 3) \mathrm{cc} 2 \mathrm{c} 1$ & 2290 & $*$ \\
\hline 3855 & $\mathrm{CN} 1 \mathrm{CCN}(\mathrm{Cc} 2 \mathrm{ccc}(\mathrm{C}(=\mathrm{O}) \mathrm{Nc} 3 \operatorname{ccc}(-\mathrm{c} 4 \mathrm{cncc}(\mathrm{C \# N}) \mathrm{c} 4 \mathrm{Nc} 4 \operatorname{ccc}(\mathrm{OCc} 5 \operatorname{ccc} n 5) \mathrm{c}(\mathrm{Cl}) \mathrm{c} 4) \mathrm{cc} 3) \mathrm{cc} 2) \mathrm{CC} 1$ & 2300 & 5.64 \\
\hline 3856 & $\operatorname{CCOC}(=\mathrm{O}) \operatorname{CCCn} 1 \mathrm{c}(=\mathrm{O}) \mathrm{oc} 2 \mathrm{cc} 3 \mathrm{ncnc}(\mathrm{Nc} 4 \mathrm{ccc}(\mathrm{OCc} 5 \mathrm{ccc} n 5) \operatorname{cc} 4) \mathrm{c} 3 \mathrm{cc} 21$ & 2300 & $*$ \\
\hline 3857 & $\mathrm{~N} \# \mathrm{C} / \mathrm{C}(=\mathrm{Clc} 1 \mathrm{ccc}(\mathrm{O}) \mathrm{c}(\mathrm{O}) \mathrm{c} 1) \mathrm{C}(=\mathrm{O}) \mathrm{c} 1 \mathrm{ccc}([\mathrm{N}+](=\mathrm{O})[\mathrm{O}-]) \mathrm{cc} 1$ & 2300 & * \\
\hline
\end{tabular}




\begin{tabular}{|c|c|c|c|}
\hline 3858 & $\mathrm{COC}[\mathrm{C} @ @ \mathrm{H}](\mathrm{Cn} 1 \mathrm{ccnc} 1[\mathrm{~N}+](=\mathrm{O})[\mathrm{O}-]) \mathrm{OC}(=\mathrm{O}) \operatorname{c} 1 \mathrm{ccc}(\mathrm{NC}=\mathrm{C} 2 \mathrm{C}(=\mathrm{O}) \mathrm{C}=\mathrm{CC} 2=\mathrm{O}) \mathrm{cc} 1$ & 2300 & * \\
\hline 3859 & $\mathrm{O}=\mathrm{C} 1 \mathrm{Cc} 2 \mathrm{ccc}(\mathrm{Oc} 3 \mathrm{ccc}(\mathrm{Nc} 4 \mathrm{ncnc} 5 \mathrm{ccn}(\mathrm{CCO}) \mathrm{c} 45) \mathrm{cc} 3 \mathrm{Cl}) \mathrm{cc} 2 \mathrm{~N} 1$ & 2300 & $*$ \\
\hline 3860 & $\mathrm{COc} 1 \mathrm{ccc}(-\mathrm{c} 2 \mathrm{nn}(\mathrm{C} 3 \mathrm{CCC} 3) \mathrm{c} 3 n \mathrm{nnc}(\mathrm{N}) \mathrm{c} 23) \mathrm{cc} 1 \mathrm{OC}$ & 2300 & $*$ \\
\hline 3861 & Nc1ncnc2c1c(-c1cccc(O)c1)cn2[C@H]1C[C@@H](CN2CCC2)C1 & 2300 & $*$ \\
\hline 3862 & $\mathrm{COc} 1 \mathrm{cc} 2 \mathrm{ncc}(\mathrm{CHN}) \mathrm{c}(\mathrm{Nc} 3 \mathrm{ccc}(\mathrm{F}) \mathrm{c}(\mathrm{Cl}) \mathrm{c} 3) \mathrm{c} 2 \mathrm{cc} 1 \mathrm{NC}(=\mathrm{O}) / \mathrm{C}=\mathrm{C} / \mathrm{CN}(\mathrm{C}) \mathrm{C}$ & 2320 & 5.63 \\
\hline 3863 & $\mathrm{O}=\mathrm{C}(\mathrm{CCCCCC}(=\mathrm{O}) \mathrm{Nc} 1 \mathrm{ccc}(\mathrm{O}) \mathrm{c}(\mathrm{C}(=\mathrm{O}) \mathrm{Nc} 2 \operatorname{cccc} 2) \mathrm{c} 1) \mathrm{NO}$ & 2340 & $*$ \\
\hline 3864 & $\mathrm{COc} 1 \mathrm{cc} 2 \mathrm{ncnc}(\mathrm{Nc} 3 \operatorname{ccc}(\mathrm{NC}(=\mathrm{O}) \mathrm{Nc} 4 \mathrm{ccc}(\mathrm{C}) \mathrm{c} 4) \mathrm{c} 3) \mathrm{c} 2 \mathrm{cc} 1 \mathrm{OCCCN} 1 \mathrm{CCOCC} 1$ & 2350 & $*$ \\
\hline 3865 & $\mathrm{Cc} 1 \mathrm{ccc}(\mathrm{C} 2=\mathrm{NN}(\mathrm{c} 3 \mathrm{nc}(-\mathrm{c} 4 \mathrm{cccc} 4) \operatorname{cs} 3) \mathrm{C}(\mathrm{c} 3 \mathrm{ccc}(\mathrm{Cl}) \mathrm{cc} 3) \mathrm{C} 2) \operatorname{cc} 1 \mathrm{C}$ & 2360 & 5.63 \\
\hline 3866 & $\mathrm{C}[\mathrm{C} @ \mathrm{H}] 1 \mathrm{CN}=\mathrm{C}(\mathrm{Nc} 2 \mathrm{ccc} 3 \mathrm{ncnc}(\mathrm{Nc} 4 \mathrm{ccc}(\mathrm{OCc} 5 \mathrm{nccs} 5) \mathrm{c}(\mathrm{Cl}) \mathrm{c} 4) \mathrm{c} 3 \mathrm{c} 2) \mathrm{O} 1$ & 2360 & $*$ \\
\hline 3867 & $\mathrm{COc} 1 \operatorname{ccc}(\mathrm{C} 2=\mathrm{NN}(\mathrm{C} 3=\mathrm{NC}(=\mathrm{O}) \mathrm{CS} 3) \mathrm{C}(\mathrm{c} 3 \operatorname{ccccc} 3) \mathrm{C} 2) \mathrm{cc} 1$ & 2370 & 5.63 \\
\hline 3868 & $\operatorname{COc} 1 \mathrm{cc} 2 \mathrm{nc}(\mathrm{Cl}) \mathrm{nc}(\mathrm{Nc} 3 \operatorname{ccc}(\mathrm{S}(\mathrm{N})(=\mathrm{O})=\mathrm{O}) \mathrm{cc} 3) \mathrm{c} 2 \mathrm{cc} 1 \mathrm{OC}$ & 2370 & $*$ \\
\hline 3869 & $\mathrm{C}[\mathrm{C} @ @ \mathrm{H}] 1 \mathrm{CN}=\mathrm{C}(\mathrm{Nc} 2 \mathrm{ccc} 3 \mathrm{ncnc}(\mathrm{Nc} 4 \mathrm{ccc}(\mathrm{OCc} 5 \mathrm{nccs} 5) \mathrm{c}(\mathrm{Cl}) \mathrm{c} 4) \mathrm{c} 3 \mathrm{c} 2) \mathrm{O} 1$ & 2370 & $*$ \\
\hline 3870 & $\mathrm{NC}(=\mathrm{S}) \mathrm{N} / \mathrm{N}=\mathrm{C}(\mathrm{C}=\mathrm{C} / \mathrm{c} 1 \operatorname{ccccc} 1) \mathrm{c} 1 \mathrm{ccccc} 1$ & 2380 & 5.62 \\
\hline 3871 & $\mathrm{COc} 1 \mathrm{cc}(\mathrm{N} 2 \mathrm{CCN}(\mathrm{C}) \mathrm{CC} 2) \operatorname{ccc} 1 \mathrm{Nc} 1 \mathrm{ncc}(\mathrm{Cl}) \mathrm{c}(\mathrm{Oc} 2 \mathrm{cccc}(\mathrm{NC}(=\mathrm{O}) \mathrm{CCN} 3 \mathrm{CCN}(\mathrm{CCO}) \mathrm{CC} 3) \mathrm{c} 2) \mathrm{n} 1$ & 2388 & 5.62 \\
\hline 3872 & $\mathrm{O}=\mathrm{C}(/ \mathrm{C}=\mathrm{C} / \mathrm{c} 1 \mathrm{ccc}(\mathrm{Br}) \mathrm{s} 1) \mathrm{Nc} 1 \mathrm{ccc} 2 \mathrm{ncnc}(\mathrm{Nc} 3 \mathrm{ccc}(\mathrm{Cl}) \mathrm{c} 3) \mathrm{c} 2 \mathrm{c} 1$ & 2400 & 5.62 \\
\hline 3873 & $\mathrm{O}=\mathrm{C} 1 \mathrm{NC}(\mathrm{Cc} 2 \operatorname{ccccc} 2)=\mathrm{CN} 2 \mathrm{C} 1 \mathrm{C}=\mathrm{C} 1 \mathrm{C}=\mathrm{C}(\mathrm{Cl}) \mathrm{C}=\mathrm{CC} 12$ & 2400 & 5.62 \\
\hline 3874 & $\mathrm{Clc} 1 \mathrm{cc}(\mathrm{Nc} 2 \mathrm{ncnc} 3 \mathrm{ccc}(\mathrm{OC} 4 \mathrm{CCOCC} 4) \mathrm{c} 23) \operatorname{ccc} 1 \mathrm{OCc} 1 \mathrm{ccc} n 1$ & 2400 & $*$ \\
\hline 3875 & $\mathrm{COc} 1 \mathrm{cc}(\mathrm{Nc} 2 \mathrm{nn} 3 \mathrm{c}(\mathrm{N}[\mathrm{C} @ \mathrm{H}](\mathrm{CO}) \mathrm{Cc} 4 \mathrm{cccc} 4) \mathrm{cc}(\mathrm{C} 4 \mathrm{CC} 4) \mathrm{nc} 3 \mathrm{c} 2 \mathrm{C}(\mathrm{N})=\mathrm{O}) \mathrm{cc}(\mathrm{OC}) \mathrm{c} 1$ & 2400 & $*$ \\
\hline 3876 & $\operatorname{COc} 1 \mathrm{cc}(-\mathrm{c} 2 \mathrm{nc}(=\mathrm{O}) \mathrm{c} 3 \mathrm{c}([\mathrm{nH}] 2) \operatorname{sc} 2 \mathrm{ccc}(\mathrm{C}) \mathrm{cc} 23) \operatorname{ccc} 1 \mathrm{OCC}(=\mathrm{O}) \mathrm{O}$ & 2400 & $*$ \\
\hline 3877 & $\mathrm{Cc} 1 \mathrm{nc}(\mathrm{C}) \mathrm{c}(\mathrm{C}=\mathrm{C} 2 \mathrm{CC}(\mathrm{C}) \mathrm{CC}(=\mathrm{C} / \mathrm{c} 3 \mathrm{nc}(\mathrm{C}) \mathrm{c}(\mathrm{C}) \mathrm{nc} 3 \mathrm{C}) / \mathrm{C} 2=\mathrm{N} / \mathrm{O}) \mathrm{nc} 1 \mathrm{C}$ & 2400 & $*$ \\
\hline 3878 & $\mathrm{~N} \# \mathrm{Cc} 1 \mathrm{ccc}(\mathrm{Nc} 2 \mathrm{ncnc} 3 \mathrm{cc}(\mathrm{OCCCN} 4 \mathrm{CCOCC} 4) \mathrm{c}(\mathrm{NC}(=\mathrm{O}) \mathrm{c} 4 \mathrm{cc}([\mathrm{N}+](=\mathrm{O})[\mathrm{O}-]) \operatorname{ccc} 4 \mathrm{~F}) \mathrm{cc} 23) \mathrm{cc} 1 \mathrm{Cl}$ & 2426 & 5.62 \\
\hline 3879 & $\mathrm{COc} 1 \mathrm{ccc}(-\mathrm{c} 2 \mathrm{cc} 3 \mathrm{c}(\mathrm{N}[\mathrm{C} @ \mathrm{H}](\mathrm{C}) \mathrm{c} 4 \mathrm{ccc}(\mathrm{OC}) \mathrm{cc} 4) \mathrm{ncnc} 3[\mathrm{nH}] 2) \mathrm{cc} 1$ & 2454 & $*$ \\
\hline 3880 & $\mathrm{Nc} 1 \mathrm{cc} 2 \mathrm{ncnc}(\mathrm{NCc} 3 \mathrm{ccc}(\mathrm{Br}) \mathrm{cc} 3) \mathrm{c} 2 \mathrm{cn} 1$ & 2460 & $*$ \\
\hline 3881 & $\mathrm{C}=\mathrm{CC}(=\mathrm{O}) \mathrm{Nc} 1 \mathrm{cc}(\mathrm{Nc} 2 \mathrm{nccc}(\mathrm{Nc} 3 \operatorname{cccc} 3 \mathrm{~S}(=\mathrm{O})(=\mathrm{O}) \mathrm{C}(\mathrm{C}) \mathrm{C}) \mathrm{n} 2) \mathrm{c}(\mathrm{OC}) \operatorname{cc} 1 \mathrm{~N}(\mathrm{C}) \mathrm{CCN}(\mathrm{C}) \mathrm{C}$ & 2480 & $*$ \\
\hline 3882 & $\mathrm{CN} 1 \mathrm{CCN}(\mathrm{Cc} 2 \mathrm{ccc}(\mathrm{C}(=\mathrm{O}) \mathrm{Nc} 3 \mathrm{ccc}(-\mathrm{c} 4 \mathrm{cncc}(\mathrm{CHN}) \mathrm{c} 4 \mathrm{Nc} 4 \mathrm{ccc}(\mathrm{OCc} 5 \mathrm{cccc}(\mathrm{F}) \mathrm{c} 5) \mathrm{c}(\mathrm{Cl}) \mathrm{c} 4) \mathrm{cc} 3) \mathrm{cc} 2) \mathrm{CC} 1$ & 2500 & 5.60 \\
\hline 3883 & $\mathrm{CCC}(=\mathrm{O}) \mathrm{N} 1 \mathrm{CC}[\mathrm{C} @ \mathrm{H}](\mathrm{N} 2 \mathrm{C}(=\mathrm{O}) \mathrm{N}(\mathrm{c} 3 \mathrm{cc}(\mathrm{OC}) \mathrm{ccc} 3 \mathrm{~F}) \mathrm{Cc} 3 \mathrm{cnc}(\mathrm{Nc} 4 \mathrm{ccc}(\mathrm{N} 5 \mathrm{CCN}(\mathrm{C}) \mathrm{CC} 5) \mathrm{cc} 4 \mathrm{C}) \mathrm{nc} 32) \mathrm{C} 1$ & 2500 & 5.60 \\
\hline 3884 & $\mathrm{~N} \# \mathrm{CC}(\mathrm{C} \# \mathrm{~N})=\mathrm{C} 1 \mathrm{C}(=\mathrm{O}) \mathrm{Nc} 2 \mathrm{cc}(\mathrm{O}) \mathrm{c}(\mathrm{O}) \mathrm{cc} 21$ & 2500 & $*$ \\
\hline 3885 & $\mathrm{O}=\mathrm{C} 1 \mathrm{NC}(=\mathrm{O}) \mathrm{c} 2 \mathrm{cc}(\mathrm{Nc} 3 \operatorname{ccc}(\mathrm{O}) \mathrm{cc} 3) \mathrm{c}(\mathrm{Nc} 3 \mathrm{ccc}(\mathrm{O}) \mathrm{cc} 3) \mathrm{cc} 21$ & 2500 & $*$ \\
\hline 3886 & $\mathrm{Cc} 1 \mathrm{ccc}(\mathrm{Nc} 2 \mathrm{cc} 3 \mathrm{c}(\mathrm{cc} 2 \mathrm{Nc} 2 \mathrm{ccc}(\mathrm{C}) \mathrm{cc} 2) \mathrm{C}(=\mathrm{O}) \mathrm{NC} 3=\mathrm{O}) \mathrm{cc} 1$ & 2500 & $*$ \\
\hline 3887 & $\mathrm{~N} \# \mathrm{CC}(\mathrm{C \# N})=\mathrm{C}(\mathrm{N}) / \mathrm{C}(\mathrm{C \# N})=\mathrm{C} / \mathrm{c} 1 \mathrm{ccc}(\mathrm{O}) \mathrm{c}(\mathrm{O}) \mathrm{c} 1$ & 2500 & $*$ \\
\hline 3888 & $\operatorname{COc} 1 \mathrm{cc}(/ \mathrm{C}=\mathrm{C}(\backslash \mathrm{C})[\mathrm{N}+](=\mathrm{O})[\mathrm{O}-]) \operatorname{ccc} 1 \mathrm{OS}(=\mathrm{O})(=\mathrm{O}) \operatorname{c1} 1 \mathrm{ccc}(\mathrm{C}(=\mathrm{O}) \mathrm{O}) \operatorname{cc} 1$ & 2500 & $*$ \\
\hline 3889 & $\mathrm{Cc} 1[\mathrm{nH}] \mathrm{c} 2 \mathrm{ncnc}(\mathrm{Oc} 3 \mathrm{cccc}(\mathrm{Cl}) \mathrm{c} 3) \mathrm{c} 2 \mathrm{c} 1 \mathrm{C}$ & 2500 & $*$ \\
\hline 3890 & $\mathrm{COc} 1 \mathrm{cc} 2 \mathrm{nccc}(\mathrm{Oc} 3 \mathrm{cccc}(\mathrm{Br}) \mathrm{c} 3) \mathrm{c} 2 \mathrm{cc} 1 \mathrm{OC}$ & 2500 & $*$ \\
\hline 3891 & $\mathrm{CC}(\mathrm{C}) \mathrm{n} 1 \mathrm{nc}(-\mathrm{c} 2 \mathrm{ccc} 3 \mathrm{cn}[\mathrm{nH}] \mathrm{c} 3 \mathrm{c} 2) \mathrm{c} 2 \mathrm{c}(\mathrm{N}) \mathrm{ncnc} 21$ & 2500 & $*$ \\
\hline 3892 & $\mathrm{Cc} 1 \mathrm{nc}(\mathrm{C}) \mathrm{c}(\mathrm{C}=\mathrm{C} 2 \mathrm{CN}(\mathrm{C}(\mathrm{C}) \mathrm{C}) \mathrm{CC}(=\mathrm{Cc} 3 \mathrm{nc}(\mathrm{C}) \mathrm{c}(\mathrm{C}) \mathrm{nc} 3 \mathrm{C}) \mathrm{C} 2=\mathrm{O}) \mathrm{nc} 1 \mathrm{C}$ & 2500 & $*$ \\
\hline 3893 & $\mathrm{CCOC}(\mathrm{OCC}) \mathrm{c} 1 \mathrm{ccc}(\mathrm{C}=\mathrm{C} 2 \mathrm{CCCC}(=\mathrm{Cc} 3 \operatorname{ccc}(\mathrm{C}(\mathrm{OCC}) \mathrm{OCC}) \operatorname{cc} 3) \mathrm{C} 2=\mathrm{NO}) \mathrm{cc} 1$ & 2500 & $*$ \\
\hline 3894 & $\operatorname{c} 1 \operatorname{ccc}(\mathrm{C} 2=\mathrm{NN}(\mathrm{c} 3 \operatorname{ccc} c 3) \mathrm{C}(\mathrm{c} 3 \operatorname{ccc} 4 \operatorname{ccc} c 34) \mathrm{C} 2) \mathrm{cc} 1$ & 2520 & 5.60 \\
\hline 3895 & $\mathrm{Nc} 1 \mathrm{ncn} 2 \mathrm{c} 1 \mathrm{c}(-\mathrm{c} 1 \mathrm{ccc}(\mathrm{O}) \mathrm{c} 1) \mathrm{cn} 2 \mathrm{C} 1 \mathrm{CCN}(\mathrm{CCO}) \mathrm{CC} 1$ & 2540 & $*$ \\
\hline 3896 & Clc1ncc2ncnc(Nc3ecce 3$) \mathrm{c} 2 \mathrm{n} 1$ & 2550 & $*$ \\
\hline 3897 & $\mathrm{Cc} 1[\mathrm{nH}] \mathrm{c}(-\mathrm{c} 2 \mathrm{ccccc} 2) \mathrm{c}(-\mathrm{c} 2 \mathrm{ccccc} 2) \mathrm{c} 1-\mathrm{c} 1 \mathrm{nnn}(\mathrm{C}) \mathrm{c} 2 \mathrm{nn}(-\mathrm{c} 3 \operatorname{ccc}(\mathrm{Cl}) \mathrm{cc} 3) \mathrm{cc} 12$ & 2550 & $*$ \\
\hline 3898 & $\mathrm{Cc} 1[\mathrm{nH}] \mathrm{c}(-\mathrm{c} 2 \operatorname{ccccc} 2) \mathrm{c}(-\mathrm{c} 2 \operatorname{ccccc} 2) \mathrm{c} 1 \mathrm{C}(=\mathrm{O}) \mathrm{c} 1 \mathrm{cn}(-\mathrm{c} 2 \operatorname{ccccc} 2) \mathrm{nc} 1-\mathrm{c} 1 \mathrm{ccccc} 1$ & 2560 & $*$ \\
\hline 3899 & $\mathrm{Cc} 1 \mathrm{ncc}([\mathrm{N}+](=\mathrm{O})[\mathrm{O}-]) \mathrm{n} 1 \mathrm{C} / \mathrm{C}(=\mathrm{N} / \mathrm{NC}(=\mathrm{O}) \operatorname{c} 1 \operatorname{ccccc} 1 \mathrm{O}) \mathrm{c} 1 \mathrm{ccc}(\mathrm{Br}) \mathrm{cc} 1$ & 2580 & 5.59 \\
\hline 3900 & $\mathrm{C}[\mathrm{C} @ @ \mathrm{H}](\mathrm{COc} 1 \mathrm{ccc} 2 \mathrm{ncnc}(\mathrm{Nc} 3 \mathrm{ccc}(\mathrm{OCc} 4 \mathrm{ccc} n 4) \mathrm{c}(\mathrm{Cl}) \mathrm{c} 3) \mathrm{c} 12) \mathrm{N}(\mathrm{C}) \mathrm{C}(=\mathrm{O}) \mathrm{CO}$ & 2580 & $*$ \\
\hline
\end{tabular}




\begin{tabular}{|c|c|c|c|}
\hline 3901 & $\mathrm{CN} 1 \mathrm{CCN}(\mathrm{CCOc} 2 \mathrm{cc}(\mathrm{OC} 3 \mathrm{CCOCC} 3) \mathrm{c} 3 \mathrm{c}(\mathrm{Nc} 4 \mathrm{c}(\mathrm{Cl}) \mathrm{ccc} 5 \mathrm{c} 4 \mathrm{OCO} 5) \mathrm{ncnc} 3 \mathrm{c} 2) \mathrm{CC} 1$ & 2590 & 5.59 \\
\hline 3902 & $\mathrm{O}=\mathrm{C}(\mathrm{O}[\mathrm{C} @ \mathrm{H}] 1 \mathrm{CN}[\mathrm{C} @ \mathrm{H}](\mathrm{C} \# \mathrm{Cc} 2 \mathrm{cc} 3 \mathrm{ncnc}(\mathrm{Nc} 4 \mathrm{ccc}(\mathrm{OCc} 5 \mathrm{cccc}(\mathrm{F}) \mathrm{c} 5) \mathrm{nc} 4) \mathrm{c} 3 \mathrm{~s} 2) \mathrm{C} 1) \mathrm{N} 1 \mathrm{CCOCC} 1$ & 2600 & 5.59 \\
\hline 3903 & $\mathrm{O}=\mathrm{c} 1 \mathrm{c}(-\mathrm{c} 2 \mathrm{ccc}(\mathrm{O}) \mathrm{cc} 2) \operatorname{coc} 2 \mathrm{cc}(\mathrm{O}) \mathrm{cc}(\mathrm{O}) \mathrm{c} 12$ & 2600 & $*$ \\
\hline 3904 & $\mathrm{NC}(=\mathrm{O}) \mathrm{C} 1=\mathrm{C}(\mathrm{N}) \mathrm{C}(=\mathrm{O}) \mathrm{C}=\mathrm{C}(\mathrm{Nc} 2 \operatorname{cccc} 2 \mathrm{O}) \mathrm{C} 1=\mathrm{O}$ & 2600 & $*$ \\
\hline 3905 & $\mathrm{CC}(\mathrm{C}) \mathrm{n} 1 \mathrm{nc}(-\mathrm{c} 2 \mathrm{ccc}(\mathrm{C \# N}) \mathrm{c}(\mathrm{O}) \mathrm{c} 2) \mathrm{c} 2 \mathrm{c}(\mathrm{N}) \mathrm{ncnc} 21$ & 2600 & $*$ \\
\hline 3906 & Nc1ncnc2c1c(-c1ccc(F)c(O)c1)nn2[C@@H]1CCOC1 & 2600 & $*$ \\
\hline 3907 & $\mathrm{Cc} 1 \operatorname{cccc}(\mathrm{Nc} 2 \mathrm{c}(\mathrm{C}(\mathrm{N})=\mathrm{O}) \operatorname{cnc} 3 \operatorname{ccc}(\mathrm{C}(=\mathrm{O}) / \mathrm{C}=\mathrm{C} / \mathrm{c} 4 \operatorname{ccc}(-\cos \operatorname{ccc}(\mathrm{S}(\mathrm{N})(=\mathrm{O})=\mathrm{O}) \operatorname{cc} 5) \mathrm{o} 4) \operatorname{cc} 23) \mathrm{c} 1$ & 2610 & $*$ \\
\hline 3908 & $\mathrm{Cc} 1 \operatorname{ccc}(\mathrm{C}(=\mathrm{O}) \mathrm{NS}(=\mathrm{O})(=\mathrm{O}) \operatorname{c} 2 \operatorname{ccc}(\mathrm{Br}) \operatorname{cc} 2) \mathrm{c}(\mathrm{Cl}) \mathrm{n} 1$ & 2640 & 5.58 \\
\hline 3909 & $\mathrm{CN}(\mathrm{C}) \mathrm{C} / \mathrm{C}=\mathrm{C} / \mathrm{C}(=\mathrm{O}) \mathrm{Nc} 1 \mathrm{cc} 2 \mathrm{c}(\mathrm{Nc} 3 \mathrm{ccc}(\mathrm{F}) \mathrm{c}(\mathrm{Cl}) \mathrm{c} 3) \mathrm{c}(\mathrm{C \# N}) \mathrm{cnc} 2 \mathrm{cc} 1 \mathrm{OC}(\mathrm{F})(\mathrm{F}) \mathrm{F}$ & 2640 & 5.58 \\
\hline 3910 & $\mathrm{Cc} 1 \mathrm{ccc}(\mathrm{C} 2 \mathrm{CC}(\mathrm{c} 3 \mathrm{ccc}(\mathrm{C}) \mathrm{c}(\mathrm{C}) \mathrm{c} 3)=\mathrm{NN} 2 \mathrm{c} 2 \mathrm{nc}(-\mathrm{c} 3 \mathrm{ccccc} 3) \mathrm{cs} 2) \mathrm{cc} 1$ & 2670 & 5.57 \\
\hline 3911 & $\mathrm{Nc} 1 \mathrm{ncnc} 2 \mathrm{c} 1 \mathrm{c}(-\mathrm{c} 1 \mathrm{ccc}(\mathrm{O}) \mathrm{cc} 1) \mathrm{cn} 2 \mathrm{C} 1 \mathrm{CCNC} 1$ & 2670 & $*$ \\
\hline 3912 & $\mathrm{Cc} 1 \mathrm{ccc}(\mathrm{NC}(=\mathrm{O}) \mathrm{c} 2 \mathrm{cc}(\mathrm{I}) \operatorname{ccc} 2 \mathrm{O}) \mathrm{cc} 1$ & 2680 & $*$ \\
\hline 3913 & $\mathrm{C}=\mathrm{C}(\mathrm{CN} 1 \mathrm{CCOCC} 1) \mathrm{C}(=\mathrm{O}) \mathrm{Nc} 1 \mathrm{ccc} 2 \mathrm{ncc}(\mathrm{C \# N}) \mathrm{c}(\mathrm{Nc} 3 \mathrm{ccc}(\mathrm{F}) \mathrm{c}(\mathrm{Cl}) \mathrm{c} 3) \mathrm{c} 2 \mathrm{c} 1$ & 2700 & 5.57 \\
\hline 3914 & $\mathrm{Cc} 1 \mathrm{oc} 2 \mathrm{ncnc}(\mathrm{Nc} 3 \operatorname{cccc}(\mathrm{Cl}) \mathrm{c} 3) \mathrm{c} 2 \mathrm{c} 1 \mathrm{C}(=\mathrm{O}) \mathrm{NCCO}$ & 2700 & $*$ \\
\hline 3915 & $\mathrm{Nc} 1 \mathrm{ncnc} 2 \mathrm{c} 1 \mathrm{c}(-\mathrm{c} 1 \mathrm{ccc}(\mathrm{Cl}) \mathrm{c}(\mathrm{O}) \mathrm{c} 1) \mathrm{nn} 2 \mathrm{CC} 1 \mathrm{CCCNC} 1$ & 2720 & $*$ \\
\hline 3916 & $\mathrm{Cc} 1 \mathrm{cccc}(\mathrm{C}) \mathrm{c} 1 \mathrm{Nc} 1 \mathrm{ncc}(-\mathrm{c} 2 \mathrm{ccc}(\mathrm{OCC} 3 \mathrm{CCCN}(\mathrm{C}) \mathrm{C} 3) \mathrm{cc} 2) \mathrm{n} 2 \mathrm{cncc} 12 . \mathrm{Cl}$ & 2730 & $*$ \\
\hline 3917 & $\mathrm{COc} 1 \mathrm{cc} 2 \mathrm{ncc}(\mathrm{CHN}) \mathrm{c}(\mathrm{Nc} 3 \mathrm{ccc}(\mathrm{C}) \mathrm{cc} 3) \mathrm{c} 2 \mathrm{cc} 1 \mathrm{OC}$ & 2730 & $*$ \\
\hline 3918 & $\mathrm{O}=\mathrm{C}(\mathrm{Nc} 1 \mathrm{ccc} 2 \mathrm{ncnc}(\mathrm{Nc} 3 \mathrm{ccc}(\mathrm{Cl}) \mathrm{c} 3) \mathrm{c} 2 \mathrm{c} 1) \mathrm{C} 1 \mathrm{CO} 2 \mathrm{cccc} 2 \mathrm{O} 1$ & 2750 & 5.56 \\
\hline 3919 & $\mathrm{COc} 1 \mathrm{ccc}(\mathrm{C} 2=\mathrm{NN}(\mathrm{C} 3=\mathrm{NC}(=\mathrm{O}) \mathrm{CS} 3) \mathrm{C}(\mathrm{c} 3 \operatorname{ccc} 4 \operatorname{ccccc} 4 \mathrm{c} 3) \mathrm{C} 2) \mathrm{cc} 1$ & 2800 & 5.55 \\
\hline 3920 & $\operatorname{COc} 1 \mathrm{cc}(-\mathrm{c} 2 \mathrm{nc} 3 \mathrm{sc}(-\mathrm{c} 4 \mathrm{ccccc} 4) \mathrm{cn} 3 \mathrm{n} 2) \mathrm{cc}(\mathrm{OC}) \mathrm{c} 1 \mathrm{OC}$ & 2800 & 5.55 \\
\hline 3921 & $\operatorname{COc} 1 \operatorname{cc}(/ \mathrm{C}=\mathrm{C} /[\mathrm{N}+](=\mathrm{O})[\mathrm{O}-]) \operatorname{ccc} 1 \mathrm{OS}(=\mathrm{O})(=\mathrm{O}) \operatorname{c} 1 \operatorname{ccc}(\mathrm{C}(=\mathrm{O}) \mathrm{O}) \operatorname{cc} 1$ & 2800 & $*$ \\
\hline 3922 & $\mathrm{COc} 1 \mathrm{ccc}(\mathrm{Nc} 2 \mathrm{ncnc} 3 \mathrm{cc}(\mathrm{OC}) \mathrm{c}(\mathrm{OC}) \mathrm{cc} 23) \mathrm{cc} 1 \mathrm{OC}$ & 2800 & * \\
\hline 3923 & $\mathrm{COc} 1 \mathrm{cc} 2 \mathrm{ncnc}(\mathrm{Nc} 3 \operatorname{cccc}(\mathrm{NC}(=\mathrm{O}) \mathrm{c} 4 \mathrm{ccccc} 4) \mathrm{c} 3 \mathrm{~F}) \mathrm{c} 2 \mathrm{cc} 1 \mathrm{OC}$ & 2800 & $*$ \\
\hline 3924 & $\operatorname{COC}(=\mathrm{O}) \mathrm{c} 1 \mathrm{c}(\mathrm{OCCN} 2 \mathrm{CCCCC} 2) \mathrm{c} 2 \operatorname{ccc} c 2 \mathrm{c} 2 \mathrm{oc} 3 \mathrm{c}(\mathrm{c} 12) \mathrm{C}(=\mathrm{O}) \mathrm{c} 1 \mathrm{cccc} 1 \mathrm{C} 3=\mathrm{O}$ & 2800 & $*$ \\
\hline 3925 & $\mathrm{CC}(=\mathrm{O}) \mathrm{c} 1 \mathrm{cccc}(-\mathrm{c} 2 \mathrm{nn}(\mathrm{C}(\mathrm{C}) \mathrm{C}) \mathrm{c} 3 \mathrm{ncnc}(\mathrm{N}) \mathrm{c} 23) \mathrm{c} 1$ & 2800 & $*$ \\
\hline 3926 & $\mathrm{O}=\mathrm{C}(\mathrm{Nc} 1 \mathrm{cccc}(\mathrm{Cl}) \mathrm{c} 1) \mathrm{c} 1 \mathrm{ccc}(\mathrm{Br}) \mathrm{cc} 1 \mathrm{O}$ & 2800 & $*$ \\
\hline 3927 & $\mathrm{O}=\mathrm{C}(/ \mathrm{C}=\mathrm{C} / \mathrm{c} 1 \mathrm{ccc} 2 \mathrm{cccc} 12) \mathrm{Nc} 1 \mathrm{ccc} 2 \mathrm{ncnc}(\mathrm{Nc} 3 \operatorname{ccc}(\mathrm{Cl}) \mathrm{c} 3) \mathrm{c} 2 \mathrm{c} 1$ & 2810 & 5.55 \\
\hline 3928 & $\operatorname{COc} 1 \mathrm{cc} 2 \mathrm{ncnc}(\mathrm{Sc} 3 \operatorname{cccc}(\mathrm{NC}(=\mathrm{S}) \mathrm{Nc} 4 \mathrm{ccc}(\mathrm{Cl}) \mathrm{cc} 4) \mathrm{c} 3) \mathrm{c} 2 \mathrm{cc} 1 \mathrm{OC}$ & 2860 & $*$ \\
\hline 3929 & $\mathrm{COc} 1 \mathrm{cccc}(\mathrm{CNc} 2 \mathrm{ncnc} 3 \mathrm{cc}(\mathrm{N}) \mathrm{ncc} 23) \mathrm{c} 1$ & 2870 & $*$ \\
\hline 3930 & $\operatorname{COc} 1 \mathrm{cc}(\mathrm{NC}(=\mathrm{O}) / \mathrm{C}=\mathrm{C} / \mathrm{CN}(\mathrm{C}) \mathrm{C}) \operatorname{cc} 2 \mathrm{c}(\mathrm{Nc} 3 \operatorname{cccc}(\mathrm{Br}) \mathrm{c} 3) \mathrm{c}(\mathrm{C \# N}) \mathrm{cnc} 12$ & 2880 & 5.54 \\
\hline 3931 & $\mathrm{Cc} 1[\mathrm{nH}] \mathrm{c}(-\mathrm{c} 2 \operatorname{ccccc} 2) \mathrm{c}(-\mathrm{c} 2 \operatorname{cccc} 2) \mathrm{c} 1-\mathrm{c} 1 \operatorname{ccc}(\mathrm{NC}(=\mathrm{O}) \mathrm{c} 2 \operatorname{ccccc} 2) \mathrm{c}(=\mathrm{O}) \mathrm{o} 1$ & 2890 & $*$ \\
\hline 3932 & $\mathrm{COc} 1 \mathrm{cc} 2 \mathrm{c}(\mathrm{cc} 1 \mathrm{OC}) \mathrm{Sc} 1 \mathrm{ncn} c(\mathrm{Sc} 3 \mathrm{cccc}(\mathrm{Cl}) \mathrm{c} 3) \mathrm{c} 1 \mathrm{NC} 2$ & 2900 & 5.54 \\
\hline 3933 & $\operatorname{Cc} 1 \operatorname{ccc} 2 \mathrm{c}(\mathrm{CCC}(=\mathrm{O}) \mathrm{O}) \mathrm{c}(\mathrm{SSc} 3[\mathrm{nH}] \mathrm{c} 4 \mathrm{cc}(\mathrm{C}) \operatorname{ccc} 4 \mathrm{c} 3 \mathrm{CCC}(=\mathrm{O}) \mathrm{O})[\mathrm{nH}] \mathrm{c} 2 \mathrm{c} 1$ & 2900 & $*$ \\
\hline 3934 & $\begin{array}{c}\mathrm{O}=\mathrm{C} 1 \mathrm{NCCc} 2 \mathrm{ccc}(\mathrm{O}) \mathrm{c}(\mathrm{c} 2) \mathrm{Oc} 2 \mathrm{c}(\mathrm{Br}) \mathrm{cc}(\mathrm{cc} 2 \mathrm{Br}) \mathrm{CCNC}(=\mathrm{O}) / \mathrm{C}(=\mathrm{N} / \mathrm{O}) \mathrm{Cc} 2 \mathrm{cc}(\mathrm{Br}) \mathrm{c}(\mathrm{O}) \mathrm{c}(\mathrm{c} 2) \mathrm{Oc} 2 \mathrm{c}(\mathrm{Br}) \mathrm{cc}(\mathrm{cc} 2 \mathrm{Br}) \mathrm{C} / \mathrm{C} 1= \\
\mathrm{N} \backslash \mathrm{O}\end{array}$ & 2900 & $*$ \\
\hline 3935 & $\mathrm{C}=\mathrm{CC}(=\mathrm{O}) \mathrm{Nc} 1 \mathrm{cccc}(\mathrm{Oc} 2 \mathrm{nc}(\mathrm{Nc} 3 \mathrm{n}[\mathrm{nH}] \mathrm{c} 4 \mathrm{ccc}(\mathrm{Br}) \operatorname{cc} 34) \mathrm{cc}(\mathrm{N} 3 \mathrm{CCN}(\mathrm{C}) \mathrm{CC} 3) \mathrm{n} 2) \mathrm{c} 1$ & 2900 & $*$ \\
\hline 3936 & $\mathrm{Nc} 1 \mathrm{ncnc} 2 \mathrm{c} 1 \mathrm{c}(-\mathrm{c} 1 \mathrm{ccc}(\mathrm{F}) \mathrm{c}(\mathrm{O}) \mathrm{c} 1) \mathrm{nn} 2 \mathrm{C} 1 \mathrm{CNC} 1$ & 2900 & $*$ \\
\hline 3937 & $\mathrm{Nc} 1 \mathrm{ncnc} 2 \mathrm{c} 1 \mathrm{c}(-\mathrm{c} 1 \mathrm{ccc}(\mathrm{F}) \mathrm{c}(\mathrm{O}) \mathrm{c} 1) \mathrm{nn} 2 \mathrm{C} 1 \mathrm{CCC} 1$ & 2900 & $*$ \\
\hline 3938 & $\mathrm{Cn} 1 \mathrm{nc}(-\mathrm{c} 2 \mathrm{ccc} 3 \mathrm{cc}[\mathrm{nH}] \mathrm{c} 3 \mathrm{c} 2) \mathrm{c} 2 \mathrm{c}(\mathrm{N}) \mathrm{ncnc} 21$ & 2900 & $*$ \\
\hline 3939 & $\mathrm{COc} 1 \mathrm{cc}(\mathrm{Br}) \mathrm{c}(\mathrm{C}=\mathrm{C} 2 \mathrm{CC}(\mathrm{C}) \mathrm{CC}(=\mathrm{Cc} 3 \mathrm{nc}(\mathrm{C}) \mathrm{c}(\mathrm{C}) \mathrm{nc} 3 \mathrm{C}) \mathrm{C} 2=\mathrm{NO}) \mathrm{cc} 1 \mathrm{OC}$ & 2900 & $*$ \\
\hline 3940 & $\mathrm{COc} 1 \mathrm{cc} 2 \mathrm{c}(\mathrm{Nc} 3 \mathrm{ccc}(\mathrm{NC}(=\mathrm{O}) \mathrm{Nc} 4 \mathrm{ccccc} 4) \mathrm{cc} 3) \mathrm{ncn} 2 \mathrm{cc} 1 \mathrm{OCc} 1 \mathrm{ccccc} 1$ & 2933 & $*$ \\
\hline 3941 & $\mathrm{COc} 1 \mathrm{ccc}(\mathrm{Nc} 2 \mathrm{ncnc} 3[\mathrm{nH}] \mathrm{ccc} 23) \mathrm{cc} 1$ & 2936.67 & $*$ \\
\hline 3942 & $\operatorname{Cc} \operatorname{lncc}([\mathrm{N}+](=\mathrm{O})[\mathrm{O}-]) \mathrm{n} 1 \mathrm{CC}(=\mathrm{O}) \mathrm{NS}(=\mathrm{O})(=\mathrm{O}) \operatorname{clccccc} 1$ & 2940 & 5.53 \\
\hline
\end{tabular}




\begin{tabular}{|c|c|c|c|}
\hline 3943 & $\operatorname{COc} 1 \mathrm{cc}(\mathrm{N} 2 \mathrm{CCN}(\mathrm{C}) \mathrm{CC} 2) \operatorname{ccc} 1 \mathrm{Nc} 1 \mathrm{ncc}(\mathrm{Cl}) \mathrm{c}(\mathrm{Oc} 2 \operatorname{ccc}(\mathrm{CCO} 3 \mathrm{no}[\mathrm{n}+]([\mathrm{O}-]) \mathrm{c} 3 \mathrm{~S}(=\mathrm{O})(=\mathrm{O}) \mathrm{c} 3 \operatorname{ccccc} 3) \operatorname{cc} 2) \mathrm{n} 1$ & 2940 & 5.53 \\
\hline 3944 & $\mathrm{Fc} 1 \mathrm{ccc}(\mathrm{Nc} 2 \mathrm{ncnc} 3 \mathrm{scc} 23) \mathrm{cc} 1 \mathrm{Cl}$ & 2980 & $*$ \\
\hline 3945 & C[C@@H](Nc1ncnc2oc(-c3eccc3)c(-c3eccc3)c12)c1cccc1 & 2991 & $*$ \\
\hline 3946 & $\mathrm{CN} 1 \mathrm{CCN}(\mathrm{Cc} 2 \mathrm{ccc}(\mathrm{C}(=\mathrm{O}) \mathrm{Nc} 3 \operatorname{ccc}(-\mathrm{c} 4 \mathrm{cncc}(\mathrm{C \# N}) \mathrm{c} 4 \mathrm{Nc} 4 \mathrm{ccc}(\mathrm{F}) \mathrm{c}(\mathrm{Cl}) \mathrm{c} 4) \mathrm{cc} 3) \mathrm{cc} 2) \mathrm{CC} 1$ & 3000 & 5.52 \\
\hline 3947 & $\mathrm{CC}(\mathrm{C}) \mathrm{Oc} 1 \mathrm{cccc}(\mathrm{Nc} 2 \mathrm{ncnc} 3 \mathrm{cc} 4 \mathrm{oc}(=\mathrm{O}) \mathrm{n}(\mathrm{CCCN} 5 \mathrm{CCOCC} 5) \mathrm{c} 4 \mathrm{cc} 23) \mathrm{c} 1$ & 3000 & $*$ \\
\hline 3948 & $\mathrm{O}=\mathrm{CN} / \mathrm{C}=\mathrm{C} / \mathrm{c} 1 \mathrm{cc}(\mathrm{O}) \operatorname{ccc} 1 \mathrm{O}$ & 3000 & $*$ \\
\hline 3949 & $\mathrm{Cc} 1 \mathrm{cc}(\mathrm{C}) \operatorname{cc}(\mathrm{COC}(=\mathrm{O}) \operatorname{c} 2 \mathrm{cc}(\mathrm{NCc} 3 \mathrm{cc}(\mathrm{O}) \operatorname{ccc} 3 \mathrm{O}) \operatorname{ccc} 2 \mathrm{O}) \mathrm{c} 1$ & 3000 & $*$ \\
\hline 3950 & $\mathrm{O}=\mathrm{P}(\mathrm{O})(\mathrm{O}) \mathrm{Cc} 1 \mathrm{cc}(\mathrm{NCc} 2 \mathrm{cc}(\mathrm{O}) \mathrm{ccc} 2 \mathrm{O}) \mathrm{ccc} 1 \mathrm{O}$ & 3000 & $*$ \\
\hline 3951 & $\operatorname{COC}(=\mathrm{O}) \mathrm{Cc} 1 \mathrm{cc}(\mathrm{NCc} 2 \mathrm{cc}(\mathrm{O}) \operatorname{ccc} 2 \mathrm{O}) \operatorname{ccc} 1 \mathrm{O}$ & 3000 & $*$ \\
\hline 3952 & $\mathrm{COc} 1 \mathrm{cc}(\mathrm{Nc} 2 \mathrm{ncnc} 3 \mathrm{cc}(\mathrm{OC}) \mathrm{c}(\mathrm{OC}) \mathrm{cc} 23) \mathrm{cc}(\mathrm{OC}) \mathrm{c} 1 . \mathrm{Cl}$ & 3000 & $*$ \\
\hline 3953 & $\mathrm{~N} \# \mathrm{CC}(\mathrm{C} \# \mathrm{~N})=\mathrm{Cc} 1 \mathrm{cc}(\mathrm{O}) \mathrm{c}(\mathrm{O}) \mathrm{c}(\mathrm{O}) \mathrm{c} 1$ & 3000 & $*$ \\
\hline 3954 & $\mathrm{COc} 1 \mathrm{cc} 2 \mathrm{ncnc}(\mathrm{N}(\mathrm{C}) \mathrm{c} 3 \mathrm{ccc}(\mathrm{Cl}) \mathrm{cc} 3) \mathrm{c} 2 \mathrm{cc} 1 \mathrm{OC} . \mathrm{Cl}$ & 3000 & $*$ \\
\hline 3955 & $\mathrm{COc} 1 \mathrm{cc} 2 \mathrm{ncnc}(\mathrm{N} 3 \mathrm{CCc} 4 \mathrm{cccc} 43) \mathrm{c} 2 \mathrm{cc} 1 \mathrm{OC} . \mathrm{Cl}$ & 3000 & $*$ \\
\hline 3956 & $\mathrm{O}=[\mathrm{N}+]([\mathrm{O}-]) \mathrm{c} 1 \mathrm{cccc}(\mathrm{Oc} 2 \operatorname{ccnc}(\mathrm{Oc} 3 \operatorname{ccc}([\mathrm{N}+](=\mathrm{O})[\mathrm{O}-]) \mathrm{c} 3) \mathrm{n} 2) \mathrm{c} 1$ & 3000 & $*$ \\
\hline 3957 & $\mathrm{NC}(=\mathrm{S}) \mathrm{N} 1 \mathrm{~N}=\mathrm{C}(\mathrm{c} 2 \operatorname{cccc} 2) \mathrm{CC} 1 \mathrm{c} 1 \operatorname{ccc} 2 \operatorname{ccc} c 2 \mathrm{c} 1$ & 3010 & 5.52 \\
\hline 3958 & $\mathrm{~N} \# \mathrm{C} / \mathrm{C}(=\mathrm{C} \backslash \mathrm{c} 1 \mathrm{ccc}(\mathrm{O}) \mathrm{c}(\mathrm{O}) \mathrm{c} 1) \mathrm{C}(=\mathrm{O}) \mathrm{NCc} 1 \mathrm{ccc}(\mathrm{O}) \mathrm{cc} 1$ & 3019.95 & $*$ \\
\hline 3959 & $\operatorname{COc} 1 \mathrm{ccc}(-\mathrm{c} 2 \mathrm{nn}(\mathrm{C}(\mathrm{C}) \mathrm{C}) \mathrm{c} 3 \mathrm{ncnc}(\mathrm{N}) \mathrm{c} 23) \mathrm{cc} 1 \mathrm{OC}$ & 3020 & $*$ \\
\hline 3960 & $\mathrm{Cc} 1 \operatorname{ccc}(\mathrm{C} 2 \mathrm{CC}(\mathrm{c} 3 \operatorname{cccc} 3)=\mathrm{NN} 2 \mathrm{C} 2=\mathrm{NC}(=\mathrm{O}) \mathrm{CS} 2) \mathrm{cc} 1$ & 3030 & 5.52 \\
\hline 3961 & $\mathrm{~N} \# \mathrm{CC}(\mathrm{C \# N})=\mathrm{CNc} 1 \mathrm{ccc} 2 \mathrm{ncnc}(\mathrm{Nc} 3 \mathrm{ccc}(\mathrm{OCc} 4 \mathrm{ccc} n 4) \mathrm{c}(\mathrm{Cl}) \mathrm{c} 3) \mathrm{c} 2 \mathrm{c} 1$ & 3050 & $*$ \\
\hline 3962 & $\mathrm{C}=\mathrm{CC}(=\mathrm{O}) \mathrm{N} 1 \mathrm{CCc} 2 \mathrm{c}(\operatorname{sc} 3 \mathrm{ncnc}(\mathrm{N}[\mathrm{C} @ @ \mathrm{H}](\mathrm{CO}) \mathrm{c} 4 \mathrm{cccc} 4) \mathrm{c} 23) \mathrm{C} 1$ & 3057 & $*$ \\
\hline 3963 & $\mathrm{Cc} 1 \mathrm{ccc}(\mathrm{C} 2=\mathrm{NN}(\mathrm{C}(\mathrm{N})=\mathrm{S}) \mathrm{C}(\mathrm{c} 3 \operatorname{ccc}([\mathrm{N}+](=\mathrm{O})[\mathrm{O}-]) \operatorname{cc} 3) \mathrm{C} 2) \operatorname{cc} 1 \mathrm{C}$ & 3060 & 5.51 \\
\hline 3964 & $\mathrm{C} \# \mathrm{Cc} 1 \mathrm{cccc}(-\mathrm{n} 2 \mathrm{ccc} 3 \mathrm{cc}(\mathrm{OC}) \mathrm{cc}(\mathrm{O}) \mathrm{c} 3 \mathrm{c} 2=\mathrm{O}) \mathrm{c} 1$ & 3060 & $*$ \\
\hline 3965 & $\mathrm{CNC}(=\mathrm{O}) \mathrm{c} 1 \mathrm{nn}(\mathrm{C}) \mathrm{c} 2 \mathrm{c} 1 \mathrm{C}(\mathrm{C})(\mathrm{C}) \mathrm{Cc} 1 \mathrm{cnc}(\mathrm{Nc} 3 \mathrm{ccc}(\mathrm{N} 4 \mathrm{CCN}(\mathrm{C}) \mathrm{CC} 4) \mathrm{cc} 3) \mathrm{nc} 1-2$ & 3069 & $*$ \\
\hline 3966 & $\mathrm{COc} 1 \mathrm{ccc}(\mathrm{C} 2 \mathrm{CC}(\mathrm{c} 3 \mathrm{ccc}(\mathrm{C}) \mathrm{c}(\mathrm{C}) \mathrm{c} 3)=\mathrm{NN} 2 \mathrm{c} 2 \mathrm{nc}(-\mathrm{c} 3 \mathrm{ccccc} 3) \mathrm{cs} 2) \mathrm{cc} 1$ & 3080 & 5.51 \\
\hline 3967 & $\mathrm{~N} \# \mathrm{C} / \mathrm{C}(=\mathrm{C} \backslash \mathrm{c} 1 \mathrm{ccc}(\mathrm{O}) \mathrm{c}(\mathrm{O}) \mathrm{c} 1) \mathrm{C}(=\mathrm{O}) \mathrm{c} 1 \mathrm{cccs} 1$ & 3100 & $*$ \\
\hline 3968 & $\mathrm{Cn} 1 \mathrm{c}(\mathrm{SSc} 2 \mathrm{c}(\mathrm{CCC}(=\mathrm{O}) \mathrm{O}) \mathrm{c} 3 \operatorname{cccc} 3 \mathrm{n} 2 \mathrm{C}) \mathrm{c}(\mathrm{CCC}(=\mathrm{O}) \mathrm{O}) \mathrm{c} 2 \mathrm{cccc} 21$ & 3100 & $*$ \\
\hline 3969 & $\mathrm{O}=\mathrm{C} 1 \mathrm{~N}=\mathrm{C}(\mathrm{N} 2 \mathrm{CCC}[\mathrm{C} @ \mathrm{H}] 2 \mathrm{C}(=\mathrm{O}) \mathrm{Nc} 2 \mathrm{ccc} 3 \mathrm{ncnc}(\mathrm{Nc} 4 \operatorname{ccc}(\mathrm{Cl}) \mathrm{c} 4) \mathrm{c} 3 \mathrm{c} 2) \mathrm{S} / \mathrm{C} 1=\mathrm{C} / \mathrm{c} 1 \mathrm{ccc}(\mathrm{Br}) \mathrm{n} 1$ & 3100 & $*$ \\
\hline 3970 & $\mathrm{C}=\mathrm{CC}(=\mathrm{O}) \mathrm{Nc} 1 \mathrm{ccc}(\mathrm{Oc} 2 \mathrm{nc}(\mathrm{Nc} 3 \mathrm{cc}(\mathrm{C})[\mathrm{nH}] \mathrm{n} 3) \mathrm{cc}(\mathrm{N} 3 \mathrm{CCN}(\mathrm{C}) \mathrm{CC} 3) \mathrm{n} 2) \mathrm{cc} 1$ & 3100 & $*$ \\
\hline 3971 & $\mathrm{COc} 1 \mathrm{cc}(\mathrm{Br}) \mathrm{c}(\mathrm{C}=\mathrm{C} 2 \mathrm{CN}(\mathrm{C}(\mathrm{C}) \mathrm{C}) \mathrm{CC}(=\mathrm{Cc} 3 \mathrm{nc}(\mathrm{C}) \mathrm{c}(\mathrm{C}) \mathrm{nc} 3 \mathrm{C}) \mathrm{C} 2=\mathrm{O}) \mathrm{cc} 1 \mathrm{OC}$ & 3100 & $*$ \\
\hline 3972 & $\operatorname{CCCCCCCCCCOC}(=0) \operatorname{COc} 1 \mathrm{cc}(\mathrm{O}) \mathrm{c} 2 \mathrm{c}(=\mathrm{O}) \mathrm{cc}(-\mathrm{c} 3 \mathrm{ccccc} 3) \mathrm{oc} 2 \mathrm{c} 1$ & 3110 & 5.51 \\
\hline 3973 & $\operatorname{Brc} 1 \mathrm{ccc}(\mathrm{CNc} 2 \mathrm{ccc} 3 \mathrm{ncnc}(\mathrm{Nc} 4 \mathrm{cccc}(\mathrm{Br}) \mathrm{c} 4) \mathrm{c} 3 \mathrm{c} 2) \mathrm{cc} 1$ & 3130 & 5.50 \\
\hline 3974 & $\operatorname{COc} 1 \mathrm{cc}(\mathrm{N} 2 \mathrm{CCC}(\mathrm{O}) \mathrm{CC} 2) \operatorname{ccc} 1 \mathrm{Nc} 1 \mathrm{ncc}(\mathrm{Cl}) \mathrm{c}(\mathrm{Oc} 2 \operatorname{ccc}(\mathrm{COc} 3 \mathrm{no}[\mathrm{n}+]([\mathrm{O}-]) \mathrm{c} 3 \mathrm{~S}(=\mathrm{O})(=\mathrm{O}) \mathrm{c} 3 \operatorname{cccc} 3) \operatorname{cc} 2) \mathrm{n} 1$ & 3150 & 5.50 \\
\hline 3975 & $\mathrm{COc} 1 \mathrm{cc} 2 \mathrm{ncc}(\mathrm{C \# N}) \mathrm{c}(\mathrm{Nc} 3 \mathrm{cc}(\mathrm{Cl}) \mathrm{c}(\mathrm{O}) \mathrm{c}(\mathrm{Cl}) \mathrm{c} 3) \mathrm{c} 2 \mathrm{cc} 1 \mathrm{OC}$ & 3150 & $*$ \\
\hline 3976 & $\mathrm{O}=\mathrm{C}(\mathrm{O}[\mathrm{C} @ \mathrm{H}] 1 \mathrm{CN}[\mathrm{C} @ \mathrm{H}](\mathrm{C} \# \mathrm{Cc} 2 \mathrm{cc} 3 \mathrm{ncnc}(\mathrm{Nc} 4 \mathrm{ccc} 5 \mathrm{c}(\mathrm{ccn} 5 \mathrm{CCc} 5 \mathrm{ccccc} 5) \mathrm{c} 4) \mathrm{c} 3 \mathrm{~s} 2) \mathrm{C} 1) \mathrm{N} 1 \mathrm{CCOCC} 1$ & 3160 & $*$ \\
\hline 3977 & $\mathrm{Cc} 1 \mathrm{ccc} 2 \mathrm{nc}(\mathrm{Oc} 3 \operatorname{ccc} c 3) \mathrm{c}(\mathrm{C}=\mathrm{N} / \mathrm{NC}(=\mathrm{O}) \mathrm{Cn} 3 \mathrm{c}([\mathrm{N}+](=\mathrm{O})[\mathrm{O}-]) \operatorname{cnc} 3 \mathrm{C}) \mathrm{cc} 2 \mathrm{c} 1$ & 3170 & 5.50 \\
\hline 3978 & $\mathrm{COc} 1 \mathrm{cc} 2 \mathrm{ncnc}(\mathrm{Sc} 3 \operatorname{ccc}(\mathrm{NC}(=\mathrm{S}) \mathrm{Nc} 4 \mathrm{ccc}(\mathrm{F}) \mathrm{c}(\mathrm{F}) \mathrm{c} 4) \mathrm{c} 3) \mathrm{c} 2 \mathrm{cc} 1 \mathrm{OC}$ & 3170 & $*$ \\
\hline 3979 & $\mathrm{O}=\mathrm{C} 1 \mathrm{CSC}(\mathrm{N} 2 \mathrm{~N}=\mathrm{C}(\mathrm{c} 3 \operatorname{ccc}(\mathrm{Br}) \mathrm{cc} 3) \mathrm{CC} 2 \mathrm{c} 2 \mathrm{cccc} 2)=\mathrm{N} 1$ & 3200 & 5.49 \\
\hline 3980 & $\mathrm{C \# Cc1} \operatorname{ccc}(\mathrm{Nc} 2 \mathrm{ncnc} 3 \mathrm{c} 2 \mathrm{NCc} 2 \mathrm{cc}(\mathrm{OC}) \mathrm{c}(\mathrm{OC}) \mathrm{cc} 2 \mathrm{O} 3) \mathrm{c} 1$ & 3200 & 5.49 \\
\hline 3981 & $\mathrm{COc} 1 \mathrm{cc} 2 \mathrm{ncnc}(\mathrm{Nc} 3 \operatorname{ccc}(\mathrm{C}) \mathrm{c}(\mathrm{NC}(=\mathrm{O}) \mathrm{c} 4 \mathrm{cccc} 4) \mathrm{c} 3) \mathrm{c} 2 \mathrm{cc} 1 \mathrm{OC}$ & 3200 & $*$ \\
\hline 3982 & $\operatorname{CCOC}(=\mathrm{O}) \mathrm{c} 1 \mathrm{nn}(-\mathrm{c} 2 \mathrm{ccc}(\mathrm{Cl}) \mathrm{cc} 2) \mathrm{cc} 1 \mathrm{C}(=\mathrm{O}) \mathrm{c} 1 \mathrm{c}(\mathrm{C})[\mathrm{nH}] \mathrm{c}(-\mathrm{c} 2 \mathrm{ccccc} 2) \mathrm{c} 1-\mathrm{c} 1 \mathrm{ccccc} 1$ & 3200 & $*$ \\
\hline 3983 & Cc1nnc(-n2c(-c3eccec3)nc3ec $(\mathrm{Cl}) \operatorname{ccc} 3 \mathrm{c} 2=\mathrm{O}) \mathrm{s} 1$ & 3210 & 5.49 \\
\hline 3984 & Oc1cccc1CNc1ecc2ncnc(Ne3ecce(Br)c3)c2c1 & 3220 & 5.49 \\
\hline 3985 & $\operatorname{CCOC}(=\mathrm{O}) \operatorname{c} 1 \mathrm{nn}(-\mathrm{c} 2 \operatorname{ccc} c 2) \operatorname{cc} 1 \mathrm{C}(=\mathrm{O}) \mathrm{c} 1 \mathrm{c}(\mathrm{C})[\mathrm{nH}] \mathrm{c}(-\mathrm{c} 2 \operatorname{ccccc} 2) \mathrm{c} 1-\mathrm{c} 1 \mathrm{cccc} 1$ & 3220 & $*$ \\
\hline
\end{tabular}




\begin{tabular}{|c|c|c|c|}
\hline 3986 & $\operatorname{Cc} 1$ ncc $([\mathrm{N}+](=\mathrm{O})[\mathrm{O}-]) \operatorname{n} 1 \mathrm{CCOC}(=\mathrm{O}) / \mathrm{C}=\mathrm{C} / \mathrm{c} 1 \mathrm{ccc}(\mathrm{Br}) \mathrm{cc} 1$ & 3240 & 5.49 \\
\hline 3987 & C[C@@H](Nc1ncnc2sc3c(c12)CCCC3)c1 1cccc1 & 3240 & $*$ \\
\hline 3988 & $\mathrm{Cc} 1 \mathrm{ccc}(\mathrm{C} 2=\mathrm{NN}(\mathrm{C} 3=\mathrm{NC}(=\mathrm{O}) \mathrm{CS} 3) \mathrm{C}(\mathrm{c} 3 \operatorname{ccc} 4 \mathrm{ccccc} 4 \mathrm{c} 3) \mathrm{C} 2) \mathrm{cc} 1$ & 3250 & 5.49 \\
\hline 3989 & $\mathrm{Cc} 1 \mathrm{ccc} 2 \mathrm{c}(\mathrm{Nc} 3 \operatorname{ccc}(\mathrm{F}) \mathrm{c}(\mathrm{Cl}) \mathrm{c} 3) \mathrm{ncnn} 12$ & 3250 & $*$ \\
\hline 3990 & $\mathrm{Cc} 1 \mathrm{ccc}(/ \mathrm{C}=\mathrm{N} / \mathrm{NC} 2=\mathrm{NC}(=\mathrm{O}) \mathrm{CS} 2) \mathrm{cc} 1$ & 3260 & 5.49 \\
\hline 3991 & $\mathrm{O}=\mathrm{C}(\mathrm{NS}(=\mathrm{O})(=\mathrm{O}) \mathrm{c} 1 \mathrm{ccc}(\mathrm{F}) \mathrm{cc} 1) \mathrm{c} 1 \mathrm{cncc}(\mathrm{Br}) \mathrm{c} 1$ & 3270 & 5.49 \\
\hline 3992 & $\mathrm{NC}(=\mathrm{S}) \mathrm{N} 1 \mathrm{~N}=\mathrm{C}(\mathrm{c} 2 \mathrm{ccc}(\mathrm{F}) \mathrm{cc} 2) \mathrm{CC} 1 \mathrm{c} 1 \mathrm{ccc} 2 \mathrm{ccccc} 2 \mathrm{c} 1$ & 3280 & 5.48 \\
\hline 3993 & $\mathrm{Cc} 1 \mathrm{cc}(\mathrm{Oc} 2 \mathrm{ncnc} 3 \mathrm{sc} 4 \mathrm{c}(\mathrm{c} 23) \mathrm{CCCC} 4) \mathrm{ccc} 1 \mathrm{NC}(=\mathrm{O}) \mathrm{Nc} 1 \mathrm{cccc}(\mathrm{Br}) \mathrm{c} 1$ & 3290 & $*$ \\
\hline 3994 & $\mathrm{O}=\mathrm{C}(\mathrm{O}) \mathrm{c} 1 \mathrm{cc}(\mathrm{CCc} 2 \mathrm{cc}(\mathrm{O}) \operatorname{ccc} 2 \mathrm{O}) \operatorname{ccc} 1 \mathrm{O}$ & 3300 & $*$ \\
\hline 3995 & $\mathrm{CN}(\mathrm{C}) \mathrm{CCOc} 1 \mathrm{ccc}(/ \mathrm{C}=\mathrm{C} / \mathrm{c} 2 \mathrm{cc}(-\mathrm{c} 3 \mathrm{cc} 4 \mathrm{c}(=\mathrm{O})[\mathrm{nH}] \mathrm{cnc} 4[\mathrm{nH}] 3) \operatorname{ccn} 2) \mathrm{cc} 1$ & 3300 & $*$ \\
\hline 3996 & COc1 $1 \mathrm{ccc}(-\mathrm{c} 2 \mathrm{nn}(\mathrm{C} 3 \mathrm{CCCC} 3) \mathrm{c} 3 \mathrm{ncnc}(\mathrm{N}) \mathrm{c} 23) \mathrm{cc} 1 \mathrm{OC}$ & 3300 & * \\
\hline 3997 & $\mathrm{C} \# \mathrm{Cc} 1 \mathrm{cccc}(\mathrm{NC}(=\mathrm{O}) \mathrm{c} 2 \mathrm{cc}(\mathrm{NC}(=\mathrm{O}) \mathrm{CCCCCC}(=\mathrm{O}) \mathrm{NO}) \operatorname{ccc} 2 \mathrm{O}) \mathrm{c} 1$ & 3310 & $*$ \\
\hline 3998 & $\mathrm{O}=\mathrm{C}(\mathrm{Nc} 1 \mathrm{cccc}(\mathrm{Nc} 2 \mathrm{ncnc} 3 \mathrm{cc}(\mathrm{OCCCN} 4 \mathrm{CCOCC} 4) \mathrm{ccc} 23) \mathrm{c} 1) \mathrm{Nc} 1 \mathrm{ccc}(\mathrm{F}) \mathrm{c}(\mathrm{Cl}) \mathrm{c} 1$ & 3315 & * \\
\hline 3999 & $\operatorname{COc} 1 \mathrm{cc} 2 \mathrm{ncc}(\mathrm{C}=\mathrm{O}) \mathrm{c}(\mathrm{Nc} 3 \operatorname{cccc}(\mathrm{Br}) \mathrm{c} 3) \mathrm{c} 2 \mathrm{cc} 1 \mathrm{OC}$ & 3370 & $*$ \\
\hline 4000 & $\mathrm{O}=\mathrm{C} 1 \mathrm{CSC}(\mathrm{N} 2 \mathrm{~N}=\mathrm{C}(\mathrm{c} 3 \operatorname{ccc} c \mathrm{c} 3) \mathrm{CC} 2 \mathrm{c} 2 \mathrm{cccc} 2)=\mathrm{N} 1$ & 3380 & 5.47 \\
\hline 4001 & $\mathrm{COc} 1 \mathrm{cc}(/ \mathrm{C}=\mathrm{C}(\backslash \mathrm{C} \# \mathrm{~N}) \mathrm{C}(\mathrm{N})=\mathrm{O}) \operatorname{cc}(\mathrm{CSc} 2 \operatorname{ccc} n 2) \mathrm{c} 1 \mathrm{O}$ & 3388.44 & $*$ \\
\hline 4002 & $\mathrm{CN} 1 \mathrm{CCN}(\mathrm{CC}(=\mathrm{O}) \mathrm{Nc} 2 \mathrm{cc} 3 \mathrm{c}(\mathrm{Nc} 4 \mathrm{ccc}(\mathrm{F}) \mathrm{c}(\mathrm{Cl}) \mathrm{c} 4) \mathrm{ncnc} 3 \mathrm{~s} 2) \mathrm{CC} 1$ & 3399 & $*$ \\
\hline 4003 & $\mathrm{Clc} 1 \mathrm{cccc}(\mathrm{Nc} 2 \mathrm{ncnc} 3 \mathrm{ccc}(\mathrm{NCc} 4 \mathrm{cccs} 4) \mathrm{cc} 23) \mathrm{c} 1$ & 3400 & 5.47 \\
\hline 4004 & COc1cc2c(cc1OC)Oc1ncne(Nc3ecc(F)cc3Cl)c1NC2 & 3400 & 5.47 \\
\hline 4005 & $\mathrm{CCC}(=\mathrm{O}) \mathrm{N} 1 \mathrm{CC}[\mathrm{C} @ \mathrm{H}](\mathrm{N} 2 \mathrm{C}(=\mathrm{O}) \mathrm{N}(\mathrm{c} 3 \mathrm{cc}(\mathrm{OC}) \mathrm{ccc} 3 \mathrm{~F}) \mathrm{Cc} 3 \mathrm{cnc}(\mathrm{Nc} 4 \mathrm{ccc}(\mathrm{N} 5 \mathrm{CCN}(\mathrm{C}) \mathrm{CC} 5) \mathrm{c}(\mathrm{C}(\mathrm{F})(\mathrm{F}) \mathrm{F}) \mathrm{c} 4) \mathrm{nc} 32) \mathrm{C} 1$ & 3400 & 5.47 \\
\hline 4006 & Oc1cc2c(cc1O)[C@@H]1c3ccc(O)c(O)c3OC[C@]1(O)C2 & 3400 & $*$ \\
\hline 4007 & $\operatorname{Cc} 1 \operatorname{ccc}(\mathrm{S}(=\mathrm{O})(=\mathrm{O}) \mathrm{NC}(=\mathrm{O}) \mathrm{Cn} 2 \mathrm{c}([\mathrm{N}+](=\mathrm{O})[\mathrm{O}-]) \operatorname{cnc} 2 \mathrm{C}) \mathrm{cc} 1$ & 3430 & 5.46 \\
\hline 4008 & $\mathrm{O}=\mathrm{C}(/ \mathrm{C}=\mathrm{C} / \mathrm{c} 1 \mathrm{ccc}([\mathrm{N}+](=\mathrm{O})[\mathrm{O}-]) \mathrm{cc} 1) \mathrm{Nc} 1 \mathrm{ccc} 2 \mathrm{ncnc}(\mathrm{Nc} 3 \operatorname{cccc}(\mathrm{Cl}) \mathrm{c} 3) \mathrm{c} 2 \mathrm{c} 1$ & 3450 & 5.46 \\
\hline 4009 & $\mathrm{Cc} 1 \mathrm{ccc}(-\mathrm{n} 2 \mathrm{cc} 3 \mathrm{c}(-\mathrm{c} 4 \mathrm{c}[\mathrm{nH}] \mathrm{c}(-\mathrm{c} 5 \mathrm{ccccc} 5) \mathrm{c} 4-\mathrm{c} 4 \mathrm{ccccc} 4) \mathrm{nnn}(\mathrm{O}) \mathrm{c} 3 \mathrm{n} 2) \mathrm{cc} 1$ & 3450 & $*$ \\
\hline 4010 & $\mathrm{Cc} 1 \operatorname{cccc}(\mathrm{CN}(\mathrm{Cc} 2 \operatorname{ccc}(\mathrm{O}) \mathrm{cc} 2) \mathrm{C}(=\mathrm{S}) \mathrm{Nc} 2 \mathrm{ccccc} 2) \mathrm{c} 1 \mathrm{O}$ & 3460 & 5.46 \\
\hline 4011 & $\mathrm{Cc} 1[\mathrm{nH}] \mathrm{c}(/ \mathrm{C}=\mathrm{C} 2 \backslash \mathrm{C}(=\mathrm{O}) \mathrm{Nc} 3 \operatorname{ccc}(\mathrm{C}(=\mathrm{O}) \mathrm{NNc} 4 \mathrm{ccccc} 4) \mathrm{cc} 32) \mathrm{c}(\mathrm{C}) \mathrm{c} 1 \mathrm{CCC}(=\mathrm{O}) \mathrm{O}$ & 3480 & $*$ \\
\hline 4012 & $\mathrm{O}=\mathrm{C} 1 \mathrm{CSC}(\mathrm{N} 2 \mathrm{~N}=\mathrm{C}(\mathrm{c} 3 \operatorname{ccccc} 3) \mathrm{CC} 2 \mathrm{c} 2 \mathrm{ccc}(\mathrm{Cl}) \mathrm{cc} 2)=\mathrm{N} 1$ & 3490 & 5.46 \\
\hline 4013 & $\mathrm{O}=\mathrm{C}(/ \mathrm{C}=\mathrm{C} / \mathrm{c} 1 \mathrm{ccc}(\mathrm{Br}) \mathrm{cc} 1) \mathrm{Nc} 1 \mathrm{ccc} 2 \mathrm{ncnc}(\mathrm{Nc} 3 \mathrm{cccc}(\mathrm{Cl}) \mathrm{c} 3) \mathrm{c} 2 \mathrm{c} 1$ & 3490 & 5.46 \\
\hline 4014 & $\mathrm{O}=\mathrm{C} 1 \mathrm{NN}(\mathrm{c} 2 \operatorname{ccc}(\mathrm{F}) \mathrm{c}(\mathrm{Cl}) \mathrm{c} 2) \mathrm{C}(=\mathrm{O}) / \mathrm{C} 1=\mathrm{C} 1 \mathrm{c} 1 \operatorname{cccc}(\mathrm{OC}(=\mathrm{O}) \mathrm{c} 2 \mathrm{cccs} 2) \mathrm{c} 1$ & 3500 & 5.46 \\
\hline 4015 & $\mathrm{CCOc} 1 \mathrm{ccc}(\mathrm{C}(=\mathrm{O}) \mathrm{Nc} 2 \mathrm{ccc}(\mathrm{OCc} 3 \operatorname{cccc} 3) \mathrm{c}(\mathrm{Cl}) \mathrm{c} 2) \mathrm{cc} 1 \mathrm{NC}(=\mathrm{O}) \mathrm{c} 1 \mathrm{ccc}(\mathrm{CN} 2 \mathrm{CCN}(\mathrm{C}) \mathrm{CC} 2) \mathrm{cc} 1$ & 3500 & 5.46 \\
\hline 4016 & $\mathrm{CN}(\mathrm{C}) \mathrm{C} / \mathrm{C}=\mathrm{C} / \mathrm{C}(=\mathrm{O}) \mathrm{Nc} 1 \mathrm{ccc}(-\mathrm{c} 2 \mathrm{cncc}(\mathrm{CHN}) \mathrm{c} 2 \mathrm{Nc} 2 \mathrm{ccc}(\mathrm{F}) \mathrm{c}(\mathrm{Cl}) \mathrm{c} 2) \mathrm{cc} 1$ & 3500 & 5.46 \\
\hline 4017 & $\operatorname{Cn} 1 \mathrm{c}([\mathrm{Se}][\mathrm{Se}] \mathrm{c} 2 \mathrm{c}(\mathrm{C}(=\mathrm{O}) \mathrm{O}) \mathrm{c} 3 \operatorname{ccc} c \mathrm{n} 2 \mathrm{C}) \mathrm{c}(\mathrm{C}(=\mathrm{O}) \mathrm{O}) \mathrm{c} 2 \mathrm{ccccc} 21$ & 3500 & $*$ \\
\hline 4018 & $\mathrm{O}=\mathrm{C}(/ \mathrm{C}=\mathrm{C} / \mathrm{c} 1 \mathrm{ccccc} 1) \mathrm{N} 1 \mathrm{CCc} 2 \mathrm{c}(\mathrm{sc} 3 \mathrm{ncnc}(\mathrm{N}[\mathrm{C} @ \mathrm{H}](\mathrm{CO}) \mathrm{c} 4 \mathrm{ccccc} 4) \mathrm{c} 23) \mathrm{C} 1$ & 3503 & $*$ \\
\hline 4019 & 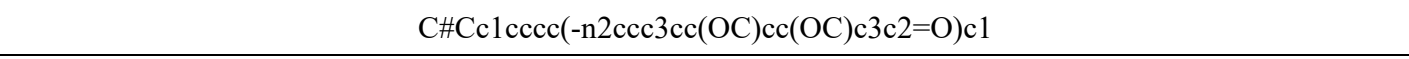 & 3510 & $*$ \\
\hline 4020 & $\mathrm{O}=\mathrm{C}(/ \mathrm{C}=\mathrm{C} / \mathrm{c} 1 \mathrm{ccc} 2 \mathrm{c}(\mathrm{c} 1) \mathrm{OCCCCO} 2) \mathrm{Nc} 1 \mathrm{ccc}(\mathrm{Br}) \mathrm{cc} 1$ & 3520 & $*$ \\
\hline 4021 & $\mathrm{O}=\mathrm{C}(\mathrm{CCCCCC}(=\mathrm{O}) \mathrm{Nc} 1 \mathrm{ccc}(\mathrm{O}) \mathrm{c}(\mathrm{C}(=\mathrm{O}) \mathrm{Nc} 2 \mathrm{ccc}(\mathrm{F}) \mathrm{c}(\mathrm{Cl}) \mathrm{c} 2) \mathrm{c} 1) \mathrm{NO}$ & 3530 & $*$ \\
\hline 4022 & Oc1 $\operatorname{ccccc} 1 \mathrm{CNc} 1 \mathrm{ccc} 2 \mathrm{ncnc}(\mathrm{Nc} 3 \mathrm{cccc}(\mathrm{Cl}) \mathrm{c} 3) \mathrm{c} 2 \mathrm{c} 1$ & 3540 & 5.45 \\
\hline 4023 & $\mathrm{Cc} 1[\mathrm{nH}] \mathrm{c}(-\mathrm{c} 2 \mathrm{ccccc} 2) \mathrm{c}(-\mathrm{c} 2 \mathrm{cccc} 2) \mathrm{c} 1 \mathrm{C}(=\mathrm{O}) \mathrm{c} 1 \mathrm{cn}(-\mathrm{c} 2 \mathrm{cccc} 2) \mathrm{nc} 1 \mathrm{C}(=\mathrm{O}) \mathrm{Nc} 1 \mathrm{ccccc} 1$ & 3560 & $*$ \\
\hline 4024 & $\mathrm{COc} 1 \mathrm{cc} 2 \mathrm{ncnc}(\mathrm{Sc} 3 \operatorname{ccc}(\mathrm{NC}(=\mathrm{S}) \mathrm{Nc} 4 \mathrm{ccc}(\mathrm{Cl}) \mathrm{cc} 4 \mathrm{Cl}) \mathrm{c} 3) \mathrm{c} 2 \mathrm{cc} 1 \mathrm{OC}$ & 3560 & $*$ \\
\hline 4025 & $\operatorname{CCCCCCCCCNC}(=0) \operatorname{COc} 1 \mathrm{cc}(\mathrm{O}) \mathrm{c} 2 \mathrm{c}(=\mathrm{O}) \mathrm{cc}(-\mathrm{c} 3 \mathrm{ccccc} 3) \mathrm{oc} 2 \mathrm{c} 1$ & 3580 & 5.45 \\
\hline 4026 & $\mathrm{CC}(=\mathrm{O}) \mathrm{NC}[\mathrm{C} @ \mathrm{H}] 1 \mathrm{CC}[\mathrm{C} @ \mathrm{H}](\mathrm{c} 2 \mathrm{nc}(-\mathrm{c} 3 \mathrm{cc} 4 \mathrm{ccccc} 4[\mathrm{nH}] 3) \mathrm{c} 3 \mathrm{c}(\mathrm{N}) \mathrm{nccn} 32) \mathrm{CC} 1$ & 3580 & $*$ \\
\hline 4027 & $\mathrm{O}=\mathrm{C}(/ \mathrm{C}=\mathrm{C} / \mathrm{c} 1 \mathrm{cccnc} 1 \mathrm{Cl}) \mathrm{Nc} 1 \mathrm{ccc} 2 \mathrm{ncnc}(\mathrm{Nc} 3 \operatorname{ccc}(\mathrm{Cl}) \mathrm{c} 3) \mathrm{c} 2 \mathrm{c} 1$ & 3600 & 5.44 \\
\hline 4028 & $\operatorname{COc} 1 \operatorname{ccc}(\mathrm{C}(=\mathrm{O}) \mathrm{n} 2 \mathrm{nc}(-\mathrm{c} 3 \operatorname{ccc} n \mathrm{c} 3) \mathrm{nc} 2 \mathrm{~N}) \mathrm{cc} 1$ & 3600 & 5.44 \\
\hline
\end{tabular}




\begin{tabular}{|c|c|c|c|}
\hline 4029 & $\operatorname{COc} 1 \operatorname{ccc} 2 \mathrm{c}(\mathrm{C}(=\mathrm{O}) \mathrm{Nc} 3 \operatorname{ccc} c 3) \mathrm{c}(\mathrm{SSc} 3 \mathrm{c}(\mathrm{C}(=\mathrm{O}) \mathrm{Nc} 4 \operatorname{ccccc} 4) \mathrm{c} 4 \mathrm{ccc}(\mathrm{OC}) \operatorname{cc} 4 \mathrm{n} 3 \mathrm{C}) \mathrm{n}(\mathrm{C}) \mathrm{c} 2 \mathrm{c} 1$ & 3600 & $*$ \\
\hline 4030 & $\mathrm{C}=\mathrm{CC}(=\mathrm{O}) \mathrm{Nc} 1 \mathrm{cccc}(\mathrm{Oc} 2 \mathrm{nc}(\mathrm{Nc} 3 \mathrm{n}[\mathrm{nH}] \mathrm{c} 4 \mathrm{cccc} 34) \operatorname{cc}(\mathrm{N} 3 \mathrm{CCN}(\mathrm{C}(\mathrm{C})=\mathrm{O}) \mathrm{CC} 3) \mathrm{n} 2) \mathrm{c} 1$ & 3600 & $*$ \\
\hline 4031 & Oc1nnc(-c2c[nH]c(-c3eccec 3$) \mathrm{c} 2-\mathrm{c} 2 \mathrm{cccc} 2) \mathrm{c} 2 \mathrm{cn}(-\mathrm{c} 3 \operatorname{ccc} c 3) \mathrm{nc} 12$ & 3600 & $*$ \\
\hline 4032 & $\mathrm{O}=\mathrm{C}(/ \mathrm{C}=\mathrm{C} / \mathrm{c} 1 \mathrm{ccccc} 1) \mathrm{Nc} 1 \mathrm{ccc} 2 \mathrm{ncnc}(\mathrm{Nc} 3 \operatorname{ccc}(\mathrm{Cl}) \mathrm{c} 3) \mathrm{c} 2 \mathrm{c} 1$ & 3610 & 5.44 \\
\hline 4033 & $\operatorname{Cc} 1 \operatorname{lnc}([\mathrm{N}+](=\mathrm{O})[\mathrm{O}-]) \mathrm{n} 1 \mathrm{CCOC}(=\mathrm{O}) / \mathrm{C}=\mathrm{C} / \mathrm{c} 1 \operatorname{ccc}(\mathrm{Cl}) \operatorname{cc} 1$ & 3620 & 5.44 \\
\hline 4034 & $\mathrm{COc} 1 \mathrm{cccc}(-\mathrm{c} 2 \mathrm{nn}(\mathrm{C}(\mathrm{C}) \mathrm{C}) \mathrm{c} 3 \mathrm{ncnc}(\mathrm{N}) \mathrm{c} 23) \mathrm{c} 1 \mathrm{OC}$ & 3660 & $*$ \\
\hline 4035 & $\mathrm{Cc} 1 \mathrm{c}(\mathrm{C}(=\mathrm{O}) \mathrm{c} 2 \cos 3 \operatorname{ccc}(\mathrm{O}) \mathrm{cc} 23)[\mathrm{nH}] \mathrm{c}(-\mathrm{c} 2 \operatorname{ccc} c 2) \mathrm{c} 1-\mathrm{c} 1 \mathrm{ccccc} 1$ & 3670 & $*$ \\
\hline 4036 & $\mathrm{O}=\mathrm{C}(\mathrm{Nc} 1 \mathrm{ccc} 2 \mathrm{ncnc}(\mathrm{Nc} 3 \operatorname{ccc}(\mathrm{Br}) \mathrm{c} 3) \mathrm{c} 2 \mathrm{c} 1) \mathrm{C} 1 \mathrm{COc} 2 \mathrm{cccc} 2 \mathrm{O} 1$ & 3680 & 5.43 \\
\hline 4037 & $\mathrm{C}[\mathrm{C} @ \mathrm{H}](\mathrm{Nc} 1 \mathrm{ncnc} 2 \mathrm{cc} 3 \mathrm{oc}(=\mathrm{O}) \mathrm{n}(\mathrm{CCCN} 4 \mathrm{CCOCC} 4) \mathrm{c} 3 \mathrm{cc} 12) \mathrm{c} 1 \mathrm{ccccc} 1$ & 3700 & $*$ \\
\hline 4038 & $\mathrm{CCC}(=\mathrm{O}) \mathrm{Nc} 1 \mathrm{cccc}(-\mathrm{c} 2 \mathrm{nc}(\mathrm{Nc} 3 \mathrm{cc}[\mathrm{nH}] \mathrm{n} 3) \mathrm{c} 3 \operatorname{ccc} c \mathrm{n} 2) \mathrm{c} 1$ & 3700 & $*$ \\
\hline 4039 & COc1cccc1Nc1ncnc2cc(N)ncc12 & 3710 & $*$ \\
\hline 4040 & $\mathrm{COc} 1 \mathrm{cc} 2 \mathrm{ncnc}(\mathrm{Nc} 3 \operatorname{ccc} c 3 \mathrm{~N}) \mathrm{c} 2 \mathrm{cn} 1$ & 3715.35 & $*$ \\
\hline 4041 & $\mathrm{CC}(\mathrm{C}) \mathrm{n} 1 \mathrm{nc}(-\mathrm{c} 2 \mathrm{cccc}(\mathrm{O}) \mathrm{c} 2 \mathrm{~F}) \mathrm{c} 2 \mathrm{c}(\mathrm{N}) \mathrm{ncnc} 21$ & 3720 & $*$ \\
\hline 4042 & $\mathrm{NC}(=\mathrm{S}) \mathrm{N} / \mathrm{N}=\mathrm{C}(/ \mathrm{C}=\mathrm{C} / \mathrm{c} 1 \operatorname{cccc}([\mathrm{N}+](=\mathrm{O})[\mathrm{O}-]) \mathrm{c} 1) \mathrm{c} 1 \mathrm{ccccc} 1$ & 3740 & 5.43 \\
\hline 4043 & $\mathrm{CC} \# \mathrm{CC}(=\mathrm{O}) \mathrm{Nc} 1 \mathrm{cnc} 2 \mathrm{ncc}(\mathrm{CHN}) \mathrm{c}(\mathrm{Nc} 3 \mathrm{ccc}(\mathrm{F}) \mathrm{c}(\mathrm{Cl}) \mathrm{c} 3) \mathrm{c} 2 \mathrm{c} 1$ & 3762.4 & 5.42 \\
\hline 4044 & $\mathrm{Cc} 1[\mathrm{nH}] \mathrm{c}(-\mathrm{c} 2 \operatorname{ccccc} 2) \mathrm{c}(-\mathrm{c} 2 \operatorname{ccccc} 2) \mathrm{c} 1 \mathrm{C}(=\mathrm{O}) \mathrm{c} 1 \mathrm{cn}(-\mathrm{c} 2 \operatorname{ccc}(\mathrm{Cl}) \mathrm{cc} 2) \mathrm{nc} 1 \mathrm{C}(=\mathrm{O}) \mathrm{Nc} 1 \mathrm{ccccc} 1$ & 3780 & $*$ \\
\hline 4045 & $\mathrm{Cc} 1[\mathrm{nH}] \mathrm{c}(\mathrm{C}=\mathrm{C} 2 \backslash \mathrm{C}(=\mathrm{O}) \mathrm{Nc} 3 \operatorname{ccc}(\mathrm{S}(=\mathrm{O})(=\mathrm{O}) \mathrm{Cc} 4 \mathrm{c}(\mathrm{Cl}) \mathrm{cccc} 4 \mathrm{Cl}) \mathrm{cc} 32) \mathrm{c}(\mathrm{C}) \mathrm{c} 1 \mathrm{C}(=\mathrm{O}) \mathrm{N} 1 \mathrm{CCC}[\mathrm{C} @ @ \mathrm{H}] 1 \mathrm{CN} 1 \mathrm{CCCC} 1$ & 3800 & $*$ \\
\hline 4046 & $\mathrm{COc} 1 \mathrm{cc} 2 \mathrm{ncc}(\mathrm{C \# N}) \mathrm{c}(\mathrm{Nc} 3 \mathrm{cccc}(\mathrm{Br}) \mathrm{c} 3) \mathrm{c} 2 \mathrm{cc} 1 \mathrm{NC}(=\mathrm{O}) / \mathrm{C}=\mathrm{C} / \mathrm{CN} 1 \mathrm{CCOCC} 1$ & 3830 & 5.42 \\
\hline 4047 & $\mathrm{Cc} 1 \operatorname{ccc}(\mathrm{C} 2=\mathrm{NN}(\mathrm{c} 3 \mathrm{nc}(-\mathrm{c} 4 \operatorname{cccc} 4) \operatorname{cs} 3) \mathrm{C}(\mathrm{c} 3 \operatorname{ccc}([\mathrm{N}+](=\mathrm{O})[\mathrm{O}-]) \operatorname{cc} 3) \mathrm{C} 2) \operatorname{cc} 1 \mathrm{C}$ & 3850 & 5.41 \\
\hline 4048 & $\operatorname{COc} 1 \mathrm{cc}(-\mathrm{c} 2 \mathrm{nn}(\mathrm{C}(\mathrm{C}) \mathrm{C}) \mathrm{c} 3 \mathrm{ncnc}(\mathrm{N}) \mathrm{c} 23) \mathrm{ccc} 1 \mathrm{~N}$ & 3850 & $*$ \\
\hline 4049 & $\operatorname{COc} 1 \mathrm{cc}(-\mathrm{c} 2 \mathrm{nn}(\mathrm{C}(\mathrm{C}) \mathrm{C}) \mathrm{c} 3 \mathrm{ncnc}(\mathrm{N}) \mathrm{c} 23) \mathrm{ccc} 1 \mathrm{~F}$ & 3860 & $*$ \\
\hline 4050 & $\mathrm{Cc} 1 \mathrm{ccc}(\mathrm{C} 2=\mathrm{NN}(\mathrm{C}(\mathrm{N})=\mathrm{S}) \mathrm{C}(\mathrm{c} 3 \operatorname{ccccc} 3 \mathrm{Cl}) \mathrm{C} 2) \mathrm{cc} 1 \mathrm{C}$ & 3870 & 5.41 \\
\hline 4051 & $\mathrm{Cc} 1 \mathrm{ncc}([\mathrm{N}+](=\mathrm{O})[\mathrm{O}-]) \mathrm{n} 1 \mathrm{CCOC}(=\mathrm{O}) / \mathrm{C}=\mathrm{C} / \operatorname{c} 1 \operatorname{cccc} 2 \operatorname{ccccc} 12$ & 3880 & 5.41 \\
\hline 4052 & Brc1 $1 \mathrm{c} 2 \mathrm{c}(\mathrm{NCc} 3 \mathrm{ccncc} 3) \mathrm{ncnc} 2 \mathrm{~s} 1$ & 3883 & * \\
\hline 4053 & $\mathrm{Cc} 1[\mathrm{nH}] \mathrm{c}(-\mathrm{c} 2 \mathrm{ccccc} 2) \mathrm{c}(-\mathrm{c} 2 \operatorname{ccccc} 2) \mathrm{c} 1-\mathrm{c} 1 \mathrm{nnn}(\mathrm{C}) \mathrm{c} 2 \mathrm{nn}(-\mathrm{c} 3 \operatorname{ccccc} 3) \mathrm{cc} 12$ & 3890 & $*$ \\
\hline 4054 & $\mathrm{COc} 1 \mathrm{cc}(/ \mathrm{C}=\mathrm{C} 2 \backslash \mathrm{CCC} / \mathrm{C}(=\mathrm{C} \backslash \mathrm{c} 3 \operatorname{ccc}(\mathrm{N}(\mathrm{C}) \mathrm{C}) \mathrm{cc} 3) \mathrm{C} 2=\mathrm{O}) \mathrm{cc}(\mathrm{OC}) \mathrm{c} 1$ & 3900 & 5.40 \\
\hline 4055 & $\mathrm{Cc} 1 \mathrm{ccc}(\mathrm{C}(=\mathrm{O}) \mathrm{Nc} 2 \operatorname{ccc}(\mathrm{CN} 3 \mathrm{CCN}(\mathrm{C}) \mathrm{CC} 3) \mathrm{c}(\mathrm{C}(\mathrm{F})(\mathrm{F}) \mathrm{F}) \mathrm{c} 2) \operatorname{cc} 1 \mathrm{NC}(=\mathrm{O}) \mathrm{c} 1 \mathrm{cnc} n 1$ & 3900 & 5.41 \\
\hline 4056 & $\mathrm{CCC} 1=\mathrm{C} 2 \mathrm{C}=\mathrm{C}(\mathrm{C}(\mathrm{F})(\mathrm{F}) \mathrm{F}) \mathrm{C}=\mathrm{CC} 2 \mathrm{~N} 2 \mathrm{C}=\mathrm{C}(\mathrm{Cc} 3 \operatorname{ccccc} 3) \mathrm{NC}(=\mathrm{O}) \mathrm{C} 12$ & 3900 & 5.41 \\
\hline 4057 & CCCOc1cc2ncnc(Nc3ecc $(\mathrm{NC}(=\mathrm{O}) \mathrm{OCC}) \mathrm{c}(\mathrm{C}) \mathrm{c} 3) \mathrm{c} 2 \mathrm{cc} 1 \mathrm{OC} . \mathrm{Cl}$ & 3900 & $*$ \\
\hline 4058 & $\mathrm{CN}(\mathrm{C}) \mathrm{CC}(\mathrm{CNNC}(\mathrm{N})=\mathrm{O}) \mathrm{C}(=\mathrm{O}) \mathrm{c} 1 \mathrm{ccc}(\mathrm{OCc} 2 \operatorname{cccc} 2) \operatorname{cc} 1 . \mathrm{Cl}$ & 3900 & $*$ \\
\hline 4059 & $\mathrm{Cc} 1 \mathrm{cc}(\mathrm{Nc} 2 \mathrm{cc}(\mathrm{N} 3 \mathrm{CCN}(\mathrm{C}) \mathrm{CC} 3) \mathrm{nc}(\mathrm{Oc} 3 \operatorname{cccc}([\mathrm{N}+](=\mathrm{O})[\mathrm{O}-]) \mathrm{c} 3) \mathrm{n} 2) \mathrm{n}[\mathrm{nH}] 1$ & 3900 & $*$ \\
\hline 4060 & $\mathrm{Cc} 1 \mathrm{nc}(\mathrm{C}) \mathrm{c}(\mathrm{C}=\mathrm{C} 2 \mathrm{CN}(\mathrm{C}(\mathrm{C}) \mathrm{C}) \mathrm{CC}(=\mathrm{C} / \mathrm{c} 3 \mathrm{nc}(\mathrm{C}) \mathrm{c}(\mathrm{C}) \mathrm{nc} 3 \mathrm{C}) / \mathrm{C} 2=\mathrm{N} / \mathrm{O}) \mathrm{nc} 1 \mathrm{C}$ & 3900 & $*$ \\
\hline 4061 & $\mathrm{Cc} 1 \mathrm{ccc} 2 \mathrm{c}(\mathrm{C}) \mathrm{nc}(\mathrm{Nc} 3 \mathrm{nc}(\mathrm{O}) \mathrm{cc}(\mathrm{CSc} 4 \mathrm{nnnn} 4-\mathrm{c} 4 \mathrm{ccccc} 4) \mathrm{n} 3) \mathrm{nc} 2 \mathrm{c} 1$ & 3920 & $*$ \\
\hline 4062 & $\mathrm{O}=\mathrm{C}(\mathrm{Nc} 1 \mathrm{ccc}(\mathrm{Nc} 2 \mathrm{ncnc} 3 \mathrm{sc} 4 \mathrm{c}(\mathrm{c} 23) \mathrm{CCCC} 4) \mathrm{cc} 1) \mathrm{Nc} 1 \mathrm{cccc}(\mathrm{Br}) \mathrm{c} 1$ & 3950 & $*$ \\
\hline 4063 & $\mathrm{Cc} 1 \mathrm{ccc}(\mathrm{C} 2=\mathrm{NN}(\mathrm{C} 3=\mathrm{NC}(\mathrm{c} 4 \operatorname{ccccc} 4) \mathrm{CS} 3) \mathrm{C}(\mathrm{c} 3 \operatorname{cccc} 4 \operatorname{ccccc} 34) \mathrm{C} 2) \mathrm{cc} 1 \mathrm{C}$ & 3960 & 5.40 \\
\hline 4064 & $\mathrm{COc} 1 \mathrm{ccc}(\mathrm{N}(\mathrm{CCCl}) \mathrm{CCNN}=\mathrm{Nc} 2 \mathrm{ccc} 3 \mathrm{ncnc}(\mathrm{Nc} 4 \mathrm{cccc}(\mathrm{Cl}) \mathrm{c} 4) \mathrm{c} 3 \mathrm{c} 2) \mathrm{cc} 1$ & 3960 & $*$ \\
\hline 4065 & $\mathrm{COC}(=\mathrm{O}) \mathrm{Nc} 1 \mathrm{ccc}(\mathrm{Nc} 2 \mathrm{ncnc} 3 \mathrm{cc}(\mathrm{OC}) \mathrm{c}(\mathrm{OC}) \mathrm{cc} 23) \mathrm{cc} 1 \mathrm{C} . \mathrm{Cl}$ & 4000 & $*$ \\
\hline 4066 & $\mathrm{COC}(=\mathrm{O}) \mathrm{Nc} 1 \mathrm{ccc}(\mathrm{Nc} 2 \mathrm{ncnc} 3 \mathrm{cc}(\mathrm{OC}) \mathrm{c}(\mathrm{OC}) \mathrm{cc} 23) \mathrm{cc} 1 \mathrm{C}$ & 4000 & * \\
\hline 4067 & $\mathrm{~N} \# \mathrm{C} / \mathrm{C}(=\mathrm{C} \backslash \mathrm{c} 1 \mathrm{ccc}(\mathrm{O}) \mathrm{c}(\mathrm{O}) \mathrm{c} 1) \mathrm{C}(\mathrm{N})=\mathrm{O}$ & 4000 & $*$ \\
\hline 4068 & $\operatorname{CCOP}(=\mathrm{O})(\mathrm{Cc} 1 \mathrm{cc}(\mathrm{NCc} 2 \mathrm{cc}(\mathrm{O}) \mathrm{ccc} 2 \mathrm{O}) \mathrm{ccc} 1 \mathrm{O}) \mathrm{OCC}$ & 4000 & $*$ \\
\hline 4069 & $\mathrm{COc} 1 \mathrm{cc} 2 \mathrm{ncnc}(\mathrm{N}(\mathrm{C}) \mathrm{c} 3 \mathrm{ccccc} 3) \mathrm{c} 2 \mathrm{cc} 1 \mathrm{OC} . \mathrm{Cl}$ & 4000 & $*$ \\
\hline 4070 & $\mathrm{CNC}(=\mathrm{O}) \operatorname{c} 1 \operatorname{ccc}(\mathrm{S}(=\mathrm{O})(=\mathrm{O}) \mathrm{Oc} 2 \operatorname{ccc}(/ \mathrm{C}=\mathrm{C}(\backslash \mathrm{C})[\mathrm{N}+](=\mathrm{O})[\mathrm{O}-]) \operatorname{cc} 2 \mathrm{OC}) \operatorname{cc} 1$ & 4000 & $*$ \\
\hline 4071 & $\mathrm{COc} 1 \mathrm{cc} 2 \mathrm{ncnc}(\mathrm{N}(\mathrm{C}) \mathrm{c} 3 \mathrm{ccc}(\mathrm{C}) \mathrm{cc} 3) \mathrm{c} 2 \mathrm{cc} 1 \mathrm{OC} . \mathrm{Cl}$ & 4000 & $*$ \\
\hline
\end{tabular}




\begin{tabular}{|c|c|c|c|}
\hline 4072 & $\mathrm{COc} 1 \mathrm{cc}(\mathrm{O}) \mathrm{c} 2 \mathrm{c}(=\mathrm{O}) \mathrm{c}(-\mathrm{c} 3 \operatorname{ccc}(\mathrm{Cl}) \mathrm{c} 3) \mathrm{cn}(\mathrm{CCc} 3 \operatorname{ccc} c 3) \mathrm{c} 2 \mathrm{c} 1$ & 4000 & $*$ \\
\hline 4073 & $\mathrm{O}=[\mathrm{N}+]([\mathrm{O}-]) \mathrm{c} 1 \mathrm{cccc}(\mathrm{Oc} 2 \mathrm{ccnc}(\mathrm{Nc} 3 \operatorname{ccc} c 3 \mathrm{O}) \mathrm{n} 2) \mathrm{c} 1$ & 4000 & $*$ \\
\hline 4074 & $\mathrm{C}=\mathrm{CC}(=\mathrm{O}) \mathrm{NCc} 1 \mathrm{cccc}(-\mathrm{c} 2 \mathrm{nc}(\mathrm{C} 3 \mathrm{CC} 3) \mathrm{c}(-\mathrm{c} 3 \mathrm{ccnc} 4[\mathrm{nH}] \mathrm{c}(-\mathrm{c} 5 \mathrm{cccc} 5) \mathrm{cc} 34)[\mathrm{nH}] 2) \mathrm{c} 1$ & 4050 & $*$ \\
\hline 4075 & $\mathrm{Clc} 1 \mathrm{ccc}(\mathrm{Nc} 2 \mathrm{ncnc} 3 \operatorname{ccc}(\mathrm{NCc} 4 \mathrm{ccc}(\mathrm{Br}) \mathrm{n} 4) \mathrm{cc} 23) \mathrm{c} 1$ & 4100 & 5.39 \\
\hline 4076 & $\mathrm{O}=\mathrm{C}(\mathrm{O}) \mathrm{c} 1 \mathrm{cc}(\mathrm{N}(\mathrm{Cc} 2 \operatorname{ccc} c 2 \mathrm{O}) \mathrm{Cc} 2 \mathrm{cc}(\mathrm{O}) \operatorname{ccc} 2 \mathrm{O}) \operatorname{ccc} 1 \mathrm{O}$ & 4100 & $*$ \\
\hline 4077 & $\mathrm{c} 1 \mathrm{ccc}(\mathrm{CCNc} 2 \mathrm{ncnc} 3 \operatorname{ccc} c 23) \mathrm{cc} 1$ & 4100 & $*$ \\
\hline 4078 & $\mathrm{CCN}(\mathrm{CC}) \mathrm{CCn} 1 \mathrm{c} 2 \mathrm{ccccc} 2 \mathrm{c} 2 \mathrm{c}(\mathrm{Nc} 3 \operatorname{ccc}(\mathrm{Br}) \mathrm{c} 3) \mathrm{ncnc} 21$ & 4100 & $*$ \\
\hline 4079 & $\mathrm{CN}(\mathrm{C}) \mathrm{CCCC}(=\mathrm{O}) \mathrm{Nc} 1 \mathrm{ccc} 2 \mathrm{c}(\mathrm{CHN}) \mathrm{cnc}(\mathrm{Nc} 3 \mathrm{cccc}(\mathrm{Br}) \mathrm{c} 3) \mathrm{c} 2 \mathrm{c} 1$ & 4100 & $*$ \\
\hline 4080 & $\mathrm{CCN}(\mathrm{CC}) \mathrm{CCn} 1 \mathrm{c} 2 \operatorname{ccccc} 2 \mathrm{c} 2 \mathrm{c}(\mathrm{Nc} 3 \operatorname{ccc}(\mathrm{Br}) \mathrm{c} 3) \mathrm{ncnc} 21 . \mathrm{Cl}$ & 4100 & $*$ \\
\hline 4081 & $\operatorname{Cc} 1 \operatorname{lncc}([\mathrm{N}+](=\mathrm{O})[\mathrm{O}-]) \mathrm{n} 1 \mathrm{CCOC}(=\mathrm{O}) / \mathrm{C}=\mathrm{C} / \mathrm{c} 1 \mathrm{ccc}(\mathrm{F}) \mathrm{cc} 1$ & 4120 & 5.39 \\
\hline 4082 & $\mathrm{O}=\mathrm{C} 1 \mathrm{CSC}(\mathrm{N} 2 \mathrm{~N}=\mathrm{C}(\mathrm{c} 3 \mathrm{ccc}(\mathrm{Br}) \mathrm{cc} 3) \mathrm{CC} 2 \mathrm{c} 2 \mathrm{ccc}(\mathrm{Cl}) \mathrm{cc} 2)=\mathrm{N} 1$ & 4120 & 5.39 \\
\hline 4083 & $\mathrm{Cc} 1 \mathrm{ncnc}(\mathrm{Nc} 2 \mathrm{ccc}(\mathrm{OCc} 3 \operatorname{ccc}(\mathrm{F}) \mathrm{c} 3) \mathrm{c}(\mathrm{Cl}) \mathrm{c} 2) \mathrm{c} 1 \mathrm{C} \# \mathrm{CCN} 1 \mathrm{CCOCC} 1$ & 4130 & 5.38 \\
\hline 4084 & $\mathrm{Cc} 1 \mathrm{nn}(-\mathrm{c} 2 \mathrm{ccc}(\mathrm{Cl}) \mathrm{cc} 2) \mathrm{c}(\mathrm{Cl}) \mathrm{c} 1 \mathrm{C} 1 \mathrm{C}(\mathrm{C} \# \mathrm{~N})=\mathrm{C}(\mathrm{N}) \mathrm{N}(\mathrm{c} 2 \mathrm{ccc} n \mathrm{c} 2) \mathrm{C} 2=\mathrm{C} 1 \mathrm{C}(=\mathrm{O}) \mathrm{CCC} 2$ & 4150 & 5.38 \\
\hline 4085 & $\mathrm{O}=\mathrm{C}(\mathrm{Nc} 1 \mathrm{ccccc} 1) \mathrm{N}(\mathrm{Cc} 1 \mathrm{ccc}(\mathrm{F}) \mathrm{cc} 1) \mathrm{Cc} 1 \mathrm{cc}(\mathrm{Cl}) \mathrm{cc}(\mathrm{Cl}) \mathrm{c} 1 \mathrm{O}$ & 4150 & 5.38 \\
\hline 4086 & $\mathrm{COc} 1 \mathrm{cc} 2 \mathrm{ncnc}(\mathrm{Oc} 3 \operatorname{cccc}(\mathrm{NC}(=\mathrm{S}) \mathrm{Nc} 4 \mathrm{ccc}(\mathrm{Cl}) \mathrm{cc} 4) \mathrm{c} 3) \mathrm{c} 2 \mathrm{cc} 1 \mathrm{OC}$ & 4170 & $*$ \\
\hline 4087 & $\mathrm{COc} 1 \mathrm{cc} 2 \mathrm{ncc}(\mathrm{CHN}) \mathrm{c}(\mathrm{Nc} 3 \mathrm{ccccc} 3 \mathrm{Br}) \mathrm{c} 2 \mathrm{cc} 1 \mathrm{OC}$ & 4180 & $*$ \\
\hline 4088 & $\mathrm{O}=\mathrm{C}(\mathrm{O}) \mathrm{CCc} 1 \mathrm{c}(\mathrm{SSc} 2[\mathrm{nH}] \mathrm{c} 3 \operatorname{ccc} c 3 \mathrm{c} 2 \mathrm{CCC}(=\mathrm{O}) \mathrm{O})[\mathrm{nH}] \mathrm{c} 2 \operatorname{ccccc} 12$ & 4200 & $*$ \\
\hline 4089 & $\operatorname{CONC}(=\mathrm{O}) \mathrm{c} 1 \mathrm{cc}(\mathrm{Nc} 2 \mathrm{ncnn} 3 \mathrm{cc}(\mathrm{NC}(=\mathrm{O}) \mathrm{OCCCS}(\mathrm{C})(=\mathrm{O})=\mathrm{O}) \mathrm{c}(\mathrm{C}(\mathrm{C}) \mathrm{C}) \mathrm{c} 23) \mathrm{c}(\mathrm{F}) \mathrm{cc} 1 \mathrm{~F}$ & 4200 & $*$ \\
\hline 4090 & $\mathrm{O}=\mathrm{C}(\mathrm{CCCCCC}(=\mathrm{O}) \mathrm{Nc} 1 \operatorname{ccc}(\mathrm{O}) \mathrm{c}(\mathrm{C}(=\mathrm{O}) \mathrm{Nc} 2 \operatorname{cccc}(\mathrm{C}(\mathrm{F})(\mathrm{F}) \mathrm{F}) \mathrm{c} 2) \mathrm{c} 1) \mathrm{NO}$ & 4200 & $*$ \\
\hline 4091 & $\mathrm{Cc} 1 \mathrm{ccc}(\mathrm{C} 2=\mathrm{NN}(\mathrm{C}(\mathrm{N})=\mathrm{S}) \mathrm{C}(\mathrm{c} 3 \operatorname{ccccc} 3 \mathrm{Br}) \mathrm{C} 2) \mathrm{cc} 1 \mathrm{C}$ & 4210 & 5.38 \\
\hline 4092 & $\mathrm{COc} 1 \operatorname{ccc}(\mathrm{C} 2 \mathrm{CC}(\mathrm{c} 3 \operatorname{ccc}(\mathrm{C}) \mathrm{cc} 3)=\mathrm{NN} 2 \mathrm{C} 2=\mathrm{NC}(=\mathrm{O}) \mathrm{CS} 2) \mathrm{cc} 1$ & 4240 & 5.37 \\
\hline 4093 & $\mathrm{Nc} 1 \mathrm{cc} 2 \mathrm{ncnc}(\mathrm{NCc} 3 \operatorname{cccc} 3[\mathrm{~N}+](=\mathrm{O})[\mathrm{O}-]) \mathrm{c} 2 \mathrm{cn} 1$ & 4250 & $*$ \\
\hline 4094 & $\mathrm{COc} 1 \operatorname{ccc}(\mathrm{C} 2 \mathrm{CC}(\mathrm{c} 3 \operatorname{ccccc} 3)=\mathrm{NN} 2 \mathrm{C} 2=\mathrm{NC}(=\mathrm{O}) \mathrm{CS} 2) \mathrm{cc} 1$ & 4270 & 5.37 \\
\hline 4095 & $\mathrm{CCN}(\mathrm{CC}) \mathrm{CCn} 1 \mathrm{c} 2 \mathrm{ccc}(\mathrm{OC}) \mathrm{cc} 2 \mathrm{c} 2 \mathrm{c}(\mathrm{Nc} 3 \mathrm{cccc}(\mathrm{Br}) \mathrm{c} 3) \mathrm{ncnc} 21$ & 4270 & $*$ \\
\hline 4096 & $\mathrm{CCN}(\mathrm{CC}) \mathrm{CCn} 1 \mathrm{c} 2 \mathrm{ccc}(\mathrm{OC}) \mathrm{cc} 2 \mathrm{c} 2 \mathrm{c}(\mathrm{Nc} 3 \mathrm{ccc}(\mathrm{Br}) \mathrm{c} 3) \mathrm{ncnc} 21 . \mathrm{Cl}$ & 4270 & $*$ \\
\hline 4097 & $\mathrm{O}=\mathrm{C}(/ \mathrm{C}=\mathrm{C} / \mathrm{c} 1 \mathrm{cccc} 1 \mathrm{Br}) \mathrm{Nc} 1 \mathrm{ccc} 2 \mathrm{ncnc}(\mathrm{Nc} 3 \operatorname{ccc}(\mathrm{Br}) \mathrm{c} 3) \mathrm{c} 2 \mathrm{c} 1$ & 4280 & 5.37 \\
\hline 4098 & $\mathrm{CN}(\mathrm{C}) \mathrm{CCN}(\mathrm{C}) \mathrm{CC}(=\mathrm{O}) \mathrm{Nc} 1 \mathrm{cc} 2 \mathrm{c}(\mathrm{Nc} 3 \mathrm{ccc}(\mathrm{F}) \mathrm{c}(\mathrm{Cl}) \mathrm{c} 3) \mathrm{ncnc} 2 \mathrm{~s} 1$ & 4286 & $*$ \\
\hline 4099 & $\mathrm{COC}(=\mathrm{O}) \mathrm{C} 1=\mathrm{C}(\mathrm{N}) \mathrm{N}(\mathrm{c} 2 \mathrm{cccnc} 2) \mathrm{C} 2=\mathrm{C}(\mathrm{C}(=\mathrm{O}) \mathrm{CCC} 2) \mathrm{C} 1 \mathrm{c} 1 \mathrm{cc} 2 \mathrm{cc}(\mathrm{C}) \mathrm{ccc} 2 \mathrm{n} 2 \mathrm{nnnc} 12$ & 4300 & 5.37 \\
\hline 4100 & $\mathrm{COc} 1 \operatorname{ccc} 2 \mathrm{c} 1 \mathrm{C}(=\mathrm{O}) \operatorname{c} 1 \mathrm{c}(\mathrm{O}) \operatorname{ccc}(\mathrm{O}) \mathrm{c} 1 \mathrm{C} 2=\mathrm{O}$ & 4300 & * \\
\hline 4101 & $\mathrm{COc} 1 \mathrm{cc} 2 \mathrm{nc}(\mathrm{Cl}) \mathrm{nc}(\mathrm{Nc} 3 \mathrm{ccc}(\mathrm{O}) \mathrm{cc} 3) \mathrm{c} 2 \mathrm{cc} 1 \mathrm{OC}$ & 4300 & $*$ \\
\hline 4102 & $\mathrm{~N} \# \mathrm{C} / \mathrm{C}(=\mathrm{Clc} 1 \mathrm{ccc}(\mathrm{O}) \mathrm{c}(\mathrm{O}) \mathrm{c} 1) \mathrm{C}(=\mathrm{O}) \mathrm{N} 1 \mathrm{CCN}(\mathrm{c} 2 \mathrm{ccccc} 2) \mathrm{CC} 1$ & 4300 & $*$ \\
\hline 4103 & $\mathrm{Cn} 1 \mathrm{c}(\mathrm{SSc} 2 \mathrm{c}(\mathrm{C}(=\mathrm{O}) \mathrm{Nc} 3 \operatorname{cccc} 3) \mathrm{c} 3 \mathrm{cc}(\mathrm{Cl}) \operatorname{ccc} 3 \mathrm{n} 2 \mathrm{C}) \mathrm{c}(\mathrm{C}(=\mathrm{O}) \mathrm{Nc} 2 \mathrm{cccc} 2) \mathrm{c} 2 \mathrm{cc}(\mathrm{Cl}) \operatorname{ccc} 21$ & 4300 & $*$ \\
\hline 4104 & $\mathrm{COc} 1 \mathrm{ccc}(-\mathrm{c} 2 \mathrm{nn}(\mathrm{C}(\mathrm{C}) \mathrm{C}) \mathrm{c} 3 \mathrm{n} \mathrm{cnc}(\mathrm{N}) \mathrm{c} 23) \mathrm{cc} 1$ & 4300 & $*$ \\
\hline 4105 & $\begin{array}{c}\mathrm{Cc} 1 \mathrm{nc}(\mathrm{Nc} 2 \mathrm{ncc}(\mathrm{C}(=\mathrm{O}) \mathrm{Nc} 3 \mathrm{c}(\mathrm{C}) \mathrm{cccc} 3 \mathrm{Cl}) \mathrm{s} 2) \mathrm{cc}(\mathrm{N} 2 \mathrm{CCN}(\mathrm{CCOC}(=\mathrm{O}) \mathrm{c} 3 \operatorname{ccc}(\mathrm{C}(=\mathrm{O}) \mathrm{Nc} 4 \operatorname{ccc} 5 \mathrm{ncnc}(\mathrm{Nc} 6 \mathrm{cccc}(\mathrm{Cl}) \mathrm{c} 6) \mathrm{c} 5 \mathrm{c} \\
4) \mathrm{nc} 3) \mathrm{CC} 2) \mathrm{n} 1\end{array}$ & 4300 & $*$ \\
\hline 4106 & COCOc1cc(-c2nn $(\mathrm{C}(\mathrm{C}) \mathrm{C}) \mathrm{c} 3 \mathrm{ncnc}(\mathrm{N}) \mathrm{c} 23) \mathrm{ccc} 1 \mathrm{Br}$ & 4320 & $*$ \\
\hline 4107 & $\mathrm{CN}(\mathrm{C}) \mathrm{CCCCCC}(=\mathrm{O}) \mathrm{Nc} 1 \mathrm{cccc}(-\mathrm{c} 2 \mathrm{c}(-\mathrm{c} 3 \operatorname{ccccc} 3) \mathrm{oc} 3 \mathrm{ncnc}(\mathrm{N}[\mathrm{C} @ \mathrm{H}](\mathrm{CO}) \mathrm{c} 4 \mathrm{cccc} 4) \mathrm{c} 23) \mathrm{c} 1$ & 4327 & $*$ \\
\hline 4108 & $\mathrm{O}=\mathrm{C}(\mathrm{Nc} 1 \mathrm{ccccc} 1 \mathrm{Cl}) \mathrm{c} 1 \mathrm{cc}(\mathrm{I}) \mathrm{ccc} 1 \mathrm{O}$ & 4370 & $*$ \\
\hline 4109 & Oc1nnc(-c2c[nH]c(-c3eccec 3$) \mathrm{c} 2-\mathrm{c} 2 \operatorname{ccc} c \mathrm{c} 2) \mathrm{c} 2 \mathrm{cn}(-\mathrm{c} 3 \operatorname{ccc}(\mathrm{Cl}) \mathrm{cc} 3) \mathrm{nc} 12$ & 4390 & $*$ \\
\hline 4110 & $\mathrm{CCCCNc} 1 \mathrm{ncc} 2 \mathrm{cc}(-\mathrm{c} 3 \mathrm{c}(\mathrm{Cl}) \mathrm{cccc} 3 \mathrm{Cl}) \mathrm{c}(=\mathrm{O}) \mathrm{n}(\mathrm{C}) \mathrm{c} 2 \mathrm{n} 1$ & 4400 & * \\
\hline 4111 & $\mathrm{CC}(\mathrm{C}) \mathrm{n} 1 \mathrm{nc}(-\mathrm{c} 2 \mathrm{cc} 3 \mathrm{cc}(\mathrm{O}) \mathrm{ccc} 3[\mathrm{nH}] 2) \mathrm{c} 2 \mathrm{c}(\mathrm{N}) \mathrm{ncnc} 21$ & 4400 & $*$ \\
\hline 4112 & $\mathrm{Clc} 1 \mathrm{ccc}(\mathrm{CNc} 2 \mathrm{ccc} 3 \mathrm{ncnc}(\mathrm{Nc} 4 \mathrm{cccc}(\mathrm{Cl}) \mathrm{c} 4) \mathrm{c} 3 \mathrm{c} 2) \mathrm{cc} 1$ & 4410 & 5.36 \\
\hline 4113 & $\mathrm{CC}(=\mathrm{O}) \mathrm{c} 1 \mathrm{nn}(-\mathrm{c} 2 \mathrm{ccc}(\mathrm{Cl}) \mathrm{cc} 2) \mathrm{cc} 1 \mathrm{C}(=\mathrm{O}) \mathrm{c} 1 \mathrm{c}(\mathrm{C})[\mathrm{nH}] \mathrm{c}(-\mathrm{c} 2 \mathrm{ccccc} 2) \mathrm{c} 1-\mathrm{c} 1 \mathrm{cccc} 1$ & 4480 & $*$ \\
\hline
\end{tabular}




\begin{tabular}{|c|c|c|c|}
\hline 4114 & $\mathrm{Cc} 1 \mathrm{ccc}(-\mathrm{n} 2 \mathrm{cc}(\mathrm{C}(=\mathrm{O}) \mathrm{c} 3 \mathrm{c}(\mathrm{C})[\mathrm{nH}] \mathrm{c}(-\mathrm{c} 4 \mathrm{cccc} 4) \mathrm{c} 3-\mathrm{c} 3 \operatorname{ccc} c 3) \mathrm{c}(\mathrm{C}(=\mathrm{O}) \mathrm{Nc} 3 \operatorname{ccc} \mathrm{c} 3) \mathrm{n} 2) \mathrm{cc} 1$ & 4490 & $*$ \\
\hline 4115 & $\mathrm{CCOc} 1 \mathrm{cc}(\mathrm{N}) \mathrm{c}(\mathrm{C}(=\mathrm{O}) \mathrm{Nc} 2 \operatorname{ccc}(\mathrm{F}) \mathrm{c}(\mathrm{Cl}) \mathrm{c} 2) \mathrm{cc} 1 \mathrm{NC}(=\mathrm{O}) / \mathrm{C}=\mathrm{C} / \mathrm{CN}(\mathrm{C}) \mathrm{C}$ & 4500 & 5.35 \\
\hline 4116 & $\mathrm{C}[\mathrm{C} @ @ \mathrm{H}](\mathrm{Nc} 1 \mathrm{ncnc} 2 \mathrm{cc} 3 \mathrm{oc}(=\mathrm{O}) \mathrm{n}(\mathrm{CCCN} 4 \mathrm{CCOCC} 4) \mathrm{c} 3 \mathrm{cc} 12) \mathrm{c} 1 \mathrm{ccccc} 1$ & 4500 & $*$ \\
\hline 4117 & $\mathrm{CCNc} 1 \mathrm{ncc} 2 \mathrm{cc}(-\mathrm{c} 3 \mathrm{c}(\mathrm{Cl}) \mathrm{cccc} 3 \mathrm{Cl}) \mathrm{c}(=\mathrm{O}) \mathrm{n}(\mathrm{C}) \mathrm{c} 2 \mathrm{n} 1$ & 4500 & $*$ \\
\hline 4118 & $\mathrm{CN} 1 \mathrm{CCN}(\mathrm{CCCCCNc} 2 \mathrm{ncc} 3 \mathrm{cc}(-\mathrm{c} 4 \mathrm{c}(\mathrm{Cl}) \operatorname{cccc} 4 \mathrm{Cl}) \mathrm{c}(=\mathrm{O}) \mathrm{n}(\mathrm{C}) \mathrm{c} 3 \mathrm{n} 2) \mathrm{CC} 1$ & 4500 & * \\
\hline 4119 & $\mathrm{COc} 1 \mathrm{ccc}(\mathrm{NC}(=\mathrm{O}) / \mathrm{C}=\mathrm{C} / \mathrm{CN}(\mathrm{C}) \mathrm{C}) \operatorname{cc} 1 \mathrm{Nc} 1 \mathrm{ncc}(\mathrm{Cl}) \mathrm{c}(\mathrm{Nc} 2 \mathrm{ccccc} 2 \mathrm{Cl}) \mathrm{n} 1$ & 4560 & $*$ \\
\hline 4120 & $\mathrm{COc} 1 \mathrm{cc}(/ \mathrm{C}=\mathrm{C} 2 \backslash \mathrm{CCC} / \mathrm{C}(=\mathrm{C} \backslash \mathrm{c} 3 \operatorname{ccc}(\mathrm{O}) \mathrm{cc} 3) \mathrm{C} 2=\mathrm{O}) \mathrm{cc}(\mathrm{OC}) \mathrm{c} 1$ & 4600 & 5.33 \\
\hline 4121 & $\mathrm{COc} 1 \mathrm{cc} 2 \mathrm{c}(\mathrm{cc} 1 \mathrm{OC}) \mathrm{Oc} 1 \mathrm{ncnc}(\mathrm{Oc} 3 \mathrm{cccc}(\mathrm{Br}) \mathrm{c} 3) \mathrm{c} 1 \mathrm{~N}(\mathrm{C}) \mathrm{C} 2$ & 4600 & 5.34 \\
\hline 4122 & $\operatorname{COc} 1 \mathrm{ccc}(\mathrm{C}(=\mathrm{O}) \mathrm{n} 2 \mathrm{nc}(-\mathrm{c} 3 \mathrm{ccncc} 3) \mathrm{nc} 2 \mathrm{~N}) \mathrm{cc} 1$ & 4600 & 5.34 \\
\hline 4123 & $\mathrm{CCN}(\mathrm{CC}) \mathrm{CCNC}(=\mathrm{O}) \mathrm{c} 1 \mathrm{c}([\mathrm{Se}][\mathrm{Se}] \mathrm{c} 2[\mathrm{nH}] \mathrm{c} 3 \operatorname{cccc} 3 \mathrm{c} 2 \mathrm{C}(=\mathrm{O}) \mathrm{NCCN}(\mathrm{CC}) \mathrm{CC})[\mathrm{nH}] \mathrm{c} 2 \mathrm{ccccc} 12$ & 4600 & $*$ \\
\hline 4124 & $\mathrm{~N}=\mathrm{C}(\mathrm{N}) \mathrm{SCCCn} 1 \mathrm{c}(=\mathrm{O}) \mathrm{c} 2 \mathrm{c}(\mathrm{c} 1=\mathrm{O}) \mathrm{n} 1 \mathrm{c} 3 \mathrm{ccccc} 3 \mathrm{cc} 1 \mathrm{c} 1 \mathrm{ccc} 3 \mathrm{ccn} 2 \mathrm{c} 31$ & 4600 & * \\
\hline 4125 & $\mathrm{CC}(\mathrm{C}) \mathrm{n} 1 \mathrm{nc}(-\mathrm{c} 2 \mathrm{cccc} 3[\mathrm{nH}] \mathrm{ccc} 23) \mathrm{c} 2 \mathrm{c}(\mathrm{N}) \mathrm{ncnc} 21$ & 4600 & * \\
\hline 4126 & $\operatorname{Br} . \mathrm{CC}(\mathrm{Nc} 1 \mathrm{ncnc} 2[\mathrm{nH}] \mathrm{c}(-\mathrm{c} 3 \mathrm{ccc}(\mathrm{O}) \mathrm{cc} 3) \mathrm{cc} 12) \mathrm{c} 1 \mathrm{ccc}(\mathrm{C}(\mathrm{F})(\mathrm{F}) \mathrm{F}) \mathrm{cc} 1$ & 4608 & $*$ \\
\hline 4127 & $\mathrm{COc} 1 \mathrm{cc} 2 \mathrm{c}(\mathrm{Nc} 3 \mathrm{ccc}(\mathrm{NC}(=\mathrm{O}) \mathrm{c} 4 \mathrm{ccccc} 4) \mathrm{cc} 3) \mathrm{ncnc} 2 \mathrm{cc} 1 \mathrm{OCCN} 1 \mathrm{CCCCC} 1$ & 4610 & * \\
\hline 4128 & $\mathrm{COc} 1 \mathrm{cc} 2 \mathrm{c}(\mathrm{Nc} 3 \operatorname{ccc}(\mathrm{NC}(=\mathrm{O}) \mathrm{Nc} 4 \operatorname{cccc}(\mathrm{Cl}) \mathrm{c} 4) \mathrm{cc} 3) \operatorname{ncn} \mathrm{2} \operatorname{cc} 1 \mathrm{OCc} 1 \mathrm{cccc} 1$ & 4649 & * \\
\hline 4129 & $\mathrm{CN} 1 \mathrm{CCC}(=\mathrm{O}) / \mathrm{C}(=\mathrm{C} / \mathrm{c} 2 \mathrm{ccc}(\mathrm{CC} 3 \mathrm{CCCC} 3) \mathrm{cc} 2) \mathrm{C} 1$ & 4660 & * \\
\hline 4130 & $\mathrm{CC}(=\mathrm{O}) \mathrm{c} 1 \mathrm{nn}(-\mathrm{c} 2 \operatorname{ccccc} 2) \mathrm{cc} 1 \mathrm{C}(=\mathrm{O}) \mathrm{c} 1 \mathrm{c}(\mathrm{C})[\mathrm{nH}] \mathrm{c}(-\mathrm{c} 2 \mathrm{ccccc} 2) \mathrm{c} 1-\mathrm{c} 1 \mathrm{ccccc} 1$ & 4670 & $*$ \\
\hline 4131 & $\mathrm{O}=\mathrm{C}(\mathrm{Nc} 1 \mathrm{ccccc} 1) \mathrm{N}(\mathrm{Cc} 1 \mathrm{ccc}(\mathrm{F}) \mathrm{cc} 1) \mathrm{Cc} 1 \mathrm{cc}(\mathrm{Br}) \mathrm{cc}(\mathrm{Br}) \mathrm{c} 1 \mathrm{O}$ & 4680 & 5.33 \\
\hline 4132 & $\mathrm{COc} 1 \mathrm{ccc}(\mathrm{C} 2=\mathrm{NN}(\mathrm{c} 3 \mathrm{nc}(-\mathrm{c} 4 \mathrm{ccc}(\mathrm{Cl}) \operatorname{cc} 4) \operatorname{cs} 3) \mathrm{C}(\mathrm{c} 3 \operatorname{ccc}(\mathrm{C}) \mathrm{cc} 3) \mathrm{C} 2) \mathrm{cc} 1$ & 4680 & 5.33 \\
\hline 4133 & $\mathrm{O}=\mathrm{C}(/ \mathrm{C}=\mathrm{C} / \mathrm{c} 1 \mathrm{cccnc} 1) \mathrm{Nc} 1 \mathrm{ccc} 2 \mathrm{ncnc}(\mathrm{Nc} 3 \operatorname{ccc}(\mathrm{Cl}) \mathrm{c} 3) \mathrm{c} 2 \mathrm{c} 1$ & 4700 & 5.33 \\
\hline 4134 & $\mathrm{O}=\mathrm{C}(\mathrm{CCl}) \mathrm{OCCn} 1 \mathrm{c}(=\mathrm{O}) \mathrm{oc} 2 \mathrm{cc} 3 \operatorname{ncnc}(\mathrm{Nc} 4 \mathrm{ccc}(\mathrm{F}) \mathrm{c}(\mathrm{F}) \mathrm{c} 4) \mathrm{c} 3 \mathrm{cc} 21$ & 4700 & 5.33 \\
\hline 4135 & $\mathrm{CCN}(\mathrm{CC}) \mathrm{CCNC}(=\mathrm{O}) \mathrm{c} 1 \mathrm{c}([\mathrm{Se}][\mathrm{Se}] \mathrm{c} 2 \mathrm{c}(\mathrm{C}(=\mathrm{O}) \mathrm{NCCN}(\mathrm{CC}) \mathrm{CC}) \mathrm{c} 3 \operatorname{ccccc} 3 \mathrm{n} 2 \mathrm{C}) \mathrm{n}(\mathrm{C}) \mathrm{c} 2 \operatorname{ccccc} 12$ & 4700 & * \\
\hline 4136 & $\operatorname{Nc1} 1 \mathrm{cc} 2 \mathrm{ncnc}(\mathrm{Nc} 3 \operatorname{ccc}(\mathrm{C}(\mathrm{F})(\mathrm{F}) \mathrm{F}) \mathrm{cc} 3) \mathrm{c} 2 \mathrm{cn} 1$ & 4700 & $*$ \\
\hline 4137 & $\mathrm{COc} 1 \mathrm{cc} 2 \mathrm{ncnc}(\mathrm{Nc} 3 \mathrm{ccc}(\mathrm{C}(\mathrm{C})(\mathrm{F}) \mathrm{F}) \mathrm{cc} 3) \mathrm{c} 2 \mathrm{cc} 1 \mathrm{OC}$ & 4700 & $*$ \\
\hline 4138 & $\mathrm{O}=\mathrm{C} 1 \mathrm{CSC}(\mathrm{N} / \mathrm{N}=\mathrm{C} / \mathrm{c} 2 \operatorname{ccc}(\mathrm{O}) \mathrm{cc} 2)=\mathrm{N} 1$ & 4710 & 5.33 \\
\hline 4139 & COc1cce2c(c1)SCc1cnc(-c3eccec3)nc1-2 & 4720 & 5.33 \\
\hline 4140 & $\mathrm{Nc} 1 \mathrm{cc}(\mathrm{C}(\mathrm{F})(\mathrm{F}) \mathrm{F}) \mathrm{ccc} 1 \mathrm{Nc} 1 \mathrm{ncnc} 2 \mathrm{ccncc} 12$ & 4786.3 & $*$ \\
\hline 4141 & $\mathrm{O}=\mathrm{C} 1 \mathrm{CSC}(\mathrm{N} 2 \mathrm{~N}=\mathrm{C}(\mathrm{c} 3 \operatorname{ccc}(\mathrm{F}) \mathrm{cc} 3) \mathrm{CC} 2 \mathrm{c} 2 \mathrm{ccc}(\mathrm{Br}) \mathrm{cc} 2)=\mathrm{N} 1$ & 4790 & 5.32 \\
\hline 4142 & $\mathrm{COc} 1 \mathrm{cc}(/ \mathrm{C}=\mathrm{C} 2 \backslash \mathrm{CCC} / \mathrm{C}(=\mathrm{C} \backslash \mathrm{c} 3 \mathrm{cc}(\mathrm{C}(\mathrm{C})(\mathrm{C}) \mathrm{C}) \mathrm{c}(\mathrm{O}) \mathrm{c}(\mathrm{C}(\mathrm{C})(\mathrm{C}) \mathrm{C}) \mathrm{c} 3) \mathrm{C} 2=\mathrm{O}) \mathrm{cc}(\mathrm{OC}) \mathrm{c} 1$ & 4800 & 5.32 \\
\hline 4143 & $\mathrm{~N} \# \mathrm{CC} 1=\mathrm{C}(\mathrm{N}) \mathrm{N}(\mathrm{c} 2 \mathrm{cccnc} 2) \mathrm{C} 2=\mathrm{C}(\mathrm{C}(=\mathrm{O}) \mathrm{CCC} 2) \mathrm{C} 1 \mathrm{c} 1 \mathrm{cc} 2 \mathrm{cccc} 2 \mathrm{n} 2 \mathrm{nnnc} 12$ & 4800 & 5.32 \\
\hline 4144 & $\operatorname{COc} 1 \mathrm{cc}(\mathrm{N} 2 \mathrm{CCN}(\mathrm{C}) \mathrm{CC} 2) \operatorname{ccc} 1 \mathrm{Nc} 1 \mathrm{ncc}(\mathrm{Cl}) \mathrm{c}(\mathrm{Oc} 2 \operatorname{cccc}(\mathrm{NC}(=\mathrm{O}) / \mathrm{C}(\mathrm{C \# N})=\mathrm{C} / \mathrm{c} 3 \operatorname{ccc}(\mathrm{SC}) \mathrm{cc} 3) \mathrm{c} 2) \mathrm{n} 1$ & 4800 & 5.32 \\
\hline 4145 & COc1cc2ncnc $(\mathrm{Nc} 3 \operatorname{ccc}(\mathrm{NC}(=\mathrm{O}) \mathrm{OC}(\mathrm{C}) \mathrm{C}) \mathrm{cc} 3) \mathrm{c} 2 \mathrm{cc} 1 \mathrm{OC}$ & 4800 & $*$ \\
\hline 4146 & $\operatorname{CCCCNC}(=\mathrm{O}) \operatorname{c} 1 \operatorname{ccc}(\mathrm{S}(=\mathrm{O})(=\mathrm{O}) \mathrm{Oc} 2 \operatorname{ccc}(/ \mathrm{C}=\mathrm{C} /[\mathrm{N}+](=\mathrm{O})[\mathrm{O}-]) \operatorname{cc} 2) \operatorname{cc} 1$ & 4800 & $*$ \\
\hline 4147 & Nc1ncnc2c1c(-c1ccc(F)c(O)c1)nn2[C@H]1CCOC1 & 4800 & $*$ \\
\hline 4148 & $\mathrm{C}[\mathrm{C} @ \mathrm{H}](\mathrm{CN}) \mathrm{n} 1 \mathrm{nc}(-\mathrm{c} 2 \mathrm{ccc}(\mathrm{Cl}) \mathrm{c}(\mathrm{O}) \mathrm{c} 2) \mathrm{c} 2 \mathrm{c}(\mathrm{N}) \mathrm{ncnc} 21$ & 4800 & $*$ \\
\hline 4149 & $\mathrm{CN}(\mathrm{C}) \mathrm{C} / \mathrm{C}=\mathrm{C} / \mathrm{C}(=\mathrm{O}) \mathrm{Nc} 1 \mathrm{cccc}(\mathrm{Nc} 2 \mathrm{ncc}(\mathrm{Cl}) \mathrm{c}(\mathrm{Nc} 3 \operatorname{ccc} 4 \operatorname{ccccc} 4 \mathrm{c} 3) \mathrm{n} 2) \mathrm{c} 1$ & 4800 & $*$ \\
\hline 4150 & $\mathrm{CCN}(\mathrm{CC}) \mathrm{C}(\mathrm{C}) / \mathrm{C}=\mathrm{C} / \mathrm{C}(=\mathrm{O}) \mathrm{Nc} 1 \mathrm{cc} 2 \mathrm{c}(\mathrm{Nc} 3 \mathrm{ccc}(\mathrm{F}) \mathrm{c}(\mathrm{Cl}) \mathrm{c} 3) \mathrm{c}(\mathrm{CHN}) \mathrm{cnc} 2 \mathrm{cc} 1 \mathrm{OC}$ & 4840 & 5.32 \\
\hline 4151 & $\mathrm{O}=\mathrm{C} 1 \mathrm{CSC}(\mathrm{N} 2 \mathrm{~N}=\mathrm{C}(\mathrm{c} 3 \operatorname{ccccc} 3) \mathrm{CC} 2 \mathrm{c} 2 \mathrm{ccc}(\mathrm{F}) \mathrm{cc} 2)=\mathrm{N} 1$ & 4860 & 5.31 \\
\hline 4152 & $\mathrm{CN}(\mathrm{C}) \mathrm{c} 1 \mathrm{ccc}(\mathrm{Nc} 2 \mathrm{ncnc} 3 \mathrm{cc}(\mathrm{N}) \mathrm{ncc} 23) \mathrm{cc} 1$ & 4860 & $*$ \\
\hline 4153 & $\mathrm{COc} 1 \mathrm{cc} 2 \mathrm{ncnc}(\mathrm{Oc} 3 \operatorname{cccc}(\mathrm{NC}(=\mathrm{S}) \mathrm{Nc} 4 \mathrm{ccc}(\mathrm{F}) \mathrm{c}(\mathrm{F}) \mathrm{c} 4) \mathrm{c} 3) \mathrm{c} 2 \mathrm{cc} 1 \mathrm{OC}$ & 4880 & $*$ \\
\hline 4154 & $\mathrm{CN}(\mathrm{C}) \mathrm{C} / \mathrm{C}=\mathrm{C} / \mathrm{C}(=\mathrm{O}) \mathrm{N} 1 \mathrm{CCc} 2 \mathrm{c}(\operatorname{sc} 3 \mathrm{ncnc}(\mathrm{NCCO}) \mathrm{c} 23) \mathrm{C} 1$ & 4884 & $*$ \\
\hline 4155 & $\mathrm{CN}(\mathrm{C}) \mathrm{c} 1 \mathrm{ccc}(\mathrm{Nc} 2 \mathrm{ncnc} 3 \mathrm{ccncc} 23) \mathrm{c}(\mathrm{N}) \mathrm{c} 1$ & 4897.79 & $*$ \\
\hline 4156 & COc1 $1 \mathrm{ccc} 2 \mathrm{ncnc}(\mathrm{NCc} 3 \operatorname{ccc} \mathrm{c} 3) \mathrm{c} 12$ & 4900 & $*$ \\
\hline
\end{tabular}




\begin{tabular}{|c|c|c|c|}
\hline 4157 & $\mathrm{CN}(\mathrm{C}) \mathrm{Cc} 1 \mathrm{cc}(\mathrm{C}(=\mathrm{O}) \mathrm{N}[\mathrm{C} @ @ \mathrm{H}] 2 \mathrm{CCc} 3 \operatorname{ccc}(\mathrm{Oc} 4 \mathrm{ccnc} 5 \mathrm{c} 4 \mathrm{CCC}(=\mathrm{O}) \mathrm{N} 5) \mathrm{cc} 3 \mathrm{C} 2) \mathrm{cc}(\mathrm{C}(\mathrm{F})(\mathrm{F}) \mathrm{F}) \mathrm{c} 1$ & 4900 & $*$ \\
\hline 4158 & $\mathrm{COc} 1 \mathrm{cc}(\mathrm{Br}) \mathrm{c}(\mathrm{C}=\mathrm{C} 2 \mathrm{CN}(\mathrm{C}(\mathrm{C}) \mathrm{C}) \mathrm{CC}(=\mathrm{Cc} 3 \mathrm{nc}(\mathrm{C}) \mathrm{c}(\mathrm{C}) \mathrm{nc} 3 \mathrm{C}) \mathrm{C} 2=\mathrm{NO}) \mathrm{cc} 1 \mathrm{OC}$ & 4900 & * \\
\hline 4159 & $\mathrm{COc} 1 \mathrm{ccc}(\mathrm{C} 2=\mathrm{NN}(\mathrm{c} 3 \mathrm{nc}(-\mathrm{c} 4 \mathrm{ccccc} 4) \operatorname{cs} 3) \mathrm{C}(\mathrm{c} 3 \operatorname{ccc}(\mathrm{Cl}) \mathrm{cc} 3) \mathrm{C} 2) \mathrm{cc} 1$ & 4940 & 5.31 \\
\hline 4160 & $\operatorname{CCCCCCCCCOC}(=0) \operatorname{COc} 1 \mathrm{cc}(\mathrm{O}) \mathrm{c} 2 \mathrm{c}(=\mathrm{O}) \mathrm{cc}(-\mathrm{c} 3 \mathrm{ccccc} 3) \mathrm{oc} 2 \mathrm{c} 1$ & 4960 & 5.30 \\
\hline 4161 & $\mathrm{COC}(=\mathrm{O}) \mathrm{CC}(=\mathrm{O}) \mathrm{Nc} 1 \mathrm{cc} 2 \mathrm{c}(\mathrm{Nc} 3 \mathrm{ccc}(\mathrm{F}) \mathrm{c}(\mathrm{Cl}) \mathrm{c} 3) \mathrm{ncnc} 2 \mathrm{~s} 1$ & 4997 & $*$ \\
\hline 4162 & $\operatorname{CCOc} 1 \mathrm{cc}([\mathrm{N}+](=\mathrm{O})[\mathrm{O}-]) \mathrm{c}(\mathrm{C}(=\mathrm{O}) \mathrm{Nc} 2 \mathrm{ccc}(\mathrm{F}) \mathrm{c}(\mathrm{Cl}) \mathrm{c} 2) \mathrm{cc} 1 \mathrm{NC}(=\mathrm{O}) \mathrm{c} 1 \mathrm{ccc}(\mathrm{CN} 2 \mathrm{CCN}(\mathrm{C}) \mathrm{CC} 2) \mathrm{cc} 1$ & 5000 & 5.30 \\
\hline 4163 & $\mathrm{Cc} 1 \operatorname{ccc}(\mathrm{NC}(=\mathrm{O}) / \mathrm{C}=\mathrm{C} / \mathrm{CN}(\mathrm{C}) \mathrm{C}) \mathrm{cc} 1 \mathrm{C}(=\mathrm{O}) \mathrm{Nc} 1 \mathrm{nccc}(-\mathrm{c} 2 \mathrm{cccnc} 2) \mathrm{n} 1$ & 5000 & 5.30 \\
\hline 4164 & $\mathrm{CCOc} 1 \mathrm{cc}(\mathrm{N}) \mathrm{c}(\mathrm{C}(=\mathrm{O}) \mathrm{Nc} 2 \mathrm{ccc}(\mathrm{OCc} 3 \operatorname{ccc}(\mathrm{F}) \mathrm{c} 3) \mathrm{c}(\mathrm{Cl}) \mathrm{c} 2) \mathrm{cc} 1 \mathrm{NC}(=\mathrm{O}) \mathrm{c} 1 \mathrm{ccc}(\mathrm{CN} 2 \mathrm{CCN}(\mathrm{C}) \mathrm{CC} 2) \mathrm{cc} 1$ & 5000 & 5.30 \\
\hline 4165 & $\mathrm{CCOC}(=\mathrm{O}) \mathrm{Nc} 1 \mathrm{cc}(\mathrm{Nc} 2 \mathrm{ncnc} 3 \mathrm{cc}(\mathrm{OC}) \mathrm{c}(\mathrm{OC}) \mathrm{cc} 23) \mathrm{ccc} 1 \mathrm{C} . \mathrm{Cl}$ & 5000 & $*$ \\
\hline 4166 & $\mathrm{CCOC}(=\mathrm{O}) \mathrm{Nc} 1 \mathrm{cc}(\mathrm{Nc} 2 \mathrm{ncnc} 3 \mathrm{cc}(\mathrm{OC}) \mathrm{c}(\mathrm{OC}) \mathrm{cc} 23) \mathrm{ccc} 1 \mathrm{C}$ & 5000 & $*$ \\
\hline 4167 & $\mathrm{Cn} 1 \mathrm{c}(\mathrm{SSc} 2 \mathrm{c}(\mathrm{C}(=\mathrm{O}) \mathrm{Nc} 3 \operatorname{cccc} 3) \mathrm{c} 3 \mathrm{cc}([\mathrm{N}+](=\mathrm{O})[\mathrm{O}-]) \operatorname{ccc} 3 \mathrm{n} 2 \mathrm{C}) \mathrm{c}(\mathrm{C}(=\mathrm{O}) \mathrm{Nc} 2 \operatorname{cccc} 2) \mathrm{c} 2 \mathrm{cc}([\mathrm{N}+](=\mathrm{O})[\mathrm{O}-]) \operatorname{ccc} 21$ & 5000 & * \\
\hline 4168 & Oc1 $1 \mathrm{cc} 2 \mathrm{cc}(-\mathrm{c} 3 \mathrm{ccncc} 3) \mathrm{cnc} 2 \mathrm{cc} 1 \mathrm{O}$ & 5000 & $*$ \\
\hline 4169 & $\mathrm{O}=\mathrm{C}(\mathrm{Oc} 1 \mathrm{ccc}(-\mathrm{c} 2 \mathrm{cccc} 2) \mathrm{cc} 1) \mathrm{c} 1 \mathrm{cc}(\mathrm{NCc} 2 \mathrm{cc}(\mathrm{O}) \mathrm{ccc} 2 \mathrm{O}) \mathrm{ccc} 1 \mathrm{O}$ & 5000 & $*$ \\
\hline 4170 & $\mathrm{CC}(\mathrm{C})(\mathrm{C}) \mathrm{ONC}(=\mathrm{O}) \mathrm{Cc} 1 \mathrm{cc}(\mathrm{NCc} 2 \mathrm{cc}(\mathrm{O}) \operatorname{ccc} 2 \mathrm{O}) \operatorname{ccc} 1 \mathrm{O}$ & 5000 & $*$ \\
\hline 4171 & $\mathrm{O}=\mathrm{C}(\mathrm{O}) \mathrm{c} 1 \mathrm{cc}(/ \mathrm{N}=\mathrm{C} / \mathrm{c} 2 \mathrm{cc}(\mathrm{O}) \operatorname{ccc} 2 \mathrm{O}) \operatorname{ccc} 1 \mathrm{O}$ & 5000 & * \\
\hline 4172 & $\mathrm{O}=[\mathrm{N}+]([\mathrm{O}-]) \mathrm{c} 1 \mathrm{ccc} 2 \mathrm{ncnc}(\mathrm{Nc} 3 \operatorname{ccccc} 3) \mathrm{c} 2 \mathrm{c} 1$ & 5000 & * \\
\hline 4173 & $\mathrm{CC}(\mathrm{C}) \mathrm{n} 1 \mathrm{nc}(-\mathrm{c} 2 \mathrm{ccc} 3 \mathrm{c}(\mathrm{c} 2) \mathrm{CCO} 3) \mathrm{c} 2 \mathrm{c}(\mathrm{N}) \mathrm{ncnc} 21$ & 5000 & $*$ \\
\hline 4174 & $\mathrm{O}=[\mathrm{N}+]([\mathrm{O}-]) \mathrm{c} 1 \mathrm{cccc}(-\mathrm{c} 2 \mathrm{cc} 3 \mathrm{c}(\mathrm{Nc} 4 \mathrm{ccc}(\mathrm{Cl}) \mathrm{cc} 4 \mathrm{~F}) \mathrm{ncnc} 3 \mathrm{o} 2) \mathrm{c} 1$ & 5000 & * \\
\hline 4175 & $\mathrm{c} 1 \mathrm{ccc}(\mathrm{Cc} 2 \mathrm{nc} 3 \mathrm{cc}(\mathrm{Nc} 4 \mathrm{ncnc} 5 \mathrm{nn} 6 \mathrm{ccccc} 6 \mathrm{c} 45) \mathrm{ccc} 3[\mathrm{nH}] 2) \mathrm{cc} 1$ & 5010 & $*$ \\
\hline 4176 & $\mathrm{CSc} 1 \mathrm{cn} 2 \mathrm{c}(-\mathrm{c} 3 \mathrm{cn}[\mathrm{nH}] \mathrm{c} 3) \mathrm{cnc} 2 \mathrm{c}(\mathrm{Nc} 2 \mathrm{cc}(\mathrm{C}) \mathrm{ns} 2) \mathrm{n} 1$ & 5048 & * \\
\hline 4177 & $\mathrm{COc} 1 \mathrm{ccc}(\mathrm{C} 2=\mathrm{NN}(\mathrm{c} 3 \mathrm{nc}(-\mathrm{c} 4 \mathrm{ccc}(\mathrm{Cl}) \mathrm{cc} 4) \operatorname{cs} 3) \mathrm{C}(\mathrm{c} 3 \mathrm{ccc}(\mathrm{F}) \mathrm{cc} 3) \mathrm{C} 2) \mathrm{cc} 1$ & 5070 & 5.29 \\
\hline 4178 & COc1cc2ncnc(N[C@@H](C)c3eccc3)c2cc1OCCCCCCC $(=\mathrm{O}) \mathrm{NO}$ & 5077 & 5.29 \\
\hline 4179 & $\mathrm{C}=\mathrm{CCn} 1 \mathrm{nc}(-\mathrm{c} 2 \mathrm{ccc}(\mathrm{OCC}) \mathrm{c}(\mathrm{OC}) \mathrm{c} 2) \mathrm{c} 2 \mathrm{c}(\mathrm{N}) \mathrm{ncnc} 21$ & 5080 & $*$ \\
\hline 4180 & 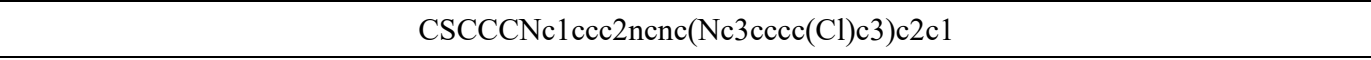 & 5100 & 5.29 \\
\hline 4181 & $\operatorname{COCCn} 1 \mathrm{c}(=\mathrm{O}) \mathrm{oc} 2 \mathrm{cc} 3 \mathrm{ncnc}(\mathrm{Nc} 4 \mathrm{ccc}(\mathrm{OC}) \mathrm{cc} 4) \mathrm{c} 3 \mathrm{cc} 21$ & 5100 & $*$ \\
\hline 4182 & $\mathrm{Cc} 1 \operatorname{ccc}(\mathrm{C}) \mathrm{c} 1 \mathrm{NC}(=\mathrm{O}) / \mathrm{C}(\mathrm{C \# N})=\mathrm{C} / \mathrm{c} 1 \operatorname{ccc}(\mathrm{O}) \mathrm{c}(\mathrm{O}) \mathrm{c} 1$ & 5100 & $*$ \\
\hline 4183 & $\mathrm{COc} 1 \mathrm{cc}(\mathrm{Nc} 2 \mathrm{nccc}(-\mathrm{c} 3 \mathrm{ccc}(\mathrm{NCCN}) \mathrm{nc} 3) \mathrm{n} 2) \mathrm{cc}(\mathrm{OC}) \mathrm{c} 1 \mathrm{OC}$ & 5100 & * \\
\hline 4184 & $\mathrm{CCN}(\mathrm{CC}) \mathrm{CCOc} 1 \mathrm{c}(\mathrm{C}(=\mathrm{O}) \mathrm{OC}) \mathrm{c} 2 \mathrm{c} 3 \mathrm{c}(\mathrm{oc} 2 \mathrm{c} 2 \mathrm{cccc} 12) \mathrm{C}(=\mathrm{O}) \mathrm{c} 1 \mathrm{ccccc} 1 \mathrm{C} 3=\mathrm{O}$ & 5100 & * \\
\hline 4185 & $\mathrm{Cc} 1 \mathrm{c}(\mathrm{C}(=\mathrm{O}) \mathrm{c} 2 \cos 3 \mathrm{c} 2 \mathrm{cc}(\mathrm{O}) \mathrm{c} 2 \operatorname{ccccc} 23)[\mathrm{nH}] \mathrm{c}(-\mathrm{c} 2 \mathrm{ccccc} 2) \mathrm{c} 1-\mathrm{c} 1 \mathrm{ccccc} 1$ & 5100 & $*$ \\
\hline 4186 & $\mathrm{O}=\mathrm{C}(\mathrm{Nc} 1 \mathrm{cccc}(\mathrm{O}) \mathrm{c} 1) \mathrm{c} 1 \mathrm{ccc}(-\mathrm{c} 2 \mathrm{ccc}([\mathrm{N}+](=\mathrm{O})[\mathrm{O}-]) \mathrm{cc} 2) \operatorname{cc} 1 \mathrm{O}$ & 5100 & $*$ \\
\hline 4187 & $\mathrm{NC}(=\mathrm{S}) \mathrm{N} / \mathrm{N}=\mathrm{C}(/ \mathrm{C}=\mathrm{C} / \mathrm{c} 1 \mathrm{ccc}(-\mathrm{c} 2 \operatorname{ccccc} 2) \operatorname{cc} 1) \mathrm{c} 1 \operatorname{ccccc} 1$ & 5110 & 5.29 \\
\hline 4188 & Fc1 $1 \mathrm{ccc} 1-\mathrm{c} 1 \mathrm{nnn}(\mathrm{SCc} 2 \mathrm{cccc} 2) \mathrm{o} 1$ & 5110 & 5.29 \\
\hline 4189 & $\mathrm{Cc} 1 \mathrm{ncc}([\mathrm{N}+](=\mathrm{O})[\mathrm{O}-]) \mathrm{n} 1 \mathrm{CC}(=\mathrm{O}) \mathrm{N} / \mathrm{N}=\mathrm{C} / \mathrm{c} 1 \mathrm{cc} 2 \operatorname{ccccc} 2 \mathrm{nc} 1 \mathrm{Oc} 1 \mathrm{ccc}(\mathrm{Cl}) \mathrm{cc} 1$ & 5120 & 5.29 \\
\hline 4190 & $\mathrm{C}=\mathrm{CC}(=\mathrm{O}) \mathrm{Nc} 1 \mathrm{ccc}(-\mathrm{n} 2 \mathrm{c}(=\mathrm{O}) \mathrm{cnc} 3 \mathrm{cnc}(\mathrm{Nc} 4 \mathrm{ccc}(\mathrm{OC}) \mathrm{cc} 4) \mathrm{nc} 32) \mathrm{cc} 1$ & 5129 & 5.29 \\
\hline 4191 & $\mathrm{COc} 1 \mathrm{cc}(-\mathrm{c} 2 \mathrm{nn}(\mathrm{C}(\mathrm{C}) \mathrm{C}) \mathrm{c} 3 \mathrm{ncnc}(\mathrm{N}) \mathrm{c} 23) \mathrm{cc}(\mathrm{OC}) \mathrm{c} 1 \mathrm{OC}$ & 5140 & $*$ \\
\hline 4192 & 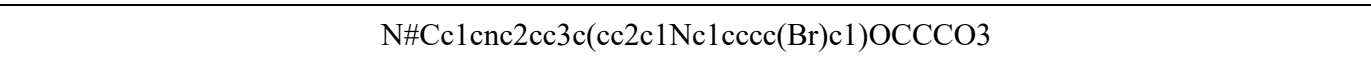 & 5150 & $*$ \\
\hline 4193 & $\mathrm{O}=\mathrm{C}(/ \mathrm{C}=\mathrm{C} / \mathrm{c} 1 \operatorname{ccc}([\mathrm{N}+](=\mathrm{O})[\mathrm{O}-]) \mathrm{cc} 1) \mathrm{Nc} 1 \mathrm{ccc} 2 \mathrm{ncnc}(\mathrm{Nc} 3 \operatorname{ccc}(\mathrm{Br}) \mathrm{c} 3) \mathrm{c} 2 \mathrm{c} 1$ & 5160 & 5.29 \\
\hline 4194 & $\mathrm{C} \# \mathrm{Cc} 1 \mathrm{cccc}(\mathrm{NC}(=\mathrm{O}) \mathrm{c} 2 \mathrm{cc}(\mathrm{NC}(=\mathrm{O}) \mathrm{CCCCCC}(=\mathrm{O}) \mathrm{NO}) \operatorname{ccc} 2 \mathrm{OC}) \mathrm{c} 1$ & 5160 & $*$ \\
\hline 4195 & $\mathrm{COc} 1 \operatorname{ccccc} 1 \mathrm{NC}(=\mathrm{O}) / \mathrm{C}=\mathrm{C} / \mathrm{c} 1 \operatorname{ccccc} 1$ & 5160 & $*$ \\
\hline 4196 & $\mathrm{O}=\mathrm{C}(\mathrm{Cc} 1 \mathrm{ccc}(\mathrm{F}) \mathrm{cc} 1) \mathrm{NS}(=\mathrm{O})(=\mathrm{O}) \mathrm{c} 1 \mathrm{ccc}(\mathrm{F}) \mathrm{cc} 1$ & 5170 & 5.29 \\
\hline 4197 & $\mathrm{Cc} 1 \operatorname{ccc}(\mathrm{C} 2=\mathrm{NN}(\mathrm{C}(\mathrm{N})=\mathrm{S}) \mathrm{C}(\mathrm{c} 3 \operatorname{ccccc} 3 \mathrm{~F}) \mathrm{C} 2) \operatorname{cc} 1 \mathrm{C}$ & 5190 & 5.28 \\
\hline 4198 & $\mathrm{CACc} 1 \mathrm{cccc}(\mathrm{Nc} 2 \mathrm{ncnc} 3 \mathrm{cc} 4 \mathrm{oc}(=\mathrm{O}) \mathrm{n}(\mathrm{CCOC}(=\mathrm{O}) \mathrm{CBr}) \mathrm{c} 4 \mathrm{cc} 23) \mathrm{c} 1$ & 5200 & 5.28 \\
\hline 4199 & $\mathrm{Cc} 1 \mathrm{cc}(\mathrm{Nc} 2 \mathrm{ncc}(\mathrm{C}(=\mathrm{O}) \mathrm{Nc} 3 \mathrm{c}(\mathrm{C}) \operatorname{ccc} 3 \mathrm{Cl}) \mathrm{s} 2) \mathrm{nc}(\mathrm{C}) \mathrm{n} 1$ & 5200 & * \\
\hline
\end{tabular}




\begin{tabular}{|c|c|c|c|}
\hline 4200 & $\mathrm{COc} 1 \mathrm{cc} 2 \mathrm{ncc}(\mathrm{C \# N}) \mathrm{c}(\mathrm{Nc} 3 \operatorname{ccc}(\mathrm{F}) \mathrm{c}(\mathrm{Cl}) \mathrm{c} 3) \mathrm{c} 2 \mathrm{cc} 1 \mathrm{NC}(=\mathrm{O}) / \mathrm{C}=\mathrm{C} / \mathrm{C}(\mathrm{C}) \mathrm{N}(\mathrm{C}) \mathrm{C}$ & 5220 & 5.28 \\
\hline 4201 & $\mathrm{CN}(\mathrm{C}) \mathrm{CCCN}(\mathrm{C}) \mathrm{CC}(=\mathrm{O}) \mathrm{Nc} 1 \mathrm{cc} 2 \mathrm{c}(\mathrm{Nc} 3 \mathrm{ccc}(\mathrm{F}) \mathrm{c}(\mathrm{Cl}) \mathrm{c} 3) \mathrm{ncnc} 2 \mathrm{~s} 1$ & 5222 & $*$ \\
\hline 4202 & $\operatorname{COc} 1 \mathrm{cc}(/ \mathrm{C}=\mathrm{C}(\backslash \mathrm{C} \# \mathrm{~N}) \mathrm{C}(\mathrm{N})=\mathrm{O}) \operatorname{cc}(\mathrm{CSc} 2 \mathrm{nc} 3 \operatorname{ccccc} 3 \mathrm{o} 2) \mathrm{c} 1 \mathrm{O}$ & 5248.07 & * \\
\hline 4203 & $\mathrm{Nc} 1 \mathrm{cc} 2 \mathrm{ncnc}(\mathrm{Nc} 3 \operatorname{ccc} \mathrm{c} 3 \mathrm{~N}) \mathrm{c} 2 \mathrm{cn} 1$ & 5250 & $*$ \\
\hline 4204 & $\mathrm{Cc} 1 \mathrm{ccc}(\mathrm{C} 2=\mathrm{NN}(\mathrm{C} 3=\mathrm{NC}(\mathrm{c} 4 \operatorname{ccccc} 4) \mathrm{CS} 3) \mathrm{C}(\mathrm{c} 3 \operatorname{ccc} 4 \operatorname{ccccc} 4 \mathrm{c} 3) \mathrm{C} 2) \mathrm{cc} 1$ & 5260 & 5.28 \\
\hline 4205 & $\mathrm{NC}(=\mathrm{S}) \mathrm{N} 1 \mathrm{~N}=\mathrm{C}(\mathrm{c} 2 \mathrm{ccc}(\mathrm{Cl}) \mathrm{c}(\mathrm{Cl}) \mathrm{c} 2) \mathrm{CC} 1 \mathrm{c} 1 \mathrm{ccc}(\mathrm{O}) \mathrm{cc} 1$ & 5270 & 5.28 \\
\hline 4206 & $\mathrm{Cc} 1 \mathrm{cccc} 2 \mathrm{nc}(\mathrm{NC}(=\mathrm{O}) \mathrm{c} 3 \operatorname{cccc}(\mathrm{C}(\mathrm{F})(\mathrm{F}) \mathrm{F}) \mathrm{c} 3) \mathrm{n}([\mathrm{C} @ \mathrm{H}] 3 \mathrm{CC}[\mathrm{C} @ \mathrm{H}](\mathrm{O}) \mathrm{CC} 3) \mathrm{c} 12$ & 5270 & $*$ \\
\hline 4207 & $\mathrm{CN}(\mathrm{C}) \mathrm{c} 1 \mathrm{ccc}(/ \mathrm{C}=\mathrm{C} / \mathrm{C}(=\mathrm{O}) \mathrm{c} 2 \operatorname{ccc} 3 \mathrm{ncc}(\mathrm{C}(\mathrm{N})=\mathrm{O}) \mathrm{c}(\mathrm{Nc} 4 \mathrm{ccc}(\mathrm{Cl}) \mathrm{cc} 4) \mathrm{c} 3 \mathrm{c} 2) \mathrm{cc} 1$ & 5283 & * \\
\hline 4208 & $\mathrm{COc} 1 \mathrm{cc}(/ \mathrm{C}=\mathrm{C} 2 \backslash \mathrm{CCC} / \mathrm{C}(=\mathrm{C} \backslash \mathrm{c} 3 \operatorname{ccc}(\mathrm{OC}) \mathrm{c}(\mathrm{O}) \mathrm{c} 3) \mathrm{C} 2=\mathrm{O}) \mathrm{cc}(\mathrm{OC}) \mathrm{c} 1$ & 5300 & 5.27 \\
\hline 4209 & $\mathrm{Nc} 1 \mathrm{nn} 2 \mathrm{c}(=\mathrm{O}) \mathrm{cc}(-\mathrm{c} 3 \mathrm{ccccc} 3)[\mathrm{nH}] \mathrm{c} 2 \mathrm{c} 1 \mathrm{~N}=\mathrm{Nc} 1 \mathrm{ccc} 2 \mathrm{c}(\mathrm{c} 1) \mathrm{OCO} 2$ & 5300 & 5.28 \\
\hline 4210 & $\mathrm{CC}(=\mathrm{O}) \mathrm{Oc} 1 \mathrm{ccc} 2 \mathrm{c}(\mathrm{c} 1) \mathrm{c}(\mathrm{C}(=\mathrm{O}) \mathrm{Nc} 1 \mathrm{ccc} c 1) \mathrm{c}(\mathrm{SSc} 1 \mathrm{c}(\mathrm{C}(=\mathrm{O}) \mathrm{Nc} 3 \operatorname{ccc} c 3) \mathrm{c} 3 \mathrm{cc}(\mathrm{OC}(\mathrm{C})=\mathrm{O}) \operatorname{ccc} 3 \mathrm{n} 1 \mathrm{C}) \mathrm{n} 2 \mathrm{C}$ & 5300 & $*$ \\
\hline 4211 & CCn1cnc2c(Nc3cccc(Cl)c3)nc(N[C@H]3CCC[C@@H](N)C3)nc21 & 5300 & $*$ \\
\hline 4212 & $\mathrm{Cc} 1 \mathrm{cc}(\mathrm{C}(=\mathrm{O}) \mathrm{NCCN} 2 \mathrm{CCOCC} 2)[\mathrm{nH}] \mathrm{c} 1 / \mathrm{C}=\mathrm{C} 1 \backslash \mathrm{C}(=\mathrm{O}) \mathrm{N}(\mathrm{C}) \mathrm{c} 2 \mathrm{ncnc}(\mathrm{Nc} 3 \operatorname{ccc}(\mathrm{F}) \mathrm{c}(\mathrm{Cl}) \mathrm{c} 3) \mathrm{c} 21$ & 5310 & $*$ \\
\hline 4213 & $\mathrm{COc} 1 \mathrm{cc}(-\mathrm{c} 2 \mathrm{nn}(\mathrm{C}(\mathrm{C}) \mathrm{C}) \mathrm{c} 3 \mathrm{ncnc}(\mathrm{N}) \mathrm{c} 23) \mathrm{ccc} 1 \mathrm{NC}(\mathrm{C}) \mathrm{CO}$ & 5320 & $*$ \\
\hline 4214 & $\operatorname{CCCCCCCCNC}(=\mathrm{O}) \operatorname{COc} 1 \mathrm{cc}(\mathrm{O}) \mathrm{c} 2 \mathrm{c}(=\mathrm{O}) \mathrm{cc}(-\mathrm{c} 3 \operatorname{ccccc} 3) \mathrm{oc} 2 \mathrm{c} 1$ & 5330 & 5.27 \\
\hline 4215 & $\mathrm{O}=\mathrm{C} 1 \mathrm{CSC}(\mathrm{N} 2 \mathrm{~N}=\mathrm{C}(\mathrm{c} 3 \operatorname{ccc}(\mathrm{Cl}) \operatorname{cc} 3) \mathrm{CC} 2 \mathrm{c} 2 \mathrm{cccc} 2)=\mathrm{N} 1$ & 5340 & 5.27 \\
\hline 4216 & $\mathrm{COc} 1 \mathrm{ccc}(\mathrm{C} 2=\mathrm{NN}(\mathrm{C} 3=\mathrm{NC}(=\mathrm{O}) \mathrm{CS} 3) \mathrm{C}(\mathrm{c} 3 \operatorname{ccc}(\mathrm{Cl}) \mathrm{cc} 3) \mathrm{C} 2) \mathrm{cc} 1$ & 5350 & 5.27 \\
\hline 4217 & $\mathrm{COc} 1 \mathrm{ccc}(\mathrm{C} 2=\mathrm{NN}(\mathrm{c} 3 \mathrm{nc}(-\mathrm{c} 4 \mathrm{cccc} 4) \operatorname{cs} 3) \mathrm{C}(\mathrm{c} 3 \mathrm{ccc}(\mathrm{O}) \mathrm{cc} 3) \mathrm{C} 2) \mathrm{cc} 1$ & 5350 & 5.27 \\
\hline 4218 & $\operatorname{COc} 1 \mathrm{cc} 2 \mathrm{ncnc}(\mathrm{Sc} 3 \operatorname{ccc}(\mathrm{NC}(=\mathrm{S}) \mathrm{Nc} 4 \mathrm{ccc}(\mathrm{F}) \mathrm{cc} 4) \mathrm{c} 3) \mathrm{c} 2 \mathrm{cc} 1 \mathrm{OC}$ & 5350 & $*$ \\
\hline 4219 & $\operatorname{COc} 1 \mathrm{cc}(\mathrm{NC}(=\mathrm{O}) / \mathrm{C}=\mathrm{C} / \mathrm{CN} 2 \mathrm{CCOCC} 2) \mathrm{cc} 2 \mathrm{c}(\mathrm{Nc} 3 \operatorname{cccc}(\mathrm{Br}) \mathrm{c} 3) \mathrm{c}(\mathrm{C \# N}) \mathrm{cnc} 12$ & 5390 & 5.27 \\
\hline 4220 & $\mathrm{COc} 1 \mathrm{ccc} 2 \mathrm{c}(\mathrm{c} 1) \operatorname{cc}(\mathrm{C} 1 \mathrm{C}(\mathrm{C \# N})=\mathrm{C}(\mathrm{N}) \mathrm{N}(\mathrm{c} 3 \mathrm{cccnc} 3) \mathrm{C} 3=\mathrm{C} 1 \mathrm{C}(=\mathrm{O}) \mathrm{CCC} 3) \mathrm{c} 1 \mathrm{nnnn} 12$ & 5400 & 5.27 \\
\hline 4221 & $\operatorname{NCCNC}(=\mathrm{O}) \operatorname{c} 1 \operatorname{ccc}(\mathrm{S}(=\mathrm{O})(=\mathrm{O}) \mathrm{Oc} 2 \operatorname{ccc}(/ \mathrm{C}=\mathrm{C} /[\mathrm{N}+](=\mathrm{O})[\mathrm{O}-]) \operatorname{cc} 2) \operatorname{cc} 1$ & 5400 & * \\
\hline 4222 & $\mathrm{O}=[\mathrm{N}+]([\mathrm{O}-]) \mathrm{c} 1 \mathrm{cc}(\mathrm{NCc} 2 \mathrm{cc}(\mathrm{O}) \operatorname{ccc} 2 \mathrm{O}) \mathrm{ccc} 1 \mathrm{O}$ & 5400 & $*$ \\
\hline 4223 & $\operatorname{COc} 1 \mathrm{c}(\mathrm{NC}(=\mathrm{O}) \mathrm{Nc} 2 \operatorname{ccc}(-\mathrm{c} 3 \operatorname{ccc}(\mathrm{CN} 4 \mathrm{CCOCC} 4) \mathrm{nc} 3) \operatorname{coc} \operatorname{ccc} 23) \operatorname{cc}(\mathrm{C}(\mathrm{C})(\mathrm{C}) \mathrm{C}) \operatorname{cc} 1 \mathrm{NS}(\mathrm{C})(=\mathrm{O})=\mathrm{O}$ & 5400 & $*$ \\
\hline 4224 & Cc1cce $(-n 2 \operatorname{cc} 3 c(-c 4 c(C)[n H] c(-c 5 c c c c c 5) c 4-c 4 c c c c c 4) n n c(C) c 3 n 2) c c 1$ & 5430 & $*$ \\
\hline 4225 & $\operatorname{COc} 1 \operatorname{ccc}(\mathrm{C} 2=\mathrm{NN}(\mathrm{C} 3=\mathrm{NC}(=\mathrm{O}) \mathrm{CS} 3) \mathrm{C}(\mathrm{c} 3 \operatorname{ccc}(\mathrm{C}) \mathrm{cc} 3) \mathrm{C} 2) \mathrm{cc} 1$ & 5460 & 5.26 \\
\hline 4226 & $\mathrm{COc} 1 \mathrm{cc}(\mathrm{OC}) \mathrm{c} 2 \mathrm{c}(=\mathrm{O}) \mathrm{n}(-\mathrm{c} 3 \mathrm{ccc}(\mathrm{F}) \mathrm{c}(\mathrm{Cl}) \mathrm{c} 3) \mathrm{ccc} 2 \mathrm{c} 1$ & 5490 & * \\
\hline 4227 & $\operatorname{CCOc} 1 \mathrm{cc}([\mathrm{N}+](=\mathrm{O})[\mathrm{O}-]) \mathrm{c}(\mathrm{C}(=\mathrm{O}) \mathrm{Nc} 2 \mathrm{ccc}(\mathrm{OCc} 3 \operatorname{cccc}(\mathrm{F}) \mathrm{c} 3) \mathrm{c}(\mathrm{Cl}) \mathrm{c} 2) \mathrm{cc} 1 \mathrm{NC}(=\mathrm{O}) \mathrm{c} 1 \mathrm{ccc}(\mathrm{CN} 2 \mathrm{CCN}(\mathrm{C}) \mathrm{CC} 2) \mathrm{cc} 1$ & 5500 & 5.26 \\
\hline 4228 & $\operatorname{COc} 1 \mathrm{cc}(\mathrm{C}(=\mathrm{O}) \mathrm{n} 2 \mathrm{nc}(-\mathrm{c} 3 \mathrm{ccc}(\mathrm{Cl}) \mathrm{cc} 3) \mathrm{nc} 2 \mathrm{~N}) \mathrm{cc}(\mathrm{OC}) \mathrm{c} 1 \mathrm{OC}$ & 5500 & 5.26 \\
\hline 4229 & $\mathrm{CCCOc} 1 \mathrm{cc} 2 \mathrm{ncnc}(\mathrm{Nc} 3 \mathrm{ccc}(\mathrm{NC}(=\mathrm{O}) \mathrm{OCC}) \mathrm{c}(\mathrm{Cl}) \mathrm{c} 3) \mathrm{c} 2 \mathrm{cc} 1 \mathrm{OC} . \mathrm{Cl}$ & 5500 & $*$ \\
\hline 4230 & $\operatorname{COCCn} 1 \mathrm{c}(=\mathrm{O}) \mathrm{oc} 2 \mathrm{cc} 3 \mathrm{ncnc}(\mathrm{Nc} 4 \mathrm{ccc}(\mathrm{OC}) \mathrm{c}(\mathrm{OC}) \mathrm{c} 4) \mathrm{c} 3 \mathrm{cc} 21$ & 5500 & $*$ \\
\hline 4231 & $\operatorname{Brc} 1 \operatorname{ccc}(\mathrm{Nc} 2 \operatorname{ccnc} 3 \operatorname{cccc} 23) \mathrm{c} 1$ & 5500 & $*$ \\
\hline 4232 & $\mathrm{CCN}(\mathrm{c} 1 \mathrm{ccccc} 1) \mathrm{c} 1 \mathrm{ncnc} 2 \mathrm{cc}(\mathrm{OC}) \mathrm{c}(\mathrm{OC}) \mathrm{cc} 12 . \mathrm{Cl}$ & 5500 & $*$ \\
\hline 4233 & $\mathrm{CONC}(=\mathrm{O}) \mathrm{c} 1 \mathrm{cc}(\mathrm{Nc} 2 \mathrm{ncnn} 3 \mathrm{cc}(\mathrm{NC}(=\mathrm{O}) \mathrm{OCC} 4 \mathrm{CCCO} 4) \mathrm{c}(\mathrm{C}(\mathrm{C}) \mathrm{C}) \mathrm{c} 23) \mathrm{c}(\mathrm{F}) \mathrm{cc} 1 \mathrm{~F}$ & 5500 & $*$ \\
\hline 4234 & $\mathrm{C} / \mathrm{C} 1=\mathrm{C} / \mathrm{CC}[\mathrm{C} @] 23 \mathrm{O}[\mathrm{C} @ \mathrm{H}] 2[\mathrm{C} @ @ \mathrm{H}](\mathrm{OC} 3=\mathrm{O}) \mathrm{C} 2=\mathrm{C}(\mathrm{C} 1) \mathrm{C}(=\mathrm{O}) \mathrm{C}(\mathrm{O})=\mathrm{CC} 2=\mathrm{O}$ & 5500 & $*$ \\
\hline 4235 & $\mathrm{COc} 1 \operatorname{ccc}(\mathrm{C} 2=\mathrm{NN}(\mathrm{C} 3=\mathrm{NC}(=\mathrm{O}) \mathrm{CS} 3) \mathrm{C}(\mathrm{c} 3 \operatorname{cccc} 4 \operatorname{ccccc} 34) \mathrm{C} 2) \mathrm{cc} 1$ & 5530 & 5.26 \\
\hline 4236 & $\mathrm{CC}(\mathrm{C})(\mathrm{C}) \mathrm{NC}(=\mathrm{O}) \mathrm{Nc} 1 \mathrm{nc} 2 \mathrm{nc}(\mathrm{N}) \mathrm{ncc} 2 \mathrm{cc} 1-\mathrm{c} 1 \mathrm{ccccc} 1$ & 5530 & $*$ \\
\hline 4237 & $\mathrm{Cc} 1 \mathrm{ccc}(\mathrm{C}(=\mathrm{O}) \mathrm{Nc} 2 \operatorname{ccc}(\mathrm{CN} 3 \mathrm{CCN}(\mathrm{C}) \mathrm{CC} 3) \mathrm{c}(\mathrm{C}(\mathrm{F})(\mathrm{F}) \mathrm{F}) \mathrm{c} 2) \operatorname{cc} 1 \mathrm{NC}(=\mathrm{O}) \mathrm{c} 1 \mathrm{cnc}(\mathrm{N}(\mathrm{C}) \mathrm{C}) \mathrm{nc} 1$ & 5540 & 5.26 \\
\hline 4238 & $\operatorname{COc} 1 \operatorname{ccc}(\mathrm{C} 2=\mathrm{NN}(\mathrm{c} 3 \mathrm{nc}(-\mathrm{c} 4 \operatorname{ccccc} 4) \operatorname{cs} 3) \mathrm{C}(\mathrm{c} 3 \mathrm{ccc}(\mathrm{Br}) \mathrm{cc} 3) \mathrm{C} 2) \mathrm{cc} 1$ & 5560 & 5.25 \\
\hline 4239 & $\mathrm{Cc} 1 \mathrm{ccc}(\mathrm{C} 2 \mathrm{CC}(\mathrm{c} 3 \operatorname{ccc}(\mathrm{Br}) \operatorname{cc} 3)=\mathrm{NN} 2 \mathrm{C} 2=\mathrm{NC}(=\mathrm{O}) \mathrm{CS} 2) \mathrm{cc} 1$ & 5580 & 5.25 \\
\hline 4240 & $\mathrm{C}=\mathrm{CC}(=\mathrm{O}) \mathrm{Nc} 1 \mathrm{ccc}(-\mathrm{n} 2 \mathrm{c}(=\mathrm{O}) \mathrm{cnc} 3 \mathrm{cnc}(\mathrm{Nc} 4 \mathrm{ccc}(\mathrm{N} 5 \mathrm{CCOCC} 5) \mathrm{cc} 4) \mathrm{nc} 32) \mathrm{cc} 1$ & 5585 & 5.25 \\
\hline 4241 & $\mathrm{COc} 1 \mathrm{cc}(/ \mathrm{C}=\mathrm{C} 2 \backslash \mathrm{CCC} / \mathrm{C}(=\mathrm{C} \backslash \mathrm{c} 3 \operatorname{ccc}(\mathrm{F}) \mathrm{cc} 3) \mathrm{C} 2=\mathrm{O}) \mathrm{cc}(\mathrm{OC}) \mathrm{c} 1$ & 5600 & 5.25 \\
\hline 4242 & $\mathrm{O}=\mathrm{C} 1 \mathrm{NN}(\mathrm{c} 2 \mathrm{ccc}(\mathrm{F}) \mathrm{cc} 2) \mathrm{C}(=\mathrm{O}) / \mathrm{C} 1=\mathrm{C} \mid \mathrm{c} 1 \mathrm{cccc}(\mathrm{OCc} 2 \mathrm{cccc} 2 \mathrm{~F}) \mathrm{c} 1$ & 5600 & 5.25 \\
\hline
\end{tabular}




\begin{tabular}{|c|c|c|c|}
\hline 4243 & $\mathrm{COc} 1 \mathrm{cc} 2 \mathrm{c}(\mathrm{cc} 1 \mathrm{OC}) \mathrm{Oc} 1 \mathrm{ncnc}(\mathrm{Nc} 3 \mathrm{ccc} 4 \mathrm{ncsc} 4 \mathrm{c} 3) \mathrm{c} 1 \mathrm{NC} 2$ & 5600 & 5.25 \\
\hline 4244 & $\mathrm{COc} 1 \mathrm{cc}(\mathrm{N} 2 \mathrm{CCN}(\mathrm{C}) \mathrm{CC} 2) \operatorname{ccc} 1 \mathrm{Nc} 1 \mathrm{ncc}(\mathrm{Cl}) \mathrm{c}(\mathrm{Oc} 2 \operatorname{ccc}(\mathrm{NC}(=\mathrm{O}) / \mathrm{C}=\mathrm{C} / \mathrm{C} 3 \mathrm{CC} 3) \mathrm{c} 2) \mathrm{n} 1$ & 5600 & 5.25 \\
\hline 4245 & $\operatorname{COc} 1 \mathrm{ccc}(-\mathrm{c} 2 \mathrm{nc} 3 \mathrm{sc}(-\mathrm{c} 4 \mathrm{cccc} 4) \mathrm{cn} 3 \mathrm{n} 2) \mathrm{cc} 1$ & 5600 & 5.25 \\
\hline 4246 & $\mathrm{COc} 1 \mathrm{cc} 2 \mathrm{ncnc}(\mathrm{C} \# \mathrm{Cc} 3 \mathrm{cccc} 3) \mathrm{c} 2 \mathrm{cc} 1 \mathrm{OC}$ & 5600 & $*$ \\
\hline 4247 & $\mathrm{C}=\mathrm{C}(\mathrm{CN}(\mathrm{C}) \mathrm{C}) \mathrm{C}(=\mathrm{O}) \mathrm{c} 1 \mathrm{ccccc} 1 . \mathrm{Cl}$ & 5600 & $*$ \\
\hline 4248 & $\mathrm{Cn} 1 \mathrm{c}(=\mathrm{O}) \mathrm{c}(-\mathrm{c} 2 \mathrm{c}(\mathrm{Cl}) \mathrm{cccc} 2 \mathrm{Cl}) \mathrm{cc} 2 \mathrm{cnc}(\mathrm{N}) \mathrm{nc} 21$ & 5600 & $*$ \\
\hline 4249 & $\mathrm{COc} 1 \mathrm{cc} 2 \mathrm{ncnc}(\mathrm{Nc} 3 \operatorname{ccc}(\mathrm{NC}(=\mathrm{O}) \mathrm{c} 4 \mathrm{cccc} 4) \mathrm{c} 3) \mathrm{c} 2 \mathrm{cc} 1 \mathrm{OC}$ & 5600 & $*$ \\
\hline 4250 & $\mathrm{Clc} 1 \mathrm{ccc}(\mathrm{Nc} 2 \mathrm{ncnc} 3 \mathrm{ccc}(\mathrm{NCc} 4 \mathrm{ccc}(\mathrm{Br}) \mathrm{cc} 4) \mathrm{cc} 23) \mathrm{c} 1$ & 5670 & 5.25 \\
\hline 4251 & $\mathrm{NC}(=\mathrm{S}) \mathrm{N} 1 \mathrm{~N}=\mathrm{C}(\mathrm{c} 2 \operatorname{ccc}(\mathrm{Br}) \mathrm{cc} 2) \mathrm{CC} 1 \mathrm{c} 1 \mathrm{cccc} 2 \mathrm{ccccc} 12$ & 5680 & 5.25 \\
\hline 4252 & $\mathrm{COc} 1 \mathrm{cc} 2 \mathrm{ncnc}(\mathrm{Nc} 3 \mathrm{ccc}(\mathrm{Br}) \mathrm{cc} 3 \mathrm{~F}) \mathrm{c} 2 \mathrm{cc} 1 \mathrm{OC}$ & 5700 & $*$ \\
\hline 4253 & $\mathrm{C} \# \mathrm{Cc} 1 \mathrm{cccc}(\mathrm{Nc} 2 \mathrm{ncnc} 3 \mathrm{cc} 4 \mathrm{oc}(=\mathrm{O}) \mathrm{n}(\mathrm{CCCC}(=\mathrm{O}) \mathrm{OCC}) \mathrm{c} 4 \mathrm{cc} 23) \mathrm{c} 1$ & 5700 & $*$ \\
\hline 4254 & $\mathrm{CC}(=\mathrm{O}) \mathrm{N} 1 \mathrm{CCc} 2 \mathrm{ccc}(\mathrm{Nc} 3 \mathrm{nc}(\mathrm{Nc} 4 \mathrm{ccc}(\mathrm{N} 5 \mathrm{CCN}(\mathrm{C}) \mathrm{CC} 5) \operatorname{cc} 4) \mathrm{ncc} 3 \mathrm{Br}) \mathrm{cc} 21$ & 5700 & $*$ \\
\hline 4255 & $\mathrm{COc} 1 \mathrm{ccc}(\mathrm{C} 2=\mathrm{NN}(\mathrm{c} 3 \mathrm{nc}(-\mathrm{c} 4 \mathrm{cccc} 4) \mathrm{cs} 3) \mathrm{C}(\mathrm{c} 3 \mathrm{ccc}(\mathrm{F}) \mathrm{cc} 3) \mathrm{C} 2) \mathrm{cc} 1$ & 5710 & 5.24 \\
\hline 4256 & $\mathrm{Cc} 1 \mathrm{ccccc} 1-\mathrm{c} 1 \mathrm{nnn}(\mathrm{SCc} 2 \mathrm{cccc} 2) \mathrm{o} 1$ & 5720 & 5.24 \\
\hline 4257 & $\mathrm{COc} 1 \operatorname{ccc}(\mathrm{C} 2 \mathrm{CC}(\mathrm{c} 3 \operatorname{ccc}(\mathrm{Cl}) \mathrm{c}(\mathrm{Cl}) \mathrm{c} 3)=\mathrm{NN} 2 \mathrm{C}(\mathrm{N})=\mathrm{S}) \mathrm{cc} 1$ & 5740 & 5.24 \\
\hline 4258 & $\mathrm{Cc} 1 \mathrm{ncc}([\mathrm{N}+](=\mathrm{O})[\mathrm{O}-]) \mathrm{n} 1 \mathrm{CCOC}(=\mathrm{O}) / \mathrm{C}=\mathrm{C} / \mathrm{c} 1 \operatorname{ccc} 2 \operatorname{ccccc} 2 \mathrm{c} 1$ & 5760 & 5.24 \\
\hline 4259 & $\mathrm{COc} 1 \mathrm{ccc}(/ \mathrm{C}=\mathrm{N} / \mathrm{NC} 2=\mathrm{NC}(=\mathrm{O}) \mathrm{CS} 2) \mathrm{cc} 1$ & 5780 & 5.24 \\
\hline 4260 & $\mathrm{COc} 1 \mathrm{cc}(\mathrm{C} 2=\mathrm{C}(\mathrm{c} 3 \mathrm{c}[\mathrm{nH}] \mathrm{c} 4 \mathrm{ccc}(\mathrm{Br}) \mathrm{cc} 34) \mathrm{C}(=\mathrm{O}) \mathrm{NC} 2=\mathrm{O}) \mathrm{cc}(\mathrm{OC}) \mathrm{c} 1 \mathrm{OC}$ & 5797 & $*$ \\
\hline 4261 & $\operatorname{CCOC}(=\mathrm{O}) \mathrm{c} 1 \mathrm{ccc}(\mathrm{Nc} 2 \mathrm{ncnc} 3 \mathrm{cc} 4 \mathrm{oc}(=\mathrm{O}) \mathrm{n}(\mathrm{CCCN} 5 \mathrm{CCOCC} 5) \mathrm{c} 4 \mathrm{cc} 23) \mathrm{cc} 1$ & 5800 & $*$ \\
\hline 4262 & $\mathrm{COc} 1 \mathrm{cc} 2 \mathrm{ncnc}(\mathrm{Nc} 3 \mathrm{ccc}(\mathrm{NC}(=\mathrm{O}) \mathrm{OC}(\mathrm{C}) \mathrm{C}) \mathrm{c}(\mathrm{C}) \mathrm{c} 3) \mathrm{c} 2 \mathrm{cc} 1 \mathrm{OC}$ & 5800 & $*$ \\
\hline 4263 & $\mathrm{Cc} 1 \mathrm{cc}(\mathrm{C}) \mathrm{c}(\mathrm{O}) \mathrm{c}(\mathrm{CN}(\mathrm{Cc} 2 \mathrm{ccc}(\mathrm{O}) \mathrm{cc} 2) \mathrm{C}(=\mathrm{S}) \mathrm{Nc} 2 \mathrm{ccccc} 2) \mathrm{c} 1$ & 5830 & 5.23 \\
\hline 4264 & $\operatorname{CCCCCCCCOC}(=\mathrm{O}) \operatorname{COc} 1 \mathrm{cc}(\mathrm{O}) \mathrm{c} 2 \mathrm{c}(=\mathrm{O}) \mathrm{cc}(-\mathrm{c} 3 \operatorname{ccccc} 3) \mathrm{oc} 2 \mathrm{c} 1$ & 5840 & 5.23 \\
\hline 4265 & $\mathrm{COc} 1 \mathrm{cc} 2 \mathrm{c}(\mathrm{cc} 1 \mathrm{OC}) \mathrm{Sc} 1 \mathrm{ncnc}(\mathrm{Nc} 3 \mathrm{ccc}(\mathrm{Br}) \mathrm{c} 3) \mathrm{c} 1 \mathrm{NC} 2$ & 5900 & 5.23 \\
\hline 4266 & $\mathrm{COc} 1 \mathrm{cc} 2 \mathrm{ncnc}(\mathrm{Oc} 3 \mathrm{ccc}(\mathrm{Br}) \mathrm{c}(\mathrm{F}) \mathrm{c} 3) \mathrm{c} 2 \mathrm{cc} 1 \mathrm{OC}$ & 5900 & $*$ \\
\hline 4267 & $\mathrm{O}=[\mathrm{N}+]([\mathrm{O}-]) \mathrm{c} 1 \mathrm{ccc} 2 \mathrm{c}(\mathrm{NCc} 3 \mathrm{cccc} 3) \mathrm{ncnc} 2 \mathrm{c} 1$ & 5900 & $*$ \\
\hline 4268 & Nc1 $1 \mathrm{cc}(\mathrm{Nc} 2 \mathrm{ncnc} 3 \mathrm{cc}(\mathrm{N}) \mathrm{ncc} 23) \mathrm{cc} 1$ & 5900 & $*$ \\
\hline 4269 & $\mathrm{COc} 1 \mathrm{cc} 2 \mathrm{ncnc}(\mathrm{Oc} 3 \operatorname{ccc}(\mathrm{NC}(=\mathrm{S}) \mathrm{Nc} 4 \mathrm{ccc}(\mathrm{F}) \mathrm{cc} 4) \mathrm{c} 3) \mathrm{c} 2 \mathrm{cc} 1 \mathrm{OC}$ & 5900 & $*$ \\
\hline 4270 & $\mathrm{O}=\mathrm{C}(\mathrm{Cc} 1 \mathrm{ccc}(\mathrm{F}) \operatorname{cc} 1) \mathrm{NS}(=\mathrm{O})(=\mathrm{O}) \mathrm{c} 1 \mathrm{ccc}(\mathrm{Cl}) \mathrm{cc} 1$ & 5930 & 5.23 \\
\hline 4271 & $\mathrm{COc} 1 \mathrm{ccc}(\mathrm{C} 2=\mathrm{NN}(\mathrm{C} 3=\mathrm{NC}(=\mathrm{O}) \mathrm{CS} 3) \mathrm{C}(\mathrm{c} 3 \operatorname{ccc}(\mathrm{F}) \mathrm{cc} 3) \mathrm{C} 2) \mathrm{cc} 1$ & 5950 & 5.23 \\
\hline 4272 & CCOc1cce(-c2nn $(\mathrm{C}(\mathrm{C}) \mathrm{C}) \mathrm{c} 3 \mathrm{ncnc}(\mathrm{N}) \mathrm{c} 23) \mathrm{cc} 1 \mathrm{OC}$ & 5950 & $*$ \\
\hline 4273 & $\mathrm{Cc} 1 \mathrm{ccc}(\mathrm{Nc} 2 \mathrm{nccc}(\mathrm{N}(\mathrm{C}) \mathrm{c} 3 \operatorname{ccc} 4 \mathrm{c}(\mathrm{C}) \mathrm{n}(\mathrm{C}) \mathrm{nc} 4 \mathrm{c} 3) \mathrm{n} 2) \operatorname{cc} 1 \mathrm{~S}(\mathrm{~N})(=\mathrm{O})=\mathrm{O}$ & 5950 & $*$ \\
\hline 4274 & $\mathrm{CC}(\mathrm{C}) \mathrm{n} 1 \mathrm{nc}(-\mathrm{c} 2 \mathrm{cc}(\mathrm{C}=\mathrm{O}) \operatorname{co} 2) \mathrm{c} 2 \mathrm{c}(\mathrm{N}) \mathrm{ncn} \mathrm{c} 21$ & 5960 & $*$ \\
\hline 4275 & $\operatorname{CCOc} 1 \operatorname{ccc}(\mathrm{C}(=\mathrm{O}) \mathrm{Nc} 2 \mathrm{nccc}(-\mathrm{c} 3 \operatorname{ccc} n \mathrm{c} 3) \mathrm{n} 2) \mathrm{cc} 1 \mathrm{NC}(=\mathrm{O}) / \mathrm{C}=\mathrm{C} / \mathrm{CN}(\mathrm{C}) \mathrm{C}$ & 6000 & 5.22 \\
\hline 4276 & $\mathrm{Cc} 1 \mathrm{ccc}(\mathrm{NC}(=\mathrm{O}) \mathrm{c} 2 \operatorname{ccc}(\mathrm{CN} 3 \mathrm{CCN}(\mathrm{C}) \mathrm{CC} 3) \operatorname{cc} 2) \operatorname{cc} 1 \mathrm{C}(=\mathrm{O}) \mathrm{Nc} 1 \mathrm{nccc}(-\mathrm{c} 2 \operatorname{ccc}(\mathrm{F}) \mathrm{c} 2) \mathrm{n} 1$ & 6000 & 5.22 \\
\hline 4277 & $\mathrm{CCOc} 1 \mathrm{cc}([\mathrm{N}+](=\mathrm{O})[\mathrm{O}-]) \mathrm{c}(\mathrm{C}(=\mathrm{O}) \mathrm{Nc} 2 \mathrm{ccc}(\mathrm{F}) \mathrm{c}(\mathrm{Cl}) \mathrm{c} 2) \mathrm{cc} 1 \mathrm{NC}(=\mathrm{O}) / \mathrm{C}=\mathrm{C} / \mathrm{CN}(\mathrm{C}) \mathrm{C}$ & 6000 & 5.22 \\
\hline 4278 & $\mathrm{O}=\mathrm{C}(\mathrm{O}) \mathrm{Cc} 1 \mathrm{cc}(\mathrm{NCc} 2 \mathrm{cc}(\mathrm{O}) \mathrm{ccc} 2 \mathrm{O}) \mathrm{ccc} 1 \mathrm{O}$ & 6000 & $*$ \\
\hline 4279 & $\operatorname{COc} 1 \mathrm{cc}(\mathrm{C}=\mathrm{C}(\mathrm{C \# N}) \mathrm{CHN}) \mathrm{cc}(\mathrm{O}) \mathrm{c} 1 \mathrm{O}$ & 6000 & $*$ \\
\hline 4280 & $\mathrm{COc} 1 \mathrm{cc} 2 \mathrm{nccc}(\mathrm{Oc} 3 \operatorname{ccc}(\mathrm{N}(\mathrm{C}) \mathrm{C}(=\mathrm{O}) \mathrm{c} 4 \mathrm{ccc}(\mathrm{C}(\mathrm{C})(\mathrm{C}) \mathrm{C}) \mathrm{cc} 4) \mathrm{cc} 3) \mathrm{c} 2 \mathrm{cc} 1 \mathrm{OC}$ & 6000 & $*$ \\
\hline 4281 & $\mathrm{COc} 1 \mathrm{ccc}(/ \mathrm{C}=\mathrm{C} / \mathrm{C}(=\mathrm{O}) \mathrm{Nc} 2 \mathrm{ccc} 3 \mathrm{ncnc}(\mathrm{Nc} 4 \operatorname{ccc}(\mathrm{Br}) \mathrm{c} 4) \mathrm{c} 3 \mathrm{c} 2) \mathrm{c} 1$ & 6020 & 5.22 \\
\hline 4282 & $\mathrm{COc} 1 \mathrm{cccc}(/ \mathrm{C}=\mathrm{C} 2 \backslash \mathrm{CCC} / \mathrm{C}(=\mathrm{C} \backslash \mathrm{c} 3 \mathrm{cc}(\mathrm{OC}) \mathrm{cc}(\mathrm{OC}) \mathrm{c} 3) \mathrm{C} 2=\mathrm{O}) \mathrm{c} 1$ & 6100 & 5.21 \\
\hline 4283 & $\mathrm{CNC}(=\mathrm{O}) \mathrm{c} 1 \mathrm{c}([\mathrm{Se}][\mathrm{Se}] \mathrm{c} 2 \mathrm{c}(\mathrm{C}(=\mathrm{O}) \mathrm{NC}) \mathrm{c} 3 \operatorname{cccc} 3 \mathrm{n} 2 \mathrm{C}) \mathrm{n}(\mathrm{C}) \mathrm{c} 2 \mathrm{cccc} 12$ & 6100 & $*$ \\
\hline 4284 & $\mathrm{O}=[\mathrm{N}+]([\mathrm{O}-]) \mathrm{c} 1 \mathrm{ccc} 2 \mathrm{c}(\mathrm{Nc} 3 \mathrm{ccc}(\mathrm{F}) \mathrm{c} 3) \mathrm{ncnc} 2 \mathrm{c} 1$ & 6100 & $*$ \\
\hline 4285 & $\mathrm{Cc} 1 \mathrm{ccc}(\mathrm{C}(=\mathrm{O}) \mathrm{N} / \mathrm{N}=\mathrm{C}(/ \mathrm{Cn} 2 \mathrm{c}([\mathrm{N}+](=\mathrm{O})[\mathrm{O}-]) \operatorname{cnc} 2 \mathrm{C}) \mathrm{c} 2 \mathrm{ccc}(\mathrm{Br}) \mathrm{cc} 2) \mathrm{cc} 1$ & 6130 & 5.21 \\
\hline
\end{tabular}




\begin{tabular}{|c|c|c|c|}
\hline 4286 & $\mathrm{CCOC}(=\mathrm{O}) \mathrm{C} 1=\mathrm{C}(\mathrm{N}) \mathrm{N}(\mathrm{c} 2 \mathrm{cccnc} 2) \mathrm{C} 2=\mathrm{C}(\mathrm{C}(=\mathrm{O}) \mathrm{CCC} 2) \mathrm{C} 1 \mathrm{c} 1 \mathrm{c}(\mathrm{C}) \mathrm{nn}(-\mathrm{c} 2 \mathrm{ccc}(\mathrm{Cl}) \mathrm{cc} 2) \mathrm{c} 1 \mathrm{Cl}$ & 6150 & 5.21 \\
\hline 4287 & $\mathrm{COC}(=\mathrm{O}) \mathrm{Nc} 1 \mathrm{ccc}(\mathrm{Nc} 2 \mathrm{ncnc} 3 \mathrm{cc}(\mathrm{OC}) \mathrm{c}(\mathrm{OC}) \mathrm{cc} 23) \mathrm{cc} 1 \mathrm{Cl} . \mathrm{Cl}$ & 6150 & $*$ \\
\hline 4288 & $\mathrm{COC}(=\mathrm{O}) \mathrm{Nc} 1 \mathrm{ccc}(\mathrm{Nc} 2 \mathrm{ncnc} 3 \mathrm{cc}(\mathrm{OC}) \mathrm{c}(\mathrm{OC}) \mathrm{cc} 23) \mathrm{cc} 1 \mathrm{Cl}$ & 6150 & $*$ \\
\hline 4289 & $\mathrm{C} \# \mathrm{Cc} 1 \mathrm{cccc}(\mathrm{NC}(=\mathrm{O}) \mathrm{c} 2 \operatorname{ccc}(\mathrm{NC}(=\mathrm{O}) \mathrm{CCCCCC}(=\mathrm{O}) \mathrm{NO}) \mathrm{c} 2) \mathrm{c} 1$ & 6170 & $*$ \\
\hline 4290 & $\mathrm{CCN}(\mathrm{CC}) \mathrm{CCCNc} 1 \mathrm{ncc} 2 \mathrm{cc}(-\mathrm{c} 3 \mathrm{c}(\mathrm{Cl}) \mathrm{cccc} 3 \mathrm{Cl}) \mathrm{c}(\mathrm{NC}(=\mathrm{O}) \mathrm{NC}(\mathrm{C})(\mathrm{C}) \mathrm{C}) \mathrm{nc} 2 \mathrm{n} 1$ & 6200 & $*$ \\
\hline 4291 & $\mathrm{CCC}(=\mathrm{O}) \mathrm{N} 1 \mathrm{CC}[\mathrm{C} @ \mathrm{H}](\mathrm{N} 2 \mathrm{C}(=\mathrm{O}) \mathrm{N}(\mathrm{c} 3 \mathrm{cc}(\mathrm{OC}) \mathrm{ccc} 3 \mathrm{~F}) \mathrm{Cc} 3 \mathrm{cnc}(\mathrm{Nc} 4 \mathrm{ccc}(\mathrm{N} 5 \mathrm{CCOCC} 5) \mathrm{c}(\mathrm{C}) \mathrm{c} 4) \mathrm{nc} 32) \mathrm{C} 1$ & 6265 & 5.20 \\
\hline 4292 & $\mathrm{CC \# CC}(=\mathrm{O}) \mathrm{Nc} 1 \mathrm{cnc} 2 \mathrm{ncc}(\mathrm{C \# N}) \mathrm{c}(\mathrm{Nc} 3 \mathrm{cccc}(\mathrm{Br}) \mathrm{c} 3) \mathrm{c} 2 \mathrm{c} 1$ & 6266.2 & 5.20 \\
\hline 4293 & $\mathrm{NC}(=\mathrm{S}) \mathrm{N} 1 \mathrm{~N}=\mathrm{C}(\mathrm{c} 2 \mathrm{ccc}(\mathrm{Cl}) \mathrm{c}(\mathrm{Cl}) \mathrm{c} 2) \mathrm{CC} 1 \mathrm{c} 1 \mathrm{ccc}(\mathrm{F}) \mathrm{cc} 1$ & 6270 & 5.20 \\
\hline 4294 & $\mathrm{COc} 1 \mathrm{ccc}(\mathrm{C} 2=\mathrm{NN}(\mathrm{c} 3 \mathrm{nc}(-\mathrm{c} 4 \mathrm{ccc}(\mathrm{Cl}) \mathrm{cc} 4) \operatorname{cs} 3) \mathrm{C}(\mathrm{c} 3 \mathrm{ccc}(\mathrm{OC}) \mathrm{cc} 3) \mathrm{C} 2) \mathrm{cc} 1$ & 6270 & 5.20 \\
\hline 4295 & $\operatorname{CCCCCCCNC}(=\mathrm{O}) \operatorname{COc} 1 \mathrm{cc}(\mathrm{O}) \mathrm{c} 2 \mathrm{c}(=\mathrm{O}) \mathrm{cc}(-\mathrm{c} 3 \operatorname{cccc} 3) \mathrm{oc} 2 \mathrm{c} 1$ & 6280 & 5.20 \\
\hline 4296 & Fc1 $1 \mathrm{ccc}(-\mathrm{c} 2 \mathrm{nn} 3 \mathrm{ccccc} 3 \mathrm{c} 2-\mathrm{c} 2 \mathrm{ccncc} 2) \mathrm{cc} 1$ & 6300 & $*$ \\
\hline 4297 & $\mathrm{O}=\mathrm{C} 1 \mathrm{CSC}(\mathrm{N} 2 \mathrm{~N}=\mathrm{C}(\mathrm{c} 3 \operatorname{ccc} \mathrm{c} 3) \mathrm{CC} 2 \mathrm{c} 2 \mathrm{ccc} 3 \operatorname{ccc} c \mathrm{c} 3 \mathrm{c} 2)=\mathrm{N} 1$ & 6310 & 5.20 \\
\hline 4298 & $\mathrm{COc} 1 \mathrm{ccc}(\mathrm{C} 2=\mathrm{NN}(\mathrm{c} 3 \mathrm{nc}(-\mathrm{c} 4 \mathrm{ccc}(\mathrm{Cl}) \mathrm{cc} 4) \mathrm{cs} 3) \mathrm{C}(\mathrm{c} 3 \mathrm{ccc}(\mathrm{Br}) \mathrm{cc} 3) \mathrm{C} 2) \mathrm{cc} 1$ & 6310 & 5.20 \\
\hline 4299 & $\mathrm{COc} 1 \mathrm{ccc}(-\mathrm{c} 2 \mathrm{nn}(\mathrm{C}(\mathrm{C})(\mathrm{C}) \mathrm{C}) \mathrm{c} 3 \mathrm{ncnc}(\mathrm{N}) \mathrm{c} 23) \mathrm{cc} 1 \mathrm{OC}$ & 6340 & $*$ \\
\hline 4300 & $\mathrm{COc} 1 \mathrm{cc} 2 \mathrm{ncc}(\mathrm{CHN}) \mathrm{c}(\mathrm{Nc} 3 \operatorname{ccc}(\mathrm{O}) \mathrm{c} 3) \mathrm{c} 2 \mathrm{cc} 1 \mathrm{OC}$ & 6360 & $*$ \\
\hline 4301 & $\mathrm{O}=\mathrm{C}(\mathrm{CBr}) \mathrm{OCCn} 1 \mathrm{c}(=\mathrm{O}) \mathrm{oc} 2 \mathrm{cc} 3 \mathrm{ncnc}(\mathrm{Nc} 4 \mathrm{ccc}(\mathrm{OCc} 5 \mathrm{ccc}(\mathrm{Cl}) \mathrm{cc} 5) \mathrm{cc} 4) \mathrm{c} 3 \mathrm{cc} 21$ & 6400 & 5.19 \\
\hline 4302 & $\operatorname{CCCCOC}(=\mathrm{O}) \mathrm{Nc} 1 \mathrm{ccc}(\mathrm{Nc} 2 \mathrm{ncnc} 3 \mathrm{cc}(\mathrm{OC}) \mathrm{c}(\mathrm{OC}) \mathrm{cc} 23) \mathrm{cc} 1 \mathrm{Cl} . \mathrm{Cl}$ & 6400 & $*$ \\
\hline 4303 & $\operatorname{CCCCOC}(=\mathrm{O}) \mathrm{Nc} 1 \mathrm{ccc}(\mathrm{Nc} 2 \mathrm{ncnc} 3 \mathrm{cc}(\mathrm{OC}) \mathrm{c}(\mathrm{OC}) \mathrm{cc} 23) \mathrm{cc} 1 \mathrm{Cl}$ & 6400 & $*$ \\
\hline 4304 & $\mathrm{O}=\mathrm{C}(\mathrm{Cc} 1 \mathrm{ccc}(\mathrm{F}) \operatorname{cc} 1) \mathrm{NS}(=\mathrm{O})(=\mathrm{O}) \mathrm{c} 1 \mathrm{ccc}(\mathrm{Br}) \mathrm{cc} 1$ & 6410 & 5.19 \\
\hline 4305 & $\mathrm{C} / \mathrm{C}=\mathrm{C}(\backslash \mathrm{C}) \mathrm{C}(=\mathrm{O}) \mathrm{Nc} 1 \mathrm{cc} 2 \mathrm{c}(\mathrm{Nc} 3 \mathrm{ccc}(\mathrm{F}) \mathrm{c}(\mathrm{Cl}) \mathrm{c} 3) \mathrm{ncnc} 2 \mathrm{~s} 1$ & 6414 & $*$ \\
\hline 4306 & $\mathrm{NC}(=\mathrm{S}) \mathrm{N} 1 \mathrm{~N}=\mathrm{C}(\mathrm{c} 2 \mathrm{ccc}(\mathrm{Cl}) \mathrm{c}(\mathrm{Cl}) \mathrm{c} 2) \mathrm{CC} 1 \mathrm{c} 1 \mathrm{ccccc} 1 \mathrm{Br}$ & 6430 & 5.19 \\
\hline 4307 & $\mathrm{CCn} 1 \mathrm{nc}(-\mathrm{c} 2 \mathrm{ccc}(\mathrm{OC}) \mathrm{c}(\mathrm{O}) \mathrm{c} 2) \mathrm{c} 2 \mathrm{c}(\mathrm{N}) \mathrm{ncnc} 21$ & 6450 & $*$ \\
\hline 4308 & $\mathrm{O}=\mathrm{C} 1 \mathrm{CSC}(\mathrm{N} 2 \mathrm{~N}=\mathrm{C}(\mathrm{c} 3 \mathrm{ccc}(\mathrm{Br}) \mathrm{cc} 3) \mathrm{CC} 2 \mathrm{c} 2 \mathrm{ccc}(\mathrm{F}) \mathrm{cc} 2)=\mathrm{N} 1$ & 6480 & 5.19 \\
\hline 4309 & $\operatorname{COc} 1 \mathrm{cc}(\mathrm{C}(=\mathrm{O}) \mathrm{n} 2 \mathrm{nc}(-\mathrm{c} 3 \mathrm{cc}(\mathrm{OC}) \mathrm{c}(\mathrm{OC}) \mathrm{c}(\mathrm{OC}) \mathrm{c} 3) \mathrm{nc} 2 \mathrm{~N}) \mathrm{cc}(\mathrm{OC}) \mathrm{c} 1 \mathrm{OC}$ & 6500 & 5.19 \\
\hline 4310 & $\operatorname{COc} 1 \operatorname{ccc} 2 \mathrm{c}(\mathrm{C}(=\mathrm{O}) \mathrm{Nc} 3 \operatorname{ccc} c 3) \mathrm{c}(\mathrm{SSc} 3 \mathrm{c}(\mathrm{C}(=\mathrm{O}) \mathrm{Nc} 4 \operatorname{cccc} 4) \mathrm{c} 4 \operatorname{ccc}(\mathrm{OC}) \mathrm{c} 4 \mathrm{n} 3 \mathrm{C}) \mathrm{n}(\mathrm{C}) \mathrm{c} 12$ & 6500 & $*$ \\
\hline 4311 & $\mathrm{Cc} 1 \mathrm{cccc}(\mathrm{N}(\mathrm{C}) \mathrm{c} 2 \mathrm{ncnc} 3 \mathrm{cc}(\mathrm{C}) \mathrm{c}(\mathrm{C}) \mathrm{cc} 23) \mathrm{c} 1 . \mathrm{Cl}$ & 6500 & $*$ \\
\hline 4312 & $\mathrm{Cc} 1 \mathrm{cccc}(\mathrm{C}=\mathrm{C} 2 / \mathrm{SC}(\mathrm{N} 3 \mathrm{CCC}[\mathrm{C} @ \mathrm{H}] 3 \mathrm{C}(=\mathrm{O}) \mathrm{Nc} 3 \mathrm{ccc} 4 \mathrm{ncnc}(\mathrm{Nc} 5 \mathrm{cccc}(\mathrm{Cl}) \mathrm{c} 5) \mathrm{c} 4 \mathrm{c} 3)=\mathrm{NC} 2=\mathrm{O}) \mathrm{n} 1$ & 6500 & $*$ \\
\hline 4313 & $\mathrm{COc} 1 \operatorname{ccc}(\mathrm{C} 2=\mathrm{NN}(\mathrm{C}(=\mathrm{O}) \mathrm{Cc} 3 \mathrm{nc} 4 \operatorname{ccccc} 4[\mathrm{nH}] 3) \mathrm{C}(\mathrm{c} 3 \operatorname{ccc}(\mathrm{Br}) \mathrm{cc} 3) \mathrm{C} 2) \mathrm{cc} 1$ & 6500 & $*$ \\
\hline 4314 & $\operatorname{COc} 1 \mathrm{cc} 2 \operatorname{nccc}(\mathrm{Oc} 3 \operatorname{ccc}(\mathrm{NC}(=\mathrm{O}) \mathrm{NC} 4 \mathrm{CC} 4) \mathrm{c}(\mathrm{Cl}) \mathrm{c} 3) \mathrm{c} 2 \mathrm{cc} 1 \mathrm{C}(\mathrm{N})=\mathrm{O}$ & 6500 & $*$ \\
\hline 4315 & $\mathrm{NC}(=\mathrm{S}) \mathrm{N} 1 \mathrm{~N}=\mathrm{C}(\mathrm{c} 2 \mathrm{ccc}(\mathrm{Cl}) \mathrm{c}(\mathrm{Cl}) \mathrm{c} 2) \mathrm{CC} 1 \mathrm{c} 1 \mathrm{ccccc} 1 \mathrm{~F}$ & 6560 & 5.18 \\
\hline 4316 & $\mathrm{COc} 1 \operatorname{ccc}(/ \mathrm{C}=\mathrm{C} / \mathrm{C}(=\mathrm{O}) \mathrm{Nc} 2 \operatorname{ccc} 3 n \mathrm{ncnc}(\mathrm{Nc} 4 \operatorname{cccc}(\mathrm{Cl}) \mathrm{c} 4) \mathrm{c} 3 \mathrm{c} 2) \mathrm{c} 1$ & 6630 & 5.18 \\
\hline 4317 & $\mathrm{COc} 1 \mathrm{cc} 2 \mathrm{ncc}(\mathrm{CHN}) \mathrm{c}(\mathrm{Nc} 3 \mathrm{ccc}(\mathrm{Br}) \mathrm{cc} 3) \mathrm{c} 2 \mathrm{cc} 1 \mathrm{OC}$ & 6650 & $*$ \\
\hline 4318 & $\mathrm{Cc} 1 \mathrm{ccc}(\mathrm{C} 2 \mathrm{CC}(\mathrm{c} 3 \operatorname{ccc}(\mathrm{Cl}) \mathrm{cc} 3)=\mathrm{NN} 2 \mathrm{C} 2=\mathrm{NC}(=\mathrm{O}) \mathrm{CS} 2) \mathrm{cc} 1$ & 6670 & 5.18 \\
\hline 4319 & $\mathrm{Cc} 1 \mathrm{cc}(\mathrm{C}) \mathrm{c}(\mathrm{C}) \mathrm{c}(-\mathrm{c} 2 \mathrm{cc} 3 \mathrm{cnc}(\mathrm{N}) \mathrm{nc} 3 \mathrm{nc} 2 \mathrm{NC}(=\mathrm{O}) \mathrm{NC}(\mathrm{C})(\mathrm{C}) \mathrm{C}) \mathrm{c} 1 \mathrm{C}$ & 6680 & $*$ \\
\hline 4320 & $\mathrm{O}=\mathrm{C}(\mathrm{O}) \mathrm{CCCC} 1 \mathrm{C}(\mathrm{S})=\mathrm{Nc} 2 \operatorname{cccc} 21$ & 6700 & $*$ \\
\hline 4321 & $\mathrm{CN} 1 \mathrm{C}(=\mathrm{S}) \mathrm{C}(\mathrm{CCC}(=\mathrm{O}) \mathrm{O}) \mathrm{c} 2 \operatorname{ccccc} 21$ & 6700 & $*$ \\
\hline 4322 & $\mathrm{CN}(\mathrm{C}) \mathrm{C} / \mathrm{C}=\mathrm{C} / \mathrm{C}(=\mathrm{O}) \mathrm{Nc} 1 \mathrm{cccc}(\mathrm{Oc} 2 \mathrm{nc}(\mathrm{Nc} 3 \mathrm{n}[\mathrm{nH}] \mathrm{c} 4 \mathrm{cccc} 34) \operatorname{cc}(\mathrm{N} 3 \mathrm{CCN}(\mathrm{C}) \mathrm{CC} 3) \mathrm{n} 2) \mathrm{c} 1$ & 6700 & $*$ \\
\hline 4323 & $\mathrm{CC}(\mathrm{C}) \mathrm{n} 1 \mathrm{nc}(-\mathrm{c} 2 \mathrm{ccc} 3[\mathrm{nH}] \mathrm{c}(=\mathrm{O}) \mathrm{ccc} 3 \mathrm{c} 2) \mathrm{c} 2 \mathrm{c}(\mathrm{N}) \mathrm{ncnc} 21$ & 6700 & $*$ \\
\hline 4324 & $\mathrm{O}=\mathrm{C}(\mathrm{Cc} 1 \mathrm{ccc}(\mathrm{F}) \operatorname{cc} 1) \mathrm{NS}(=\mathrm{O})(=\mathrm{O}) \mathrm{c} 1 \mathrm{ccccc} 1$ & 6740 & 5.17 \\
\hline 4325 & COCOc1 1 c $2 n c c(C \# N) c(N c 3 c c c c(B r) c 3) c 2 c c 1 O C O C$ & 6750 & $*$ \\
\hline 4326 & $\mathrm{COc} 1 \mathrm{cc}(\mathrm{C}=\mathrm{C}(\mathrm{CHN}) \mathrm{C \# N}) \operatorname{cc}(\mathrm{CSc} 2 \operatorname{ccccc} 2) \mathrm{c} 1 \mathrm{O}$ & 6760.83 & $*$ \\
\hline 4327 & $\mathrm{COc} 1 \operatorname{ccc}(\mathrm{NC}(=\mathrm{O}) / \mathrm{C}=\mathrm{C} / \mathrm{c} 2 \mathrm{ccc} 3 \mathrm{c}(\mathrm{c} 2) \mathrm{OCCCCO} 3) \mathrm{c} 1$ & 6780 & $*$ \\
\hline 4328 & $\mathrm{~N} \# \mathrm{Cc} 1 \mathrm{cnc} 2 \mathrm{cc} 3 \mathrm{c}(\mathrm{cc} 2 \mathrm{c} 1 \mathrm{Nc} 1 \mathrm{cccc}(\mathrm{Br}) \mathrm{c} 1) \mathrm{OCO} 3$ & 6790 & $*$ \\
\hline
\end{tabular}




\begin{tabular}{|c|c|c|c|}
\hline 4329 & $\mathrm{O}=\mathrm{C}(\mathrm{Cn} 1 \mathrm{c}(-\mathrm{c} 2 \operatorname{ccccc} 2) \mathrm{cc}(=\mathrm{O}) \mathrm{n} 2 \mathrm{ncnc} 12) \mathrm{NNC}(=\mathrm{S}) \mathrm{Nc} 1 \mathrm{ccccc} 1$ & 6800 & 5.17 \\
\hline 4330 & $\mathrm{COc} 1 \mathrm{cc}(/ \mathrm{C}=\mathrm{C} 2 \backslash \mathrm{CCC} / \mathrm{C}(=\mathrm{C} \backslash \mathrm{c} 3 \operatorname{ccc}(\mathrm{Br}) \mathrm{c} 3) \mathrm{C} 2=\mathrm{O}) \operatorname{cc}(\mathrm{OC}) \mathrm{c} 1$ & 6800 & 5.41 \\
\hline 4331 & $\mathrm{CC}(=\mathrm{O}) \mathrm{c} 1 \mathrm{cccc}(\mathrm{Nc} 2 \mathrm{ncnc} 3 \mathrm{cc} 4 \mathrm{oc}(=\mathrm{O}) \mathrm{n}(\mathrm{CCCN} 5 \mathrm{CCOCC} 5) \mathrm{c} 4 \mathrm{cc} 23) \mathrm{c} 1$ & 6800 & $*$ \\
\hline 4332 & $\mathrm{CN} 1 \mathrm{CCN}(\mathrm{c} 2 \mathrm{ccc}(\mathrm{Nc} 3 \mathrm{ncc}(\mathrm{Br}) \mathrm{c}(\mathrm{Nc} 4 \mathrm{ccc} 5 \mathrm{c}(\mathrm{c} 4) \mathrm{CCC} 5) \mathrm{n} 3) \mathrm{cc} 2) \mathrm{CC} 1$ & 6800 & $*$ \\
\hline 4333 & $\operatorname{Cc} 1 \operatorname{lnc}([\mathrm{N}+](=\mathrm{O})[\mathrm{O}-]) \operatorname{n} 1 \mathrm{CCOC}(=\mathrm{O}) / \mathrm{C}=\mathrm{C} / \mathrm{c} 1 \mathrm{ccc}(\mathrm{C}(\mathrm{C}) \mathrm{C}) \operatorname{cc} 1$ & 6820 & 5.17 \\
\hline 4334 & $\mathrm{O}=\mathrm{C} 1 \mathrm{CSC}(\mathrm{N} / \mathrm{N}=\mathrm{C} / \mathrm{c} 2 \operatorname{ccc}([\mathrm{N}+](=\mathrm{O})[\mathrm{O}-]) \mathrm{cc} 2)=\mathrm{N} 1$ & 6820 & 5.17 \\
\hline 4335 & $\mathrm{NC}(=\mathrm{S}) \mathrm{N} 1 \mathrm{~N}=\mathrm{C}(\mathrm{c} 2 \mathrm{ccc}(\mathrm{Cl}) \mathrm{c}(\mathrm{Cl}) \mathrm{c} 2) \mathrm{CC} 1 \mathrm{c} 1 \mathrm{ccc}(\mathrm{Br}) \mathrm{cc} 1$ & 6850 & 5.16 \\
\hline 4336 & $\mathrm{COC}(=\mathrm{O}) \mathrm{Nc} 1 \mathrm{ccc}(\mathrm{Nc} 2 \mathrm{ncnc} 3 \mathrm{cc}(\mathrm{OC}) \mathrm{c}(\mathrm{OC}) \mathrm{cc} 23) \mathrm{cc} 1$ & 6900 & $*$ \\
\hline 4337 & $\mathrm{CNC}(=\mathrm{O}) \mathrm{c} 1 \mathrm{c}(\mathrm{SSc} 2 \mathrm{c}(\mathrm{C}(=\mathrm{O}) \mathrm{NC}) \mathrm{c} 3 \operatorname{cccc} 3 \mathrm{n} 2 \mathrm{C}) \mathrm{n}(\mathrm{C}) \mathrm{c} 2 \operatorname{cccc} 12$ & 6900 & $*$ \\
\hline 4338 & $\mathrm{CCN}(\mathrm{CC}) \mathrm{CCn} 1 \mathrm{c}([\mathrm{Se}][\mathrm{Se}] \mathrm{c} 2 \mathrm{c}(\mathrm{C}(=\mathrm{O}) \mathrm{NC}) \mathrm{c} 3 \operatorname{ccccc} 3 \mathrm{n} 2 \mathrm{CCN}(\mathrm{CC}) \mathrm{CC}) \mathrm{c}(\mathrm{C}(=\mathrm{O}) \mathrm{NC}) \mathrm{c} 2 \operatorname{ccccc} 21$ & 6900 & $*$ \\
\hline 4339 & $\mathrm{CC}(\mathrm{C}) \mathrm{n} 1 \mathrm{nc}(-\mathrm{c} 2 \mathrm{cc}(\mathrm{F}) \mathrm{c}(\mathrm{O}) \mathrm{cc} 2 \mathrm{~F}) \mathrm{c} 2 \mathrm{c}(\mathrm{N}) \mathrm{ncnc} 21$ & 6900 & $*$ \\
\hline 4340 & $\mathrm{~N} \# \mathrm{Cc} 1 \mathrm{cnc}(\mathrm{Nc} 2 \mathrm{cccc}(\mathrm{Br}) \mathrm{c} 2) \mathrm{c} 2 \mathrm{cc}(\mathrm{NC}(=\mathrm{O}) \mathrm{CCN} 3 \mathrm{CCOCC} 3) \mathrm{ccc} 12$ & 6900 & $*$ \\
\hline 4341 & $\mathrm{Cc} 1 \mathrm{cc}(=\mathrm{O}) \mathrm{n}(-\mathrm{c} 2 \mathrm{ccc}(\mathrm{F}) \mathrm{cc} 2) \mathrm{nc} 1 \mathrm{C}(=\mathrm{O}) \mathrm{Nc} 1 \mathrm{ccc}(\mathrm{Oc} 2 \mathrm{ncnc} 3 \operatorname{ccsc} 23) \mathrm{c}(\mathrm{F}) \mathrm{c} 1$ & 6900 & $*$ \\
\hline 4342 & $\mathrm{COc} 1 \mathrm{ccc}(\mathrm{C} 2=\mathrm{NN}(\mathrm{c} 3 \mathrm{nc}(-\mathrm{c} 4 \mathrm{ccccc} 4) \operatorname{cs} 3) \mathrm{C}(\mathrm{c} 3 \mathrm{ccc}(\mathrm{OC}) \mathrm{cc} 3) \mathrm{C} 2) \mathrm{cc} 1$ & 6920 & 5.16 \\
\hline 4343 & $\mathrm{Cc} 1 \mathrm{nc}(\mathrm{NC} 2 \mathrm{CCCCC} 2) \mathrm{c} 2 \mathrm{c}(\mathrm{C}) \mathrm{c}(\mathrm{C})[\mathrm{nH}] \mathrm{c} 2 \mathrm{n} 1$ & 6920 & $*$ \\
\hline 4344 & $\operatorname{CCOC}(=\mathrm{O}) \mathrm{C} 1=\mathrm{C}(\mathrm{N}) \mathrm{N}(\mathrm{c} 2 \mathrm{cccnc} 2) \mathrm{C} 2=\mathrm{C}(\mathrm{C}(=\mathrm{O}) \mathrm{CCC} 2) \mathrm{C} 1 \mathrm{c} 1 \mathrm{cc} 2 \mathrm{cc}(\mathrm{C}) \mathrm{ccc} 2 \mathrm{n} 2 \mathrm{nnnn} 12$ & 7000 & 5.15 \\
\hline 4345 & $\operatorname{COc} 1 \mathrm{cc}(\mathrm{N} 2 \mathrm{CCN}(\mathrm{C}) \mathrm{CC} 2) \operatorname{ccc} 1 \mathrm{Nc} 1 \mathrm{ncc}(\mathrm{Cl}) \mathrm{c}(\mathrm{Oc} 2 \operatorname{cccc}(\mathrm{NC}(=\mathrm{O}) / \mathrm{C}(\mathrm{C \# N})=\mathrm{C} / \mathrm{c} 3 \operatorname{ccc}(\mathrm{F}) \mathrm{cc} 3) \mathrm{c} 2) \mathrm{n} 1$ & 7000 & 5.15 \\
\hline 4346 & $\mathrm{O}=\mathrm{CN} / \mathrm{C}=\mathrm{C} / \mathrm{c} 1 \mathrm{ccc}(\mathrm{O}) \mathrm{c}(\mathrm{O}) \mathrm{c} 1$ & 7000 & $*$ \\
\hline 4347 & $\mathrm{~N} \# \mathrm{CC}(\mathrm{C} \# \mathrm{~N})=\mathrm{C} 1 \mathrm{CCc} 2 \mathrm{c} 1 \mathrm{ccc}(\mathrm{O}) \mathrm{c} 2 \mathrm{O}$ & 7000 & $*$ \\
\hline 4348 & $\mathrm{CC}(\mathrm{C}) \mathrm{CCCC}(\mathrm{C}) \mathrm{CCOC}(=\mathrm{O}) \mathrm{c} 1 \mathrm{cc}(\mathrm{NCc} 2 \mathrm{cc}(\mathrm{O}) \operatorname{ccc} 2 \mathrm{O}) \operatorname{ccc} 1 \mathrm{O}$ & 7000 & $*$ \\
\hline 4349 & $\mathrm{CCOC}(=\mathrm{O}) \mathrm{Cc} 1 \mathrm{cc}(\mathrm{NCc} 2 \mathrm{cc}(\mathrm{O}) \operatorname{ccc} 2 \mathrm{O}) \operatorname{ccc} 1 \mathrm{O}$ & 7000 & $*$ \\
\hline 4350 & $\mathrm{Clc} 1 \mathrm{ccc}(\mathrm{CNc} 2 \mathrm{ncnc} 3 \mathrm{ccccc} 23) \mathrm{cc} 1$ & 7000 & $*$ \\
\hline 4351 & $\begin{array}{c}\mathrm{O}=\mathrm{C}(\mathrm{NCc} 1 \mathrm{ccccc} 1)[\mathrm{C} @ \mathrm{H}](\mathrm{Cc} 1 \mathrm{c}([\mathrm{Se}][\mathrm{Se}] \mathrm{c} 2[\mathrm{nH}] \mathrm{c} 3 \operatorname{ccccc} 3 \mathrm{c} 2 \mathrm{C}[\mathrm{C} @ @ \mathrm{H}](\mathrm{NC}(=\mathrm{O}) \mathrm{C}(\mathrm{F})(\mathrm{F}) \mathrm{F}) \mathrm{C}(=\mathrm{O}) \mathrm{NCc} 2 \mathrm{ccccc} 2)[\mathrm{n} \\
\mathrm{H}] \mathrm{c} 2 \mathrm{cccc} 12) \mathrm{NC}(=\mathrm{O}) \mathrm{C}(\mathrm{F})(\mathrm{F}) \mathrm{F}\end{array}$ & 7000 & * \\
\hline 4352 & $\mathrm{C}[\mathrm{C} @ @ \mathrm{H}](\mathrm{NC}(=\mathrm{O})[\mathrm{C} @ @ \mathrm{H}](\mathrm{C}) \mathrm{NC}(=\mathrm{O}) \mathrm{c} 1 \mathrm{ccc}(\mathrm{S}(=\mathrm{O})(=\mathrm{O}) \mathrm{Oc} 2 \mathrm{ccc}(/ \mathrm{C}=\mathrm{C} /[\mathrm{N}+](=\mathrm{O})[\mathrm{O}-]) \mathrm{cc} 2) \mathrm{cc} 1) \mathrm{C}(=\mathrm{O}) \mathrm{O}$ & 7000 & $*$ \\
\hline 4353 & $\mathrm{Cc} 1 \mathrm{cc}(\mathrm{C}) \mathrm{c}(\mathrm{C}) \mathrm{c}(-\mathrm{c} 2 \mathrm{cc} 3 \mathrm{cnc}(\mathrm{NCCCN} 4 \mathrm{CCN}(\mathrm{C}) \mathrm{CC} 4) \mathrm{nc} 3 \mathrm{nc} 2 \mathrm{NC}(=\mathrm{O}) \mathrm{NC}(\mathrm{C})(\mathrm{C}) \mathrm{C}) \mathrm{c} 1 \mathrm{C}$ & 7000 & $*$ \\
\hline 4354 & $\mathrm{CC}(\mathrm{C}) \mathrm{n} 1 \mathrm{nc}(-\mathrm{c} 2 \mathrm{ccc} 3 \mathrm{nc}(\mathrm{NN}) \mathrm{ccc} 3 \mathrm{c} 2) \mathrm{c} 2 \mathrm{c}(\mathrm{N}) \mathrm{ncnc} 21$ & 7000 & $*$ \\
\hline 4355 & $\operatorname{CCCOC}(=\mathrm{O}) \mathrm{Nc} 1 \mathrm{ccc}(\mathrm{Nc} 2 \mathrm{ncnc} 3 \mathrm{cc}(\mathrm{OC}) \mathrm{c}(\mathrm{OC}) \mathrm{cc} 23) \mathrm{cc} 1 . \mathrm{Cl}$ & 7050 & $*$ \\
\hline 4356 & $\operatorname{CCCOC}(=\mathrm{O}) \mathrm{Nc} 1 \mathrm{ccc}(\mathrm{Nc} 2 \mathrm{ncnc} 3 \mathrm{cc}(\mathrm{OC}) \mathrm{c}(\mathrm{OC}) \mathrm{cc} 23) \mathrm{cc} 1$ & 7050 & $*$ \\
\hline 4357 & $\mathrm{COc} 1 \mathrm{cc}(/ \mathrm{C}=\mathrm{C} 2 \backslash \mathrm{CCC} / \mathrm{C}(=\mathrm{C} \backslash \mathrm{c} 3 \operatorname{ccc}(\mathrm{Br}) \mathrm{cc} 3) \mathrm{C} 2=\mathrm{O}) \mathrm{cc}(\mathrm{OC}) \mathrm{c} 1$ & 7100 & 5.15 \\
\hline 4358 & $\mathrm{COc} 1 \mathrm{cc} 2 \mathrm{c}(\mathrm{cc} 1 \mathrm{OC}) \mathrm{Oc} 1 \mathrm{ncnc}(\mathrm{Nc} 3 \mathrm{ccc}(\mathrm{F}) \mathrm{cc} 3) \mathrm{c} 1 \mathrm{NC} 2$ & 7100 & 5.15 \\
\hline 4359 & $\mathrm{c} 1 \mathrm{cc}(\mathrm{Nc} 2 \mathrm{nccc}(-\mathrm{c} 3 \mathrm{ccc} n \mathrm{c} 3) \mathrm{n} 2) \mathrm{cc}(\mathrm{OCCn} 2 \mathrm{ccnc} 2) \mathrm{c} 1$ & 7100 & $*$ \\
\hline 4360 & COCCOc1cc2ncnc(Nc3c(Cl)ccc4c3OCO4)c2cc1NC(=O)[C@@H]1CCCN1 & 7130 & 5.15 \\
\hline 4361 & $\mathrm{COc} 1 \mathrm{cc}(\mathrm{N} 2 \mathrm{CCN}(\mathrm{C}) \mathrm{CC} 2) \operatorname{ccc} 1 \mathrm{Nc} 1 \mathrm{ncc}(\mathrm{Cl}) \mathrm{c}(\mathrm{Oc} 2 \operatorname{cccc}(\mathrm{NC}(=\mathrm{O}) / \mathrm{C}(\mathrm{C \# N})=\mathrm{C} / \mathrm{C} 3 \mathrm{CC} 3) \mathrm{c} 2) \mathrm{n} 1$ & 7200 & 5.14 \\
\hline 4362 & Clc1 $1 \mathrm{ccc}(-\mathrm{c} 2 \mathrm{cn} 3 \mathrm{nc}(-\mathrm{c} 4 \mathrm{ccccc} 4) \mathrm{nc} 3 \mathrm{~s} 2) \mathrm{cc} 1$ & 7200 & 5.14 \\
\hline 4363 & $\mathrm{CN}(\mathrm{c} 1 \mathrm{ccccc} 1) \mathrm{c} 1 \mathrm{ncnc} 2 \mathrm{cc} 3 \mathrm{oc}(=\mathrm{O}) \mathrm{n}(\mathrm{CCCN} 4 \mathrm{CCOCC} 4) \mathrm{c} 3 \mathrm{cc} 12$ & 7200 & $*$ \\
\hline 4364 & $\mathrm{COC}(=\mathrm{O}) \mathrm{Nc} 1 \mathrm{cc}(\mathrm{Nc} 2 \mathrm{ncnc} 3 \mathrm{cc}(\mathrm{OC}) \mathrm{c}(\mathrm{OC}) \mathrm{cc} 23) \mathrm{ccc} 1 \mathrm{C} . \mathrm{Cl}$ & 7200 & $*$ \\
\hline 4365 & $\mathrm{COC}(=\mathrm{O}) \mathrm{Nc} 1 \mathrm{cc}(\mathrm{Nc} 2 \mathrm{ncnc} 3 \mathrm{cc}(\mathrm{OC}) \mathrm{c}(\mathrm{OC}) \mathrm{cc} 23) \mathrm{ccc} 1 \mathrm{C}$ & 7200 & $*$ \\
\hline 4366 & $\mathrm{COc} 1 \mathrm{ccc}(/ \mathrm{C}=\mathrm{C} / \mathrm{C}(=\mathrm{O}) \mathrm{Nc} 2 \mathrm{ccc} 3 \mathrm{ncnc}(\mathrm{Nc} 4 \mathrm{cccc}(\mathrm{Br}) \mathrm{c} 4) \mathrm{c} 3 \mathrm{c} 2) \mathrm{cc} 1$ & 7220 & 5.14 \\
\hline 4367 & $\operatorname{CCCCCCCOC}(=\mathrm{O}) \operatorname{COc} 1 \mathrm{cc}(\mathrm{O}) \mathrm{c} 2 \mathrm{c}(=\mathrm{O}) \mathrm{cc}(-\mathrm{c} 3 \operatorname{ccccc} 3) \mathrm{oc} 2 \mathrm{c} 1$ & 7230 & 5.14 \\
\hline 4368 & $\mathrm{O}=\mathrm{C}(/ \mathrm{C}=\mathrm{C} / \mathrm{c} 1 \mathrm{ccc} 2 \mathrm{c}(\mathrm{c} 1) \mathrm{OCCCCO} 2) \mathrm{Nc} 1 \mathrm{ccc}([\mathrm{N}+](=\mathrm{O})[\mathrm{O}-]) \mathrm{cc} 1$ & 7250 & $*$ \\
\hline 4369 & $\mathrm{NC}(=\mathrm{S}) \mathrm{N} 1 \mathrm{~N}=\mathrm{C}(\mathrm{c} 2 \operatorname{ccc}(\mathrm{Cl}) \mathrm{c}(\mathrm{Cl}) \mathrm{c} 2) \mathrm{CC} 1 \mathrm{c} 1 \mathrm{cccc} 1 \mathrm{Cl}$ & 7280 & 5.14 \\
\hline 4370 & $\mathrm{CCN}(\mathrm{CC})[\mathrm{C} @ @](\mathrm{C})(\mathrm{C} \# \mathrm{Cc} 1 \mathrm{ncnc} 2 \mathrm{cc}(\mathrm{OC}) \mathrm{c}(\mathrm{OC}) \mathrm{cc} 12) \mathrm{c} 1 \mathrm{ccccc} 1$ & 7300 & $*$ \\
\hline
\end{tabular}




\begin{tabular}{|c|c|c|c|}
\hline 4371 & $\mathrm{CN}(\mathrm{C}) \mathrm{CC}(\mathrm{CSc} 1 \operatorname{cccc} 1) \mathrm{C}(=\mathrm{O}) \mathrm{c} 1 \mathrm{ccc}(\mathrm{OCc} 2 \operatorname{ccc} c 2) \operatorname{cc} 1 . \mathrm{Cl}$ & 7300 & $*$ \\
\hline 4372 & $\mathrm{O}=\mathrm{C}(\mathrm{Nc} 1 \mathrm{ccc}(\mathrm{Cl}) \mathrm{cc} 1) \mathrm{c} 1 \mathrm{cccc} 1 \mathrm{NCc} 1 \mathrm{ccncc} 1$ & 7300 & $*$ \\
\hline 4373 & $\mathrm{CCN}(\mathrm{CC}) \mathrm{C}(\mathrm{C})(\mathrm{C} \# \mathrm{Cc} 1 \mathrm{ncnc} 2 \mathrm{cc}(\mathrm{OC}) \mathrm{c}(\mathrm{OC}) \mathrm{cc} 12) \mathrm{c} 1 \mathrm{cccc} 1$ & 7300 & $*$ \\
\hline 4374 & $\mathrm{NC}(=\mathrm{S}) \mathrm{N} 1 \mathrm{~N}=\mathrm{C}(\mathrm{c} 2 \mathrm{ccc}(\mathrm{Cl}) \mathrm{c}(\mathrm{Cl}) \mathrm{c} 2) \mathrm{CC} 1 \mathrm{c} 1 \mathrm{ccc}(\mathrm{Cl}) \mathrm{cc} 1$ & 7320 & 5.14 \\
\hline 4375 & $\mathrm{O}=\mathrm{C}(/ \mathrm{C}=\mathrm{C} / \mathrm{c} 1 \mathrm{ccccc} 1) \mathrm{Nc} 1 \operatorname{ccc} c 1 \mathrm{~F}$ & 7370 & $*$ \\
\hline 4376 & $\mathrm{Cc} 1 \mathrm{ccc}(\mathrm{C} 2 \mathrm{CC}(\mathrm{c} 3 \operatorname{ccc}(\mathrm{Cl}) \mathrm{c}(\mathrm{Cl}) \mathrm{c} 3)=\mathrm{NN} 2 \mathrm{C}(\mathrm{N})=\mathrm{S}) \mathrm{cc} 1$ & 7380 & 5.13 \\
\hline 4377 & $\mathrm{COc} 1 \mathrm{cc} 2 \mathrm{ncc}(\mathrm{C} \# \mathrm{~N}) \mathrm{c}(\mathrm{Nc} 3 \operatorname{ccc}(\mathrm{C}(\mathrm{C})=\mathrm{O}) \mathrm{c} 3) \mathrm{c} 2 \mathrm{cc} 1 \mathrm{OC}$ & 7380 & $*$ \\
\hline 4378 & $\mathrm{COc} 1 \mathrm{cc} 2 \mathrm{c}(\mathrm{cc} 1 \mathrm{OC}) \mathrm{Oc} 1 \mathrm{ncnc}(\mathrm{Nc} 3 \mathrm{ccc}(\mathrm{C}) \mathrm{c} 3) \mathrm{c} 1 \mathrm{NC} 2$ & 7400 & 5.13 \\
\hline 4379 & $\mathrm{COc} 1 \mathrm{cc}(\mathrm{C}(=\mathrm{O}) \mathrm{Nc} 2 \mathrm{nc}(-\mathrm{c} 3 \operatorname{ccc}(\mathrm{Cl}) \mathrm{c} 3) \mathrm{n}[\mathrm{nH}] 2) \mathrm{cc}(\mathrm{OC}) \mathrm{c} 1 \mathrm{OC}$ & 7400 & 5.13 \\
\hline 4380 & $\mathrm{NC}(\mathrm{Cc} 1 \mathrm{c}(\mathrm{SSc} 2[\mathrm{nH}] \mathrm{c} 3 \operatorname{ccc} \operatorname{cc} 3 \mathrm{c} 2 \mathrm{CC}(\mathrm{N}) \mathrm{C}(=\mathrm{O}) \mathrm{NCc} 2 \operatorname{cccc} 2)[\mathrm{nH}] \mathrm{c} 2 \operatorname{ccccc} 12) \mathrm{C}(=\mathrm{O}) \mathrm{NC} 1 \mathrm{ccccc} 1$ & 7400 & $*$ \\
\hline 4381 & $\mathrm{O}=\mathrm{C}(\mathrm{CCc} 1 \mathrm{c}(\mathrm{SSc} 2[\mathrm{nH}] \mathrm{c} 3 \operatorname{ccccc} 3 \mathrm{c} 2 \mathrm{CCC}(=\mathrm{O}) \mathrm{NCc} 2 \operatorname{ccc}(\mathrm{C}(=\mathrm{O}) \mathrm{O}) \mathrm{cc} 2)[\mathrm{nH}] \mathrm{c} 2 \operatorname{ccccc} 12) \mathrm{NCc} 1 \operatorname{ccc}(\mathrm{C}(=\mathrm{O}) \mathrm{O}) \mathrm{cc} 1$ & 7400 & $*$ \\
\hline 4382 & $\mathrm{CCNCc} 1 \mathrm{cn} 2 \mathrm{ncnc}(\mathrm{Nc} 3 \mathrm{ccc} 4 \mathrm{c}(\mathrm{cnn} 4 \mathrm{Cc} 4 \mathrm{ccccc} 4) \mathrm{c} 3) \mathrm{c} 2 \mathrm{c} 1 \mathrm{CC}$ & 7400 & $*$ \\
\hline 4383 & $\mathrm{O}=\mathrm{C} 1 \mathrm{~N}=\mathrm{C}(\mathrm{N} 2 \mathrm{CCC}[\mathrm{C} @ \mathrm{H}] 2 \mathrm{C}(=\mathrm{O}) \mathrm{Nc} 2 \mathrm{ccc} 3 \mathrm{ncnc}(\mathrm{Nc} 4 \mathrm{cccc}(\mathrm{Cl}) \mathrm{c} 4) \mathrm{c} 3 \mathrm{c} 2) \mathrm{S} / \mathrm{C} 1=\mathrm{C} / \mathrm{c} 1 \mathrm{cccnc} 1 \mathrm{Cl}$ & 7400 & $*$ \\
\hline 4384 & OCCCCNc1 cnec(-c2ence( $\mathrm{Nc} 3 \mathrm{cccc}(\mathrm{Cl}) \mathrm{c} 3) \mathrm{n} 2) \mathrm{c} 1$ & 7400 & $*$ \\
\hline 4385 & $\mathrm{CC}(\mathrm{C}) \mathrm{n} 1 \mathrm{nc}(-\mathrm{c} 2 \mathrm{ccc} 3 \mathrm{nc}[\mathrm{nH}] \mathrm{c}(=\mathrm{O}) \mathrm{c} 3 \mathrm{c} 2) \mathrm{c} 2 \mathrm{c}(\mathrm{N}) \mathrm{ncnc} 21$ & 7400 & $*$ \\
\hline 4386 & $\mathrm{CC}(\mathrm{C})(\mathrm{C}) \mathrm{c} 1 \mathrm{ccc}(-\mathrm{c} 2 \mathrm{nnc}(\mathrm{SCc} 3 \mathrm{cccc} 3) \mathrm{o} 2) \mathrm{cc} 1$ & 7440 & 5.13 \\
\hline 4387 & $\mathrm{COc} 1 \mathrm{cc}(\mathrm{N} 2 \mathrm{CCN}(\mathrm{C}) \mathrm{CC} 2) \operatorname{ccc} 1 \mathrm{Nc} 1 \mathrm{ncc}(\mathrm{Cl}) \mathrm{c}(\mathrm{Oc} 2 \mathrm{cccc}(\mathrm{NC}(=\mathrm{O}) \mathrm{CCN} 3 \mathrm{CCN}(\mathrm{C}) \mathrm{CC} 3) \mathrm{c} 2) \mathrm{n} 1$ & 7442 & 5.13 \\
\hline 4388 & $\mathrm{O}=\mathrm{C} 1 \mathrm{CSC}(\mathrm{N} / \mathrm{N}=\mathrm{C} / \mathrm{c} 2 \operatorname{cccc}(\mathrm{Br}) \mathrm{c} 2)=\mathrm{N} 1$ & 7460 & 5.13 \\
\hline 4389 & $\mathrm{COc} 1 \mathrm{ccc}(\mathrm{C} 2=\mathrm{NN}(\mathrm{c} 3 \mathrm{nc}(-\mathrm{c} 4 \mathrm{cccc} 4) \operatorname{cs} 3) \mathrm{C}(\mathrm{c} 3 \operatorname{ccc}(\mathrm{C}) \mathrm{cc} 3) \mathrm{C} 2) \mathrm{cc} 1$ & 7480 & 5.13 \\
\hline 4390 & $\mathrm{COc} 1 \mathrm{cc}(/ \mathrm{C}=\mathrm{C} 2 \backslash \mathrm{CCC} / \mathrm{C}(=\mathrm{C} \backslash \mathrm{C} 3 \mathrm{CCCCC} 3) \mathrm{C} 2=\mathrm{O}) \mathrm{cc}(\mathrm{OC}) \mathrm{c} 1$ & 7500 & 5.12 \\
\hline 4391 & $\mathrm{C} / \mathrm{C}=\mathrm{C} / \mathrm{C}(=\mathrm{O}) \mathrm{Nc} 1 \mathrm{cc} 2 \mathrm{c}(\mathrm{Nc} 3 \mathrm{ccc}(\mathrm{F}) \mathrm{c}(\mathrm{Cl}) \mathrm{c} 3) \mathrm{c}(\mathrm{C} \# \mathrm{~N}) \mathrm{cnc} 2 \mathrm{cc} 1 \mathrm{OCC}$ & 7500 & 5.12 \\
\hline 4392 & $\operatorname{CCOC}(=\mathrm{O}) \mathrm{CCCn} 1 \mathrm{c}(=\mathrm{O}) \mathrm{oc} 2 \mathrm{cc} 3 \mathrm{ncnc}(\mathrm{Nc} 4 \mathrm{ccc}(\mathrm{OC}) \mathrm{cc} 4) \mathrm{c} 3 \mathrm{cc} 21$ & 7500 & $*$ \\
\hline 4393 & $\mathrm{CNc} 1 \mathrm{ncc} 2 \mathrm{cc}(-\mathrm{c} 3 \mathrm{c}(\mathrm{Cl}) \mathrm{ccc} 3 \mathrm{Cl}) \mathrm{c}(=\mathrm{O}) \mathrm{n}(\mathrm{C}) \mathrm{c} 2 \mathrm{n} 1$ & 7500 & $*$ \\
\hline 4394 & $\mathrm{Cc} 1 \operatorname{ccc}(\mathrm{CN}(\mathrm{Cc} 2 \operatorname{ccc}(\mathrm{O}) \operatorname{cc} 2) \mathrm{C}(=\mathrm{O}) \mathrm{Nc} 2 \operatorname{cccc} 2) \mathrm{c} 1 \mathrm{O}$ & 7510 & 5.12 \\
\hline 4395 & $\operatorname{CCCCOC}(=\mathrm{O}) \mathrm{Nc} 1 \mathrm{ccc}(\mathrm{Nc} 2 \mathrm{ncnc} 3 \mathrm{cc}(\mathrm{OC}) \mathrm{c}(\mathrm{OC}) \mathrm{cc} 23) \mathrm{cc} 1 \mathrm{C} . \mathrm{Cl}$ & 7600 & $*$ \\
\hline 4396 & $\mathrm{CCCCOC}(=\mathrm{O}) \mathrm{Nc} 1 \mathrm{ccc}(\mathrm{Nc} 2 \mathrm{ncnc} 3 \mathrm{cc}(\mathrm{OC}) \mathrm{c}(\mathrm{OC}) \mathrm{cc} 23) \mathrm{cc} 1 \mathrm{C}$ & 7600 & $*$ \\
\hline 4397 & $\mathrm{O}=\mathrm{C} 1 \mathrm{~N}=\mathrm{C}(\mathrm{N} 2 \mathrm{CCC}[\mathrm{C} @ \mathrm{H}] 2 \mathrm{C}(=\mathrm{O}) \mathrm{Nc} 2 \mathrm{ccc} 3 \mathrm{ncnc}(\mathrm{Nc} 4 \mathrm{cccc}(\mathrm{Cl}) \mathrm{c} 4) \mathrm{c} 3 \mathrm{c} 2) \mathrm{S} / \mathrm{C} 1=\mathrm{C} / \mathrm{c} 1 \mathrm{ccc}(\mathrm{Cl}) \mathrm{cc} 1$ & 7600 & $*$ \\
\hline 4398 & $\mathrm{COc} 1 \mathrm{ccc}(\mathrm{C} 2=\mathrm{NN}(\mathrm{c} 3 \mathrm{nc}(-\mathrm{c} 4 \mathrm{ccc}(\mathrm{Cl}) \operatorname{cc} 4) \operatorname{cs} 3) \mathrm{C}(\mathrm{c} 3 \operatorname{ccc}(\mathrm{O}) \mathrm{cc} 3) \mathrm{C} 2) \mathrm{cc} 1$ & 7660 & 5.12 \\
\hline 4399 & $\mathrm{O}=\mathrm{c} 1 \mathrm{ccc} 2 \mathrm{ccc}(\mathrm{O}) \mathrm{c}(\mathrm{O}) \mathrm{c} 2 \mathrm{o} 1$ & 7670 & $*$ \\
\hline 4400 & $\operatorname{COc} 1 \mathrm{cc} 2 \mathrm{ncc}(\mathrm{C} \# \mathrm{~N}) \mathrm{c}(\mathrm{Nc} 3 \operatorname{cccc}(\mathrm{C}(\mathrm{N})=\mathrm{O}) \mathrm{c} 3) \mathrm{c} 2 \mathrm{cc} 1 \mathrm{OC}$ & 7690 & $*$ \\
\hline 4401 & $\mathrm{COc} 1 \mathrm{cccc}(\mathrm{Nc} 2 \mathrm{ccnc}(\mathrm{Nc} 3 \operatorname{ccc}(\mathrm{OC}) \mathrm{c} 3) \mathrm{n} 2) \mathrm{c} 1$ & 7700 & $*$ \\
\hline 4402 & $\mathrm{COc} 1 \operatorname{cccc} 1 / \mathrm{C}=\mathrm{C} / \mathrm{C}(=\mathrm{O}) \mathrm{Nc} 1 \mathrm{ccc} 2 \mathrm{ncnc}(\mathrm{Nc} 3 \operatorname{ccc}(\mathrm{Br}) \mathrm{c} 3) \mathrm{c} 2 \mathrm{c} 1$ & 7710 & 5.11 \\
\hline 4403 & $\mathrm{COc} 1 \mathrm{cc} 2 \mathrm{ncnc}(\mathrm{Nc} 3 \mathrm{ccc}(\mathrm{NC}(=\mathrm{O}) \mathrm{Nc} 4 \mathrm{cccc}(\mathrm{Br}) \mathrm{c} 4) \mathrm{cc} 3) \mathrm{c} 2 \mathrm{cc} 1 \mathrm{OC}$ & 7710 & $*$ \\
\hline 4404 & $\mathrm{COc} 1 \mathrm{cc} 2 \mathrm{ncnc}(\mathrm{Oc} 3 \operatorname{cccc}(\mathrm{NC}(=\mathrm{S}) \mathrm{Nc} 4 \mathrm{ccc}(\mathrm{Cl}) \mathrm{cc} 4 \mathrm{Cl}) \mathrm{c} 3) \mathrm{c} 2 \mathrm{cc} 1 \mathrm{OC}$ & 7710 & $*$ \\
\hline 4405 & $\mathrm{NC}(=\mathrm{S}) \mathrm{N} 1 \mathrm{~N}=\mathrm{C}(\mathrm{c} 2 \mathrm{ccc}(\mathrm{Cl}) \mathrm{c}(\mathrm{Cl}) \mathrm{c} 2) \mathrm{CC} 1 \mathrm{c} 1 \mathrm{ccc}([\mathrm{N}+](=\mathrm{O})[\mathrm{O}-]) \mathrm{cc} 1$ & 7780 & 5.11 \\
\hline 4406 & $\mathrm{COc} 1 \mathrm{ccc}(\mathrm{C} 2=\mathrm{NN}(\mathrm{c} 3 \mathrm{nc}(-\mathrm{c} 4 \mathrm{ccc}(\mathrm{Cl}) \mathrm{cc} 4) \operatorname{cs} 3) \mathrm{C}(\mathrm{c} 3 \mathrm{ccc}(\mathrm{Cl}) \mathrm{cc} 3) \mathrm{C} 2) \mathrm{cc} 1$ & 7780 & 5.11 \\
\hline 4407 & $\mathrm{Cc} 1 \mathrm{c}(\mathrm{OCC}(\mathrm{F})(\mathrm{F}) \mathrm{F}) \mathrm{ccnc} 1 \mathrm{COc} 1 \mathrm{ccc}(\mathrm{Nc} 2 \mathrm{ncnc} 3 \mathrm{cc} 4 \mathrm{oc}(=\mathrm{O}) \mathrm{n}(\mathrm{CCCN} 5 \mathrm{CCOCC} 5) \mathrm{c} 4 \mathrm{cc} 23) \mathrm{cc} 1$ & 7800 & $*$ \\
\hline 4408 & $\operatorname{CCOC}(=\mathrm{O}) \mathrm{CCCn} 1 \mathrm{c}(=\mathrm{O}) \operatorname{oc} 2 \mathrm{cc} 3 \mathrm{ncnc}(\mathrm{Nc} 4 \mathrm{ccc}(\mathrm{F}) \mathrm{c}(\mathrm{Cl}) \mathrm{c} 4) \mathrm{c} 3 \mathrm{cc} 21$ & 7800 & $*$ \\
\hline 4409 & $\mathrm{Nc} 1 \mathrm{cccc}(-\mathrm{c} 2 \mathrm{cc}(=\mathrm{O}) \mathrm{c} 3 \mathrm{c}(\mathrm{N}) \mathrm{c}(\mathrm{O}) \mathrm{c}(\mathrm{N}) \mathrm{cc} 3 \mathrm{o} 2) \mathrm{c} 1$ & 7800 & $*$ \\
\hline 4410 & $\mathrm{O}=\mathrm{C}(\mathrm{Nc} 1 \mathrm{cccc} 1 \mathrm{Br}) \mathrm{c} 1 \mathrm{ccc}(\mathrm{N}(\mathrm{CCCl}) \mathrm{CCCl}) \mathrm{cc} 1$ & 7820 & 5.11 \\
\hline 4411 & $\operatorname{Cc} \operatorname{lncc}([\mathrm{N}+](=\mathrm{O})[\mathrm{O}-]) \mathrm{n} 1 \mathrm{CCOC}(=\mathrm{O}) / \mathrm{C}=\mathrm{C} / \mathrm{c} 1 \operatorname{ccccc} 1$ & 7830 & 5.11 \\
\hline 4412 & $\operatorname{COc} 1 \operatorname{ccc}(\mathrm{C}(/ \mathrm{C}=\mathrm{C} / \mathrm{c} 2 \operatorname{cccc} 2 \mathrm{Cl})=\mathrm{N} \backslash \mathrm{NC}(\mathrm{N})=\mathrm{S}) \mathrm{cc} 1$ & 7830 & 5.11 \\
\hline 4413 & $\operatorname{CCOC}(=\mathrm{O}) \mathrm{c} 1 \mathrm{nn}(-\mathrm{c} 2 \mathrm{ccc}(\mathrm{C}) \mathrm{cc} 2) \operatorname{cc} 1 \mathrm{C}(=\mathrm{O}) \mathrm{c} 1 \mathrm{c}(\mathrm{C})[\mathrm{nH}] \mathrm{c}(-\mathrm{c} 2 \mathrm{ccccc} 2) \mathrm{c} 1-\mathrm{c} 1 \mathrm{ccccc} 1$ & 7880 & * \\
\hline
\end{tabular}




\begin{tabular}{|c|c|c|c|}
\hline 4414 & $\mathrm{COC}(=\mathrm{O})[\mathrm{C} @ @ \mathrm{H}](\mathrm{Nc} 1 \mathrm{ncn} 2 \mathrm{oc}(-\mathrm{c} 3 \mathrm{cccc} 3) \mathrm{c}(-\mathrm{c} 3 \mathrm{cccc} 3) \mathrm{c} 12) \mathrm{c} 1 \mathrm{ccccc} 1$ & 7893 & * \\
\hline 4415 & $\operatorname{COc} 1 \operatorname{cc}(/ \mathrm{C}=\mathrm{C} /[\mathrm{N}+](=\mathrm{O})[\mathrm{O}-]) \operatorname{ccc} 1 \mathrm{O}$ & 7900 & $*$ \\
\hline 4416 & Brc $1 \mathrm{cc} 2 \mathrm{c}(\mathrm{NCc} 3 \mathrm{ccc} n 3) \mathrm{ncnc} 2 \mathrm{~s} 1$ & 7904 & $*$ \\
\hline 4417 & $\operatorname{COc} 1 \mathrm{cc}(\mathrm{C}=\mathrm{C}(\mathrm{C \# N}) \mathrm{C} \# \mathrm{~N}) \operatorname{cc}(\mathrm{CSc} 2 \operatorname{cccc} 2 \mathrm{C}(=\mathrm{O}) \mathrm{O}) \mathrm{c} 1 \mathrm{O}$ & 7943.28 & $*$ \\
\hline 4418 & $\mathrm{COc} 1 \mathrm{ccc}(\mathrm{C} 2 \mathrm{CC}(\mathrm{c} 3 \operatorname{ccc}(\mathrm{Br}) \mathrm{cc} 3)=\mathrm{NN} 2 \mathrm{C} 2=\mathrm{NC}(=\mathrm{O}) \mathrm{CS} 2) \mathrm{cc} 1$ & 7960 & 5.10 \\
\hline 4419 & $\mathrm{COc} 1 \mathrm{cc}(/ \mathrm{C}=\mathrm{C} 2 \backslash \mathrm{CCC} / \mathrm{C}(=\mathrm{C} \backslash \mathrm{c} 3 \operatorname{cccc} 3 \mathrm{Br}) \mathrm{C} 2=\mathrm{O}) \operatorname{cc}(\mathrm{OC}) \mathrm{c} 1$ & 8000 & $*$ \\
\hline 4420 & $\mathrm{CCOC}(=\mathrm{O}) \mathrm{Nc} 1 \mathrm{ccc}(\mathrm{Nc} 2 \mathrm{ncnc} 3 \mathrm{cc}(\mathrm{OCCN} 4 \mathrm{CCOCC} 4) \mathrm{c}(\mathrm{OC}) \mathrm{cc} 23) \mathrm{cc} 1 \mathrm{C} . \mathrm{Cl}$ & 8000 & $*$ \\
\hline 4421 & $\mathrm{O}=[\mathrm{N}+]([\mathrm{O}-]) \mathrm{c} 1 \mathrm{ccc} 2 \mathrm{ncnc}(\mathrm{NCc} 3 \mathrm{ccccc} 3) \mathrm{c} 12$ & 8000 & $*$ \\
\hline 4422 & $\mathrm{Nc} 1 \mathrm{cc} 2 \mathrm{ncnc}(\mathrm{NCc} 3 \operatorname{ccc}(\mathrm{C}(\mathrm{F})(\mathrm{F}) \mathrm{F}) \mathrm{cc} 3) \mathrm{c} 2 \mathrm{cn} 1$ & 8000 & $*$ \\
\hline 4423 & $\mathrm{CN}=\mathrm{NNc} 1 \mathrm{ccc} 2 \mathrm{ncnc}(\mathrm{N}(\mathrm{C}) \mathrm{c} 3 \mathrm{ccccc} 3) \mathrm{c} 2 \mathrm{c} 1$ & 8000 & $*$ \\
\hline 4424 & $\mathrm{CCOc} 1 \mathrm{cc}(-\mathrm{c} 2 \mathrm{nn}(\mathrm{CCO}) \mathrm{c} 3 \mathrm{ncnc}(\mathrm{N}) \mathrm{c} 23) \mathrm{ccc} 1 \mathrm{OC}$ & 8010 & $*$ \\
\hline 4425 & $\mathrm{Cc} 1 \mathrm{ccc} 2 \mathrm{nc}(/ \mathrm{C}=\mathrm{C} / \mathrm{c} 3 \operatorname{ccc}(\mathrm{N}(\mathrm{C}) \mathrm{C}) \mathrm{cc} 3) \operatorname{cc}(\mathrm{C}(=\mathrm{O}) \mathrm{O}) \mathrm{c} 2 \mathrm{c} 1$ & 8010 & $*$ \\
\hline 4426 & $\mathrm{COc} 1 \mathrm{cc}(\mathrm{OC}(\mathrm{C}) \mathrm{C}) \mathrm{c} 2 \mathrm{c}(\mathrm{Nc} 3 \mathrm{ccc}(\mathrm{F}) \mathrm{c}(\mathrm{Cl}) \mathrm{c} 3) \mathrm{ncnc} 2 \mathrm{c} 1$ & 8068 & $*$ \\
\hline 4427 & $\mathrm{COc} 1 \mathrm{cc}(\mathrm{OC} 2 \mathrm{CC} 2) \mathrm{c} 2 \mathrm{c}(\mathrm{Nc} 3 \mathrm{ccc}(\mathrm{F}) \mathrm{c}(\mathrm{Cl}) \mathrm{c} 3) n \mathrm{ncnc} 2 \mathrm{c} 1$ & 8068 & $*$ \\
\hline 4428 & $\mathrm{COc} 1 \mathrm{ccc}(\mathrm{C} 2 \mathrm{CC}(\mathrm{c} 3 \operatorname{ccc}(\mathrm{Br}) \mathrm{c}(\mathrm{Br}) \mathrm{c} 3)=\mathrm{NN} 2 \mathrm{C}(\mathrm{N})=\mathrm{S}) \mathrm{cc} 1$ & 8090 & 5.09 \\
\hline 4429 & $\mathrm{COC}(=\mathrm{O}) \mathrm{C} 1=\mathrm{C}(\mathrm{N}) \mathrm{N}(\mathrm{c} 2 \mathrm{cccnc} 2) \mathrm{C} 2=\mathrm{C}(\mathrm{C}(=\mathrm{O}) \mathrm{CCC} 2) \mathrm{C} 1 \mathrm{c} 1 \mathrm{cc} 2 \mathrm{cc}(\mathrm{Cl}) \mathrm{ccc} 2 \mathrm{n} 2 \mathrm{nnnn} 12$ & 8100 & 5.09 \\
\hline 4430 & $\mathrm{O}=\mathrm{C} 1 \mathrm{~N}=\mathrm{C}(\mathrm{N} 2 \mathrm{CCC}[\mathrm{C} @ \mathrm{H}] 2 \mathrm{C}(=\mathrm{O}) \mathrm{Nc} 2 \mathrm{ccc} 3 \mathrm{ncnc}(\mathrm{Nc} 4 \operatorname{ccc}(\mathrm{Cl}) \mathrm{c} 4) \mathrm{c} 3 \mathrm{c} 2) \mathrm{S} / \mathrm{C} 1=\mathrm{C} / \mathrm{c} 1 \mathrm{cccs} 1$ & 8100 & $*$ \\
\hline 4431 & $\mathrm{Cc} 1 \mathrm{ccc}(/ \mathrm{C}=\mathrm{C} / \mathrm{C}(=\mathrm{O}) \mathrm{OCCn} 2 \mathrm{c}([\mathrm{N}+](=\mathrm{O})[\mathrm{O}-]) \operatorname{cnc} 2 \mathrm{C}) \mathrm{cc} 1$ & 8110 & 5.09 \\
\hline 4432 & $\mathrm{O}=\mathrm{C} 1 \mathrm{CSC}(\mathrm{N} 2 \mathrm{~N}=\mathrm{C}(\mathrm{c} 3 \operatorname{ccc}(\mathrm{F}) \operatorname{cc} 3) \mathrm{CC} 2 \mathrm{c} 2 \mathrm{cccc} 2)=\mathrm{N} 1$ & 8140 & 5.09 \\
\hline 4433 & $\mathrm{NC}(=\mathrm{S}) \mathrm{N} 1 \mathrm{~N}=\mathrm{C}(\mathrm{c} 2 \mathrm{ccc}(\mathrm{Br}) \mathrm{c}(\mathrm{Br}) \mathrm{c} 2) \mathrm{CC} 1 \mathrm{c} 1 \mathrm{ccc}(\mathrm{Cl}) \mathrm{cc} 1$ & 8150 & 5.09 \\
\hline 4434 & $\mathrm{O}=\mathrm{C} 1 \mathrm{CSC}(\mathrm{N} 2 \mathrm{~N}=\mathrm{C}(\mathrm{c} 3 \mathrm{ccc}(\mathrm{Cl}) \mathrm{cc} 3) \mathrm{CC} 2 \mathrm{c} 2 \mathrm{ccc}(\mathrm{Cl}) \mathrm{cc} 2)=\mathrm{N} 1$ & 8160 & 5.09 \\
\hline 4435 & $\mathrm{Cc} 1 \mathrm{ncc}([\mathrm{N}+](=\mathrm{O})[\mathrm{O}-]) \mathrm{n} 1 \mathrm{C} / \mathrm{C}(=\mathrm{N} / \mathrm{NC}(=\mathrm{O}) \mathrm{c} 1 \mathrm{ccncc} 1) \mathrm{c} 1 \mathrm{ccc}(\mathrm{Br}) \mathrm{cc} 1$ & 8190 & 5.09 \\
\hline 4436 & COc1 $\mathrm{cc} 2 \mathrm{c}(\mathrm{cc} 1 \mathrm{OC}) \mathrm{Sc} 1 \mathrm{ncnc}(\mathrm{Nc} 3 \mathrm{ccc}(\mathrm{F}) \mathrm{c}(\mathrm{Cl}) \mathrm{c} 3) \mathrm{c} 1 \mathrm{NC} 2$ & 8200 & 5.09 \\
\hline 4437 & $\mathrm{O}=\mathrm{C}(\mathrm{Nc} 1 \mathrm{ccc}(\mathrm{Cl}) \mathrm{c} 1) \mathrm{c} 1 \mathrm{ccc}(\mathrm{Br}) \mathrm{cc} 1 \mathrm{OCc} 1 \mathrm{cccc} 1$ & 8200 & $*$ \\
\hline 4438 & $\mathrm{NC}(=\mathrm{S}) \mathrm{N} 1 \mathrm{~N}=\mathrm{C}(\mathrm{c} 2 \operatorname{ccc}(\mathrm{F}) \mathrm{cc} 2) \mathrm{CC} 1 \mathrm{c} 1 \mathrm{cccc} 2 \mathrm{cccc} 12$ & 8250 & 5.08 \\
\hline 4439 & $\operatorname{Cc} 1 \operatorname{ccc}(\mathrm{S}(=\mathrm{O})(=\mathrm{O}) \mathrm{NC}(=\mathrm{O}) \mathrm{Cc} 2 \operatorname{ccc}(\mathrm{F}) \operatorname{cc} 2) \operatorname{cc} 1$ & 8280 & 5.08 \\
\hline 4440 & $\mathrm{Cn} 1 \mathrm{c}(\mathrm{SSc} 2 \mathrm{c}(\mathrm{CCCC}(=\mathrm{O}) \mathrm{O}) \mathrm{c} 3 \operatorname{ccc} c 3 \mathrm{n} 2 \mathrm{C}) \mathrm{c}(\mathrm{CCCC}(=\mathrm{O}) \mathrm{O}) \mathrm{c} 2 \operatorname{ccc} c 21$ & 8300 & $*$ \\
\hline 4441 & $\mathrm{CC}(\mathrm{C})(\mathrm{C}) \mathrm{OC}(=\mathrm{O}) \mathrm{N} 1 \mathrm{CCC}(\mathrm{n} 2 \mathrm{cc}(-\mathrm{c} 3 \operatorname{cccc} 3) \mathrm{c} 3 \mathrm{c}(\mathrm{N}) \mathrm{ncnc} 32) \mathrm{C} 1$ & 8300 & $*$ \\
\hline 4442 & $\mathrm{CC}(\mathrm{C}) \mathrm{n} 1 \mathrm{nc}(-\mathrm{c} 2 \mathrm{ccc} 3 \mathrm{nonc} 3 \mathrm{c} 2) \mathrm{c} 2 \mathrm{c}(\mathrm{N}) \mathrm{ncnc} 21$ & 8300 & $*$ \\
\hline 4443 & $\mathrm{O}=[\mathrm{N}+]([\mathrm{O}-]) \mathrm{c} 1 \mathrm{ccc} 2 \mathrm{ncnc}(\mathrm{Nc} 3 \mathrm{ccc}(\mathrm{OCc} 4 \mathrm{nccs} 4) \mathrm{c}(\mathrm{Cl}) \mathrm{c} 3) \mathrm{c} 2 \mathrm{c} 1$ & 8320 & $*$ \\
\hline 4444 & $\mathrm{Cc} 1 \mathrm{ccc}(\mathrm{C} 2 \mathrm{CC}(\mathrm{c} 3 \mathrm{ccc}(\mathrm{F}) \mathrm{cc} 3)=\mathrm{NN} 2 \mathrm{C} 2=\mathrm{NC}(=\mathrm{O}) \mathrm{CS} 2) \mathrm{cc} 1$ & 8360 & 5.08 \\
\hline 4445 & $\mathrm{CCOc} 1 \mathrm{ccc}(-\mathrm{c} 2 \mathrm{cc}(\mathrm{C}(\mathrm{F})(\mathrm{F}) \mathrm{F}) \mathrm{c}(\mathrm{C \# N}) \mathrm{c}(\mathrm{SCC}(=\mathrm{O}) \mathrm{NCC}(=\mathrm{O}) \mathrm{O}) \mathrm{n} 2) \mathrm{cc} 1$ & 8400 & 5.08 \\
\hline 4446 & $\mathrm{Cc} 1 \mathrm{ccc} 2[\mathrm{nH}] \mathrm{c}(\mathrm{SSc} 3[\mathrm{nH}] \mathrm{c} 4 \mathrm{ccc}(\mathrm{C}) \operatorname{cc} 4 \mathrm{c} 3 \mathrm{CCC}(=\mathrm{O}) \mathrm{O}) \mathrm{c}(\mathrm{CCC}(=\mathrm{O}) \mathrm{O}) \mathrm{c} 2 \mathrm{c} 1$ & 8400 & $*$ \\
\hline 4447 & $\mathrm{Cc} 1 \operatorname{ccsc} 1 \mathrm{C}(=\mathrm{O}) \mathrm{n} 1 \mathrm{nc}(\mathrm{Nc} 2 \operatorname{ccc}(\mathrm{S}(\mathrm{N})(=\mathrm{O})=\mathrm{O}) \mathrm{cc} 2) \mathrm{nc} 1 \mathrm{~N}$ & 8400 & $*$ \\
\hline 4448 & $\mathrm{CN}(\mathrm{c} 1 \mathrm{ccccc} 1) \mathrm{c} 1 \mathrm{ncnc} 2 \mathrm{ccc}(\mathrm{N}) \mathrm{cc} 12$ & 8400 & $*$ \\
\hline 4449 & $\operatorname{COc} 1 \operatorname{ccc}(\mathrm{C} 2=\mathrm{NN}(\mathrm{c} 3 \mathrm{nc}(-\mathrm{c} 4 \operatorname{ccc}(\mathrm{Cl}) \operatorname{cc} 4) \operatorname{cs} 3) \mathrm{C}(\mathrm{c} 3 \operatorname{ccc}([\mathrm{N}+](=\mathrm{O})[\mathrm{O}-]) \operatorname{cc} 3) \mathrm{C} 2) \mathrm{cc} 1$ & 8430 & 5.07 \\
\hline 4450 & $\mathrm{O}=\mathrm{C}(\mathrm{Cc} 1 \mathrm{c}[\mathrm{nH}] \mathrm{c} 2 \mathrm{ccccc} 12) \mathrm{NNC}(=\mathrm{S}) \mathrm{Nc} 1 \mathrm{ncccc} 1 \mathrm{Br}$ & 8490 & $*$ \\
\hline 4451 & $\mathrm{O}=\mathrm{C}(\mathrm{Nc} 1 \mathrm{ccc}(\mathrm{Nc} 2 \mathrm{ncnc} 3 \mathrm{cc} 4 \mathrm{oc}(=\mathrm{O}) \mathrm{n}(\mathrm{CCOC}(=\mathrm{O}) \mathrm{CBr}) \mathrm{c} 4 \mathrm{cc} 23) \mathrm{cc} 1) \mathrm{NC} 1 \mathrm{CCCCC} 1$ & 8500 & 5.07 \\
\hline 4452 & $\mathrm{CCOC}(=\mathrm{O}) \mathrm{Nc} 1 \mathrm{ccc}(\mathrm{Nc} 2 \mathrm{ncnc} 3 \mathrm{cc}(\mathrm{OCCN} 4 \mathrm{CCOCC} 4) \mathrm{c}(\mathrm{OC}) \mathrm{cc} 23) \mathrm{cc} 1 \mathrm{Cl} . \mathrm{Cl}$ & 8500 & $*$ \\
\hline 4453 & $\mathrm{O}=\mathrm{C}(\mathrm{CCc} 1 \mathrm{c}(\mathrm{SSc} 2[\mathrm{nH}] \mathrm{c} 3 \operatorname{ccc} c 3 \mathrm{c} 2 \mathrm{CCC}(=\mathrm{O}) \mathrm{NCc} 2 \operatorname{ccc}(\mathrm{C}(=\mathrm{O}) \mathrm{O}) \mathrm{c}(\mathrm{O}) \mathrm{c} 2)[\mathrm{nH}] \mathrm{c} 2 \operatorname{cccc} 12) \mathrm{NCc} 1 \operatorname{ccc}(\mathrm{C}(=\mathrm{O}) \mathrm{O}) \mathrm{c}(\mathrm{O}) \mathrm{c} 1$ & 8500 & $*$ \\
\hline 4454 & $\mathrm{Cc} 1 \operatorname{ccc}(\mathrm{CN}(\mathrm{Cc} 2 \operatorname{ccc}(\mathrm{F}) \mathrm{cc} 2) \mathrm{C}(=\mathrm{S}) \mathrm{Nc} 2 \operatorname{ccccc} 2) \mathrm{c} 1 \mathrm{O}$ & 8540 & 5.07 \\
\hline 4455 & $\mathrm{COc} 1 \mathrm{ccc}(\mathrm{C} 2 \mathrm{CC}(\mathrm{c} 3 \mathrm{ccc}(\mathrm{Cl}) \mathrm{cc} 3)=\mathrm{NN} 2 \mathrm{C} 2=\mathrm{NC}(=\mathrm{O}) \mathrm{CS} 2) \mathrm{cc} 1$ & 8580 & 5.07 \\
\hline 4456 & $\mathrm{COc} 1 \mathrm{cc}(/ \mathrm{C}=\mathrm{C} / \mathrm{C}(=\mathrm{O}) / \mathrm{C}=\mathrm{C}(\mathrm{O}) / \mathrm{C}=\mathrm{C} / \mathrm{c} 2 \mathrm{ccc}(\mathrm{O}) \mathrm{c}(\mathrm{OC}) \mathrm{c} 2) \mathrm{ccc} 1 \mathrm{O}$ & 8600 & 5.07 \\
\hline
\end{tabular}




\begin{tabular}{|c|c|c|c|}
\hline 4457 & $\mathrm{Cc} 1 \mathrm{ccc}(\mathrm{N} 2 \mathrm{NC}(=\mathrm{O}) / \mathrm{C}(=\mathrm{C} / \mathrm{c} 3 \operatorname{ccc}(\mathrm{OCc} 4 \operatorname{ccccc} 4) \operatorname{cc} 3) \mathrm{C} 2=\mathrm{O}) \operatorname{cc} 1 \mathrm{Cl}$ & 8600 & 5.07 \\
\hline 4458 & $\mathrm{COc} 1 \operatorname{ccc}(\mathrm{C} 2=\mathrm{NN}(\mathrm{c} 3 \mathrm{nc}(-\mathrm{c} 4 \operatorname{cccc} 4) \operatorname{cs} 3) \mathrm{C}(\mathrm{c} 3 \operatorname{ccc}([\mathrm{N}+](=\mathrm{O})[\mathrm{O}-]) \operatorname{cc} 3) \mathrm{C} 2) \mathrm{cc} 1$ & 8630 & 5.06 \\
\hline 4459 & $\mathrm{COc} 1 \mathrm{cc}(/ \mathrm{C}=\mathrm{C} / \mathrm{C}(=\mathrm{O}) \mathrm{CC}(=\mathrm{O}) / \mathrm{C}=\mathrm{C} / \mathrm{c} 2 \operatorname{ccc}(\mathrm{O}) \mathrm{c}(\mathrm{OC}) \mathrm{c} 2) \operatorname{ccc} 1 \mathrm{O}$ & 8650 & 5.06 \\
\hline 4460 & $\mathrm{Cc} 1 \mathrm{ccc} 2 \mathrm{nc}(\mathrm{Oc} 3 \operatorname{ccc}(\mathrm{Cl}) \mathrm{cc} 3) \mathrm{c}(\mathrm{C}=\mathrm{N} / \mathrm{NC}(=\mathrm{O}) \mathrm{Cn} 3 \mathrm{c}([\mathrm{N}+](=\mathrm{O})[\mathrm{O}-]) \operatorname{cnc} 3 \mathrm{C}) \mathrm{cc} 2 \mathrm{c} 1$ & 8660 & 5.06 \\
\hline 4461 & $\operatorname{COc} 1 \operatorname{ccc}(\mathrm{C}(/ \mathrm{C}=\mathrm{C} / \mathrm{c} 2 \operatorname{ccccc} 2)=\mathrm{N} \backslash \mathrm{NC}(\mathrm{N})=\mathrm{S}) \mathrm{cc} 1$ & 8660 & 5.06 \\
\hline 4462 & $\mathrm{COc} 1 \mathrm{cc} 2 \mathrm{c}(\mathrm{cc} 1 \mathrm{OC}) \mathrm{Oc} 1 \mathrm{ncnc}(\mathrm{Nc} 3 \mathrm{ccc}(\mathrm{Br}) \mathrm{cc} 3) \mathrm{c} 1 \mathrm{NC} 2$ & 8700 & 5.06 \\
\hline 4463 & $\operatorname{COc} 1 \mathrm{cc}(\mathrm{N} 2 \mathrm{CCN}(\mathrm{C}) \mathrm{CC} 2) \operatorname{ccc} 1 \mathrm{Nc} 1 \mathrm{ncc}(\mathrm{Cl}) \mathrm{c}(\mathrm{Oc} 2 \operatorname{ccc}(\mathrm{NC}(=\mathrm{O}) / \mathrm{C}(\mathrm{C \# N})=\mathrm{C} / \mathrm{c} 3 \operatorname{ccncc} 3) \mathrm{c} 2) \mathrm{n} 1$ & 8700 & 5.06 \\
\hline 4464 & $\mathrm{CN}(\mathrm{c} 1 \operatorname{ccccc} 1) \mathrm{c} 1 \mathrm{cc} 2 \mathrm{c}(\operatorname{cc} 1 \mathrm{Nc} 1 \operatorname{ccc} \mathrm{c} 1) \mathrm{C}(=\mathrm{O}) \mathrm{NC} 2=\mathrm{O}$ & 8700 & $*$ \\
\hline 4465 & $\operatorname{Nc} 1 \operatorname{ccc}(-\operatorname{coc}(=\mathrm{O}) \operatorname{c} 3 \mathrm{cc}(\mathrm{N}) \operatorname{ccc} 3 \mathrm{o} 2) \mathrm{cc} 1$ & 8700 & $*$ \\
\hline 4466 & $\mathrm{CN} 1 \mathrm{CCN}(\mathrm{CCCNc} 2 \mathrm{ncc} 3 \mathrm{cc}(-\mathrm{c} 4 \mathrm{c}(\mathrm{Cl}) \mathrm{cccc} 4 \mathrm{Cl}) \mathrm{c}(=\mathrm{O}) \mathrm{n}(\mathrm{C}) \mathrm{c} 3 \mathrm{n} 2) \mathrm{CC} 1$ & 8700 & $*$ \\
\hline 4467 & Nc1ncnc2c1c(-c1ccc(F)c(O)c1)nn2[C@H]1CCNC1 & 8700 & * \\
\hline 4468 & $\mathrm{C}=\mathrm{CC}(=\mathrm{O}) \mathrm{Nc} 1 \mathrm{cc}(\mathrm{Nc} 2 \mathrm{ncc}(\mathrm{Br}) \mathrm{c}(\mathrm{Nc} 3 \operatorname{ccc} 4[\mathrm{nH}] \operatorname{ccc} 4 \mathrm{c} 3) \mathrm{n} 2) \operatorname{ccc} 1 \mathrm{~N}(\mathrm{C}) \mathrm{CCN}(\mathrm{C}) \mathrm{C}$ & 8700 & $*$ \\
\hline 4469 & $\operatorname{COc} 1 \mathrm{cc}(/ \mathrm{C}=\mathrm{C}(\backslash \mathrm{C} \# \mathrm{~N}) \mathrm{C}(\mathrm{N})=\mathrm{O}) \operatorname{cc}(\mathrm{CSC} 2=\mathrm{NCCS} 2) \mathrm{c} 1 \mathrm{O}$ & 8709.64 & $*$ \\
\hline 4470 & $\operatorname{CCCCCCNC}(=\mathrm{O}) \operatorname{COc} 1 \mathrm{cc}(\mathrm{O}) \mathrm{c} 2 \mathrm{c}(=\mathrm{O}) \mathrm{cc}(-\mathrm{c} 3 \operatorname{ccccc} 3) \mathrm{oc} 2 \mathrm{c} 1$ & 8710 & 5.06 \\
\hline 4471 & $\operatorname{COc} 1 \mathrm{cc} 2 \mathrm{ncc}(\mathrm{C}(=\mathrm{O}) \mathrm{O}) \mathrm{c}(\mathrm{Nc} 3 \operatorname{ccc}(\mathrm{Br}) \mathrm{c} 3) \mathrm{c} 2 \mathrm{cc} 1 \mathrm{OC}$ & 8719 & 5.06 \\
\hline 4472 & $\mathrm{CN}(\mathrm{C}) \mathrm{c} 1 \mathrm{ccc}(/ \mathrm{C}=\mathrm{C} / \mathrm{c} 2 \mathrm{cc}(-\mathrm{c} 3 \mathrm{nnn}(\mathrm{N}) \mathrm{s} 3) \mathrm{c} 3 \mathrm{cc}(\mathrm{Br}) \mathrm{ccc} 3 \mathrm{n} 2) \mathrm{cc} 1$ & 8780 & $*$ \\
\hline 4473 & $\mathrm{O}=\mathrm{C}(/ \mathrm{C}=\mathrm{C} / \mathrm{c} 1 \mathrm{cccs} 1) \mathrm{Nc} 1 \mathrm{ccc} 2 \mathrm{ncnc}(\mathrm{Nc} 3 \operatorname{ccc}(\mathrm{Cl}) \mathrm{c} 3) \mathrm{c} 2 \mathrm{c} 1$ & 8800 & 5.06 \\
\hline 4474 & $\mathrm{O}=[\mathrm{N}+]([\mathrm{O}-]) / \mathrm{C}=\mathrm{C} / \mathrm{c} 1 \mathrm{ccc}(\mathrm{O}) \mathrm{c}(\mathrm{O}) \mathrm{c} 1$ & 8800 & $*$ \\
\hline 4475 & $\mathrm{COC}(=\mathrm{O}) \mathrm{c} 1 \mathrm{cccc} 1 \mathrm{SCC}(\mathrm{CN}(\mathrm{C}) \mathrm{C}) \mathrm{C}(=\mathrm{O}) \mathrm{c} 1 \mathrm{ccc}(\mathrm{OCc} 2 \operatorname{cccc} 2) \operatorname{cc} 1 . \mathrm{Cl}$ & 8800 & $*$ \\
\hline 4476 & $\mathrm{CN}(\mathrm{C}) \mathrm{CC}(\mathrm{CSCCN}) \mathrm{C}(=\mathrm{O}) \mathrm{c} 1 \mathrm{ccc}(\mathrm{OCc} 2 \mathrm{cccc} 2) \mathrm{cc} 1 . \mathrm{Cl}$ & 8800 & $*$ \\
\hline 4477 & $\operatorname{COc} 1 \operatorname{ccc}(-\mathrm{c} 2 \operatorname{ccc} 3 \mathrm{c}(\mathrm{c} 2) \mathrm{NC}(=\mathrm{O}) / \mathrm{C} 3=\mathrm{C} \mid \mathrm{c} 2[\mathrm{nH}] \mathrm{c} 3 \mathrm{c}(\mathrm{c} 2 \mathrm{CCC}(=\mathrm{O}) \mathrm{O}) \mathrm{CCCC} 3) \mathrm{c} 1$ & 8880 & $*$ \\
\hline 4478 & $\mathrm{COc} 1 \mathrm{ccc}(\mathrm{C} 2=\mathrm{NN}(\mathrm{C} 3=\mathrm{NC}(=\mathrm{O}) \mathrm{CS} 3) \mathrm{C}(\mathrm{c} 3 \operatorname{ccc}(\mathrm{OC}) \mathrm{cc} 3) \mathrm{C} 2) \mathrm{cc} 1$ & 8890 & 5.05 \\
\hline 4479 & $\operatorname{COc} 1 \operatorname{ccc}(\mathrm{C}(=\mathrm{O}) \mathrm{n} 2 \mathrm{nc}(-\mathrm{c} 3 \operatorname{cccc} 3) \mathrm{nc} 2 \mathrm{~N}) \mathrm{cc} 1$ & 8900 & 5.05 \\
\hline 4480 & $\mathrm{CC}(\mathrm{C}) \mathrm{n} 1 \mathrm{nc}(-\mathrm{c} 2 \mathrm{ccc}(\mathrm{C \# N}) \mathrm{c}(\mathrm{F}) \mathrm{c} 2) \mathrm{c} 2 \mathrm{c}(\mathrm{N}) \mathrm{ncnc} 21$ & 8900 & $*$ \\
\hline 4481 & $\mathrm{NC}(=\mathrm{S}) \mathrm{N} 1 \mathrm{~N}=\mathrm{C}(\mathrm{c} 2 \mathrm{ccc}(\mathrm{Br}) \mathrm{c}(\mathrm{Br}) \mathrm{c} 2) \mathrm{CC} 1 \mathrm{c} 1 \mathrm{ccc}(\mathrm{F}) \mathrm{cc} 1$ & 8920 & 5.05 \\
\hline 4482 & $\operatorname{Brc} 1 \operatorname{ccc}(\mathrm{C} 2=\mathrm{NN}(\mathrm{c} 3 \mathrm{nc}(-\mathrm{c} 4 \operatorname{ccccc} 4) \operatorname{cs} 3) \mathrm{C}(\mathrm{c} 3 \operatorname{ccc}(\mathrm{Br}) \mathrm{cc} 3) \mathrm{C} 2) \mathrm{cc} 1$ & 8950 & 5.05 \\
\hline 4483 & $\mathrm{O}=\mathrm{C}(/ \mathrm{C}=\mathrm{C} / \mathrm{c} 1 \mathrm{ccc} 2 \mathrm{c}(\mathrm{c} 1) \mathrm{OCCCCO} 2) \mathrm{Nc} 1 \mathrm{ccccc} 1 \mathrm{Cl}$ & 8970 & $*$ \\
\hline 4484 & $\operatorname{COC}(=\mathrm{O}) \mathrm{c} 1 \mathrm{c}(\mathrm{OCCN} 2 \mathrm{CCCC} 2) \mathrm{c} 2 \mathrm{cccc} 2 \mathrm{c} 2 \mathrm{oc} 3 \mathrm{c}(\mathrm{c} 12) \mathrm{C}(=\mathrm{O}) \mathrm{c} 1 \mathrm{cccc} 1 \mathrm{C} 3=\mathrm{O}$ & 9000 & $*$ \\
\hline 4485 & $\mathrm{COc} 1 \mathrm{cc}(\mathrm{C} 2=\mathrm{C}(\mathrm{c} 3 \mathrm{cn}(\mathrm{COC}(\mathrm{C})(\mathrm{C}) \mathrm{C}) \mathrm{c} 4 \mathrm{ccccc} 34) \mathrm{CNC} 2=\mathrm{O}) \mathrm{cc}(\mathrm{OC}) \mathrm{c} 1 \mathrm{OC}$ & 9000 & $*$ \\
\hline 4486 & $\mathrm{CC}(\mathrm{C}) \mathrm{n} 1 \mathrm{nc}(-\mathrm{c} 2 \mathrm{ccc}(\mathrm{C}=\mathrm{O}) \mathrm{c}(\mathrm{F}) \mathrm{c} 2) \mathrm{c} 2 \mathrm{c}(\mathrm{N}) \mathrm{ncnc} 21$ & 9000 & $*$ \\
\hline 4487 & $\mathrm{CS}(=\mathrm{O}) \mathrm{CCCCN}=\mathrm{C}=\mathrm{S}$ & 9000 & $*$ \\
\hline 4488 & $\mathrm{COc} 1 \mathrm{cc} 2 \mathrm{ncc}(\mathrm{C}(=\mathrm{O}) \mathrm{O}) \mathrm{c}(\mathrm{Nc} 3 \mathrm{ccc}(\mathrm{Cl}) \mathrm{c} 3) \mathrm{c} 2 \mathrm{cc} 1 \mathrm{OC}$ & 9021 & 5.04 \\
\hline 4489 & $\mathrm{COc} 1 \mathrm{cc} 2 \mathrm{ncc}(\mathrm{CHN}) \mathrm{c}(\mathrm{Nc} 3 \mathrm{ccc}(\mathrm{O}) \mathrm{c}(\mathrm{Cl}) \mathrm{c} 3) \mathrm{c} 2 \mathrm{cc} 1 \mathrm{OC}$ & 9040 & $*$ \\
\hline 4490 & $\mathrm{COc} 1 \operatorname{ccc}(\mathrm{NC}(=\mathrm{O}) / \mathrm{C}=\mathrm{C} / \mathrm{c} 2 \operatorname{cccc} 2) \operatorname{cc} 1$ & 9050 & $*$ \\
\hline 4491 & $\mathrm{CCN}(\mathrm{CC}) \mathrm{CCOc} 1 \mathrm{cc} 2 \mathrm{c}(\mathrm{Nc} 3 \mathrm{ccc}(\mathrm{Br}) \mathrm{cc} 3 \mathrm{~F}) \mathrm{ncnc} 2 \mathrm{cc} 1 \mathrm{OC}$ & 9100 & $*$ \\
\hline 4492 & $\operatorname{CCCCCCOC}(=0) \operatorname{COc} 1 \operatorname{cc}(O) \operatorname{coc}(=\mathrm{O}) \operatorname{cc}(-\mathrm{c} 3 \operatorname{cccc} 3) \mathrm{oc} 2 \mathrm{c} 1$ & 9120 & 5.04 \\
\hline 4493 & $\mathrm{C}[\mathrm{C} @ @ \mathrm{H}](\mathrm{CN}) \mathrm{n} 1 \mathrm{nc}(-\mathrm{c} 2 \mathrm{ccc}(\mathrm{Cl}) \mathrm{c}(\mathrm{O}) \mathrm{c} 2) \mathrm{c} 2 \mathrm{c}(\mathrm{N}) \mathrm{ncnc} 21$ & 9140 & $*$ \\
\hline 4494 & $\mathrm{CCCCOc} 1 \mathrm{cc} 2 \mathrm{c}(\mathrm{Nc} 3 \mathrm{ccc}(\mathrm{NC}(=\mathrm{O}) \mathrm{OCC}) \mathrm{c}(\mathrm{Cl}) \mathrm{c} 3) \mathrm{ncnc} 2 \mathrm{cc} 1 \mathrm{OCCN}(\mathrm{CC}) \mathrm{CC}$ & 9150 & * \\
\hline 4495 & $\mathrm{CC}(=\mathrm{O}) \mathrm{c} 1 \mathrm{nn}(-\mathrm{c} 2 \mathrm{ccc}(\mathrm{C}) \mathrm{cc} 2) \mathrm{cc} 1 \mathrm{C}(=\mathrm{O}) \mathrm{c} 1 \mathrm{c}(\mathrm{C})[\mathrm{nH}] \mathrm{c}(-\mathrm{c} 2 \mathrm{ccccc} 2) \mathrm{c} 1-\mathrm{c} 1 \mathrm{ccccc} 1$ & 9190 & $*$ \\
\hline 4496 & $\mathrm{Cc} 1 \mathrm{cc}(\mathrm{C}) \mathrm{c}(\mathrm{O}) \mathrm{c}(\mathrm{CN}(\mathrm{Cc} 2 \mathrm{ccc}(\mathrm{O}) \mathrm{cc} 2) \mathrm{C}(=\mathrm{O}) \mathrm{Nc} 2 \mathrm{cccc} 2) \mathrm{c} 1$ & 9260 & 5.03 \\
\hline 4497 & $\mathrm{C}=\mathrm{CC}(=\mathrm{O}) \mathrm{Nc} 1 \mathrm{cc}(\mathrm{Nc} 2 \mathrm{n}[\mathrm{nH}] \mathrm{c} 3 \operatorname{ccccc} 23) \mathrm{c}(\mathrm{OC}) \mathrm{cc} 1 \mathrm{~N}(\mathrm{C}) \mathrm{CCN}(\mathrm{C}) \mathrm{C}$ & 9272 & $*$ \\
\hline 4498 & $\operatorname{COc} 1 \mathrm{cc} 2 \mathrm{ncc}(\mathrm{C}(=\mathrm{O}) \mathrm{O}) \mathrm{c}(\mathrm{Nc} 3 \mathrm{ccc}(\mathrm{F}) \mathrm{c}(\mathrm{Cl}) \mathrm{c} 3) \mathrm{c} 2 \mathrm{cc} 1 \mathrm{OC}$ & 9284 & 5.03 \\
\hline 4499 & $\mathrm{O}=\mathrm{C}(\mathrm{CBr}) \mathrm{OCCn} 1 \mathrm{c}(=\mathrm{O}) \mathrm{oc} 2 \mathrm{cc} 3 \mathrm{ncnc}(\mathrm{Nc} 4 \mathrm{ccc}(\mathrm{NC}(=\mathrm{O}) \mathrm{N} 5 \mathrm{CCCCC} 5) \mathrm{cc} 4) \mathrm{c} 3 \mathrm{cc} 21$ & 9300 & 5.03 \\
\hline
\end{tabular}




\begin{tabular}{|c|c|c|c|}
\hline 4500 & $\mathrm{O}=\mathrm{C}(\mathrm{O}) \mathrm{Cc} 1 \mathrm{c}(\mathrm{SSSc} 2[\mathrm{nH}] \mathrm{c} 3 \operatorname{ccc} c 3 \mathrm{c} 2 \mathrm{CC}(=\mathrm{O}) \mathrm{O})[\mathrm{nH}] \mathrm{c} 2 \operatorname{cccc} 12$ & 9300 & $*$ \\
\hline 4501 & $\mathrm{CN}(\mathrm{c} 1 \mathrm{ccccc} 1) \mathrm{c} 1 \mathrm{ncnc} 2 \mathrm{ccc}(\mathrm{NN}=\mathrm{NCc} 3 \operatorname{ccc} \mathrm{c} 3) \mathrm{cc} 12$ & 9300 & $*$ \\
\hline 4502 & $\mathrm{CCOc} 1 \operatorname{ccc} 1 \mathrm{NC}(=\mathrm{O}) / \mathrm{C}=\mathrm{C} / \mathrm{c} 1 \operatorname{ccccc} 1$ & 9350 & $*$ \\
\hline 4503 & $\mathrm{Clc} 1 \mathrm{ccc}(\mathrm{C} 2 \mathrm{CC}(\mathrm{c} 3 \operatorname{ccc}(\mathrm{Br}) \mathrm{cc} 3)=\mathrm{NN} 2 \mathrm{c} 2 \mathrm{nc}(-\mathrm{c} 3 \operatorname{ccccc} 3) \operatorname{cs} 2) \mathrm{cc} 1$ & 9370 & 5.03 \\
\hline 4504 & $\mathrm{Nc} 1 \mathrm{ncnc} 2 \mathrm{c} 1 \mathrm{c}(-\mathrm{c} 1 \mathrm{ccc}(\mathrm{Cl}) \mathrm{c}(\mathrm{O}) \mathrm{c} 1) \mathrm{nn} 2 \mathrm{CC} 1 \mathrm{CCCN} 1$ & 9380 & $*$ \\
\hline 4505 & $\mathrm{COc} 1 \mathrm{ccc}(\mathrm{C}(=\mathrm{O}) \mathrm{n} 2 \mathrm{nc}(-\mathrm{c} 3 \mathrm{cc}(\mathrm{OC}) \mathrm{c}(\mathrm{OC}) \mathrm{c}(\mathrm{OC}) \mathrm{c} 3) \mathrm{nc} 2 \mathrm{~N}) \mathrm{cc} 1$ & 9400 & 5.03 \\
\hline 4506 & $\mathrm{C} / \mathrm{C}(=\mathrm{C} \mid \mathrm{c} 1 \mathrm{ccc}(\mathrm{O}) \mathrm{c}(\mathrm{O}) \mathrm{c} 1)[\mathrm{N}+](=\mathrm{O})[\mathrm{O}-]$ & 9400 & $*$ \\
\hline 4507 & $\mathrm{CNC}(=\mathrm{O}) \mathrm{CCc} 1 \mathrm{c}(\mathrm{SSc} 2[\mathrm{nH}] \mathrm{c} 3 \operatorname{ccc} \operatorname{coc} 2 \mathrm{CCC}(=\mathrm{O}) \mathrm{NC})[\mathrm{nH}] \mathrm{c} 2 \operatorname{ccccc} 12$ & 9400 & $*$ \\
\hline 4508 & $\mathrm{CCN}(\mathrm{CC}) \mathrm{CCOc} 1 \mathrm{cc} 2 \mathrm{ncnc}(\mathrm{Nc} 3 \mathrm{ccc}(\mathrm{C}) \mathrm{c}(\mathrm{Br}) \mathrm{c} 3) \mathrm{c} 2 \mathrm{cc} 1 \mathrm{OC}$ & 9450 & $*$ \\
\hline 4509 & $\mathrm{O}=\mathrm{C}(\mathrm{Nc} 1 \mathrm{ccccc} 1 \mathrm{Cl}) \mathrm{c} 1 \mathrm{ccc}(\mathrm{N}(\mathrm{CCCl}) \mathrm{CCCl}) \mathrm{cc} 1$ & 9460 & 5.02 \\
\hline 4510 & $\mathrm{~N}=\mathrm{C}(\mathrm{Nc} 1 \operatorname{cccc} 1) \operatorname{SCCCN} 1 \mathrm{C}(=\mathrm{O}) \mathrm{C} 2=\mathrm{C}(\mathrm{C} 1=\mathrm{O}) \mathrm{n} 1 \operatorname{ccc} 3 \operatorname{ccc}(\mathrm{c} 31) \mathrm{C} 1 \mathrm{Cc} 3 \operatorname{ccc} c 3 \mathrm{~N} 21$ & 9500 & $*$ \\
\hline 4511 & $\mathrm{O}=\mathrm{C}(\mathrm{Cc} 1 \mathrm{ccc}(\mathrm{Cl}) \mathrm{cc} 1) \mathrm{NS}(=\mathrm{O})(=\mathrm{O}) \mathrm{c} 1 \mathrm{ccc}(\mathrm{F}) \mathrm{cc} 1$ & 9590 & 5.02 \\
\hline 4512 & Nc1nccn2c1c(-c1ccc3ccc(-c4cccc4)nc3c1)nc2[C@H]1C[C@@H](CN2CCC2)C1 & 9600 & $*$ \\
\hline 4513 & $\operatorname{COc} 1 \mathrm{cc}(\mathrm{OC} 2 \mathrm{CCN}(\mathrm{S}(\mathrm{C})(=\mathrm{O})=\mathrm{O}) \mathrm{CC} 2) \mathrm{c} 2 \mathrm{c}(\mathrm{Nc} 3 \mathrm{ccc}(\mathrm{F}) \mathrm{c}(\mathrm{Cl}) \mathrm{c} 3) \mathrm{ncnc} 2 \mathrm{c} 1$ & 9601 & $*$ \\
\hline 4514 & $\mathrm{O}=\mathrm{C}(\mathrm{Nc} 1 \mathrm{ccc}(\mathrm{Cl}) \mathrm{cc} 1 \mathrm{Cl}) \mathrm{c} 1 \mathrm{cc}(\mathrm{I}) \mathrm{ccc} 1 \mathrm{O}$ & 9660 & $*$ \\
\hline 4515 & $\mathrm{O}=\mathrm{S}(=\mathrm{O})(\mathrm{c} 1 \mathrm{ccc}(\mathrm{N}=\mathrm{C} / \mathrm{c} 2 \mathrm{cc}(\mathrm{Br}) \operatorname{ccc} 2 \mathrm{O}) \mathrm{cc} 1) \mathrm{N} 1 \mathrm{CCCCC} 1$ & 9700 & 5.01 \\
\hline 4516 & $\mathrm{COc} 1 \mathrm{cc} 2 \mathrm{nc}(\mathrm{Cl}) \mathrm{nc}(\mathrm{Nc} 3 \operatorname{ccc}(\mathrm{S}(=\mathrm{O})(=\mathrm{O}) \mathrm{Nc} 4 \mathrm{nccs} 4) \operatorname{cc} 3) \mathrm{c} 2 \mathrm{cc} 1 \mathrm{OC}$ & 9700 & $*$ \\
\hline 4517 & $\mathrm{CNC}(=\mathrm{O}) \mathrm{c} 1 \mathrm{cc}(\mathrm{NCc} 2 \mathrm{cc}(\mathrm{O}) \mathrm{ccc} 2 \mathrm{O}) \mathrm{ccc} 1 \mathrm{O}$ & 9700 & $*$ \\
\hline 4518 & $\mathrm{NC}(=\mathrm{S}) \mathrm{N} / \mathrm{N}=\mathrm{C}(/ \mathrm{C}=\mathrm{C} / \mathrm{c} 1 \mathrm{cccc} 1) \mathrm{c} 1 \mathrm{ccc}(\mathrm{Cl}) \mathrm{c}(\mathrm{Cl}) \mathrm{c} 1$ & 9780 & 5.01 \\
\hline 4519 & $\mathrm{c} 1 \mathrm{ccc}(-\mathrm{c} 2 \mathrm{nc} 3 \mathrm{sc}(-\mathrm{c} 4 \mathrm{cccc} 4) \mathrm{cn} 3 \mathrm{n} 2) \mathrm{cc} 1$ & 9800 & 5.01 \\
\hline 4520 & $\mathrm{CCCCOc} 1 \mathrm{cc} 2 \mathrm{c}(\mathrm{Nc} 3 \operatorname{ccc}(\mathrm{NC}(=\mathrm{O}) \mathrm{OCC}) \mathrm{c}(\mathrm{Cl}) \mathrm{c} 3) \mathrm{ncnc} 2 \mathrm{cc} 1 \mathrm{OCCN}(\mathrm{CC}) \mathrm{CC} . \mathrm{Cl}$ & 9800 & $*$ \\
\hline 4521 & $\mathrm{O}=\mathrm{C} 1 \mathrm{~N}=\mathrm{C}(\mathrm{N} 2 \mathrm{CCC}[\mathrm{C} @ \mathrm{H}] 2 \mathrm{C}(=\mathrm{O}) \mathrm{Nc} 2 \mathrm{ccc} 3 n \mathrm{nc} c(\mathrm{Nc} 4 \mathrm{cccc}(\mathrm{Cl}) \mathrm{c} 4) \mathrm{c} 3 \mathrm{c} 2) \mathrm{S} / \mathrm{C} 1=\mathrm{C} / \mathrm{c} 1 \mathrm{cccnc} 1$ & 9800 & $*$ \\
\hline 4522 & $\mathrm{Cc} 1 \mathrm{ccc}(\mathrm{C} 2 \mathrm{CC}(\mathrm{c} 3 \operatorname{ccc}(\mathrm{Br}) \mathrm{c}(\mathrm{Br}) \mathrm{c} 3)=\mathrm{NN} 2 \mathrm{C}(\mathrm{N})=\mathrm{S}) \mathrm{cc} 1$ & 9830 & 5.01 \\
\hline 4523 & $\mathrm{O}=\mathrm{C}(/ \mathrm{C}=\mathrm{C} / \mathrm{c} 1 \mathrm{ccccc} 1) \mathrm{Nc} 1 \mathrm{ccccc} 1 \mathrm{Cl}$ & 9860 & $*$ \\
\hline 4524 & $\mathrm{CCN}(\mathrm{CC}) \mathrm{CCOc} 1 \mathrm{cc} 2 \mathrm{ncnc}(\mathrm{Nc} 3 \mathrm{ccc}(\mathrm{F}) \mathrm{c}(\mathrm{Cl}) \mathrm{c} 3) \mathrm{c} 2 \mathrm{cc} 1 \mathrm{OC}$ & 9900 & $*$ \\
\hline 4525 & $\mathrm{CC}(=\mathrm{O}) \mathrm{Oc} 1 \mathrm{ccc} 2 \mathrm{c}(\mathrm{C}(=\mathrm{O}) \mathrm{Nc} 3 \operatorname{ccc} c 3) \mathrm{c}(\mathrm{SSc} 3 \mathrm{c}(\mathrm{C}(=\mathrm{O}) \mathrm{Nc} 4 \mathrm{cccc} 4) \mathrm{c} 4 \mathrm{ccc}(\mathrm{OC}(\mathrm{C})=\mathrm{O}) \mathrm{c} 4 \mathrm{n} 3 \mathrm{C}) \mathrm{n}(\mathrm{C}) \mathrm{c} 12$ & 9900 & $*$ \\
\hline 4526 & $\mathrm{Cc} 1 \mathrm{cc}(-\mathrm{c} 2 \mathrm{nn}(\mathrm{C}(\mathrm{C}) \mathrm{C}) \mathrm{c} 3 n \mathrm{nnc}(\mathrm{N}) \mathrm{c} 23) \mathrm{sc} 1 \mathrm{C}=\mathrm{O}$ & 9900 & $*$ \\
\hline 4527 & $\mathrm{COC}(=\mathrm{O}) \mathrm{CNC}(=\mathrm{O}) \mathrm{c} 1 \mathrm{ccc}(\mathrm{Nc} 2 \mathrm{ncnc} 3 \mathrm{cc}(\mathrm{OCCN} 4 \mathrm{CCCCC} 4) \mathrm{c}(\mathrm{OC}) \mathrm{cc} 23) \mathrm{cc} 1$ & 9941 & $*$ \\
\hline 4528 & $\mathrm{COc} 1 \mathrm{cc}(\mathrm{N} 2 \mathrm{CCN}(\mathrm{C}) \mathrm{CC} 2) \operatorname{ccc} 1 \mathrm{Nc} 1 \mathrm{ncc}(\mathrm{Cl}) \mathrm{c}(\mathrm{Oc} 2 \mathrm{cccc}(\mathrm{NC}(=\mathrm{O}) \mathrm{CCN} 3 \mathrm{CCCCC} 3) \mathrm{c} 2) \mathrm{n} 1$ & 10000 & 5.00 \\
\hline 4529 & $\mathrm{Fc} 1 \mathrm{cccc}(\mathrm{COc} 2 \mathrm{ccc}(\mathrm{Nc} 3 \mathrm{cc}(\mathrm{Oc} 4 \mathrm{ccccc} 4) \mathrm{ncn} 3) \mathrm{cc} 2 \mathrm{Cl}) \mathrm{c} 1$ & 10000 & 5.00 \\
\hline 4530 & $\mathrm{~N} \# \mathrm{C} / \mathrm{C}(=\mathrm{C} \mid \mathrm{c} 1 \mathrm{cc}(\mathrm{O}) \operatorname{ccc} 1 \mathrm{O}) \mathrm{C}(\mathrm{N})=\mathrm{O}$ & 10000 & $*$ \\
\hline 4531 & $\mathrm{Cn} 1 \mathrm{c}(\mathrm{SSc} 2 \mathrm{c}(\mathrm{C}(=\mathrm{O}) \mathrm{Nc} 3 \operatorname{ccc} c 3) \operatorname{coc} \operatorname{ccc} 3 \mathrm{n} 2 \mathrm{C}) \mathrm{c}(\mathrm{C}(=\mathrm{O}) \mathrm{Nc} 2 \operatorname{ccccc} 2) \mathrm{c} 2 \operatorname{ccccc} 21$ & 10000 & $*$ \\
\hline 4532 & $\mathrm{COc} 1 \mathrm{ccc}(\mathrm{CNc} 2 \mathrm{ncnc} 3 \mathrm{cccc} 23) \mathrm{cc} 1$ & 10000 & $*$ \\
\hline 4533 & $\mathrm{Nc} 1 \mathrm{cc} 2 \mathrm{ncnc}(\mathrm{Nc} 3 \mathrm{ccccc} 3 \mathrm{C}(\mathrm{F})(\mathrm{F}) \mathrm{F}) \mathrm{c} 2 \mathrm{cn} 1$ & 10000 & $*$ \\
\hline 4534 & $\mathrm{CN}(\mathrm{C}) \mathrm{c} 1 \mathrm{cccc}(\mathrm{CNc} 2 \mathrm{ncnc} 3 \mathrm{cc}(\mathrm{N}) \mathrm{ncc} 23) \mathrm{c} 1$ & 10000 & $*$ \\
\hline 4535 & $\mathrm{Nc} 1 \mathrm{cc} 2 \mathrm{ncnc}(\mathrm{NCc} 3 \operatorname{cccc} 3 \mathrm{C}(\mathrm{F})(\mathrm{F}) \mathrm{F}) \mathrm{c} 2 \mathrm{cn} 1$ & 10000 & $*$ \\
\hline 4536 & $\mathrm{~N} \# \mathrm{C} / \mathrm{C}(=\mathrm{C} / \mathrm{c} 1 \mathrm{ccc}(\mathrm{O}) \mathrm{c}(\mathrm{O}) \mathrm{c} 1) \mathrm{C}(=\mathrm{O}) \mathrm{NCCN} 1 \mathrm{CCN}(\mathrm{C}(=\mathrm{O}) / \mathrm{C}(\mathrm{C} \# \mathrm{~N})=\mathrm{C} / \mathrm{c} 2 \mathrm{ccc}(\mathrm{O}) \mathrm{c}(\mathrm{O}) \mathrm{c} 2) \mathrm{CC} 1$ & 10000 & $*$ \\
\hline 4537 & $\mathrm{Nc} 1 n c n c 20 c c(-\mathrm{c} 3 \mathrm{ccc}(\mathrm{NC}(=\mathrm{O}) \mathrm{Nc} 4 \mathrm{cc}(\mathrm{C}(\mathrm{F})(\mathrm{F}) \mathrm{F}) \mathrm{ccc} 4 \mathrm{~F}) \mathrm{cc} 3) \mathrm{c} 12$ & 10000 & $*$ \\
\hline 4538 & $\operatorname{COc} 1 \mathrm{cc} 2 \mathrm{ncnc}(\mathrm{Nc} 3 \operatorname{cccc} 3 \mathrm{C}(\mathrm{F})(\mathrm{F}) \mathrm{F}) \mathrm{c} 2 \mathrm{cc} 1 \mathrm{OC}$ & 10000 & $*$ \\
\hline 4539 & $\mathrm{Cc} 1 \operatorname{cccc}(\mathrm{Cl}) \mathrm{c} 1 \mathrm{NC}(=\mathrm{O}) \mathrm{c} 1 \mathrm{cnc}(\mathrm{NC}(=\mathrm{O}) \mathrm{C} 2 \mathrm{CC} 2) \mathrm{s} 1$ & 10000 & $*$ \\
\hline 4540 & $\mathrm{NC}[\mathrm{C} @ \mathrm{H}](\mathrm{Cc} 1 \mathrm{cccc}(\mathrm{F}) \mathrm{c} 1) \mathrm{NC}(=\mathrm{O}) \mathrm{c} 1 \mathrm{cc}(\mathrm{Br}) \mathrm{c}(-\mathrm{c} 2 \mathrm{ccnc} 3[\mathrm{nH}] \mathrm{ccc} 23) \mathrm{s} 1$ & 10000 & $*$ \\
\hline 4541 & $\mathrm{Cn} 1 \mathrm{nc}(-\mathrm{c} 2 \mathrm{ccc} 3 \mathrm{occc}(=\mathrm{O}) \mathrm{c} 3 \mathrm{c} 2) \mathrm{c} 2 \mathrm{c}(\mathrm{N}) \mathrm{ncnc} 21$ & 10000 & $*$ \\
\hline 4542 & $\mathrm{CC}(\mathrm{C}) \mathrm{n} 1 \mathrm{nc}(-\mathrm{c} 2 \mathrm{cc}(\mathrm{F}) \mathrm{c}(\mathrm{C}=\mathrm{O}) \mathrm{c}(\mathrm{F}) \mathrm{c} 2) \mathrm{c} 2 \mathrm{c}(\mathrm{N}) \mathrm{ncnc} 21$ & 10000 & $*$ \\
\hline
\end{tabular}




\begin{tabular}{|c|c|c|c|}
\hline 4543 & $\mathrm{CN}(\mathrm{C}) \mathrm{CCNc} 1 \mathrm{ncnc} 2[\mathrm{nH}] \mathrm{c} 3 \operatorname{ccc} c 3 \mathrm{c} 12$ & 10000 & * \\
\hline 4544 & $\mathrm{CCOC}(\mathrm{C})=\mathrm{O} \cdot \mathrm{CN}(\mathrm{C}) \mathrm{CCN} 1 \mathrm{ncnc} 2[\mathrm{nH}] \mathrm{c} 3 \operatorname{ccc} c \mathrm{c} 3 \mathrm{c} 12$ & 10000 & $*$ \\
\hline 4545 & $\mathrm{Cc} 1 \mathrm{nc}(\mathrm{Nc} 2 \mathrm{cccc}(\mathrm{Br}) \mathrm{c} 2) \mathrm{c} 2 \mathrm{c}(\mathrm{n} 1)[\mathrm{nH}] \mathrm{c} 1 \mathrm{ccccc} 12 . \mathrm{Cl}$ & 10000 & $*$ \\
\hline 4546 & $\mathrm{COc} 1 \mathrm{ccc}(\mathrm{Oc} 2 \mathrm{ccnc} 3 \mathrm{cc}(\mathrm{OC}) \mathrm{c}(\mathrm{OC}) \mathrm{cc} 23) \mathrm{cc} 1 \mathrm{OC}$ & 10000 & $*$ \\
\hline 4547 & $\mathrm{O}=\mathrm{C}(\mathrm{Nc} 1 \operatorname{ccc}(\mathrm{Cl}) \mathrm{c} 1) \mathrm{c} 1 \mathrm{cc} 2 \operatorname{ccc} c 2 \mathrm{cc} 1 \mathrm{O}$ & 10000 & * \\
\hline 4548 & $\mathrm{Cc} 1 \mathrm{ccc}(\mathrm{C}(=\mathrm{O}) \mathrm{Nc} 2 \operatorname{cccc}(\mathrm{Cl}) \mathrm{c} 2) \mathrm{c}(\mathrm{O}) \mathrm{c} 1$ & 10000 & $*$ \\
\hline 4549 & $\mathrm{O}=\mathrm{C}(\mathrm{Nc} 1 \mathrm{cccc}(\mathrm{Cl}) \mathrm{c} 1) \mathrm{c} 1 \mathrm{ccc}(\mathrm{OS}(=\mathrm{O})(=\mathrm{O}) \mathrm{C}(\mathrm{F})(\mathrm{F}) \mathrm{F}) \mathrm{cc} 1 \mathrm{O}$ & 10000 & $*$ \\
\hline 4550 & $\mathrm{CCN}(\mathrm{CC}) \mathrm{c} 1 \mathrm{ccc}(\mathrm{C}(=\mathrm{O}) \mathrm{Nc} 2 \operatorname{cccc}(\mathrm{Cl}) \mathrm{c} 2) \mathrm{c}(\mathrm{O}) \mathrm{c} 1$ & 10000 & $*$ \\
\hline 4551 & $\mathrm{COc} 1 \mathrm{ccc}(-\mathrm{c} 2 \mathrm{cc} 3 \mathrm{c}(\mathrm{NC}(\mathrm{C}) \mathrm{c} 4 \mathrm{ccc}(\mathrm{C}(\mathrm{C})(\mathrm{C}) \mathrm{C}) \mathrm{cc} 4) \mathrm{ncnc} 3[\mathrm{nH}] 2) \mathrm{cc} 1$ & 10000 & * \\
\hline 4552 & $\mathrm{COc} 1 \mathrm{cc} 2 \mathrm{c}(\mathrm{Oc} 3 \mathrm{ccc}(\mathrm{NC}(=\mathrm{O}) \mathrm{c} 4 \mathrm{nnn}(-\mathrm{c} 5 \mathrm{ccc}(\mathrm{F}) \mathrm{cc} 5) \mathrm{c} 4 \mathrm{C}(\mathrm{F})(\mathrm{F}) \mathrm{F}) \mathrm{cc} 3 \mathrm{~F}) \mathrm{ccnc} 2 \mathrm{cc} 1 \mathrm{OCCCN} 1 \mathrm{CCCC} 1$ & 10000 & * \\
\hline 4553 & $\mathrm{COc} 1 \mathrm{ccc}(\mathrm{NC}(=\mathrm{O}) / \mathrm{C}=\mathrm{C} / \mathrm{CN}(\mathrm{C}) \mathrm{C}) \mathrm{cc} 1 \mathrm{Nc} 1 \mathrm{ncc}(\mathrm{Cl}) \mathrm{c}(\mathrm{Oc} 2 \mathrm{ccc} 3 \operatorname{ccc} c \mathrm{c} 2) \mathrm{n} 1$ & 10000 & $*$ \\
\hline 4554 & $\mathrm{COc} 1 \mathrm{ccc}(\mathrm{NC}(=\mathrm{O}) / \mathrm{C}=\mathrm{C} / \mathrm{CN}(\mathrm{C}) \mathrm{C}) \operatorname{cc} 1 \mathrm{Nc} 1 \mathrm{ncc}(\mathrm{Cl}) \mathrm{c}(\mathrm{Sc} 2 \operatorname{ccc} 3 \operatorname{ccccc} 3 \mathrm{c} 2) \mathrm{n} 1$ & 10000 & $*$ \\
\hline 4555 & $\mathrm{O}=\mathrm{C}(\mathrm{O}) \mathrm{C} 1 \mathrm{CCC} 2(\mathrm{CC} 1) \mathrm{OOC} 1(\mathrm{OO} 2) \mathrm{C} 2 \mathrm{CC} 3 \mathrm{CC}(\mathrm{C} 2) \mathrm{CC} 1 \mathrm{C} 3$ & 10000 & * \\
\hline 4556 & $\mathrm{C}=\mathrm{CC}(=\mathrm{O}) \mathrm{Nc} 1 \mathrm{cc}(\mathrm{Nc} 2 \mathrm{n}[\mathrm{nH}] \mathrm{c} 3 \operatorname{ccccc} 23) \operatorname{ccc} 1 \mathrm{~N}(\mathrm{C}) \mathrm{CCN}(\mathrm{C}) \mathrm{C}$ & 10000 & $*$ \\
\hline 4557 & $\mathrm{CCC}(=\mathrm{O}) \mathrm{Nc} 1 \mathrm{cc}(\mathrm{Nc} 2 \mathrm{n}[\mathrm{nH}] \mathrm{c} 3 \mathrm{ccccc} 23) \mathrm{ccc} 1 \mathrm{~N}(\mathrm{C}) \mathrm{CCN}(\mathrm{C}) \mathrm{C}$ & 10000 & $*$ \\
\hline 4558 & $\mathrm{CCC}(=\mathrm{O}) \mathrm{Nc} 1 \mathrm{cc}(\mathrm{Nc} 2 \mathrm{n}[\mathrm{nH}] \mathrm{c} 3 \mathrm{cccc} 23) \mathrm{c}(\mathrm{OC}) \mathrm{cc} 1 \mathrm{~N}(\mathrm{C}) \mathrm{CCN}(\mathrm{C}) \mathrm{C}$ & 10000 & * \\
\hline 4559 & $\mathrm{CN} 1 \mathrm{CCN}(\mathrm{c} 2 \mathrm{ccc}(\mathrm{Nc} 3 \mathrm{ncc}(\mathrm{Br}) \mathrm{c}(\mathrm{Nc} 4 \mathrm{ccc} 5 \mathrm{ncccc} 5 \mathrm{c} 4) \mathrm{n} 3) \mathrm{cc} 2) \mathrm{CC} 1$ & 10000 & * \\
\hline 4560 & $\operatorname{COc} 1 \operatorname{cccc}(\mathrm{Nc} 2 \operatorname{cc}(\mathrm{Nc} 3 \operatorname{ccc}(\mathrm{S}(\mathrm{N})(=\mathrm{O})=\mathrm{O}) \operatorname{cc} 3) \mathrm{ncn} 2) \mathrm{c} 1$ & 10000 & * \\
\hline 4561 & $\mathrm{CCOc} 1 \mathrm{ccc}(\mathrm{Nc} 2 \mathrm{cc}(\mathrm{NC}(=\mathrm{O}) \mathrm{c} 3 \mathrm{ccccc} 3) \mathrm{ncn} 2) \mathrm{cc} 1$ & 10000 & $*$ \\
\hline 4562 & $\mathrm{O}=\mathrm{C}(\mathrm{O}) \mathrm{CCC}(=\mathrm{O}) \mathrm{Nc} 1 \mathrm{cc}(\mathrm{Nc} 2 \mathrm{ccc}(\mathrm{Cl}) \mathrm{cc} 2) \mathrm{ncn} 1$ & 10000 & $*$ \\
\hline 4563 & $\mathrm{COc} 1 \mathrm{cccc}(\mathrm{Nc} 2 \mathrm{cc}(\mathrm{Nc} 3 \operatorname{cccc}(\mathrm{Cl}) \mathrm{c} 3) \mathrm{ncn} 2) \mathrm{c} 1$ & 10000 & * \\
\hline 4564 & $\mathrm{O}=\mathrm{C}(\mathrm{O}) \mathrm{CCCC}(=\mathrm{O}) \mathrm{Nc} 1 \mathrm{cc}(\mathrm{Nc} 2 \mathrm{ccc}(\mathrm{Cl}) \mathrm{cc} 2) \mathrm{ncn} 1$ & 10000 & * \\
\hline 4565 & $\operatorname{CCOC}(=\mathrm{O}) \mathrm{CCC}(=\mathrm{O}) \mathrm{Nc} 1 \mathrm{cc}(\mathrm{Nc} 2 \mathrm{cccc}(\mathrm{Br}) \mathrm{c} 2) \mathrm{ncn} 1$ & 10000 & * \\
\hline 4566 & $\mathrm{O}=\mathrm{C}(\mathrm{O}) \mathrm{CCCC}(=\mathrm{O}) \mathrm{Nc} 1 \mathrm{cc}(\mathrm{Nc} 2 \mathrm{ccccc} 2) \mathrm{ncn} 1$ & 10000 & * \\
\hline 4567 & $\mathrm{CCOC}(=\mathrm{O}) \mathrm{c} 1 \mathrm{ccc}(\mathrm{Nc} 2 \mathrm{cc}(\mathrm{Nc} 3 \mathrm{cccc}(\mathrm{OC}) \mathrm{c} 3) \mathrm{ncn} 2) \mathrm{cc} 1$ & 10000 & $*$ \\
\hline 4568 & $\mathrm{O}=\mathrm{C}(\mathrm{Nc} 1 \mathrm{cc}(\mathrm{Nc} 2 \mathrm{ccc}(\mathrm{Cl}) \mathrm{cc} 2) \mathrm{ncn} 1) \mathrm{c} 1 \mathrm{ccc}(\mathrm{F}) \mathrm{cc} 1$ & 10000 & $*$ \\
\hline 4569 & $\mathrm{Cc} 1 \mathrm{ncc}([\mathrm{N}+](=\mathrm{O})[\mathrm{O}-]) \mathrm{n} 1 \mathrm{C} / \mathrm{C}(=\mathrm{N} / \mathrm{NC}(=\mathrm{O}) \mathrm{c} 1 \mathrm{ccccc} 1) \mathrm{c} 1 \mathrm{ccc}(\mathrm{Br}) \mathrm{cc} 1$ & 10020 & 5.00 \\
\hline 4570 & $\mathrm{O}=\mathrm{C}(/ \mathrm{C}=\mathrm{C} / \mathrm{c} 1 \mathrm{ccccc} 1) \mathrm{Nc} 1 \mathrm{ccc}(\mathrm{F}) \mathrm{cc} 1$ & 10020 & $*$ \\
\hline 4571 & $\mathrm{NC}(=\mathrm{S}) \mathrm{N} 1 \mathrm{~N}=\mathrm{C}(\mathrm{c} 2 \mathrm{ccc}(\mathrm{Br}) \mathrm{c}(\mathrm{Br}) \mathrm{c} 2) \mathrm{CC} 1 \mathrm{c} 1 \mathrm{ccc}(\mathrm{Br}) \mathrm{cc} 1$ & 10060 & 5.00 \\
\hline 4572 & $\mathrm{O}=[\mathrm{N}+]([\mathrm{O}-]) / \mathrm{C}=\mathrm{C} / \mathrm{c} 1 \mathrm{ccc}(\mathrm{O}) \mathrm{cc} 1$ & 10100 & $*$ \\
\hline 4573 & $\mathrm{Nc} 1 \mathrm{cc} 2 \mathrm{ncnc}(\mathrm{NCc} 3 \operatorname{cccc}([\mathrm{N}+](=\mathrm{O})[\mathrm{O}-]) \mathrm{c} 3) \mathrm{c} 2 \mathrm{cn} 1$ & 10100 & $*$ \\
\hline 4574 & $\mathrm{Cc} 1 \operatorname{cccc}(\mathrm{Nc} 2 \mathrm{c}(\mathrm{C} \# \mathrm{~N}) \operatorname{cnc} 3 \operatorname{ccc}(\mathrm{C}(=\mathrm{O}) / \mathrm{C}=\mathrm{C} / \mathrm{c} 4 \mathrm{ccc}(-\mathrm{c} 5 \operatorname{ccc}(\mathrm{S}(\mathrm{N})(=\mathrm{O})=\mathrm{O}) \operatorname{cc} 5) \mathrm{)} 4) \mathrm{cc} 23) \mathrm{c} 1$ & 10110 & * \\
\hline 4575 & $\mathrm{Cc} 1 \mathrm{ccc}(-\mathrm{n} 2 \mathrm{nc}(\mathrm{C}) \mathrm{c}(\mathrm{C} 3 \mathrm{C}(\mathrm{C} \# \mathrm{~N})=\mathrm{C}(\mathrm{N}) \mathrm{N}(\mathrm{c} 4 \mathrm{cccnc} 4) \mathrm{C} 4=\mathrm{C} 3 \mathrm{C}(=\mathrm{O}) \mathrm{CCC} 4) \mathrm{c} 2 \mathrm{Cl}) \mathrm{cc} 1$ & 10120 & 4.99 \\
\hline 4576 & $\mathrm{CN}(\mathrm{c} 1 \mathrm{ccc} 2 \mathrm{c}(\mathrm{ccn} 2 \mathrm{C}) \mathrm{c} 1) \mathrm{c} 1 \mathrm{ccnc}(\mathrm{Nc} 2 \mathrm{ccc}(\mathrm{N} 3 \mathrm{CCOCC} 3) \mathrm{cc} 2) \mathrm{n} 1$ & 10120 & * \\
\hline 4577 & $\mathrm{COc} 1 \mathrm{ccc}(\mathrm{C} 2 \mathrm{CC}(\mathrm{c} 3 \mathrm{ccc}(\mathrm{Br}) \mathrm{cc} 3)=\mathrm{NN} 2 \mathrm{c} 2 \mathrm{nc}(-\mathrm{c} 3 \mathrm{ccccc} 3) \mathrm{cs} 2) \mathrm{cc} 1$ & 10170 & 4.99 \\
\hline 4578 & $\mathrm{O}=\mathrm{C}(\mathrm{O}) \mathrm{C} c 1 \mathrm{c}(\mathrm{SSc} 2[\mathrm{nH}] \mathrm{c} 3 \operatorname{cccc} 3 \mathrm{c} 2 \mathrm{CC}(=\mathrm{O}) \mathrm{O})[\mathrm{nH}] \mathrm{c} 2 \mathrm{cccc} 12$ & 10200 & $*$ \\
\hline 4579 & $\operatorname{COc} 1 \mathrm{cc}(\mathrm{F}) \mathrm{c}(-\mathrm{c} 2 \mathrm{nn}(\mathrm{C}(\mathrm{C}) \mathrm{C}) \mathrm{c} 3 \mathrm{ncnc}(\mathrm{N}) \mathrm{c} 23) \mathrm{cc} 1 \mathrm{~F}$ & 10200 & $*$ \\
\hline 4580 & $\operatorname{CCOc} 1 \operatorname{ccc}(\mathrm{NC}(=\mathrm{O}) / \mathrm{C}=\mathrm{C} / \mathrm{c} 2 \operatorname{ccccc} 2) \mathrm{cc} 1$ & 10230 & $*$ \\
\hline 4581 & $\mathrm{~N} \# \mathrm{C} / \mathrm{C}(=\mathrm{Clc} 1 \mathrm{ccc}(\mathrm{O}) \mathrm{c}(\mathrm{O}) \mathrm{c} 1) \mathrm{C}(=\mathrm{O}) \mathrm{NCc} 1 \mathrm{cccc}(\mathrm{CNC}(=\mathrm{O}) / \mathrm{C}(\mathrm{C} \# \mathrm{~N})=\mathrm{C} / \mathrm{c} 2 \mathrm{ccc}(\mathrm{O}) \mathrm{c}(\mathrm{O}) \mathrm{c} 2) \mathrm{c} 1$ & 10300 & * \\
\hline 4582 & $\mathrm{O}=\mathrm{S}(=\mathrm{O})(\mathrm{O}) \mathrm{c} 1 \mathrm{cc}(\mathrm{NCc} 2 \mathrm{cc}(\mathrm{O}) \operatorname{ccc} 2 \mathrm{O}) \operatorname{ccc} 1 \mathrm{O}$ & 10300 & $*$ \\
\hline 4583 & $\mathrm{CCOc} 1 \mathrm{cc} 2 \mathrm{ncc}(\mathrm{C} \# \mathrm{~N}) \mathrm{c}(\mathrm{Nc} 3 \mathrm{cccc}(\mathrm{Br}) \mathrm{c} 3) \mathrm{c} 2 \mathrm{cc} 1 \mathrm{NC}(=\mathrm{O}) / \mathrm{C}=\mathrm{C} / \mathrm{CN} 1 \mathrm{CCOCC} 1$ & 10320 & 4.99 \\
\hline 4584 & $\mathrm{O}=\mathrm{C}(\mathrm{Cc} 1 \mathrm{ccc}(\mathrm{Cl}) \mathrm{cc} 1) \mathrm{NS}(=\mathrm{O})(=\mathrm{O}) \mathrm{c} 1 \mathrm{ccc}(\mathrm{Cl}) \mathrm{cc} 1$ & 10340 & 4.99 \\
\hline 4585 & $\mathrm{Cc} 1 \mathrm{ncc}([\mathrm{N}+](=\mathrm{O})[\mathrm{O}-]) \mathrm{n} 1 \mathrm{CC}(=\mathrm{O}) \mathrm{N} / \mathrm{N}=\mathrm{C} / \mathrm{c} 1 \mathrm{cc} 2 \mathrm{ccccc} 2 \mathrm{nc} 1 \mathrm{Oc} 1 \mathrm{ccccc} 1$ & 10350 & 4.99 \\
\hline
\end{tabular}




\begin{tabular}{|c|c|c|c|}
\hline 4586 & $\mathrm{Cc} 1 \operatorname{ccc} 2 \mathrm{c}(\mathrm{c} 1) \operatorname{cc}(\mathrm{ClC}(\mathrm{C} \# \mathrm{~N})=\mathrm{C}(\mathrm{N}) \mathrm{N}(\mathrm{c} 3 \operatorname{ccc} n \mathrm{c} 3) \mathrm{C} 3=\mathrm{C} 1 \mathrm{C}(=\mathrm{O}) \mathrm{CCC} 3) \mathrm{c} 1 \mathrm{nnnn} 12$ & 10400 & 4.98 \\
\hline 4587 & $\operatorname{COc} 1 \operatorname{ccc}(\mathrm{C} 2=\mathrm{NN}(\mathrm{C}(=\mathrm{O}) \mathrm{c} 3 \operatorname{ccc}(\mathrm{Cl}) \mathrm{cc} 3 \mathrm{O}) \mathrm{C}(\mathrm{c} 3 \mathrm{ccc}(\mathrm{Cl}) \mathrm{cc} 3) \mathrm{C} 2) \mathrm{cc} 1$ & 10490 & * \\
\hline 4588 & $\begin{array}{c}\mathrm{CCC}(\mathrm{C})[\mathrm{C} @ \mathrm{H}] 1[\mathrm{C} @](\mathrm{C})(\mathrm{O}) \mathrm{C}(=\mathrm{O})[\mathrm{C} @ @] 2(\mathrm{O}) \mathrm{C}[\mathrm{C} @](\mathrm{C})(\mathrm{O}) \mathrm{C}[\mathrm{C} @ @ \mathrm{H}](\mathrm{C})[\mathrm{C} @ @ \mathrm{H}] 2[\mathrm{C} @] 1(\mathrm{C}) \mathrm{C}(=\mathrm{O}) / \mathrm{C}=\mathrm{C} / \mathrm{O} \\
\mathrm{C}\end{array}$ & 10500 & $*$ \\
\hline 4589 & $\mathrm{COc} 1 \mathrm{cc} 2 \mathrm{ncc}(\mathrm{C} \# \mathrm{~N}) \mathrm{c}(\mathrm{Nc} 3 \mathrm{ccc}(\mathrm{F}) \mathrm{c}(\mathrm{Cl}) \mathrm{c} 3) \mathrm{c} 2 \mathrm{cc} 1 \mathrm{NC}(=\mathrm{O}) / \mathrm{C}=\mathrm{C} / \mathrm{C}(\mathrm{C}) \mathrm{N} 1 \mathrm{CCOCC} 1$ & 10590 & 4.97 \\
\hline 4590 & $\mathrm{NC}(=\mathrm{S}) \mathrm{N} 1 \mathrm{~N}=\mathrm{C}(\mathrm{c} 2 \mathrm{ccc}(\mathrm{Br}) \mathrm{c}(\mathrm{Br}) \mathrm{c} 2) \mathrm{CC} 1 \mathrm{c} 1 \mathrm{ccc}([\mathrm{N}+](=\mathrm{O})[\mathrm{O}-]) \mathrm{cc} 1$ & 10640 & 4.97 \\
\hline 4591 & $\mathrm{CN}(\mathrm{C}) \mathrm{C} / \mathrm{C}=\mathrm{C} / \mathrm{C}(=\mathrm{O}) \mathrm{Nc} 1 \mathrm{cccc}(\mathrm{Nc} 2 \mathrm{nc}(\mathrm{N} / \mathrm{N}=\mathrm{C} / \mathrm{c} 3 \operatorname{ccc}(\mathrm{F}) \mathrm{cc} 3) \mathrm{ncc} 2 \mathrm{Cl}) \mathrm{c} 1$ & 10650 & $*$ \\
\hline 4592 & $\mathrm{COc} 1 \mathrm{ccc}(\mathrm{C} 2 \mathrm{CC}(\mathrm{c} 3 \operatorname{ccc}(\mathrm{F}) \mathrm{cc} 3)=\mathrm{NN} 2 \mathrm{C} 2=\mathrm{NC}(=\mathrm{O}) \mathrm{CS} 2) \mathrm{cc} 1$ & 10690 & 4.97 \\
\hline 4593 & $\mathrm{Cc} 1 \mathrm{cc}(\mathrm{C}) \mathrm{c}(\mathrm{C}(=\mathrm{O}) / \mathrm{C}(\mathrm{C} \# \mathrm{~N})=\mathrm{C} / \mathrm{c} 2 \mathrm{ccc}(\mathrm{O}) \mathrm{c}(\mathrm{O}) \mathrm{c} 2) \mathrm{c}(\mathrm{C}) \mathrm{c} 1$ & 10700 & $*$ \\
\hline 4594 & $\mathrm{O}=\mathrm{C} 1 \mathrm{CSC}(\mathrm{N} / \mathrm{N}=\mathrm{C} / \mathrm{c} 2 \operatorname{cccc}(\mathrm{Cl}) \mathrm{c} 2)=\mathrm{N} 1$ & 10780 & 4.97 \\
\hline 4595 & $\mathrm{COc} 1 \mathrm{cc} 2 \mathrm{c}(\mathrm{cc} 1 \mathrm{OC}) \mathrm{Oc} 1 \mathrm{ncnc}(\mathrm{Oc} 3 \mathrm{ccc}(\mathrm{F}) \mathrm{c}(\mathrm{Cl}) \mathrm{c} 3) \mathrm{c} 1 \mathrm{~N}(\mathrm{C}) \mathrm{C} 2$ & 10800 & 4.97 \\
\hline 4596 & $\operatorname{COc} 1 \operatorname{ccc}(/ \mathrm{C}=\mathrm{C} / \mathrm{C}(=\mathrm{O}) \mathrm{OCCn} 2 \mathrm{c}([\mathrm{N}+](=\mathrm{O})[\mathrm{O}-]) \mathrm{cnc} 2 \mathrm{C}) \mathrm{cc} 1$ & 10850 & 4.96 \\
\hline 4597 & $\mathrm{~N} \# \mathrm{Cc} 1 \mathrm{ccc} 2 \mathrm{c}(\mathrm{c} 1) \mathrm{C}(\mathrm{c} 1 \mathrm{ccccc} 1 \mathrm{~F})=\mathrm{Nc} 1 \mathrm{c}[\mathrm{nH}] \mathrm{nc} 1 \mathrm{~N} 2$ & 10900 & $*$ \\
\hline 4598 & $\mathrm{O}=\mathrm{C} 1 \mathrm{CSC}(\mathrm{N} 2 \mathrm{~N}=\mathrm{C}(\mathrm{c} 3 \mathrm{ccc}(\mathrm{F}) \mathrm{cc} 3) \mathrm{CC} 2 \mathrm{c} 2 \mathrm{ccc}(\mathrm{Cl}) \mathrm{cc} 2)=\mathrm{N} 1$ & 10920 & 4.96 \\
\hline 4599 & $\operatorname{COc} 1 \operatorname{cccc}(/ \mathrm{C}=\mathrm{C} / \mathrm{C}(=\mathrm{N} / \mathrm{NC}(\mathrm{N})=\mathrm{S}) \mathrm{c} 2 \operatorname{ccccc} 2) \mathrm{c} 1$ & 10950 & 4.96 \\
\hline 4600 & $\mathrm{NC}(=\mathrm{S}) \mathrm{N} 1 \mathrm{~N}=\mathrm{C}(\mathrm{c} 2 \operatorname{ccc}(\mathrm{Br}) \mathrm{c}(\mathrm{Br}) \mathrm{c} 2) \mathrm{CC} 1 \mathrm{c} 1 \mathrm{ccccc} 1 \mathrm{Br}$ & 10970 & 4.96 \\
\hline 4601 & $\mathrm{COc} 1 \mathrm{cc} 2 \mathrm{ncnc}(\mathrm{Nc} 3 \mathrm{cc}(\mathrm{NC}(=\mathrm{O}) \mathrm{c} 4 \mathrm{ccccc} 4) \mathrm{ccc} 3 \mathrm{Cl}) \mathrm{c} 2 \mathrm{cc} 1 \mathrm{OC}$ & 11000 & $*$ \\
\hline 4602 & $\mathrm{Cc} 1 \mathrm{cccc}(\mathrm{Nc} 2 \mathrm{ccnc}(\mathrm{Nc} 3 \mathrm{ccc}(\mathrm{N} 4 \mathrm{CCN}(\mathrm{C}) \mathrm{CC} 4) \mathrm{cc} 3) \mathrm{n} 2) \mathrm{c} 1$ & 11000 & * \\
\hline 4603 & $\mathrm{~N} \# C C C C C n 1 n c(-\mathrm{c} 2 \mathrm{ccc}(\mathrm{F}) \mathrm{c}(\mathrm{O}) \mathrm{c} 2) \mathrm{c} 2 \mathrm{c}(\mathrm{N}) \mathrm{ncnc} 21$ & 11000 & $*$ \\
\hline 4604 & $\mathrm{COc} 1 \mathrm{cc}(\mathrm{Br}) \mathrm{cc}(-\mathrm{c} 2 \mathrm{nn}(\mathrm{C}(\mathrm{C}) \mathrm{C}) \mathrm{c} 3 \mathrm{ncnc}(\mathrm{N}) \mathrm{c} 23) \mathrm{c} 1$ & 11000 & $*$ \\
\hline 4605 & $\mathrm{CCOC}(=\mathrm{O}) \mathrm{C} 1=\mathrm{C}(\mathrm{N}) \mathrm{N}(\mathrm{c} 2 \mathrm{cccnc} 2) \mathrm{C} 2=\mathrm{C}(\mathrm{C}(=\mathrm{O}) \mathrm{CC}(\mathrm{C})(\mathrm{C}) \mathrm{C} 2) \mathrm{C} 1 \mathrm{c} 1 \mathrm{c}(\mathrm{C}) \mathrm{nn}(-\mathrm{c} 2 \mathrm{ccccc} 2) \mathrm{c} 1 \mathrm{Cl}$ & 11180 & 4.95 \\
\hline 4606 & $\mathrm{COc1} \operatorname{ccccc} 1 \mathrm{CNc} 1 \mathrm{ccc} 2 \mathrm{ncnc}(\mathrm{Nc} 3 \mathrm{cccc}(\mathrm{Br}) \mathrm{c} 3) \mathrm{c} 2 \mathrm{c} 1$ & 11220 & 4.95 \\
\hline 4607 & $\mathrm{Fc} 1 \mathrm{ccc}(\mathrm{C} 2 \mathrm{CC}(\mathrm{c} 3 \mathrm{ccc}(\mathrm{Br}) \mathrm{cc} 3)=\mathrm{NN} 2 \mathrm{c} 2 \mathrm{nc}(-\mathrm{c} 3 \mathrm{ccccc} 3) \mathrm{cs} 2) \mathrm{cc} 1$ & 11240 & 4.95 \\
\hline 4608 & $\mathrm{NC}(=\mathrm{S}) \mathrm{N} 1 \mathrm{~N}=\mathrm{C}(\mathrm{c} 2 \mathrm{ccc}(\mathrm{Br}) \mathrm{c}(\mathrm{Br}) \mathrm{c} 2) \mathrm{CC} 1 \mathrm{c} 1 \mathrm{ccc}(\mathrm{O}) \mathrm{cc} 1$ & 11270 & 4.95 \\
\hline 4609 & $\mathrm{O}=\mathrm{C}(\mathrm{Cc} 1 \mathrm{ccc}(\mathrm{Cl}) \operatorname{cc} 1) \mathrm{NS}(=\mathrm{O})(=\mathrm{O}) \mathrm{c} 1 \mathrm{ccc}(\mathrm{Br}) \mathrm{cc} 1$ & 11290 & 4.95 \\
\hline 4610 & $\mathrm{Cn} 1 \mathrm{c}(\mathrm{SSc} 2 \mathrm{c}(\mathrm{C}(=\mathrm{O}) \mathrm{Nc} 3 \mathrm{ccccc} 3) \mathrm{c} 3 \mathrm{cc}(\mathrm{Br}) \operatorname{ccc} 3 \mathrm{n} 2 \mathrm{C}) \mathrm{c}(\mathrm{C}(=\mathrm{O}) \mathrm{Nc} 2 \mathrm{ccccc} 2) \mathrm{c} 2 \mathrm{cc}(\mathrm{Br}) \mathrm{ccc} 21$ & 11400 & $*$ \\
\hline 4611 & $\mathrm{O}=\mathrm{C}(\mathrm{Nc} 1 \mathrm{ccccc} 1 \mathrm{~F}) \mathrm{c} 1 \mathrm{ccc}(\mathrm{N}(\mathrm{CCCl}) \mathrm{CCCl}) \mathrm{cc} 1$ & 11570 & 4.94 \\
\hline 4612 & $\mathrm{O}=\mathrm{C}(/ \mathrm{C}=\mathrm{C} / \mathrm{c} 1 \mathrm{ccccc} 1) \mathrm{Nc} 1 \mathrm{ccc}(\mathrm{F}) \mathrm{cc} 1 \mathrm{~F}$ & 11690 & $*$ \\
\hline 4613 & $\mathrm{C}=\mathrm{CC}(=\mathrm{O}) \mathrm{Nc} 1 \mathrm{cccc}(\mathrm{Nc} 2 \mathrm{nc}(\mathrm{N} / \mathrm{N}=\mathrm{C}(\backslash \mathrm{C}) \mathrm{c} 3 \operatorname{ccc}(\mathrm{F}) \mathrm{cc} 3 \mathrm{~F}) \mathrm{ncc} 2 \mathrm{Cl}) \mathrm{c} 1$ & 11750 & $*$ \\
\hline 4614 & $\mathrm{O}=\mathrm{C}(\mathrm{Cc} 1 \mathrm{ccc}(\mathrm{Cl}) \mathrm{cc} 1) \mathrm{NS}(=\mathrm{O})(=\mathrm{O}) \mathrm{c} 1 \mathrm{ccccc} 1$ & 11910 & 4.92 \\
\hline 4615 & CCOc1 $1 \mathrm{cc} 2 \mathrm{ncnc}(\mathrm{Nc} 3 \operatorname{cccc}(-\mathrm{c} 4 \mathrm{csc}(\mathrm{C}) \mathrm{n} 4) \mathrm{c} 3) \mathrm{c} 2 \mathrm{cc} 1 \mathrm{OCC}$ & 11920 & $*$ \\
\hline 4616 & $\mathrm{CN}(\mathrm{C}) \mathrm{C}(=\mathrm{O}) \mathrm{CCc} 1 \mathrm{c}(\mathrm{SSc} 2[\mathrm{nH}] \mathrm{c} 3 \operatorname{ccc} c 3 \mathrm{c} 2 \mathrm{CCC}(=\mathrm{O}) \mathrm{N}(\mathrm{C}) \mathrm{C})[\mathrm{nH}] \mathrm{c} 2 \operatorname{ccccc} 12$ & 12000 & * \\
\hline 4617 & $\mathrm{O}=[\mathrm{N}+]([\mathrm{O}-]) \mathrm{c} 1 \mathrm{ccc} 2 \mathrm{c}(\mathrm{Nc} 3 \mathrm{cccc} 3) \mathrm{ncnc} 2 \mathrm{c} 1$ & 12000 & * \\
\hline 4618 & $\mathrm{COc} 1 \mathrm{cc} 2 \mathrm{ncnc}(\mathrm{N}(\mathrm{C}) \mathrm{c} 3 \mathrm{cccc}(\mathrm{C}) \mathrm{c} 3) \mathrm{c} 2 \mathrm{cc} 1 \mathrm{OC} . \mathrm{Cl}$ & 12000 & * \\
\hline 4619 & $\mathrm{CC}(=\mathrm{O}) \mathrm{c} 1 \mathrm{ccc}(-\mathrm{c} 2 \mathrm{nn}(\mathrm{C}(\mathrm{C}) \mathrm{C}) \mathrm{c} 3 \mathrm{ncnc}(\mathrm{N}) \mathrm{c} 23) \mathrm{cc} 1$ & 12000 & * \\
\hline 4620 & Nc1ncne2c1e(-c1ecn3ecnc3c1)nn2C1CCCC1 & 12000 & * \\
\hline 4621 & $\mathrm{CC}(\mathrm{C}) \mathrm{n} 1 \mathrm{nc}(-\mathrm{c} 2 \mathrm{ccc} 3 \mathrm{nc}(\mathrm{N}) \mathrm{ccc} 3 \mathrm{c} 2) \mathrm{c} 2 \mathrm{c}(\mathrm{N}) \mathrm{ncnc} 21$ & 12000 & $*$ \\
\hline 4622 & $\mathrm{COc} 1 \mathrm{ccc}(-\mathrm{c} 2 \mathrm{nn}(\mathrm{C}[\mathrm{C} @ \mathrm{H}](\mathrm{C}) \mathrm{CO}) \mathrm{c} 3 \mathrm{ncnc}(\mathrm{N}) \mathrm{c} 23) \mathrm{cc} 1 \mathrm{OC}$ & 12000 & $*$ \\
\hline 4623 & $\mathrm{Cc} 1 \mathrm{cccc}(\mathrm{NC}(=\mathrm{O}) / \mathrm{C}=\mathrm{C} / \mathrm{c} 2 \mathrm{ccc} 3 \mathrm{c}(\mathrm{c} 2) \mathrm{OCCCCO}) \mathrm{c} 1$ & 12040 & * \\
\hline 4624 & $\mathrm{Cn} 1 \mathrm{cccc} 1-\mathrm{c} 1 \mathrm{nc} 2 \mathrm{cc}(\mathrm{NC}(=\mathrm{O}) \mathrm{CCl}) \operatorname{ccc} 2[\mathrm{nH}] 1$ & 12070 & $*$ \\
\hline 4625 & $\mathrm{Cc} 1 \operatorname{ccc}(\mathrm{S}(=\mathrm{O})(=\mathrm{O}) \mathrm{NC}(=\mathrm{O}) \mathrm{c} 2 \mathrm{cncc}(\mathrm{Br}) \mathrm{c} 2) \mathrm{cc} 1$ & 12110 & 4.92 \\
\hline 4626 & $\mathrm{O}=\mathrm{C}(\mathrm{Nc} 1 \mathrm{ccc}(\mathrm{Cl}) \mathrm{cc} 1) \mathrm{c} 1 \mathrm{cc}(\mathrm{Br}) \mathrm{cc}(\mathrm{Br}) \mathrm{c} 1 \mathrm{O}$ & 12190 & $*$ \\
\hline 4627 & $\mathrm{NC}(=\mathrm{S}) \mathrm{N} / \mathrm{N}=\mathrm{C}(/ \mathrm{C}=\mathrm{C} / \mathrm{c} 1 \mathrm{ccccc} 1) \mathrm{c} 1 \mathrm{ccc}(\mathrm{Br}) \mathrm{cc} 1$ & 12240 & 4.91 \\
\hline
\end{tabular}




\begin{tabular}{|c|c|c|c|}
\hline 4628 & $\mathrm{NC}(=\mathrm{S}) \mathrm{N} 1 \mathrm{~N}=\mathrm{C}(\mathrm{c} 2 \mathrm{ccc}(\mathrm{Br}) \mathrm{c}(\mathrm{Br}) \mathrm{c} 2) \mathrm{CC} 1 \mathrm{c} 1 \mathrm{cccc} 1 \mathrm{Cl}$ & 12260 & 4.91 \\
\hline 4629 & $\mathrm{Cc} 1 \operatorname{ccccc} 1 \mathrm{NC}(=\mathrm{O}) / \mathrm{C}=\mathrm{C} / \mathrm{c} 1 \operatorname{ccccc} 1$ & 12290 & $*$ \\
\hline 4630 & $\mathrm{COc} 1 \mathrm{ccccc} 1-\mathrm{c} 1 \mathrm{nn} n(\mathrm{SCc} 2 \mathrm{cccc} 2) \mathrm{o} 1$ & 12320 & 4.91 \\
\hline 4631 & Nc1ncnc2c1c(-c1ccc(Cl)c(O)c1)nn2[C@@H]1CCNC1 & 12400 & $*$ \\
\hline 4632 & $\mathrm{Cc} 1 \mathrm{ccc}(-\mathrm{c} 2 \mathrm{n}[\mathrm{nH}] \mathrm{c} 3 \mathrm{ncnc}(\mathrm{N}) \mathrm{c} 23) \mathrm{cc} 1 \mathrm{O}$ & 12400 & $*$ \\
\hline 4633 & $\operatorname{Cc} 1 \operatorname{lncc}([\mathrm{N}+](=\mathrm{O})[\mathrm{O}-]) \mathrm{n} 1 \mathrm{CCOC}(=\mathrm{O}) / \mathrm{C}=\mathrm{C} / \mathrm{c} 1 \mathrm{cccc}(\mathrm{F}) \mathrm{c} 1$ & 12420 & 4.91 \\
\hline 4634 & $\mathrm{O}=\mathrm{C}(/ \mathrm{C}=\mathrm{C} / \mathrm{c} 1 \mathrm{ccc} 2 \mathrm{c}(\mathrm{c} 1) \mathrm{OCCCCO} 2) \mathrm{Nc} 1 \mathrm{ccc}(\mathrm{Cl}) \mathrm{c} 1$ & 12420 & $*$ \\
\hline 4635 & $\mathrm{Cc} 1 \mathrm{ncc}([\mathrm{N}+](=\mathrm{O})[\mathrm{O}-]) \mathrm{n} 1 \mathrm{C} / \mathrm{C}(=\mathrm{N} / \mathrm{NC}(=\mathrm{O}) \mathrm{c} 1 \mathrm{ccc}(\mathrm{Cl}) \operatorname{cc} 1) \mathrm{c} 1 \mathrm{ccc}(\mathrm{Br}) \mathrm{cc} 1$ & 12450 & 4.90 \\
\hline 4636 & $\mathrm{~N} \# \mathrm{CC}(\mathrm{C} \# \mathrm{~N})=\mathrm{C} 1 \mathrm{C}(=\mathrm{O}) \mathrm{Nc} 2 \mathrm{ccc}(\mathrm{O}) \mathrm{cc} 21$ & 12500 & $*$ \\
\hline 4637 & $\operatorname{COC}(=\mathrm{O}) \mathrm{c} 1 \mathrm{c}(\mathrm{OC}) \mathrm{c} 2 \mathrm{cccc} 2 \mathrm{c} 2 \mathrm{oc} 3 \mathrm{c}(\mathrm{c} 12) \mathrm{C}(=\mathrm{O}) \mathrm{c} 1 \mathrm{cccc} 1 \mathrm{C} 3=\mathrm{O}$ & 12600 & $*$ \\
\hline 4638 & COc1ccc(-c2nn([C@@H]3CCNC3)c3ncnc(N)c23)cc1O & 12600 & * \\
\hline 4639 & $\mathrm{Cc} 1 \mathrm{ccc}(\mathrm{NC}(=\mathrm{O}) / \mathrm{C}=\mathrm{C} / \mathrm{c} 2 \operatorname{cccc} 2) \operatorname{cc} 1$ & 12690 & $*$ \\
\hline 4640 & $\mathrm{CCOc} 1 \mathrm{cc} 2 \mathrm{ncc}(\mathrm{C} \# \mathrm{~N}) \mathrm{c}(\mathrm{Nc} 3 \operatorname{ccc}(\mathrm{N} 4 \mathrm{CCOCC} 4) \mathrm{c}(\mathrm{Cl}) \mathrm{c} 3) \mathrm{c} 2 \mathrm{cc} 1 \mathrm{NC}(=\mathrm{O}) / \mathrm{C}=\mathrm{C} / \mathrm{CN}(\mathrm{C}) \mathrm{C}$ & 12700 & 4.90 \\
\hline 4641 & $\mathrm{C}=\mathrm{CCNC}(=\mathrm{S}) \mathrm{Nc} 1 \mathrm{scc}(-\mathrm{c} 2 \mathrm{ccc} 3 \mathrm{ncc}(\mathrm{CHN}) \mathrm{c}(\mathrm{Nc} 4 \operatorname{cccc}(\mathrm{Br}) \mathrm{c} 4) \mathrm{c} 3 \mathrm{c} 2) \mathrm{c} 1 \mathrm{C} \# \mathrm{~N}$ & 12770 & $*$ \\
\hline 4642 & $\mathrm{CC}(\mathrm{C}) \mathrm{n} 1 \mathrm{nc}(-\mathrm{c} 2 \mathrm{ccc}(\mathrm{NS}(\mathrm{C})(=\mathrm{O})=\mathrm{O}) \mathrm{cc} 2) \mathrm{c} 2 \mathrm{c}(\mathrm{N}) \operatorname{ncnc} 21$ & 12800 & $*$ \\
\hline 4643 & $\mathrm{CCOC}(=\mathrm{O}) \mathrm{Nc} 1 \mathrm{ccc} 2 \mathrm{c}(\mathrm{C \# N}) \mathrm{cnc}(\mathrm{Nc} 3 \mathrm{cccc}(\mathrm{Br}) \mathrm{c} 3) \mathrm{c} 2 \mathrm{c} 1$ & 12800 & $*$ \\
\hline 4644 & $\mathrm{O}=\mathrm{C}(/ \mathrm{C}=\mathrm{C} / \mathrm{c} 1 \mathrm{ccccc} 1) \mathrm{Nc} 1 \mathrm{cc}(\mathrm{F}) \mathrm{c}(\mathrm{F}) \mathrm{c}(\mathrm{F}) \mathrm{c} 1$ & 12880 & $*$ \\
\hline 4645 & $\mathrm{CCOc} 1 \mathrm{cc} 2 \mathrm{ncc}(\mathrm{CHN}) \mathrm{c}(\mathrm{Nc} 3 \operatorname{ccc}(\mathrm{OCc} 4 \mathrm{ccccc} 4) \mathrm{c} 3) \mathrm{c} 2 \mathrm{cc} 1 \mathrm{NC}(=\mathrm{O}) / \mathrm{C}=\mathrm{C} / \mathrm{CN}(\mathrm{C}) \mathrm{C}$ & 13000 & 4.89 \\
\hline 4646 & $\mathrm{CNC}(=\mathrm{O}) \mathrm{c} 1 \mathrm{c}([\mathrm{Se}][\mathrm{Se}] \mathrm{c} 2[\mathrm{nH}] \mathrm{c} 3 \operatorname{ccccc} 3 \mathrm{c} 2 \mathrm{C}(=\mathrm{O}) \mathrm{NC})[\mathrm{nH}] \mathrm{c} 2 \operatorname{ccccc} 12$ & 13000 & $*$ \\
\hline 4647 & $\mathrm{CC}(\mathrm{C}) \mathrm{n} 1 \mathrm{nc}(-\mathrm{c} 2 \mathrm{ccc}(\mathrm{CC} \# \mathrm{~N}) \mathrm{cc} 2) \mathrm{c} 2 \mathrm{c}(\mathrm{N}) \mathrm{ncnc} 21$ & 13000 & $*$ \\
\hline 4648 & $\mathrm{O}=\mathrm{C}(\mathrm{Nc} 1 \mathrm{ccc}(\mathrm{Cl}) \mathrm{cc} 1) \mathrm{c} 1 \mathrm{cc}(\mathrm{I}) \mathrm{ccc} 1 \mathrm{O}$ & 13040 & $*$ \\
\hline 4649 & $\mathrm{O}=\mathrm{C} 1 \mathrm{~N}=\mathrm{C}(\mathrm{N} 2 \mathrm{CCC}[\mathrm{C} @ \mathrm{H}] 2 \mathrm{C}(=\mathrm{O}) \mathrm{Nc} 2 \mathrm{ccc} 3 \mathrm{ncnc}(\mathrm{Nc} 4 \mathrm{cccc}(\mathrm{Cl}) \mathrm{c} 4) \mathrm{c} 3 \mathrm{c} 2) \mathrm{S} / \mathrm{C} 1=\mathrm{C} / \mathrm{c} 1 \mathrm{ccc}(-\mathrm{c} 2 \mathrm{ccccc} 2) \mathrm{cc} 1$ & 13200 & * \\
\hline 4650 & $\mathrm{O}=\mathrm{C}(/ \mathrm{C}=\mathrm{C} / \mathrm{c} 1 \mathrm{ccccc} 1) \mathrm{Nc} 1 \mathrm{cc}(\mathrm{F}) \mathrm{cc}(\mathrm{F}) \mathrm{c} 1$ & 13230 & $*$ \\
\hline 4651 & $\mathrm{CN}(\mathrm{C}) \mathrm{N}=\mathrm{Nc} 1 \mathrm{ccc} 2 \mathrm{ncnc}(\mathrm{N}(\mathrm{C}) \mathrm{c} 3 \mathrm{ccccc} 3) \mathrm{c} 2 \mathrm{c} 1$ & 13350 & $*$ \\
\hline 4652 & $\mathrm{NC}(=\mathrm{S}) \mathrm{N} 1 \mathrm{~N}=\mathrm{C}(\mathrm{c} 2 \mathrm{ccc}(\mathrm{Br}) \mathrm{c}(\mathrm{Br}) \mathrm{c} 2) \mathrm{CC} 1 \mathrm{c} 1 \mathrm{ccccc} 1 \mathrm{~F}$ & 13370 & 4.87 \\
\hline 4653 & $\operatorname{CCCCC}(\mathrm{Cc} 1 \operatorname{coc} 2 \mathrm{nc}(\mathrm{N}) \mathrm{nc}(\mathrm{N}) \mathrm{c} 12) \mathrm{c} 1 \mathrm{ccccc} 1 \mathrm{OC}$ & 13400 & $*$ \\
\hline 4654 & $\mathrm{Nc} 1 \mathrm{ncn} 2 \mathrm{c} 1 \mathrm{c}(-\mathrm{c} 1 \mathrm{ccccc} 1) \mathrm{cn} 2 \mathrm{C} 1 \mathrm{CCNC} 1$ & 13400 & $*$ \\
\hline 4655 & $\mathrm{~N} \# \mathrm{CC}(\mathrm{C \# N})=\mathrm{C}(\mathrm{O}) \mathrm{c} 1 \mathrm{cc}(\mathrm{O}) \mathrm{c}(\mathrm{O}) \mathrm{c}(\mathrm{O}) \mathrm{c} 1$ & 13500 & $*$ \\
\hline 4656 & $\mathrm{N \# C/C}(=\mathrm{Clc1} \operatorname{ccc}(\mathrm{O}) \mathrm{c}(\mathrm{O}) \mathrm{c} 1) \mathrm{C}(=\mathrm{O}) \mathrm{NC} 1 \mathrm{CCCC}[\mathrm{C} @ @ \mathrm{H}] 1 \mathrm{NC}(=\mathrm{O}) / \mathrm{C}(\mathrm{C \# N})=\mathrm{C} / \mathrm{c} 1 \mathrm{ccc}(\mathrm{O}) \mathrm{c}(\mathrm{O}) \mathrm{c} 1$ & 13500 & $*$ \\
\hline 4657 & $\mathrm{O}=\mathrm{C} 1 \mathrm{CSC}(\mathrm{N} / \mathrm{N}=\mathrm{C} / \mathrm{c} 2 \operatorname{cccc}(\mathrm{F}) \mathrm{c} 2)=\mathrm{N} 1$ & 13530 & 4.87 \\
\hline 4658 & $\mathrm{COc} 1 \mathrm{cc} 2 \mathrm{ncc}(\mathrm{C \# N}) \mathrm{c}(\mathrm{Nc} 3 \operatorname{ccc}(\mathrm{F}) \mathrm{c}(\mathrm{Cl}) \mathrm{c} 3) \mathrm{c} 2 \mathrm{cc} 1 \mathrm{NC}(=\mathrm{O}) / \mathrm{C}=\mathrm{C} / \mathrm{CN} 1 \mathrm{CCOCC} 1$ & 13570 & 4.87 \\
\hline 4659 & $\operatorname{COC}(=\mathrm{O}) \mathrm{c} 1 \mathrm{c}(\mathrm{OCCCN}(\mathrm{C}) \mathrm{C}) \mathrm{c} 2 \mathrm{ccccc} 2 \mathrm{c} 2 \mathrm{oc} 3 \mathrm{c}(\mathrm{c} 12) \mathrm{C}(=\mathrm{O}) \mathrm{c} 1 \mathrm{cccc} 1 \mathrm{C} 3=\mathrm{O}$ & 13600 & $*$ \\
\hline 4660 & $\mathrm{O}=\mathrm{C}(\mathrm{Nc} 1 \mathrm{ccc}(\mathrm{Br}) \mathrm{cc} 1) \mathrm{c} 1 \mathrm{cc}(\mathrm{I}) \mathrm{ccc} 1 \mathrm{O}$ & 13700 & $*$ \\
\hline 4661 & $\mathrm{O}=\mathrm{C}(/ \mathrm{C}=\mathrm{C} / \mathrm{c} 1 \mathrm{cccc} 1) \mathrm{Nc} 1 \mathrm{ccc}(\mathrm{Cl}) \mathrm{cc} 1$ & 13710 & $*$ \\
\hline 4662 & $\operatorname{Cc} 1 \operatorname{ccc}(\mathrm{S}(=\mathrm{O})(=\mathrm{O}) \mathrm{NC}(=\mathrm{O}) \mathrm{Cc} 2 \operatorname{ccc}(\mathrm{Cl}) \operatorname{cc} 2) \operatorname{cc} 1$ & 13730 & 4.86 \\
\hline 4663 & $\mathrm{COc} 1 \mathrm{cc} 2 \mathrm{ncc}(\mathrm{C \# N}) \mathrm{c}(\mathrm{Nc} 3 \mathrm{ccc}(\mathrm{Cl}) \mathrm{cc} 3 \mathrm{~F}) \mathrm{c} 2 \mathrm{cc} 1 \mathrm{OC}$ & 13850 & $*$ \\
\hline 4664 & $\operatorname{COc} 1 \operatorname{cccc}(/ \mathrm{C}=\mathrm{C} / \mathrm{C}(=\mathrm{O}) \mathrm{OCCn} 2 \mathrm{c}([\mathrm{N}+](=\mathrm{O})[\mathrm{O}-]) \mathrm{cnc} 2 \mathrm{C}) \mathrm{c} 1$ & 13870 & 4.86 \\
\hline 4665 & $\mathrm{COc} 1 \mathrm{ccccc} 1 \mathrm{CNc} 1 \mathrm{ccc} 2 \mathrm{ncnc}(\mathrm{Nc} 3 \operatorname{ccc}(\mathrm{Cl}) \mathrm{c} 3) \mathrm{c} 2 \mathrm{c} 1$ & 13880 & 4.86 \\
\hline 4666 & $\mathrm{O}=\mathrm{C}(/ \mathrm{C}=\mathrm{C} / \mathrm{c} 1 \mathrm{ccccc} 1) \mathrm{Nc} 1 \mathrm{cc}(\mathrm{Cl}) \mathrm{cc}(\mathrm{Cl}) \mathrm{c} 1$ & 13930 & $*$ \\
\hline 4667 & $\mathrm{O}=\mathrm{C}(\mathrm{NCc} 1 \mathrm{ccccc} 1) \mathrm{C}(\mathrm{O}) \mathrm{Cc} 1 \mathrm{c}(\mathrm{SSc} 2[\mathrm{nH}] \mathrm{c} 3 \operatorname{ccc} c 3 \mathrm{c} 2 \mathrm{CC}(\mathrm{O}) \mathrm{C}(=\mathrm{O}) \mathrm{NCc} 2 \operatorname{ccc} c \mathrm{2})[\mathrm{nH}] \mathrm{c} 2 \operatorname{ccc} c \mathrm{1} 12$ & 14000 & $*$ \\
\hline 4668 & $\mathrm{COc} 1 \mathrm{cc}(\mathrm{C} 2=\mathrm{C}(\mathrm{c} 3 \mathrm{cn}(\mathrm{COCc} 4 \mathrm{cccc} 4) \mathrm{c} 4 \mathrm{ccccc} 34) \mathrm{CNC} 2=\mathrm{O}) \mathrm{cc}(\mathrm{OC}) \mathrm{c} 1 \mathrm{OC}$ & 14000 & $*$ \\
\hline 4669 & $\mathrm{COc} 1 \mathrm{cc} 2 \mathrm{n} \operatorname{ccc}(\mathrm{Oc} 3 \operatorname{cccc} 3 \mathrm{C}(=\mathrm{O}) \mathrm{c} 3 \operatorname{cccc} 3) \mathrm{c} 2 \mathrm{cc} 1 \mathrm{OC}$ & 14000 & $*$ \\
\hline 4670 & $\mathrm{COc} 1 \mathrm{cc} 2 \mathrm{nccc}(\mathrm{Oc} 3 \mathrm{cccc}(\mathrm{C}) \mathrm{c} 3) \mathrm{c} 2 \mathrm{cc} 1 \mathrm{OC}$ & 14000 & $*$ \\
\hline
\end{tabular}




\begin{tabular}{|c|c|c|c|}
\hline 4671 & $\mathrm{COc} 1 \mathrm{cc} 2 \mathrm{c}(\mathrm{cc} 1 \mathrm{OC}) \mathrm{Sc} 1 \mathrm{ncnc}(\mathrm{Nc} 3 \mathrm{ccc} 4 \mathrm{c}[\mathrm{nH}] \mathrm{nc} 4 \mathrm{c} 3) \mathrm{c} 1 \mathrm{NC} 2$ & 14100 & 4.85 \\
\hline 4672 & $\mathrm{Nc} 1 \mathrm{ccc}(-\mathrm{c} 2 \mathrm{cc}(=\mathrm{O}) \mathrm{c} 3 \mathrm{cc}(\mathrm{N}) \mathrm{c}(\mathrm{O}) \mathrm{cc} 3 \mathrm{o} 2) \mathrm{cc} 1$ & 14100 & $*$ \\
\hline 4673 & $\mathrm{COc} 1 \mathrm{cc} 2 \mathrm{ncc}(\mathrm{CHN}) \mathrm{c}(\mathrm{Nc} 3 \mathrm{ccc}(\mathrm{CHN}) \mathrm{c} 3) \mathrm{c} 2 \mathrm{cc} 1 \mathrm{OC}$ & 14180 & $*$ \\
\hline 4674 & $\mathrm{O}=\mathrm{C}(\mathrm{Nc} 1 \mathrm{ccccc} 1 \mathrm{Cl}) \mathrm{c} 1 \mathrm{cccc} 1 \mathrm{O}$ & 14180 & $*$ \\
\hline 4675 & $\mathrm{O}=\mathrm{C} 1 \mathrm{CSC}(\mathrm{N} 2 \mathrm{~N}=\mathrm{C}(\mathrm{c} 3 \operatorname{ccc}(\mathrm{Cl}) \mathrm{cc} 3) \mathrm{CC} 2 \mathrm{c} 2 \mathrm{ccc}(\mathrm{F}) \mathrm{cc} 2)=\mathrm{N} 1$ & 14210 & 4.85 \\
\hline 4676 & $\mathrm{CC}(=\mathrm{O}) \mathrm{N} 1 \mathrm{CCc} 2 \mathrm{cc}(\mathrm{Nc} 3 \mathrm{nc}(\mathrm{Nc} 4 \mathrm{ccc}(\mathrm{N} 5 \mathrm{CCN}(\mathrm{C}) \mathrm{CC} 5) \mathrm{cc} 4) \mathrm{ncc} 3 \mathrm{Br}) \operatorname{ccc} 21$ & 14300 & $*$ \\
\hline 4677 & $\operatorname{COc} 1 \mathrm{cc}(/ \mathrm{C}=\mathrm{C}(\backslash \mathrm{CHN}) \mathrm{C}(\mathrm{N})=\mathrm{O}) \operatorname{cc}(\mathrm{CSc} 2 \mathrm{nc} 3 \operatorname{cccc} 3[\mathrm{nH}] 2) \mathrm{c} 1 \mathrm{O}$ & 14454.4 & $*$ \\
\hline 4678 & $\mathrm{COc} 1 \mathrm{cc} 2 \mathrm{c}(\mathrm{cc} 1 \mathrm{OC}) \mathrm{Sc} 1 \mathrm{nc}(\mathrm{C}) \mathrm{nc}(\mathrm{Nc} 3 \mathrm{ccc} 4[\mathrm{nH}] \mathrm{cnc} 4 \mathrm{c} 3) \mathrm{c} 1 \mathrm{NC} 2$ & 14500 & 4.84 \\
\hline 4679 & $\operatorname{Cc} 1 \operatorname{lnc}([\mathrm{N}+](=\mathrm{O})[\mathrm{O}-]) \operatorname{n} 1 \mathrm{CCOC}(=\mathrm{O}) / \mathrm{C}=\mathrm{C} / \mathrm{c} 1 \operatorname{cccc}([\mathrm{N}+](=\mathrm{O})[\mathrm{O}-]) \mathrm{c} 1$ & 14530 & 4.84 \\
\hline 4680 & $\mathrm{O}=\mathrm{C}(\mathrm{Cc} 1 \mathrm{ccc}(\mathrm{Br}) \operatorname{cc} 1) \mathrm{NS}(=\mathrm{O})(=\mathrm{O}) \mathrm{c} 1 \mathrm{ccc}(\mathrm{F}) \mathrm{cc} 1$ & 14530 & 4.84 \\
\hline 4681 & $\mathrm{CC}(\mathrm{C}) \mathrm{c} 1 \operatorname{ccc}(\mathrm{NC}(=\mathrm{O}) / \mathrm{C}=\mathrm{C} / \mathrm{c} 2 \operatorname{ccccc} 2) \mathrm{cc} 1$ & 14580 & $*$ \\
\hline 4682 & $\mathrm{O}=\mathrm{C}(/ \mathrm{C}=\mathrm{C} / \mathrm{c} 1 \mathrm{cccc} 1) \mathrm{Nc} 1 \operatorname{ccc}(\mathrm{Cl}) \mathrm{c} 1$ & 14590 & $*$ \\
\hline 4683 & $\mathrm{Cc} 1 \mathrm{ccc}(-\mathrm{n} 2 \mathrm{nc}(\mathrm{C}) \mathrm{c}(\mathrm{C} 3 \mathrm{C}(\mathrm{CHN})=\mathrm{C}(\mathrm{N}) \mathrm{N}(\mathrm{c} 4 \mathrm{cccnc} 4) \mathrm{C} 4=\mathrm{C} 3 \mathrm{C}(=\mathrm{O}) \mathrm{CC}(\mathrm{C})(\mathrm{C}) \mathrm{C} 4) \mathrm{c} 2 \mathrm{Cl}) \mathrm{cc} 1$ & 14700 & 4.83 \\
\hline 4684 & $\mathrm{CN}(\mathrm{C}(=\mathrm{O}) \mathrm{c} 1 \mathrm{ccc}(\mathrm{N}(\mathrm{CCCl}) \mathrm{CCCl}) \mathrm{cc} 1) \mathrm{c} 1 \mathrm{cccc} 1$ & 14720 & 4.83 \\
\hline 4685 & $\operatorname{COc} 1 \operatorname{ccc}(/ \mathrm{C}=\mathrm{C} / \mathrm{C}(=\mathrm{N} / \mathrm{NC}(\mathrm{N})=\mathrm{S}) \mathrm{c} 2 \operatorname{cccc} 2) \mathrm{cc} 1$ & 14830 & 4.83 \\
\hline 4686 & $\mathrm{O}=\mathrm{C}(\mathrm{O}) \mathrm{CC} 1 \mathrm{C}(\mathrm{S})=\mathrm{Nc} 2 \operatorname{ccc} c 21$ & 14900 & $*$ \\
\hline 4687 & $\mathrm{Cc} 1 \mathrm{cccc}(-\mathrm{n} 2 \mathrm{ncc} 3 \mathrm{c}(\mathrm{NCc} 4 \mathrm{ccc} 5 \mathrm{c}(\mathrm{c} 4) \mathrm{OCO} 5) \mathrm{ncnc} 32) \mathrm{c} 1$ & 15000 & $*$ \\
\hline 4688 & $\mathrm{Cn} 1 \mathrm{nc}(-\mathrm{c} 2 \mathrm{cnc} 3[\mathrm{nH}] \mathrm{ccc} 3 \mathrm{c} 2) \mathrm{c} 2 \mathrm{c}(\mathrm{N}) \mathrm{ncnc} 21$ & 15000 & $*$ \\
\hline 4689 & $\mathrm{CC}(\mathrm{C}) \mathrm{n} 1 \mathrm{nc}(-\mathrm{c} 2 \mathrm{ccc} 3 \mathrm{c}(\mathrm{c} 2) \mathrm{OCCO} 3) \mathrm{c} 2 \mathrm{c}(\mathrm{N}) \mathrm{ncnc} 21$ & 15000 & $*$ \\
\hline 4690 & $\operatorname{COc} 1 \mathrm{cc}(\mathrm{N}(\mathrm{C}) \mathrm{CCN}(\mathrm{C}) \mathrm{C}) \mathrm{c}(\mathrm{N}) \mathrm{cc} 1 \mathrm{Nc} 1 \mathrm{nccc}(-\mathrm{c} 2 \mathrm{cn}(\mathrm{C}) \mathrm{c} 3 \operatorname{ccccc} 23) \mathrm{n} 1$ & 15000 & $*$ \\
\hline 4691 & $\operatorname{Cc} 1 \operatorname{ccc}(\mathrm{S}(=\mathrm{O})(=\mathrm{O}) \mathrm{NC}(=\mathrm{O}) \operatorname{c} 2 \operatorname{ccc}(\mathrm{C}) \mathrm{nc} 2 \mathrm{Cl}) \mathrm{cc} 1$ & 15020 & 4.82 \\
\hline 4692 & $\operatorname{COc} 1 \mathrm{cc} 2 \operatorname{ncc}(\mathrm{C}(\mathrm{N})=\mathrm{O}) \mathrm{c}(\mathrm{Nc} 3 \mathrm{cccc}(\mathrm{Br}) \mathrm{c} 3) \mathrm{c} 2 \mathrm{cc} 1 \mathrm{OC}$ & 15170 & $*$ \\
\hline 4693 & $\mathrm{COc} 1 \mathrm{cc} 2 \mathrm{c}(\mathrm{cc} 1 \mathrm{OC}) \mathrm{Sc} 1 \mathrm{nc}(\mathrm{C}) \mathrm{nc}(\mathrm{Nc} 3 \mathrm{ccc} 4 \mathrm{ncsc} 4 \mathrm{c} 3) \mathrm{c} 1 \mathrm{NC} 2$ & 15200 & 4.82 \\
\hline 4694 & $\mathrm{COc} 1 \mathrm{ccc}(\mathrm{C} 2 \mathrm{CC}(\mathrm{c} 3 \operatorname{ccc}(\mathrm{C}) \mathrm{c}(\mathrm{C}) \mathrm{c} 3)=\mathrm{NN} 2 \mathrm{C}(\mathrm{C})=\mathrm{O}) \mathrm{cc} 1$ & 15240 & 4.82 \\
\hline 4695 & $\mathrm{COc} 1 \mathrm{cc}(/ \mathrm{C}=\mathrm{C} 2 \backslash \mathrm{CCC} / \mathrm{C}(=\mathrm{C} \backslash \mathrm{c} 3 \operatorname{ccc}(\mathrm{Cl}) \mathrm{cc} 3) \mathrm{C} 2=\mathrm{O}) \mathrm{cc}(\mathrm{OC}) \mathrm{c} 1$ & 15300 & 4.82 \\
\hline 4696 & $\mathrm{C} / \mathrm{C}(=\mathrm{N} \backslash \mathrm{Nc} 1 \mathrm{ncc}(\mathrm{Cl}) \mathrm{c}(\mathrm{Nc} 2 \operatorname{cccc}(\mathrm{NC}(=\mathrm{O}) / \mathrm{C}=\mathrm{C} / \mathrm{CN}(\mathrm{C}) \mathrm{C}) \mathrm{c} 2) \mathrm{n} 1) \mathrm{c} 1 \mathrm{ccc}(\mathrm{F}) \mathrm{cc} 1$ & 15320 & $*$ \\
\hline 4697 & $\mathrm{CC}(=\mathrm{O}) \mathrm{N} 1 \mathrm{~N}=\mathrm{C}(\mathrm{c} 2 \mathrm{ccc}(\mathrm{C}) \mathrm{c}(\mathrm{C}) \mathrm{c} 2) \mathrm{CC} 1 \mathrm{c} 1 \mathrm{ccc}(\mathrm{F}) \mathrm{cc} 1$ & 15560 & 4.81 \\
\hline 4698 & Nc1ncnc2c1c(-c1ccc(F)c(O)c1)nn2[C@@H]1CCNC1 & 15600 & $*$ \\
\hline 4699 & $\mathrm{O}=\mathrm{C}(\mathrm{NS}(=\mathrm{O})(=\mathrm{O}) \mathrm{c} 1 \mathrm{ccc}(\mathrm{Br}) \mathrm{cc} 1) \mathrm{c} 1 \mathrm{cccnc} 1 \mathrm{Cl}$ & 15680 & 4.80 \\
\hline 4700 & $\mathrm{O}=[\mathrm{N}+]([\mathrm{O}-]) \mathrm{c} 1 \mathrm{ccc}(\mathrm{C} 2 \mathrm{CC}(\mathrm{c} 3 \operatorname{ccc}(\mathrm{Br}) \mathrm{cc} 3)=\mathrm{NN} 2 \mathrm{c} 2 \mathrm{nc}(-\mathrm{c} 3 \operatorname{ccccc} 3) \operatorname{cs} 2) \mathrm{cc} 1$ & 15720 & 4.80 \\
\hline 4701 & $\mathrm{O}=\mathrm{C}(/ \mathrm{C}=\mathrm{C} / \mathrm{c} 1 \operatorname{ccccc} 1) \mathrm{Nc} 1 \operatorname{ccccc} 1 \mathrm{Br}$ & 15740 & $*$ \\
\hline 4702 & $\operatorname{COc} 1 \mathrm{cc}(/ \mathrm{C}=\mathrm{C}(/ \mathrm{C} \# \mathrm{~N}) \mathrm{C}(\mathrm{N})=\mathrm{O}) \operatorname{cc}(\mathrm{CSC} 2 \operatorname{ccc}(\mathrm{Cl}) \mathrm{cc} 2) \mathrm{c} 1 \mathrm{O}$ & 15848.93 & $*$ \\
\hline 4703 & $\mathrm{O}=\mathrm{C}(\mathrm{Cc} 1 \mathrm{ccc}(\mathrm{Br}) \operatorname{cc} 1) \mathrm{NS}(=\mathrm{O})(=\mathrm{O}) \mathrm{c} 1 \mathrm{ccc}(\mathrm{Cl}) \mathrm{cc} 1$ & 15920 & 4.80 \\
\hline 4704 & $\mathrm{NC}(=\mathrm{O}) \mathrm{CCc} 1 \mathrm{c}(\mathrm{SSc} 2[\mathrm{nH}] \mathrm{c} 3 \operatorname{ccccc} 3 \mathrm{c} 2 \mathrm{CCC}(\mathrm{N})=\mathrm{O})[\mathrm{nH}] \mathrm{c} 2 \operatorname{ccccc} 12$ & 16000 & $*$ \\
\hline 4705 & $\mathrm{O}=\mathrm{C}(/ \mathrm{C}=\mathrm{C} / \mathrm{c} 1 \operatorname{ccc}(\mathrm{O}) \mathrm{c}(\mathrm{O}) \mathrm{c} 1) \mathrm{c} 1 \operatorname{ccc}(\mathrm{O}) \mathrm{cc} 1 \mathrm{O}$ & 16000 & $*$ \\
\hline 4706 & $\mathrm{COc} 1 \mathrm{cc} 2 \mathrm{nccc}(\mathrm{Oc} 3 \mathrm{ccc}(\mathrm{O}) \mathrm{cc} 3) \mathrm{c} 2 \mathrm{cc} 1 \mathrm{OC}$ & 16000 & $*$ \\
\hline 4707 & $\mathrm{COc} 1 \mathrm{cc} 2 \mathrm{nccc}(\mathrm{Oc} 3 \operatorname{ccc}(\mathrm{C}(=\mathrm{O}) \mathrm{c} 4 \operatorname{cccs} 4) \operatorname{cc} 3) \mathrm{c} 2 \mathrm{cc} 1 \mathrm{OC}$ & 16000 & $*$ \\
\hline 4708 & $\operatorname{COc} 1 \operatorname{cc} 2 n \operatorname{ccc}(\mathrm{Oc} 3 \operatorname{ccc}(\mathrm{C}(=\mathrm{O}) \mathrm{c} 4 \operatorname{cccs} 4) \mathrm{c} 3) \mathrm{c} 2 \mathrm{cc} 1 \mathrm{OC}$ & 16000 & $*$ \\
\hline 4709 & $\operatorname{CCOC}(=\mathrm{O}) \mathrm{C}(\mathrm{C \# N}) \mathrm{C}(=\mathrm{O}) \mathrm{c} 1 \mathrm{cc}(/ \mathrm{C}=\mathrm{C} / \mathrm{c} 2 \operatorname{ccc}(\mathrm{N}(\mathrm{C}) \mathrm{C}) \mathrm{cc} 2) \mathrm{nc} 2 \operatorname{ccc}(\mathrm{Br}) \mathrm{cc} 12$ & 16010 & $*$ \\
\hline 4710 & $\mathrm{CC}(=\mathrm{O}) \mathrm{N} 1 \mathrm{~N}=\mathrm{C}(\mathrm{c} 2 \mathrm{ccc}(\mathrm{Cl}) \mathrm{c}(\mathrm{Cl}) \mathrm{c} 2) \mathrm{CC} 1 \mathrm{c} 1 \mathrm{ccc}(\mathrm{Cl}) \mathrm{cc} 1$ & 16140 & 4.79 \\
\hline 4711 & $\mathrm{O}=\mathrm{C}(/ \mathrm{C}=\mathrm{C} / \mathrm{c} 1 \operatorname{ccccc} 1) \mathrm{Nc} 1 \operatorname{ccc}(\mathrm{Cl}) \mathrm{cc} 1 \mathrm{Cl}$ & 16170 & $*$ \\
\hline 4712 & $\mathrm{COc} 1 \mathrm{cc} 2 \mathrm{c}(\mathrm{cc} 1 \mathrm{OC}) \mathrm{Sc} 1 \mathrm{nc}(\mathrm{C}) \mathrm{nc}(\mathrm{Nc} 3 \mathrm{ccc} 4 \mathrm{c}(\mathrm{c} 3) \mathrm{CN}=\mathrm{N} 4) \mathrm{c} 1 \mathrm{NC} 2$ & 16200 & 4.79 \\
\hline 4713 & $\mathrm{Cc} 1[\mathrm{nH}] \mathrm{c} 2 \mathrm{ncnc}(\mathrm{Nc} 3 \operatorname{ccc}(\mathrm{C}(=\mathrm{O}) \mathrm{O}) \mathrm{c} 3) \mathrm{c} 2 \mathrm{c} 1 \mathrm{C}$ & 16300 & $*$ \\
\hline
\end{tabular}




\begin{tabular}{|c|c|c|c|}
\hline 4714 & $\mathrm{C}=\mathrm{CC}(=\mathrm{O}) \mathrm{Nc} 1 \mathrm{ccc}(-\mathrm{n} 2 \mathrm{c}(=\mathrm{O}) \mathrm{c}(\mathrm{C}) \mathrm{nc} 3 \mathrm{cnc}(\mathrm{Nc} 4 \mathrm{ccc}(\mathrm{OC}) \mathrm{cc} 4) \mathrm{nc} 32) \mathrm{cc} 1$ & 16338 & 4.79 \\
\hline 4715 & $\mathrm{c} 1 \mathrm{ccc}(\mathrm{CSc} 2 \mathrm{nnc}(-\mathrm{c} 3 \operatorname{ccccc} 3) \mathrm{o} 2) \mathrm{cc} 1$ & 16630 & 4.78 \\
\hline 4716 & $\mathrm{CCOC}(=\mathrm{O}) \mathrm{C} 1=\mathrm{C}(\mathrm{N}) \mathrm{N}(\mathrm{c} 2 \mathrm{cccnc} 2) \mathrm{C} 2=\mathrm{C}(\mathrm{C}(=\mathrm{O}) \mathrm{CCC} 2) \mathrm{C} 1 \mathrm{c} 1 \mathrm{cc} 2 \mathrm{cc}(\mathrm{Cl}) \operatorname{ccc} 2 \mathrm{n} 2 \mathrm{nnnc} 12$ & 16700 & 4.78 \\
\hline 4717 & $\mathrm{O}=\mathrm{C} 1 \mathrm{CSC}(\mathrm{N} 2 \mathrm{~N}=\mathrm{C}(\mathrm{c} 3 \operatorname{ccc}(\mathrm{F}) \mathrm{cc} 3) \mathrm{CC} 2 \mathrm{c} 2 \mathrm{ccc}(\mathrm{F}) \mathrm{cc} 2)=\mathrm{N} 1$ & 16920 & 4.77 \\
\hline 4718 & $\mathrm{COc} 1 \mathrm{cc} 2 \mathrm{c}(\mathrm{cc} 1 \mathrm{OC}) \mathrm{Sc} 1 \mathrm{nc}(\mathrm{C}) \mathrm{nc}(\mathrm{Nc} 3 \mathrm{ccc} 4 \mathrm{cccc} 4 \mathrm{c} 3) \mathrm{c} 1 \mathrm{NC} 2$ & 17000 & 4.77 \\
\hline 4719 & $\mathrm{C}[\mathrm{C} @ @ \mathrm{H}](\mathrm{NC}(=\mathrm{O}) \operatorname{c} 1 \operatorname{ccc}(\mathrm{S}(=\mathrm{O})(=\mathrm{O}) \mathrm{Oc} 2 \mathrm{ccc}(/ \mathrm{C}=\mathrm{C} /[\mathrm{N}+](=\mathrm{O})[\mathrm{O}-]) \mathrm{cc} 2) \mathrm{cc} 1) \mathrm{C}(=\mathrm{O}) \mathrm{N}[\mathrm{C} @ \mathrm{H}](\mathrm{C}) \mathrm{C}(=\mathrm{O}) \mathrm{NCCN}$ & 17000 & $*$ \\
\hline 4720 & $\mathrm{CC}(\mathrm{C}) \mathrm{n} 1 \mathrm{nc}(-\mathrm{c} 2 \mathrm{cccc}(\mathrm{CC} \# \mathrm{~N}) \mathrm{c} 2) \mathrm{c} 2 \mathrm{c}(\mathrm{N}) \mathrm{ncnc} 21$ & 17000 & $*$ \\
\hline 4721 & $\mathrm{COc} 1 \mathrm{ccc}(-\mathrm{c} 2 \mathrm{nn}(\mathrm{C} 3 \mathrm{CNC} 3) \mathrm{c} 3 \mathrm{ncnc}(\mathrm{N}) \mathrm{c} 23) \mathrm{cc} 1 \mathrm{O}$ & 17000 & $*$ \\
\hline 4722 & $\mathrm{COc} 1 \mathrm{cc} 2 \mathrm{ncc}(\mathrm{CHN}) \mathrm{c}(\mathrm{Nc} 3 \mathrm{cc}(\mathrm{Cl}) \mathrm{ccc} 3 \mathrm{O}) \mathrm{c} 2 \mathrm{cc} 1 \mathrm{OC} . \mathrm{Cl}$ & 17020 & $*$ \\
\hline 4723 & $\mathrm{COc} 1 \mathrm{ccc}(\mathrm{C} 2 \mathrm{CC}(\mathrm{c} 3 \mathrm{ccc}(\mathrm{Cl}) \mathrm{c}(\mathrm{Cl}) \mathrm{c} 3)=\mathrm{NN} 2 \mathrm{C}(\mathrm{C})=\mathrm{O}) \mathrm{cc} 1$ & 17190 & 4.76 \\
\hline 4724 & $\mathrm{O}=\mathrm{C}(\mathrm{Cc} 1 \mathrm{ccc}(\mathrm{Br}) \mathrm{cc} 1) \mathrm{NS}(=\mathrm{O})(=\mathrm{O}) \mathrm{c} 1 \mathrm{ccc}(\mathrm{Br}) \mathrm{cc} 1$ & 17260 & 4.76 \\
\hline 4725 & $\mathrm{COc} 1 \mathrm{cc}(\mathrm{OC}) \mathrm{cc}(\mathrm{C} 2 \mathrm{CC}(\mathrm{c} 3 \operatorname{ccc}(\mathrm{C}) \mathrm{c}(\mathrm{C}) \mathrm{c} 3)=\mathrm{NN} 2 \mathrm{C}(\mathrm{C})=\mathrm{O}) \mathrm{c} 1$ & 17310 & 4.76 \\
\hline 4726 & $\mathrm{Cc} 1 \operatorname{ccc}(/ \mathrm{C}=\mathrm{C} / \mathrm{C}(=\mathrm{N} / \mathrm{NC}(\mathrm{N})=\mathrm{S}) \operatorname{coc} \operatorname{ccc} 2) \operatorname{cc} 1$ & 17390 & 4.76 \\
\hline 4727 & $\mathrm{CC}(=\mathrm{O}) \mathrm{N} 1 \mathrm{~N}=\mathrm{C}(\mathrm{c} 2 \mathrm{ccc}(\mathrm{C}) \mathrm{c}(\mathrm{C}) \mathrm{c} 2) \mathrm{CC} 1 \mathrm{c} 1 \mathrm{ccc}(\mathrm{C}) \mathrm{cc} 1$ & 17490 & 4.76 \\
\hline 4728 & $\mathrm{O}=\mathrm{C}(\mathrm{NCc} 1 \mathrm{cccc} 1) \mathrm{c} 1 \mathrm{ccc}(\mathrm{N}(\mathrm{CCCl}) \mathrm{CCCl}) \mathrm{cc} 1$ & 17510 & 4.76 \\
\hline 4729 & $\mathrm{O}=\mathrm{C}(\mathrm{Cc} 1 \mathrm{ccc}(\mathrm{Br}) \operatorname{cc} 1) \mathrm{NS}(=\mathrm{O})(=\mathrm{O}) \mathrm{c} 1 \mathrm{ccccc} 1$ & 17810 & 4.75 \\
\hline 4730 & $\mathrm{Clc} 1 \mathrm{ccc}(-\mathrm{c} 2 \csc (\mathrm{N} 3 \mathrm{~N}=\mathrm{C}(\mathrm{c} 4 \mathrm{ccc}(\mathrm{Br}) \mathrm{cc} 4) \mathrm{CC} 3 \mathrm{c} 3 \mathrm{ccc}(\mathrm{Cl}) \mathrm{cc} 3) \mathrm{n} 2) \mathrm{cc} 1$ & 17840 & 4.75 \\
\hline 4731 & $\mathrm{O}=\mathrm{C}(\mathrm{O}) \mathrm{CCC} 1 \mathrm{c}(\mathrm{SSc} 2[\mathrm{nH}] \mathrm{c} 3 \operatorname{ccc} c 3 \mathrm{c} 2 \mathrm{CCCC}(=\mathrm{O}) \mathrm{O})[\mathrm{nH}] \mathrm{c} 2 \operatorname{ccccc} 12$ & 18000 & $*$ \\
\hline 4732 & $\operatorname{COC}(=\mathrm{O}) \operatorname{Cc} 1 \mathrm{c}(\mathrm{SSc} 2[\mathrm{nH}] \mathrm{c} 3 \operatorname{ccc} c 3 \mathrm{c} 2 \mathrm{CC}(=\mathrm{O}) \mathrm{OC})[\mathrm{nH}] \mathrm{c} 2 \operatorname{cccc} 12$ & 18000 & $*$ \\
\hline 4733 & $\mathrm{COc} 1 \mathrm{cc} 2 \mathrm{cc} 3 \mathrm{ncc}(\mathrm{CHN}) \mathrm{c}(\mathrm{Nc} 4 \mathrm{ccc}(\mathrm{F}) \mathrm{c}(\mathrm{Cl}) \mathrm{c} 4) \mathrm{c} 3 \mathrm{cc} 2 \mathrm{cc} 1 \mathrm{OC}$ & 18000 & $*$ \\
\hline 4734 & $\mathrm{Cc} 1 \mathrm{ccc} 2 \operatorname{ccc}(-\mathrm{c} 3 n n(\mathrm{C}(\mathrm{C}) \mathrm{C}) \mathrm{c} 4 \mathrm{ncnc}(\mathrm{N}) \mathrm{c} 34) \operatorname{cc} 2 \mathrm{n} 1$ & 18000 & * \\
\hline 4735 & COc1ccc(-c2nn(C[C@@H](C)CO)c3ncnc(N)c23)cc1OC & 18000 & $*$ \\
\hline 4736 & $\mathrm{CC}(\mathrm{C}) n 1 \mathrm{nc}(-\mathrm{c} 2 \mathrm{ccc} 3 \mathrm{nccnc} 3 \mathrm{c} 2) \mathrm{c} 2 \mathrm{c}(\mathrm{N}) \mathrm{ncnc} 21$ & 18000 & $*$ \\
\hline 4737 & $\mathrm{~N} \# C C C C n 1 n c(-\mathrm{c} 2 \mathrm{ccc}(\mathrm{F}) \mathrm{c}(\mathrm{O}) \mathrm{c} 2) \mathrm{c} 2 \mathrm{c}(\mathrm{N}) \mathrm{ncnc} 21$ & 18000 & $*$ \\
\hline 4738 & $\mathrm{COc} 1 \mathrm{cccc}(\mathrm{Oc} 2 \mathrm{ccnc} 3 \mathrm{cc}(\mathrm{OC}) \mathrm{c}(\mathrm{OC}) \mathrm{cc} 23) \mathrm{c} 1$ & 18000 & $*$ \\
\hline 4739 & $\mathrm{Nc} 1 \mathrm{ccc}(-\mathrm{c} 2 \mathrm{nc} 3 \mathrm{c}(\mathrm{Nc} 4 \mathrm{ccc}(\mathrm{Cl}) \mathrm{cc} 4) \mathrm{ncnc} 3 \mathrm{o} 2) \mathrm{cc} 1$ & 18000 & $*$ \\
\hline 4740 & $\mathrm{Cc} 1 \mathrm{nn}(-\mathrm{c} 2 \mathrm{cccc} 2) \mathrm{c}(\mathrm{Cl}) \mathrm{c} 1 \mathrm{C} 1 \mathrm{C}(\mathrm{C \# N})=\mathrm{C}(\mathrm{N}) \mathrm{N}(\mathrm{c} 2 \mathrm{ccc} n \mathrm{c} 2) \mathrm{C} 2=\mathrm{C} 1 \mathrm{C}(=\mathrm{O}) \mathrm{CCC} 2$ & 18020 & 4.74 \\
\hline 4741 & $\operatorname{CCCCN}(\mathrm{Cc} 1 \operatorname{ccc}(\mathrm{Cl}) \mathrm{c} 1 \mathrm{O}) \mathrm{C}(=\mathrm{S}) \mathrm{Nc} 1 \mathrm{cccc} 1$ & 18120 & 4.74 \\
\hline 4742 & $\mathrm{O}=\mathrm{C}(\mathrm{NS}(=\mathrm{O})(=\mathrm{O}) \mathrm{c} 1 \mathrm{ccc}(\mathrm{Cl}) \mathrm{cc} 1) \mathrm{c} 1 \mathrm{ccc}(\mathrm{Cl}) \mathrm{nc} 1$ & 18150 & 4.74 \\
\hline 4743 & $\mathrm{COc} 1 \mathrm{ccccc} 1 \mathrm{C}(\mathrm{Cc} 1 \operatorname{coc} 2 \mathrm{nc}(\mathrm{N}) \mathrm{nc}(\mathrm{N}) \mathrm{c} 12) \mathrm{C}(\mathrm{C}) \mathrm{C}$ & 18200 & $*$ \\
\hline 4744 & $\operatorname{COc} 1 \mathrm{ccc}(-\mathrm{n} 2 \mathrm{c}(=\mathrm{O}) \mathrm{cnc} 3 \mathrm{cnc}(\mathrm{Nc} 4 \mathrm{cccc}(\mathrm{N}) \mathrm{c} 4) \mathrm{nc} 32) \mathrm{cc} 1$ & 18280 & 4.74 \\
\hline 4745 & $\mathrm{~N} \# \mathrm{CC} 1=\mathrm{C}(\mathrm{N}) \mathrm{N}(\mathrm{c} 2 \mathrm{cccnc} 2) \mathrm{C} 2=\mathrm{C}(\mathrm{C}(=\mathrm{O}) \mathrm{CCC} 2) \mathrm{C} 1 \mathrm{c} 1 \mathrm{cc} 2 \mathrm{cc}(\mathrm{Cl}) \mathrm{ccc} 2 \mathrm{n} 2 \mathrm{nnnn} 12$ & 18300 & 4.74 \\
\hline 4746 & $\mathrm{CN}(\mathrm{C}) \mathrm{S}(=\mathrm{O})(=\mathrm{O}) \mathrm{c} 1 \mathrm{ccc}(\mathrm{Nc} 2 \mathrm{nc}(\mathrm{Cl}) \mathrm{nc} 3 \mathrm{cc} 4 \mathrm{c}(\mathrm{cc} 23) \mathrm{OCO} 4) \mathrm{cc} 1$ & 18300 & $*$ \\
\hline 4747 & $\operatorname{Cc} 1 \operatorname{ccc}(\mathrm{S}(=\mathrm{O})(=\mathrm{O}) \mathrm{NC}(=\mathrm{O}) \mathrm{Cc} 2 \operatorname{ccc}(\mathrm{Br}) \operatorname{cc} 2) \operatorname{cc} 1$ & 18350 & 4.74 \\
\hline 4748 & $\mathrm{CC}(=\mathrm{O}) \mathrm{N} 1 \mathrm{~N}=\mathrm{C}(\mathrm{c} 2 \mathrm{ccc}(\mathrm{Cl}) \mathrm{c}(\mathrm{Cl}) \mathrm{c} 2) \mathrm{CC} 1 \mathrm{c} 1 \mathrm{ccc}(\mathrm{F}) \mathrm{cc} 1$ & 18350 & 4.74 \\
\hline 4749 & $\mathrm{CC}(\mathrm{C})(\mathrm{C}) \mathrm{c} 1 \mathrm{ccc}(\mathrm{OC}[\mathrm{C} @ \mathrm{H}](\mathrm{Cn} 2 \mathrm{ccnc} 2[\mathrm{~N}+](=\mathrm{O})[\mathrm{O}-]) \mathrm{OC}(=\mathrm{O}) \mathrm{c} 2 \mathrm{ccc}(\mathrm{NC}=\mathrm{C} 3 \mathrm{C}(=\mathrm{O}) \mathrm{C}=\mathrm{CC} 3=\mathrm{O}) \mathrm{cc} 2) \mathrm{cc} 1$ & 18400 & $*$ \\
\hline 4750 & $\mathrm{CC}(=\mathrm{O}) \mathrm{N} 1 \mathrm{~N}=\mathrm{C}(\mathrm{c} 2 \mathrm{ccc}(\mathrm{Cl}) \mathrm{c}(\mathrm{Cl}) \mathrm{c} 2) \mathrm{CC} 1 \mathrm{c} 1 \mathrm{ccc}(\mathrm{Br}) \mathrm{cc} 1$ & 18450 & 4.73 \\
\hline 4751 & $\mathrm{COc} 1 \mathrm{ccc}(/ \mathrm{C}=\mathrm{C} 2 \backslash \mathrm{CCC} / \mathrm{C}(=\mathrm{C} \backslash \mathrm{c} 3 \mathrm{cc}(\mathrm{OC}) \mathrm{cc}(\mathrm{OC}) \mathrm{c} 3) \mathrm{C} 2=\mathrm{O}) \mathrm{cc} 1$ & 18600 & 4.73 \\
\hline 4752 & $\mathrm{COc} 1 \mathrm{cc}(/ \mathrm{C}=\mathrm{C} 2 \backslash \mathrm{CCCCC} 2=\mathrm{O}) \mathrm{cc}(\mathrm{OC}) \mathrm{c} 1$ & 18670 & 4.73 \\
\hline 4753 & $\mathrm{O}=\mathrm{C}(\mathrm{Cc} 1 \mathrm{cccc}(\mathrm{Br}) \mathrm{c} 1) \mathrm{NS}(=\mathrm{O})(=\mathrm{O}) \mathrm{c} 1 \mathrm{ccc}(\mathrm{F}) \mathrm{cc} 1$ & 18720 & 4.73 \\
\hline 4754 & $\operatorname{COc} 1 \mathrm{cc}(/ \mathrm{C}=\mathrm{C}(\backslash \mathrm{C} \# \mathrm{~N}) \mathrm{C}(=\mathrm{O}) \mathrm{NCCCCNC}(=\mathrm{O}) / \mathrm{C}(\mathrm{C \# N})=\mathrm{C} / \mathrm{c} 2 \mathrm{cc}(\mathrm{OC}) \mathrm{c}(\mathrm{O}) \mathrm{c}([\mathrm{N}+](=\mathrm{O})[\mathrm{O}-]) \mathrm{c} 2) \mathrm{cc}([\mathrm{N}+](=\mathrm{O})[\mathrm{O}-]) \mathrm{c} 1 \mathrm{O}$ & 19000 & $*$ \\
\hline 4755 & $\mathrm{Cc} 1 \mathrm{ccc}(-\mathrm{c} 2 \mathrm{nn}(\mathrm{C}) \mathrm{c} 3 \mathrm{ncnc}(\mathrm{N}) \mathrm{c} 23) \mathrm{cc} 1 \mathrm{O}$ & 19000 & $*$ \\
\hline 4756 & $\mathrm{COc} 1 \mathrm{cc} 2 \mathrm{nccc}(\mathrm{Oc} 3 \mathrm{cccc}(\mathrm{O}) \mathrm{c} 3) \mathrm{c} 2 \mathrm{cc} 1 \mathrm{OC}$ & 19000 & $*$ \\
\hline
\end{tabular}




\begin{tabular}{|c|c|c|c|}
\hline 4757 & $\operatorname{COc} 1 \mathrm{cc}(/ \mathrm{C}=\mathrm{C}(\backslash \mathrm{C} \# \mathrm{~N}) \mathrm{C}(\mathrm{N})=\mathrm{O}) \operatorname{cc}(\mathrm{CSc} 2 \mathrm{nc} 3 \operatorname{cccc} 3 \mathrm{~s} 2) \mathrm{c} 1 \mathrm{O}$ & 19054.61 & $*$ \\
\hline 4758 & $\mathrm{Cc} 1 \mathrm{cc}(\mathrm{C}) \mathrm{c}(\mathrm{NC}(=\mathrm{O}) / \mathrm{C}(\mathrm{C} \# \mathrm{~N})=\mathrm{C} / \mathrm{c} 2 \operatorname{ccc}(\mathrm{O}) \mathrm{c}(\mathrm{O}) \mathrm{c} 2) \mathrm{c}(\mathrm{C}) \mathrm{c} 1$ & 19054.61 & $*$ \\
\hline 4759 & $\mathrm{NC}(=\mathrm{S}) \mathrm{N} / \mathrm{N}=\mathrm{C}(/ \mathrm{C}=\mathrm{C} / \mathrm{c} 1 \mathrm{ccc}(\mathrm{F}) \mathrm{cc} 1) \mathrm{c} 1 \mathrm{ccccc} 1$ & 19120 & 4.72 \\
\hline 4760 & $\mathrm{O}=\mathrm{C}(\mathrm{Nc} 1 \mathrm{ccc}([\mathrm{N}+](=\mathrm{O})[\mathrm{O}-]) \operatorname{cc} 1) \mathrm{c} 1 \mathrm{ccc}(\mathrm{N}(\mathrm{CCCl}) \mathrm{CCCl}) \mathrm{cc} 1$ & 19260 & 4.72 \\
\hline 4761 & $\mathrm{COc} 1 \mathrm{cc} 2 \mathrm{c}(\mathrm{cc} 1 \mathrm{OC}) \mathrm{Sc} 1 \mathrm{ncnc}(\mathrm{Oc} 3 \mathrm{cccc}(\mathrm{Cl}) \mathrm{c} 3 \mathrm{~F}) \mathrm{c} 1 \mathrm{NC} 2$ & 19300 & 4.71 \\
\hline 4762 & $\mathrm{O}=\mathrm{C} 1 \mathrm{CSC}(\mathrm{N} / \mathrm{N}=\mathrm{C} / \mathrm{c} 2 \operatorname{cccc}(\mathrm{O}) \mathrm{c} 2)=\mathrm{N} 1$ & 19320 & 4.71 \\
\hline 4763 & $\mathrm{CC}(=\mathrm{O}) \mathrm{N} 1 \mathrm{~N}=\mathrm{C}(\mathrm{c} 2 \mathrm{ccc}(\mathrm{Cl}) \mathrm{c}(\mathrm{Cl}) \mathrm{c} 2) \mathrm{CC} 1 \mathrm{c} 1 \mathrm{ccc}(\mathrm{C}) \mathrm{cc} 1$ & 19320 & 4.71 \\
\hline 4764 & $\mathrm{Cc} 1 \mathrm{cc}(\mathrm{C}) \mathrm{c}(\mathrm{O}) \mathrm{c}(\mathrm{CN}(\mathrm{Cc} 2 \mathrm{ccc}(\mathrm{F}) \mathrm{cc} 2) \mathrm{C}(=\mathrm{S}) \mathrm{Nc} 2 \mathrm{cccc} 2) \mathrm{c} 1$ & 19410 & 4.71 \\
\hline 4765 & $\mathrm{Cc} 1 \mathrm{ccc}(\mathrm{C} 2 \mathrm{CC}(\mathrm{c} 3 \mathrm{ccc}(\mathrm{Br}) \mathrm{cc} 3)=\mathrm{NN} 2 \mathrm{c} 2 \mathrm{nc}(-\mathrm{c} 3 \mathrm{cccc} 3) \mathrm{cs} 2) \mathrm{cc} 1$ & 19640 & 4.71 \\
\hline 4766 & $\mathrm{Cc} 1 \operatorname{ccc}(\mathrm{NC}(=\mathrm{O}) / \mathrm{C}=\mathrm{C} / \mathrm{c} 2 \operatorname{ccccc} 2) \mathrm{c} 1$ & 19690 & $*$ \\
\hline 4767 & $\mathrm{CC}(=\mathrm{O}) \mathrm{N} 1 \mathrm{~N}=\mathrm{C}(\mathrm{c} 2 \operatorname{ccc}(\mathrm{C}) \mathrm{c}(\mathrm{C}) \mathrm{c} 2) \mathrm{CC} 1 \mathrm{c} 1 \mathrm{ccc}(\mathrm{Cl}) \mathrm{cc} 1$ & 19730 & 4.70 \\
\hline 4768 & $\mathrm{CCOc} 1 \mathrm{cc} 2 \mathrm{nc} 3 \mathrm{c}(\mathrm{c}(\mathrm{Nc} 4 \mathrm{cccc}(-\mathrm{c} 5 \mathrm{csc}(\mathrm{C}) \mathrm{n} 5) \mathrm{c} 4) \mathrm{c} 2 \mathrm{cc} 1 \mathrm{OCC}) \mathrm{CCC} 3$ & 19740 & $*$ \\
\hline 4769 & $\mathrm{COc} 1 \mathrm{ccc}(\mathrm{C} 2 \mathrm{CC}(\mathrm{c} 3 \mathrm{ccc}(\mathrm{Br}) \mathrm{cc} 3)=\mathrm{NN} 2 \mathrm{c} 2 \mathrm{nc}(-\mathrm{c} 3 \mathrm{ccc}(\mathrm{Cl}) \mathrm{cc} 3) \mathrm{cs} 2) \mathrm{cc} 1$ & 19830 & 4.70 \\
\hline 4770 & $\mathrm{O}=\mathrm{C}(\mathrm{NS}(=\mathrm{O})(=\mathrm{O}) \mathrm{c} 1 \mathrm{ccc}(\mathrm{Cl}) \mathrm{cc} 1) \mathrm{c} 1 \mathrm{ccc} n \mathrm{c} 1 \mathrm{Cl}$ & 19830 & 4.70 \\
\hline 4771 & $\mathrm{Cc} 1 \mathrm{c}(\mathrm{Nc} 2 \mathrm{ccc}(\mathrm{OCc} 3 \mathrm{cccc}(\mathrm{F}) \mathrm{c} 3) \mathrm{c}(\mathrm{Cl}) \mathrm{c} 2) \mathrm{ncnc} 1-\mathrm{c} 1 \mathrm{ccccc} 1$ & 20000 & 4.70 \\
\hline 4772 & $\mathrm{CC}(=\mathrm{O}) \mathrm{Oc} 1 \mathrm{ccc} 2 \mathrm{c} 1 \mathrm{c}(\mathrm{C}(=\mathrm{O}) \mathrm{Nc} 1 \mathrm{cccc} 1) \mathrm{c}(\mathrm{SSc} 1 \mathrm{c}(\mathrm{C}(=\mathrm{O}) \mathrm{Nc} 3 \operatorname{ccc} c \mathrm{~s}) \mathrm{c} 3 \mathrm{c}(\mathrm{OC}(\mathrm{C})=\mathrm{O}) \operatorname{ccc} 3 \mathrm{n} 1 \mathrm{C}) \mathrm{n} 2 \mathrm{C}$ & 20000 & $*$ \\
\hline 4773 & $\mathrm{COc} 1 \mathrm{cc} 2 \mathrm{nccc}(\mathrm{Oc} 3 \mathrm{ccc}(\mathrm{Br}) \mathrm{cc} 3) \mathrm{c} 2 \mathrm{cc} 1 \mathrm{OC}$ & 20000 & $*$ \\
\hline 4774 & $\mathrm{CC}(=\mathrm{O}) \mathrm{N} 1 \mathrm{~N}=\mathrm{C}(\mathrm{c} 2 \mathrm{ccc}(\mathrm{C}) \mathrm{c}(\mathrm{C}) \mathrm{c} 2) \mathrm{CC} 1 \mathrm{c} 1 \mathrm{cccc} 1$ & 20040 & 4.70 \\
\hline 4775 & $\mathrm{O}=\mathrm{C}(\mathrm{NS}(=\mathrm{O})(=\mathrm{O}) \mathrm{c} 1 \mathrm{ccccc} 1) \mathrm{c} 1 \mathrm{cncc}(\mathrm{Br}) \mathrm{c} 1$ & 20190 & 4.69 \\
\hline 4776 & $\mathrm{C}=\mathrm{CCNC}(=\mathrm{S}) \mathrm{Nc} 1 \mathrm{scc}(-\mathrm{c} 2 \mathrm{ccc} 3 \mathrm{ncc}(\mathrm{C}(\mathrm{N})=\mathrm{O}) \mathrm{c}(\mathrm{Nc} 4 \operatorname{cccc}(\mathrm{Br}) \mathrm{c} 4) \mathrm{c} 3 \mathrm{c} 2) \mathrm{c} 1 \mathrm{C} \# \mathrm{~N}$ & 20450 & $*$ \\
\hline 4777 & $\mathrm{NC}(=\mathrm{S}) \mathrm{N} / \mathrm{N}=\mathrm{C}(/ \mathrm{C}=\mathrm{C} / \mathrm{c} 1 \mathrm{ccc}(\mathrm{Cl}) \mathrm{cc} 1) \mathrm{c} 1 \mathrm{ccccc} 1$ & 20480 & 4.69 \\
\hline 4778 & $\mathrm{Nc} 1 \mathrm{ncnc} 2 \mathrm{c} 1 \mathrm{c}(-\mathrm{c} 1 \mathrm{ccc}(\mathrm{Cl}) \mathrm{c}(\mathrm{O}) \mathrm{c} 1) \mathrm{nn} 2 \mathrm{CCC} 1 \mathrm{CCCNC} 1$ & 20500 & $*$ \\
\hline 4779 & $\mathrm{CC}(=\mathrm{O}) \mathrm{N} 1 \mathrm{~N}=\mathrm{C}(\mathrm{c} 2 \operatorname{ccc}(\mathrm{C}) \mathrm{c}(\mathrm{C}) \mathrm{c} 2) \mathrm{CC} 1 \mathrm{c} 1 \mathrm{ccc}(\mathrm{Br}) \mathrm{cc} 1$ & 20610 & 4.69 \\
\hline 4780 & $\operatorname{COc} 1 \mathrm{cc}(/ \mathrm{C}=\mathrm{C} 2 \backslash \mathrm{CCC} / \mathrm{C}(=\mathrm{C} \backslash \mathrm{c} 3 \operatorname{cccc} 3 \mathrm{OC}) \mathrm{C} 2=\mathrm{O}) \mathrm{cc}(\mathrm{OC}) \mathrm{c} 1$ & 20800 & 4.68 \\
\hline 4781 & $\mathrm{CCC}(=\mathrm{O}) \mathrm{Nc} 1 \mathrm{ccc} 2 \mathrm{c}(\mathrm{C \# N}) \operatorname{cnc}(\mathrm{Nc} 3 \operatorname{ccc}(\mathrm{Br}) \mathrm{c} 3) \mathrm{c} 2 \mathrm{c} 1$ & 20800 & $*$ \\
\hline 4782 & $\operatorname{Cc} 1 \mathrm{ncc}([\mathrm{N}+](=\mathrm{O})[\mathrm{O}-]) \mathrm{n} 1 \mathrm{CCOC}(=\mathrm{O}) / \mathrm{C}=\mathrm{C} / \mathrm{c} 1 \mathrm{ccccc} 1 \mathrm{Cl}$ & 20810 & 4.68 \\
\hline 4783 & $\mathrm{COC}(=\mathrm{O}) \mathrm{CCc} 1 \mathrm{c}(\mathrm{SSc} 2[\mathrm{nH}] \mathrm{c} 3 \operatorname{ccc} \operatorname{coc} 2 \mathrm{CCC}(=\mathrm{O}) \mathrm{OC})[\mathrm{nH}] \mathrm{c} 2 \mathrm{cccc} 12$ & 21000 & $*$ \\
\hline 4784 & $\mathrm{~N} \# \mathrm{C} / \mathrm{C}(=\mathrm{C} \backslash \mathrm{c} 1 \mathrm{ccc}(\mathrm{O}) \mathrm{c}(\mathrm{O}) \mathrm{c} 1) \mathrm{C}(=\mathrm{O}) \mathrm{NCCCCCCCCNC}(=\mathrm{O}) / \mathrm{C}(\mathrm{C \# N})=\mathrm{C} / \mathrm{c} 1 \mathrm{ccc}(\mathrm{O}) \mathrm{c}(\mathrm{O}) \mathrm{c} 1$ & 21000 & $*$ \\
\hline 4785 & $\mathrm{Cc} 1 \mathrm{cc}(\mathrm{C} 2 \mathrm{CCN}(\mathrm{CCCF}) \mathrm{CC} 2) \mathrm{cc} 2[\mathrm{nH}] \mathrm{c}(-\mathrm{c} 3 \mathrm{c}(\mathrm{NCCn} 4 \mathrm{cc}(\mathrm{Cl}) \mathrm{cn} 4) \mathrm{cc}[\mathrm{nH}] \mathrm{c} 3=\mathrm{O}) \mathrm{nc} 12$ & 21000 & $*$ \\
\hline 4786 & CCOc1cec2ce(-c3nn(C)c4ncnc(N)c34)ccc2c1 & 21000 & $*$ \\
\hline 4787 & $\mathrm{COc} 1 \mathrm{cc} 2 \mathrm{nccc}(\mathrm{Oc} 3 \operatorname{ccc}(\mathrm{C}(=\mathrm{O}) \mathrm{c} 4 \mathrm{cccc} 4 \mathrm{C}(\mathrm{F})(\mathrm{F}) \mathrm{F}) \mathrm{cc} 3) \mathrm{c} 2 \mathrm{cc} 1 \mathrm{OC}$ & 21000 & $*$ \\
\hline 4788 & $\operatorname{Cc} 1 n \operatorname{cc}([\mathrm{N}+](=\mathrm{O})[\mathrm{O}-]) \mathrm{n} 1 \mathrm{CC}(=\mathrm{O}) \mathrm{N} / \mathrm{N}=\mathrm{C} / \mathrm{c} 1 \mathrm{cc} 2 \mathrm{ccccc} 2 \mathrm{nc} 1 \mathrm{Oc} 1 \mathrm{ccc}(\mathrm{F}) \mathrm{cc} 1$ & 21020 & 4.68 \\
\hline 4789 & Clc1cce2c(c1)SCc1 nc $(\mathrm{Nc} 3 \mathrm{cccc} 3) \mathrm{nc} 1-2$ & 21180 & 4.67 \\
\hline 4790 & $\mathrm{CCOc} 1 \mathrm{cc} 2 \mathrm{c}(\mathrm{Nc} 3 \mathrm{ccc}(\mathrm{C}) \mathrm{c}(\mathrm{O}) \mathrm{c} 3) \mathrm{c}(\mathrm{C} \# \mathrm{~N}) \mathrm{cnc} 2 \mathrm{cc} 1 \mathrm{OC}$ & 21190 & $*$ \\
\hline 4791 & $\mathrm{O}=\mathrm{C}(\mathrm{Cc} 1 \mathrm{cccc}(\mathrm{Br}) \mathrm{c} 1) \mathrm{NS}(=\mathrm{O})(=\mathrm{O}) \mathrm{c} 1 \mathrm{ccc}(\mathrm{Cl}) \mathrm{cc} 1$ & 21280 & 4.67 \\
\hline 4792 & $\mathrm{CC}(\mathrm{C})(\mathrm{C}) \mathrm{OC}[\mathrm{C} @ @ \mathrm{H}](\mathrm{Cn} 1 \mathrm{ccnc} 1[\mathrm{~N}+](=\mathrm{O})[\mathrm{O}-]) \mathrm{OC}(=\mathrm{O}) \mathrm{c} 1 \mathrm{ccc}(\mathrm{NC}=\mathrm{C} 2 \mathrm{C}(=\mathrm{O}) \mathrm{C}=\mathrm{CC} 2=\mathrm{O}) \mathrm{cc} 1$ & 21300 & $*$ \\
\hline 4793 & $\mathrm{CC}(=\mathrm{O}) \mathrm{N} 1 \mathrm{~N}=\mathrm{C}(\mathrm{c} 2 \mathrm{ccc}(\mathrm{C}) \mathrm{c}(\mathrm{C}) \mathrm{c} 2) \mathrm{CC} 1 \mathrm{c} 1 \mathrm{ccccc} 1 \mathrm{Cl}$ & 21480 & 4.67 \\
\hline 4794 & $\mathrm{Oc} 1 \mathrm{ccc}(\mathrm{C} 2 \mathrm{CC}(\mathrm{c} 3 \operatorname{ccc}(\mathrm{Br}) \mathrm{cc} 3)=\mathrm{NN} 2 \mathrm{c} 2 \mathrm{nc}(-\mathrm{c} 3 \mathrm{ccc}(\mathrm{Cl}) \mathrm{cc} 3) \mathrm{cs} 2) \mathrm{cc} 1$ & 21520 & 4.67 \\
\hline 4795 & $\mathrm{COc} 1 \mathrm{ccc}(\mathrm{Nc} 2 \mathrm{ncc} 3 \mathrm{c}(\mathrm{n} 2)-\mathrm{c} 2 \mathrm{ccc}(\mathrm{Cl}) \mathrm{cc} 2 \mathrm{SC} 3) \mathrm{cc} 1$ & 21560 & 4.67 \\
\hline 4796 & $\operatorname{Cc} 1 \operatorname{ccc}(\mathrm{C}(=\mathrm{O}) \mathrm{NS}(=\mathrm{O})(=\mathrm{O}) \mathrm{c} 2 \operatorname{ccccc} 2) \mathrm{c}(\mathrm{Cl}) \mathrm{n} 1$ & 21560 & 4.67 \\
\hline 4797 & $\mathrm{COc} 1 \mathrm{cc} 2 \mathrm{c}(\mathrm{cc} 1 \mathrm{OC}) \mathrm{Sc} 1 \mathrm{ncnc}(\mathrm{Oc} 3 \mathrm{cccc}(\mathrm{Br}) \mathrm{c} 3) \mathrm{c} 1 \mathrm{NC} 2$ & 21700 & 4.66 \\
\hline 4798 & $\mathrm{Cc} 1 \operatorname{ccc}(\mathrm{CN}(\mathrm{Cc} 2 \operatorname{ccc}(\mathrm{F}) \mathrm{cc} 2) \mathrm{C}(=\mathrm{O}) \mathrm{Nc} 2 \operatorname{cccc} 2) \mathrm{c} 1 \mathrm{O}$ & 21710 & 4.66 \\
\hline 4799 & $\operatorname{COc} 1 \operatorname{ccc}(\mathrm{CC}(=\mathrm{O}) \mathrm{NS}(=\mathrm{O})(=\mathrm{O}) \operatorname{c} 2 \operatorname{ccc}(\mathrm{F}) \mathrm{cc} 2) \mathrm{cc} 1$ & 21840 & 4.66 \\
\hline
\end{tabular}




\begin{tabular}{|c|c|c|c|}
\hline 4800 & $\mathrm{COc} 1 \mathrm{cc}(/ \mathrm{C}=\mathrm{C}(\backslash \mathrm{C} \# \mathrm{~N}) \mathrm{C}(\mathrm{N})=\mathrm{O}) \operatorname{cc}(\mathrm{CSc} 2 \operatorname{cccc} 2 \mathrm{NC}(\mathrm{C})=\mathrm{O}) \mathrm{c} 1 \mathrm{O}$ & 21877.62 & $*$ \\
\hline 4801 & $\mathrm{O}=\mathrm{C}(\mathrm{Nc} 1 \mathrm{ccccc} 1 \mathrm{Br}) \mathrm{c} 1 \mathrm{cccc} 1 \mathrm{O}$ & 21920 & $*$ \\
\hline 4802 & $\mathrm{Fc} 1 \mathrm{cccc}(\mathrm{COc} 2 \mathrm{ccc}(\mathrm{Nc} 3 \mathrm{cc}(-\mathrm{c} 4 \mathrm{ccsc} 4) \mathrm{ncn} 3) \mathrm{cc} 2 \mathrm{Cl}) \mathrm{c} 1$ & 22000 & 4.66 \\
\hline 4803 & $\mathrm{NC}(=\mathrm{O}) \mathrm{CCC} 1 \mathrm{C}(\mathrm{S})=\mathrm{Nc} 2 \operatorname{cccc} 21$ & 22000 & $*$ \\
\hline 4804 & $\mathrm{COc} 1 \mathrm{cc}(\mathrm{C} 2=\mathrm{C}(\mathrm{c} 3 \mathrm{cn}(\mathrm{COCC}[\mathrm{Si}](\mathrm{C})(\mathrm{C}) \mathrm{C}) \mathrm{c} 4 \mathrm{cccc} 34) \mathrm{CNC} 2=\mathrm{O}) \mathrm{cc}(\mathrm{OC}) \mathrm{c} 1 \mathrm{OC}$ & 22000 & $*$ \\
\hline 4805 & $\mathrm{CN} 1 \mathrm{CC}[\mathrm{C} @ \mathrm{H}](\mathrm{c} 2 \mathrm{c}(\mathrm{O}) \mathrm{cc}(\mathrm{O}) \mathrm{c} 3 \mathrm{c}(=\mathrm{O}) \mathrm{cc}(-\mathrm{c} 4 \mathrm{cccc} 4 \mathrm{Cl}) \mathrm{oc} 23)[\mathrm{C} @ \mathrm{H}](\mathrm{O}) \mathrm{C} 1$ & 22000 & $*$ \\
\hline 4806 & $\mathrm{CCCCN}(\mathrm{Cc} 1 \operatorname{cccc}(\mathrm{Br}) \mathrm{c} 1 \mathrm{O}) \mathrm{C}(=\mathrm{S}) \mathrm{Nc} 1 \mathrm{ccccc} 1$ & 22040 & 4.66 \\
\hline 4807 & $\mathrm{Cc} 1 \mathrm{ccc}(\mathrm{C}(=\mathrm{O}) \mathrm{Nc} 2 \operatorname{cccc} 2 \mathrm{Br}) \mathrm{c}(\mathrm{O}) \mathrm{c} 1$ & 22190 & $*$ \\
\hline 4808 & $\mathrm{Cn} 1 \mathrm{c}(\mathrm{SSc} 2 \mathrm{c}(\mathrm{C}(=\mathrm{O}) \mathrm{Nc} 3 \operatorname{cccc} 3) \mathrm{c} 3 \operatorname{ccc} n \mathrm{n} 2 \mathrm{n} 2) \mathrm{c}(\mathrm{C}(=\mathrm{O}) \mathrm{Nc} 2 \operatorname{cccc} 2) \mathrm{c} 2 \mathrm{cccnc} 21$ & 22300 & $*$ \\
\hline 4809 & $\mathrm{Oc} 1 \mathrm{ccc}(\mathrm{C} 2 \mathrm{CC}(\mathrm{c} 3 \mathrm{ccc}(\mathrm{Br}) \mathrm{cc} 3)=\mathrm{NN} 2 \mathrm{c} 2 \mathrm{nc}(-\mathrm{c} 3 \mathrm{cccc} 3) \mathrm{cs} 2) \mathrm{cc} 1$ & 22360 & 4.65 \\
\hline 4810 & $\mathrm{NC}(=\mathrm{S}) \mathrm{N} / \mathrm{N}=\mathrm{C}(/ \mathrm{C}=\mathrm{C} / \mathrm{c} 1 \operatorname{ccccc} 1 \mathrm{~F}) \mathrm{c} 1 \mathrm{ccccc} 1$ & 22360 & 4.65 \\
\hline 4811 & $\mathrm{COc} 1 \mathrm{ccc}(\mathrm{NC}(=\mathrm{O}) \mathrm{c} 2 \mathrm{cc}(\mathrm{Br}) \mathrm{cc}(\mathrm{Br}) \mathrm{c} 2 \mathrm{O}) \mathrm{cc} 1$ & 22390 & $*$ \\
\hline 4812 & $\operatorname{CCCCNC}(=\mathrm{O}) \mathrm{c} 1 \mathrm{ccc}(\mathrm{N}(\mathrm{CCCl}) \mathrm{CCCl}) \mathrm{cc} 1$ & 22810 & 4.64 \\
\hline 4813 & $\mathrm{COc} 1 \mathrm{cc}(\mathrm{C}=\mathrm{C}(\mathrm{C} \# \mathrm{~N}) \mathrm{C} \# \mathrm{~N}) \operatorname{cc}(\mathrm{CS}(=\mathrm{O})(=\mathrm{O}) \mathrm{c} 2 \mathrm{ccc}(\mathrm{C}) \mathrm{cc} 2) \mathrm{c} 1 \mathrm{O}$ & 22908.68 & $*$ \\
\hline 4814 & $\mathrm{COC}[\mathrm{C} @ \mathrm{H}](\mathrm{Cn} 1 \mathrm{ccnc} 1[\mathrm{~N}+](=\mathrm{O})[\mathrm{O}-]) \mathrm{OC}(=\mathrm{O}) \mathrm{c} 1 \mathrm{ccc}(\mathrm{NC}=\mathrm{C} 2 \mathrm{C}(=\mathrm{O}) \mathrm{C}=\mathrm{CC} 2=\mathrm{O}) \mathrm{cc} 1$ & 23000 & $*$ \\
\hline 4815 & $\mathrm{COc} 1 \mathrm{cc}(\mathrm{C} 2=\mathrm{C}(\mathrm{c} 3 \mathrm{c}[\mathrm{nH}] \mathrm{c} 4 \mathrm{cccc} 34) \mathrm{CNC} 2=\mathrm{O}) \mathrm{cc}(\mathrm{OC}) \mathrm{c} 1 \mathrm{OC}$ & 23000 & $*$ \\
\hline 4816 & $\mathrm{Cc} 1 \operatorname{ccc}(\mathrm{N} 2 \mathrm{NC}(=\mathrm{O}) / \mathrm{C}(=\mathrm{C} / \mathrm{c} 3 \operatorname{ccc}(-\mathrm{c} 4 \operatorname{ccccc} 4 \mathrm{~F}) \mathrm{o} 3) \mathrm{C} 2=\mathrm{O}) \mathrm{c} 1$ & 23100 & 4.64 \\
\hline 4817 & $\mathrm{Cc} 1 \mathrm{ccc}(\mathrm{Oc} 2 \mathrm{nc} 3 \operatorname{ccc} c 3 \operatorname{cc} 2 / \mathrm{C}=\mathrm{N} / \mathrm{NC}(=\mathrm{O}) \mathrm{Cn} 2 \mathrm{c}([\mathrm{N}+](=\mathrm{O})[\mathrm{O}-]) \mathrm{cnc} 2 \mathrm{C}) \mathrm{cc} 1$ & 23130 & 4.64 \\
\hline 4818 & $\mathrm{O}=\mathrm{C}(/ \mathrm{C}=\mathrm{C} / \mathrm{c} 1 \operatorname{cccc} 1) \mathrm{Nc} 1 \operatorname{ccc} c 1$ & 23160 & $*$ \\
\hline 4819 & $\mathrm{NC}(=\mathrm{S}) \mathrm{N} / \mathrm{N}=\mathrm{C}(/ \mathrm{C}=\mathrm{C} / \mathrm{c} 1 \mathrm{ccccc} 1 \mathrm{Cl}) \mathrm{c} 1 \mathrm{ccccc} 1$ & 23270 & 4.63 \\
\hline 4820 & $\mathrm{Cc} 1 \mathrm{cccc}(\mathrm{C}=\mathrm{N} / \mathrm{NC} 2=\mathrm{NC}(=\mathrm{O}) \mathrm{CS} 2) \mathrm{c} 1$ & 23490 & 4.63 \\
\hline 4821 & $\mathrm{CC} 1=\mathrm{C}(\mathrm{C}(=\mathrm{O}) \mathrm{Nc} 2 \operatorname{ccc}(\mathrm{C}) \mathrm{cc} 2) \mathrm{C}(\mathrm{c} 2 \mathrm{ccc}(\mathrm{O}) \mathrm{cc} 2 \mathrm{O}) \mathrm{NC}(\mathrm{NCc} 2 \mathrm{ccccc} 2)=\mathrm{N} 1$ & 23500 & $*$ \\
\hline 4822 & $\mathrm{O}=\mathrm{C}(\mathrm{CCc} 1 \mathrm{c}(\mathrm{SSc} 2[\mathrm{nH}] \mathrm{c} 3 \operatorname{ccc} c 3 \mathrm{c} 2 \mathrm{CCC}(=\mathrm{O}) \mathrm{NCC} 2 \operatorname{ccc} \mathrm{c} 2)[\mathrm{nH}] \mathrm{c} 2 \mathrm{cccc} 12) \mathrm{NCC} 1 \mathrm{ccc} c 1$ & 24000 & $*$ \\
\hline 4823 & $\mathrm{COc} 1 \mathrm{cc} 2 \mathrm{nccc}(\mathrm{Oc} 3 \mathrm{cccc}(\mathrm{F}) \mathrm{c} 3) \mathrm{c} 2 \mathrm{cc} 1 \mathrm{OC}$ & 24000 & $*$ \\
\hline 4824 & $\mathrm{Cc} 1 \mathrm{nn}(-\mathrm{c} 2 \mathrm{ccc}(\mathrm{Cl}) \mathrm{cc} 2) \mathrm{c}(\mathrm{Cl}) \mathrm{c} 1 \mathrm{C} 1 \mathrm{C}(\mathrm{C \# N})=\mathrm{C}(\mathrm{N}) \mathrm{N}(\mathrm{c} 2 \mathrm{cccnc} 2) \mathrm{C} 2=\mathrm{C} 1 \mathrm{C}(=\mathrm{O}) \mathrm{CC}(\mathrm{C})(\mathrm{C}) \mathrm{C} 2$ & 24050 & 4.62 \\
\hline 4825 & $\operatorname{COc} 1 \operatorname{ccc}(\mathrm{CC}(=\mathrm{O}) \mathrm{NS}(=\mathrm{O})(=\mathrm{O}) \mathrm{c} 2 \mathrm{ccc}(\mathrm{Br}) \mathrm{cc} 2) \mathrm{cc} 1$ & 24150 & 4.62 \\
\hline 4826 & $\mathrm{CC}(=\mathrm{O}) \mathrm{N} 1 \mathrm{~N}=\mathrm{C}(\mathrm{c} 2 \mathrm{ccc}(\mathrm{Cl}) \mathrm{c}(\mathrm{Cl}) \mathrm{c} 2) \mathrm{CC} 1 \mathrm{c} 1 \mathrm{cccc} 1 \mathrm{Cl}$ & 24150 & 4.62 \\
\hline 4827 & $\mathrm{Fc} 1 \mathrm{ccc}(\mathrm{C} 2 \mathrm{CC}(\mathrm{c} 3 \mathrm{ccc}(\mathrm{Br}) \mathrm{cc} 3)=\mathrm{NN} 2 \mathrm{c} 2 \mathrm{nc}(-\mathrm{c} 3 \mathrm{ccc}(\mathrm{Cl}) \mathrm{cc} 3) \mathrm{cs} 2) \mathrm{cc} 1$ & 24160 & 4.62 \\
\hline 4828 & $\mathrm{Clc} 1 \mathrm{cccc}(\mathrm{Nc} 2[\mathrm{nH}] \mathrm{nc} 3 \mathrm{ncnc}(\mathrm{Oc} 4 \mathrm{cccc}(\mathrm{Cl}) \mathrm{c} 4) \mathrm{c} 23) \mathrm{c} 1$ & 24200 & $*$ \\
\hline 4829 & $\mathrm{Cc} 1 \mathrm{ncc}([\mathrm{N}+](=\mathrm{O})[\mathrm{O}-]) \mathrm{n} 1 \mathrm{CCOC}(=\mathrm{O}) / \mathrm{C}=\mathrm{C} / \mathrm{c} 1 \mathrm{ccccc} 1 \mathrm{Br}$ & 24320 & 4.61 \\
\hline 4830 & $\mathrm{O}=\mathrm{C}(\mathrm{Cc} 1 \mathrm{cccc}(\mathrm{Br}) \mathrm{c} 1) \mathrm{NS}(=\mathrm{O})(=\mathrm{O}) \mathrm{c} 1 \mathrm{ccc}(\mathrm{Br}) \mathrm{cc} 1$ & 24330 & 4.61 \\
\hline 4831 & $\mathrm{O}=[\mathrm{N}+]([\mathrm{O}-]) \mathrm{c} 1 \mathrm{ccc}(\mathrm{C} 2 \mathrm{CC}(\mathrm{c} 3 \mathrm{ccc}(\mathrm{Br}) \mathrm{cc} 3)=\mathrm{NN} 2 \mathrm{c} 2 \mathrm{nc}(-\mathrm{c} 3 \mathrm{ccc}(\mathrm{Cl}) \mathrm{cc} 3) \operatorname{cs} 2) \mathrm{cc} 1$ & 24370 & 4.61 \\
\hline 4832 & $\mathrm{COc} 1 \mathrm{cc} 2 \mathrm{c}(\mathrm{cc} 1 \mathrm{OC}) \mathrm{Sc} 1 \mathrm{nc}(\mathrm{C}) \mathrm{nc}(\mathrm{Nc} 3 \mathrm{ccc} 4 \mathrm{c}[\mathrm{nH}] \mathrm{nc} 4 \mathrm{c} 3) \mathrm{c} 1 \mathrm{NC} 2$ & 24600 & 4.61 \\
\hline 4833 & $\mathrm{CCCCN}(\mathrm{Cc} 1 \mathrm{cc}(\mathrm{Cl}) \mathrm{cc}(\mathrm{Cl}) \mathrm{c} 1 \mathrm{O}) \mathrm{C}(=\mathrm{S}) \mathrm{Nc} 1 \mathrm{ccccc} 1$ & 24650 & 4.61 \\
\hline 4834 & $\mathrm{O}=\mathrm{C}(\mathrm{Cc} 1 \operatorname{cccc}(\mathrm{Br}) \mathrm{c} 1) \mathrm{NS}(=\mathrm{O})(=\mathrm{O}) \mathrm{c} 1 \mathrm{ccccc} 1$ & 24680 & 4.61 \\
\hline 4835 & $\operatorname{Cc} 1 \operatorname{ccc}(\mathrm{S}(=\mathrm{O})(=\mathrm{O}) \mathrm{NC}(=\mathrm{O}) \mathrm{c} 2 \operatorname{ccc} n \mathrm{c} 2) \mathrm{cc} 1$ & 24830 & 4.61 \\
\hline 4836 & $\mathrm{O}=\mathrm{C}(\mathrm{Nc} 1 \mathrm{ccccc} 1 \mathrm{~F}) \mathrm{c} 1 \operatorname{ccccc} 1 \mathrm{O}$ & 24830 & $*$ \\
\hline 4837 & $\operatorname{Cc} 1 n \operatorname{cc}([\mathrm{N}+](=\mathrm{O})[\mathrm{O}-]) \mathrm{n} 1 \mathrm{CCOC}(=\mathrm{O}) / \mathrm{C}=\mathrm{C} / \mathrm{c} 1 \operatorname{ccccc} 1[\mathrm{~N}+](=\mathrm{O})[\mathrm{O}-]$ & 25000 & 4.60 \\
\hline 4838 & $\mathrm{~N} \# \mathrm{C} / \mathrm{C}(=\mathrm{Clc} 1 \mathrm{ccc}(\mathrm{O}) \mathrm{c}(\mathrm{O}) \mathrm{c} 1) \mathrm{C}(=\mathrm{O}) \mathrm{O}$ & 25000 & $*$ \\
\hline 4839 & $\mathrm{O}=\mathrm{C}(\mathrm{CCc} 1 \mathrm{c}(\mathrm{SSc} 2[\mathrm{nH}] \mathrm{c} 3 \operatorname{ccc} c 3 \mathrm{c} 2 \mathrm{CCC}(=\mathrm{O}) \mathrm{Nc} 2 \operatorname{ccc} c 2)[\mathrm{nH}] \mathrm{c} 2 \operatorname{ccccc} 12) \mathrm{Nc} 1 \operatorname{ccccc} 1$ & 25000 & $*$ \\
\hline 4840 & $\mathrm{~N} \# \mathrm{C} / \mathrm{C}(=\mathrm{Clc} 1 \mathrm{ccc}(\mathrm{O}) \mathrm{c}(\mathrm{O}) \mathrm{c} 1) \mathrm{C}(=\mathrm{O}) \mathrm{N} 1 \mathrm{CCN}(\mathrm{C}(=\mathrm{O}) / \mathrm{C}(\mathrm{C \# N})=\mathrm{C} / \mathrm{c} 2 \mathrm{ccc}(\mathrm{O}) \mathrm{c}(\mathrm{O}) \mathrm{c} 2) \mathrm{CC} 1$ & 25000 & $*$ \\
\hline 4841 & $\mathrm{CNc} 1 \mathrm{ncnc}(-\mathrm{c} 2 \mathrm{cccnc} 2 \mathrm{Oc} 2 \mathrm{ccc}(\mathrm{F}) \mathrm{c}(\mathrm{C}(=\mathrm{O}) \mathrm{Nc} 3 \mathrm{cc}(\mathrm{C}(\mathrm{F})(\mathrm{F}) \mathrm{F}) \operatorname{ccc} 3 \mathrm{~N}(\mathrm{C}) \mathrm{CCCN}(\mathrm{C}) \mathrm{C}) \mathrm{c} 2) \mathrm{n} 1$ & 25000 & $*$ \\
\hline 4842 & $\mathrm{CNc} 1 \mathrm{ncnc}(-\mathrm{c} 2 \mathrm{cccnc} 2 \mathrm{Oc} 2 \mathrm{cc}(\mathrm{NC}(=\mathrm{O}) \mathrm{c} 3 \operatorname{cccc}(\mathrm{OC}(\mathrm{F})(\mathrm{F}) \mathrm{C}(\mathrm{F}) \mathrm{F}) \mathrm{c} 3) \operatorname{ccc} 2 \mathrm{C}) \mathrm{n} 1$ & 25000 & * \\
\hline
\end{tabular}




\begin{tabular}{|c|c|c|c|}
\hline 4843 & $\mathrm{CC}(\mathrm{C}) \mathrm{n} 1 \mathrm{nc}(-\mathrm{c} 2 \mathrm{ccc} 3 \mathrm{cnccc} 3 \mathrm{c} 2) \mathrm{c} 2 \mathrm{c}(\mathrm{N}) \mathrm{ncnc} 21$ & 25000 & $*$ \\
\hline 4844 & $\mathrm{Nc} 1 \mathrm{ccc} 2 \mathrm{ncnc}(\mathrm{Nc} 3 \mathrm{ccc}(\mathrm{OCc} 4 \mathrm{nccs} 4) \mathrm{c}(\mathrm{Cl}) \mathrm{c} 3) \mathrm{c} 2 \mathrm{c} 1$ & 25000 & $*$ \\
\hline 4845 & $\mathrm{CC}(=\mathrm{O}) \mathrm{Nc} 1 \mathrm{ccc}(\mathrm{C \# C} 2 \mathrm{cncnc} 2 \mathrm{Nc} 2 \mathrm{ccc}(\mathrm{OCc} 3 \mathrm{ccc}(\mathrm{F}) \mathrm{c} 3) \mathrm{c}(\mathrm{Cl}) \mathrm{c} 2) \mathrm{cc} 1$ & 25100 & $*$ \\
\hline 4846 & $\mathrm{O}=\mathrm{C}(\mathrm{Cc} 1 \mathrm{nc} 2 \operatorname{ccccc} 2[\mathrm{nH}] 1) \mathrm{N} 1 \mathrm{~N}=\mathrm{C}(\mathrm{c} 2 \mathrm{ccc}(\mathrm{Cl}) \mathrm{cc} 2) \mathrm{CC} 1 \mathrm{c} 1 \mathrm{ccc}(\mathrm{Br}) \mathrm{cc} 1$ & 25200 & $*$ \\
\hline 4847 & $\mathrm{O}=\mathrm{C}(\mathrm{NS}(=\mathrm{O})(=\mathrm{O}) \mathrm{c} 1 \mathrm{ccc}(\mathrm{Cl}) \mathrm{cc} 1) \mathrm{c} 1 \mathrm{ccc} n \mathrm{c} 1$ & 25360 & 4.60 \\
\hline 4848 & $\mathrm{COc} 1 \mathrm{cc}(\mathrm{OC}) \mathrm{cc}(\mathrm{C} 2 \mathrm{CC}(\mathrm{c} 3 \mathrm{ccc}(\mathrm{Cl}) \mathrm{c}(\mathrm{Cl}) \mathrm{c} 3)=\mathrm{NN} 2 \mathrm{C}(\mathrm{C})=\mathrm{O}) \mathrm{c} 1$ & 25470 & 4.59 \\
\hline 4849 & $\mathrm{O}=\mathrm{C}(\mathrm{O}) \mathrm{c} 1 \mathrm{ccc}(\mathrm{Nc} 2[\mathrm{nH}] \mathrm{cnc} 3 \mathrm{nc} 4 \mathrm{c}(\mathrm{c} 2-3) \mathrm{CCCC} 4) \mathrm{c} 1$ & 25700 & $*$ \\
\hline 4850 & $\mathrm{Clc} 1 \mathrm{ccc}(-\mathrm{c} 2 \mathrm{csc}(\mathrm{N} 3 \mathrm{~N}=\mathrm{C}(\mathrm{c} 4 \mathrm{ccc}(\mathrm{Br}) \mathrm{cc} 4) \mathrm{CC} 3 \mathrm{c} 3 \mathrm{ccc}(\mathrm{Br}) \mathrm{cc} 3) \mathrm{n} 2) \mathrm{cc} 1$ & 25740 & 4.59 \\
\hline 4851 & $\mathrm{Cc} 1 \operatorname{ccc}(\mathrm{NC}(=\mathrm{O}) \operatorname{c} 2 \operatorname{cccc} 2 \mathrm{O}) \operatorname{cc} 1$ & 25740 & $*$ \\
\hline 4852 & $\operatorname{COc} 1 \mathrm{ccc}(-\mathrm{n} 2 \mathrm{c}(=\mathrm{O}) \mathrm{cnc} 3 \mathrm{cnc}(\mathrm{Nc} 4 \mathrm{ccc}(\mathrm{N}) \mathrm{cc} 4) \mathrm{nc} 32) \mathrm{cc} 1$ & 25825 & 4.59 \\
\hline 4853 & $\mathrm{CN}(\mathrm{C}) \mathrm{c} 1 \mathrm{nc}(\mathrm{N} / \mathrm{N}=\mathrm{C} / \mathrm{c} 2 \mathrm{cc}(\mathrm{Br}) \mathrm{c}(\mathrm{O}) \mathrm{c}(\mathrm{Br}) \mathrm{c} 2 \mathrm{O}) \mathrm{nc}(\mathrm{Nc} 2 \mathrm{ccc}(\mathrm{F}) \mathrm{cc} 2) \mathrm{n} 1$ & 25900 & $*$ \\
\hline 4854 & $\mathrm{NC}(=\mathrm{S}) \mathrm{N} / \mathrm{N}=\mathrm{C}(\mathrm{C}=\mathrm{C} / \mathrm{c} 1 \mathrm{ccccc} 1 \mathrm{Br}) \mathrm{c} 1 \mathrm{ccccc} 1$ & 26000 & 4.59 \\
\hline 4855 & $\mathrm{CN} 1 \mathrm{C}(=\mathrm{O}) \mathrm{C}(=\mathrm{C}(\mathrm{CHN}) \mathrm{CHN}) \mathrm{c} 2 \mathrm{cc}(\mathrm{O}) \operatorname{ccc} 21$ & 26000 & $*$ \\
\hline 4856 & $\mathrm{C}[\mathrm{C} @ @ \mathrm{H}](\mathrm{CN}) \mathrm{n} 1 \mathrm{nc}(-\mathrm{c} 2 \mathrm{ccc}(\mathrm{F}) \mathrm{c}(\mathrm{O}) \mathrm{c} 2) \mathrm{c} 2 \mathrm{c}(\mathrm{N}) \mathrm{ncnc} 21$ & 26000 & $*$ \\
\hline 4857 & C/C1=C/CC[C@]23O[C@H]2[C@@H](OC3=O)c2c(O)ccc(O)c2C1 & 26000 & $*$ \\
\hline 4858 & $\mathrm{COc} 1 \mathrm{cc}(\mathrm{OC}) \mathrm{cc}(-\mathrm{c} 2 \mathrm{nnc}(\mathrm{SCc} 3 \mathrm{cccc} 3) \mathrm{o} 2) \mathrm{c} 1$ & 26060 & 4.58 \\
\hline 4859 & $\operatorname{Cc} 1 \operatorname{ccc}(\mathrm{S}(=\mathrm{O})(=\mathrm{O}) \mathrm{NC}(=\mathrm{O}) \mathrm{Cc} 2 \operatorname{cccc}(\mathrm{Br}) \mathrm{c} 2) \operatorname{cc} 1$ & 26170 & 4.58 \\
\hline 4860 & $\operatorname{COc} 1 \operatorname{ccc}(\mathrm{CC}(=\mathrm{O}) \mathrm{NS}(=\mathrm{O})(=\mathrm{O}) \operatorname{c} 2 \operatorname{ccccc} 2) \operatorname{cc} 1$ & 26200 & 4.58 \\
\hline 4861 & $\mathrm{C}=\mathrm{CC}(=\mathrm{O}) \mathrm{Nc} 1 \mathrm{cc}(\mathrm{Nc} 2 \mathrm{ncc}(\mathrm{Br}) \mathrm{c}(\mathrm{Nc} 3 \operatorname{ccc} 4 \mathrm{c}(\mathrm{c} 3) \mathrm{CCC} 4) \mathrm{n} 2) \operatorname{ccc} 1 \mathrm{~N}(\mathrm{C}) \mathrm{CCN}(\mathrm{C}) \mathrm{C}$ & 26200 & $*$ \\
\hline 4862 & $\operatorname{COc} 1 \operatorname{ccc}(\mathrm{Nc} 2 \mathrm{ncc} 3 \mathrm{ncc}(=\mathrm{O}) \mathrm{n}(-\mathrm{c} 4 \mathrm{cccc}(\mathrm{NC}(=\mathrm{O}) / \mathrm{C}=\mathrm{C} / \mathrm{CN}(\mathrm{C}) \mathrm{C}) \mathrm{c} 4) \mathrm{c} 3 \mathrm{n} 2) \mathrm{cc} 1$ & 26283 & 4.58 \\
\hline 4863 & $\mathrm{NC}(=\mathrm{S}) \mathrm{N} / \mathrm{N}=\mathrm{C}(/ \mathrm{C}=\mathrm{C} / \mathrm{c} 1 \mathrm{ccc}(\mathrm{Br}) \mathrm{cc} 1) \mathrm{c} 1 \mathrm{ccccc} 1$ & 26560 & 4.58 \\
\hline 4864 & $\mathrm{C}=\mathrm{C}(\mathrm{N} / \mathrm{N}=\mathrm{C} / \mathrm{c} 1 \mathrm{cn}[\mathrm{nH}] \mathrm{c} 1-\mathrm{c} 1 \mathrm{cccc} 1)[\mathrm{C} @ \mathrm{H}](\mathrm{C}) \mathrm{Cc} 1 \mathrm{ccccc} 1$ & 26600 & 4.58 \\
\hline 4865 & $\begin{array}{c}\mathrm{Cc} 1 \mathrm{nc}(\mathrm{Nc} 2 \mathrm{ncc}(\mathrm{C}(=\mathrm{O}) \mathrm{Nc} 3 \mathrm{c}(\mathrm{C}) \mathrm{cccc} 3 \mathrm{Cl}) \mathrm{s} 2) \mathrm{cc}(\mathrm{N} 2 \mathrm{CCN}(\mathrm{CCOC}(=\mathrm{O}) \mathrm{c} 3 \operatorname{ccc}(\mathrm{C}(=\mathrm{O}) \mathrm{Nc} 4 \operatorname{ccc} 5 \mathrm{ncnc}(\mathrm{Nc} 6 \mathrm{cccc}(\mathrm{Cl}) \mathrm{c} 6) \mathrm{c} 5 \mathrm{c} \\
4) \mathrm{cn} 3) \mathrm{CC} 2) \mathrm{n} 1\end{array}$ & 26600 & $*$ \\
\hline 4866 & $\mathrm{O}=\mathrm{C} 1 \mathrm{CSC}(\mathrm{N} / \mathrm{N}=\mathrm{C} / \mathrm{c} 2 \operatorname{cccc}([\mathrm{N}+](=\mathrm{O})[\mathrm{O}-]) \mathrm{c} 2)=\mathrm{N} 1$ & 26610 & 4.57 \\
\hline 4867 & $\mathrm{Cc} 1 \mathrm{ncc}([\mathrm{N}+](=\mathrm{O})[\mathrm{O}-]) \mathrm{n} 1 \mathrm{CCOC}(=\mathrm{O}) / \mathrm{C}=\mathrm{C} / \mathrm{c} 1 \operatorname{ccccc} 1 \mathrm{~F}$ & 26740 & 4.57 \\
\hline 4868 & $\mathrm{C}=\mathrm{CC}(=\mathrm{O}) \mathrm{Nc} 1 \mathrm{cc}(\mathrm{Nc} 2 \mathrm{nccc}(\mathrm{Nc} 3 \mathrm{ccc} 4 \mathrm{c}(\mathrm{ccn} 4 \mathrm{C}) \mathrm{c} 3) \mathrm{n} 2) \mathrm{c}(\mathrm{OC}) \mathrm{cc} 1 \mathrm{~N} 1 \mathrm{CCN}(\mathrm{C}) \mathrm{CC} 1$ & 26900 & $*$ \\
\hline 4869 & $\mathrm{O}=\mathrm{C} 1 \mathrm{CSC}(\mathrm{NN}=\mathrm{C} 2 \mathrm{CCCCCCC} 2)=\mathrm{N} 1$ & 27000 & 4.57 \\
\hline 4870 & $\mathrm{COc} 1 \mathrm{cc} 2 \mathrm{c}(\mathrm{cc} 1 \mathrm{OC}) \mathrm{Sc} 1 \mathrm{ncnc}(\mathrm{N}(\mathrm{C}) \mathrm{c} 3 \mathrm{ccc}(\mathrm{Cl}) \mathrm{c} 3) \mathrm{c} 1 \mathrm{NC} 2$ & 27000 & 4.57 \\
\hline 4871 & $\operatorname{CONC}(=\mathrm{O}) \mathrm{c} 1 \mathrm{cc}(\mathrm{N}=\mathrm{C} / \mathrm{c} 2 \mathrm{cc}(\mathrm{O}) \operatorname{ccc} 2 \mathrm{O}) \mathrm{ccc} 1 \mathrm{O}$ & 27000 & $*$ \\
\hline 4872 & $\mathrm{C} / \mathrm{C} 1=\mathrm{C} / \mathrm{CC}[\mathrm{C} @] 23 \mathrm{O}[\mathrm{C} @ \mathrm{H}] 2[\mathrm{C} @ @ \mathrm{H}](\mathrm{OC} 3=\mathrm{O}) \mathrm{C} 2=\mathrm{C}(\mathrm{C} 1) \mathrm{C}(=\mathrm{O}) \mathrm{C}=\mathrm{CC} 2=\mathrm{O}$ & 27000 & $*$ \\
\hline 4873 & $\operatorname{Cc} 1 \operatorname{ccc}(\mathrm{S}(=\mathrm{O})(=\mathrm{O}) \mathrm{NC}(=\mathrm{O}) \mathrm{c} 2 \operatorname{ccc} n \mathrm{c} 2 \mathrm{Cl}) \mathrm{cc} 1$ & 27050 & 4.57 \\
\hline 4874 & $\operatorname{CCCCCCCCCCCCCCNC}(=\mathrm{O}) \operatorname{c} 1 \operatorname{cc}(\mathrm{NCc} 2 \mathrm{cc}(\mathrm{O}) \operatorname{ccc} 2 \mathrm{O}) \operatorname{ccc} 1 \mathrm{O}$ & 27200 & * \\
\hline 4875 & $\mathrm{Cc} 1 \mathrm{cc}(\mathrm{C}) \mathrm{c}(\mathrm{O}) \mathrm{c}(\mathrm{CN}(\mathrm{Cc} 2 \mathrm{ccc}(\mathrm{F}) \mathrm{cc} 2) \mathrm{C}(=\mathrm{O}) \mathrm{Nc} 2 \mathrm{cccc} 2) \mathrm{c} 1$ & 27350 & 4.56 \\
\hline 4876 & $\mathrm{CO}[\mathrm{C} @ \mathrm{H}](\mathrm{C}) \mathrm{c} 1 \mathrm{c}(\mathrm{O}) \mathrm{cc} 2 \mathrm{c}(\mathrm{c} 1 \mathrm{O}) \mathrm{C}(=\mathrm{O}) \mathrm{c} 1 \mathrm{c}(\mathrm{O}) \mathrm{cc}(\mathrm{O}) \mathrm{cc} 1 \mathrm{C} 2=\mathrm{O}$ & 27500 & $*$ \\
\hline 4877 & $\mathrm{CC}(=\mathrm{O}) \mathrm{OC}(\mathrm{Cc} 1 \mathrm{c}(\mathrm{SSc} 2[\mathrm{nH}] \mathrm{c} 3 \operatorname{ccc} c 3 \mathrm{c} 2 \mathrm{CC}(\mathrm{OC}(\mathrm{C})=\mathrm{O}) \mathrm{C}(=\mathrm{O}) \mathrm{NCc} 2 \operatorname{ccccc} 2)[\mathrm{nH}] \mathrm{c} 2 \operatorname{ccccc} 12) \mathrm{C}(=\mathrm{O}) \mathrm{NCc} 1 \mathrm{ccccc} 1$ & 28000 & $*$ \\
\hline 4878 & $\mathrm{~N} \# \mathrm{Cc} 1 \mathrm{cnc}(\mathrm{Nc} 2 \operatorname{cccc}(\mathrm{Br}) \mathrm{c} 2) \mathrm{c} 2 \mathrm{cc}(\mathrm{NC}(=\mathrm{O}) \mathrm{CCc} 3 \operatorname{cc} 4 \operatorname{ccccc} 4[\mathrm{nH}] 3) \operatorname{ccc} 12$ & 28000 & $*$ \\
\hline 4879 & $\mathrm{COc} 1 \mathrm{cc} 2 \mathrm{nccc}(\mathrm{Oc} 3 \operatorname{ccc}(\mathrm{C}(=\mathrm{O}) \mathrm{c} 4 \operatorname{cccc}(\mathrm{F}) \mathrm{c} 4) \mathrm{cc} 3) \mathrm{c} 2 \mathrm{cc} 1 \mathrm{OC}$ & 28000 & $*$ \\
\hline 4880 & $\mathrm{Cc} 1 \mathrm{ccc}(\mathrm{C} 2 \mathrm{CC}(\mathrm{c} 3 \operatorname{ccc}(\mathrm{Br}) \mathrm{cc} 3)=\mathrm{NN} 2 \mathrm{c} 2 \mathrm{nc}(-\mathrm{c} 3 \mathrm{ccc}(\mathrm{Cl}) \mathrm{cc} 3) \mathrm{cs} 2) \mathrm{cc} 1$ & 28170 & 4.55 \\
\hline 4881 & $\mathrm{O}=\mathrm{C}(\mathrm{Nc} 1 \mathrm{ccc}(\mathrm{Br}) \mathrm{cc} 1) \mathrm{c} 1 \mathrm{cc}(\mathrm{Br}) \mathrm{cc}(\mathrm{Br}) \mathrm{c} 1 \mathrm{O}$ & 28530 & $*$ \\
\hline 4882 & $\mathrm{O}=\mathrm{C}(\mathrm{NS}(=\mathrm{O})(=\mathrm{O}) \mathrm{c} 1 \mathrm{ccc}(\mathrm{F}) \mathrm{cc} 1) \mathrm{c} 1 \mathrm{cccnc} 1 \mathrm{Cl}$ & 28660 & 4.54 \\
\hline 4883 & $\mathrm{CC}(=\mathrm{O}) \mathrm{N} 1 \mathrm{~N}=\mathrm{C}(\mathrm{c} 2 \mathrm{ccc}(\mathrm{Cl}) \mathrm{c}(\mathrm{Cl}) \mathrm{c} 2) \mathrm{CC} 1 \mathrm{c} 1 \mathrm{ccccc} 1$ & 28690 & 4.54 \\
\hline 4884 & $\mathrm{O}=\mathrm{C} 1 \mathrm{NC}(=\mathrm{O}) \mathrm{c} 2 \mathrm{c} 1 \mathrm{c} 1 \mathrm{c} 3 \operatorname{ccc}(\mathrm{O}) \mathrm{c} 3[\mathrm{nH}] \mathrm{c} 1 \mathrm{c} 1[\mathrm{nH}] \mathrm{c} 3 \mathrm{c}(\mathrm{O}) \operatorname{ccc} 3 \mathrm{c} 21$ & 29000 & $*$ \\
\hline
\end{tabular}




\begin{tabular}{|c|c|c|c|}
\hline 4885 & $\mathrm{COc} 1 \mathrm{cc} 2 \mathrm{ncnc}(\mathrm{Nc} 3 \mathrm{cc}(\mathrm{NC}(=\mathrm{O}) \mathrm{c} 4 \mathrm{cccc}(\mathrm{N}(\mathrm{C}) \mathrm{C}) \mathrm{c} 4) \operatorname{ccc} 3 \mathrm{Cl}) \mathrm{c} 2 \mathrm{cc} 1 \mathrm{OC}$ & 29000 & $*$ \\
\hline 4886 & $\mathrm{CC}(\mathrm{C}) \mathrm{n} 1 \mathrm{nc}(-\mathrm{c} 2 \mathrm{ccc} 3 \mathrm{occc}(=\mathrm{O}) \mathrm{c} 3 \mathrm{c} 2) \mathrm{c} 2 \mathrm{c}(\mathrm{N}) \mathrm{ncnc} 21$ & 29000 & $*$ \\
\hline 4887 & $\mathrm{O}=\mathrm{C}(\mathrm{NS}(=\mathrm{O})(=\mathrm{O}) \mathrm{c} 1 \mathrm{ccc}(\mathrm{Br}) \mathrm{cc} 1) \mathrm{c} 1 \mathrm{ccc}(\mathrm{Cl}) \mathrm{nc} 1$ & 29070 & 4.54 \\
\hline 4888 & $\mathrm{NS}(=\mathrm{O})(=\mathrm{O}) \mathrm{c} 1 \mathrm{ccc} 2 \mathrm{c}(\mathrm{c} 1) / \mathrm{C}(=\mathrm{C} / \mathrm{c} 1[\mathrm{nH}] \mathrm{c} 3 \mathrm{c}(\mathrm{c} 1 \mathrm{CCC}(=\mathrm{O}) \mathrm{O}) \mathrm{CCCC} 3) \mathrm{C}(=\mathrm{O}) \mathrm{N} 2$ & 29100 & $*$ \\
\hline 4889 & $\mathrm{Cc} 1 \mathrm{ccc}(\mathrm{Nc} 2 \mathrm{ncnn} 3 \mathrm{c}(\mathrm{C}) \mathrm{ccc} 23) \mathrm{cc} 1 \mathrm{O}$ & 29400 & $*$ \\
\hline 4890 & $\mathrm{O}=\mathrm{C}(\mathrm{Cc} 1 \mathrm{nc} 2 \mathrm{ccccc} 2[\mathrm{nH}] 1) \mathrm{N} 1 \mathrm{~N}=\mathrm{C}(\mathrm{c} 2 \mathrm{ccc}(\mathrm{Cl}) \mathrm{cc} 2) \mathrm{CC} 1 \mathrm{c} 1 \mathrm{ccc}(\mathrm{F}) \mathrm{cc} 1$ & 29400 & $*$ \\
\hline 4891 & $\mathrm{Nc} 1 \operatorname{scc} 2 \mathrm{c} 1 \mathrm{c}(\mathrm{Nc} 1 \mathrm{ccc}(\mathrm{S}(\mathrm{N})(=\mathrm{O})=\mathrm{O}) \mathrm{cc} 1) \mathrm{nc} 1 \mathrm{ncnc}(\mathrm{N}) \mathrm{c} 12$ & 29500 & * \\
\hline 4892 & $\mathrm{CC}(\mathrm{C}) \mathrm{n} 1 \mathrm{ncc} 2 \mathrm{c}(\mathrm{NCc} 3 \mathrm{ccc}(\mathrm{N}) \mathrm{cc} 3) \mathrm{nc}(\mathrm{NCCO}) \mathrm{nc} 21$ & 29500 & $*$ \\
\hline 4893 & $\mathrm{CC}(\mathrm{C}) \mathrm{n} 1 \mathrm{ncc} 2 \mathrm{c}(\mathrm{NCc} 3 \mathrm{cccc}(\mathrm{F}) \mathrm{c} 3) \mathrm{nc}(\mathrm{NCCO}) \mathrm{nc} 21$ & 29500 & $*$ \\
\hline 4894 & $\mathrm{CC}(\mathrm{C}) \mathrm{c} 1 \mathrm{ccc}(\mathrm{NC}(=\mathrm{O}) \mathrm{c} 2 \operatorname{cccc} 2 \mathrm{O}) \mathrm{cc} 1$ & 29620 & * \\
\hline 4895 & $\mathrm{CCCN}(\mathrm{CCC}) \mathrm{C}(=\mathrm{O}) \mathrm{c} 1 \mathrm{ccc}(\mathrm{N}(\mathrm{CCCl}) \mathrm{CCCl}) \mathrm{cc} 1$ & 29830 & 4.53 \\
\hline 4896 & $\mathrm{CC}(\mathrm{C})(\mathrm{C}) \mathrm{NC}(=\mathrm{O}) / \mathrm{C}=\mathrm{C} / \mathrm{c} 1 \mathrm{ccccc} 1$ & 29850 & * \\
\hline 4897 & $\mathrm{O}=\mathrm{c} 1 \mathrm{oc} 2 \mathrm{cc} 3 \mathrm{ncnc}(\mathrm{Ne} 4 \mathrm{cccc} 4 \mathrm{O}) \mathrm{c} 3 \mathrm{cc} 2 \mathrm{n} 1 \mathrm{CCCN} 1 \mathrm{CCOCC} 1$ & 30000 & * \\
\hline 4898 & $\mathrm{COc} 1 \mathrm{cc} 2 \mathrm{ncnc}(\mathrm{N}(\mathrm{C}) \mathrm{c} 3 \operatorname{ccc}(\mathrm{C}(\mathrm{F})(\mathrm{F}) \mathrm{F}) \mathrm{c} 3) \mathrm{c} 2 \mathrm{cc} 1 \mathrm{OC} . \mathrm{Cl}$ & 30000 & $*$ \\
\hline 4899 & $\mathrm{CN} 1 \mathrm{CCC}(\mathrm{NC}(=\mathrm{O}) \mathrm{c} 2 \mathrm{cnc}(\mathrm{NCc} 3 \mathrm{cc}(\mathrm{Cl}) \mathrm{ccc} 3 \mathrm{Cl}) \mathrm{nc} 2 \mathrm{NC} 2 \mathrm{CCCC} 2) \mathrm{CC} 1$ & 30000 & * \\
\hline 4900 & CN1CCC(NC(=O)c2cnc(Nc3cc(Cl)cc(Cl)c3)nc2N[C@@H]2COC[C@H]2O)CC1 & 30000 & * \\
\hline 4901 & $\mathrm{COc} 1 \mathrm{cccc} 1 \mathrm{CNc} 1 \mathrm{ncc}(\mathrm{C}(=\mathrm{O}) \mathrm{NC} 2 \mathrm{CCN}(\mathrm{C}) \mathrm{CC} 2) \mathrm{c}(\mathrm{NC} 2 \mathrm{CCCC} 2) \mathrm{n} 1$ & 30000 & $*$ \\
\hline 4902 & $\mathrm{CN} 1 \mathrm{CCC}(\mathrm{NC}(=\mathrm{O}) \mathrm{c} 2 \mathrm{cnc}(\mathrm{Nc} 3 \mathrm{cc}(\mathrm{Cl}) \mathrm{cc}(\mathrm{Cl}) \mathrm{c} 3) \mathrm{nc} 2 \mathrm{NC} 2 \mathrm{CCC}(\mathrm{N}(\mathrm{C}) \mathrm{C}) \mathrm{CC} 2) \mathrm{CC} 1$ & 30000 & $*$ \\
\hline 4903 & $\mathrm{COc} 1 \mathrm{cc} 2 \mathrm{nccc}(\mathrm{Oc} 3 \operatorname{ccc}(\mathrm{C}(=\mathrm{O}) \mathrm{Nc} 4 \mathrm{ccc}(\mathrm{C}(\mathrm{C})(\mathrm{C}) \mathrm{C}) \mathrm{cc} 4) \mathrm{cc} 3) \mathrm{c} 2 \mathrm{cc} 1 \mathrm{OC}$ & 30000 & $*$ \\
\hline 4904 & $\mathrm{COc} 1 \mathrm{ccc}(\mathrm{OC}) \mathrm{c}(\mathrm{Nc} 2 \mathrm{cc}(\mathrm{Nc} 3 \mathrm{cc}(\mathrm{OC}) \mathrm{ccc} 3 \mathrm{OC}) \mathrm{ncn} 2) \mathrm{c} 1$ & 30000 & * \\
\hline 4905 & $\mathrm{Clc} 1 \mathrm{cccc}(\mathrm{Nc} 2 \mathrm{cc}(\mathrm{Nc} 3 \operatorname{ccc}(\mathrm{Cl}) \mathrm{c} 3) \mathrm{ncn} 2) \mathrm{c} 1$ & 30000 & * \\
\hline 4906 & $\mathrm{Clc} 1 \mathrm{cccc}(\mathrm{Nc} 2 \mathrm{cc}(\mathrm{Nc} 3 \operatorname{cccc}(\mathrm{Br}) \mathrm{c} 3) \mathrm{ncn} 2) \mathrm{c} 1$ & 30000 & * \\
\hline 4907 & $\mathrm{Fc} 1 \mathrm{ccc}(\mathrm{Nc} 2 \mathrm{cc}(\mathrm{Nc} 3 \mathrm{ccc}(\mathrm{F}) \mathrm{cc} 3) \mathrm{ncn} 2) \mathrm{cc} 1$ & 30000 & * \\
\hline 4908 & $\mathrm{COc} 1 \mathrm{cccc}(\mathrm{Nc} 2 \mathrm{cc}(\mathrm{NC}(=\mathrm{O}) \mathrm{c} 3 \mathrm{ccc}(\mathrm{F}) \mathrm{cc} 3) \mathrm{ncn} 2) \mathrm{c} 1$ & 30000 & * \\
\hline 4909 & $\mathrm{COc} 1 \mathrm{cccc}(\mathrm{Nc} 2 \mathrm{cc}(\mathrm{Nc} 3 \operatorname{ccc}(\mathrm{Cl}) \mathrm{cc} 3) \mathrm{ncn} 2) \mathrm{c} 1$ & 30000 & $*$ \\
\hline 4910 & $\mathrm{O}=\mathrm{C}(/ \mathrm{C}=\mathrm{C} / \mathrm{c} 1 \mathrm{ccc}(\mathrm{F}) \mathrm{cc} 1) \mathrm{Nc} 1 \mathrm{cc}(\mathrm{Nc} 2 \operatorname{ccc}(\mathrm{Cl}) \operatorname{cc} 2) \mathrm{ncn} 1$ & 30000 & $*$ \\
\hline 4911 & $\operatorname{CCOC}(=\mathrm{O}) \operatorname{CCC}(=\mathrm{O}) \mathrm{Nc} 1 \operatorname{cc}(\mathrm{Nc} 2 \operatorname{ccc}(\mathrm{S}(\mathrm{N})(=\mathrm{O})=\mathrm{O}) \operatorname{cc} 2) \operatorname{ncn} 1$ & 30000 & $*$ \\
\hline 4912 & $\mathrm{CN} 1 \mathrm{CCN}(\mathrm{c} 2 \mathrm{cc}(\mathrm{NC}(=\mathrm{O}) / \mathrm{C}=\mathrm{C} / \mathrm{c} 3 \operatorname{ccc}(\mathrm{F}) \mathrm{cc} 3) \mathrm{ncn} 2) \mathrm{CC} 1$ & 30000 & * \\
\hline 4913 & $\mathrm{Fc} 1 \mathrm{ccc}(\mathrm{Nc} 2 \mathrm{cc}(\mathrm{Nc} 3 \mathrm{ccc}(\mathrm{Cl}) \mathrm{cc} 3) \mathrm{ncn} 2) \mathrm{cc} 1$ & 30000 & $*$ \\
\hline 4914 & $\operatorname{COc} 1 \mathrm{ccc}(\mathrm{Nc} 2 \mathrm{cc}(\mathrm{NC}(=\mathrm{O}) \mathrm{c} 3 \mathrm{ccc}(\mathrm{F}) \mathrm{cc} 3) \mathrm{ncn} 2) \mathrm{cc} 1$ & 30000 & $*$ \\
\hline 4915 & $\operatorname{CCOC}(=\mathrm{O}) \mathrm{CC}(=\mathrm{O}) \mathrm{Nc} 1 \mathrm{cc}(\mathrm{Nc} 2 \mathrm{ccc}(\mathrm{F}) \mathrm{cc} 2) \mathrm{ncn} 1$ & 30000 & * \\
\hline 4916 & $\mathrm{O}=\mathrm{C}(\mathrm{C}=\mathrm{Cc} 1 \mathrm{cccc} 1) \mathrm{Nc} 1 \mathrm{cc}(\mathrm{Nc} 2 \mathrm{ccc}(\mathrm{N} 3 \mathrm{CCOCC} 3) \mathrm{cc} 2) \mathrm{ncn} 1$ & 30000 & $*$ \\
\hline 4917 & $\mathrm{O}=\mathrm{C}(\mathrm{Nc} 1 \mathrm{cc}(\mathrm{Nc} 2 \mathrm{cccc}(\mathrm{Cl}) \mathrm{c} 2) \mathrm{ncn} 1) \mathrm{c} 1 \mathrm{ccccc} 1$ & 30000 & $*$ \\
\hline 4918 & $\operatorname{COc} 1 \operatorname{ccc}(\mathrm{Nc} 2 \operatorname{cc}(\mathrm{NC}(=\mathrm{O}) \operatorname{c} 3 \operatorname{ccccc} 3) \mathrm{ncn} 2) \mathrm{c}([\mathrm{N}+](=\mathrm{O})[\mathrm{O}-]) \mathrm{c} 1$ & 30000 & $*$ \\
\hline 4919 & $\mathrm{O}=\mathrm{C}(/ \mathrm{C}=\mathrm{C} / \mathrm{c} 1 \mathrm{ccc}(\mathrm{F}) \mathrm{cc} 1) \mathrm{Nc} 1 \mathrm{cc}(\mathrm{Nc} 2 \mathrm{ccc}(\mathrm{N} 3 \mathrm{CCOCC} 3) \mathrm{cc} 2) \mathrm{ncn} 1$ & 30000 & $*$ \\
\hline 4920 & $\operatorname{CCOC}(=\mathrm{O}) \mathrm{CCC}(=\mathrm{O}) \mathrm{Nc} 1 \mathrm{cc}(\mathrm{Nc} 2 \mathrm{ccc}(\mathrm{Cl}) \mathrm{cc} 2) \mathrm{ncn} 1$ & 30000 & $*$ \\
\hline 4921 & $\operatorname{CCOC}(=\mathrm{O}) \mathrm{CCC}(=\mathrm{O}) \mathrm{Nc} 1 \mathrm{cc}(\mathrm{Nc} 2 \operatorname{ccc}(\mathrm{C}(=\mathrm{O}) \mathrm{OCC}) \mathrm{cc} 2) \mathrm{ncn} 1$ & 30000 & $*$ \\
\hline 4922 & $\operatorname{CCOC}(=\mathrm{O}) \mathrm{CCC}(=\mathrm{O}) \mathrm{Nc} 1 \mathrm{cc}(\mathrm{Nc} 2 \operatorname{cccc}(\mathrm{C}(=\mathrm{O}) \mathrm{OCC}) \mathrm{c} 2) \mathrm{ncn} 1$ & 30000 & $*$ \\
\hline 4923 & $\mathrm{COc} 1 \mathrm{cccc}(\mathrm{Nc} 2 \mathrm{cc}(\mathrm{Nc} 3 \mathrm{cccc}(\mathrm{Br}) \mathrm{c} 3) \mathrm{ncn} 2) \mathrm{c} 1$ & 30000 & $*$ \\
\hline 4924 & $\mathrm{COc} 1 \mathrm{ccc}(\mathrm{OC}) \mathrm{c}(\mathrm{Nc} 2 \mathrm{cc}(\mathrm{Nc} 3 \mathrm{ccc}(\mathrm{Cl}) \mathrm{cc} 3) \mathrm{ncn} 2) \mathrm{c} 1$ & 30000 & $*$ \\
\hline 4925 & $\mathrm{COc} 1 \operatorname{cccc}(\mathrm{Nc} 2 \mathrm{cc}(\mathrm{NC}(=\mathrm{O}) \mathrm{c} 3 \operatorname{ccccc} 3) \mathrm{ncn} 2) \mathrm{c} 1$ & 30000 & $*$ \\
\hline 4926 & $\mathrm{COc} 1 \mathrm{ccc}(\mathrm{Nc} 2 \mathrm{cc}(\mathrm{NC}(=\mathrm{O}) \mathrm{C}=\mathrm{Cc} 3 \operatorname{ccccc} 3) \mathrm{ncn} 2) \mathrm{cc} 1$ & 30000 & $*$ \\
\hline 4927 & $\mathrm{CCOC}(=\mathrm{O}) \mathrm{c} 1 \mathrm{c}(\mathrm{Nc} 2 \mathrm{cc}(\mathrm{NC}(=\mathrm{O}) \mathrm{CCC}(=\mathrm{O}) \mathrm{OC}(\mathrm{C}) \mathrm{C}) \mathrm{ncn} 2) \mathrm{sc} 2 \mathrm{c} 1 \mathrm{CCCC} 2$ & 30000 & * \\
\hline
\end{tabular}




\begin{tabular}{|c|c|c|c|}
\hline 4928 & $\operatorname{CCOC}(=\mathrm{O}) \mathrm{CCC}(=\mathrm{O}) \mathrm{Nc} 1 \mathrm{cc}(\mathrm{Nc} 2 \operatorname{ccc}(\mathrm{OC}) \mathrm{c} 2) \mathrm{ncn} 1$ & 30000 & $*$ \\
\hline 4929 & $\operatorname{CCCC}(\mathrm{C}) \mathrm{OC}(=\mathrm{O}) \mathrm{CCC}(=\mathrm{O}) \mathrm{Nc} 1 \mathrm{cc}(\mathrm{Nc} 2 \operatorname{cccc}(\mathrm{C}(=\mathrm{O}) \mathrm{OC}(\mathrm{C}) \mathrm{CCC}) \mathrm{c} 2) \mathrm{ncn} 1$ & 30000 & $*$ \\
\hline 4930 & $\mathrm{CCOc} 1 \mathrm{ccc}(\mathrm{Nc} 2 \mathrm{cc}(\mathrm{NC}(=\mathrm{O}) \mathrm{c} 3 \mathrm{ccc}(\mathrm{F}) \mathrm{cc} 3) \mathrm{ncn} 2) \mathrm{cc} 1$ & 30000 & $*$ \\
\hline 4931 & $\mathrm{O}=\mathrm{C}(\mathrm{Nc} 1 \mathrm{cc}(\mathrm{N} 2 \mathrm{CCOCC} 2) \mathrm{ncn} 1) \mathrm{c} 1 \mathrm{ccccc} 1$ & 30000 & $*$ \\
\hline 4932 & $\mathrm{O}=\mathrm{C}(\mathrm{O}) \mathrm{CCC}(=\mathrm{O}) \mathrm{Nc} 1 \mathrm{cc}(\mathrm{Nc} 2 \mathrm{cccc}(\mathrm{Br}) \mathrm{c} 2) \mathrm{ncn} 1$ & 30000 & $*$ \\
\hline 4933 & $\mathrm{O}=\mathrm{C}(\mathrm{Nc} 1 \mathrm{cc}(\mathrm{Nc} 2 \mathrm{cccc}(\mathrm{Cl}) \mathrm{c} 2) \mathrm{ncn} 1) \mathrm{c} 1 \mathrm{ccc}(\mathrm{F}) \mathrm{cc} 1$ & 30000 & $*$ \\
\hline 4934 & $\mathrm{CC}(\mathrm{C}) \mathrm{OC}(=\mathrm{O}) \mathrm{CCC}(=\mathrm{O}) \mathrm{Nc} 1 \mathrm{cc}(\mathrm{Nc} 2 \operatorname{ccc}(\mathrm{C}(=\mathrm{O}) \mathrm{OC}(\mathrm{C}) \mathrm{C}) \operatorname{cc} 2) \mathrm{ncn} 1$ & 30000 & $*$ \\
\hline 4935 & $\mathrm{CCNc} 1 \mathrm{cc}(\mathrm{Nc} 2 \mathrm{cc}(\mathrm{OC}) \mathrm{ccc} 2 \mathrm{OC}) \mathrm{ncn} 1$ & 30000 & $*$ \\
\hline 4936 & $\mathrm{CN} 1 \mathrm{CCN}(\mathrm{c} 2 \mathrm{cc}(\mathrm{NC}(=\mathrm{O}) \mathrm{CCCC}(=\mathrm{O}) \mathrm{O}) \mathrm{ncn} 2) \mathrm{CC} 1$ & 30000 & $*$ \\
\hline 4937 & $\operatorname{CCOC}(=\mathrm{O}) \mathrm{CCC}(=\mathrm{O}) \mathrm{Nc} 1 \mathrm{cc}(\mathrm{NCCc} 2 \operatorname{cccs} 2) \mathrm{ncn} 1$ & 30000 & $*$ \\
\hline 4938 & $\mathrm{COc} 1 \mathrm{ccc}(/ \mathrm{C}=\mathrm{C} / \mathrm{C}(=\mathrm{O}) \mathrm{Nc} 2 \mathrm{cc}(\mathrm{Nc} 3 \operatorname{ccc}(\mathrm{Cl}) \mathrm{cc} 3 \mathrm{Cl}) \mathrm{ncn} 2) \mathrm{cc} 1$ & 30000 & $*$ \\
\hline 4939 & $\operatorname{COc} 1 \operatorname{ccc}(\mathrm{Nc} 2 \operatorname{cc}(\mathrm{NC}(=\mathrm{O}) \mathrm{CCC}(=\mathrm{O}) \mathrm{O}) \mathrm{ncn} 2) \mathrm{c} 1$ & 30000 & $*$ \\
\hline 4940 & $\mathrm{O}=\mathrm{C}(\mathrm{O}) \mathrm{CCC}(=\mathrm{O}) \mathrm{Nc} 1 \mathrm{cc}(\mathrm{Nc} 2 \operatorname{ccc}(\mathrm{C}(=\mathrm{O}) \mathrm{O}) \mathrm{c} 2) \mathrm{ncn} 1$ & 30000 & $*$ \\
\hline 4941 & $\operatorname{COc} 1 \operatorname{ccc}(/ \mathrm{C}=\mathrm{C} / \mathrm{C}(=\mathrm{O}) \mathrm{Nc} 2 \mathrm{cc}(\mathrm{N} 3 \mathrm{CCN}(\mathrm{C}) \mathrm{CC} 3) \mathrm{ncn} 2) \mathrm{cc} 1$ & 30000 & $*$ \\
\hline 4942 & $\mathrm{O}=\mathrm{C}(\mathrm{Nc} 1 \mathrm{cc}(\mathrm{Nc} 2 \mathrm{ccc}(\mathrm{N} 3 \mathrm{CCOCC} 3) \mathrm{cc} 2) \mathrm{ncn} 1) \mathrm{c} 1 \mathrm{ccc}(\mathrm{F}) \mathrm{cc} 1$ & 30000 & $*$ \\
\hline 4943 & $\mathrm{CC}(\mathrm{C}) \mathrm{OC}(=\mathrm{O}) \mathrm{CCC}(=\mathrm{O}) \mathrm{Nc} 1 \mathrm{cc}(\mathrm{Nc} 2 \mathrm{ccc}(\mathrm{F}) \mathrm{cc} 2) \mathrm{ncn} 1$ & 30000 & $*$ \\
\hline 4944 & $\mathrm{O}=\mathrm{C}(\mathrm{O}) \mathrm{CCC}(=\mathrm{O}) \mathrm{Nc} 1 \mathrm{cc}(\mathrm{Nc} 2 \mathrm{cccc}(\mathrm{Cl}) \mathrm{c} 2) \mathrm{ncn} 1$ & 30000 & $*$ \\
\hline 4945 & $\mathrm{O}=\mathrm{C}(/ \mathrm{C}=\mathrm{C} / \mathrm{c} 1 \mathrm{ccc}(\mathrm{F}) \mathrm{cc} 1 \mathrm{Br}) \mathrm{Nc} 1 \mathrm{cc}(\mathrm{N} 2 \mathrm{CCOCC} 2) \mathrm{ncn} 1$ & 30000 & $*$ \\
\hline 4946 & $\mathrm{Cc} 1 \mathrm{ccc}(\mathrm{Nc} 2 \mathrm{cc}(\mathrm{NC}(=\mathrm{O}) \mathrm{c} 3 \operatorname{ccc}(\mathrm{F}) \mathrm{cc} 3) \mathrm{ncn} 2) \mathrm{cc} 1$ & 30000 & $*$ \\
\hline 4947 & $\mathrm{CCCC}(\mathrm{C}) \mathrm{OC}(=\mathrm{O}) \mathrm{CCC}(=\mathrm{O}) \mathrm{Nc} 1 \mathrm{cc}(\mathrm{Nc} 2 \operatorname{ccc}(\mathrm{Br}) \mathrm{c} 2) \mathrm{ncn} 1$ & 30000 & $*$ \\
\hline 4948 & $\mathrm{O}=\mathrm{C}(/ \mathrm{C}=\mathrm{C} / \mathrm{c} 1 \mathrm{ccc}(\mathrm{F}) \mathrm{cc} 1) \mathrm{Nc} 1 \mathrm{cc}(\mathrm{Nc} 2 \mathrm{ccc}(\mathrm{Cl}) \mathrm{cc} 2 \mathrm{Cl}) \mathrm{ncn} 1$ & 30000 & $*$ \\
\hline 4949 & $\operatorname{CCOC}(=\mathrm{O}) \mathrm{CCCC}(=\mathrm{O}) \mathrm{Nc} 1 \mathrm{cc}(\mathrm{Nc} 2 \mathrm{cc}(\mathrm{OC}) \mathrm{ccc} 2 \mathrm{OC}) \mathrm{ncn} 1$ & 30000 & $*$ \\
\hline 4950 & $\mathrm{CCOc} 1 \mathrm{ccc}(\mathrm{Nc} 2 \mathrm{cc}(\mathrm{NC}(=\mathrm{O}) \mathrm{c} 3 \operatorname{ccc}(\mathrm{F}) \mathrm{cc} 3) \mathrm{ncn} 2) \mathrm{c} 1$ & 30000 & $*$ \\
\hline 4951 & $\mathrm{COc} 1 \mathrm{ccc}(/ \mathrm{C}=\mathrm{C} / \mathrm{C}(=\mathrm{O}) \mathrm{Nc} 2 \mathrm{cc}(\mathrm{Nc} 3 \operatorname{ccc}(\mathrm{Cl}) \mathrm{cc} 3) \mathrm{ncn} 2) \mathrm{cc} 1$ & 30000 & $*$ \\
\hline 4952 & $\mathrm{CN} 1 \mathrm{CCN}(\mathrm{c} 2 \mathrm{ccc}(\mathrm{Nc} 3 \mathrm{cc}(\mathrm{NC}(=\mathrm{O}) \mathrm{CCC}(=\mathrm{O}) \mathrm{O}) \mathrm{ncn} 3) \mathrm{cc} 2) \mathrm{CC} 1$ & 30000 & $*$ \\
\hline 4953 & $\mathrm{CCOC}(=\mathrm{O}) \mathrm{CCC}(=\mathrm{O}) \mathrm{Nc} 1 \mathrm{cc}(\mathrm{Nc} 2 \mathrm{cc}(\mathrm{OC}) \operatorname{ccc} 2 \mathrm{OC}) \mathrm{ncn} 1$ & 30000 & $*$ \\
\hline 4954 & $\operatorname{CCOC}(=\mathrm{O}) \operatorname{c} 1 \operatorname{ccc}(\mathrm{Nc} 2 \mathrm{cc}(\mathrm{NC}(=\mathrm{O}) \mathrm{CCC}(=\mathrm{O}) \mathrm{O}) \mathrm{ncn} 2) \operatorname{cc} 1$ & 30000 & $*$ \\
\hline 4955 & $\mathrm{O}=\mathrm{C}(\mathrm{O}) \mathrm{CCCC}(=\mathrm{O}) \mathrm{Nc} 1 \mathrm{cc}(\mathrm{Nc} 2 \operatorname{cccc} 2 \mathrm{Br}) \mathrm{ncn} 1$ & 30000 & $*$ \\
\hline 4956 & $\mathrm{Clc} 1 \mathrm{ccc}(\mathrm{Nc} 2 \mathrm{cc}(\mathrm{Nc} 3 \mathrm{ccc}(\mathrm{Cl}) \mathrm{cc} 3) \mathrm{ncn} 2) \mathrm{cc} 1$ & 30000 & $*$ \\
\hline 4957 & $\mathrm{Clc} 1 \mathrm{ccc}(\mathrm{Nc} 2 \mathrm{cc}(\mathrm{Nc} 3 \mathrm{ccc} 4 \mathrm{cn}[\mathrm{nH}] \mathrm{c} 4 \mathrm{c} 3) \mathrm{ncn} 2) \mathrm{cc} 1$ & 30000 & $*$ \\
\hline 4958 & $\mathrm{O}=\mathrm{C}(\mathrm{Nc} 1 \mathrm{cc}(\mathrm{Nc} 2 \mathrm{ccc}(\mathrm{Cl}) \mathrm{cc} 2) \mathrm{ncn} 1) \mathrm{c} 1 \mathrm{ccccc} 1$ & 30000 & $*$ \\
\hline 4959 & $\mathrm{CCOc} 1 \operatorname{ccc}(\mathrm{Nc} 2 \mathrm{cc}(\mathrm{NC}(=\mathrm{O}) \mathrm{C}=\mathrm{Cc} 3 \operatorname{ccccc} 3) \mathrm{ncn} 2) \mathrm{cc} 1$ & 30000 & $*$ \\
\hline 4960 & $\operatorname{COc} 1 \operatorname{ccc}(\mathrm{Nc} 2 \mathrm{cc}(\mathrm{NC}(=\mathrm{O}) \mathrm{C}=\mathrm{Cc} 3 \operatorname{ccc} c 3) \mathrm{ncn} 2) \mathrm{c} 1$ & 30000 & $*$ \\
\hline 4961 & $\operatorname{COc} 1 \operatorname{ccc}(\mathrm{Nc} 2 \operatorname{cc}(\mathrm{NC}(=\mathrm{O}) \mathrm{C}=\mathrm{Cc} 3 \operatorname{ccccc} 3) \operatorname{ncn} 2) \mathrm{c}([\mathrm{N}+](=\mathrm{O})[\mathrm{O}-]) \mathrm{c} 1$ & 30000 & $*$ \\
\hline 4962 & $\mathrm{O}=\mathrm{C}(\mathrm{C}=\mathrm{Cc} 1 \mathrm{cccc} 1) \mathrm{Nc} 1 \mathrm{cc}(\mathrm{Nc} 2 \mathrm{ccc}(\mathrm{O}) \mathrm{cc} 2) \mathrm{ncn} 1$ & 30000 & $*$ \\
\hline 4963 & $\mathrm{O}=\mathrm{C}(/ \mathrm{C}=\mathrm{C} / \mathrm{c} 1 \mathrm{ccc}(\mathrm{F}) \mathrm{cc} 1 \mathrm{Br}) \mathrm{Nc} 1 \mathrm{cc}(\mathrm{Nc} 2 \mathrm{ccc}(\mathrm{Cl}) \mathrm{cc} 2 \mathrm{Cl}) \mathrm{ncn} 1$ & 30000 & $*$ \\
\hline 4964 & $\operatorname{COc} 1 \operatorname{ccc}(\mathrm{Nc} 2 \mathrm{cc}(\mathrm{NC}(=\mathrm{O}) / \mathrm{C}=\mathrm{C} / \mathrm{c} 3 \operatorname{ccc}(\mathrm{F}) \operatorname{cc} 3 \mathrm{Br}) \operatorname{ncn} 2) \mathrm{c}([\mathrm{N}+](=\mathrm{O})[\mathrm{O}-]) \mathrm{c} 1$ & 30000 & $*$ \\
\hline 4965 & $\mathrm{O}=\mathrm{C}(/ \mathrm{C}=\mathrm{C} / \mathrm{c} 1 \mathrm{ccc}(\mathrm{F}) \mathrm{cc} 1 \mathrm{Br}) \mathrm{Nc} 1 \mathrm{cc}(\mathrm{Nc} 2 \mathrm{ccc}(\mathrm{N} 3 \mathrm{CCOCC} 3) \mathrm{cc} 2) \mathrm{ncn} 1$ & 30000 & $*$ \\
\hline 4966 & $\mathrm{CN} 1 \mathrm{CCN}(\mathrm{c} 2 \mathrm{ccc}(\mathrm{Nc} 3 \mathrm{cc}(\mathrm{NC}(=\mathrm{O}) / \mathrm{C}=\mathrm{C} / \mathrm{c} 4 \mathrm{ccc}(\mathrm{F}) \mathrm{cc} 4) \mathrm{ncn} 3) \mathrm{cc} 2) \mathrm{CC} 1$ & 30000 & $*$ \\
\hline 4967 & $\operatorname{COc} 1 \operatorname{ccc}(/ \mathrm{C}=\mathrm{C} / \mathrm{C}(=\mathrm{O}) \mathrm{Nc} 2 \mathrm{cc}(\mathrm{Nc} 3 \operatorname{cccc}(\mathrm{Br}) \mathrm{c} 3) \mathrm{ncn} 2) \mathrm{cc} 1$ & 30000 & $*$ \\
\hline 4968 & $\mathrm{CCOc} 1 \mathrm{ccc}(\mathrm{Nc} 2 \mathrm{cc}(\mathrm{NC}(=\mathrm{O}) / \mathrm{C}=\mathrm{C} / \mathrm{c} 3 \operatorname{ccc}(\mathrm{OC}) \operatorname{cc} 3) \mathrm{ncn} 2) \mathrm{cc} 1$ & 30000 & $*$ \\
\hline 4969 & $\operatorname{COc} 1 \operatorname{ccc}(/ \mathrm{C}=\mathrm{C} / \mathrm{C}(=\mathrm{O}) \mathrm{Nc} 2 \mathrm{cc}(\mathrm{N} 3 \mathrm{CCOCC} 3) \mathrm{ncn} 2) \mathrm{cc} 1$ & 30000 & $*$ \\
\hline 4970 & $\mathrm{Clc} 1 \mathrm{ccc}(\mathrm{Nc} 2 \mathrm{cc}(\mathrm{Nc} 3 \mathrm{ccc}(\mathrm{Cl}) \mathrm{c} 3) \mathrm{ncn} 2) \mathrm{cc} 1$ & 30000 & $*$ \\
\hline
\end{tabular}




\begin{tabular}{|c|c|c|c|}
\hline 4971 & $\operatorname{CCOC}(=\mathrm{O}) \mathrm{c} 1 \mathrm{ccc}(\mathrm{Nc} 2 \mathrm{cc}(\mathrm{Nc} 3 \mathrm{ccc}(\mathrm{C}(=\mathrm{O}) \mathrm{OCC}) \mathrm{cc} 3) \mathrm{ncn} 2) \mathrm{cc} 1$ & 30000 & $*$ \\
\hline 4972 & $\operatorname{CCOC}(=\mathrm{O}) \mathrm{CCC}(=\mathrm{O}) \mathrm{Nc} 1 \mathrm{cc}(\mathrm{Nc} 2 \mathrm{ccc}(\mathrm{N} 3 \mathrm{CCN}(\mathrm{C}) \mathrm{CC} 3) \mathrm{cc} 2) \mathrm{ncn} 1$ & 30000 & $*$ \\
\hline 4973 & $\mathrm{COc} 1 \mathrm{cc} 2 \mathrm{c}(\mathrm{cc} 1 \mathrm{OC}) \mathrm{Sc} 1 \mathrm{nc}(\mathrm{C}) \mathrm{nc}(\mathrm{Nc} 3 \mathrm{cccc}(\mathrm{Br}) \mathrm{c} 3) \mathrm{c} 1 \mathrm{NC} 2$ & 30700 & 4.51 \\
\hline 4974 & $\mathrm{CC}(\mathrm{C})(\mathrm{C}) \mathrm{ONC}(=\mathrm{O}) \mathrm{Cc} 1 \mathrm{cc}(/ \mathrm{N}=\mathrm{C} / \mathrm{c} 2 \mathrm{cc}(\mathrm{O}) \mathrm{ccc} 2 \mathrm{O}) \mathrm{ccc} 1 \mathrm{O}$ & 31000 & $*$ \\
\hline 4975 & $\operatorname{COC}(=\mathrm{O}) \mathrm{c} 1 \mathrm{c}(\mathrm{OCCN}(\mathrm{C}) \mathrm{C}) \mathrm{c} 2 \mathrm{cccc} 2 \mathrm{c} 2 \mathrm{oc} 3 \mathrm{c}(\mathrm{c} 12) \mathrm{C}(=\mathrm{O}) \mathrm{c} 1 \mathrm{cccc} 1 \mathrm{C} 3=\mathrm{O}$ & 31000 & $*$ \\
\hline 4976 & $\operatorname{cOc} 1 \mathrm{cc} 2 \mathrm{nccc}(\mathrm{Oc} 3 \operatorname{ccc}(\mathrm{C}(=\mathrm{O}) \mathrm{c} 4 \mathrm{ccc}(\mathrm{Cl}) \mathrm{c}(\mathrm{Cl}) \mathrm{c} 4) \mathrm{cc} 3) \mathrm{c} 2 \mathrm{cc} 1 \mathrm{OC}$ & 31000 & $*$ \\
\hline 4977 & $\mathrm{Cc} 1 \mathrm{ccc}(\mathrm{C}(=\mathrm{O}) \mathrm{Nc} 2 \mathrm{ccc}(\mathrm{Cl}) \operatorname{cc} 2 \mathrm{Cl}) \mathrm{c}(\mathrm{O}) \mathrm{c} 1$ & 31090 & $*$ \\
\hline 4978 & $\operatorname{CCCCN}(\mathrm{CCCC}) \mathrm{C}(=\mathrm{O}) \mathrm{c} 1 \mathrm{ccc}(\mathrm{N}(\mathrm{CCCl}) \mathrm{CCCl}) \mathrm{cc} 1$ & 31180 & 4.51 \\
\hline 4979 & $\mathrm{COc} 1 \operatorname{cccc}(/ \mathrm{C}=\mathrm{N} / \mathrm{NC} 2=\mathrm{NC}(=\mathrm{O}) \mathrm{CS} 2) \mathrm{c} 1$ & 31250 & 4.51 \\
\hline 4980 & $\mathrm{O}=\mathrm{C} 1 \mathrm{~N}=\mathrm{C}(\mathrm{N} 2 \mathrm{CCC}[\mathrm{C} @ \mathrm{H}] 2 \mathrm{C}(=\mathrm{O}) \mathrm{Nc} 2 \mathrm{ccc} 3 \mathrm{ncnc}(\mathrm{Nc} 4 \operatorname{cccc}(\mathrm{Cl}) \mathrm{c} 4) \mathrm{c} 3 \mathrm{c} 2) \mathrm{S} / \mathrm{C} 1=\mathrm{C} / \mathrm{c} 1 \mathrm{ccc}(\mathrm{Br}) \mathrm{s} 1$ & 31400 & $*$ \\
\hline 4981 & $\mathrm{CC}(\mathrm{C})(\mathrm{C}) \mathrm{NC}(=\mathrm{O}) \mathrm{c} 1 \mathrm{ccc}(\mathrm{N}(\mathrm{CCCl}) \mathrm{CCCl}) \mathrm{cc} 1$ & 31430 & 4.50 \\
\hline 4982 & $\mathrm{CCCCN}(\mathrm{Cc} 1 \mathrm{cc}(\mathrm{Br}) \mathrm{cc}(\mathrm{Br}) \mathrm{c} 1 \mathrm{O}) \mathrm{C}(=\mathrm{S}) \mathrm{Nc} 1 \mathrm{cccc} 1$ & 31940 & 4.50 \\
\hline 4983 & $\operatorname{COc} 1 \operatorname{cccc} 1 / \mathrm{C}=\mathrm{C} / \mathrm{C}(=\mathrm{O}) \mathrm{OCCn} 1 \mathrm{c}([\mathrm{N}+](=\mathrm{O})[\mathrm{O}-]) \operatorname{cnc} 1 \mathrm{C}$ & 32000 & 4.49 \\
\hline 4984 & $\mathrm{~N} \# \mathrm{CCc} 1 \mathrm{c}(\mathrm{SSc} 2[\mathrm{nH}] \mathrm{c} 3 \operatorname{ccccc} 3 \mathrm{c} 2 \mathrm{CC} \# \mathrm{~N})[\mathrm{nH}] \mathrm{c} 2 \mathrm{ccccc} 12$ & 32000 & $*$ \\
\hline 4985 & $\mathrm{COc} 1 \mathrm{cc}(\mathrm{C} 2=\mathrm{C}(\mathrm{c} 3 \mathrm{c}[\mathrm{nH}] \mathrm{c} 4 \mathrm{cccc} 34) \mathrm{C}(=\mathrm{O}) \mathrm{NC} 2=\mathrm{O}) \mathrm{cc}(\mathrm{OC}) \mathrm{c} 1 \mathrm{OC}$ & 32000 & $*$ \\
\hline 4986 & $\operatorname{CCCCN}(\operatorname{Cc} 1 \operatorname{cccc}(\mathrm{Cl}) \mathrm{c} 1 \mathrm{O}) \mathrm{C}(=\mathrm{O}) \mathrm{Nc} 1 \mathrm{ccccc} 1$ & 32120 & 4.49 \\
\hline 4987 & $\mathrm{Cc} 1 \mathrm{nn}(-\mathrm{c} 2 \operatorname{cccc} 2) \mathrm{c}(\mathrm{Cl}) \mathrm{c} 1 \mathrm{C} 1 \mathrm{C}(\mathrm{CHN})=\mathrm{C}(\mathrm{N}) \mathrm{N}(\mathrm{c} 2 \mathrm{cccnc} 2) \mathrm{C} 2=\mathrm{C} 1 \mathrm{C}(=\mathrm{O}) \mathrm{CC}(\mathrm{C})(\mathrm{C}) \mathrm{C} 2$ & 32130 & 4.49 \\
\hline 4988 & $\operatorname{COc} 1 \operatorname{ccc}(\mathrm{CC}(=\mathrm{O}) \mathrm{NS}(=\mathrm{O})(=\mathrm{O}) \mathrm{c} 2 \operatorname{ccc}(\mathrm{Cl}) \mathrm{cc} 2) \mathrm{cc} 1$ & 32850 & 4.48 \\
\hline 4989 & $\mathrm{COc} 1 \operatorname{cccc} 1 / \mathrm{C}=\mathrm{C} / \mathrm{C}(=\mathrm{N} / \mathrm{NC}(\mathrm{N})=\mathrm{S}) \operatorname{c} 1 \operatorname{ccccc} 1$ & 33000 & 4.48 \\
\hline 4990 & $\operatorname{COC}(=\mathrm{O}) \mathrm{Cc} 1 \mathrm{c}(\mathrm{SSc} 2 \mathrm{c}(\mathrm{CC}(=\mathrm{O}) \mathrm{OC}) \mathrm{c} 3 \operatorname{ccccc} 3 \mathrm{n} 2 \mathrm{C}) \mathrm{n}(\mathrm{C}) \mathrm{c} 2 \operatorname{ccccc} 12$ & 33000 & $*$ \\
\hline 4991 & $\mathrm{CCOc} 1 \mathrm{cc} 2 \mathrm{ncc}(\mathrm{CHN}) \mathrm{c}(\mathrm{Nc} 3 \operatorname{ccc}(\mathrm{Br}) \mathrm{c} 3) \mathrm{c} 2 \mathrm{cc} 1 \mathrm{OC}$ & 33020 & $*$ \\
\hline 4992 & $\mathrm{C}=\mathrm{CC}(=\mathrm{O}) \mathrm{Nc} 1 \mathrm{ccc}(\mathrm{Nc} 2 \mathrm{ncc} 3 \mathrm{ncc}(=\mathrm{O}) \mathrm{n}(-\mathrm{c} 4 \mathrm{ccc}(\mathrm{OC}) \mathrm{cc} 4) \mathrm{c} 3 \mathrm{n} 2) \mathrm{cc} 1$ & 33885 & 4.47 \\
\hline 4993 & $\mathrm{Cn} 1 \mathrm{nc}(-\mathrm{c} 2 \mathrm{ccc} 3 \mathrm{nccc} 3 \mathrm{c} 2) \mathrm{c} 2 \mathrm{c}(\mathrm{N}) \mathrm{ncnc} 21$ & 34000 & $*$ \\
\hline 4994 & $\mathrm{Cc} 1 \mathrm{ccc}(-\mathrm{c} 2 \mathrm{nnn}(\mathrm{SCc} 3 \operatorname{cccc} 3) \mathrm{o} 2) \mathrm{c}(\mathrm{O}) \mathrm{c} 1$ & 34250 & 4.47 \\
\hline 4995 & $\mathrm{CC}(=\mathrm{O}) \mathrm{c} 1 \operatorname{cccc} 1 \mathrm{C}(=\mathrm{O}) \mathrm{Nn} 1 \mathrm{c}(-\mathrm{c} 2 \operatorname{cccc} 2) \mathrm{nc} 2 \operatorname{cc}(\mathrm{Cl}) \operatorname{ccc} 2 \mathrm{c} 1=\mathrm{O}$ & 34320 & 4.46 \\
\hline 4996 & $\mathrm{NS}(=\mathrm{O})(=\mathrm{O}) \mathrm{c} 1 \mathrm{ccc}(\mathrm{Nc} 2 \mathrm{nc}(\mathrm{Cl}) \mathrm{nc} 3 \mathrm{cc} 4 \mathrm{c}(\mathrm{cc} 23) \mathrm{OCO} 4) \mathrm{cc} 1$ & 34600 & $*$ \\
\hline 4997 & $\mathrm{Cc} 1 \mathrm{ccc}(\mathrm{NC}(=\mathrm{O}) \mathrm{c} 2 \mathrm{ccc}(\mathrm{C}) \mathrm{cc} 2 \mathrm{O}) \mathrm{cc} 1$ & 34670 & $*$ \\
\hline 4998 & $\mathrm{O}=\mathrm{C}(\mathrm{O}) \mathrm{Cc} 1 \mathrm{cc}(/ \mathrm{N}=\mathrm{C} / \mathrm{c} 2 \mathrm{cc}(\mathrm{O}) \operatorname{ccc} 2 \mathrm{O}) \operatorname{ccc} 1 \mathrm{O}$ & 35000 & $*$ \\
\hline 4999 & $\operatorname{COC}(=\mathrm{O}) \mathrm{Cc} 1 \mathrm{c}(\mathrm{SSSc} 2[\mathrm{nH}] \mathrm{c} 3 \operatorname{cccc} 3 \mathrm{c} 2 \mathrm{CC}(=\mathrm{O}) \mathrm{OC})[\mathrm{nH}] \mathrm{c} 2 \operatorname{ccccc} 12$ & 35000 & $*$ \\
\hline 5000 & $\mathrm{Nc} 1 \mathrm{ncnc} 2 \mathrm{c} 1 \mathrm{ncn} 2 \mathrm{CC}(=\mathrm{O}) \mathrm{c} 1 \mathrm{c}[\mathrm{nH}] \mathrm{c} 2 \mathrm{ccccc} 12$ & 35000 & $*$ \\
\hline 5001 & $\operatorname{COc} 1 \mathrm{cc} 2 \mathrm{nccc}(\mathrm{Oc} 3 \operatorname{ccc}([\mathrm{N}+](=\mathrm{O})[\mathrm{O}-]) \mathrm{c} 3) \mathrm{c} 2 \mathrm{cc} 1 \mathrm{OC}$ & 35000 & $*$ \\
\hline 5002 & $\mathrm{O}=\mathrm{C}(\mathrm{NC} 1 \mathrm{CCCC} 1) \mathrm{c} 1 \mathrm{ccc}(\mathrm{N}(\mathrm{CCCl}) \mathrm{CCCl}) \mathrm{cc} 1$ & 35290 & 4.45 \\
\hline 5003 & $\mathrm{CC}(=\mathrm{O}) \mathrm{Nc} 1 \operatorname{ccc}(\mathrm{S}(=\mathrm{O})(=\mathrm{O}) \mathrm{Nc} 2 \mathrm{nc} 3 \operatorname{cccc} 3 \mathrm{nc} 2 \mathrm{Nc} 2 \operatorname{ccc}(\mathrm{C}(=\mathrm{O}) \mathrm{O}) \mathrm{cc} 2) \mathrm{cc} 1$ & 35800 & $*$ \\
\hline 5004 & $\mathrm{O}=\mathrm{C} 1 \mathrm{CSC}(\mathrm{NN}=\mathrm{C} 2 \mathrm{CCCCCC} 2)=\mathrm{N} 1$ & 36000 & 4.44 \\
\hline 5005 & $\mathrm{COc} 1 \mathrm{cc} 2 \mathrm{nc}(\mathrm{Cl}) \mathrm{nc}(\mathrm{Nc} 3 \mathrm{ccc}(\mathrm{N}(\mathrm{C}) \mathrm{C}) \mathrm{cc} 3) \mathrm{c} 2 \mathrm{cc} 1 \mathrm{OC}$ & 36000 & $*$ \\
\hline 5006 & $\mathrm{Cn} 1 \mathrm{ncc} 2 \mathrm{c}(\mathrm{Nc} 3 \mathrm{cccc}(\mathrm{F}) \mathrm{c} 3) \mathrm{nc}(\mathrm{N}(\mathrm{CCO}) \mathrm{CCO}) \mathrm{nc} 21$ & 36300 & $*$ \\
\hline 5007 & $\mathrm{Cn} 1 \mathrm{ncc} 2 \mathrm{c}(\mathrm{NCc} 3 \mathrm{cccc}(\mathrm{Br}) \mathrm{c} 3) \mathrm{nc}(\mathrm{NCCO}) \mathrm{nc} 21$ & 36300 & $*$ \\
\hline 5008 & $\operatorname{CCCCN}(\mathrm{Cc} 1 \mathrm{cccc}(\mathrm{Br}) \mathrm{c} 1 \mathrm{O}) \mathrm{C}(=\mathrm{O}) \mathrm{Nc} 1 \mathrm{ccccc} 1$ & 36880 & 4.43 \\
\hline 5009 & $\mathrm{~N} \# \mathrm{CC}(\mathrm{CHN})=\mathrm{Cc} 1 \mathrm{cc}(\mathrm{O}) \mathrm{cc}(\mathrm{O}) \mathrm{c} 1$ & 37000 & $*$ \\
\hline 5010 & $\mathrm{C}[\mathrm{C} @ @ \mathrm{H}](\mathrm{O}) \mathrm{c} 1 \mathrm{c}(\mathrm{O}) \mathrm{cc} 2 \mathrm{c}(\mathrm{c} 1 \mathrm{O}) \mathrm{C}(=\mathrm{O}) \mathrm{c} 1 \mathrm{c}(\mathrm{O}) \mathrm{cc}(\mathrm{O}) \mathrm{cc} 1 \mathrm{C} 2=\mathrm{O}$ & 37500 & $*$ \\
\hline 5011 & $\mathrm{COc} 1 \mathrm{cc} 2 \mathrm{nc}(\mathrm{Cl}) \mathrm{nc}(\mathrm{Nc} 3 \mathrm{ccc}(\mathrm{NC}(\mathrm{C})=\mathrm{O}) \mathrm{cc} 3) \mathrm{c} 2 \mathrm{cc} 1 \mathrm{OC}$ & 37600 & $*$ \\
\hline 5012 & $\mathrm{O}=\mathrm{C}(\mathrm{Cc} 1 \mathrm{c}(\mathrm{SSc} 2[\mathrm{nH}] \mathrm{c} 3 \operatorname{cccc} 3 \mathrm{c} 2 \mathrm{CC}(=\mathrm{O}) \mathrm{NCc} 2 \operatorname{ccc} c \mathrm{2})[\mathrm{nH}] \mathrm{c} 2 \operatorname{ccccc} 12) \mathrm{NCc} 1 \operatorname{ccccc} 1$ & 38000 & $*$ \\
\hline 5013 & $\mathrm{O}=[\mathrm{N}+]([\mathrm{O}-]) \mathrm{c} 1 \mathrm{ccccc} 1-\mathrm{c} 1 \mathrm{nn} \mathrm{c}(\mathrm{SCc} 2 \mathrm{ccccc} 2) \mathrm{o} 1$ & 38320 & 4.42 \\
\hline
\end{tabular}




\begin{tabular}{|c|c|c|c|}
\hline 5014 & CCOc1 $1 \mathrm{ccc} 1-\mathrm{c} 1 \mathrm{nnn}(\mathrm{SCc} 2 \mathrm{cccc} 2) \mathrm{o} 1$ & 38430 & 4.42 \\
\hline 5015 & $\operatorname{CCCCCCCCCCCCNC}(=\mathrm{O}) / \mathrm{C}=\mathrm{C} / \mathrm{c} 1 \operatorname{ccccc} 1$ & 38460 & $*$ \\
\hline 5016 & $\operatorname{COc} 1 \operatorname{ccc}(\mathrm{CC}(=\mathrm{O}) \mathrm{NS}(=\mathrm{O})(=\mathrm{O}) \mathrm{c} 2 \operatorname{ccc}(\mathrm{C}) \operatorname{cc} 2) \operatorname{cc} 1$ & 38520 & 4.41 \\
\hline 5017 & $\mathrm{Cc} 1 \mathrm{ccc}(\mathrm{C} 2=\mathrm{NN}(\mathrm{C}(=\mathrm{O}) \mathrm{Cc} 3 \mathrm{nc} 4 \operatorname{cccc} 4[\mathrm{nH}] 3) \mathrm{C}(\mathrm{c} 3 \operatorname{ccc}(\mathrm{Br}) \operatorname{cc} 3) \mathrm{C} 2) \mathrm{cc} 1$ & 39700 & $*$ \\
\hline 5018 & $\operatorname{COc} 1 \operatorname{ccc}(\mathrm{NC}(=\mathrm{O}) \operatorname{c} 2 \operatorname{ccc} 2 \mathrm{O}) \operatorname{cc} 1$ & 39980 & $*$ \\
\hline 5019 & $\mathrm{~N} \# \mathrm{CC}(\mathrm{C} \# \mathrm{~N})=\mathrm{Cc} 1 \mathrm{ccc}(\mathrm{O}) \mathrm{c}(\mathrm{O}) \mathrm{c} 1$ & 40000 & $*$ \\
\hline 5020 & $\mathrm{~N} \# \mathrm{CC}(\mathrm{C \# N})=\mathrm{C} 1 \mathrm{C}(=\mathrm{O}) \mathrm{Nc} 2 \mathrm{ccc}([\mathrm{N}+](=\mathrm{O})[\mathrm{O}-]) \operatorname{cc} 21$ & 40000 & $*$ \\
\hline 5021 & $\mathrm{C}[\mathrm{C} @ @ \mathrm{H}](\mathrm{NC}(=\mathrm{O}) \mathrm{c} 1 \mathrm{ccc}(\mathrm{S}(=\mathrm{O})(=\mathrm{O}) \mathrm{Oc} 2 \mathrm{ccc}(/ \mathrm{C}=\mathrm{C} /[\mathrm{N}+](=\mathrm{O})[\mathrm{O}-]) \mathrm{cc} 2) \mathrm{cc} 1) \mathrm{C}(=\mathrm{O}) \mathrm{N}[\mathrm{C} @ \mathrm{H}](\mathrm{C}) \mathrm{C}(=\mathrm{O}) \mathrm{OC}(\mathrm{C})(\mathrm{C}) \mathrm{C}$ & 40000 & $*$ \\
\hline 5022 & $\mathrm{COc} 1 \mathrm{cc} 2 \mathrm{nccc}(\mathrm{Oc} 3 \mathrm{cccc}(\mathrm{N}) \mathrm{c} 3) \mathrm{c} 2 \mathrm{cc} 1 \mathrm{OC}$ & 40000 & * \\
\hline 5023 & $\mathrm{Cc} 1 \mathrm{ccc}(\mathrm{C}(=\mathrm{O}) \mathrm{Nc} 2 \mathrm{ccc}(\mathrm{F}) \mathrm{cc} 2) \mathrm{c}(\mathrm{O}) \mathrm{c} 1$ & 40170 & $*$ \\
\hline 5024 & $\mathrm{Cn} 1 \mathrm{c}(\mathrm{SSc} 2 \mathrm{c}(\mathrm{C}(=\mathrm{O}) \mathrm{Nc} 3 \operatorname{ccc} c 3) \mathrm{c} 3 \operatorname{cc}(\mathrm{O}) \operatorname{ccc} 3 \mathrm{n} 2 \mathrm{C}) \mathrm{c}(\mathrm{C}(=\mathrm{O}) \mathrm{Nc} 2 \operatorname{cccc} 2) \mathrm{c} 2 \mathrm{cc}(\mathrm{O}) \operatorname{ccc} 21$ & 40500 & * \\
\hline 5025 & $\mathrm{O}=\mathrm{C} 1 \mathrm{CSC}(\mathrm{NN}=\mathrm{C} 2 \mathrm{CCCCC} 2)=\mathrm{N} 1$ & 41000 & 4.39 \\
\hline 5026 & $\mathrm{CO}[\mathrm{C} @ \mathrm{H}](\mathrm{C}) \mathrm{c} 1 \mathrm{c}(\mathrm{O}) \mathrm{cc} 2 \mathrm{c}(\mathrm{c} 1 \mathrm{O}) \mathrm{C}(=\mathrm{O}) \mathrm{c} 1 \mathrm{c}(\mathrm{cc}(\mathrm{O}) \mathrm{c}(\mathrm{O}) \mathrm{c} 1 \mathrm{O}) \mathrm{C} 2=\mathrm{O}$ & 41000 & $*$ \\
\hline 5027 & $\mathrm{O}=\mathrm{C}(\mathrm{Cc} 1 \mathrm{nc} 2 \operatorname{ccccc} 2[\mathrm{nH}] 1) \mathrm{N} 1 \mathrm{~N}=\mathrm{C}(\mathrm{c} 2 \mathrm{ccc}(\mathrm{O}) \operatorname{cc} 2) \mathrm{CC} 1 \mathrm{c} 1 \mathrm{ccc}(\mathrm{Cl}) \mathrm{cc} 1$ & 41000 & $*$ \\
\hline 5028 & $\mathrm{O}=\mathrm{C}(\mathrm{Nc} 1 \mathrm{ccc}(\mathrm{Cl}) \mathrm{cc} 1) \mathrm{c} 1 \mathrm{cccc} 1 \mathrm{O}$ & 41760 & $*$ \\
\hline 5029 & $\mathrm{Oc} 1 \mathrm{ccc}(\mathrm{NCc} 2 \mathrm{cc}(\mathrm{O}) \operatorname{ccc} 2 \mathrm{O}) \mathrm{cc} 1$ & 41900 & $*$ \\
\hline 5030 & $\operatorname{COc} 1 \mathrm{cc} 2 \mathrm{nccc}(\mathrm{Oc} 3 \operatorname{ccc}(\mathrm{C}(=\mathrm{O}) \mathrm{c} 4 \mathrm{cccc} 4 \mathrm{C}) \mathrm{cc} 3) \mathrm{c} 2 \mathrm{cc} 1 \mathrm{OC}$ & 43000 & $*$ \\
\hline 5031 & $\operatorname{CCCCN}(\mathrm{Cc} 1 \mathrm{cccc}(\mathrm{C}) \mathrm{c} 1 \mathrm{O}) \mathrm{C}(=\mathrm{S}) \mathrm{Nc} 1 \mathrm{ccccc} 1$ & 43210 & 4.36 \\
\hline 5032 & $\mathrm{Cn} 1 \mathrm{c}(\mathrm{SSc} 2 \mathrm{c}(\mathrm{C}(=\mathrm{O}) \mathrm{Nc} 3 \operatorname{ccc} c 3) \operatorname{c} 3 \operatorname{ccc}(\mathrm{O}) \operatorname{cc} 3 \mathrm{n} 2 \mathrm{C}) \mathrm{c}(\mathrm{C}(=\mathrm{O}) \mathrm{Nc} 2 \operatorname{cccc} 2) \operatorname{coc} c(\mathrm{O}) \operatorname{cc} 21$ & 44000 & $*$ \\
\hline 5033 & $\operatorname{COC}(=\mathrm{O}) \operatorname{c} 1 \operatorname{ccc}(\mathrm{CNC}(=\mathrm{O}) \mathrm{CCc} 2 \mathrm{c}(\mathrm{SSc} 3[\mathrm{nH}] \mathrm{c} 4 \operatorname{ccc} c 4 \mathrm{c} 3 \mathrm{CCC}(=\mathrm{O}) \mathrm{NC} 3 \operatorname{ccc}(\mathrm{C}(=\mathrm{O}) \mathrm{OC}) \operatorname{cc} 3)[\mathrm{nH}] \mathrm{c} 3 \operatorname{ccc} 23) \operatorname{cc} 1$ & 44000 & $*$ \\
\hline 5034 & $\mathrm{CC}(\mathrm{O}) \mathrm{C}(\mathrm{N}=\mathrm{C} 1 / \mathrm{C}=\mathrm{C}(\mathrm{O}) / \mathrm{C}(=\mathrm{N} \backslash \mathrm{C}(\mathrm{C}(=\mathrm{O}) \mathrm{O}) \mathrm{C}(\mathrm{C}) \mathrm{O}) \mathrm{C}=\mathrm{C} 1 \mathrm{O}) \mathrm{C}(=\mathrm{O}) \mathrm{O}$ & 44000 & * \\
\hline 5035 & $\mathrm{COc} 1 \mathrm{ccc}(\mathrm{Oc} 2 \mathrm{ccnc} 3 \mathrm{cc}(\mathrm{OC}) \mathrm{c}(\mathrm{OC}) \mathrm{cc} 23) \mathrm{cc} 1$ & 44000 & $*$ \\
\hline 5036 & $\operatorname{NCCCNC}(=\mathrm{O}) \mathrm{c} 1 \mathrm{cccc}(\mathrm{Nc} 2 \mathrm{nccc}(-\mathrm{c} 3 \operatorname{ccc} n \mathrm{c} 3) \mathrm{n} 2) \mathrm{c} 1$ & 45000 & $*$ \\
\hline 5037 & $\mathrm{CC}(\mathrm{C}) \mathrm{n} 1 \mathrm{nc}(-\mathrm{c} 2 \mathrm{ccn} 3 \mathrm{ccnc} 3 \mathrm{c} 2) \mathrm{c} 2 \mathrm{c}(\mathrm{N}) \mathrm{ncnc} 21$ & 45000 & $*$ \\
\hline 5038 & $\mathrm{O}=\mathrm{C}(\mathrm{N} / \mathrm{N}=\mathrm{C} / \mathrm{c} 1 \mathrm{ccc} 1 \mathrm{CCCN} 1 \mathrm{CCCC} 1) \mathrm{Nc} 1 \mathrm{ccc}(\mathrm{Oc} 2 \mathrm{ccnc} 3[\mathrm{nH}] \operatorname{ccc} 23) \mathrm{cc} 1$ & 45000 & $*$ \\
\hline 5039 & $\mathrm{~N} \# \mathrm{Cc} 1 \mathrm{cnc}(\mathrm{Nc} 2 \mathrm{cccc}(\mathrm{Br}) \mathrm{c} 2) \mathrm{c} 2 \mathrm{cc}(\mathrm{NC}(=\mathrm{O}) \mathrm{c} 3 \operatorname{ccoc} 3) \mathrm{ccc} 12$ & 45200 & $*$ \\
\hline 5040 & $\mathrm{O}=\mathrm{C}(\mathrm{Nc} 1 \mathrm{ccc}(\mathrm{Cl}) \mathrm{cc} 1 \mathrm{Cl}) \mathrm{c} 1 \mathrm{cccc} 1 \mathrm{O}$ & 45290 & $*$ \\
\hline 5041 & $\mathrm{Clc} 1 \mathrm{ccc}(\mathrm{Nc} 2 \mathrm{ncc} 3 \mathrm{c}(\mathrm{n} 2)-\mathrm{c} 2 \mathrm{ccc}(\mathrm{Cl}) \mathrm{cc} 2 \mathrm{SC} 3) \mathrm{cc} 1$ & 45700 & 4.34 \\
\hline 5042 & $\mathrm{Cc} 1 \mathrm{ccc}(\mathrm{F}) \mathrm{c}(\mathrm{C}(=\mathrm{O}) \mathrm{n} 2 \mathrm{nc}(\mathrm{Nc} 3 \operatorname{ccc}(\mathrm{S}(\mathrm{N})(=\mathrm{O})=\mathrm{O}) \mathrm{cc} 3) \mathrm{nc} 2 \mathrm{C}) \mathrm{c} 1 \mathrm{~F}$ & 45800 & $*$ \\
\hline 5043 & $\mathrm{COc} 1 \mathrm{cc} 2 \mathrm{c}(\mathrm{cc} 1 \mathrm{OC}) \operatorname{Sc} 1 \mathrm{nc}(\mathrm{C}) \mathrm{nc}(\mathrm{Nc} 3 \mathrm{ccc}(\mathrm{F}) \mathrm{c}(\mathrm{Cl}) \mathrm{c} 3) \mathrm{c} 1 \mathrm{NC} 2$ & 45900 & 4.34 \\
\hline 5044 & $\mathrm{Fc} 1 \mathrm{cccc}(\mathrm{COc} 2 \mathrm{ccc}(\mathrm{Nc} 3 \mathrm{cc}(-\mathrm{c} 4 \mathrm{cccnc} 4) \mathrm{ncn} 3) \mathrm{cc} 2 \mathrm{Cl}) \mathrm{c} 1$ & 47000 & 4.33 \\
\hline 5045 & $\mathrm{~N} \# \mathrm{C} / \mathrm{C}(=\mathrm{C} \mid c 1 \operatorname{ccc}(\mathrm{C}=\mathrm{O}) \operatorname{cc} 1) \mathrm{C}(=\mathrm{O}) \mathrm{O}$ & 47000 & $*$ \\
\hline 5046 & $\mathrm{~N} \# \mathrm{CCC} 1 \mathrm{c}(\mathrm{SSc} 2[\mathrm{nH}] \mathrm{c} 3 \mathrm{cccc} 3 \mathrm{c} 2 \mathrm{CCC} \# \mathrm{~N})[\mathrm{nH}] \mathrm{c} 2 \mathrm{ccccc} 12$ & 47000 & $*$ \\
\hline 5047 & $\operatorname{COc} 1 \mathrm{cc}(/ \mathrm{C}=\mathrm{C}(\mathrm{C} \# \mathrm{~N}) \mathrm{C}(\mathrm{N})=\mathrm{O}) \operatorname{cc}(\operatorname{SCCCC}(=\mathrm{O}) \mathrm{O}) \mathrm{c} 1 \mathrm{O}$ & 47863.01 & $*$ \\
\hline 5048 & $\mathrm{Cc} 1 \mathrm{c}(\mathrm{C \# N}) \mathrm{c}(\mathrm{NCCO}) \mathrm{nc} 2 \mathrm{nc}(\mathrm{NCCO}) \mathrm{nc}(\mathrm{N}) \mathrm{c} 12$ & 47900 & $*$ \\
\hline 5049 & $\mathrm{CC} 1=\mathrm{C}(\mathrm{C}(=\mathrm{O}) \mathrm{Nc} 2 \operatorname{ccc}([\mathrm{N}+](=\mathrm{O})[\mathrm{O}-]) \mathrm{c} 2) \mathrm{C}(\mathrm{c} 2 \mathrm{ccc}(\mathrm{O}) \operatorname{cc} 2 \mathrm{O}) \mathrm{NC}(\mathrm{NN})=\mathrm{N} 1$ & 47900 & $*$ \\
\hline 5050 & $\mathrm{CC}(\mathrm{C}) \mathrm{n} 1 \mathrm{ncc} 2 \mathrm{c}(\mathrm{NCc} 3 \mathrm{cccc} 3) \mathrm{nc}(\mathrm{NCCO}) \mathrm{nc} 21$ & 47900 & $*$ \\
\hline 5051 & $\mathrm{Cn} 1 \mathrm{ncc} 2 \mathrm{c}(\mathrm{NCc} 3 \mathrm{cccc}(\mathrm{Br}) \mathrm{c} 3) \mathrm{nc}(\mathrm{N}(\mathrm{CCO}) \mathrm{CCO}) \mathrm{nc} 21$ & 47900 & $*$ \\
\hline 5052 & $\mathrm{COc} 1 \mathrm{cc} 2 \mathrm{ncc}(\mathrm{C \# N}) \mathrm{c}(\mathrm{Nc} 3 \mathrm{ccc}(\mathrm{F}) \mathrm{cc} 3) \mathrm{c} 2 \mathrm{cc} 1 \mathrm{OC}$ & 47940 & $*$ \\
\hline 5053 & $\mathrm{COc} 1 \mathrm{cc} 2 \mathrm{nccc}(\mathrm{Oc} 3 \operatorname{ccc}(\mathrm{NC}(=\mathrm{O}) \mathrm{c} 4 \mathrm{ccc}(\mathrm{Br}) \mathrm{cc} 4) \mathrm{cc} 3) \mathrm{c} 2 \mathrm{cc} 1 \mathrm{OC}$ & 48000 & $*$ \\
\hline 5054 & $\mathrm{O}=\mathrm{C}(\mathrm{Cc} 1 \mathrm{ccc}(\mathrm{F}) \mathrm{cc} 1) \mathrm{Nc} 1 \mathrm{cc}(\mathrm{SC}[\mathrm{C} @ @ \mathrm{H}](\mathrm{O}) \mathrm{CO}) \mathrm{cc}([\mathrm{N}+](=\mathrm{O})[\mathrm{O}-]) \mathrm{c} 1$ & 48600 & 4.31 \\
\hline 5055 & $\mathrm{COc} 1 \mathrm{cc}(\mathrm{OC}) \mathrm{cc}(\mathrm{Oc} 2 \mathrm{ccnc} 3 \mathrm{cc}(\mathrm{OC}) \mathrm{c}(\mathrm{OC}) \mathrm{cc} 23) \mathrm{c} 1$ & 49000 & $*$ \\
\hline 5056 & $\operatorname{CCOC}(=\mathrm{O}) \mathrm{c} 1 \mathrm{cc}(/ \mathrm{N}=\mathrm{C} / \mathrm{c} 2 \mathrm{cc}(\mathrm{O}) \operatorname{ccc} 2 \mathrm{O}) \operatorname{ccc} 1 \mathrm{O}$ & 50000 & $*$ \\
\hline
\end{tabular}




\begin{tabular}{|c|c|c|c|}
\hline 5057 & $\mathrm{O}=\mathrm{C}(\mathrm{Cc} 1 \mathrm{cc}(/ \mathrm{N}=\mathrm{C} / \mathrm{c} 2 \mathrm{cc}(\mathrm{O}) \operatorname{ccc} 2 \mathrm{O}) \operatorname{ccc} 1 \mathrm{O}) \mathrm{NOC} 1 \mathrm{cccc} 1$ & 50000 & $*$ \\
\hline 5058 & $\mathrm{CCN}(\mathrm{CC}) \mathrm{c} 1 \mathrm{ccc}(\mathrm{Nc} 2 \mathrm{cc} 3 \mathrm{c}(\mathrm{cc} 2 \mathrm{Nc} 2 \mathrm{ccc}(\mathrm{N}(\mathrm{CC}) \mathrm{CC}) \mathrm{cc} 2) \mathrm{C}(=\mathrm{O}) \mathrm{NC} 3=\mathrm{O}) \mathrm{cc} 1$ & 50000 & $*$ \\
\hline 5059 & $\mathrm{COc} 1 \mathrm{cc}(\mathrm{OC}) \mathrm{cc}(-\mathrm{c} 2 \mathrm{cc} 3 \mathrm{cnc}(\mathrm{N}) \mathrm{nc} 3 \mathrm{nc} 2 \mathrm{NC}(=\mathrm{O}) \mathrm{NC}(\mathrm{C})(\mathrm{C}) \mathrm{C}) \mathrm{c} 1$ & 50000 & $*$ \\
\hline 5060 & Nc1 $\operatorname{ccc}(\mathrm{Nc} 2 \mathrm{nccc}(-\mathrm{c} 3 \mathrm{cccnc} 3) \mathrm{n} 2) \mathrm{c} 1$ & 50000 & * \\
\hline 5061 & $\mathrm{O}=\mathrm{C}(\mathrm{Nc} 1 \mathrm{cccc}(-\mathrm{c} 2 \mathrm{cn} 3 \mathrm{ccnc} 3 \mathrm{c}(\mathrm{NCc} 3 \mathrm{ccncc} 3) \mathrm{n} 2) \mathrm{c} 1) \mathrm{Nc} 1 \mathrm{cccc}(\mathrm{C}(\mathrm{F})(\mathrm{F}) \mathrm{F}) \mathrm{c} 1$ & 50000 & $*$ \\
\hline 5062 & $\operatorname{COc} 1 \mathrm{cc} 2 \mathrm{nccc}(\mathrm{Oc} 3 \mathrm{cccc} 3) \mathrm{c} 2 \mathrm{cc} 1 \mathrm{OC}$ & 50000 & $*$ \\
\hline 5063 & $\operatorname{COc} 1 \operatorname{cc} 2 n \operatorname{ccc}(\mathrm{Oc} 3 \operatorname{ccc}(\mathrm{C}(=\mathrm{O}) \mathrm{c} 4 \operatorname{cccc} 4) \operatorname{cc} 3) \mathrm{c} 2 \mathrm{cc} 1 \mathrm{OC}$ & 50000 & $*$ \\
\hline 5064 & $\mathrm{O}=\mathrm{C}(\mathrm{Nc} 1 \mathrm{ccccc} 1) \mathrm{c} 1 \mathrm{cccc} 1 \mathrm{O}$ & 50000 & $*$ \\
\hline 5065 & $\mathrm{O}=\mathrm{C}(\mathrm{Nc} 1 \mathrm{ccc}(\mathrm{Br}) \mathrm{cc} 1) \mathrm{c} 1 \mathrm{cccc} 1 \mathrm{O}$ & 50000 & $*$ \\
\hline 5066 & $\mathrm{O}=\mathrm{C}(\mathrm{Nc} 1 \mathrm{ccc}(\mathrm{F}) \mathrm{cc} 1) \mathrm{c} 1 \mathrm{cccc} 1 \mathrm{O}$ & 50000 & $*$ \\
\hline 5067 & $\operatorname{Cc} 1 \operatorname{ccc}(\mathrm{C}(=\mathrm{O}) \mathrm{Nc} 2 \operatorname{cccc} 2) \mathrm{c}(\mathrm{O}) \mathrm{c} 1$ & 50000 & $*$ \\
\hline 5068 & $\mathrm{O}=\mathrm{C}(\mathrm{Nc} 1 \mathrm{ccc}(\mathrm{F}) \mathrm{cc} 1) \mathrm{c} 1 \mathrm{cc}(\mathrm{Br}) \mathrm{cc}(\mathrm{Br}) \mathrm{c} 1 \mathrm{O}$ & 50000 & $*$ \\
\hline 5069 & $\mathrm{O}=\mathrm{C}(\mathrm{Nc} 1 \mathrm{ccc}(\mathrm{F}) \mathrm{cc} 1 \mathrm{~F}) \mathrm{c} 1 \mathrm{cccc} 1 \mathrm{O}$ & 50000 & $*$ \\
\hline 5070 & $\mathrm{Cc} 1 \operatorname{ccc}(\mathrm{C}(=\mathrm{O}) \mathrm{Nc} 2 \operatorname{ccc}(\mathrm{Cl}) \mathrm{cc} 2) \mathrm{c}(\mathrm{O}) \mathrm{c} 1$ & 50000 & $*$ \\
\hline 5071 & $\mathrm{O}=\mathrm{C}(\mathrm{Nc} 1 \mathrm{ccc}(\mathrm{F}) \mathrm{cc} 1) \mathrm{c} 1 \mathrm{cc}(\mathrm{I}) \mathrm{ccc} 1 \mathrm{O}$ & 50000 & $*$ \\
\hline 5072 & $\mathrm{Cc} 1 \operatorname{ccc}(\mathrm{C}(=\mathrm{O}) \mathrm{Nc} 2 \operatorname{ccc}(\mathrm{C}(\mathrm{C}) \mathrm{C}) \mathrm{cc} 2) \mathrm{c}(\mathrm{O}) \mathrm{c} 1$ & 50000 & $*$ \\
\hline 5073 & $\mathrm{Cc} 1 \mathrm{ccc}(\mathrm{C}(=\mathrm{O}) \mathrm{Nc} 2 \operatorname{ccc}(\mathrm{F}) \mathrm{cc} 2 \mathrm{~F}) \mathrm{c}(\mathrm{O}) \mathrm{c} 1$ & 50000 & $*$ \\
\hline 5074 & $\mathrm{COc} 1 \mathrm{ccc}(\mathrm{Nc} 2 \mathrm{c}(\mathrm{C \# N}) \mathrm{cnc} 3 \mathrm{cc}(\mathrm{OC}) \mathrm{c}(\mathrm{OC}) \mathrm{cc} 23) \mathrm{cc} 1 \mathrm{OC}$ & 50490 & $*$ \\
\hline 5075 & $\mathrm{CC}(=\mathrm{O}) \mathrm{NC}(\mathrm{Cc} 1 \mathrm{c}(\mathrm{SSc} 2[\mathrm{nH}] \mathrm{c} 3 \operatorname{ccccc} 3 \mathrm{c} 2 \mathrm{CC}(\mathrm{NC}(\mathrm{C})=\mathrm{O}) \mathrm{C}(=\mathrm{O}) \mathrm{NCc} 2 \operatorname{cccc} 2)[\mathrm{nH}] \mathrm{c} 2 \operatorname{ccccc} 12) \mathrm{C}(=\mathrm{O}) \mathrm{NCc} 1 \operatorname{cccc} 1$ & 51000 & $*$ \\
\hline 5076 & $\mathrm{Cn} 1 \mathrm{c}(\mathrm{SSc} 2 \mathrm{c}(\mathrm{CC}(=\mathrm{O}) \mathrm{O}) \mathrm{c} 3 \operatorname{ccc} c 3 \mathrm{n} 2 \mathrm{C}) \mathrm{c}(\mathrm{CC}(=\mathrm{O}) \mathrm{O}) \mathrm{c} 2 \operatorname{ccccc} 21$ & 53000 & $*$ \\
\hline 5077 & $\operatorname{COc} 1 \mathrm{cc}(\mathrm{C}=\mathrm{C}(\mathrm{C \# N}) \mathrm{CHN}) \operatorname{cc}(\mathrm{SCC}(=\mathrm{O}) \mathrm{O}) \mathrm{c} 1 \mathrm{O}$ & 53703.18 & $*$ \\
\hline 5078 & $\mathrm{Cn} 1 \mathrm{c}(\mathrm{SSc} 2 \mathrm{c}(\mathrm{C}(=\mathrm{O}) \mathrm{Nc} 3 \operatorname{cccc} 3) \mathrm{c} 3 \operatorname{cc}(\mathrm{C \# N}) \operatorname{ccc} 3 \mathrm{n} 2 \mathrm{C}) \mathrm{c}(\mathrm{C}(=\mathrm{O}) \mathrm{Nc} 2 \operatorname{cccc} 2) \mathrm{c} 2 \mathrm{cc}(\mathrm{C \# N}) \operatorname{ccc} 21$ & 54100 & $*$ \\
\hline 5079 & $\mathrm{CCOc} 1 \mathrm{cc}(-\mathrm{c} 2 \mathrm{nn}(\mathrm{C}(\mathrm{C}) \mathrm{C}) \mathrm{c} 3 \mathrm{ncnc}(\mathrm{N}) \mathrm{c} 23) \mathrm{ccc} 1 \mathrm{OC}$ & 54200 & $*$ \\
\hline 5080 & $\mathrm{CCCCc} 1 \mathrm{cc}(/ \mathrm{C}=\mathrm{C}(\mid \mathrm{C} \# \mathrm{~N}) \mathrm{C}(\mathrm{N})=\mathrm{O}) \mathrm{cc}(\mathrm{CCCC}) \mathrm{c} 1 \mathrm{O}$ & 55000 & $*$ \\
\hline 5081 & $\mathrm{Cn} 1 \mathrm{ncc} 2 \mathrm{c}(\mathrm{NCc} 3 \mathrm{ccccc} 3) \mathrm{nc}(\mathrm{N}(\mathrm{CCO}) \mathrm{CCO}) \mathrm{nc} 21$ & 55000 & $*$ \\
\hline 5082 & $\mathrm{CC} 1=\mathrm{C}(\mathrm{C}(=\mathrm{O}) \mathrm{Nc} 2 \operatorname{cccc}([\mathrm{N}+](=\mathrm{O})[\mathrm{O}-]) \mathrm{c} 2) \mathrm{C}(\mathrm{c} 2 \operatorname{ccc}(\mathrm{O}) \operatorname{cc} 2 \mathrm{O}) \mathrm{NC}(\mathrm{SCc} 2 \operatorname{cccc} 2)=\mathrm{N} 1$ & 55600 & $*$ \\
\hline 5083 & $\mathrm{~N} \# \mathrm{Cc} 1 \mathrm{cnc}(\mathrm{Nc} 2 \mathrm{cccc}(\mathrm{Br}) \mathrm{c} 2) \mathrm{c} 2 \mathrm{cc}(\mathrm{NC}(=\mathrm{O}) \mathrm{c} 3 \mathrm{ccco} 3) \mathrm{ccc} 12$ & 55600 & $*$ \\
\hline 5084 & $\operatorname{COc} 1 \mathrm{cc}(/ \mathrm{C}=\mathrm{C} 2 \backslash \mathrm{SC}(=\mathrm{N}) \mathrm{NC} 2=\mathrm{O}) \mathrm{ccc} 1 \mathrm{OCCCOc} 1 \mathrm{cc}(\mathrm{C}) \mathrm{cc}(\mathrm{C}) \mathrm{c} 1$ & 56000 & $*$ \\
\hline 5085 & $\mathrm{COc} 1 \mathrm{ccccc} 1 \mathrm{C}(\mathrm{Cc} 1 \operatorname{coc} 2 \mathrm{nc}(\mathrm{N}) \mathrm{nc}(\mathrm{N}) \mathrm{c} 12) \mathrm{C} 1 \mathrm{CC} 1$ & 56500 & $*$ \\
\hline 5086 & $\mathrm{O}=\mathrm{C}(\mathrm{O}) \mathrm{CCc} 1 \mathrm{c}(/ \mathrm{C}=\mathrm{C} 2 \backslash \mathrm{C}(=\mathrm{O}) \mathrm{Nc} 3 \operatorname{ccc}(\mathrm{C}(=\mathrm{O}) \mathrm{O}) \mathrm{cc} 32)[\mathrm{nH}] \mathrm{c} 2 \mathrm{c} 1 \mathrm{CCCC} 2$ & 56500 & $*$ \\
\hline 5087 & $\mathrm{O}=\mathrm{c} 1 \mathrm{c}(-\mathrm{c} 2 \mathrm{cccc}(\mathrm{Cl}) \mathrm{c} 2) \operatorname{coc} 2 \mathrm{cc}(\mathrm{O}) \mathrm{ccc} 12$ & 58800 & $*$ \\
\hline 5088 & $\mathrm{CCCNN} 1 \mathrm{C}(=\mathrm{O}) \mathrm{c} 2 \mathrm{c}(\mathrm{c} 3 \mathrm{c} 4 \mathrm{ccc}(\mathrm{O}) \mathrm{c} 4 \mathrm{n}(\mathrm{C} 4 \mathrm{OC}(\mathrm{CO}) \mathrm{C}(\mathrm{O}) \mathrm{C}(\mathrm{O}) \mathrm{C} 4 \mathrm{O}) \mathrm{c} 3 \mathrm{c} 3[\mathrm{nH}] \mathrm{c} 4 \mathrm{c}(\mathrm{O}) \mathrm{cccc} 4 \mathrm{c} 23) \mathrm{C} 1=\mathrm{O}$ & 59000 & $*$ \\
\hline 5089 & $\mathrm{COc} 1 \mathrm{cc} 2 \mathrm{c}(\mathrm{cc} 1 \mathrm{O}) \mathrm{NC}(=\mathrm{O}) \mathrm{C} 2=\mathrm{C}(\mathrm{C \# N}) \mathrm{C \# N}$ & 60000 & $*$ \\
\hline 5090 & $\mathrm{~N} \# \mathrm{CC}(\mathrm{C} \# \mathrm{~N})=\mathrm{Cc} 1 \mathrm{ccc}(\mathrm{C}=\mathrm{O}) \mathrm{cc} 1$ & 60000 & $*$ \\
\hline 5091 & $\mathrm{~N} \# \mathrm{CC}(\mathrm{C} \# \mathrm{~N})=\mathrm{C}(\mathrm{N}) / \mathrm{C}(\mathrm{C \# N})=\mathrm{C} / \mathrm{c} 1 \mathrm{ccc}(\mathrm{O}) \mathrm{c}([\mathrm{N}+](=\mathrm{O})[\mathrm{O}-]) \mathrm{c} 1$ & 60000 & $*$ \\
\hline 5092 & $\mathrm{CC} 1=\mathrm{C}(\mathrm{C}(=\mathrm{O}) \mathrm{Nc} 2 \operatorname{ccc}(\mathrm{C}) \operatorname{cc} 2) \mathrm{C}(\mathrm{c} 2 \operatorname{ccc}(\mathrm{O}) \operatorname{cc} 2 \mathrm{O}) \mathrm{NC}(\mathrm{Nc} 2 \operatorname{ccc}([\mathrm{N}+](=\mathrm{O})[\mathrm{O}-]) \operatorname{cc} 2 \mathrm{Cl})=\mathrm{N} 1$ & 60900 & $*$ \\
\hline 5093 & $\operatorname{COc} 1 \mathrm{cc} 2 \mathrm{nc}(\mathrm{Cl}) \mathrm{nc}(\mathrm{Nc} 3 \operatorname{ccc}(\mathrm{S}(\mathrm{C})(=\mathrm{O})=\mathrm{O}) \mathrm{cc} 3) \mathrm{c} 2 \mathrm{cc} 1 \mathrm{OC}$ & 61500 & $*$ \\
\hline 5094 & $\mathrm{Cc} 1 \mathrm{cc}(\mathrm{C}=\mathrm{C}(\mathrm{C} \# \mathrm{~N}) \mathrm{C} \# \mathrm{~N}) \mathrm{cc}(\mathrm{O}) \mathrm{c} 1 \mathrm{O}$ & 61659.5 & * \\
\hline 5095 & $\mathrm{COc} 1 \mathrm{cc} 2 \mathrm{ncc}(\mathrm{C \# N}) \mathrm{c}(\mathrm{Nc} 3 \operatorname{ccc}(\mathrm{C}(\mathrm{C}) \mathrm{C}) \mathrm{c} 3) \mathrm{c} 2 \mathrm{cc} 1 \mathrm{OC}$ & 62320 & $*$ \\
\hline 5096 & $\mathrm{COc} 1 \mathrm{cc} 2 \mathrm{c}(\mathrm{cc} 1 \mathrm{OC}) \mathrm{Sc} 1 \mathrm{ncnc}(\mathrm{Nc} 3 \mathrm{ccc}(\mathrm{Cl}) \mathrm{c} 3 \mathrm{~F}) \mathrm{c} 1 \mathrm{NC} 2$ & 62900 & 4.20 \\
\hline 5097 & $\mathrm{C}=\mathrm{CC}(=\mathrm{O}) \mathrm{Nc} 1 \mathrm{cc}(\mathrm{Nc} 2 \mathrm{nccc}(-\mathrm{c} 3 \mathrm{cn}(\mathrm{C}) \mathrm{c} 4 \mathrm{ccc} n \mathrm{c} 34) \mathrm{n} 2) \mathrm{c}(\mathrm{OC}) \mathrm{cc} 1 \mathrm{~N}(\mathrm{C}) \mathrm{CCN}(\mathrm{C}) \mathrm{C}$ & 63000 & $*$ \\
\hline 5098 & $\mathrm{O}=\mathrm{c} 1 \mathrm{oc} 2 \mathrm{cc} 3 \mathrm{ncnc}(\mathrm{NCc} 4 \mathrm{cccc} 4) \mathrm{c} 3 \mathrm{cc} 2 \mathrm{n} 1 \mathrm{CCCN} 1 \mathrm{CCOCC} 1$ & 65000 & $*$ \\
\hline 5099 & $\mathrm{Nc} 1 \mathrm{cc} 2 \mathrm{ncnc}(\mathrm{Nc} 3 \operatorname{ccc}([\mathrm{N}+](=\mathrm{O})[\mathrm{O}-]) \operatorname{cc} 3) \mathrm{c} 2 \mathrm{cn} 1$ & 65000 & $*$ \\
\hline
\end{tabular}




\begin{tabular}{|c|c|c|c|}
\hline 5100 & $\mathrm{Cc} 1 \mathrm{ccc}(\mathrm{NC}(=\mathrm{O}) \mathrm{c} 2 \operatorname{ccccc} 2) \operatorname{cc} 1 \mathrm{Nc} 1 \mathrm{nccc}(-\mathrm{c} 2 \mathrm{cccnc} 2) \mathrm{n} 1$ & 65000 & * \\
\hline 5101 & $\mathrm{Nc} 1 \mathrm{scc} 2 \mathrm{c} 1 \mathrm{c}(\mathrm{NCCO}) \mathrm{nc} 1 \mathrm{nc}(\mathrm{NCCO}) \mathrm{nc}(\mathrm{N}) \mathrm{c} 12$ & 66100 & $*$ \\
\hline 5102 & $\mathrm{Cn} 1 \mathrm{ncc} 2 \mathrm{c}(\mathrm{Nc} 3 \mathrm{ccc}(\mathrm{F}) \mathrm{c} 3) \mathrm{nc}(\mathrm{NCCO}) \mathrm{nc} 21$ & 66100 & $*$ \\
\hline 5103 & $\mathrm{OCCN}(\mathrm{CCO}) \mathrm{c} 1 \mathrm{nc}(\mathrm{NCc} 2 \mathrm{cccc}(\mathrm{F}) \mathrm{c} 2) \mathrm{c} 2 \mathrm{cn}[\mathrm{nH}] \mathrm{c} 2 \mathrm{n} 1$ & 66100 & $*$ \\
\hline 5104 & $\mathrm{COc} 1 \mathrm{cc} 2 \mathrm{nc}(\mathrm{Cl}) \mathrm{nc}(\mathrm{Nc} 3 \operatorname{ccc}(\mathrm{S}(=\mathrm{O})(=\mathrm{O}) \mathrm{N}(\mathrm{C}) \mathrm{C}) \mathrm{cc} 3) \mathrm{c} 2 \mathrm{cc} 1 \mathrm{OC}$ & 67200 & $*$ \\
\hline 5105 & $\operatorname{CONC}(=\mathrm{O}) \mathrm{CCc} 1 \mathrm{c}(\mathrm{SSc} 2[\mathrm{nH}] \mathrm{c} 3 \operatorname{ccc} \cos 2 \mathrm{CCC}(=\mathrm{O}) \mathrm{NOC})[\mathrm{nH}] \mathrm{c} 2 \mathrm{ccccc} 12$ & 68000 & $*$ \\
\hline 5106 & $\mathrm{CN}(\mathrm{C}) \mathrm{c} 1 \mathrm{ccccc} 1 \mathrm{Nc} 1 \mathrm{ncnc} 2 \mathrm{cc}(\mathrm{N}) \mathrm{ncc} 12$ & 69000 & $*$ \\
\hline 5107 & $\mathrm{COc} 1 \mathrm{cc} 2 \mathrm{ncc}(\mathrm{C} \# \mathrm{~N}) \mathrm{c}(\mathrm{Nc} 3 \mathrm{cccc}(\mathrm{NC}(\mathrm{C})=\mathrm{O}) \mathrm{c} 3) \mathrm{c} 2 \mathrm{cc} 1 \mathrm{OC}$ & 69400 & $*$ \\
\hline 5108 & $\mathrm{N \# CC}(\mathrm{Cc} 1 \mathrm{ccc}(\mathrm{O}) \mathrm{c}(\mathrm{O}) \mathrm{c} 1) \mathrm{C}(=\mathrm{N}) \mathrm{S}$ & 70000 & $*$ \\
\hline 5109 & $\mathrm{CC}(\mathrm{C}) \mathrm{n} 1 \mathrm{nc}(-\mathrm{c} 2 \mathrm{cnc} 3 \mathrm{nccnc} 3 \mathrm{c} 2) \mathrm{c} 2 \mathrm{c}(\mathrm{N}) \mathrm{ncnc} 21$ & 70000 & $*$ \\
\hline 5110 & $\mathrm{COc} 1 \mathrm{cc} 2 \mathrm{c}(\mathrm{CHN}) \mathrm{cnc}(\mathrm{Nc} 3 \mathrm{cccc}(\mathrm{Br}) \mathrm{c} 3) \mathrm{c} 2 \mathrm{cc} 1 \mathrm{OC} . \mathrm{Cl}$ & 70840 & $*$ \\
\hline 5111 & $\mathrm{Cc} 1 \mathrm{nn}(\mathrm{C}) \mathrm{cc} 1 \mathrm{C}(=\mathrm{O}) \mathrm{Nc} 1 \mathrm{ccn}(\mathrm{Cc} 2 \mathrm{c}(\mathrm{F}) \operatorname{cccc} 2 \mathrm{Cl}) \mathrm{n} 1$ & 72400 & 4.14 \\
\hline 5112 & $\mathrm{Cc} 1 \operatorname{ccc}(\mathrm{N} 2 \mathrm{NC}(=\mathrm{O}) / \mathrm{C}(=\mathrm{C} \backslash \operatorname{coccc}(-\operatorname{coc}([\mathrm{N}+](=\mathrm{O})[\mathrm{O}-]) \operatorname{ccc} 4 \mathrm{O}) \mathrm{o} 3) \mathrm{C} 2=\mathrm{O}) \operatorname{cc} 1 \mathrm{C}$ & 74300 & 4.13 \\
\hline 5113 & $\mathrm{Cc} 1 \mathrm{cc}(\mathrm{C}) \mathrm{cc}(\mathrm{Nc} 2 \mathrm{ncnc} 3 \mathrm{cc} 4 \mathrm{oc}(=\mathrm{O}) \mathrm{n}(\mathrm{CCCN} 5 \mathrm{CCOCC} 5) \mathrm{c} 4 \mathrm{cc} 23) \mathrm{c} 1$ & 75000 & $*$ \\
\hline 5114 & $\mathrm{~N} \# \mathrm{C} / \mathrm{C}(=\mathrm{C} / \mathrm{c} 1 \mathrm{cc}(\mathrm{O}) \operatorname{ccc} 1 \mathrm{O}) \mathrm{C}(=\mathrm{O}) \mathrm{O}$ & 75000 & $*$ \\
\hline 5115 & $\mathrm{COc} 1 \mathrm{cc} 2 \mathrm{c}(\mathrm{cc} 1 \mathrm{OC}) \mathrm{Nc} 1 \mathrm{ncnc}(\mathrm{O}) \mathrm{c} 1 \mathrm{C} 2$ & 75000 & $*$ \\
\hline 5116 & $\mathrm{Nc} 1 \mathrm{ncnc} 2 \mathrm{c} 1 \mathrm{ncn} 2 \mathrm{CC}(=\mathrm{O}) \mathrm{c} 1 \mathrm{ccccc} 1$ & 75000 & $*$ \\
\hline 5117 & $\mathrm{COc} 1 \mathrm{cc} 2 \mathrm{nccc}(\mathrm{Oc} 3 \operatorname{ccc}(\mathrm{C}(=\mathrm{O}) \mathrm{c} 4 \mathrm{ccc}(\mathrm{F}) \mathrm{cc} 4) \mathrm{cc} 3) \mathrm{c} 2 \mathrm{cc} 1 \mathrm{OC}$ & 75000 & $*$ \\
\hline 5118 & $\mathrm{Cc} 1[\mathrm{nH}] \mathrm{c} 2 \mathrm{ncnc}(\mathrm{Nc} 3 \mathrm{ccccc} 3 \mathrm{Cl}) \mathrm{c} 2 \mathrm{c} 1 \mathrm{C}$ & 75100 & $*$ \\
\hline 5119 & $\operatorname{COc} 1 \mathrm{ccc} 2 \mathrm{c} 3 \mathrm{oc}(=\mathrm{O}) \mathrm{cc}(\mathrm{O}) \mathrm{c} 3 \mathrm{c}(=\mathrm{O}) \mathrm{n}(\mathrm{C}) \mathrm{c} 2 \mathrm{c} 1$ & 76400 & $*$ \\
\hline 5120 & $\mathrm{C}=\mathrm{CC}(=\mathrm{O}) \mathrm{Nc} 1 \mathrm{cc}(\mathrm{Nc} 2 \mathrm{nccc}(-\mathrm{c} 3 \mathrm{cn}(\mathrm{C}) \mathrm{c} 4 \mathrm{cccnc} 34) \mathrm{n} 2) \mathrm{c}(\mathrm{OC}) \mathrm{cc} 1 \mathrm{NCCN}(\mathrm{C}) \mathrm{C} . \mathrm{Cl}$ & 77000 & * \\
\hline 5121 & $\mathrm{CCc} 1 \mathrm{ccc}(\mathrm{Nc} 2[\mathrm{nH}] \mathrm{cnc} 3 \mathrm{nc}(\mathrm{C}) \mathrm{c}(\mathrm{C}) \mathrm{c} 2-3) \mathrm{cc} 1$ & 77500 & $*$ \\
\hline 5122 & $\mathrm{Cn} 1 \mathrm{ncc} 2 \mathrm{c}(\mathrm{NCc} 3 \operatorname{ccc}([\mathrm{N}+](=\mathrm{O})[\mathrm{O}-]) \mathrm{cc} 3) \mathrm{nc}(\mathrm{NCCO}) \mathrm{nc} 21$ & 77600 & $*$ \\
\hline 5123 & $\mathrm{O}=\mathrm{c} 1 \mathrm{c} 2 \operatorname{ccc} c 2 \mathrm{nc}(-\mathrm{c} 2 \operatorname{ccc} \mathrm{c} 2) \mathrm{n} 1-\mathrm{c} 1 \mathrm{nn} \mathrm{c}(-\mathrm{c} 2 \mathrm{cccc} 2 \mathrm{Cl}) \mathrm{s} 1$ & 78230 & 4.11 \\
\hline 5124 & $\mathrm{CC}(\mathrm{C})(\mathrm{C}) \mathrm{c} 1 \mathrm{ccc}(\mathrm{Nc} 2 \mathrm{ncnc} 3 \mathrm{cc} 4 \mathrm{oc}(=\mathrm{O}) \mathrm{n}(\mathrm{CCCN} 5 \mathrm{CCOCC} 5) \mathrm{c} 4 \mathrm{cc} 23) \mathrm{cc} 1$ & 79000 & $*$ \\
\hline 5125 & $\mathrm{CC} 1=\mathrm{C}(\mathrm{C}(=\mathrm{O}) \mathrm{Nc} 2 \operatorname{cccc}([\mathrm{N}+](=\mathrm{O})[\mathrm{O}-]) \mathrm{c} 2) \mathrm{C}(\mathrm{c} 2 \operatorname{ccc}(\mathrm{O}) \operatorname{cc} 2 \mathrm{O}) \mathrm{NC}(\mathrm{Nc} 2 \operatorname{ccc}(\mathrm{S}(=\mathrm{O})(=\mathrm{O}) \mathrm{Nc} 3 \mathrm{nc}(\mathrm{C}) \mathrm{cc}(\mathrm{C}) \mathrm{n} 3) \mathrm{cc} 2)=\mathrm{N} 1$ & 79800 & $*$ \\
\hline 5126 & $\mathrm{COc} 1 \mathrm{ccc}(\mathrm{Nc} 2 \mathrm{ccnc} 3 \mathrm{cc}(\mathrm{OC}) \mathrm{c}(\mathrm{OC}) \mathrm{cc} 23) \mathrm{cc} 1 \mathrm{OC}$ & 80500 & $*$ \\
\hline 5127 & $\mathrm{CC} 1=\mathrm{C}(\mathrm{C}(=\mathrm{O}) \mathrm{Nc} 2 \operatorname{ccc}([\mathrm{N}+](=\mathrm{O})[\mathrm{O}-]) \mathrm{c} 2) \mathrm{C}(\mathrm{c} 2 \operatorname{ccc}(\mathrm{O}) \operatorname{cc} 2 \mathrm{O}) \mathrm{NC}(\mathrm{NN} 2 \mathrm{C}(=\mathrm{O}) / \mathrm{C}(=\mathrm{Clc} 3 \operatorname{cccs} 3) \mathrm{SC} 2=\mathrm{S})=\mathrm{N} 1$ & 80600 & $*$ \\
\hline 5128 & $\mathrm{COc} 1 \mathrm{cc} 2 \mathrm{nccc}(\mathrm{Oc} 3 \mathrm{c}(\mathrm{OC}) \mathrm{ccc} 3 \mathrm{OC}) \mathrm{c} 2 \mathrm{cc} 1 \mathrm{OC}$ & 81000 & $*$ \\
\hline 5129 & $\mathrm{Cc} 1 \mathrm{ccc}(-\mathrm{n} 2 \mathrm{c}(\mathrm{SCC}(=\mathrm{O}) \mathrm{Nc} 3 \mathrm{cccc} 3 \mathrm{Cl}) \mathrm{nc} 3 \mathrm{sc}(\mathrm{C}) \mathrm{c}(\mathrm{C}) \mathrm{c} 3 \mathrm{c} 2=\mathrm{O}) \mathrm{cc} 1$ & 81600 & $*$ \\
\hline 5130 & $\mathrm{CCOC}(=\mathrm{O}) \mathrm{c} 1 \mathrm{cnc} 2 \mathrm{cc}(\mathrm{OC}) \mathrm{c}(\mathrm{OC}) \mathrm{cc} 2 \mathrm{c} 1 \mathrm{Nc} 1 \mathrm{ccc}(\mathrm{Br}) \mathrm{c} 1$ & 81800 & $*$ \\
\hline 5131 & $\mathrm{Nc} 1 \mathrm{ncnc} 2 \mathrm{ncn}(\mathrm{CC}(=\mathrm{O}) \mathrm{c} 3 \mathrm{c}[\mathrm{nH}] \mathrm{c} 4 \mathrm{ccccc} 34) \mathrm{c} 12$ & 82000 & $*$ \\
\hline 5132 & $\mathrm{COc} 1 \mathrm{cc}(/ \mathrm{C}=\mathrm{C}(\backslash \mathrm{CHN}) \mathrm{C}(\mathrm{N})=\mathrm{O}) \operatorname{cc}(\mathrm{CSc} 2 \mathrm{nc} 3 \mathrm{cc}(\mathrm{Cl}) \operatorname{ccc} 3 \mathrm{~s} 2) \mathrm{c} 1 \mathrm{O}$ & 83176.38 & $*$ \\
\hline 5133 & $\mathrm{Cn} 1 \mathrm{c}(\mathrm{NCc} 2 \operatorname{cccc}(\mathrm{C}(\mathrm{F})(\mathrm{F}) \mathrm{F}) \mathrm{c} 2) \mathrm{cc}(=\mathrm{O}) \mathrm{n}(\mathrm{C}) \mathrm{c} 1=\mathrm{O}$ & 83900 & 4.08 \\
\hline 5134 & $\mathrm{Cc} 1[\mathrm{nH}] \mathrm{c}(/ \mathrm{C}=\mathrm{C} 2 \backslash \mathrm{C}(=\mathrm{O}) \mathrm{Nc} 3 \operatorname{ccc}(\mathrm{S}(\mathrm{N})(=\mathrm{O})=\mathrm{O}) \mathrm{cc} 32) \mathrm{c}(\mathrm{C}) \mathrm{c} 1 \mathrm{CCC}(=\mathrm{O}) \mathrm{O}$ & 84800 & $*$ \\
\hline 5135 & $\mathrm{O}=\mathrm{c} 1 \mathrm{c} 2 \mathrm{c}(-\mathrm{c} 3 \operatorname{ccccc} 3) \mathrm{c} 3 \mathrm{c}(\mathrm{nc} 2 \mathrm{nc} 2[\mathrm{nH}] \mathrm{nc}(\mathrm{S}) \mathrm{n} 12)-\mathrm{c} 1 \mathrm{ccccc} 1 \mathrm{CC} 3$ & 85600 & $*$ \\
\hline 5136 & $\operatorname{COc} 1 \mathrm{cc}(\mathrm{C}=\mathrm{C}(\mathrm{CHN}) \mathrm{C \# N}) \mathrm{cc}(\mathrm{C}) \mathrm{c} 1 \mathrm{O}$ & 87096.36 & $*$ \\
\hline 5137 & $\mathrm{COc} 1 \mathrm{cc} 2 \mathrm{c}(\mathrm{C \# N}) \mathrm{cnc}(\mathrm{Nc} 3 \mathrm{cccc}(\mathrm{Cl}) \mathrm{c} 3) \mathrm{c} 2 \mathrm{cc} 1 \mathrm{OC}$ & 88290 & $*$ \\
\hline 5138 & $\mathrm{CC} 1=\mathrm{C}(\mathrm{C}(=\mathrm{O}) \mathrm{Nc} 2 \operatorname{ccc}([\mathrm{N}+](=\mathrm{O})[\mathrm{O}-]) \mathrm{c} 2) \mathrm{C}(\mathrm{c} 2 \operatorname{ccc}(\mathrm{O}) \operatorname{cc} 2 \mathrm{O}) \mathrm{NC}(\mathrm{Nc} 2 \operatorname{ccc}(\mathrm{S}(=\mathrm{O})(=\mathrm{O}) \mathrm{Nc} 3 \mathrm{ncccn} 3) \operatorname{cc} 2)=\mathrm{N} 1$ & 88300 & $*$ \\
\hline 5139 & $\mathrm{O}=[\mathrm{N}+]([\mathrm{O}-]) \mathrm{CCc} 1 \mathrm{c}(\mathrm{SSc} 2[\mathrm{nH}] \mathrm{c} 3 \operatorname{ccccc} 3 \mathrm{c} 2 \mathrm{CC}[\mathrm{N}+](=\mathrm{O})[\mathrm{O}-])[\mathrm{nH}] \mathrm{c} 2 \operatorname{ccccc} 12$ & 89000 & * \\
\hline 5140 & $\mathrm{Nc} 1 \mathrm{ncnc} 2 \mathrm{c} 1 \mathrm{ncn} 2 \mathrm{CC}(=\mathrm{O}) \mathrm{c} 1 \mathrm{ccc} n 1$ & 89000 & $*$ \\
\hline 5141 & $\operatorname{COc} 1 \mathrm{cc} 2 \mathrm{nccc}(\mathrm{Oc} 3 \operatorname{ccc}(\mathrm{C}(=\mathrm{O}) \mathrm{c} 4 \mathrm{ccccc} 4) \mathrm{c} 3) \mathrm{c} 2 \mathrm{cc} 1 \mathrm{OC}$ & 89000 & $*$ \\
\hline 5142 & $\mathrm{O}=\mathrm{C}(\mathrm{O}) \mathrm{c} 1 \mathrm{ccc}(\mathrm{NN} 2 \mathrm{C}(=\mathrm{O}) \mathrm{c} 3 \mathrm{c}(\mathrm{c} 4 \mathrm{c} 5 \mathrm{cccc}(\mathrm{O}) \mathrm{c} 5 \mathrm{n}(\mathrm{C} 5 \mathrm{OC}(\mathrm{CO}) \mathrm{C}(\mathrm{O}) \mathrm{C}(\mathrm{O}) \mathrm{C} 5 \mathrm{O}) \mathrm{c} 4 \mathrm{c} 4[\mathrm{nH}] \mathrm{c} 5 \mathrm{c}(\mathrm{O}) \operatorname{ccc} 5 \mathrm{c} 34) \mathrm{C} 2=\mathrm{O}) \mathrm{cc} 1$ & 90000 & * \\
\hline
\end{tabular}




\begin{tabular}{|c|c|c|c|}
\hline 5143 & $\mathrm{O}=\mathrm{C} 1 \mathrm{NC}(=\mathrm{O}) \mathrm{c} 2 \mathrm{c} 1 \mathrm{c} 1 \mathrm{c} 3 \operatorname{ccc}(\mathrm{O}) \mathrm{c} 3[\mathrm{nH}] \mathrm{c} 1 \mathrm{c} 1 \mathrm{c} 2 \mathrm{c} 2 \mathrm{cccc}(\mathrm{O}) \mathrm{c} 2 \mathrm{n} 1 \mathrm{C} 1 \mathrm{OC}(\mathrm{CO}) \mathrm{C}(\mathrm{O}) \mathrm{C}(\mathrm{O}) \mathrm{C} 1 \mathrm{O}$ & 90000 & $*$ \\
\hline 5144 & COc1 $\operatorname{cccc} 1 \mathrm{Nc} 1 \mathrm{ccnc}(\mathrm{Ne} 2 \mathrm{cccc} 2 \mathrm{OC}) \mathrm{n} 1$ & 90400 & $*$ \\
\hline 5145 & $\mathrm{COc} 1 \mathrm{cc} 2 \mathrm{ncc}(\mathrm{C} \# \mathrm{~N}) \mathrm{c}(\mathrm{Nc} 3 \mathrm{ccc}(\mathrm{Br}) \mathrm{cc} 3 \mathrm{~F}) \mathrm{c} 2 \mathrm{cc} 1 \mathrm{OC} . \mathrm{Cl}$ & 91200 & $*$ \\
\hline 5146 & $\mathrm{COc} 1 \mathrm{cc} 2 \mathrm{nccc}(\mathrm{Oc} 3 \mathrm{cccc} 3 \mathrm{OC}) \mathrm{c} 2 \mathrm{cc} 1 \mathrm{OC}$ & 92000 & $*$ \\
\hline 5147 & $\mathrm{C}=\mathrm{CC}(=\mathrm{O}) \mathrm{Nc} 1 \mathrm{cc}(\mathrm{Nc} 2 \mathrm{ncc}(\mathrm{Br}) \mathrm{c}(\mathrm{Nc} 3 \mathrm{ccc} 4[\mathrm{nH}] \operatorname{ccc} 4 \mathrm{c} 3) \mathrm{n} 2) \mathrm{c}(\mathrm{OC}) \mathrm{cc} 1 \mathrm{~N} 1 \mathrm{CCN}(\mathrm{C}) \mathrm{CC} 1$ & 92100 & $*$ \\
\hline 5148 & $\operatorname{CCOC}(=\mathrm{O}) \mathrm{c} 1 \mathrm{ccc}(\mathrm{NC}(=\mathrm{O}) \mathrm{CSc} 2 \mathrm{nnc}(\mathrm{CNc} 3 \operatorname{ccc}(\mathrm{OC}) \mathrm{cc} 3) \mathrm{n} 2-\mathrm{c} 2 \operatorname{ccccc} 2) \mathrm{cc} 1$ & 92400 & $*$ \\
\hline 5149 & $\mathrm{Nc} 1 \mathrm{ncnc} 2 \mathrm{c} 1 \mathrm{ncn} 2 \mathrm{CC}(=\mathrm{O}) \mathrm{c} 1 \mathrm{cccnc} 1$ & 93000 & $*$ \\
\hline 5150 & $\mathrm{COc} 1 \mathrm{cc} 2 \mathrm{nccc}(\mathrm{Oc} 3 \operatorname{ccc}(\mathrm{NC}(=\mathrm{O}) \mathrm{c} 4 \mathrm{ccc}(\mathrm{C}(\mathrm{F})(\mathrm{F}) \mathrm{F}) \mathrm{cc} 4) \mathrm{cc} 3) \mathrm{c} 2 \mathrm{cc} 1 \mathrm{OC}$ & 93000 & $*$ \\
\hline 5151 & $\mathrm{~N} \# \mathrm{Cc} 1 \mathrm{cc} 2 \mathrm{c}(\mathrm{N}) \mathrm{ncnc} 2 \mathrm{nc} 1 \mathrm{NCCO}$ & 93300 & $*$ \\
\hline 5152 & $\mathrm{Cn} 1 \mathrm{ncc} 2 \mathrm{c}(\mathrm{NCc} 3 \mathrm{cccc} 3) \mathrm{nc}(\mathrm{NCCO}) \mathrm{nc} 21$ & 93300 & $*$ \\
\hline 5153 & $\mathrm{CC} 1=\mathrm{C}(\mathrm{C}(=\mathrm{O}) \mathrm{Nc} 2 \operatorname{ccc}(\mathrm{C}) \operatorname{cc} 2) \mathrm{C}(\mathrm{c} 2 \operatorname{ccc}(\mathrm{O}) \operatorname{cc} 2 \mathrm{O}) \mathrm{NC}(\mathrm{SCc} 2 \operatorname{cccc} 2)=\mathrm{N} 1$ & 93500 & * \\
\hline 5154 & $\mathrm{O}=\mathrm{C}(\mathrm{Nc} 1 \mathrm{ccccc} 1) \mathrm{NN} 1 \mathrm{C}(=\mathrm{O}) \mathrm{c} 2 \mathrm{c}(\mathrm{c} 3 \mathrm{c} 4 \mathrm{ccc}(\mathrm{O}) \mathrm{c} 4 \mathrm{n}(\mathrm{C} 4 \mathrm{OC}(\mathrm{CO}) \mathrm{C}(\mathrm{O}) \mathrm{C}(\mathrm{O}) \mathrm{C} 4 \mathrm{O}) \mathrm{c} 3 \mathrm{c} 3[\mathrm{nH}] \mathrm{c} 4 \mathrm{c}(\mathrm{O}) \operatorname{ccc} 4 \mathrm{c} 23) \mathrm{C} 1=\mathrm{O}$ & 95000 & $*$ \\
\hline 5155 & $\mathrm{COc} 1 \mathrm{cc} 2 \mathrm{nccc}(\mathrm{Oc} 3 \operatorname{ccc}(\mathrm{C}(=\mathrm{O}) \mathrm{c} 4 \operatorname{cccc}(\mathrm{C}) \mathrm{c} 4) \mathrm{cc} 3) \mathrm{c} 2 \mathrm{cc} 1 \mathrm{OC}$ & 95000 & * \\
\hline 5156 & $\mathrm{~N} \# \mathrm{CC}(\mathrm{C} \# \mathrm{~N})=\mathrm{Cc} 1 \mathrm{cc}(\mathrm{O}) \operatorname{ccc} 1[\mathrm{~N}+](=\mathrm{O})[\mathrm{O}-]$ & 96000 & $*$ \\
\hline 5157 & $\mathrm{C}[\mathrm{S}+]([\mathrm{O}-]) \mathrm{c} 1 \mathrm{ccc}(-\mathrm{c} 2 \mathrm{nc}(-\mathrm{c} 3 \mathrm{ccc}(\mathrm{F}) \mathrm{cc} 3) \mathrm{c}(-\mathrm{c} 3 \mathrm{ccncc} 3)[\mathrm{nH}] 2) \mathrm{cc} 1$ & 96000 & $*$ \\
\hline 5158 & $\mathrm{COC}(=\mathrm{O}) \mathrm{C} 1 \mathrm{CCN}(\mathrm{c} 2 \mathrm{ncnc} 3 \mathrm{cc}(\mathrm{OC}) \mathrm{c}(\mathrm{OC}) \mathrm{cc} 23) \mathrm{CC} 1$ & 97600 & $*$ \\
\hline 5159 & COc1cc2ncnc(Nc3cc $(=\mathrm{O})[\mathrm{nH}] \mathrm{c}(\mathrm{SC}) \mathrm{n} 3) \mathrm{c} 2 \mathrm{cc} 1 \mathrm{OC}$ & 99100 & $*$ \\
\hline 5160 & $\mathrm{CC} 1=\mathrm{C}(\mathrm{C}(=\mathrm{O}) \mathrm{Nc} 2 \operatorname{cccc}([\mathrm{N}+](=\mathrm{O})[\mathrm{O}-]) \mathrm{c} 2) \mathrm{C}(\mathrm{c} 2 \operatorname{ccc}(\mathrm{O}) \operatorname{cc} 2 \mathrm{O}) \mathrm{NC}(\mathrm{NN} 2 \mathrm{C}(=\mathrm{O}) / \mathrm{C}(=\mathrm{C} \mid \mathrm{c} 3 \operatorname{ccco} 3) \mathrm{SC} 2=\mathrm{S})=\mathrm{N} 1$ & 99300 & $*$ \\
\hline 5161 & $\mathrm{O}=\mathrm{C} 1 / \mathrm{C}(=\mathrm{C} \mid \mathrm{c} 2 \mathrm{ccc}(\mathrm{O}) \mathrm{c}(\mathrm{O}) \mathrm{c} 2) \mathrm{Oc} 2 \mathrm{ccccc} 21$ & 100000 & 4.00 \\
\hline 5162 & $\mathrm{Cn} 1 \mathrm{c}(\mathrm{SSc} 2 \mathrm{c}(\mathrm{C}(=\mathrm{O}) \mathrm{Nc} 3 \operatorname{cccc} 3) \mathrm{c} 3 \operatorname{ccc}(\mathrm{O}) \mathrm{c} 3 \mathrm{n} 2 \mathrm{C}) \mathrm{c}(\mathrm{C}(=\mathrm{O}) \mathrm{Nc} 2 \operatorname{ccccc} 2) \operatorname{c} 2 \operatorname{ccc}(\mathrm{O}) \mathrm{c} 21$ & 100000 & $*$ \\
\hline 5163 & $\mathrm{Cn} 1 \mathrm{c}(\mathrm{SSc} 2 \mathrm{c}(\mathrm{C}(=\mathrm{O}) \mathrm{Nc} 3 \operatorname{ccc} c 3) \mathrm{c} 3 \mathrm{c}(\mathrm{Cl}) \operatorname{ccc} 3 \mathrm{n} 2 \mathrm{C}) \mathrm{c}(\mathrm{C}(=\mathrm{O}) \mathrm{Nc} 2 \operatorname{ccccc} 2) \mathrm{c} 2 \mathrm{c}(\mathrm{Cl}) \operatorname{ccc} 21$ & 100000 & $*$ \\
\hline 5164 & $\operatorname{CCOC}(=\mathrm{O}) \operatorname{Cc} 1 \operatorname{cc}(/ \mathrm{N}=\mathrm{C} / \mathrm{c} 2 \operatorname{cc}(\mathrm{O}) \operatorname{ccc} 2 \mathrm{O}) \operatorname{ccc} 1 \mathrm{O}$ & 100000 & * \\
\hline 5165 & $\operatorname{COC}(=\mathrm{O}) \mathrm{Cc} 1 \mathrm{cc}(/ \mathrm{N}=\mathrm{C} / \mathrm{c} 2 \mathrm{cc}(\mathrm{O}) \operatorname{ccc} 2 \mathrm{O}) \operatorname{ccc} 1 \mathrm{O}$ & 100000 & $*$ \\
\hline 5166 & $\mathrm{CN}(\mathrm{c} 1 \mathrm{ccccc} 1) \mathrm{c} 1 \mathrm{ncnc} 2 \mathrm{ccccc} 12$ & 100000 & * \\
\hline 5167 & $\operatorname{COC}(=\mathrm{O}) \mathrm{CC} 1 \mathrm{C}(\mathrm{S})=\mathrm{Nc} 2 \operatorname{ccccc} 21$ & 100000 & $*$ \\
\hline 5168 & 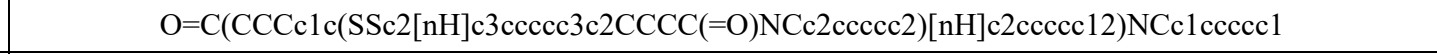 & 100000 & $*$ \\
\hline 5169 & $\mathrm{O}=\mathrm{C}(\mathrm{CCC} 1 \mathrm{C}(\mathrm{S})=\mathrm{Nc} 2 \operatorname{ccccc} 21) \mathrm{NCc} 1 \operatorname{ccccc} 1$ & 100000 & $*$ \\
\hline 5170 & $\begin{array}{c}\operatorname{COC}(=\mathrm{O}) \mathrm{c} 1 \operatorname{ccc}(\mathrm{CNC}(=\mathrm{O}) \mathrm{CCc} 2 \mathrm{c}(\mathrm{SSc} 3[\mathrm{nH}] \mathrm{c} 4 \operatorname{ccccc} 4 \mathrm{c} 3 \mathrm{CCC}(=\mathrm{O}) \mathrm{NCc} 3 \operatorname{ccc}(\mathrm{C}(=\mathrm{O}) \mathrm{OC}) \mathrm{c}(\mathrm{O}) \mathrm{c} 3)[\mathrm{nH}] \mathrm{c} 3 \operatorname{ccccc} 23) \operatorname{cc} 1 \\
\mathrm{O}\end{array}$ & 100000 & $*$ \\
\hline 5171 & $\mathrm{O}=\mathrm{C}(\mathrm{CC} 1 \mathrm{C}(\mathrm{S})=\mathrm{Nc} 2 \operatorname{cccc} 21) \mathrm{NCc} 1 \operatorname{ccccc} 1$ & 100000 & $*$ \\
\hline 5172 & COc1cccce1CNc1ncnc2cc(N)ncc12 & 100000 & $*$ \\
\hline 5173 & $\mathrm{CC}(\mathrm{CN}(\mathrm{C}) \mathrm{C}) \mathrm{C}(=\mathrm{O}) \mathrm{c} 1 \operatorname{ccc}(\mathrm{OS}(=\mathrm{O})(=\mathrm{O}) \mathrm{c} 2 \mathrm{ccc}(\mathrm{C}(=\mathrm{O}) \mathrm{O}) \operatorname{cc} 2) \mathrm{cc} 1 . \mathrm{Cl}$ & 100000 & * \\
\hline 5174 & $\operatorname{COc} 1 \operatorname{ccccc} 1 \mathrm{C}(=\mathrm{O}) \mathrm{Nc} 1 \operatorname{cccc}(\mathrm{Nc} 2 \mathrm{nccc}(-\mathrm{c} 3 \operatorname{ccc} n \mathrm{c} 3) \mathrm{n} 2) \mathrm{c} 1$ & 100000 & $*$ \\
\hline 5175 & $\mathrm{O}=[\mathrm{N}+]([\mathrm{O}-]) \mathrm{c} 1 \mathrm{cccc}(\mathrm{Nc} 2 \mathrm{nccc}(-\mathrm{c} 3 \operatorname{ccc} n \mathrm{c} 3) \mathrm{n} 2) \mathrm{c} 1$ & 100000 & $*$ \\
\hline 5176 & $\mathrm{c} 1 \mathrm{ccc}(\mathrm{Nc} 2 \mathrm{nccc}(-\mathrm{c} 3 \mathrm{ccc} n \mathrm{c} 3) \mathrm{n} 2) \mathrm{cc} 1$ & 100000 & $*$ \\
\hline 5177 & $\mathrm{CNN} 1 \mathrm{C}(=\mathrm{O}) \mathrm{c} 2 \mathrm{c}(\mathrm{c} 3 \mathrm{c} 4 \operatorname{cccc}(\mathrm{O}) \mathrm{c} 4 \mathrm{n}(\mathrm{C} 4 \mathrm{OC}(\mathrm{CO}) \mathrm{C}(\mathrm{O}) \mathrm{C}(\mathrm{O}) \mathrm{C} 4 \mathrm{O}) \mathrm{c} 3 \mathrm{c} 3[\mathrm{nH}] \mathrm{c} 4 \mathrm{c}(\mathrm{O}) \operatorname{ccc} 4 \mathrm{c} 23) \mathrm{C} 1=\mathrm{O}$ & 100000 & $*$ \\
\hline 5178 & $\mathrm{Cc} 1 \mathrm{nc}(\mathrm{O}) \mathrm{c} 2 \mathrm{c}(\mathrm{ccc} 3[\mathrm{nH}] \mathrm{c}(\mathrm{Nc} 4 \mathrm{c}(\mathrm{Cl}) \mathrm{cccc} 4 \mathrm{Cl}) \mathrm{nc} 32) \mathrm{c} 1 \mathrm{C}$ & 100000 & $*$ \\
\hline 5179 & $\mathrm{CC}(\mathrm{C}) \mathrm{n} 1 \mathrm{nc}(-\mathrm{c} 2 \mathrm{cncnc} 2) \mathrm{c} 2 \mathrm{c}(\mathrm{N}) \mathrm{ncnc} 21$ & 100000 & $*$ \\
\hline 5180 & $\mathrm{CC}(\mathrm{C}) \mathrm{n} 1 \mathrm{nc}(-\mathrm{c} 2 \mathrm{ccc} 3 \mathrm{nccc}(\mathrm{N}) \mathrm{c} 3 \mathrm{c} 2) \mathrm{c} 2 \mathrm{c}(\mathrm{N}) \mathrm{ncnc} 21$ & 100000 & $*$ \\
\hline 5181 & $\mathrm{CC}(\mathrm{C}) \mathrm{n} 1 \mathrm{nc}(-\mathrm{c} 2 \mathrm{ccc}(\mathrm{C \# N}) \mathrm{nc} 2) \mathrm{c} 2 \mathrm{c}(\mathrm{N}) \mathrm{ncnc} 21$ & 100000 & $*$ \\
\hline 5182 & Nc1ncnc2c1c(-c1cce(F)c(O)c1)nn2CC1CCNCC1 & 100000 & $*$ \\
\hline 5183 & COc1ccc(-c2n[nH]c3ncnc(N)c23)cc1O & 100000 & * \\
\hline 5184 & $\mathrm{CC}(\mathrm{C}) \mathrm{n} 1 \mathrm{nc}(-\mathrm{c} 2 \mathrm{cccnc} 2) \mathrm{c} 2 \mathrm{c}(\mathrm{N}) \mathrm{ncnc} 21$ & 100000 & $*$ \\
\hline
\end{tabular}




\begin{tabular}{|c|c|c|c|}
\hline 5185 & $\mathrm{CCOc} 1 \mathrm{ccc}(-\mathrm{c} 2 \mathrm{n}[\mathrm{nH}] \mathrm{c} 3 \mathrm{ncnc}(\mathrm{N}) \mathrm{c} 23) \mathrm{cc} 1 \mathrm{OC}$ & 100000 & $*$ \\
\hline 5186 & $\mathrm{CC}(\mathrm{C}) \mathrm{n} 1 \mathrm{nc}(-\mathrm{c} 2 \mathrm{cccc}(\mathrm{CHN}) \mathrm{c} 2) \mathrm{c} 2 \mathrm{c}(\mathrm{N}) \mathrm{ncnc} 21$ & 100000 & $*$ \\
\hline 5187 & $\mathrm{Cc} 1 \mathrm{ccc} 2 \mathrm{cc}(-\mathrm{c} 3 n n(\mathrm{C}(\mathrm{C}) \mathrm{C}) \mathrm{c} 4 \mathrm{ncnc}(\mathrm{N}) \mathrm{c} 34) \operatorname{ccc} 2 \mathrm{n} 1$ & 100000 & $*$ \\
\hline 5188 & $\mathrm{Cn} 1 \mathrm{nc}(-\mathrm{c} 2 \mathrm{ccc}(\mathrm{Br}) \mathrm{c}(\mathrm{O}) \mathrm{c} 2) \mathrm{c} 2 \mathrm{c}(\mathrm{N}) \mathrm{ncnc} 21$ & 100000 & $*$ \\
\hline 5189 & $\mathrm{CC}(\mathrm{C}) \mathrm{n} 1 \mathrm{nc}(-\mathrm{c} 2 \mathrm{cccc}(\mathrm{NS}(\mathrm{C})(=\mathrm{O})=\mathrm{O}) \mathrm{c} 2) \mathrm{c} 2 \mathrm{c}(\mathrm{N}) \mathrm{ncnc} 21$ & 100000 & $*$ \\
\hline 5190 & $\mathrm{CC}(\mathrm{C}) \mathrm{n} 1 \mathrm{nc}(-\mathrm{c} 2 \mathrm{ccc} 3 \mathrm{ccncc} 3 \mathrm{c} 2) \mathrm{c} 2 \mathrm{c}(\mathrm{N}) \mathrm{ncnc} 21$ & 100000 & $*$ \\
\hline 5191 & $\mathrm{CC}(\mathrm{C}) \mathrm{n} 1 \mathrm{nc}(-\mathrm{c} 2 \mathrm{cccc}(\mathrm{CO}) \mathrm{c} 2) \mathrm{c} 2 \mathrm{c}(\mathrm{N}) \mathrm{ncnc} 21$ & 100000 & $*$ \\
\hline 5192 & Nc1ncnc2c1c(-c1ccc(Cl)c(O)c1)nn2CC1CCNCC1 & 100000 & $*$ \\
\hline 5193 & $\mathrm{Cc} 1 \mathrm{nn}(-\mathrm{c} 2 \mathrm{ccccc} 2) \mathrm{nc} 1 \mathrm{Cn} 1 \mathrm{nc}(-\mathrm{c} 2 \mathrm{ccc}(\mathrm{F}) \mathrm{c}(\mathrm{O}) \mathrm{c} 2) \mathrm{c} 2 \mathrm{c}(\mathrm{N}) \mathrm{ncn} 21$ & 100000 & $*$ \\
\hline 5194 & $\mathrm{CC}(\mathrm{C}) \mathrm{n} 1 \mathrm{nc}(-\mathrm{c} 2 \mathrm{cccc}(\mathrm{S}(\mathrm{N})(=\mathrm{O})=\mathrm{O}) \mathrm{c} 2) \mathrm{c} 2 \mathrm{c}(\mathrm{N}) \mathrm{ncnc} 21$ & 100000 & $*$ \\
\hline 5195 & $\mathrm{COc} 1 \mathrm{ccc}(-\mathrm{c} 2 \mathrm{nn}(\mathrm{C}) \mathrm{c} 3 \mathrm{ncnc}(\mathrm{N}) \mathrm{c} 23) \mathrm{cc} 1 \mathrm{O}$ & 100000 & $*$ \\
\hline 5196 & $\mathrm{CC}(\mathrm{C}) \mathrm{n} 1 \mathrm{nc}(-\mathrm{c} 2 \mathrm{ccc} 3 \mathrm{nc}(\mathrm{Cl}) \mathrm{ccc} 3 \mathrm{c} 2) \mathrm{c} 2 \mathrm{c}(\mathrm{N}) \mathrm{ncnc} 21$ & 100000 & $*$ \\
\hline 5197 & $\mathrm{CC}(\mathrm{C}) \mathrm{n} 1 \mathrm{nc}(-\mathrm{c} 2 \mathrm{cc} 3 \mathrm{cc}(\mathrm{C}=\mathrm{O}) \operatorname{ccc} 3 \mathrm{~s} 2) \mathrm{c} 2 \mathrm{c}(\mathrm{N}) \mathrm{ncnc} 21$ & 100000 & $*$ \\
\hline 5198 & $\mathrm{CC}(\mathrm{C}) \mathrm{n} 1 \mathrm{nc}(-\mathrm{c} 2 \mathrm{ccc} 3 \mathrm{nccc}(\mathrm{NC}(=\mathrm{O}) \mathrm{OC}(\mathrm{C})(\mathrm{C}) \mathrm{C}) \mathrm{c} 3 \mathrm{c} 2) \mathrm{c} 2 \mathrm{c}(\mathrm{N}) \mathrm{ncnc} 21$ & 100000 & $*$ \\
\hline 5199 & Nc1ncnc2c1c(-c1ecc(F)c(O)c1)nn2Cc1ocnc1-c1eccec1 & 100000 & $*$ \\
\hline 5200 & $\mathrm{CC}(\mathrm{C}) \mathrm{n} 1 \mathrm{nc}(-\mathrm{c} 2 \mathrm{ccc}(\mathrm{F}) \mathrm{c}(\mathrm{C \# N}) \mathrm{c} 2) \mathrm{c} 2 \mathrm{c}(\mathrm{N}) \mathrm{ncnc} 21$ & 100000 & * \\
\hline 5201 & $\mathrm{C}[\mathrm{C} @ \mathrm{H}](\mathrm{CN}) \mathrm{n} 1 \mathrm{nc}(-\mathrm{c} 2 \mathrm{ccc}(\mathrm{F}) \mathrm{c}(\mathrm{O}) \mathrm{c} 2) \mathrm{c} 2 \mathrm{c}(\mathrm{N}) \mathrm{ncnc} 21$ & 100000 & $*$ \\
\hline 5202 & $\mathrm{CC}(\mathrm{C}) \mathrm{n} 1 \mathrm{nc}(-\mathrm{c} 2 \mathrm{cc} 3 \mathrm{ccccc} 3 \mathrm{nc} 2 \mathrm{Cl}) \mathrm{c} 2 \mathrm{c}(\mathrm{N}) \mathrm{ncnc} 21$ & 100000 & $*$ \\
\hline 5203 & COc1ncc(-c2nn(C(C)C)c3ncnc(N)c23)c(OC)n1 & 100000 & $*$ \\
\hline 5204 & $\mathrm{CC}(\mathrm{C}) \mathrm{n} 1 \mathrm{nc}(-\mathrm{c} 2 \mathrm{ccc}(\mathrm{C}(\mathrm{N})=\mathrm{O}) \mathrm{c}(\mathrm{Cl}) \mathrm{c} 2) \mathrm{c} 2 \mathrm{c}(\mathrm{N}) \mathrm{ncnc} 21$ & 100000 & * \\
\hline 5205 & $\mathrm{CC}(\mathrm{C}) \mathrm{n} 1 \mathrm{nc}(-\mathrm{c} 2 \mathrm{ccc}(\mathrm{S}(\mathrm{N})(=\mathrm{O})=\mathrm{O}) \mathrm{cc} 2) \mathrm{c} 2 \mathrm{c}(\mathrm{N}) \mathrm{ncnc} 21$ & 100000 & $*$ \\
\hline 5206 & Nc1ncnc2c1c(-c1ccc3occc(=O)c3c1)nn2C1CCCC1 & 100000 & * \\
\hline 5207 & $\mathrm{C}[\mathrm{C} @ \mathrm{H}](\mathrm{Nc} 1 \mathrm{ncnc} 2 \mathrm{c} 1[\mathrm{nH}] \mathrm{c} 1 \mathrm{ccccc} 12) \mathrm{c} 1 \mathrm{ccccc} 1$ & 100000 & $*$ \\
\hline 5208 & $\mathrm{c} 1 \mathrm{ccc} 2 \mathrm{c}(\mathrm{c} 1)[\mathrm{nH}] \mathrm{c} 1 \mathrm{c}(\mathrm{NC} 3 \mathrm{CCCCC} 3) \mathrm{ncnc} 12$ & 100000 & * \\
\hline 5209 & $\mathrm{Cc} 1 \mathrm{nc}(\mathrm{Nc} 2 \operatorname{cccc}(\mathrm{Br}) \mathrm{c} 2) \mathrm{c} 2 \mathrm{c}(\mathrm{n} 1)[\mathrm{nH}] \mathrm{c} 1 \mathrm{ccccc} 12$ & 100000 & * \\
\hline 5210 & $\mathrm{C}[\mathrm{C} @ \mathrm{H}](\mathrm{Nc} 1 \mathrm{ncnc} 2 \mathrm{c} 1[\mathrm{nH}] \mathrm{c} 1 \mathrm{cccc} 12) \mathrm{c} 1 \mathrm{ccccc} 1 . \mathrm{Cl}$ & 100000 & $*$ \\
\hline 5211 & $\mathrm{CN}(\mathrm{C}) \mathrm{CCNc} 1 \mathrm{ncnc} 2 \mathrm{c} 1[\mathrm{nH}] \mathrm{c} 1 \mathrm{ccccc} 12 . \mathrm{Cl}$ & 100000 & $*$ \\
\hline 5212 & OCCNc1nc(Nc2 $\operatorname{cccc}(\mathrm{F}) \mathrm{c} 2) \mathrm{c} 2 \mathrm{cn}[\mathrm{nH}] \mathrm{c} 2 \mathrm{n} 1$ & 100000 & * \\
\hline 5213 & $\mathrm{COc} 1 \mathrm{cccc}(\mathrm{Nc} 2 \mathrm{nc}(\mathrm{NCCO}) \mathrm{nc} 3[\mathrm{nH}] \mathrm{ncc} 23) \mathrm{c} 1$ & 100000 & $*$ \\
\hline 5214 & $\mathrm{COc} 1 \mathrm{cccc}(\mathrm{Nc} 2 \mathrm{nc}(\mathrm{NCCO}) \mathrm{nc} 3 \mathrm{c} 2 \mathrm{cnn} 3 \mathrm{C}) \mathrm{c} 1$ & 100000 & $*$ \\
\hline 5215 & $\mathrm{OCCNc} 1 \mathrm{nc}(\mathrm{Nc} 2 \mathrm{cccc}(\mathrm{Br}) \mathrm{c} 2) \mathrm{c} 2 \mathrm{cn}[\mathrm{nH}] \mathrm{c} 2 \mathrm{n} 1$ & 100000 & $*$ \\
\hline 5216 & $\mathrm{Cn} 1 \mathrm{ncc} 2 \mathrm{c}(\mathrm{Nc} 3 \operatorname{cccc}(\mathrm{Br}) \mathrm{c} 3) \mathrm{nc}(\mathrm{NCCO}) \mathrm{nc} 21$ & 100000 & * \\
\hline 5217 & $\mathrm{Cn} 1 \mathrm{ncc} 2 \mathrm{c}(\mathrm{NCc} 3 \mathrm{ccc}(\mathrm{N}) \mathrm{cc} 3) \mathrm{nc}(\mathrm{NCCO}) \mathrm{nc} 21$ & 100000 & $*$ \\
\hline 5218 & $\mathrm{CC}(\mathrm{C}) \mathrm{n} 1 \mathrm{ncc} 2 \mathrm{c}(\mathrm{Nc} 3 \mathrm{cccc}(\mathrm{F}) \mathrm{c} 3) \mathrm{nc}(\mathrm{NCCO}) \mathrm{nc} 21$ & 100000 & $*$ \\
\hline 5219 & $\mathrm{CC}(\mathrm{C}) \mathrm{n} 1 \mathrm{ncc} 2 \mathrm{c}(\mathrm{Nc} 3 \operatorname{cccc}(\mathrm{Br}) \mathrm{c} 3) \mathrm{nc}(\mathrm{NCCO}) \mathrm{nc} 21$ & 100000 & * \\
\hline 5220 & $\mathrm{COc} 1 \mathrm{ccc}(\mathrm{Nc} 2 \mathrm{nc}(\mathrm{NCCO}) \mathrm{nc} 3 \mathrm{c} 2 \mathrm{cnn} 3 \mathrm{C}(\mathrm{C}) \mathrm{C}) \mathrm{c} 1$ & 100000 & $*$ \\
\hline 5221 & $\mathrm{OCCN}(\mathrm{CCO}) \mathrm{c} 1 \mathrm{nc}(\mathrm{NCc} 2 \mathrm{ccccc} 2) \mathrm{c} 2 \mathrm{cn}[\mathrm{nH}] \mathrm{c} 2 \mathrm{n} 1$ & 100000 & * \\
\hline 5222 & $\mathrm{OCCN}(\mathrm{CCO}) \mathrm{c} 1 \mathrm{nc}(\mathrm{Nc} 2 \mathrm{cccc}(\mathrm{Br}) \mathrm{c} 2) \mathrm{c} 2 \mathrm{cn}[\mathrm{nH}] \mathrm{c} 2 \mathrm{n} 1$ & 100000 & $*$ \\
\hline 5223 & $\mathrm{COc} 1 \mathrm{cccc}(\mathrm{Nc} 2 \mathrm{nc}(\mathrm{N}(\mathrm{CCO}) \mathrm{CCO}) \mathrm{nc} 3[\mathrm{nH}] \mathrm{ncc} 23) \mathrm{c} 1$ & 100000 & $*$ \\
\hline 5224 & $\mathrm{OCCN}(\mathrm{CCO}) \mathrm{c} 1 \mathrm{nc}(\mathrm{Nc} 2 \mathrm{cccc}(\mathrm{F}) \mathrm{c} 2) \mathrm{c} 2 \mathrm{cn}[\mathrm{nH}] \mathrm{c} 2 \mathrm{n} 1$ & 100000 & * \\
\hline 5225 & $\mathrm{COc} 1 \mathrm{cccc}(\mathrm{Nc} 2 \mathrm{nc}(\mathrm{N}(\mathrm{CCO}) \mathrm{CCO}) \mathrm{nc} 3 \mathrm{c} 2 \mathrm{cnn} 3 \mathrm{C}) \mathrm{c} 1$ & 100000 & $*$ \\
\hline 5226 & $\mathrm{CC}(\mathrm{C}) \mathrm{n} 1 \mathrm{ncc} 2 \mathrm{c}(\mathrm{NCc} 3 \operatorname{ccc}([\mathrm{N}+](=\mathrm{O})[\mathrm{O}-]) \mathrm{cc} 3) \mathrm{nc}(\mathrm{NCCO}) \mathrm{nc} 21$ & 100000 & $*$ \\
\hline 5227 & $\mathrm{CC}(\mathrm{C}) \mathrm{n} 1 \mathrm{ncc} 2 \mathrm{c}(\mathrm{NCc} 3 \mathrm{ccccc} 3) \mathrm{nc}(\mathrm{N}(\mathrm{CCO}) \mathrm{CCO}) \mathrm{nc} 21$ & 100000 & $*$ \\
\hline
\end{tabular}




\begin{tabular}{|c|c|c|c|}
\hline 5228 & $\mathrm{Cn} 1 \mathrm{ncc} 2 \mathrm{c}(\mathrm{Nc} 3 \mathrm{cccc}(\mathrm{Br}) \mathrm{c} 3) \mathrm{nc}(\mathrm{N}(\mathrm{CCO}) \mathrm{CCO}) \mathrm{nc} 21$ & 100000 & $*$ \\
\hline 5229 & $\mathrm{CC}(\mathrm{C}) \mathrm{n} 1 \mathrm{ncc} 2 \mathrm{c}(\mathrm{Nc} 3 \mathrm{cccc}(\mathrm{F}) \mathrm{c} 3) \mathrm{nc}(\mathrm{N}(\mathrm{CCO}) \mathrm{CCO}) \mathrm{nc} 21$ & 100000 & $*$ \\
\hline 5230 & $\mathrm{CC}(\mathrm{C}) \mathrm{n} 1 \mathrm{ncc} 2 \mathrm{c}(\mathrm{Nc} 3 \mathrm{cccc}(\mathrm{Br}) \mathrm{c} 3) \mathrm{nc}(\mathrm{N}(\mathrm{CCO}) \mathrm{CCO}) \mathrm{nc} 21$ & 100000 & $*$ \\
\hline 5231 & $\mathrm{COc} 1 \mathrm{ccc}(\mathrm{Nc} 2 \mathrm{nc}(\mathrm{N}(\mathrm{CCO}) \mathrm{CCO}) \mathrm{nc} 3 \mathrm{c} 2 \mathrm{cnn} 3 \mathrm{C}(\mathrm{C}) \mathrm{C}) \mathrm{c} 1$ & 100000 & $*$ \\
\hline 5232 & OCCNc1nc(NCc2 $\operatorname{cccc}(\mathrm{Br}) \mathrm{c} 2) \mathrm{c} 2 \mathrm{cn}[\mathrm{nH}] \mathrm{c} 2 \mathrm{n} 1$ & 100000 & $*$ \\
\hline 5233 & $\mathrm{OCCN}(\mathrm{CCO}) \mathrm{c} 1 \mathrm{nc}(\mathrm{NCc} 2 \mathrm{cccc}(\mathrm{Br}) \mathrm{c} 2) \mathrm{c} 2 \mathrm{cn}[\mathrm{nH}] \mathrm{c} 2 \mathrm{n} 1$ & 100000 & $*$ \\
\hline 5234 & $\mathrm{CC}(\mathrm{C}) \mathrm{n} 1 \mathrm{ncc} 2 \mathrm{c}(\mathrm{NCc} 3 \operatorname{ccc}(\mathrm{Br}) \mathrm{c} 3) \mathrm{nc}(\mathrm{NCCO}) \mathrm{nc} 21$ & 100000 & $*$ \\
\hline 5235 & $\mathrm{CC}(\mathrm{C}) \mathrm{n} 1 \mathrm{ncc} 2 \mathrm{c}(\mathrm{NCc} 3 \operatorname{ccc}(\mathrm{Br}) \mathrm{c} 3) \mathrm{nc}(\mathrm{N}(\mathrm{CCO}) \mathrm{CCO}) \mathrm{nc} 21$ & 100000 & $*$ \\
\hline 5236 & OCCNc1nc(NCc2 $\operatorname{ccc}(\mathrm{F}) \mathrm{c} 2) \mathrm{c} 2 \mathrm{cn}[\mathrm{nH}] \mathrm{c} 2 \mathrm{n} 1$ & 100000 & $*$ \\
\hline 5237 & $\mathrm{Cn} 1 \mathrm{ncc} 2 \mathrm{c}(\mathrm{NCc} 3 \mathrm{cccc}(\mathrm{F}) \mathrm{c} 3) \mathrm{nc}(\mathrm{NCCO}) \mathrm{nc} 21$ & 100000 & $*$ \\
\hline 5238 & $\mathrm{Cn} 1 \mathrm{ncc} 2 \mathrm{c}(\mathrm{NCc} 3 \mathrm{cccc}(\mathrm{F}) \mathrm{c} 3) \mathrm{nc}(\mathrm{N}(\mathrm{CCO}) \mathrm{CCO}) \mathrm{nc} 21$ & 100000 & $*$ \\
\hline 5239 & $\mathrm{CC}(\mathrm{C}) \mathrm{n} 1 \mathrm{ncc} 2 \mathrm{c}(\mathrm{NCc} 3 \operatorname{cccc}(\mathrm{F}) \mathrm{c} 3) \mathrm{nc}(\mathrm{N}(\mathrm{CCO}) \mathrm{CCO}) \mathrm{nc} 21$ & 100000 & $*$ \\
\hline 5240 & $\mathrm{COc} 1 \mathrm{cccc}(\mathrm{CNc} 2 \mathrm{nc}(\mathrm{NCCO}) \mathrm{nc} 3[\mathrm{nH}] \mathrm{ncc} 23) \mathrm{c} 1$ & 100000 & $*$ \\
\hline 5241 & $\mathrm{COc} 1 \mathrm{cccc}(\mathrm{CNc} 2 \mathrm{nc}(\mathrm{N}(\mathrm{CCO}) \mathrm{CCO}) \mathrm{nc} 3[\mathrm{nH}] \mathrm{ncc} 23) \mathrm{c} 1$ & 100000 & $*$ \\
\hline 5242 & $\mathrm{COc} 1 \mathrm{ccc}(\mathrm{CNc} 2 \mathrm{nc}(\mathrm{NCCO}) \mathrm{nc} 3 \mathrm{c} 2 \mathrm{cnn} 3 \mathrm{C}) \mathrm{c} 1$ & 100000 & $*$ \\
\hline 5243 & $\mathrm{COc} 1 \mathrm{cccc}(\mathrm{CNc} 2 \mathrm{nc}(\mathrm{N}(\mathrm{CCO}) \mathrm{CCO}) \mathrm{nc} 3 \mathrm{c} 2 \mathrm{cnn} 3 \mathrm{C}) \mathrm{c} 1$ & 100000 & $*$ \\
\hline 5244 & $\mathrm{COc} 1 \mathrm{cccc}(\mathrm{CNc} 2 \mathrm{nc}(\mathrm{NCCO}) \mathrm{nc} 3 \mathrm{c} 2 \mathrm{cnn} 3 \mathrm{C}(\mathrm{C}) \mathrm{C}) \mathrm{c} 1$ & 100000 & $*$ \\
\hline 5245 & $\mathrm{COc} 1 \mathrm{cccc}(\mathrm{CNc} 2 \mathrm{nc}(\mathrm{N}(\mathrm{CCO}) \mathrm{CCO}) \mathrm{nc} 3 \mathrm{c} 2 \mathrm{cnn} 3 \mathrm{C}(\mathrm{C}) \mathrm{C}) \mathrm{c} 1$ & 100000 & $*$ \\
\hline 5246 & $\mathrm{COc} 1 \mathrm{cc} 2 \mathrm{nccc}(\mathrm{Oc} 3 \mathrm{ccc}(\mathrm{N}) \mathrm{cc} 3) \mathrm{c} 2 \mathrm{cc} 1 \mathrm{OC}$ & 100000 & $*$ \\
\hline 5247 & $\operatorname{COc} 1 \mathrm{cc} 2 \mathrm{nccc}(\mathrm{Oc} 3 \operatorname{ccc}(\mathrm{C}(=\mathrm{O}) \mathrm{c} 4 \operatorname{ccc}(\mathrm{C}(\mathrm{C})(\mathrm{C}) \mathrm{C}) \mathrm{cc} 4) \mathrm{cc} 3) \mathrm{c} 2 \mathrm{cc} 1 \mathrm{OC}$ & 100000 & $*$ \\
\hline 5248 & $\mathrm{COc} 1 \mathrm{cc} 2 \mathrm{nccc}(\mathrm{Oc} 3 \operatorname{ccc}(\mathrm{NC}(=\mathrm{O}) \mathrm{c} 4 \operatorname{cccs} 4) \operatorname{cc} 3) \mathrm{c} 2 \mathrm{cc} 1 \mathrm{OC}$ & 100000 & $*$ \\
\hline 5249 & $\operatorname{cOc} 1 \mathrm{cc} 2 \mathrm{nccc}(\mathrm{Oc} 3 \operatorname{ccc}(\mathrm{NC}(=\mathrm{O}) \mathrm{c} 4 \mathrm{ccco} 4) \mathrm{cc} 3) \mathrm{c} 2 \mathrm{cc} 1 \mathrm{OC}$ & 100000 & $*$ \\
\hline 5250 & $\mathrm{COc} 1 \mathrm{cc} 2 \mathrm{nccc}(\mathrm{Oc} 3 \mathrm{ccc}(\mathrm{OC}) \mathrm{c} 3 \mathrm{OC}) \mathrm{c} 2 \mathrm{cc} 1 \mathrm{OC}$ & 100000 & $*$ \\
\hline 5251 & $\operatorname{COc} 1 \operatorname{cc} 2 n \operatorname{ccc}(\mathrm{Oc} 3 \operatorname{cccc}(\mathrm{C}(\mathrm{C})=\mathrm{O}) \mathrm{c} 3) \mathrm{c} 2 \mathrm{cc} 1 \mathrm{OC}$ & 100000 & $*$ \\
\hline 5252 & $\operatorname{cOc} 1 \operatorname{cc} 2 n \operatorname{ccc}(\mathrm{Oc} 3 \operatorname{ccc}(\mathrm{C}(=\mathrm{O}) \mathrm{c} 4 \mathrm{ccc}(\mathrm{C}) \mathrm{cc} 4) \mathrm{cc} 3) \mathrm{c} 2 \mathrm{cc} 1 \mathrm{OC}$ & 100000 & $*$ \\
\hline 5253 & $\mathrm{COc} 1 \mathrm{cc} 2 \mathrm{nccc}(\mathrm{Oc} 3 \operatorname{ccc}(\mathrm{C}(=\mathrm{O}) \mathrm{c} 4 \mathrm{ccc}(\mathrm{Br}) \mathrm{cc} 4) \mathrm{cc} 3) \mathrm{c} 2 \mathrm{cc} 1 \mathrm{OC}$ & 100000 & $*$ \\
\hline 5254 & $\operatorname{COc} 1 \operatorname{cc} 2 n \operatorname{ccc}(\mathrm{Oc} 3 \operatorname{ccc}(\mathrm{C}(=\mathrm{O}) \mathrm{c} 4 \operatorname{ccc}(\mathrm{Cl}) \operatorname{cc} 4) \operatorname{cc} 3) \operatorname{coc} 1 \mathrm{OC}$ & 100000 & $*$ \\
\hline 5255 & $\mathrm{COc} 1 \mathrm{cc} 2 \mathrm{nccc}(\mathrm{Oc} 3 \operatorname{ccc}(\mathrm{NC}(=\mathrm{O}) \mathrm{C} 4 \mathrm{CCCC} 4) \operatorname{cc} 3) \mathrm{c} 2 \mathrm{cc} 1 \mathrm{OC}$ & 100000 & $*$ \\
\hline 5256 & $\operatorname{COc} 1 \mathrm{cc} 2 \mathrm{nccc}(\mathrm{Oc} 3 \operatorname{ccc}(\mathrm{C}(=\mathrm{O}) \mathrm{c} 4 \mathrm{ccc}(\mathrm{I}) \mathrm{cc} 4) \mathrm{cc} 3) \mathrm{c} 2 \mathrm{cc} 1 \mathrm{OC}$ & 100000 & $*$ \\
\hline 5257 & $\mathrm{COc} 1 \mathrm{cc} 2 \mathrm{nccc}(\mathrm{Oc} 3 \operatorname{ccc}(\mathrm{C}(=\mathrm{O}) \mathrm{C} 4 \mathrm{CCCCC} 4) \mathrm{cc} 3) \mathrm{c} 2 \mathrm{cc} 1 \mathrm{OC}$ & 100000 & $*$ \\
\hline 5258 & $\operatorname{COc} 1 \mathrm{cc} 2 \mathrm{nccc}(\mathrm{Oc} 3 \operatorname{ccc}(\mathrm{C}(=\mathrm{O}) \mathrm{c} 4 \mathrm{ccc}([\mathrm{N}+](=\mathrm{O})[\mathrm{O}-]) \operatorname{cc} 4) \operatorname{cc} 3) \mathrm{c} 2 \mathrm{cc} 1 \mathrm{OC}$ & 100000 & $*$ \\
\hline 5259 & $\operatorname{COc} 1 \mathrm{cc} 2 \mathrm{nccc}(\mathrm{Oc} 3 \operatorname{ccc}(\mathrm{C}(=\mathrm{O}) \mathrm{c} 4 \mathrm{ccc}(\mathrm{C \# N}) \mathrm{cc} 4) \mathrm{cc} 3) \mathrm{c} 2 \mathrm{cc} 1 \mathrm{OC}$ & 100000 & $*$ \\
\hline 5260 & $\mathrm{COc} 1 \mathrm{cc} 2 \mathrm{nccc}(\mathrm{Oc} 3 \operatorname{ccc}(\mathrm{NC}(=\mathrm{O}) \mathrm{c} 4 \mathrm{ccc}(\mathrm{C}(\mathrm{C})=\mathrm{O}) \mathrm{cc} 4) \mathrm{cc} 3) \mathrm{c} 2 \mathrm{cc} 1 \mathrm{OC}$ & 100000 & $*$ \\
\hline 5261 & $\mathrm{COc} 1 \mathrm{cc} 2 \mathrm{nccc}(\mathrm{Oc} 3 \operatorname{ccc}(\mathrm{NC}(=\mathrm{O}) \mathrm{c} 4 \mathrm{ccc}(\mathrm{C}(\mathrm{C})(\mathrm{C}) \mathrm{C}) \mathrm{cc} 4) \mathrm{cc} 3) \mathrm{c} 2 \mathrm{cc} 1 \mathrm{OC}$ & 100000 & $*$ \\
\hline 5262 & $\operatorname{COc} 1 \operatorname{cc} 2 \mathrm{n} \operatorname{ccc}(\mathrm{Oc} 3 \operatorname{ccc}(\mathrm{NC}(=\mathrm{O}) \mathrm{c} 4 \operatorname{ccc}([\mathrm{N}+](=\mathrm{O})[\mathrm{O}-]) \operatorname{cc} 4) \operatorname{cc} 3) \mathrm{c} 2 \mathrm{cc} 1 \mathrm{OC}$ & 100000 & $*$ \\
\hline 5263 & $\operatorname{CCCCc} 1 \operatorname{ccc}(\mathrm{C}(=\mathrm{O}) \mathrm{c} 2 \mathrm{ccc}(\mathrm{Oc} 3 \operatorname{ccnc} 4 \mathrm{cc}(\mathrm{OC}) \mathrm{c}(\mathrm{OC}) \mathrm{cc} 34) \mathrm{cc} 2) \mathrm{cc} 1$ & 100000 & $*$ \\
\hline 5264 & $\operatorname{COc} 1 \mathrm{cc} 2 \mathrm{nccc}(\mathrm{Oc} 3 \operatorname{ccc}(\mathrm{C}(=\mathrm{O}) \mathrm{c} 4 \mathrm{ccc}(\mathrm{C}(\mathrm{F})(\mathrm{F}) \mathrm{F}) \mathrm{cc} 4) \mathrm{cc} 3) \mathrm{c} 2 \mathrm{cc} 1 \mathrm{OC}$ & 100000 & $*$ \\
\hline 5265 & $\operatorname{COc} 1 \mathrm{cc} 2 \mathrm{nccc}(\mathrm{Oc} 3 \operatorname{ccc}(\mathrm{C}(=\mathrm{O}) \mathrm{c} 4 \mathrm{cccc}(\mathrm{C}(\mathrm{F})(\mathrm{F}) \mathrm{F}) \mathrm{c} 4) \mathrm{cc} 3) \mathrm{c} 2 \mathrm{cc} 1 \mathrm{OC}$ & 100000 & $*$ \\
\hline 5266 & $\mathrm{COc} 1 \mathrm{cc} 2 \mathrm{nccc}(\mathrm{Oc} 3 \operatorname{ccc}(\mathrm{NC}(=\mathrm{O}) \mathrm{C} 4 \mathrm{CCCCC} 4) \mathrm{cc} 3) \mathrm{c} 2 \mathrm{cc} 1 \mathrm{OC}$ & 100000 & $*$ \\
\hline 5267 & $\mathrm{COc} 1 \mathrm{cc} 2 \mathrm{nccc}(\mathrm{Oc} 3 \operatorname{ccc}(\mathrm{C}(=\mathrm{O}) \mathrm{c} 4 \mathrm{ccc}(\mathrm{OC}(\mathrm{F})(\mathrm{F}) \mathrm{F}) \mathrm{cc} 4) \mathrm{cc} 3) \mathrm{c} 2 \mathrm{cc} 1 \mathrm{OC}$ & 100000 & $*$ \\
\hline 5268 & $\operatorname{COc} 1 \operatorname{ccc}(\mathrm{C}(=\mathrm{O}) \mathrm{Nc} 2 \operatorname{ccc}(\mathrm{Oc} 3 \mathrm{ccnc} 4 \mathrm{cc}(\mathrm{OC}) \mathrm{c}(\mathrm{OC}) \operatorname{cc} 34) \mathrm{cc} 2) \mathrm{cc} 1 \mathrm{OC}$ & 100000 & $*$ \\
\hline 5269 & $\mathrm{CCCCc} 1 \mathrm{ccc}(\mathrm{C}(=\mathrm{O}) \mathrm{Nc} 2 \mathrm{ccc}(\mathrm{Oc} 3 \mathrm{ccnc} 4 \mathrm{cc}(\mathrm{OC}) \mathrm{c}(\mathrm{OC}) \mathrm{cc} 34) \mathrm{cc} 2) \mathrm{cc} 1$ & 100000 & $*$ \\
\hline 5270 & $\mathrm{COc} 1 \mathrm{cc} 2 \mathrm{nccc}(\mathrm{Oc} 3 \operatorname{ccc}(\mathrm{NC}(=\mathrm{O}) \mathrm{c} 4 \mathrm{ccc}(-\mathrm{c} 5 \mathrm{ccc} \operatorname{cc} 5) \operatorname{cc} 4) \operatorname{cc} 3) \mathrm{c} 2 \mathrm{cc} 1 \mathrm{OC}$ & 100000 & $*$ \\
\hline
\end{tabular}




\begin{tabular}{|c|c|c|c|}
\hline 5271 & $\mathrm{CCCCOc} 1 \mathrm{ccc}(\mathrm{C}(=\mathrm{O}) \mathrm{Nc} 2 \mathrm{ccc}(\mathrm{Oc} 3 \mathrm{ccnc} 4 \mathrm{cc}(\mathrm{OC}) \mathrm{c}(\mathrm{OC}) \operatorname{cc} 34) \mathrm{cc} 2) \mathrm{cc} 1$ & 100000 & $*$ \\
\hline 5272 & $\operatorname{COc} 1 \mathrm{cc} 2 \mathrm{nccc}(\mathrm{Oc} 3 \operatorname{ccc}(\mathrm{C}(\mathrm{C})=\mathrm{O}) \mathrm{cc} 3) \mathrm{c} 2 \mathrm{cc} 1 \mathrm{OC}$ & 100000 & $*$ \\
\hline 5273 & $\operatorname{COC}(=\mathrm{O}) \mathrm{c} 1 \mathrm{cccc}(\mathrm{Oc} 2 \mathrm{ccnc} 3 \mathrm{cc}(\mathrm{OC}) \mathrm{c}(\mathrm{OC}) \mathrm{cc} 23) \mathrm{c} 1$ & 100000 & $*$ \\
\hline 5274 & $\mathrm{COc} 1 \mathrm{cc} 2 \mathrm{nccc}(\mathrm{Oc} 3 \operatorname{ccc}(\mathrm{NC}(\mathrm{C})=\mathrm{O}) \mathrm{cc} 3) \mathrm{c} 2 \mathrm{cc} 1 \mathrm{OC}$ & 100000 & $*$ \\
\hline 5275 & $\operatorname{COc} 1 \mathrm{cc} 2 \mathrm{nccc}(\mathrm{Oc} 3 \operatorname{ccc}(\mathrm{C}(=\mathrm{O}) \mathrm{c} 4 \mathrm{ccco} 4) \mathrm{cc} 3) \mathrm{c} 2 \mathrm{cc} 1 \mathrm{OC}$ & 100000 & $*$ \\
\hline 5276 & $\operatorname{COc} 1 \operatorname{cc} 2 \mathrm{nccc}(\mathrm{Oc} 3 \operatorname{ccc}(\mathrm{C}(=\mathrm{O}) \mathrm{c} 4 \mathrm{ccc}(-\mathrm{c} 5 \mathrm{cccc} 5) \operatorname{cc} 4) \operatorname{cc} 3) \mathrm{c} 2 \mathrm{cc} 1 \mathrm{OC}$ & 100000 & $*$ \\
\hline 5277 & $\mathrm{CCCc} 1 \operatorname{ccc}(\mathrm{C}(=\mathrm{O}) \mathrm{c} 2 \mathrm{ccc}(\mathrm{Oc} 3 \operatorname{ccnc} 4 \mathrm{cc}(\mathrm{OC}) \mathrm{c}(\mathrm{OC}) \operatorname{cc} 34) \mathrm{cc} 2) \mathrm{cc} 1$ & 100000 & $*$ \\
\hline 5278 & $\mathrm{CCOc} 1 \mathrm{cc} 2 \mathrm{nc} 3 \mathrm{c}(\mathrm{c}(\mathrm{Nc} 4 \mathrm{cccc}(-\mathrm{c} 5 \mathrm{csc}(\mathrm{C}) \mathrm{n} 5) \mathrm{c} 4) \mathrm{c} 2 \mathrm{cc} 1 \mathrm{OCC}) \mathrm{CC}(\mathrm{CN}) \mathrm{C} 3$ & 100000 & $*$ \\
\hline 5279 & $\mathrm{CCOc} 1 \mathrm{cc} 2 \mathrm{nc} 3 \mathrm{c}(\mathrm{c}(\mathrm{Nc} 4 \mathrm{cccc}(-\mathrm{c} 5 \mathrm{csc}(\mathrm{C}) \mathrm{n} 5) \mathrm{c} 4) \mathrm{c} 2 \mathrm{cc} 1 \mathrm{OCC}) \mathrm{C}(\mathrm{CNC}(\mathrm{C})=\mathrm{O}) \mathrm{CC} 3$ & 100000 & * \\
\hline 5280 & $\mathrm{COc} 1 \mathrm{cc} 2 \mathrm{c}(\mathrm{Oc} 3 \operatorname{ccc}(\mathrm{NC}=\mathrm{C} 4 \mathrm{C}(=\mathrm{O}) \mathrm{NC}(=\mathrm{O}) \mathrm{N}(\mathrm{c} 5 \mathrm{ccc}(\mathrm{C}) \mathrm{cc} 5) \mathrm{C} 4=\mathrm{O}) \mathrm{cc} 3 \mathrm{~F}) \mathrm{ccnc} 2 \mathrm{cc} 1 \mathrm{OCCCN} 1 \mathrm{CCCC} 1$ & 100000 & $*$ \\
\hline 5281 & $\mathrm{COc} 1 \mathrm{cc} 2 \mathrm{c}(\mathrm{Oc} 3 \mathrm{ccc}(\mathrm{NC}(=\mathrm{O}) \mathrm{c} 4 \mathrm{c}(\mathrm{Cl}) \mathrm{c} 5 \mathrm{cccc} 5 \mathrm{n}(-\mathrm{c} 5 \mathrm{ccc}(\mathrm{F}) \mathrm{cc} 5) \mathrm{c} 4=\mathrm{O}) \mathrm{cc} 3 \mathrm{~F}) \mathrm{ccn} \operatorname{coc} 1 \mathrm{OCCCN} 1 \mathrm{CCN}(\mathrm{C}) \mathrm{CC} 1$ & 100000 & $*$ \\
\hline 5282 & $\mathrm{O}=\mathrm{C}(\mathrm{N} / \mathrm{N}=\mathrm{C} / \mathrm{c} 1 \mathrm{ccc}(\mathrm{O}) \mathrm{cc} 1) \mathrm{Nc} 1 \mathrm{ccc}(\mathrm{Oc} 2 \mathrm{ccnc} 3[\mathrm{nH}] \operatorname{ccc} 23) \mathrm{c}(\mathrm{F}) \mathrm{c} 1$ & 100000 & $*$ \\
\hline 5283 & $\mathrm{CCOc} 1 \mathrm{cc} 2 \mathrm{nc} 3 \mathrm{c}(\mathrm{c}(\mathrm{NCCCCCN} 4 \mathrm{c} 5 \mathrm{c}(\mathrm{nc} 6 \mathrm{cc}(\mathrm{OCC}) \mathrm{c}(\mathrm{OCC}) \mathrm{cc} 46) \mathrm{CCC} 5) \mathrm{c} 2 \mathrm{cc} 1 \mathrm{OCC}) \mathrm{CCC} 3$ & 101620 & $*$ \\
\hline 5284 & $\mathrm{COc} 1 \mathrm{cc}(/ \mathrm{C}=\mathrm{C}(\backslash \mathrm{C \# N}) \mathrm{C}(=\mathrm{O}) \mathrm{NCCCCNC}(=\mathrm{O}) / \mathrm{C}(\mathrm{C \# N})=\mathrm{C} / \mathrm{c} 2 \mathrm{cc}(\mathrm{Br}) \mathrm{c}(\mathrm{O}) \mathrm{c}(\mathrm{OC}) \mathrm{c} 2) \mathrm{cc}(\mathrm{Br}) \mathrm{c} 1 \mathrm{O}$ & 102000 & $*$ \\
\hline 5285 & $\mathrm{COc} 1 \mathrm{cc} 2 \mathrm{ncc}(\mathrm{CO}) \mathrm{c}(\mathrm{Nc} 3 \mathrm{cccc}(\mathrm{Br}) \mathrm{c} 3) \mathrm{c} 2 \mathrm{cc} 1 \mathrm{OC}$ & 102200 & $*$ \\
\hline 5286 & $\mathrm{~N} \# \mathrm{Cc} 1 \mathrm{cnc} 2 \mathrm{cc} 3 \mathrm{c}(\mathrm{cc} 2 \mathrm{c} 1 \mathrm{Nc} 1 \mathrm{ccc}(\mathrm{Br}) \mathrm{c} 1) \mathrm{OCCO} 3$ & 104700 & $*$ \\
\hline 5287 & $\operatorname{CCOC}(=\mathrm{O}) \mathrm{c} 1 \mathrm{c}(\mathrm{Nc} 2 \mathrm{ncnc} 3 \mathrm{cc}(\mathrm{OC}) \mathrm{c}(\mathrm{OC}) \mathrm{cc} 23) \mathrm{sc} 2 \mathrm{c} 1 \mathrm{CCCC} 2$ & 108200 & $*$ \\
\hline 5288 & $\mathrm{COc} 1 \mathrm{ccccc} 1 \mathrm{C}(=\mathrm{Cc} 1 \operatorname{coc} 2 \mathrm{nc}(=\mathrm{N})[\mathrm{nH}] \mathrm{c}(\mathrm{N}) \mathrm{c} 12) \mathrm{C}(\mathrm{C}) \mathrm{C}$ & 111400 & $*$ \\
\hline 5289 & $\mathrm{COc} 1 \mathrm{cc} 2 \mathrm{ncnc}(\mathrm{Sc} 3 \mathrm{nnc}(\mathrm{NC}(=\mathrm{O}) \mathrm{c} 4 \mathrm{ccccc} 4 \mathrm{~F}) \mathrm{s} 3) \mathrm{c} 2 \mathrm{cc} 1 \mathrm{OC}$ & 115800 & $*$ \\
\hline 5290 & $\mathrm{~N} \# \mathrm{CC}(\mathrm{C} \# \mathrm{~N})=\mathrm{Cc} 1 \mathrm{ccc}(\mathrm{O}) \mathrm{c}([\mathrm{N}+](=\mathrm{O})[\mathrm{O}-]) \mathrm{c} 1$ & 125000 & * \\
\hline 5291 & $\mathrm{COc} 1 \mathrm{cc} 2 \mathrm{ncnc}(\mathrm{Nc} 3 \mathrm{nc} 4 \mathrm{cccc} 4[\mathrm{nH}] 3) \mathrm{c} 2 \mathrm{cc} 1 \mathrm{OC}$ & 127400 & $*$ \\
\hline 5292 & COc1cc2ncnc(Nc3nnc(S)s3)c $2 \mathrm{cc} 1 \mathrm{OC}$ & 139200 & $*$ \\
\hline 5293 & $\operatorname{COc} 1 \mathrm{cc}(\mathrm{C}=\mathrm{C}(\mathrm{C} \# \mathrm{~N}) \mathrm{C} \# \mathrm{~N}) \mathrm{cc}(\mathrm{Br}) \mathrm{c} 1 \mathrm{O}$ & 153000 & $*$ \\
\hline 5294 & $\operatorname{COc} 1 \mathrm{cc} 2 \mathrm{ncnc}(\mathrm{Sc} 3 \mathrm{nnc}(\mathrm{NC}(=\mathrm{O}) \mathrm{c} 4 \mathrm{cccc} 4) \mathrm{s} 3) \mathrm{c} 2 \mathrm{cc} 1 \mathrm{OC}$ & 154300 & * \\
\hline 5295 & $\operatorname{COc} 1 \mathrm{cc}(\mathrm{C}=\mathrm{C}(\mathrm{C} \# \mathrm{~N}) \mathrm{C} \# \mathrm{~N}) \operatorname{cc}([\mathrm{N}+](=\mathrm{O})[\mathrm{O}-]) \mathrm{c} 1 \mathrm{O}$ & 160000 & $*$ \\
\hline 5296 & $\mathrm{COc} 1 \mathrm{cc} 2 \mathrm{c}(\mathrm{cc} 1 \mathrm{OC}) \mathrm{Nc} 1 \ln \mathrm{cn}(\mathrm{C}) \mathrm{c}(=\mathrm{O}) \mathrm{c} 1 \mathrm{C} 2$ & 160000 & $*$ \\
\hline 5297 & $\mathrm{CCCC}(=\mathrm{Cc} 1 \operatorname{coc} 2 \mathrm{nc}(=\mathrm{N})[\mathrm{nH}] \mathrm{c}(\mathrm{N}) \mathrm{c} 12) \mathrm{c} 1 \mathrm{cccc} 1 \mathrm{OC}$ & 160300 & $*$ \\
\hline 5298 & $\mathrm{~N} \# \mathrm{C} / \mathrm{C}(=\mathrm{C} \mid \mathrm{c} 1 \mathrm{ccc}(\mathrm{O}) \mathrm{cc} 1) \mathrm{C}(=\mathrm{O}) \mathrm{O}$ & 165000 & $*$ \\
\hline 5299 & $\mathrm{CCOc} 1 \mathrm{ccc} 2 \mathrm{sc}(\mathrm{SCc} 3 \mathrm{cc}(/ \mathrm{C}=\mathrm{C}(\backslash \mathrm{C} \# \mathrm{~N}) \mathrm{C}(\mathrm{N})=\mathrm{O}) \mathrm{cc}(\mathrm{OC}) \mathrm{c} 3 \mathrm{O}) \mathrm{nc} 2 \mathrm{c} 1$ & 165958.7 & $*$ \\
\hline 5300 & $\mathrm{COc} 1 \mathrm{cc} 2 \mathrm{ncnc}(\mathrm{Nc} 3 \mathrm{cc}(=\mathrm{O})[\mathrm{nH}] \mathrm{c}(\mathrm{S}) \mathrm{n} 3) \mathrm{c} 2 \mathrm{cc} 1 \mathrm{OC}$ & 169500 & $*$ \\
\hline 5301 & $\mathrm{CCOC}(=\mathrm{O}) \mathrm{c} 1 \mathrm{c}(\mathrm{Nc} 2 \mathrm{ncnc} 3 \mathrm{cc}(\mathrm{OC}) \mathrm{c}(\mathrm{OC}) \mathrm{cc} 23) \mathrm{sc} 2 \mathrm{c} 1 \mathrm{CCCCC} 2$ & 173000 & * \\
\hline 5302 & $\mathrm{COc} 1 \mathrm{cc} 2 \mathrm{ncnc}(\mathrm{Sc} 3 \mathrm{nnc}(\mathrm{NC}(=\mathrm{O}) \mathrm{c} 4 \mathrm{ccccc} 4 \mathrm{C}) \mathrm{s} 3) \mathrm{c} 2 \mathrm{cc} 1 \mathrm{OC}$ & 175200 & $*$ \\
\hline 5303 & $\mathrm{O}=\mathrm{C} 1 \mathrm{c} 2 \mathrm{c}(\mathrm{c} 3 \mathrm{c} 4 \mathrm{cccc}(\mathrm{O}) \mathrm{c} 4 \mathrm{n}(\mathrm{C} 4 \mathrm{OC}(\mathrm{CO}) \mathrm{C}(\mathrm{O}) \mathrm{C}(\mathrm{O}) \mathrm{C} 4 \mathrm{O}) \mathrm{c} 3 \mathrm{c} 3[\mathrm{nH}] \mathrm{c} 4 \mathrm{c}(\mathrm{O}) \mathrm{cccc} 4 \mathrm{c} 23) \mathrm{C}(=\mathrm{O}) \mathrm{N} 1 \mathrm{NCC}(\mathrm{O}) \mathrm{CO}$ & 180000 & $*$ \\
\hline 5304 & Nc1ncnc2c1ncn2[C@@H]1O[C@H](CO)[C@@H](O)[C@H]1O & 195000 & $*$ \\
\hline 5305 & $\mathrm{COc} 1 \mathrm{cc}(\mathrm{C}=\mathrm{C}(\mathrm{C} \# \mathrm{~N}) \mathrm{C} \# \mathrm{~N}) \mathrm{ccc} 1 \mathrm{O}$ & 200000 & $*$ \\
\hline 5306 & $\mathrm{C}=\mathrm{CC}(=\mathrm{O}) \mathrm{Nc} 1 \mathrm{cc}(\mathrm{Nc} 2 \mathrm{ncc}(\mathrm{Br}) \mathrm{c}(\mathrm{Nc} 3 \mathrm{ccc} 4 \mathrm{c}(\mathrm{c} 3) \mathrm{CCC} 4) \mathrm{n} 2) \mathrm{c}(\mathrm{OC}) \mathrm{cc} 1 \mathrm{~N} 1 \mathrm{CCN}(\mathrm{C}) \mathrm{CC} 1$ & 202500 & $*$ \\
\hline 5307 & $\operatorname{COc} 1 \mathrm{cc} 2 \mathrm{ncnc}(\mathrm{Sc} 3 \mathrm{nc} 4 \mathrm{ccccc} 4[\mathrm{nH}] 3) \mathrm{c} 2 \mathrm{cc} 1 \mathrm{OC}$ & 207900 & $*$ \\
\hline 5308 & $\mathrm{CC}(\mathrm{C})(\mathrm{C}) \mathrm{OC}[\mathrm{C} @ \mathrm{H}](\mathrm{Cn} 1 \mathrm{ccnc} 1[\mathrm{~N}+](=\mathrm{O})[\mathrm{O}-]) \mathrm{OC}(=\mathrm{O}) \mathrm{c} 1 \mathrm{ccc}(\mathrm{NC}=\mathrm{C} 2 \mathrm{C}(=\mathrm{O}) \mathrm{C}=\mathrm{CC} 2=\mathrm{O}) \mathrm{cc} 1$ & 213000 & * \\
\hline 5309 & $\mathrm{~N} \# \mathrm{CC}(\mathrm{C} \# \mathrm{~N})=\mathrm{Cc} 1 \mathrm{cccnc} 1$ & 225000 & $*$ \\
\hline 5310 & $\mathrm{~N} \# \mathrm{CC}(\mathrm{C \# N})=\mathrm{NNc} 1 \mathrm{ccc}(\mathrm{O}) \mathrm{cc} 1$ & 225000 & * \\
\hline 5311 & $\mathrm{C}=\mathrm{CC}(=\mathrm{O}) \mathrm{Nc} 1 \mathrm{cc}(\mathrm{Nc} 2 \mathrm{nccc}(\mathrm{Nc} 3 \operatorname{cc} 4 \operatorname{ccccc} 4 \mathrm{n} 3 \mathrm{C}) \mathrm{n} 2) \mathrm{c}(\mathrm{OC}) \mathrm{cc} 1 \mathrm{~N}(\mathrm{C}) \mathrm{CCN}(\mathrm{C}) \mathrm{C}$ & 228900 & * \\
\hline 5312 & $\mathrm{~N} \# \mathrm{CC}(\mathrm{C} \# \mathrm{~N})=\mathrm{C}(\mathrm{O}) \mathrm{c} 1 \mathrm{ccc}(\mathrm{O}) \mathrm{cc} 1$ & 230000 & $*$ \\
\hline 5313 & $\mathrm{C}=\mathrm{CC}(=\mathrm{O}) \mathrm{Nc} 1 \mathrm{cc}(\mathrm{Nc} 2 \mathrm{ncc}(\mathrm{Br}) \mathrm{c}(\mathrm{Nc} 3 \operatorname{ccc} 4[\mathrm{nH}] \operatorname{ccc} 4 \mathrm{c} 3) \mathrm{n} 2) \operatorname{ccc} 1 \mathrm{~N} 1 \mathrm{CCN}(\mathrm{C}) \mathrm{CC} 1$ & 233800 & $*$ \\
\hline
\end{tabular}




\begin{tabular}{|c|c|c|c|}
\hline 5314 & $\mathrm{O}=\mathrm{P}(\mathrm{O})(\mathrm{O}) \mathrm{C}(\mathrm{O}) \mathrm{c} 1 \mathrm{ccc} 2 \operatorname{ccc} c 2 \mathrm{c} 1$ & 250000 & * \\
\hline 5315 & $\mathrm{N \# CC}(\mathrm{C \# N})=\mathrm{Cc} 1 \mathrm{ccncc} 1$ & 250000 & * \\
\hline 5316 & $\mathrm{~N} \# \mathrm{CC}(\mathrm{CHN})=\mathrm{Cc} 1 \mathrm{ccc}[\mathrm{nH}] 1$ & 260000 & $*$ \\
\hline 5317 & $\operatorname{COc} 1 \mathrm{cc}(/ \mathrm{C}=\mathrm{C}(\mathrm{C} \# \mathrm{~N}) \mathrm{C}(=\mathrm{O}) \mathrm{O}) \mathrm{cc}(\mathrm{OC}) \mathrm{c} 1 \mathrm{O}$ & 264000 & $*$ \\
\hline 5318 & $\mathrm{C}=\mathrm{CC}(=\mathrm{O}) \mathrm{Nc} 1 \mathrm{cc}(\mathrm{Nc} 2 \mathrm{nccc}(-\mathrm{c} 3 \mathrm{cn}(\mathrm{C}) \mathrm{c} 4 \mathrm{cccnc} 34) \mathrm{n} 2) \mathrm{c}(\mathrm{OC}) \mathrm{cc} 1 \mathrm{~N}(\mathrm{C}) \mathrm{CCNC} . \mathrm{Cl}$ & 277000 & $*$ \\
\hline 5319 & $\mathrm{C}=\mathrm{CC}(=\mathrm{O}) \mathrm{Nc} 1 \mathrm{cc}(\mathrm{Nc} 2 \mathrm{ncc}(\mathrm{Br}) \mathrm{c}(\mathrm{Nc} 3 \mathrm{ccc} 4 \mathrm{c}(\mathrm{ccn} 4 \mathrm{C}) \mathrm{c} 3) \mathrm{n} 2) \mathrm{c}(\mathrm{OC}) \mathrm{cc} 1 \mathrm{~N} 1 \mathrm{CCN}(\mathrm{C}) \mathrm{CC} 1$ & 280400 & $*$ \\
\hline 5320 & $\operatorname{COc} 1 \operatorname{ccc}(\mathrm{C}(=\mathrm{O}) \mathrm{c} 2 \mathrm{ccc}(=\mathrm{O}) \mathrm{n}(\mathrm{CCN}(\mathrm{C}) \mathrm{C}) \mathrm{c} 2) \mathrm{c}(\mathrm{O}) \mathrm{c} 1$ & 300000 & $*$ \\
\hline 5321 & $\mathrm{COc} 1 \mathrm{cc} 2 \mathrm{ncnc}(\mathrm{NC} 3 \mathrm{CCC}(\mathrm{O}) \mathrm{CC} 3) \mathrm{c} 2 \mathrm{cc} 1 \mathrm{OC}$ & 318500 & $*$ \\
\hline 5322 & $\mathrm{CC}(\mathrm{C})(\mathrm{C}) \mathrm{c} 1 \mathrm{cc}(\mathrm{C}=\mathrm{C} 2 \mathrm{C}(=\mathrm{O}) \mathrm{C}=\mathrm{CC} 2=\mathrm{O}) \mathrm{cc}(\mathrm{C}(\mathrm{C})(\mathrm{C}) \mathrm{C}) \mathrm{c} 1 \mathrm{O}$ & 320000 & * \\
\hline 5323 & $\operatorname{COc} 1 \mathrm{cc}(/ \mathrm{C}=\mathrm{C}(\backslash \mathrm{C} \# \mathrm{~N}) \mathrm{C}(=\mathrm{O}) \mathrm{O}) \operatorname{ccc} 1 \mathrm{O}$ & 325000 & $*$ \\
\hline 5324 & $\mathrm{~N} \# \mathrm{CC}(\mathrm{C \# N})=\mathrm{Cc} 1 \mathrm{ccc} 2 \mathrm{c}(\mathrm{c} 1) \mathrm{OCO} 2$ & 350000 & $*$ \\
\hline 5325 & $\mathrm{N \# CC}(\mathrm{C \# N})=\mathrm{CNc} 1 \mathrm{ccc}(\mathrm{O}) \mathrm{cc} 1$ & 350000 & $*$ \\
\hline 5326 & $\mathrm{~N} \# \mathrm{CC}(\mathrm{C} \# \mathrm{~N})=\mathrm{Cc} 1 \operatorname{ccc}(\mathrm{O}) \mathrm{c} 1$ & 375000 & * \\
\hline 5327 & $\mathrm{C}=\mathrm{CC}(=\mathrm{O}) \mathrm{Nc} 1 \mathrm{cc}(\mathrm{Nc} 2 \mathrm{ncc}(\mathrm{Br}) \mathrm{c}(\mathrm{Nc} 3 \operatorname{ccc} 4 \mathrm{c}(\mathrm{ccn} 4 \mathrm{C}) \mathrm{c} 3) \mathrm{n} 2) \operatorname{ccc} 1 \mathrm{~N} 1 \mathrm{CCN}(\mathrm{C}) \mathrm{CC} 1$ & 414100 & $*$ \\
\hline 5328 & $\mathrm{~N} \# \mathrm{CC}(\mathrm{C} \# \mathrm{~N})=\mathrm{Cc} 1 \mathrm{ccc}(\mathrm{C}(=\mathrm{O}) \mathrm{O}) \mathrm{cc} 1$ & 430000 & $*$ \\
\hline 5329 & $\mathrm{Cc} 1 \mathrm{cc}(\mathrm{C}=\mathrm{C} 2 \mathrm{C}(=\mathrm{O}) \mathrm{C}=\mathrm{CC} 2=\mathrm{O}) \mathrm{cc}(\mathrm{C}) \mathrm{c} 1 \mathrm{O}$ & 440000 & $*$ \\
\hline 5330 & $\mathrm{Cn} 1 \mathrm{cnc} 2 \mathrm{c}(\mathrm{NCc} 3 \mathrm{ccccc} 3) \mathrm{nc}(\mathrm{NCCO}) \mathrm{nc} 21$ & 440000 & * \\
\hline 5331 & $\mathrm{~N} \# \mathrm{CC}(\mathrm{C} \# \mathrm{~N})=\mathrm{Cc} 1 \mathrm{ccc}([\mathrm{N}+](=\mathrm{O})[\mathrm{O}-]) \mathrm{c}(\mathrm{O}) \mathrm{c} 1$ & 450000 & $*$ \\
\hline 5332 & $\mathrm{COc} 1 \mathrm{ccc}(\mathrm{C}(\mathrm{O})=\mathrm{C}(\mathrm{C} \# \mathrm{~N}) \mathrm{C} \# \mathrm{~N}) \mathrm{cc} 1$ & 450000 & $*$ \\
\hline 5333 & $\mathrm{~N} \# \mathrm{CC}(\mathrm{C \# N})=\mathrm{Cc} 1 \operatorname{ccc}(/ \mathrm{C}=\mathrm{C} / \mathrm{C}(=\mathrm{O}) \mathrm{O}) \mathrm{cc} 1$ & 450000 & $*$ \\
\hline 5334 & $\mathrm{CC}(\mathrm{C})(\mathrm{C}) \mathrm{c} 1 \mathrm{cc}(\mathrm{C}=\mathrm{C}(\mathrm{C} \# \mathrm{~N}) \mathrm{C} \# \mathrm{~N}) \mathrm{cc}(\mathrm{C}(\mathrm{C})(\mathrm{C}) \mathrm{C}) \mathrm{c} 1 \mathrm{O}$ & 460000 & $*$ \\
\hline 5335 & $\mathrm{C}=\mathrm{CC}(=\mathrm{O}) \mathrm{Nc} 1 \mathrm{cc}(\mathrm{Nc} 2 \mathrm{ncc}(\mathrm{Br}) \mathrm{c}(\mathrm{Nc} 3 \mathrm{ccc} 4 \mathrm{c}(\mathrm{c} 3) \mathrm{CCC} 4) \mathrm{n} 2) \mathrm{ccc} 1 \mathrm{~N} 1 \mathrm{CCN}(\mathrm{C}) \mathrm{CC} 1$ & 465700 & $*$ \\
\hline 5336 & $\mathrm{CC}(=\mathrm{C}(\mathrm{C \# N}) \mathrm{C} \# \mathrm{~N}) \mathrm{c} 1 \mathrm{ccc}(\mathrm{NC}(=\mathrm{O}) \mathrm{CCC}(=\mathrm{O}) \mathrm{O}) \mathrm{cc} 1$ & 500000 & $*$ \\
\hline 5337 & $\mathrm{COc} 1 \mathrm{cc}(\mathrm{OC}) \mathrm{c} 2 \mathrm{c}(=\mathrm{O}) \mathrm{c}(-\mathrm{c} 3 \mathrm{cccc}(\mathrm{Cl}) \mathrm{c} 3) \operatorname{coc} 2 \mathrm{c} 1$ & 500000 & $*$ \\
\hline 5338 & $\mathrm{CC}(\mathrm{C})(\mathrm{C}) \mathrm{Oc} 1 \mathrm{cc}(/ \mathrm{C}=\mathrm{C}(\mathrm{C} \# \mathrm{~N}) \mathrm{C}(=\mathrm{N}) \mathrm{S}) \mathrm{cc}(\mathrm{C}(\mathrm{C})(\mathrm{C}) \mathrm{C}) \mathrm{c} 1 \mathrm{O}$ & 501187.2 & $*$ \\
\hline 5339 & $\operatorname{CCCCC}(=\mathrm{Cc} 1 \operatorname{coc} 2 \mathrm{nc}(=\mathrm{N})[\mathrm{nH}] \mathrm{c}(\mathrm{N}) \mathrm{c} 12) \mathrm{c} 1 \mathrm{ccccc} 1 \mathrm{OC}$ & 529300 & * \\
\hline 5340 & $\mathrm{N \# CC}(\mathrm{C \# N})=\mathrm{Cc} 1 \mathrm{ncc}[\mathrm{nH}] 1$ & 532000 & $*$ \\
\hline 5341 & $\mathrm{~N} \# \mathrm{CC}(\mathrm{C} \# \mathrm{~N})=\mathrm{Cc} 1 \mathrm{ccc}(\mathrm{O}) \mathrm{cc} 1$ & 560000 & * \\
\hline 5342 & $\mathrm{~N} \# \mathrm{CC}(\mathrm{C} \# \mathrm{~N})=\mathrm{Cc} 1 \mathrm{cc} 2 \mathrm{c}(\mathrm{cc} 1[\mathrm{~N}+](=\mathrm{O})[\mathrm{O}-]) \mathrm{OCO} 2$ & 560000 & $*$ \\
\hline 5343 & $\mathrm{COC}(=\mathrm{O})[\mathrm{C} @ @] 1(\mathrm{Cc} 2 \operatorname{ccc}(\mathrm{O}) \mathrm{c}(\mathrm{CC}=\mathrm{C}(\mathrm{C}) \mathrm{C}) \mathrm{c} 2) \mathrm{OC}(=\mathrm{O}) \mathrm{C}(\mathrm{O})=\mathrm{C} 1 \mathrm{c} 1 \mathrm{ccc}(\mathrm{O}) \mathrm{cc} 1$ & 590000 & $*$ \\
\hline 5344 & $\operatorname{COc} 1 \mathrm{ccc}(\mathrm{NN}=\mathrm{C}(\mathrm{C \# N}) \mathrm{C \# N}) \mathrm{cc} 1$ & 600000 & $*$ \\
\hline 5345 & $\mathrm{~N} \# \mathrm{CCNC}(=\mathrm{O}) / \mathrm{C}(\mathrm{C \# N})=\mathrm{C} / \mathrm{c} 1 \mathrm{ccc}(\mathrm{O}) \mathrm{cc} 1$ & 625000 & $*$ \\
\hline 5346 & $\mathrm{~N} \# \mathrm{CC}(\mathrm{C} \# \mathrm{~N})=\mathrm{Cc} 1 \mathrm{ccc}(\mathrm{NC}(=\mathrm{O}) \mathrm{CCC}(=\mathrm{O}) \mathrm{O}) \mathrm{cc} 1$ & 640000 & $*$ \\
\hline 5347 & $\operatorname{COc} 1 \operatorname{ccc}(\mathrm{C}=\mathrm{C}(\mathrm{C} \# \mathrm{~N}) \mathrm{C} \# \mathrm{~N}) \operatorname{cc} 1 \mathrm{~F}$ & 800000 & $*$ \\
\hline 5348 & $\mathrm{~N} \# \mathrm{C} / \mathrm{C}(=\mathrm{C} \backslash \mathrm{c} 1 \mathrm{ccc}(\mathrm{O}) \mathrm{cc} 1) \mathrm{C}(\mathrm{N})=\mathrm{O}$ & 800000 & $*$ \\
\hline 5349 & $\mathrm{~N} \# \mathrm{CC}(\mathrm{C} \# \mathrm{~N})=\mathrm{C}(\mathrm{N}) / \mathrm{C}(\mathrm{C \# N})=\mathrm{C} / \mathrm{c} 1 \mathrm{ccc} 2[\mathrm{nH}] \mathrm{ccc} 2 \mathrm{c} 1$ & 820000 & $*$ \\
\hline 5350 & $\mathrm{~N} \# \mathrm{C} / \mathrm{C}(=\mathrm{Clc} 1 \mathrm{ccc}(\mathrm{F}) \mathrm{cc} 1) \mathrm{C}(=\mathrm{O}) \mathrm{O}$ & 833000 & $*$ \\
\hline 5351 & $\mathrm{COc} 1 \mathrm{ccc}(/ \mathrm{C}=\mathrm{C}(\backslash \mathrm{C} \# \mathrm{~N}) \mathrm{C}(=\mathrm{O}) \mathrm{O}) \mathrm{cc} 1$ & 833000 & $*$ \\
\hline 5352 & $\mathrm{COc} 1 \mathrm{cc}(\mathrm{C}=\mathrm{C}(\mathrm{C} \# \mathrm{~N}) \mathrm{C} \# \mathrm{~N}) \mathrm{cc}(\mathrm{OC}) \mathrm{c} 1 \mathrm{O}$ & 850000 & $*$ \\
\hline 5353 & $\mathrm{~N} \# \mathrm{C} / \mathrm{C}(=\mathrm{Clc} 1 \mathrm{ccccc} 1) \mathrm{C}(=\mathrm{O}) \mathrm{O}$ & 850000 & $*$ \\
\hline 5354 & $\mathrm{~N}[\mathrm{C} @ @ \mathrm{H}](\mathrm{Cc} 1 \mathrm{ccc}(\mathrm{O}) \mathrm{c}(\mathrm{O}) \mathrm{c} 1) \mathrm{C}(=\mathrm{O}) \mathrm{O}$ & 900000 & $*$ \\
\hline 5355 & $\mathrm{CN}(\mathrm{C}) \mathrm{CCNc} 1 \mathrm{ncnc} 2 \mathrm{c} 1[\mathrm{nH}] \mathrm{c} 1 \mathrm{ccccc} 12$ & 1000000 & * \\
\hline 5356 & $\mathrm{COc} 1 \mathrm{cc}(/ \mathrm{C}(\mathrm{C})=\mathrm{C}(\mathrm{C} \# \mathrm{~N}) \mathrm{C}(=\mathrm{O}) \mathrm{O}) \operatorname{ccc} 1 \mathrm{O}$ & 1100000 & * \\
\hline
\end{tabular}




\begin{tabular}{|c|c|c|c|}
\hline 5357 & $\mathrm{~N} \# \mathrm{CC}(\mathrm{C} \# \mathrm{~N})=\mathrm{C} 1 \mathrm{CCCc} 2 \mathrm{c}(\mathrm{O}) \operatorname{cccc} 21$ & 1200000 & $*$ \\
\hline 5358 & $\mathrm{O}=\mathrm{C}(\mathrm{O}) / \mathrm{C}=\mathrm{C} / \mathrm{c} 1 \mathrm{ccc}(\mathrm{O}) \mathrm{c}(\mathrm{O}) \mathrm{c} 1$ & 1200000 & $*$ \\
\hline 5359 & $\mathrm{~N} \# \mathrm{CC}(\mathrm{C \# N})=\mathrm{Cc} 1 \mathrm{cc}[\mathrm{n}+]([\mathrm{O}-]) \mathrm{cc} 1$ & 1300000 & $*$ \\
\hline 5360 & $\mathrm{~N} \# \mathrm{C} / \mathrm{C}(=\mathrm{Clc} 1 \operatorname{ccc}([\mathrm{N}+](=\mathrm{O})[\mathrm{O}-]) \operatorname{cc} 1) \mathrm{C}(=\mathrm{O}) \mathrm{O}$ & 1300000 & $*$ \\
\hline 5361 & $\mathrm{N \# C/C}(=\mathrm{C} / \mathrm{c} 1 \mathrm{ccc}[\mathrm{nH}] 1) \mathrm{C}(=\mathrm{O}) \mathrm{O}$ & 1360000 & $*$ \\
\hline 5362 & $\mathrm{~N} \# \mathrm{CC}(\mathrm{C \# N})=\mathrm{Cc} 1 \mathrm{ccc}(\mathrm{C \# N}) \mathrm{cc} 1$ & 1400000 & $*$ \\
\hline 5363 & $\mathrm{~N} \# \mathrm{CC}(\mathrm{C} \# \mathrm{~N})=\mathrm{C} 1 \mathrm{C}(=\mathrm{O}) \mathrm{NC}(=\mathrm{O}) \mathrm{NC} 1=\mathrm{O}$ & 1400000 & $*$ \\
\hline 5364 & $\mathrm{~N} \# \mathrm{CC}(\mathrm{C} \# \mathrm{~N})=\mathrm{Cc} 1 \mathrm{cc}[\mathrm{nH}] \mathrm{n} 1$ & 1480000 & $*$ \\
\hline 5365 & $\mathrm{O}=\mathrm{C}(\mathrm{O}) \mathrm{C}(=\mathrm{Cc} 1 \operatorname{ccc}(\mathrm{O}) \operatorname{cc} 1) \mathrm{C}(=\mathrm{O}) \mathrm{O}$ & 1500000 & $*$ \\
\hline 5366 & $\mathrm{C}[\mathrm{S}+]([\mathrm{O}-]) \mathrm{c} 1 \mathrm{ccc}(\mathrm{C}=\mathrm{C}(\mathrm{C \# N}) \mathrm{C} \# \mathrm{~N}) \mathrm{cc} 1$ & 1800000 & $*$ \\
\hline 5367 & $\mathrm{~N} \# \mathrm{CC}(\mathrm{C} \# \mathrm{~N})=\mathrm{Cc} 1 \mathrm{ccc} 2[\mathrm{nH}] \operatorname{ccc} 2 \mathrm{c} 1$ & 2200000 & $*$ \\
\hline 5368 & $\mathrm{~N} \# \mathrm{C} / \mathrm{C}=\mathrm{C} / \mathrm{c} 1 \mathrm{ccc}(\mathrm{O}) \mathrm{cc} 1$ & 2400000 & * \\
\hline 5369 & $\mathrm{O}=\mathrm{C}(\mathrm{O}) / \mathrm{C}=\mathrm{C} / \mathrm{c} 1 \mathrm{ccc}(\mathrm{O}) \mathrm{cc} 1$ & 3000000 & $*$ \\
\hline 5370 & $\mathrm{CN}(\mathrm{c} 1 \mathrm{cccnc} 1) \mathrm{c} 1 \mathrm{cc} 2 \mathrm{c}(\mathrm{Nc} 3 \mathrm{ccc}(\mathrm{F}) \mathrm{c}(\mathrm{Cl}) \mathrm{c} 3) \mathrm{c}(\mathrm{CHN}) \mathrm{cnc} 2 \mathrm{cn} 1$ & 5000000 & $*$ \\
\hline 5371 & $\mathrm{~N} \# \mathrm{CC}(\mathrm{C} \# \mathrm{~N}) \mathrm{Cc} 1 \mathrm{ccc}(\mathrm{O}) \mathrm{cc} 1$ & 6500000 & $*$ \\
\hline
\end{tabular}

References:

(1) Zhang, Q.; Diao, Y.; Wang, F.; Fu, Y.; Tang, F.; You, Q.; Zhou, H. Design and Discovery of 4-Anilinoquinazoline Ureas as Multikinase Inhibitors Targeting BRAF, VEGFR-2 and EGFR. Medchemcomm 2013, 4 (6), 979-986. https://doi.org/10.1039/c3md00096f.

(2) Jang, J.; Son, J. B.; To, C.; Bahcall, M.; Kim, S. Y.; Kang, S. Y.; Mushajiang, M.; Lee, Y.; Jänne, P. A.; Choi, H. G.; Gray, N. S. Discovery of a Potent Dual ALK and EGFR T790M Inhibitor. Eur. J. Med. Chem. 2017, 136, 497-510. https://doi.org/10.1016/j.ejmech.2017.04.079.

(3) Zhang, H. Q.; Gong, F. H.; Ye, J. Q.; Zhang, C.; Yue, X. H.; Li, C. G.; Xu, Y. G.; Sun, L. P. Design and Discovery of 4 Anilinoquinazoline-Urea Derivatives as Dual TK Inhibitors of EGFR and VEGFR-2. Eur. J. Med. Chem. 2016, 125, $245-254$. https://doi.org/10.1016/j.ejmech.2016.09.039.

(4) Yi, Y.; Wang, L.; Zhao, D.; Huang, S.; Wang, C.; Liu, Z.; Sun, H.; Liu, K.; Ma, X.; Li, Y. Structural Optimization of Diphenylpyrimidine Scaffold as Potent and Selective Epidermal Growth Factor Receptor Inhibitors against L858R/T790M Resistance Mutation in Nonsmall Cell Lung Cancer. Chem. Biol. Drug Des. 2018, 92 (6), 1988-1997. https://doi.org/10.1111/cbdd.13370.

(5) Zhang, D.; Yan, Y.; Jin, G.; Liu, B.; Ma, X.; Han, D.; Jia, X. Synthesis and Antitumor Evaluation of Novel 4-Anilino-7,8Dihydropyrido[4,3-d]Pyrimidine-6(5H)-Carboxylate Derivatives as Potential EGFR Inhibitors. Arch. Pharm. (Weinheim). 2018, 351 (9), 1-11. https://doi.org/10.1002/ardp.201800110.

(6) Li, D. D.; Fang, F.; Li, J. R.; Du, Q. R.; Sun, J.; Gong, H. Bin; Zhu, H. L. Discovery of 6-Substituted 4-Anilinoquinazolines with Dioxygenated Rings as Novel EGFR Tyrosine Kinase Inhibitors. Bioorganic Med. Chem. Lett. 2012, 22 (18), 5870-5875. https://doi.org/10.1016/j.bmcl.2012.07.079.

(7) Kang, B. R.; Shan, A. L.; Li, Y. P.; Xu, J.; Lu, S. M.; Zhang, S. Q. Discovery of 2-Aryl-8-Hydroxy (or Methoxy)-Isoquinolin-1(2H)Ones as Novel EGFR Inhibitor by Scaffold Hopping. Bioorganic Med. Chem. 2013, 21 (22), 6956-6964. https://doi.org/10.1016/j.bmc.2013.09.027.

(8) Smaill, J. B.; Rewcastle, G. W.; Loo, J. A.; Greis, K. D.; Chan, O. H.; Reyner, E. L.; Lipka, E.; Showalter, H. D. H.; Vincent, P. W.; Elliott, W. L.; Denny, W. A. Tyrosine Kinase Inhibitors. 17. Irreversible Inhibitors of the Epidermal Growth Factor Receptor: 4(Phenylamino)Quinazoline- and 4- (Phenylamino)Pyrido[3,2-d]Pyrimidine-6-Acrylamides Bearing Additional Solubilizing Functions. J. Med. Chem. 2000, 43 (7), 1380-1397. https://doi.org/10.1021/jm990482t.

(9) Suzuki, N.; Shiota, T.; Watanabe, F.; Haga, N.; Murashi, T.; Ohara, T.; Matsuo, K.; Oomori, N.; Yari, H.; Dohi, K.; Inoue, M.; Iguchi, M.; Sentou, J.; Wada, T. Synthesis and Evaluation of Novel Pyrimidine-Based Dual EGFR/Her-2 Inhibitors. Bioorganic Med. Chem. Lett. 2011, 21 (6), 1601-1606. https://doi.org/10.1016/j.bmcl.2011.01.119. 
(10) Lüth, A.; Löwe, W. Syntheses of 4-(Indole-3-Yl)Quinazolines - A New Class of Epidermal Growth Factor Receptor Tyrosine Kinase Inhibitors. Eur. J. Med. Chem. 2008, 43 (7), 1478-1488. https://doi.org/10.1016/j.ejmech.2007.09.018.

(11) Lv, P. C.; Li, H. Q.; Sun, J.; Zhou, Y.; Zhu, H. L. Synthesis and Biological Evaluation of Pyrazole Derivatives Containing Thiourea Skeleton as Anticancer Agents. Bioorganic Med. Chem. 2010, 18 (13), 4606-4614. https://doi.org/10.1016/j.bmc.2010.05.034.

(12) Qiu, K. M.; Wang, H. H.; Wang, L. M.; Luo, Y.; Yang, X. H.; Wang, X. M.; Zhu, H. L. Design, Synthesis and Biological Evaluation of Pyrazolyl-Thiazolinone Derivatives as Potential EGFR and HER-2 Kinase Inhibitors. Bioorganic Med. Chem. 2012, 20 (6), 20102018. https://doi.org/10.1016/j.bmc.2012.01.051.

(13) Lv, P. C.; Li, D. D.; Li, Q. S.; Lu, X.; Xiao, Z. P.; Zhu, H. L. Synthesis, Molecular Docking and Evaluation of Thiazolyl-Pyrazoline Derivatives as EGFR TK Inhibitors and Potential Anticancer Agents. Bioorganic Med. Chem. Lett. 2011, 21 (18), $5374-5377$. https://doi.org/10.1016/j.bmcl.2011.07.010.

(14) Li, H. Q.; Yan, T.; Yang, Y.; Shi, L.; Zhou, C. F.; Zhu, H. L. Synthesis and Structure-Activity Relationships of N-Benzyl-N-(X-2Hydroxybenzyl)-N'-Phenylureas and Thioureas as Antitumor Agents. Bioorganic Med. Chem. 2010, 18 (1), $305-313$. https://doi.org/10.1016/j.bmc.2009.10.054.

(15) Han, J.; Kaspersen, S. J.; Nervik, S.; Nørsett, K. G.; Sundby, E.; Hoff, B. H. Chiral 6-Aryl-Furo[2,3-d]Pyrimidin-4-Amines as EGFR Inhibitors. Eur. J. Med. Chem. 2016, 119, 278-299. https://doi.org/10.1016/j.ejmech.2016.04.054.

(16) Eldebss, T. M. A.; Gomha, S. M.; Abdulla, M. M.; Arafa, R. K. Novel Pyrrole Derivatives as Selective CHK1 Inhibitors: Design, Regioselective Synthesis and Molecular Modeling. Medchemcomm 2015, 6 (5), 852-859. https://doi.org/10.1039/c4md00560k.

(17) Ravez, S.; Arsenlis, S.; Barczyk, A.; Dupont, A.; Frédérick, R.; Hesse, S.; Kirsch, G.; Depreux, P.; Goossens, L. Synthesis and Biological Evaluation of Di-Aryl Urea Derivatives as c-Kit Inhibitors. Bioorganic Med. Chem. 2015, 23 (22), 7340-7347. https://doi.org/10.1016/j.bmc.2015.10.035.

(18) Bugge, S.; Buene, A. F.; Jurisch-Yaksi, N.; Moen, I. U.; Skjønsfjell, E. M.; Sundby, E.; Hoff, B. H. Extended Structure-Activity Study of Thienopyrimidine-Based EGFR Inhibitors with Evaluation of Drug-like Properties. Eur. J. Med. Chem. 2016, 107, $255-274$. https://doi.org/10.1016/j.ejmech.2015.11.012.

(19) Engel, J.; Richters, A.; Getlik, M.; Tomassi, S.; Keul, M.; Termathe, M.; Lategahn, J.; Becker, C.; Mayer-Wrangowski, S.; Grütter, C.; Uhlenbrock, N.; Krüll, J.; Schaumann, N.; Eppmann, S.; Kibies, P.; Hoffgaard, F.; Heil, J.; Menninger, S.; Ortiz-Cuaran, S.; Heuckmann, J. M.; Tinnefeld, V.; Zahedi, R. P.; Sos, M. L.; Schultz-Fademrecht, C.; Thomas, R. K.; Kast, S. M.; Rauh, D. Targeting Drug Resistance in EGFR with Covalent Inhibitors: A Structure-Based Design Approach. J. Med. Chem. 2015, 58 (17), $6844-6863$. https://doi.org/10.1021/acs.jmedchem.5b01082.

(20) Li, S. N.; Xu, Y. Y.; Gao, J. Y.; Yin, H. R.; Zhang, S. L.; Li, H. Q. Combination of 4-Anilinoquinazoline and Rhodanine as Novel Epidermal Growth Factor Receptor Tyrosine Kinase Inhibitors. Bioorganic Med. Chem. 2015, 23 (13), 3221-3227. https://doi.org/10.1016/j.bmc.2015.04.065.

(21) Cheng, H.; Chang, Y.; Zhang, L.; Luo, J.; Tu, Z.; Lu, X.; Zhang, Q.; Lu, J.; Ren, X.; Ding, K. Identification and Optimization of New Dual Inhibitors of B-Raf and Epidermal Growth Factor Receptor Kinases for Overcoming Resistance against Vemurafenib. J. Med. Chem. 2014, 57 (6), 2692-2703. https://doi.org/10.1021/jm500007h.

(22) Hamed, M. M.; Abou El Ella, D. A.; Keeton, A. B.; Piazza, G. A.; Engel, M.; Hartmann, R. W.; Abadi, A. H. Quinazoline and Tetrahydropyridothieno[2,3-d]Pyrimidine Derivatives as Irreversible EGFR Tyrosine Kinase Inhibitors: Influence of the Position 4 Substituent. Medchemcomm 2013, 4 (8), 1202-1207. https://doi.org/10.1039/c3md00118k.

(23) Vacondio, F.; Carmi, C.; Galvani, E.; Bassi, M.; Silva, C.; Lodola, A.; Rivara, S.; Cavazzoni, A.; Alfieri, R. R.; Petronini, P. G.; Mor, M. Long-Lasting Inhibition of EGFR Autophosphorylation in A549 Tumor Cells by Intracellular Accumulation of Non-Covalent Inhibitors. Bioorganic Med. Chem. Lett. 2013, 23 (19), 5290-5294. https://doi.org/10.1016/j.bmcl.2013.08.008.

(24) Chen, X.; Du, Y.; Sun, H.; Wang, F.; Kong, L.; Sun, M. Synthesis and Biological Evaluation of Novel Tricyclic Oxazine and Oxazepine Fused Quinazolines. Part 1: Erlotinib Analogs. Bioorganic Med. Chem. Lett. 2014, 24 (3), 884-887. https://doi.org/10.1016/j.bmcl.2013.12.079.

(25) Lin, J.; Shen, W.; Xue, J.; Sun, J.; Zhang, X.; Zhang, C. Novel Oxazolo[4,5-g]Quinazolin-2(1H)-Ones: Dual Inhibitors of EGFR and 
Src Protein Tyrosine Kinases. Eur. J. Med. Chem. 2012, 55, 39-48. https://doi.org/10.1016/j.ejmech.2012.06.055.

(26) Suzuki, N.; Shiota, T.; Watanabe, F.; Haga, N.; Murashi, T.; Ohara, T.; Matsuo, K.; Omori, N.; Yari, H.; Dohi, K.; Inoue, M.; Iguchi, M.; Sentou, J.; Wada, T. Discovery of Novel 5-Alkynyl-4-Anilinopyrimidines as Potent, Orally Active Dual Inhibitors of EGFR and Her-2 Tyrosine Kinases. Bioorganic Med. Chem. Lett. 2012, 22 (1), 456-460. https://doi.org/10.1016/j.bmcl.2011.10.103.

(27) Kawakita, Y.; Seto, M.; Ohashi, T.; Tamura, T.; Yusa, T.; Miki, H.; Iwata, H.; Kamiguchi, H.; Tanaka, T.; Sogabe, S.; Ohta, Y.; Ishikawa, T. Design and Synthesis of Novel Pyrimido[4,5-b]Azepine Derivatives as HER2/EGFR Dual Inhibitors. Bioorganic Med. Chem. 2013, 21 (8), 2250-2261. https://doi.org/10.1016/j.bmc.2013.02.014.

(28) Liu, T.; Shirai, R.; Matsui, T.; Umezawa, K.; Iwasaki, S. Synthesis and Biological Activity of 5-[(2,5Dihydroxybenzyl)Amino]Salicylic Acid Analogs as Inhibitors of EGF Receptor-Associated Protein Tyrosine Kinase. Bioorganic Med. Chem. Lett. 1997, 7 (3), 365-368. https://doi.org/10.1016/S0960-894X(97)00014-0.

(29) Lü, S.; Zheng, W.; Ji, L.; Luo, Q.; Hao, X.; Li, X.; Wang, F. Synthesis, Characterization, Screening and Docking Analysis of 4Anilinoquinazoline Derivatives as Tyrosine Kinase Inhibitors. Eur. J. Med. Chem. 2013, 61, 84-94. https://doi.org/10.1016/j.ejmech.2012.07.036.

(30) Mahboobi, S.; Sellmer, A.; Winkler, M.; Eichhorn, E.; Pongratz, H.; Ciossek, T.; Baer, T.; Maier, T.; Beckers, T. Novel Chimeric Histone Deacetylase Inhibitors: A Series of Lapatinib Hybrides as Potent Inhibitors of Epidermal Growth Factor Receptor (EGFR), Human Epidermal Growth Factor Receptor 2 (HER2), and Histone Deacetylase Activity. J. Med. Chem. 2010, 53 (24), $8546-8555$. https://doi.org/10.1021/jm100665z.

(31) Pisaneschi, F.; Nguyen, Q. De; Shamsaei, E.; Glaser, M.; Robins, E.; Kaliszczak, M.; Smith, G.; Spivey, A. C.; Aboagye, E. O. Development of a New Epidermal Growth Factor Receptor Positron Emission Tomography Imaging Agent Based on the 3 Cyanoquinoline Core: Synthesis and Biological Evaluation; 2010; Vol. 18. https://doi.org/10.1016/j.bmc.2010.08.004.

(32) Luo, Y.; Li, Y.; Qiu, K. M.; Lu, X.; Fu, J.; Zhu, H. L. Metronidazole Acid Acyl Sulfonamide: A Novel Class of Anticancer Agents and Potential EGFR Tyrosine Kinase Inhibitors. Bioorganic Med. Chem. 2011, 19 (20), 6069-6076. https://doi.org/10.1016/j.bmc.2011.08.038.

(33) Uto, Y.; Nagasawa, H.; Jin, C. Z.; Nakayama, S.; Tanaka, A.; Kiyoi, S.; Nakashima, H.; Shimamura, M.; Inayama, S.; Fujiwara, T.; Takeuchi, Y.; Uehara, Y.; Kirk, K. L.; Nakata, E.; Hori, H. Design of Antiangiogenic Hypoxic Cell Radiosensitizers: 2Nitroimidazoles Containing a 2-Aminomethylene-4-Cyclopentene-1,3-Dione Moiety. Bioorganic Med. Chem. 2008, 16 (11), $6042-$ 6053. https://doi.org/10.1016/j.bmc.2008.04.041.

(34) Smith, L.; Wong, W. C.; Kiselyov, A. S.; Burdzovic-Wizemann, S.; Mao, Y.; Xu, Y.; Duncton, M. A. J.; Kim, K.; Piatnitski, E. L.; Doody, J. F.; Wang, Y.; Rosler, R. L.; Milligan, D.; Columbus, J.; Balagtas, C.; Lee, S. P.; Konovalov, A.; Hadari, Y. R. Novel Tricyclic Azepine Derivatives: Biological Evaluation of Pyrimido[4,5-b]-1,4-Benzoxazepines, Thiazepines, and Diazepines as Inhibitors of the Epidermal Growth Factor Receptor Tyrosine Kinase. Bioorganic Med. Chem. Lett. 2006, 16 (19), $5102-5106$. https://doi.org/10.1016/j.bmcl.2006.07.031.

(35) Wissner, A.; Hamann, P. R.; Nilakantan, R.; Greenberger, L. M.; Ye, F.; Rapuano, T. A.; Loganzo, F. Syntheses and EGFR Kinase Inhibitory Activity of 6-Substituted-4-Anilino [1,7] and [1,8] Naphthyridine-3-Carbonitriles. Bioorganic Med. Chem. Lett. 2004, 14 (6), 1411-1416. https://doi.org/10.1016/j.bmcl.2004.01.034.

(36) Kubo, K.; Shimizu, T.; Ohyama, S. I.; Murooka, H.; Nishitoba, T.; Kato, S.; Kobayashi, Y.; Yagi, M.; Isoe, T.; Nakamura, K.; Osawa, T.; Izawa, T. A Novel Series of 4-Phenoxyquinolines: Potent and Highly Selective Inhibitors of PDGF Receptor Autophosphorylation. Bioorganic Med. Chem. Lett. 1997, 7 (23), 2935-2940. https://doi.org/10.1016/S0960-894X(97)10117-2.

(37) Schroeder, M. C.; Hamby, J. M.; Connolly, C. J. C.; Grohar, P. J.; Winters, R. T.; Barvian, M. R.; Moore, C. W.; Boushelle, S. L.; Crean, S. M.; Kraker, A. J.; Driscoll, D. L.; Vincent, P. W.; Elliott, W. L.; Lu, G. H.; Batley, B. L.; Dahring, T. K.; Major, T. C.; Panek, R. L.; Doherty, A. M.; Hollis Showalter, H. D. Soluble 2-Substituted Aminopyrido[2,3-d]Pyrimidin-7-Y1 Ureas. StructureActivity Relationships against Selected Tyrosine Kinases and Exploration of in Vitro and in Vivo Anticancer Activity. J. Med. Chem. 2001, 44 (12), 1915-1926. https://doi.org/10.1021/jm0004291.

(38) Mastalerz, H.; Chang, M.; Chen, P.; Fink, B. E.; Gavai, A.; Han, W. C.; Johnson, W.; Langley, D.; Lee, F. Y.; Leavitt, K.; Marathe, 
P.; Norris, D.; Oppenheimer, S.; Sleczka, B.; Tarrant, J.; Tokarski, J. S.; Vite, G. D.; Vyas, D. M.; Wong, H.; Wong, T. W.; Zhang, H.; Zhang, G. 5-((4-Aminopiperidin-1-Yl)Methyl)Pyrrolotriazine Dual Inhibitors of EGFR and HER2 Protein Tyrosine Kinases. Bioorganic Med. Chem. Lett. 2007, 17 (17), 4947-4954. https://doi.org/10.1016/j.bmcl.2007.06.019.

(39) Gibson, K. H.; Grundy, W.; Godfrey, A. A.; Woodburn, J. R.; Ashton, S. E.; Curry, B. J.; Scarlett, L.; Barker, A. J.; Brown, D. S. Epidermal Growth Factor Receptor Tyrosine Kinase: Structure-Activity Relationships and Antitumour Activity of Novel Quinazolines. Bioorg. Med. Chem. Lett. 1997, 7 (21), 2723-2728. https://doi.org/10.1016/s0960-894x(97)10059-2.

(40) Rewcastle, G. W.; Denny, W. A.; Bridges, A. J.; Zhou, H.; Cody, D. R.; Mcmichae, A.; Fry, D. W. Tyrosine Kinase Inhibitors. 5. Synthesis and Structure-Activity Relationships for 4-[(Phenylmethyl)Amino]- and 4-(Phenylamino)Quinazolines as Potent Adenosine 5'-Triphosphate Binding Site Inhibitors of the Tyrosine Kinase Domain of the Epidermal Growth Fa. J. Med. Chem. 1996, 38 (18), 3482-3487. https://doi.org/10.1021/jm00018a008.

(41) Hunt, J. T.; Mitt, T.; Borzilleri, R.; Gullo-Brown, J.; Fargnoli, J.; Fink, B.; Han, W. C.; Mortillo, S.; Vite, G.; Wautlet, B.; Wong, T.; Yu, C.; Zheng, X.; Bhide, R. Discovery of the Pyrrolo[2,1-f][1,2,4]Triazine Nucleus as a New Kinase Inhibitor Template. J. Med. Chem. 2004, 47 (16), 4054-4059. https://doi.org/10.1021/jm049892u.

(42) Rewcastle, G. W.; Palmer, B. D.; Dobrusin, E. M.; Fry, D. W.; Kraker, A. J.; Denny, W. A. Tyrosine Kinase Inhibitors. 3. StructureActivity Relationships for Inhibition of Protein Tyrosine Kinases by Nuclear-Substituted Derivatives of 2,2'-Dithiobis(1-Methyl-NPhenyl-1H-Indole-3-Carboxamide). J. Med. Chem. 1994, 37 (13), 2033-2042. https://doi.org/10.1021/jm00039a016.

(43) Myers, M. R.; Setzer, N. N.; Spada, A. P.; Zulli, A. L.; Hsu, C.-Y. J.; Zilberstein, A.; Johnson, S. E.; Hook, L. E.; Jacoski, M. V. The Preparation and Sar of 4-(Anilino), 4-(Phenoxy), and 4-(Thiophenoxy)-Quinazolines: Inhibitors of P56lck and EGF-R Tyrosine Kinase Activity. Bioorg. Med. Chem. Lett. 1997, 7 (4), 417-420.

(44) Klutchko, S. R.; Hamby, J. M.; Boschelli, D. H.; Wu, Z.; Kraker, A. J.; Amar, A. M.; Hartl, B. G.; Shen, C.; Klohs, W. D.; Steinkampf, R. W.; Driscoll, D. L.; Nelson, J. M.; Elliott, W. L.; Roberts, B. J.; Stoner, C. L.; Vincent, P. W.; Dykes, D. J.; Panek, R. L.; Lu, G. H.; Major, T. C.; Dahring, T. K.; Hallak, H.; Bradford, L. A.; Showalter, H. D. H.; Doherty, A. M. 2-Substituted Aminopyrido[2,3-d]Pyrimidin-7(8H)-Ones. Structure-Activity Relationships against Selected Tyrosine Kinases and in Vitro and in Vivo Anticancer Activity. J. Med. Chem. 1998, 41 (17), 3276-3292. https://doi.org/10.1021/jm9802259.

(45) Zimmermann, J.; Buchdunger, E.; Mett, H.; Meyer, T.; Lydon, N. B. Potent and Selective Inhibitors of the Abl-Kinase: Phenylaminopyrimidine (PAP) Derivatives. Bioorganic Med. Chem. Lett. 1997, 7 (2), 187-192. https://doi.org/10.1016/S0960894X(96)00601-4.

(46) Traxler, P.; Trinks, U.; Buchdunger, E.; Mett, H.; Meyer, T.; Müller, M.; Regenass, U.; Rösel, J.; Lydon, N. [(Alkylamino)Methyl]Acrylophenones: Potent and Selective Inhibitors of the Epidermal Growth Factor Receptor Protein Tyrosine Kinase. J. Med. Chem. 1995, 38 (13), 2441-2448. https://doi.org/10.1021/jm00013a020.

(47) Myers, M. R.; Setzer, N. N.; Spada, A. P.; Persons, P. E.; Ly, C. Q.; Maguire, M. P.; Zulli, A. L.; Cheney, D. L.; Zilberstein, A.; Johnson, S. E.; Franks, C. F.; Mitchell, K. J. The Synthesis and SAR of New 4-(N-Alkyl-N-Phenyl)Amino-6,7Dimethoxyquinazolines and 4-(N-Alkyl-N-Phenyl)Amino-Pyrazolo[3,4-d]Pyrimidines, Inhibitors of CSF-1R Tyrosine Kinase Activity. Bioorganic Med. Chem. Lett. 1997, 7 (4), 421-424. https://doi.org/10.1016/S0960-894X(97)00035-8.

(48) Rewcastle, G. W.; Bridges, A. J.; Fry, D. W.; Rubin, J. R.; Denny, W. A. Tyrosine Kinase Inhibitors. 12. Synthesis and StructureActivity Relationships for 6-Substituted 4-(Phenylamino)Pyrimido[5,4-d]Pyrimidines Designed as Inhibitors of the Epidermal Growth Factor Receptor. J. Med. Chem. 1997, 40 (12), 1820-1826. https://doi.org/10.1021/jm960879m.

(49) Hamby, J. M.; Connolly, C. J. C.; Schroeder, M. C.; Winters, R. T.; Showalter, H. D. H.; Panek, R. L.; Major, T. C.; Olsewski, B.; Ryan, M. J.; Dahring, T.; Lu, G. H.; Keiser, J.; Amar, A.; Shen, C.; Kraker, A. J.; Slintak, V.; Nelson, J. M.; Fry, D. W.; Bradford, L.; Hallak, H.; Doherty, A. M. Structure-Activity Relationships for a Novel Series of Pyrido[2,3- d]Pyrimidine Tyrosine Kinase Inhibitors. J. Med. Chem. 1997, 40 (15), 2296-2303. https://doi.org/10.1021/jm970367n.

(50) Tsou, H. R.; Mamuya, N.; Johnson, B. D.; Reich, M. F.; Gruber, B. C.; Ye, F.; Nilakantan, R.; Shen, R.; Discafani, C.; DeBlanc, R.; Davis, R.; Koehn, F. E.; Greenberger, L. M.; Wang, Y. F.; Wissner, A. 6-Substituted-4-(3-Bromophenylamino)Quinazolines as Putative Irreversible Inhibitors of the Epidermal Growth Factor Receptor (EGFR) and Human Epidermal Growth Factor Receptor 
(HER-2) Tyrosine Kinases with Enhanced Antitumor Activity. J. Med. Chem. 2001, 44 (17), 2719-2734.

https://doi.org/10.1021/jm0005555.

(51) Ibrahim, D. A.; El-Metwally, A. M. Design, Synthesis, and Biological Evaluation of Novel Pyrimidine Derivatives as CDK2 Inhibitors. Eur. J. Med. Chem. 2010, 45 (3), 1158-1166. https://doi.org/10.1016/j.ejmech.2009.12.026.

(52) Ban, H. S.; Tanaka, Y.; Nabeyama, W.; Hatori, M.; Nakamura, H. Enhancement of EGFR Tyrosine Kinase Inhibition by C-C Multiple Bonds-Containing Anilinoquinazolines. Bioorganic Med. Chem. 2010, 18 (2), 870-879.

https://doi.org/10.1016/j.bmc.2009.11.035.

(53) Fink, B. E.; Norris, D.; Mastalerz, H.; Chen, P.; Goyal, B.; Zhao, Y.; Kim, S. H.; Vite, G. D.; Lee, F. Y.; Zhang, H.; Oppenheimer, S.; Tokarski, J. S.; Wong, T. W.; Gavai, A. V. Novel Pyrrolo[2,1-f][1,2,4]Triazin-4-Amines: Dual Inhibitors of EGFR and HER2 Protein Tyrosine Kinases. Bioorganic Med. Chem. Lett. 2011, 21 (2), 781-785. https://doi.org/10.1016/j.bmcl.2010.11.100.

(54) Liu, K.; Lu, X.; Zhang, H. J.; Sun, J.; Zhu, H. L. Synthesis, Molecular Modeling and Biological Evaluation of 2-(Benzylthio)-5Aryloxadiazole Derivatives as Anti-Tumor Agents. Eur. J. Med. Chem. 2012, 47 (1), 473-478. https://doi.org/10.1016/j.ejmech.2011.11.015.

(55) Bai, F.; Liu, H.; Tong, L.; Zhou, W.; Liu, L.; Zhao, Z.; Liu, X.; Jiang, H.; Wang, X.; Xie, H.; Li, H. Discovery of Novel Selective Inhibitors for EGFR-T790M/L858R. Bioorganic Med. Chem. Lett. 2012, 22 (3), 1365-1370. https://doi.org/10.1016/j.bmcl.2011.12.067.

(56) Zhao, B.; Xiao, Z.; Qi, J.; Luo, R.; Lan, Z.; Zhang, Y.; Hu, X.; Tang, Q.; Zheng, P.; Xu, S.; Zhu, W. Design, Synthesis and Biological Evaluation of AZD9291 Derivatives as Selective and Potent EGFRL858R/T790M Inhibitors. Eur. J. Med. Chem. 2019, 163 (2019), 367-380. https://doi.org/10.1016/j.ejmech.2018.11.069.

(57) Kohler, A. M.; Widner, J.; Bold, G.; Meyer, T.; Se $\quad$ quin, U.; Traxler, P. Furo[2,3-d]Pyrimidines and Oxazolo[5,4-d]Pyrimidines as Inhibitors of Receptor Tyrosine Kinases (RTK). Helv. Chim. Acta 2004, 87, 956-975. https://doi.org/10.1002/hlca.200490089.

(58) Das, D.; Xie, L.; Wang, J.; Xu, X.; Zhang, Z.; Shi, J.; Le, X.; Hong, J. Discovery of New Quinazoline Derivatives as Irreversible Dual EGFR/HER2 Inhibitors and Their Anticancer Activities - Part 1. Bioorganic Med. Chem. Lett. 2019, 29 (4), 591-596. https://doi.org/10.1016/j.bmcl.2018.12.056.

(59) Schnute, M. E.; Benoit, S. E.; Buchler, I. P.; Caspers, N.; Grapperhaus, M. L.; Han, S.; Hotchandani, R.; Huang, N.; Hughes, R. O.; Juba, B. M.; Kim, K. H.; Liu, E.; McCarthy, E.; Messing, D.; Miyashiro, J. S.; Mohan, S.; O’Connell, T. N.; Ohren, J. F.; Parikh, M. D.; Schmidt, M.; Selness, S. R.; Springer, J. R.; Thanabal, V.; Trujillo, J. I.; Walker, D. P.; Wan, Z. K.; Withka, J. M.; Wittwer, A. J.; Wood, N. L.; Xing, L.; Zapf, C. W.; Douhan, J. Aminopyrazole Carboxamide Bruton's Tyrosine Kinase Inhibitors. Irreversible to Reversible Covalent Reactive Group Tuning. ACS Med. Chem. Lett. 2019, 10 (1), 80-85. https://doi.org/10.1021/acsmedchemlett.8b00461.

(60) Brignola, P. S.; Lackey, K.; Kadwell, S. H.; Hoffman, C.; Horne, E.; Luke Carter, H.; Darren Stuart, J.; Blackburn, K.; Moyer, M. B.; Alligood, K. J.; Knight, W. B.; Wood, E. R. Comparison of the Biochemical and Kinetic Properties of the Type 1 Receptor Tyrosine Kinase Intracellular Domains: Demonstration of Differential Sensitivity to Kinase Inhibitors. J. Biol. Chem. 2002, 277 (2), $1576-$ 1585. https://doi.org/10.1074/jbc.M105907200.

(61) Kim, D. C.; Lee, Y. R.; Yang, B. S.; Shin, K. J.; Kim, D. J.; Chung, B. Y.; Yoo, K. H. Synthesis and Biological Evaluations of Pyrazolo[3,4-d]Pyrimidines as Cyclin-Dependent Kinase 2 Inhibitors. Eur. J. Med. Chem. 2003, 38 (5), 525-532. https://doi.org/10.1016/S0223-5234(03)00065-5.

(62) Showalter, H. D. H.; Bridges, A. J.; Zhou, H.; Sercel, A. D.; McMichael, A.; Fry, D. W. Tyrosine Kinase Inhibitors. 16. 6,5,6Tricyclic Benzothieno[3,2-d]Pyrimidines and Pyrimido[5,4-b]- and -[4,5- b]Indoles as Potent Inhibitors of the Epidermal Growth Factor Receptor Tyrosine Kinase. J. Med. Chem. 1999, 42 (26), 5464-5474. https://doi.org/10.1021/jm9903949.

(63) Wissner, A.; Berger, D. M.; Boschelli, D. H.; Brawner Floyd, M.; Greenberger, L. M.; Gruber, B. C.; Johnson, B. D.; Mamuya, N.; Nilakantan, R.; Reich, M. F.; Shen, R.; Tsou, H. R.; Upeslacis, E.; Yu Fen Wang; Wu, B.; Ye, F.; Zhang, N. 4-Anilino-6,7Dialkoxyquinoline-3-Carbonitrile Inhibitors of Epidermal Growth Factor Receptor Kinase and Their Bioisosteric Relationship To the 4-Anilino-6,7-Dialkoxyquinazoline Inhibitors. J. Med. Chem. 2000, 43 (17), 3244-3256. https://doi.org/10.1021/jm000206a. 
(64) Cassinelli, G.; Lanzi, C.; Pensa, T.; Gambetta, R. A.; Nasini, G.; Cuccuru, G.; Cassinis, M.; Pratesi, G.; Polizzi, D.; Tortoreto, M.; Zunino, F. Clavilactones, a Novel Class of Tyrosine Kinase Inhibitors of Fungal Origin. Biochem. Pharmacol. 2000, 59 (12), 1539 1547. https://doi.org/10.1016/S0006-2952(00)00278-1.

(65) Lee, J. Y.; Park, Y. K.; Seo, S. H.; Yang, B. S.; Park, H.; Lee, Y. S. 7-Substituted-[1,4]Dioxano[2,3-g]Quinazolines as Inhibitors of Epidermal Growth Factor Receptor Kinase. Arch. Pharm. (Weinheim). 2002, 335 (10), 487-494. https://doi.org/10.1002/ardp.200290003.

(66) Xu, S.; Zhang, L.; Chang, S.; Luo, J.; Lu, X.; Tu, Z.; Liu, Y.; Zhang, Z.; Xu, Y.; Ren, X.; Ding, K. Design, Synthesis and Biological Evaluation of New Molecules Inhibiting Epidermal Growth Factor Receptor Threonine790 $\rightarrow$ Methionine 790 Mutant.

Medchemcomm 2012, 3 (9), 1155-1159. https://doi.org/10.1039/c2md20078c.

(67) Hamed, M. M.; AbouElElla, D. A.; Keeton, A. B.; Piazza, G. A.; Abadi, A. H.; Hartmann, R. W.; Engel, M. 6-Aryl and Heterocycle Quinazoline Derivatives as Potent EGFR Inhibitors with Improved Activity toward Gefitinib-Sensitive and -Resistant Tumor Cell Lines. ChemMedChem 2013, 8 (9), 1495-1504. https://doi.org/10.1002/cmdc.201300147.

(68) Hu, M.; Ye, W.; Li, J.; Zhong, G.; He, G.; Xu, Q.; Zhang, Y. Synthesis and Evaluation of Salicylanilide Derivatives as Potential Epidermal Growth Factor Receptor Inhibitors. Chem. Biol. Drug Des. 2015, 85 (3), 280-289. https://doi.org/10.1111/cbdd.12383.

(69) Yuan, J. W.; Qiu, H. Y.; Wang, P. F.; Makawana, J. A.; Yang, Y. A.; Zhang, F.; Yin, Y.; Lin, J.; Wang, Z. C.; Zhu, H. L. Synthesis of Caffeic Acid Amides Bearing 2,3,4,5-Tetrahydrobenzo[ b][1,4]Dioxocine Moieties and Their Biological Evaluation as Antitumor Agents. Molecules 2014, 19 (6), 7269-7286. https://doi.org/10.3390/molecules19067269.

(70) Qin, H. L.; Leng, J.; Youssif, B. G. M.; Amjad, M. W.; Raja, M. A. G.; Hussain, M. A.; Hussain, Z.; Kazmi, S. N.; Bukhari, S. N. A. Synthesis and Mechanistic Studies of Curcumin Analog-Based Oximes as Potential Anticancer Agents. Chem. Biol. Drug Des. 2017, 90 (3), 443-449. https://doi.org/10.1111/cbdd.12964.

(71) Günther, M.; Lategahn, J.; Juchum, M.; Döring, E.; Keul, M.; Engel, J.; Tumbrink, H. L.; Rauh, D.; Laufer, S. Trisubstituted Pyridinylimidazoles as Potent Inhibitors of the Clinically Resistant L858R/T790M/C797S EGFR Mutant: Targeting of Both Hydrophobic Regions and the Phosphate Binding Site. J. Med. Chem. 2017, 60 (13), 5613-5637. https://doi.org/10.1021/acs.jmedchem.7b00316.

(72) Zha, G. F.; Qin, H. L.; Youssif, B. G. M.; Amjad, M. W.; Raja, M. A. G.; Abdelazeem, A. H.; Bukhari, S. N. A. Discovery of Potential Anticancer Multi-Targeted Ligustrazine Based Cyclohexanone and Oxime Analogs Overcoming the Cancer Multidrug Resistance. Eur. J. Med. Chem. 2017, 135, 34-48. https://doi.org/10.1016/j.ejmech.2017.04.025.

(73) Kurup, S.; McAllister, B.; Liskova, P.; Mistry, T.; Fanizza, A.; Stanford, D.; Slawska, J.; Keller, U.; Hoellein, A. Design, Synthesis and Biological Activity of N4-Phenylsubstituted-7H-Pyrrolo[2,3-d]Pyrimidin-4-Amines as Dual Inhibitors of Aurora Kinase A and Epidermal Growth Factor Receptor Kinase. J. Enzyme Inhib. Med. Chem. 2018, 33 (1), 74-84. https://doi.org/10.1080/14756366.2017.1376666.

(74) Fukuda, T.; Umeki, T.; Tokushima, K.; Xiang, G.; Yoshida, Y.; Ishibashi, F.; Oku, Y.; Nishiya, N.; Uehara, Y.; Iwao, M. Design, Synthesis, and Evaluation of A-Ring-Modified Lamellarin N Analogues as Noncovalent Inhibitors of the EGFR T790M/L858R Mutant. Bioorganic Med. Chem. 2017, 25 (24), 6563-6580. https://doi.org/10.1016/j.bmc.2017.10.030.

(75) Zhang, H.; Wang, J.; Zhao, H. Y.; Yang, X. Y.; Lei, H.; Xin, M.; Cao, Y. X.; Zhang, S. Q. Synthesis and Biological Evaluation of Irreversible EGFR Tyrosine Kinase Inhibitors Containing Pyrido[3,4-d]Pyrimidine Scaffold. Bioorganic Med. Chem. 2018, 26 (12), 3619-3633. https://doi.org/10.1016/j.bmc.2018.05.039.

(76) OuYang, Y.; Wang, C.; Zhao, B.; Xiong, H.; Xiao, Z.; Zhang, B.; Zheng, P.; Hu, J.; Gao, Y.; Zhang, M.; Zhu, W.; Xu, S. Design, Synthesis, Antiproliferative Activity and Docking Studies of Quinazoline Derivatives Bearing Oxazole or Imidazole as Potential EGFR Inhibitors. New J. Chem. 2018, 42 (21), 17203-17215. https://doi.org/10.1039/c8nj03594f.

(77) Zhang, H.; Wang, J.; Shen, Y.; Wang, H. Y.; Duan, W. M.; Zhao, H. Y.; Hei, Y. Y.; Xin, M.; Cao, Y. X.; Zhang, S. Q. Discovery of 2,4,6-Trisubstitued Pyrido[3,4-d]Pyrimidine Derivatives as New EGFR-TKIs. Eur. J. Med. Chem. 2018, 148, $221-237$. https://doi.org/10.1016/j.ejmech.2018.02.051.

(78) Eldehna, W. M.; El-Naggar, D. H.; Hamed, A. R.; Ibrahim, H. S.; Ghabbour, H. A.; Abdel-Aziz, H. A. One-Pot Three-Component 
Synthesis of Novel Spirooxindoles with Potential Cytotoxic Activity against Triple-Negative Breast Cancer MDA-MB-231 Cells. J. Enzyme Inhib. Med. Chem. 2018, 33 (1), 309-318. https://doi.org/10.1080/14756366.2017.1417276.

(79) Hossam, M.; Lasheen, D. S.; Ismail, N. S. M.; Esmat, A.; Mansour, A. M.; Singab, A. N. B.; Abouzid, K. A. M. Discovery of Anilino-Furo[2,3-d]Pyrimidine Derivatives as Dual Inhibitors of EGFR/HER2 Tyrosine Kinase and Their Anticancer Activity. Eur. J. Med. Chem. 2018, 144, 330-348. https://doi.org/10.1016/j.ejmech.2017.12.022.

(80) El-Sherief, H. A. M.; Youssif, B. G. M.; Abbas Bukhari, S. N.; Abdelazeem, A. H.; Abdel-Aziz, M.; Abdel-Rahman, H. M. Synthesis, Anticancer Activity and Molecular Modeling Studies of 1,2,4-Triazole Derivatives as EGFR Inhibitors. Eur. J. Med. Chem. 2018, 156, 774-789. https://doi.org/10.1016/j.ejmech.2018.07.024.

(81) Ismail, R. S. M.; Abou-Seri, S. M.; Eldehna, W. M.; Ismail, N. S. M.; Elgazwi, S. M.; Ghabbour, H. A.; Ahmed, M. S.; Halaweish, F. T.; Abou El Ella, D. A. Novel Series of 6-(2-Substitutedacetamido)-4-Anilinoquinazolines as EGFR-ERK Signal Transduction Inhibitors in MCF-7 Breast Cancer Cells. Eur. J. Med. Chem. 2018, 155, 782-796. https://doi.org/10.1016/j.ejmech.2018.06.024.

(82) Zhang, Y.; Zhang, Y.; Liu, J.; Chen, L.; Zhao, L.; Li, B.; Wang, W. Synthesis and in Vitro Biological Evaluation of Novel Quinazoline Derivatives. Bioorganic Med. Chem. Lett. 2017, 27 (7), 1584-1587. https://doi.org/10.1016/j.bmcl.2017.02.027.

(83) Aly, R. M.; Serya, R. A. T.; El-Motwally, A. M.; Esmat, A.; Abbas, S.; Abou El Ella, D. A. Novel Quinoline-3-Carboxamides (Part 2): Design, Optimization and Synthesis of Quinoline Based Scaffold as EGFR Inhibitors with Potent Anticancer Activity. Bioorg. Chem. 2017, 75, 368-392. https://doi.org/10.1016/j.bioorg.2017.10.018.

(84) Hamed, M. M.; Darwish, S. S.; Herrmann, J.; Abadi, A. H.; Engel, M. First Bispecific Inhibitors of the Epidermal Growth Factor Receptor Kinase and the NF-KB Activity As Novel Anticancer Agents. J. Med. Chem. 2017, 60 (7), 2853-2868. https://doi.org/10.1021/acs.jmedchem.6b01774.

(85) X., Z.; T., P.; X., J.; J., L.; L., T.; Z., L.; W., Y.; Y., X.; M., L.; J., D.; H., J.; H., X.; H., L. Design, Synthesis and Biological Evaluation of Novel 4-Anilinoquinazolines with C-6 Urea-Linked Side Chains as Inhibitors of the Epidermal Growth Factor Receptor. Bioorganic Med. Chem. 2013, 21 (24), 7988-7998.

(86) Sun, S.; Zhang, J.; Wang, N.; Kong, X.; Fu, F.; Wang, H.; Yao, J. Design and Discovery of Quinazoline- and Thiourea-Containing Sorafenib Analogs as EGFR and VEGFR-2 Dual TK Inhibitors. Molecules 2018, 23 (1). https://doi.org/10.3390/molecules23010024.

(87) Milik, S. N.; Abdel-Aziz, A. K.; Lasheen, D. S.; Serya, R. A. T.; Minucci, S.; Abouzid, K. A. M. Surmounting the Resistance against EGFR Inhibitors through the Development of Thieno[2,3-d]Pyrimidine-Based Dual EGFR/HER2 Inhibitors. Eur. J. Med. Chem. 2018, 155, 316-336. https://doi.org/10.1016/j.ejmech.2018.06.011.

(88) Zhou, F.; Zhang, L.; Jin, Y.; Liu, W.; Cheng, P.; He, X.; Xie, J.; Shen, S.; Lei, J.; Ji, H.; Hu, Y.; Liu, Y.; Cui, Y.; Lv, Q.; Lan, J. Discovery of N-Aryl-N'-Pyrimidin-4-Y1 Ureas as Irreversible L858R/T790M Mutant Selective Epidermal Growth Factor Receptor Inhibitors. Bioorganic Med. Chem. Lett. 2018, 28 (7), 1257-1261. https://doi.org/10.1016/j.bmcl.2017.12.009.

(89) Xun, Q.; Zhang, Z.; Luo, J.; Tong, L.; Huang, M.; Wang, Z.; Zou, J.; Liu, Y.; Xu, Y.; Xie, H.; Tu, Z. C.; Lu, X.; Ding, K. Design, Synthesis, and Structure-Activity Relationship Study of 2-Oxo-3,4-Dihydropyrimido[4,5- d] Pyrimidines as New Colony Stimulating Factor 1 Receptor (CSF1R) Kinase Inhibitors. J. Med. Chem. 2018, 61 (6), 2353-2371.

https://doi.org/10.1021/acs.jmedchem.7b01612.

(90) Yu, L.; Huang, M.; Xu, T.; Tong, L.; Yan, X. e.; Zhang, Z.; Xu, Y.; Yun, C.; Xie, H.; Ding, K.; Lu, X. A Structure-Guided Optimization of Pyrido[2,3-d]Pyrimidin-7-Ones as Selective Inhibitors of EGFRL858R/T790Mmutant with Improved Pharmacokinetic Properties. Eur. J. Med. Chem. 2017, 126, 1107-1117. https://doi.org/10.1016/j.ejmech.2016.12.006.

(91) Banerjee, R.; Rachid, Z.; McNamee, J.; Jean-Claude, B. J. Synthesis of a Prodrug Designed to Release Multiple Inhibitors of the Epidermal Growth Factor Receptor Tyrosine Kinase and an Alkylating Agent: A Novel Tumor Targeting Concept. J. Med. Chem. 2003, 46 (25), 5546-5551. https://doi.org/10.1021/jm030423m.

(92) Patel, H. M.; Pawara, R.; Ansari, A.; Noolvi, M.; Surana, S. Design and Synthesis of Quinazolinones as EGFR Inhibitors to Overcome EGFR Resistance Obstacle. Bioorganic Med. Chem. 2017, 25 (10), 2713-2723. https://doi.org/10.1016/j.bmc.2017.03.039.

(93) El-Sharief, A. M. S.; Ammar, Y. A.; Belal, A.; El-Sharief, M. A. M. S.; Mohamed, Y. A.; Mehany, A. B. M.; Elhag Ali, G. A. M.; Ragab, A. Design, Synthesis, Molecular Docking and Biological Activity Evaluation of Some Novel Indole Derivatives as Potent 
Anticancer Active Agents and Apoptosis Inducers. Bioorg. Chem. 2019, 85 (January), 399-412.

https://doi.org/10.1016/j.bioorg.2019.01.016.

(94) Wu, K. Da; Chen, G. S.; Liu, J. R.; Hsieh, C. E.; Chern, J. W. Acrylamide Functional Group Incorporation Improves Drug-like Properties: An Example with EGFR Inhibitors. ACS Med. Chem. Lett. 2019, 10 (1), 22-26.

https://doi.org/10.1021/acsmedchemlett.8b00270.

(95) Song, J.; Jang, S.; Lee, J. W.; Jung, D.; Lee, S.; Min, K. H. Click Chemistry for Improvement in Selectivity of Quinazoline-Based Kinase Inhibitors for Mutant Epidermal Growth Factor Receptors. Bioorganic Med. Chem. Lett. 2019, 29 (3), 477-480.

https://doi.org/10.1016/j.bmcl.2018.12.020.

(96) Mohareb, R. M.; Samir, E. M.; Halim, P. A. Synthesis, and Anti-Proliferative, Pim-1 Kinase Inhibitors and Molecular Docking of Thiophenes Derived from Estrone. Bioorg. Chem. 2019, 83, 402-413. https://doi.org/10.1016/j.bioorg.2018.10.067.

(97) Zhu, Z. W.; Shi, L.; Ruan, X. M.; Yang, Y.; Li, H. Q.; Xu, S. P.; Zhu, H. L. Synthesis and Antiproliferative Activities against Hep-G2 of Salicylanide Derivatives: Potent Inhibitors of the Epidermal Growth Factor Receptor (EGFR) Tyrosine Kinase. J. Enzyme Inhib. Med. Chem. 2011, 26 (1), 37-45. https://doi.org/10.3109/14756361003671060.

(98) Wang, C.; Xu, S.; Peng, L.; Zhang, B.; Zhang, H.; Hu, Y.; Zheng, P.; Zhu, W. Design, Synthesis and Biological Evaluation of Novel 4-Anlinoquinazoline Derivatives as EGFR Inhibitors with the Potential to Inhibit the Gefitinib-Resistant Nonsmall Cell Lung Cancers. J. Enzyme Inhib. Med. Chem. 2019, 34 (1), 204-218. https://doi.org/10.1080/14756366.2018.1518957.

(99) Romagnoli, R.; Prencipe, F.; Oliva, P.; Baraldi, S.; Baraldi, P. G.; Schiaffino Ortega, S.; Chayah, M.; Kimatrai Salvador, M.; LopezCara, L. C.; Brancale, A.; Ferla, S.; Hamel, E.; Ronca, R.; Bortolozzi, R.; Mariotto, E.; Mattiuzzo, E.; Viola, G. Design, Synthesis, and Biological Evaluation of 6-Substituted Thieno[3,2- d]Pyrimidine Analogues as Dual Epidermal Growth Factor Receptor Kinase and Microtubule Inhibitors. J. Med. Chem. 2019, 62 (3), 1274-1290. https://doi.org/10.1021/acs.jmedchem.8b01391.

(100) Cruz-Lopez, O.; Conejo-Garcia, A.; C. Nunez, M.; Kimatrai, M.; E. Garcia-Rubino, M.; Morales, F.; Gomez-Perez, V.; M. Campos, J. Novel Substituted Quinazolines for Potent EGFR Tyrosine Kinase Inhibitors. Curr. Med. Chem. 2011, 18 (7), $943-963$. https://doi.org/10.2174/092986711794940824.

(101) Ishikawa, T.; Seto, M.; Banno, H.; Kawakita, Y.; Oorui, M.; Taniguchi, T.; Ohta, Y.; Tamura, T.; Nakayama, A.; Miki, H.; Kamiguchi, H.; Tanaka, T.; Habuka, N.; Sogabe, S.; Yano, J.; Aertgeerts, K.; Kamiyama, K. Design and Synthesis of Novel Human Epidermal Growth Factor Receptor 2 (HER2)/Epidermal Growth Factor Receptor (EGFR) Dual Inhibitors Bearing a Pyrrolo[3,2d]Pyrimidine Scaffold. J. Med. Chem. 2011, 54 (23), 8030-8050. https://doi.org/10.1021/jm2008634.

(102) Castelli, R.; Bozza, N.; Cavazzoni, A.; Bonelli, M.; Vacondio, F.; Ferlenghi, F.; Callegari, D.; Silva, C.; Rivara, S.; Lodola, A.; Digiacomo, G.; Fumarola, C.; Alfieri, R.; Petronini, P. G.; Mor, M. Balancing Reactivity and Antitumor Activity: Heteroarylthioacetamide Derivatives as Potent and Time-Dependent Inhibitors of EGFR. Eur. J. Med. Chem. 2019, 162, 507-524. https://doi.org/10.1016/j.ejmech.2018.11.029.

(103) Zhang, Y.; Lv, H.; Luo, L.; Xu, Y.; Pan, Y.; Wang, Y.; Lin, H.; Xiong, J.; Guo, P.; Zhang, J.; Li, X.; Ye, F. Design, Synthesis and Pharmacological Evaluation of N4,N6-Disubstituted Pyrimidine-4,6-Diamine Derivatives as Potent EGFR Inhibitors in Non-Small Cell Lung Cancer. Eur. J. Med. Chem. 2018, 157, 1300-1325. https://doi.org/10.1016/j.ejmech.2018.08.031.

(104) Mohareb, R. M.; Al Farouk, F. O.; Wardakhan, W. W. Uses of Dimedone for the Synthesis of New Heterocyclic Derivatives with Anti-Tumor, c-Met, Tyrosine, and Pim-1 Kinases Inhibitions. Med. Chem. Res. 2018, 27 (8), 1984-2003. https://doi.org/10.1007/s00044-018-2208-7.

(105) Mphahlele, M. J.; Maluleka, M. M.; Aro, A.; McGaw, L. J.; Choong, Y. S. Benzofuran-Appended 4-Aminoquinazoline Hybrids as Epidermal Growth Factor Receptor Tyrosine Kinase Inhibitors: Synthesis, Biological Evaluation and Molecular Docking Studies. $J$. Enzyme Inhib. Med. Chem. 2018, 33 (1), 1516-1528. https://doi.org/10.1080/14756366.2018.1510919.

(106) Youssif, B. G. M.; Abdelrahman, M. H.; Abdelazeem, A. H.; abdelgawad, M. A.; Ibrahim, H. M.; Salem, O. I. A.; Mohamed, M. F. A.; Treambleau, L.; Bukhari, S. N. A. Design, Synthesis, Mechanistic and Histopathological Studies of Small-Molecules of Novel Indole-2-Carboxamides and Pyrazino[1,2-a]Indol-1(2H)-Ones as Potential Anticancer Agents Effecting the Reactive Oxygen Species Production. Eur. J. Med. Chem. 2018, 146, 260-273. https://doi.org/10.1016/j.ejmech.2018.01.042. 
(107) Mohareb, R. M.; Al-Omran, F.; Ibrahim, R. A. The Uses of Cyclohexan-1,4-Dione for the Synthesis of Thiophene Derivatives as New Anti-Proliferative, Prostate Anticancer, c-Met and Tyrosine Kinase Inhibitors. Med. Chem. Res. 2018, 27 (2), 618-633. https://doi.org/10.1007/s00044-017-2087-3.

(108) Chen, L.; Chi, F.; Wang, T.; Wang, N.; Li, W.; Liu, K.; Shu, X.; Ma, X.; Xu, Y. The Synthesis of 4-Arylamido-2Arylaminoprimidines as Potent EGFR T790M/L858R Inhibitors for NSCLC. Bioorganic Med. Chem. 2018, 26 (23-24), 6087-6095. https://doi.org/10.1016/j.bmc.2018.11.009.

(109) Ju, Y.; Wu, J.; Yuan, X.; Zhao, L.; Zhang, G.; Li, C.; Qiao, R. Design and Evaluation of Potent EGFR Inhibitors through the Incorporation of Macrocyclic Polyamine Moieties into the 4-Anilinoquinazoline Scaffold. J. Med. Chem. 2018, 61 (24), $11372-$ 11383. https://doi.org/10.1021/acs.jmedchem.8b01612.

(110) Ihmaid, S.; Ahmed, H. E. A.; Zayed, M. F. The Design and Development of Potent Small Molecules as Anticancer Agents Targeting EGFR TK and Tubulin Polymerization. Int. J. Mol. Sci. 2018, 19 (2). https://doi.org/10.3390/ijms19020408.

(111) OuYang, Y.; Zou, W.; Peng, L.; Yang, Z.; Tang, Q.; Chen, M.; Jia, S.; Zhang, H.; Lan, Z.; Zheng, P.; Zhu, W. Design, Synthesis, Antiproliferative Activity and Docking Studies of Quinazoline Derivatives Bearing 2,3-Dihydro-Indole or 1,2,3,4-

Tetrahydroquinoline as Potential EGFR Inhibitors. Eur. J. Med. Chem. 2018, 154, 29-43.

https://doi.org/10.1016/j.ejmech.2018.05.006.

(112) El-Husseiny, W. M.; El-Sayed, M. A. A.; Abdel-Aziz, N. I.; El-Azab, A. S.; Ahmed, E. R.; Abdel-Aziz, A. A. M. Synthesis, Antitumour and Antioxidant Activities of Novel $\alpha, \beta$-Unsaturated Ketones and Related Heterocyclic Analogues: EGFR Inhibition and Molecular Modelling Study. J. Enzyme Inhib. Med. Chem. 2018, 33 (1), 507-518. https://doi.org/10.1080/14756366.2018.1434519.

(113) Hao, Y.; Lyu, J.; Qu, R.; Tong, Y.; Sun, D.; Feng, F.; Tong, L.; Yang, T.; Zhao, Z.; Zhu, L.; Ding, J.; Xu, Y.; Xie, H.; Li, H. Design, Synthesis, and Biological Evaluation of Pyrimido[4,5- d]Pyrimidine-2,4(1 H,3 H)-Diones as Potent and Selective Epidermal Growth Factor Receptor (EGFR) Inhibitors against L858R/T790M Resistance Mutation. J. Med. Chem. 2018, 61 (13), $5609-5622$. https://doi.org/10.1021/acs.jmedchem.8b00346.

(114) Mohareb, R. M.; Klapötke, T. M.; Reinhardt, E. Uses of Dimedone for the Synthesis of Thiazole Derivatives as New Anti-Tumor, cMet, Tyrosine Kinase, and Pim-1 Inhibitions. Med. Chem. Res. 2018, 27 (11-12), 2494-2511. https://doi.org/10.1007/s00044-0182252-3.

(115) Jang, J.; Son, J. B.; To, C.; Bahcall, M.; Kim, S. Y.; Kang, S. Y.; Mushajiang, M.; Lee, Y.; Jänne, P. A.; Choi, H. G.; Gray, N. S. Discovery of a Potent Dual ALK and EGFR T790M Inhibitor. Eur. J. Med. Chem. 2017, 136, 497-510. https://doi.org/10.1016/j.ejmech.2017.04.079.

(116) Chen, L.; Fu, W.; Feng, C.; Qu, R.; Tong, L.; Zheng, L.; Fang, B.; Qiu, Y.; Hu, J.; Cai, Y.; Feng, J.; Xie, H.; Ding, J.; Liu, Z.; Liang, G. Structure-Based Design and Synthesis of 2,4-Diaminopyrimidines as EGFR L858R/T790M Selective Inhibitors for NSCLC. Eur. J. Med. Chem. 2017, 140, 510-527. https://doi.org/10.1016/j.ejmech.2017.08.061.

(117) Zhang, Y.; Gao, H.; Liu, R.; Liu, J.; Chen, L.; Li, X.; Zhao, L.; Wang, W.; Li, B. Quinazoline-1-Deoxynojirimycin Hybrids as High Active Dual Inhibitors of EGFR and $\alpha$-Glucosidase. Bioorganic Med. Chem. Lett. 2017, 27 (18), 4309-4313. https://doi.org/10.1016/j.bmcl.2017.08.035.

(118) Tomassi, S.; Lategahn, J.; Engel, J.; Keul, M.; Tumbrink, H. L.; Ketzer, J.; Mühlenberg, T.; Baumann, M.; Schultz-Fademrecht, C.; Bauer, S.; Rauh, D. Indazole-Based Covalent Inhibitors To Target Drug-Resistant Epidermal Growth Factor Receptor. J. Med. Chem. 2017, 60 (6), 2361-2372. https://doi.org/10.1021/acs.jmedchem.6b01626.

(119) Yang, J.; Tu, Z.; Xu, X.; Luo, J.; Yan, X.; Ran, C.; Mao, X.; Ding, K.; Qiao, C. Novel Conjugates of Endoperoxide and 4Anilinoquinazoline as Potential Anticancer Agents. Bioorganic Med. Chem. Lett. 2017, 27 (6), 1341-1345. https://doi.org/10.1016/j.bmcl.2017.02.023.

(120) Lee, Y. S.; Seo, S. H.; Yang, B. S.; Lee, J. Y. Synthesis and Biological Evaluation of Bis(Methoxy-Methyl)-7,8-Dihydro-[1, 4]Dioxino[2,3-g]Quinazolines as EGFR Tyrosine Kinase Inhibitors. Arch. Pharm. (Weinheim). 2005, 338 (10), $502-505$. https://doi.org/10.1002/ardp.200500126.

(121) Rusnak, D. W.; Affleck, K.; Cockerill, S. G.; Stubberfield, C.; Harris, R.; Page, M.; Smith, K. J.; Guntrip, S. B.; Carter, M. C.; Shaw, 
R. J.; Jowett, A.; Stables, J.; Topley, P.; Wood, E. R.; Brignola, P. S.; Kadwell, S. H.; Reep, B. R.; Mullin, R. J.; Alligood, K. J.; Keith, B. R.; Crosby, R. M.; Murray, D. M.; Knight, W. B.; Gilmer, T. M.; Lackey, K. The Characterization of Novel, Dual ErbB2/EGFR, Tyrosine Kinase Inhibitors: Potential Therapy for Cancer. Cancer Res. 2001, 61 (19), 7196-7203.

(122) Lee, J. Y.; Park, Y. K.; Seo, S. H.; Yang, B.; Park, H. 7-Substituted-[1,4]Dioxano[2,3-g]Quinazolines as Inhibitors of Epidermal Growth Factor Receptor Kinase. Arch. Pharm. (Weinheim). 2002, 335 (10), 487-494. https://doi.org/10.1002/ardp.200290003.

Rosini, M.; Mancini, F.; Tarozzi, A.; Colizzi, F.; Andrisano, V.; Bolognesi, M. L.; Hrelia, P.; Melchiorre, C. Design, Synthesis, and Biological Evaluation of Substituted 2,3-Dihydro-1H-Cyclopenta[b]Quinolin-9-Ylamine Related Compounds as Fructose-1,6Bisphosphatase Inhibitors. Bioorganic Med. Chem. 2006, 14 (23), 7846-7853. https://doi.org/10.1016/j.bmc.2006.07.059.

(124) Liechti, C.; Séquin, U.; Bold, G.; Furet, P.; Meyer, T.; Traxler, P. Salicylanilides as Inhibitors of the Protein Tyrosine Kinase Epidermal Growth Factor Receptor. Eur. J. Med. Chem. 2004, 39 (1), 11-26. https://doi.org/10.1016/j.ejmech.2003.09.010.

Ha, J. Du; Seung, K. K.; Kim, K. Do; Choi, J. K.; Jae, Y. K.; Ahn, C. H. Design and Synthesis of Novel Epidermal Growth Factor Receptor Kinase Inhibitors. Bull. Korean Chem. Soc. 2005, 26 (6), 959-965. https://doi.org/10.5012/bkcs.2005.26.6.959.

Kubo, K.; Ohyama, S. I.; Shimizu, T.; Takami, A.; Murooka, H.; Nishitoba, T.; Kato, S.; Yagi, M.; Kobayashi, Y.; Iinuma, N.; Isoe, T.; Nakamura, K.; Iijima, H.; Osawa, T.; Izawa, T. Synthesis and Structure-Activity Relationship for New Series of 4Phenoxyquinoline Derivatives as Specific Inhibitors of Platelet-Derived Growth Factor Receptor Tyrosine Kinase. Bioorganic Med. Chem. 2003, 11 (23), 5117-5133. https://doi.org/10.1016/j.bmc.2003.08.020.

(127) Thompson, A. M.; Murray, D. K.; Elliott, W. L.; Fry, D. W.; Nelson, J. A.; Showalter, H. D. H.; Roberts, B. J.; Vincent, P. W.; Denny, W. A. Tyrosine Kinase Inhibitors. 13. Structure - Activity Relationships for Soluble 7-Substituted 4-[(3-

Bromophenyl)Amino]Pyrido[4,3-d]Pyrimidines Designed as Inhibitors of the Tyrosine Kinase Activity of the Epidermal Growth Factor Receptor. J. Med. Chem. 1997, 40 (24), 3915-3925. https://doi.org/10.1021/jm970366v.

(128) Palmer, B. D.; Trumpp-Kallmeyer, S.; Fry, D. W.; Nelson, J. M.; Showalter, H. D. H.; Denny, W. A. Tyrosine Kinase Inhibitors. 11. Soluble Analogues of Pyrrolo- and Pyrazoloquinazolines as Epidermal Growth Factor Receptor Inhibitors: Synthesis, Biological Evaluation, and Modeling of the Mode of Binding. J. Med. Chem. 1997, 40 (10), 1519-1529. https://doi.org/10.1021/jm960789h.

(129) Rewcastle, G. W.; Murray, D. K.; Elliott, W. L.; Fry, D. W.; Howard, C. T.; Nelson, J. M.; Roberts, B. J.; Vincent, P. W.; Hollis Showalter, H. D.; Thomas Winters, R.; Denny, W. A. Tyrosine Kinase Inhibitors. 14. Structure-Activity Relationships for MethylAmino-Substituted Derivatives of 4-[3-Bromophenyl)Amino]-6- (Methylamino)-Pyrido[3,4-d]Pyrimidine (PD 158780), a Potent and Specific Inhibitor of the Tyrosine Kinase Activity of R. J. Med. Chem. 1998, 41 (5), 742-751. https://doi.org/10.1021/jm970641d.

(130) Rewcastle, G. W.; Palmer, B. D.; Thompson, A. M.; Bridges, A. J.; Cody, D. R.; Zhou, H.; Fry, D. W.; Mcmichael, A.; Denny, W. a. Pyrimidines Are Potent ATP Binding Site Inhibitors of the Tyrosine Kinase Function of the Epidermal Growth Factor Receptor. $J$. Med. Chem. 1996, 39, 1823-1835. https://doi.org/10.1021/jm9508651.

(131) Showalter, H. D. H.; Sercel, A. D.; Leja, B. M.; Wolfangel, C. D.; Ambroso, L. A.; Elliott, W. L.; Fry, D. W.; Kraker, A. J.; Howard, C. T.; Lu, G. H.; Moore, C. W.; Nelson, J. M.; Roberts, B. J.; Vincent, P. W.; Denny, W. A.; Thompson, A. M. Tyrosine Kinase Inhibitors. 6. Structure-Activity Relationships among N- and 3-Substituted 2,2'-Diselenobis(1H-Indoles) for Inhibition of Protein Tyrosine Kinases and Comparative in Vitro and in Vivo Studies against Selected Sulfur Congeners. J. Med. Chem. 1997, 40 (4), $413-$ 426. https://doi.org/10.1021/jm960689b.

(132) Brauers, G.; Edrada, R. A.; Ebel, R.; Proksch, P.; Wray, V.; Berg, A.; Gräfe, U.; Schächtele, C.; Totzke, F.; Finkenzeller, G.; Marme, D.; Kraus, J.; Münchbach, M.; Michel, M.; Bringmann, G.; Schaumann, K. Anthraquinones and Betaenone Derivatives from the Sponge-Associated Fungus Microsphaeropsis Species: Novel Inhibitors of Protein Kinases. J. Nat. Prod. 2000, 63 (6), $739-745$. https://doi.org/10.1021/np9905259.

(133) Smaill, J. B.; Palmer, B. D.; Rewcastle, G. W.; Denny, W. A.; McNamara, D. J.; Dobrusin, E. M.; Bridges, A. J.; Zhou, H.; Showalter, H. D. H.; Winters, R. T.; Leopold, W. R.; Fry, D. W.; Nelson, J. M.; Slintak, V.; Elliot, W. L.; Roberts, B. J.; Vincent, P. W.; Patmore, S. J. Tyrosine Kinase Inhibitors. 15. 4-(Phenylamino)Quinazoline and 4- (Phenylamino)Pyrido[d]Pyrimidine Acrylamides as Irreversible Inhibitors of the ATP Binding Site of the Epidermal Growth Factor Receptor. J. Med. Chem. 1999, 42 (10), 1803-1815. https://doi.org/10.1021/jm9806603. 
(134) L.F., H.; E.S.E., S.; A.P., T.; C., J.; P.A., P.; D.J., O.; M., D.; S.R., W.; J., K.; Hennequin, L. F. [Reprint author]; Stokes, E. S. E. [Author]; Thomas, A. P. [Author]; Johnstone, C. [Author]; Ple, P. A. [Author]; Ogilvie, D. J. [Author]; Dukes, M. [Author]; Wedge, S. R. [Author]; Kendrew, J. [Author]; Curwen, J. O. [Author; E. laurent. hennequin@astrazeneca. com. Novel 4-Anilinoquinazolines with C-7 Basic Side Chains: Design and Structure Activity Relationship of a Series of Potent, Orally Active, VEGF Receptor Tyrosine Kinase Inhibitors. J. Med. Chem. 2002, 45 (6), 1300-1312. https://doi.org/http://dx.doi.org/10.1021/jm011022e.

Altmann, E.; Missbach, M.; Green, J.; Mira, S.; Wagenknecht, H.; Widler, L. Pyrimidines — Potent Inhibitors of the Tyrosine Kinase c-Src. Bioorg. Med. Chem. Lett. 2001, 11, 853-856.

(136) Wissner, A.; Overbeek, E.; Reich, M. F.; Floyd, M. B.; Johnson, B. D.; Mamuya, N.; Rosfjord, E. C.; Discafani, C.; Davis, R.; Shi, X.; Rabindran, S. K.; Gruber, B. C.; Ye, F.; Hallett, W. A.; Nilakantan, R.; Shen, R.; Wang, Y. F.; Greenberger, L. M.; Tsou, H. R. Synthesis and Structure-Activity Relationships of 6,7-Disubstituted 4-Anilinoquinoline-3-Carbonitriles. The Design of an Orally Active, Irreversible Inhibitor of the Tyrosine Kinase Activity of the Epidermal Growth Factor Receptor (EGFR) and the Human Epi. J. Med. Chem. 2003, 46 (1), 49-63. https://doi.org/10.1021/jm020241c.

Barker, A. J.; Gibson, K. H.; Grundy, W.; Godfrey, A. A.; Barlow, J. J.; Healy, M. P.; Woodburn, J. R.; Ashton, S. E.; Curry, B. J.; Scarlett, L.; Henthorn, L.; Richards, L. Studies Leading to the Identification of ZD1839 (Iressa ${ }^{\mathrm{TM}}$ ): An Orally Active, Selective Epidermal Growth Factor Receptor Tyrosine Kinase Inhibitor Targeted to the Treatment of Cancer. Bioorganic Med. Chem. Lett. 2001, 11 (14), 1911-1914. https://doi.org/10.1016/S0960-894X(01)00344-4.

(138) Kamath, S.; Buolamwini, J. K. Receptor-Guided Alignment-Based Comparative 3D-QSAR Studies of Benzylidene Malonitrile Tyrphostins as EGFR and HER-2 Kinase Inhibitors. J. Med. Chem. 2003, 46 (22), 4657-4668. https://doi.org/10.1021/jm030065n.

(139) Smaill, J. B.; Showalter, H. D. H.; Zhou, H.; Bridges, A. J.; Mcnamara, D. J.; Fry, D. W.; Nelson, J. M.; Sherwood, V.; Vincent, P. W.; Roberts, B. J.; Elliott, W. L.; Denny, W. A. 4-Anilinopyrido [ 3 , 4-d ] Pyrimidines as Soluble , Irreversible Inhibitors of the Epidermal Growth Factor Receptor. Society 2001, 44 (3), 429-440.

(140) Sun, L.; Cui, J.; Liang, C.; Zhou, Y.; Nematalla, A.; Wang, X.; Chen, H.; Tang, C.; Wei, J. Rational Design of as a Novel Class of Inhibitors of Epidermal Growth Factor Receptor ( EGF-R ) and Her2 ( P185 ErbB ) Tyrosine Kinases. Bioorg. Med. Chem. Lett. 2002, $12,2153-2157$.

(141) Wissner, A.; Brawner Floyd, M.; Rabindran, S. K.; Nilakantan, R.; Greenberger, L. M.; Shen, R.; Wang, Y. F.; Tsou, H. R. Syntheses and EGFR and HER-2 Kinase Inhibitory Activities of 4-Anilinoquinoline-3-Carbonitriles: Analogues of Three Important 4Anilinoquinazolines Currently Undergoing Clinical Evaluation as Therapeutic Antitumor Agents. Bioorganic Med. Chem. Lett. 2002, 12 (20), 2893-2897. https://doi.org/10.1016/S0960-894X(02)00598-X.

(142) Rachid, Z.; Brahimi, F.; Katsoulas, A.; Teoh, N.; Jean-Claude, B. J. The Combi-Targeting Concept: Chemical Dissection of the Dual Targeting Properties of a Series of “Combi-Triazenes.” J. Med. Chem. 2003, 46 (20), 4313-4321. https://doi.org/10.1021/jm030142e.

(143) Cumming, J. G.; McKenzie, C. L.; Bowden, S. G.; Campbell, D.; Masters, D. J.; Breed, J.; Jewsbury, P. J. Novel, Potent and Selective Anilinoquinazoline and Anilinopyrimidine Inhibitors of P38 MAP Kinase. Bioorganic Med. Chem. Lett. 2004, 14 (21), $5389-5394$. https://doi.org/10.1016/j.bmcl.2004.08.007.

(144) Munchhof, M. J.; Beebe, J. S.; Casavant, J. M.; Cooper, B. A.; Doty, J. L.; Higdon, R. C.; Hillerman, S. M.; Soderstrom, C. I.; Knauth, E. A.; Marx, M. A.; Rossi, A. M. K.; Sobolov, S. B.; Sun, J. Design and SAR of Thienopyrimidine and Thienopyridine Inhibitors of VEGFR-2 Kinase Activity. Bioorganic Med. Chem. Lett. 2004, 14 (1), 21-24. https://doi.org/10.1016/j.bmcl.2003.10.030.

(145) Akula, N.; Bhalla, J.; Sridhar, J.; Pattabiraman, N. Binding Modes of 6,7 Di-Substituted 4-Anilinoquinoline-3-Carbonitriles to EGFR. Bioorganic Med. Chem. Lett. 2004, 14 (13), 3397-3400. https://doi.org/10.1016/j.bmcl.2004.04.080.

(146) Chen, H.; Boiziau, J.; Parker, F.; Mailliet, P.; Commerçon, A.; Tocque, B.; Le Pecq, J. B.; Roques, B. P.; Garbay, C. StructureActivity Relationships in a Series of 5-[(2,5-Dihydroxybenzyl)Amino]Salicylate Inhibitors of EGF-Receptor-Associated Tyrosine Kinase: Importance of Additional Hydrophobic Aromatic Interactions. J. Med. Chem. 1994, 37 (6), 845-859. https://doi.org/10.1021/jm00032a020.

(147) Zhang, Y. M.; Cockerill, S.; Guntrip, S. B.; Rusnak, D.; Smith, K.; Vanderwall, D.; Wood, E.; Lackey, K. Synthesis and SAR of 
Potent EGFR/ErbB2 Dual Inhibitors. Bioorganic Med. Chem. Lett. 2004, 14 (1), 111-114.

https://doi.org/10.1016/j.bmcl.2003.10.010.

(148) Fink, B. E.; Vite, G. D.; Mastalerz, H.; Kadow, J. F.; Kim, S. H.; Leavitt, K. J.; Du, K.; Crews, D.; Mitt, T.; Wong, T. W.; Hunt, J. T.; Vyas, D. M.; Tokarski, J. S. New Dual Inhibitors of EGFR and HER2 Protein Tyrosine Kinases. Bioorganic Med. Chem. Lett. 2005, 15 (21), 4774-4779. https://doi.org/10.1016/j.bmcl.2005.07.027.

(149) Rachid, Z.; Brahimi, F.; Domarkas, J.; Jean-Claude, B. J. Synthesis of Half-Mustard Combi-Molecules with Fluorescence Properties: Correlation with EGFR Status. Bioorganic Med. Chem. Lett. 2005, 15 (4), 1135-1138. https://doi.org/10.1016/j.bmcl.2004.12.015.

(150) Ballard, P.; Bradbury, R. H.; Hennequin, L. F. A.; Hickinson, D. M.; Johnson, P. D.; Kettle, J. G.; Klinowska, T.; Morgentin, R.; Ogilvie, D. J.; Olivier, A. 5-Substituted 4-Anilinoquinazolines as Potent, Selective and Orally Active Inhibitors of ErbB2 Receptor Tyrosine Kinase. Bioorganic Med. Chem. Lett. 2005, 15 (19), 4226-4229. https://doi.org/10.1016/j.bmcl.2005.06.068.

(151) Traxler, P.; Green, J.; Mett, H.; Séquin, U.; Furet, P. Use of a Pharmacophore Model for the Design of EGFR Tyrosine Kinase Inhibitors: Isoflavones and 3-Phenyl-4(1H)-Quinolones. J. Med. Chem. 1999, 42 (6), 1018-1026. https://doi.org/10.1021/jm980551o.

(152) Alberti, M. J.; Auten, E. P.; Lackey, K. E.; McDonald, O. B.; Wood, E. R.; Preugschat, F.; Cutler, G. J.; Kane-Carson, L.; Liu, W.; Jung, D. K. Discovery and in Vitro Evaluation of Potent Kinase Inhibitors: Pyrido[1',2':1,5]Pyrazolo[3,4-d]Pyrimidines. Bioorganic Med. Chem. Lett. 2005, 15 (16), 3778-3781. https://doi.org/10.1016/j.bmcl.2005.05.100.

(153) Nussbaumer, P.; Winiski, A. P.; Cammisuli, S.; Hiestand, P.; Weckbecker, G.; Stütz, A. Novel Antiproliferative Agents Derived from Lavendustin A. J. Med. Chem. 1994, 37 (24), 4079-4084. https://doi.org/10.1021/jm00050a005.

(154) Tsou, H. R.; Overbeek-Klumpers, E. G.; Hallett, W. A.; Reich, M. F.; Floyd, M. B.; Johnson, B. D.; Michalak, R. S.; Nilakantan, R.; Discafani, C.; Golas, J.; Rabindran, S. K.; Shen, R.; Shi, X.; Wang, Y. F.; Upeslacis, J.; Wissner, A. Optimization of 6,7Disubstituted-4-(Arylamino)Quinoline-3-Carbonitriles as Orally Active, Irreversible Inhibitors of Human Epidermal Growth Factor Receptor-2 Kinase Activity. J. Med. Chem. 2005, 48 (4), 1107-1131. https://doi.org/10.1021/jm040159c.

(155) Showalter, H. D. H.; Bridges, A. J.; Zhou, H.; Sercel, A. D.; Mcmichael, A.; Fry, D. W. Tyrosine Kinase Inhibitors. 16. 6,5,6Tricyclic Benzothieno[3,2-d]Pyrimidines and Pyrimido[5,4-b]- and -[4,5-b]Indoles as Potent Inhibitors of the Epidermal Growth Factor Receptor Tyrosine Kinase. J. Med. Chem. 1999, 42 (26), 5464-5474. https://doi.org/10.1021/jm9903949.

(156) Traxler, P. M.; Furet, P.; Mett, H.; Buchdunger, E.; Meyer, T.; Lydon, N. Inhibitors of the EGF-Receptor Protein Tyrosine Kinase. 1996, 716 (96), 2285-2292.

(157) Sunami, S.; Nishimura, T.; Nishimura, I.; Ito, S.; Arakawa, H.; Ohkubo, M. Synthesis and Biological Activities of Topoisomerase I Inhibitors, 6-Arylmethylamino Analogues of Edotecarin. J. Med. Chem. 2009, 52 (10), 3225-3237. https://doi.org/10.1021/jm801641t.

(158) Tamiz, A. P.; Cai, S. X.; Zhou, Z. L.; Yuen, P. W.; Schelkun, R. M.; Whittemore, E. R.; Weber, E.; Woodward, R. M.; Keana, J. F. W. Structure-Activity Relationship of N-(Phenylalkyl)Cinnamides as Novel NR2B Subtype-Selective NMDA Receptor Antagonists. J. Med. Chem. 1999, 42 (17), 3412-3420. https://doi.org/10.1021/jm990199u.

(159) Gazit, A.; Osherov, N.; Gilon, C.; Levitzki, A. Tyrphostins. 6. Dimeric Benzylidenemalononitrile Tyrphostins: Potent Inhibitors of EGF Receptor Tyrosine Kinase in Vitro. J. Med. Chem. 1996, 39 (25), 4905-4911. https://doi.org/10.1021/jm960225d.

(160) Bridges, A. J.; Zhou, H.; Cody, D. R.; Rewcastle, G. W.; McMichael, A.; Showalter, H. D. H.; Fry, D. W.; Kraker, A. J.; Denny, W. A. Tyrosine Kinase Inhibitors. 8. An Unusually Steep Structure-Activity Relationship for Analogues of 4-(3-Bromoanilino)-6,7Dimethoxyquinazoline (PD 153035), a Potent Inhibitor of the Epidermal Growth Factor Receptor. J. Med. Chem. 1996, 39 (1), 267276. https://doi.org/10.1021/jm9503613.

(161) Traxler, P.; Bold, G.; Frei, J.; Lang, M.; Lydon, N.; Mett, H.; Buchdunger, E.; Meyer, T.; Mueller, M.; Furet, P. Use of a Pharmacophore Model for the Design of EGF-R Tyrosine Kinase Inhibitors: 4-(Phenylamino)Pyrazolo[3,4-d]Pyrimidines. J. Med. Chem. 1997, 40 (22), 3601-3616. https://doi.org/10.1021/jm970124v.

(162) Thompson, A. M.; Fry, D. W.; Kraker, A. J.; Denny, W. A. Protein Tyrosine Activity against Epidermal Growth Factor Receptor and Pp60v-Rrc Kinases. 1994, 598-609.

(163) Thompson, A. M.; Bridges, A. J.; Fry, D. W.; Kraker, A. J.; Denny, W. A. Tyrosine Kinase Inhibitors. 7. 7-Amino-4-(Phenylamino)- 
and 7-Amino-4-[(Phenylmethyl)Amino]Pyrido[4,3-d]Pyrimidines: A New Class of Inhibitors of the Tyrosine Kinase Activity of the Epidermal Growth Factor Receptor. J. Med. Chem. 1995, 38 (19), 3780-3788. https://doi.org/10.1021/jm00019a007.

Gazit, A.; Yaish, P.; Gilon, C.; Levitzki, A. Tyrphostins I: Synthesis and Biological Activity of Protein Tyrosine Kinase Inhibitors. J. Med. Chem. 1989, 32 (10), 2344-2352. https://doi.org/10.1021/jm00130a020.

(165) Thompson, A. M.; Rewcastle, G. W.; Tercel, M.; Dobrusin, E. M.; Fry, D. W.; Kraker, A. J.; Denny, W. A. Tyrosine Kinase Inhibitors. 1. Structure-Activity Relationships for Inhibition of Epidermal Growth Factor Receptor Tyrosine Kinase Activity. 1993.

(166) Trinks, U.; Buchdunger, E.; Furet, P.; Kump, W.; Mett, H.; Meyer, T.; Müller, M.; Regenass, U.; Rihs, G.; Lydon, N.; Traxler, P. Dianilinophthalimides: Potent and Selective, ATP-Competitive Inhibitors of the EGF-Receptor Protein Tyrosine Kinase. J. Med. Chem. 1994, 37 (7), 1015-1027. https://doi.org/10.1021/jm00033a019.

(167) Traxler, P. M.; Wacker, O.; Bach, H. L.; Geissler, J. F.; Kump, W.; Meyer, T.; Regenass, U.; Roesel, J. L.; Lydon, N. Sulfonylbenzoyl-Nitrostyrenes: Potential Bisubstrate Type Inhibitors of the EGF-Receptor Tyrosine Protein Kinase. J. Med. Chem. 1991, 34 (8), 2328-2337. https://doi.org/10.1021/jm00112a003.

(168) Gazit, A.; Osherov, N.; Posner, I.; Yaish, P.; Poradosu, E.; Levitzki, A.; Gazit, A.; Gilon, C. Tyrphostins. 2. Heterocyclic and $\alpha-$ Substituted Benzylidenemalononitrile Tyrphostins as Potent Inhibitors of EGF Receptor and ErbB2/Neu Tyrosine Kinases. J. Med. Chem. 1991, 34 (6), 1896-1907. https://doi.org/10.1021/jm00110a022.

(169) Rewcastle, G. W.; Palmer, B. D.; Bridges, A. J.; Showalter, H. D. H.; Sun, L.; Nelson, J.; McMichael, A.; Kraker, A. J.; Fry, D. W.; Denny, W. A. Tyrosine Kinase Inhibitors. 9. Synthesis and Evaluation of Fused Tricyclic Quinazoline Analogues as ATP Site Inhibitors of the Tyrosine Kinase Activity of the Epidermal Growth Factor Receptor. J. Med. Chem. 1996, 39 (4), $918-928$. https://doi.org/10.1021/jm950692f.

(170) Ballard, P.; Bradbury, R. H.; Harris, C. S.; Hennequin, L. F. A.; Hickinson, M.; Kettle, J. G.; Kendrew, J.; Klinowska, T.; Ogilvie, D. J.; Pearson, S. E.; Williams, E. J.; Wilson, I. Inhibitors of Epidermal Growth Factor Receptor Tyrosine Kinase: Optimisation of Potency and in Vivo Pharmacokinetics. Bioorganic Med. Chem. Lett. 2006, 16 (18), 4908-4912. https://doi.org/10.1016/j.bmcl.2006.06.054.

(171) Liu, L. T.; Yuan, T. T.; Liu, H. H.; Chen, S. F.; Wu, Y. T. Synthesis and Biological Evaluation of Substituted 6-Alkynyl-4Anilinoquinazoline Derivatives as Potent EGFR Inhibitors. Bioorganic Med. Chem. Lett. 2007, 17 (22), 6373-6377. https://doi.org/10.1016/j.bmcl.2007.08.061.

(172) Fedorov, O.; Marsden, B.; Pogacic, V.; Rellos, P.; Muller, S.; Bullock, A. N.; Schwaller, J.; Sundstrom, M.; Knapp, S. A Systematic Interaction Map of Validated Kinase Inhibitors with Ser/Thr Kinases. Proc. Natl. Acad. Sci. 2007, 104 (51), 20523-20528. https://doi.org/10.1073/pnas.0708800104.

(173) Waterson, A. G.; Stevens, K. L.; Reno, M. J.; Zhang, Y. M.; Boros, E. E.; Bouvier, F.; Rastagar, A.; Uehling, D. E.; Dickerson, S. H.; Reep, B.; McDonald, O. B.; Wood, E. R.; Rusnak, D. W.; Alligood, K. J.; Rudolph, S. K. Alkynyl Pyrimidines as Dual EGFR/ErbB2 Kinase Inhibitors. Bioorganic Med. Chem. Lett. 2006, 16 (9), 2419-2422. https://doi.org/10.1016/j.bmcl.2006.01.111.

(174) Petrov, K. G.; Zhang, Y. M.; Carter, M.; Cockerill, G. S.; Dickerson, S.; Gauthier, C. A.; Guo, Y.; Mook, R. A.; Rusnak, D. W.; Walker, A. L.; Wood, E. R.; Lackey, K. E. Optimization and SAR for Dual ErbB-1/ErbB-2 Tyrosine Kinase Inhibition in the 6Furanylquinazoline Series. Bioorganic Med. Chem. Lett. 2006, 16 (17), 4686-4691. https://doi.org/10.1016/j.bmcl.2006.05.090.

(175) Hennequin, L. F. A.; Ballard, P.; Boyle, F. T.; Delouvrié, B.; Ellston, R. P. A.; Halsall, C. T.; Harris, C. S.; Hudson, K.; Kendrew, J.; Pease, J. E.; Ross, H. S.; Smith, P.; Vincent, J. L. Novel 4-Anilinoquinazolines with C-6 Carbon-Linked Side Chains: Synthesis and Structure-Activity Relationship of a Series of Potent, Orally Active, EGF Receptor Tyrosine Kinase Inhibitors. Bioorganic Med. Chem. Lett. 2006, 16 (10), 2672-2676. https://doi.org/10.1016/j.bmcl.2006.02.025.

(176) Lee, K. I.; Park, Y.; Park, S. J.; Hwang, J. H.; Lee, S. J.; Kim, G. Do; Park, W. K.; Lee, S.; Jeong, D.; Kong, J. Y.; Kang, H. K.; Cho, H. Naphthofuroquinone Derivatives: Inhibition of Receptor Tyrosine Kinases. Bioorganic Med. Chem. Lett. 2006,16 (3), 737-742. https://doi.org/10.1016/j.bmcl.2005.08.115.

(177) Ballard, P.; Bradbury, R. H.; Harris, C. S.; Hennequin, L. F. A.; Hickinson, M.; Johnson, P. D.; Kettle, J. G.; Klinowska, T.; Leach, A G.; Morgentin, R.; Pass, M.; Ogilvie, D. J.; Olivier, A.; Warin, N.; Williams, E. J. Inhibitors of Epidermal Growth Factor Receptor 
Tyrosine Kinase: Novel C-5 Substituted Anilinoquinazolines Designed to Target the Ribose Pocket. Bioorganic Med. Chem. Lett. 2006, 16 (6), 1633-1637. https://doi.org/10.1016/j.bmcl.2005.12.028.

(178) Klutchko, S. R.; Zhou, H.; Winters, R. T.; Tran, T. P.; Bridges, A. J.; Althaus, I. W.; Amato, D. M.; Elliott, W. L.; Ellis, P. A.; Meade M. A.; Roberts, B. J.; Fry, D. W.; Gonzales, A. J.; Harvey, P. J.; Nelson, J. M.; Sherwood, V.; Han, H. K.; Pace, G.; Smaill, J. B.;

Denny, W. A.; Showalter, H. D. H. Tyrosine Kinase Inhibitors. 19. 6-Alkynamides of 4-Anilinoquinazolines and 4-Anilinopyrido[3,4 d]Pyrimidines as Irreversible Inhibitors of the ErbB Family of Tyrosine Kinase Receptors. J. Med. Chem. 2006, 49 (4), $1475-1485$. https://doi.org/10.1021/jm050936o.

(179) Apsel, B.; Blair, J. A.; Gonzalez, B.; Nazif, T. M.; Feldman, M. E.; Aizenstein, B.; Hoffman, R.; Williams, R. L.; Shokat, K. M.; Knight, Z. A. Targeted Polypharmacology: Discovery of Dual Inhibitors of Tyrosine and Phosphoinositide Kinases. Nat. Chem. Biol. 2008, 4 (11), 691-699. https://doi.org/10.1038/nchembio.117.

(180) Xu, G.; Searle, L. L.; Hughes, T. V.; Beck, A. K.; Connolly, P. J.; Abad, M. C.; Neeper, M. P.; Struble, G. T.; Springer, B. A.; Emanuel, S. L.; Gruninger, R. H.; Pandey, N.; Adams, M.; Moreno-Mazza, S.; Fuentes-Pesquera, A. R.; Middleton, S. A.; Greenberger, L. M. Discovery of Novel 4-Amino-6-Arylaminopyrimidine-5-Carbaldehyde Oximes as Dual Inhibitors of EGFR and ErbB-2 Protein Tyrosine Kinases. Bioorganic Med. Chem. Lett. 2008, 18 (12), 3495-3499.

https://doi.org/10.1016/j.bmcl.2008.05.024.

(181) Rachid, Z.; Brahimi, F.; Qiu, Q.; Williams, C.; Hartley, J. M.; Hartley, J. A.; Jean-Claude, B. J. Novel Nitrogen Mustard-Armed Combi-Molecules for the Selective Targeting of Epidermal Growth Factor Receptor Overexperessing Solid Tumors: Discovery of an Unusual Structure-Activity Relationship. J. Med. Chem. 2007, 50 (11), 2605-2608. https://doi.org/10.1021/jm070144p.

(182) Hubbard, R. D.; Dickerson, S. H.; Emerson, H. K.; Griffin, R. J.; Reno, M. J.; Hornberger, K. R.; Rusnak, D. W.; Wood, E. R.; Uehling, D. E.; Waterson, A. G. Dual EGFR/ErbB-2 Inhibitors from Novel Pyrrolidinyl-Acetylenic Thieno[3,2-d]Pyrimidines. Bioorganic Med. Chem. Lett. 2008, 18 (21), 5738-5740. https://doi.org/10.1016/j.bmcl.2008.09.090.

(183) Kolb, P.; Huang, D.; Dey, F.; Caflisch, A. Discovery of Kinase Inhibitors by High-Throughput Docking and Scoring Based on A. J. Med. Chem. 2008, 51 (5), 1179-1188. https://doi.org/10.1021/jm070654j.

(184) Xu, G.; Abad, M. C.; Connolly, P. J.; Neeper, M. P.; Struble, G. T.; Springer, B. A.; Emanuel, S. L.; Pandey, N.; Gruninger, R. H.; Adams, M.; Moreno-Mazza, S.; Fuentes-Pesquera, A. R.; Middleton, S. A. 4-Amino-6-Arylamino-Pyrimidine-5-Carbaldehyde Hydrazones as Potent ErbB-2/EGFR Dual Kinase Inhibitors. Bioorganic Med. Chem. Lett. 2008, 18 (16), 4615-4619. https://doi.org/10.1016/j.bmcl.2008.07.020.

(185) Peifer, C.; Selig, R.; Kinkel, K.; Ott, D.; Totzke, F.; Schächtele, C.; Heidenreich, R.; Röcken, M.; Schollmeyer, D.; Laufer, S. Design, Synthesis, and Biological Evaluation of Novel 3-Aryl-4-(1H-Indole- 3yl)-1,5-Dihydro-2H-Pyrrole-2-Ones as Vascular Endothelial Growth Factor Receptor (VEGF-R) Inhibitors. J. Med. Chem. 2008, 51 (13), 3814-3824. https://doi.org/10.1021/jm8001185.

(186) Ban, H. S.; Onagi, S.; Uno, M.; Nabeyama, W.; Nakamura, H. Allene as an Alternative Functional Group for Drug Design: Effect of C-C Multiple Bonds Conjugated with Quinazolines on the Inhibition of EGFR Tyrosine Kinase. ChemMedChem 2008, 3 (7), 10941103. https://doi.org/10.1002/cmdc.200800073.

(187) Wood, E. R.; Shewchuk, L. M.; Ellis, B.; Brignola, P.; Brashear, R. L.; Caferro, T. R.; Dickerson, S. H.; Dickson, H. D.; Donaldson, K. H.; Gaul, M.; Griffin, R. J.; Hassell, A. M.; Keith, B.; Mullin, R.; Petrov, K. G.; Reno, M. J.; Rusnak, D. W.; Tadepalli, S. M.; Ulrich, J. C.; Wagner, C. D.; Vanderwall, D. E.; Waterson, A. G.; Williams, J. D.; White, W. L.; Uehling, D. E. 6-Ethynylthieno[3,2d]- and 6-Ethynylthieno[2,3-d]Pyrimidin-4-Anilines as Tunable Covalent Modifiers of ErbB Kinases. Proc. Natl. Acad. Sci. 2008, 105 (8), 2773-2778. https://doi.org/10.1073/pnas.0708281105.

(188) Fridrich, D.; Glabasnia, A.; Fritz, J.; Esselen, M.; Pahlke, G.; Hofmann, T.; Marko, D. Oak Ellagitannins Suppress the Phosphorylation of the Epidermal Growth Factor Receptor in Human Colon Carcinoma Cells. J. Agric. Food Chem. 2008, 56 (9), 3010-3015. https://doi.org/10.1021/jf073427z.

(189) Larroque, A. L.; Peori, B.; Williams, C.; Fang, Y. Q.; Qiu, Q.; Rachid, Z.; Jean-Claude, B. J. Synthesis of Water Soluble BisTriazenoquinazolines: An Unusual Predicted Mode of Binding to the Epidermal Growth Factor Receptor Tyrosine Kinase. Chem. Biol. Drug Des. 2008, 71 (4), 374-379. https://doi.org/10.1111/j.1747-0285.2008.00638.x. 
(190) Wissner, A.; Fraser, H. L.; Ingalls, C. L.; Dushin, R. G.; Floyd, M. B.; Cheung, K.; Nittoli, T.; Ravi, M. R.; Tan, X.; Loganzo, F. Dual Irreversible Kinase Inhibitors: Quinazoline-Based Inhibitors Incorporating Two Independent Reactive Centers with Each Targeting Different Cysteine Residues in the Kinase Domains of EGFR and VEGFR-2. Bioorganic Med. Chem. 2007, 15 (11), $3635-3648$. https://doi.org/10.1016/j.bmc.2007.03.055.

(191) Mastalerz, H.; Chang, M.; Gavai, A.; Johnson, W.; Langley, D.; Lee, F. Y.; Marathe, P.; Mathur, A.; Oppenheimer, S.; Tarrant, J.; Tokarski, J. S.; Vite, G. D.; Vyas, D. M.; Wong, H.; Wong, T. W.; Zhang, H.; Zhang, G. Novel C-5 Aminomethyl Pyrrolotriazine Dual Inhibitors of EGFR and HER2 Protein Tyrosine Kinases. Bioorganic Med. Chem. Lett. 2007, 17 (10), $2828-2833$. https://doi.org/10.1016/j.bmcl.2007.02.050.

(192) Kitano, Y.; Suzuki, T.; Kawahara, E.; Yamazaki, T. Synthesis and Inhibitory Activity of 4-Alkynyl and 4-Alkenylquinazolines: Identification of New Scaffolds for Potent EGFR Tyrosine Kinase Inhibitors. Bioorganic Med. Chem. Lett. 2007, 17 (21), $5863-5867$. https://doi.org/10.1016/j.bmcl.2007.08.020.

(193) Mastalerz, H.; Chang, M.; Chen, P.; Dextraze, P.; Fink, B. E.; Gavai, A.; Goyal, B.; Han, W. C.; Johnson, W.; Langley, D.; Lee, F. Y.; Marathe, P.; Mathur, A.; Oppenheimer, S.; Ruediger, E.; Tarrant, J.; Tokarski, J. S.; Vite, G. D.; Vyas, D. M.; Wong, H.; Wong, T. W.; Zhang, H.; Zhang, G. New C-5 Substituted Pyrrolotriazine Dual Inhibitors of EGFR and HER2 Protein Tyrosine Kinases. Bioorganic Med. Chem. Lett. 2007, 17 (7), 2036-2042. https://doi.org/10.1016/j.bmcl.2007.01.002.

(194) Ballard, P.; Barlaam, B. C.; Bradbury, R. H.; Dishington, A.; Hennequin, L. F. A.; Hickinson, D. M.; Hollingsworth, I. M.; Kettle, J. G.; Klinowska, T.; Ogilvie, D. J.; Pearson, S. E.; Scott, J. S.; Suleman, A.; Whittaker, R.; Williams, E. J.; Wood, R.; Wright, L. Neutral 5-Substituted 4-Anilinoquinazolines as Potent, Orally Active Inhibitors of ErbB2 Receptor Tyrosine Kinase. Bioorganic Med. Chem. Lett. 2007, 17 (22), 6326-6329. https://doi.org/10.1016/j.bmcl.2007.08.073.

(195) Lv, P. C.; Wang, K. R.; Li, Q. S.; Chen, J.; Sun, J.; Zhu, H. L. Design, Synthesis and Biological Evaluation of Chrysin Long-Chain Derivatives as Potential Anticancer Agents. Bioorganic Med. Chem. 2010, 18 (3), 1117-1123. https://doi.org/10.1016/j.bmc.2009.12.048.

(196) Rode, H. B.; Sos, M. L.; Grütter, C.; Heynck, S.; Simard, J. R.; Rauh, D. Synthesis and Biological Evaluation of 7-Substituted-1-(3Bromophenylamino) Isoquinoline-4-Carbonitriles as Inhibitors of Myosin Light Chain Kinase and Epidermal Growth Factor Receptor. Bioorganic Med. Chem. 2011, 19 (1), 429-439. https://doi.org/10.1016/j.bmc.2010.11.007.

(197) Wu, C. H.; Coumar, M. S.; Chu, C. Y.; Lin, W. H.; Chen, Y. R.; Chen, C. T.; Shiao, H. Y.; Rafi, S.; Wang, S. Y.; Hsu, H.; Chen, C. H.; Chang, C. Y.; Chang, T. Y.; Lien, T. W.; Fang, M. Y.; Yeh, K. C.; Chen, C. P.; Yeh, T. K.; Hsieh, S. H.; Hsu, J. T. A.; Liao, C. C.; Chao, Y. S.; Hsieh, H. P. Design and Synthesis of Tetrahydropyridothieno[2,3-d]Pyrimidine Scaffold Based Epidermal Growth Factor Receptor (EGFR) Kinase Inhibitors: The Role of Side Chain Chirality and Michael Acceptor Group for Maximal Potency. J. Med. Chem. 2010, 53 (20), 7316-7326. https://doi.org/10.1021/jm100607r.

(198) Kaspersen, S. J.; Sørum, C.; Willassen, V.; Fuglseth, E.; Kjøbli, E.; Bjørkøy, G.; Sundby, E.; Hoff, B. H. Synthesis and in Vitro EGFR (ErbB1) Tyrosine Kinase Inhibitory Activity of 4-N-Substituted 6-Aryl-7H-Pyrrolo[2,3-d]Pyrimidine-4-Amines. Eur. J. Med. Chem. 2011, 46 (12), 6002-6014. https://doi.org/10.1016/j.ejmech.2011.10.012.

(199) Zhang, H. J.; Qian, Y.; Zhu, D. Di; Yang, X. G.; Zhu, H. L. Synthesis, Molecular Modeling and Biological Evaluation of Chalcone Thiosemicarbazide Derivatives as Novel Anticancer Agents. Eur. J. Med. Chem. 2011, 46 (9), 4702-4708. https://doi.org/10.1016/j.ejmech.2011.07.016.

(200) Li, D. D.; Lv, P. C.; Zhang, H.; Zhang, H. J.; Hou, Y. P.; Liu, K.; Ye, Y. H.; Zhu, H. L. The Combination of 4-Anilinoquinazoline and Cinnamic Acid: A Novel Mode of Binding to the Epidermal Growth Factor Receptor Tyrosine Kinase. Bioorganic Med. Chem. 2011, 19 (16), 5012-5022. https://doi.org/10.1016/j.bmc.2011.06.044.

(201) Fink, B. E.; Norris, D.; Mastalerz, H.; Chen, P.; Goyal, B.; Zhao, Y.; Kim, S. H.; Vite, G. D.; Lee, F. Y.; Zhang, H.; Oppenheimer, S.; Tokarski, J. S.; Wong, T. W.; Gavai, A. V. Novel Pyrrolo[2,1-f][1,2,4]Triazin-4-Amines: Dual Inhibitors of EGFR and HER2 Protein Tyrosine Kinases. Bioorganic Med. Chem. Lett. 2011, 21 (2), 781-785. https://doi.org/10.1016/j.bmcl.2010.11.100.

(202) Garofalo, A.; Goossens, L.; Lemoine, A.; Ravez, S.; Six, P.; Howsam, M.; Farce, A.; Depreux, P. [4-(6,7-Disubstituted Quinazolin-4Ylamino)Phenyl] Carbamic Acid Esters: A Novel Series of Dual EGFR/VEGFR-2 Tyrosine Kinase Inhibitors. Medchemcomm 2011, 
2 (1), 65-72. https://doi.org/10.1039/c0md00183j.

(203) Ibrahim, D. A.; Ismail, N. S. M. Design, Synthesis and Biological Study of Novel Pyrido[2,3-d]Pyrimidine as Anti-Proliferative CDK2 Inhibitors. Eur. J. Med. Chem. 2011, 46 (12), 5825-5832. https://doi.org/10.1016/j.ejmech.2011.09.041.

(204) Garofalo, A.; Goossens, L.; Six, P.; Lemoine, A.; Ravez, S.; Farce, A.; Depreux, P. Impact of Aryloxy-Linked Quinazolines: A Novel Series of Selective VEGFR-2 Receptor Tyrosine Kinase Inhibitors. Bioorganic Med. Chem. Lett. 2011, 21 (7), $2106-2112$. https://doi.org/10.1016/j.bmcl.2011.01.137.

(205) Waterson, A. G.; Petrov, K. G.; Hornberger, K. R.; Hubbard, R. D.; Sammond, D. M.; Smith, S. C.; Dickson, H. D.; Caferro, T. R.; Hinkle, K. W.; Stevens, K. L.; Dickerson, S. H.; Rusnak, D. W.; Spehar, G. M.; Wood, E. R.; Griffin, R. J.; Uehling, D. E. Synthesis and Evaluation of Aniline Headgroups for Alkynyl Thienopyrimidine Dual EGFR/ErbB-2 Kinase Inhibitors. Bioorganic Med. Chem. Lett. 2009, 19 (5), 1332-1336. https://doi.org/10.1016/j.bmcl.2009.01.080.

(206) Gangjee, A.; Li, W.; Lin, L.; Zeng, Y.; Ihnat, M.; Warnke, L. A.; Green, D. W.; Cody, V.; Pace, J.; Queener, S. F. Design, Synthesis, and X-Ray Crystal Structures of 2,4-Diaminofuro[2,3-d]Pyrimidines as Multireceptor Tyrosine Kinase and Dihydrofolate Reductase Inhibitors. Bioorganic Med. Chem. 2009, 17 (20), 7324-7336. https://doi.org/10.1016/j.bmc.2009.08.044.

(207) Rheault, T. R.; Caferro, T. R.; Dickerson, S. H.; Donaldson, K. H.; Gaul, M. D.; Goetz, A. S.; Mullin, R. J.; McDonald, O. B.; Petrov, K. G.; Rusnak, D. W.; Shewchuk, L. M.; Spehar, G. M.; Truesdale, A. T.; Vanderwall, D. E.; Wood, E. R.; Uehling, D. E. Thienopyrimidine-Based Dual EGFR/ErbB-2 Inhibitors. Bioorganic Med. Chem. Lett. 2009, 19 (3), 817-820. https://doi.org/10.1016/j.bmcl.2008.12.011.

(208) Stevens, K. L.; Alligood, K. J.; Alberti, J. G. B.; Caferro, T. R.; Chamberlain, S. D.; Dickerson, S. H.; Dickson, H. D.; Emerson, H. K.; Griffin, R. J.; Hubbard, R. D.; Keith, B. R.; Mullin, R. J.; Petrov, K. G.; Gerding, R. M.; Reno, M. J.; Rheault, T. R.; Rusnak, D. W.; Sammond, D. M.; Smith, S. C.; Uehling, D. E.; Waterson, A. G.; Wood, E. R. Synthesis and Stereochemical Effects of Pyrrolidinyl-Acetylenic Thieno[3,2-d]Pyrimidines as EGFR and ErbB-2 Inhibitors. Bioorganic Med. Chem. Lett. 2009, 19 (1), $21-26$. https://doi.org/10.1016/j.bmcl.2008.11.023.

(209) Peifer, C.; Bühler, S.; Hauser, D.; Kinkel, K.; Totzke, F.; Schächtele, C.; Laufer, S. Design, Synthesis and Characterization of N9/N7Substituted 6-Aminopurines as VEGF-R and EGF-R Inhibitors. Eur. J. Med. Chem. 2009, 44 (4), 1788-1793.

https://doi.org/10.1016/j.ejmech.2008.04.012.

(210) Gavai, A. V.; Fink, B. E.; Fairfax, D. J.; Martin, G. S.; Rossiter, L. M.; Holst, C. L.; Kim, S. H.; Leavitt, K. J.; Mastalerz, H.; Han, W. C.; Norris, D.; Goyal, B.; Swaminathan, S.; Patel, B.; Mathur, A.; Vyas, D. M.; Tokarski, J. S.; Chiang, Y.; Oppenheimer, S.; Hongjian, Z.; Marathe, P.; Fargnoli, J.; Lee, F. Y.; Wong, T. W.; Vite, G. D. Discovery and Preclinical Evaluation of [4-[[1-(3Fluorophenyl)Methyl]-1H- Indazol-5-Ylamino]-5-Methylpyrrolo[2,1-f][1,2,4]Triazin-6-Yl]Carbamic Acid, (3S)-3-

Morpholinylmethyl Ester (BMS-599626), a Selective and Orally Efficacious Inhibitor of Human Epide. J. Med. Chem. 2009, 52 (21), 6527-6530. https://doi.org/10.1021/jm9010065.

(211) Nakamura, H.; Horikoshi, R.; Usui, T.; Ban, H. S. Selective Inhibition of EGFR and VEGFR2 Tyrosine Kinases Controlled by a Boronic Acid Substituent on 4-Anilinoquinazolines. Medchemcomm 2010, 1 (4), 282-286. https://doi.org/10.1039/c0md00115e.

(212) Carmi, C.; Cavazzoni, A.; Vezzosi, S.; Bordi, F.; Vacondio, F.; Silva, C.; Rivara, S.; Lodola, A.; Alfieri, R. R.; Monica, S. La; Galetti, M.; Ardizzoni, A.; Petronini, P. G.; Mor, M. Novel Irreversible Epidermal Growth Factor Receptor Inhibitors by Chemical Modulation of the Cysteine-Trap Portion. J. Med. Chem. 2010, 53 (5), 2038-2050. https://doi.org/10.1021/jm901558p.

(213) Qian, Y.; Zhang, H. J.; Zhang, H.; Xu, C.; Zhao, J.; Zhu, H. L. Synthesis, Molecular Modeling, and Biological Evaluation of Cinnamic Acid Metronidazole Ester Derivatives as Novel Anticancer Agents. Bioorganic Med. Chem. 2010, 18 (14), $4991-4996$. https://doi.org/10.1016/j.bmc.2010.06.003.

(214) Cai, X.; Zhai, H. X.; Wang, J.; Forrester, J.; Qu, H.; Yin, L.; Lai, C. J.; Bao, R.; Qian, C. Discovery of 7-(4-(3-Ethynylphenylamino)7-Methoxyquinazolin-6-Yloxy)-N- Hydroxyheptanamide (CUDC-101) as a Potent Multi-Acting HDAC, EGFR, and HER2 Inhibitor for the Treatment of Cancer. J. Med. Chem. 2010, 53 (5), 2000-2009. https://doi.org/10.1021/jm901453q.

(215) Lv, P. C.; Zhou, C. F.; Chen, J.; Liu, P. G.; Wang, K. R.; Mao, W. J.; Li, H. Q.; Yang, Y.; Xiong, J.; Zhu, H. L. Design, Synthesis and Biological Evaluation of Thiazolidinone Derivatives as Potential EGFR and HER-2 Kinase Inhibitors. Bioorganic Med. Chem. 2010, 
18 (1), 314-319. https://doi.org/10.1016/j.bmc.2009.10.051.

(216) Zheng, Q. Z.; Zhang, F.; Cheng, K.; Yang, Y.; Chen, Y.; Qian, Y.; Zhang, H. J.; Li, H. Q.; Zhou, C. F.; An, S. Q.; Jiao, Q. C.; Zhu, H. L. Synthesis, Biological Evaluation and Molecular Docking Studies of Amide-Coupled Benzoic Nitrogen Mustard Derivatives as Potential Antitumor Agents. Bioorganic Med. Chem. 2010, 18 (2), 880-886. https://doi.org/10.1016/j.bmc.2009.11.037.

(217) Zhang, L.; Fan, C.; Guo, Z.; Li, Y.; Zhao, S.; Yang, S.; Yang, Y.; Zhu, J.; Lin, D. Discovery of a Potent Dual EGFR/HER-2 Inhibitor L-2 (Selatinib) for the Treatment of Cancer. Eur. J. Med. Chem. 2013, 69, 833-841. https://doi.org/10.1016/j.ejmech.2013.09.032.

(218) Makawana, J. A.; Sun, J.; Zhu, H. L. Schiff's Base Derivatives Bearing Nitroimidazole Moiety: New Class of Antibacterial, Anticancer Agents and Potential EGFR Tyrosine Kinase Inhibitors. Bioorganic Med. Chem. Lett. 2013, 23 (23), 6264-6268. https://doi.org/10.1016/j.bmcl.2013.09.086.

(219) Zhang, M.; Lu, X.; Zhang, H. J.; Li, N.; Xiao, Y.; Zhu, H. L.; Ye, Y. H. Synthesis, Structure, and Biological Assay of Cinnamic Amides as Potential EGFR Kinase Inhibitors. Med. Chem. Res. 2013, 22 (2), 986-994. https://doi.org/10.1007/s00044-012-0093-z.

(220) Xu, Y. Y.; Li, S. N.; Yu, G. J.; Hu, Q. H.; Li, H. Q. Discovery of Novel 4-Anilinoquinazoline Derivatives as Potent Inhibitors of Epidermal Growth Factor Receptor with Antitumor Activity. Bioorganic Med. Chem. 2013, 21 (19), 6084-6091. https://doi.org/10.1016/j.bmc.2013.06.070.

(221) Zhao, F.; Lin, Z.; Wang, F.; Zhao, W.; Dong, X. Four-Membered Heterocycles-Containing 4-Anilino-Quinazoline Derivatives as Epidermal Growth Factor Receptor (EGFR) Kinase Inhibitors. Bioorganic Med. Chem. Lett. 2013, 23 (19), 5385-5388. https://doi.org/10.1016/j.bmcl.2013.07.049.

(222) Zhou, W.; Liu, X.; Tu, Z.; Zhang, L.; Ku, X.; Bai, F.; Zhao, Z.; Xu, Y.; Ding, K.; Li, H. Discovery of Pteridin-7(8H)-One-Based Irreversible Inhibitors Targeting Epidermal Growth Factor Receptor (EGFR) Kinase T790M/L858R Mutant. J. Med. Chem. 2013, 56 (20), 7821-7837. https://doi.org/10.1021/jm401045n.

(223) Han, C.; Huang, Z.; Zheng, C.; Wan, L.; Zhang, L.; Peng, S.; Ding, K.; Ji, H.; Tian, J.; Zhang, Y. Novel Hybrids of (Phenylsulfonyl)Furoxan and Anilinopyrimidine as Potent and Selective Epidermal Growth Factor Receptor Inhibitors for Intervention of Non-Small-Cell Lung Cancer. J. Med. Chem. 2013, 56 (11), 4738-4748. https://doi.org/10.1021/jm400463q.

(224) Yang, W.; Hu, Y.; Yang, Y. S.; Zhang, F.; Zhang, Y. Bin; Wang, X. L.; Tang, J. F.; Zhong, W. Q.; Zhu, H. L. Design, Modification and 3D QSAR Studies of Novel Naphthalin-Containing Pyrazoline Derivatives with/without Thiourea Skeleton as Anticancer Agents. Bioorganic Med. Chem. 2013, 21 (5), 1050-1063. https://doi.org/10.1016/j.bmc.2013.01.013.

(225) Mao, Y.; Zhu, W.; Kong, X.; Wang, Z.; Xie, H.; Ding, J.; Terrett, N. K.; Shen, J. Design, Synthesis and Biological Evaluation of Novel Pyrimidine, 3-Cyanopyridine and m-Amino-N-Phenylbenzamide Based Monocyclic EGFR Tyrosine Kinase Inhibitors. Bioorganic Med. Chem. 2013, 21 (11), 3090-3104. https://doi.org/10.1016/j.bmc.2013.03.053.

(226) Peng, Y. H.; Shiao, H. Y.; Tu, C. H.; Liu, P. M.; Hsu, J. T. A.; Amancha, P. K.; Wu, J. S.; Coumar, M. S.; Chen, C. H.; Wang, S. Y.; Lin, W. H.; Sun, H. Y.; Chao, Y. S.; Lyu, P. C.; Hsieh, H. P.; Wu, S. Y. Protein Kinase Inhibitor Design by Targeting the Asp-PheGly (DFG) Motif: The Role of the DFG Motif in the Design of Epidermal Growth Factor Receptor Inhibitors. J. Med. Chem. 2013, 56 (10), 3889-3903. https://doi.org/10.1021/jm400072p.

(227) Niemann, H.; Lin, W.; Müller, W. E. G.; Kubbutat, M.; Lai, D.; Proksch, P. Trimeric Hemibastadin Congener from the Marine Sponge Ianthella Basta. J. Nat. Prod. 2013, 76 (1), 121-125. https://doi.org/10.1021/np300764u.

(228) Han, C.; Huang, Z.; Zheng, C.; Wan, L.; Lai, Y.; Peng, S.; Ding, K.; Ji, H.; Zhang, Y. Nitric Oxide Donating Anilinopyrimidines: Synthesis and Biological Evaluation as EGFR Inhibitors. Eur. J. Med. Chem. 2013, 66, 82-90. https://doi.org/10.1016/j.ejmech.2013.05.026.

(229) Powell, N. A.; Hoffman, J. K.; Ciske, F. L.; Kohrt, J. T.; Baxi, S. M.; Peng, Y.-W.; Zhong, M.; Catana, C.; Ohren, J.; Perrin, L. A.; Edmunds, J. J. Optimization of Highly Selective 2,4-Diaminopyrimidine-5-Carboxamide Inhibitors of Sky Kinase. Bioorg. Med. Chem. Lett. 2012, 23 (4), 1051-1055. https://doi.org/10.1016/j.bmcl.2012.12.028.

(230) Xu, Y. Y.; Cao, Y.; Ma, H.; Li, H. Q.; Ao, G. Z. Design, Synthesis and Molecular Docking of $\alpha, \beta$-Unsaturated Cyclohexanone Analogous of Curcumin as Potent EGFR Inhibitors with Antiproliferative Activity. Bioorganic Med. Chem. 2013, 21 (2), $388-394$. https://doi.org/10.1016/j.bmc.2012.11.031. 
(231) McDermott, L. A.; Simcox, M.; Higgins, B.; Nevins, T.; Kolinsky, K.; Smith, M.; Yang, H.; Li, J. K.; Chen, Y.; Ke, J.; Mallalieu, N.; Egan, T.; Kolis, S.; Railkar, A.; Gerber, L.; Luk, K. C. RO4383596, an Orally Active KDR, FGFR, and PDGFR Inhibitor: Synthesis and Biological Evaluation. Bioorganic Med. Chem. 2005, 13 (16), 4835-4841. https://doi.org/10.1016/j.bmc.2005.05.012.

(232) Li, S.; Guo, C.; Sun, X.; Li, Y.; Zhao, H.; Zhan, D.; Lan, M.; Tang, Y. Synthesis and Biological Evaluation of Quinazoline and Quinoline Bearing 2,2,6,6-Tetramethylpiperidine-N-Oxyl as Potential Epidermal Growth Factor Receptor(EGFR) Tyrosine Kinase Inhibitors and EPR Bio-Probe Agents. Eur. J. Med. Chem. 2012, 49, 271-278. https://doi.org/10.1016/j.ejmech.2012.01.021. Yadav, S.; Sinha, D.; Singh, S. K.; Singh, V. K. Novel Benzimidazole Analogs as Inhibitors of EGFR Tyrosine Kinase. Chem. Biol. Drug Des. 2012, 80 (4), 625-630. https://doi.org/10.1111/j.1747-0285.2012.01407.x.

(234) Chang, S.; Zhang, L.; Xu, S.; Luo, J.; Lu, X.; Zhang, Z.; Xu, T.; Liu, Y.; Tu, Z.; Xu, Y.; Ren, X.; Geng, M.; Ding, J.; Pei, D.; Ding, K Design, Synthesis, and Biological Evaluation of Novel Conformationally Constrained Inhibitors Targeting Epidermal Growth Factor Receptor Threonine $790 \rightarrow$ Methionine 790 Mutant. J. Med. Chem. 2012, 55 (6), 2711-2723. https://doi.org/10.1021/jm201591k. Li, S.; Sun, X.; Zhao, H.; Tang, Y.; Lan, M. Discovery of Novel EGFR Tyrosine Kinase Inhibitors by Structure-Based Virtual Screening. Bioorganic Med. Chem. Lett. 2012, 22 (12), 4004-4009. https://doi.org/10.1016/j.bmcl.2012.04.092. Li, H. Q.; Li, D. D.; Lu, X.; Xu, Y. Y.; Zhu, H. L. Design and Synthesis of 4,6-Substituted-(Diaphenylamino)Quinazolines as Potent EGFR Inhibitors with Antitumor Activity. Bioorganic Med. Chem. 2012, 20 (1), 317-323. https://doi.org/10.1016/j.bmc.2011.10.085. Zhang, H.; Lu, X.; Zhang, L. R.; Liu, J. J.; Yang, X. H.; Wang, X. M.; Zhu, H. L. Design, Synthesis and Biological Evaluation of NPhenylsulfonylnicotinamide Derivatives as Novel Antitumor Inhibitors. Bioorganic Med. Chem. 2012, 20 (4), $1411-1416$. https://doi.org/10.1016/j.bmc.2012.01.004.

(238) Kawakita, Y.; Miwa, K.; Seto, M.; Banno, H.; Ohta, Y.; Tamura, T.; Yusa, T.; Miki, H.; Kamiguchi, H.; Ikeda, Y.; Tanaka, T.; Kamiyama, K.; Ishikawa, T. Design and Synthesis of Pyrrolo[3,2-d]Pyrimidine HER2/EGFR Dual Inhibitors: Improvement of the Physicochemical and Pharmacokinetic Profiles for Potent in Vivo Anti-Tumor Efficacy. Bioorganic Med. Chem. 2012, 20 (20), $6171-$ 6180. https://doi.org/10.1016/j.bmc.2012.08.002.

(239) Hu, S.; Xie, G.; Zhang, D. X.; Davis, C.; Long, W.; Hu, Y.; Wang, F.; Kang, X.; Tan, F.; Ding, L.; Wang, Y. Synthesis and Biologica Evaluation of Crown Ether Fused Quinazoline Analogues as Potent EGFR Inhibitors. Bioorganic Med. Chem. Lett. 2012, 22 (19), 6301-6305. https://doi.org/10.1016/j.bmcl.2012.06.067.

(240) Wu, P.; Hu, Y. Small Molecules Targeting Phosphoinositide 3-Kinases. Medchemcomm 2012, 3 (11), 1337-1355. https://doi.org/10.1039/c2md20044a.

(241) Carmi, C.; Galvani, E.; Vacondio, F.; Rivara, S.; Lodola, A.; Russo, S.; Aiello, S.; Bordi, F.; Costantino, G.; Cavazzoni, A.; Alfieri, R. R.; Ardizzoni, A.; Petronini, P. G.; Mor, M. Irreversible Inhibition of Epidermal Growth Factor Receptor Activity by 3Aminopropanamides. J. Med. Chem. 2012, 55 (5), 2251-2264. https://doi.org/10.1021/jm201507x.

(242) Garofalo, A.; Farce, A.; Ravez, S.; Lemoine, A.; Six, P.; Chavatte, P.; Goossens, L.; Depreux, P. Synthesis and Structure-Activity Relationships of (Aryloxy)Quinazoline Ureas as Novel, Potent, and Selective Vascular Endothelial Growth Factor Receptor-2 Inhibitors. J. Med. Chem. 2012, 55 (3), 1189-1204. https://doi.org/10.1021/jm2013453.

(243) Zuo, M.; Zheng, Y. W.; Lu, S. M.; Li, Y.; Zhang, S. Q. Synthesis and Biological Evaluation of N-Aryl Salicylamides with a Hydroxamic Acid Moiety at 5-Position as Novel HDAC-EGFR Dual Inhibitors. Bioorganic Med. Chem. 2012, 20 (14), $4405-4412$. https://doi.org/10.1016/j.bmc.2012.05.034.

(244) Kawakita, Y.; Banno, H.; Ohashi, T.; Tamura, T.; Yusa, T.; Nakayama, A.; Miki, H.; Iwata, H.; Kamiguchi, H.; Tanaka, T.; Habuka, N.; Sogabe, S.; Ohta, Y.; Ishikawa, T. Design and Synthesis of Pyrrolo[3,2- d ]Pyrimidine Human Epidermal Growth Factor Receptor 2 (HER2)/Epidermal Growth Factor Receptor (EGFR) Dual Inhibitors: Exploration of Novel Back-Pocket Binders. J. Med. Chem. 2012, 55 (8), 3975-3991. https://doi.org/10.1021/jm300185p.

(245) Li, S.; Guo, C.; Zhao, H.; Tang, Y.; Lan, M. Synthesis and Biological Evaluation of 4-[3-Chloro-4-(3-Fluorobenzyloxy) Anilino]-6(3-Substituted-Phenoxy)Pyrimidines as Dual EGFR/ErbB-2 Kinase Inhibitors. Bioorganic Med. Chem. 2012, 20 (2), 877-885. https://doi.org/10.1016/j.bmc.2011.11.056.

(246) Beckers, T.; Sellmer, A.; Eichhorn, E.; Pongratz, H.; Schächtele, C.; Totzke, F.; Kelter, G.; Krumbach, R.; Fiebig, H. H.; Böhmer, F. 
D.; Mahboobi, S. Novel Inhibitors of Epidermal Growth Factor Receptor: (4-(Arylamino)-7H- Pyrrolo[2,3-d]Pyrimidin-6-Y1)(1HIndol-2-Yl)Methanones and (1H-Indol-2-Yl)(4- (Phenylamino)Thieno[2,3-d]Pyrimidin-6-Y1)Methanones. Bioorganic Med. Chem. 2012, 20 (1), 125-136. https://doi.org/10.1016/j.bmc.2011.11.023.

(247) Singh, V. K.; Sharma, H.; Singh, S. K.; Gangwar, L. Synthesis and in Vitro Evaluation of N-Aryl Pyrido-Quinazolines Derivatives as Potent Epidermal Growth Factor Receptor Inhibitors. Chem. Biol. Drug Des. 2013, 82 (1), 119-124. https://doi.org/10.1111/cbdd.12133.

Hamed, M. M.; AbouElElla, D. A.; Keeton, A. B.; Piazza, G. A.; Abadi, A. H.; Hartmann, R. W.; Engel, M. 6-Aryl and Heterocycle Quinazoline Derivatives as Potent EGFR Inhibitors with Improved Activity toward Gefitinib-Sensitive and -Resistant Tumor Cell Lines. ChemMedChem 2013, 8 (9), 1495-1504. https://doi.org/10.1002/cmdc. 201300147.

(249) Yang, Y. A.; Tang, W. J.; Zhang, X.; Yuan, J. W.; Liu, X. H.; Zhu, H. L. Synthesis, Molecular Docking and Biological Evaluation of Glycyrrhizin Analogs as Anticancer Agents Targeting EGFR. Molecules 2014, 19 (5), 6368-6381.

https://doi.org/10.3390/molecules19056368.

(250) Cheng, W.; Zhu, S.; Ma, X.; Qiu, N.; Peng, P.; Sheng, R.; Hu, Y. Design, Synthesis and Biological Evaluation of 6-(Nitroimidazole-1 $\mathrm{H}$-Alkyloxyl)-4-Anilinoquinazolines as Efficient EGFR Inhibitors Exerting Cytotoxic Effects Both under Normoxia and Hypoxia. Eur. J. Med. Chem. 2015, 89, 826-834. https://doi.org/10.1016/j.ejmech.2014.11.010.

(251) Kaspersen, S. J.; Han, J.; Nørsett, K. G.; Rydså, L.; Kjøbli, E.; Bugge, S.; Bjørkøy, G.; Sundby, E.; Hoff, B. H. Identification of New 4-N-Substituted 6-Aryl-7H-Pyrrolo[2,3-d]Pyrimidine-4- Amines as Highly Potent EGFR-TK Inhibitors with Src-Family Activity. Eur. J. Pharm. Sci. 2014, 59 (1), 69-82. https://doi.org/10.1016/j.ejps.2014.04.011.

(252) Hou, X.; Zhang, J.; Zhao, X.; Chang, L.; Hu, P.; Liu, H. Design, Synthesis and Bioactivities Evaluation of Novel Quinazoline Analogs Containing Oxazole Units. Chinese J. Chem. 2014, 32 (6), 538-544. https://doi.org/10.1002/cjoc.201400271.

(253) Sangani, C. B.; Makawana, J. A.; Duan, Y. T.; Yin, Y.; Teraiya, S. B.; Thumar, N. J.; Zhu, H. L. Design, Synthesis and Molecular Modeling of Biquinoline-Pyridine Hybrids as a New Class of Potential EGFR and HER-2 Kinase Inhibitors. Bioorganic Med. Chem. Lett. 2014, 24 (18), 4472-4476. https://doi.org/10.1016/j.bmcl.2014.07.094.

(254) Elkamhawy, A.; Farag, A. K.; Viswanath, A. N. I.; Bedair, T. M.; Leem, D. G.; Lee, K. T.; Pae, A. N.; Roh, E. J. Targeting EGFR/HER2 Tyrosine Kinases with a New Potent Series of 6-Substituted 4-Anilinoquinazoline Hybrids: Design, Synthesis, Kinase Assay, Cell-Based Assay, and Molecular Docking. Bioorganic Med. Chem. Lett. 2015, 25 (22), 5147-5154. https://doi.org/10.1016/j.bmcl.2015.10.003.

(255) Hao, Y.; Wang, X.; Zhang, T.; Sun, D.; Tong, Y.; Xu, Y.; Chen, H.; Tong, L.; Zhu, L.; Zhao, Z.; Chen, Z.; Ding, J.; Xie, H.; Xu, Y.; Li, H. Discovery and Structural Optimization of N5-Substituted 6,7-Dioxo-6,7-Dihydropteridines as Potent and Selective Epidermal Growth Factor Receptor (EGFR) Inhibitors against L858R/T790M Resistance Mutation. J. Med. Chem. 2016, 59 (15), $7111-7124$. https://doi.org/10.1021/acs.jmedchem.6b00403.

(256) Yin, S.; Zhou, L.; Lin, J.; Xue, L.; Zhang, C. Design, Synthesis and Biological Activities of Novel Oxazolo[4,5- g ]Quinazolin-2(1H) One Derivatives as EGFR Inhibitors. Eur. J. Med. Chem. 2015, 101, 462-475. https://doi.org/10.1016/j.ejmech.2015.07.008.

(257) Zhang, Y.; Tortorella, M. D.; Liao, J.; Qin, X.; Chen, T.; Luo, J.; Guan, J.; Talley, J. J.; Tu, Z. Synthesis and Evaluation of Novel Erlotinib-NSAID Conjugates as More Comprehensive Anticancer Agents. ACS Med. Chem. Lett. 2015, 6 (10), 1086-1090. https://doi.org/10.1021/acsmedchemlett.5b00286.

(258) Zhang, L.; Yang, Y.; Zhou, H.; Zheng, Q.; Li, Y.; Zheng, S.; Zhao, S.; Chen, D.; Fan, C. Structure-Activity Study of Quinazoline Derivatives Leading to the Discovery of Potent EGFR-T790M Inhibitors. Eur. J. Med. Chem. 2015, 102, 445-463. https://doi.org/10.1016/j.ejmech.2015.08.026.

(259) Bugge, S.; Moen, I. U.; Kragseth Sylte, K. O.; Sundby, E.; Hoff, B. H. Truncated Structures Used in Search for New Lead Compounds and in a Retrospective Analysis of Thienopyrimidine-Based EGFR Inhibitors. Eur. J. Med. Chem. 2015, 94, $175-194$. https://doi.org/10.1021/jm4006059.

(260) Sun, M.; Zhao, J.; Chen, X.; Zong, Z.; Han, J.; Du, Y.; Sun, H.; Wang, F. Synthesis and Biological Evaluation of Novel Tricyclic Oxazine and Oxazepine Fused Quinazolines. Part 2: Gefitinib Analogs. Bioorganic Med. Chem. Lett. 2016, 26 (19), $4842-4845$. 
https://doi.org/10.1016/j.bmcl.2016.08.007.

(261) Ji, X.; Peng, T.; Zhang, X.; Li, J.; Yang, W.; Tong, L.; Qu, R.; Jiang, H.; Ding, J.; Xie, H.; Liu, H. Design, Synthesis and Biological Evaluation of Novel 6-Alkenylamides Substituted of 4-Anilinothieno[2,3-d]Pyrimidines as Irreversible Epidermal Growth Factor Receptor Inhibitors. Bioorganic Med. Chem. 2014, 22 (7), 2366-2378. https://doi.org/10.1016/j.bmc.2014.01.035.

(262) Xia, G.; Chen, W.; Zhang, J.; Shao, J.; Zhang, Y.; Huang, W.; Zhang, L.; Qi, W.; Sun, X.; Li, B.; Xiang, Z.; Ma, C.; Xu, J.; Deng, H.; Li, Y.; Li, P.; Miao, H.; Han, J.; Liu, Y.; Shen, J.; Yu, Y. A Chemical Tuned Strategy to Develop Novel Irreversible EGFR-TK Inhibitors with Improved Safety and Pharmacokinetic Profiles. J. Med. Chem. 2014, 57 (23), 9889-9900. https://doi.org/10.1021/jm5014659.

(263) Cheng, W.; Yuan, Y.; Qiu, N.; Peng, P.; Sheng, R.; Hu, Y. Identification of Novel 4-Anilinoquinazoline Derivatives as Potent EGFR Inhibitors Both under Normoxia and Hypoxia. Bioorganic Med. Chem. 2014, 22 (24), 6796-6805. https://doi.org/10.1016/j.bmc.2014.10.038.

(264) Lyu, A.; Fang, L.; Gou, S. Design and Synthesis of Lapatinib Derivatives Containing a Branched Side Chain as HER1/HER2 Targeting Antitumor Drug Candidates. Eur. J. Med. Chem. 2014, 87, 631-642. https://doi.org/10.1016/j.ejmech.2014.10.006.

(265) Rao, S.; Larroque-Lombard, A. L.; Peyrard, L.; Thauvin, C.; Rachid, Z.; Williams, C.; Jean-Claude, B. J. Target Modulation by a Kinase Inhibitor Engineered to Induce a Tandem Blockade of the Epidermal Growth Factor Receptor (EGFR) and c-Src: The Concept of Type III Combi-Targeting. PLoS One 2015, 10 (2), 1-24. https://doi.org/10.1371/journal.pone.0117215.

(266) Han, C.; Wan, L.; Ji, H.; Ding, K.; Huang, Z.; Lai, Y.; Peng, S.; Zhang, Y. Synthesis and Evaluation of 2-Anilinopyrimidines Bearing 3-Aminopropamides as Potential Epidermal Growth Factor Receptor Inhibitors. Eur. J. Med. Chem. 2014, 77, $75-83$. https://doi.org/10.1016/j.ejmech.2014.02.032.

(267) Makawana, J. A.; Sangani, C. B.; Lin, L.; Zhu, H. L. Schiff’s Base Derivatives Bearing Nitroimidazole and Quinoline Nuclei: New Class of Anticancer Agents and Potential EGFR Tyrosine Kinase Inhibitors. Bioorganic Med. Chem. Lett. 2014, 24 (7), $1734-1736$. https://doi.org/10.1016/j.bmcl.2014.02.041.

(268) Yuan, J. W.; Wang, S. F.; Luo, Z. L.; Qiu, H. Y.; Wang, P. F.; Zhang, X.; Yang, Y. A.; Yin, Y.; Zhang, F.; Zhu, H. L. Synthesis and Biological Evaluation of Compounds Which Contain Pyrazole, Thiazole and Naphthalene Ring as Antitumor Agents. Bioorganic Med. Chem. Lett. 2014, 24 (10), 2324-2328. https://doi.org/10.1016/j.bmcl.2014.03.072.

(269) Song, J.; Yoo, J.; Kwon, A.; Kim, D.; Nguyen, H. K.; Lee, B. Y.; Suh, W.; Min, K. H. Structure-Activity Relationship of IndoleTethered Pyrimidine Derivatives That Concurrently Inhibit Epidermal Growth Factor Receptor and Other Angiokinases. PLoS One 2015, 10 (9), 1-17. https://doi.org/10.1371/journal.pone.0138823.

(270) Barbosa, M. L. D. C.; Lima, L. M.; Tesch, R.; Sant’Anna, C. M. R.; Totzke, F.; Kubbutat, M. H. G.; Schächtele, C.; Laufer, S. A.; Barreiro, E. J. Novel 2-Chloro-4-Anilino-Quinazoline Derivatives as EGFR and VEGFR-2 Dual Inhibitors. Eur. J. Med. Chem. 2014, 71, 1-14. https://doi.org/10.1016/j.ejmech.2013.10.058.

(271) Sangani, C. B.; Makawana, J. A.; Zhang, X.; Teraiya, S. B.; Lin, L.; Zhu, H. L. Design, Synthesis and Molecular Modeling of Pyrazole-Quinoline-Pyridine Hybrids as a New Class of Antimicrobial and Anticancer Agents. Eur. J. Med. Chem. 2014, 76, 549557. https://doi.org/10.1016/j.ejmech.2014.01.018.

(272) Xu, T.; Peng, T.; Ren, X.; Zhang, L.; Yu, L.; Luo, J.; Zhang, Z.; Tu, Z.; Tong, L.; Huang, Z.; Lu, X.; Geng, M.; Xie, H.; Ding, J.; Ding, K. C5-Substituted Pyrido[2,3-d]Pyrimidin-7-Ones as Highly Specific Kinase Inhibitors Targeting the Clinical ResistanceRelated EGFRT790M Mutant. Medchemcomm 2015, 6 (9), 1693-1697. https://doi.org/10.1039/c5md00208g.

(273) Zhang, Y.; Zhang, K.; Zhao, M.; Zhang, L.; Qin, M.; Guo, S.; Zhao, Y.; Gong, P. Discovery of a Novel Class Anti-Proliferative Agents and Potential Inhibitors of EGFR Tyrosine Kinases Based on 4-Anilinotetrahydropyrido[4,3-d]Pyrimidine Scaffold: Design, Synthesis and Biological Evaluations. Bioorganic Med. Chem. 2015, 23 (15), 4591-4607. https://doi.org/10.1016/j.bmc.2015.05.059.

(274) Chan, S.; Han, K.; Qu, R.; Tong, L.; Li, Y.; Zhang, Z.; Cheng, H.; Lu, X.; Patterson, A.; Smaill, J.; Ren, X.; Ding, J.; Xie, H.; Ding, K. 2,4-Diarylamino-Pyrimidines as Kinase Inhibitors Co-Targeting IGF1R and EGFRL858R/T790M. Bioorganic Med. Chem. Lett. 2015, 25 (19), 4277-4281. https://doi.org/10.1016/j.bmcl.2015.07.089.

(275) Yin, S.; Tang, C.; Wang, B.; Zhang, Y.; Zhou, L.; Xue, L.; Zhang, C. Design, Synthesis and Biological Evaluation of Novel 
EGFR/HER2 Dual Inhibitors Bearing a Oxazolo[4,5-g]Quinazolin-2(1H)-One Scaffold. Eur. J. Med. Chem. 2016, 120, 26-36. https://doi.org/10.1016/j.ejmech.2016.04.072.

(276) Smaill, J. B.; Gonzales, A. J.; Spicer, J. A.; Lee, H.; Reed, J. E.; Sexton, K.; Althaus, I. W.; Zhu, T.; Black, S. L.; Blaser, A.; Denny, W. A.; Ellis, P. A.; Fakhoury, S.; Harvey, P. J.; Hook, K.; McCarthy, F. O. J.; Palmer, B. D.; Rivault, F.; Schlosser, K.; Ellis, T.; Thompson, A. M.; Trachet, E.; Winters, R. T.; Tecle, H.; Bridges, A. Tyrosine Kinase Inhibitors. 20. Optimization of Substituted Quinazoline and Pyrido[3,4-d]Pyrimidine Derivatives as Orally Active, Irreversible Inhibitors of the Epidermal Growth Factor Receptor Family. J. Med. Chem. 2016, 59 (17), 8103-8124. https://doi.org/10.1021/acs.jmedchem.6b00883.

Amin, K. M.; Barsoum, F. F.; Awadallah, F. M.; Mohamed, N. E. Identification of New Potent Phthalazine Derivatives with VEGFR 2 and EGFR Kinase Inhibitory Activity. Eur. J. Med. Chem. 2016, 123, 191-201. https://doi.org/10.1016/j.ejmech.2016.07.049. Wang, Y.; Zhang, G.; Hu, G.; Bu, Y.; Lei, H.; Zuo, D.; Han, M.; Zhai, X.; Gong, P. Design, Synthesis and Biological Evaluation of Novel 4-Arylaminopyrimidine Derivatives Possessing a Hydrazone Moiety as Dual Inhibitors of L1196M ALK and ROS1. Eur. J. Med. Chem. 2016, 123, 80-89. https://doi.org/10.1016/j.ejmech.2016.06.056.

(279) Shao, J.; Chen, E.; Shu, K.; Chen, W.; Zhang, G.; Yu, Y. 6-Oxooxazolidine-Quinazolines as Noncovalent Inhibitors with the Potential to Target Mutant Forms of EGFR. Bioorganic Med. Chem. 2016, 24 (16), 3359-3370.

https://doi.org/10.1016/j.bmc.2016.04.046.

(280) Youssif, B. G. M.; El-Sherief, H. A. M.; Abdel-Rahman, H. M.; Bukhari, S. N. A.; Abdel-Aziz, M. Novel 1,2,4-Triazole Derivatives as Potential Anticancer Agents: Design, Synthesis, Molecular Docking and Mechanistic Studies. Bioorg. Chem. 2017, 76, 314-325. https://doi.org/10.1016/j.bioorg.2017.12.013.

(281) El-Sayed, M. A. A.; El-Husseiny, W. M.; Abdel-Aziz, N. I.; El-Azab, A. S.; Abuelizz, H. A.; Abdel-Aziz, A. A. M. Synthesis and Biological Evaluation of 2-Styrylquinolines as Antitumour Agents and EGFR Kinase Inhibitors: Molecular Docking Study. J. Enzyme Inhib. Med. Chem. 2018, 33 (1), 199-209. https://doi.org/10.1080/14756366.2017.1407926.

(282) Qin, X.; Lv, Y.; Liu, P.; Li, Z.; Hu, L.; Zeng, C.; Yang, L. Novel Morpholin-3-One Fused Quinazoline Derivatives as EGFR Tyrosine Kinase Inhibitors. Bioorganic Med. Chem. Lett. 2016, 26 (6), 1571-1575. https://doi.org/10.1016/j.bmcl.2016.02.009.

(283) Zhang, X.; Peng, T.; Ji, X.; Li, J.; Tong, L.; Li, Z.; Yang, W.; Xu, Y.; Li, M.; Ding, J.; Jiang, H.; Xie, H.; Liu, H. Design, Synthesis and Biological Evaluation of Novel 4-Anilinoquinazolines with C-6 Urea-Linked Side Chains as Inhibitors of the Epidermal Growth Factor Receptor. Bioorganic Med. Chem. 2013, 21 (24), 7988-7998. https://doi.org/10.1016/j.bmc.2013.09.049.

(284) Sun, H.; Wang, C.; Ma, X.; Yu, H.; Meng, Q.; Liu, K.; Huang, S.; Li, Y.; Shu, X.; Song, Z.; Jiang, Y. Synthesis and Biological Evaluation of Morpholine-Substituted Diphenylpyrimidine Derivatives (Mor-DPPYs) as Potent EGFR T790M Inhibitors with Improved Activity toward the Gefitinib-Resistant Non-Small Cell Lung Cancers (NSCLC). Eur. J. Med. Chem. 2017, 133, 329-339. https://doi.org/10.1016/j.ejmech.2017.03.083.

(285) Song, A.; Zhang, J.; Ge, Y.; Wang, C.; Meng, Q.; Tang, Z.; Peng, J.; Liu, K.; Li, Y.; Ma, X. C-2 (E)-4-(Styryl)Aniline Substituted Diphenylpyrimidine Derivatives (Sty-DPPYs) as Specific Kinase Inhibitors Targeting Clinical Resistance Related EGFRT790M Mutant. Bioorganic Med. Chem. 2017, 25 (10), 2724-2729. https://doi.org/10.1016/j.bmc.2017.03.032.

(286) Ding, C.; Chen, S.; Zhang, C.; Hu, G.; Zhang, W.; Li, L.; Chen, Y. Z.; Tan, C.; Jiang, Y. Synthesis and Investigation of Novel 6(1,2,3-Triazol-4-Y1)-4-Aminoquinazolin Derivatives Possessing Hydroxamic Acid Moiety for Cancer Therapy. Bioorganic Med. Chem. 2017, 25 (1), 27-37. https://doi.org/10.1016/j.bmc.2016.10.006.

(287) Zheng, Y.; Li, Y.; Ge, Z.; Lin, S.; Cheng, T.; Luo, L.; Li, R.; Sun, Q. Design, Synthesis and Biological Evaluation of QuinazolinePhosphoramidate Mustard Conjugates as Anticancer Drugs. Eur. J. Med. Chem. 2017, 127, 442-458. https://doi.org/10.1016/j.ejmech.2016.12.055.

(288) Joshi, G.; Nayyar, H.; Kalra, S.; Sharma, P.; Munshi, A.; Singh, S.; Kumar, R. Pyrimidine Containing Epidermal Growth Factor Receptor Kinase Inhibitors: Synthesis and Biological Evaluation. Chem. Biol. Drug Des. 2017, 90 (5), 995-1006. https://doi.org/10.1111/cbdd.13027.

(289) Lämmerhofer, M.; Laufer, S.; Günther, M.; Sievers-Engler, A.; Juchum, M.; Döring, E. Trisubstituted Imidazoles with a Rigidized Hinge Binding Motif Act As Single Digit NM Inhibitors of Clinically Relevant EGFR L858R/T790M and L858R/T790M/C797S 
Mutants: An Example of Target Hopping. J. Med. Chem. 2017, 60 (11), 4636-4656. https://doi.org/10.1021/acs.jmedchem.7b00178.

Ghorab, M. M.; Alsaid, M. S.; Soliman, A. M. Dual EGFR/HER2 Inhibitors and Apoptosis Inducers: New Benzo[g]Quinazoline

Derivatives Bearing Benzenesulfonamide as Anticancer and Radiosensitizers. Bioorg. Chem. 2018, 80, 611-620.

https://doi.org/10.1016/j.bioorg.2018.07.015.

(291) Yu, H.; Li, Y.; Ge, Y.; Song, Z.; Wang, C.; Huang, S.; Jin, Y.; Han, X.; Zhen, Y.; Liu, K.; Zhou, Y.; Ma, X. Novel 4-

Anilinoquinazoline Derivatives Featuring an 1-Adamantyl Moiety as Potent EGFR Inhibitors with Enhanced Activity against NSCLC Cell Lines. Eur. J. Med. Chem. 2016, 110, 195-203. https://doi.org/10.1016/j.ejmech.2016.01.045.

(292) Mowafy, S.; Galanis, A.; Doctor, Z. M.; Paranal, R. M.; Lasheen, D. S.; Farag, N. A.; Jänne, P. A.; Abouzid, K. A. M. Toward Discovery of Mutant EGFR Inhibitors; Design, Synthesis and in Vitro Biological Evaluation of Potent 4-Arylamino-6-Ureido and Thioureido-Quinazoline Derivatives. Bioorganic Med. Chem. 2016, 24 (16), 3501-3512. https://doi.org/10.1016/j.bmc.2016.05.063.

(293) Zhang, H. Q.; Gong, F. H.; Li, C. G.; Zhang, C.; Wang, Y. J.; Xu, Y. G.; Sun, L. P. Design and Discovery of 4-AnilinoquinazolineAcylamino Derivatives as EGFR and VEGFR-2 Dual TK Inhibitors. Eur. J. Med. Chem. 2016, 109, 371-379.

https://doi.org/10.1016/j.ejmech.2015.12.032.

(294) Xiao, Q.; Qu, R.; Gao, D.; Yan, Q.; Tong, L.; Zhang, W.; Ding, J.; Xie, H.; Li, Y. Discovery of 5-(Methylthio)Pyrimidine Derivatives as L858R/T790M Mutant Selective Epidermal Growth Factor Receptor (EGFR) Inhibitors. Bioorganic Med. Chem. 2016, 24 (12), 2673-2680. https://doi.org/10.1016/j.bmc.2016.04.032.

(295) Qin, X.; Li, Z.; Yang, L.; Liu, P.; Hu, L.; Zeng, C.; Pan, Z. Discovery of New [1,4]Dioxino[2,3-f]Quinazoline-Based Inhibitors of EGFR Including the T790M/L858R Mutant. Bioorganic Med. Chem. 2016, 24 (13), 2871-2881.

https://doi.org/10.1016/j.bmc.2016.01.003.

(296) Shan, Y.; Wang, C.; Zhang, L.; Wang, J.; Wang, M.; Dong, Y. Expanding the Structural Diversity of Diarylureas as Multi-Target Tyrosine Kinase Inhibitors. Bioorganic Med. Chem. 2016, 24 (4), 750-758. https://doi.org/10.1016/j.bmc.2015.12.038.

(297) Sheng, J.; Liu, Z.; Yan, M.; Zhang, X.; Wang, D.; Xu, J.; Zhang, E.; Zou, Y. Biomass-Involved Synthesis of: N -Substituted Benzofuro[2,3- d] Pyrimidine-4-Amines and Biological Evaluation as Novel EGFR Tyrosine Kinase Inhibitors. Org. Biomol. Chem. 2017, 15 (23), 4971-4977. https://doi.org/10.1039/c7ob00793k.

(298) Kassab, A. E.; Gedawy, E. M.; El-Nassan, H. B. Synthesis of 4-Heteroaryl-Quinazoline Derivatives as Potential Anti-Breast Cancer Agents. J. Heterocycl. Chem. 2017, 54 (1), 624-633. https://doi.org/10.1002/jhet.2634.

(299) Ghorab, M. M.; Alsaid, M. S.; Soliman, A. M.; Al-Mishari, A. A. Benzo[g]Quinazolin-Based Scaffold Derivatives as Dual EGFR/HER2 Inhibitors. J. Enzyme Inhib. Med. Chem. 2018, 33 (1), 67-73. https://doi.org/10.1080/14756366.2017.1389922.

(300) Zheng, Y. G.; Su, J.; Gao, C. Y.; Jiang, P.; An, L.; Xue, Y. S.; Gao, J.; Liu, Y. Design, Synthesis, and Biological Evaluation of Novel 4-Anilinoquinazoline Derivatives Bearing Amino Acid Moiety as Potential EGFR Kinase Inhibitors. Eur. J. Med. Chem. 2017, 130, 393-405. https://doi.org/10.1016/j.ejmech.2017.02.061.

(301) Akhtar, M. J.; Khan, A. A.; Ali, Z.; Dewangan, R. P.; Rafi, M.; Hassan, M. Q.; Akhtar, M. S.; Siddiqui, A. A.; Partap, S.; Pasha, S.; Yar, M. S. Synthesis of Stable Benzimidazole Derivatives Bearing Pyrazole as Anticancer and EGFR Receptor Inhibitors. Bioorg. Chem. 2018, 78, 158-169. https://doi.org/10.1016/j.bioorg.2018.03.002.

(302) Hou, W.; Ren, Y.; Zhang, Z.; Sun, H.; Ma, Y.; Yan, B. Novel Quinazoline Derivatives Bearing Various 6-Benzamide Moieties as Highly Selective and Potent EGFR Inhibitors. Bioorganic Med. Chem. 2018, 26 (8), 1740-1750.

https://doi.org/10.1016/j.bmc.2018.02.022.

(303) Chen, D.; Guo, D.; Yan, Z.; Zhao, Y. Allenamide as a Bioisostere of Acrylamide in the Design and Synthesis of Targeted Covalent Inhibitors. Medchemcomm 2018, 9 (2), 244-253. https://doi.org/10.1039/c7md00571g.

(304) Hu, J.; Han, Y.; Wang, J.; Liu, Y.; Zhao, Y.; Liu, Y.; Gong, P. Discovery of Selective EGFR Modulator to Inhibit L858R/T790M Double Mutants Bearing a N-9-Diphenyl-9H-Purin-2-Amine Scaffold. Bioorganic Med. Chem. 2018, 26 (8), 1810-1822. https://doi.org/10.1016/j.bmc.2018.02.029.

(305) Liu, Z.; Wang, L.; Feng, M.; Yi, Y.; Zhang, W.; Liu, W.; Li, L.; Liu, Z.; Li, Y.; Ma, X. New Acrylamide-Substituted Quinazoline Derivatives with Enhanced Potency for the Treatment of EGFR T790M-Mutant Non-Small-Cell Lung Cancers. Bioorg. Chem. 2018, 
Table S2. Dataset 2 for generating queries from crystal structures.

\begin{tabular}{|c|c|c|c|c|c|}
\hline Num & Ligand name & PDB code & Num & Ligand name & PDB code \\
\hline 1 & $1 \mathrm{c} 9$ & $4 \mathrm{I} 23$ & 13 & ire & 4WKQ \\
\hline 2 & $1 \mathrm{wy}$ & $4 \mathrm{LI} 5$ & 14 & $\mathrm{kj} 8$ & 4JQ8 \\
\hline 3 & $03 \mathrm{p}$ & $3 \mathrm{POZ}$ & 15 & $\mathrm{kjq}$ & 4JQ7 \\
\hline 4 & $4 \mathrm{zq}$ & $5 \mathrm{CAV}$ & 16 & $\mathrm{kjr}$ & 4JR3 \\
\hline
\end{tabular}




\begin{tabular}{|c|c|c|c|c|c|}
\hline 5 & $5 q 4$ & 5EM8 & 17 & kjv & 4JRV \\
\hline 6 & $5 \times 4$ & 5FED & 18 & o44 & $5 \mathrm{~V} 8 \mathrm{~L}$ \\
\hline 7 & aee & $2 \mathrm{~J} 6 \mathrm{M}$ & 19 & own & $4 \mathrm{G} 5 \mathrm{~J}$ \\
\hline 8 & aq4 & $1 \mathrm{M} 17$ & 20 & pox & 3BEL \\
\hline 9 & cko & $6 \mathrm{JZO}$ & 21 & w19 & 3 W33 \\
\hline 10 & djk & $2 \mathrm{~J} 5 \mathrm{~F}$ & 22 & w32 & $3 \mathrm{~W} 32$ \\
\hline 11 & fmm & $1 \mathrm{XKK}$ & 23 & yun & 4LRM \\
\hline 12 & hyz & 2RGP & 24 & yy3 & $4 \mathrm{ZAU}$ \\
\hline
\end{tabular}


Table S3. The optimized parameters used in SAR and QSAR models.

\begin{tabular}{|c|c|}
\hline Model & Optimized parameters \\
\hline Model 1A & C: $\{8\}$, gamma: $\{0.03125\}$ \\
\hline Model 1B & $\begin{array}{l}\text { C: }\{4\} \text {, gamma: }\{64\} \text {, descriptors: \{3DACorr:PiChg:Cor3D:ori1_1,3DACorr:PiEN:Cor3D:ori1_2, } \\
\text { 3DACorr:LpEN:Cor3D:ori1_5, ComplexRing, 3DACorr:PiChg:Cor3D:ori1_4, } \\
\text { 3DACorr:Polariz:Cor3D:ori1_6,3DACorr:PiEN:Cor3D:ori1_10,3DACorr:PiEN:Cor3D:ori1_3,HAccN, } \\
\text { 3DACorr:PiChg:Cor3D:ori1_2, 3DACorr:LpEN:Cor3D:ori1_2, 3DACorr:Ident:Cor3D:ori1_11, } \\
\text { 3DACorr:TotChg:Cor3D:ori1_2, 3DACorr:SigChg:Cor3D:ori1_5, TPSA }\}\end{array}$ \\
\hline Model 2A & C: $\{4\}$, gamma: $\{0.03125\}$ \\
\hline Model 2B & $\begin{array}{l}\text { C: }\{4\} \text {, gamma: }\{32\} \text {, descriptors: \{3DACorr:LpEN:Cor3D:ori1_5, HAccN, 3DACorr:Ident:Cor3D:ori1_3, } \\
\text { 3DACorr:Ident:Cor3D:ori1_1, 3DACorr:PiChg:Cor3D:ori1_4, 3DACorr:SigChg:Cor3D:ori1_5, } \\
\text { HAcc,3DACorr:PiEN:Cor3D:ori1_2, 3DACorr:PiEN:Cor3D:ori1_12, 3DACorr:Ident:Cor3D:ori1_11, } \\
\text { 3DACorr:Polariz:Cor3D:ori1_12, 3DACorr:LpEN:Cor3D:ori1_8, 3DACorr:LpEN:Cor3D:ori1_10, } \\
\text { 3DACorr:PiEN:Cor3D:ori1_6, 3DACorr:SigEN:Cor3D:ori1_9, 3DACorr:PiChg:Cor3D:ori1_5, } \\
\text { 3DACorr:TotChg:Cor3D:ori1_2, 3DACorr:TotChg:Cor3D:ori1_1, 3DACorr:SigChg:Cor3D:ori1_1, } \\
\text { 3DACorr:SigChg:Cor3D:ori1_2\} }\end{array}$ \\
\hline Model 3A & $\begin{array}{l}\text { C: }\{4\} \text {, epsilon: }\{0.25\} \text {, gamma: }\{8\} \text {, descriptors: }\{\text { HAccN, BondsRot, 3DACorr:PiChg:Cor3D:ori1_4, } \\
\text { 3DACorr:SigEN:Cor3D:ori1_3, ComplexRing, 3DACorr:LpEN:Cor3D:ori1_8, 3DACorr:SigChg:Cor3D:ori1_1, } \\
\text { 3DACorr:LpEN:Cor3D:ori1_2, 3DACorr:TotChg:Cor3D:ori1_8, 3DACorr:SigChg:Cor3D:ori1_8, } \\
\text { 3DACorr:SigChg:Cor3D:ori1_6, 3DACorr:TotChg:Cor3D:ori1_5, 3DACorr:TotChg:Cor3D:ori1_4, } \\
\text { 3DACorr:LpEN:Cor3D:ori1_10, 3DACorr:TotChg:Cor3D:ori1_7, 3DACorr:PiEN:Cor3D:ori1_8, } \\
\text { 3DACorr:PiEN:Cor3D:ori1_4, 3DACorr:Polariz:Cor3D:ori1_4, 3DACorr:SigChg:Cor3D:ori1_3\} }\end{array}$ \\
\hline Model 3B & $\begin{array}{l}\text { C: }\{8\} \text {, epsilon: }\{0.125\} \text {, gamma: }\{8\} \text {, descriptors: \{3DACorr:Polariz:Cor3D:ori1_2, 3DACorr:Polariz:Cor3D:ori1_5, } \\
\text { HAccN, 3DACorr:PiChg:Cor3D:ori1_4, BondsRot, 3DACorr:SigChg:Cor3D:ori1_6, 3DACorr:LpEN:Cor3D:ori1_8, } \\
\text { 3DACorr:SigEN:Cor3D:ori1_8, Ro5ViolExt, 3DACorr:TotChg:Cor3D:ori1_8, 3DACorr:SigChg:Cor3D:ori1_8, } \\
\text { 3DACorr:LpEN:Cor3D:ori1_2, 3DACorr:PiEN:Cor3D:ori1_6, 3DACorr:PiEN:Cor3D:ori1_4, } \\
\text { 3DACorr:PiEN:Cor3D:ori1_8, ComplexRing, 3DACorr:SigChg:Cor3D:ori1_1, 3DACorr:SigChg:Cor3D:ori1_3, HAccO, } \\
\text { 3DACorr:TotChg:Cor3D:ori1_5, HDon }\}\end{array}$ \\
\hline Model 3C & $\begin{array}{l}\text { C: }\{4\} \text {, epsilon: }\{0.25\} \text {, gamma: }\{8\} \text {, descriptors: }\{3 \text { DACorr:SigEN:Cor3D:ori1_6, 3DACorr:SigEN:Cor3D:ori1_5, HAccN, } \\
\text { ComplexRing, 3DACorr:PiChg:Cor3D:ori1_4, 3DACorr:SigChg:Cor3D:ori1_6, 3DACorr:TotChg:Cor3D:ori1_4, } \\
\text { 3DACorr:TotChg:Cor3D:ori1_5, 3DACorr:PiEN:Cor3D:ori1_6, 3DACorr:LpEN:Cor3D:ori1_8, } \\
\text { 3DACorr:SigChg:Cor3D:ori1_1, 3DACorr:LpEN:Cor3D:ori1_2, 3DACorr:TotChg:Cor3D:ori1_8, } \\
\text { 3DACorr:SigChg:Cor3D:ori1_8, 3DACorr:TotChg:Cor3D:ori1_7, BondsRot, HAccO, 3DACorr:PiEN:Cor3D:ori1_8, } \\
\text { 3DACorr:TotChg:Cor3D:ori1_1\} }\end{array}$ \\
\hline
\end{tabular}


Table S4. IC 50 curves for hit compounds experimented on EGFR and ErbB-2.

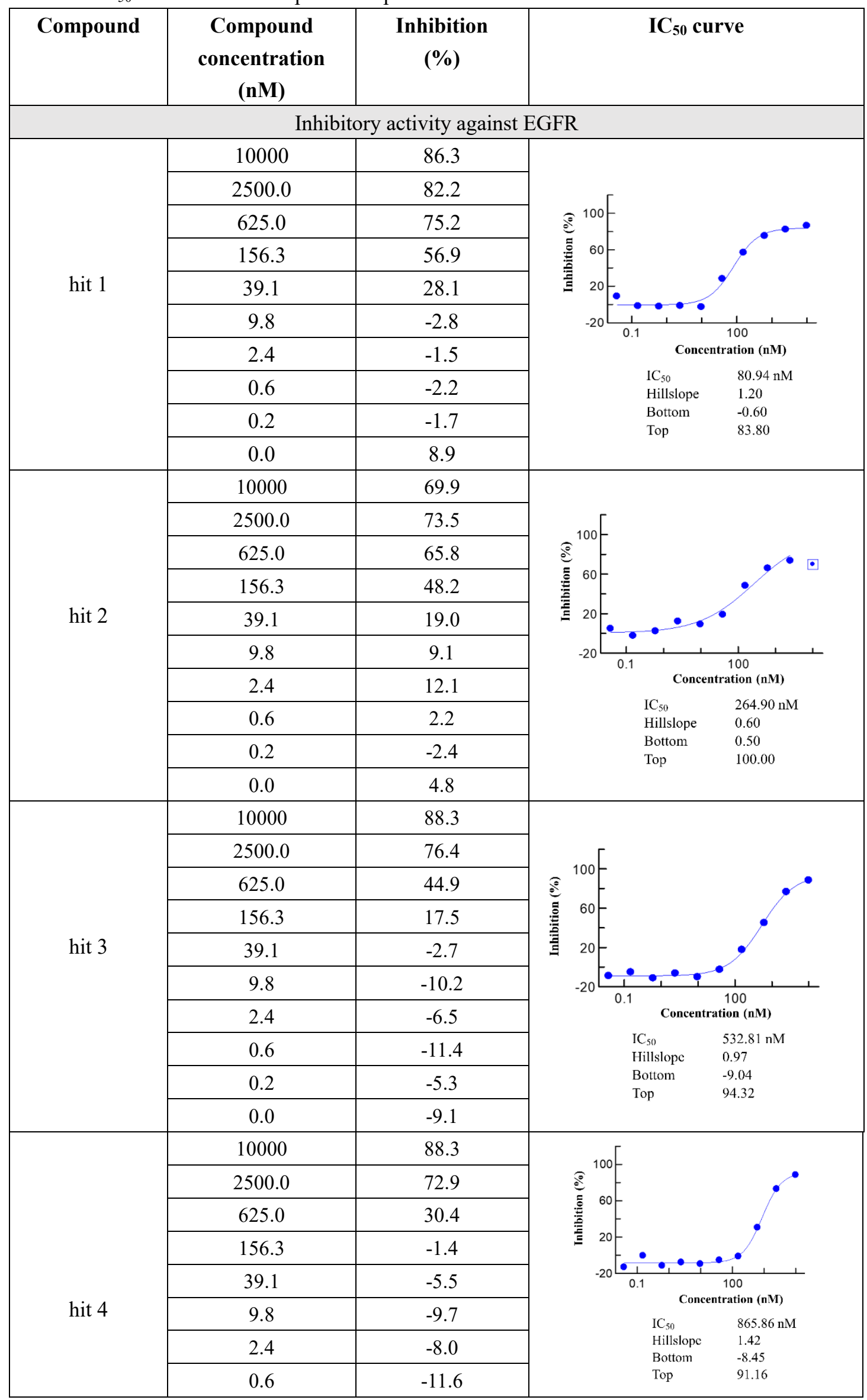




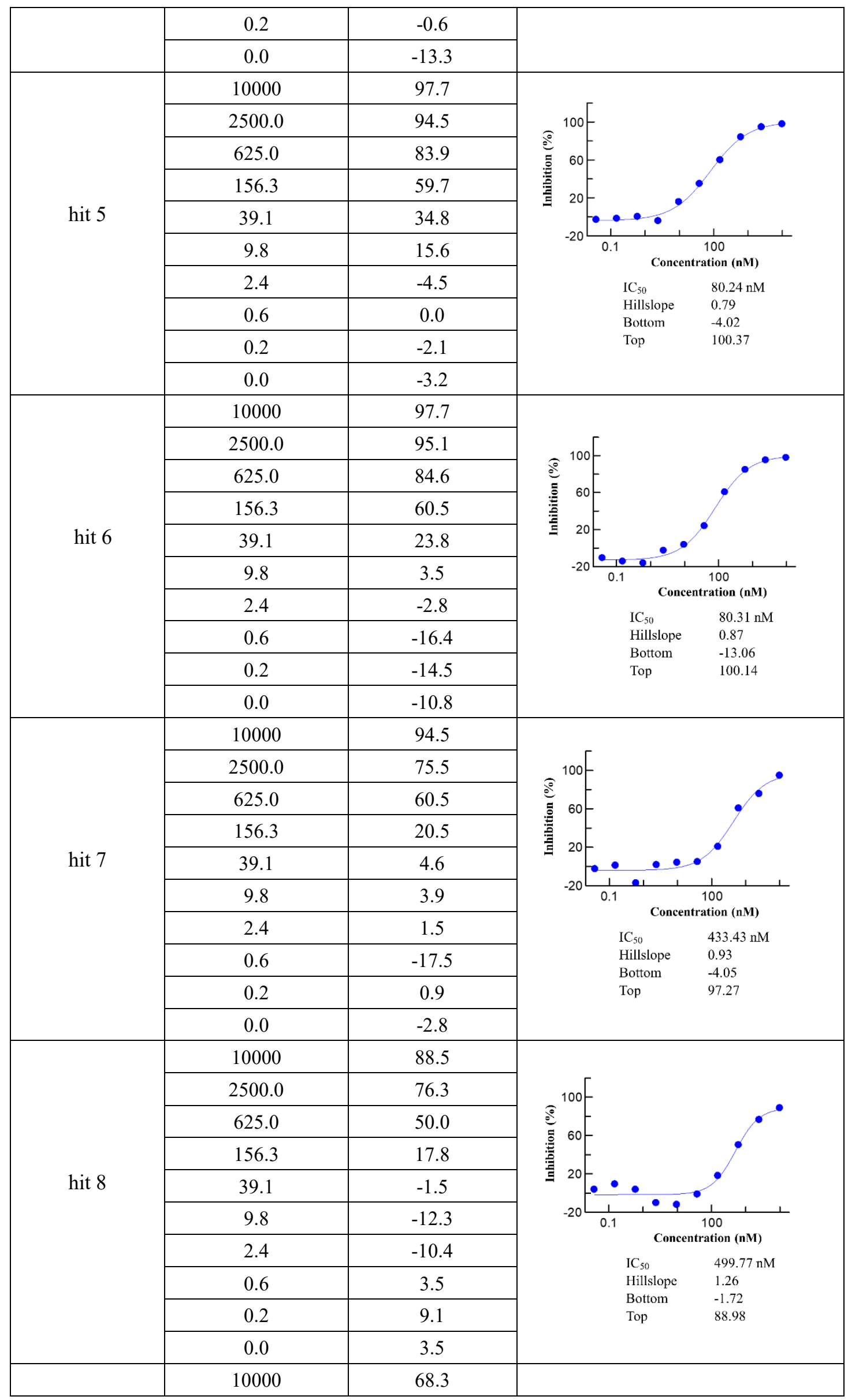




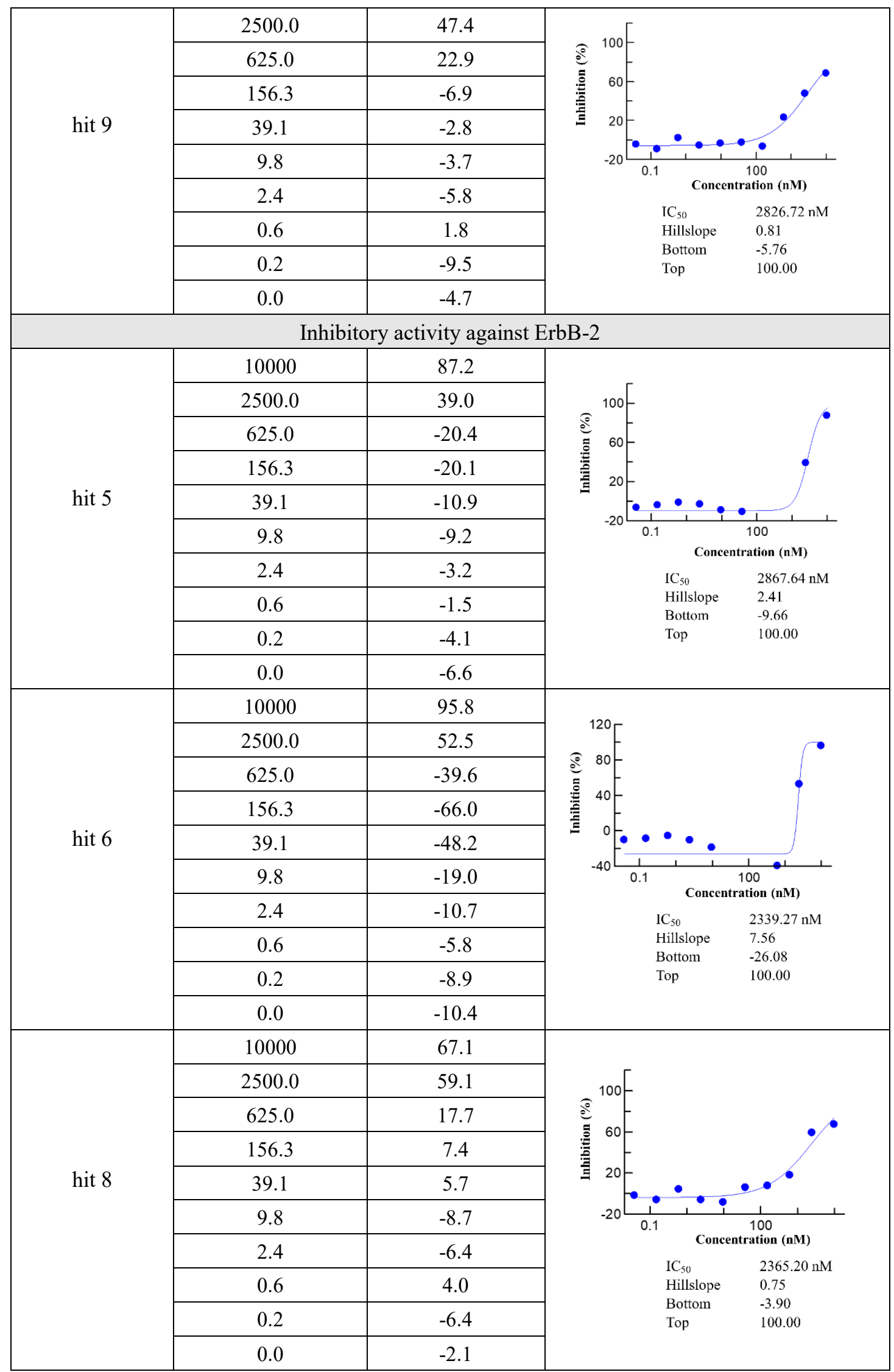



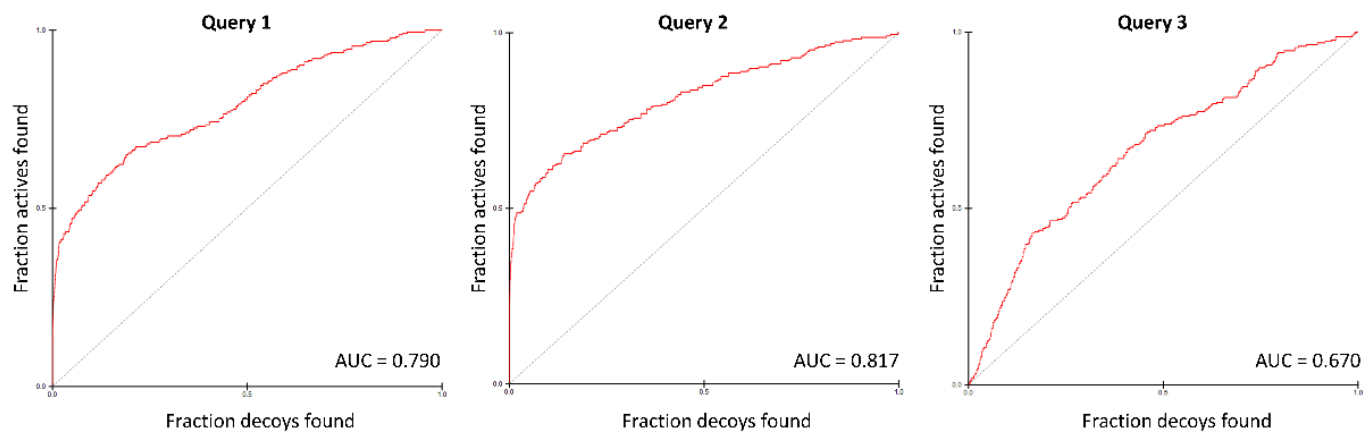

Figure S1. The ROC curves and AUC values of 3 queries. Query 1 was generated from crystal structure djk in 2J5F. Query 2 was generated from crystal structures ire and kj8 in 4WKQ and 4JQ8, respectively. Query 3 was generated from DGMG model. 


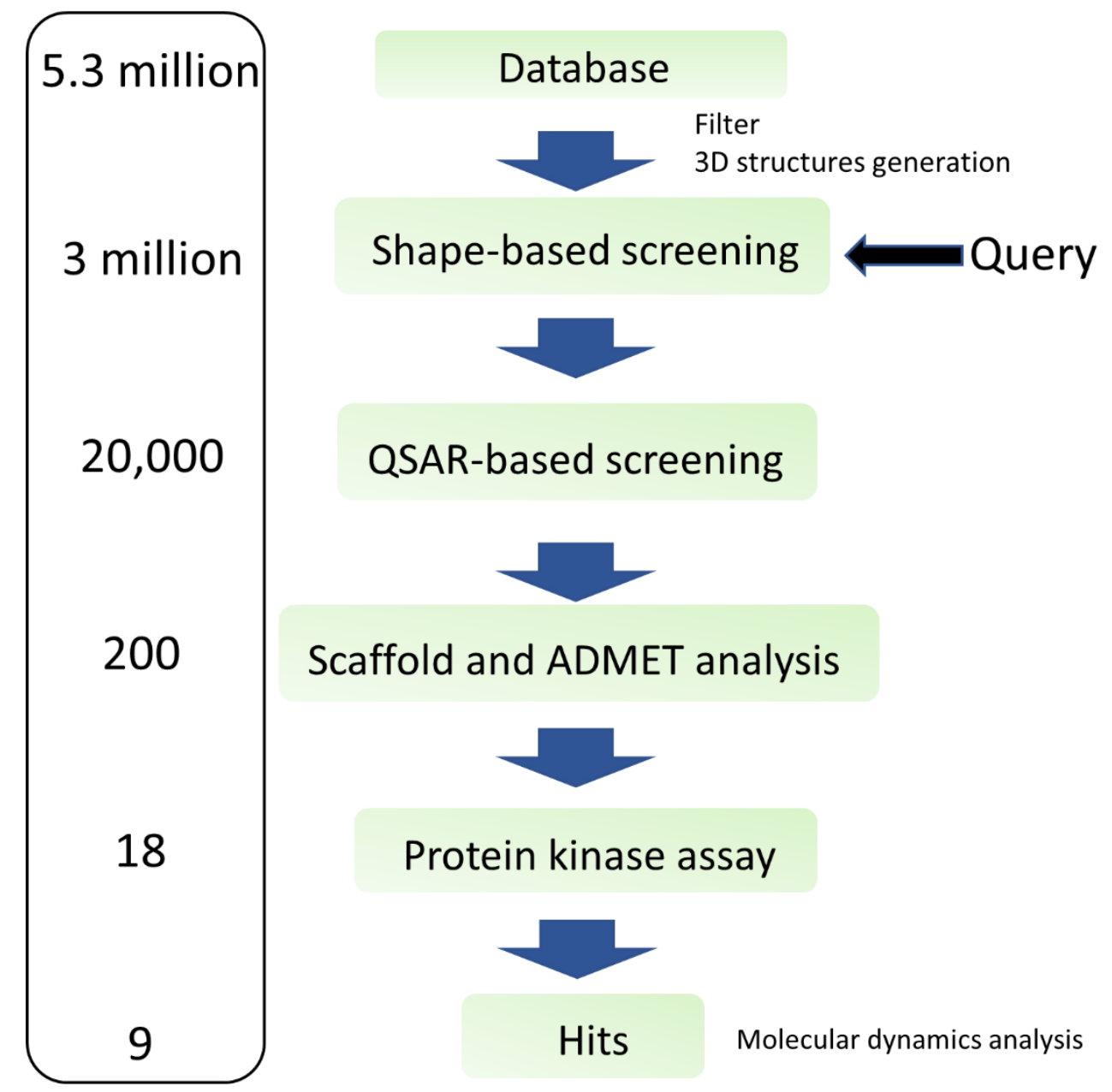

Figure S2. The cascade of the hierarchical ligand-based virtual screening of novel EGFR inhibitors. For shape-based similarity screening, two queries were from crystal structures and one query was generated from DGMG model. 


\section{Kinase assay method}

We tested 20 compounds (18 selected compounds and 2 reference molecules) for the in vitro inhibitory activities against EGFR and ErbB-2 by using Mobility Shift Assay. The compounds were tested from $10 \mu \mathrm{M}$ for 10 concentrations, 4 -fold, in single. The details of the experimental materials and process are as following:

\section{Materials}

EGFR (Eurofins, Cat.No 14-531, Lot. No WAB0528)

HER2 (Invitrogen, Cat.No. PV3590, Lot. No. 1689418B)

Peptide FAM-P22 (GL Biochem, Cat. No. 112393, Lot. No. P180116-MJ112393)

ATP (MCE, Cat. No. HY-15141, Lot. No.21226)

DMSO (Sigma, Cat. No. D2650, Lot. No. 474382)

EDTA (Sigma, Cat. No. E5134, CAS No. 60-00-4)

96-well plate (Corning, Cat. No. 3365, Lot. No. 22008026)

384-well plate (Corning, Cat. No. 3573, Lot. No. 12608008)

Kinases reaction condition

\begin{tabular}{|c|c|c|c|c|}
\hline Kinase & $\begin{array}{c}\text { Enzyme } \\
\text { concentration } \\
(\mathrm{nM})\end{array}$ & $\begin{array}{c}\text { ATP } \\
\text { concentration } \\
(\mu \mathrm{M})\end{array}$ & Substrate & $\begin{array}{c}\text { Substrate } \\
\text { concentration } \\
(\mu \mathrm{M})\end{array}$ \\
\hline HER2 & 20 & 8.8 & Peptide22 & 3 \\
\hline EGFR & 6 & 1 & Peptide22 & 3 \\
\hline
\end{tabular}

Instrument information

\begin{tabular}{|c|c|c|c|}
\hline Name & Model & Manufacturer & SN \\
\hline $\begin{array}{c}\text { Caliper EZ Reader } \\
\text { (No.2) }\end{array}$ & EZ ReaderII & Perkin Elmer & DS1152N0107 \\
\hline Precision & PRC384U & BioTek & 214145 \\
\hline Biochemical incubator & SPX-100B-Z & Boxun & $/$ \\
\hline Centrifuge & 5810R & Eppendorf & 5811L941179 \\
\hline
\end{tabular}

In vitro kinase assays

All compounds were initially prepared as $10 \mathrm{mM}$ stocks in DMSO and subsequently diluted in DMSO to $50 \times$ their final concentrations. Ten $\mu \mathrm{L}$ of each DMSO dilution was transferred to a well in a fresh 96-well cluster plate containing $90 \mu \mathrm{L} 1 \times$ Kinase buffer (50 mM HEPES pH 7.5, $10 \mathrm{mM} \mathrm{MgCl} 2,2 \mathrm{mM}$ DTT and 0.0015\% Brij35 ) and then mixed for $10 \mathrm{~min}$. Five $\mu \mathrm{L}$ of each compound dilution was subsequently added to 384-well plate in duplicate. To each well, $10 \mu \mathrm{L}$ of enzyme solution containing either HER2(final concentrations $20 \mathrm{nM}$ ) or EGFR (final concentrations $6 \mathrm{nM}$ ) in $1 \times$ Kinase buffer and the mix incubated at room temperature for $10 \mathrm{~min}$. To initiate each reaction, $10 \mu \mathrm{L}$ of peptide solution containing FAM-labelled peptide (final concentrations $3000 \mathrm{nM}$ FAM-22 and ATP (final concentrations $8.8 \mu \mathrm{M}$ or $1 \mu \mathrm{M}$, 
respectively) in $1 \times$ Kinase buffer was added to each well. All reactions were incubated at $28^{\circ} \mathrm{C}$ for a period time and then terminated by the addition of $25 \mu \mathrm{L}$ stop buffer (100 mM HEPES pH 7.5, 50 mM EDTA, 0.2\% Coating Reagent \#3 and 0.015\% Brij-35).

All samples were then subjected to analysis using Caliper EZ ReaderII (Down stream voltages:-500V, Up stream voltages:-2250V, Base pressure -0.5 PSI, Screen pressure 1.2 PSI)to read conversion values. Conversion values were transformed into \% inhibition of kinase activity using the formula: \% Inhibition $=[(\mathrm{MA}-\mathrm{X}) /(\mathrm{MA}-\mathrm{MI})]$ $\times 100 \%$ where $\mathrm{MA}=$ conversion value of $\mathrm{DMSO}$ only controls, $\mathrm{MI}=$ conversion value of no enzyme controls and $\mathrm{X}=$ conversion value at any given compound dose. IC50 values were then calculated by plotting dose-response curves and then using the XLfit application in Excel software. 